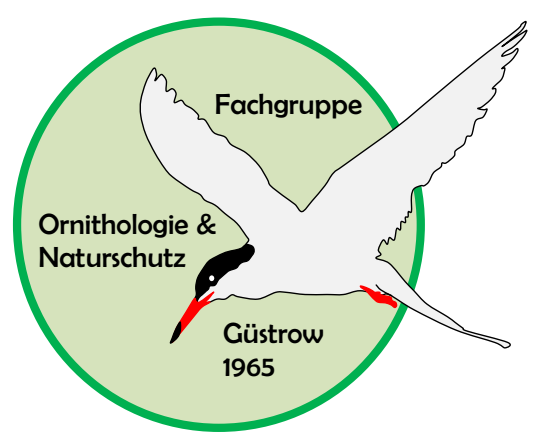

Aus der 50-jährigen Geschichte der Fachgruppe Ornithologie und Naturschutz Güstrow

Joachim Loose und Angela Martin
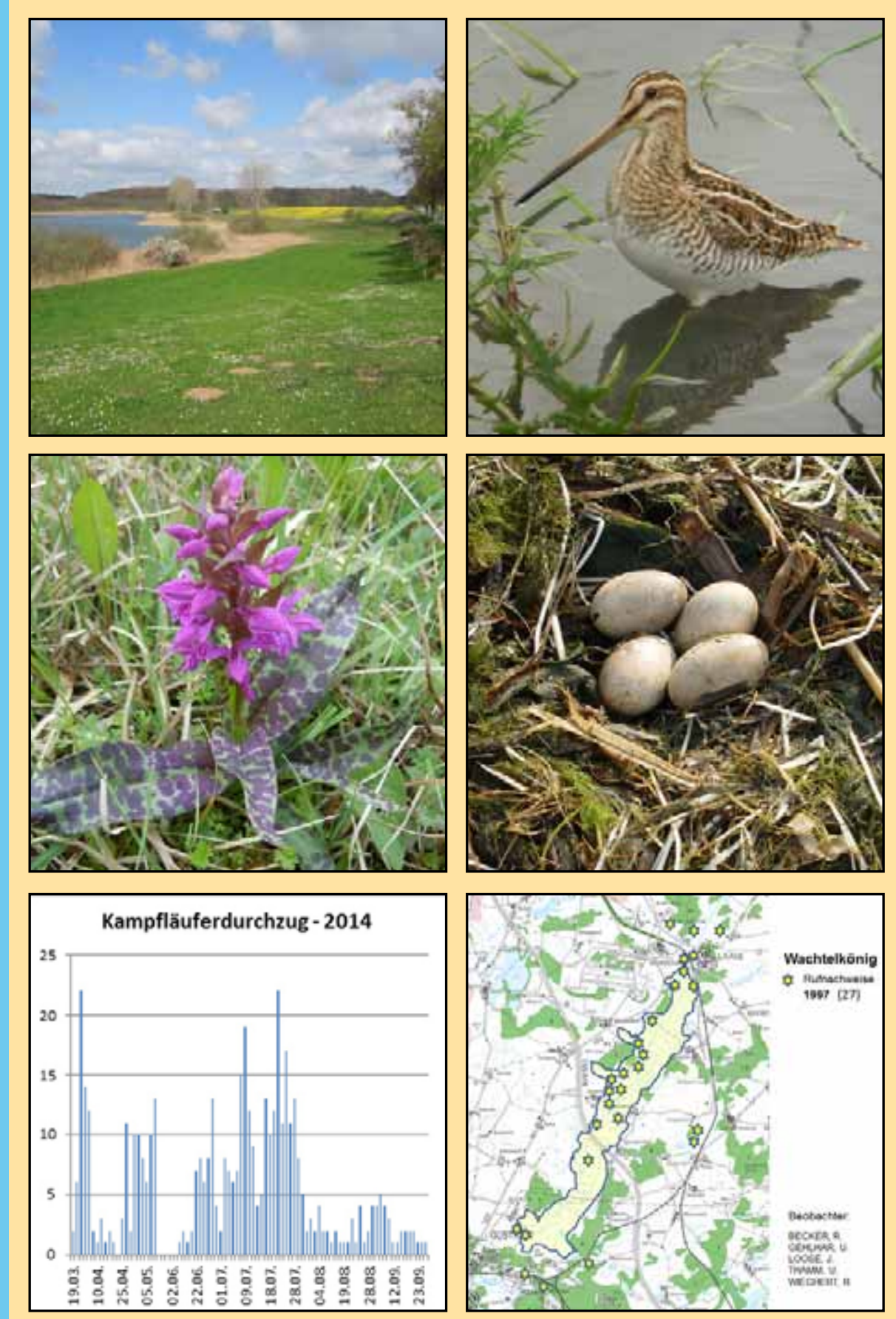



\title{
Aus der 50-jährigen Geschichte der Fachgruppe Ornithologie und Naturschutz Güstrow
}

\author{
Joachim Loose und Angela Martin
}

\author{
unter Mitwirkung von \\ Wolfgang Köhler, Sebastian Lorenz, Manfred Montschko, \\ Helmut Richter, Reinhard Schaugstat, Eckhard Schlüter, Guntram Trost
}

Zum Andenken an unseren Freund und Gründer der Fachgruppe

Dr. Wolfgang Neubauer

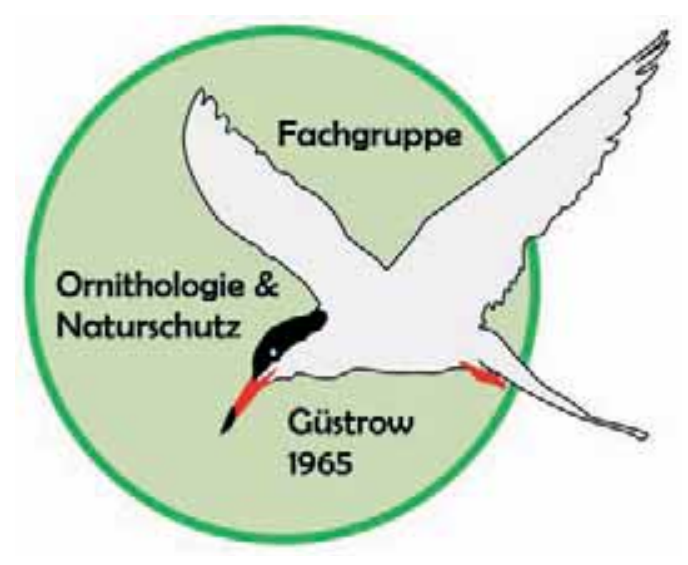




\section{Impressum}

Herausgeber: NABU-Ortsgruppe Güstrow e.V.

für die Fachgruppe Ornithologie und Naturschutz Güstrow

Leitung: Dr. Angela Martin, Hafenstraße 19e, 18273 Güstrow

Redaktionsschluss: 29.Februar 2016

Alle Rechte vorbehalten! Nachdruck, auch auszugsweise, sowie fotomechanische Wiedergabe nur mit Genehmigung des Herausgebers

Redaktion: Joachim Loose und Angela Martin

Gesamtherstellung: Geozon Science Media, Berlin

DOI: $10.3285 /$ g.00016

Titelfotos: J. Loose 


\section{Danksagung}

Die kritischen Manuskriptdurchsichten übernahmen die Fachgruppenmitglieder Wolfgang Köhler und Guntram Trost, denen auch für textliche Korrekturvorschläge unser besonderer Dank gilt.

Für die kostenlose Bereitstellung der verwendeten Fotos wird den genannten Bildautoren gedankt. 


\section{Sponsoring}

Der Druck der vorliegenden Broschüre wäre für eine rein ehrenamtlich arbeitende Gruppe ohne Unterstützung von außen nicht möglich gewesen. Wir haben deshalb Hilfe bei Freunden, mit denen uns eine langjährige Zusammenarbeit verbindet, gesucht. Wir danken den nachfolgend genannten Einrichtungen, Verwaltungen und Betrieben für ihre freundlichen Spenden in der Reihenfolge der eingegangenen Spenden:

- Stiftung der Ostseesparkasse Rostock

- Ingenieurbüro KULTA, Güstrow

- Biota - Institut für ökologische Forschung und Planung, Bützow

- Förderverein Natur- und Umweltpark Güstrow, Wildpark- MV

- FRG Hansa Güstrow

- Allgemeine Wohnungsgenossenschaft Güstrow

- Wohnungsgesellschaft Güstrow

- WOKRA für die Stadt Krakow am See

- Energieversorgungsbetrieb WEMAG, Schwerin

- Betreiber der PVA Güstrow - FP LUX Investments S.A. SICAV-SIF

- Stiftung Reepsholt für Naturschutz und umweltgerechte Ressourcennutzung

- Ornithologische Arbeitsgemeinschaft Mecklenburg-Vorpommern e.V.

\section{OSPA-Stiftung KULGE:}
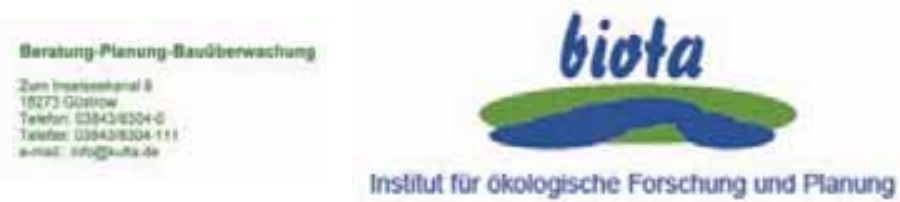
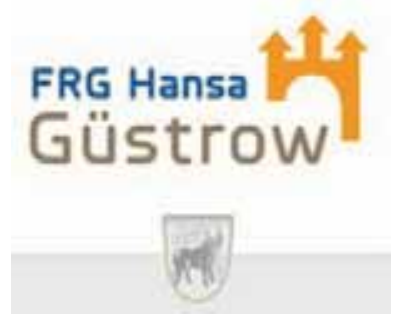

WEMAC

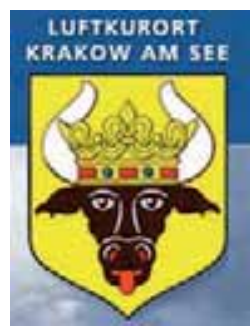

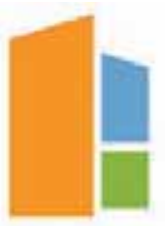

Wohnungsgesellschaft Güstrow

FP LUX INVESTMENTS

S.A. SICAV-SIF

Wildpark-MV.de

Natur- und Umweltpark Güstrow

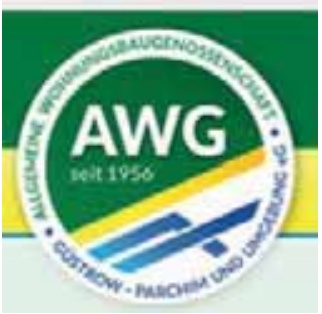

\section{Stiftung Reepsholt \\ für Naturschutz \\ und umweltgerechte \\ Ressourcennutzung}

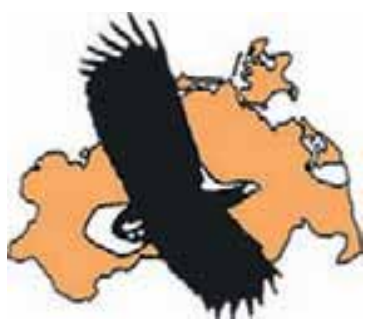

Ein besonderer Dank geht an nachfolgende Privatpersonen:

Dr. Andreas Hertkorn

Dr. Angela Martin

Dr. Beate Meder-Trost

Dr. Ingolf Schult

Unseren Dank richten wir ganz besonders auch an alle derzeit aktiven Mitglieder der Fachgruppen Ornithologie und Naturschutz Güstrow, die einen nicht unerheblichen finanziellen Beitrag leisteten. 
1. Einleitung

2ur Geschichte und Arbeit der Fachgruppe

8

3. Aus der Fachgruppe geboren -

die Botanik-Arbeitsgemeinschaft

4. Besondere Aktivitäten der Fachgruppe

5. Öffentlichkeitsarbeiten

5.1 Vorträge, Broschüren und Artikel in der Lokalpresse

5.2 Informationstafeln

5.3 „Die Leute vom Kulturbund“ TV-Film (1982)

5.4 Vogelstimmenexkursionen

6. Andenken an verstorbene Mitglieder der Fachgruppe

7. Besondere Ehrungen von Mitgliedern der Fachgruppe

8. Über das Naturschutzwirken der Fachgruppe 50

8.1 Gebietsausweisungen und Betreuung Naturschutzgebiete (NSG)

8.1.1 NSG Krakower Obersee

8.1.2 NSG Breeser See

8.1.3 NSG Upahler und Lenzener See

8.1.4 NSG Zehlendorfer Moor

8.1.5 NSG Schlichtes Moor

8.1.6 NSG Gutower Moor und Schöninsel

8.1.7 Aktivitäten in andere NSG

8.2 Gebietsausweisungen und Betreuung Flächennaturdenkmale (FND)

8.3 Entwicklungen und Beobachtungen in anderen Gebieten

8.3.1 Augrabengebiet

8.3.2 Zuckerfabrik-/PVA-Teich(e)

8.3.3 Polder Gutow

8.3.4 Polder Klaber

8.3.5 Ochsenauge

Spezieller Teil

9. Ausgewählte Darstellungen von

Artbearbeitungen innerhalb von 50 Jahren

9.1 Weißstorch

9.2 Graureiher

9.3 Arbeit mit den Adlern (Seeadler, Fischadler)

9.4 Kranich

9.5 Saatkrähe
9.6 Was wir sonst noch zusammengetragen haben 144

9.6.1 Fische, Lurche und Kriechtiere 144

9.6.2 Säugetiere 148

9.6.3 Insekten 152

10. Projektarbeiten der Fachgruppe 156

10.1 Mehr als 55 Jahre Forschung an

10.2 27 Jahre Kunstinseln für Flussseeschwalben im NSG Breeser See 159

10.3 18 Jahre Haubenlerchen-Farbberingungsprogramm in Güstrow 167

10.4 28 Jahre Sperberhorsterfassung und Beringung von Jungsperbern

10.5 Das Projekt Wanderfalke - erfolgreiche Gemeinschaftsarbeit mit dem LJV

10.6 Herrichtung von Trafohäusern als Lebensraum für Tierarten

10.7 Fledermausschutz durch Quartierbereitstellung in Eiskellern

10.8 Nisthilfen für Mauersegler 186

10.9 Dohlen und andere Kirchenbewohner $\quad 189$

10.9.1 Die Dohlenkolonie in der Kirche von Laage 189

10.9.2 Aktionen in Güstrow 191

10.10 Wasservogelzählungen 194

10.11 Wintervogel- und Agrarvogelzählungen 197

10.12 Wissenschaftliche Vogelberingung 203

11. Resümee und Ausblick für die weitere Arbeit der Fachgruppe

- Verwendete Abkürzungen

- Literatur

Anhang

1 - Liste der Fachgruppenmitglieder 214

2 - Literaturverzeichnis $\quad 216$

3 - Posterserien der FG und des NABU 222

4 - Poster der Ausstellung zum 80.Jahrestag des NSG Krakower Obersee

5 - Wahleingabe der FG - zu 8.1.6 232

6 - Landschaftsentwicklungsvisionen 236

- Über die Autoren 238

- Rückseite:

Vogelvignetten von den Titelseiten der

FG-Jahresberichte ab 1987 


\section{Einleitung}

Die „ORMIG“-Abzüge der ersten im Ordner abgelegten Jahresberichte der Fachgruppe Ornithologie und Naturschutz Güstrow sind bereits so verblasst, dass man sie kaum noch lesen kann. Diejenigen, die später dazu kamen und sich von den vorangegangenen Berichten zeitgemäß damals nur Kopien auf Thermopapier anfertigten, sind ganz schlecht dran - sie sehen heute auf dem dünnen Papier nichts mehr.

Aus 50 Jahren Fachgruppenarbeit gibt es viel zu berichten, viel mehr, als in einer langen Festrede vorgetragen werden könnte. Um Altes in Erinnerung zu bewahren, wollen wir mit diesem Heft die ehrenamtliche Arbeit der Ornithologen und Naturschützer aus einem halben Jahrhundert in dem bis 1994 als Kreis Güstrow bezeichneten Gebiet darstellen und für nachfolgende Generationen bewahren.

Das Betätigungsfeld der Fachgruppe umfasst bis heute die Fläche des Altkreises Güstrow, wie er administrativ nach der Verwaltungsreform vom 25. Juli 1952 bis zum 12. Juni 1994 in einer Flächengröße von $1.002 \mathrm{~km}^{2}$ existierte.

Viele unserer ehemals aktiven Mitglieder aus der Fachgruppe weilen nicht mehr unter uns und können den Neuhinzugekommenen nicht mehr von ihren Erlebnissen und Forschungen erzählen. Umso wichtiger erscheint es uns, dass neben fachlichen Darstellungen auch die ganz persönlichen Erinnerungen und Erfahrungen unserer Akteure in den einzelnen Beiträgen zum Ausdruck gebracht werden.

Die Geschichte der Fachgruppe „Ornithologie und Naturschutz Güstrow“ begann im Dezember 1965.

Seitdem haben in ihr 67 Mitglieder mehr oder weniger aktiv mitgearbeitet. Etwa 10 Personen kamen nur für kurze Zeit zu den FG-Abenden, ohne sich dann weiter einzubringen. Es gab intensive Kontakte zur Jägerschaft, zu Landund Forstwirten, Fischern und Storchen- oder anderen Vogelliebhabern. Weit mehr als 50 Gewährsleute haben ergänzende Informationen für die Fachgruppen-Beobachtungskartei geliefert.

Ornithologisch interessante Beobachtungen, Eier- und Balgsammlungen aus dem Raum Güstrow sind bereits aus dem 18. und 19. Jahrhundert belegt und in die avifaunistische Literatur eingegangen. Insbesondere das Gebiet um den Krakower See war bereits früher häufig von namhaften Ornithologen und Sammlern aufgesucht worden. Einen umfassenden Überblick über bedeutsame Feststellungen aus „historischer“ Zeit findet man bei Neubauer, W. (2004) im Einführungskapitel in „Die Vogelwelt des Altkreises Güstrow“. Deshalb wird dieses Thema im vorliegenden Heft nicht erneut aufgegriffen.

Sehr froh sind wir, dass es Wolfgang Neubauer unter Mitarbeit der Fachgruppenmitglieder gelang, die ornithologischen Ergebnisse unserer Fachgruppenarbeit bis zum Jah- re 2002 auszuwerten und mit vorgenanntem Titel $\mathrm{zu}$ publizieren. Diese Zusammenfassung wird für nachfolgende Generationen die Basis für eine Bewertung von künftigen Veränderungen in der Vogelwelt sein. Auch können neue Ornithologen unserer Gruppe mit dieser Zwischenschau ihre selbst gemachten Beobachtungen in ihrer Bedeutung leichter einordnen.

Mit unserer Broschüre zum 50jährigen Jubiläum der Fachgruppe wollen auch wir an die nicht mehr unter uns weilenden Mitglieder und ihr ornithologisches Wirken erinnern. Es wird vom praktischen Naturschutz, der zu einer anderen Zeit weitgehend nur von Ehrenamtlichen getragen wurde, berichtet. Schließlich werden auch einige Forschungsergebnisse dargestellt, die noch nicht in unsere Kreisavifauna Eingang finden konnten, da sie erst nach 2002 entstanden sind.

Wie in anderen ehrenamtlich arbeitenden Gruppen auch, verzeichnen wir mit unserem eigenen Älterwerden eine wesentliche Erhöhung des Durchschnittsalters unserer FGMitglieder. Es fehlt an jungen interessierten Ornithologen. „Unsere neu dazugekommenen Jungs“ aus den 1980er Jahren sind in ihren Berufen "gefangen" und zudem gestandene Familienväter, so dass ihre Zeit für ornithologische Beobachtungen oder gar umfangreichere Arbeiten knapp geworden ist.

Wie die Teilnahme an öffentlichen Vogelstimmenwanderungen und Kranichexkursionen sowie Besuche von Vorträgen $\mathrm{zu}$ ornithologischen Themen zeigen, scheint ein Interesse an unserer heimischen Vogelwelt in breiten Bevölkerungskreisen vorhanden zu sein. Nur wenige Neue haben jedoch den Weg in unsere Fachgruppe gefunden.

$\mathrm{Zu}$ verzeichnen ist in unserem Land besonders in jüngerer Zeit die Zunahme von Hobbyfotografen, die ihre Freude am Ablichten von Vogelarten gefunden haben. Die faszinierende technische Entwicklung bei den Digitalkameras mit Objektiven von immer größeren Zoombereichen befördert diese neue "Sammelleidenschaft", die sich im Internet in immer neuen Homepages präsentiert. Über Erfassungsprogramme (wie z.B. geese.org, icora.de, ornitho.de, oamv.de) stellen Ornithologen heute ihre Daten ins Netz, so dass sehr schnell auch Hobbyfotografen an den besonderen Sammelpunkten von Vögeln auftauchen. Als Ornithologen sehen wir diese Entwicklung kritisch. Auch wir bedienen uns der Fotografie als Belegmittel und zur Dokumentation unserer Forschungsarbeit. Weniger wichtig ist uns dabei, ob die letzte Feder des Vogels auch scharf geworden ist. Unsere ornithologische Arbeit sollte auch künftig ihren Schwerpunkt in der weiteren avifaunistischen Erforschung unseres Gebietes finden. Das Fortführen von kontinuierlichen Erfassungen von Arten in den verschiedenen Gebieten, Siedlungsdichteuntersuchungen, 
brutbiologische Studien und praktische Naturschutzarbeiten sehen wir als wesentlich wertvoller für einen Erkenntnisgewinn über die Tierwelt an, als ein stundenlanges Ansitzen in einem Fotoversteck für ein gelungenes Foto. Welchen Nutzen für die Gesellschaft besitzt ein neues Foto in einer privaten Sammlung? Gibt es nicht bereits genügend professionell arbeitende Vogelfotografen? Natürlich können auch bei einem Ansitz bedeutsame Beobachtungen gemacht werden, die weitergegeben werden sollten. Deshalb ist uns auch jeder Vogelfotograf in unserer Gruppe willkommen, er sollte sich jedoch nicht nur mit gelungenen Fotos an unserer Arbeit beteiligen. Wir werden auch künftig in unserer FG nicht um die besten Fotos wetteifern und zu einem Foto-Club mutieren.

Wie in hier folgenden Beiträgen aufgezeigt wird, gibt es viele Gebiete in unserem Wirkungsbereich, die einer näheren Untersuchung bedürfen oder in denen die Forschung kontinuierlich fortgesetzt werden muss.
Wir hoffen, dass sich auch künftig ein Personenkreis wirklich „Fachgruppe Ornithologie und Naturschutz“ nennen kann, weil ihm die weitere Erforschung unserer Tier- und Pflanzenwelt und der Naturschutz eine wirkliche Herzenssache sind.

Mit dem Jahresbericht Nr.46/2013 wurde ein von Guntram Trost entworfenes Logo für unsere Fachgruppe eingeführt (siehe Titelseite). Mit der Flussseeschwalbe als der darin zu sehenden Vogelart wollen wir das Andenken an Dr. Wolfgang Neubauer, den Gründer unserer Fachgruppe, bewahren, hat er sich doch einen Großteil seines Lebens mit dieser Vogelart beschäftigt und wertvolles Datenmaterial gesammelt. Die von ihm dabei gezeigte Beharrlichkeit und Kontinuität bei der Datensammlung soll uns Ansporn und Beispiel sein, ihm nachzueifern.

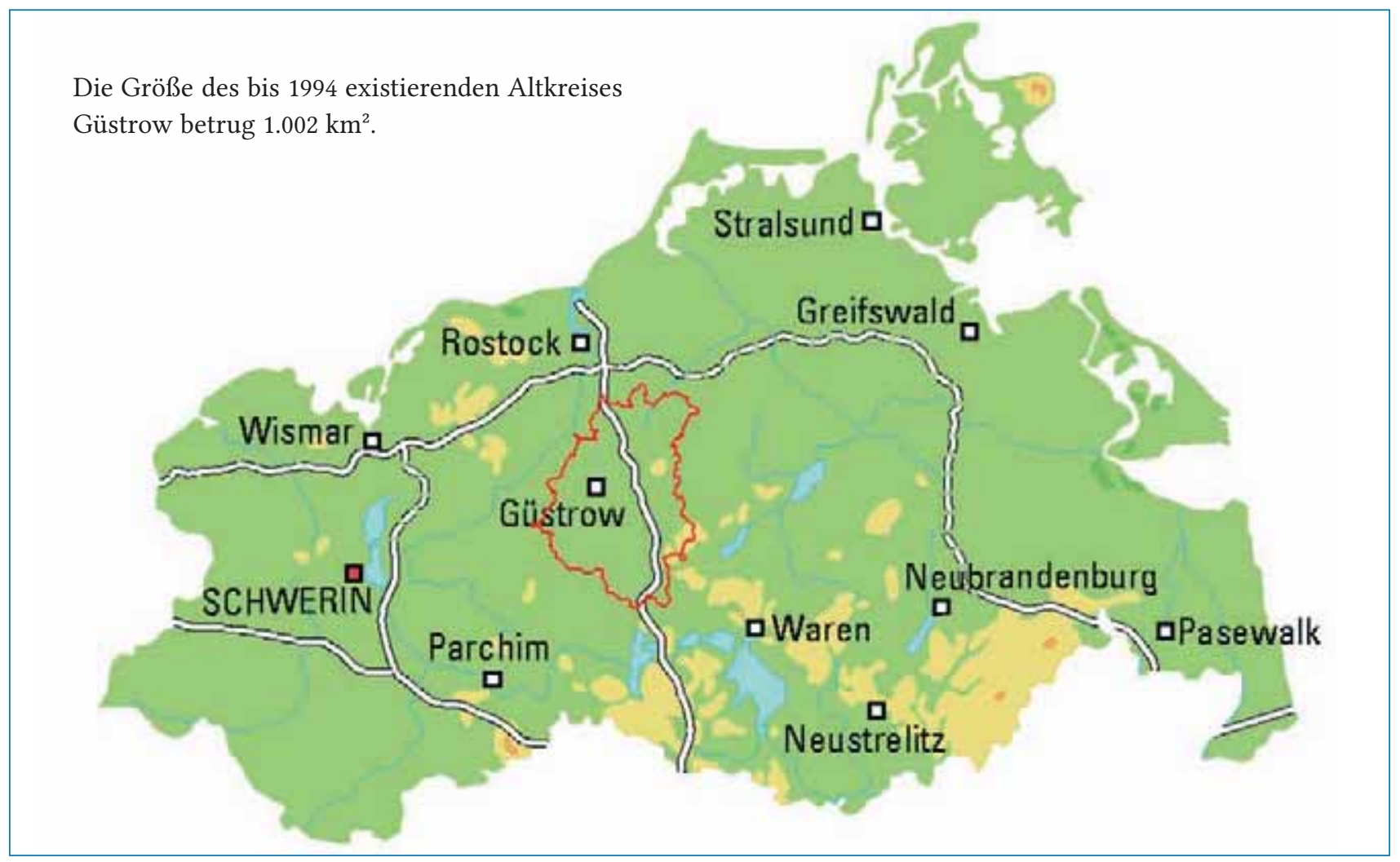

Karte 1: Der Wirkungsbereich der Fachgruppe Ornithologie und Naturschutz Güstrow in Mecklenburg-Vorpommern.

Auf einem separat für die Fachgruppe anlässlich des Jubiläums erzeugten Datenträger wurden die seit Gründung der FG verfassten Protokolle und in Jahresberichten gesammelten Daten als pdf-Dateien für eine Nutzung durch Artbearbeiter und anderweitig Interessierte zur Verfügung gestellt. Sie sollen damit in breiterem Umfang für die Zukunft gesichert werden.

Ergänzend wurde eine Reihe von Fotodokumenten aus den persönlichen Archiven von FG-Mitgliedern beigefügt. Mit den Fotos werden auch in einigen Gebieten abgelaufene Entwicklungen dokumentiert. Im Textteil eingefügt hätte die Menge der Fotos den Rahmen gesprengt. Auch „Die Vogelwelt des Altkreises Güstrow“ (NEUBAUER, W., 2004) kann separat als pdf-Datei gegen eine Schutzgebühr zur Verfügung gestellt werden.

Die Datenträger können bei begründetem Bedarf bei der FG angefordert werden. 


\title{
2. Zur Geschichte und Arbeit der Fachgruppe Ornithologie und Naturschutz Güstrow
}

\author{
Joachim Loose \\ unter Zuarbeiten von Angela Martin, Manfred Montschko und Wolfgang Neubauer ( $\dagger$ )
}

Im damaligen Bezirk Schwerin war es Werner Kaiser zu verdanken, dass sich nach seinen unermüdlichen Aufrufen unter dem Mantel des Kulturbundes der DDR die zahlreichen Einzelornithologen in den 1960er Jahren zu Kreisfachgruppen zusammen zu schließen begannen. Damit wurde die Arbeit des bereits 1954 gegründeten Bezirksfachausschusses Ornithologie (BFA) wesentlich unterstützt.

Auf Initiative des Lehrers Wolfgang Neubauer aus Krakow am See kamen im Dezember 1965 die zu dieser Zeit aktiven Ornithologen des Kreises Güstrow im Haus des Kulturbundes, dem Kersting-Klub, zusammen und gründeten die Kreisfachgruppe Ornithologie und Naturschutz Güstrow. $\mathrm{Zu}$ den Gründungsvätern gehörten neben Wolfgang Neubauer die Herren Reinhard Becker, Dr. Otto Jessen, Kurt Pohlmann und Georg Strache, von denen heute keiner mehr lebt. Die Fachgruppe (FG) hat mit ihnen von der Gemeinschaft anerkannte und die sie wesentlich tragende Ornithologen verloren. Die Lücken, die sie hinterlassen haben, konnten bis heute nicht wieder geschlossen werden.

Kurzzeitig gab es zu der 1965 gegründeten Fachgruppe eine Art Vorgängerin. 1955 wurde am damaligen Pädagogischen Institut Güstrow von dem Magdeburger Ornithologen Curt Kreibig, einem Mitarbeiter im Bereich Zoologie, eine studentische Arbeitsgemeinschaft gegründet und geleitet, die jedoch nicht sonderlich aktiv war. Immerhin gelang es Kreibig, einigen Studenten die Ornithologie näher zu bringen und deren vorhandene geringe ornithologische Kenntnisse, insbesondere zu Vogelstimmen, zu erweitern.

Von 1956 bis 1958 wurde diese Gruppe von Walter Kintzel geleitet. Wolfgang Neubauer hatte eine lockere Verbindung und nahm hauptsächlich an Exkursionen teil. Von der Arbeit dieser Studenten-AG ist nichts überliefert.

Die Kulturbundfunktionäre waren bestrebt, möglichst viele Personen in den Fachgruppen zu vereinen. In der Güstrower FG war man sich von Anfang an einig, dass man keine allgemeine Interessensgemeinschaft will, bei der viele passive Mitglieder nur mit Vorträgen, Lichtbildern, Fahrten, Exkursionen und anderen Dingen unterhalten werden. Die Mitglieder der FG sollten sich aktiv einbringen. Die Teilnahme in der FG setzte nicht die Mitgliedschaft im Kulturbund der DDR (KB) voraus. Es wurde für die Fachgruppe bewusst die Bezeichnung Ornithologie und Naturschutz gewählt. Wie sich anderenorts Fachgruppen dem Namen nach auch dem Vogelschutz widmen wollten, legten sich die Güstrower fest, es nicht nur beim Vogelschutz zu belassen. Neben den Vogelbeobachtungen wurden von Anfang an auch andere Organismengruppen erfasst.

Die Leitung der Fachgruppe Güstrow übernahm Wolfgang Neubauer aus Krakow am See. Er arbeitete bereits ab 1955 im Bezirksfachausschuss Schwerin mit und war dort auch später viele Jahre darüber hinaus als Beringungsobmann und Mitarbeiter der Arbeitsgruppe Gänsevögel tätig.

An Hand der lückenlos vorliegenden Jahresberichte der FG lässt sich die Entwicklung der Gruppe verfolgen. Eine erste Informationsschrift der FG berichtet 1968 über die Bildung der Fachgruppe und ihre bisherige Arbeit. Betont wurde, dass enge Kontakte zur Naturschutzverwaltung des Kreises bestehen, alle Mitglieder auch Naturschutzhelfer sind und der Fachgruppenleiter selbst berufener Kreisnaturschutzbeauftragter ist. Zwei Mitglieder der Fachgruppe (W. Neubauer und K.Pohlmann, beides Lehrer) leiten Arbeitsgemeinschaften „Vogelkunde“ für Schüler der Klassen 6 bis 10. Die ältesten und aktivsten Schüler durften auch an den Zusammenkünften der FG teilnehmen. Kleine Erfassungsaufgaben wurden von den Schülern übernommen, so z.B. die Erfassung der Türkentaube und Zählung der Dohlenbrutpaare in der Stadt Güstrow. Weiterhin wurden Gewölle von Schleiereulen untersucht.

Die FG-Mitglieder widmeten sich in dieser ersten Zeit u.a. der Wasservogelzählung, der Kontrolle der Gänse-Schlafplätze und der Brutbestandserfassung des Weißstorches. Weiterhin wurde festgestellt, dass bereits recht gutes Zahlenmaterial für Kolkraben, Fisch- und Seeadler, Kraniche, Fischreiher, Höckerschwäne und Türkentauben vorhanden sei. Begonnen wurde mit der Erfassung der Graugänse, Milane und Weihen (damals brütete die Wiesenweihe noch im Augrabengebiet nördlich von Güstrow). Das NSG „Krakower Obersee“ werde intensiv durch den Leiter der FG betreut. Einige Mitglieder beobachteten besonders im Augrabental und am Breeser See. Es wurde erkannt, dass diese Gebiete ornithologisch noch wenig erforscht seien und offensichtlich eine reiche Vogelfauna beherbergen.

Etwa zeitgleich stellte Kurt Pohlmann den 1. Jahresbericht der FG Güstrow mit den Beobachtungen von 1967 und 1968 zusammen, der aus heutiger Sicht bemerkenswerte Beobachtungen u.a. von Zwergdommeln, Schwarzstorch, Brandgans, Kolbenente, Moorente, Schreiadler, Wiesenweihe, Kleinem Sumpfhuhn, Sumpfohreule, Zwergschnepfe, Zwergschnäpper, Raubwürger und Blaukehlchen aus dem Kreisgebiet enthielt. 
Aus den Jahren 1970 bis 1972 liegen von Reinhard Becker unterzeichnete Protokolle über die Sitzungen der Fachgruppe im Kersting-Klub in Güstrow vor. Teilgenommen hatten damals zwischen 8 bis 16 FG-Mitglieder. Auf der Tagesordnung standen Themen wie Koordinierung der Wasservogelzählungen, Greifvogelerfassung, Zuarbeiten zur Avifauna Mecklenburgs, Erstellung von Jahresberichten, Fragen zur Artkartei, Beringung von jungen Kolkraben zur Klärung von Massenansammlungen im Raum Parchim und Hinweise zur Markierung von Graugänsen mit den damals noch mit „Wimpeln“ versehenen Halsbändern. Interessant war die Notiz im Protokoll vom 11.2.1972, dass beim Rat des Kreises jetzt eine Planstelle für Landeskultur frei sei. (Die Besetzung der Stelle wurde der FG jedoch nie bekannt gegeben und dürfte wohl nicht erfolgt sein.)

Protokolle über die Zusammenkünfte fertigte man dann später offenbar nicht mehr an. Beibehalten wurden bis 1989 jedoch die monatlichen Treffen der FG-Mitglieder an einem Freitag, meist Mitte des Monats mit dem Treffpunkt 19:00 Uhr im Kersting-Klub in Güstrow. Hierzu wurden an die Mitglieder vorgefertigte Postkarten als Einladung verschickt (damals noch zum Porto von 5 Pfennigen).
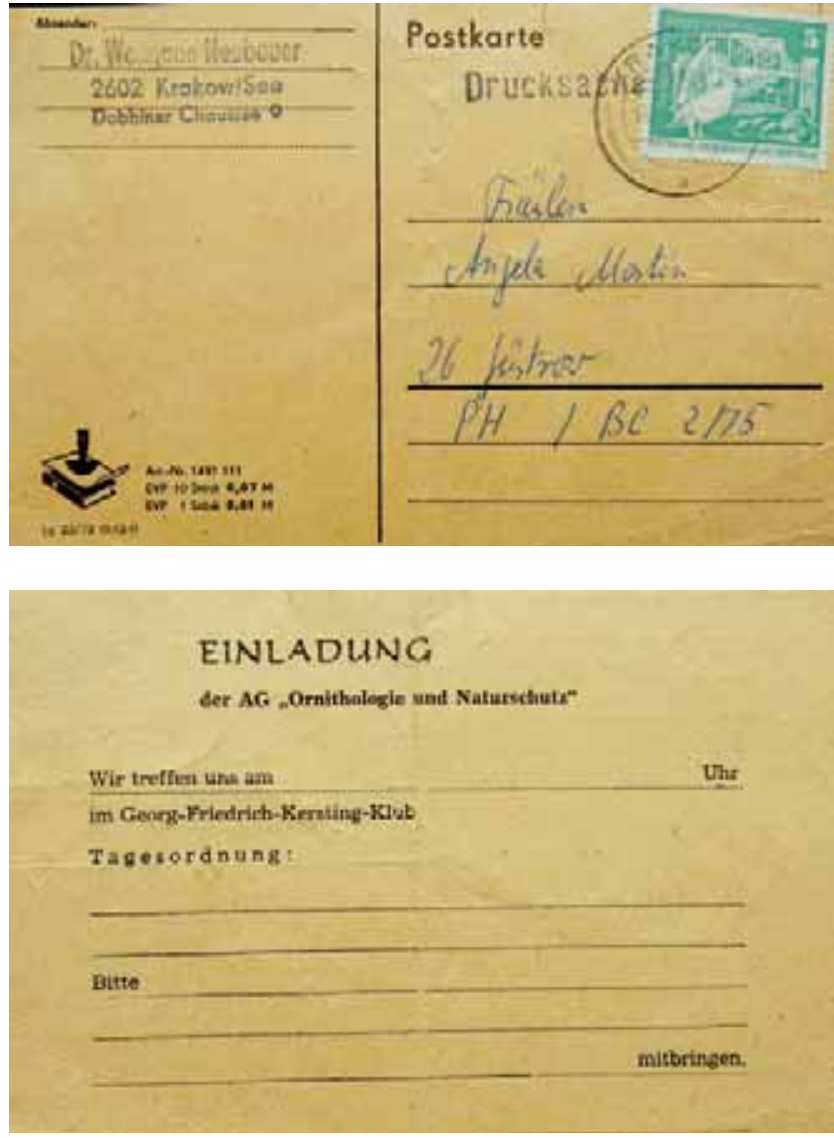

Abb. 1: Verwendete Einladungskarte von 1978

Gern wurde von den Güstrower Mitgliedern, die keine längeren Fahrwege hatten, die Möglichkeit im Klub genutzt, sich nach der FG-Sitzung in gemütlicher Runde beim Abendbrot, Bier oder anderen Getränken im Gaststätten- bereich des Klubs persönlich unterhalten zu können. An anderen Orten, wo sich die Fachgruppe später traf, war das dann nicht mehr möglich.

Während in den nachfolgenden Jahresberichten bis Nr.4 weiterhin „nur" bemerkenswerte Einzelbeobachtungen, dabei auch aus anderen Landesteilen, notiert wurden, gab es bereits ab Nr.5/1972 die ersten zusammenfassenden Berichte über das Vorkommen von einzelnen Arten im Kreisgebiet (z.B. Grauganserfassung) und Berichte über die Vogelwelt spezieller Gebiete (1973 - Brutvogelbestand des Breeser See).

Mit dem Wachsen der Datensammlung hatte man sich 1971 in der Fachgruppe geeinigt, die Daten in einer üblichen Artkartei zu sammeln, damals in der modernen Form der Notierung auf Kerblochkarten, was bis heute auch im Zeitalter des Computers so noch teilweise fortgeführt wird.

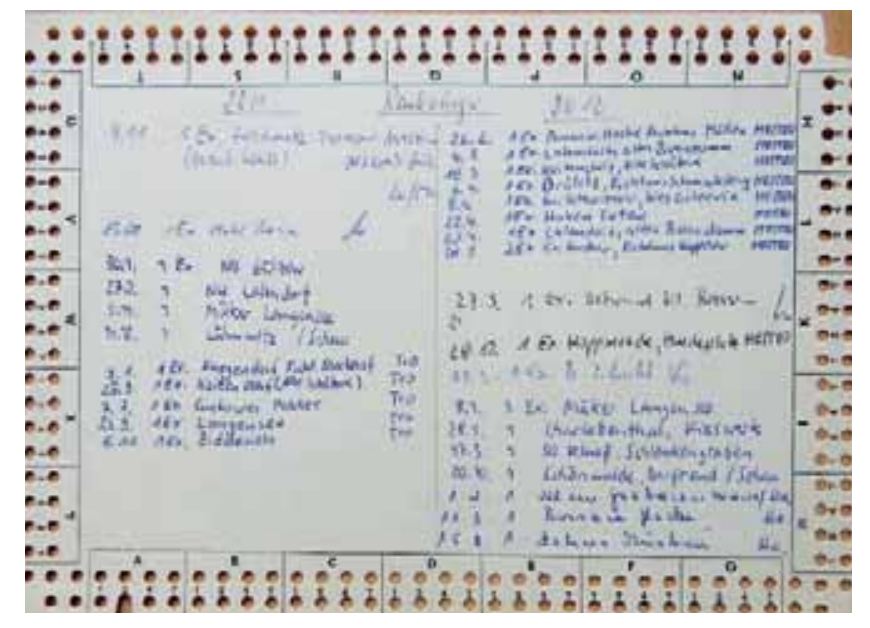

Abb. 2: Kerblochkarte aus der FG-Kartei

W. Neubauer erhielt den Auftrag, sich um die Beschaffung derartiger Lochkarten zu kümmern. Offensichtlich hatte er gut vorgesorgt, so dass sie uns auch heute noch ausreichend zur Verfügung stehen. Jeweils zum Jahresende kreist auch heute noch ein Aktenkoffer mit aktuellen Lochkarten zum Eintragen unter den Mitgliedern, die ihre Daten nicht einem Computer anvertrauen können. So kann im Frühjahr des Folgejahres die Rubrik der hervorhebenswerten Beobachtungen für den Jahresbericht zusammengestellt werden.

Im Jahresbericht Nr.5/1972 befindet sich neben ornithologischen Daten auch eine Abrechnung der geleisteten Arbeiten der FG-Mitglieder, die sich mit heutigen Aktivitäten durchaus messen können, ja in einigen Positionen durchaus nachahmenswert sind und deshalb hier aufgezählt werden:

Zur Fachgruppe gehörten im Jahr 1972 insgesamt 30 Mitglieder, davon waren 17 Schüler; 15 Mitglieder waren auch 
Naturschutzhelfer. Es fanden zehn FG-Zusammenkünfte statt. Abgerechnet wurden:

$120 \mathrm{~h}$ Wasservogelzählung

$60 \mathrm{~h}$ Bleß- und Saatganserfassung

$60 \mathrm{~h}$ Grauganserfassung

$35 \mathrm{~h}$ Storchennestkontrollen

150 h Betreuung des NSG Krakower Obersee (Raubzeugbekämpfung, Reparatur der Zäune, Möwenregulierung, Bestandserfassungen, Entenhege)

- Ausbringung von 40 Nistkästen für Enten, Eulen und Meisen

- 32 öffentliche Vorträge mit über 600 Besuchern

- 4 Zeitungsartikel

- 3 Veröffentlichungen in Fachzeitschriften

- Die Behandlungsrichtlinie für das NSG Krakower Obersee wurde als erste im Bezirk Schwerin von der FG erarbeitet und dem Bezirk übergeben.

- Wolfgang Köhler leistete Vorarbeiten für die Unterschutzstellung des Peetscher See als NSG (190 h Beobachtungen).

- Reinhard Becker erbrachte Vorarbeiten für ein neues NSG „Augrabental“.

- Im NSG Krakower Obersee wurde durch die FG eine Schutzhütte auf dem Großen Werder fertig gestellt und eine Beobachtungskanzel errichtet $(60 \mathrm{~h})$.

Bemerkenswert war eine sehr hohe Zielvorgabe für die Fachgruppe im Jahresbericht Nr. 6/1973:

„Unser Vorhaben ist es, bis 1977 die Avifauna des Kreises Güstrow zu schaffen. All unsere Vorhaben sind diesem großen Ziel untergeordnet. Durch die Einteilung des Kreises Güstrow in Beobachtungsgebiete und durch die Einführung des Artbearbeitersystems sind wir unserem Vorhaben ein großes Stück näher gekommen. Neben obligatorischen Zählungen gelang es uns, 1973 zum ersten Mal Siedlungsdichteuntersuchungen durchzuführen."

Die Fertigstellung einer Kreisavifauna konnte bei aller Euphorie auf der Grundlage der Datensammlung erst deutlich später umgesetzt werden (siehe weiter unten).

Ebenfalls im Jahresbericht Nr. 6/1973 erschien eine Liste der Güstrower Ornithologen und die nachfolgenden kurzen Aussagen:

„Von den 23 aktiven Ornithologen des Kreises Güstrow sind neun aus der AG der POS Mühl Rosin (Polytechnische Oberschule) hervorgegangen. Zur Zeit besteht an der POS eine AG mit 30 Mitgliedern, die systematisch angeleitet werden."

„Vogelkunde und Naturschutz sind nicht zu trennen. 1973 konnten die Voraussetzungen für die Unterschutzstellung des Breeser Sees erarbeitet werden."

Die Tätigkeit der Schüler-Arbeitsgruppe in Mühl Rosin wird so nebenbei erwähnt, es steckte aber ein erhebliches Engagement dahinter, was heute wohl nirgends mehr zu finden ist. Deshalb erscheinen die nachfolgenden Erläuterungen dazu angebracht:

Ab Anfang 1972 haben die AG-Mitglieder unter Leitung ihres Lehrers und FG-Mitgliedes Kurt Pohlmann verstärkt an der Erfassung des Brut- und Rastvogelbestandes am Breeser See gearbeitet. Der See wurde für einzelne Beobachter in Segmente aufgeteilt und fortan an fast jedem Wochenende an mindestens einem Tag aufgesucht. Erleichtert wurden die Erfassungsarbeiten dadurch, dass bereits frühzeitig eine kleine Behelfsunterkunft gebaut wurde, und später im Ort Rothbeck in der Nähe des Breeser Sees die Nutzung einiger Räume in einem ehemaligen Bauernhaus möglich war.

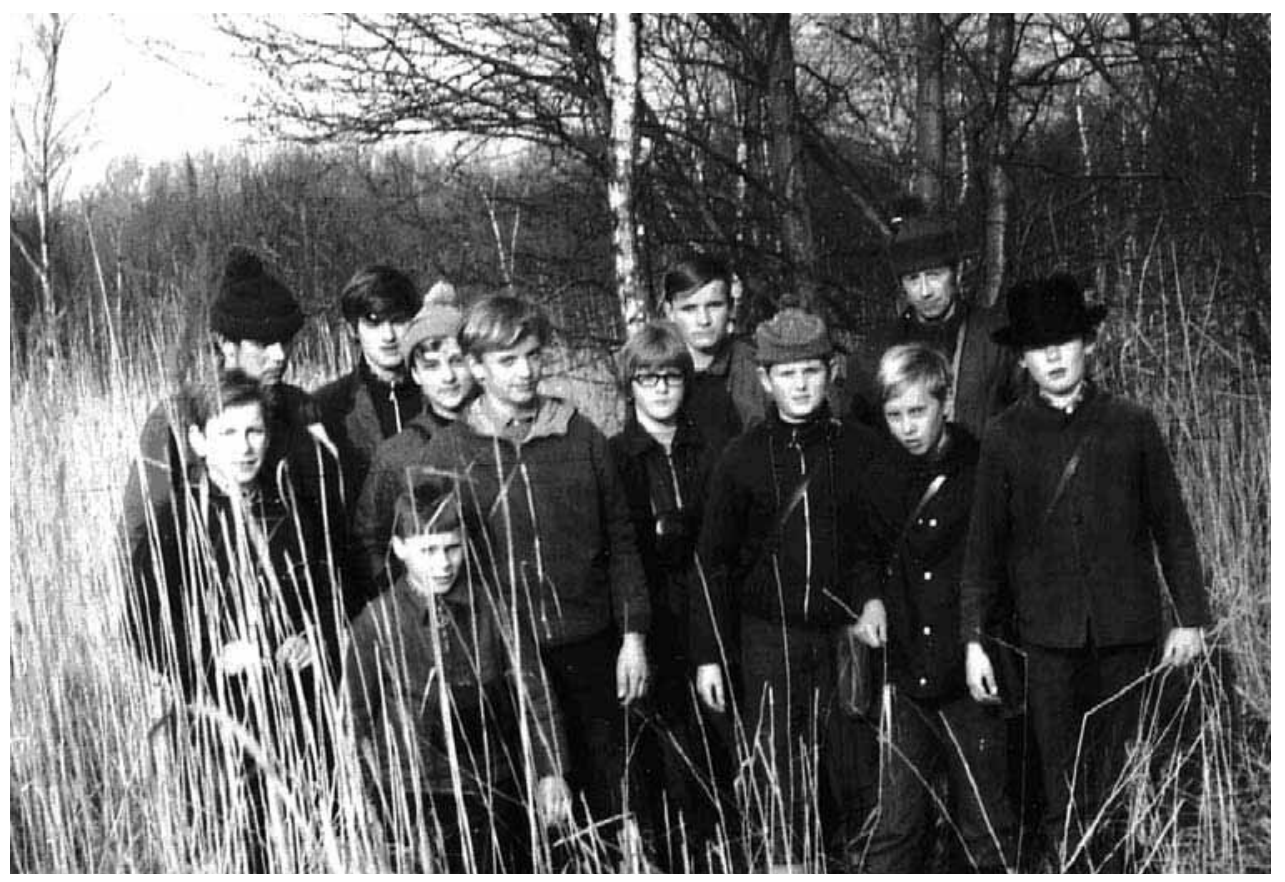

Abb. 3: Mitglieder der AG Vogelkunde an der POS Mühl Rosin am 25.03.1973 auf Exkursion am Breeser See (v.l.n.r.):

hinten:

fürgen Mevius, Willi Brüshaver, Manfred Montschko, Fritz Anderlik; Mitte: Bernhard Woynowski, Ingolf Schult, Andreas Hertkorn; vorne: Manfred Böhlke, Lothar Daubner, Frank Iffländer, Gerd Möller, Rolf Hein.

Foto: K. Pohlmann. 
So konnte die AG 1973 eine Artenliste vorlegen, die es auf Grund des Nachweises vieler seltener Vogelarten ermöglichte, beim Rat des Kreises eine einstweilige Sicherung des Breeser Sees als Naturschutzgebiet zu erwirken.

Kurt Pohlmann verstand es, die Interessen der Jugendlichen mit ersten Ansätzen für ein wissenschaftliches Beobachten und Arbeiten zu verbinden - heute würde man sagen: mit viel „Fun for the Kids“.

Manfred Monschko als ehemaliges Mitglied der SchülerAG berichtete in einem Artikel über die damalige Tätigkeiten u.a. (MONTSCHKO, M., 2015)

„dass sehr viele AG-Mitglieder ihre Aktivitäten nicht nur auf die AG-Zusammenkünfte beschränkten, sondern auch darüber hinaus aktiv waren, egal ob einzeln oder in kleinen Gruppen. Die von Pohlmann organisierte Arbeit war sehr abwechslungsreich und zumeist so angelegt, dass neben der Lern- und Übungstätigkeit die Faktoren Spaß und Abenteuer dabei nicht zu kurz kamen."

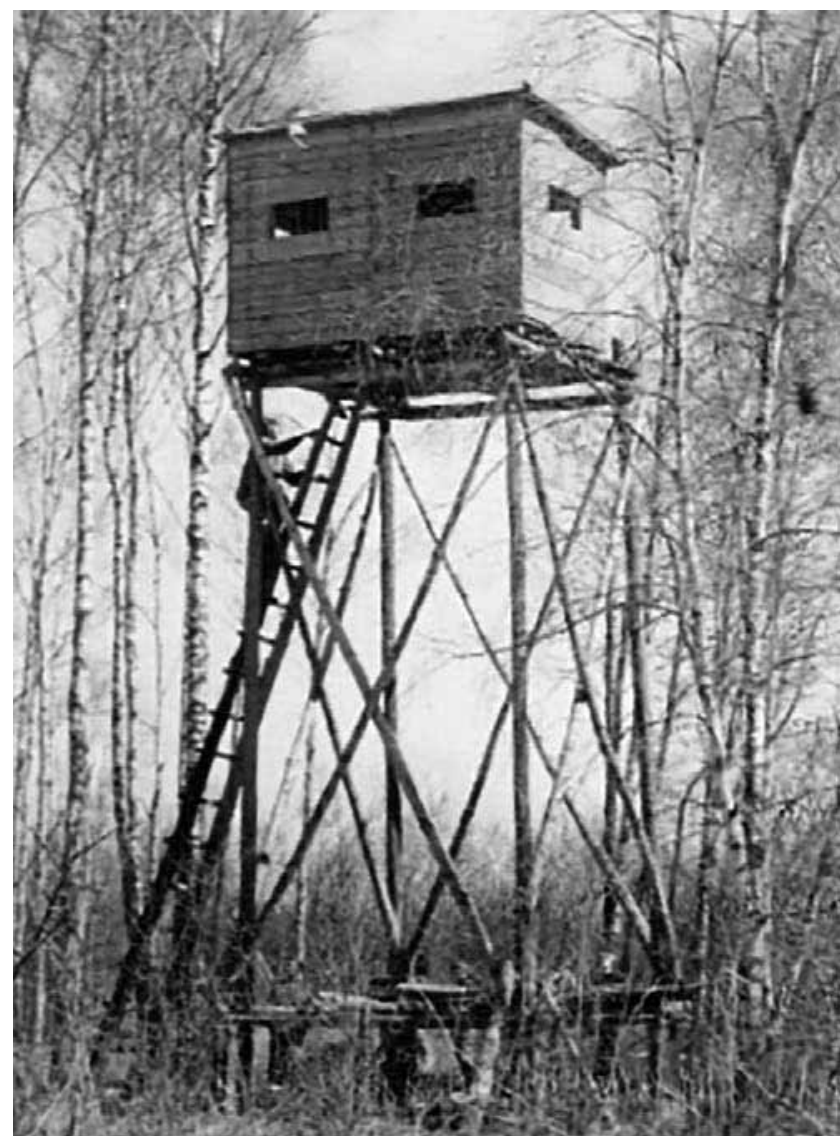

Abb. 4: Baumhaus der Schüler-AG am Westufer im NSG Breeser See - Bauzeit 1979/1980. Foto: A. Martin.

Dabei spielte es dann auch mal keine Rolle, dass ein Baumhaus (Abb.4) als geplanter Beobachtungspunkt mehr als $8 \mathrm{~m}$ hoch weit ab vom Ufer des Breeser Sees errichtet wurde und vom Vogelleben auf dem See von dort nicht viel zu sehen war. Auch bei der Errichtung einer künstlichen Insel für gewünschte Flussseeschwalbenbruten fehlte noch das technische Know-how. Aber die Jugendlichen waren mit
Eifer bei der Sache. Über Arbeits- und Versicherungsschutz machte man sich nicht so sehr viele Gedanken, Eltern sahen nicht immer beim Lehrer den Schuldigen, wenn etwas passierte.

Über die Arbeit der AG Vogelkunde berichtet Montschko weiter: „Bei völlig unwirtlichem Wetter, zumeist im Winter, gab es Zusammenkünfte in der Schule oder bei Pohlmanns im Wohnzimmer. Es wurde Theorie und Grundwissen vermittelt: Vogelstimmenschulung, Flugbilder der Greife, allgemeine Bestimmungsübungen, Informationen zu Zug und Wanderungen der Brutvögel und Wintergäste waren angesagt. Es war wohl auch ein wenig Botanik dabei, genauso wie Wissenswertes über andere Tierartengruppen. Auch das Dokumentieren der Beobachtungen und das Führen der Beobachtungsbücher waren Bestandteil der theoretischen Schulungen. In unregelmäßigen Abständen sammelte Pohlmann die Beobachtungsbücher ein, um diese zu sichten und zu bewerten. Anschließend gab es Hinweise und Vorschläge, manchmal aber auch Kritik für eingetragene Beobachtungen, die zumindest fragwürdig waren. Interessanter waren die vielen Exkursionen zu jeder fahreszeit, die an fast jedem Wochenende und in den Ferien auch innerhalb der Woche entweder zu Fuß oder aber mit dem Fahrrad absolviert wurden. Dabei kam es durchaus vor, dass mit dem Fahrrad $60 \mathrm{~km}$ und mehr am Stück zurückgelegt wurden. Hier wurden dann in der freien Natur Bestimmungsübungen nach Ruf/Gesang, Flugbild oder auch einfach nach visuellen Erkenntnissen durchgeführt. In der Anfangszeit haben die AG-Mitglieder bei ihren Exkursionen als Nebenbeschäftigung auch noch die vom „Klassenfeind“ abgeworfenen Flugblätter eingesammelt.

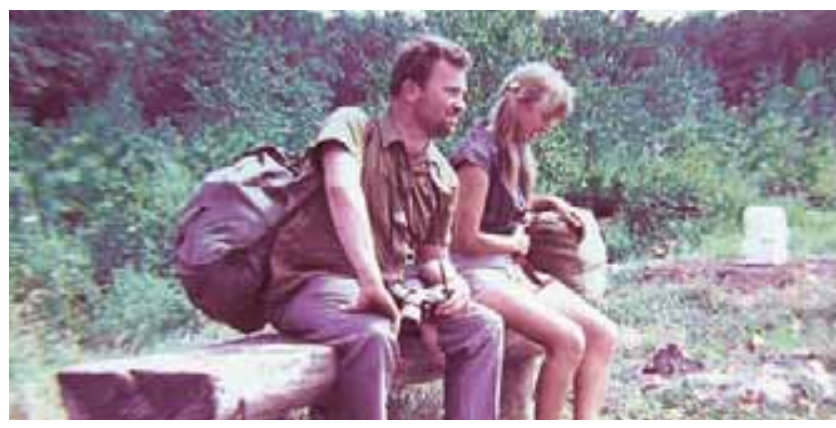

Abb. 5: Kurt Pohlmann auf Wandertour - Wer hat Mut? Foto: unbekannt.

* Bei der Recherche, wer die Begleiterin auf dem Bild ist, konnte niemand Auskunft geben. Ingolf Schult lieferte nachfolgende plausible Vermutung: Wir sind auf Tour. KP trägt Bart und großen Rucksack. 2 mal eindeutig. Vermutlich im Ausland, Bank an einer Bushaltestelle, davor Sand, kein Gras. KP und süße Kleine kommunizieren nicht. Kennen die sich? Sie reist, aber wandert nicht, wie denn auch mit den Riemchensandalen? Wie kommt KP neben sie aufs Foto? - Wir warten auf den Bus. Sie auch.

KP: Hey, Jungs, wer traut sich, die anzubaggern? (natürlich keiner!) KP: Ich schon, ich zeig Euch mal, wie man das macht. Setzt sich Knips.

Foto fertig! - Ich meine mich zu erinnern, dass es mal so etwas gab KP war so und gern mal zu einem Scherz bereit. 
Besondere Höhepunkte bei diesen Exkursionen in der näheren und weiteren Umgebung von Mühl Rosin waren immer einige Nachtwanderungen, die irgendwann am Abend begannen und erst in den frühen Morgenstunden endeten. Im Frühjahr und Sommer wurden der Brutvogelbestand, im Herbst und Spätwinter/Frühjahr die Zugvögel und im Winter die Wintergäste erfasst und in den Wäldern nach Horsten und Nestern gesucht und deren Standorte kartiert. Die größten Highlights waren jedoch die Exkursionen, die mindestens eine Woche dauerten. Dazu wurden die Zelte von der Schule ausgeliehen und es ging eine Gruppe von bis zu 15 Personen unterschiedlichsten Alters auf Fahrt. Anfangs ging es in den Sommerferien nach Poel, wo die Zelte auf einem Privatgrundstück in Malchow aufgeschlagen wurden. Später wurden die Entfernungen größer. Nun hießen die Ziele Polens Urwald Bialowieza oder mehrere Male Bulgarien."

Bis zu seinem viel zu frühen Tod 1981 trug Kurt Pohlmann unermüdlich mit seinen Schülern Datenmaterial über die Vogelwelt des Kreises Güstrow zusammen. Wenigstens drei seiner Schüler (L. Daubner, J. Mevius, M. Montschko) sind auch heute noch ernsthafte Ornithologen und als solche in Mecklenburg-Vorpommern tätig.

Aktivitäten mit einer Schüler-AG gab es auch bei Wolfgang Neubauer in Krakow am See, der interessierte Schüler mit in „sein“ NSG Krakower Obersee nahm. Trotz vieler Bemühungen einzelner FG-Mitglieder, an anderen Schulen naturkundliche Arbeitsgemeinschaften aufzubauen, gelang dieses nicht. Außerhalb von Schul-Arbeitsgemeinschaften kam nur selten junger Nachwuchs in die FG.

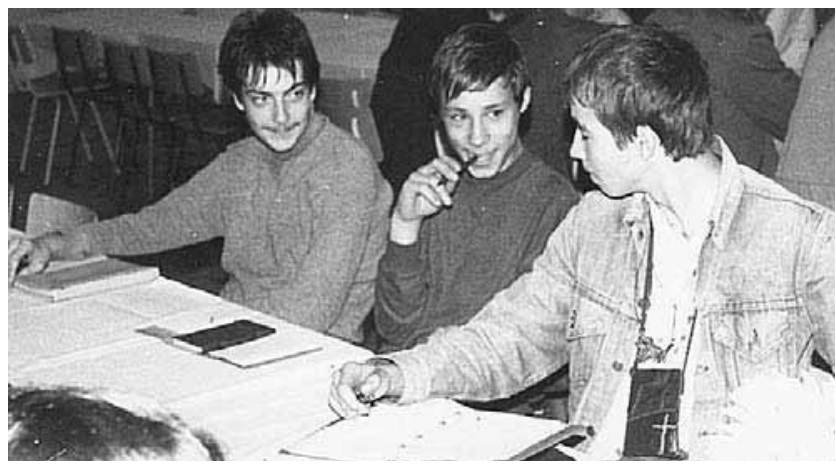

Abb. 6: Remo Wiechert und Uwe Gehlhar fanden 1985 den Weg in die FG (hier neben dem etwas älteren Andreas Schilf) bei der Tagung der Ornithologen des Bezirkes Schwerin. Foto: A. Martin.

Ornithologische Themen und Auswertungen nehmen in den späteren Jahresberichten der FG den Hauptteil ein: Seit 1973 durchgehend ist der Storchenbericht, zunächst von Georg Strache, nach dessen Tod von Reinhard Schaugstat verfasst, fester Bestandteil eines jeden Jahresberichtes. Genauso kontinuierlich gibt es einen Kranich-Bericht von Karl-Heinz Koop (ab 1981) und Guntram Trost (ab 2013) sowie den Bericht zum Graureiher-Brutbestand (ab 1994) von Reinhard Schaugstat.
Der Brutbestand der Saatkrähen in den Kolonien in Güstrow und Laage wird jährlich von mehreren FG-Mitgliedern erfasst und immer mal wieder in seiner Entwicklung in Jahresberichten dargestellt (Remo Wiechert). Besonders bei dieser Art zeigt sich, wie wichtig kontinuierliche Erfassungen sind. Saatkrähen inmitten der Bebauung machen Lärm und Schmutz und haben wenige Freunde. Regelmäßig kamen Wünsche bei den Stadtvätern zur Reduzierung der Bestände auf. Hier hatte man noch in Erinnerung, dass es zu DDR-Zeiten - zumindest in Güstrow - durchaus „üblich" war, dass die Feuerwehr die Nester der Saatkrähe von den Bäumen spritzte. Diesen Vorstellungen konnten wir (natürlich nur in Verbindung mit der zuständigen Naturschutzbehörde) bis heute erfolgreich mit rechtlichen als auch mit fachlichen Argumenten und konkreten Zahlenangaben entgegen treten.

In den Jahresberichten gab es als Vorbereitung für eine Kreisavifauna auch bereits zahlreiche Artzusammenfassungen, so z.B. für

- Lariden und Limicolen (1978)

- Eulen, See- und Lappentaucher, Kormoran (1979)

- Seltene Arten - Wiedehopf, Ziegenmelker, Schwarzstorch, Seidenschwanz (1979)

- Entenarten (1980)

- Seeuferarten - Drosselrohrsänger, Rohrschwirl, Sprosser (1986)

n Lachmöwe, Trauerseeschwalbe, Wacholderdrossel, Raubwürger (1986)

Damit konnte jeder sehen, wieweit bereits Material vorliegt und wo noch besondere Erfassungen notwendig waren. Besonders Siedlungsdichteuntersuchungen kommuner Arten fehlten bis Mitte der 1990er Jahre noch weitgehend. Das im Jahresbericht 1973 genannte ehrgeizige Artbearbeitersystem hatte sich in der FG nicht durchgesetzt; es hatte keiner der damals genannten Personen auch ernsthaft an Artmanuskripten gearbeitet. Vielfach waren in den 1980er Jahren auch zahlreiche Mitglieder aus den verschiedensten Gründen nicht mehr in der FG tätig. Die Auswertungen bisher vorliegender Erkenntnisse erfolgte weitgehend allein von Wolfgang Neubauer; Joachim Loose und Angela Martin lieferten kleinere Beiträge. Für das Gemeinschaftswerk der Mecklenburger Ornithologen, das in drei Ausgaben 1977, 1979 und 1987 erschienene Buch „Die Vogelwelt Mecklenburgs", lieferte die Fachgruppe Güstrow mit den in den Jahresberichten enthaltenen Artauswertungen und auf Lochkarten erfassten Daten zahlreiche Zuarbeiten an die Artbearbeiter.

$\mathrm{Zu}$ den Artbearbeitern und Mitarbeitern an einzelnen Arten dieses Buches gehörten die FG-Mitglieder R. Becker, W. Köhler, K.-H. Koop, J. Loose, W. Neubauer (Artbearbeiter: Flussseeschwalbe), K. Pohlmann, G. Strache und M. Völkel. Für die 3. Auflage des Buches stellte die Rasterkartierung der Brutvögel von 1978 bis 1982/83 eine wesentliche Grund- 
lage dar. Das Kreisgebiet mit gesamt elf Messtischblättern (insgesamt $42 \mathrm{MTB} / \mathrm{Q}$ ) wurde durch die vorgenannten Personenkreis vollständig kontrolliert. Die 1980er Jahre waren für die Fachgruppe sehr ergebnisreich.

In Gemeinschaftsarbeit errichteten FG-Mitglieder mit finanzieller Unterstützung durch den Rat des Kreises 1980 eine neue Feldstation auf dem Großen Werder im den NSG Krakower Obersee. Gleiches geschah 1983/84 auch im NSG Breeser See. Die Arbeit der Ornithologen und Naturschützer konnte in diesen Gebieten dadurch wesentlich verbessert werden.

Nach dem Tode von Kurt Pohlmann übernahm Joachim Loose die Betreuung des NSG Breeser Sees und begann hier eine intensivere Beringungstätigkeit. Die Arbeit mit der Jugendgruppe der AG aus Mühl Rosin konnte er nicht fortsetzen.

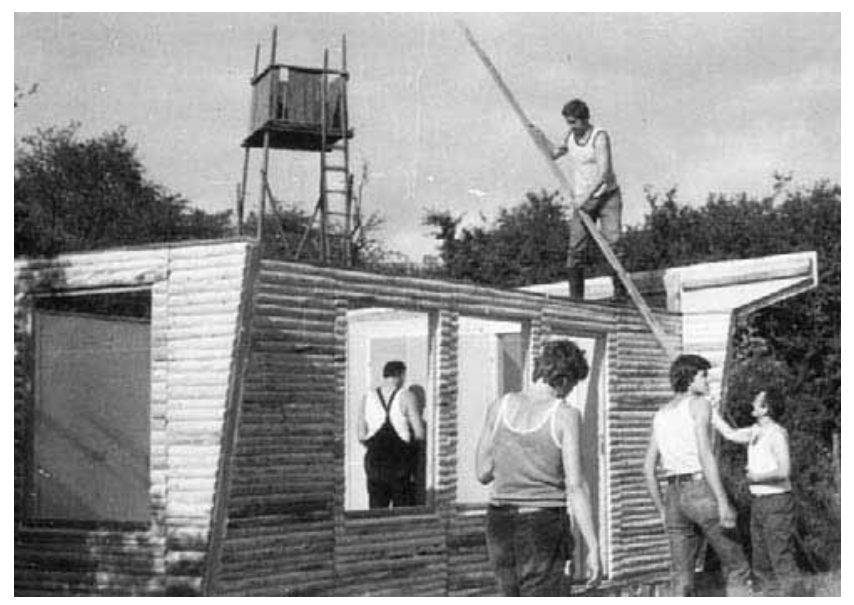

Abb. 7: Errichtung der Feldstation auf dem Großen Werder im NSG Krakower Obersee (im Bild - Wolfgang Neubauer, Reinhard Kaatz, foachim Loose, Michael Nehls, Wolfgang Köhler). Foto: A. Martin.

Die auf Antrag von Mitgliedern der FG 1974 (Breeser See) und 1976 (Upahler und Lenzener See) einstweilig gesicherten Naturschutzgebiete wurden durch den Bezirkstag Schwerin 1982 als NSG endgültig gesichert, wofür die weiter vorgelegten Beobachtungen der Ornithologen und die von ihnen erarbeiteten Behandlungsrichtlinien wesentliche Argumente lieferten.

1983 kamen wir in die für DDR-Verhältnisse komfortable Situation, dass ein Mitglied der Fachgruppe hauptamtlich im Naturschutz eine Tätigkeit aufnehmen konnte. Nach Abschluss ihres Forschungsstudiums an der Pädagogischen Hochschule Güstrow besetzte Angela Martin die im Staatlichen Forstwirtschaftsbetrieb (StFB) Güstrow frei werdende Stelle als Mitarbeiter Landeskultur/Naturschutz. Die Übernahme dieser Funktion vom Koll. Borrock schilderte A. Martin uns später so:

„Das Übergabegespräch dauerte 15 Minuten und endete mit dem aufmunternden Satz: „Sie werden noch an meine Worte denken." - gemeint war damit - es kann eben nichts erreicht werden."
Durch den StFB gab es keine fachlichen Vorgaben für das neue Betätigungsfeld. So konnte sich A. Martin als für den Naturschutz brennende Person voll in unserem Sinne entfalten. Durch die Ansiedlung der Planstelle bei der Forst kam es zu dem Nebeneffekt, dass dort die Berührungsängste mit dem Naturschutz recht klein blieben. Für die ornithologische Arbeit waren insbesondere Kontakte zu Förstern und Weidgenossen wichtig. Zu den Jägern hatte W. Neubauer als Kreisnaturschutzeauftragter, auch Mitglied im Jagdbeirat und selbst ein Jäger, bereits sehr gute Verbindungen in diese Kreise gepflegt. Mit dem von 1983 bis 1989 wirkenden Trio Angela Martin - Wolfgang Neubauer - Heinz Stegemann (dem Sekretär für Jagd und Naturschutz beim Rat des Kreises Güstrow) konnten bei sehr guter Zusammenarbeit viele nachteilige Folgen für den Naturhaushalt abgewendet oder zumindest abgeschwächt werden. Die große schwerwiegende Melioration der 1960/1970er Jahre war vorbei. Dennoch lebte der Wahnsinn der Trockenlegung von Moorflächen immer mal wieder auf. So war auch die Trockenlegung der Sumpfseeniederung westlich von Gutow 1984 nicht durch die drei zu verhindern. Mit viel Aufwand wurde hier das Gebiet über ein errichtetes Schöpfwerk in den nördlich liegenden Sumpfsee entwässert. Die Lebensräume von Bekassine, Kiebitz, Blaukehlchen und Knabenkräutern gingen verloren (in den 1950er Jahren riefen hier noch Brachvogel und Rotschenkel). Auch 1986 wurden u. a. noch weitreichende Meliorationen auf Feuchtwiesen im Randbereich des NSG Breeser See durchgeführt. Das wirkt bis heute nach. Wenn der Wasserund Bodenverband auf Forderungen der Landwirte hin die Randgräben beräumen muss, können Nährstoffe von den Äckern immer wieder ungebremst in den See gelangen.

Als dann gar noch Ende der 1980er Jahre auch die südlich des Inselsees liegende Feuchtniederung analog zum entstandenen Gutower Polder der Landwirtschaft zum Opfer fallen sollte, ging die Fachgruppe mit einer so genannten „Wahleingabe“ auf die Barrikaden. Das wirkte. Es kamen dann auch tatsächlich zwei Herren im schwarzen Anzug aus Berlin und hörten sich unsere Argumente an. Ob hier die politische Wende hilfreich war oder man tatsächlich vernünftige Abwägungen getroffen hat, bleibt dahingestellt. Im Ergebnis wurde in das Gebiet nicht eingegriffen. Es steht seit dem Beschluss vom 7.7.1993 als Naturschutzgebiet „Gutower Moor“ (ab 5.1.2000 in erweiterter Form als NSG „Gutower Moor und Schöninsel") unter Schutz.

Etwas später „löckten“ die FG-Mitglieder ein zweites Mal wider den Stachel. Sie organisierten erfolgreich eine Protestaktion gegen die Errichtung des neuen Verkehrshofes von Güstrow, der im Landschaftsschutzgebiet „Inselsee und Heidberge“ vor den Toren der Stadt an der Plauer Chaussee geplant war. Spätestens jetzt war die Fachgruppe wohl eine „Umweltorganisation“, der von bestimmten Kreisen Aufmerksamkeit zu widmen war (in Stasi-Akten über einige FG-Mitglieder nachlesbar). 
Spätestens mit den 1980er Jahren gab es in allen Kreisen des Bezirkes unter dem Dach des Kulturbundes, später der Gesellschaft für Natur und Umwelt (GNU) funktionierende Fachgruppen, deren Arbeit systembedingt und möglichst im Wettbewerb verglichen werden sollte. In den Jahresberichten Nr.13, 15, 19 und 21 finden sich tabellarische Übersichten mit namentlichen Angaben je FG-Mitglied zu einzelnen Abrechnungsparametern. Diese waren zentral vom Kulturbund des Bezirkes Schwerin, ggf. auch von höherer Stelle, vorgegeben.

Bemerkenswert ist besonders die geleistete Öffentlichkeitsarbeit in Form von Vorträgen und Veröffentlichungen $\mathrm{zu}$ jener Zeit (Tab. 1).

Besonders gute Leistungen Einzelner wurden auf dieser Basis durch den Rat des Kreises prämiert oder mit Abzeichen und Urkunde für gute Naturschutzleistungen in Bronze oder Silber geehrt. Ein Versuch, weniger Aktive zu mehr zu animieren und typisch für die Zeit der Wettbewerbe! Anlässlich des 20-jährigen Bestehens unserer Fachgruppe fand die bezirkliche Ornithologentagung am 22.9.1985 in Güstrow statt. Die Hälfte der fachlichen Vorträge wurde von Mitgliedern der FG Güstrow gehalten (Abb. 8). Wolfgang Neubauer berichtete über die bisherige Geschichte der Fachgruppe und sprach in einem zweiten Beitrag über den Krakower Obersee als Mauserplatz von Tauchenten. Angela Martin stellte das gerade durch ihr Wirken unter Schutz gestellte System der Flächennaturdenkmale vor. Die Verbreitung des Fischadlers im Bezirk Schwerin und die Bestandsentwicklung des Graureihers im Kreis Güstrow waren Themen von Wolfgang Köhler und Reinhard Becker. Joachim Loose berichtete von den Besonderheiten des NSG Breeser See.

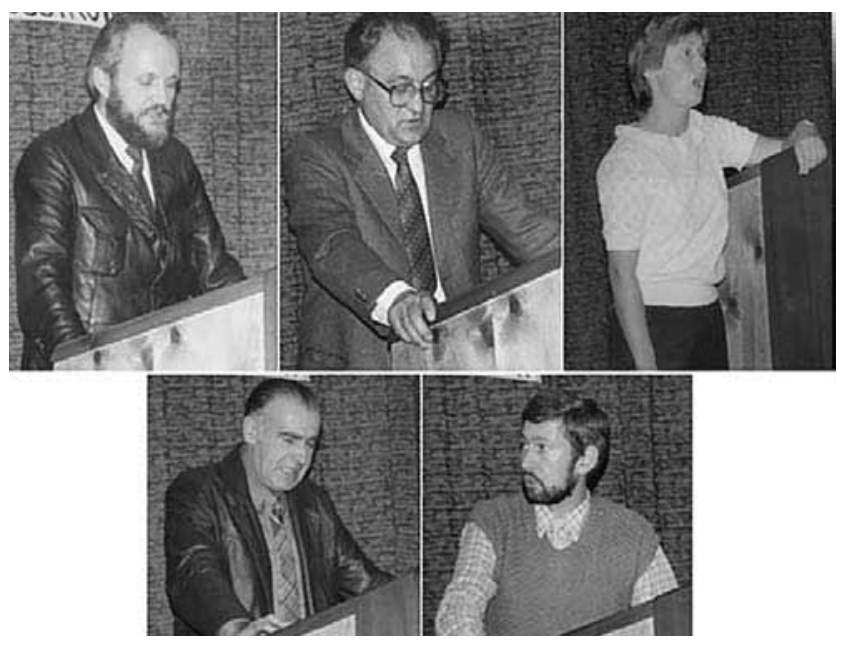

Abb. 8: Die Referenten der FG auf der Bezirks-Ornithologentagung 1985 waren W. Köhler, R. Becker, A. Martin, W. Neubauer, F. Loose. Fotos: A. Martin.

Der Jahresbericht der FG Nr.20 für 1987 erschien erstmalig im Titelblatt mit einer von Angela Martin gestalteten Vignette.

Als Art wurde fortan ein Vogel gewählt, der in dem Berichtsjahr als Besonderheit aufgefallen oder für den eine umfassende Erfassung gelaufen war. Sperber, Kiebitz, Eisvogel, Schleiereule, Rothalstaucher, Odinshühnchen, Sterntaucher, Säbelschnäbler, Birkenzeisig, Bekassine, Wachtelkönig, Weißflügelseeschwalbe, Rauhfußkauz, Schwarzkehlchen, Haubentaucher, Schwarzhalstaucher, Zwergdommel, Schwarzkopfmöwe, Silberreiher, Gänsegeier, Wanderfalke, Uhu, Brandgänse, Kiefernkreuzschnäbel, Wiedehopf, Nilgänse, Flussseeschwalbe und Steinschmätzer schafften bisher den Sprung auf die Titelseiten der Jahresberichte (vgl. Heftrückseite).

\begin{tabular}{|c|c|c|c|c|c|}
\hline \multicolumn{2}{|l|}{ Aufgabe } & \multirow{2}{*}{$\begin{array}{c}1980 \\
1\end{array}$} & \multirow{2}{*}{$\begin{array}{c}1982 \\
15\end{array}$} & \multirow{2}{*}{$\begin{array}{c}1986 \\
19\end{array}$} & \multirow{2}{*}{$\begin{array}{c}1988 \\
20\end{array}$} \\
\hline Anzahl der abrechnenden FG-Mitglieder & \multirow{10}{*}{ Angabe in Std. } & & & & \\
\hline Betreuung von NSG [und LSG] & & 1048 & 486 & 295 & 551 \\
\hline Geschützte Tiere und Pflanzen & & 370 & 261 & 435 & 186 \\
\hline Rasterkartierung & & 494 & 453 & - & - \\
\hline Wasservogelzählung & & 82 & 69 & 151 & 187 \\
\hline Beringung & & - & - & 254 & 381 \\
\hline Allgemeine Beobachtungen & & 988 & 746 & २२०५ & २०८२ \\
\hline Arbeit mit Behörden & & 64 & 252 & - & - \\
\hline Öffentlichkeitsarbeit/Ausstellung & & 144 & - & 43 & - \\
\hline Summe & & 3190 & 2267 & 3340 & 3387 \\
\hline Vorträge/Veröffentlichungen & \multirow{2}{*}{ Stück } & $16 / 6$ & $15 / 15$ & $44 / 7$ & $61 / 12$ \\
\hline Nisthilfen und Futterstellen & & 90 & 170 & - & - \\
\hline
\end{tabular}

Tabelle 1: Abrechnung der Leistungen aller FG-Mitglieder (Einzelabrechnungen zusammengefasst) 
Nachdem von 1989 bis 1999 die Jahresberichte im Format A5 erschienen waren, wechselten wir mit der Nr. 33 im Jahr 2000 wieder auf die zuvor verwendete A4-Größe zurück, was auch mit einem Qualitätssprung im Druck einherging. Ab 2012 gibt es sogar Farbdrucke im Heft.

Mit Entwicklung der Technik wurden alte Hefte eingescant. So stehen inzwischen die Daten und Berichte auch einem breiteren Artbearbeiterkreis für Auswertungszwecke in Form von pdf-Dateien zur Verfügung.

Nach 1989 kamen weniger Mitglieder zu den FG-Abenden. Nach den Teilnehmerlisten (unsere einzige Formalität) kamen vor der Wende bis zu knapp 30, danach meist nur noch 14 bis 18 Mitglieder.

1990 wurde die Leitung der FG Ornithologie und Naturschutz an Angela Martin übertragen, die nach einem folgenschweren Unfall 1989 mit viel Energie wieder aktiv werden konnte.

Zentrale Aufgabe in den 1990er Jahren war die Durchführung der 2. Rasterkartierung der Brutvögel in Mecklenburg-Vorpommern von 1994 bis 1998, die wie bereits die erste Kartierung auf Basis der MTB-Quadranten erfolgte. Die Fläche des Altkreises Güstrow konnte wiederum vollständig von Mitgliedern der FG abgedeckt werden. Bei der Kartierung beteiligten sich R. Becker, U. Gehlhar, W. Köhler, K.-H. Koop, M. Lemke, J. Loose, W. Neubauer, G. Strache, U. Thamm und R. Wiechert.

Die bereits 1973 formulierte Zielstellung und für 1977 anvisierte Fertigstellung einer lokalen Avifauna konnte nach langer Verzögerung schließlich durch Wolfgang Neubauer 2004 doch noch umgesetzt werden: In der Schriftenreihe Natur und Naturschutz in Mecklenburg-Vorpommern erschien als Sonderheft - Band XXXIX „Die Vogelwelt des Altkreises Güstrow“ (Abb. 9).

J. Loose und S. Lorenz wirkten in geringem Maße mit. Zum ausgewerteten Datenpool hatten alle FG-Mitglieder und mehr als 100 Gewährsleute beigetragen. Einführend zur Avifauna schrieb Neubauer:

„Mit dem Ablauf des fahres 2002 sind in der Kartei 261 Vogelarten erfasst. Davon sind 175 in der Vergangenheit oder in neuerer Zeit als Brutvögel nachgewiesen, 83 erscheinen mehr oder weniger regelmäßig auf dem Zug im Kreisgebiet und 3 sind offensichtlich Gefangenschaftsflüchtlinge."

Nach dem Abschluss der Datenauswertung wurden unsere Jahresberichte wieder etwas dünner. Neben den obligatorischen Berichten zu Weißstorch, Kranich und Graureiher berichtete ab 2001 A. Martin über die Ergebnisse ihrer Planbeobachtungen und Beringungen von Sperbern. J. Loose und W. Neubauer werteten in mehreren Beiträgen Vogelberingungen und Wiederfunde beringter Vögel aus.
Die neue Zeit ermöglichte es, begangene Fehler in der Melioration rückgängig zu machen und Feuchtgebiete wieder herzustellen. Derartigen Gebieten widmeten sich fortan einige Ornithologen. So wurden die ersten Beobachtungen nach der Renaturierung der Polder Gutow, Klaber und Bossow in Jahresberichten ausgewertet.

Aus den Jahresberichten der Fachgruppe können nicht alle Aktivitäten ihrer Mitglieder entnommen werden.

Seit Beginn der Wasservogelzählungen an ausgewählten Gewässern des Landes wurden in sechs Zählgebieten im Altkreis (Parumer See, Inselsee, Sumpfsee, Upahler See, Breeser See und Krakower Obersee) regelmäßig die Wasservögel durch R. Wiechert, W. Köhler, M. Montschko, J.Loose und W. Neubauer an vorgegebenen Terminen jährlich von September bis März/April erfasst. Dabei wurden auch die rastenden Gänse gezählt.

J.Loose und M.Montschko beteiligten sich von 03/1985 bis 12/1990 an einem vom ILN Greifswald koordinierten „Vogelschlag-Warndienst“-Programm und meldeten auf speziellen Formblättern mehrfach monatlich die Vogelrastbestände von ausgewählten Seen und Feldfluren. Die Daten wurden für den militärischen Flugdienst ausgewertet.

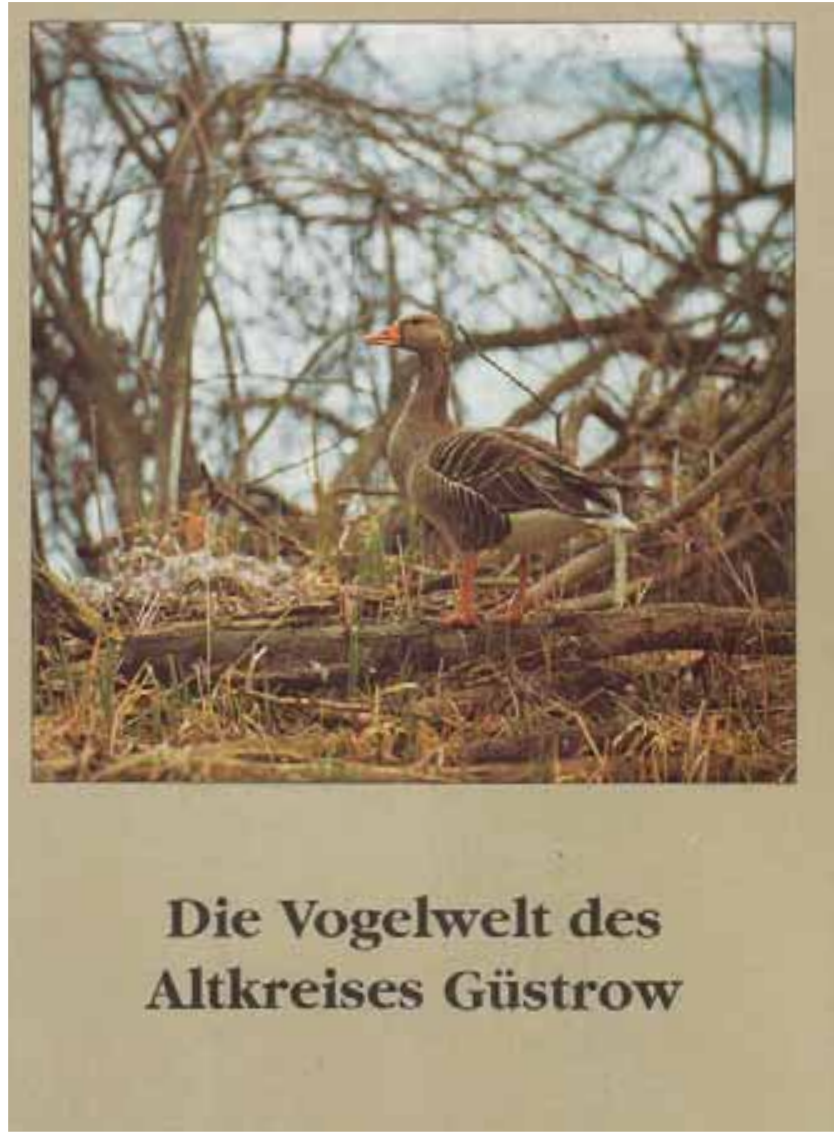

Abb. 9: Titelblatt der Kreisavifauna (2004)

Fast allen vom OAMV oder DDA gestarteten Aufrufen von zentral gewünschten periodischen Erfassung einzelner Arten (wie z. B. Höckerschwan, Kormoran, Graugans, 
Graureiher, Lachmöwe, Rotmilan) waren die FG-Mitglieder gefolgt und lieferten ihre Erfassungsbögen ab, wobei es zunehmend weniger gelang, das gesamte Altkreisgebiet abzudecken und überhaupt verlässliche Mitarbeiter zu gewinnen.

W. Köhler und W. Neubauer betreuten über Jahre Seeund Fischadler innerhalb unseres Wirkungsbereiches. W. Köhler war außerdem Mitglied der Bezirks-Arbeitsgruppe für „vom Aussterben bedrohter Tiere“ (AKSAT) und ist heute analog beim LUNG aktiv.

FG-Mitglieder widmeten sich auch ganz praktischen $\mathrm{Na}$ turschutzarbeiten.

1996 wurden mit Unterstützung der NABU-Gruppe aus Rostock in der Pfarrkirche und im Dom Güstrow 28 Dohlenbrutkästen eingebaut. Ab 1997 engagierte sich Reinhard Becker mit Unterstützung von A. Martin bei Gebäudesanierungen in Güstrow für den den Einbau von Nistkästen für Mauersegler.

In Verbindung mit der WEMAG veranlaßte J. Loose die Anbringung von zehn Turmfalkenkästen an Strommasten in der freien Feldmark. Wo es notwendig wurde, organisierte R. Schaugstat die Erneuerung von Weißstorchnisthilfen. Vom Energietrieb frei gegebene erhaltenswürdige Trafohäuser wurden in zehn Orten durch das FG-Mitglied Jörg Bußmann im Auftrag der NABU-Ortsgruppe Güstrow als mögliche Heimstatt für Schleiereulen, Turmfalken, Fledermäuse, Hornissen u.ä. unter Nutzung von Fördermitteln hergerichtet. Durch Helmut Richter erfolgten 2012 bis 2014 mit viel Engagement an den Stationen noch erforderliche Nachrüstungen und Optimierungen. Er führte anschließend auch die notwendigen Erfolgskontrollen durch.

Die FG veranlasste den Bau zahlreicher Nistkästen durch die geschützte Werkstatt in Güstrow und von behinderten Schülern der Anne-Frank-Schule Güstrow, die am Bossower See, am Breeser See, auf dem Friedhof Güstrow und in Forstrevier Lohmen ausgebracht wurden.

Mit diesen Arbeiten wird die enge Verbindung der Fachgruppe Ornithologie und Naturschutz mit der NABU-Ortsgruppe Güstrow deutlich. So wie früher die FG den aktiven Kern der Kreisorganisation in der GNU bildete, bestimmt sie auch heute neben einer sehr aktiven botanischen Gruppe die Arbeit in der NABU-Gruppe.

FG-Mitglieder hatten sich stets besonders für die Naturschutzgebiete im Kreis Güstrow eingesetzt. Kurt Pohlmann erkannte die Bedeutung des Breeser Sees und Hans Georg Müller die des Schlichten Moores. Das NSG Upahler und Lenzener See entstand auf Anregung von Adolf Kretschmann, Wolfgang Köhler, Kurt Pohlmann und Georg Strache.
Die Unterschutzstellung des NSG Nebeltal wurde durch Angela Martin und Wolfgang Neubauer wesentlich vorangetrieben. Auch bei der Betreuung der NSG sind die FGMitglieder tätig. Für die Erstellung des 2003 erschienenen Buches „Die Naturschutzgebiete in Mecklenburg-Vorpommern" wurde von den Betreuern auch die Kapitelbearbeitung zu ihren NSG übernommen:

- NSG Upahler und Lenzener See (Nr. 116) durch

A. Kretschmann

- NSG Breeser See (Nr. 105) durch J. Loose

- NSG Zehlendorfer Moor (Nr. 86) durch A. Martin

- NSG Gutower Moor und Schöninsel (Nr. 261) durch M. Montschko

- NSG Krakower Obersee (Nr. 119) durch W. Neubauer

Bereits zu Beginn der Rasterkartierung 1994-1998 war als zentrales Anliegen der OAMV die Ergebnisauswertung als „Atlas der Brutvögel in Mecklenburg-Vorpommern“ vorgesehen. Die Herausgabe dieses bedeutsamen Buches verzögerte sich bis 2006.

FG-Mitglieder übernahmen auch hier die Bearbeitung von Artkapiteln:

W. Köhler - Fischadler, Wanderfalke

J. Loose - Rohrdommel, Zwergdommel, Bartmeise

W. Neubauer - Gänsesäger, Flussseeschwalbe

Beim nächsten großen Gemeinschaftsvorhaben, der ADEBAR-Kartierung von 2005-2009/10, konnte unser Altkreis in der Gesamtfläche nicht mehr vollständig durch FGMitglieder abgedeckt werden. Insbesondere im Norden und Nordwesten fehlten die früheren Bearbeiter R. Becker und G. Strache. So musste für die MTB 2039 und 2139 Unterstützung von Doberan angefordert werden. An der Kartierung beteiligten sich dieses Mal K.-H. Koop, W. Köhler, H. Kusch, J. Loose, A. Martin, W. Neubauer, H. Richter, E. Schlüter, U. Thamm und R. Wiechert. Für einige „Neulinge" bei der Kartierung stellte sich diese Aufgabe durchaus als eine Herausforderung dar. Das Studium der Vogelstimmen als Basis für eine effektive Kartierung darf halt nicht vernachlässigt werden.

Nachdem wir bei einem Vogelstimmen-Quiz in den 1980er Jahre feststellen mussten, dass lange nicht alle Mitglieder so sattelfest waren, wie es für Ornithologen bei Kartierungsarbeiten im Felde erforderlich ist, wurden Stimmenschulungen insbesondere im Frühjahr zum festen Bestandteil unserer FG-Abende eines jeden Jahres. Ebenfalls gab es durch unserer FG-Mitgieder G. Strache und A. Martin geführte Vogelstimmenexkursionen für interessierte Bürger. In neuerer Zeit war es unsere Dienstleistung, die alljährlich über die Kreisvolkshochschule Güstrow (KVHS) an mehreren Wochenenden von März bis Juni angeboten wurde. Regelmäßige Teilnehmerzahlen um 15 Personen waren hier zu 
verzeichnen; meist kamen ältere Bürger, ein Nachwuchsproblem ließ sich für die Fachgruppe auf diesem Wege bisher nicht lösen.

Das Angebot der Vogelstimmenexkursionen über die KVHS galt als ein Entgegenkommen an unseren Quartiergeber für unsere FG-Abende. Nach der Auflösung des Kulturbundes der DDR 1990 und Schließung des Kersting-Klubs fanden wir uns kurzzeitig im Internat der EOS Güstrow zusammen und wechselten dann an den Rand der Stadt in den Tierpark Güstrow. Die ungünstige Erreichbarkeit des Tierparks $\mathrm{zu}$ abendlicher Zeit trieb uns dann in die Räume der neu entstandenen Kreisvolkshochschule - hier war es auch für interessierte Bürger einfacher, einmal als Gast bei den Ornithologen reinzuschauen.

Für die FG-Zusammenkünfte wurden ab Mitte der 1980er Jahre jeweils halbjährliche Themenpläne erstellt. Die von allen FG-Mitgliedern vorgeschlagenen Themen hatten nicht nur ornithologische Inhalte. Entsprechend unserer Ausrichtung als Fachgruppe für Ornithologie und Naturschutz kamen häufiger auch Beiträge über andere Artengruppen auf die Tagesordnung. So wurden Nachweise von Fledermausarten im Kreisgebiet und herpeto- und entomologische sowie botanische Themen vorgetragen. Dazu wurden vielfach auch Referenten von außerhalb eingeladen.

Einen festen Platz nahmen die jährlichen Berichte der NSG-Betreuer über „ihre“ Naturschutzgebiete ein. Ebenso informierte uns W. Köhler jährlich über Brutbestandsergebnisse von Seeadler, Fischadler und Wanderfalke. Vor dem Erscheinen der Brutberichte zu Weißstorch, Kranich und Graureiher im jeweiligen Jahresbericht wurden die Ergebnisse vorgetragen und durch die FG-Mitglieder ergänzende Hinweise gegeben.

Seit 1990 stand auch eine Rubrik „Neues aus der unteren Naturschutzbehörde“ auf der Tagesordnung. Die Tradition der engen Verbindung zwischen der Fachgruppe und dem amtlichen Naturschutz konnte fortgesetzt werden, da mit der politischen Wende neue Naturschutzstrukturen beim Landkreis geschaffen wurden und wir vielerorts im Lande „unsere Leute“ in diese Positionen bringen konnten. Durch Unterstützung von W. Neubauer, dessen Stimme als altgedienter Kreisnaturschutzbeauftragter (KNB) beim aufgelösten Rat des Kreises und neu eingesetzten Landrat noch genügend Gewicht hatte, konnte Joachim Loose von der FG die Funktion des Amtsleiters Naturschutz und Landschaftspflege übernehmen. Mitarbeiter wurden die FG-Mitglieder Maren Fritsche und Manfred Montschko.

Wenngleich durch neue Naturschutzgesetzgebungen und politische Strömungen 1994 die bis dahin tätigen KNB Wolfgang Neubauer und Fritz Holst offiziell abberufen wurden und es hinterher nicht gelang, nach dem Gesetz mögliche Naturschutzwarte zu bestellen, arbeiteten die bis dahin als Naturschutzhelfer tätigen FG-Mitglieder im bisherigen Sinne dem Naturschutz verbunden weiter.
Gemeinschaftsaktivitäten zur Pflege von Biotopen (Mahd und Entbuschungen), wie wir sie früher jährlich mit viel Spaß durchführten, sind heute sehr selten geworden. Nach Schaffung der neuen Naturschutzstrukturen war es anfangs für den amtlichen Naturschutz überhaupt kein Problem, alle notwendigen Pflegemaßnahmen von Firmen durchführen zu lassen. Bald verringerte sich jedoch die finanzielle Ausstattung der Behörde.

Inzwischen wäre eine ehrenamtliche Hilfe wieder gewünscht, aber die gewachsene Tradition ist erst einmal zerstört. Des Weiteren besteht auch eine geänderte berufliche Belastung einzelner FG-Mitglieder, die ihre geringere Freizeit der Familie widmen möchten. Zeiten, wo wir für die Betreuung von Seevogelschutzgebieten von den Betrieben bezahlt freigestellt wurden und diese Arbeit als gesellschaftlich notwendig und wertvoll galt, gibt es in einer auf Leistung orientierten Gesellschaft leider nicht mehr. Da bei den Behörden kaum noch genügend Geld zur Verfügung steht, sind vielfach deutliche Mängel in der Unterhaltung der 1984 und 1987 als Flächennaturdenkmale (FND) durch Kreistagsbeschluss gesicherten Flächen und in einigen NSG zu verzeichnen.

Der Bericht über die nunmehr 50jährige Arbeit der Fachgruppe darf nicht ohne die Hervorhebung einiger besondere Forschungsarbeiten einzelner FG-Mitglieder abgeschlossen werden.

Wolfgang Neubauer forschte seit 1958 bis zu seinem Tode 2013 an Flussseeschwalben. In den Brutkolonien am Krakower Obersee, im Kieswerk Langhagen, am Drewitzund Dreiersee hat er bis 2013 mehr als 12.190 Individuen beringt und mit speziellen Fangkörben mindestens 3.291 Vögel wieder gefangen. Daraus konnte er u. a. bedeutsame Ergebnisse zum Altersaufbau einer Brutkolonie sowie zu langzeitlichen Partnerbeziehungen bei Flussseeschwalben ableiten. Zu seinen besonderen Aktivitäten gehörten auch mehrjährige Untersuchungen an einer Haubentaucherkolonie im Krakower Obersee sowie mehrjährige Siedlungsdichteuntersuchungen in zwei Waldgebieten (NSG Großes Holz; Wald-Totalreservat Großer Barkhorst) und an mehreren Feldhecken.

Angela Martin unternahm von 1988 bis 2003 intensiv die Suche von Nestern der Haubenlerchen und beringte insgesamt 289 Vögel dieser Art, davon 266 mit Farbringen. Die Bedeutung dieser Arbeit, bei der zahlreiche brutbiologische Daten erhoben wurden, wird erst heute erkennbar, wo wir überall einen drastischen Rückgang dieser Art feststellen müssen.

Ab 1985 suchte A. Martin mit viel Energie und hohem Fahrrad-Fahraufwand im Kreisgebiet nach Sperberhorsten und beringte mit Hilfe von FG-Mitgliedern und Forstarbeitern bis 2015 insgesamt 704 Jungsperber. Auch bei dieser Arbeit wurden vielfältige brutbiologische Daten, wie das Geschlechterverhältnis der Jungvögel, bevorzugte Horstbaumarten, Höhe der Horste u. a., erfasst. 
Joachim Loose widmete sich im NSG Breeser See mit dem Aufbau einer Beringungsfeldstation intensiv der Beringung von Bartmeisen. Ab 1983 hat er hier kontinuierlich den jährlichen Brutpaarbestand der Bartmeisen erfasst, der in einigen Jahren bis zu 50 Brutpaare betrug. Bis einschließlich 2015 beringte er 1893 Bartmeisen. Als „Beifänge“ wurden mehr als 6.000 Individuen im Schilf und in angrenzenden Gehölzen brütender Singvögel beringt.

Die Zunahme des Blaukehlchens und dessen Status als erfolgreicher Brutvogel mit hoher Rückkehrrate zum Breeser See konnte belegt werden. Von 1983 bis 2015 wurden 128 Blaukehlchen beringt. Gleichfalls im NSG Breeser See unterstützte er durch das Angebot künstlicher Nistplattformen die Ansiedlung von Flussseeschwalben. Ab 1989 hat sich kontinuierlich steigend ein Brutbestand von bis zu 162 Brutpaaren eingestellt. Von 1989 bis 2011 sind 1.715 Küken dieser Art flügge geworden, von 2012 bis 2015 haben verschiedene Prädatorenarten zu völligen Brutverlusten geführt.

Wolfgang Köhler leitete in Verbindung mit seiner Mitgliedschaft im Landesjagdverband ein Projekt zur Wiederansiedlung von Wanderfalken in Mecklenburg-Vorpommern. Das von 1995 bis 2010 laufende Auswilderungsprogramm ver- zeichnet inzwischen bis 2015 Bruterfolge von mindestens vierzehn wieder auf Bäumen brütenden Wanderfalkenpaaren. Die Projektgruppe Wanderfalke des LJV MecklenburgVorpommern e.V. erhielt für ihr Engagement den Naturschutzpreis 2001 des Deutschen Jagdschutz-Verbandes.

Uwe Gehlhar und Remo Wiechert hatten Langzeitbeobachtung an rastenden Limikolen in den Klärteichen der Zuckerfabrik bis zu deren Abriss getätigt und ausgewertet. Dadurch haben sie wesentlich dazu beigetragen, dass es im Rahmen eines Ausgleichsprojektes gelang, nach dem Wegfall einer Wasserbeschickung aus der Zuckerfabrik Güstrow wenigstens einen Absetzteich langfristig als Limikolenrastplatz zu erhalten. W. Köhler und J. Loose begleiteten in einem dreijährigen Monitoring die Entwicklung dieses neu geschaffenen Biotops und konnten belegen, dass Limikolen auch weiterhin intensiv diesen Platz als Nahrungs- und Rasthabitat nutzten und er eine große Bedeutung hat.

Die Forschungsergebnisse sind publiziert worden oder befinden sich in Vorbereitung für eine Publikation und sind u. a. im Anhang dieses Heftes im Literaturverzeichnis ausgewiesen.

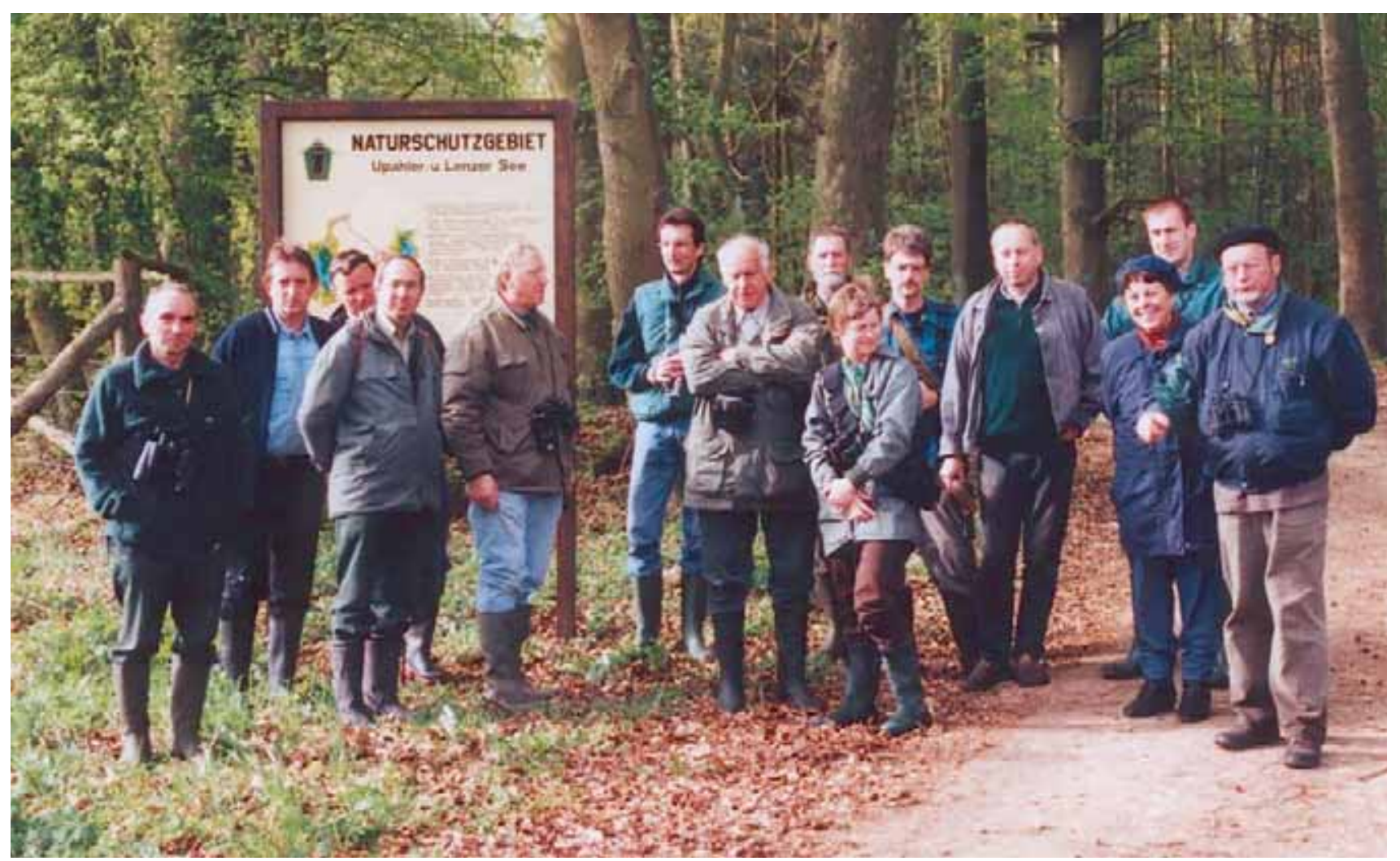

Abb. 10: Teilnehmer der FGExkursion am 5.5.2001 zum NSG Upahl-Lenzener See

(v.l.n.r..) Adolf Kretschmann, Bernhard Oosterloo, Manfred Montschko, Karl-Heinz Koop, Klaus Lingsminat, Jörg Bußmann, Wolfgang Neubauer, Volker Bösel, Angela Martin, Remo Wiechert, Guntram Trost, Uwe Thamm, Angelika und Eckard Bomke. Foto: 7. Loose. 

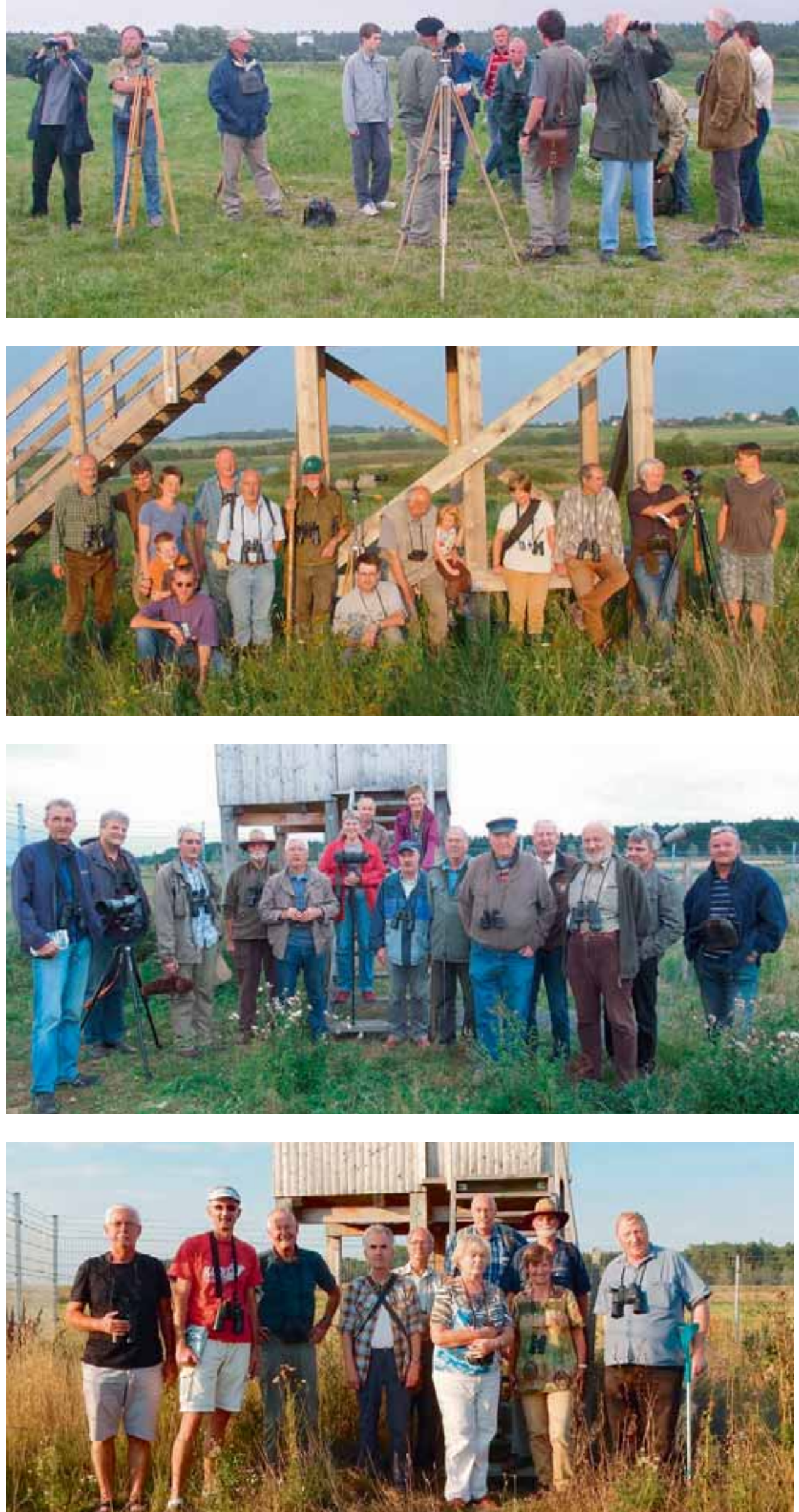

Abb. 11: Teilnehmer der FG-

Exkursion am 26.8.2004 zu den Zuckerfabrik-Klärteichen (v.l.n.r..) - unbekannt, Carsten Vick, Wolfgang Pfannenschmidt, Robert Jänicke, Wolfgang Neubauer, Joachim Loose (verdeckt), Manfred Montschko, Adolf Kretschmann, Remo Wiechert, Herald Kusch, Uwe Gehlhar (verdeckt), Wolfgang Köhler, Steffen Thiel. Foto: A. Martin.

Abb. 12: Teilnehmer der Fachgruppenexkursion am 24.8.2007 zum Sumpfseepolder (v. l.n.r..) - Wolfgang Köhler, Steffen Thiel, Elke Zielonka, Jörg Bußmann mit Sohn fonas, Klaus Lingsminat, Helmut Richter, Volker Bösel, Remo Wiechert, Wolfgang Neubauer mit Tochter Charlotte von Remo, Angela Martin, Karl-Heinz Koop, foachim Loose, Uwe Gehlhar. Foto: f. Loose.

Abb. 13: Teilnehmer der Fachgruppenexkursion am 22.8.2014 zum PVA-Teich (v.l.n.r..) - Förg Bußmann, Reinhard Kaatz, Remo Wiechert, Volker Bösel, foachim Loose, Beate MederTrost, Guntram Trost, Angela Martin, Helmut Richter, KarlHeinz Koop, Klaus Lingsminat, Eckard Schlüter, Wolfgang Köhler, Steffen Thiel, Manfred Montschko. Foto: F. Loose.

Abb. 14: Teilnehmer der Fachgruppenexkursion am 21.8.2015 zum PVA-Teich (v.l.n.r..) foachim Loose, förg Bußmann, Eckard Schlüter, Klaus Kirschnick, Karl-Heinz Koop, Christiane Bösel, Helmut Richter, Volker Bösel, Angela Martin, Klaus Lingsminat. Foto: 7. Loose. 


\title{
3. Aus der Fachgruppe geboren - die Botanik-Arbeitsgemeinschaft
}

\author{
Angela Martin
}

1980 bat mich Kurt Pohlmann während einer Exkursion, ihm und einigen Mitgliedern der Fachgruppe doch „ein paar Pflanzen beizubringen“. Sie würden durch so viele Gebiete streifen und wüssten nicht, welchen seltenen Pflanzenarten sie begegnen. Auf Grund meiner botanischen Arbeiten zum Diplom und später zur Promotion rückte die Pflanzenwelt bei mir immer mehr in den Mittelpunkt. Meine daraus erwachsene zunehmende Kenntnis der Pflanzenarten war wohl nicht ganz unentdeckt geblieben.

Den Auftrag nahm ich in ,jugendlichem Leichtsinn“ an und warb in der FG während einer Tagung der BezirksOrnithologen in Güstrow-Schabernack um Teilnehmer für ein erstes Treffen zur Schulung pflanzlicher Artenkenntnis. Zunächst gab es für diese Zusammenkünfte keine großen Pläne. Wir fingen einfach mittendrin in der bunten Pflanzenwelt am 20. Februar 1981 mit der Gattung Hahnenfuß an. Zu meinem ersten Seminar - wie ich diese Zusammenkünfte nannte - kamen fünf Ornithologen der FG: Fritz Anderlik, Wolfgang Köhler, Joachim Loose, Hans-Georg Müller und Georg Strache. Zu den Teilnehmern in den nächsten Zusammenkünften, die bereits damals in einem 14-tägigen Rhythmus stattfanden, gehörten später weitere FG-Mitglieder: Adolf Kretschmann, Manfred Montschko, Wolfgang Neubauer, Andreas Schilf, Marga Völkel. Nur der eigentliche Initiator Kurt Pohlmann kam nie zu der neuen Gruppe. Ihm gingen meine Aktivitäten plötzlich zu schnell. Wahrscheinlich war er bereits von seiner schweren Krankheit beeinflusst.

Zunächst waren wir Ornithologen fast unter uns und die neue Botanik-AG als ein echter Ableger der Fachgruppe Ornithologie und Naturschutz geboren. Nach und nach stießen aber auch Nicht-FG-Mitglieder auf unterschiedlichen Wegen zu unserer Botanik-AG. Eine Werbung durch irgendwelche Massenmedien hätte wahrscheinlich nicht wirklich Interessierte angelockt. Vielfach hatte meine berufliche Naturschutzarbeit, aber auch die mündliche Propaganda oder auch Unterhaltungen am Rande meiner Vortragstätigkeit einige Personen zu uns geführt.

Nach der Wende war die untere Naturschutzbehörde mehrfach erste Anlaufstelle für interessierte Menschen, die sich in Güstrow und Umgebung ansiedelten und nach Betätigungsfeldern in der Natur ihrer neuen Heimat suchten. Sie wurden von dort durch Joachim Loose, der selbst Mitglied in beiden Gruppen war, sofort weiter zur FG und zur AG vermittelt. Auf diese Art und Weise erhielt sowohl die FG Ornithologie und Naturschutz als auch die BotanikAG Verstärkung. U. a. bei Volkmar Rowinsky, Silke Schulze, Bärbel Walter und Elke Zielonka lief es so ab.
Aus den Reihen der FG Ornithologie fanden später auch noch einige Mitglieder den Weg für kürzer oder länger zur Botanik-AG (Remo Wiechert, Bodo Degen, Volker Thiele). Bereits regelmäßig ab 1997 kam Volker Bösel zu den Botanikern, erst ab Januar 2000 auch zu den FG-Abenden der Ornithologen.

Heute hat sich die botanische Arbeitsgemeinschaft gemausert (um im Ornithologenjargon zu reden) und in den über drei Jahrzehnten Existenz völlig eigenständig entwickelt. Damit hat sie natürlich auch eine eigene Geschichte, die zu erzählen hier den Rahmen sprengen würde. Es soll nur kurz die Arbeit der Botanik-AG dargestellt werden.

Seit dem Bestehen der Gruppe werden in der Vegetationszeit von Anfang April bis Ende September abendliche mehrstündige Exkursionen zu bedeutsamen oder bislang unbekannten Gebieten durchgeführt. Die Winterzeit ist mit Theorie ausgefüllt, d.h. mittels Abbildungen, Fotos und Herbaren wird die Artenkenntnis geschult. Als sehr förderlich haben sich die von mir angefertigten „Hilfsbestimmungsschlüssel“ erwiesen. Sie sind entstanden, um die für manche Leute schwierigen Bestimmungswege aus üblichen botanischen Werken in verschiedener Hinsicht zu vereinfachen. Sie enthalten nur die bei uns vorkommenden oder zu erwartenden Pflanzenarten und als Merkmale manchmal weniger wissenschaftliche, aber dafür augenfällige Kennzeichen zur Artbestimmung. Das botanische Standartwerk von RoTHMALER blieb zunächst im Hintergrund. Nach anfänglichen Berührungsängsten wird er heute ständig einbezogen, wobei meist zuerst zum Atlas-Band gegriffen wird. Fundortdaten von allen in $\mathrm{M}-\mathrm{V}$ vorkommenden Pflanzenarten werden in der Geobotanik-Datenbank in Greifswald gesammelt. Daraus entstehen Verbreitungskarten, die auch bei häufigen Arten mitunter unerklärliche Lücken aufweisen. Exkursionen unserer AG dienen oft auch der Nachsuche in solchen Gebieten ohne Funde, um diese Kenntnislücken zu schließen.

Ziel für die Gruppe ist es, mit Freude etwas Neues zu lernen und Arten selbst erkennen zu können. Die strengeren Arbeitsweisen der organisierten Geobotaniker wurden nicht als Grundlage angesehen; so werden vielfach an der Natur interessierte Leute nicht durch allzu wissenschaftliches Arbeiten abgeschreckt. Bei allen Exkursionen gilt unser Blick stets auch anderen Lebewesen wie Käfern, Schmetterlingen, Libellen und auch Vögeln, so dass eine „Rundum-Schulung“ stattfindet. Möglicherweise ist das auch ein Grund, der gegenüber der FG Ornithologie deut- 
lich zu einem stärkeren Zulauf von Mitgliedern geführt hat. $\mathrm{Zu}$ den Seminaren und Exkursionen sind inzwischen über die Jahre mehr als 90 Personen erschienen. Einige von ihnen schauten nur mal kurz rein, andere verließen nach längerer Teilnahme auf Grund verschiedener familiärer Veränderungen Güstrow und damit auch die AG. Man kann heute von einem jährlich festen Stamm von etwa 25 Mitgliedern ausgehen. Von denen sind auch heute noch fünf Mitglieder in der FG Ornithologie und Naturschutz.

Eines hat die AG Botanik der FG Ornithologie und Naturschutz weiterhin voraus: Seit 1994 gibt es jährlich eine gemeinsame größere Wochenend-Exkursion in besonders interessante Gebiete. Sie geht auf eine Initiative von Georg Strache („Schüler der 1.Stunde“ der AG) zurück. Er wollte damals unbedingt die blühenden Orchideen im NSG Leutratal bei Jena sehen.
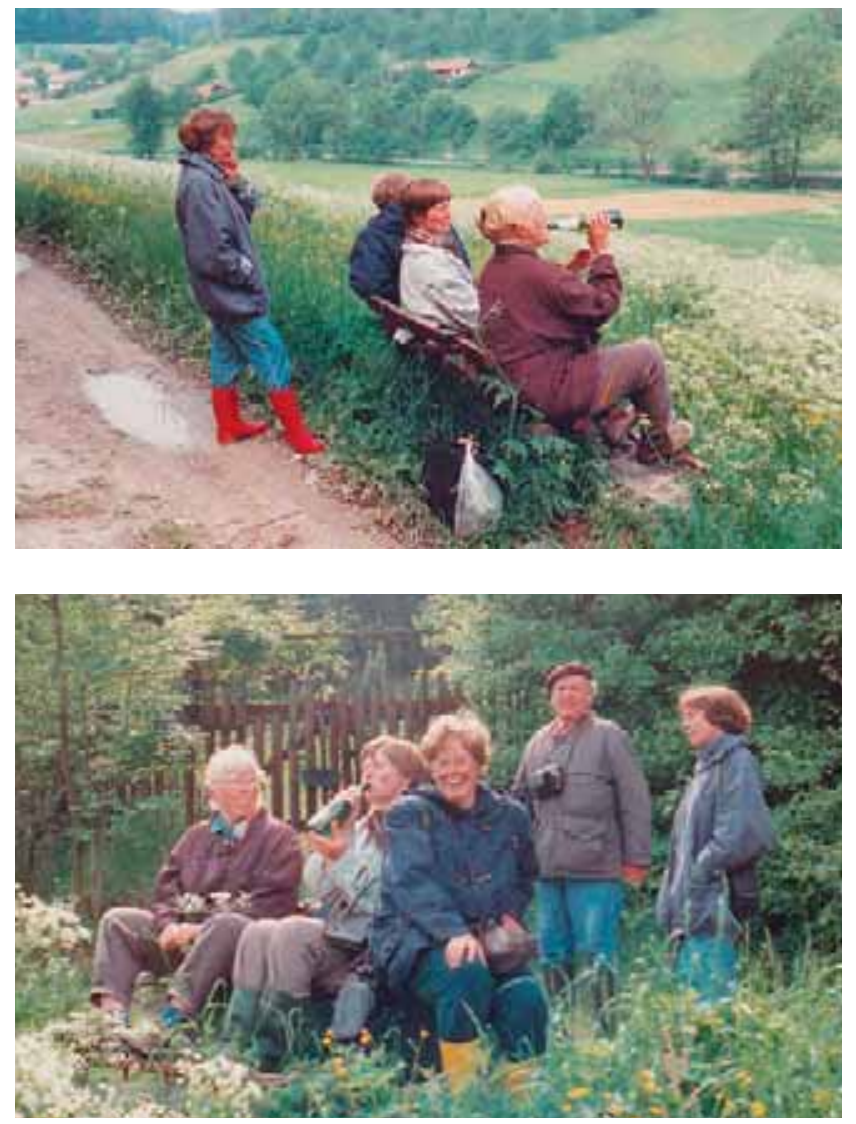

Abb. 15/16: Teilnehmer der ersten Wochenendexkursion ins NSG Leutratal bei fena (Sekt gab's nicht auf die vielen Orchideen, sondern auf den Fund der Erd-Segge Carex humulis). Teilnehmer waren: Ilse Cöster, Angela Martin, Silke Schulze, Georg Strache, Gudrun Schützler (foachim Loose fotografierte).

Seitdem besuchten wir mit 10-18 Personen die Oderhänge bei Lebus, den Nationalpark (NP) Harz, den Spreewald, den Kyffhäuser, die Elbaue bei Steckby, das Tagebaugebiet in der Lausitz, den NP Hainich, Gegenden um
Rheinsberg, Templin und im Erzgebirge, aber auch Gebiete in unserem Lande (Rügen, Usedom, Darß, Küste bei Poel/Boiensdorf, Elbaue Dömitz). Exkursionen führten uns auch an die Nordsee nach Westerhever (ein zweites Mal nur als Botanikergruppe) und ins Ausland nach Polen (NP Warthemündung) sowie zur dänischen Insel Mön. Vielfach hatten wir ortskundige Führer und konnten alte Freundschaften mit „Naturschutzkämpfern“ aus DDR-Zeiten wie Hans-Ulrich Peter, Uwe Wegener, Heinz Sluschny, Hubert Illig, Ernst Paul Dörfler auffrischen, die nach der Wende z. T. Leitungsfunktionen im Naturschutz übernommen hatten. Neben botanisch geprägten Erlebnissen festigten diese Mehrtagesfahrten auch das Miteinander in unserer Gruppen ganz enorm. Bei diesen „Großen Exkursionen“ wurden auch meist die auf dem Wege liegenden kulturellen Sehenswürdigkeiten mit aufgesucht (wie z.B. Festung Königstein, Kyffhäuser Denkmal, Gedenkstätte Peenemünde). Niemand möchte heute solche Wochenenden mehr missen.

Eines darf an dieser Stelle nicht unerwähnt bleiben, da es für die Gruppe eine existenzielle Angelegenheit war. Ab 7.7.1989 fiel ich durch einen schweren Unfall monatelang aus, anfangs war es unklar, ob nicht sogar für immer. Georg Strache nahm es in die Hand, die Gruppe in unserem Rhythmus am Laufen zu halten. Während im Sommer die Wahl von Exkursionszielen relativ einfach war, gestaltete sich die Winterarbeit ohne mich recht schwierig, wie man mir gestand. Als ich im Juli 1990 wieder „auftauchte“, konnte ich nach der Pause weitermachen und brauchte nicht bei Null anzufangen. Obwohl es inzwischen lange Zeit zurückliegt und Georg Strache nicht mehr unter uns weilt, soll ihm an dieser Stelle nochmals gedankt werden. Er hat zum einen wesentlich zum Erhalt der AG und zum anderen mit seinem Anstoß zu den jährlichen Wochenendausflügen zur Festigung unserer Gemeinschaft beigetragen.
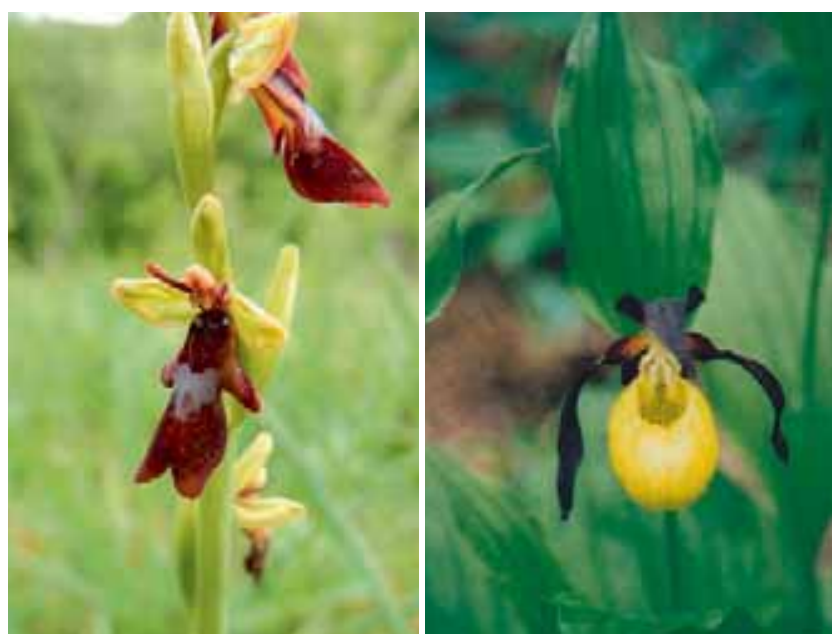

Abb. 17/18: Fliegen-Ragwurz und Frauenschuh waren zwei bemerkenswerte und für uns neue Orchideenarten auf Hügeln des Leutratals bzw. im Kyffhäuser. Fotos: F. Loose. 

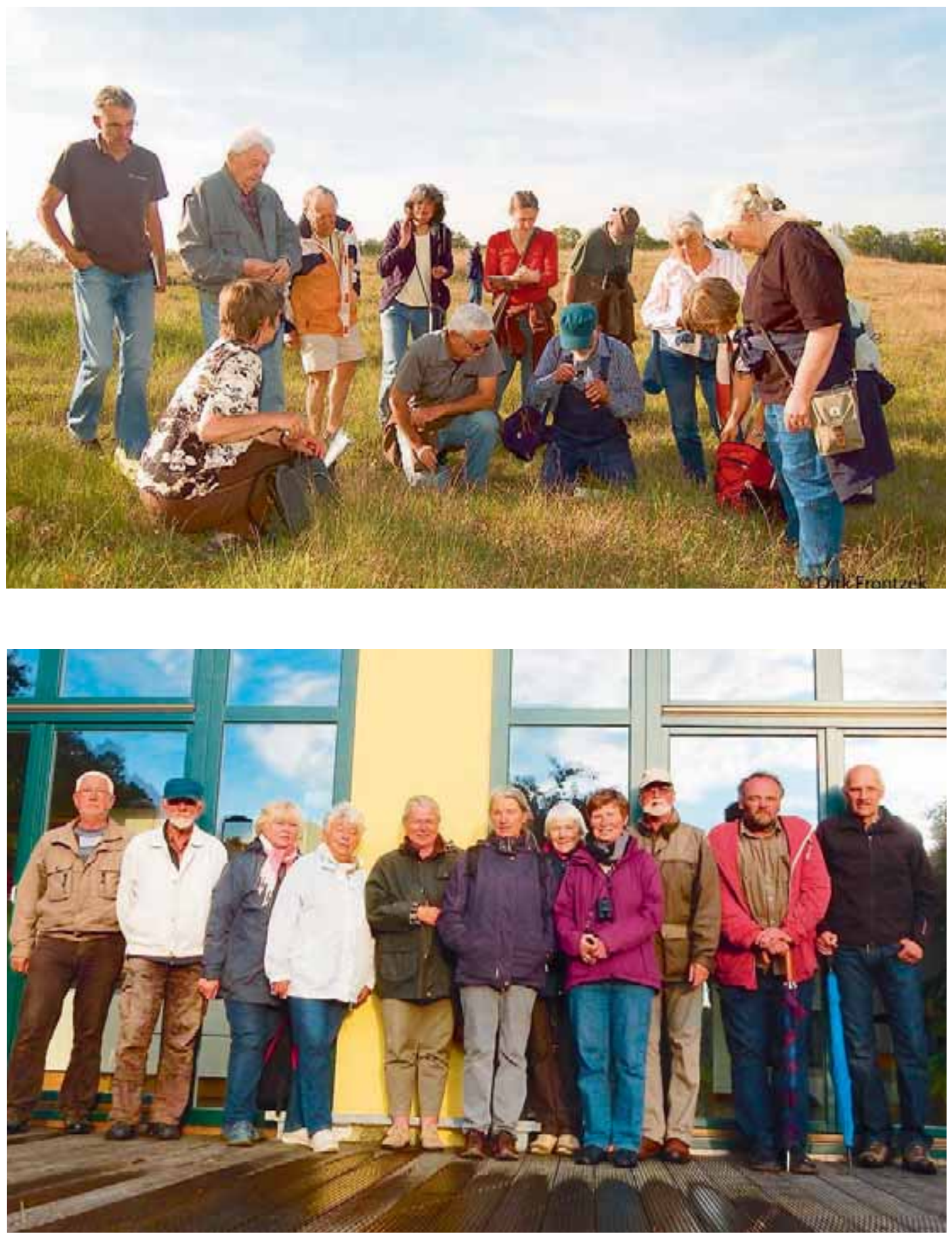

Abb. 19: Mitglieder der Botanik-AG bei einer Exkursion am 29.4.2014 im NSG Bockhorst (v.l.) förg Bußmann, Fritz Holst, Angela Martin, ein Gast, Bärbel Walter, Joachim Loose, Marina Kahrmann, Siegfried Rüdiger, Volker Bösel, Anneliese Erdtmann, Conny Dettmann, Ilse Cöster. Foto: D. Frontzek.

Abb. 20: Mitglieder der Botanik-AG be der Exkursion vom 18.6. bis 21.6.2015 ins Elbsandsteingebirge (v.l.) foachim Loose, Siefried Rüdiger, Christiane Bösel, Anneliese Erdtmann, Uta Neumann, Gisela Klingbeil, Christiane Müller, Angela Martin, Volker Bösel, Andreas Küchler und Heinrich Neumann. Foto: f. Loose. 


\section{Besondere Aktivitäten der Fachgruppe}

Das Beobachten und planmäßige Kartieren einzelner Vogelarten führten die FG-Mitglieder in „ihren“ Gebieten meist allein durch. Nur in den Jahren nach der Gründung der FG und zu Zeiten der Aktivitäten der Schüler-AG um Kurt Pohlmann und Wolfgang Neubauer gab es ein häufiges Beobachten und Lernen in der Gruppe. Neben den monatlichen Zusammenkünften der FG-Mitglieder hatten die wenigen gemeinschaftlich durchgeführten Exkursionen eine erhebliche Bedeutung für den Zusammenhalt der Gruppe.

Die Ornithologen-Exkursion auf die Insel Poel im zeitigen Frühjahr oder Frühherbst hatte besonders für die Ornithologen des Bezirks Schwerin eine lange Tradition. Hier schlossen sich bis zur Wende auch die Güstrower Ornithologen an.

Vor allem konnten auf den Salzwiesen und an den Prielen im Binnenland selten anzutreffende Limikolenarten beobachtet werden. Es standen genügend Sachkundige den Neulingen zur Verfügung, um die eine oder andere Artbestimmung abzusichern. Zu DDR-Zeiten war es auch etwas Besonderes, wenn wir das NSG Langenwerder betreten durften. Dazu musste am Grenzturm auf dem Steilufer den Grenzern Bescheid gesagt werden, dass die zuvor angemeldeten Personen jetzt die Insel betreten möchten. Es war schon etwas Privilegierung dabei und ein tolles Gefühl, dazu gehören zu dürfen. Auch das notwendige Durchwaten zur Insel war immer etwas Besonderes; man musste auch mal Härte zeigen, wenn das Wasser schon etwas kälter war und höher stand.

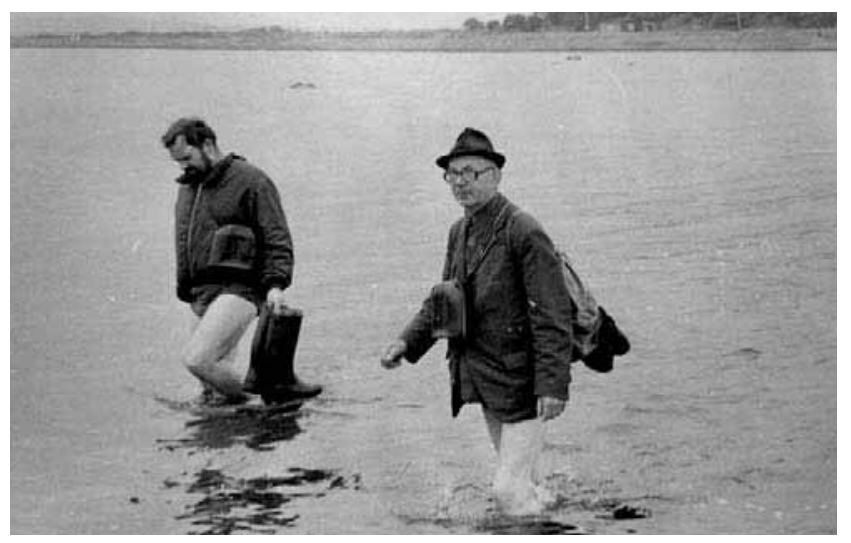

Abb. 21: Kurt Pohlmann mit Werner Kaiser beim Durchwaten zur Insel Langenwerder. Foto: $\mathcal{7}$. Loose.

Außer der Beobachtung von Vögeln waren diese Poeltreffen auch wichtig für das Kennenlernen sowie den Erfahrungsaustausch der Ornithologen des Bezirkes Schwerin untereinander.

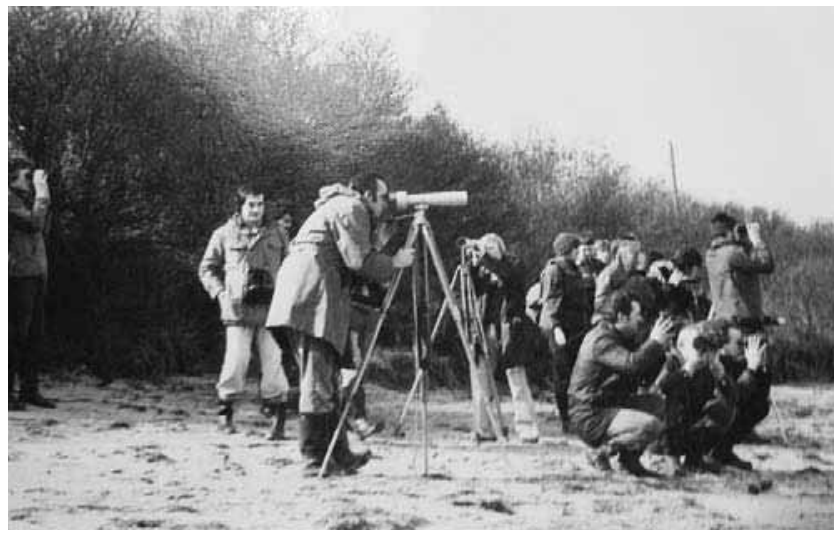

Abb. 22: Mit den Schweriner Ornithologen auf der Insel Poel. Foto: f. Loose.

Bisweilen sonderte sich die Güstrower Truppe etwas von den übrigen ab. Es hatte sich bei ihnen ein „harter Kern“ aus vier Leuten gebildet, der die übliche Eintagesexkursion auf das gesamte Wochenende ausdehnte. Unser FGMitglied Georg Strache konnte uns als Beschäftigter bei der Deutschen Post Unterkunft im Posthotel in Kirchdorf besorgen. Wir reisten also bereits freitags an und wanderten an gleichen Abend bei jedem Wind und Wetter noch in den ca. zwei Kilometer entfernt liegenden „Schwarzen Busch“, eine Gaststätte auf der nördlichen Seite der Insel. Das gleiche taten wir am darauffolgenden Abend. Wenn die ganze Schweriner Gruppe tagsüber in eine Gaststätte „einfiel“, standen an der einen Wand aufgereiht unsere Asiolas mit Holzstativen und jeder im Ort wusste, die Ornithologen sind wieder da. Dass man uns auch als Güstrower wahrscheinlich doch in guter Erinnerung behalten hat, zeigt nachfolgende kleine Episode:

In unserer Gaststätte „Am Schwarzen Busch“ stand noch eine alte Musikbox, und der Wirt sorgte dafür, dass ständig Musik spielte. 1983 hatte Angela Martin gerade im Staatlichen Forstwirtschaftsbetrieb als Mitarbeiter für Landeskultur/ Naturschutz angefangen; sie war damit Forstangestellte geworden. Georg Strache ging kurzerhand an die Theke und brachte den Wunsch vor, ob denn das „OberförsterLied“ gespielt werden könnte, wir hätten nämlich eine neue "Oberförsterin“ unter uns. Der Titel war aber in der Musikbox leider nicht vorhanden.

Fast genau ein Jahr später kamen wir wieder zu unserer Gaststätte. Mit unserem Aufzug waren wir unverkennbar. Wir hatten kaum Platz genommen, da ertönte aus dem Lautsprecher das Oberförsterlied! So hatte der „alte Seebär" uns also sehr wohl in Erinnerung behalten.

Nach der Wende hatten insbesondere die Ornithologen der Parchimer FG um Ernst Schmidt die Poeltreffen wieder aktiviert. Bei uns Güstrowern kam - eigentlich leider - keine Resonanz auf die Einladungen zustande. 
In der Rückschau waren andere gemeinschaftliche Exkursionen der FG eher seltener. Während der Winterzeit gab es auf den FG-Versammlungen stets viele Vorstellungen zu unbedingt anzusteuernden Zielen. Rückte die Saison dann näher, reduzierten sich oft die Teilnahmemeldungen. Die Halbtagesexkursionen im Mai führten uns meist in weniger bekannte Gebiete des eigenen Kreises.

In den Jahren der Rasterkartierung fielen Exkursionen mitunter völlig weg, oder eine solche wurde kurzfristig in einen MTB/Quadrant gelegt, für den der Bearbeitungsstand noch ungenügend war, um hier Abhilfe zu schaffen.

Aber es gab doch einige Exkursionen der FG, die uns in weiter entfernte Gebiete führten.

Durch die Verbindungen von W. Neubauer als Studienleiter für das Fach Biologie am Landesinstitut für Schule und Ausbildung (LISA) und seine Referendar-Ausbildung hatten wir die Möglichkeit, vom 13. -15.9.1996 das Wattenmeer der Nordsee mit seinen Watvögeln kennenzulernen. Der Leuchtturm von Westerhever war für ein Wochenende unser Quartier. Wir lachten herzlich, als wir morgens Martin Lemke in der Badewanne schlafend vorfanden. Er war wegen des Schnarchens seines Zimmergenossen Joachim Ulbricht ausgezogen und fand das gar nicht lustig.

Für den FG-Jahresbericht Nr. 29 durfte M. Lemke dann auch den Reisebericht verfassen. Er konnte sich damit von einer Vielzahl von auszugebenden Getränkerunden „freikaufen“. - Wir hatten mal auf Poel eingeführt, dass jeder, der eine Vogelart zum ersten Mal sieht, eine Runde an die Mitbeobachter auszugeben hat. - Für Martin waren es bei dieser Exkursion ins Wattenmeer elf neue Arten, die ihm als Student natürlich erlassen wurden ...

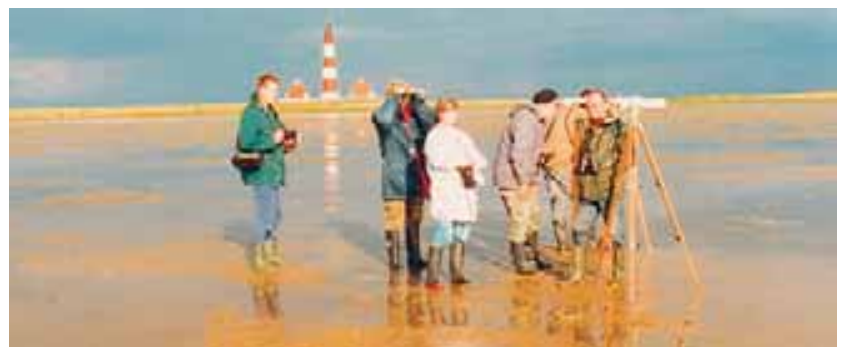

Abb. 23: Exkursion 1999 ins Wattenmeer bei Westerhever.

Foto: 7. Loose.
Martin Lemke organisierte dann auch als Student in Potsdam die nächste Fernexkursion. Mit der FG besuchten wir am 24.4.1999 die Trappenauswilderungsstation von Dr. Heinz Litzsbarski in Buckau im Brandenburgischen und schauten auch gleich mal am NSG Gülper See vorbei.

$\mathrm{Zu}$ einer Ganztagesexkursion fuhren wir im Mai 2004 in die Lewitz, wo uns der NSG-Betreuer Dr. Horst Zimmermann durch die artenreiche Teichlandschaft führte. Erst am 21.5.2011 gab es eine ähnliche Fortsetzung - Ziel waren die renaturierten (vernässten) Wiesen in Peenetalmoor und das NSG Anklamer Stadtbruch, wo wir ortskundige Führung durch unser ehemaliges Botanik-AG-Mitglied Steffen Päßler hatten, der hier inzwischen als Naturpark-Ranger angestellt war.

Nachdem anlässlich des 80. Jahrestages des NSG Krakower Obersee 2012 unsere Mai-Exkursion in dieses Gebiet führte, wurde die frisch aufkommende Tradition der nach außerhalb führenden ornithologischen Touren im Mai 2013 mit schönen Beobachtungen von Rothalstauchern bei einem Besuch des Stuerschen Sees fortgesetzt. 2014 startete die FG erstmalig zu einer Mehrtagestour mit 14 Mitfahrern nach Südschweden. Guntram Trost hatte diese Exkursionswoche von der Unterkunft im Ferienhaus bis zu den anzusteuernden Schutzgebieten bis ins Detail geplant.

Da nicht alle möglichen Plätze von Mitgliedern der FG genutzt wurden, fuhren auch einige aus der Botanik-AG mit. So war es nicht nur eine sehr interessante ornithologische, sondern auch botanische Erkundungsreise geworden, zu der wir ein Jahresbericht-Sonderheft mit den Beobachtungen erstellen konnten. Diese Reise hatte viel Anklang gefunden und sollte ihre Fortsetzung finden. Auch 2015 war Guntram Trost wieder unser „Reiseleiter“, der uns am letzten Wochenende im Mai ins Saale-Unstrut-Gebiet zu Bienenfressern am Geiseltalsee und zu Orchideen im 827 ha großen NSG „Tote Täler“ südlich von Freyburg im Burgenlandkreis führte. Auch dieses Mal waren wieder Mitglieder der Botanik-AG dabei.

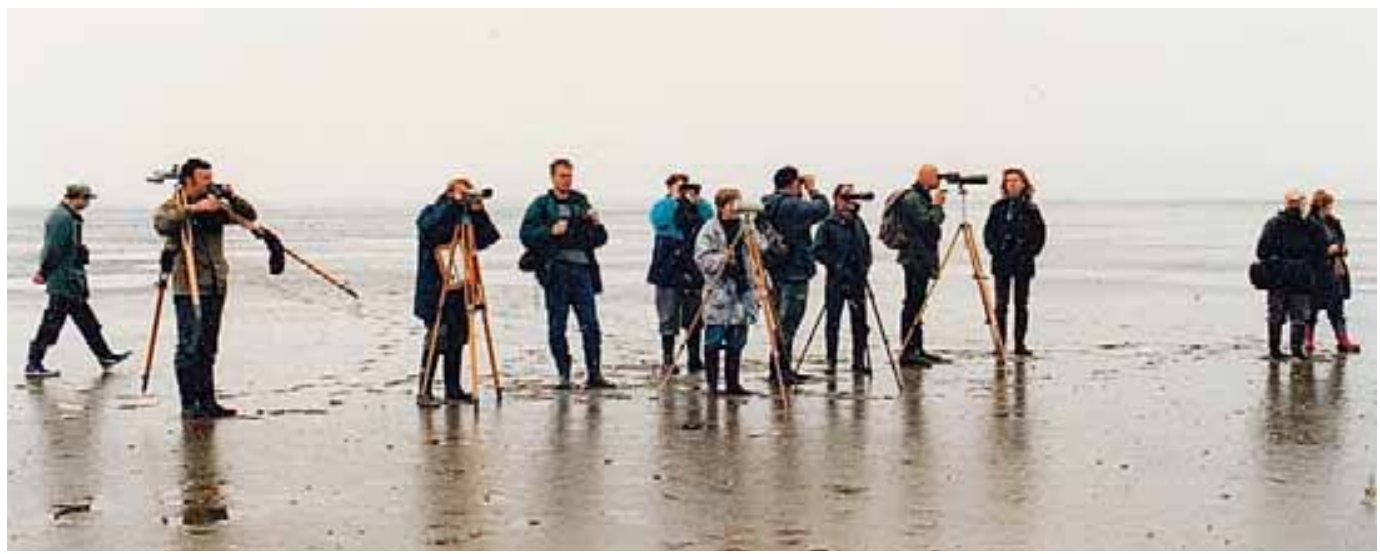

Abb. 24: Exkursionsteilnehmer auf dem Foto waren (v. l.n.r..): K.-H. Koop, M. Montschko, V. Rowinski, U. Thamm, G. Strache, A.Martin, W. Neubauer, A. Kretschmann, 7. Ulbricht, U. Knoche-Ulbricht I. Cöster, S. Schulze. Foto: J. Loose 
Die erste große Tour nach Schweden sollte einmalig sein Wir kennen das schon von den Botanikern - schnell kann eine liebgewordene Tradition entstehen. Möge es so weiter gehen, es gibt noch viele interessante Ziele, die man sich in Gemeinschaft erschließen kann.

Neben den Exkursionen im Mai wurde seit 1998 das zweite Halbjahr Ende August mit Exkursionen in die nähere Umgebung Güstrows begonnen. Die nahe gelegenen Klärteiche der Zuckerfabrik, später der als Kompensationsmaßnahme an gleicher Stelle angelegte „PVA-Teich“ sowie der renaturierte Gutower Polder am Sumpfsee boten die Chance, hier insbesondere Limikolen kennenzulernen. 2012 kam jemand auf die Idee, diese abends durchgeführte Exkursion mit einem Grillabend zu verknüpfen. Beim ersten Mal gab's die Bratwurst gleich neben dem PVA-Teich, später machten wir es uns am Ufer des Inselsees bequemer. Auch das ist inzwischen zur Tradition geworden.

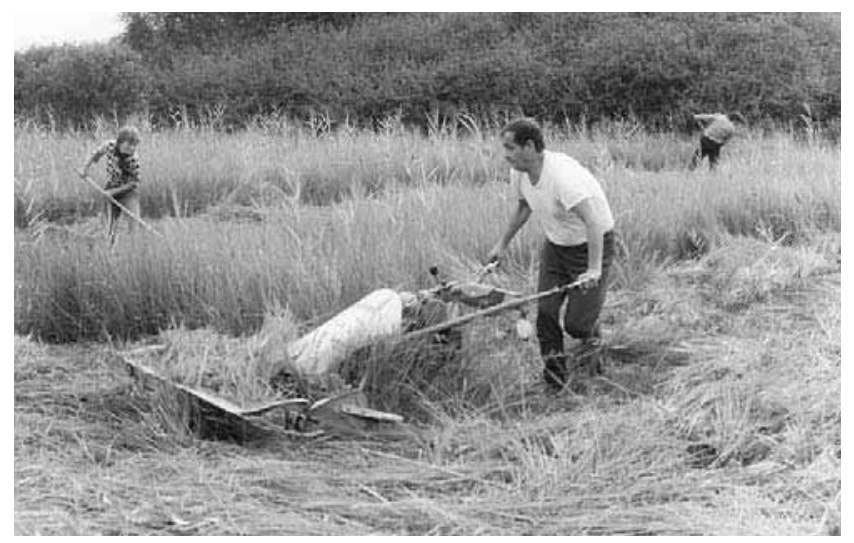

Abb. 25: Klaus Dauber (am MF70), Angela Martin und Harry Jahr bei der Arbeit auf der Orchideenwiese im NSG Breeser See. Foto: f. Loose.

Die meisten FG-Mitglieder waren zu DDR-Zeiten auch Naturschutzhelfer. So gehörten jährliche Arbeitseinsätze zur Pflege von Flächen mit besonders geschützten Pflanzenarten zum Programm der FG. Meist ging es dabei um Feuchtwiesen mit Orchideenvorkommen, auf denen keine Nutzung durch die Landwirte mehr erfolgte. Eine solche ca. 1,5 ha große Wiese am Ostufer des Breeser Sees war mehrfach im Spätsommer ein Arbeitsort für die Ornithologen, die teilweise auch ihre Familienangehörigen zur Unterstützung mitbrachten. Uns stand das eigens für Naturschutzzwecke vom Forstwirtschaftsbetrieb auf Betreiben von Angela Martin hin angeschaffte Mähgerät „MF70“ zur Verfügung.

Das musste natürlich erst einmal zum Ort der Pflege gebracht werden. Damals ging so etwas fast immer mit betrieblicher Unterstützung - so konnte Manfred Montschko dafür am Wochenende einen Multicar von seiner Arbeitsstelle kostenfrei ausleihen. Das Mähgut wurde per Handarbeit aus der Fläche entfernt und am Rande abgelegt. Diese
Ablage war zwar nicht günstig, aber für eine Verwendung außerhalb ließ sich kein Landwirt gewinnen. In den Arbeitspausen saß man zusammen im Heuhaufen, und es gab den ersten mitgebrachten Pflaumenkuchen - eine schöne Erinnerung an die Arbeiten, die gleichfalls den Gruppenzusammenhalt förderten.

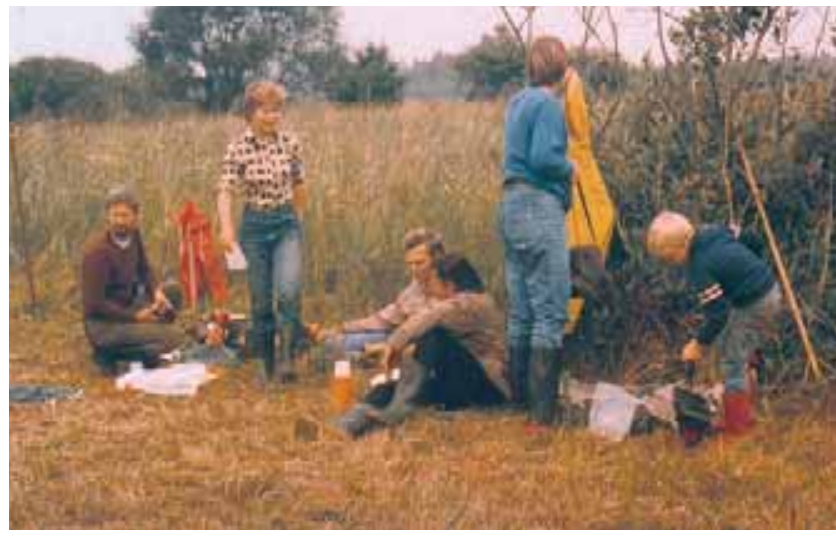

Abb. 26: Kaffeepause am Rande der Mähfläche. Foto: Archiv.

Neben notwendigen Mäharbeiten ging es in anderen Flächen auch um das Zurückdrängen der aufwachsenden Grau-Weiden und Schlehenbüsche. So gab es mehrere Einsätze auf der „Braunkehlchenwiese“ gleichfalls im NSG Breeser See, oder es wurde u.a. auf einem schmalen artenreichen Feuchtwiesenstreifen am Ostufer des Parumer Sees mit einigen jüngeren Menschen zu DDR-Zeiten eine Entbuschungsaktion vorgenommen.

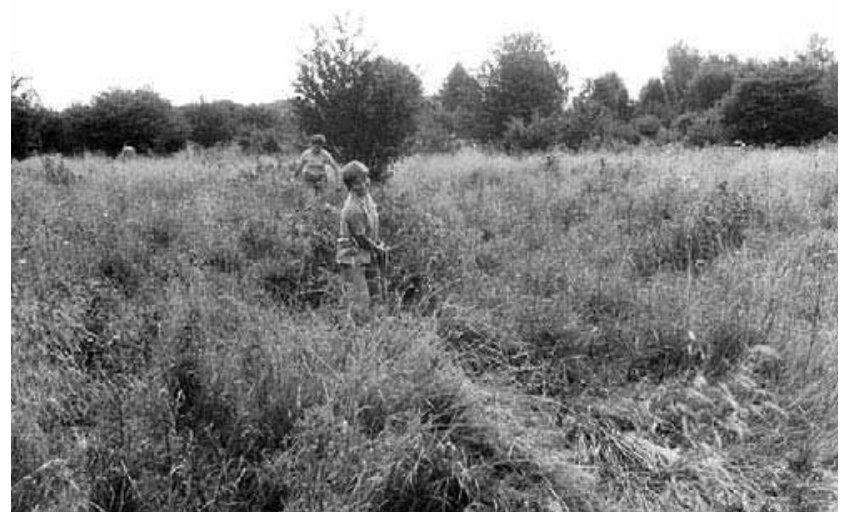

Abb. 27: Entbuschung am Breeser See - A. Martin und M. Fritsche schleppen abgeschnittene Sträucher durch hohes Land-Reitgras an den Rand der „Braunkehlchenwiese“. Foto: f. Loose.

Über weitere gemeinsame Arbeitseinsätze z.B. im NSG Zehlendorfer Moor und zur Errichtung von Schutzhütten vor der Wende wird in anderen Kapiteln berichtet.

Nach der Wende stand der Naturschutzbehörde für notwendige Pflegemaßnahmen Geld zur Verfügung. Joachim Loose aus unserer FG war hier als Amtsleiter tätig und setzte sich anfangs bei der Planung der Haushaltsmittel gegen die Kämmerei der Kreisverwaltung durch. So wurden 
Firmen beauftragt, die wesentlich mehr Arbeiten ausführen konnten, als es in Freizeittätigkeit den Ehrenamtlichen überhaupt möglich gewesen wäre. Als Nachteil brachen die bisherigen ehrenamtlichen Aktivitäten weg, und mit der gleichfalls nicht mehr gesetzlichen bestehenden Legitimationsmöglichkeit von Naturschutzhelfern entstand eine Kluft zwischen amtlichen und ehrenamtlichen Naturschutz. Von der neuen gesetzlich möglichen Benennung von Naturschutzwarten wollte man im Landkreis Güstrow keinen Gebrauch machen - man hatte politisch Angst, dass hierdurch eine „Polizeitruppe“ für den Umweltschutz entstehen könnte, da die im Naturschutzgesetz vorgesehenen Vollmachten eines Naturschutzwartes recht weitreichend waren. So kam bei einigen „altgedienten“ Ehrenamtlichen das Gefühl auf, nicht mehr gebraucht zu werden.

Bei der Naturschutzbehörde wurden im Laufe der Jahre die Haushaltsmittel immer mehr gekürzt, so dass nach und nach viele pflegebedürftige Flächen auf der Strecke blieben. Einige Feuchtflächen konnten weiterhin zum Glück durch Förderprogramme über das StALUMM Rostock gepflegt werden.

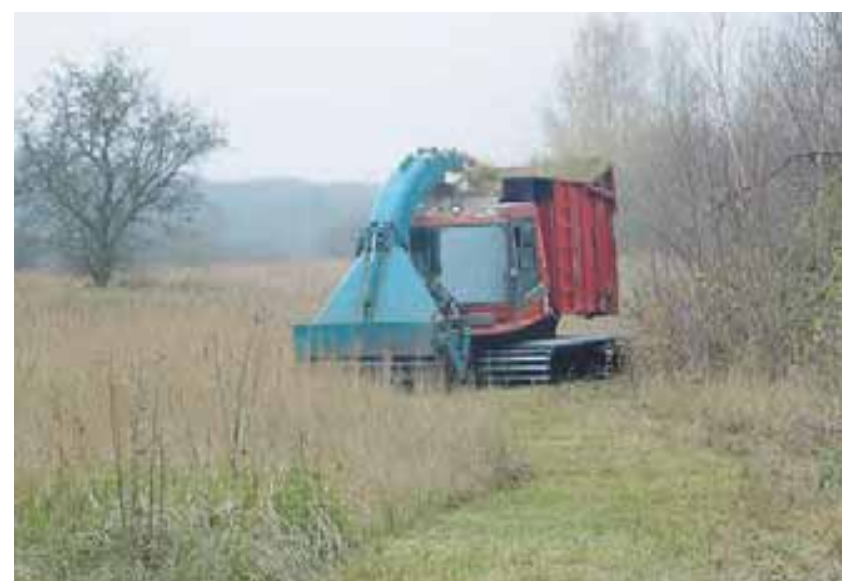

Abb. 28: Mähraupe im Einsatz auf der Orchideenwiese im NSG Breeser See - 2014. Foto: 7. Loose.

Wenngleich es bis heute seitens der Naturschutzbehörde zu keinen Berufungen von Naturschutzwarten gekommen ist (nicht einmal die langjährigen NSG-Betreuer sind nach dem Auslaufen der Verträge mit dem Umweltministerium offiziell als solche bestellt worden), arbeiten die Mitglieder der FG im Sinne des Naturschutzes weiter, und es gab auch nach der Wende einige Pflegemaßnahmen in geschützten Biotopen.

Am 27.10.2007 fanden sich acht Personen im FND Bornbruch bei Krakow am See zu einem Einsatz mit Hacken, Schippen und Schubkarre ein. An mehreren Stellen wurde die Vegetationsdecke abgehoben (abgeplaggt), um neuen Rohboden zu schaffen. Damit sollten dem ehedem hier vorkommenden Sumpf-Enzian Gentianella uliginosa besiedelbare Flächen geboten werden. Unsere Aktion beruhte auf der Hoffnung, dass noch keimfähiger Samen im Boden vorhanden ist. Der Aufruf für die Durchführung dieser Arbeiten ging vornehmlich an Mitglieder der AG Botanik, durch die Doppelmitgliedschaft in der AG und der FG von fünf Teilnehmern, darf der Einsatz auch der FG angerechnet werden.

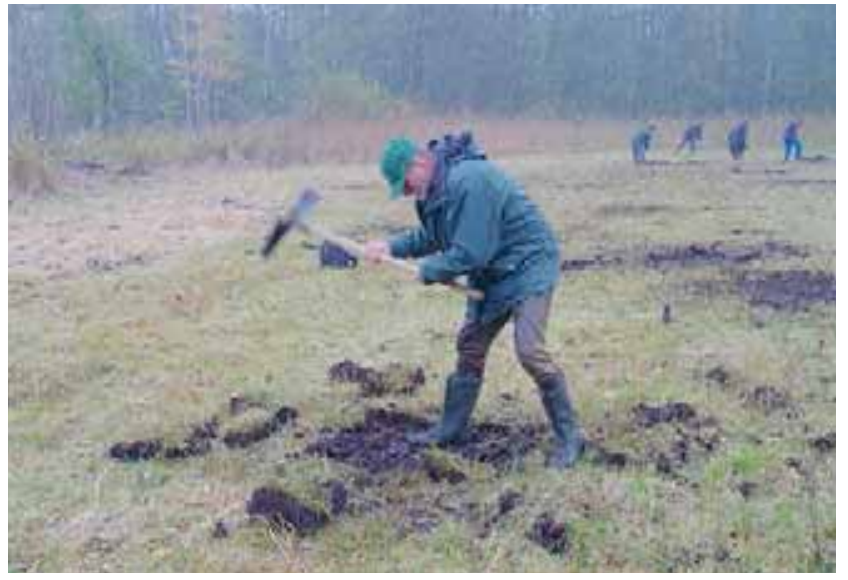

Abb. 29: V. Bösel u. a. beim Plaggen im Bornbruch - 2007. Foto: 7. Loose.

Zur Förderung eines kleinen Vorkommens des SumpfHerzblattes Parnassia palustris, einer fast unscheinbaren maximal $25 \mathrm{~cm}$ hohen weißblühenden Moorwiesenart, fand am 7.11.2009 ein Einsatz durch sechs FG-Mitglieder mit Motorsense und Durchforstungsscheren auf einer kleinen Fläche am Ostufer des Parumer Sees statt, um die locker von Weiden und Birken bestandene Fläche freizustellen. Schließlich fanden auf Initiative von Guntram Trost ab September 2014 Pflegearbeiten auf dem Bölkower Burgwall im NSG Gutower Moor und Schöninsel statt. Mitglieder der FG und der Botanik-AG sowie des Bisdede-Vereins Mühl Rosin beteiligten sich an den insgesamt 14 Einsätzen (siehe dazu auch Pkt. 8.1.6). Durch die Beseitigung des dort aufgewachsenen Gebüsches aus Schlehen und Weiden und die Mahd der Feuchtwiesen soll das ehemals vorhandene Vorkommen von Wiesenorchideen wieder belebt und der Burgwall als Magerrasenhang entwickelt werden.

Wer arbeitet, darf auch feiern. Anstelle der FG-Zusammenkunft im Dezember wurden Weihnachtsfeiern bei uns erst ab 1999 eingeführt. Die Partner der FG-Mitglieder wurden zu diesen Veranstaltungen eingeladen, auch die Kinder der Jüngeren kamen in einigen Fällen mit dazu. Den Partnern unserer Mitglieder konnte so Danke für das Verständnis gesagt werden, was sie für die vielen Freizeitstunden aufgebracht haben, in denen unsere FG-Mitglieder in der Natur unterwegs und sie alleine waren.

Selbstverständlich war es für uns, auch die Verbindung zu den Partnern unserer verstorbenen FG-Mitglieder aufrecht $\mathrm{zu}$ halten und sie zu unseren kleinen Feiern einzuladen. Den Eiersalat von Frau Strache, mit dem sie sich revanchierte, möchten wir nicht missen. 
Da sich nach der Wende die Reisemöglichkeiten auf die gesamte Welt ausgedehnt hatten, spiegelte sich diese Änderung auch bei den Urlaubsreisen der FG-Mitglieder wider. Neben Essen und Getränken wurde eine „kulturelle Umrahmung" unserer Zusammenkünfte von Anfang an eingeplant. Jedes Jahr stellten andere FG-Mitglieder, die größere Fahrten unternommen hatten, ihre Erlebnisse und Eindrücke, natürlich vor allem in zoologischer und botanischer Hinsicht vor. Länder und Inseln Europas von Spanien bis Norwegen, von Grönland bis Kreta waren Vortragsthemen. Einige flogen aber auch auf andere Kontinente: Kenia, Südafrika, Namibia, Uganda, Tansania und die Mongolei waren Ziele. Wir sahen dazu stets beeindruckende Bilder.
Da sich gerade in der sowieso arbeitsintensiven Vorweihnachtszeit derartige Feierlichkeiten in allen Bereichen des täglichen Lebens stark konzentrieren, kam unser langjährige FG-Leiter Wolfgang Neubauer auf die hervorragende Idee, unsere Weihnachtsfeier auf den Jahresanfang zu vertagen. Seit 2006 wird Mitte Januar der sogenannte Jahreseinstieg begangen.

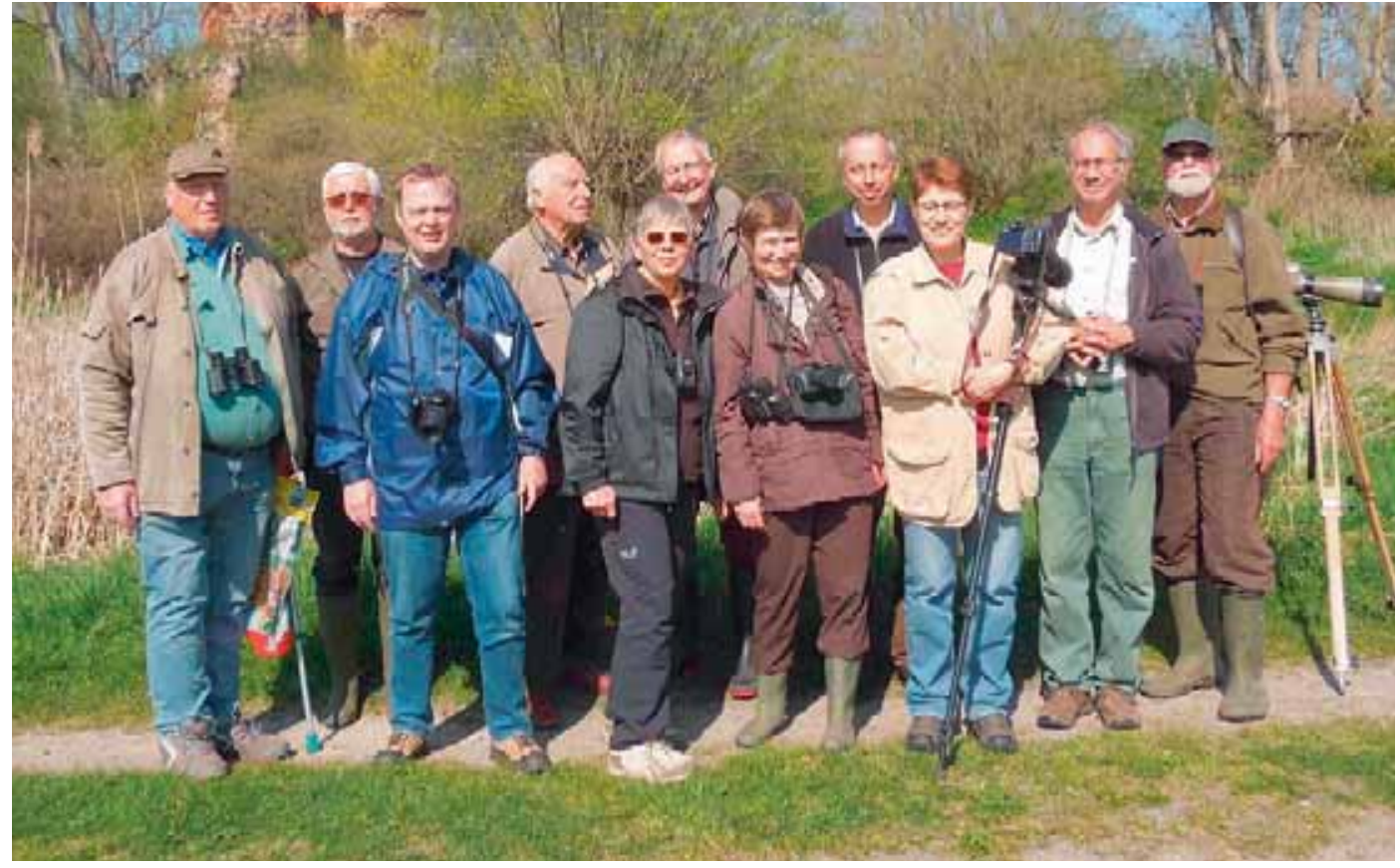

Abb. 30: Die Exkursionsgruppe 2013 am Stuerschen See (v.l.n.r..): Klaus Lingsminat, foachim Loose, Matthias Schneider, Wolfgang Neubauer, Ina und Eckhard Schlüter, Angela Martin, Guntram Trost, Beate Meder-Trost, KarlHeiz Koop, Volker Bösel. Foto: f. Loose. 


\section{5. Öffentlichkeitsarbeiten}

\section{Joachim Loose}

Ornithologische Fachgruppenarbeit, die sich nur auf das Beobachten von Vögeln und das Sammeln von Daten beschränkt, erzielt kaum eine Wirkung nach außen. Als „OstOrnithologen" beobachteten wir, dass zunehmend einige namhafte Ornithologen „im Westen“ nur mit Akribie registrierten, wie eine Vogelart nach der anderen aus der Landschaft verschwand. Bereits mit dem Namen unserer FG wollten wir zum Ausdruck bringen, dass wir anders handeln wollten. Unsere Beobachtungen wollten wir nicht für uns behalten. Sie sollten uns zum Handeln dienen und mussten in die Öffentlichkeit getragen werden. Dafür gab es die verschiedensten Möglichkeiten. Einige in dieser Beziehung beschrittenen Wege werden nachfolgend näher dargestellt.

Die Kommunikation mit Gleichgesinnten und der Austausch des erworbenen Fachwissens war uns stets eine wichtige Angelegenheit. Seit Gründung der FG fühlten wir uns dem Bezirksfachausschuss Ornithologie und Vogelschutz im Bezirk Schwerin als Organisation des Kulturbundes der DDR verbunden. Für unsere FG-Mitglieder war die Mitgliedschaft im Kulturbund nicht bindend. Der Kulturbund bot im Wesentlichen für die meisten von uns nur den Raum für unsere Veranstaltungen. Nach der politischen Wende sind es die OAMV und der NABU, mit denen wir zusammenarbeiten. Einige FG-Mitglieder sind gleichfalls Mitglied in anderen Vereinigungen und erhöhen über die Vogelwelt hinaus mit speziellen Kenntnissen zu anderen Artengruppen dadurch die Fachkompetenz der Fachgruppe.

Mit der FG als offene Untergliederung der eigenständigen NABU-Ortsgruppe Güstrow e.V. ergab sich die Möglichkeit, im Rahmen der gesetzlich vorgeschriebener Beteiligung anerkannter Naturschutzverbände bei verschiedenen bedeutsamen Vorhaben unsere fachlichen Erkenntnisse vortragen zu können.

Da die NABU-OG vom Finanzamt eine Anerkennung der Gemeinnützigkeit erfährt, ist sie auch berechtigt, für eingeworbenen Spenden eine Spendenbescheinigung auszustellen. Über diese Verbindung gelang es uns mehrfach, für die von der FG initiierten Artenschutzmaßnahmen Spenden einzuwerben. Auch das sind heute wichtige Möglichkeiten unsere Öffentlichkeitsarbeit.

\subsection{Artikel in der Lokalpresse, Broschüren und Vorträge}

\section{Angela Martin}

Seit den 70er Jahren erschienen bis zur Wende auf der Kreisseite unserer Lokalzeitung „SVZ“ regelmäßig kleine Beiträge von uns zu Naturschutzthemen in der „Kellerspalte", das war der Abschnitt auf der letzten Seite ganz unten. Mitunter boten sich kleine Serien an, so z.B. schrieb Wolfgang Neubauer über das NSG Krakower Obersee (mit Fotos), Angela Martin über Frühblüher (mit Tuschezeichnungen). Wir konnten die Bevölkerung über Naturschutzaktivitäten der FG informierten. In den frühen 1990er Jahren gab es viele neue Aspekte einer anderen Naturschutzarbeit für Beiträge in der Tagespresse. Wolfgang Neubauer und Wolfgang Köhler stellten neue Naturschutzgebiete vor, Joachim Loose und Angela Martin die vielen gesetzlich geschützten Biotope wie Moore und Brüche, Sölle, Feldhecken und Feldgehölze u. a.

Für mich kam der Anstoß zum Schreiben in der SVZ wohl von Kurt Pohlmann. Als Student wurde ich vermutlich als des „Schreibens bisschen kundig“ angesehen. So sollte ich über die Aktion des Bauens einer künstlichen Insel im NSG Breeser See durch seine Schüler-AG im Winter 1979/80 berichten. Diese Insel sollte der Ansiedlung von Flussseeschwalben dienen. Ein Foto eines brütenden Vogels dieser Art von Wolfgang Neubauer illustrierte diesen kleinen Ar- tikel. So hatte ich meinen ersten Beitrag in der Lokalpresse eingebracht. Der fand sogar als Kurzvermerk den Weg ins „Neue Deutschland“ (ND), damals eine Zeitung, die in der ganzen DDR erschien. - Angemerkt muss hier werden, dass an der Insel nicht weitergebaut wurde; Krankheit und Tod Kurt Pohlmanns standen dem entgegen. Die Anfangselemente der Insel dienten später vor allem Kormoranen als Sitzwarte. Ihr eigentlicher Errichtungsgrund geriet in Vergessenheit. Erst 1989 kam es hier tatsächlich zu einer Brut eines Flussseeschwalbenpaares. Die sich daran anschließende Entwicklung wird unter dem Brutfloß-Projekt (Pkt. 10.2) von J. Loose erzählt.

Im Zusammenhang mit meiner Schreibtätigkeit für die Zeitung soll hier eine kleine Begebenheit erwähnt werden: Es wird Mitte der 80er Jahre gewesen sein. Eines Tages wurde ich zum Direktor des Staatlicher Forstwirtschaftsbetrieb (StFB) zitiert. Als ich sein Zimmer betrat, saß dort bereits der Parteisekretär. Mir wurde sofort ganz anders. Nur ältere „DDR-Bürger“, die nicht in die Partei wollten, werden diese Situation nachempfinden können. Ich ging davon aus, dass man mich für den Eintritt in die SED werben wollte. Man kam schnell auf den Punkt: Da ich öfters Artikel für die Tageszeitung verfasste, möge ich doch stets „StFB“ darunter setzen. Da fiel mir ein Stein vom Herzen. Das können sie haben - ich war sehr erleichtert. 
Etwas später stand unter meinen Artikeln dann VK Dr. Angela Martin. Ich hatte mich „hinaufgearbeitet“ und war „Volkskorrespondent“ geworden.

[Lt. Wikipedia: Volkskorrespondent war die amtliche Bezeichnung für die freien Mitarbeiter von DDR-Zeitungen in der Zeit zwischen 1945 und 1989. Artikel, die von Volkskorrespondenten verfasst waren, wurden in den DDR-Zeitungen unterzeichnet mit „VK N.N.“. Volkskorrespondenten waren die Zuträger lokaler Nachrichten und erfüllten somit eine wichtige Rolle. Sie sollten fähig sein, eine lokale Begebenheit in den offiziell gewünschten Kontext einzuordnen und sachlich darüber zu berichten. Politisch anspruchsvollere Artikel waren in der Regel den Redakteuren der Presse vorbehalten.]

Als „Zuträger“ für lokale Nachrichten hätte ich mich nie bezeichnen lassen. Das Verbreiten von Naturschutzthemen und Wissen über die heimische Flora und Fauna war mir aber immer ein wichtiges Anliegen.

In DDR-Zeiten war eine breitere Öffentlichkeitsarbeit mitunter mit erheblichen Schwierigkeiten verbunden. So waren unzählige Fürsprachen notwendig, bis ein Heft über „Natur und Naturschutz im Kreis Güstrow“ zur Dokumentation der Schutzgebiete unseres Gebietes gedruckt werden konnte. Von den Autoren A. Martin, W. Neubauer und K.-H. Koop waren vier Teile geplant. Nur für den Südostteil des Gebietes lag schließlich 1987 ein 17seitiges Heftchen (Abb. 31) im DIN A5-Format mit Zeichnungen und Fotos (alles schwarz-weiß!) vor. Die unendliche Geschichte fand keine Fortsetzung, die Wende kam „dazwischen“ - und mit ihr völlig neue Möglichkeiten.

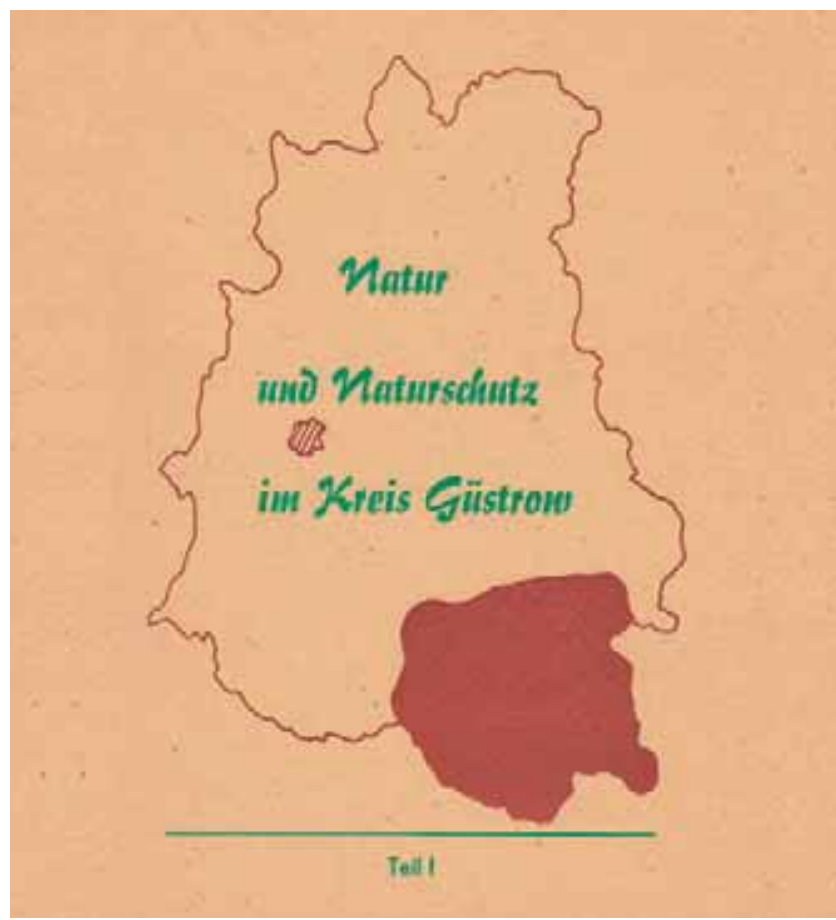

Abb. 31: Naturschutzbroschüre von 1987
Den Gedanken zur notwendigen Darstellung unserer $\mathrm{Na}$ turschutzobjekte aufgreifend, gestalteten Joachim Loose, Angela Martin und Wolfgang Neubauer gleich 1991 eine 36seitige Broschüre mit vielen Farbaufnahmen im Format 21 x $20 \mathrm{~cm}$. Der Titel lautete „Landschaftspflege und Naturschutz im Raum Güstrow" (Abb. 32), so dass bei bereits anstehender Kreisgebietsreform eine Aktualität gewahrt bleiben würde und eine Erweiterung um zwei Hefte für die Altkreise Bützow und Teterow nahtlos hätte geschehen können.

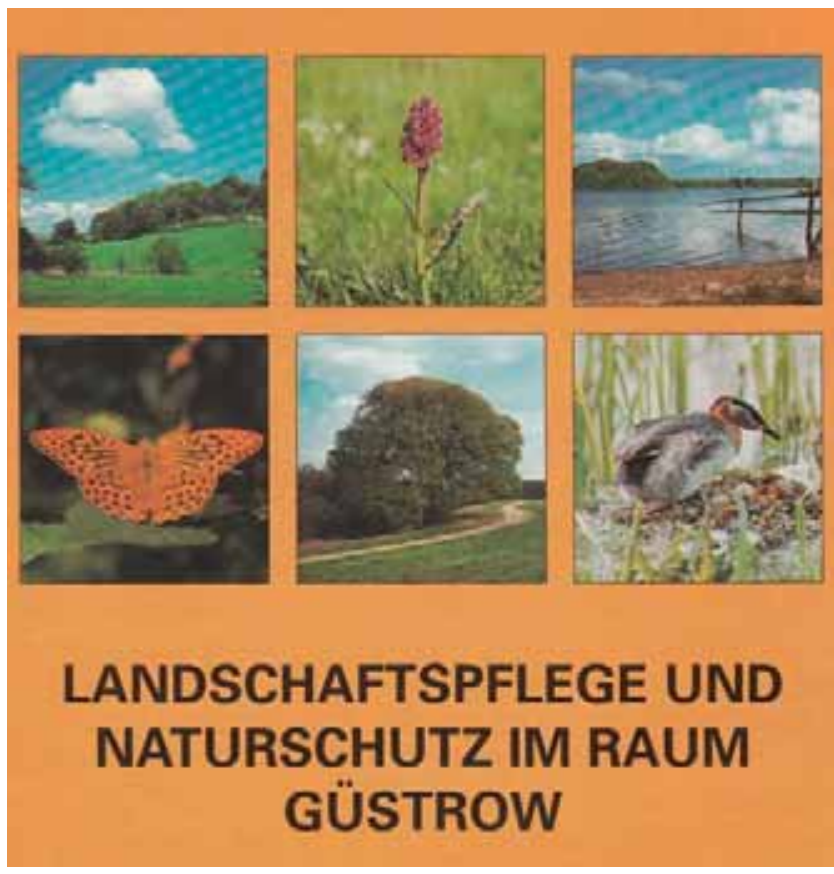

Abb. 32: Naturschutzbroschüre von 1991

Herausgeber war zwar das Naturschutzamt im Landkreis Güstrow, die umfangreichen Herstellungsarbeiten waren jedoch in ehrenamtlicher Tätigkeit der drei Autoren in vielen Sitzungen erfolgt. Nach der Kreisgebietsreform war dann für die geplante Fortsetzung der Hefte leider kein Geld mehr vorhanden.

$\mathrm{Zu}$ den Broschüren, die nach der Wende deutlich leichter herzustellen und auch über verschiedene Quellen finanzierbar waren, zählen einige Druckwerke, bei denen wir die Hauptarbeit erledigt haben.

1990 erstellte Wolfgang Neubauer ein 18seitiges Heft mit farbigen Bildern über das Naturschutzgebiet Krakower Obersee. Es löste eine kleine von ihm erstellte Informationsschrift mit drei Seiten Text und einigen SchwarzweißFotos ab, die er über den Bezirksvorstand des Kulturbundes Schwerin 1985 hatte drucken lassen können. Seit der Wende lagen in der öffentlichen Kanzel im NSG Breeser See in Kopien hergestellte farbige Faltblätter aus. In diesen gab Joachim Loose Informationen zum Gebiet. Im Jahre 2002 wurde das im „Selbstverlag“ hergestellte Faltblatt durch einen ordentlichen Druck ersetzt. 
Beide Informationsschriften waren vom Umweltministerium herausgegeben worden und richteten sich an die einheimische Bevölkerung und besonders auch an die unsere Region besuchenden Touristen. Ein von Manfred Montschko für das NSG Gutower Moor und Schöninsel erstelltes, ebenfalls nur in Farbkopien hergestelltes Faltblatt schaffte es aus Finanzierungsgründen nicht mehr bis zu einem offiziellen Druck.

Die Publikationen „Zur Vogelwelt des Naturschutzgebietes Breeser See“ (LOOSE, J. in ORM 29/1986 und 33/1990) und „Die Vögel des Naturschutzgebietes Krakower Obersee“ (Neubauer, w. als Sonderheft Bd. 36/2001 der Heftreihe $\mathrm{NN}$ in MV) waren als Fachliteratur mehr an Fachleute gerichtet.

Naturschutzthemen ließen sich auch besonders gut mit Diavorträgen in die Bevölkerung tragen.

Wolfgang Neubauer hielt vor allem im Krakower Raum seit den 1960er Jahren sehr viele Vorträge über die fantastische Landschaft, die Schutzgebiete und ihren Schutzgrund, also die Pflanzen- und Tierarten.

Mitte bis Ende der 1980er Jahre ging ich mit einem Vortrag (illustriert mit 6x6-Dias - diese Qualität stellte damals Vorträge mit kleinformatigen Dias in den Schatten) zu den Schutzgebieten im Kreis auf Wanderschaft durch viele Schulen, Gemeinden und Betriebe. Mit diesem Vortrag wurde nicht nur eine nüchterne Übersicht gegeben, sondern ich scheute mich auch nicht, alle Widerstände und Schwierigkeiten beim Umsetzen von Naturschutzmaßnahmen aus eigenem Erleben zu nennen. Wahrscheinlich unterschied sich dieser auf Tatsachen beruhende Bericht wohltuend von der gebetsmühlenartig einseitig positiven Darstellung aller Dinge. Dieser Vortrag wurde immer beliebter, sogar Organisatoren von Parteilehrjahren forderten ihn an.

Einige Male habe ich Heimatkundelehrer hinsichtlich Naturschutz und heimischer Pflanzen- und Tierwelt weitergebildet. An einen Vortrag schloss sich eine Exkursion an. Dass wir ohne Auto auf Exkursion gingen, war wohl von der Mehrheit nicht erwartet worden. Bei einem Gang durch das Neubaugebiet der Güstrower Südstadt fanden wir über 40 Pflanzenarten und warfen einen Blick in ein Haubenlerchennest. Das hat wohl jeden wenigstens einmal davon überzeugt, dass Natur auch vor unserer Haustür zu finden ist.

Als Nachfolgekandidat im Kreistag hatte ich einmal die Gelegenheit, über mein ureigenes Thema „Naturschutz“ zu sprechen. Auch bei diesem Beitrag blieb ich natürlich bei der Wahrheit. Am darauffolgenden Tag erhielt ich vom Lokalredakteur einen Anruf, ich solle meinen Beitrag möglichst bis morgen zum Druck bei ihm abgeben. Er gab mir keinen Tag Aufschub, obwohl ich beschrieb, für solche Dinge momentan keine Minute übrig zu haben, denn es herr- sche gerade "Saison“ u.a. in meinem Haubenlerchen-Projekt. Sechs Wochen lang geschah gar nichts, dann erschien der Artikel ungekürzt. Ein Kollege im Betrieb meinte dazu: „Ich dachte, jetzt wird die Zeitung ehrlich!“. Ohne Zensur hatte mein Text vermutlich nach langen Überlegungen dann doch die Instanz der Stasi passiert...

Die beispielhaft in einigen FG-Jahresberichten ausgewiesenen Aktivitäten aller FG-Mitglieder zusammen belegen mit Zahlenangaben (Vorträge/Veröffentlichungen) eine intensive Öffentlichkeitsarbeit in jener Zeit:

\begin{tabular}{c|c|c|c}
\hline $\mathbf{1 9 8 0}$ & $\mathbf{1 9 8 2}$ & $\mathbf{1 9 8 6}$ & $\mathbf{1 9 8 8}$ \\
\hline $16 / 6$ & $15 / 15$ & $44 / 7$ & $61 / 12$ \\
\hline
\end{tabular}

Noch bis Mitte der 90er Jahre nahm die Lokalzeitung fertige Artikel von uns an und druckte diese unverändert. Immer öfter waren dann Lokalredakteure bei mehr oder weniger großen Aktionen dabei und verfassten ohne unsere Mitarbeit ihre Beiträge. Mitunter ging das gehörig schief, d.h. es wimmelte von fachlichen Fehlern. Es wäre besser gewesen, man hätte uns zur Vermeidung von Missverständnissen die Manuskripte zuvor zum Durchlesen gegeben. Unverständlich für uns blieben Äußerungen mancher Redakteure, dass die Zeit der Zensur ja wohl vorbei sei. Mitunter entsteht leider der Eindruck, die Pressearbeit auch in den Lokalzeitungen ist heute deutlich mehr auf „Sensationen“ ausgelegt.

Dennoch gibt es auch heute gute gelungene Zeitungsbeiträge. Besonders die jährliche Rückschau auf das Storchenjahr in der Region Güstrow und Berichte über Kraniche und Adler kamen bei der Bevölkerung gut an.

Von Wolfgang Neubauer verfasste Beiträge anlässlich des 80jährigen Bestehens des NSG Krakower Obersee wurden in mehreren Fortsetzungen in der SVZ gedruckt. Es wurde auch über die jährlich für die Öffentlichkeit über den Tourismusverein Krakow am See angebotenen von uns geführten Exkursionen im Mai sowie sogar ganzseitig über die Leserreise im August 2015 mit Sebastian Lorenz in dieses Gebiet berichtet.

Guntram Trost gelang es, einen Beitrag „Auf der Suche nach Kriechtieren“ einzubringen, auf den er einige Leserreaktionen erhielt. Es sollte unser Anliegen bleiben, die Presse auch weiterhin mit aktuellen Themen zu Vogel- und Naturschutz zu beliefern. 


\subsection{Informationstafeln}

\section{Joachim Loose}

Mit einer Kampagne versuchte die Fachgruppe etwa ab 1987 vornehmlich in den Schulen des Kreises Nachwuchs $\mathrm{zu}$ werben. Angela Martin und Joachim Loose waren die Hauptakteure bei der Erarbeitung einer Wanderausstellung über Biotop- und Artenschutz. In der Eingangstafel wiesen sie dabei auch auf die Verfassung der DDR mit dem Artikel 15 Abs. 2 (Abb. 6) hin:

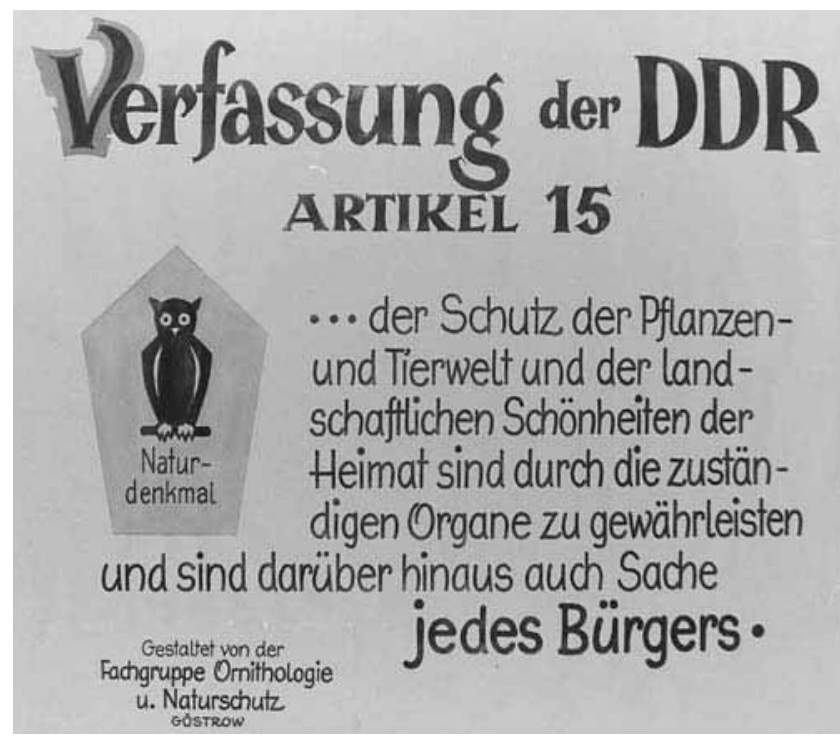

Abb. 33: Eingangstafel für die Wanderausstellung

Unsere damals sechs NSG im Kreisgebiet wurden auf jeweils einer Tafel vorgestellt. Wie bereits an anderer Stelle erwähnt, hatte die FG bei deren Ausweisung erheblichen Anteil. Weitere Tafeln trugen folgende Titel:

Blühende Wiesen - eine Seltenheit

Moore - gefährdete Lebensräume

Hecken - wichtige Elemente in der offenen

Landschaft

Kies- und Sandgruben - Ersatzlebensraum aus Menschenhand

Kranich - vor dem Aussterben bewahrt

Weißstorch - immer stärker bestandsgefährdet

Fledermäuse - geschützte Schädlingsbekämpfer

Lurche und Kriechtiere - wichtige Glieder im

Naturhaushalt

Beringung - Hilfsmittel der Forschung

In Ermangelung anderer Möglichkeiten waren die 15 Tafeln „wandzeitungsähnlich“ angefertigt. Die von einem Krakower Zeichenlehrer gemalten Überschriften gaben der Ausstellung einen professionellen Anstrich.

Die selbst verfassten Texte, eigene Zeichnungen und ausgeschnittene Fotos wurden aufgeklebt. Die farbigen Fotos stammten vielfach aus bunten „West-Broschüren“, die wir von Freunden erhalten hatten. Wir standen vielfach vor dem Konflikt, dass wir dieses Material, was es in dieser Art und Qualität in der DDR ja kaum gab, zerstören mussten. Heute mit den Möglichkeiten des Computers und des Internets kann man sich die mühselige Puzzle-Arbeit bei den damaligen Tafelherstellungen nicht mehr vorstellen. Bei dieser Arbeitsweise war es auch kein Wunder, dass es sehr lange dauerte, bis wir mit unseren eigenen Texten zufrieden waren und endlich eine Tafel fertig wurde.

Die Tafeln waren ordentlich gerahmt, hatten eine Glasplatte und waren über ein Ständersystem aneinander gereiht aufstellbar.

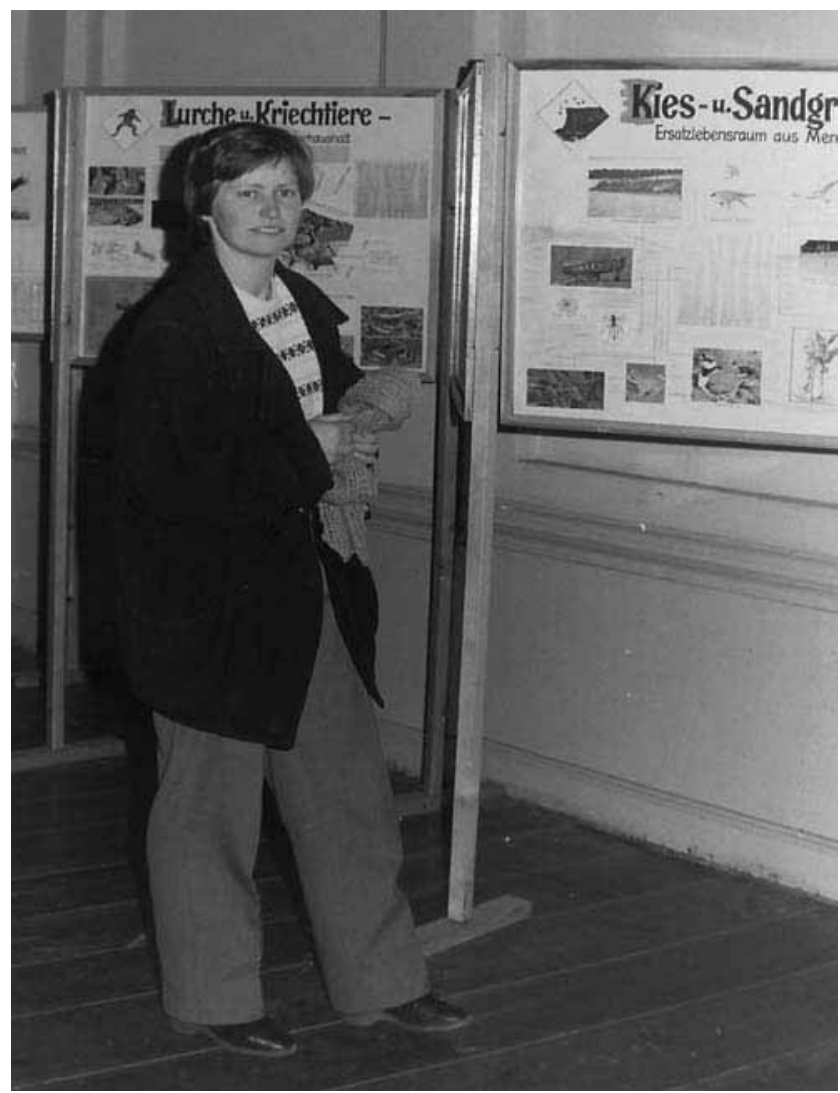

Abb. 34: Angela Martin vor den Ausstellungstafeln der ersten Fassung. Foto: f. Loose.

Sozusagen als Wanderausstellung wurde sie ab März 1987 bis zur Wende 1989 an mehr als 30 Orten gezeigt, z.B. in vielen Schulen des Kreises, in kleinen Museen und auf den Zeltplätzen in Krakow am See und Garden. Mit einem „Fotofaltprospekt“ wurde an verschiedenen Stellen für diese Ausstellung geworben. Einzelne Tafeln wurden zeitweilig an Freunde auch nach Schwerin und Oranienburg ausgeliehen. 
Anlässlich des Tages der deutschen Einheit stand die komplette Ausstellung am 03.10.1990 sogar auf dem Hof des Schlosses Güstrow.

Wie ein noch vorhandenes Begleitheft zur Ausstellung belegt, fanden auch nach der politischen Wende diese Informationstafeln über das neue Naturschutzamt des Landkreises weiter den Weg in unsere Schulen und an andere Orte:

04.10. - 15.12.1990 Ernst-Thälmann/ Dimitroff Oberschule Güstrow

16.03. - 01.04.1991 Ausstellung Naturschutz und Jagd im Museum Schloß Güstrow

04.04. - 22.04.1991 Goethe-Oberschule Güstrow

22.04. - 26.04.1991 Grundschule Lohmen

26.04. - 27.05.1991 Oberschule Zehna

27.05. - 10.06.1991 Oberschule Mühl Rosin

11.06. - 02.07.1991 Distelbergschule Güstrow

03.07. - 07.07.1991 Stadt Laage anlässlich deren 775 Jahr-Feier

08.07. - 30.07.1991 Zeltplatz Garden/Lohmen

Solche Einträge im Begleitheft wie:

„Wir Schüler der POS Lohmen haben uns sehr gefreut, dass die Ausstellung „Arten und Biotopschutz" an unserer kleinen Schule stehen durfte und alle Schüler der Klassen ihre Kenntnisse über naturgeschützte Gebiete in unserem Heimatkreis erweitern konnten. ...Wir wollen nun gemeinsam mit Herrn Loose und Herrn Montschko die Vögel und Pflanzen am Breeser See beobachten. Wer hat denn schon einmal von uns eine Orchideenwiese betrachtet? Künftig wollen wir mit offenen Augen durch die Natur gehen, um Pflanzen und Tiere bewusst zu erkennen. Sie sollen in Ruhe leben und sich vermehren können. In diesem Sinne wollen wir künftig handeln und uns dementsprechend in der Natur verhalten - Klasse 3."

wurden eindeutig von den Lehrern geschrieben und stellen ein Wunschdenken, aber immerhin auch einen (kurzzeitig wirkenden) Lehrinhalt dar. Nach der Ausstellung fand dann später tatsächlich noch eine Exkursion mit den Schülern ins NSG Breeser See statt. Ein Mehr, gar die Bildung einer Natur-Arbeitsgemeinschaft an der Schule (wie die Hoffnung anfangs auch in Zehna nach einer Exkursion ins NSG vor der Haustür bestand), folgte diesem Anstoß leider nirgends. Immerhin wurde durch Lehrer vermerkt: „Diese Ausstellung hat aufklärend und zur Naturbeobachtung anregend gewirkt; das haben die Schüler im Biologieunterricht zum Ausdruck gebracht."

Anlässlich der 775 Jahr Feier in Laage wurde die Ausstellung auch insbesondere nach Einträgen von Erwachsenen hinsichtlich Inhalt und Engagement der Hersteller sehr gelobt.

Nach etwa fünfährigem Umlauf der Ausstellung verstaubten die Tafeln im Lager der unteren Naturschutzbehörde ab 1992. Sie sollten technisch überarbeitet werden. Heute sind sie nach vielen Umzügen der Verwaltung und Lager- auflösungen verschollen. (Fotos im Anhang belegen noch ihre Existenz)

Mit Gründung der NABU-Ortsgruppe Güstrow, deren tragende Säule die Fachgruppe Ornithologie und Naturschutz ist, stand erneut die Aufgabe, die Tätigkeiten der FG einer breiten Öffentlichkeit bekannt zu machen und über Themen des Arten- und Biotopschutzes zu informieren. Als Vorsitzender der Ortsgruppe drängte Wolfgang Neubauer auf die Anfertigung einer neuen Posterserie. Inzwischen gab es mit der neuen Computer- und Drucktechnik verglichen zu den am Ende der 1980er Jahre hergestellten Tafeln völlig neue Möglichkeiten, die auch deutlich weniger arbeitsaufwändig waren. In das Konzept der Tafeln wurden vom Redaktionsteam die jeweiligen Artbearbeiter und NSG-Betreuer einbezogen und das Ergebnis wurde in den FG-Sitzungen vorgestellt und diskutiert. Eine erste Aufstellung fanden die Tafeln bei einer OAMV-Tagung im Bürgerhaus in Güstrow.

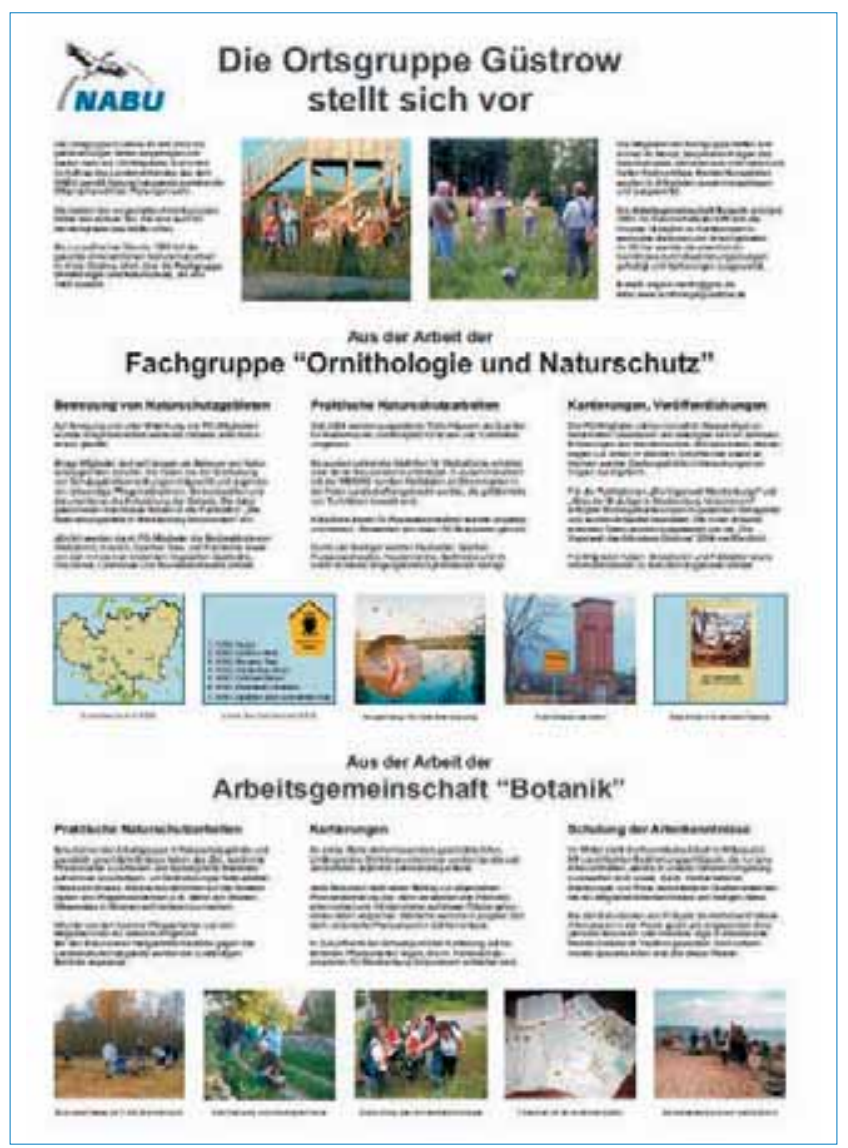

Abb. 35: Eingangstafel zur neuen Posterserie

Einige doppelt angefertigte Tafeln bekamen einen Dauerplatz in Regionen des Kreises (Linstow, Lohmen, Kuchelmiß), wo regelmäßig eine größere Zahl von Touristen Urlaub machen. Die neu gestalteten Tafeln sind als Anhang 3 zur Anschauung beigefügt. Als künftige Aufgabe steht hier die Ergänzung der bisherigen 13 Tafeln um botanische Themen zum Biotop- und Artenschutz analog zu den Tafeln der ersten Serie an. 
Anlässlich des 80.Jahrestages des NSG Krakower Obersee im Jahre 2012 organisierte ein Redaktionsteam der Fachgruppe, federführend natürlich der NSG-Betreuer Wolfgang Neubauer, eine große Ausstellung in der Synagoge von Krakow am See (Abb. 36). Hier wurden auf insgesamt 22 eindrucksvollen Postern nachfolgende Themen präsentiert:

- Entstehung und Entwicklung des Krakower Sees

- Unterschutzstellung

- Erforschungsgeschichte

- Nutzung des Gebietes

- Ökologischer Zustand des Gebietes

- Pflanzen des Gebietes (2x)

- Brutvögel (Flussseeschwalbe, Lachmöwe, Silbermöwe, Kormoran, Haubentaucher, Seeadler, Fischadler, Kranich, Rohrdommel, Rohrweihe, Rallen, Graugans, Höckerschwan, Eisvogel, Singvögel)

- Ehemalige Brutvögel (2x)

- Mauserplatz

n Durchzügler und Wintergäste

- Seltene Gäste

Die Fertigstellung und Endgestaltung der Tafeln lag in den Händen der Naturparkverwaltung des NP Nossentiner/ Schwinzer Heide. Für die Tafeln standen neben Fotos von W. Neubauer und einigen Fachgruppenmitgliedern zahlreiche beeindruckende Bilddokumente von befreundeten Ornithologen und Naturschützern unseres Landes (20 Personen) zur Verfügung, so dass eine sehr anspruchsvolle Dokumentation bei der Festveranstaltung am 14.07.2012 der Öffentlichkeit präsentiert werden konnte. Nach der Präsen- tation wurden die Tafeln der Naturparkverwaltung im Karower Meiler übergeben. Die Herstellung der Ausstellung war durch den NABU-Landesverband finanziell unterstützt worden. Im Anhang 4 sind auch diese Tafeln für das FGArchiv abgebildet.

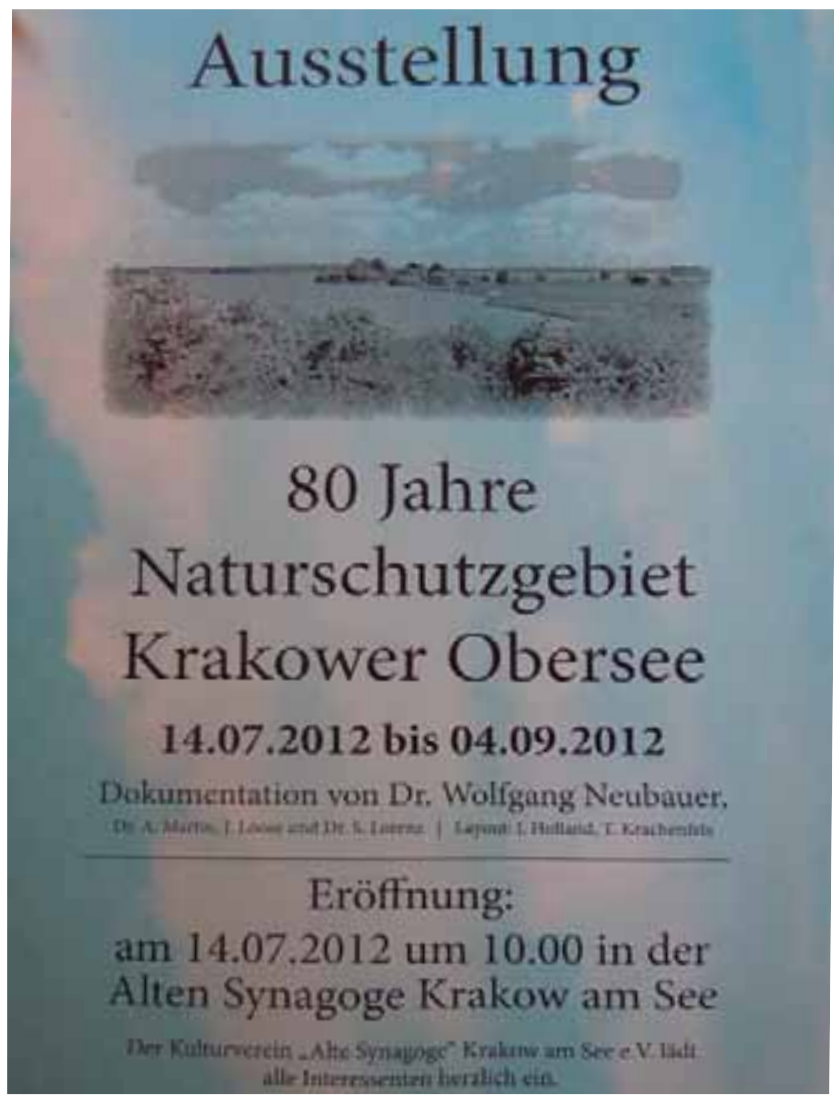

Abb. 36: Plakat zur KOS-Festveranstaltung

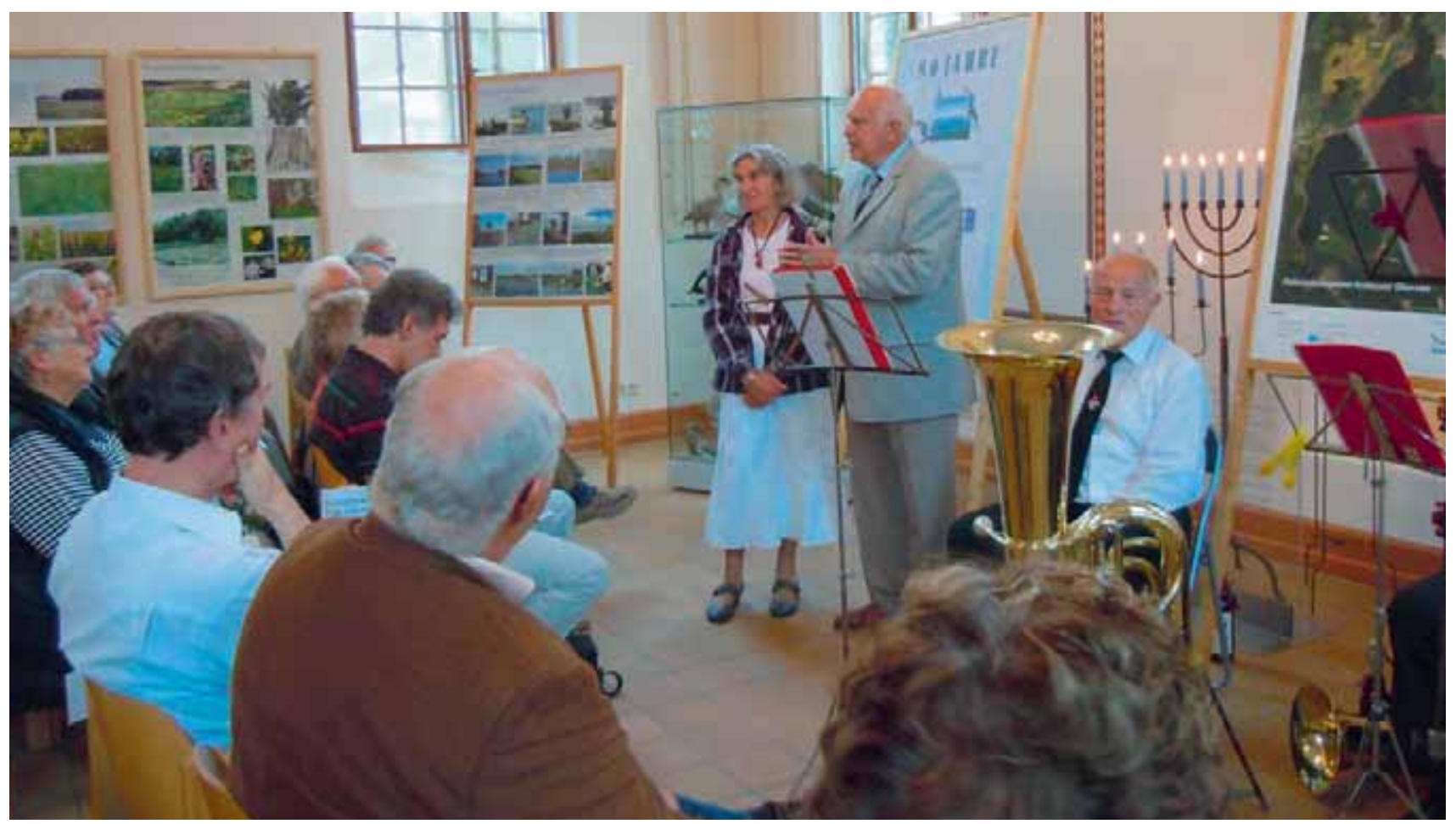

Abb. 37: Dr. Wolfgang Neubauer spricht beim Festakt zur Ausstellungseröffnung 80 Jahre NSG Krakower Obersee am 14.07.2012 in der Synagoge in Krakow am See. Foto: 7. Loose. 


\section{3. „Die Leute vom Kulturbund" [TV-Film von 1982]}

\section{Joachim Loose}

Es lässt sich heute nicht mehr ganz zurückverfolgen, wie es dazu kam, dass plötzlich das Fernsehen der DDR über drei Leute vom Kulturbund aus unserer Fachgruppe berichten wollte. Die Erstsendung des knapp 30 minütigen Films erfolgte im Fernsehen der DDR am 13.6.1982. Sich an den Film erinnernd, haben wir ihn erst vor kurzem im Deutschen Rundfunkarchiv Babelsberg suchen lassen. Die Mitarbeiter dort wurden fündig (Quelle: BC 11829), und wir erhielten eine Filmkopie mit der Erlaubnis, den Film zum Zwecke der Dokumentation der Fachgruppenarbeit zeigen zu dürfen.

Die drei tragenden Personen in dem Film, der den Untertitel „Beobachtungen im Kreis Güstrow“ trug, waren Forschungsstudentin an der Pädagogischen Hochschule Güstrow Angela Martin (25), Biologie- und Chemie-Lehrer an der POS Krakow am See Dr. Wolfgang Neubauer (47) und Oberinspektor der Deutschen Post beim Fernmeldeamt Güstrow Georg Strache (55). „Sie sind drei von Tausenden (im Kulturbund), die ihren Neigungen nachgehen und dabei Kultur und Landschaft behüten", heißt es in der Vorstellung. (Wie waren wir doch alle jung damals...)
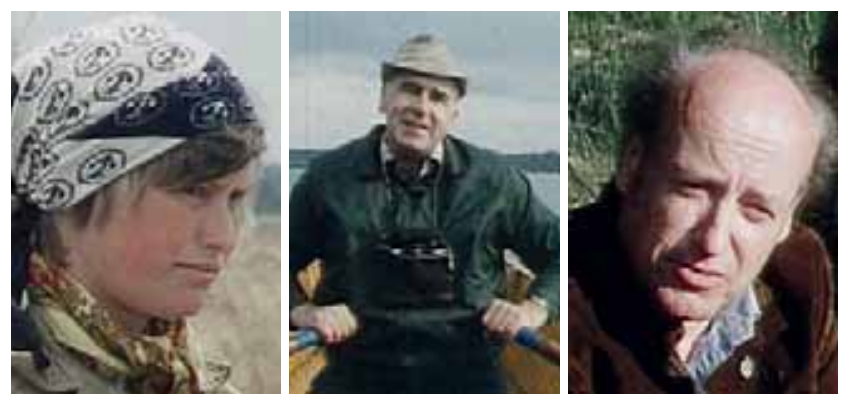

Abb. 38-40: Die Hauptakteure im TV-Film (Kopien aus dem Filmmaterial des DRA)

Die Filmemacher haben mit dem Streifen einen durchaus sehr umweltkritischen Film abgeliefert. Inhaltlich wurde eingangs auf das Engagement der Freizeitornithologen bei der 1.Rasterkartierung der Brutvögel in der DDR (19781982) eingegangen. Laut Angela Martin sollten die Ergebnisse in einen Brutvogelatlas der DDR einfließen. Mit dem könne man spätere Veränderungen in der Natur dokumentieren, erklärte sie. Mit solchen müsse man u. a. durch den immer stärkeren Einsatz von Pestiziden in der Landwirtschaft rechnen.

Im weiteren Verlauf stellt Wolfgang Neubauer die Bedeutung des NSG Krakower Obersees dar. Er berichtete, wie er als aktiver Ornithologe frühzeitig zum Kreisnaturschutzbeauftragten (KNB) ernannt wurde und diese von ihm ehrenamtlich geleisteten Arbeiten in der Summe eine halbe hauptamtliche Stelle ausfüllen würden.

Ein Schwerpunkt des Films handelte vom Hauptproblem im NSG Krakower Obersee: der Verschmutzung durch Eintrag von Nährsalzen aus der Felderdüngung, die über Abschwemmungen in den See gelangen. Besonders ging es um Jauche, die hier aus zwei Quellen in den See einfließt (von der LPG Dobbin und dem Teilbetrieb des VEG Laage in Glave).

Der Rat des Kreises Güstrow hatte zu einem Ortstermin nach Glave geladen, der teilweise im Film dokumentiert wurde. Heinz Stegemann als Sekretär für Jagd und Naturschutz stellte die Teilnehmer vor: der Bürgermeister von Dobbin, Genosse Brüggemann - Direktor des VEG Laage als verursachender Betrieb, die Staatliche Gewässeraufsicht und der KNB waren anwesend.

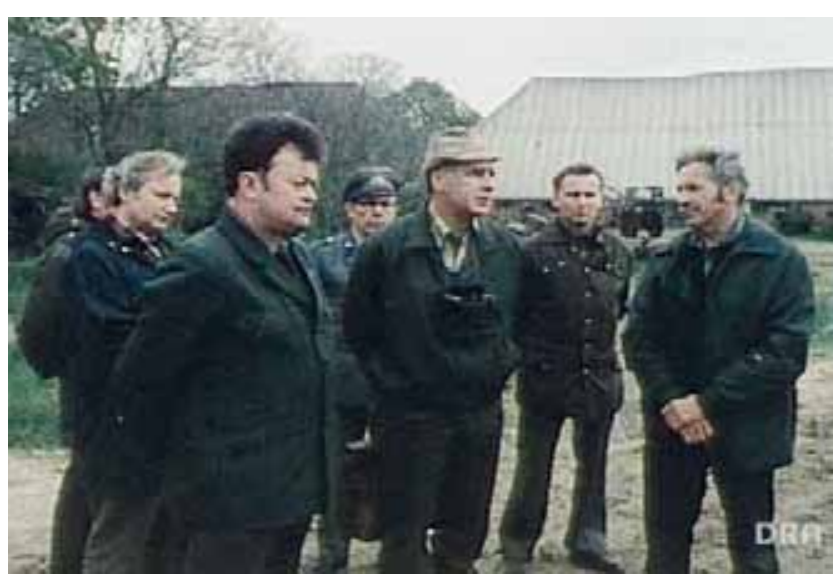

Abb. 41: Teilnehmerkreis beim Ortstermin in Glave (Quelle: DRA)

Die Kamera schwenkte während der Gespräche immer wieder über marode Ställe, Misthaufen und unbefestigte Jaucheseen. Die Probleme der fehlenden Jauchezisternen und Lagerkapazitäten seien jahrelang bekannt gewesen.

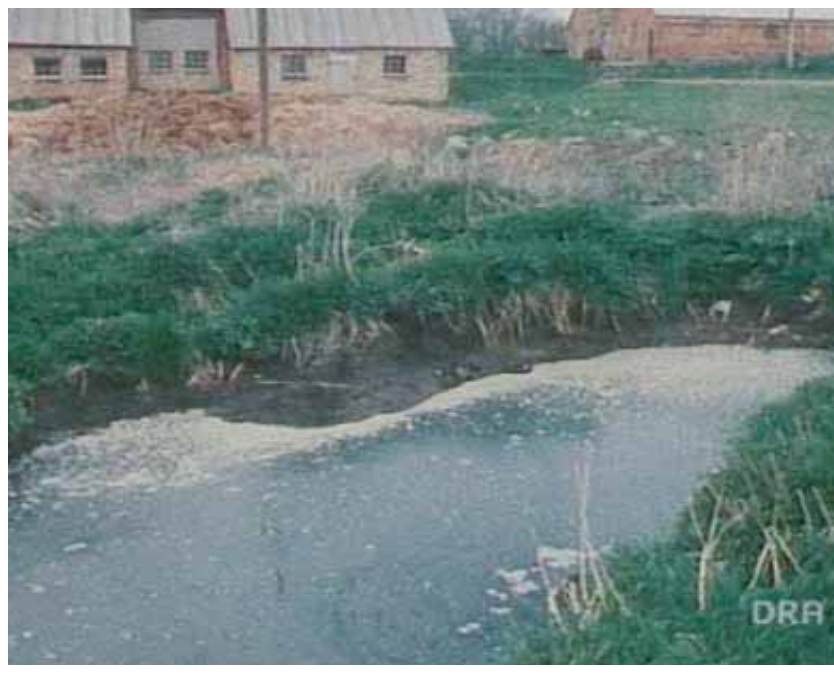

Abb. 42: Missstände mit Dunglege und fauchengrube in Glave (Quelle: DRA) 
Genosse Brüggemann erklärte: „Wir bewirtschaften nicht nur hier in Glave, sondern auch in Laage sehr interessante Naturschutzgebiete und sind bemüht, diese Missstände im Umweltschutz zu beseitigen. " - Glave wäre erst vor sieben Jahren übernommen worden, die Gebäudesubstanz sei teilweise über 100 Jahre alt, es sei keine Kanalisation, keine Abwässerbewirtschaftung vorhanden.

Ziel der nicht vor der Kamera geführten Beratung war es, zu klären, wie die stattfindende Verschmutzung des Krakower Obersees in den nächsten Monaten, in den nächsten Jahren abgebaut werden könne.

Am Ende der Beratung erklärte der Direktor des VEG:

„Wir werden diese Anlage, die Sie hier sehen, die keine befestigte Dunglege hat, mit einer befestigten Dunglege versehen, wir werden hier Zisternen bauen, ein festes Durchfahrtsilo auch mit einer Abwasserzisterne, mit einer Sickersaftzisterne, und wir werden hier eine Hofbefestigung vornehmen, damit die Jauche, die Sickersäfte und andere Umwelt verschmutzende Faktoren ausgeschaltet werden. Wir sehen die Erfüllung der genannten Maßnahmen genauso wichtig an wie unsere tägliche Planerfüllung, denn wir können nicht nur die Produktion sehen, wir müssen hier die exponierte Stellung dieses Gebietes (des NSG KOS) im Rahmen des Natur- und Umweltschutzes sehen.

Das Statement des KNB Wolfgang Neubauer lautete: „Fa es ist selbstverständlich, dass wir solche Dinge, die ja doch recht kostenaufwendig sind, nicht übers Knie brechen können. Das geht nicht, dass man das alles von heute auf morgen regelt. Und wenn das so verwirklicht wird, wie das im Protokoll festgelegt wurde, und es dann verwirklicht wird, glaube ich, können wir doch ganz zufrieden sein. Dann wird also in absehbarer Zeit, in wenigen Jahren oder Monaten schon, ein Teil dieser Verschmutzungen beseitigt sein und der See wird von dieser Seite her weniger belastet sein. Also insgesamt kann gesagt werden, mit dem was heute festgelegt worden ist, und wenn das so verwirklicht wird, können wir durchaus zufrieden sein."

Im Film wird zu einem anderen Kapitel übergeleitet, während der Sprecher anmerkt:

„Die Sicherung unserer Ernährungsbasis, die Steigerung unserer Produktion, sind Gründe genug, um in Landschaften einzugreifen. Vernünftige Lösungen zu finden, bedarf mitunter beachtlicher Aufwendungen. Wir trafen aber auch auf leichter lösbare Probleme, die eigentlich gar keine wären, wenn vorher nachgedacht worden wäre."

Es wurde die Errichtung eines Grabenstaus im NSG Zehlendorfer Moor gezeigt, wo zahlreiche Mitglieder unserer FG einen Abfluss aus dem Moor zum Augraben mit Erde und Strauchwerk verstopfen wollten.

Angela Martin erklärte einsichtig die Maßnahme: „Wir brauchen Nutzflächen für die Ernährung und deshalb kann man Moore nur noch in kleinen Teilstücken erhalten. ... So wichtige Lebensräume wie Moore müssen für Arten erhalten werden, so gut wie es geht .... Vom ILN Greifswald hatte uns Dr. Jeschke Hinweise für durchzuführende Maßnahme zur Sicherung des Moores gegeben."

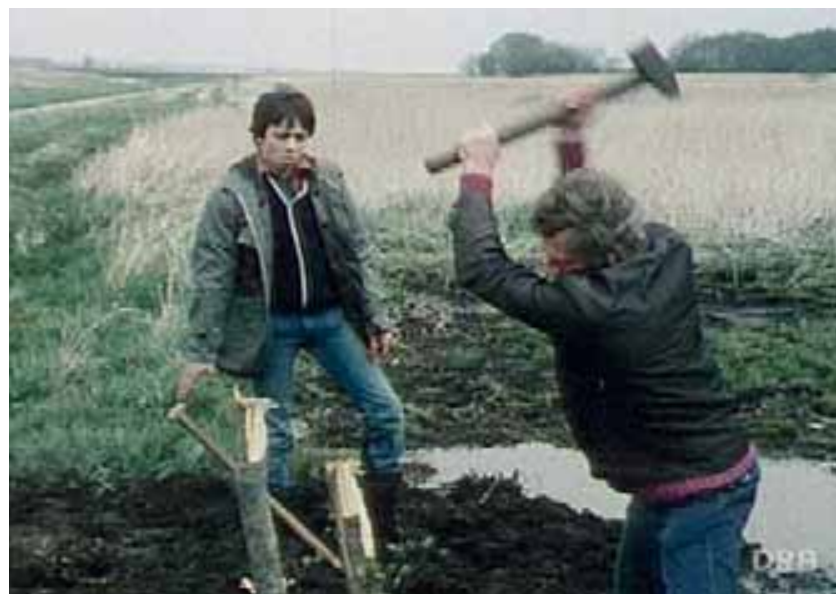

Abb. 43: Andreas Schilf und Fritz Anderlik beim Bau eines Grabenstaues im NSG Zehlendorfer Moor. (Quelle: DRA)

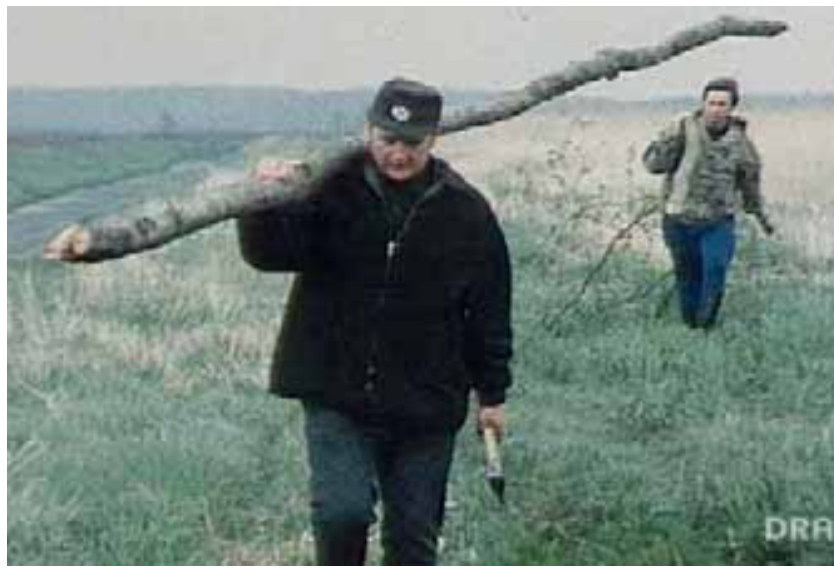

Abb. 44: Wolfgang Köhler und foachim Loose beim Materialtransport für den Bau eines Grabenstaues im NSG Zehlendorfer Moor. (Quelle: DRA)

Es gäbe aber auch noch den Vorschlag zur Stauerrichtung in Höhe der Autobahn. Hier seien noch Kämpfe mit der Melioration zu erwarten, ebenso wie auch bereits durchgeführte Absprachen mit der Landwirtschaft nicht immer reibungslos abgelaufen seien.

Im Schlussbeitrag wird Georg Strache auf einer ungeordneten Mülldeponie gezeigt. Und dann im Gespräch mit der Obrigkeit, einem Bürgermeister.

Dieser erklärt die gezeigten Missstände mit „Nachlässigkeit bei den Fahrern, Uneinsichtigkeit einiger Bürger, Traktoristen ganz konkret“ und bemerkt dazu: „da haben wir als staatliche Leiter noch zu kämpfen, da sind wir bei weitem nicht durch". 


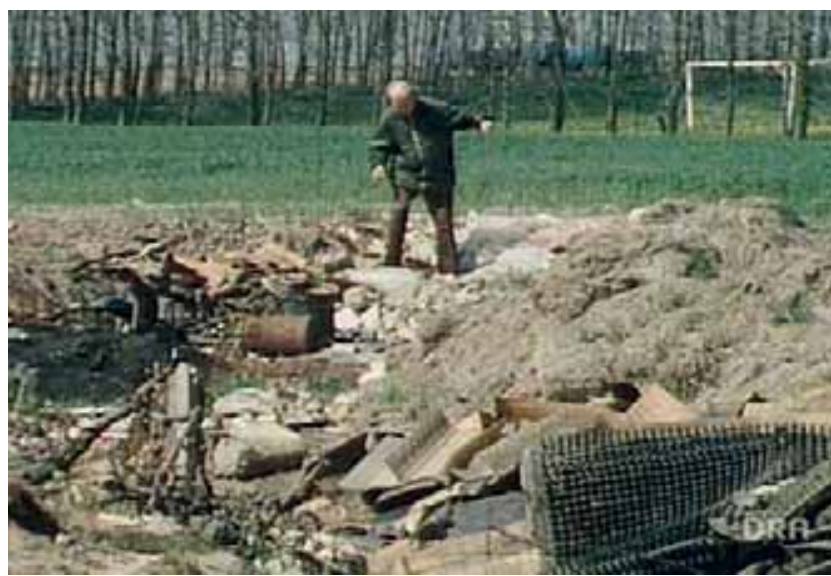

Abb. 45: Georg Strache prangert Müllablagen am Rande eines Solls als ungeordnete Deponie an. (Quelle: DRA)

Den Schlusssatz des Sprechers zu diesem Thema kann man nur unterstreichen:

„Der Natur- und Umweltschutz ist gesetzlich fixiert. Gedankenlosigkeit ist eine freundliche Umschreibung dessen, was in Wirklichkeit Gesetzesverletzung und Rechtsbruch heißt, und das geht jeden an, nicht nur die Leute vom Kulturbund."

Dem Film von damals sind einige Kommentare aus heutiger Sicht anzufügen.

Wie würde wohl nach heutigen rechtlichen Bestimmungen der Wasserwirtschaft mit der Gewässerbelastung durch Jauche wie damals in Glave umgegangen werden? Das VEG Laage hatte ganze sieben Jahre lang nach Übernahme der Stallungen nichts am Zustand verändert. Jetzt sollten bis zur Umsetzung des Versprechens zur Beseitigung der Belastungen weitere Monate oder wenige Jahre vergehen. Wie „genügsam" hatten wir Naturschützer damals sein müssen!? Leider konnte man die Aussage im Film nicht als Satire ansehen...
Der Versuch, Wasser im Zehlendorfer Moor durch einen einfachen Grabenstau zu halten, war nicht von Erfolg gekrönt. Bereits wenige Stunden nach der Filmszene waren das Wasser im verschlossenen Graben und der Wasserdruck so hoch gestiegen, dass das von uns errichtete primitive Staubauwerk umspült wurde. Dem Großmeliorationsprojekt aus den 1960er Jahren konnte nur mit einem neuen Ingenieurprojekt begegnet werden. Auf ein solches (leider mit noch unbefriedigender Lösung) musste noch mehr als 20 Jahre gewartet werden. (vgl. Beitrag zum NSG Zehlendorfer Moor - Pkt. 8.1.4)

Jedes Dorf hatte früher eine kleine Kies- oder Sandgrube, die fast alle in der Folge zu Mülldeponien wurden und schließlich abgedeckt wurden. Welches Potenzial für den Artenschutz ging hier verloren! Wie im Filmbeitrag zu sehen war, wurde Müll nicht nur am Rande sondern auch in Kleingewässer eingebracht und diese schließlich verfüllt. Georg Strache berichtete uns in den FG-Sitzungen regelmäßig von neuen von ihm in der Landschaft entdeckten Müllablagerungen, die er bei den Behörden angezeigt hat. Er blieb in dieser Hinsicht unnachgiebig und hartnäckig. In den seltensten Fällen konnte die Natur wieder hergestellt werden; in der Regel wurde der Unrat nur abgedeckt. Leider muss heute von uns allen immer wieder festgestellt werden, dass immer noch viele Bürger kein Umweltbewusstsein haben. Kühlschränke, Autowracks, Fernseher und anderes werden immer noch oft mitten im Wald oder in Söllen liegend gefunden, obwohl sie kostenfrei über Wertstoffhöfe entsorgt werden könnten. Lediglich die Verfolgung von Ordnungswidrigkeiten im Bereich geschützter Biotope und in Gewässern wird heute - nur soweit sie entdeckt und angezeigt wurden - nach den gesetzlichen Bestimmungen schärfer und auch bis zur Wiederherstellung verfolgt.

\subsection{Vogelstimmen- u. a. öffentliche Exkursionen}

\section{Angela Martin}

Georg Strache hatte als exzellenter Kenner der Vogelstimmen frühzeitig begonnen, der interessierten Bevölkerung jährlich mehrere Exkursionen zum Kennenlernen der Vögel über ihre Gesänge anzubieten. Für seine Routen nutzte er meist den Gehölzreichtum des Güstrower Friedhofes mit dort zahlreich vorkommenden Singvogelarten. Ich unterstützte ihn bei größeren Gruppen mehrfach. Einige Male zog ich auch bereits in DDR-Zeiten selbst mit einer kleinen Gruppe von Menschen in frühen Morgenstunden, einmal bereits auch ab 5:00 Uhr, in die nahe Umgebung Güstrows. Für die meisten Teilnehmer war es schwierig, aus dem weitgehend anonymen Vogelkonzert einige Interpreten herauszuhören. Wie bringt man Leuten das Wesentliche beim Unterscheiden der Vogelstimmen bei? Ein schwieriges Unterfangen!

Seit dem Jahr 2007 waren drei bis vier Vogelstimmen-Exkursionen im Jahr ein fester Bestandteil des Programms der Kreisvolkshochschule. Auch in den Jahren davor gab es immer wieder einzelne Veranstaltungen, ausnahmsweise auch in den Abendstunden.

Als Fachgruppe kamen wir mit diesem Programmpunkt der Volkshochschule als unserem Quartiergeber für die FGVersammlungen entgegen.

Obgleich wir bei den Stimmen-Schulungen an den FG- 
Abenden gemerkt haben, dass auch einige FG-Mitglieder durchaus noch an ihrer Kenntnis der Vogelstimmen arbeiten müssten, beschränkte sich die Teilnahme an den Exkursionen meist nur auf Leute außerhalb der FG.

Im Laufe der Zeit bildete sich ein gewisser Stamm an Exkursionsteilnehmern heraus, die im Juni auch nicht vor dem recht frühen 6 Uhr-Termin zurückschreckten.

Am zahlreichsten fanden sich Teilnehmer beim jährlichen Termin Ende März ein. Hier gab es noch die für viele angenehmere Anfangszeit um 8 Uhr. Vielfach mochten auch der beginnende Frühling zur Vogelbeobachtung aktiviert haben - Gartenbesitzer und Vogelfreunde nahmen sich mal wieder vor, doch endlich einige Gesänge der richtigen Art zuordnen zu können.

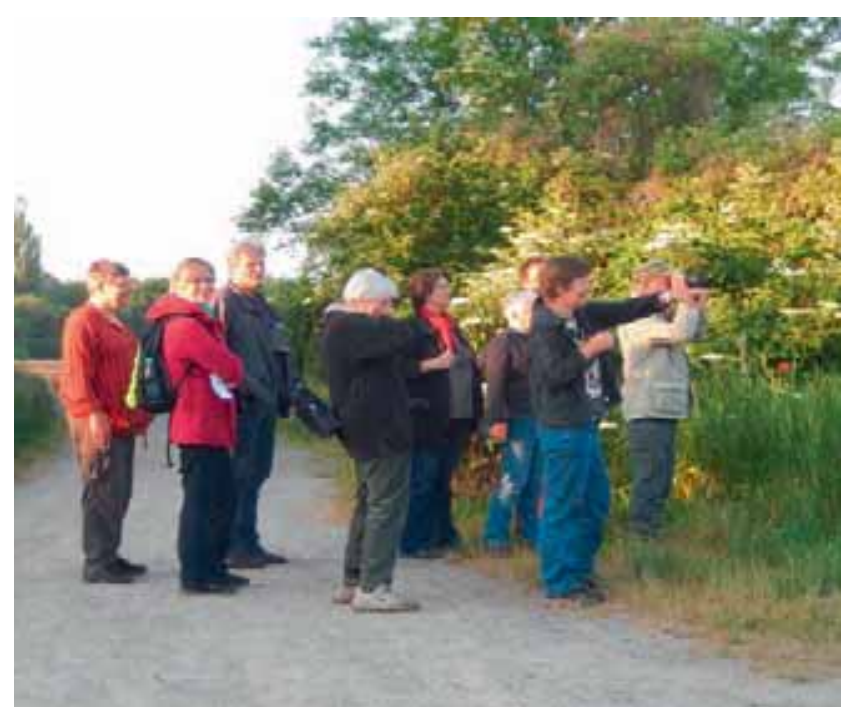

Abb. 46: A. Martin bei der öffentlichen Vogelstimmenwanderung Foto: 7. Loose.

Aus meinen Erfahrungen kann ich berichten, dass bei diesen Exkursionen auf gar keinen Fall die gesamte Vogelwelt des durchwanderten Gebietes oder eine große Zahl verschiedener Sängern vorgestellt werden sollte.

Nach dem Motto: Weniger ist mehr, geht es um das Vorstellen weniger Arten. Die Teilnehmer wurden immer wieder darauf hingewiesen, höchstens zwei bis drei Arten bei einer Exkursion lernen zu wollen. Das Gehör soll vor allem auf ein „Herausfiltern“ von Arten trainiert werden: bekannte Arten sollen „abgeschaltet“ und die Aufmerksamkeit auf einen unbekannten Gesang oder Ruf konzentriert werden. Besonders wichtig ist das bei einem Vogelkonzert im Mai/ Juni - eine Einzelstimme ist dann kaum noch „vorführbar“, weil ringsum alles singt.

Die Sichtbeobachtung einiger Vogelarten war jedoch stets der Höhepunkt. Wenn man einen Vogel beim Singen sieht, ist der Lerneffekt natürlich am größten.

Die Routen für die etwa zweistündigen Vogelstimmenexkursionen wechselten, um je nach Jahreszeit immer wieder unterschiedliche Arten erleben zu können. Die Wanderungen führten u. a. durch die Gartenanlage an der Schanze bis zum Ufer des Sumpfsees oder auf dem Barlachweg entlang des Inselsees. So war es möglich, neben Gartenvögeln auch Arten des Schilfgürtels vorzustellen: Teich- und Drosselrohrsänger, Rohrammer, Rohrschwirl, Beutelmeise, Wasserralle, mitunter auch Große Rohrdommel. Nicht jedem war anfangs klar, dass der Gesang des Rohrschwirls tatsächlich von einem Vogel stammt. Die Inselsee-Exkursion wurde meist mit einem Abstecher in den Heidberg verknüpft, wo Waldarten vorgestellt werden konnten. Besonders einprägsam war hier die „Schwirrstrophe“ des Waldlaubsängers. Auf der seeabgewandten Seite des Barlachweges bringt das gebüsch- und schilfreiche Gebiet eine solche große Vielfalt an Rufen und Gesängen, dass sich ein Lernen dort als recht schwierig erweist. Jedoch gab es einmal eine Ausnahme: Es waren die unverkennbaren Rufreihen des Wendehalses.

Ende Juni ging es über den landschaftlich attraktiven Rundweg auf Schöninsel, wo die noch singenden Schilfbewohner wiederholt werden konnten.

Da bei vielen Vogelarten ein Herbstgesang zu vernehmen ist, wurde seit 2009 auch im September eine Führung angeboten. Neben Gesängen charakterisieren auch „frühlingsunabhängige“ markante Rufe die Vogelarten. Der Weg führte durch die Gartenanlage am Sumpfsee und zum See selbst. Hier weilten zu dieser Zeit immer große Mengen von Gänsen, so dass auch dieses Schauspiel die meisten Teilnehmer beeindruckte. Wie bereits erwähnt, werden Sichtbeobachtungen intensiver erlebt, als das bloße Verhören von Vogelstimmen. An einem klaren Septembermorgen konnten über dem Schilf sogar Bartmeisen bei ihren Höhenflügen beobachtet werden.

In den vergangenen Jahren wurden die monatlich gewählten Routen beibehalten. Bei der Auftakt-Tour Ende März musste die Stadt nicht verlassen werden, um die ersten Balzrufe und Gesänge zu vernehmen. Die April-Exkursion führte entlang des Nebelkanals, wo einige Drosselarten vorgestellt werden konnten, es zogen auch noch Trupps der Wacholderdrossel durch.

Am Gleviner Platz in Güstrow waren Birkenzeisige in der Brutzeit gut zu beobachten. Ich fand dort sogar ein Nest. So legte ich die Wegstrecke für die Aprilführung in diese Gegend und konnte dem Teilnehmerkreis diese bei uns selten nachgewiesene Brutvogelart vorführen. Wenn sich der eine oder andere den sehr charakteristischen Ruf der Birkenzeisige eingeprägt hat, besteht die Hoffnung, dass er den Ornithologen von anderen Nachweisorten einen wertvollen Hinweis gibt.

In eine andere Art der „Nachwuchsförderung“ wurde ich 2003 „hineingestoßen“. Die Kita Glasewitz suchte für ihre „Waldwoche“ einen fachkundigen Führer. Das fand dann seine jährliche Fortsetzung bis 2011. Jeweils an einem Tag 
im Juni erklärte ich den „Lütten“ bei einem Waldspaziergang oder auch am Libowsee einige Dinge der Natur. Mit Feuereifer waren sie dabei. Auch die Erzieherinnen lernten so einiges dazu. So früh würde eine Förderung Sinn machen, denn die Jüngsten sind noch begeisterungsfähig. Bei ihnen könnte der Grundstein für ein Interesse gelegt werden. Leider lässt die Ausbildung der Erzieherinnen in dieser Richtung früher wie heute stark zu wünschen übrig.

Die jährliche Durchführung des Tages der Artenvielfalt, bei uns initiiert durch Lothar Brockmöller vom LUNG, richtete sich an ältere Schülergruppen. In fünf Jahren hintereinander sicherte ich die fachliche Seite bei der Bestimmung von Pflanzenarten ab und versuchte auch, die Schüler an einige Vogelstimmen heranzuführen.

Die Schüler zeigten sich durchaus interessiert, aber bei weitem nicht wie die Kindergartenkinder. Durch ein mangelndes Engagement der Lehrer werden die Kinder in Naturhinsicht nicht gefördert. Es bliebe den Lehrern frei gestellt, sich Unterstützung bei uns Ehrenamtlern zu holen. Das ist jedoch nie geschehen...
Andere öffentliche Exkursionen führte W. Neubauer jährlich einmal für interessierte Bürger und Urlauber der Gegend in Zusammenarbeit mit dem Tourismusverein Krakow am See durch. Er wollte damit für sein NSG Krakower Obersee werben und Verständnis dafür wecken, dass dieses Gebiet weitgehend für die öffentliche Nutzung verschlossen bleiben muss. Die Exkursionen waren stets ausgebucht. Die Tradition wird nunmehr nach dem Tode von W. Neubauer durch Sebastian Lorenz als neuer NSG-Betreuer fortgesetzt.

Nachdem Joachim Loose 2014 mit einem Fotovortrag öffentlich über die Bedeutung des PVA-Teiches berichtet hatte, wurde von interessierten Bürgern der Wunsch nach geführten Exkursionen in dieses Gebiet geäußert. Dem wurde mit Exkursionen im Frühjahr 2015 zur Limikolenbeobachtung und einer Herbstexkursion zum Schlafplatz der Kraniche in Verbindung mit der Kreisvolkshochschule (KVHS) entsprochen. Die Exkursionen waren im Halbjahresprogrammheft der Schule angekündigt. Der Kreis der interessierten Bürger hatte auch hier einen hohen Altersdurchschnitt und führte zu keinem erhofften Neuzugang für die Fachgruppe.

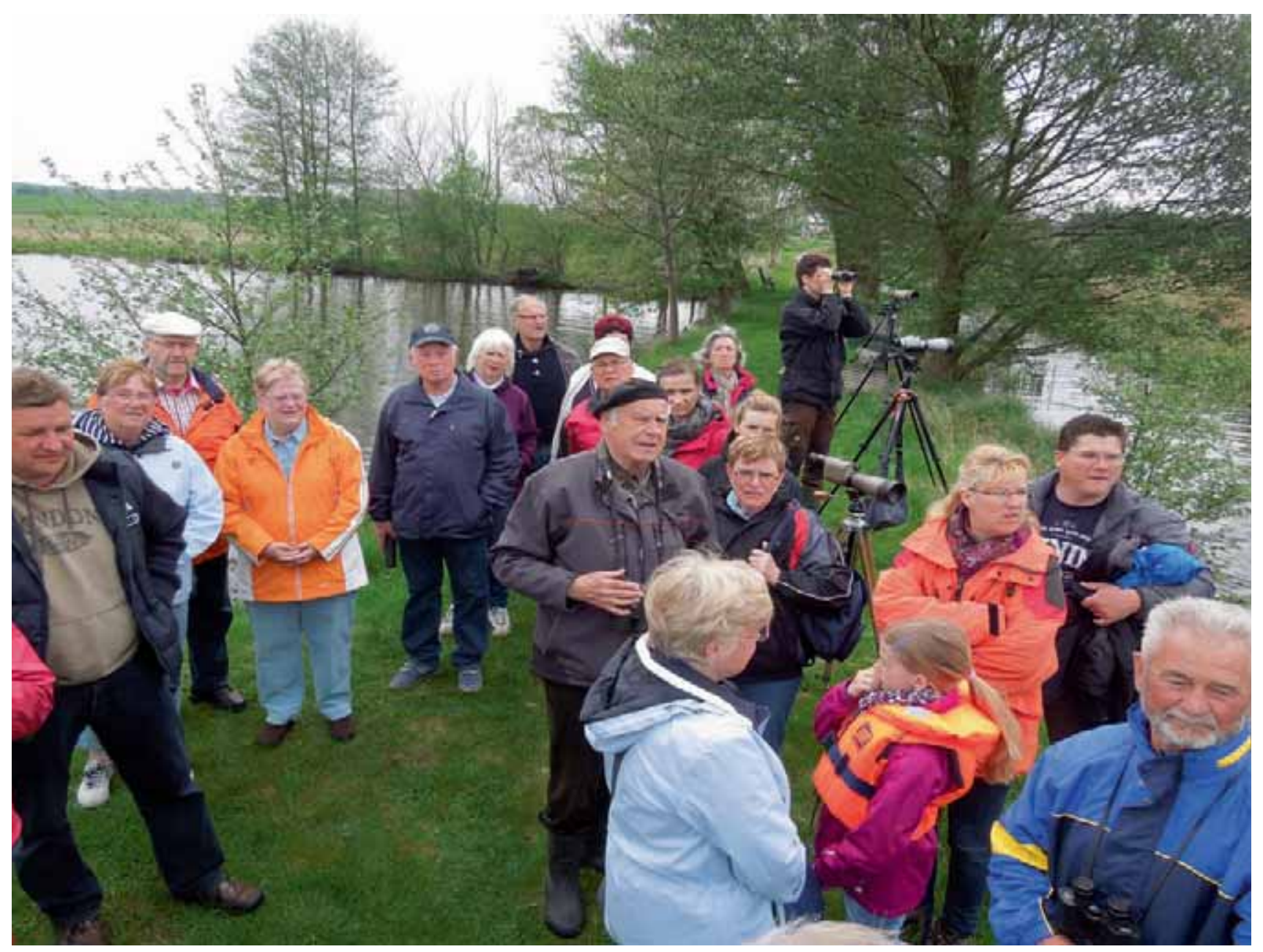

Abb. 47: Exkursionsteilnehmer am Krakower Obersee vor der „Einschiffung“ zur Fahrt auf den Großen Werder - 11.5.2013. Foto: 7. Loose 


\section{Andenken an verstorbene FG-Mitglieder}

Mit den Ornithologen der ersten Stunden, die inzwischen alle für immer von uns gegangen sind, verbinden sich für einige von uns noch gemeinsame Erlebnisse. Die Zahl neu hinzugekommener Mitglieder wurde mit den Jahren größer. Immer öfter tauchen von jenen beim Betrachten von älteren Gruppenfotos solche Fragen wie, wer war denn der und in welchem Gebiet hatte der beobachtet, auf.

Aus den Anfängen der Fachgruppe nicht mehr unter uns weilen inzwischen

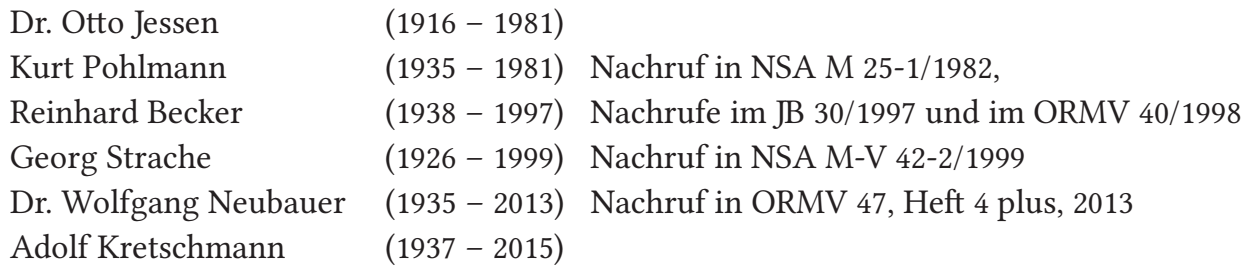

sowie die später zur Fachgruppe gekommenen Mitglieder
Klaus Dauber
$(1942-2006)$
Uwe Thamm
(1967 - 2007) Nachruf im JB 39/2006
Silke Schulze
$(1943-2008)$

Mit ihrem Tod entstanden immer wieder große Lücken bei der Beobachtungsintensität in einzelnen Gebieten und Teilen des Kreises und in der Gruppenarbeit, die durch andere bis heute nicht wieder geschlossen werden konnten.

\section{Dr. Otto Jessen [gest. 1981]}

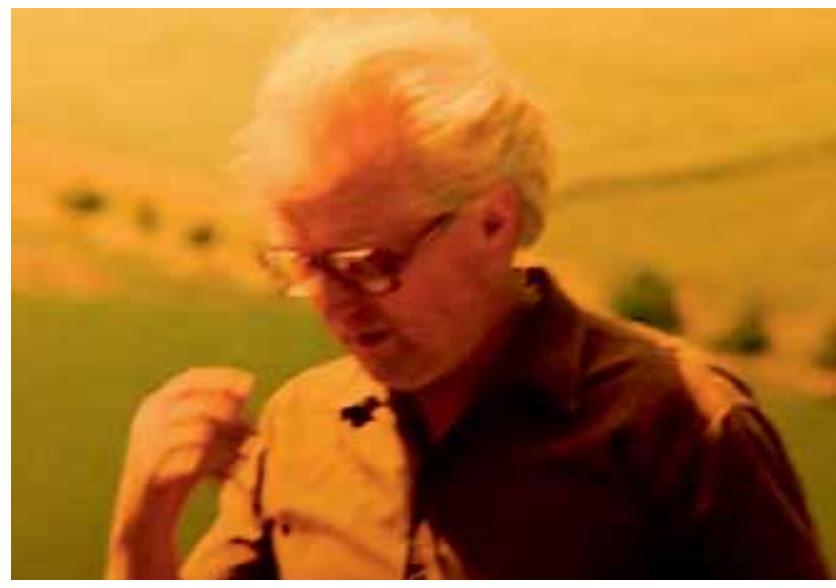

Über sein Wirken in und für die Fachgruppe kann heute kaum noch etwas berichtet werden, da uns die Zeitzeugen fehlen.

Dr. Otto Jessen war am damaligen Pädagogischen Institut Güstrow im Fachbereich Biologie als Dozent tätig. Sein Name taucht in einigen Protokollen der FG-Zusammenkünfte auf. Er wird aber in der FG selbst nicht weiter tätig. Beobachtungseinträge von ihm in der FG-Kartei konnten nicht gefunden werden.

\section{Kurt Pohlmann [26.6.1935 - 7.6.1981]}

Kurt Pohlmann wurde am 26.6.1935 in Bahni (im heutigen Polen) geboren. Nach der Umsiedlung 1945 kam er mit seiner Mutter und seinem Bruder nach Neu Bernitt, Altkreis Bützow. Sein Vater war im Krieg gefallen. Nach dem Abschluss der 8. Klasse arbeitete er zunächst bei einem Bauern. Von 1953 bis 1956 ließ er sich zum Elektriker ausbilden. An der Arbeiter-und-Bauern-Fakultät (ABF) in Leipzig erwarb er von 1958 bis 1961 die Hochschulreife und begann danach am damaligen Pädagogischen Institut Güstrow sein Lehrerstudium in der Fachkombination Biologie/Landwirtschaftliche Produktion.

Nach zweijährigem Direktstudium war er seit 1963 als Lehrer an der Schule in Mühl Rosin bei Güstrow tätig. Das Fachlehrerexamen legte er nach einem dreijährigen Fernstudium ab. Seine Staatsexamensarbeit schrieb er über „Die Vogelwelt des Sumpfsees“. (POHLMANN, K., 1966) Sein In- 
teresse an der Natur galt in besonderem Maße den Vögeln. So war es logisch, dass Kurt Pohlmann 1965 auch zu den Mitbegründern der Fachgruppe Güstrow gehörte. Als Lehrer verstand er es ausgezeichnet, seine Begeisterung und Tierliebe auf die Kinder und Jugendlichen zu übertragen. An seiner Schule in Mühl Rosin leitete er eine Schüler-AG „Vogelkunde und Naturschutz", mit der er allwöchentliche Exkursionen durchführte.

Er entdeckte den Vogelreichtum des Breeser Sees und lieferte mit den Mitgliedern seiner AG durch systematische Erfassungen und die Erstellung einer Artenliste die Grundlagen für eine Unterschutzstellung dieses Gebietes als Naturschutzgebiet. Die Nutzung von Räumlichkeiten in einem nahen Bauerngehöft als Feldstation förderte die weitere Erforschung des ab 1974 als NSG gesicherten Sees wesentlich.

Mit den älteren Schülern unternahm er mehrtägige Exkursionen in die interessantesten Gebiete Mecklenburgs sowie Ferienfahrten nach Polen, Ungarn und Bulgarien. Die Arbeit seiner AG war keineswegs einseitig ornithologisch ausgerichtet. Er achtete darauf, dass die Schüler auch gute Kenntnisse anderer Tierartengruppen und botanisches Wissen erwarben. Kurt Pohlmann war Freund und Vertrauter "seiner" Jungs; er freute sich mit ihnen über eine neu entdeckte Tierart oder eine seltene Pflanze, er weckte ihren Sinn für die Schönheit der Natur, saß mit ihnen am abendlichen Lagerfeuer und trieb mit ihnen Sport. Aber er lehrte sie auch, sich mit ganzer Kraft für den Schutz der Natur einzusetzen. Dafür war er ihnen als aktiver Mitarbeiter im Naturschutz ein gutes Vorbild. Ein Teil der jüngeren Mitglieder unserer Fachgruppe ging aus seiner Schüler-AG hervor. Sucht man den Namen Kurt Pohlmann in den Autorenregistern von Fachzeitschriften, wird man nur wenig Er-

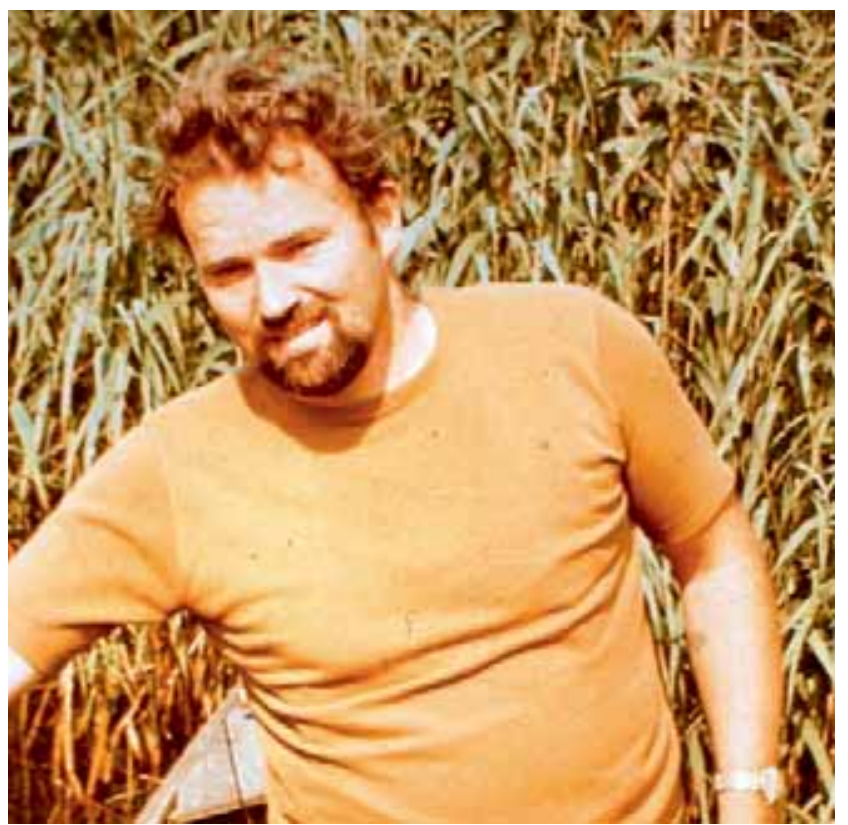

Abb. 49: Kurt Pohlmann am Breeser See. Foto: H.-G. Müller.

folg haben. Er griff nur zögernd zur Feder, obwohl zahlreiche Artbearbeiter der „Vogelwelt Mecklenburgs" von ihm mit Beobachtungsdaten aus dem Kreis Güstrow bedient wurden.

Seine besondere Stärke war die Leitung der Schülerarbeitsgemeinschaft. Für die Betreuung und Fortsetzung der Forschungsarbeiten im NSG Breeser See konnte ein Nachfolger gefunden werden. Es gelang jedoch nach seinem Tode nicht, auch die Schüler-AG fortzuführen, so dass hier eine nicht ausfüllbare Lücke entstanden ist.

Kurt Pohlmann bleibt nicht nur seinen Schülern, sondern auch den Fachgruppenmitgliedern, die ihn noch kennenlernen konnten, als guter Freund in Erinnerung.

\section{Reinhard Becker [21.1.1938 - 20.11.1997]}

Reinhard Becker wurde am 21. Januar 1938 in Reichwalde/ Ostpreußen geboren. Mit der Aussiedlung 1945 verschlug es seine Familie nach Hadmersleben in Sachsen-Anhalt. Dort absolvierte er seine Schulausbildung und anschlieBend ein Ingenieurstudium. Nach dessen erfolgreichem Abschluss wurde er nach Groß Plasten bei Waren (Müritz) vermittelt. Ein Jahr später nahm er in Güstrow beim VEB Agro-Technik als Mitarbeiter im Kundendienst eine Arbeit auf und wurde bald zum Technischen Leiter berufen.

Im Dezember 1965 gründete er mit gleichgesinnten Naturfreunden die Fachgruppe Ornithologie und Naturschutz. In dieser Gemeinschaft fand Reinhard Becker neben seiner Familie und seinem Beruf die Erfüllung seines Lebens. Reinhard Becker war ein recht lebensfroher, optimistischer Mensch, der sehr schnell Kontakte herstellte und begeistern konnte. Seine besondere Vorliebe galt den Greifvögeln und den Limikolen. Als das Augrabengebiet noch nicht melioriert war, galt seine Aufmerksamkeit den dort noch brü- tenden Wiesenweihen. Im östlichen Kreisgebiet erfasste er jährlich die Greifvogelbruten.

Jahrelang fing er an den Absetzteichen der Zuckerfabrik mit selbst konstruierten Schlagfallen durchziehende Limikolen.

An allen Arbeiten, ob winterliche Wasservogelzählungen, Gänsezählungen, Rasterkartierungen u.a. nahm er regelmäßig teil. Er übernahm dabei meist Gebiete, die etwas abgelegen und mit höherem Aufwand zu erreichen waren. Eine ganz besondere Freude war es ihm, im Winter bei Frost und Schnee Spuren der zu jenen Jahren sehr seltenen Fischotter zu suchen. Reinhard Becker scheute sich auch nicht, zielstrebig Nachweise für weniger bearbeitete Vogelgruppen zu erbringen. So hatte er große Teile des Kreisgebietes nach Eulen abgesucht oder eine systematische Erfassung des Wachtelkönigs in geeigneten Biotopen durchgeführt. 


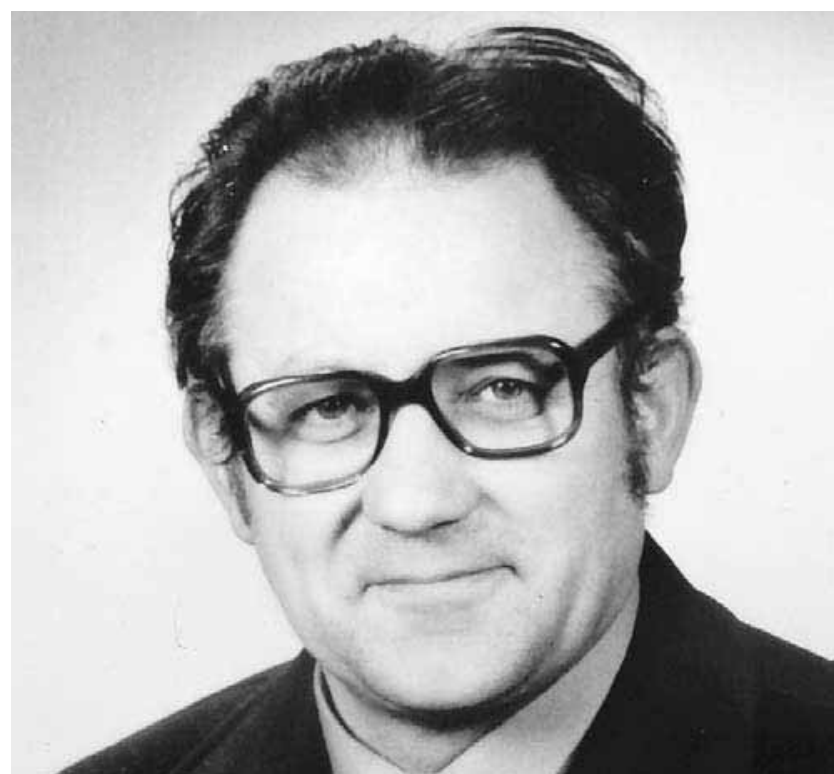

Abb. 50: Reinhard Becker. Foto: privat.

Seine letzten Aktivitäten galten den Mauerseglern und den Fledermäusen. Er schaffte es zusammen mit einer ABMGruppe und der Wohnungsgesellschaft, dass bei den Plattenbausanierungen regelmäßig Nist- und Rastquartiere eingebaut wurden.
Als er in den vorzeitigen Ruhestand ging, hatte er noch viele Pläne und Vorhaben, die leider unausgeführt bleiben mussten.

Reinhard Becker war sehr kritisch und nicht immer leicht zu überzeugen, er war Pragmatiker und Realist gleichermaßen. Stets wusste er, was machbar und durchsetzbar war, er sah aber auch die Grenzen des Naturschutzes in der damaligen Zeit. Als Mitstreiter und Freund war er stets Optimist und sehr hilfsbereit. In gemütlicher Runde, oft bei einer Flasche Wein, konnte man mit ihm einen sehr intensiven Gedankenaustausch pflegen und über neue Pläne und Vorhaben diskutieren.

Reinhard Becker hat eine sehr große Lücke in der Arbeitsgemeinschaft hinterlassen, die bisher nicht wieder geschlossen werden konnte. So hat sich noch kein Ersatz für flächenmäßige Bearbeitungen im Norden und Osten unseres Gebietes gefunden, und neuere Vogelkartierungen mussten von außerhalb der FG abgesichert werden. Reinhard Becker bleibt allen, die ihn gekannt haben, durch viele Exkursionen und gemeinsam verbrachte Stunden stets in guter Erinnerung.

\section{Georg Strache [29.8.1926 - 26.8.1999]}

Georg Strache wurde am 29.8.1926 in Berlin-Charlottenburg geboren. Bis 1939 lebte er in seiner Geburtsstadt, dann siedelte seine Familie nach Falkensee um. 1941 beendete er die Volksschule und begann eine Lehre als Fernmeldemonteur bei Siemens. 1944 wurde er zum Arbeitsdienst eingezogen und kam noch im März des gleichen Jahres zur Wehrmacht. Im Mai 1945 geriet er bei Danzig in sowjetische Gefangenschaft und wurde im Herbst krank entlassen. 1946 beendete er die Lehre mit der Facharbeiterprüfung und arbeitete danach bis 1951 bei der Firma Siemens. Von 1951 bis 1954 war er für die Firma RFT Berlin als Fernmeldemonteur in Schwerin tätig. Im Februar 1954 wechselte Georg Strache ins Fernmeldeamt Güstrow. Außer zahlreichen Qualifizierungslehrgängen absolvierte er von 1962 bis 1965 ein Fernstudium an der Ingenieurschule in Leipzig und schloss diese als Techniker für Fernsprech- und Fernschreibtechnik ab. Von 1972 bis zum Eintritt ins Rentenalter war er Leiter der Übertragungsstelle in Güstrow.

Georg Strache gehörte zu den Mitbegründern der Güstrower Fachgruppe Ornithologie und Naturschutz. Er nahm regelmäßig an deren monatlichen Zusammenkünften und allen anderen Veranstaltungen, wie auch an Arbeitseinsätzen in Schutzgebieten und Exkursionen teil. Er führte zentrale und regionale Zählungen und Erfassungen in bestimmten Teilgebieten des Kreises durch; z.B. die periodischen Wasservogel- und Gänsezählungen, sowie die Erfassung der Brutbestände von Graugans und Höckerschwan. Als der DDA für das Brutvogel-Monitoring die Punkt-StoppZählung einführte, beteiligte er sich mit einer Zählstrecke von Anfang an. Er war ein exzellenter Kenner der heimischen Vogelstimmen. Unter seiner Leitung fanden jährlich mehrere öffentliche Vogelstimmenexkursionen statt.

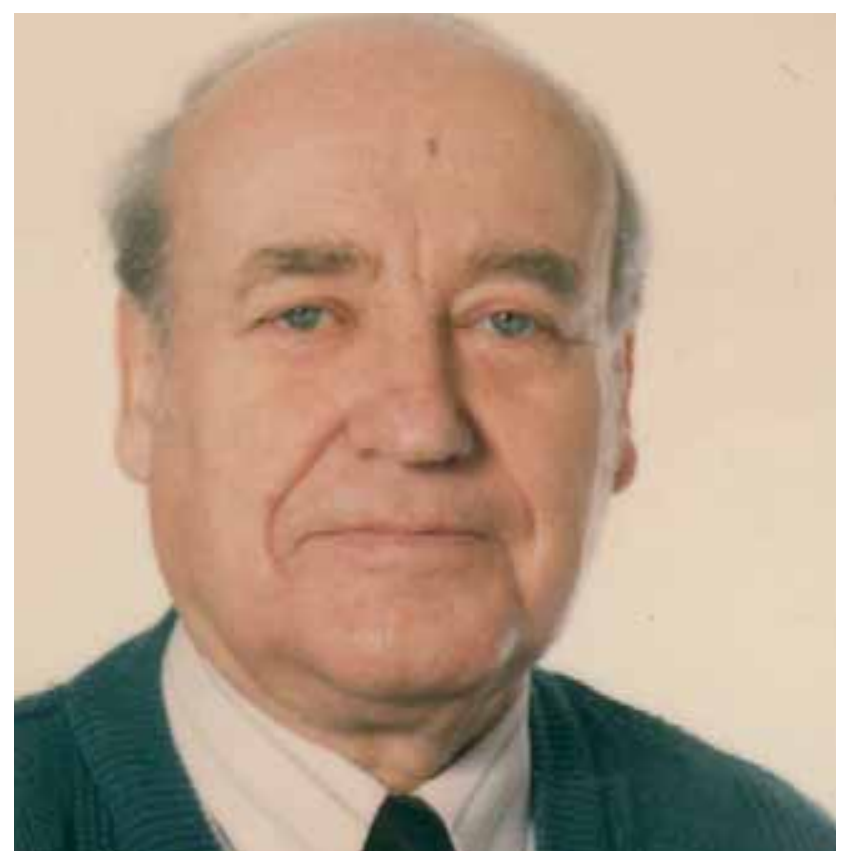

Abb. 51: Georg Strache. Foto: privat. 
Als Naturschutzhelfer des Kreises zeigte er regelmäßig bestehende Missstände in Natur und Landschaft an und setzte sich aktiv für deren Beseitigung ein. Dabei machte er sich naturgemäß nicht nur Freunde.

Viele Jahre galt seine besondere Aufmerksamkeit dem Weißstorch. Georg Strache kontrollierte alljährlich die Storchenhorste im nördlichen Teil des Kreises, fasste die Ergebnisse für den gesamten Kreis zusammen und gab einen Bericht an die Naturschutzverwaltung und die Fachgruppe. Eine Kartei aller Weißstorchenhorste wurde angelegt und jährlich mit den Brutergebnissen ergänzt. Er regte die Reparatur oder Neuanlage von Horstunterlagen an. Diese Aktivitäten brachten ihm den ehrenvollen Namen „Storchenvater“ ein.
Seit dem Bestehen einer Arbeitsgemeinschaft Botanik in Güstrow beteiligte er sich aktiv an deren Veranstaltungen und hatte sich ein gutes botanisches Grundwissen angeeignet. Ihm ist es zu verdanken, dass die AG Botanik nach dem Unfall ihrer Leiterin Angela Martin bis zu deren Genesung fortgeführt wurde.

Wenngleich die Arbeit des „Storchenvaters“ durch ein FGMitglied übernommen werden konnte, entstand durch den Tod unseres aktiven Mitstreiters eine sehr empfindliche Lücke in unsere Fachgruppe. Mit Dankbarkeit erinnern wir uns an viele Streitgespräche mit ihm, in denen es immer um unser gemeinsames Anliegen, die Bewahrung der heimischen Natur, ging.

\section{Klaus Dauber [24.8.1942 - 31.7. 2006]}

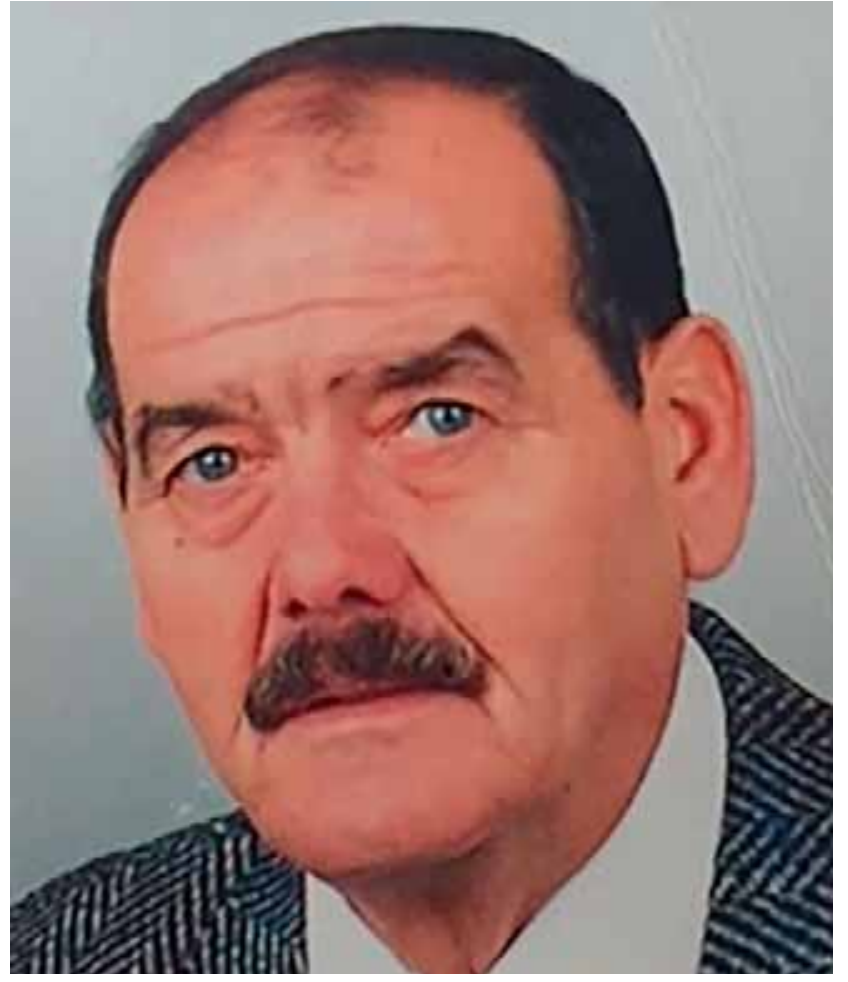

Abb. 52: Klaus Dauber. Foto: privat.

Klaus Dauber wurde am 24.8.1942 in Neuenkirchen im Saarland geboren. Seine Mutter floh mit ihm als Baby in den Kriegswirren nach Güstrow zu ihrer Mutter. In Güstrow wuchs Klaus dann auf und ging zur Schule. Nach einem Ingenieurstudium in Wismar war er als Bauingenieur und Bauleiter im komplexen Wohnungsbau tätig und hatte nach der politischen Wende eine Anstellung im neu errichteten Klinikum Güstrow.

Wenn wir heute in der Beobachtungskartei oder in der Rubrik der „Besonderen (Wichtigen) Beobachtungen“ in den Jahresberichten der FG blättern, finden wir das Namenskürzel „DAU“ nur in den Jahren 1972 bis 1987. Hinter dem Kürzel verbirgt sich anfangs Lothar Daubner, der als Lehrling früher bei uns FG-Mitglied war, bevor er in die FG nach Sternberg wechselte. Beobachtungen von Klaus Dauber tauchen erstmalig 1975 im Jahresbericht mit voller Namensnennung auf. Danach sind seine Einträge auch mit „Dau“ abgekürzt, was bei der Recherche zu Irritationen geführt hat.

Beide Personen hatten auf der von den FG-Mitgliedern auszufüllenden Karteikarte als bevorzugte Beobachtungsgebiete den Güstrower Inselsee genannt, Klaus Dauber ergänzend auch die östlich gelegenen Seen Flacher und Tiefer Ziest, Hofsee, Warinsee und Radener See. Sein Interessensgebiet lag bei der Beobachtung von Wasservögeln.

Die letzten Aktivitäten von Klaus Dauber gemeinsam mit der Gruppe der Ornithologen stammen aus den 1980er Jahren. Er beteiligte sich 1982 an drei Pflegeeinsätzen im NSG Breeser See. Im April 1986 erfasste er den Saatkrähen-Brutbestand in Laage und lieferte im Sommer einen Überblick über die Anzahl singender Drossel- und Schilfrohrsänger, Rohrschwirle und Sprosser an den fünf „Ostseen“.

1987 meldete er Austernfischer in den Zuckerfabrikteichen und lieferte Angaben zu den Saatkrähen-Brutkolonien in Güstrow.

Nach der Wende ermöglichte er uns den Zutritt zu den begrünten Dachflächen des neuen Klinikums, wo kurzzeitig auch Haubenlerchen gebrütet haben. Da sich Klaus Dauber nach der Wende aus der FG-Arbeit zurückgezogen hatte, wurde sein Ableben - und sein zwei Jahre währender Kampf gegen eine Krankheit - auch kaum von uns wahrgenommen. Einige fehlende Daten über ihn lieferten uns erst seine hinterlassene Ehefrau und seine Tochter. 


\section{Uwe Thamm [17.3.1967 - 29.1.2007]}

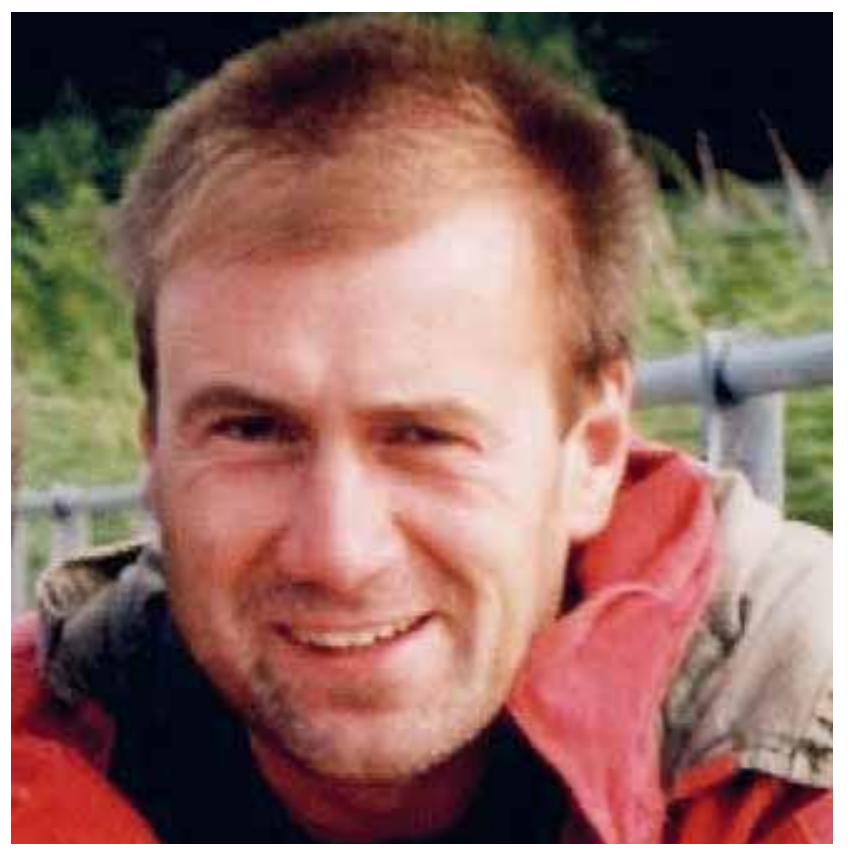

Abb. 53: Uwe Thamm. Foto: privat.

Uwe Thamm wurde am 17.3.1967 geboren und verbrachte seine Kindheit in Grambow bei Schwerin.

Nach der Schulausbildung erlernte er im Institut für Pflanzenzucht in Gülzow von 1983 bis 1985 den Beruf des Agrotechnikers. Er absolvierte nach seinem Grundwehrdienst in der NVA ein Fachschulstudium an der Agrar-Ingenieurschule Quedlinburg. Seine dabei zu erbringenden Praktika leistete er wiederum im Institut für Pflanzenzucht. Dort arbeitete er dann auch nach Abschluss des Studiums bis Ende 1991. Es schloss sich eine kurze Tätigkeit in einer ABM an, die seinen persönlichen Interessen entgegen kam - in einem „Nebel-Projekt“ befasste er sich mit der ökologischen Bewertung und Inventarisierung an Fließgewässern mit den Schwerpunkten Libellen, Lurche und Vögel. Danach nahm er eine Arbeit in der Landesforschungsanstalt für Landwirtschaft und Fischerei Mecklenburg-Vorpommern in Gülzow auf, die er bis zu seinem Tode ausübte. Schon früh wurde seine Liebe zur Natur geweckt. Dafür war die Landschaft um Grambow mit dem Grambower Moor wie geschaffen. Hier lernte er Walter Thiel kennen, unter dessen Anleitung Uwe Thamm 1978 begann, zusammen mit zwei weiteren Freunden Greifvögel an ihren Horsten zu kontrollieren und zu beringen. Während dieser acht Jahre andauernden Betätigung fand er auch den ersten Kontakt zum ehrenamtlichen Naturschutz und zu den Schweriner Ornithologen. Walter Thiel war es auch, der ihn an die Naturfotografie heranführte.

Als Uwe Thamm nach Abschluss seiner Ausbildung in Gülzow zu arbeiten begann, wurde er bald Mitglied der FG Ornithologie und Naturschutz Güstrow. Für den FG-Jahresbericht von 1992 erstellte er eine Übersicht zum Stand der Libellenerfassung im Kreis Güstrow als Basis für die weiteren Erforschungen. Er bereicherte den recht kleinen Kreis engagierter „Nachwuchs“-Ornithologen. Seine Mitarbeit bei Arterfassungen wurde von der FG sehr geschätzt. Ebenso engagierte er sich im NABU, wo er die Tätigkeit als Schriftführer ausübte. Es war ihm immer ein besonderes Anliegen, sich für den Erhalt der Natur einzusetzen. So übernahm er auch häufig bei Vorhabenbeteiligungen die Anfertigung von Stellungnahmen im Namen des NABU. Seine zweite - für viele unbekannt gebliebene - Leidenschaft galt der Malerei. Bevorzugte Motive fand er in der Mecklenburger Landschaft.

Die vielen gemeinsamen Stunden und Erlebnisse bleiben jenen, mit denen Uwe Thamm näher befreundet war und die seine offene und fröhliche Art, mit der er Leute aus ihrem Alltag entreißen konnte, in Erinnerung. Ursachen für Depressionen, die ihn befielen und schließlich zu seinem Tode führten, hielt er uns als Fachgruppe gegenüber verborgen. So konnten wir ihm leider nicht beistehen. Mit ihm verloren wir einen sehr aktiven jungen Ornithologen aus unserer Gemeinschaft. Er hinterließ mit seiner Lebensgefährtin auch seine Tochter Luise.

\section{Silke Schulze [16.8.1943 - 24.2.2008]}

Silke Schulze wurde am 16.8.1943 in Boitzenburg in der Uckermark/Brandenburg geboren. Als sie im Raum Güstrow nach dem schweren Verlust ihres Mannes einen Neuanfang wagte, stellte sie sich bei Joachim Loose bei der unteren Naturschutzbehörde mit der Frage vor, wo sie am besten etwas für die Natur tun könne.

Entsprechend ihren Interessen kam sie fortan sowohl zu Fachgruppenabenden der Ornithologen als auch zu den Veranstaltungen der Botanik-AG und wurde in beiden recht aktiv.

Besonders bei den Botanikern fühlte sie sich wohl. Im Frühjahr 1992 war sie das erste Mal bei einer Exkursion dabei; auch bei der Sechs-Mann-Gruppe, die die erste Sommertour nach Jena unternahm, war Silke mit von der Partie. Zunächst wohnte sie in Gremmelin und war Erzieherin im Kindergarten Vietgest. Sie hatte ein besonderes Talent, Kindern das Schöne zu zeigen. Folgendes Beispiel ist uns in Erinnerung geblieben: Als sie an einem Sommermorgen mit den Kindern auf eine Wiese ging, richtete sie das Augenmerk auf die dort glitzernden Tautropfen: „Guckt mal, wer hat denn diese Edelsteine verstreut!?"

Noch besser konnte sie ihre Kreativität im Kinder- und Jugendkunsthaus in Güstrow einbringen. Die Fantasie junger Menschen zu fördern und sie dabei gleichzeitig zum 
Schönen zu erziehen, das war für sie die Erfüllung in ihrem Berufsleben.

Später war Silke in Klein Grabow zu Hause. Ob hier oder in Gremmelin - sie wohnte immer vielen interessanten Biotopen recht nahe, auf die sie uns z.T. erst aufmerksam machte.

Durch ihre Frage, ob es sein kann, dass sie bei Klein Grabow aus einem Soll eine Sperbereule gehört haben könne, stellten wir für uns erstaunt fest, dass es hier eine Ähnlichkeit in der Stimme zwischen Sperbereule und Wechselkröte gibt (letztere hatte sie natürlich gehört; wir „tricksten“ sie mit der Lurchstimme aus, die sie natürlich wiedererkannte).

Wenn Silke Schulze in der Landschaft Verstöße gegen die Natur feststellte, alarmierte sie die UNB und sprach auch selbst mit den hier wirtschaftenden Landwirten.

Uns bleibt ihr großer Garten in Erinnerung, in den einige von uns gern zur Kirschenernte kamen und in dem ihre Hunde genügend Auslauf fanden.

Silke kam seit dem 17.9.1999 nicht mehr zu unseren Fachgruppenabenden und nahm auch nicht mehr an den Exkursionen der Botanik-AG teil. Sie wollte sich nur noch auf spezielle Dinge, die ihr bedeutsam waren, konzentrieren.
Mit Silke Schulze ging uns eine wissbegierige und aufmerksame Mitstreiterin verloren.

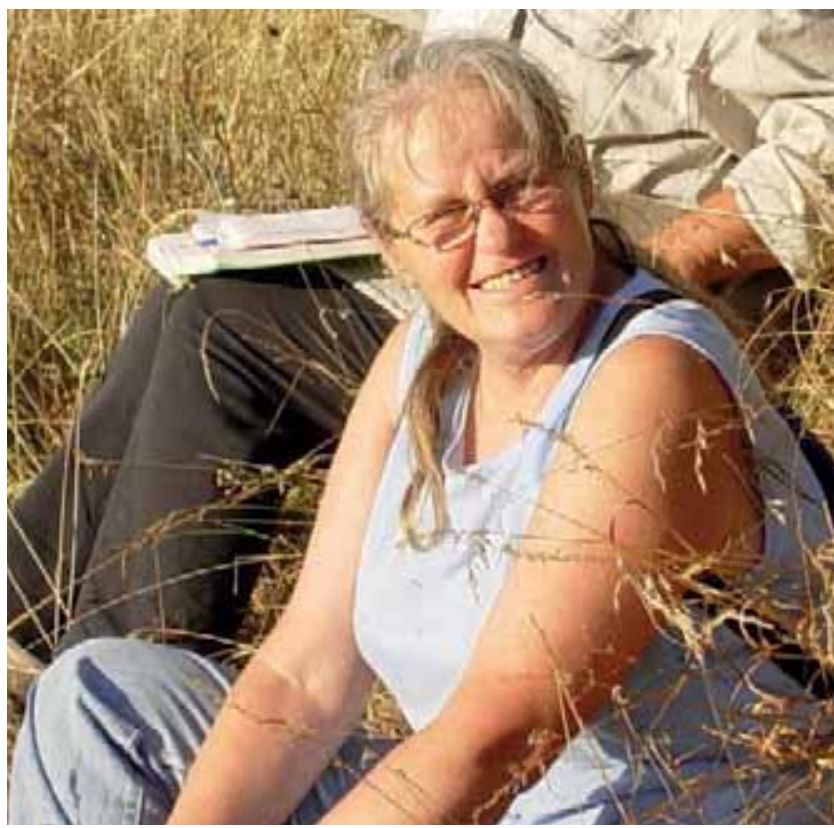

Abb. 54: Silke Schulze bei einer Exkursion 1998. Foto: 7. Loose.

\section{Dr. Wolfgang Neubauer [26. 5. 1935 - 26. 8. 2013]}

Geboren wurde Wolfgang Neubauer am 26.Mai 1935 in Unterköditz in Thüringen. Nach seinem 1953 an der Oberschule Rudolstadt abgelegten Abitur führte ihn sein Studium an das damalige Pädagogische Institut Güstrow. Bereits zwei Jahre später wurde er als Biologie- und Chemielehrer in Krakow am See eingesetzt. Es entsprach durchaus seinem Wunsch, diese Tätigkeit in dem ornithologisch sehr vielseitigem Mecklenburg ausüben zu dürfen. Durch ein Fernstudium an der Pädagogischen Hochschule Potsdam von 19601965 erlangte er die Lehrbefähigung bis Klasse 12.

Im Jahr 1974 promovierte Wolfgang Neubauer mit einer Arbeit über Flussseeschwalben an der Humboldt Universität Berlin zum Dr. rer. nat. Von 1991 bis zu seinem Renteneintritt 1998 war er Studienleiter für das Fach Biologie am Landesinstitut für Schule und Ausbildung (LISA) und hier für die Referendar-Ausbildung zuständig.

Als aktiver Ornithologe fand Wolfgang Neubauer sehr früh den Kontakt zu Gleichgesinnten und arbeitete bereits ab 1954 im Bezirksfachausschuss Ornithologie und Vogelschutz Schwerin mit, wo er als Beringungsobmann und in der AG Gänsevögel tätig war. Durch das Wirken von Werner Kaiser beeinflusst, trug er maßgeblich zur Gründung der Fachgruppe Ornithologie und Naturschutz Güstrow im Dezember 1965 bei und übernahm bis 1990 deren Leitung. Als mit der politischen Wende für die Fachgruppe die Trägerschaft durch den Kulturbund entfiel, war er Gründungsmitglied und bis 2011 auch Vorsitzender der 1991 gegründeten NABU-Ortsgruppe Güstrow. Von 1990 bis 1997 war er Mitglied im Vorstand der Ornithologischen Arbeitsge- meinschaft Mecklenburg-Vorpommern. Seine liebenswürdige Art hatte großen Einfluss auf den Zusammenhalt der Naturfreunde und der ornithologischen Gemeinschaft im ganzen Land.

Von 1955 bis 1994 war Wolfgang Neubauer ehrenamtlicher Kreisnaturschutzbeauftragter (KNB). Bei unvermeidbaren Auseinandersetzungen mit staatlichen Organen und Betrieben verstand er es stets, durch sachliche Argumentationen zu überzeugen. Als KNB koordinierte er die Arbeit der mehr als 20 Naturschutzhelfer im Kreis, im Rahmen der Fachgruppenarbeit gab er ihnen fachliche Unterstützung. Während seiner Lehrtätigkeit an der Krakower Schule leitete er bis 1991 eine AG Naturschutz; viele seiner Schüler sind heute noch naturkundlich aktiv. Bei allen war er eine geachtete Persönlichkeit, man hörte auf ihn. Wesentlichen Anteil hatte Wolfgang Neubauer bei der Ausweisung von Naturschutzgebieten im Kreisgebiet. Er drängte auf die Erarbeitung von NSG-Behandlungsrichtlinien, die unter Mitwirkung von Fachgruppenmitgliedern von uns als einem der ersten Kreise an die Bezirksnaturschutzverwaltung zur Beschlussfassung übergeben werden konnten. Schließlich hatte sein Wort auch Gewicht bei der Gestaltung und Stellenbesetzung der nach der politischen Wende neu geschaffenen Naturschutzstrukturen im Landkreis Güstrow.

Als seine Lebensaufgabe nahm er sich der Betreuung des nach Ramser Konvention bedeutsamen Feuchtgebietes und Naturschutzgebietes Krakower Obersee an, zu dessen Gebietsbetreuer er berufen worden war. Mit eigenen Vorträ- 
gen und Beiträgen in der Lokalpresse legte Wolfgang Neubauer stets besonderen Wert auf eine umfassende Öffentlichkeitsarbeit. Er wollte den Leuten verständlich machen, warum die Natur unbedingt auch Rückzugsräume braucht, die von Menschen möglichst wenig gestört werden sollten. Mit den zur Tradition gewordenen Exkursionen in „sein“ NSG mit Krakower Bürgern und geladenen Gästen sorgte er für eine wachsende Akzeptanz der eingeschränkten Nutzung eines großen Gebietes vor den Toren der Stadt Krakow am See.

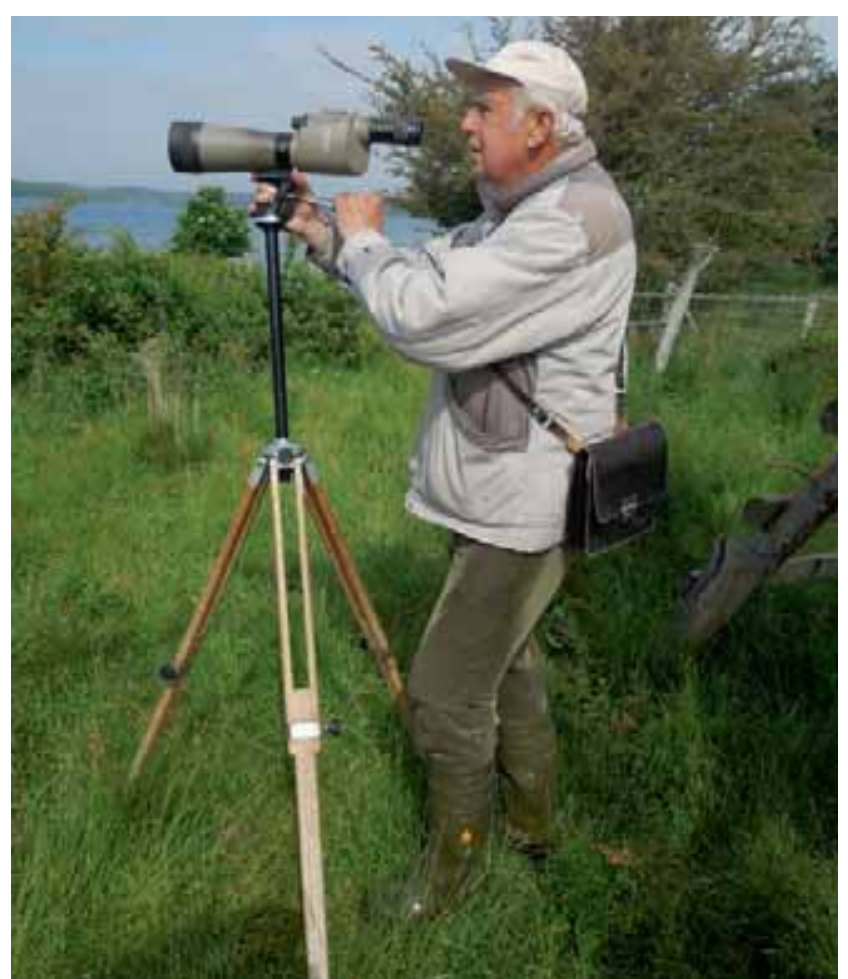

Abb. 55: Wolfgang Neubauer auf unserer letzten gemeinsamen Exkursion auf dem großen Werder - 11.6.2013. Foto: 7. Loose.
Naturschutzbemühungen für dieses Gebiet beruhten über 57 Jahre auf seinem Wirken. In diesen Jahren leistete Wolfgang Neubauer neben der Gebietsbetreuung auch wertvolle Forschungsarbeit an Flussseeschwalben und Wasservögeln. In den Brutkolonien am Krakower Obersee, im Kieswerk Langhagen sowie am Drewitzer- und Dreiersee hat er mehr als 12.000 Flussseeschwalben beringt und mit selbst gefertigten Fangkörben mehr als 3.500 Vögel wieder gefangen.

Mit über 70 wissenschaftlichen Publikationen in der Fachliteratur hat er sich ein Denkmal gesetzt.

Zahlreiche Arbeiten betreffen die Flussseeschwalbe und die Bedeutung des NSG Krakower Obersee. Seine Auswertung der umfangreichen Beobachtungsdaten der Fachgruppe Ornithologie und Naturschutz Güstrow als „Die Vogelwelt des Altkreises Güstrow“ (2004) wird noch lange Zeit Basis für die weitere ornithologische Arbeit in dieser Region sein. Mit zahlreichen Siedlungsdichteuntersuchungen an Feldhecken und in Waldflächen hat er die bestehenden Lücken in den ornithologischen Aufzeichnungen der FG weitgehend geschlossen.

Wolfgang Neubauer war nicht nur den jüngeren Ornithologen ein „väterlicher Freund“, sondern ein ausgeprägter Familienmensch, dem Traditionen wichtig waren und der auch gern feierte. In geselliger Runde oder auch am Rande von Tagungen konnte er so manchen Witz erzählen.

Es war schwer, mit ihm einen Termin abzustimmen, wenn sich seine beiden Töchter oder drei Enkelkinder zu einem Besuch angekündigt hatten, die dann immer Vorrang hatten.

\section{Adolf Kretschmann [17.7.1938 - 25.9.2015]}

Adolf Kretschmann wurde am 17. Juli 1938 in Prositten Kreis Rößel/Ostpreußen geboren. Seinen Vater hat er nicht mehr bewusst kennen gelernt, er fiel gleich in den ersten Kriegsmonaten. Daraus und durch die Erlebnisse bei der folgenden Vertreibung aus seiner Heimat ergab sich eine sehr enge Verbindung zu seiner Mutter, aus der er sich, auch als erwachsener Mann, nicht mehr richtig lösen konnte.

Seine neue Heimat fand er zunächst in Jülchendorf bei Sternberg. Dort arbeitete seine Mutter als Waldarbeiterin. Als strebsamer Junge konnte er nach der Schulentlassung seinen Wunschberuf in der Forstwirtschaft ergreifen. Er besuchte die Ingenieurfachschule für Forstwirtschaft in Raben-Steinfeld und erhielt danach eine Anstellung als Arbeitsökonom im Staatlichen Forstwirtschaftsbetrieb in Güstrow. Sein Wunsch war aber eine Stelle im Außendienst. Dieser Wunsch konnte nach einigen Jahren durch die Neubesetzung des Reviers Diekhof verwirklicht werden. Dieses Revier war zersplittert und durch die Nachkriegsereignisse sehr zerschlagen und vorratsarm. Das Bestreben von Adolf Kretschmann war es, durch Umwandlung der vielen minderwertigen Bestockungen wieder voll produzierende Bestände aufzubauen. Das erforderte viel Kraft, Geld und Organisationsaufwand. Mit Beharrlichkeit und Fleiß gelang es ihm, nach und nach qualitätsmäßig hochwertige Laubholzkulturen und Jungbestände aufzubauen. Als nach einigen Jahren das Revier Groß Upahl frei wurde, bewarb er sich um dieses Revier. Das neue Revier entsprach seinen Wünschen in idealer Weise: Es lag in einer reizvollen Endmoränenlandschaft, es war relativ vorratsreich und überwiegend mit Laubholz bestockt. In der Zeit seiner Tätigkeit in diesem Revier hat er hervorragende Kulturen geschaffen. „Seinen“ Wald hegte er wie sein Eigentum und in umfassender Weise. 


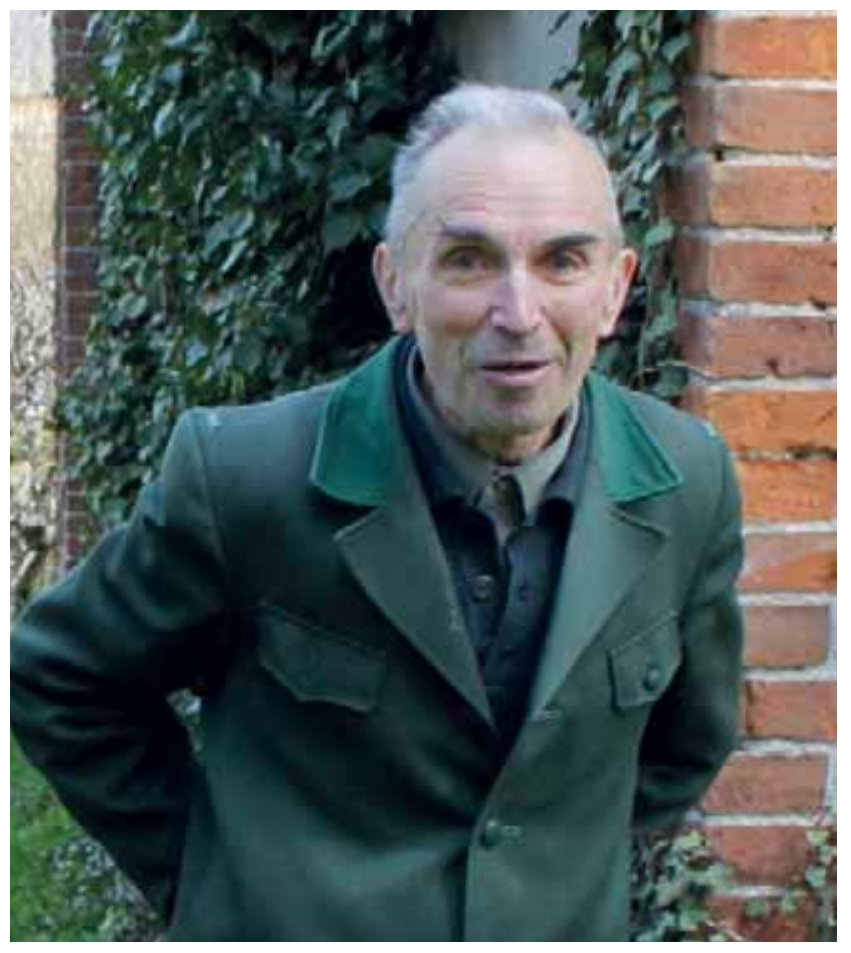

Abb. 56: Adolf Kretschmann 2015. Foto: B. Meder-Trost

Schon frühzeitig bezog er auch den Naturschutz in seine Arbeit mit ein. Die Ausweisung des NSG Upahler und Lenzener See unterstützte er tatkräftig. Er wurde als Betreuer dieses Gebietes eingesetzt und so waren für ihn Hobby und Beruf eng verbunden. In vielen Belangen über einen ökologisch aufgebauten Wald war er den damals geltenden Ansichten weit voraus. Er betreute die in seinem Wald gelegenen drei Seeadlerhorste und kümmerte sich um eine Verbesserung des ökologischen Zustandes des Gebietes (siehe Bericht zu diesem NSG).

Ernst Schmidt berichtete uns, dass es Adolf Kretschmann war, der bereits ab 1994 die Unterschutzstellung des NSG „Trockenhänge bei Jülchendorf und Schönlager See“ im Landkreis Parchim anregte. In Jülchendorf bei Sternberg hatte er seine Kindheit und Jugend verbracht. Er kannte die Gegend sehr gut und konnte als Naturschützer den Wert der Flächen richtig einschätzen.

Da sich Fortschritte in anderen Dingen oft nur ganz langsam einstellten und durch seine pessimistische Grundeinstellung war Adolf Kretschmann oft sehr frustriert. Der Umgang mit ihm war daher nicht immer ganz einfach. Zu seinen Mitarbeitern hatte er ein sehr differenziertes Verhältnis. Selbst war er äußerst bescheiden und fleißig. Mit Wehmut musste er erleben, wie viele seiner Arbeitsergebnisse nach der Wende und der Teilprivatisierung vernichtet wurden. Leider ist nach seinem Eintritt in den Ruhestand das Revier aufgelöst worden.
Die Betreuung des NSG Upahler und Lenzener See, die er ab 2008 nicht mehr wahrnehmen konnte, ist noch nicht wieder neu geregelt worden.

Nach dem Tod seiner Mutter, mit der er sein ganzes Leben verbracht hatte, zog er sich zunehmend zurück. Er war in den letzten Jahren seines Lebens von einer Krankheit gezeichnet, deren Ursache er in einer nicht erkannten und frühzeitig behandelten Borreliose sah. Adolf Kretschmann war zeitlebens Einzelgänger und konnte keine dauerhaften Freundschaften aufbauen. Angebotene Hilfe nahm er nur selten an.

Obwohl er seine Geburtsheimat nicht mehr bewusst kennen gelernt hatte, pflegte er zum Heimatverein Ostpreußen eine stetige Verbindung.

Adolf Kretschmann war sicher ein nicht ganz einfacher Mensch, aber er war in weit überdurchschnittlichem Maß für die Forstwirtschaft und den Naturschutz tätig. Wir brauchten mehr solche Mitstreiter.

Adolf war am 25.8.2005 das letzte Mal bei einem Fachgruppenabend. Er traute sich danach abends das Autofahren im Dunkeln nicht mehr zu.

Dem Naturschutz verbunden und als Mitglied im Naturschutzbund Deutschland vererbte Adolf Kretschmann ein in seinem Besitz befindliches im NSG Upahler und Lenzener See gelegenes 1,07 ha großes Waldstück an die NABUOrtsgruppe Güstrow. 


\section{Besondere Ehrungen von Mitgliedern der Fachgruppe}

Urkunden in Verbindung mit der Ehrennadel für besondere Verdienste im Naturschutz in Bronze und Silber (Abb. 57) sowie Geld- und Buchprämien waren durch den Rat des Kreises Güstrow zu DDR-Zeiten an verschiedene Mitglieder der Fachgruppe regelmäßig für ihr Engagement verliehen worden.

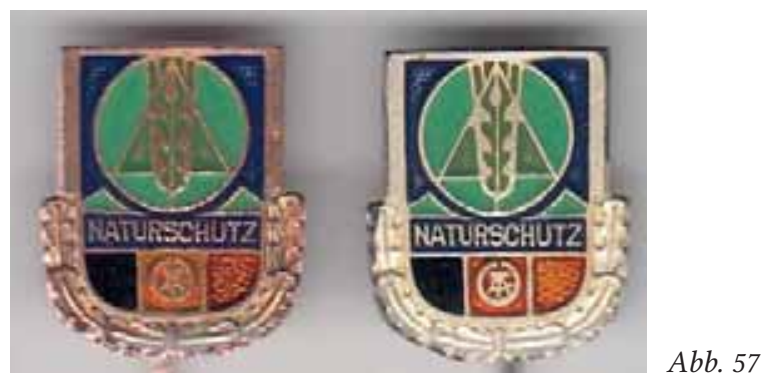

Unsere Fachgruppenmitglieder Georg Strache und Kurt Pohlmann erhielten vom Rat des Bezirkes Schwerin für Erfolge im praktischen Naturschutz und in der Jugendarbeit als Auszeichnung diese Ehrennadel für besondere Verdienste im Naturschutz in Gold.

Herausragende Ehrungen erhielten

\section{Dr. Angela Martin}

Am 26.11.1999 wurde an Angela Martin im Festsaal des Schlosses Güstrow vom Kuratorium der Alfred Töpfer Stiftung der Hans-Klose-Preis für das Jahr 1999 verliehen.

Der Hans-Klose-Preis war am 3.10.1990 zur Förderung des Naturschutzes und der Landschaftspflege in den fünf neuen Bundesländern von der Stiftung geschaffen worden und 1999 zum letzten Mal ausgelobt worden.

Mit der Auszeichnung ehrte das Kuratorium den erfolgreichen Einsatz von A. Martin im ehrenamtlichen und beruflichen Naturschutz an der Basis zur Erhaltung und Bewahrung des heimatlichen Naturerbes. In der Auszeichnungsurkunde heißt es:

„Durch ihre fundierte Naturkenntnis, insbesondere auf dem Gebiet der Botanik und der Ornithologie, hat sie wertvolle Beiträge zur Sicherung und Unterschutzstellung gefährdeter Landschaftsräume geleistet.

Sie hat es weiter verstanden, auch in schwierigen Zeiten Mitarbeiterinnen und Mitarbeiter für einen engagierten Einsatz im Naturschutz vor Ort zu gewinnen und eine breite Öffentlichkeit mit den Anliegen des Naturschutzes und der Landschaftspflege fachlich begründet vertraut zu machen".

Angela Martin steht mit dieser Auszeichnung u. a. mit so bekannten Persönlichkeiten wie Prof. Michael Succow und dem Umweltminister Matthias Platzeck in der Reihe von Preisempfängern.
Die Laudatio bei der Feierstunde hielt Herr Dr. Heinz Henker u. a. mit nachfolgenden Worten:

„Bereits im Fahr 1981 haben Sie in Güstrow die Arbeitsgruppe Botanik gegründet und seitdem ehrenamtlich geleitet. Des weiteren leiten Sie seit ca. fünf Jahren die Fachgruppe Ornithologie und Naturschutz. Ein besonderes Anliegen ist Ihnen die Umsetzung stadtökologische Belange. Sie haben mit sehr viel Energie z.B. dafür gesorgt, dass bei der Modernisierung von Plattenbauten Mauerseglernistkästen und Fledermauskästen installiert und damit Lebensräume für die Tiere geschaffen wurden. Sie haben ein Beringungs-Forschungsprogramm für die Haubenlerchen erarbeitet und nehmen mit Beharrlichkeit Einfluss auf die Mahd von Grünflächen im Brutbereich dieser Tiere. Es ist für Sie nicht immer ganz einfach, auf offene Ohren bei der Stadtverwaltung zu stoßen. Sie führen einen Kampf gegen das - nach Ihrer Meinung - übertriebene und kostenträchtige pausenlose Mähen der Grünflächen in unserer Stadt. Sie haben die notwendigen Dohlenund Turmfalkenkästen im Dom und in der Pfarrkirsche organisiert.

Ich habe Sie bereits zu DDR-Zeiten im Kersting-Klub als engagierte, kritisch fordernde, als eine Frau, die die Menschen wachrütteln will, erlebt. Dieses Engagement haben Sie bis heute nicht aufgegeben, weil es auch heute noch ebenso notwendig ist, die Menschen für die Natur und Umwelt zu sensibilisieren.

Sie arbeiten Tag für Tag, Jahr für Jahr, in einem solchen wichtigen Ehrenamt und setzen Ihre ganzen Kräfte für unsere $\mathrm{Na-}$ tur und Umwelt ein. Eine Stadt, die den Titel „Umweltgerechte Stadt 1996"trägt, kann nicht dankbar genug für eine solche kritische und fordernde Stimme im Ehrenamt sein."

Angela Martin bedankte sich für die Auszeichnung mit einem Vortrag über das von ihr im Kreis Güstrow etablierte System von Flächennaturdenkmalen.

Es muss erwähnt werden, dass mit der Verleihung des Hans-Klose-Preises ein Preisgeld von 10.000 DM verbunden war, das Angela Martin in vollem Umfange für Zwecke des Naturschutzes und die Unterstützung der Arbeit in den von ihr geleiteten Fach- und Arbeitsgruppen einsetzte. 


\section{Dr. Wolfgang Neubauer}

Als ehrenamtlicher Kreisnaturschutzbeauftragte erhielt Dr. Wolfgang Neubauer für seine Leistungen im Naturschutz zahlreiche Auszeichnungen und Ehrungen.

Eine besondere war 2001 die

Verleihung des Verdienstkreuzes am Bande des Verdienstordens der Bundesrepublik Deutschland

für seine Tätigkeit im Naturschutz.

Die Übergabe dieser hohen Auszeichnung nahm der Ministerpräsident des Landes Mecklenburg-Vorpommern Dr. Harald Ringstorff im Festsaal des Schlosses Schwerin vor. Er wandte sich zunächst an alle zur Auszeichnung Geladenen mit nachfolgenden Worten:

„Es hat noch niemand etwas Ordentliches geleistet, der nicht etwas Außerordentliches leisten wollte", sagte die Schriftstellerin Marie von Ebner-Eschenbach einmal. Sie haben nicht nur Ordentliches auf Ihrem jeweiligen Gebiet, sondern Außerordentliches geleistet. Zumeist schon in jungen Jahren haben Sie sich für eine Aufgabe begeistert, die Sie nicht mehr losgelassen hat. Ihr Engagement hat Sie immer auch zum Vorbild für andere gemacht. Mit Ihrem Einsatz haben Sie sich auf besondere Weise um Ihre Mitmenschen und die Gesellschaft verdient gemacht. Ich habe daher heute die große Ehre und die angenehme Aufgabe, Ihnen im Namen des Herrn Bundespräsidenten den Verdienstorden der Bundesrepublik Deutschland aushändigen zu dürfen."

Und an Wolfgang Neubauer gerichtet:

„Seit mehr als 40 fahren engagieren Sie sich für den $\mathrm{Na}$ turschutz im Mecklenburg-Vorpommern. 1955 wurden Sie zum Naturschutzbeauftragten des Kreises Güstrow berufen. Sie haben darauf geachtet, dass die naturschutzrechtlichen Vorschriften eingehalten wurden. Unter Ihrer maßgeblichen Mitwirkung wurden im Kreis Güstrow bis heute acht $\mathrm{Na}$ turschutzgebiete und zahlreiche Flächennaturdenkmale ausgewiesen. Ein besonderes Anliegen war Ihnen stets das seit 1939") bestehende Naturschutzgebiet „Krakower Obersee“. Es ist im Wesentlichen Ihrer Initiative zu verdanken, dass der Naturschutzwert dieses Gebietes bis heute erhalten werden konnte.

\footnotetext{
* Hier war der Herr Ministerpräsident, Dr. Harald Ringstorff, falsch informiert worden: Das NSG Krakower Obersee gibt es bereits seit 1932. Im Jahre 2012 begingen wir das 80jährige Bestehen des NSG mit einer maßgeblich von W. Neubauer gestalteten eindrucksvollen Ausstellung und öffentlichen Exkursionen in das NSG.
}

Sehr geehrter Herr Neubauer,

auch auf dem Gebiet der Ornithologie betätigen Sie sich intensiv. Sie waren langjährig Leiter der Kreisfachgruppe Ornithologie im Bezirk Schwerin sowie Vorstandsmitglied der Ornithologischen Arbeitsgemeinschaft Mecklenburg-Vorpommern. Forschungen über die besonders geschützte Art der Flussseeschwalbe haben Ihnen über die Landesgrenzen hinaus Anerkennung gebracht. Ihr umfangreiches Wissen auf dem Gebiet der Feldbiologie haben Sie an Schüler und fugendliche weitergegeben und sie mit Ihrem Engagement für den Naturschutz begeistert.

\section{Sehr geehrter Herr Neubauer,}

für Ihren unermüdlichen persönlichen Einsatz um den Naturschutz in Mecklenburg-Vorpommern darf ich Ihnen heute im Namen des Herrn Bundespräsidenten das Verdienstkreuz am Bande des Verdienstordens der Bundesrepublik Deutschland überreichen."

An alle Ausgezeichneten schließt der Ministerpräsident mit den Worten:

„Meine sehr verehrten Damen und Herren,

ich gratuliere Ihnen allen $z u$ Ihrer heutigen hohen öffentlichen Auszeichnung. Diese Auszeichnung ist für die meisten von Ihnen die Anerkennung eines reichen und langen Lebenswerkes, das Sie von jungen fahren an begleitet und nicht mehr losgelassen hat.

'Ohne Vorbild kann niemand recht tun', heißt es. Es fällt heute nicht immer leicht, auf die Frage nach dem persönlichen Vorbild eine Antwort zu finden. Wir erwarten von Vorbildern, dass sie glaubhaft Werte verkörpern. Solche Werte sind beständig und damit unabhängig von kurzfristigen Trends oder bloßen Modeerscheinungen. Das Leistungsprinzip gehört zu diesen anerkannten Grundwerten. Leistung kann gerade in Zeiten des Wandels Sicherheit, Verlässlichkeit und Perspektive vermitteln. Wer etwas leistet, dem bieten sich in der Regel auch bessere Lebensperspektiven.

Meine sehr verehrten Damen und Herren,

mit Ihrem Lebenswerk sind Sie glaubhafte Vorbilder - gerade auch für die jüngere Generation. Sie haben gezeigt, dass sich Leistung lohnt. Sie haben bewiesen, was man mit Einsatz und Engagement schaffen kann.

Mit Ihnen und dem ganzen Land freue ich mich über Ihre heutige Auszeichnung. Ich wünsche Ihnen auch für die Zukunft alles Gute und für heute einen schönen und erinnerungsreichen Tag!"

Für besonderes Engagement in seiner Heimatstadt erhielt Wolfgang Neubauer von der Stadt Krakow am See im Jahre 2010 die Ehrenbürgerschaft verliehen. 


\section{Wolfgang Köhler}

Für sein großes Engagement und die erzielten Erfolge bei der Wiederansiedlung baumbrütender Wanderfalken in Mecklenburg-Vorpommern (siehe auch Pkt. 10.5) erhielt Wolfgang Köhler den vom Arbeitskreis Wanderfalkenschutz e.V. (AWS) vergebenen Falco-peregrinus-Preis 2010.

Der Vorsitzende des AWS Dr. Gert Kleinstäuber begründet seinen Auszeichnungsvorschlag u. a. wie folgt:

„Herr Wolfgang Köhler gehört seit mehr als 15 fahren zu den wichtigsten Pfeilern, auf denen die Auswilderung von jungen Wanderfalken im Rahmen des ostdeutschen Projektes zur Wiederbegründung der Wanderfalken-Baumbrüterpopulation im bewaldeten Tiefland Mitteleuropas ruht. Zusammen mit der in erster Linie von ihm ins Leben gerufenen und bis heute geleiteten Gruppe des Landesjagdverbandes Mecklenburg-Vorpommerns, die die Wanderfalkenauswilderung in der Station Damm-Malchow bei Parchim seit dem Jahr 1995 durchführt, hat er einen bedeutenden Beitrag zum erfolgreichen Verlauf und zum Erreichen des anspruchsvollen Zieles, das wir uns alle gesteckt hatten, geleistet.

Als Wolfgang Köhler in Zusammenarbeit mit der Wanderfalken-Forschungs- und Nachzuchtstation von Professor Christian Saar (Hamburg), mit dem Vorstand des Landesjagdverbandes Mecklenburg-Vorpommern und mit Falknern der Region im Jahr 1994 die Initiative zur Errichtung und zum Betrieb der zweiten wichtigen Wanderfalken-Auswilderungsstation im ostdeutschen Baumbrüterareal ergriff, hatten wir noch keinen Beweis dafür, dass die Wiederbegründung der zum Ende der 1960er Jahre ausgestorbenen Baumbrüter gelingen könnte. In der Naturschutzstation Woblitz waren zwar seit 1990 insgesamt schon über 60 junge Wanderfalken ausgewildert und auf das Baumbrüterhabitat geprägt worden, doch die erste erfolgreiche Ansiedlung eines neuen Baumbrüterpaares konnten wir erst im fahr 1996 feiern.

Inzwischen sind von der Arbeitsgruppe um Wolfgang Köhler in den zurückliegenden 15 Jahren aus den drei verschiedenen Auswilderungsgehegen im Bereich der Station Damm-Malchow nach Prägung auf ihre Umgebung insgesamt 175 junge Wanderfalken freigelassen worden, die überwiegend von Prof.
Christian Saar aus der vom Deutschen Falkenorden uneigennützig unterstützten Hamburger Station zur Verfügung gestellt wurden."...

„Von all den 175 in Damm-Malchow ausgewilderten Vögeln konnten wir bis dato 15 Individuen in Wanderfalkenrevieren als Brutvögel wieder ausfindig machen und an Hand ihrer Farb- und Kennberingung eindeutig dem Auswilderungsort Damm-Malchow zuordnen. Als Baumbrüter haben sich neun Falken niedergelassen, sämtlich im angestammten (ehemaligen) Baumbrüterareal zwischen Elbe und Oder.

Dem Absaugeffekt hoher Industriebauten sind nur drei Individuen unterlegen, während ein junges Weibchen ihrer angeborenen Neigung zur Felsbrut gefolgt ist und trotz der großen Entfernung vom Auswilderungsort in den fahren 1998 bis 2006 im Eldorado der Felsbrüter - der Sächsischen Schweiz lebte und nistete. Darüber hinaus sind auch zwei in DammMalchow ausgewilderte Wanderfalkenweibchen in Dänemark als Brutvögel entdeckt worden, wo sie ganz wesentlich zur Neubegründung der auch dort ausgestorben gewesenen Wanderfalkenvorkommen beitrugen.

Im fünften fahr nach Beginn der Auswilderungsarbeit in Damm-Malchow wurde die erste Ansiedlung eines Wanderfalkenpaares im Kiefernhochwald nahe der Auswilderungsgehege entdeckt.

Inzwischen gibt es in Mecklenburg-Vorpommern wieder zehn Wanderfalken-Brutvorkommen (sieben als Baumbrüter und je ein Brutpaar im Fels, im Bauwerk und im Gittermast), deren Betreuung Wolfgang Köhler mit zu seinen wichtigsten Anliegen gemacht hat. Als Mitglied unseres Arbeitskreises und mit seinen langjährigen Erfahrungen im Greifvogelschutz und guten Kontakten zu Förstern, zu Naturschutz-, Forst- und Jagdbehörden wie auch zu Ornithologen in Mecklenburg-Vorpommern ist er im Norden Ostdeutschlands für den AWS-Vorstand und für die AWS-Projektleitungen auf vielfältige Weise eine wertvolle Unterstützung. ...

Mit der Ehrung seiner Person soll aber gleichzeitig auch die langjährige, wichtige Arbeit der anderen Mitglieder der nordostdeutschen Wanderfalkenschutz-Gruppe und die Unterstützung dieser Arbeit durch den Landesjagdverband Mecklenburg-Vorpommerns gewürdigt werden." 


\title{
8. Über das Naturschutzwirken der Fachgruppe
}

\subsection{Gebietsausweisungen und Betreuung - Naturschutzgebiete [NSG]}

\author{
Joachim Loose
}

In der Übersicht „Die Naturschutzgebiete der Deutschen Demokratischen Republik“ - 2. erweiterte und ergänzte Auflage (ILN Halle, 1964) werden für den Kreis Güstrow im Jahr 1964 lediglich vier Naturschutzgebiete aufgeführt:

Nr. 52 „Dünenzug am Recknitzufer“ nordöstlich Laage (81,80 ha) - Verordnung vom 22.2.1939

Durch Randzertalung verdüntes Hügelland, artenreiche Trockenrasen mit Kuhschellen und Feld-Enzian sowie Bergwohlverleih (Arnika) und in einem Ausstich von Sumpf-Bärlapp

Nr. 53 „Großes Holz“ südöstlich Kuchelmiß (30 ha) - Verordnung vom 30.3.1961

Waldkomplex mit naturnahem Restbestand eines PerlgrasBuchenwaldes mit Trauben-Eiche und Winter-Linde, ornithologisch: Brutgebiet des Seeadlers
Nr. 54 ,Jasenberg“ südlich Klein Upahl (5,40 ha) - Verordnung vom 30.3.1961

Stein- und blockreicher Moränenstandort mit Perlgras-Buchenwald mit Berg-Ulme und Trauben-Eiche

Nr. 55 „Krakower Obersee“ (868,20 ha) südlich Krakow Verordnung vom 6.6.1939

Hervorragendes Vogelschutzgebiet mit Lachmöwenkolonie und Brutpaaren von Flussseeschwalben, Gänsesäger, Rotschenkel und Kolbenente. Zur Zugzeit Rastgebiet für Entenvögel

Das Handbuch der Naturschutzgebiete der DDR - Band 1 „Die Naturschutzgebiete der Bezirke Rostock, Schwerin und Neubrandenburg“ von 1980/2. überarbeitete Auflage (WEINITSCHKE, H., 1980) enthält für unseren Kreis im Bezirk Schwerin vier neue Gebiete. Diese konnten insbesondere durch das Wirken einzelner Mitglieder unserer Fachgruppe als NSG ausgewiesen werden.

$\begin{array}{ll}\text { B } 9 & \text { "Jasenberg“ } \\ \text { B } 10 & \text { "Krakower Obersee“ } \\ \text { B } 11 & \text { "Großes Holz“ } \\ \text { B } 31 & \text { "Zehlendorfer Moor“ (70 ha) } \\ \text { B } 33 & \text { "Breeser See“ (114 ha) } \\ \text { B } 34 & \text { "Schlichtes Moor“ (7,35 ha) } \\ \text { B } 37 & \text { „Upahler und Lenzener See“ (393 ha) }\end{array}$

Die Umwandlung des Jasenberges in ein Flächennaturdenkmal (FND) war auf Grund der geringen Größe seinerzeit zentral angestrebtes Ziel und bei ähnlich kleinen Gebieten auch anderenorts praktiziert worden. Die Ausweisung als FND erfolgte durch den Rat des Kreises Güstrow 1984.

Im Handbuch wird das NSG „Dünenzug am Recknitzufer“ nicht mehr genannt. Der Wegfall dieses NSG muss kommentiert werden, da hier ein Stück Naturschutzpraxis in jener Zeit der Intensivierung der Landwirtschaft in den 1970er Jahren belegt wird:

Die Ausweisung der Flächen am Recknitztalrand als Naturschutzgebiet geht auf Prof. Bauch von der Universität Rostock zurück. Ihm war es zu verdanken, dass die o.g. seltenen Pflanzenarten in einem Naturschutzgebiet gesichert wurden. In einem bei der heutigen Naturschutzbehörde noch vorhandenem Brief an den Leiter der Kreisnaturschutzbehörde aus dem Herbst 1944 erfahren wir, dass
Prof. Bauch selbst bei Kriegsereignissen an eine Erweiterung des Schutzgebietes glaubte. Er mahnte, dass man sich gleich nach Ende des Krieges um die Hinzunahme von Niederungsflächen zum NSG (vermutlich Flächen der südöstlich gelegenen „Börnung“) wegen des dortigen großen Vorkommens von Trollblumen bemühen müsse. - Da man nach dem Krieg sicher Wichtigeres zu tun hatte, wurde daraus dann jedoch nichts.

Die auch im Umfeld des NSG ablaufende zunehmende Intensivierung der Landwirtschaft, die Begradigung der Recknitz und insbesondere die Düngung der stark entwässerten Niedermoorwiesen vom Flugzeug aus schädigten die Vegetation der Trockenhügel nachhaltig. Die Flächen wurden beim Überfliegen nicht von der Düngung ausgenommen. Nicht allein Bürger aus Laage, die Kuhschellen zu sich in den Garten holten, reduzierten die früher auf den Trockenhügeln hier einstmals in großen Beständen vorkommenden beiden Kuhschellenarten (Pulsatilla pratensis, P. vulgaris). Vielmehr sind die Ursachen für das in erschreckendem Ma- 
ße stattfindende Verschwinden von Kuhschellen in den hohen Stickstoffgaben, die aus dem Flugzeug auch auf diese Flächen fielen, zu suchen. Es ist bekannt, dass Kuhschellen auf Magerrasen nachteilig auf Düngergaben reagieren, und irgendwann kamen diese unten bei den mehr als $25 \mathrm{~cm}$ langen Pfahlwurzeln auch an. Andere Arten wurden durch die Düngung bevorteilt und für die Kuhschellen entstand zusätzlich ein starker Konkurrenzdruck. Von der ehemals häufigen Arnika fand Dr. Fritz Holst, Botaniker aus Güstrow und einer der Kreisnaturschutzbeauftragten des Kreises, bereits Ende der 1960er Jahre nur noch wenige Exemplare. Es gab keinen Weg, das NSG nachhaltig zu sichern und seine wertvolle Pflanzenwelt zu erhalten. Die Steigerung der
Produktion des hier wirtschaftenden VEG Laage wurde seitens der staatlichen Behörden gegenüber den Beschwerden der Naturschützer als vorrangig angesehen. Die Löschung des Naturschutzgebietes erfolgte zur Vermeidung weiterer Konflikte durch einfache Mitteilung des Rates des Bezirkes Schwerin. Chronisten der Stadt Laage sehen die Löschung als nicht formgemäß an und betrachten fälschlicherweise das heutige Flächennaturdenkmal immer noch als NSG.

Eine aktualisierte Übersicht über „Die Naturschutzgebiete in Mecklenburg-Vorpommern" wurde vom UMWELTMINISTERIUM M-V (2003) als Buch herausgegeben und enthält für unser Gebiet nunmehr nachfolgende NSG:

$\begin{array}{ll}\text { Nr. } 227 & \text { „Ahrenshäger See“ } \\ \text { Nr. } 290 & \text { „Bockhorst“ } \\ \text { Nr. } 105 & \text { „Breeser See“ } \\ \text { Nr. } 262 & \text { "Cossensee“ } \\ \text { Nr. } 30 & \text { „Göldenitzer Moor“ } \\ \text { Nr. } 31 & \text { "Großes Holz“ } \\ \text { Nr. } 198 & \text { „Gültzsee“ } \\ \text { Nr. } 261 & \text { „Gutower Moor und Schöninsel“ } \\ \text { Nr. } 119 & \text { „Krakower Obersee“ } \\ \text { Nr. } 137 & \text { „Nebel“ } \\ \text { Nr. } 114 & \text { "Schlichtes Moor“ } \\ \text { Nr. } 116 & \text { "Upahler und Lenzener See“ } \\ \text { Nr. } 281 & \text { „Wüste und Glase“ } \\ \text { Nr. } 86 & \text { „Zehlendorfer Moor“ }\end{array}$

Weitere NSG (Fettdruck) kamen hinzu, bestehende wurden vergrößert. Die Nummerierung wurde für eine landesweite Auflistung angepasst. Angeführte kursiv gedruckte Gebiete befinden sich nur teilweise im Wirkungsbereich der Fachgruppe, an diesen NSG-Ausweisungen haben wir nicht mitgewirkt.

In dem gewichtigen Buch „Die Naturschutzgebiete in Mecklenburg-Vorpommern“ werden die Naturschutzgebiete auf jeweils einer Doppelseite beschrieben, die weitgehend von den Betreuern der NSG verfasst wurden. Für „unsere Gebiete“ sind die Betreuer meist auch Mitglieder der FG Ornithologie und Naturschutz Güstrow.

In den nachfolgenden Abschnitten berichten NSG-Betreuer oder FG-Mitglieder, die sich stärker engagiert hatten, über Aktivitäten und persönliche Erlebnisse in ihren Gebieten. Weitere fachliche Informationen zu diesen Gebieten sind im Handbuch nachzulesen.

Die Lage der aktuell ausgewiesenen Naturschutzgebiete ist in Karte 1 dargestellt.

Mit großer Genugtuung hatten wir in der Fachgruppe nach der politischen Wende zur Kenntnis genommen, dass die von dem Naturschützer Kurt Kretschmann aus Bad Freienwalde 1950 als Symbol für den Naturschutz in der DDR kreierte Waldohreule (Abb. 58) auf der Umweltministerkonferenz 1991 als gesamtdeutsches Zeichen zur Vereinheitlichung der Naturschutzgebiete empfohlen wurde. „So hat die Eule als Zeichen der Weisheit über den Adler als Zeichen der Macht gesiegt."(Wikipedia)

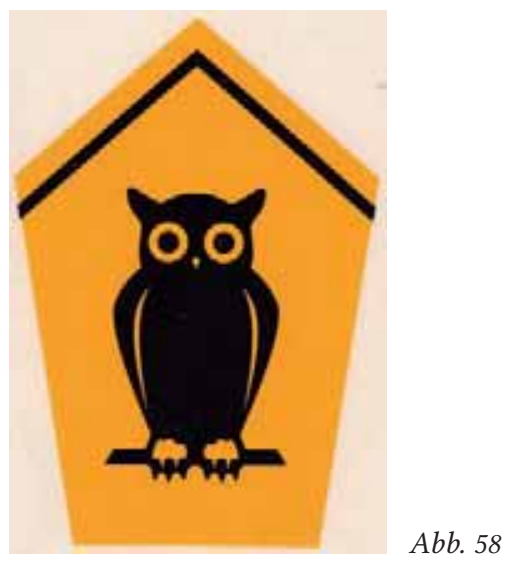

Der Hamburger Naturschutzbeauftragte Karl Duwe, der 1955 den Seeadler zum Naturschutzsymbol der Bundesrepublik gemacht hatte, konnte mit dem auf Naturschutztafeln viel zu weißköpfig dargestellten Seeadler für Deutschland sowieso nicht zufrieden sein, da hier leicht eine Assoziation mit dem Weißkopfseeadler, dem Wappentier der USA, entstand. 
Karte 2: Lage der Naturschutzgebiet im Wirkungsbereich der Fachgruppe (grün - Grenze der Verwaltungsämter)

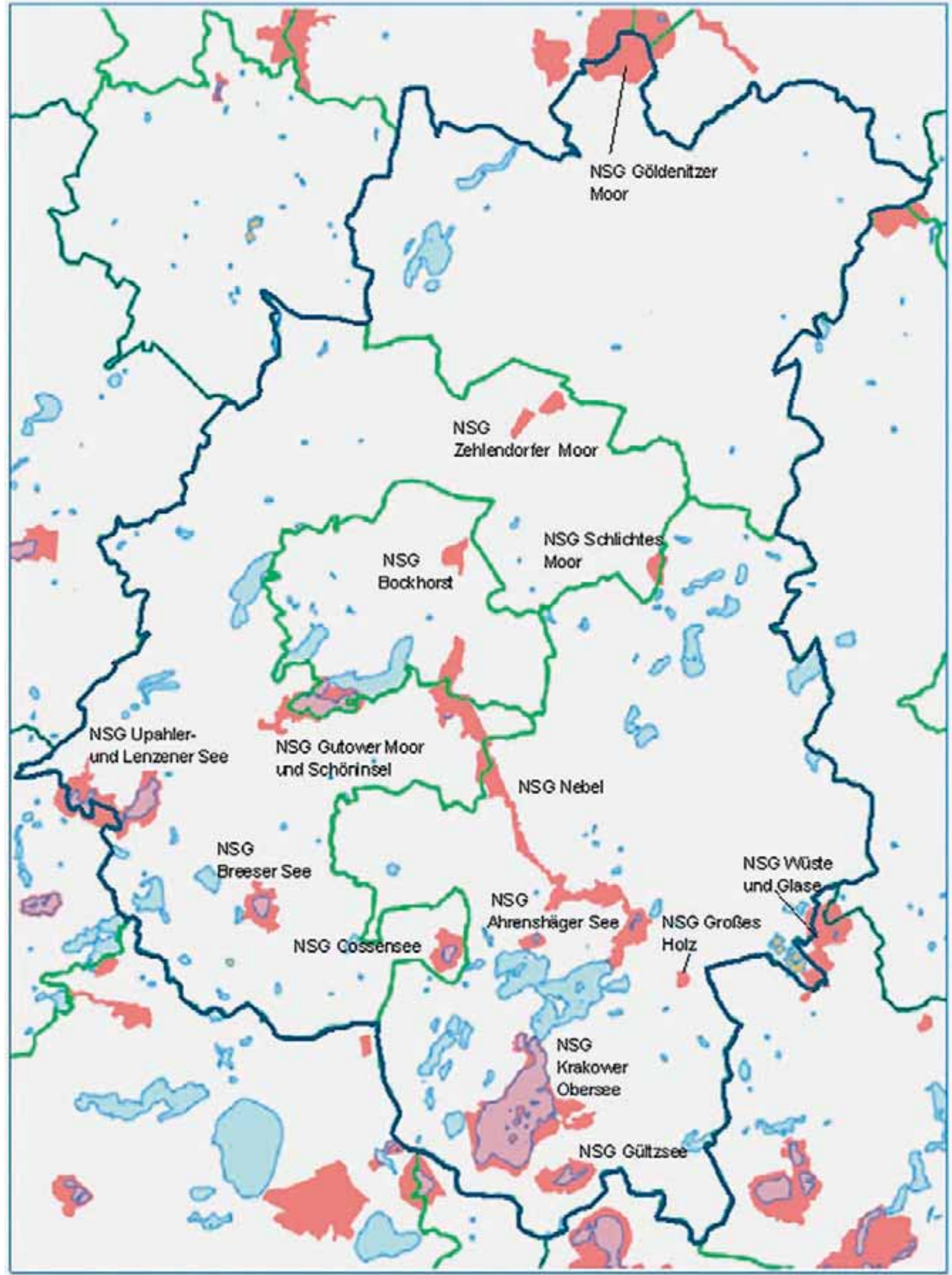




\subsubsection{NSG Krakower Obersee}

Sebastian Lorenz, Greifswald (NSG-Betreuer seit 2013)

\section{Schutzgebietsdaten}

Erste Unterschutzstellung am $\quad 08.08 .1932$

Gebietserweiterung - VO vom $\quad 21.11 .2000$

Größe zunächst 868,2 ha, erweitert auf 1.189 ha

davon Gewässer 848,2 ha

\section{Bedeutung/Schutzziel}

Wichtiges Reservat für Wasservögel und als Rast- und Schlafplatzgewässer für Enten, Gänse und Schwäne, Brutkolonien von Lachmöwen und Kormoranen, bedeutsames Mausergewässer für Reiherund Tafelenten sowie für Graugänse

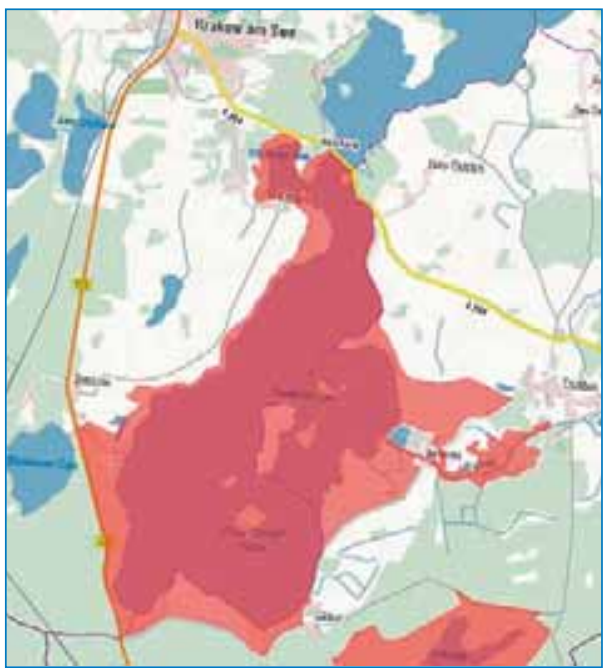

Karte 3

Quelle: Kartenportal LUNG

Seit 31.07.1978 internationales Feuchtgebiet nach Ramser Konvention 1992 Integration in das EU-Vogelschutzgebiet DE 2339-402 Nossentiner/Schwinzer Heide

2007 Integration in das FFH-Gebiet DE 2239-301 Nebeltal mit Zuflüssen, verbundenen Seen und angrenzenden Wäldern

Das Unterschutzstellungsdatum des Krakower Obersee wurde im Handbuch der NSG der DDR mit dem Datum der VO vom 6.6.1939 falsch angegeben. Die Unterschutzstellung wurde bereits 1932 veranlasst, was lange unbekannt blieb. Erst bei Recherchen von W. Neubauer als NSGBetreuer im Landeshauptarchiv Schwerin wurde die Bekanntmachung wieder entdeckt (Abb. 59).

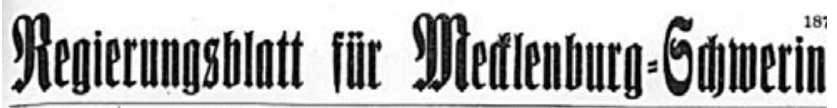 1932 Edwerin, Sounabend, ben 20. 2uguf́t 1932}

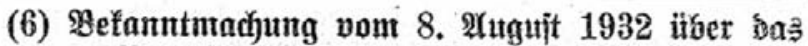

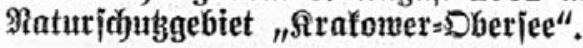

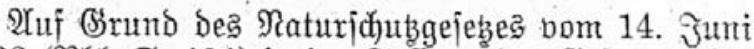

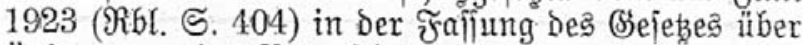
2̇tnderungen Des Raturjhubgejebses nom 6. Dezember

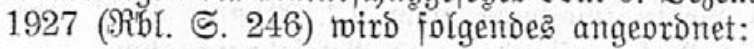

Abb. 59: Nachweis der Unterschutzstellung von 1932 (Quelle: Landeshauptarchiv Schwerin)

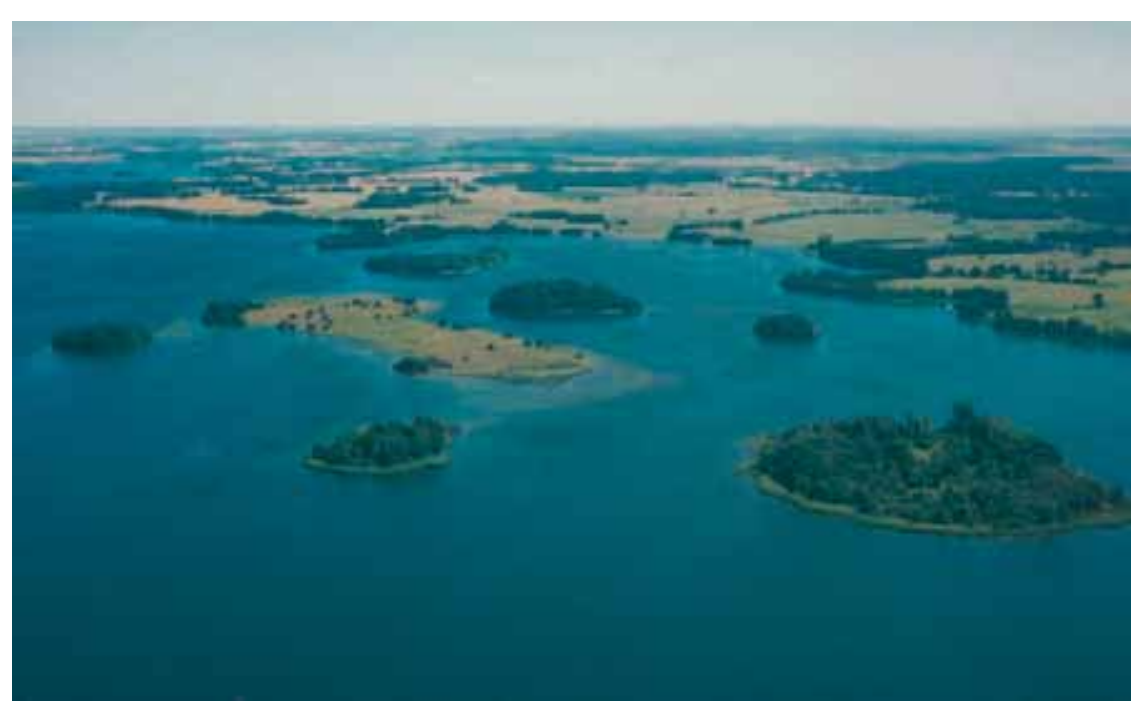

Im Jahr 1939 erfolgte eine erneute Unterschutzstellung als Vogelfreistätte nach dem Reichsnaturschutzgesetz. Das war wohl vor allem als Reaktion auf das immer noch erfolgte Befahren mit Booten und die Bejagung des Gebietes anzusehen. Nach 1950 wurde auf dem Krakower Obersee nicht mehr gejagt, eine gezielte Bejagung auf Schwarz- und Raubwild erfolgte jährlich nur noch nach Abstimmung mit der Naturschutzverwaltung.

Noch bis 1974 durfte der Krakower Obersee mit Sportbooten befahren werden, bis in die 1960er Jahre ganzjährig, danach nur noch außerhalb der Brutzeiten. Viele ältere Krakower kennen den See und vor allem den Großen Werder noch aus jener Zeit, er war Ausflugsziel für Angler und Zeltfreunde. Kaum jemand aus der FG wusste etwas über die Besuche auch von Uwe Johnson auf der Insel. Der aus Krakow stammende Publizist Heinz Lehmbäcker, der seit Jugendzeiten mit dem Schriftsteller befreundet war, schildert in einem Aufsatz den gemeinsamen Ausflug von 1952 auf den See, das Zelten, oder das Sammeln von Eiern

(LEHMBÄCKER, H. (1998). Daraus konnte man auch erfahren, dass es damals auf dem großen Werder bereits eine $4 \mathrm{~m}$ x $8 \mathrm{~m}$ messende Holzhütte mit einer Küche, Boden und Stallung gab. Die befand sich am Nordwestufer, wo heute noch im Gehölzbestand ein damals gepflanzter Nussbaum steht.

Abb. 60: Luftbild von 1999 - Blick von Süden auf den Großen Werder, die einzige nicht bewaldete Insel im NSG. Die anderen Inseln jeweils von rechts nach links: im Vordergrund - Süfs, Hardenort und Steinwerder, dahinter - Lindenwerder, Rauhwerder und Laubwerder sowie die Landzunge Dorfstätte. Foto: Ch. Berg. 
Die Hütte ist 1956 abgebrannt, als Bossower Kinder über das Eis gelaufen waren und in der Hütte Feuer gemacht hatten.

Im Jahr 1956 übernahm Wolfgang Neubauer als junger ornithologisch interessierter Biologie/Chemie-Lehrer die Betreuung des Naturschutzgebietes „Krakower Obersee“. Bis zu seinem Tod im August 2013 war er dem Krakower Obersee über 57 Jahre eng verbunden. Er hat in diesen Jahren die ornithologische Erforschung und Naturschutzbemühungen im NSG wesentlich gestaltet und vorangetrieben. Seine Beobachtungen und faunistischen Untersuchungen fanden Niederschlag in einem großen Fundus wissenschaftlicher und populärwissenschaftlicher Veröffentlichungen. Dabei war es vor allem die Flussseeschwalbe, der sein Forschungsinteresse galt (siehe Pkt. 10.1).

Unzählige Exkursionen hat Wolfgang Neubauer am Krakower Obersee geführt, die bei sehr vielen Leuten bleibende Erinnerungen hinterlassen haben.

Er war immer darum bemüht, dass die eingeschränkte Nutzung des Obersees auch von der Allgemeinheit akzeptiert wird. Mit den zur Tradition gewordenen Exkursionen in das NSG zeigte er Krakower Bürgern und geladenen Gästen, warum die vielfältige Tierwelt des Gebietes diesen Rückzugsraum braucht.

Im FG-Jahresbericht Nr. 5/1972 wird berichtet, dass durch FG-Mitgliedern auf dem Großen Werder die Schutzhütte fertiggestellt und eine Beobachtungskanzel errichtet wurde.

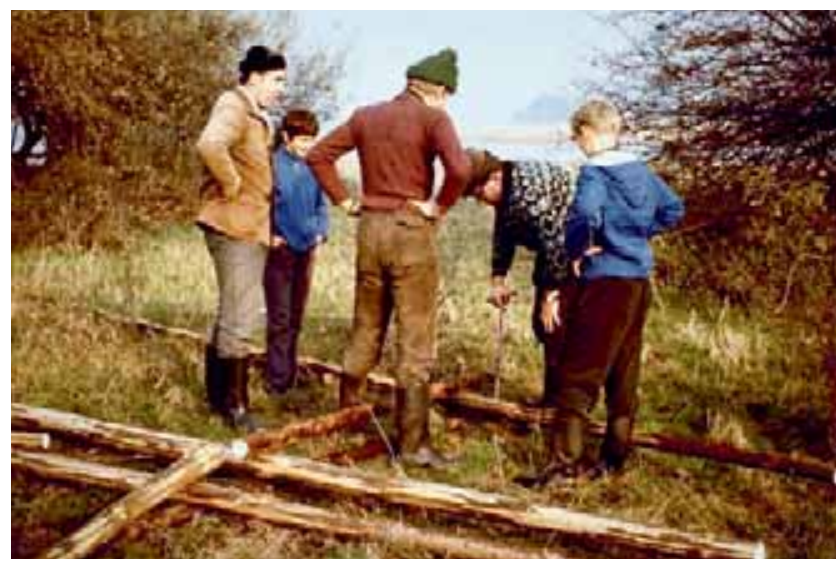

Abb. 61: Wolfgang Neubauer, Fritz Anderlik und Reinhard Becker beim Aufbau der ersten Beobachtungskanzel 1972 auf dem Großen Werder. Foto: H.-G. Müller.

1980 spendierte der Rat des Kreises Güstrow das Geld für den Neubau einer komfortableren Unterkunft auf dem Großen Werder. Das wurde ein im Rahmen der Konsumgüterproduktion beim Staatlichen Forstwirtschaftsbetrieb (StFB) hergestellter Bungalow mit Pultdach aus Wellasbestplatten, der auf einer Betonplatte aufgestellt wurde. Bei der Herstellung der Bodenplatte konnte Wolfgang Neubauer auf die Hilfe seiner Lehrerkollegen aus Krakow zurückgrei- fen. Die vorgefertigten Seitenwandelemente und das übrige Material wurden mit Hilfe von Kähnen des VEB Binnenfischerei durch Fritz Anderlik und zahlreiche FG-Mitglieder vom Wadehäng zum Großen Werder transportiert und dort gemeinsam montiert (vgl. Abb. 7 auf Seite 13). Da die Blechkähne mit der Last einen gehörigen Tiefgang hatten und am Westufer des Werders nicht bis an das Ufer kamen, mussten die einzelnen Elemente bereits weit draußen im Wasser entladen und an Land getragen werden.

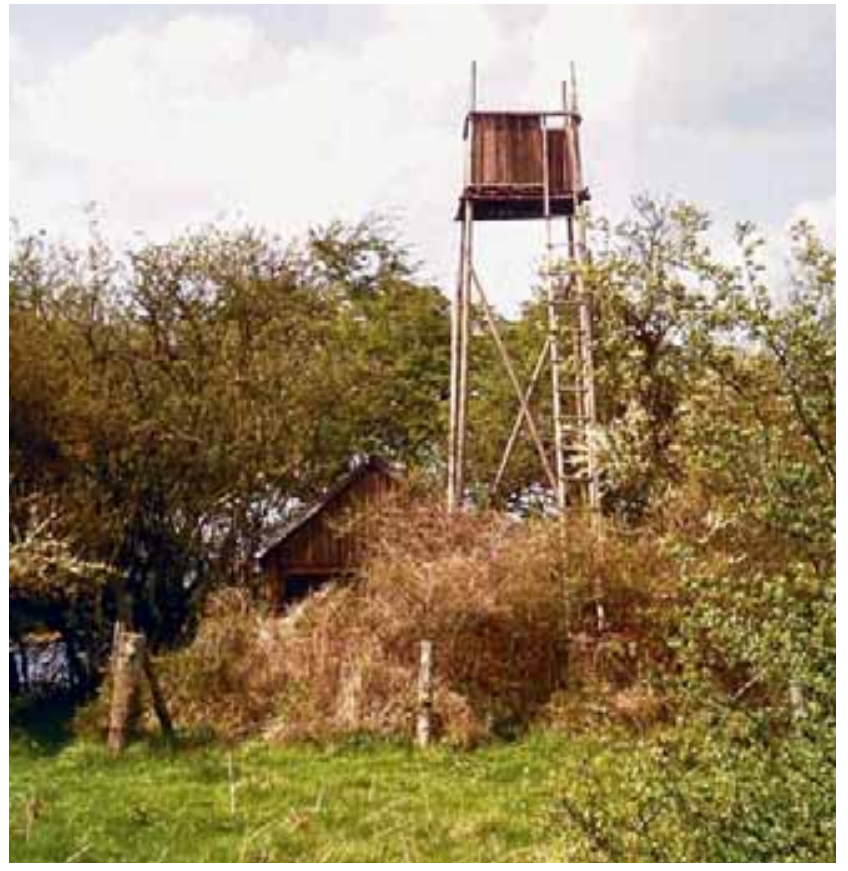

Abb 62: Die 1972 errichtete Beobachtungskanzel neben der alten Hütte war 1980 baufällig und wurde mit der Errichtung des neuen Bungalows durch einen Neubau ersetzt. Foto: W. Neubauer.

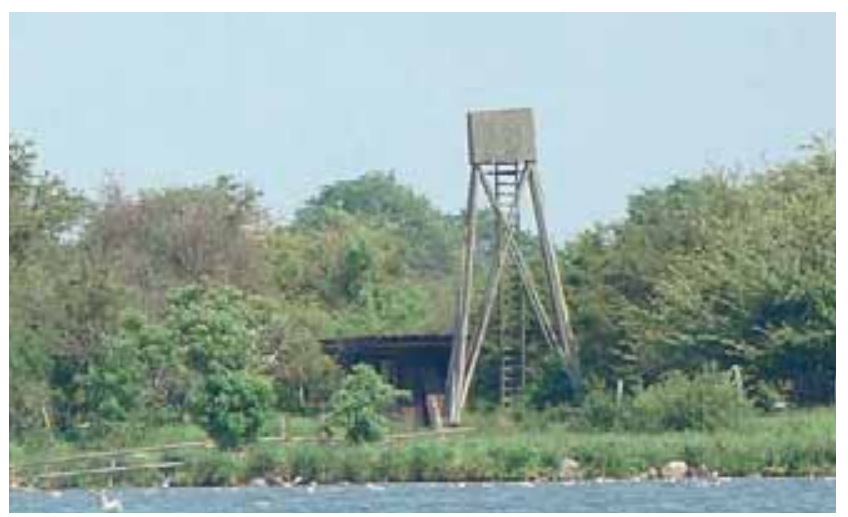

Abb 63: Die neue Feldstation versteckt sich idyllisch hinter Büschen, von der neuen Kanzel hatte man einen guten Einblick in die Brutkolonien von Lachmöwen und Flussseeschwalben. Foto: A. Martin.

Die Nutzung der Unterkünfte erfolgte nicht allein durch W. Neubauer. Zeugnis davon gibt das Gästebuch aus der Hütte, in dem Ornithologen und andere Naturfreunde ihren Dank, vor allem aber auch ihre Bewunderung für die Schönheit und Artenvielfalt des Sees zum Ausdruck brachten. Erste Eintragungen in diesem Gästebuch stammen bereits von 1968. 
Darunter befinden sich neben den Einträgen von Mitgliedern zahlreicher Fachgruppen auch die Danksagungen von Prof. Dr. Erich Rutschke (1969), Prof. Dr. Günter Tembrock (1972) und Dr. Heinz Litzbarski (1975/1976). Letzterer dankte für die Unterstützung bei der erfolgreichen Gänsefangaktion am See mit „künstlerischen“ Zeichnungen im Gästebuch:
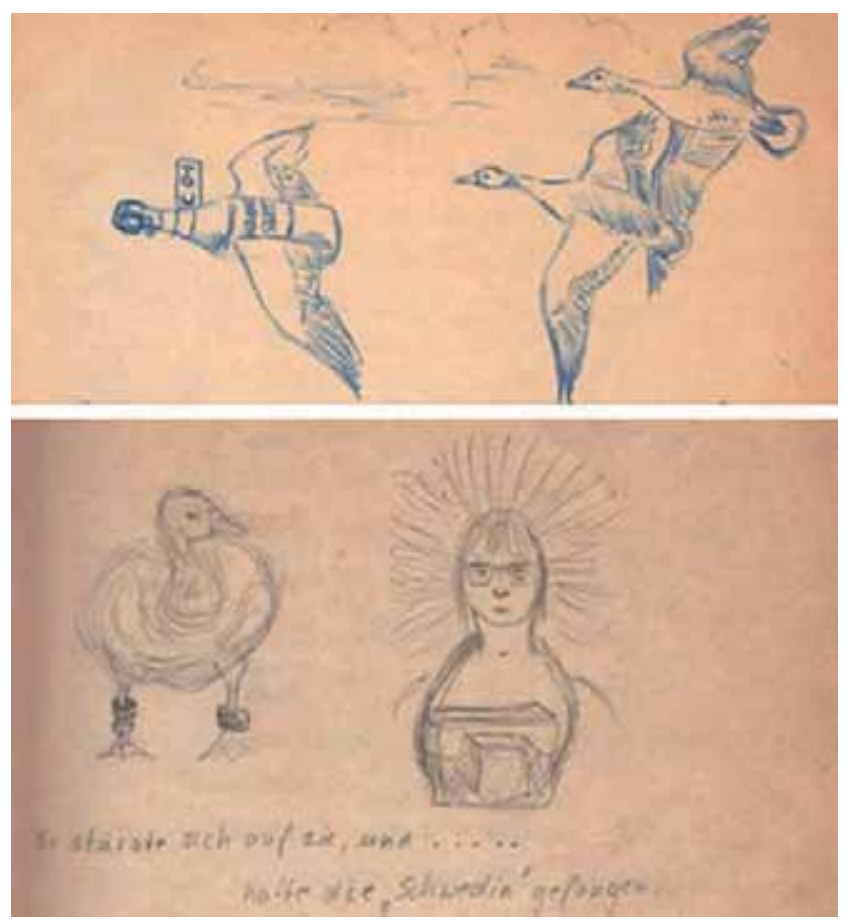

Abb. 64/65: Zeichnungen von Heinz Litzbarski im Gästebuch aus den Jahren 1975 und 1976 nach erfolgreichem Gänsefang.

Auf den Besuch von Glutz von Blotzheim in seinem NSG im Jahre 2005 war W. Neubauer besonders stolz, leider gibt es dazu keine Dokumentation.

Zu seinen Touren auf den Krakower Obersee hat Wolfgang Neubauer regelmäßig auch interessierte Krakower Schüler mitgenommen, die dann den See, seine Inseln und die im Naturschutzgebiet nötigen Arbeiten miterlebten und dabei halfen. Durch seine Tätigkeit als Biologie-Lehrer an der Krakower Schule verstand er es, sehr anschaulich und an Beispielen aus der heimischen Tier- und Pflanzenwelt zoologische und botanische Sachverhalte zu vermitteln. Auch ich erinnere mich an frühe Ausflüge auf den Krakower Obersee als Grundschüler zum Ende der 1980er Jahre, an die Anfahrt nach Dobbin mit dem Fahrrad oder dem Trabant, an das Möwengeschrei, an zur Beringung gefangene Flussseeschwalben, große Nistkästen für Schellenten und das Rudern in einem Holzkahn. Diese Ausflüge mit ihrem Lehrer müssen bei vielen Schülern bleibende Eindrücke hinterlassen haben, denn noch heute berichten mir viele von früheren Ausflügen mit ,Dr. Neubauer' auf den Krakower Obersee.

Mein ornithologisches Interesse für den See und vor allem die Wasservögel erwachte dann während meines Zivil- dienstes 1996/97 bei der Unteren Naturschutzbehörde des Kreises Güstrow. Hier ermunterten mich Joachim Loose ebenso wie mein ehemaliger Lehrer Wolfgang Neubauer zu gezielten Beobachtungen und luden mich zu Sitzungen der Güstrower Fachgruppe ein. Seit dieser Zeit war ich dann regelmäßig auf dem Krakower Obersee und in seiner Umgebung unterwegs, meistens als Begleiter von Wolfgang Neubauer, häufig auch allein.

Das „Rüberfahren“ auf den Krakower Obersee bedeutete stets erst das Klarmachen des Ruderboots. Beim Rudern hin und zurück wechselte man sich ab, so lernte ich auch das Rudern. Gerudert wurde nur so schnell, dass man sich nebenbei unterhalten konnte. Jede Kursabweichung wurde durch ein dezentes Handzeichen und ein Augenzwinkern von Wolfgang angezeigt. Aufgrund Wolfgangs beeindruckend langer Gebietskenntnis gab es für fast jede Stelle auf und am Krakower Obersee eine Geschichte zu erzählen.

Noch heute ragt zwischen Rauhwerder und der NebelEinmündung bei Dobbin bei Niedrigwasser ein Pfosten der alten „Kuhfähre“ knapp aus dem Wasser. Sie zerbrach in den 1980er Jahren altersschwach, beladen voll mit jungen Kühen und versank mitten auf dem See, wobei sich alle Kühe und auch die Besatzung schwimmend ans Ufer retteten. Die Reste der Fähre aber wurden nicht geborgen. Dem naturgemäß nicht in Fahrtrichtung schauenden Ruderer beschert dieser Pfosten noch heute einen gehörigen Schreck, wenn er nichtsahnend mitten auf dem See mit ihm kollidiert.

Das Rudern gehört zum Obersee einfach dazu. Erst kurz vor seinem Tod, da hatte er schon länger zwei künstliche Hüftgelenke und die 75 Jahre erreicht, ließ sich Wolfgang zu einem Bootsmotor überreden. Allerdings waren Motoren gar nicht sein Ding, und so waren es stets die drei für den Motor wichtigen Elixiere, die er vor oder beim Motorstart wiederholte, um den Motor erfolgreich in Gang zu setzen - Luft (Belüftungsschraube am Tankdeckel), Benzin (Benzinhahn öffnen) und der Zündfunke (Sichern des Zündunterbrechers).

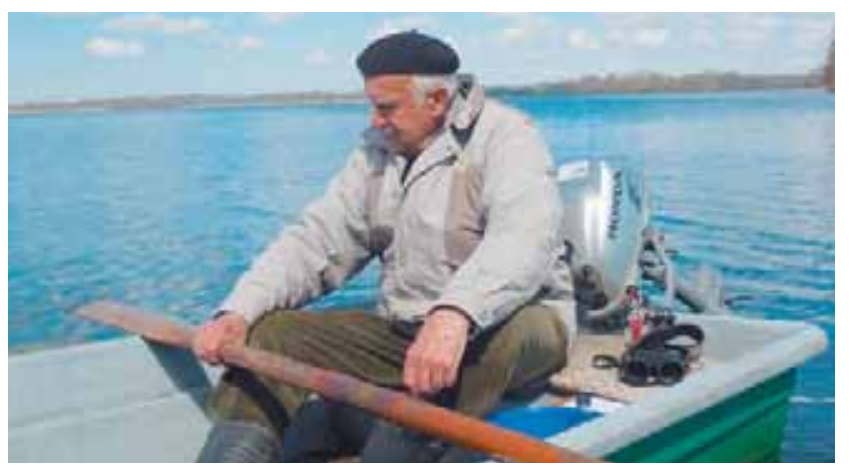

Abb. 66: Wolfgang Neubauer wollte so lange wie möglich selbst rudern - der Bootsmotor kam erst ab 2010 zum Einsatz.

(Foto: f. Loose) 
Uns wird er immer als exzellenter Ruderer in Erinnerung bleiben und die von ihm erreichten dreizehn Minuten Ruderzeit zwischen Dobbiner Forellenzucht und Südostufer des Großen Werders ( 1,4 km) sind mit den heutigen GFKBooten schwer zu unterbieten. Noch bis in die Mitte der 1990er Jahre lag ein „schnittiger“ Holzkahn am Obersee, der zwar schwerer war, aber deutlich besser unter Rudern lief. Die Boote galt es nach dem Anlegen auf den Werdern immer gut gegen Abtreiben zu sichern, weswegen lange Ketten daran befestigt waren. Dabei hatten die langen Ketten auch noch einen anderen Grund. Die Beweidung des Großen Werders erfolgte bis Ende der 1980er Jahre noch mit Jungrindern (Färsen), die zum Saufen Zugang zum See hatten. Auf das Ufer gezogene Boote erweckten immer das Interesse der Kühe, und es kam mehrfach vor, dass bei der Rückkehr zum Boot mindestens eine Kuh im Boot stand und der Boden durchgetreten war. Das bedeutete für wenigstens einen, zum Ufer zurück schwimmen zu müssen. Mit den langen Ketten konnten die Boote vor dem Ufer schwimmend vertäut werden.

Die Inseln des Krakower Sees sind von ausgedehnten Flachwasserbereichen umsäumt, die mit großen Steinen bestreut sind, von denen längst nicht alle aus dem Wasser ragen. Vor allem den Großen Werder gilt es sorgsam zu umfahren. Bis in die 1970er Jahre sind es diese Flachwasserbereiche um die Inseln (im norddeutschen Sprachgebrauch als Werder bezeichnet) gewesen, die von ausgedehnten RöhrichtGürteln bestanden waren. Die von Neubauer bei Kontrolltouren um die Inseln beschriebenen früheren Breiten der Schilfzonen sind heute nur schwer vorstellbar. So waren die heute von Röhricht freien Inseln Großer Werder und Lockwerder bis in die 1970er Jahre von so breiten Schilfgürteln umgeben, dass Schilfbrüter (Schilfrohrsänger, Rohrdommel, Haubentaucher) eine wichtige Artengruppe für die genannten Inseln waren. Der Flurname ,Lockwerder deutet sogar auf die frühere Rohrwerbung mit dem Ernten von Schilf hin. Mit dem Rückgang der Schilfgürtel hat eine deutliche Uferdynamik eingesetzt, die sich am Großen Werder mit einer starken Erosion des Südufers (vermulmte Niedermoortorfe) und Kliffbildung bemerkbar macht. Die heute fehlenden Schilfgürtel sind nur ein deutlich sichtbares Zeichen eines Wandels, den der Krakower Obersee in den vergangenen fünf Jahrzehnten durchgemacht hat.

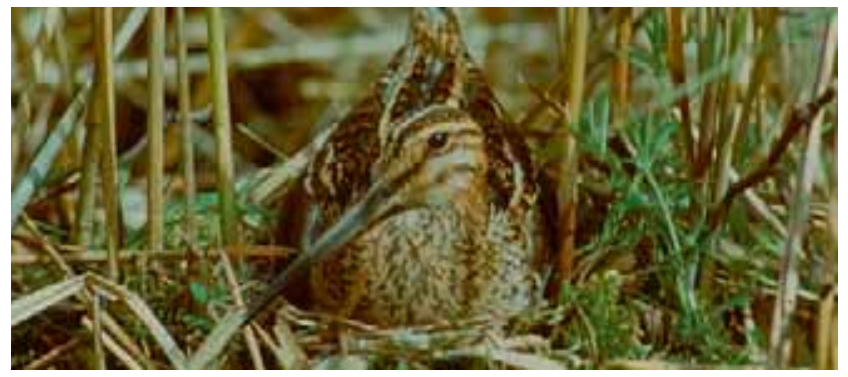

Abb. 67: Auf dem Großen Werder saß Wolfgang Neubauer 1972 noch am Nest der Bekassine an. Foto: W. Neubauer.
Der Rückgang der Bestände an Wiesenbrütern ist eine weitere Veränderung, die nicht so auffällig ist. Wann immer Wolfgang mit mir über den Großen Werder lief, berichtete er von der früher vorhandenen großen Anzahl der bodenbrütenden Wiesenvögel, dem dichten Nebeneinander von Kiebitzgelegen auf den Wiesen des Großen Werders (1968 > $50 \mathrm{BP}$ ), dem Brüten von Bekassine und Rotschenkel. Zu gut klingt mir noch seine Redensart „Ach, es ist zum Heulen, wenn ich an die alten Zeiten denke." in den Ohren. Heutzutage freut man sich schon, wenn man diese Arten hier rastend beobachten kann. Eine wichtige Ursache für den starken Rückgang der Bodenbrüter war das Aufkommen der Prädatoren Mink, Marderhund und Waschbär. Mit großem Aufwand versuchte W. Neubauer mittels Fallen deren Zahl zu dezimieren. Auf allen Inseln standen und stehen Kastenfallen frei oder eingegraben. Mit den Jägern Fritz Anderlik und Peter Warschewski war er mehrfach im Jahr unterwegs, um Baue aufzuspüren und Bejagungsmöglichkeiten zu verbessern.

Wolfgang Neubauer hatte seine langjährigen Beobachtungen regelmäßig ausgewertet und publiziert. Anlässlich des 80. Jahrestages der Unterschutzstellung des NSG stellte er auch einen Überblick über die Entwicklungen und Veränderungen in fünf Jahrzehnten seiner Gebietsbetreuung zusammen (Naturschutzarbeit in $\mathrm{M}-\mathrm{V}, 55,2012$, S. 53-62), so dass ich hier auf wiederholende Ausführungen zu den Veränderungen verzichten möchte und auf seine Publikationen verweise (siehe Anhang 2).

Die ornithologischen Erfassungen und naturschutzrelevanten Tätigkeiten im NSG folgen dem Jahreslauf. Das Winterhalbjahr ist ornithologisch vor allem durch die Erfassung der Wasservögel geprägt, die am Obersee sowohl rastend und überwinternd, als auch als reine Schlafgäste auftreten. Typische Rast- und Überwinterungsarten sind Reiher- und Tafelente, Gänse- und Zwergsäger und auch der Haubentaucher, der mit bis zu 350 Exemplaren zu beobachten ist. Reine Schlafgäste sind vor allem die Saat- und Blässgänse, die den gesamten Krakower See nutzen. Die Erfassung der Wasservögel erfolgt per Zählung von acht Zählstellen rund um den Krakower Obersee (Möllener See, Anhöhe zwischen Möllen und Bossow, Tiefes Bruch Bossow, Glaver Koppel, Glaver Bucht, Dobbiner See - Forellenzucht, Nordteil Obersee sowie Wadehäng) sowie an einer am Krakower Untersee (alter Melkstand bei Neu Dobbin). Sofern der See nicht zugefroren ist und es der Wind zulässt, erfolgen weitere Zählungen vom Wasser und vom Großen Werder aus. Die Insel ermöglicht das Absuchen der großen Wasserflächen nördlich und westlich des Großen Werders, die von Land aus nicht optimal eingesehen werden können. Ich folge dabei der gewählten Zählroute von Wolfgang Neubauer, den ich gelegentlich bei den Zählungen begleitet hatte und setze damit die Tradition fort.

Die Brutzeit von Seeadler, Kranich und Graugans vermittelt in das Frühjahr. Das Sommerhalbjahr ist die Zeit der 


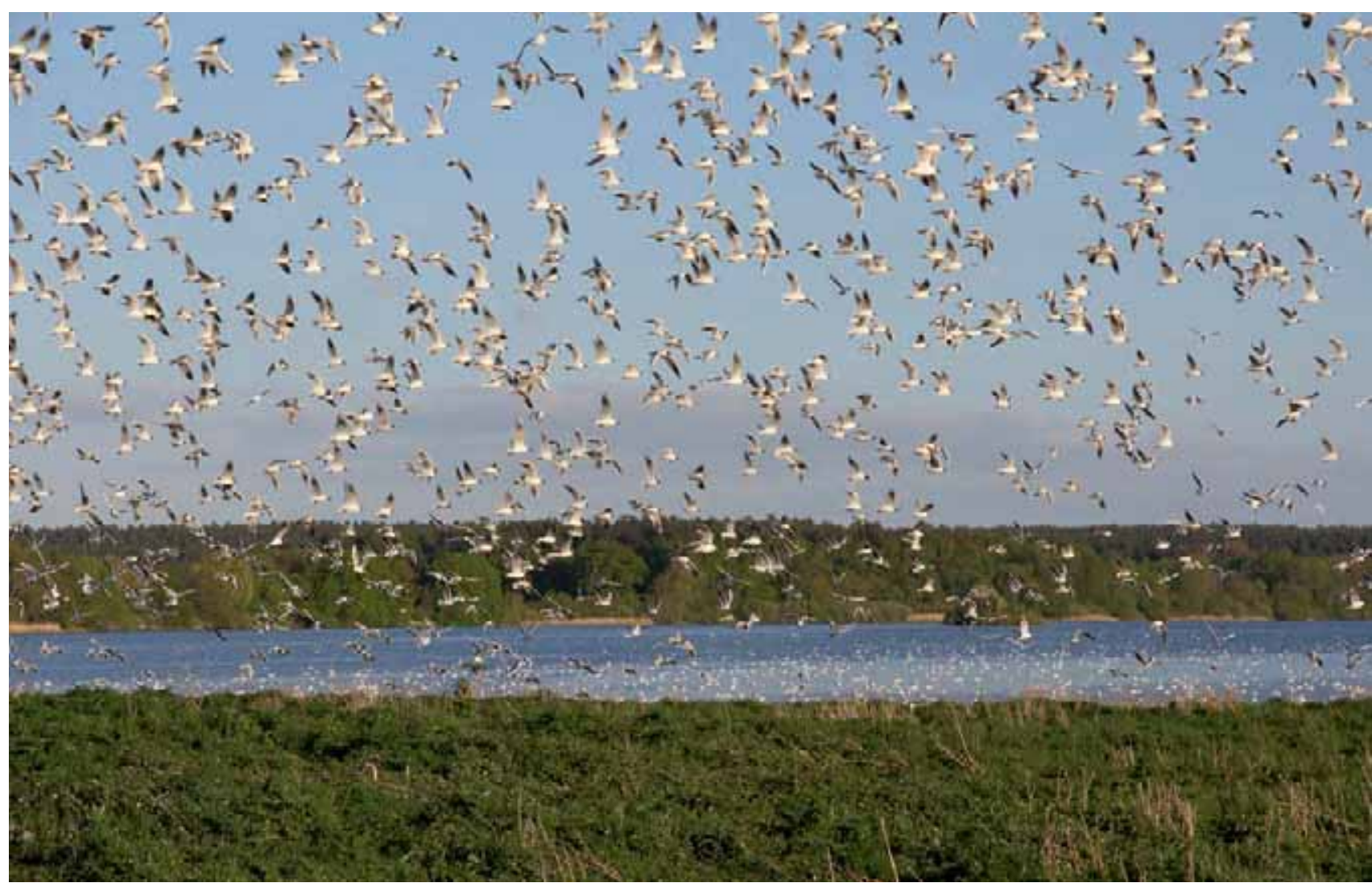

Abb. 68: Bei der Zählung der Brutpaare ist die Luft erfüllt vom Geschrei tausender Lachmöwen. Foto: S. Lorenz.

Brutvogelerfassung, wobei es vor allem die Kolonien der Lachmöwe und des Kormorans sind, die zahlenmäßig auffallen. Ab April verwandelt sich die Südspitze des Großen Werders in die größte binnenländische Brutkolonie der Lachmöwe in Mecklenburg-Vorpommern. In dieser Zeit ist die Luft Tag und Nacht vom Geschrei der Möwen erfüllt, welches man nach ein paar Stunden Aufenthalt auf der Insel aber kaum noch wahrnimmt. Die Zahl der Brutpaare ist nur durch systematisches Auszählen von Transekten mit Hilfe von langen Leinen durch mehrere Helfer ermittelbar.

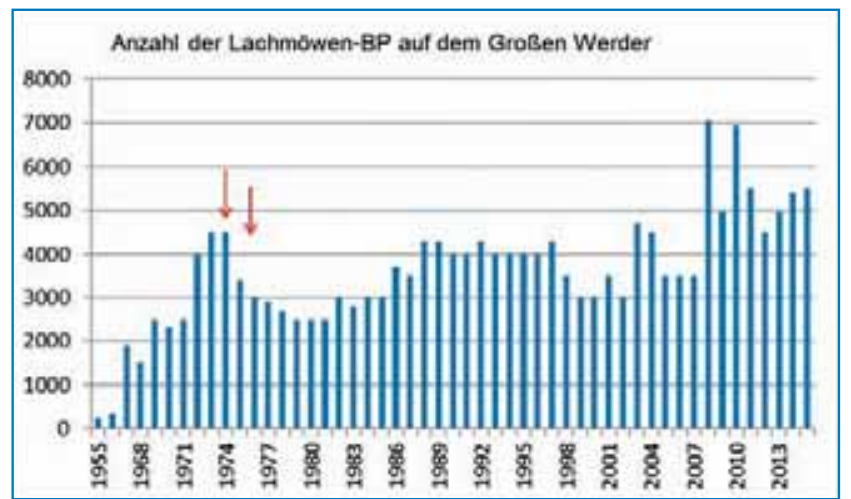

Diagramm 1: Bestandsentwicklung bei den Lachmöwen-Brutpaaren, Dezimierungen 1974 und 1976 (rote Pfeile) führten nur kurzzeitig zu einer Bestandsverminderung.

Karl-Heinz Koop und andere FG-Mitglieder halfen Wolfgang Neubauer und später mir bei diesen Aktionen. Nicht immer wurde die ganze Südspitze des Werders ausgezählt, vielfach konnte aus einer Teilermittlung auch auf den Gesamtbestand hochgerechnet werden. Im Laufe der Jahre hat sich die Fläche der Brutkolonie durch die Kotbelastung der Möwen von einer Wiese in ein Dickicht aus Brennnesseln verwandelt. In jüngster Zeit wächst hier nun auch verstärkt der Gefleckte Schierling bis weit über $2 \mathrm{~m}$ Höhe auf und erschwert die Erfassung der Nester. Ein Zaun trennt die Brutkolonie von den restlichen Weideflächen ab, damit das ab Ende Mai auf den Großen Werder gebrachte Weidevieh nicht die Nester zerstört.

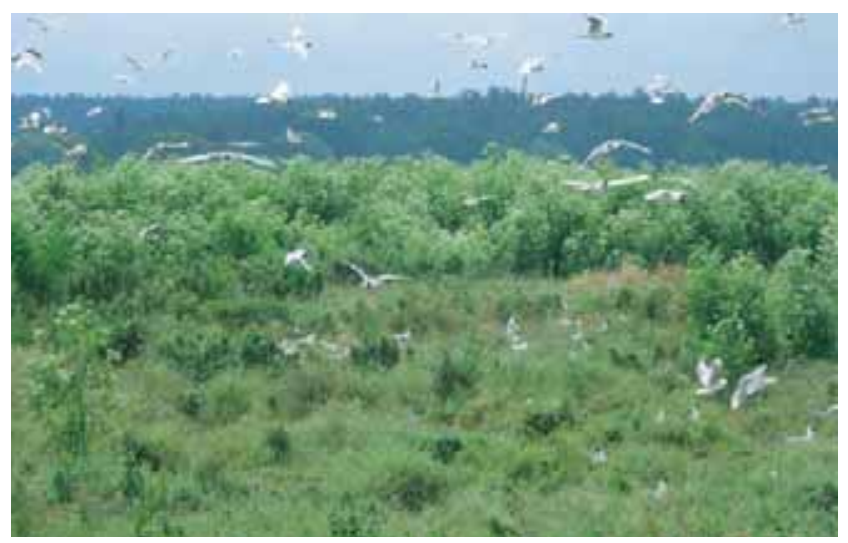

Abb. 69: Der Gefleckte Schierling nimmt immer größere Flächen in der Brutkolonie der Lachmöwen ein - 2014. Foto: F. Loose

Nach der Brutsaison wird der Zaun geöffnet, aber im Gegensatz zu den Brennnesseln wird der Schierling nicht gefressen, wodurch er sich immer weiter ausbreiten konnte. 


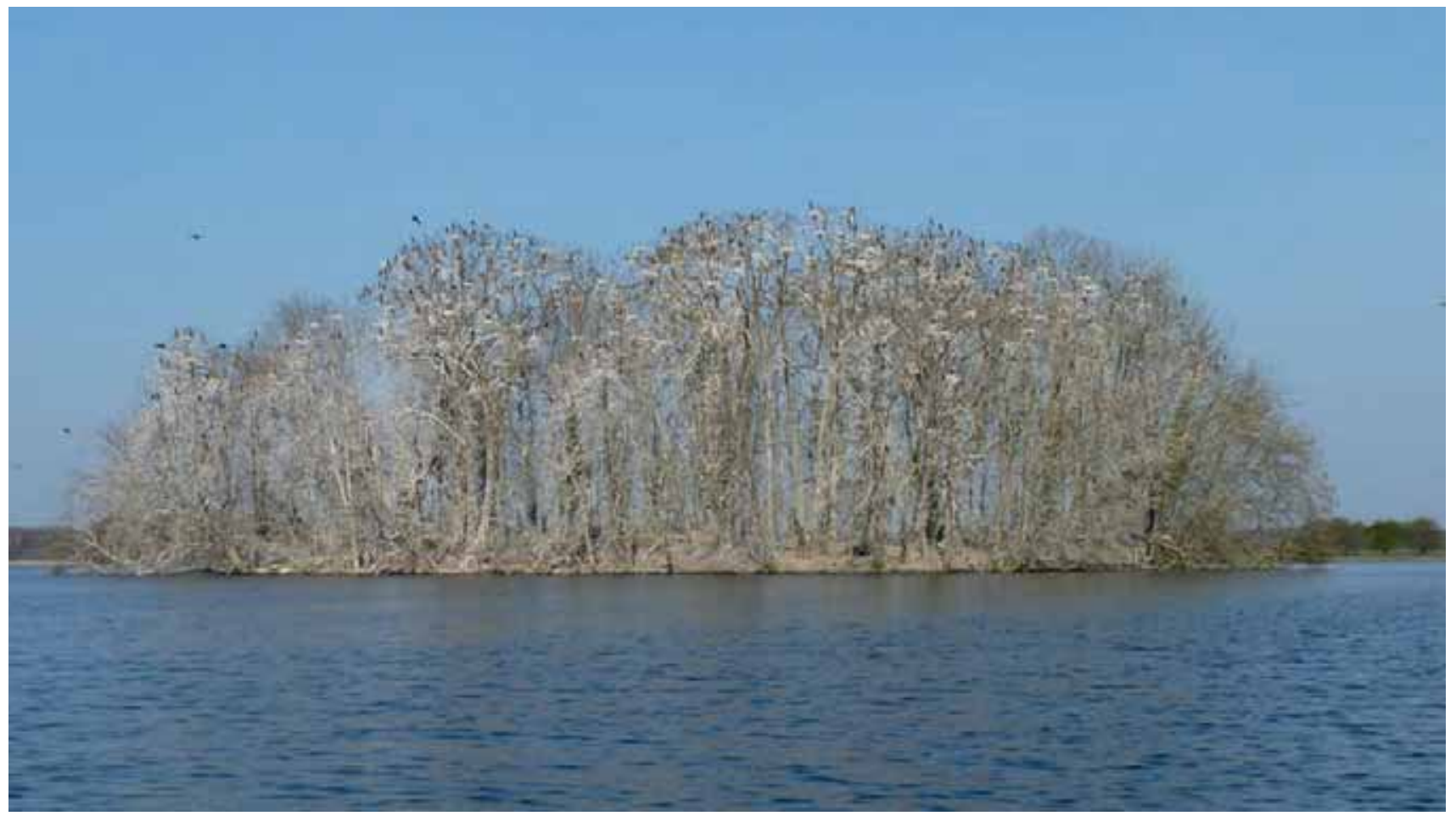

Abb. 70: Die Bäume auf dem Lock-(Linden)werder sind von der Brutkolonie der Kormorane stark durch den Kot belastet. Foto: S. Lorenz.

Neben dem Möwengeschrei sind zu dieser Zeit ebenfalls die Bettelrufe der jungen Kormorane vom benachbarten Lockwerder weithin hörbar. Seit ungefähr dem Jahr 2000 hat sich auf dieser ehemals dicht mit Erlen, Eschen und Linden bewaldeten Insel eine Kormorankolonie etabliert. Die Anzahl der Nester stieg sprunghaft an. Aktuell ist ein Teil der Brutpaare auf den Wolbenwerder im Krakower Untersee umgesiedelt, wodurch die Zahl im Obersee niedriger lag.

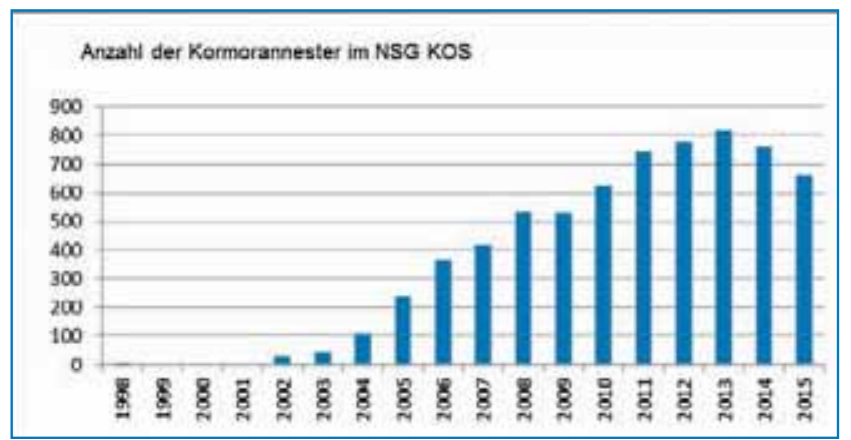

Diagramm 2: Die Entwicklung der Kormorankolonie im NSG KOS

Durch die Kotbelastung und den dichten Nistbetrieb sind die meisten Bäume mittlerweile abgängig, so dass nur noch Kronenreste vorhanden sind. Das nötige Nistmaterial besorgen sich die Kormorane von den Nachbarinseln. Während der Hauptfütterungszeit im Juni wird die Insel stark von Lachmöwen und Seeadlern besucht, die den heruntergefallenen Fisch und verendete Jungvögel absammeln. Die Vielzahl der gleichzeitig anwesenden Seeadler (im Juni 2015 bis 27 Indiv.) reizte Tierfilmer, hier aus einem von der Naturschutzbehörde genehmigten Versteck in der Kormo- rankolonie heraus Filmaufnahmen zu machen.

Der häufig sehr emotional geführten „Kormoran-Debatte“ zwischen Fischern, Anglern, Anwohnern und Artenschützern versuchte Wolfgang Neubauer Zahlen als Argumentationsgrundlage hinzuzufügen.

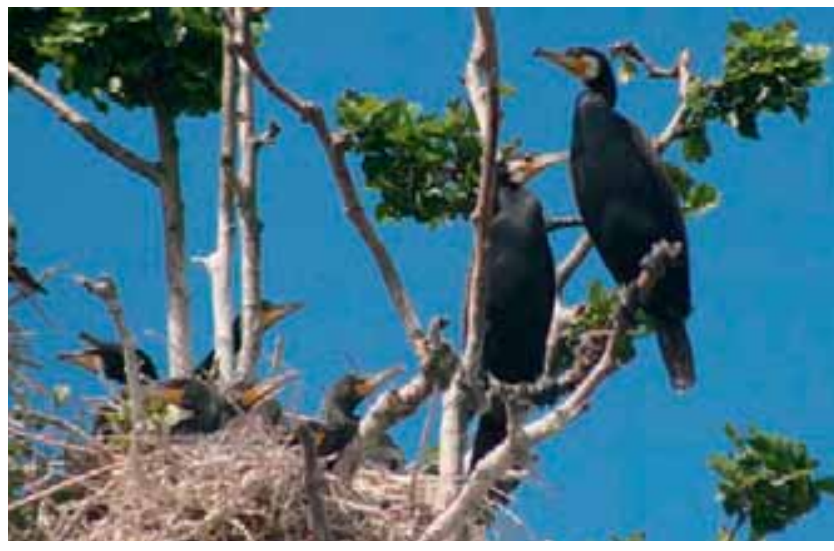

Abb. 71: In den Kormorannestern ist reichlich Nachwuchs. Foto: $\mathcal{7}$. Loose.

So sammelte er in der Brutzeit der Kormorane von 2010 bis 2012 insgesamt mehr als 1.700 Fische und Fischreste unter den Horstbäumen auf, bestimmte deren Arten und Abmessungen. Die meisten ließen sich für eine Nahrungsanalyse auswerten (siehe Tabelle 2). J. Loose fand auf der Festplatte des Computers von W. Neubauer ein 6-seitiges Manuskript mit dem Titel „Die Nahrung des Kormorans Phalacrocorax carbo in der Kolonie im NSG Krakower Obersee" im Anhang mit Auswertungen zu Fischarten gestaffelt nach Größenklassen. Eine Veröffentlichung seiner Untersuchungen ist postum von der FG vorgesehen. 
Tabelle 2: Ergebnisse von Nahrungsanalysen 2010-2012

\begin{tabular}{l|l|l}
\hline Fischart & Anzahl & \% \\
\hline Plötze Rutilus rutilus & 671 & 41,80 \\
\hline Flussbarsch Perca fluviatilis & 532 & 33,10 \\
\hline Schlei Tinca tinca & 148 & 9,21 \\
\hline Brassen [Blei] Abramis brama & 74 & 4,60 \\
\hline Ukelei Alburnus alburnus & 61 & 3,80 \\
\hline Hecht Esox lucius & 39 & 2,43 \\
\hline Rotfeder Scardinius erythrophthalamus & 22 & 1,37 \\
\hline Karausche Carassius carassius & 21 & 1,31 \\
\hline Kleine Maräne Coregonus albula & 9 & 0,56 \\
\hline Aal Anguilla anguilla & 13 & 0,81 \\
\hline Güster [Pliete] Blicca bjoegna & 9 & 0,56 \\
\hline Kaulbarsch Gymnocephalus cernua & 8 & 0,50 \\
\hline Summe & 1.607 & 100
\end{tabular}

Mit den analysierten Futterresten zeichnete sich sehr deutlich ab, dass es vor allem der kleinere Weißfisch und der Flussbarsch (73,6 \%) waren, den die Kormorane im Obersee fischten und verfütterten.

Neben den vorgenannten Arten sind es Flussseeschwalben, Graugänse, Reiher- und Schellenten, die zahlreich am Krakower Obersee brüten und möglichst jährlich in ihren Brutbeständen erfasst werden. Den Flussseeschwalben hatte sich Wolfgang Neubauer in besonderem Maße gewidmet. Dazu kann unter Kapitel 10.1 nachgelesen werden.

Vor allem bei den zeitig im Frühjahr am Boden brütenden Graugänsen ist jedes Jahr ein erheblicher Verlust durch Prädatoren zu verzeichnen, welche die Gelege auf den Inseln ausfressen oder Elterntiere am Nest reißen. Für die Schellenten waren bereits zum Anfang der Schutzgebietsbetreuung von Neubauer auf allen Werdern zahlreiche Nistkästen ausgebracht worden. In der Hoffnung, dass vielleicht auch einmal wieder ein Paar des Gänsesägers darin zur Brut schreitet, wurden auch in neuerer Zeit immer wieder Kästen neu aufgehängt.

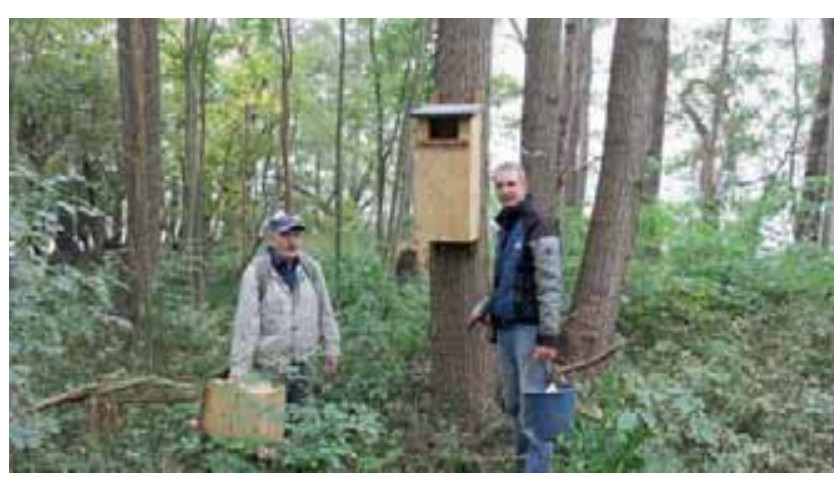

Abb. 72: Die FG-Mitglieder Helmut Richter und Jörg Bußmann leisteten im Herbst 2014 Unterstützung beim Bau und bei der Anbringung von Nistkästen. Foto: S. Lorenz.

Mit Festsetzung des Naturparkes „Nossentiner/Schwinzer Heide" und Einrichtung einer Naturparkverwaltung gab es wesentliche Unterstützungen durch Mitarbeiter der Naturparkwacht bei allen erforderlichen Reparatur- und Pflegearbeiten im NSG. Mehrfach musste der Zaun zwischen der Möwenkolonie und der Wiesennutzung auf dem Großen Werder instandgesetzt werden. Entbuschungen waren notwendig. Auch die Pflegemahd des zum NSG gehörenden Kalkflachmoores am Ufer der Glaver Koppel wird jetzt regelmäßig durch den Naturpark veranlasst. Durch die heute wieder sehr effektive Beweidung der Wiesenflächen mit Schafen und Ziegen, die mittels Fähre im Mai von den Landwirten Wilfried und Olaf Baldermann aus Dobbin bzw. Linstow auf die Insel gebracht werden, konnten die sich in der Wiese stark ausbreitenden Bestände der Nickenden Distel nicht zurückgedrängt werden. Die Disteln mussten per Hand ausgestochen werden. Das Dach der in die Jahre gekommenen Feldstation musste erneuert werden. Ein Marder hatte hier Zugang gefunden und die Zwischendecke durch Urin stark geschädigt. Mit finanzieller Hilfe durch die Stiftung Umwelt und Natur M-V, die Eigentümer der Insel geworden ist, und Leute vom Naturpark konnte diese komfortable Unterkunft 2014/2015 wieder hergerichtet werden.

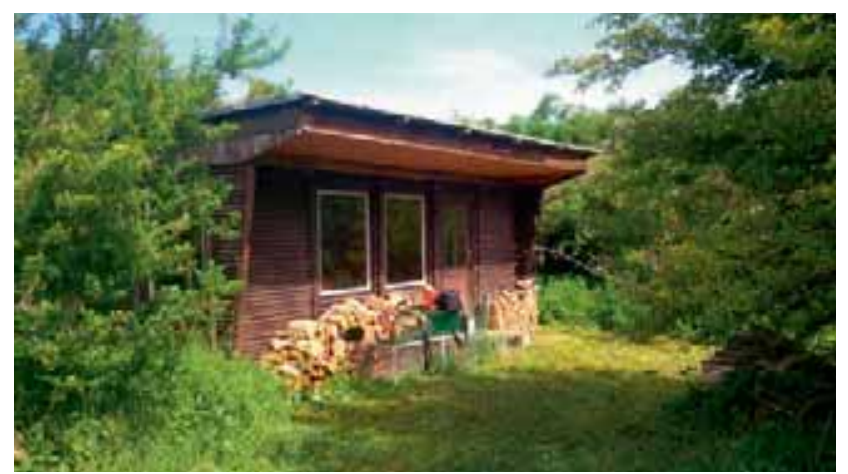

Abb. 73: Die mit neuem Dach ausgestattete Feldstation - 2015.

Foto: S. Lorenz.

Die Schutzgebietsbetreuung ist in meinen Augen ein über viele Jahre gewachsenes gutes Miteinander von Naturpark (in Vertretung für alle Jörg Gast und Ralf Koch), Unterer Naturschutzbehörde (Frank Vökler), dem Staatlichen Amt für Landwirtschaft Umwelt und Natur in Rostock, der Stiftung für Umwelt und Natur Mecklenburg-Vorpommern in Schwerin sowie den ansässigen Land- und Forstwirten und Anwohnern (Betrieb Baldermann, Forellenzucht Dobbin, Forstamt Sandhof/Revier Bossow) geworden. Wenngleich ich mit meinem Wohnort in Greifswald von Seiten der Anfahrt zum NSG nicht so gute Bedingungen habe, wie Wolfgang Neubauer sie hatte, sehe ich mich doch immer noch als Teil der FG Güstrow und übernahm nach dem Tod von Wolfgang sehr gern die Gebietsbetreuung. Mir war es nach vielen Jahren ornithologischer Tätigkeit am Krakower Obersee und einer Diplom- und Doktorarbeit zum Krakower Seengebiet eine Herzensangelegenheit, die Schutzgebietsbetreuung in Erinnerung an meinen ehemaligen Lehrer und in dessen Sinne weiter zu führen. 


\subsubsection{NSG Breeser See}

\section{Joachim Loose (Gebietsbetreuer)}

\section{Schutzgebietsdaten}

Einstweilige Sicherung am

07.08.1974

Behandlungsrichtlinie vom

19.08.1979

22.03 .1982

Unterschutzstellung am

Größe 163 ha

davon Wasser

Röhrichte

Wald, Gebüsch

Wiesen
39 ha

54 ha

48 ha

22 ha

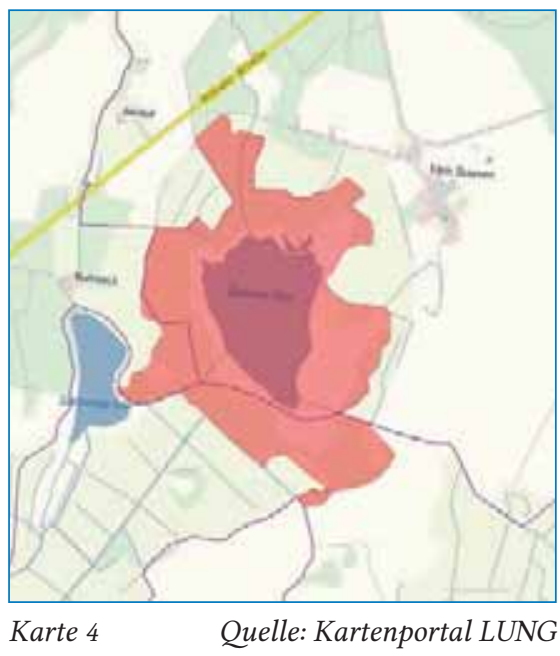

\section{Bedeutung/Schutzziel}

Ungestörter Lebensraum für Röhrichte bewohnende Singvogel-, Rallen- und Entenarten in bis zu 300 m breiten Schilfsäumen, Rast- und Schlafplatzgewässer für Gänse, Kraniche, Stare und Schwalben

1992 Integration in das EU-Vogelschutzgebiet DE 2339-402 Nossentiner/Schwinzer Heide 2007 Integration in das FFH-Gebiet DE 2338-304 Mildenitztal mit Zufüssen und verbundenen Seen

Auf die Bedeutung des Breeser Sees für die Vogelwelt war Kurt Pohlmann aufmerksam geworden, der hier ab 1972 mit seiner Schüler-AG Bestandsaufnahmen der Brut- und Rastvögel vornahm.

Dem Antrag der Fachgruppe auf Unterschutzstellung als NSG vom 15.10.1973 an den Rat des Kreises Güstrow fügte Kurt Pohlmann einen Anhang mit einer ersten Artenliste von insgesamt $102 \mathrm{im}$ Gebiet festgestellten Brutvogelarten bei. Mit der dreiseitigen Begründung unter Berufung auf die in „den letzten fahren zunehmende Veränderung der Umwelt durch Meliorationsmaßnahmen" und einen Ratsbeschluss über „Die Aufgaben zur Durchführung des Gesetzes über die planmäßige Gestaltung der sozialistischen Landeskultur im Kreis Güstrow" gelang es, die einstweilige Sicherstellung des Breeser Sees als Naturschutzgebiet mit Kreistagsbeschluss vom 7.8.1974 zu jener Zeit relativ schnell durchzusetzen. Das damalige ILN, Zweigstelle Greifswald hatte den Antrag mit Schreiben vom 05.11.1973 vollinhaltlich befürwortet. Die von der FG angestrebte und durch das ILN bekräftigte Flächenabgrenzung mit einer Größe von 222 ha für das künftige NSG wurde jedoch durch den Landwirtschaftsbereich, dem auch das Referat Naturschutz beim Rat des Kreises unterstand, auf eine Größe von 163 ha eingegrenzt. Besonders bei den im Norden und Osten angrenzenden feuchten Niedermoorwiesen ist der Verlust noch heute sehr zu beklagen. Auf diesen Flächen unmittelbar an den Grenzen zum NSG wurden in den Jahren 1984 und 1985 bis in die Randbereiche des Sees noch weitere Meliorationsmaßnahmen zur Entwässerung der Niedermoorwiesen durchgeführt. Auf diesen Wiesen werden auch heute noch mineralische Dünger und Gülle ausgebracht. Dadurch gelangen Nährstoffe in den See, was sich sehr nachteilig auf die Wasserqualität auswirkt.

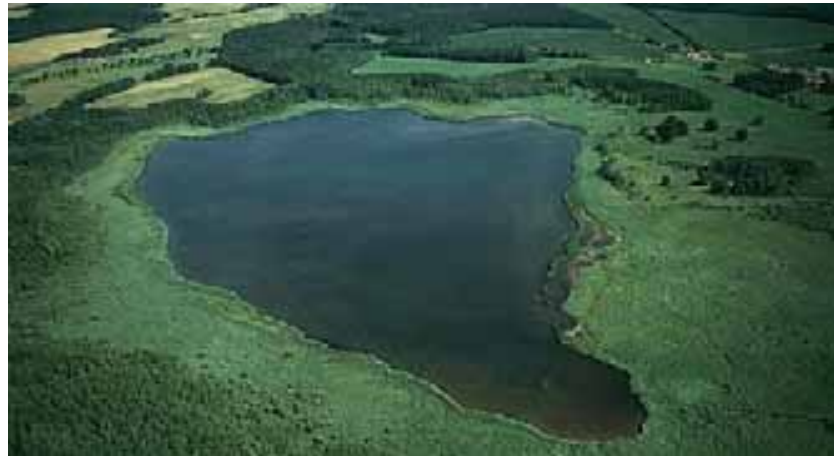

Abb. 74: Breeser See von Süden - Luftbild 1999. Foto: Ch. Berg.

Auch nach der Unterschutzstellung des Sees betätigte sich die Schüler-AG mit Kurt Pohlmann weiter intensiv mit der Vogelwelt des Gebietes. Der See wurde für einzelne Beobachter in Abschnitte aufgeteilt und fortan an fast jedem Wochenende an mindestens einem Tag aufgesucht. Am Nordufer des Sees wurde eine kleine Unterkunft mit Schilfwänden errichtet, in der einige größere Schüler auch mal übernachteten und im Umfeld Rallen fingen.

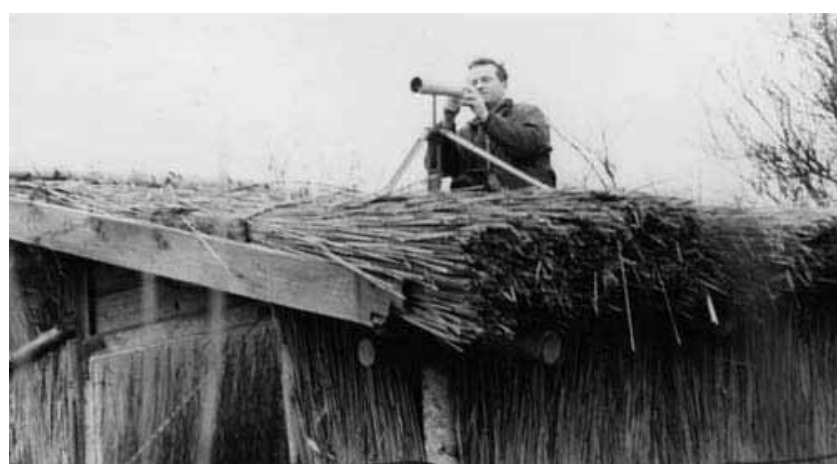

Abb. 75: Kurt Pohlmann an der Schilfhütte am Nordufer des Breeser Sees. Foto: Archiv M. Montschko. 
Später gab es im „Ort“ Rothbeck in der Nähe des Breeser Sees die Möglichkeit, in dem ehemaligen Bauernhaus, dem einzigen Wohnhaus des Ortes, einen Raum durch die Schüler-AG zu nutzen. Jetzt waren öfter auch Exkursionen am Abend in den Bruchwaldgürtel oder entlang der NSGGrenze möglich.

Kurt Pohlmann verstand es, die Interessen der Jugendlichen mit Spiel und ersten Ansätzen für ein wissenschaftliches Beobachten und Arbeiten zu verbinden. Ein im Westwald des Bruchwaldgürtels als geplanter Beobachtungspunkt in ca. $8 \mathrm{~m}$ Höhe errichtetes Baumhaus weit ab vom Ufer des Sees war weniger geeignet, das Vogelleben auf dem See zu beobachten.

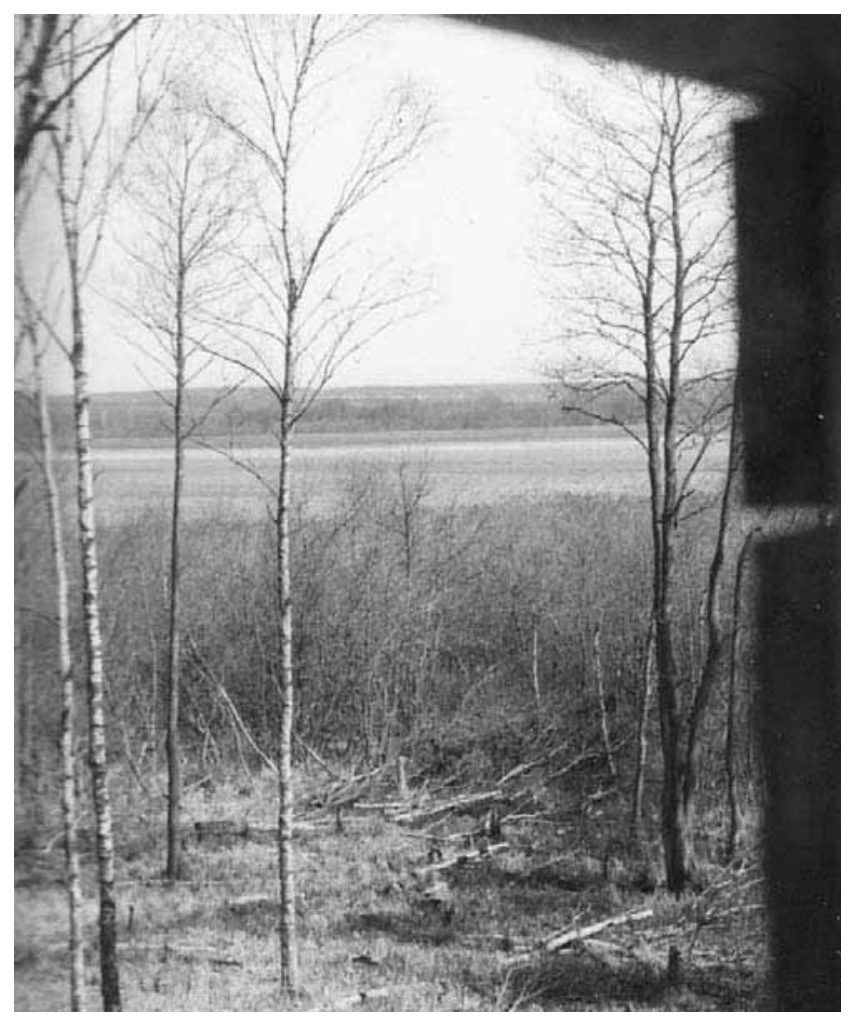

Abb. 76: Blick aus dem Baumhaus der Schüler-AG auf den See. Die Wasserfläche liegt weit entfernt und konnte nur in geringen Teilen eingesehen werden. Foto: A. Martin.

Die für eine Sichtachse geschlagenen Birkenstämme wurden dann aber für die Errichtung einer künstlichen Insel für gewünschte Flussseeschwalbenbruten verwendet. Kurt Pohlmann machte mir auf einer FG-Sitzung klar, dass man die Jugendlichen auch durch den Bau eines „ungeeigneten“ Baumhauses „bei der Stange halten“ konnte. Und sie waren mit Eifer bei der Sache. Über Arbeits- und Versicherungsschutz machte man sich damals kaum Sorgen; Eltern sahen nicht immer gleich beim Lehrer den Schuldigen, wenn etwas passierte.

Als ich im Herbst 1982 nach dem Tod von Kurt Pohlmann als Nachfolger die NSG-Betreuung übernahm, war es mir leider nicht möglich, die AG-Tätigkeit mit den Schülern fortzusetzen.
Geprägt durch meine frühere Betreuertätigkeit des NSG Schelldorfer See in Sachsen-Anhalt wusste ich von den Vorteilen einer Arbeitsunterkunft direkt im Gebiet (dort hatten wir eine schwimmende Hütte am Ufer verankert). So gab es bei mir frühzeitig Überlegungen, wo man eine solche Hütte am besten am Ufer des Breeser See errichten könne. Das noch nicht ganz fertig gestellte Baumhaus (siehe Abb. 4, S. 11) von Kurt Pohlmann war kein Äquivalent, konnte man doch von diesem Standort den See kaum sehen. Dort, wo die Gruppe einmal die Schilfhütte im Nordufer errichtet hatte, sah ich den besten Punkt, der auch gut von außen erreichbar war. Eine feststehende Unterkunft auf Pfählen erschien mir zweckmäßig. Über meinen Betrieb, den damaligen HAN-SA, ein Ausrüstungsbetrieb für den in Erweiterung befindlichen Landmaschinenbaubetrieb Güstrow, bekam ich eine große Transportkiste einer riesigen $8 \mathrm{t}$ schweren Flachschleifmaschine aus Kiew, die mir der Betrieb in Einzelteile zerlegt im Herbst 1982 bis zum Breeser See transportierte.

Damals war die Nordwiese noch nicht melioriert, der „Straßen“-W 50 versackte im Moorboden, ich musste erst einen Traktor aus Zehna zum Rausschleppen besorgen und hatte dann noch Ärger, weil wir mit dem Transport-LKW zu spät wieder im Betrieb waren.

Das Material lag vor Ort, jetzt war Gemeinschaftsarbeit erforderlich. Dafür standen die FG-Mitglieder bereit. Mit insgesamt vierzehn beteiligten Leuten errichteten wir ab 21.11.1983 unsere Hütte im NSG.

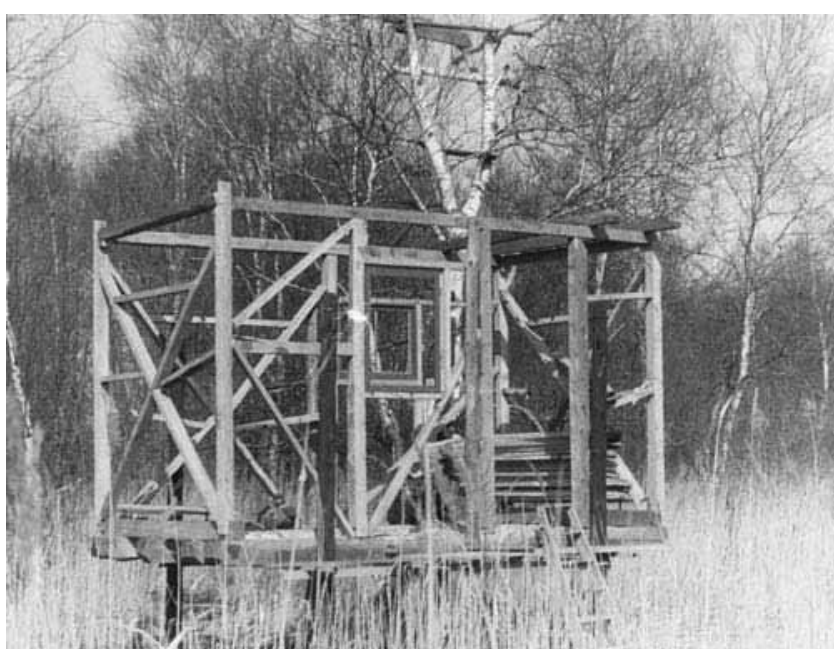

Abb. 77: Das Gerüst für die neue Unterkunft ist im Herbst 1983 fertiggestellt. In der Birke dahinter war ein Hochsitz der Schüler-AG. Foto: 7. Loose.

Als Standpfähle dienten Telefonmasten, die bis zu sechs Meter in den sumpfigen Untergrund auf geniale Weise unter Anleitung von Fritz Anderlik angespitzt und eingedreht wurden. Die Masten hatte Georg Strache von seinem PostFernmeldebetrieb besorgt. Sie waren bestens „konserviert“ (heute wären sie als Sondermüll zu entsorgen), so dass sie auch heute nach über 30 Jahren Standzeit kaum verwittert sind. 


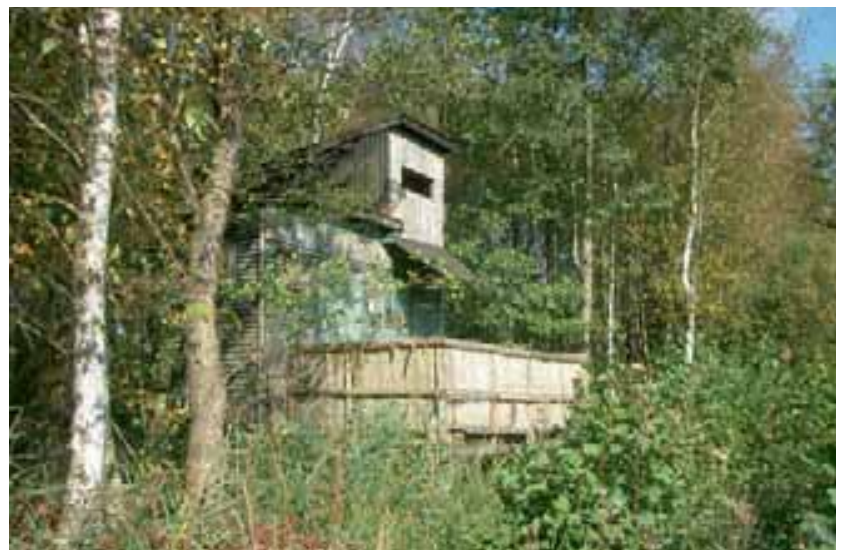

Abb. 78: Die Arbeitshütte stand ab 1984 zur Nutzung bereit. Foto: 7. Loose.

Die Hütte stand dann endlich zur ersten Übernachtung ab dem 13.Juli 1984 bereit. Die spartanische Innenausstattung hatte teilweise der Rat des Kreises finanziert, ansonsten hatte so mancher etwas beigesteuert. Das Baumhaus war abgebaut und das Material als Beobachtungskanzel auf der Hütte aufgesetzt worden. Am Nordufer des Sees stand nun eine hinreichend komfortable Station zur Verfügung, die anfangs häufiger auch von anderen FG-Mitgliedern zur Übernachtung genutzt wurde. Hier begannen wir fortan intensiv in mehreren Schilfschneisen mit Vogelfang und -beringung.

Vom Rat des Kreises wurde bald auch ein Ruderboot zur Verfügung gestellt, so dass auch Untersuchungen von der Wasserseite am Schilfsaum entlang möglich wurden. Im See war mit der Unterschutzstellung das Angeln verboten worden. Durch die häufigere Anwesenheit des Betreuers im Gebiet und die Mobilität mit dem Boot konnte das illegale Angeln stark zurückgedrängt und die Störungen im Gebiet verringert werden. Die vielfach im Schilfsaum entstandenen Anglerstege wurden von uns zurückgebaut.

Die Betreuung des NSG Breeser See umfasste nicht nur die Erfassung der Vogelwelt. Da bekanntermaßen die Wasserqualität von entscheidender Bedeutung für die Artenvielfalt ist und festzustellen war, dass ab Ende der 1970er Jahre sich diese rapide verschlechtert hatte, war dringend nach den Ursachen zu suchen. Bei Unterschutzstellung des Sees wurde dieser als mäßig eutropher Klarwassersee mit reichhaltiger Characeenvegetation eingestuft. Bereits 1979 fehlte die Submersvegetation fast vollständig. Die Sichttiefe im See war zeitweilig bis auf $10 \mathrm{~cm}$ gesunken. Höckerschwäne als auffälligste Art brüteten nicht mehr, da sie im See keine Nahrung fanden.

Zur Ursachenfindung für die hohen Nährstofffrachten, die in den See gelangten und Auslöser für die Wandlung der Wasserqualität waren, entnahmen wir in aufwendiger Aktion in den Jahren 1985 und 1986 monatlich Wasserproben von drei Stellen im See und aus allen fünf Zuläufen kurz vor dem See. Diese mussten umgehend nach der Entnahme ins Labor der Wasserwirtschaftsdirektion Küste (WWD) nach Schwerin zur Analyse geschafft werden. Die Durchführung dieser Untersuchungen war nicht selbstverständlich gewesen und hatte im Vorfeld mancher Diskussion bedurft. Ohne Unterstützung des Rates des Kreises Güstrow, hier konkret des Sekretärs für Jagd und Naturschutz Heinz Stegemann, zu dem wir auch über unseren Kreisnaturschutzbeauftragten Wolfgang Neubauer stets einen guten Kontakt hatten, wäre da in der Planwirtschaft nichts gelaufen.

Im Ergebnis der mehr als zweijährigen Beprobungen entstand ein 27 Seiten umfassender Bericht, der auf Grund seiner Brisanz (gemäß Beschluss des Ministerrates von 1982 waren Umweltdaten geheim zu halten) als Vertrauliche Dienstsache (VD S-SGA-31/87) behandelt werden musste. Da ich wegen meiner Hauptarbeit eine „VD-Berechtigung“ besaß, hatte ich auch die Möglichkeit, den Bericht einsehen zu können (heute liegt er natürlich frei für jeden in den NSG-Akten vor). Als Hauptverursacher waren Nährstoffeinträge aus einer damals in Reimershagen existierenden für den Kreis Güstrow zentral angelegten Kartoffelschäleinrichtung ermittelt worden. Ebenso gelangten unzureichend gereinigte kommunale Abwässer aus der Kläranlage der Gemeinde Zehna zunächst in den Zehnaer und danach in den Breeser See. Ein sehr hoher Anteil von Nährstoffen kam als Düngerabspülungen auch über die Landwirtschaft in den See. Aus einem ca. $32 \mathrm{~km}^{2}$ großen Einzugsgebiet gelangten jährlich Einträge von etwa $60 \mathrm{t}$ Stickstoff und $3 \mathrm{t}$ Phosphor in den See. Damit wurde eine Massenproduktion von Phytoplankton im See in Gang gesetzt, die einer guten Wasserqualität völlig abträglich war. Der von der WWD erstellte Abschlussbericht enthielt auch Vorschläge zur Abstellung der festgestellten Mängel. In der Kartoffelschäleinrichtung in Reimershagen gelangten chemische Abwässer ohne jegliche Nachklärung in die Breesenitz, den Hauptzufluss des Breeser Sees. Die Auswertung mit der Betriebsleitung hatte zum Ergebnis, dass umgehend eine Kläranlage nachgeschaltet wurde. Nachrüstungen gab es in der Folge auch in der vorhandenen Kläranlage in Zehna.

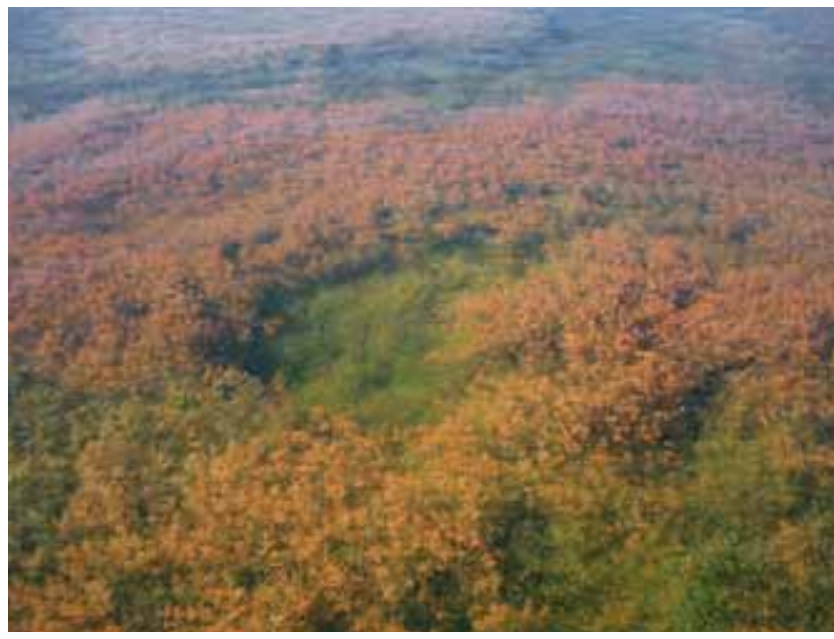

Abb. 79: Klarwasserphasen mit Characeenrasen stellten sich ab 1990 wieder auf dem See ein. Foto: 7. Loose 
Möglicherweise hatte bereits die Durchführung dieser Schwerpunktmaßnahmen zum Ergebnis, dass im Frühjahr 1989 plötzlich kurzzeitig eine Klarwasserphase im Breeser See zu beobachten war. Ich sah nach der Übernahme der Betreuungstätigkeit zum ersten Mal den Seeboden, auf dem sich in diesem Jahr bereits auch wieder eine Submersvegetation zu entwickeln begann.

Nicht allein die politische Wende im Herbst 1989 mit den vielen Veränderungen hatte also dazu geführt, das fortan wieder vermehrt, ab 1990 dann über mehrere Monate im Jahr oder auch wieder ganzjährig Klarwasserverhältnisse im See vorherrschten. Es war beeindruckend festzustellen, wie einige Pflanzen- und Tierarten erneut den See zu besiedeln begannen. Characeenarten und Mittleres Nixkraut bedeckten den Seeboden bald überall. In den freien Bereichen tummelte sich zahlreich Fischbrut.

Haubentaucher und Höckerschwäne zogen wieder erfolgreich am See Junge auf. Flussseeschwalben begannen hier zu brüten und mit den Characeen tauchten auch kurzzeitig einmal Kolbenenten auf. Das Schilfrohr im Uferröhricht zeige sich gegenüber dem Zustand in den 1970er und 1980er Jahre in Durchmesser und Größe kräftiger. Für andere Veränderungen im Schilfgürtel fehlen Erklärungen:

An vielen Stellen sind in der Breite der Uferzone Schilfzuwächse inzwischen von weit mehr als $15 \mathrm{~m}$ festzustellen. An anderen Stellen kam es hingegen zu Schilfausfällen und sogar Lagunenbildungen (Ost- und Nordostuferabschnitte). Diese Veränderungen lassen sich sehr gut im Luftbildvergleich aus Bildern verschiedener Jahre erkennen. In der Betreuung des Sees gibt es also immer wieder spannende neue Fragestellungen.
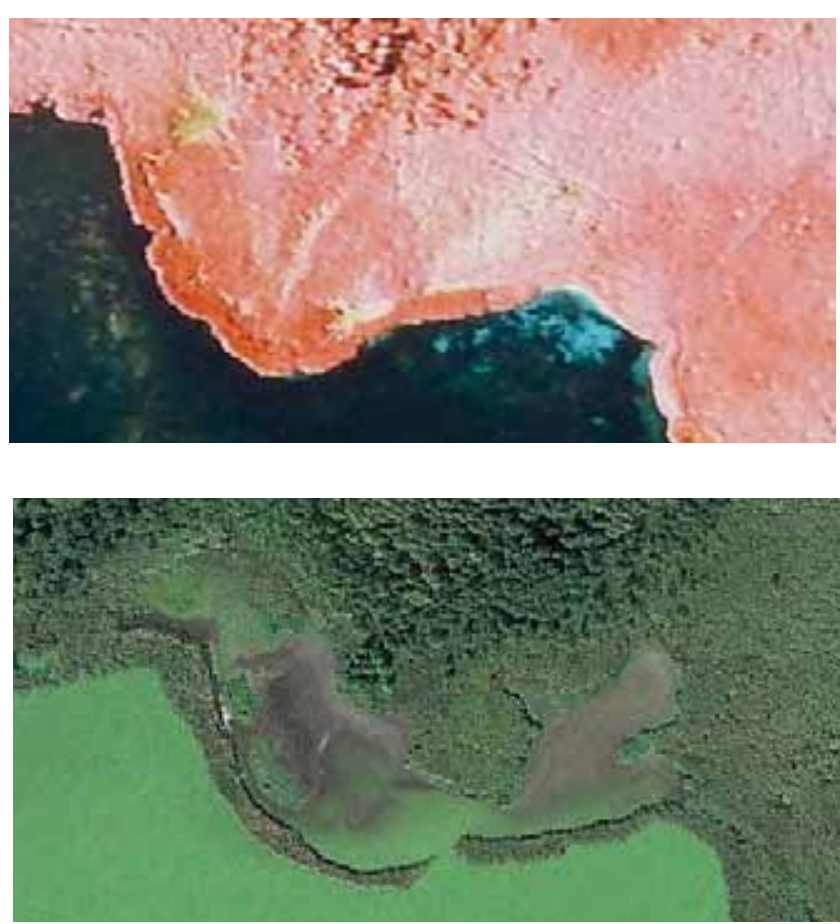

Abb. 80/81: Im Bereich des Nordostufers kam es zur Lagunenbildung. Hier befindet sich heute ein Kranichschlafplatz. (Quellen: oben CIR-Aufnahme von 1991 LUNG, unten Google Earth - 2014)
Bei den Erfassungsarbeiten im NSG strebte ich mit verschiedenen Mitteln an, auch zu anderen Tierartengruppen Inventarlisten anzulegen bzw. zu erhalten. Dort, wo mein Wissen nicht ausreichte, holte ich mir die Fachleute ins Gebiet. 1992, 1996 und 1998 kam Uwe Jueg zur Erfassung der Malakofauna und stellte fest, dass im Seebodensediment viele Arten vorhanden waren, die jedoch auf Grund der schlechten Wasserqualität abgestorben waren. Er entdeckte die Vorkommen der Windelschnecken (Vertigo moulinsiana und V. angustior) im Randbereich des Sees - heute wichtige FFH-Arten. Hans-Dieter Bringmann aus Rostock erfasste 2002/03 als Spezialist die Bockkäfer und einige andere Käferarten im NSG. Von 2001 bis 2005 suchte und bestimmte Mathias Krech die Imagines und Exuvien von Libellen. Artnachweise von Libellen gelangen auch mir regelmäßig als Beifänge in den Vogelfangnetzen. Keilfleck-Libelle und

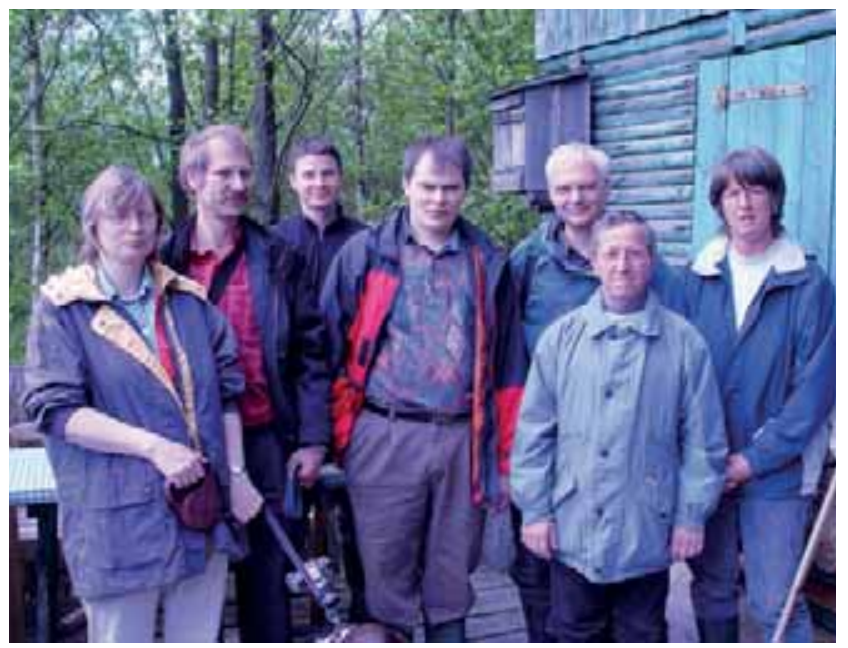

Abb 82: Entomologengruppe um Dr. Volker Thiele bei der Einweisung zur Schmetterling-Fangaktion am 22.05.2004. Foto: J. Loose.

Zweifleck waren Besonderheiten des NSG. Mitglieder der AG Entomologie Rostock unter Leitung von Dr. Volker Thiele weilten 2004/2005 mehrfach im Gebiet und erfassten auch insbesondere mit Nachtfängen die Schmetterlingsarten. Um die botanische Inventarisierung kümmerte sich alljährlich unterstützend Angela Martin von unserer Fachgruppe. Als der See wieder eine auf dem gesamten Seeboden ausgedehnte Unterwasservegetation aufwies, bestimmte Mathias Teppke 2001 die Vergesellschaftungen bei den Wasserpflanzen im Röhrichtgürtel, der Submersvegetation und in den neu entstandenen Schlenken. Ebenso war Wulf Hahne hier tätig und untersuchte u. a. die Flächen der Torfmoosentwicklung am Nordwestufer.

Bereits frühzeitig beabsichtigten wir, der Öffentlichkeit die Möglichkeit für Einblicke in das NSG zu geben. Im Schutzgebiet existieren keine öffentlichen Wege, so dass Beobachtungen lediglich von einer Besucherkanzel aus möglich waren. Eine solche errichteten uns 1984 Forstarbeiter am Ostufer am sogenannten Fischersteg in der Form einer etwas größeren Jagdkanzel, die von Klein Breesen aus über einen Fußweg zu erreichen war. - Für den Fall, dass von 
diesem Punkt zu große Störungen ausgehen würden, hatten wir uns zunächst den eventuellen Rückbau der Einrichtung vorbehalten. - Es ging alles gut. Eckhard Hackert vom Forstamt Krakow am See unterstützte uns (kurz vor Auflösung des Amtes) im Mai 2001 erneut mit dem Bau einer richtigen Besucherkanzel, als die erste soweit verwittert war, dass sie für die Öffentlichkeit gesperrt werden musste (Abb. 83). Kurt Petersen, Wilsen leitete den Neubau.

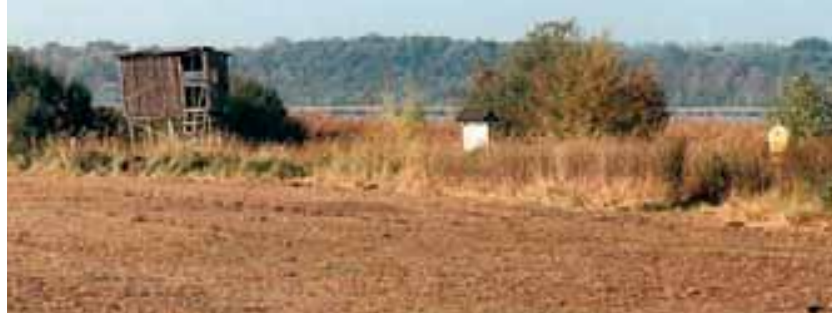

Abb. 83: Die alte öffentliche Beobachtungskanzel war baufällig und musste ersetzt werden (10/2000) - Die im Vordergrund an den See angrenzende Ost-Wiese war zu diesem Zeitpunkt für eine Neuansaat mal wieder totgespritzt und umgebrochen worden. Foto: 7. Loose.

Die hier gegebene Beobachtungsmöglichkeit wird sowohl von Einheimischen als auch Urlaubern rege genutzt. Über Infotafeln können sie an dieser Stelle auch etwas über das Gebiet und deren Tier- und Pflanzenwelt erfahren. Einem Kasten können Faltblätter zum NSG und anderes Material entnommen werden. Von hier starten in der Saison geführte Exkursionen mit kleineren Gruppen ins NSG.

Gleich nebenan im NSG befindet sich eine für die Pflanzenwelt des Gebietes bedeutsame Wiese mit Orchideenarten und zahlreichen inzwischen selten gewordenen Pflanzenarten von extensiv bewirtschafteten Feuchtwiesenstandorten. Für die Pflege dieser ca. 2 ha großen Wiese konnte nach der Wende der Jagdpächter Karl Schäfer $(\dagger)$ gewonnen werden, der mit einem RS 09 noch im Besitz der notwendigen leichten Technik war und ansonsten die Wiese in Handarbeit beräumte.

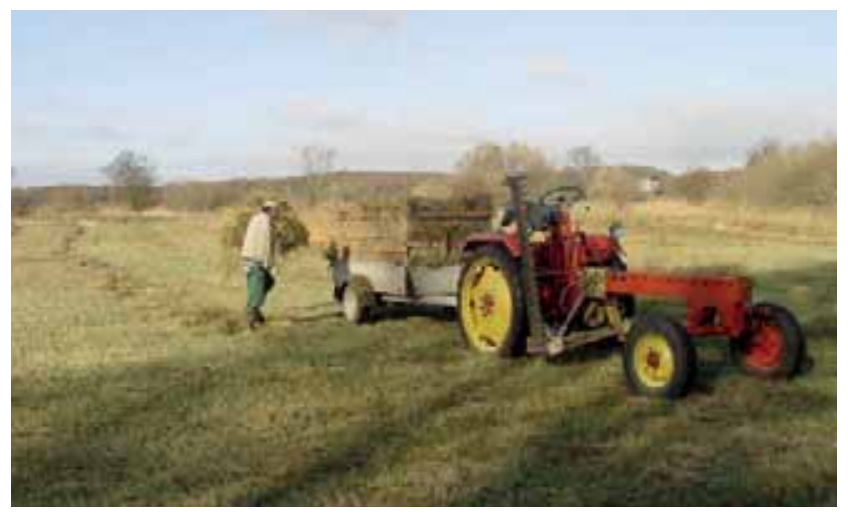

Abb. 84: K. Schäfer bewirtschaftete die Orchideenwiese bis 2012 Foto: 7. Loose.
Über staatliche Fördermittel vom STAUN Rostock konnten später geeignete Landwirtschaftsbetriebe gefunden bzw. auch eine Firma mit Mähraupe beauftragt werden, die die Mahd und Beräumung nach Vorgaben des Betreuers ausführen. Früher hatten diese zur Erhaltung notwendigen Arbeiten die FG-Mitglieder und andere Naturschutzhelfer in ehrenamtlicher Tätigkeit durchgeführt. Das Mähgut wurde damals am Rande der Mähfläche im Bruchwald abgelegt, da zum Abtransport und zur Verwertung die Möglichkeiten fehlten. Dieses gemeinschaftliche Arbeiten der FG-Mitglieder stärkte das Zusammenhörigkeitsgefühl der Gruppe. Derartige Aktivitäten sind auch in anderen Gebieten nach 1989 aus verschiedenen Gründen weggefallen und lebten erst in jüngster Zeit wieder auf (siehe Pkt. 8.1.6).

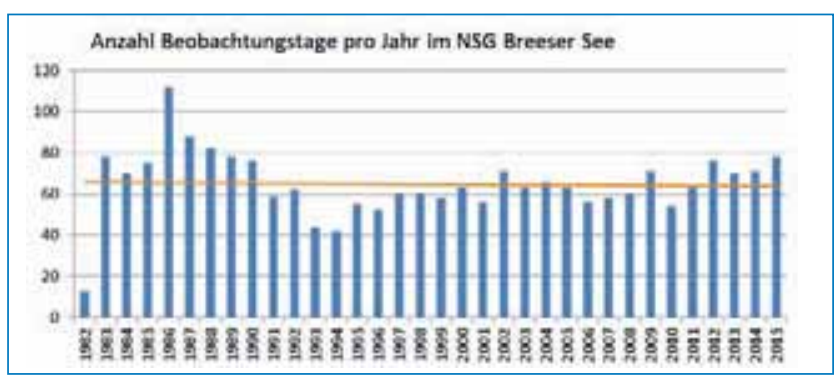

Diagramm 3: Beobachtungsintensität in 33 fahren Betreuertätigkeit

Bis 1989 beteiligten sich bis zu elf FG-Mitglieder an regelmäßigen Beobachtungen im NSG (vgl. Schlüsselvergabe für die Hütte). Die Arbeitsstation wurde anfangs für bis zu 18 Übernachtungen (1988) jährlich genutzt. Eine gleichbleibend hohe Beobachtungsintensität im Gebiet konnte über alle Betreuungsjahre sichergestellt werden (Diagramm 3). Nach 1989 stammen die Beobachtungen aus dem Gebiet weitgehend nur vom Betreuer. Soweit Arbeiten im NSG nicht durch eine Person allein erledigt werden konnten (z.B. der Grundaufbau von künstlichen Brutinseln für Flussseeschwalben - siehe Pkt. 10.2) haben auch immer andere FG-Mitglieder geholfen.

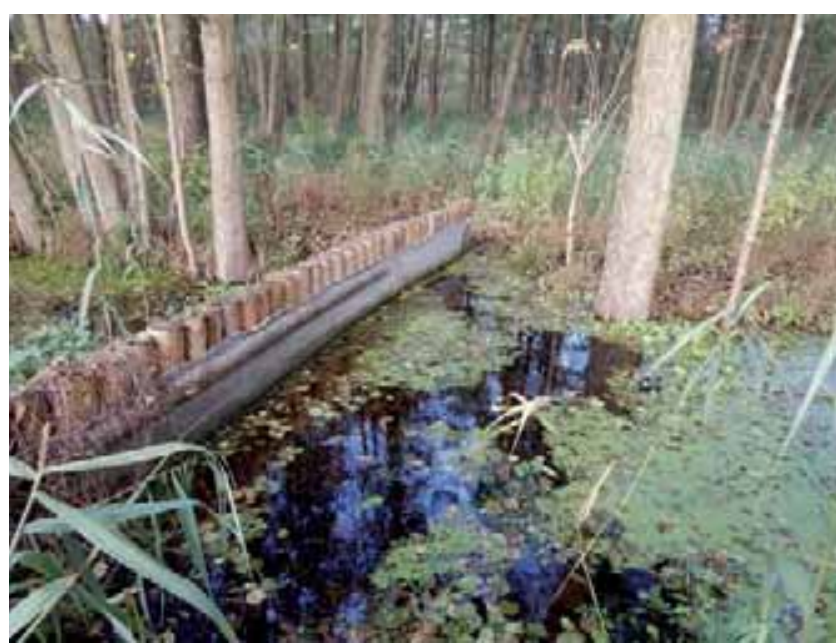

Abb. 85: Grabenverschluss im Randgraben auf der Nordostwiese. Foto: 7. Loose. 
Im Herbst 2014 konnte eine seit langem durch mich als NSG-Betreuer und in der Funktion bei der Naturschutzbehörde vorbereitete Maßnahme zur Reduzierung des Nährstoffeintrages in den See umgesetzt werden.

Nährstoffe konnten durch die regelmäßige Gülleausbringung auf der Niedermoorwiese östlich des Sees (oft noch bis Mitte November) über die 1984 gezogenen Randgräben in den See gelangen.

Diese Gräben wurden nun durch mehrere Staue verschlossen. Die Feuchtwiese soll jetzt anschließend in eine extensive Nutzung überführt werden. Aufgabe bleibt es für die nächsten Jahre, diese Maßnahme in gleicher Weise zumindest auch auf der nördlich des Sees liegenden Niedermoorwiese umzusetzen. Voraussetzungen sind auch dort durch das bei der Landgesellschaft $M-V$ liegende Eigentum für diese Flächen gegeben.

Die im Naturschutzgebiet am Ostufer liegende Orchideenwiese bildet mit ihrer Artenvielfalt einen krassen Gegensatz zu den im Umfeld intensiv genutzten Grünlandflächen. Hier kann bei den geführten Exkursionen in das NSG den Besuchern gezeigt werden, wie unsere extensiv genutzten Niedermoorwiesen früher einmal aussahen. Der Blütenreichtum auf dieser ca. 2 ha großen Fläche fasziniert jeden. In untersuchten Kontrollflächen haben wir bisher 80 Pflanzenarten festgestellt. Diese Pflanzenvielfalt zieht auch eine mannigfaltige Insektenwelt an, die sich zu erfassen lohnt. Jährlich wurden auf dieser Wiese die blühenden Orchideen gezählt und weitgehend Bestandsanstiege registriert.

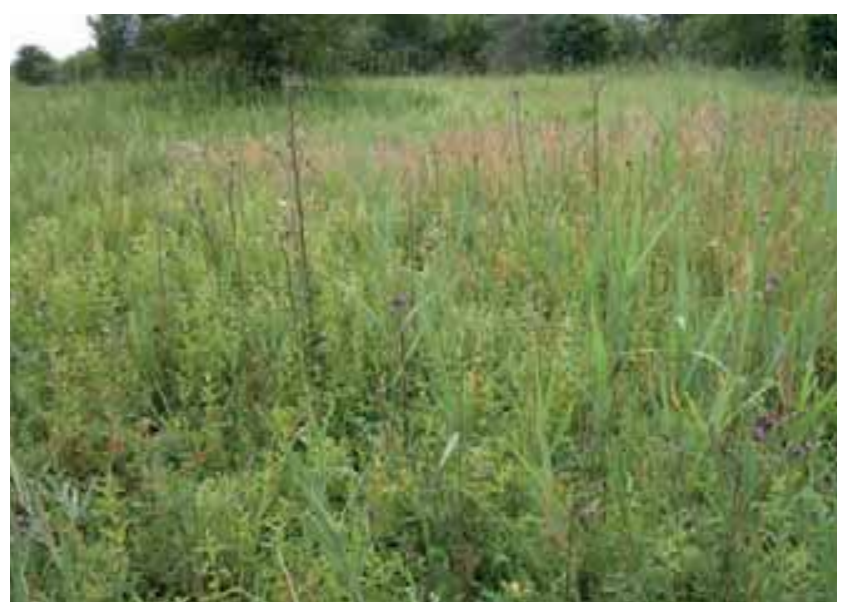

Abb. 86: Artenreiche Feuchtwiese am Ostufer des Breeser Sees. Foto: 7. Loose.

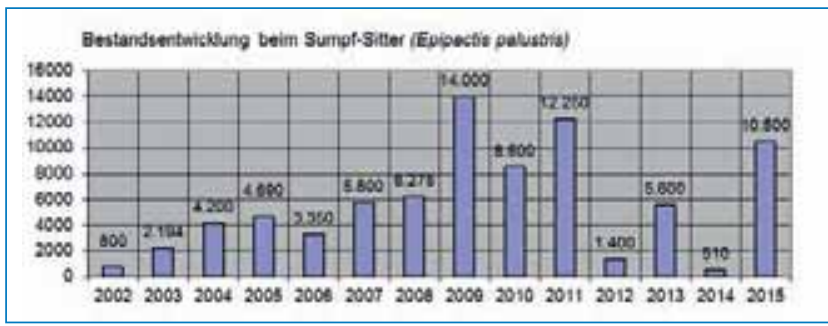

Diagramm 4: Fährlich gezählter Bestand der blühenden Exemplare des Sumpf-Sitters.

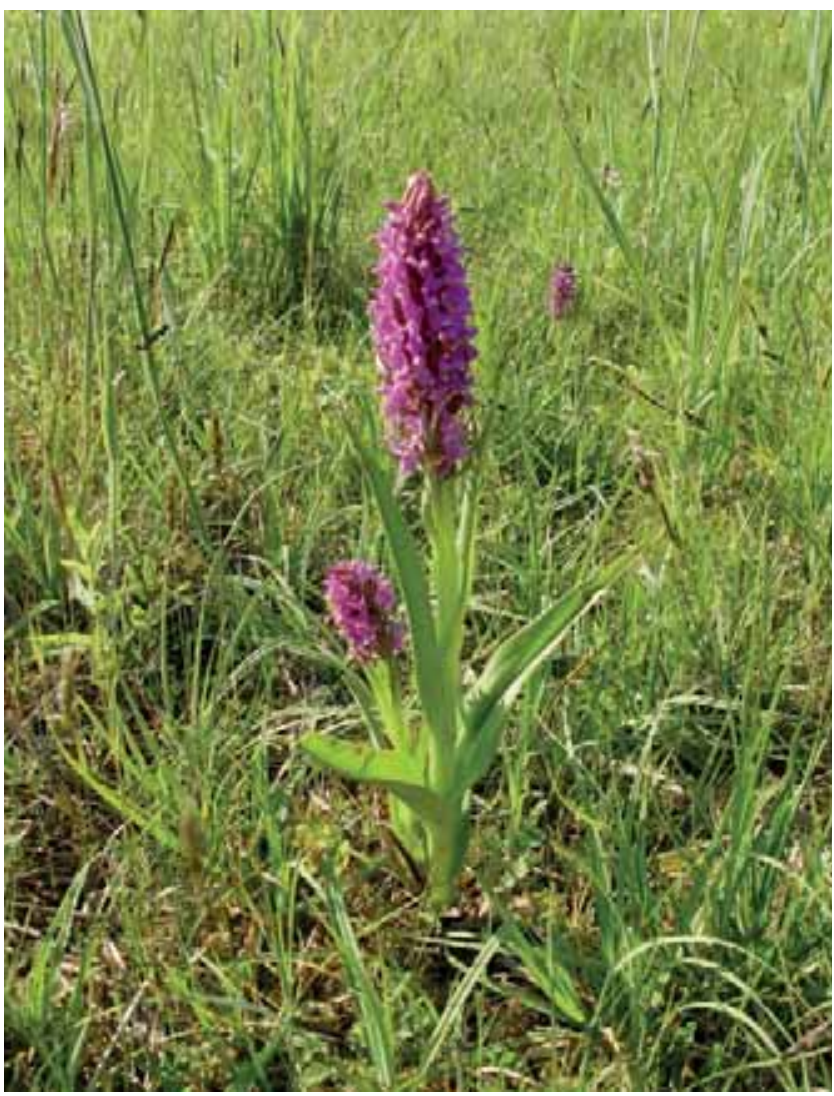

Abb. 87: Das Steifblättrige Knabenkraut kommt an keiner anderen Stelle unseres Kreises so häufig vor, wie hier auf der Ostwiese im NSG Breeser See. Foto: 7. Loose.

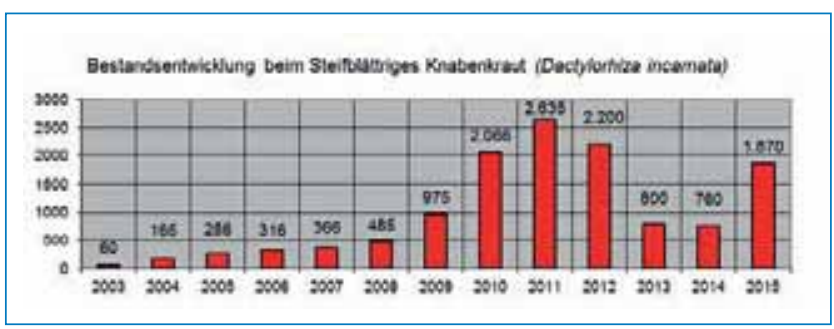

Diagramm 5: Fährlich gezählter Bestand der blühenden Exemplare des Steifblättrigen Knabenkrautes

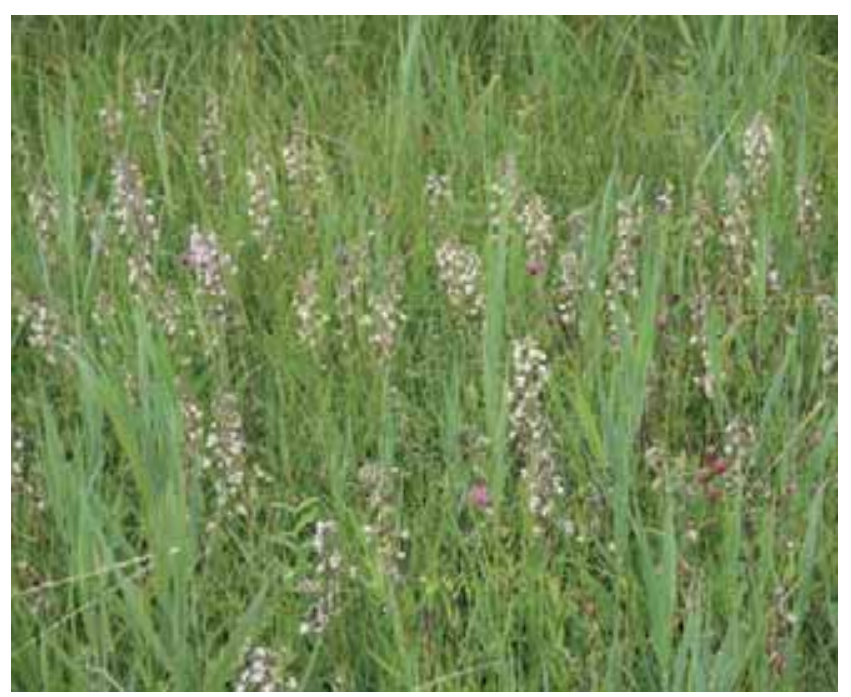

Abb. 88: Auf der Wiese stehen die Sumpf-Sitter oft dicht an dicht. Foto: 7. Loose. 
Vermutlich durch die gute Pflegemahd der Fläche ist eine Zunahme bei den beiden hier anzutreffenden Orchideenarten festzustellen. Vielleicht trägt die von mir praktizierte „Samenernte“ bei den Orchideen vor der Mahd auch dazu bei. Die Samenkapseln werden nach der Reife und vor der Mahd abgeschnitten und das geerntete Saatgut hinterher wieder auf der Fläche ausgebracht. Damit wird weitgehend verhindert, dass Orchideensamen mit dem Mähgut aus der Wiese ausgetragen wird.

Der über Klein Breesen erreichbare Beobachtungsturm wird heute häufig durch Urlauber aufgesucht, die sich vielfach begeistert über die Artenvielfalt des Gebietes im ausliegenden Gästebuch äußerten. Als besondere Erlebnisse werden die Möglichkeit der Beobachtung des Ein- und Ausflugs der Kraniche zum Schlafplatz und die in die Zehn- tausende gehende Zahl der Stare, die vielfach direkt vor dem Beobachtungsturm in das Schilf zum Schlafen einfallen, genannt. Die Beobachtung von diesem Punkt gilt quasi als „Geheimtipp“, der von umliegenden Besitzern von Ferienwohnungen an die Urlauber vermittelt wird. Bei meinen Kontrollen im Gebiet kam ich mehrfach mit Urlaubern auf dem Turm ins Gespräch und führte sie bei Interesse auch ins NSG oder nahm sie mit dem Boot während der Brutzeit mit zu der nahe am Ufer gelegenen Flussseeschwalbeninsel. Eier und Küken der Flussseeschwalbe hatten die meisten noch nie gesehen und nahmen diese Beobachtungen mit Begeisterung und Dankbarkeit auf.

Im Fazit kann ich feststellen, dass sich über den Turm im NSG auch mit den dort vorhandenen Tafeln und der Verteilung von Info-Material eine Öffentlichkeitsarbeit sehr effektiv umsetzen lässt.
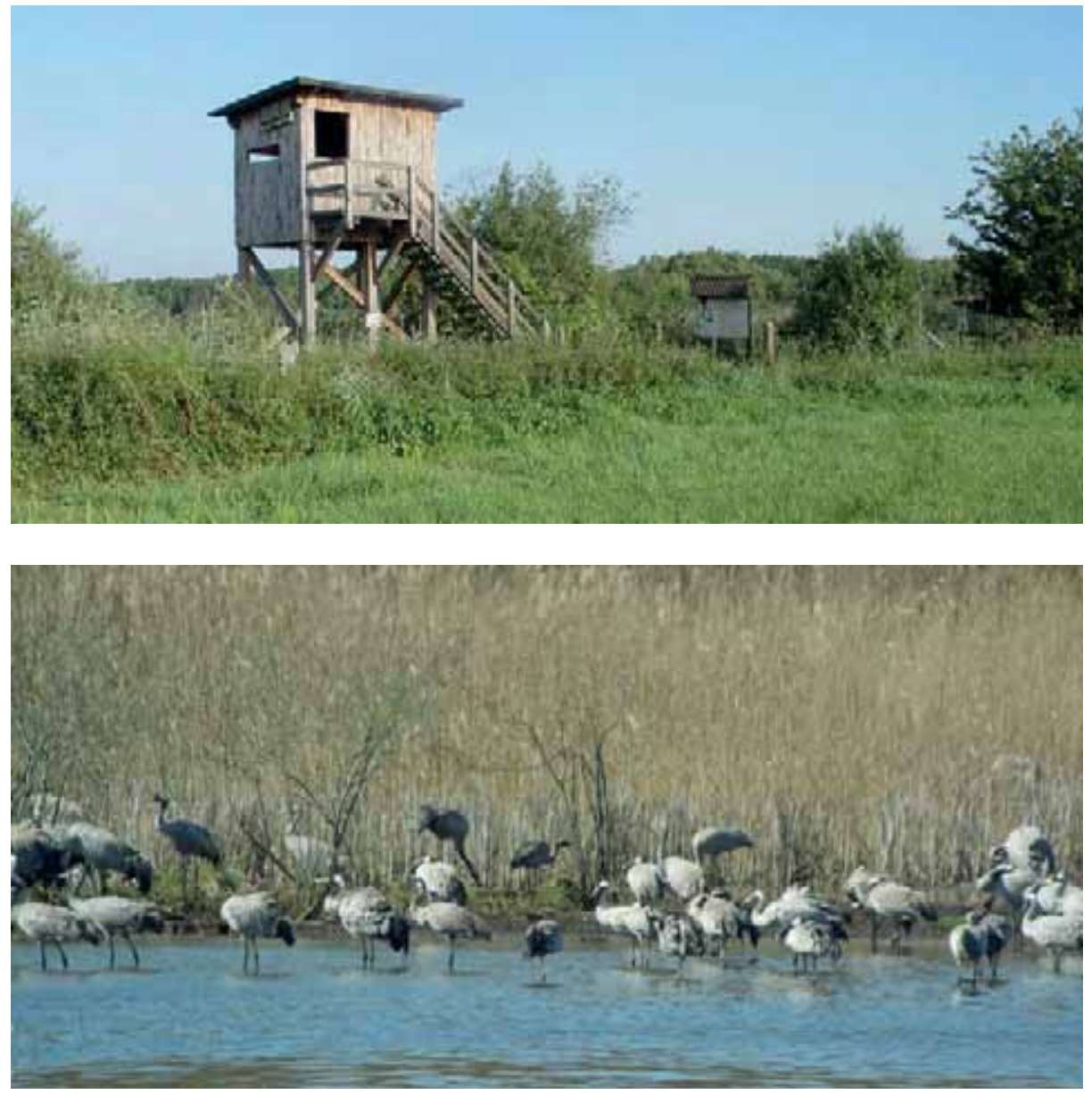

Abb. 89: Von der öffentlichen Beobachtungskanzel am Ostufer des Sees hat man einen guten Einblick in das NSG und die hier errichteten Brutinseln der Flussseeschwalben sowie den Kranichschlafplatz im der Nordost-Lagune. Foto: . Loose.

Abb. 90: Einblick in die NordostLagune, in der sich auch tagsüber Kraniche aufhalten können. Mit einem guten Spektiv lassen sich hier die Fussringkombinationen bei beringten Kranichen leicht ablesen. Foto: f. Loose. 


\subsubsection{NSG Upahler und Lenzener See}

\section{Wolfgang Köhler \\ Schutzgebietsdaten}

Einstweilige Sicherung am

Behandlungsrichtlinie vom

Unterschutzstellung am

VO mit Erweiterung vom

\subsubsection{8}

abgelöst durch VO

22.03.1982

09.07.1999

Größe 520 ha

davon Wasser 116 ha Upahler See

62,6 ha Lenzener See

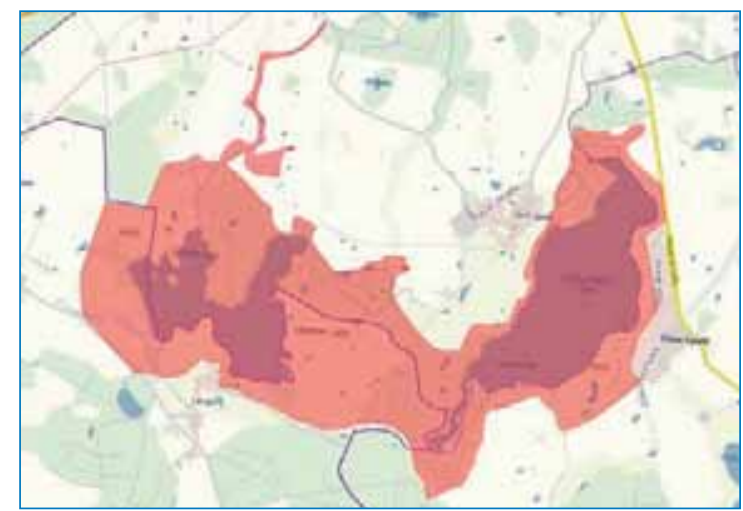

Karte 5

Quelle: Kartenportal LUNG

Bedeutung/Schutzziel

Erhaltung und Pflege einer Seenlandschaft im stark reliefierten Gebiet der Hauptmoräne mit wertvollem Waldbeständen und reicher Tier- und Pflanzenwelt

Schwerpunkt ist die Erhaltung der Wasserqualität beider Seen, insbesondere des Lenzener Sees mit seiner wertvollen Unterwasserflora.

1992 Integration in das EU-Vogelschutzgebiet DE 2339-402 Nossentiner/Schwinzer Heide 2007 Integration in das FFH-Gebiet DE 2238-302 Wald- und Gewässerlandschaft um Groß Upahl und Boitin

Das NSG verdankt seine Ausweisung als Schutzgebiet allein der Fachgruppe Ornithologie und Naturschutz Güstrow. Georg Strache hatte auf seinen zahlreichen Exkursionen im Kreis die Attraktivität und den Wert des Gebietes - hier zunächst des Upahler Sees - erkannt und in der Fachgruppe wiederholt für einen aktiven Schutz des südlichen Teils des Sees geworben, ohne dass ein spürbares Echo erfolgte. Erst als ich in meiner Funktion als zuständiger Oberförster empfahl, nicht nur einen Teil, sondern den gesamten See einschließlich der angrenzenden Waldflächen als Schutzgebiet vorzuschlagen, kam wieder Bewegung in das Vorhaben. Als Gründe für eine Unterschutzstellung trugen wir neben der ornithologischen Bedeutung des Sees vor, dass

- der See noch frei von Bungalowbebauungen war,

- es nur ausnahmsweise privilegierten Bootsverkehr gab,

- hier einer der ältesten bekannten Seeadlerbrutplätze Deutschlands (mindestens seit 1920 belegt) lag,

- eine gute Submersvegetation bei guter Wasserqualität existierte,

- die umgebenden Buchenwaldflächen sehr naturnah und altholzreich und mit einem überdurchschnittlichen Arteninventar ausgestattet waren.

Zudem befanden sich mehrere frühhistorische Siedlungsreste im Gebiet.

Adolf Kretschmann, als zuständiger örtlicher Revierförster und gleichfalls FG-Mitglied, schlug schließlich vor, auch den Lenzener See und die dazwischen liegenden Wälder

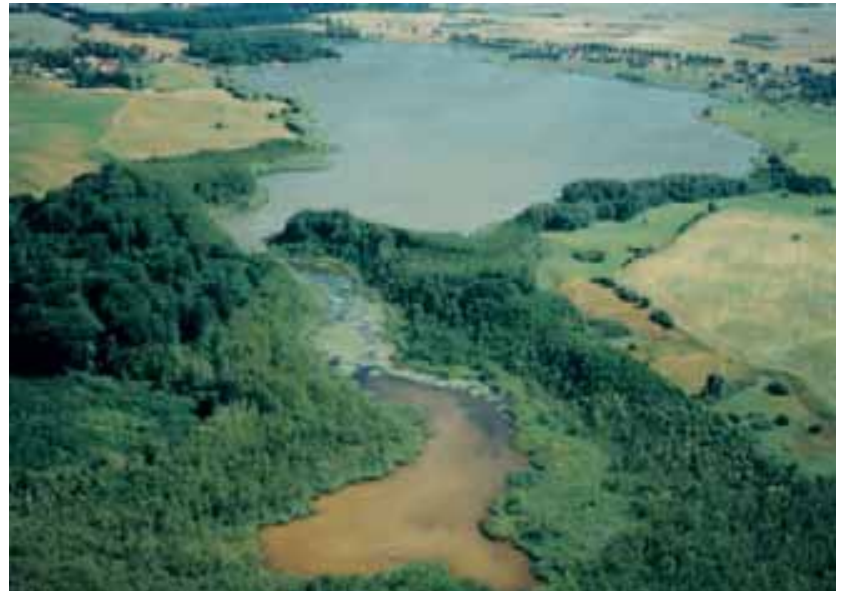

Abb. 91: Luftbild vom Südteil des Upahler Sees, von dem wegen fehlender Zugänglichkeit kaum Beobachtungen vorliegen - 1999. Foto: Ch. Berg.

einschließlich der extensiv genutzten Wiesen mit einzubeziehen, damit das Gebiet abgerundet würde. Am Lenzener See und auf der Halbinsel Bohnrat konnte der zu dieser Zeit noch seltene Fischotter nachgewiesen werden.

Trotz zum Teil heftigen Widerstandes von verschiedenen Seiten gelang es schließlich, dieses Gebiet bei einigen Grenzkorrekturen am 5.7.1978 als NSG mit einer Flächengröße von 393 ha durch den Rat des Kreises Güstrow einstweilig sichern zu lassen. Die Ausweisung als NSG durch den Bezirkstag Schwerin erfolgte wie damals üblich erst im Paket mit anderen Gebieten vier Jahre später. Nach einer Erweiterung am 9.7.1999 hat das NSG heute eine Größe von 520 ha. 


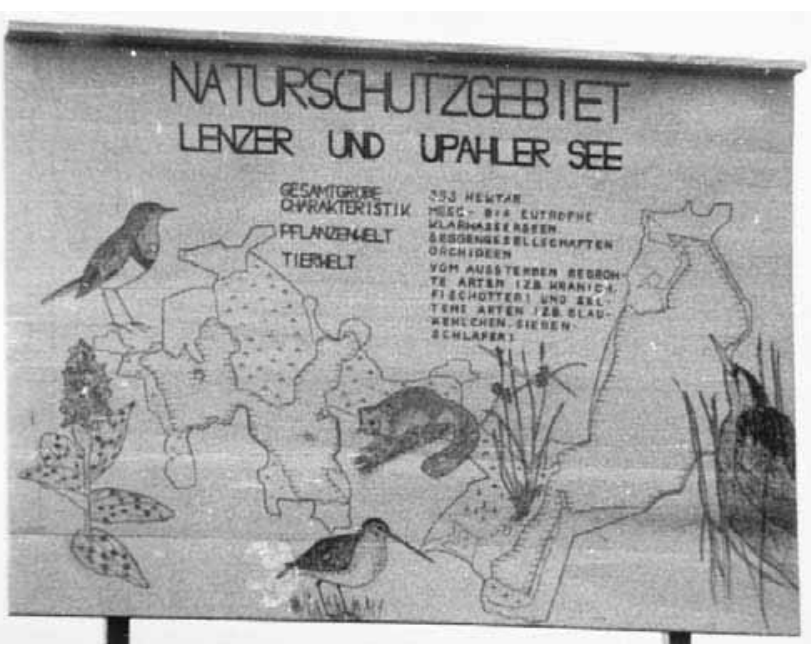

Abb. 92: Die erste Informationstafel für das NSG wurde durch Angela Martin angefertigt und von der FG 1980 auf der Ostseite des See aufgestellt. Foto: A. Martin.

Adolf Kretschmann übernahm von Anfang an mit viel Engagement die Betreuung des Naturschutzgebietes. Er organisierte alle erforderlichen Pflegemaßnahmen auf den Wiesen im Uferbereich des Upahler Sees (Pastorkoppel, Lenzener Wiese und Rieselwiese). Ein örtlicher Landwirt führte mit leichter Maschinentechnik (RS 09) regelmäßig die Mahd, anfangs auch die Beräumung des Mähgutes durch. Beim Ablegen des Mähgutes am Rande der Wiesen unterstützten ihn später Teilnehmer eines Ökocamps. Ebenso waren Teilnehmer eines Christlichen Jugendlagers und auch ein international besetztes Studentenlager, welches im Sommer in Lohmen Quartier bezogen hatte, bei den Pflegearbeiten behilflich. Den jungen Leuten war es ein Bedürfnis, etwas für sie völlig Ungewohntes für die Natur zu tun. Adolf Kretschmann leitete sie mit Freude an und war über ihre Einsatzbereitschaft auf den immerhin rund 8,5 ha großen Wiesenflächen begeistert. Den finan-

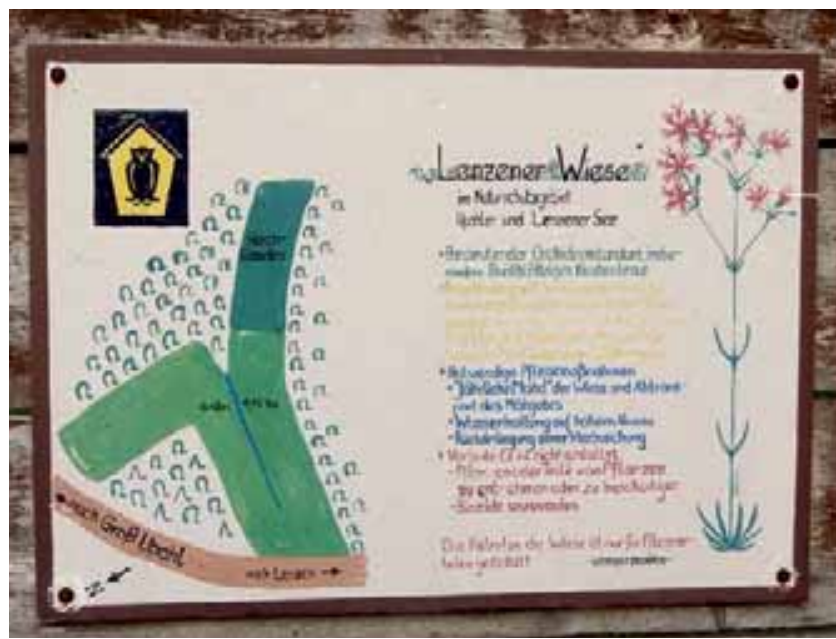

Abb. 93: Von einer Studentin 1994 gemalte Tafel. Sie wollte alles unbedingt bunt wie die Lenzener Wiese gestalten. Die Tafel war auch 2015 noch gut erhalten. Foto: F. Loose.

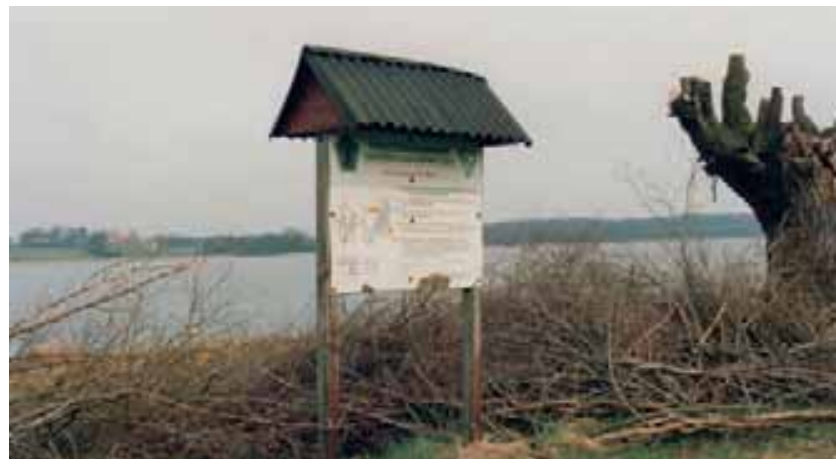

Abb. 94: Auch die Kopfweidenpflege am Upahler See organisierte A. Kretschmann. Durch die UNB wurde 1991 eine neue Info-Tafel erstellt. (noch mit beiden Naturschutzsymbolen) Foto: A. Martin.

ziellen Rückhalt für die Pflegearbeiten konnte anfangs die Untere Naturschutzbehörde, später das StAUN/StALUMM Rostock absichern.

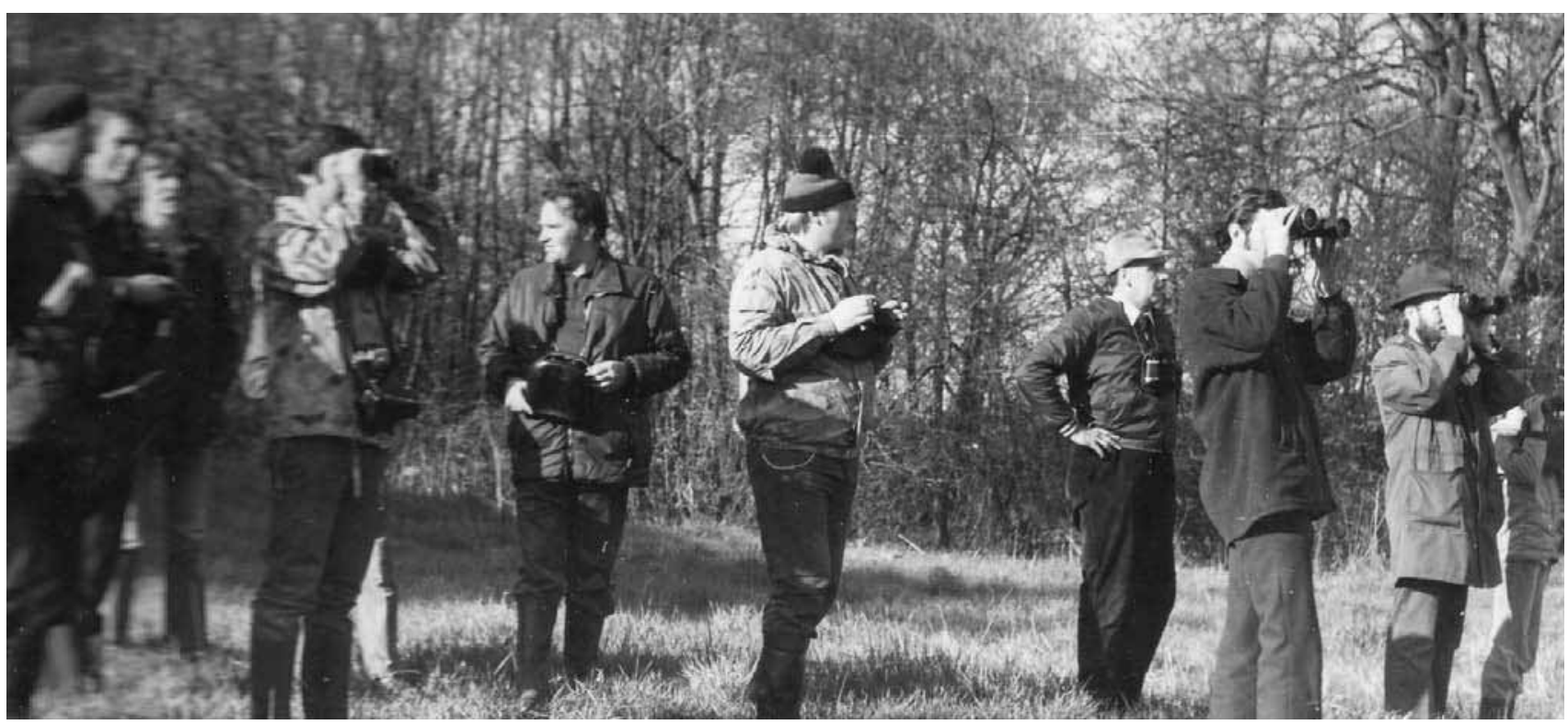

Abb. 95: FG-Exkursion am 9.5.1980 zum Upahler See (v.l.n.r.) - Georg Strache, Hans-Georg Müller, Heinz Mevius, foachim Loose, Kurt Pohlmann, Klaus Lingsminat, Wolfgang Neubauer, Karl-Heinz Koop, Wolfgang Köhler. Foto: A. Martin. 


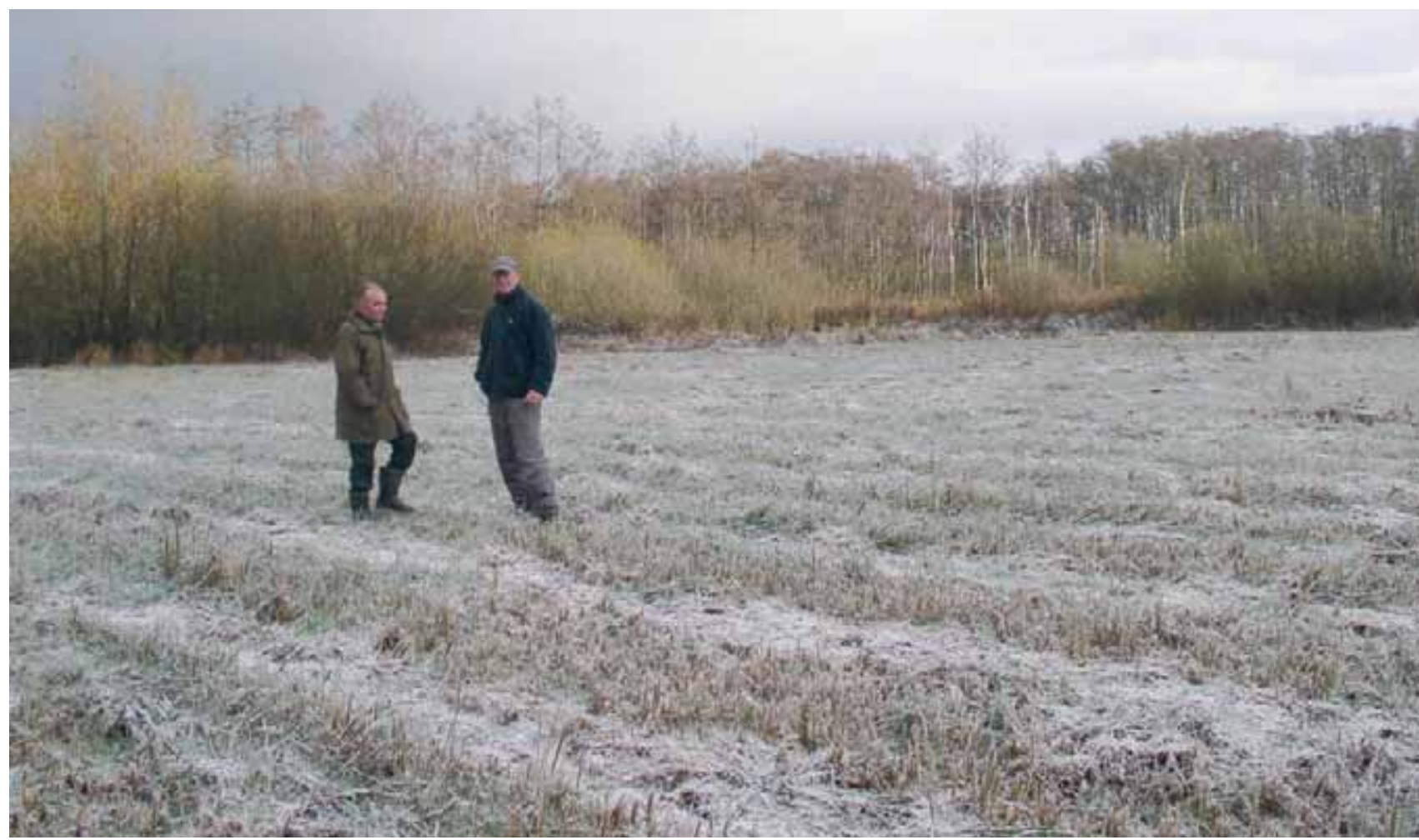

Abb. 96: Adolf Kretschmann am 31.12.2001 bei der Kontrolle des Pastorbruches, der 2001 erst sehr spät gemäht werden konnte. Foto: f. Loose.

1987 gab es vonseiten der im Umfeld des Upahler Sees wirtschaftenden LPG (P) Güstrow und Gerdshagen sowie LPG (T) Lohmen und Karcheez die Absicht, den Upahler See als Beregnungsspeicher zu nutzen. Der Auftrag für dieses Projekt war von der Oberflussmeisterei Schwerin (Ofm) ausgelöst worden. Am 04.12.1987 fand dazu eine Anlaufberatung mit Anwesenheit der Landwirtschaftsbetriebe, des planenden Meliorationsbetriebes, der Wasserwirtschaft und der Forst sowie des Rat des Kreises statt. Heinz Stegemann als Sekretär für Jagd und Naturschutz hatte sich auch Wolfgang Neubauer als KNB zur Seite geholt. Koll. Behrens von der Ofm erläuterte das Ziel des Projektes. Man hatte vor, den See auf den Hochwasserschwellenwert anzuheben, um in der niederschlagsarmen Jahreszeit das angestaute Wasser für die Beregnung von 80 ha Weidefläche der LPG (P) Tarnow nutzen zu können. Die Vertreter des Naturschutzes erklärten auf der Beratung bzw. schriftlich im Nachgang, dass durch den Anstau die Randbereiche des Upahler Sees bis in den Juni hinein beeinflusst und damit u. a. die Orchideenbestände z.B. auf der Lenzener Wiese gefährdet würden. Im übrigen war festzustellen, dass die Vorgaben der NSG-Verordnung bei dem Projekt vollkommen unbeachtet geblieben seien. Eine Seespiegelabsenkung durch die Beregnung würde in keinem Fall den natürlichen Wasserstandsschwankungen entsprechen. Im Ergebnis der Beratung sollte der Projektierungsauftrag auf Grund der Einwände dahingehend geändert werden, dass zunächst eine Studie erarbeitet wird. Dabei sollte ein Vergleich zwischen Ökonomie des Beregnungsprojektes und Ausfall von eingeschränkten Nutzbarkeiten von landwirtschaftlicher
Nutzfläche und Darstellung der negativen Auswirkungen auf das Schutzgebiet erstellt werden. Durch die politische Wende ist auch hier keine weitere Umsetzung erfolgt.

Interessant ist, dass heute unter anderen Voraussetzungen im Rahmen der Umsetzung der EU-Wasserrahmenrichtlinie (WRRL) und des Managementplanes für das FFHGebiet DE 2238-302 „Wald- und Gewässerlandschaft um Groß Upahl und Boitin“ eine Wasserstandsanhebung des Upahler Sees unter Öffnung der Ableitung (Flöthgraben) geplant ist. Eine Machbarkeitsstudie liegt bereits vor (BIOTA 2009). Die darin enthaltenen drei Varianten über die Wasserstandshöhe im Upahler See wurden jedoch noch nicht auf ihre FFH-Verträglichkeit abschließend geprüft. Die Botanik-AG wird ein wachsames Auge auf die Orchideenbestände haben.

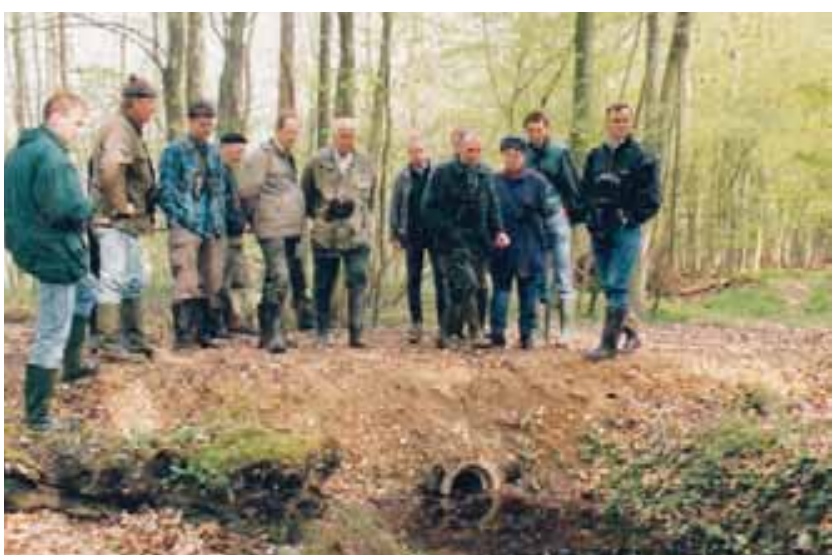

Abb. 97: Die Fachgruppe bei der „Abnahme“ der von A. Kretschmann errichteten Staubauwerke im NSG am 5.5.2001. Foto: F. Loose. 
Ein besonderes Anliegen von Adolf Kretschmann war auch die Sicherung der notwendigen Wasserstände in den Waldmooren und Bruchwäldern des NSG. Seine angelegten Staubauwerke zeigen noch heute ihre Wirkungen. Wenn er auch ständig klagte, dass einigen Flächen heute Wasser fehlt, liegen die Ursachen dafür weit außerhalb des NSG oder sind teilweise klimatisch bedingt.

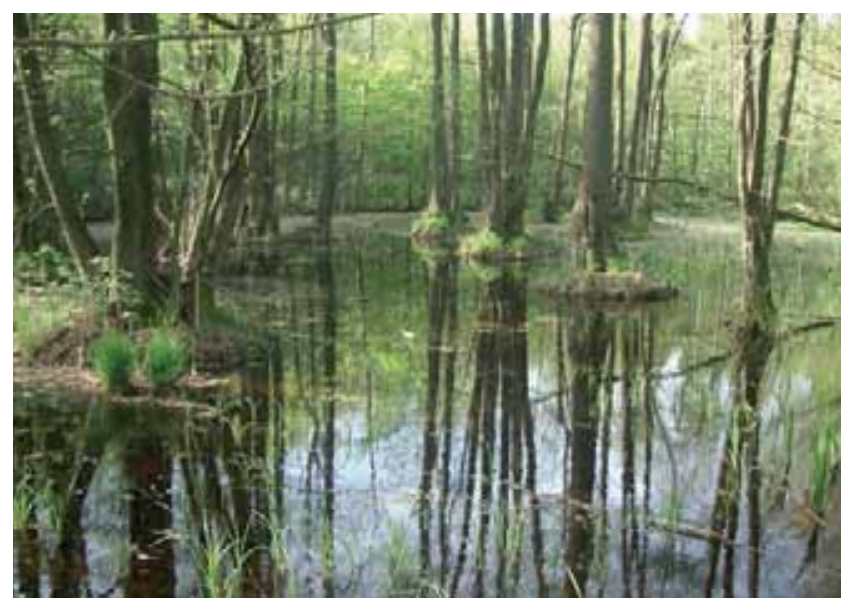

Abb. 98: Durch A. Kretschmann angestauter Bruchwald - hier am 5.5.2001. Foto: 7. Loose.

Zur NSG-Betreuung von A. Kretschmann gehörte auch die Auseinandersetzung mit den Nährstoffeinspülungen insbesondere in den Upahler See durch Abwässer aus der Gemeinde Groß Upahl und aus der Güllebewirtschaftung auf den seenahen Wiesen. Auch aus den angrenzenden Orten Klein Upahl und Lenzen liefen anfangs die häuslichen Abwässer völlig ungeklärt in beide Seen. Wenn A. Kretschmann hartnäckig an den Problemen dran blieb und auf Abstellung drängte, machte er sich selten Freunde.

Mit der konsequenten Umsetzung der EU-Wasserrahmenrichtlinie und von geplanten Maßnahmen gemäß FFHManagementplan ist zu erwarten, dass bald eine durchschlagende dauerhafte Lösung gefunden wird.

Durch den zielstrebigen und umsichtigen Einsatz von A. Kretschmann als Gebietsbetreuer gelang es, nach und nach wichtige Verbesserungen zu erreichen.

In der forstlichen Bewirtschaftung des NSG waren die Nutzungsauflagen der Forstwirtschaft auf Grund der guten Vorratsausstattung sehr hoch. Der Nutzungsdruck konnte durch das gute Zusammenwirken zwischen Revierförster A. Kretschmann und mir als zuständigen Oberförster reduziert und die Naturausstattung der Buchenwälder gestärkt werden.

Das Gebiet war stark von Kraftfahrzeugen frequentiert. Eine Sperrung des Weges zwischen Groß Upahl und Garden für den Fahrzeugverkehr führte zur spürbaren Beruhigung im Naturschutzgebiet. Das Seeadlerpaar hat seitdem in wechselnden Horsten mit dazu beigetragen, dass der Bestand in Mecklenburg weiter angestiegen ist.
2003 wurde im NSG auf dem Bohnrath auf Grund der außergewöhnlichen Naturausstattung eine Naturwaldzelle mit einer Größe von 44,8 ha ausgewiesen, die von der Abteilung Forstliches Versuchswesen in Schwerin betreut wird. Erste Auswertungen stehen bisher noch aus.

Leider ist es nicht gelungen, die kleine Kolonie von baumbrütenden Dohlen im Bohnrath zu erhalten. Der Versuch, durch das Anbringen von Dohlen-Nistkästen die wenigen Brutpaare zu stabilisieren, führte nicht zum Erfolg.

Die vorbildliche und intensive Betreuung des NSG durch A. Kretschmann endete im Jahr 2007 aus Alters- und Krankheitsgründen. Die Pflege der Lenzener Orchideenwiese lief durch Organisation über das StALUMM Rostock weiter. Die Erfassungen der Zahl von blühenden Orchideen erfolgte auch weiterhin durch unsere Botanik-AG.

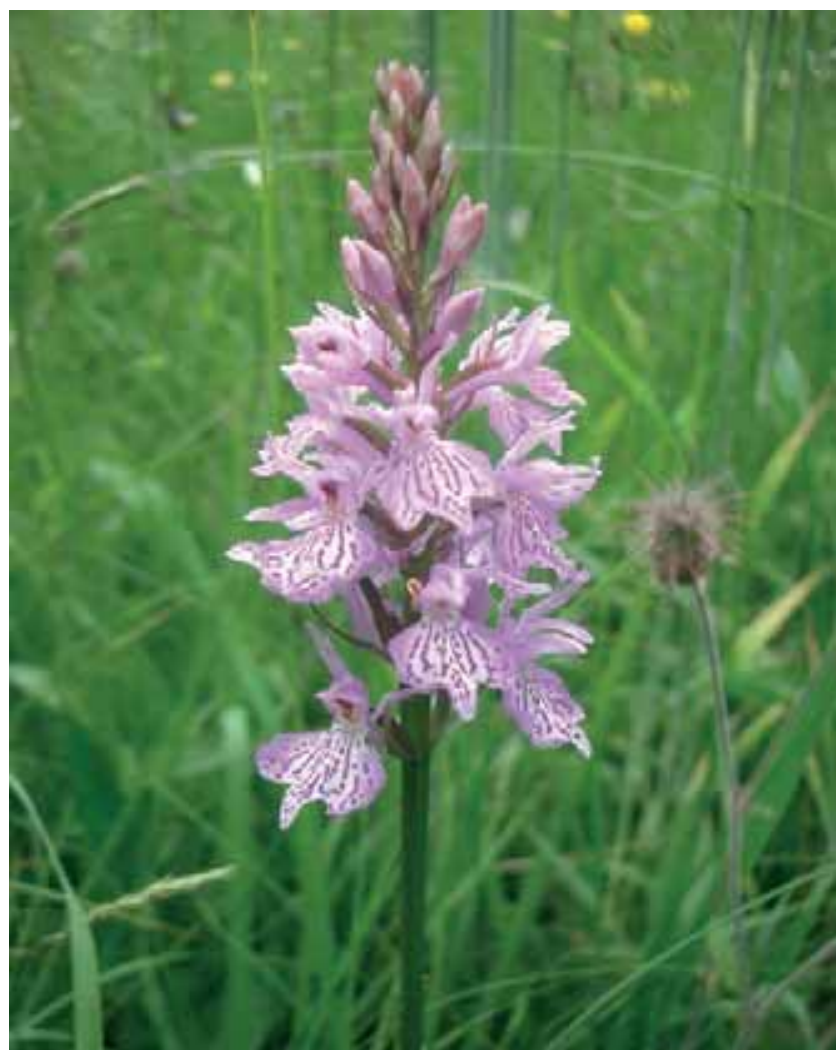

Abb. 99: Das Fuchssche Knabenkraut auf der Lenzener Wiese blüht später nach dem Breitblättrigem Knabenkraut. Foto: f. Loose.

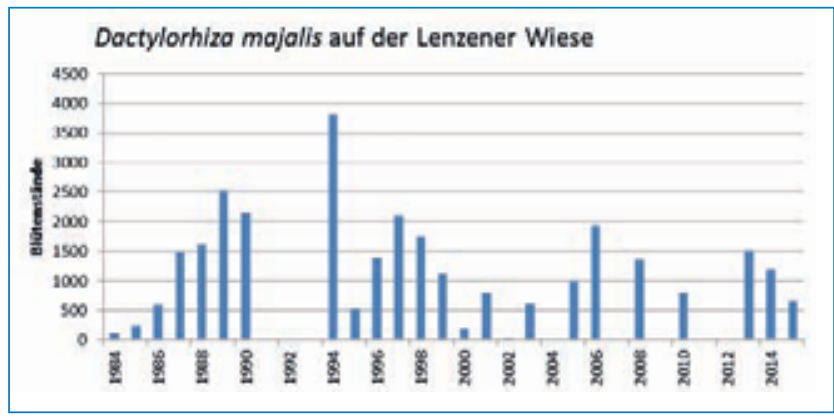

Diagramm 6: Der Bestand der Breitblättrigen Knabenkräuter auf der Lenzener Wiese wurde fast jährlich durch die Botanik-AG erfasst. Ursachen für die Schwankungen sind unbekannt. 


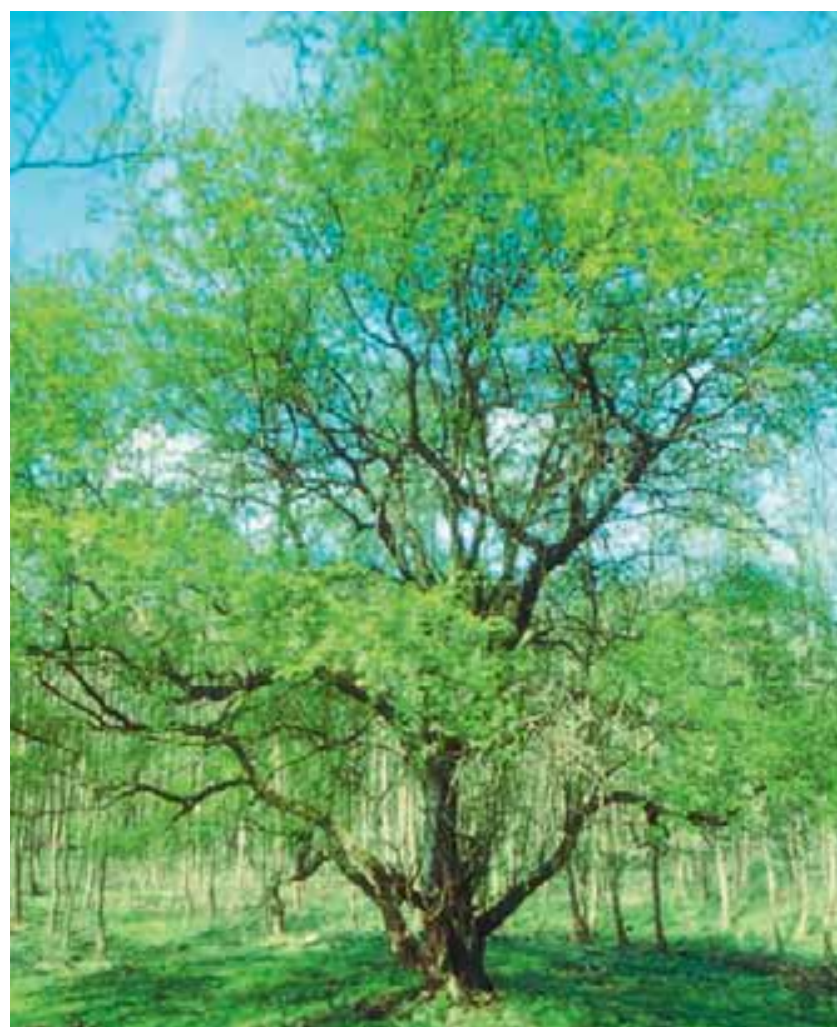

In seinem letzten Jahresbericht von 2007 beklagt Adolf Kretschmann, wie auch schon in Jahren zuvor, dass Störungen verschiedenster Art und Intensität, sowohl als Begleiterscheinung zugelassener Nutzungen (Landwirtschaft, Jagd) als auch durch häufigen unbefugten Aufenthalt von Personen abseits der Wege zugenommen und inzwischen zu fast ständiger Unruhe im NSG geführt haben. Ebenso führte er regelmäßig das Problem der Zunahme von Prädatoren als Ursache für die verringerten Bruterfolge bei Gänse- und Entenvögeln sowie Kranichen an.

Adolf Kretschmann verstarb im September 2015. Es ist zu hoffen, dass es der Naturschutzbehörde möglichst bald gelingt, einen entsprechenden Nachfolger für die Betreuung des NSG einzusetzen, damit die bisherige Arbeit kontinuierlich weitergeführt werden kann. Wir würden es sehr begrüßen, wenn dieser dann auch den Weg in unsere FG finden würde.

Abb. 100: Innerhalb des NSG von Wald umgeben steht ein alter Wildapfelbaum, der 1937 als Naturdenkmal ausgewiesen und von Adolf Kretschmann besonders gepflegt worden ist. (Dia-Kopie) Foto: A. Kretschmann.

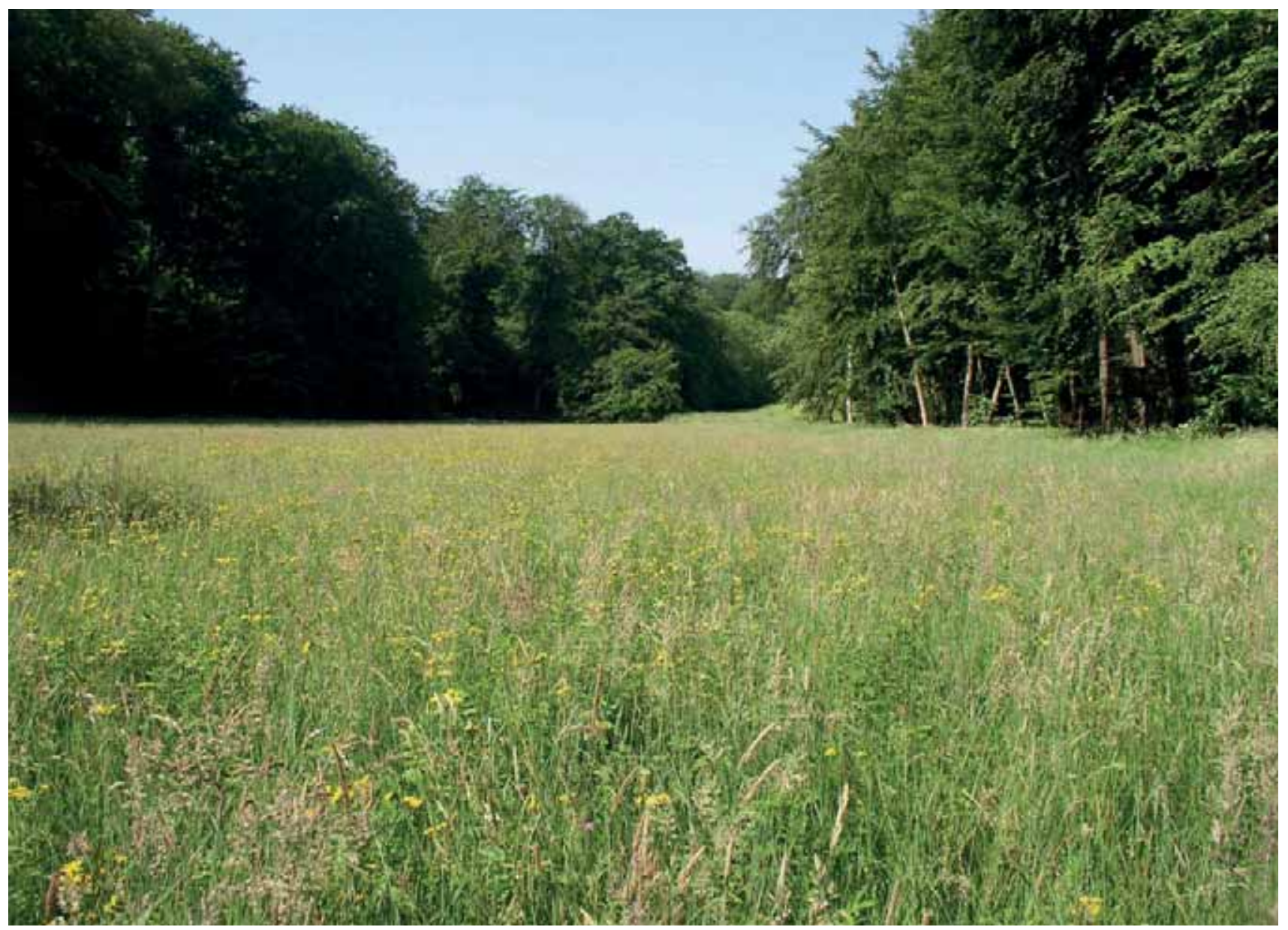

Abb. 101: Blick in die Lenzener Wiese - der Sumpf-Pippau färbt die Wiese im funi gelb. Foto: A. Martin. 


\subsubsection{NSG Zehlendorfer Moor}

Angela Martin (NSG-Betreuerin bis 1996)

\section{Schutzgebietsdaten}

Unterschutzstellung am $\quad$ 1.6.1972

Behandlungsrichtlinie vom - keine -

Größe ca. 90 ha in zwei Teilflächen

- Nordteil 50,6 ha

- Südteil 37,5 ha

davon Röhrichte, Riede 78,9 ha

Wald, Gebüsch $\quad 9,2$ ha (nur im Nordteil)

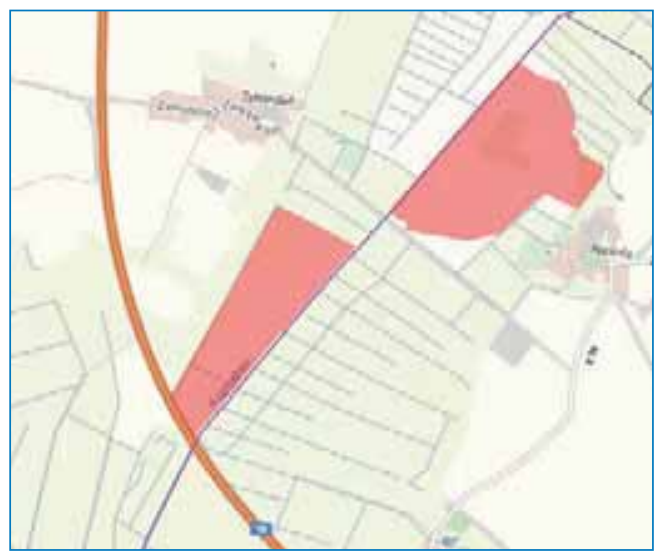

Karte 6

Quelle: Kartenportal LUNG

Bedeutung/Schutzziel

Einer der nach tiefgreifenden Entwässerungen letzten Teile eines langgestreckten Talmoores in der Augraben-RecknitzNiederung mit der Zielstellung Revitalisierung des Durchströmungsmoores

- Das NSG ist in kein FFH-/SPA-Gebiet integriert.

Nachdem ich als Studentin das nähere Umfeld von Güstrow unter Bewunderung des Naturreichtums kennengelernt hatte, begann ich, die etwas weiter entfernten NSG aufzusuchen, über die ich im NSG-Buch für die drei Nordbezirke gelesen hatte.

1977 stand ich erstmalig auf dem Zehlendorfer Damm und schaute von dort aus in das Gebiet. Selbstverständlich habe ich diesen Weg nicht verlassen, so wie es das Gesetz vorgab! Die Angabe zum Vorkommen der Wiesenweihe hatte mich zum Gebiet gelockt. Tatsächlich sah ich nun auch ein Männchen dieser Art über dem Gebiet gaukeln. Das Glück und die Seltenheit dieser Beobachtung konnte ich erst viele Jahre später so richtig ermessen. In der Fachgruppe und aus älteren Jahresberichten erfuhr ich, dass sich insbesondere Reinhard Becker um die Ausweisung des Augrabengebietes als NSG wegen der hier vorkommenden seltenen Vogelarten bemüht hatte. Ihm schwebte jedoch ein wesentlich größeres Gebiet als das ausgewiesene NSG vor.

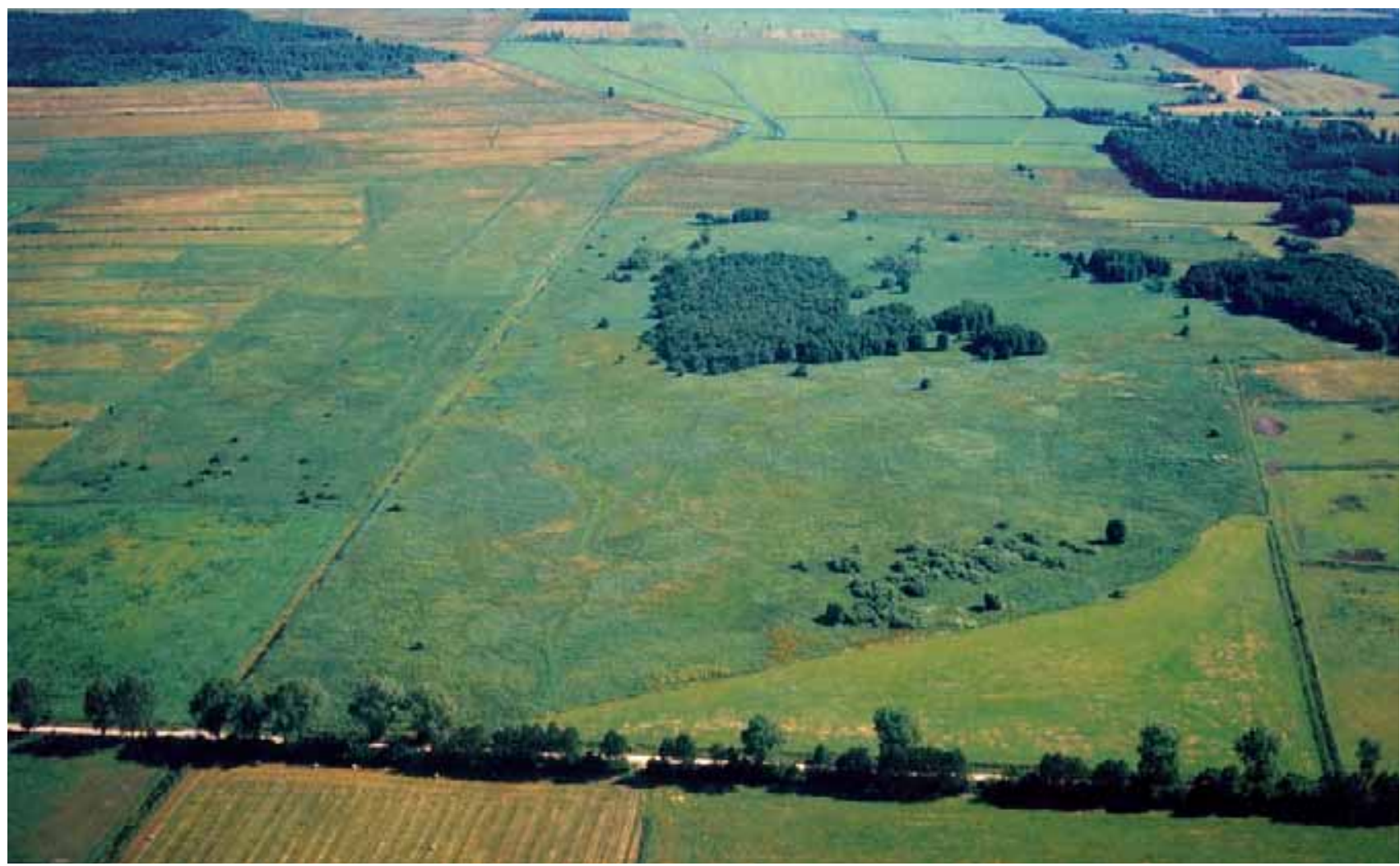

Abb. 102: Blick auf den Nordteil des NSG mit den Wald- und Gebüschflächen, im Vordergrund verläuft der Zehlendorfer Damm - Luftbild 1999. Foto: Ch. Berg. 


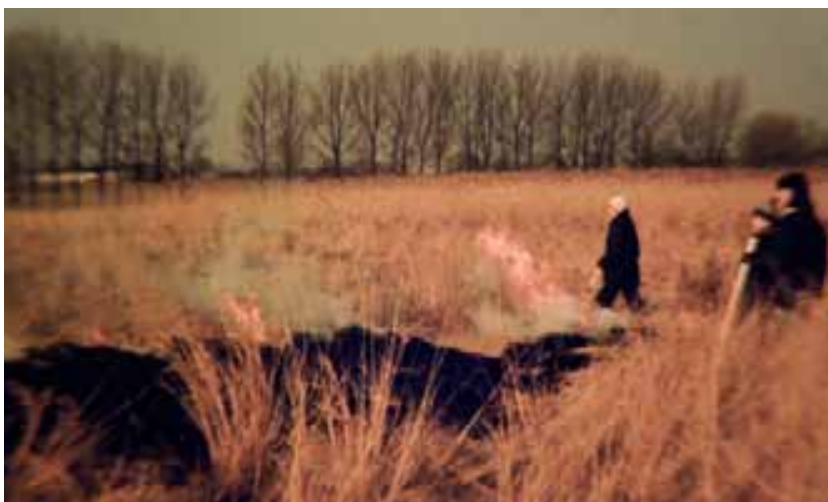

Abb. 103: Beim Brennversuch 1982 blieb das Feuer stecken. Foto: A. Martin.

1979 oder 1980 startete die Jugendgruppe um Kurt Pohlmann eine Exkursion zu diesem NSG. Er war selbst erstaunt, wie grün das Moor jetzt aussah! Er hatte es nur einige Jahre nicht gesehen - die Melioration hatte ganze Arbeit geleistet, auf der Fläche wuchsen viele nicht in ein Moor gehörende Pflanzen.

In den Jahren 1980/81 begann mein Ringen um dieses Gebiet, ein Kampf gegen Windmühlenflügel. Eine Tatsache war für diesen nerven- und kräftezehrenden Kampf ein großartiges Leitmotiv:

Das Zehlendorfer Moor ist das weit und breit einzige von der Intensivierung ausgenommene Stück in der AugrabenRecknitz-Niederung.

(Die Melioration wirkte aber auch in diesen Miniabschnitt hinein, und das Moor „blutete“ aus.)

Zunächst schrieb ich an Herr Dr. Succow. Auf seine pflanzensoziologischen Untersuchungen in diesem Teil des Augraben-Recknitz-Flusstales basierte teilweise die Unterschutzstellung. Daraufhin bekam ich Antwort von Herrn Dr. Lebrecht Jeschke, der sofort einen Termin mit mir ausmachte. Die gemeinsame Begehung erfolgte am 12.3.1981. Das Fazit des Experten lautete: Hauptprobleme für dieses Moor waren (und sind bis heute) Wassermangel und Biomasseüberschuss.

Mit folgenden zwei Aktionen wollten wir den Wassermangel etwas eindämmen:

FG-Mitglied und Revierförster Adolf Kretschmann war es gelungen, im Südteil des Gebietes mit einem LKT, das war ein Forstschlepper, die Seitengräben zu schließen. Diese führten nunmehr kein Wasser mehr zum Hauptvorfluter Augraben ab.

Im darauffolgenden Jahr 1982 verschlossen einige Mitglieder der FG in mühsamer Handarbeit die Seitengräben im Nordteil des NSG. Bereits während der Arbeitsstunden sammelte sich recht viel Wasser hinter den Dämmen an. Diese Erdabdichtungen weichten jedoch schnell wieder auf, es gab Sickerstellen und bald auch schon „Damm-

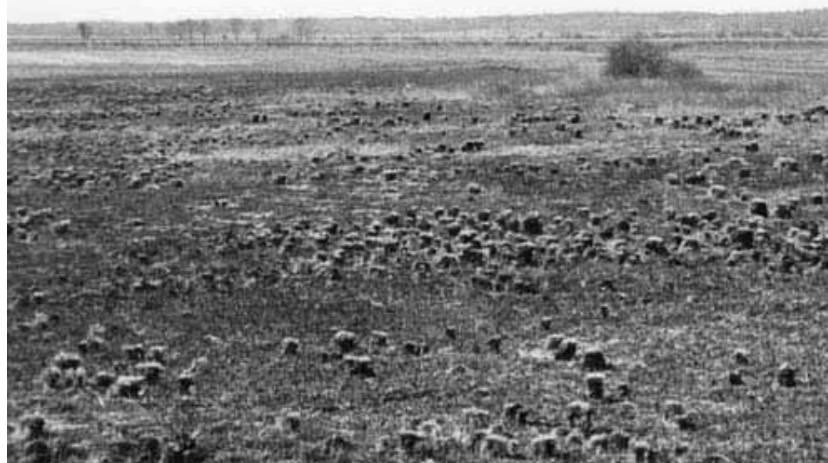

Abb. 104: Die erfolgreich abgebrannte Fläche 1984. Foto: A. Martin.

brüche“. Über diesen Einsatz wird in der TV-Dokumentation des DFF von 1982 „Leute vom Kulturbund“ berichtet. (vgl. Kapitel 5.3)

Dem zweiten großen Problem, der alles erstickenden gewaltigen Biomasseschicht, konnte in diesem durch RispenSeggen stark bultigen Gelände mit der in der damaligen LPG vorhandenen Technik nicht mit einer Mahd begegnet werden. Von dem Meliorationsbetrieb erhielt ich einen Hinweis auf geeignete Mähtechnik, aber einen genannten intakten Grabenhäcksler gab es nicht mehr.

Trotz vieler Gegenstimmen kam nur eine Brennaktion in Betracht. Ein Brennversuch im Februar 1982 erstickte im Raureif. Erst am 18.2.1984 gelang eine lange vorbereitete Aktion, bei der etwa 10 ha abgebrannt wurden.

Weil das Feuer wahrscheinlich zu flach über die Fläche gegangen war, blieb die dicke Biomasseauflage fast unverändert.

Meine Bemühungen um eine Nutzung gingen weiter. Der Leiter der Abt. Landwirtschaft, Hans-Joachim Volkmann, beim Rat des Kreises, dem auch der Naturschutz unterstellt war, äußerte sich zu meinen hartnäckigen Bemühungen um dieses Problem-NSG nur dahingehend, dass wir das NSG dann eben aufgeben müssten.

Während die Vogelwelt in den Jahren bereits auf „Allerwelts-Arten“ geschrumpft war, bot die Pflanzenwelt noch manche Überraschung. 1985 fand ich die Pracht-Nelke (Dianthus superbus) in einigen Trupps auf Rispen-SeggenBulten. Ein Bestand des seltenen Blauen Tarant (Swertia perennis) hielt sich trotz der erdrückenden Konkurrenz von Rauhhaar-Weidenröschen, Stechendem Hohlzahn, KlettenLabkraut u. a. mooruntypischen Arten.

Als Erhaltungsversuch legten Georg Strache und ich 1988 eine ca. 1,5 m x 2 m große Freifläche an, auf der wir Saatgut des sich in der Nähe befindlichen Tarant-Bestandes ausbrachten. Bis einschließlich 1990 erfassten wir jährlich im August/September die Blütenstängel. Die Zahl bewegte sich zwischen 268 und 91. Im Jahr 1991 war nichts mehr zu finden. 
Einige Suchaktionen mit mehreren Personen in den darauffolgenden Jahren blieben ohne Erfolg. Der Bestand dieses Enzian-Verwandten war plötzlich zusammengebrochen. Damit war nicht nur einer der wenigen Fundorte dieser Pflanzenart verschwunden, sondern der nordwestliche Vorposten, so dass sich das Verbreitungsgebiet wieder verkleinert hatte.

Bei einem Abendgespräch während einer MongoleiUrlaubsreise 1985 kam ich mit dem Rostocker Joachim Matthes auch über das Zehlendorfer Moor ins Gespräch. Da er selbst Meliorationsfachmann ist, wollte er uns bei diesem „meliorativen Problemfall“ unterstützen. Nach einer gemeinsamen Begehung Anfang 1986 fasste Joachim Matthes auf vier Seiten seine „Gedanken zum Zustand des NSG Zehlendorfer Moor“ zusammen. Wir erhielten wieder jede Menge Anregungen.

Im Juli 1986 entstand aus einer gemeinsamen Begehung der Moorflächen mit Dr. Lebrecht Jeschke und Joachim Matthes ein Protokoll, in dem durch das ILN die Erarbeitung einer Konzeption zur weiteren Entwicklung versprochen wurde. Diese sollte mit den aktuellen Feststellungen zum Gebietszustand und Forderungen dann dem Rat des Bezirkes Schwerin, Abt. Naturschutz unterbreitet werden. Hier tat sich dann jedoch nichts.

Zwischen 1983 und 1989 besprach ich viele Male in der Abteilung Melioration beim Rat des Kreises, vor allem mit Gerhard Witt, mögliche meliorative Maßnahmen im Sinne unseres Sorgenkindes „Zehlendorfer Moor.“ Als Grundproblem stellte sich stets dar, dass unser Gebiet zweigeteilt ist. Die jeweils dem NSG gegenüberliegenden Flächen wurden intensiv landwirtschaftlich genutzt, so dass am Augraben nördlich des Autobahndurchflusses kein Anstau erfolgen konnte, ohne die Nutzflächen zu beeinträchtigen. Um dieses Grundproblem aus der Welt zu schaffen, schwebte Wolfgang Köhler vor, die dem NSG jenseits des Augrabens liegenden Flächen, die sowieso anscheinend brach lagen, zum NSG dazu zu bekommen. Wenn W. Köhler bei mir im StFB auftauchte, war oft das Moor der Mittelpunkt des Gesprächs. Er hatte immer neue Ideen, um den Zustand des Gebietes zu verbessern.

Zu erwähnen ist in diesem Zusammenhang, dass es sich ja nie um private Parzellen handelte, sondern es stets Flächen eines landwirtschaftlichen (oder forstwirtschaftlichen) Betriebes waren und man damals damit ganz anders als heute mit privaten Flächen umgehen konnte (vgl. auch Ausweisung von FND - Pkt. 8.2). Die Flächen jenseits des Augrabens gegenüber dem Nordteil des NSG waren Eigentum der LPG (P) Kritzkow. In zahlreichen Gesprächen und auch einigen Begehungen mit den Landwirten war im Frühjahr 1989 die Sachlage soweit gediehen, dass das NSG hier nach Westen hätte erweitert werden können. Damit wäre eine Anstauschwelle im Augraben nördlich neben dem Zehlendorfer Damm möglich gewesen, die höhere Wasserstände

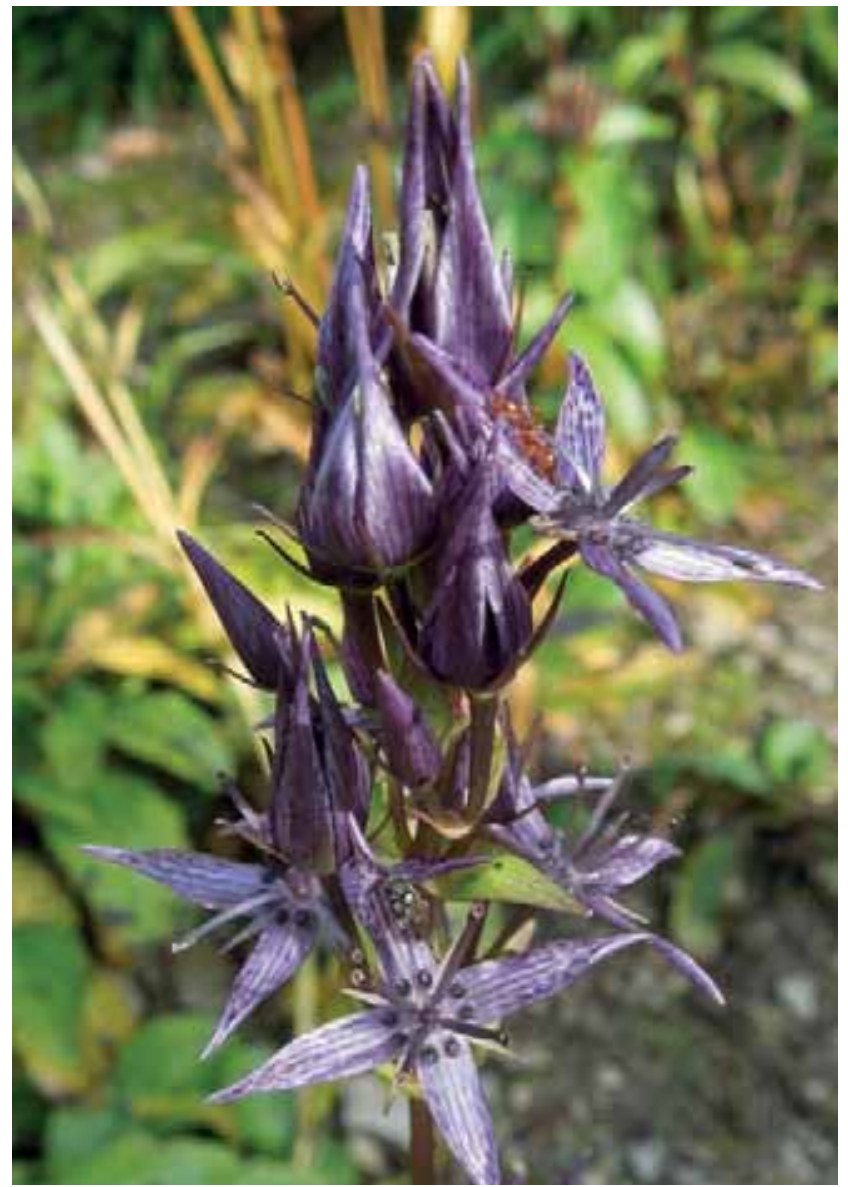

Abb. 105: Blütenstand des Blauen Tarant - Swertia perennis.

Foto: J. Loose (Foto aus dem NSG Quasliner Moor - 2015).

in den dann beiden Moorflächen erzeugen könnte. - Doch dann kam die Wende dazwischen, und es war wieder alles anders ...

Um die Biomasse zu reduzieren, verhandelte ich für die Flächen südlich des Zehlendorfer Damms mit der LPG (T) Kuhs. Hier sollte eine Beweidung mit Jungrindern erfolgen. Es gab viele Bedenken von Seiten der LPG: Darf man eine Rinderherde auf eine absolut nicht mit Top-Kraftfutter ausgestatteten Fläche treiben? Versinken die Tiere? Was fressen sie, und finden sie überhaupt genügend? - Dann endlich waren 1988 doch Jungrinder im Moor!! Und sie fraßen - wer hätte es gedacht! - Schilf! Toll, das Experiment war gelungen. Allerdings erfolgte das Abknabbern recht selektiv. Die Tiere hatten durch ihren Tritt keine vegetationsfreien Flächen geschaffen, so stark war die Biomasseauflage in dem Gebiet. Sie weideten zunächst nur $14 \mathrm{Ta}$ ge im Moor. Bei einer Kontrolle durch Mitarbeiter des ILN wurde eine längere Beweidung als unbedingt notwendig erachtet. Die ebenfalls eingeladene und anwesende Verantwortliche der LPG (T) hörte die Forderung aus berufenem Munde. Die Weidenutzung erfolgte dann auch noch etwas über die Wende hinaus. Die persönliche Verbindung war gegeben, weil die Mutter unseres FG-Mitgliedes Martin Lemke in der LPG arbeitete und ein Auge drauf hatte, dass das Experiment weiterlief. 


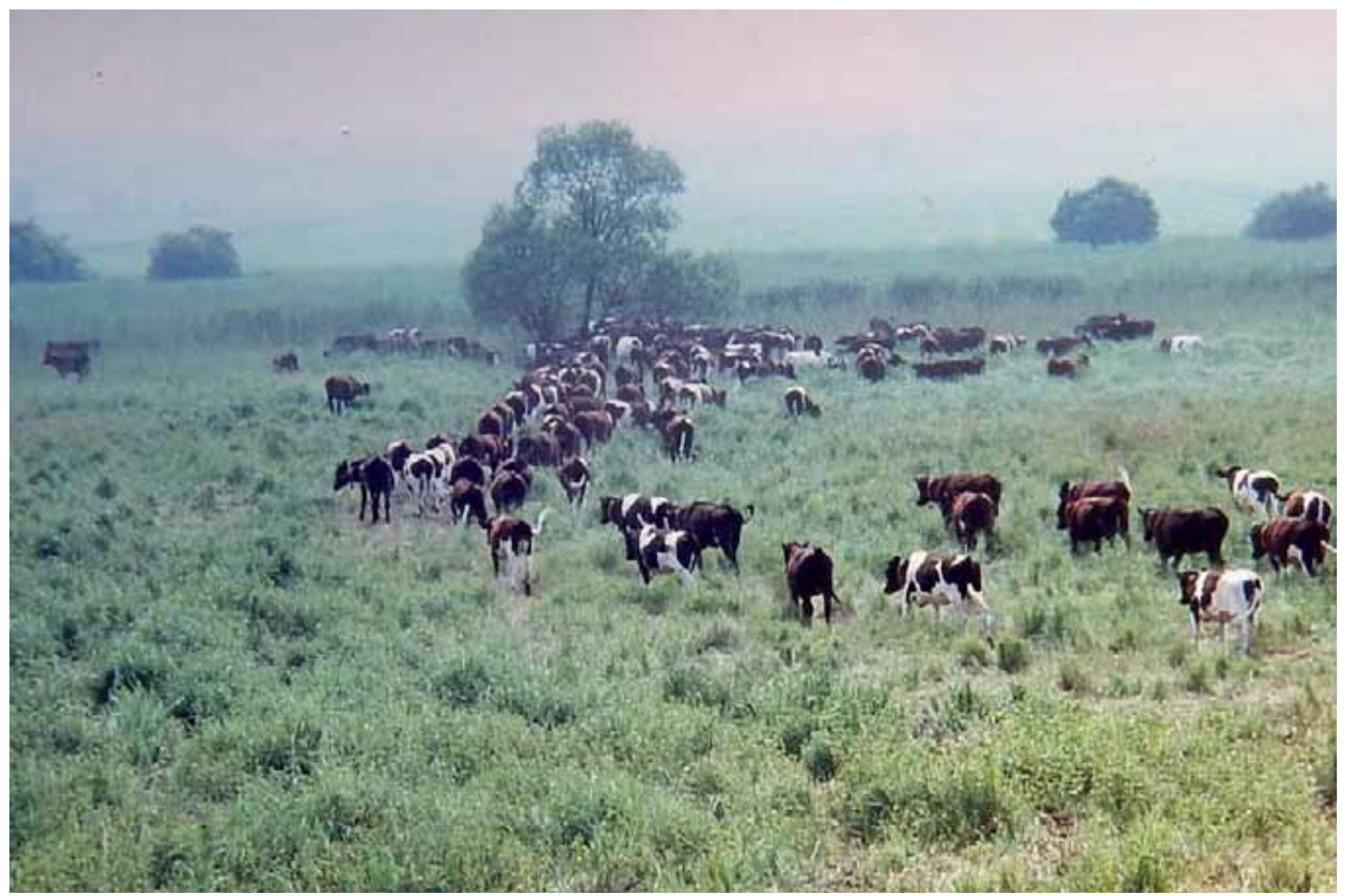

Abb. 106: Jungrinder auf dem Marsch in die Schilfflächen des südlichen NSG-Teils. Foto: A. Martin.

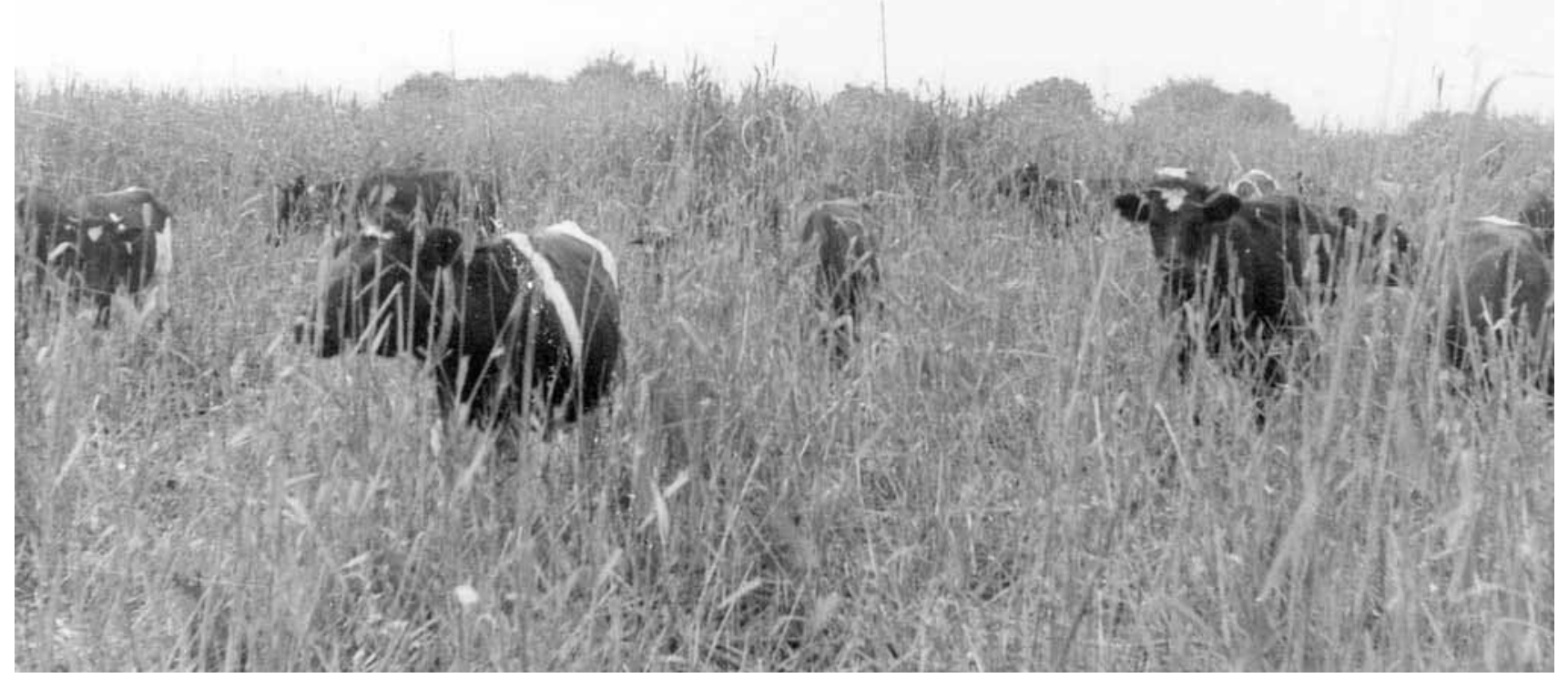

Abb. 107: Die Kühe fressen selektiv im hohen Schilf und schaffen es nicht, die Biomasse nachhaltig zurück zu drängen. Foto: A. Martin.

Anfang 1989 wurde eine durch das ILN Greifswald (Dr. Jeschke) erarbeitete Behandlungsrichtlinie für das NSG Zehlendorfer Moor an den Rat des Kreises Güstrow übergeben. Mit Datum vom 03.05.1989 wurde diese als Beschlussvorlage bestätigt. Neben der ständigen Erfassung von Pflanzenarten wurden als Aufgaben und Behandlungsgrundsätze hiermit die extensive Beweidung der Flächen im Süden und auch im Norden vorgegeben.
Nach der Wende kam das von der EU geförderte Programm der „Naturschutzgerechten Grünlandbewirtschaftung“ auf die Tagesordnung. Da Fördermittel gezahlt wurden, die die Einschränkungen bei der Bewirtschaftung ausgleichen sollten, nahmen einige hier jetzt wirtschafteten Landwirte an dem Programm teil. Auch dem NSG angrenzende Flächen unterlagen diesem Extensivierungsprogramm. 
Durch das STAUN Rostock konnten 1992 und 1993 auch Finanzmittel zum Einsatz einer Mähraupe bereit gestellt werden. Südlich des Zehlendorfer Damms liegende Teilflächen des NSG wurden gemäht. Mit dieser Spezialtechnik konnten auch Bulte von Rispen-Seggen gemäht werden. So sah man auch einmal die Moorfläche in ihrer Ebenheit.
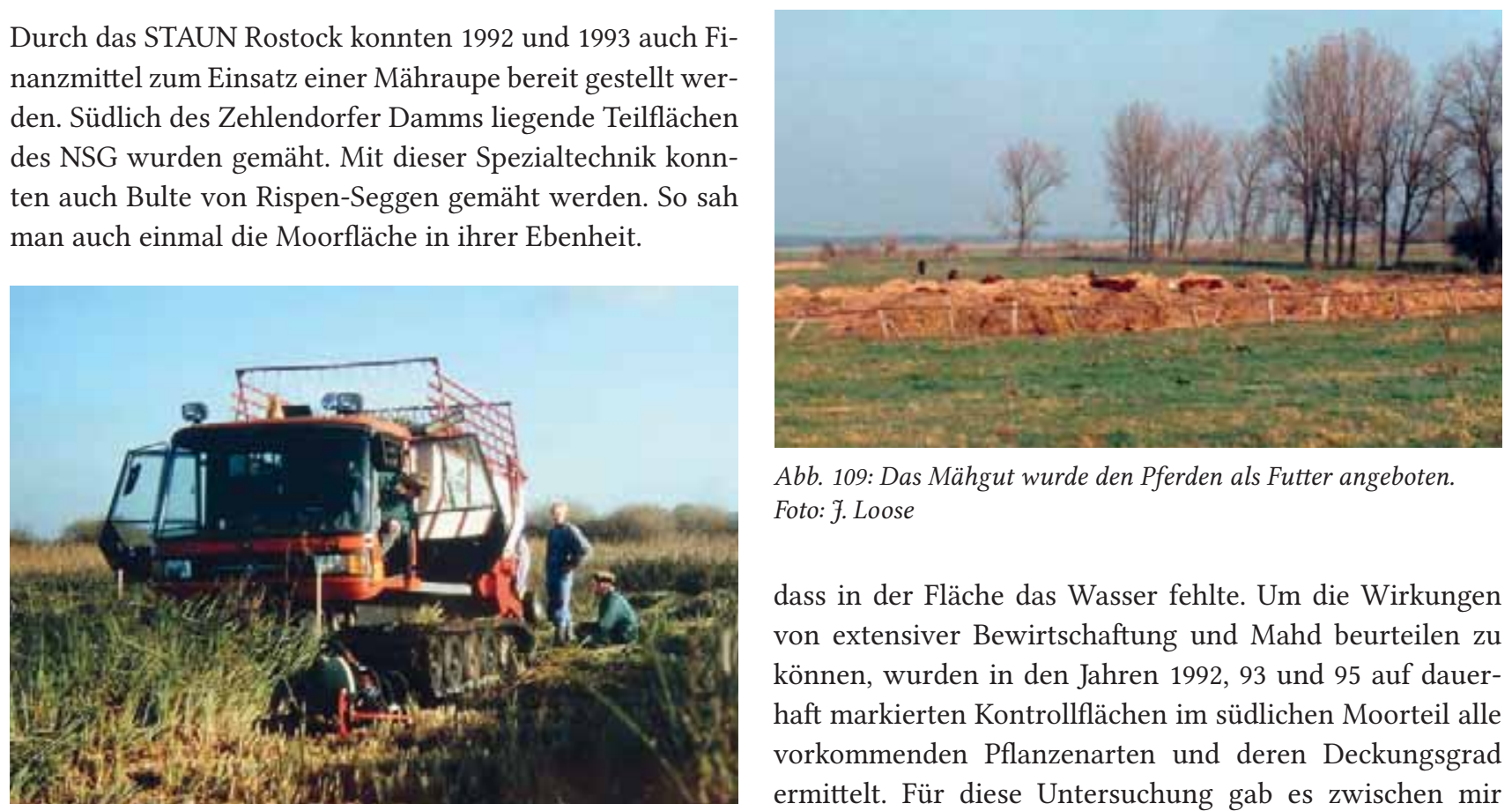

Abb. 109: Das Mähgut wurde den Pferden als Futter angeboten. Foto: 7. Loose

dass in der Fläche das Wasser fehlte. Um die Wirkungen von extensiver Bewirtschaftung und Mahd beurteilen $\mathrm{zu}$ können, wurden in den Jahren 1992, 93 und 95 auf dauerhaft markierten Kontrollflächen im südlichen Moorteil alle vorkommenden Pflanzenarten und deren Deckungsgrad ermittelt. Für diese Untersuchung gab es zwischen mir Abb. 108: Die Mähraupe im Südteil des NSG im Einsatz. Foto: f. Loose.

Für eine nachhaltige Moor-Pflanzenentwicklung hätte diese Aktion regelmäßig wiederholt werden müssen. Bei den Begehungen des Gebietes fiel jedoch immer wieder auf, als Leiterin der Botanik-AG und dem LAUN (dem heutigen LUNG) jeweils einen jährlichen Werkvertrag. Obwohl für eine belastbare Analyse Erfassungen über eine deutlich längere Zeit notwendig gewesen wären, gab es ab 1996 keine Werkverträge mehr. Unsere Erfassungslisten verschwanden in Schubladen!

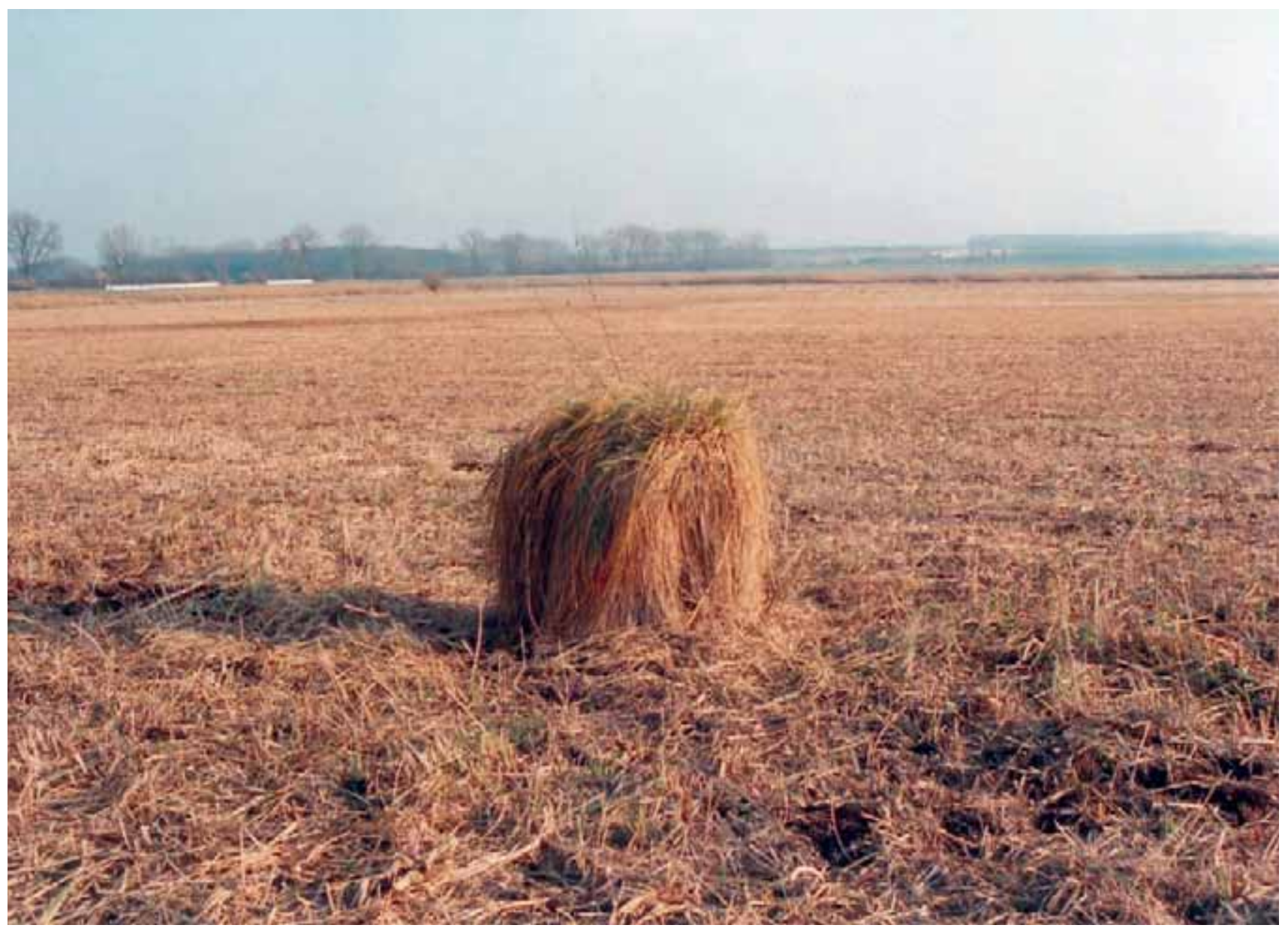

Abb. 110: Bei der Mahd der südlichen NSG-Fläche hat die Mähraupe auch die Bulte der Rispen-Segge entfernt. Foto: J. Loose. 
Nach der Wende kam es zu einem Bruch in den ehrenamtlichen NSG-Betreuungen. Durch die UNB wurden zunächst dem Umweltministerium eine Liste mit den tätigen Betreuern übergeben. Diese erhielten anschließend von dort offizielle Betreuungsverträge für ihre NSG. Für die Betreuungsaufgaben gab es sogar eine pauschale Aufwandsentschädigung. Die Zuständigkeit für fachliche Arbeiten in den NSG lag jedoch bei den Staatlichen Ämtern für Umwelt und Natur, zunächst für unser Gebiet beim StAUN Teterow, später beim StAUN Rostock.

Die Mitarbeiter aus dem StAUN mussten sich mit den NSG vertraut machen und suchten mitunter die Naturschutzgebiete ohne Kontaktaufnahme zu den Betreuern auf. Das irritierte uns Ehrenamtliche erheblich, die wir doch oft volles Engagement gezeigt hatten und nun plötzlich nicht mehr gefragt waren. So gingen auch wichtige Entscheidungen des StAUN über „mein“ NSG völlig an mir vorbei. Frustriert gab ich Ende 1996 die ehrenamtliche Betreuung des NSG auf.

Die Fachgruppe, selbst die UNB war nicht beteiligt worden, als im Rahmen eines Bodenordnungsverfahrens der erste Schritt der Investitionsmaßnahme „Renaturierung Zehlendorfer Moor" geplant und umgesetzt wurde. Mit Baubeginn im November 2004 und Fertigstellung im August 2005 wurde die unsererseits lange diskutierte Sohlschwelle im Augraben nördlich der Autobahn A 19 als Fischtreppe errichtet.

Planungsträger war der Wasser- und Bodenverband „Nebel“, die Projektierung hatte das Ingenieurbüro KULTA aus Güstrow übernommen.

Ergänzend zur Sohlschwelle im Augraben wurde versucht, die jeweils dem Augraben angrenzenden Flächen außerhalb des NSG nach Nutzungsaufgabe zu vernässen. Als Entgegenkommen an die Landwirte wurden Fanggräben errichtet, die eine weitere Bewirtschaftung der Wiesenflächen ermöglichen sollten.

Dr. Uwe Lenschow (LUNG) regte an, die Wirkung der Wasserzuführung anhand soziologischer Aufnahmen zu überprüfen. Am 31.07.2007 richteten wir als Botanik-AG gemeinsam mit ihm im Südteil des NSG im vermuteten Wirkungsbereich der Fischtreppe zwei Kontrollflächen mit deutlicher Markierung ein (Abb. 111).

Dr. Christian Berg vom StAUN Rostock bemühte sich parallel, das ehrenamtliche Betreuersystem aus DDR-Zeiten wiederzubeleben. Ende 2007 unterzeichnete ich einen über drei Jahre und Ende 2010 einen über zwei Jahre laufenden „Betreuungsvertrag“.

Die Einrichtung der Kontrollflächen und die Pflanzenkartierung war im ersten Jahr mit viel Aufwand begonnen worden. Die Kontrolluntersuchung ein Jahr später am 29.07.2008 erfolgte mit weniger Elan; im darauffolgenden

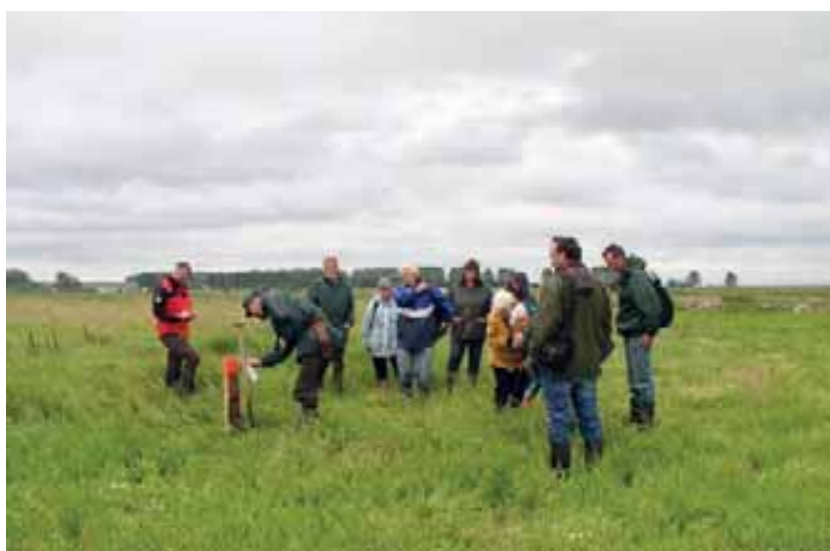

Abb. 111: Die Mitglieder der Botanik-AG bei der Einrichtung einer Kontrollfläche südöstlichen der Fischtreppe im erwarteten Vernässungsbereich. Foto: A. Martin

Jahr unterließen wir weitere Untersuchungen. Die floristische Armut enttäuschte sehr - es gab keinerlei Sensationen, wir fanden nur Ubiquisten. Die Anstaumaßnahme hatte nicht die erhoffte Wirkung gezeigt. Es ist immer noch viel zu wenig Wasser im Gebiet. Bei einer Kontrolle des Gebietes im November 2015 fanden wir auf der ehemaligen Kontrollfläche nur noch ein relativ trockenes eintöniges Sumpf-Seggenried vor.

Aus heutiger Sicht haben wir den Eindruck, dass sich niemand mehr für das NSG richtig einsetzt und zuständig fühlt. Es ist für uns unverständlich, dass aus dem südlichen Moorbereich über das Grabensystem noch immer Wasser abgeführt wird.

Obwohl für das Gebiet erhebliche finanzielle Mittel eingesetzt wurden, erscheint die gesamte Bewirtschaftung der an das NSG angrenzenden Flächen nicht als der Moorerhaltung und -entwicklung dienend. Da wir als Fachgruppe bei den Entwicklungsmaßnahmen für das Zehlendorfer Moor nicht mehr beteiligt wurden, können wir nur beurteilen, was wir vor Ort oder heute mit der Möglichkeit von Google-Earth in Luftbildern erkennen können (vgl. Abb. 112 bis 115).

Wir sehen es als erforderlich an, dass grundsätzlich über den Augraben ein höherer Wasserstand in die NSG- und die jeweils gegenüberliegenden Flächen wirken müsste. Dazu wäre der Wasserstand vor der Fischtreppe noch höher zu legen und auch nördlich des Zehlendorfer Damms eine Sohlaufhöhung im Augraben zu errichten.

Mit den heutigen Möglichkeiten dürfte es kaum Probleme bereiten, über Kompensationsleistungen für Eingriffe in Natur und Landschaft die bewirtschafteten Flächen mit lediglich einer Größe von 9,7 ha (A) bzw. 5,6 ha (B) - vgl. Abb. 118 - in eine extensive Bewirtschaftung mit deutlich erhöhten Wasserständen zu überführen.

Offenbar fehlt es hier an den „treibenden“ Kräften beim amtlichen Naturschutz. 

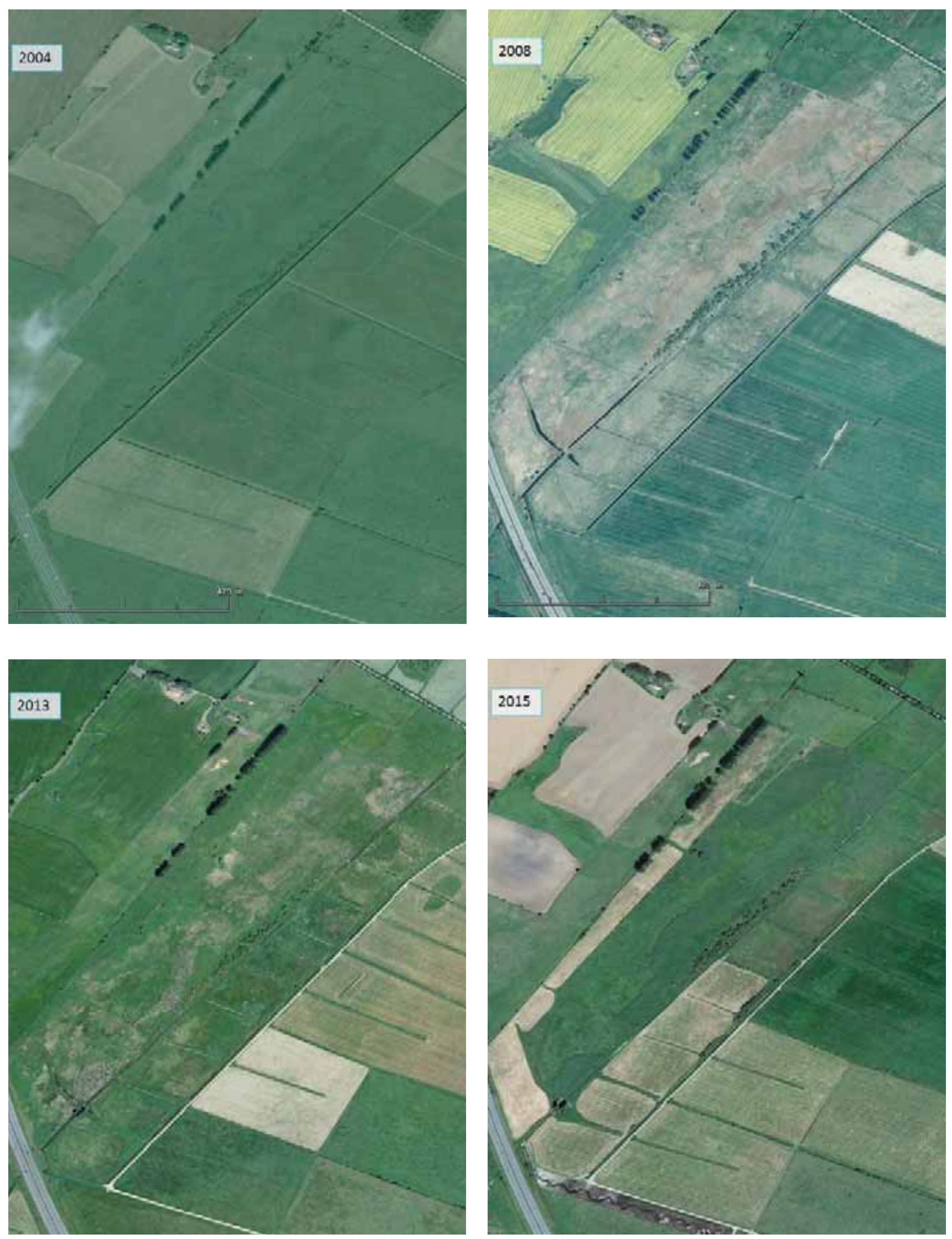

Abb. 112-115: In den Luftbildern sind die Zustände im NSG, die Entwicklung und Nutzung von Flächen in den fahren 2004, 2008, 2013 und 2015 erkennbar. Die 2015 im Rahmen der EU-WRRL realisierte Renaturierung des Spoitgendorfer Baches mit Einleitung in den Augraben nördlich der A19 hat keine Wirkung auf ein zusätzliches Wasserdargebot im Zehlendorfer Moor und diente allein der Herstellung eines durchgängigen Fließgewässers. (Foto-Quelle: Google Earth) 

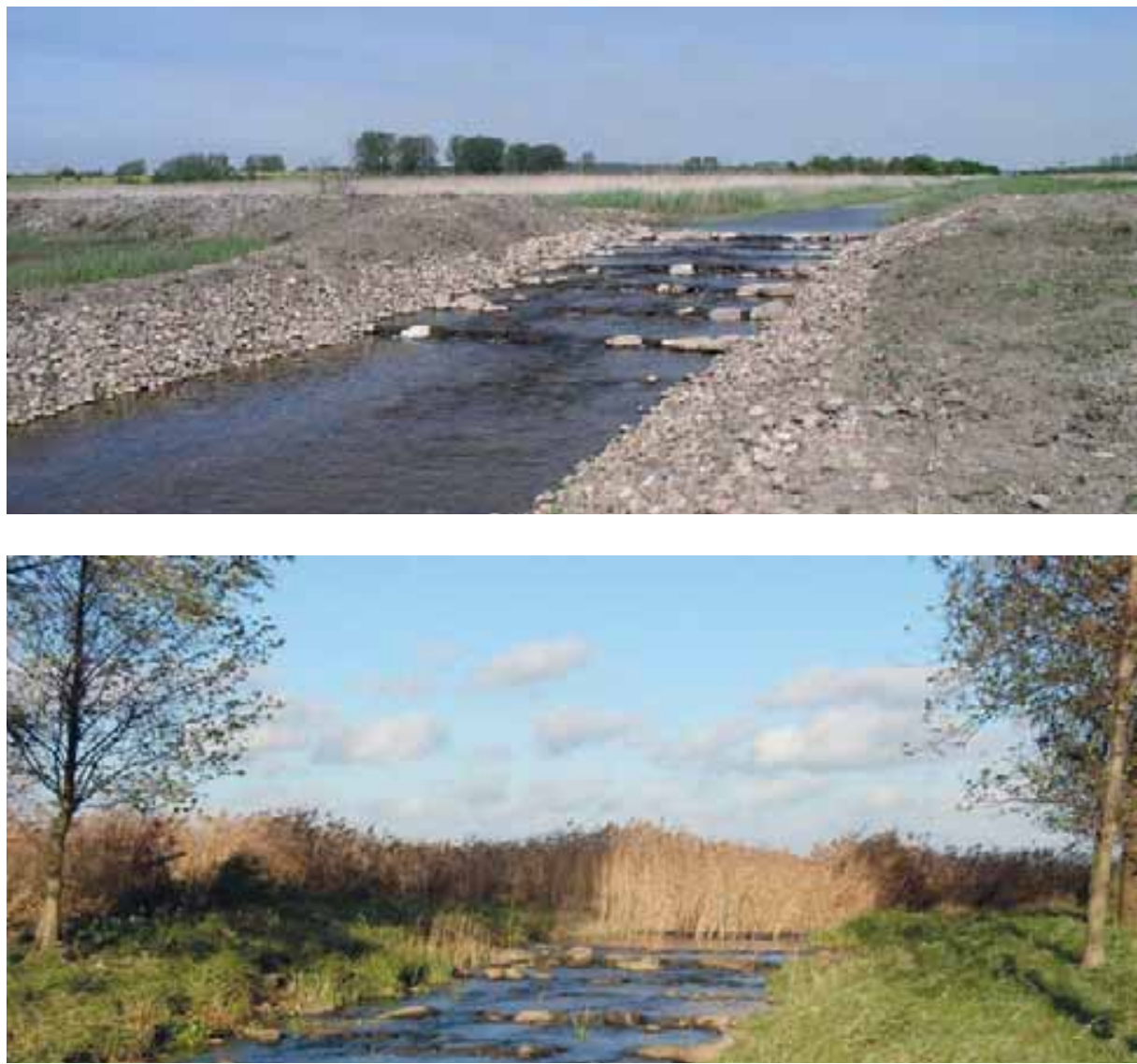

Abb. 116: Die Fischtreppe im Augraben nördlich der Autobahn A19 unmittelbar nach der Errichtung 2005. Foto: f. Loose.

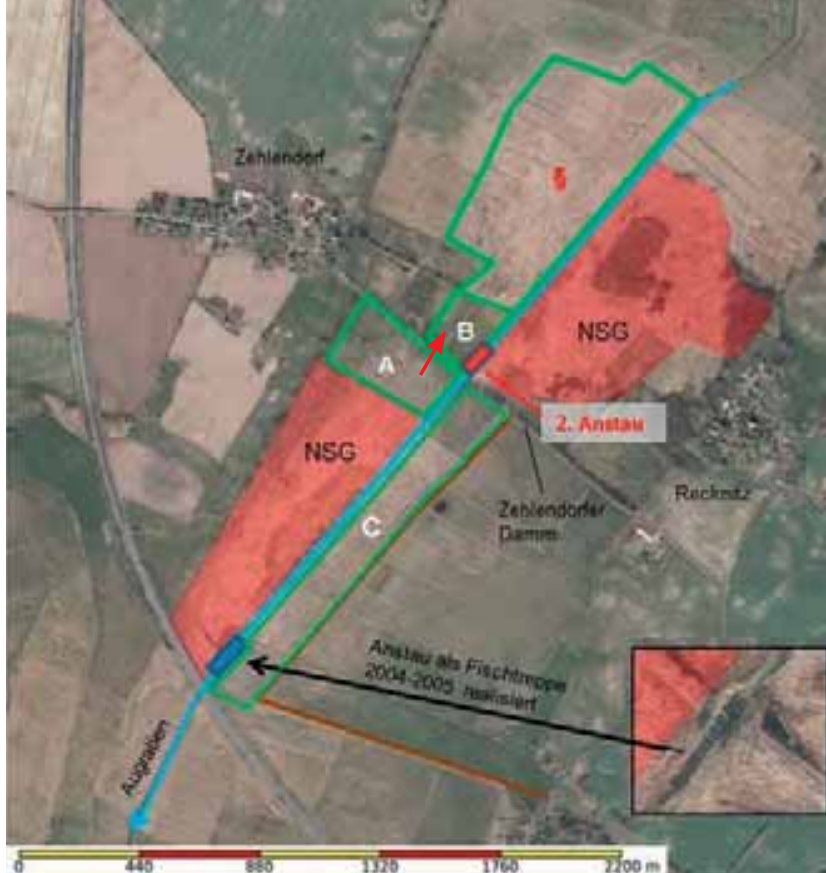

Abb. 118: Projekt zur Renaturierung des NSG Zehlendorfer Moor mit Vorschlägen der FG - braune Linie = bereits im Projekt 2005 neu errichteter Wirtschaftsweg. (Foto-Quelle: Google Earth)
Erläuterungen der durch die Fachgruppe empfohlenen Maßnahmen :

Fläche A ( 9,7 ha)

- Der Wasserabfluss aus dieser Fläche ist zu unterbinden. Die Fläche ist extensiv wie die hellgrün umrandete zu beweiden.

Fläche B ( 5,6 ha)

- Durch einen 2.Anstau des Augrabens (als Fischtreppe) unmittelbar nördlich des Zehlendorfer Damms ist die Fläche einer Sukzessionsentwicklung zu überlassen oder extensiv zu beweiden. Der Wasserstand im längs durch die Fläche laufenden Graben ist ggf. anzuheben.

Fläche C (23,8 ha)

- Die Fläche ist viel zu trocken. Durch weitere Anhebung des Augrabens über die bereits realisierte Fischtreppe sind in dieser Fläche und dem südlichen Teil des NSG höhere Wasserstände zu erzeugen. Die Fläche ist extensiv zu beweiden.

$\S$-Fläche

- Die Fläche ist nach § 20 NatSchAG M-V geschützt. Eine Vernässung der Fläche durch Anstau des Augrabens entspräche dem Biotopschutz und wäre nicht ausgleichspflichtig.

Unsere Forderungen an die Naturschutzbehörde lauten:

Die Flächen A, B und C sowie die mit § gekennzeichnete Fläche sind in die jetzigen NSG-Flächen einzubeziehen. Ein NSG-Festsetzungsverfahren mit diesen neuen NSGGrenzen ist kurzfristig einzuleiten. Die extensive Bewirtschaftung und ggf. Auflassungen von Flächen sind festzulegen. 


\subsubsection{NSG Schlichtes Moor}

Angela Martin (NSG-Betreuerin bis 1999)

$\underline{\text { Schutzgebietsdaten }}$

Einstweilige Sicherung am

Unterschutzstellung

18.8.1976 (7,35 ha)

mit Flächenerweiterung

Behandlungsrichtlinie vom

Größe 58 ha

davon Moorfläche Wald, Gebüsch
19.8.1979

22.3.1982

7,35 ha

ca. 50 ha

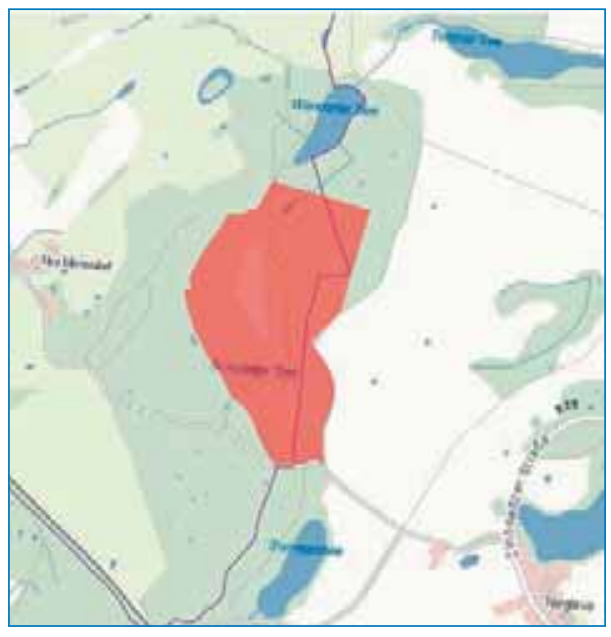

Karte 7

Quelle: Kartenportal LUNG

Bedeutung/Schutzziel

Erhalt eines nahezu ungestörten Kesselmoores inmitten eines Laubwaldkomplexes

1992 Integration in das EU-Vogelschutzgebiet DE 2239-401 Nebel und Warinsee

2007 Integration in das FFH-Gebiet DE 2239-301 Nebeltal mit Zuflüssen, verbundenen Seen und angrenzenden Wäldern

Einige NSG im Kreis Güstrow hatte ich in den Jahren 1977 und 1978 bereits selbständig nach Angaben aus dem NSGHandbuch mit dem Fahrrad erkundet. Dieses Moor jedoch wurde mir im Sommer 1979 von Hans-Georg Müller und Kurt Pohlmann gezeigt. Auf Grund seiner versteckten Lage war der Weg dorthin nicht so einfach zu finden.

Man musste einen steilen Abhang hinunter und stand vor einer Randschlenke, die sich zumindest die gesamte Ostseite entlang zog und unpassierbar schien. Ein dicker Buchenstamm lag wie eine Brücke über der Schlenke. Über diesen krochen wir - später auch Gäste! - vorsichtig ins Gebiet. Bereits einige Jahre später zeigte sich, dass unsere Furcht vor der Grundlosigkeit dieser Schlenke fehl am Platz war. Die Bedeutung des Moores hatte unser FG-Mitglied HansGeorg Müller entdeckt und sich für die einstweilige Sicherung der reinen Moorfläche einschließlich des Schwarzen Sees als Naturschutzgebiet durch den Rat des Kreises Güstrow gemeinsam mit der Fachgruppe eingesetzt. Wie zu jener Zeit üblich, erfolgte durch das ILN-Zweigstelle Greifswald nach Prüfung die begründete Antragstellung zur einstweiligen Sicherung als NSG beim Rat des Bezirkes (6.9.1976). Die endgültige Unterschutzstellung durch Beschluss des Bezirkstages geschah erst 1982 im Paket mit anderen Schutzgebieten.

Hans-Georg Müller war 1983 auch der erste Gebietsbetreuer. Als er sich aus der FG-Arbeit zurückzog, löste ihn 1984 Fritz Holst ab. G. Müller war mehr ein Botaniker als Ornithologe und zunehmend von der Naturschutzpolitik der DDR enttäuscht. Von 1985 bis 1999 übernahm ich dann die NSG-Betreuung mit offizieller Berufung.

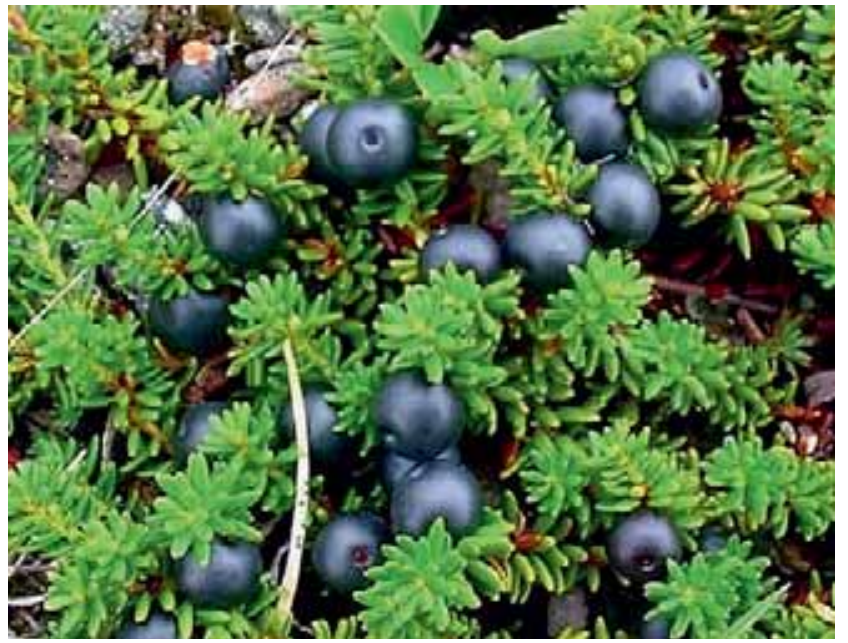

Abb. 119: Die Krähenbeere ist neuerdings häufiger in den Randflächen im Schlichten Moor zu finden. Foto: f. Loose.

Dieses Moor bietet an Pflanzenarten alles, was ein solches Feuchtgebiet in unseren Breiten erwarten lässt. Es wurde deshalb auch immer wieder Besichtigungsobjekt.

1982 hatte ich als Forschungsstudent der Pädagogischen Hochschule im Rahmen des 4. Arbeits- und Exkursionstreffen der Botaniker aus Mecklenburg die Organisation der Unterkunft und Verpflegung sowie die Führung ins Schlichte Moor als Abschlussexkursion übernommen.

Damals wurde hier die Blasenbinse Scheuchzeria palustris entdeckt, was durch ein Dia belegt ist.

Diese Art ist hier danach nie wieder gefunden worden! Wir kennen einen heute stabilen Bestand der Art nur noch aus dem FND Nr. 29 „Torfmoosmoor SO Bolzsee“ (vgl. Pkt. 8.2 und Abb. 154). 
Im gleichen Jahr habe ich Fernseh-Kameraleuten - sie drehten den Streifen „Leute vom Kulturbund“ - das Moor vorgestellt, in dem sie auch einige Einstellungen fanden.

Anlässlich der IV. Zentralen Botaniker-Tagung der DDR 1985 in Güstrow wurden drei Exkursionen organisiert, eine davon hatte ich ins NSG Schlichtes Moor zu führen. Während der Busfahrt erläuterte ich die Geomorphologie der
Landschaft, die unsere ungefähr 45 Personen starke Exkursionsgruppe durchfuhr. Nach einem längeren Anmarsch stürzte sich die Exkursionsgruppe auf die moorartige Randschlenke des Schwarzen Sees, die dem Moor nachgeschaltet ist. Meine zum Weitergehen auffordernde Aussage, dass es doch noch viel besser käme, wurde von vielen mit einem ungläubigen Gesichtsausdruck quittert.

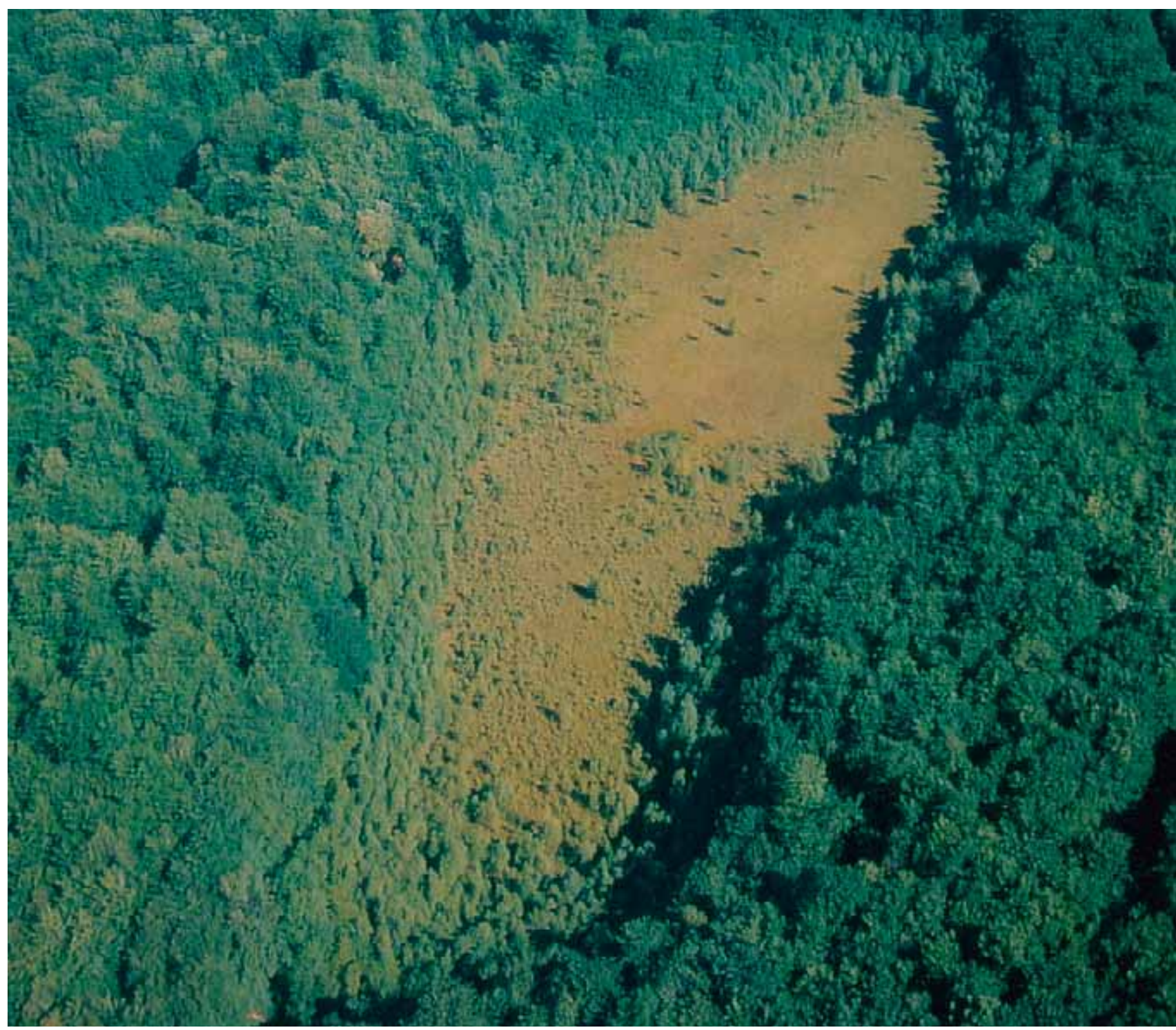

Abb. 120: Luftbild vom eigentlichen Schlichten Moor (1999) - Der zunehmende Baumaufwuchs im Südteil des Moores wird deutlich. Foto: Ch. Berg.

Als ganz besondere Pflanzenart ist im Schlichten Moor neben dem Rundblättrigen auch der Langblättrigen Sonnentau Drosera anglica zu finden. Im August 1985 sandte ich Saatgut von diesen Pflanzen in den Botanischen Garten in Dresden und im September des gleichen Jahres an Frau Spieß in die Biologische Station Serrahn (an dieser Art sollten Experimente durchgeführt werden). In ihrem Dankesschreiben drückte sie ihr Erstaunen über die Größe des Vorkommens aus, was sie anhand des umfangreichen Kapselmaterials ermessen konnte. Auf einem Quadrat- meter wurden 1984 bis 108 Individuen des Langblättrigen Sonnentaus ausgezählt.

Eine Saatgutentnahme fand dann nochmals 1990 statt. Ich schickte den Samen nach einem von E.P. Dörfler geknüpften Kontakt an Hamburger Naturschützer (wir hatten dort gleich nach der Wende einen Erfahrungsaustausch) für die Aussaat in Mooren in der Umgebung von Hamburg, wo es die Art früher auch einmal gegeben hatte. 


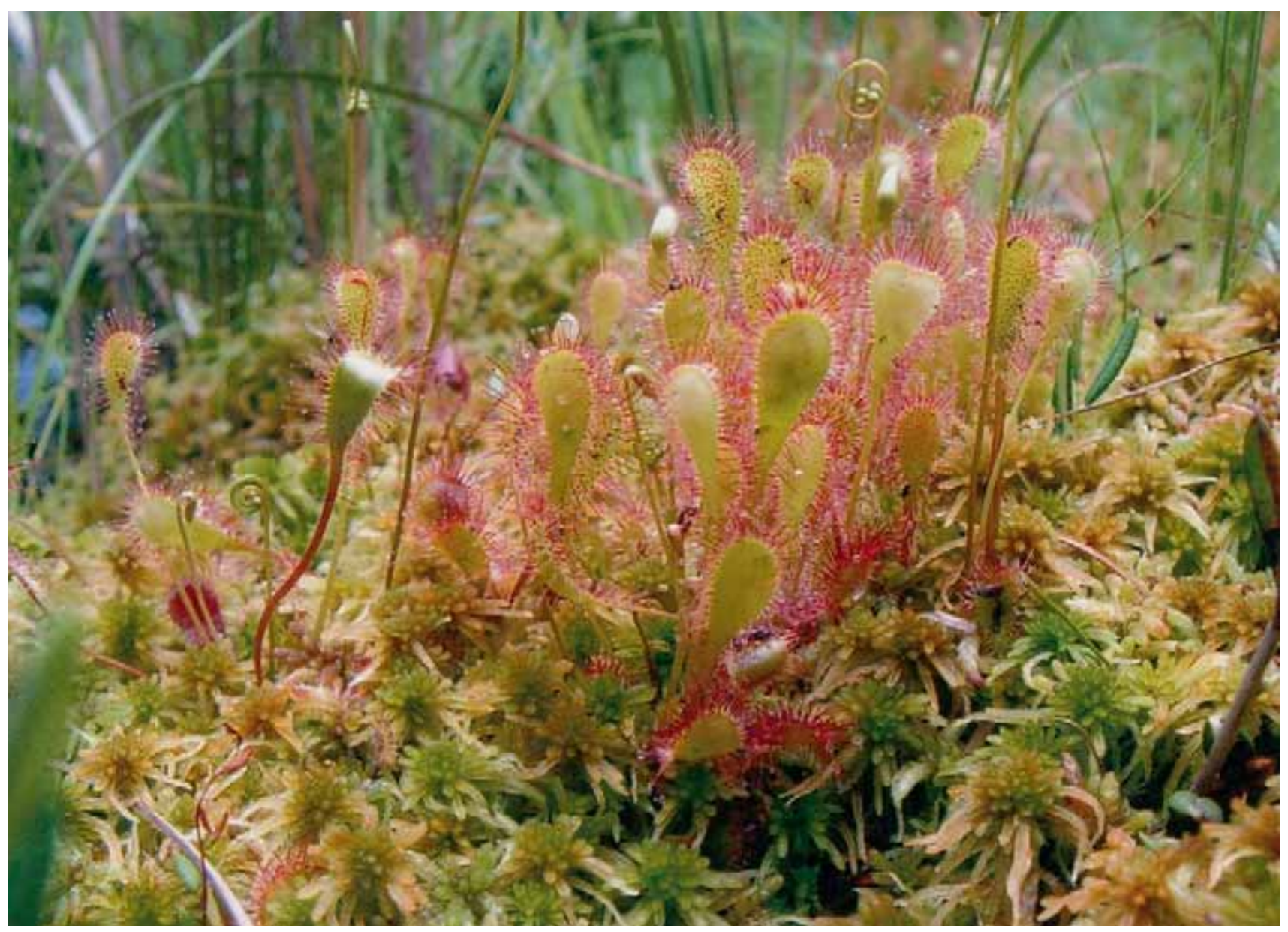

Abb. 121: Der Langblättriger Sonnentau Drosera anglica hat große Bestände im Schlichten Moor. Foto: F. Loose.

Mitte der 1980er Jahren trocknete die Randschlenke aus, und wir gingen bei Kontrollgängen „furchtlos“ an verschiedenen Stellen ins Moor. Die Frage nach einer „heimlichen“ Entwässerung kam bei solchen Gelegenheiten immer wieder auf. Beim Ablaufen des gesamten Randes konnte diese Befürchtung allein nach optischer Beurteilung zerstreut werden. Als Ursachen für die zunehmende Trockenheit im Moor wurden zum einen die „nicht zu fassende“ großräumige Melioration und zum anderen viele Jahre mit ungenügendem Niederschlag angesehen.

Um der Phase der Verheidung ein bisschen Paroli zu bieten, damit nicht alle an offene Schlenken angewiesene Arten, wie z.B. der Langblättrige Sonnentau als Hauptattraktion, verschwinden, erhielten wir einen ungewöhnlichen Hinweis. Als 1982 die Abschlussexkursion des Arbeitstreffens ins Moor führte, fragte mich Rolf Rehbein, ein Botaniker aus Rostock, ob wir nicht eine NVA-Truppe an der Hand hätten. (Er hatte Erfahrungen mit gewagten Pflegeeinsätzen.) Sie könnte uns im Gebiet durch eine Sprengung eine frische Fläche schaffen. Auf der könnten sich einige der sehr konkurrenzschwachen Moorpflanzen dann wieder entwickeln.

Da wir nicht über diese Möglichkeit verfügten und uns für das kleine Moor eine solche Maßnahme viel zu rabiat erschien, legten Wolfgang Neubauer und ich im April 1984 in
Absprache mit dem ILN einen Mini-Torfstich an, um einen ähnlichen Effekt zu erzielen. Bereits zwei Jahre später war diese kleine Fläche mit Torfmoosen völlig ausgefüllt.

Mitte der 1980er Jahre konnte ich eine Exkursion mit Forstlehrlingen der Betriebsberufsschule Klueß ins Moor durchführen. Die Reaktion der Jugendlichen war erstaunlich. Als sie an diesem grauen Novembertag auf der waldfreien Moorfläche standen, waren sie wohl ein bisschen ergriffen und einer sagte: „So was habe ich noch nie gesehen.“

So ähnlich ging es vermutlich vielen Gästen, die das Moor zum ersten Mal sahen und betraten.

Nach meinem Unfall 1989 kam ich kaum noch ins Gebiet. Zunächst war es die Unmobilität, später auch eine Vielzahl anderer Aufgaben. Für die Betreuertätigkeit in diesem NSG war das nicht so erheblich. Im Vergleich zum Zehlendorfer Moor war die Betreuung hier fast ein „Selbstläufer“ - sie konnte sich auf die reine Erfassung und Dokumentation von Wasserständen und Pflanzenentwicklung beschränken.

1994 bot sich Ausgang des Winters eine „Mitfahrgelegenheit". Auf Grund des Niederschlagsreichtums der vorangegangenen Wochen war die Randschlenke gefüllt und 
die von Jahr zu Jahr weiter geschrumpfte kleine zentrale Wasserfläche wieder etwas stärker ausgebildet. Der SumpfPorst-Bestand im randlichen Birkensaum hatte sich ausgebreitet. Eine enorme Ausdehnung war auch bei der Krä- henbeere zu verzeichnen. Diese Art hatte im Moor in den 1980er Jahren nur zwei sehr kleine Bestände. Das Aufkommen beider Zwergstraucharten kann als Zeichen einer zunehmenden Verheidung von Teilflächen angesehen werden.

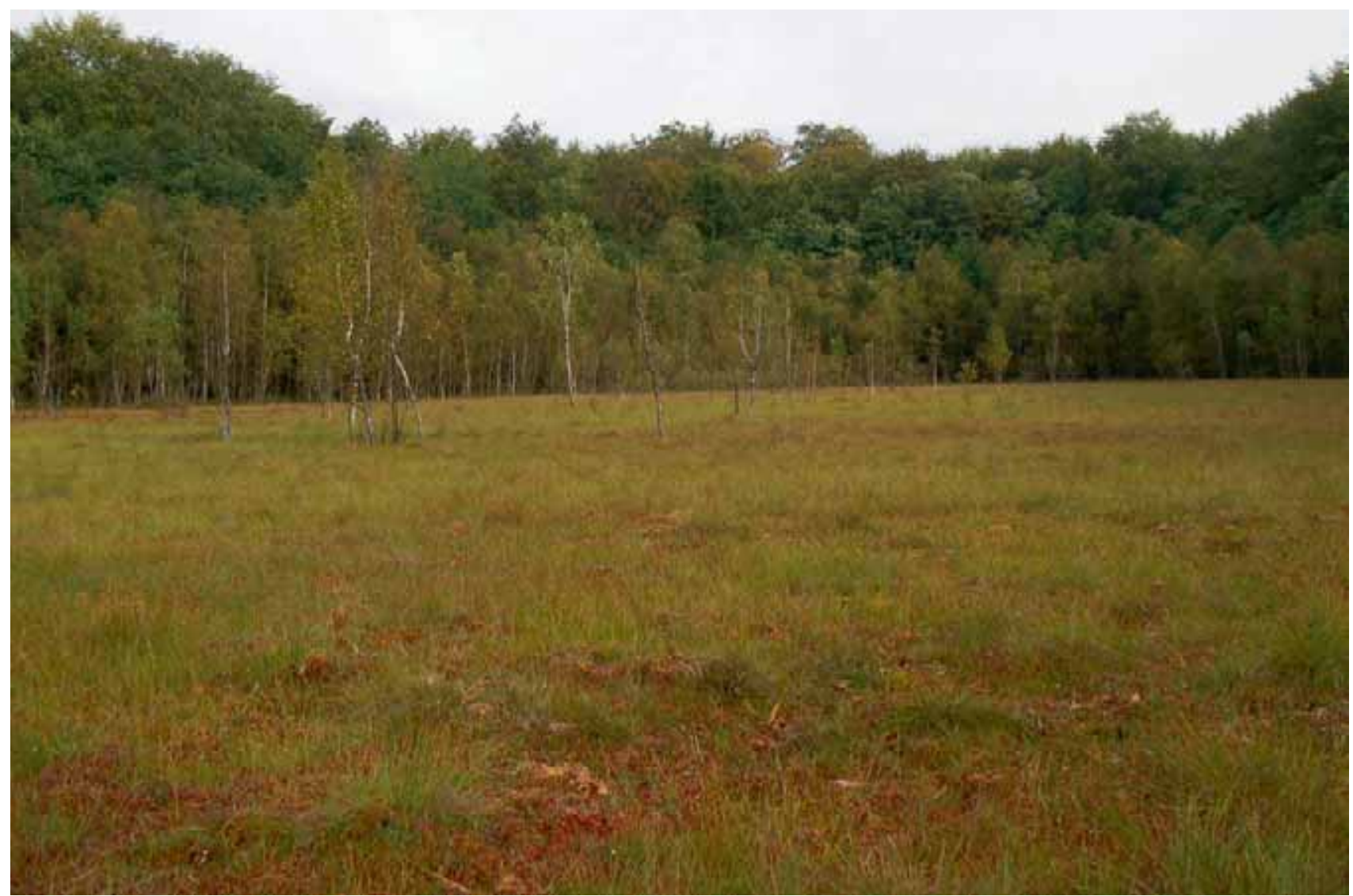

Abb. 122: Blick nach Norden in die ebene baumfreie Fläche des Schlichten Moores. Foto: F. Loose.

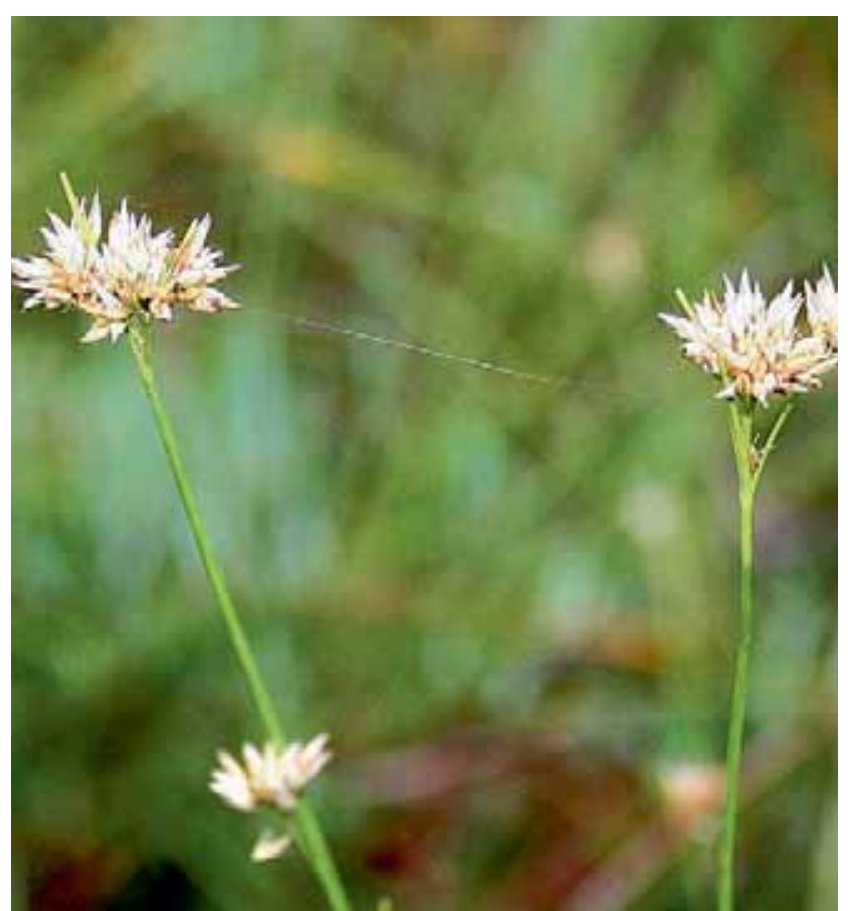

Abb. 123: Das Weiße Schnabelried Rhynchospora alba zählt zu den bei uns nur im schlichten Moor vorkommenden Arten. Foto: f. Loose.

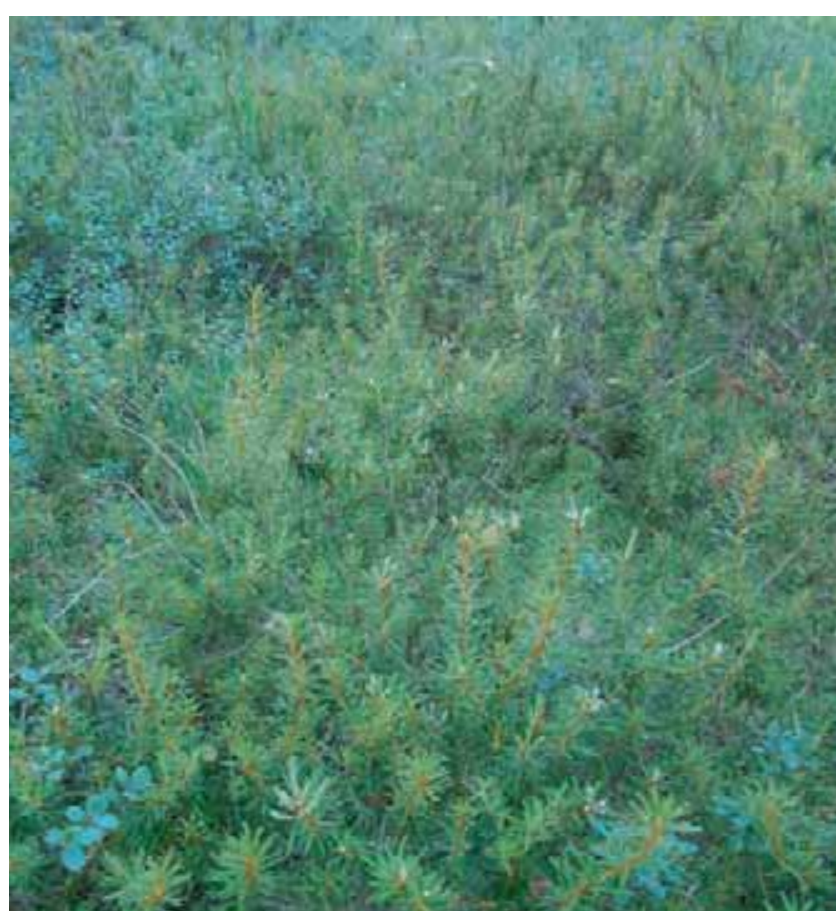

Abb. 124: Sumpf-Porst Ledum palustre und Rauschbeere Vaccinium uliginosum stehen am Rande des Moores. Foto: 7. Loose. 
In den Jahren 1997 und 1999 führte Volkmar Rowinsky (Mitglied unserer Botanik-AG) im Auftrag des StAUN Rostock innerhalb des Moores an verschiedenen Stellen Erkundungsbohrungen durch. Ich war bei den ersten Bohrungen in diesem Moor dabei. Diese zeigten bereits, dass das Schlichte Moor zu einem der tiefgründigsten in $\mathrm{M}-\mathrm{V}$ zählt. Im Ergebnis der Untersuchungen stellte V. Rowinsky fest, dass im Zentrum die Moormächtigkeit bei mehr als $20 \mathrm{~m}$ lag und die Moorbildungsrate $4 \mathrm{~mm} / \mathrm{Jahr}$ überstieg. (siehe ROWINSKY, 2013)

V. Rowinsky untersuchte im Rahmen dieses Auftrages auch nochmals die Thematik, ob es wirklich keine Abflüsse aus dem Moor gibt. Durch Höhenvermessungen und teilweise kleine Aufgrabungen im Randbereich bestätigte sich, dass aus dem Schlichten Moor kein Wasser abfließen kann. Bei dieser extremen Kessellage ist eine Wasserableitung nicht möglich. Trockene Phasen, die letztlich zu einer fortschreitenden Verheidung führen, sind allerdings nicht nur natürlichen Ursprungs (klimatische Einflüsse), sondern werden auch durch die großräumige Melioration infolge Beeinflussung der Grundwasserleiter bewirkt.

Im Gegensatz zu anderen NSG kann beim Schlichten Moor keine Verbesserung des Zustandes durch Pflege- und Erhaltungsmaßnahmen erreicht werden. Die weitere Entwicklung der Gehölzbestände kann nur beobachtet wer- den. Pflegemaßnahmen wie die Entnahme der während der Trockenphasen aufgewachsenen Birken sind aktuell nicht sinnvoll und könnten eine aus Naturschutzsicht negative Entwicklung sogar verstärken.

In anderen Mooren, wo wir mit „Pioniergeist“ die MoorBirken entfernt hatten, mussten wir feststellen, dass im Folgejahr ungleich mehr neue Birken aufgewachsen waren. Nur bei gleichzeitiger Einflussnahme auf den Wasserhaushalt kann eine Gehölzentnahme sinnvoll sein.

Da das Schlichte Moor nur vom Regenwasserdargebot abhängig und der Wasserstand nicht beeinflussbar ist, sind solche Pflegemaßnahmen nicht erfolgreich.

1999 ließ ich mich von meiner NSG-Betreuung ablösen. Volkmar Rowinsky sollte als „Moorspezialist“ in dem Gebiet die Ende der 1990er Jahre gemachten Beobachtungen fortsetzen und übernahm die Funktion des NSG-Betreuers.

Die Waldflächen des Naturschutzgebietes wurden in einigen Jahren mitunter auch von Leuten aufgesucht, die nicht an der Moorvegetation interessiert waren. Im Umfeld des Moores hatte mehrere Jahre ein Paar des Schwarzstorches erfolgreich gebrütet. Die Preisgabe dieses Brutplatzes in Forstkreisen und gar die geführten Exkursionen bis in Horstnähe fand nicht bei allen FG-Mitgliedern Zustimmung. Das Ausbleiben der Horstbesetzung in den jüngeren Jahren lag jedoch wohl nicht an dieser Bekanntmachung.

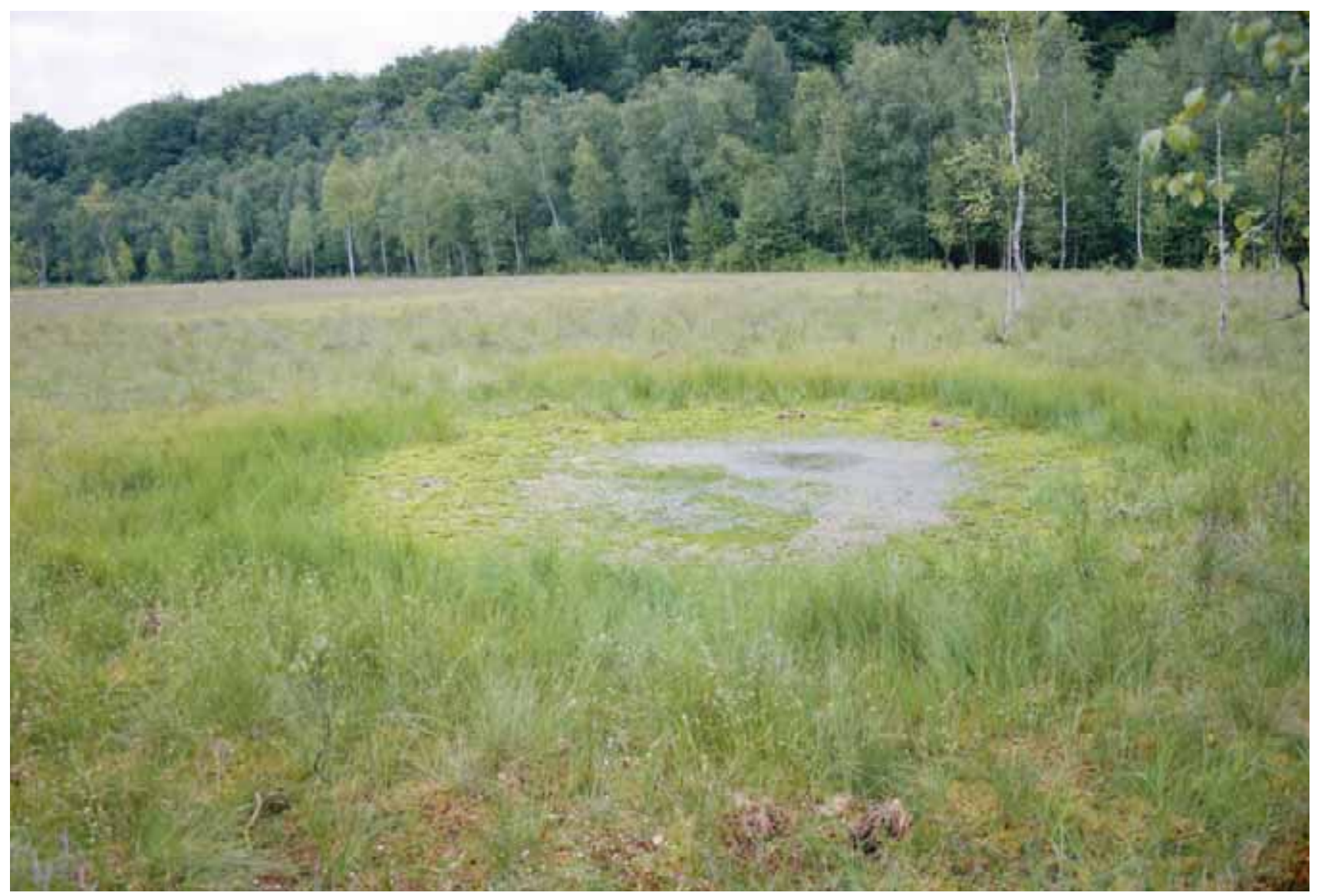

Abb. 125: Die zentral im Moor liegende Schlenke enthält von fahr zu fahr unterschiedlich viel Wasser, hier ein Foto vom 12.08.2008. Am Rand der Schlenke (hier im Vordergrund des Fotos erkennbar) steht auch das Weiße Schnabelried Rhynchospora alba. Foto: 7 . Loose 


\subsubsection{NSG Gutower Moor und Schöninsel}

\section{Manfred Montschko (NSG-Betreuer bis 2006)}

$\underline{\text { Schutzgebietsdaten }}$

Einstweilige Sicherung als

„Gutower Moor” mit einer

Größe von 130 ha am

07.07.1993

Unterschutzstellung mit VO am 05.01.2000

Größe 360 ha

\begin{tabular}{|c|c|c|}
\hline davon & Wasser & 205 ha \\
\hline & Grünfläche & 73 ha \\
\hline & Ödland & 60 ha \\
\hline & Holzungen & 9 ha \\
\hline & Acker & 6 ha \\
\hline & Verkehrsfläche & 3 ha \\
\hline & Unland & 0,5 ha \\
\hline
\end{tabular}

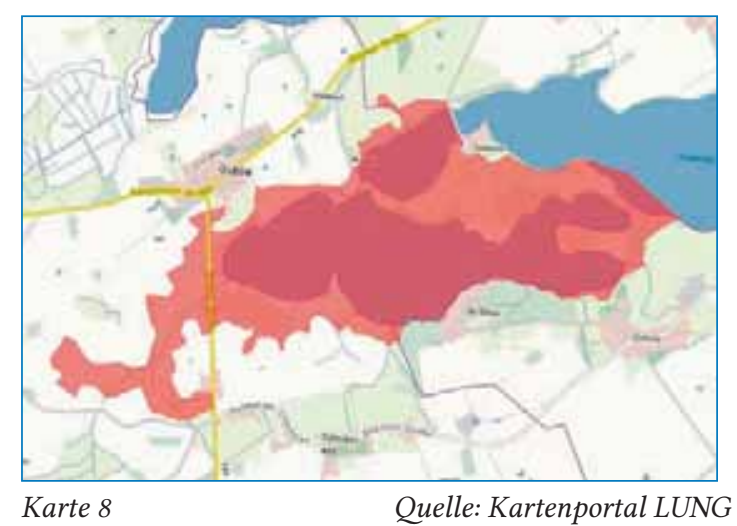

Karte 8

$\underline{\text { Bedeutung/Schutzziel }}$

Erhalt und Entwicklung des westlichen Teiles des Inselsees mit angrenzenden Durchströmungsmooren als Lebensraum für zahlreiche Tier- und Pflanzenarten sowie als überregional bedeutsames Rast-, Schlaf- und Nahrungsgewässer für Gänse- und Entenvögel

seit 05/2004 zum FFH-Gebiet DE 2239-302 „Inselsee Güstrow“ mit Gesamtfläche von 694 ha gehörend, hier wegen seiner Characeenrasen und Vorkommen von FFH-Arten bedeutsam

Das Naturschutzgebiet blickt auf eine bewegte Entstehungsgeschichte zurück, auf die zunächst eingegangen wird.

Die floristische und faunistische Bedeutung des inzwischen zunehmend aufgelassenen Niederungsbereiches vom westlichen Ausläufer des Inselsees bis nach Ganschow wurde von unserer Fachgruppe, deren Mitglieder zumeist als ehrenamtliche Naturschützer gewirkt haben, bei einer Vielzahl von Begehungen und Bestandsaufnahmen bereits in den 1970er Jahren erkannt. Im Jahre 1980 wandte sich Adolf Kretschmann im Auftrag der FG mit einem Schreiben an das ILN in Greifswald und bat um die Erstellung eines wissenschaftlichen Gutachtens für eine beabsichtigte Unterschutzstellung einer Fläche an der Südspitze des Inselsees mit einer Größe von 42 ha. Beigefügt war auch eine Begründung für eine Unterschutzstellung. Mit Schreiben vom 16.7.1980 begrüßte das ILN unsere Initiative. Es war zu lesen, dass es bereits aus botanischer Sicht in früheren Jahren einen Antrag auf Ausweisung eines Schutzgebietes gegeben hatte, der damals keine Zustimmung beim Rat des Kreises gefunden hatte. Dr. L. Jeschke betonte, dass auch unbedingt wegen der herausragenden Unterwasservegetation Teile des Sees sowie der „Burgwall“ in ein Naturschutzgebiet einbezogen werden müssten. Nach diesem Antwortschreiben gab es dann in Verbindung mit einem
Besuch des NSG Zehlendorfer Moor auch eine Gebietsbegehung durch Dr. Jeschke und A. Martin. Eine abschließende Befürwortung oder ein wissenschaftliches Gutachten des ILN ist in unseren Unterlagen nicht zu finden.

$\mathrm{Zu}$ dieser Zeit existierte in geringer Entfernung zum Gutower Moor am Südwestende des Sumpfsee noch eine Fläche mit der gleichen Habitatstruktur wie hier am Inselsee. Durch Intensivierung der Nutzung Mitte der 1980er Jahre wurden die Flächen in der Sumpfseeniederung jedoch hinsichtlich ihrer ökologischen Bedeutung erheblich entwertet (vgl. Kap. 8.3.3). Somit war der weitgehend intakten Niederung am Inselsee bei Gutow ein zusätzliches Gewicht als verbliebenes Rückzugsgebiet in diesem Bereich für viele Arten beizumessen.

Ende des Jahres 1988 gab es Bestrebungen der damals auf den Flächen wirtschaftenden LPG (P) Zehna, die Niederungsflächen einer Wiedernutzbarmachung zuzuführen. Dabei wurde auf eine Studie aus den 1960er Jahren zurückgegriffen. Am 07.12.1988 gab es mit Vertretern von Landwirtschaft, Meliorationsbau, Wasserwirtschaft und Rat des Kreises sowie unserem FG-Mitglied Angela Martin in ihrer Funktion als Mitarbeiterin für Landeskultur und Naturschutz des Staatlichen Forstwirtschaftsbetriebes eine Beratung und Variantendiskussion. Nachfolgend wurden dazu schriftliche Stellungnahmen erarbeitet. Die verständlicher- 
weise negativ ausgefallene, fachlich fundierte Stellungnahme der Naturschutzseite wurde letztendlich vom Rat des Kreises verworfen. Damit war der Weg für die Erarbeitung einer für die Landwirtschaft zielführenden Aufgabenstellung zur wirtschaftlichen Nutzung der Flächen frei. Auch wenn für das Jahr 1989 keine Mittel (erwartete Bausumme ca. 2,0 Mio. Mark) vorhanden waren, konnte sich niemand sicher sein, dass die Umsetzung des Vorhabens nicht in den nachfolgenden Jahren doch noch erfolgen könnte. Um wenigstens einen Teil der betroffenen Flächen zu retten, ver- fasste die Fachgruppe Ornithologie und Naturschutz Güstrow ihre erste Eingabe. Diese wurde mit Schreiben vom 29.04.1989 (siehe Anhang 5) wenige Wochen vor den im Mai 1989 stattfindenden Kommunalwahlen an das Ministerium für Land-, Forst- und Nahrungsgüterwirtschaft der DDR abgeschickt und war damit eine „Wahleingabe“. Mit der Eingabe erwarteten wir „eine entsprechende Unterstützung in fachlicher Beurteilung der erarbeiteten Aufgabenstellung bei erforderlicher Wichtung der Naturschutzaspekte“.

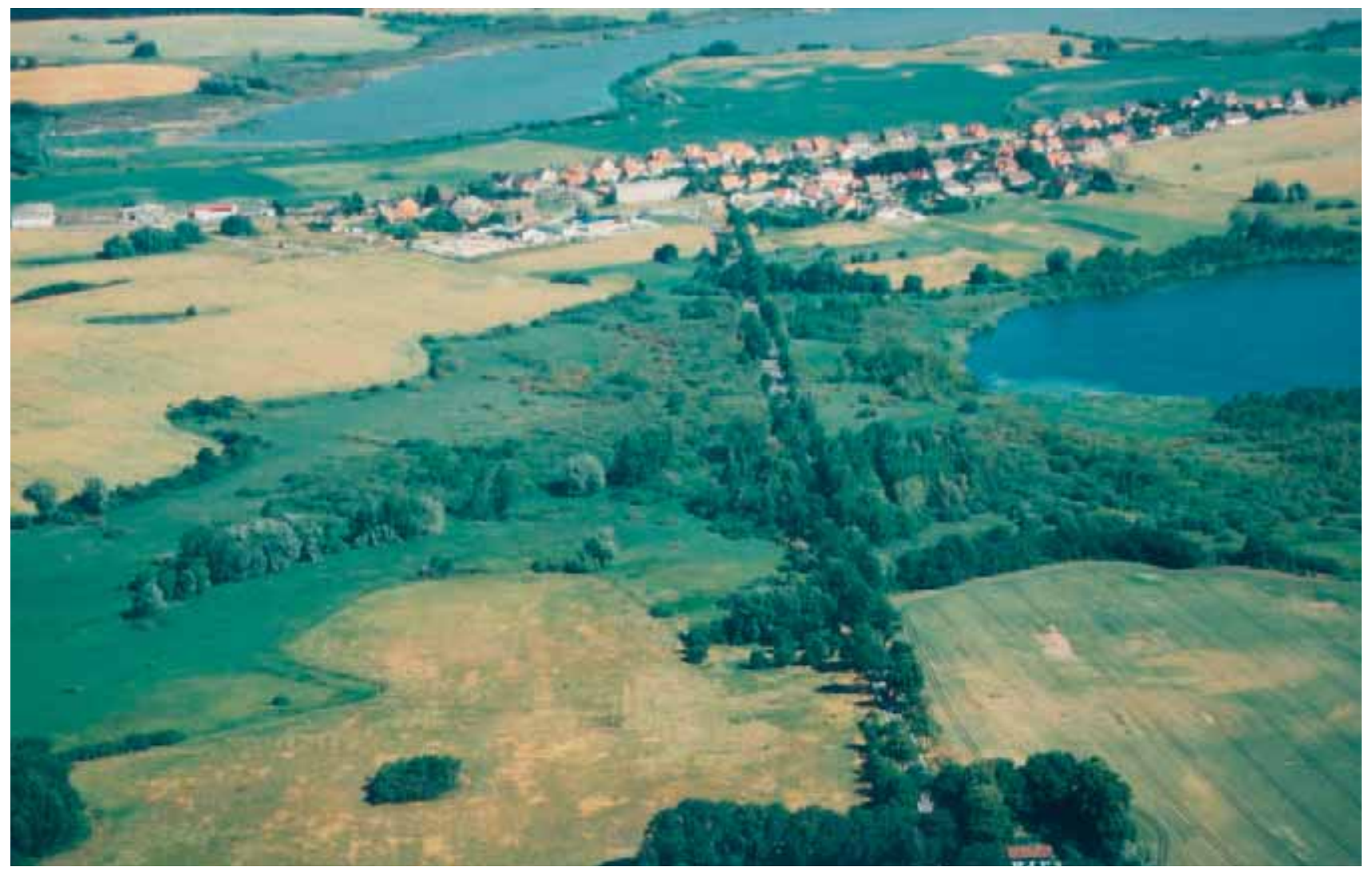

Abb.126: Blick auf das Gutower Moor, im Hintergrund die Ortschaft Gutow und der Sumpfsee. Die Straße L17 durchschneidet das GebietLuftbild von 1999. Foto: Ch. Berg.

Stellvertretend für 36 Mitglieder der FG hatten die Eingabe acht Personen unterzeichnet. Im Text war unsererseits betont worden, dass dieser „Eingabe keinerlei private Ambitionen zu Grunde liegen“. Weiter hieß es: „Wir erheben damit Einspruch gegen ein ständiges Zuwiderhandeln gegen die Artenschutzbestimmungen und in dem besonderen Fall gegen die zu befürchtende Wiedernutzbarmachung des oben genannten Grünlandes durch die LPG (T) Zehna.“

Die floristischen und faunistischen Erfassungen in der Niederung und am Gutower See wurden fortgeführt, während vom angeschriebenen Ministerium ein Zwischenbescheid einging und beim damaligen Rat des Bezirkes Schwerin zu einer Zusammenkunft (ohne uns als Eingabeschreiber) eingeladen wurde. Das Thema beschäftigte in den folgenden Wochen und Monaten mehrfach zahlreiche Personen, Betriebe und Gremien. Letztendlich sorgte wohl die politische
Wende im Herbst 1989 dafür, dass das Vorhaben endgültig in der Versenkung verschwand.

Mit der einhergehenden Neustrukturierung der Verwaltungsbehörden und verstärkten Ausweisung von Schutzgebieten wurde das Gebiet auf Grundlage der durch Mitglieder der FG vorgelegten Bestandserhebungen als „Gutower Moor" am 07.Juli 1993 in einer Größe von 130 ha als Naturschutzgebiet einstweilig unter Schutz gestellt. Bereits kurz nach dieser Sicherstellung regte die Stadt Güstrow unter Inanspruchnahme ihrer hoheitlichen Planungsrechte die Erweiterung des Naturschutzgebietes auch auf den Landschaftsteil von Schöninsel an. Im weiteren Unterschutzstellungsverfahren wurde dann mit Verordnung des Umweltministeriums des Landes Mecklenburg-Vorpommern vom 05.01.2000 das Naturschutzgebiet „Gutower Moor und Schöninsel“ in seiner heutigen Größe von 360 ha festgesetzt. 
Da ich in direkter Nachbarschaft zum neuen Naturschutzgebiet aufgewachsen bin und hier in einer Schülerarbeitsgemeinschaft die Grundlage für mein Interesse an Natur und insbesondere die Vogelwelt gelegt wurde, übernahm ich von der Phase der Vorbereitung der einstweiligen Unterschutzstellung an die Betreuung des Naturschutzgebietes und arbeitete intensiv an der Festsetzung mit. In dieser Zeit entwarf ich ein Faltblatt über das Naturschutzgebiet, das ich zu eigenen Lasten für Besucher an geeigneten Stellen angeboten habe. Während ich die avifaunistischen Erfassungen selbst durchgeführt habe, versuchte ich auch Spezialisten für andere Artengruppen in das Gebiet zu holen, um möglichst umfassende Daten zur Artenausstattung des NSG zu sammeln.

Die Untersuchungen aus dieser Zeit untermauerten weitgehend die Gründe, die Anfang der 1990er Jahre zur Unterschutzstellung des Gebietes geführt haben. Faunistisch ist die Bedeutung des Inselsees als Rast- und Nahrungsgewässer für einheimische und nordische Gänse, Tauchenten und Säger hervorzuheben. Zur Brutzeit sind Beutel- und Bartmeise, Drosselrohrsänger, Blaukehlchen, Schlagschwirl, Wachtelkönig, Schwarzmilan und Rohrdommel anzutreffen. Als Nahrungsgäste erscheinen u. a. See- und Fischadler, Baumfalke, Rotmilan und Kormoran. Sporadisch werden Spuren vom Fischotter registriert.
Bauchige und Schmale Windelschnecke, Keulige Schließmundschnecke und Zweizahn-Schnecke wurden von Fachexperten nachgewiesen und haben als Vertreter der Molluskenfauna eine große Bedeutung als FFH-Arten.

Bemerkenswerte Wasser- und Uferpflanzen sind Tannenwedel, Nadel-Sumpfsimse und Mittleres Nixkraut. Breitund Steifblättriges Knabenkraut kommen in wenigen Exemplaren nur noch auf kleinen Pflegeflächen vor. Weiter sind geringe Bestände von Sumpf-Sitter und Sumpf-Blutauge vorhanden. Der Schloßberg auf Schöninsel beherbergt ein stabiles Vorkommen der Stinkenden Nieswurz Helleborus foetidus, der Bruchwald im Süden der Insel den Gefleckten Aronstab Arum maculatum. Bei beiden letztgenannten Arten habe ich während meiner Betreuertätigkeit jährlich die blühenden Pflanzen ausgezählt.

Ich wirkte an der Organisation und Durchführung von Pflegemaßnahmen z.B. auf den Orchideenwiesen mit. In den ersten Jahren hatte ich die Hoffnung, den Bölkower Burgwall wieder einer Beweidung möglichst durch eine Mischherde aus Schafen, Ziegen und Bullen zuführen zu können. Die Umsetzung scheiterte jedoch immer daran, dass die ursprüngliche Anbindung des Burgwalles von der Landseite über einen Knüppeldamm nicht mehr erkennbar, geschweige denn nutzbar war.

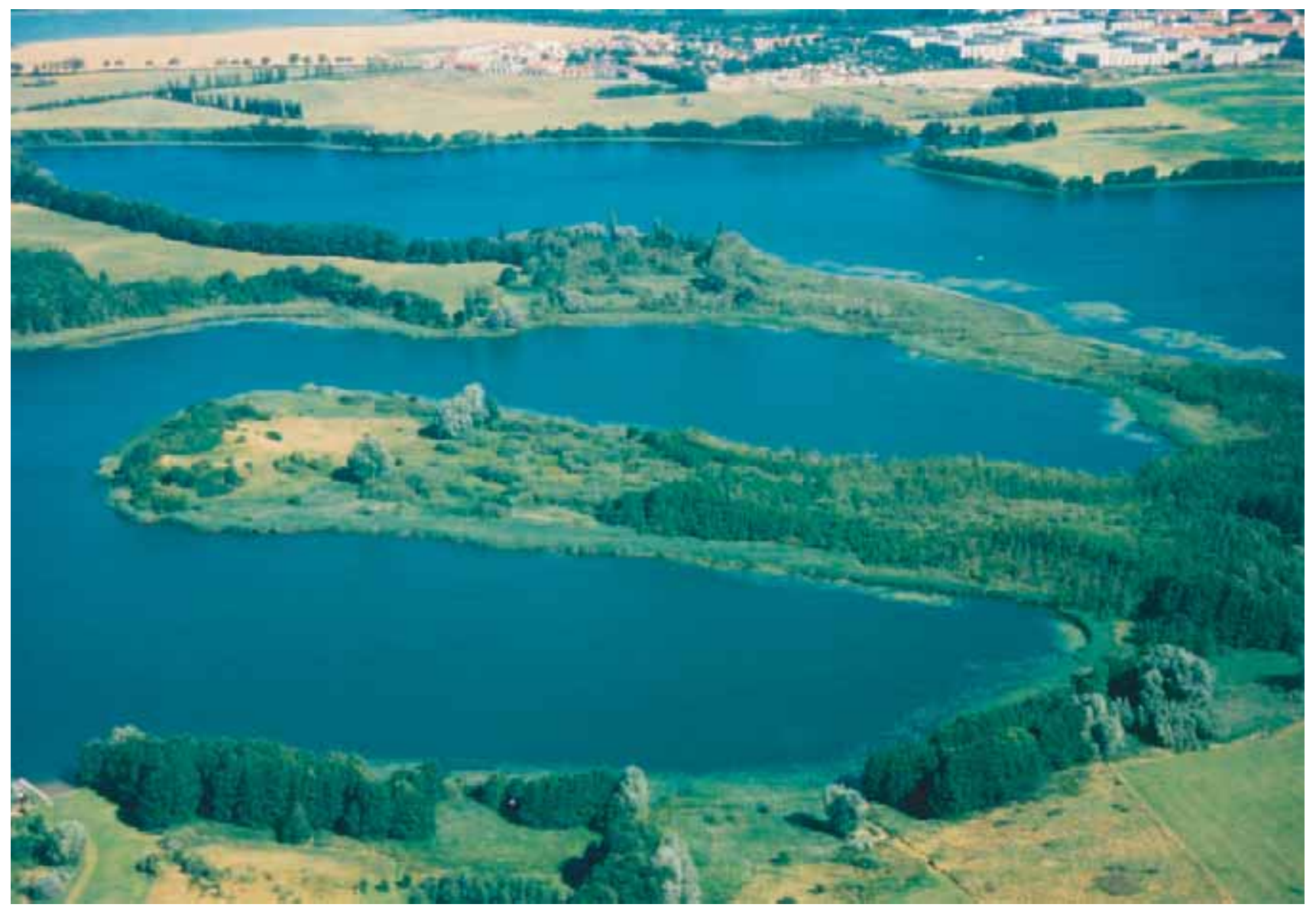

Abb. 127: Blick auf den Bölkower Burgwall, dahinter der „Schwanenhals“ als Verbindung zwischen Gutower und Inselsee - Luftbild von 1999. Foto: Ch. Berg. 
Anfang der 1990er Jahre habe ich als NSG-Betreuer für den Neubau der Straße Gutow - Bülow als Ersatzmaßnahme den Einbau von Amphibientunneln und beidseitigen, fest installierten Leiteinrichtungen an der Landesstraße L17 zwischen Gutow und Badendiek im Bereich der Moorniederung angeregt. Realisiert wurden dann auch zwölf Tunnel aus verschieden großen Betonelementen mit oben offenen Belüftungsschlitzen (DN 400 und DN 200) und beidseitig auf einer Länge von je ca. 670 m festinstallierte Leitwände. Nach damaligen Kenntnisstand waren diese Durchlasstypen amphibienökologisch und bautechnisch gute Planungslösungen. Aber bereits im Juni 1994 zeigte sich, dass die billigeren und weniger stabilen Elemente der Baugröße DN 200 dem intensiven Straßenverkehr auf dieser Straße und den Stoßbelastungen nicht standhielten. Drei Tunnel mussten als Gefahrenstellen umgehend mit Beton zugekippt werden.

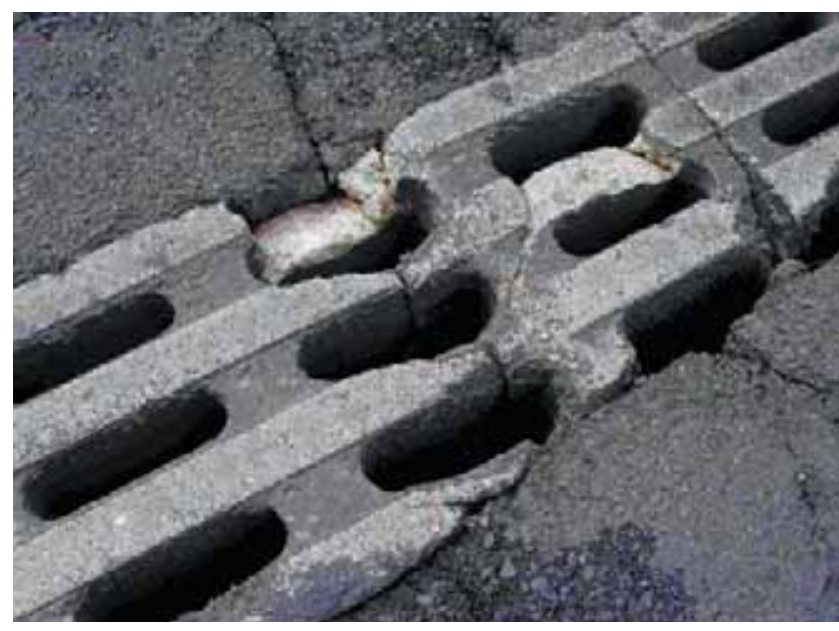

Abb. 128: Die offenen Lurchtunnel DN 200 zerbrachen sehr schnell unter der hohen Verkehrsbelastung. Foto: J. Loose

Als NSG-Betreuer und Initiator wurde ich häufig auf die Sinnhaftigkeit dieser Anlage angesprochen. Die Straße wies an jedem eingebauten Tunnel wegen des elastischen Mooruntergrundes immer wieder Absackungen auf. Das

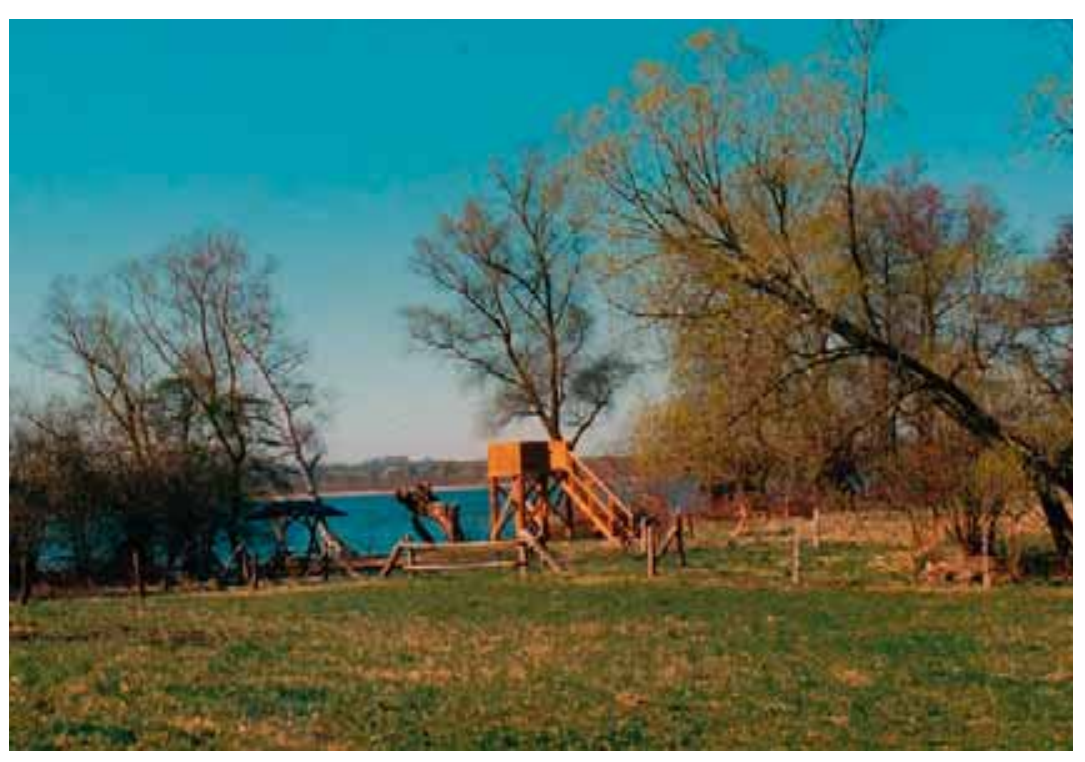

führte zu allgemeinem Unmut, der auch in der Presse eine Plattform gefunden hatte.

Um die Berechtigung der Anlage nachzuweisen, habe ich mehrfach Kontrollfänge organisiert und durchgeführt. Unterstützung fand ich durch Mitarbeiter der RABS mbH und des Fördervereins Region Güstrow e.V. Die Zählergebnisse haben die Notwendigkeit der Anlage an dieser Stelle bestätigt. Im Jahresbericht der FG 34/2001 sind Fangergebnisse dargestellt worden:

In der Zeit vom 29.2. bis 09.4.2000 wurden insgesamt 889 Frösche, Kröten und Molche in Eimern gefangen; vom 12.02. bis 11.04.2001 waren es insgesamt 1.228 Tiere.

Die Anlage wurde Jahre später noch einmal umgebaut. Die Leitwände mussten instandgesetzt werden, die Anzahl der Tunnel wurde verringert, die nach oben offenen Betonelemente durch Stahlrohre in DN 400 ersetzt. Zuvor habe ich wieder Kontrollfänge (diesmal z. T. sogar Richtungsfänge) organisiert und durchgeführt, um Tunnel dort zu belassen, wo räumlich die Hauptkorridore bei der Amphibienwanderung zu finden waren.

Während mit der Amphibienleiteinrichtung den Fröschen und Kröten geholfen werden konnte, stellt die quer durch das NSG verlaufende Landesstraße L17 eine erhebliche Zerschneidungslinie mit Wirkungen insbesondere auf die Vogelwelt dar. Häufig sind Verkehrsopfer am Straßenrand zu finden. Gegenüber dem Straßenverkehrsamt haben wir erfolglos bemängelt, dass die anfangs hier angeordnete Verkehrsgeschwindigkeit von maximal $60 \mathrm{~km} / \mathrm{h}$ wieder aufgehoben wurde und nun alle aus der Ortschaft Gutow kommenden Fahrzeuge voll bis auf $100 \mathrm{~km} / \mathrm{h}$ beschleunigen können und dies auch tun.

Mit Bewirtschaftern, Jägern, Kommunen und insbesondere dem Förderverein Region Güstrow e.V. entstand eine vertrauensvolle, konstruktive Zusammenarbeit. Durch letzteren wurden touristische Einrichtungen auf Schöninsel instand gehalten, ein Rundwanderweg mit Sitzgruppen angelegt und am Südufer auf Schöninsel eine Aussichtsplattform errichtet. Nicht weit von dieser Plattform entfernt hatten Mitte der 1980er Jahren unsere damals neu in die Fachgruppe gekommenen "Jungs", Uwe Gehlhar und Remo Wiechert, eine Baumkanzel errichtet und von hier aus zahlreiche Beobachtungen von Wasservogelansammlungen im Gutower Teil des Inselsees notiert.

Abb. 129: In Anbindung an einen Rundwanderweg befand sich mehrere fahre lang eine gern genutzte offene Beobachtungsplattform am Südufer von Schöninsel, die durch Brandstiftung verloren ging. Foto: M. Montschko. 
Da es inzwischen keinen Trägerverein mehr gibt, der die Unterhaltung einer neuen Beobachtungsplattform absichern könnte, wurde sie bisher, nach der mutwilligen Zerstörung durch Brand, nicht wieder aufgebaut.

Im Naturschutzgebiet sind zwei große und eine kleine Badestelle vorhanden. Die beiden großen Badestellen in $\mathrm{Gu}-$ tow und Bölkow wurden im Zeitraum von 2012 bis 2013 im Zusammenhang mit dem Projekt der Stadt Güstrow „Erlebnisvielfalt Inselee“ mit neuen Bootsanlegern für Rundfahrten mit einem Kutter ausgestattet. Zudem wurden an diesen Badestellen Biotoiletten errichtet.

Während durch die Kutterfahrten keine merklichen Belastungen des NSG zu spüren waren, wurden im Bereich von Bölkow Puthof nach 2010 eine Reihe von Ordnungswidrigkeiten verzeichnet.

Entgegen den geltenden Rechtsvorschriften (NSG-VO, §19 NatSchAG M-V) errichteten Einwohner zahlreiche neue Bootsstege, ohne dass die zuständige Naturschutzbehörde konsequent dagegen vorging. Ebenso sind Rodungen von Waldflächen bisher ohne Ersatzaufforstung geblieben. Dadurch ist nicht nur das Landschaftsbild in diesem Teil des NSG stark verändert worden, sondern wird auch die Vogelwelt im Uferröhricht erheblich beeinträchtigt.

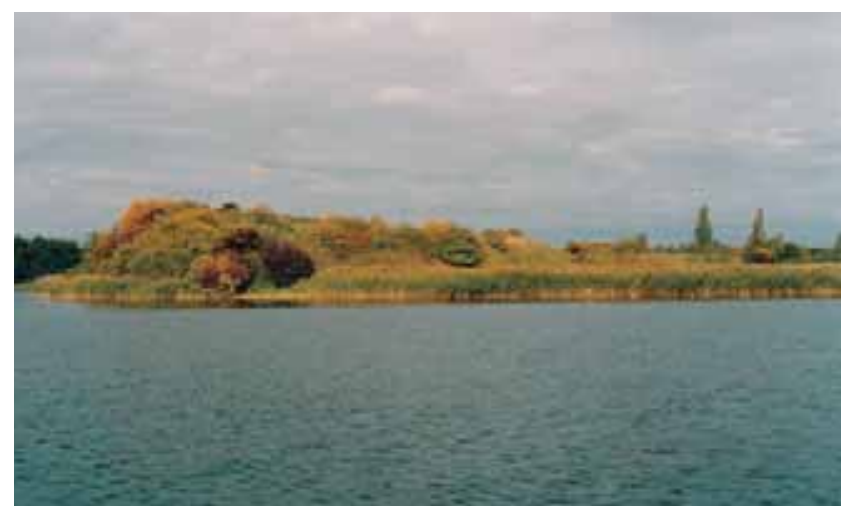

Abb. 130: Der Bölkower Burgwall ist zunehmend verbuscht - 2005. Foto: 7 . Loose

Ab 2013 starteten erste Pflegemaßnahmen auf dem Burgwall. Diese wurden durch unser FG-Mitglied Guntram Trost als Bewohner der Gemeinde Mühl Rosin, zu der der Burgwall gehört, initiiert. In der Gemeinde wirkt ein Verein, der sich den Namen der ehemals auf dem Burgwall stehenden Burg Bisdede gegeben hat. In der Vereinssatzung ist auch der Schutz der Natur verankert. Vereinsmitglieder wollen sich künftig auch um die Entwicklung auf dem Burgwall kümmern. Bei den bis 2015 erfolgten acht Einsätzen auf der Halbinsel arbeiteten acht bis zwölf Helfer etwa je zur Hälfte FG-Mitglieder und Bürger der Gemeinde tatkräftig zusammen. Zwei Feuchtwiesen wurden in Handarbeit wiederholt gemäht, ebenso der Burghügel. Drei Einsätze dienten dem Entfernen eines großen Schlehengebüsches auf dem Hügel. Auch auf der ehemaligen Wiesenfläche mussten Büsche entfernt werden.

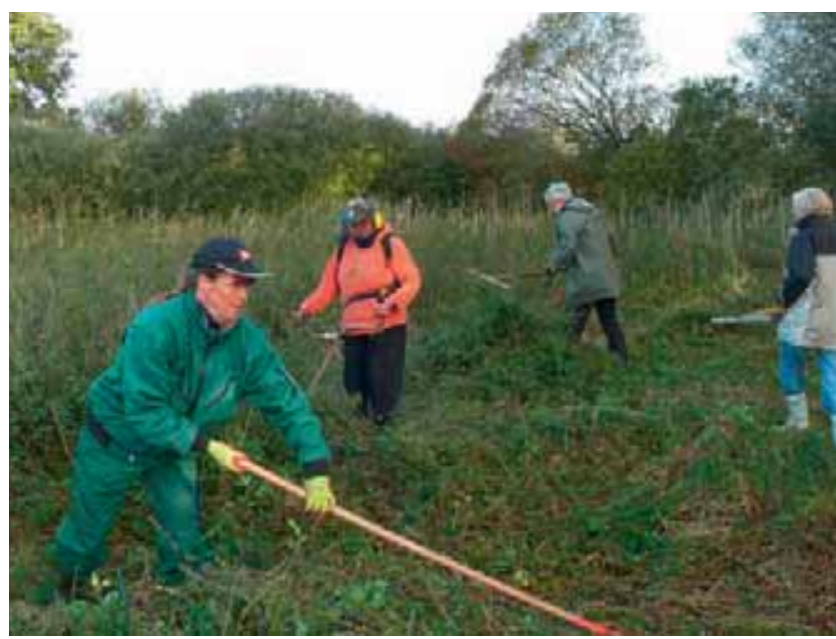

Abb. 131: Wiesenmahd mit der Motorsense (13.10.2012) Foto: B. Meder-Trost.

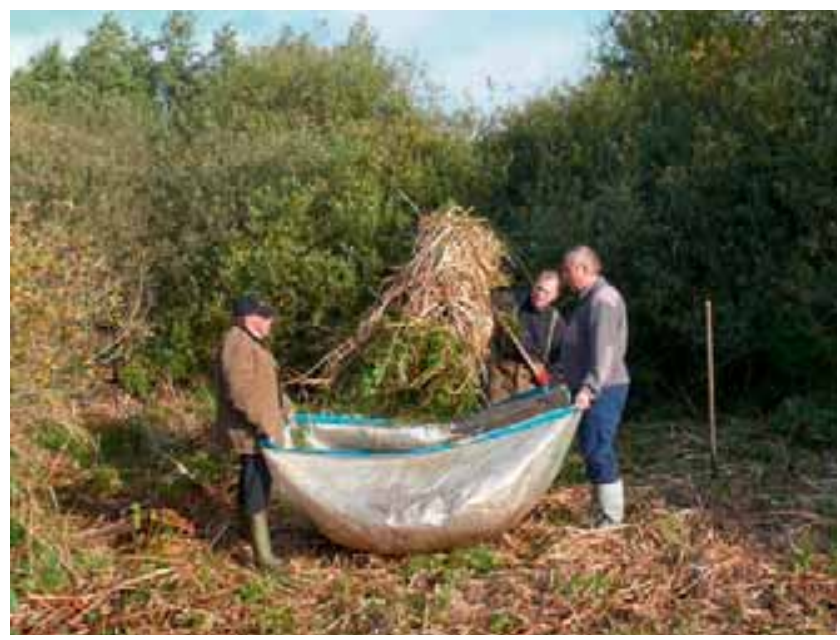

Abb. 132: Guntram Trost, Mathias Schneider und Harry Jahr tragen das Mähgut an den Rand der Mähfläche (23.11.2013).

Foto: B. Meder-Trost.

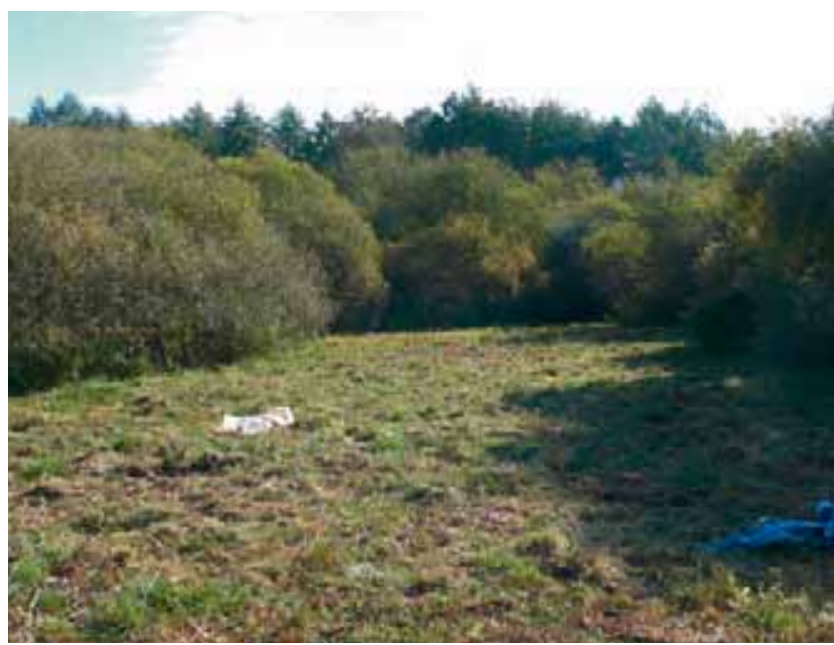

Abb. 133: Die Feuchtwiese ist von den Hochstauden befreit. Foto: B. Meder-Trost.

Im Jahre 2015 wurden zwei Schafe und zwei Ziegen auf den Burgwall gebracht. Da der Burgwall als Halbinsel nicht von Land aus zu erreichen ist, wurden die Tiere mit einem 
aufwendig gefertigten Floß 600 m über das Wasser an- und wieder abgefahren.

Diese Verfahrensweise hatte sich nicht als effizient erwiesen. Die wenigen Tiere, die mit großem Aufwand auf die Halbinsel gebracht werden konnten, zeigten auf der großen Fläche kaum Wirkung. Neue Überlegungen sind für eine effektvolle Beweidung notwendig.

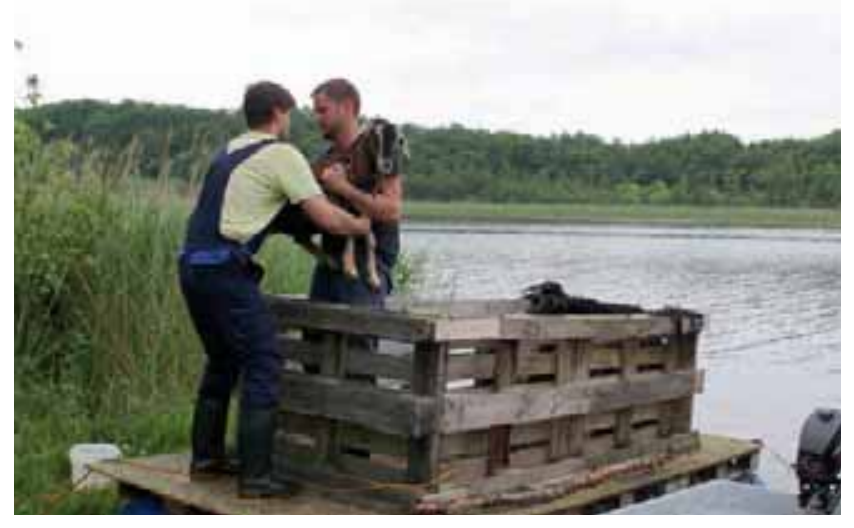

Abb. 134: Zickentransport mit dem Floß zum Burgwall. Foto: B. Meder-Trost

Die Botanikergruppe beging das Gebiet 2014 und will dies kontinuierlich fortsetzen, um Fortschritte in der Pflanzenentwicklung durch Pflegeeinsätze zu dokumentieren. Eine Begutachtung der Flächen durch Ilse Cöster von der Botanik-AG, die den Bereich aus früheren Zeiten gut kennt, brachte wichtige Erkenntnisse über ehemalige Standorte besonderer Pflanzenarten.

Die neu angelaufenen Pflegemaßnahmen wurden zuvor bei Exkursionen auf die Halbinsel von dem für die NSG zuständigen Mitarbeiter der UNB und dem StALU MM für gut befunden und abgestimmt.

Während meiner Betreuertätigkeit hingegen habe ich eine Unterstützung der Naturschutzbehörden - für die NSG war bis 2011 das STAUN Rostock zuständig - oftmals vermisst.
Die im Zusammenhang mit der Betreuertätigkeit jährlich zu verfassenden Berichte wurden von mir vertragsgemäß an das Umweltministerium und zusätzlich an das zuständige Staatliche Amt für Umwelt und Natur gereicht. Sie beinhalteten neben Aussagen zu den im Berichtszeitraum entwickelten Aktivitäten und Ergebnissen hinsichtlich Bestandsaufnahmen und Erfassungen auch Einschätzungen zum Entwicklungsverlauf des NSG und Informationen über festgestellte Probleme oder Verstöße gegen die Schutzverordnung. Gerade im Bezug auf festgestellte Probleme oder Verstöße konnte ich von Seiten des Staatlichen Amtes oftmals keine Aktivitäten zur Behebung der angesprochenen Punkte erkennen. Als Beispiel sei hier die über Jahre hinweg immer wieder in den Berichten angesprochene Situation der Bootsliegeplätze im Bereich der Badestelle Bölkow genannt, die sich zum Großteil ungeordnet im schmalen Bruchwaldsaum östlich der Badestelle befanden. Ob da überhaupt etwas - und wenn ja, was - im Hintergrund zur Behebung dieses Zustandes gelaufen ist, entzieht sich meiner Kenntnis.

Der Informationsfluss zwischen Betreuer und dem STAUN verlief überwiegend in nur eine Richtung. Daran änderten auch die jährlich einmal stattfindenden Treffen der NSGBetreuer in den Räumen des STAUN nichts. Ich fühlte mich mit den Problemen allein gelassen - wie der einsame Rufer in der Wüste. Eine solche Art von Zusammenarbeit empfand ich als wenig zielführend, sie war für mich auf Dauer deprimierend.

So habe ich dann die zeitweise mit dem Umweltministerium vertraglich gebundene Betreuung des NSG zum Ende des Jahres 2006 abgegeben. Seitdem unterliegt das Naturschutzgebiet keiner kontinuierlich planmäßigen Betreuung mehr. Erfassungen erfolgen weitgehend nur noch sporadisch. Die planmäßigen Wasservogelzählungen, die ich bereits seit vielen Jahren am Inselsee durchgeführt habe, werden jedoch von mir fortgesetzt.

\section{Foto 135:}

Blick vom Burghügel auf die verbuschte Feuchtwiese. Die Rückdrängung der Grau-Weide steht noch aus. 13.10.2012)

Foto: B. Meder-Trost.

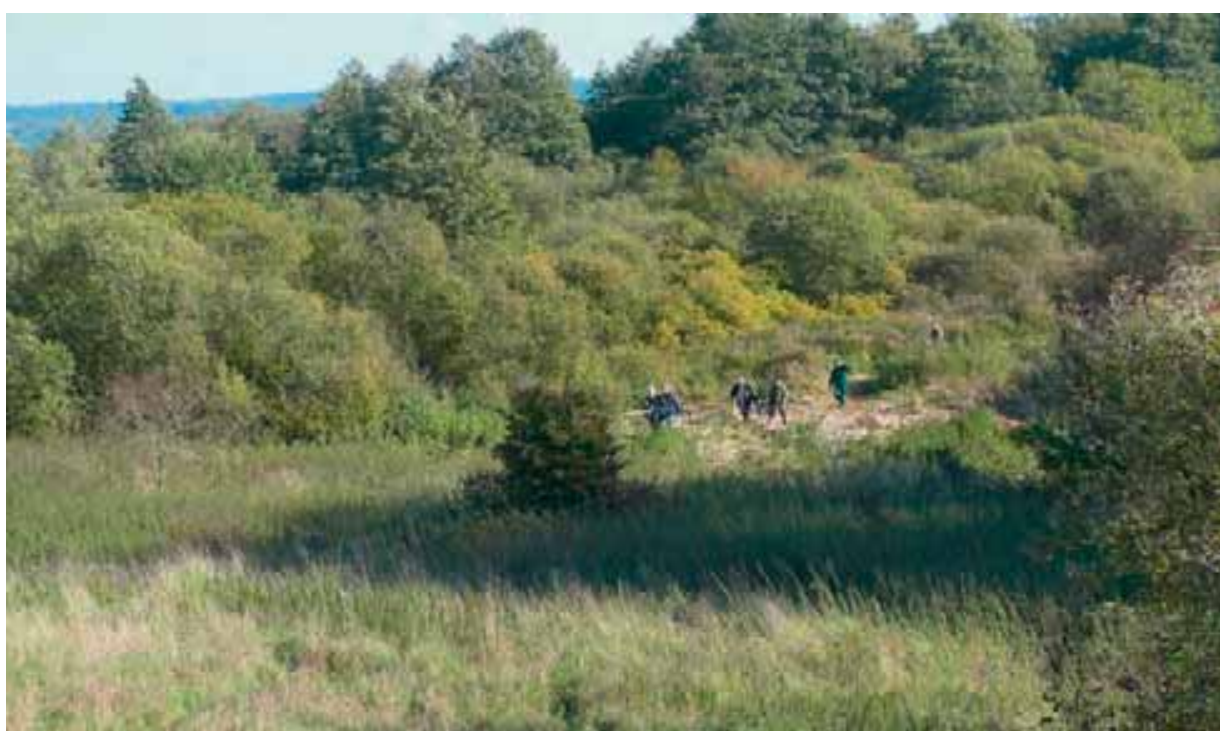




\subsubsection{Aktivitäten in anderen NSG}

\section{Joachim Loose}

Ohne dass aus unserer Fachgruppe NSG-Betreuer wie in den vorgenannten NSG tätig waren, gab es doch eine Reihe von Aktivitäten in weiteren Naturschutzgebieten, mit denen sich einzelne Mitglieder der FG insbesondere gegenüber dem Rat des Kreises für die Sicherung von Gebieten eingebracht hatten. Über einiges, was nicht vergessen werden sollte, wird nachfolgend berichtet.

\section{NSG Nebel (1)}

Ornithologisch interessant war und ist der Flusslauf der Nebel durch Brutvorkommen von Eisvogel und Gebirgsstelze und im Winter als Rastgebiet von Wasseramseln. Die Qualität des Gewässers in ichthyofaunistischer Sicht wurde uns frühzeitig an einem FG-Abend durch den Leiter der AG Heimische Wildfische, Nils Hamann, erläutert. Mit 28 in der Nebel vorkommenden Fischarten gab es regional und im Ländervergleich, selbst im nördlichen Mitteleuropa keine ähnlich artenreichen Fließgewässer. Wir erfuhren auch von dem bedeutsamen Bestand der Kleine Flussmuschel Unio crassus und den hier bereits 1982 in großer Zahl festgestellten Arten von Eintags- (18) und Steinfliegen (7), von denen einige Arten in der Nebel ihren einzigen Nachweisort in der DDR hatten. Bereits ab 1987 bemühten sich die Biologische Station Serrahn (Dr. Spieß) und das ILN, Arbeitsgruppe Greifswald (Dr. Klafs) um eine einstweilige Sicherung des Nebelabschnitts zwischen dem Krakower See und damals noch der F 103 bei Klueß als Naturschutzgebiet.

Der Leiter unserer Fachgruppe und KNB W. Neubauer berichtete 1988 in einer Artikelserie der Schweriner Volkszeitung über die faunistische Bedeutung des Flusslaufes. Zur Sicherung der Wasserqualität in der Nebel stellte Neubauer dabei öffentlich fest, dass von vielen Betrieben noch erhebliche Anstrengungen unternommen werden müssen. Gefordert waren besonders die angrenzenden Landwirtschaftsbetriebe der Tier- und Pflanzenproduktion, die Binnenfischerei und auch Gemeinden mit unzureichender Abwasserbehandlung.

$\mathrm{Zu}$ jener Zeit sollte die Forellenzucht bei Kuchelmiß ausgebaut werden. Notwendige Wasserableitungen aus der Nebel zu diesen Anlagen und Wiedereinleitungen des mit Futterresten und Pharmastoffen belasteten Wassers in die Nebel waren Gründe für uns Naturschützer, sich vehement gegen diese Ausbauabsicht zu stellen. Zur Sicherung der Wasserqualität liegen von 1988/89 zahlreiche Protokolle über Begehungen bei Landwirtschaftsbetrieben vor, in denen die Leiter der Betriebe sowohl von N. Hamann (AG Heimische Wildfische) als auch durch W. Neubauer und A. Martin auf Missstände aufmerksam gemacht und Vorschläge zur Beseitigung unterbreitet wurden.

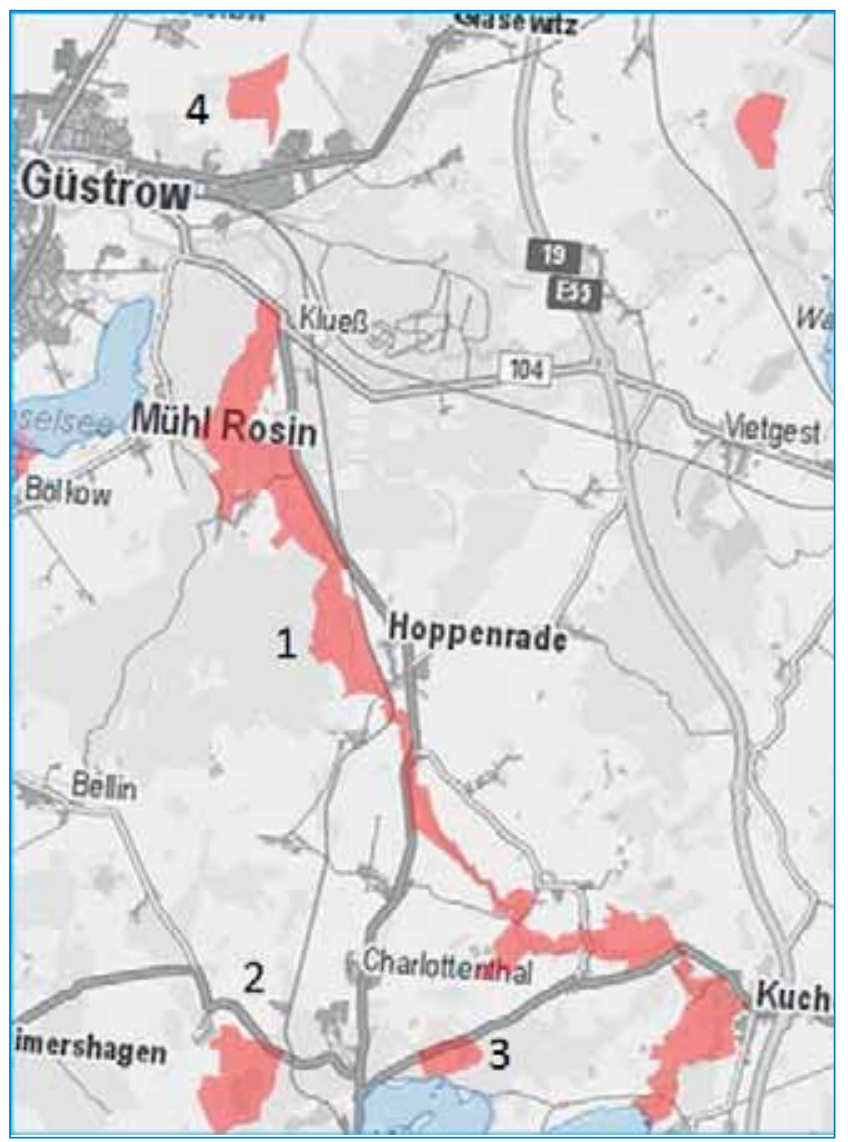

Karte 9: Lage der weiterhin beschriebenen NSG (1)-(4) (Quelle: Kartenportal LUNG)

Nach der einstweiligen Sicherung der Nebel am 5.4.1989 als NSG, damals noch in Grenzen relativ nah zum Flusslauf mit einer Größe von ca. 90 ha, bemühte sich J. Loose in seiner neuen Funktion als Amtsleiter Naturschutz um eine Fischaufstiegshilfe am Wehr Kölln. Hier stürzte das Wasser über eine Höhe von 1,80 m hinab, für Fische aus dem Unterlauf ein unüberwindbares Hindernis. $\mathrm{Zu}$ jener Zeit war nicht daran zu denken, dass einmal dieses große Wasserbauwerk jemals zurück gebaut werden könnte. Auf einer Länge von ca. $40 \mathrm{~m}$ wurde ein Gerinne aus Betonteilen errichtet, das mit großen und kleinen Feldsteinen ausgelegt war. Als die erste Umweltministerin von M-V Dr. Petra Uhlmann im Oberlauf der Warnow zu einer symbolischen Einweihung einer Fischtreppe einlud (hier hatte man nur einige Holztröge ohne wirkliche Funktionalität symbolhaft installiert), war der ohne Presse errichtete Fischbypass bei Kölln bereits in Betrieb. Auch ohne Appell der Ministerin hatten wir erkannt, dass unsere Flüsse und Bäche für wandernde Tierarten wieder durchlässig gemacht werden müssen.

Nach einer Optimierung der Steinpackungen im Gerinne Kölln wurden von Januar 1994 bis Juni 1995 Probefänge oberhalb der Fischtreppe durch unser FG-Mitglied Guntram Trost im Rahmen eines Projektes des Bundesministerium 
für Forschung und Technologie durchgeführt. Die anfangs von einigen Experten geäußerte Skepsis zur Wirksamkeit des kleinen Bypasses bei Kölln konnte mit den Ergebnissen der Probefänge zerstreut werden. Es wurde die Funktionsfähigkeit durch den registrierten Aufstieg von 166 Bachforellen und elf anderen Fischarten in beträchtlichen Zahlen belegt.

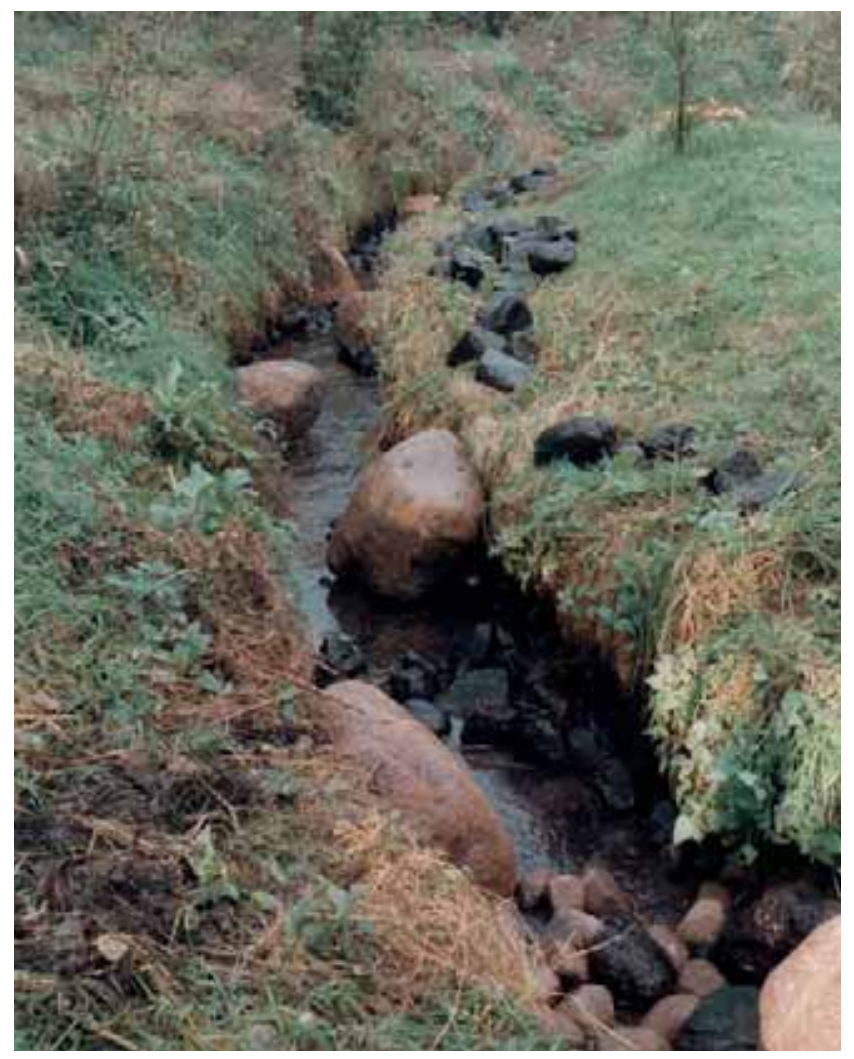

Abb. 136: Von 1991 bis 2000 wirksamer Fischbypass an der Nebel am ehemaligen Wehr Kölln (hier bei Niedrigwasser). Foto: f. Loose.
G. Trost fasste die Effizienzuntersuchungen im FG-Jahresbericht Nr. 28/1995 zusammen.

- Für zehn Jahre dürften die knapp 20.000 DM Baukosten gut angelegtes Naturschutz-Geld gewesen sein. Der inzwischen durchgeführte komplette Rückbau des Staubauwerkes hat einen ungleich höheren Nutzen gebracht, dafür aber auch eine ganze Menge mehr gekostet.

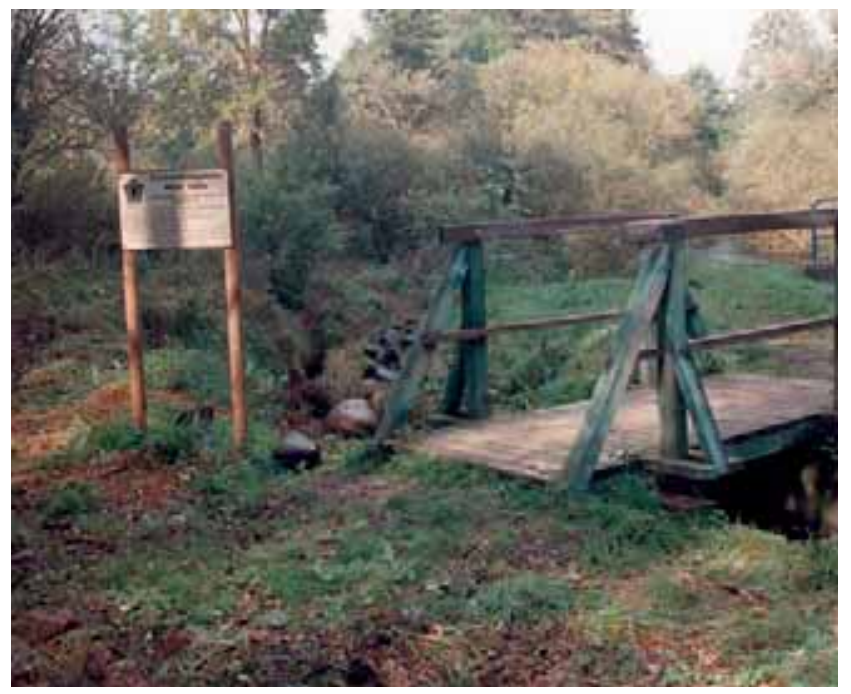

Abb. 137: Ein Wanderweg führte über den Bypass zur Mühle Kölln. Foto: 7. Loose.

Seit der Unterschutzstellung der Nebel war mehrere Jahre unser FG-Mitglied Wolfgang Köhler als Betreuer des NSG mit Vertrag des Umweltministeriums tätig. Schwerpunkt der Betreuung war die Überwachung des Fischottervorkommens und die Pflege der Wälder beidseits der Ufer. Wegen mangelnder Informationen und Zusammenarbeit mit den Behörden hatte auch er die Betreuung beendet.

\section{NSG Cossensee (2)}

Ende der 1980er Jahre suchten Landwirtschaftbetriebe und ACZ überall nach der Möglichkeit, Niedermoortorf und Seeschlamm als Dünger abzubauen. Beim Rat des Kreises hatten mehrere „Praxismodell“-Beratungen zu möglichen Gewinnungsorten stattgefunden. Es wurde auch vor großen Gewässern nicht halt gemacht. Untersuchungen ergaben, dass auch der Cossensee für den Abbau geeignete, ergiebige Lager aufwies.

Mit Schreiben vom 14.12.1988 hatte sich W. Neubauer in seiner Funktion als Kreisnaturschutzbeauftragter an den Gen. Volkmann als Stellvertreter des Vorsitzenden des Rates des Kreises Güstrow gewandt und auf die Bedeutung des Cossensee sowie die nachteiligen Folgen bei einer Seeschlammgewinnung hingewiesen. Er stellte heraus, dass die Mitarbeiter des Rates nach seiner Meinung für eine sachgerechte Entscheidung überfordert seien und für das Abschätzen der Folgen einer so tiefgreifenden Veränderung dieses Landschaftselementes nicht sachkundig gemacht wurden. Er bat um Unterstützung und forderte eine erneute Beratung ein.
Am 28.2.1990 endlich trafen sich Vertreter des Rates des Kreises, der verschiedenen Landwirtschaftsbetriebe und der Naturschutzseite (Dr. Jeschke, Dr. Naake, Dr. Holst, Dr. Neubauer).

Für die Seeschlammgewinnung am Cossensee hatte man bereits 1989 einen breiten Erddamm angelegt und inzwischen schon mit dem Abbau an dem ca. Eine-MillionenMark-Projekt begonnen. Dieses Projekt sollte nun auf Forderung des Naturschutzes beendet werden. - Der gesamte Investionsaufwand war mit 2,5 Mio. Mark eingeplant und bezog den Karower See und den Möllener See mit ein! Vonseiten der Landwirtschaft verwies man darauf, dass man mit dem Einsatz von $150 \mathrm{~m}^{3} /$ ha Seeschlamm große Mengen von Mineraldünger einsparen könne: Stickstoff 0,9 dt/ha, Phosphor 0,4 dt/ha, Kali 0,2 dt/ha, Magnesium $0,8 \mathrm{dt} / \mathrm{ha}$ und Kalk $28 \mathrm{dt} / \mathrm{ha}$. Im Übrigen seien bereits erhebliche Investitionen eingesetzt worden.

Dr. Jeschke betonte auf der Beratung, dass der Cossensee keineswegs krank sei und nicht saniert werden müsse, weil man seitens der „Abbauer“ auch immer wieder gern von 


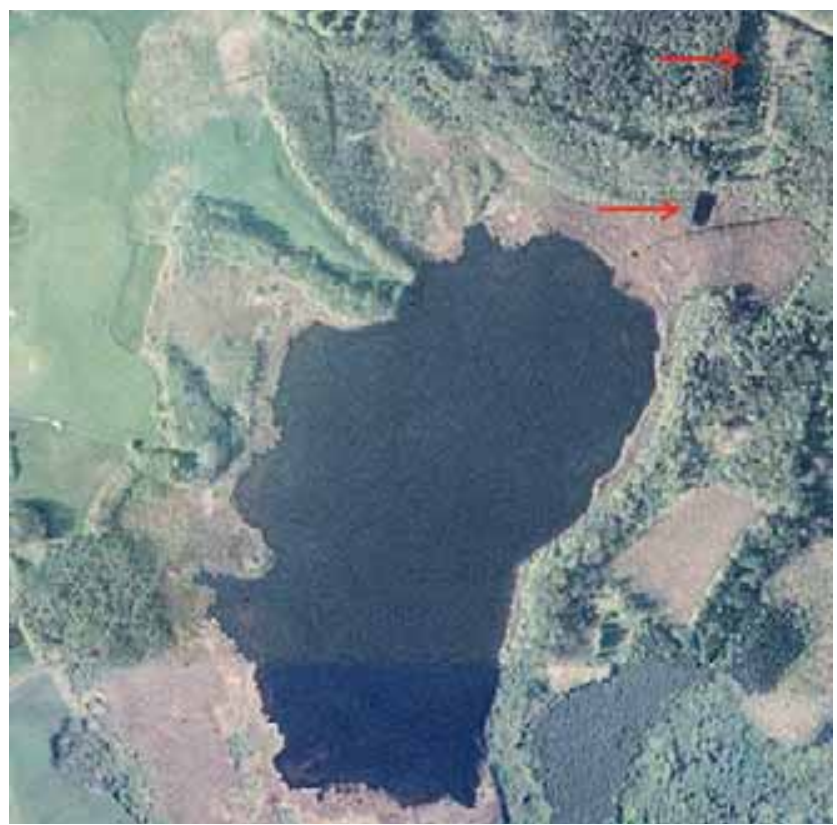

Abb. 138: Der Cossensee 2002 - im Norden von der L 11 ausgehend die Schneise zur begonnenen Abbaufläche mit dem ersten Anschnitt (rote Pfeile) - Quelle: Kartenportal LUNG

„Seensanierung“ sprach. Zukünftig hätten Fragen des Natur- und Umweltschutzes eine neue Wertigkeit. Für Maßnahmen wie Seeschlammgewinnung oder Seensanierungen müssten Umweltverträglichkeitsprüfungen vorgenommen werden.

Ein Vorgriff auf das neue Recht in der Bundesrepublik aber noch hatte der Rat des Kreises das Sagen. So beendete Gen. Volkmann auch diese Beratungsrunde mit der Festlegung, dass man bis zum 16.03.1990 in einer Arbeitsgruppe schriftliche Kompromisslösungen im Fall Cossensee erarbeiten und sich am 6.4.1990 erneut treffen wolle, um darüber zu entscheiden. Eine vom Naturschutz erarbeitete begründete Kompromisslösung enthielt die Forderungen, den gesamten Röhrichtgürtel aus den vorgesehenen Flächen zur Seeschlammgewinnung herauszunehmen sowie die Ränder der entschlammten Flächen mit solchen Böschungen $\mathrm{zu}$ versehen, dass die Ansiedlung von Schilf möglich wird. - Das war ein wirklich „fauler Kompromiss“, wie viele andere zu DDR-Zeiten, wo die Wirtschaftlichkeit Vorrang hatte. Bei einer Entnahme der bis zu $10 \mathrm{~m}$ mächtigen stark kalkhaltigen Seeschlammablagerungen

\section{NSG Ahrenshäger See (3)}

Im Gefolge des kurz vor der politischen Wende durch die letzte DDR-Regierung auf Initiative von Prof. Michael Succow beschlossenen Nationalparkprogramms wurden durch den Bezirksbeauftragten mit Beschluss vom 1.10.1990 auch eine ganze Reihe von neuen NSG im Bezirk Schwerin ausgewiesen. Für den Ahrenshäger See (auch Brinksee genannt) gab es zuvor eine einstweilige Sicherung als NSG durch den Rat des Kreises Güstrow. Nach Diskussion in unserer Fachgruppe stellte Wolfgang Neubauer mit Schreiben vom 10.2.1990 an den Rat des Bezirkes Schwerin den

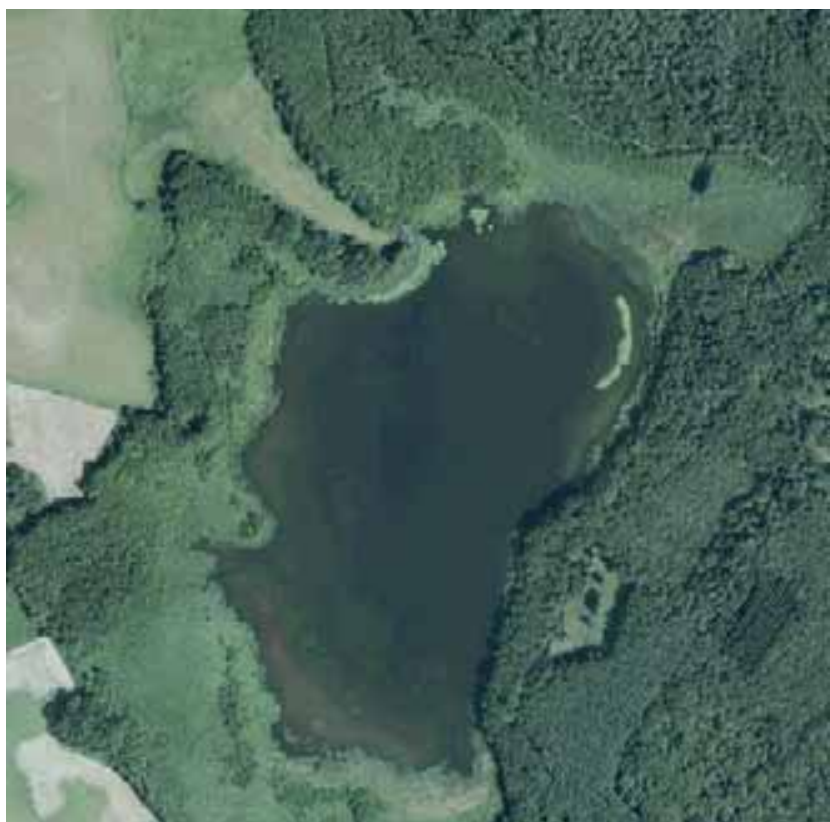

Abb.139: Der Cossensee 2013 - Quelle: Kartenportal LUNG

$\left(40 \% \mathrm{CaCO}_{3}\right)$ würde sich der bisherige Seetyp total ändern. Es würde die gesamte Unterwasserlebewelt, insbesondere der wertvolle Armleuchteralgen (Characeen)-Bestand vernichtet werden.

$\mathrm{Zu}$ den weiteren unmittelbar folgenden Entscheidungen liegen uns keine Protokolle mehr vor. Aus den Unterlagen von W. Neubauer ist jedoch ersichtlich, dass man wohl mit den vorgenannten Forderungen das Vorhaben (vermutlich wegen der nun entstandenen Unwirtschaftlichkeit) noch hatte kippen können.

Zum Glück für den Cossensee kam die politische Wende noch rechtzeitig, und der See mit seinem Umland konnte in seiner heutigen Qualität erhalten und als Naturschutzgebiet ausgewiesen werden. Fast bis zum Ende des Jahrtausends lagen die von dem Bagger benutzten Pontons noch am Waldrand zum NSG.

Mit dem NSG hatte sich dann anfangs insbesondere unser FG-Mitglied K.-H. Koop beschäftigt, ohne dass er jedoch auch eine intensivere Betreuertätigkeit übernahm.

begründeten Antrag auf einstweilige Sicherung des Sees einschließlich seines Umfeldes als Naturschutzgebiet. Als Unterschutzstellungsgrund wurden unsererseits der sehr seltene Seentyp, die sehr gute Wasserqualität des Gewässers sowie die im See und an dessen Ufern und in einem kleinen Randmoor vorkommenden seltenen Pflanzenarten vorgetragen. Der Antrag wurde am 4.4.1990 durch Hannes Wrobel, der gerade erst „Chef“ der neuen Umweltbehörde im Kreis Güstrow geworden war, dem Rat des Kreises vorgetragen und mit Beschluss Nr. 14 bestätigt. Die Zeit 
für Naturschutzbeschlüsse war beim Kreis zu jener Zeit genauso günstig, wie später in der scheidenden DDR beim Beschluss des Nationalparkprogramms.

Als Besonderheit ist anzumerken, dass nach der Ausweisung des NSG durch die Festlegung des Bezirksbeauftragten von 1990 bis heute keine weiteren Schritte zur Erstellung einer NSG-VO erfolgt sind. Die mit der einstweiligen Sicherung durch uns erstellte Behandlungsrichtlinie dürfte u.E. keine Rechtskraft mehr haben, so dass für das Gebiet eigentlich dringend Handlungsbedarf bei der zuständigen Naturschutzbehörde besteht.

Die Botanik-AG erfasste in größeren Abständen die Vegetation im Randmoor und Seeufer. Hier befindet sich ein Standort der seltenen Binsen-Schneide (Cladium mariscus).

\section{NSG Bockhorst (4)}

Vor der Wende gehörte das Gelände des heutigen NSG zum Schießplatz und Panzerübungsgelände der Sowjetarmee. Es bestand somit kein Zutritt in dieses Gebiet. Durch die militärische Sperrung und fehlende intensive landwirtschaftliche Nutzung blieben diese Flächen nährstoffarmes Offenland.

Nach dem Abzug der sowjetischen Truppen erkundeten FG-Mitglieder das Neuland. Botaniker erfassten einige floristische Besonderheiten, die den vornehmlichen Grund für eine Unterschutzstellung als NSG Ende 1994 bildeten. Auf den nordöstlichen Hügeln befanden sich neben vielen anderen bemerkenswerten Pflanzenarten der Sandmagerrasen auch Bestände von Wiesen-Kuhschellen. Ohne Pflegeeingriffe bestand die Gefahr, dass diese Arten über kurz oder lang verschwinden würden. Bereits 1991 hatte unser FG-Mitglied Volker Thiele die Schmetterlingsfauna auf den damals noch intakten Magerrasen in drei Exkursionen Anfang Juni und August erfasst. Mitsamt der gesammelten Raupen waren es 33 Arten.

Das Gebiet galt als munitionsbelastet, so dass Gespräche mit potentiellen Nutzern stets an diesem Umstand scheiterten. Staatliche Stellen konnten offiziell kein Risiko eingehen. Anders die ehrenamtliche Seite. Reinhard Becker von unserer Fachgruppe war sofort für die so dringend notwendige Mahd ansprechbar. Er hatte keine Bedenken vor eventuell auf der Fläche liegenden Blindgängern. An die notwendige Kleintechnik kam er durch gute Beziehung zu seinem früheren Betrieb (VEB Agrotechnik) heran. Mitte der 1990er Jahre unternahm er mit Angela Martin zunächst eine Geländebesichtigung, um die Flächen nach Pflegebedürftigkeit einzustufen. Die ersten Runden mit dem RS 09 bewerkstelligte R. Becker ohne Vorkommnisse. Um Erlaubnis wurde nicht gefragt. Dann gab es Schwierigkeiten mit der Technik, die überwindbar waren. Das Projekt blieb jedoch leider durch den frühen Tod von R. Becker in den Anfängen stecken. Es fand sich wie so oft kein Ersatz. Wiederholt forderten wir eine Pflege bei den Mitarbeitern des Staatlichen Amtes in Rostock zum Erhalt der wertvollen

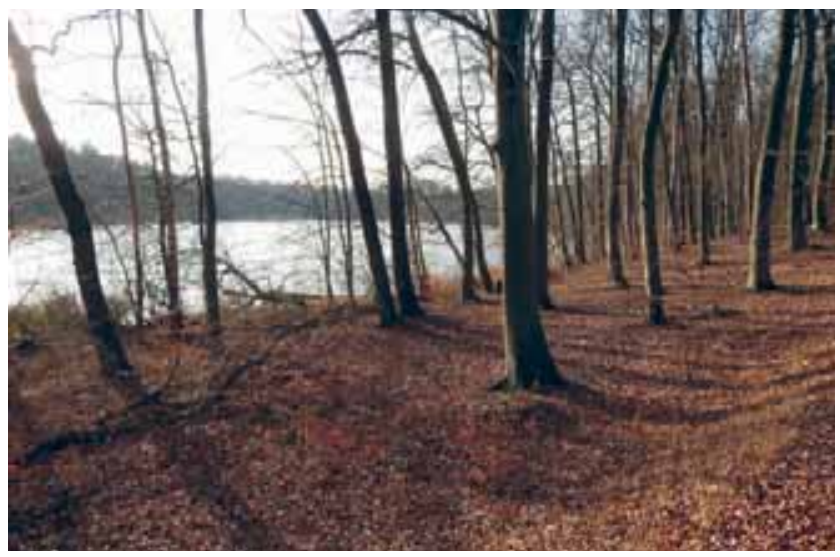

Abb. 140: Blick von der Straße auf den Ahrenshäger See. Foto: 7. Loose.

Vegetation als unbedingt notwendig ein. Bis zum heutigen Tag hat sich allerdings leider auf den Magerrasenflächen nichts getan. Eine vom StAUN Rostock initiierte Beweidung der zunehmend verbuschenden Niederungsflächen mit Heckrindern über einen privaten Landwirt war als vorrangig angesehen worden. Sie lief auf Grund entstehender administrativer Probleme nur wenige Jahre. Die hohen Kosten für die Errichtung der aufwendigen Zaunanlage waren damit weitgehend in den Sand gesetzt. - Aus unseren ehrenamtlichen Reihen fand sich niemand für die Betreuertätigkeit des NSG. Allein unsere Botanik-AG war in größeren Abständen im Gebiet und machte regelmäßig auf die immer dringender werdende Pflegenotwenigkeit bei der zuständige Stelle aufmerksam. Es wäre auch an der Zeit, einige der in den 1990er Jahren hauptamtlich für den Pflege- und Entwicklungsplan des NSG angefertigten Erfassungen zu aktualisieren. Schließlich gehört das NSG Bockhorst mit der Nr. DE 2139-301 zu den ausgewiesenen FFH-Gebieten, für die das Land $\mathrm{M}-\mathrm{V}$ eine Berichtspflicht gegenüber der EU hat.

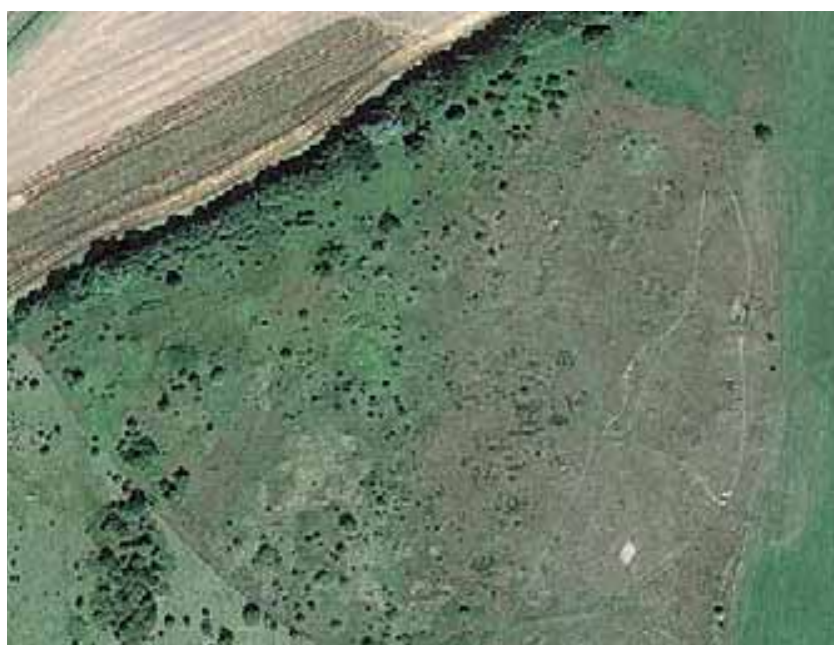

Abb. 141: Der nordöstliche Teil des NSG stellt sich als Magerrasenfläche dar und bedarf zumindest auf den östlichen Hängen einer Pflegebewirtschaftung, damit er nicht verbuscht. (Quelle: Google Earth). 


\subsection{Gebietsausweisungen und Betreuung - Flächennaturdenkmale [FND]}

In vorliegender Zusammenstellung der Leistungen unserer FG-Mitglieder darf auch dieses Kapitel nicht fehlen, wenngleich die Sicherung von Flächennaturdenkmalen mit der hauptamtlichen Tätigkeit von Angela Martin ab 1983 als Mitarbeiterin für Landeskultur/Naturschutz im StFB eng verbunden war.

Die Initiative für die Unterschutzstellungen ging dabei allein von ihr aus. An ihrer Arbeitsstätte ließ man ihr von Anfang an freie Wahl über das Ausfüllen ihres Aufgabenfeldes, d.h. es gab keinerlei direkte Aufgabenstellungen. Bereits seit dem Inkrafttreten der Ersten Durchführungsverordnung vom 14.Mai 1970 zum Landeskulturgesetz der DDR gab es die Möglichkeit, auch kleine wertvolle Gebiete als Flächennaturdenkmale auszuweisen.

Die Intensivierung in der Landwirtschaft war Ende der 1970er Jahre inzwischen so weit vorangeschritten, dass halbnatürliche (also ursprünglich vom Menschen geschaffene) Standorte mit ihrer ganz typischen Pflanzen- und Tierwelt nur noch in verschwindend kleinem Umfang vorhanden waren. Da das weitmaschige Netz von NSG in vielen Fällen nicht ausreichte, um ein möglichst breites Artenspektrum zu erhalten, musste auch bei uns dringend ein engeres Netz kleinerer Schutzgebiete ergänzt werden.

Angela Martin berichtet selbst über diese Zeit:

Mir wurde ziemlich schnell ein „Makel“ in der Naturschutzarbeit des Kreises bewusst:

Auf dem Territorium des Kreises befand sich kein einziges Flächennaturdenkmal (FND).

Die kleine und - wie sich später herausstellte - bedeutendste Flachmoorfläche „Bornbruch“ wurde vom KNB zwar als FND geführt, hatte aber diesen Schutzstatus nicht offiziell.

Als eine meiner ersten Aufgaben stellte ich potentielle FND zu einer Übersicht zusammen.

Den Anfang bildeten diejenigen Flächen, die bereits als inoffizielle FND geführt wurden. Das waren zwei Flächen bei Krakow am See und die Fläche des gelöschten NSG „Binnendünen an der Recknitz" bei Laage. Weiterhin erhielt ich zufällig Unterstützung durch die Botaniker Mecklenburgs, deren drittes Exkursions- und Arbeitstreffen 1982 in Güstrow stattfand. Dabei trugen sie eine große Menge an Fundorten zusammen und hatten auch einige Flächen mit hoher botanischer Bedeutsamkeit entdeckt, die als FND gesichert werden sollten.

Einen Großteil der potentiellen FND bildeten jedoch Torfmoosmoore und Brüche, die im Bereich des Forstbetriebes lagen. Sie wurden zunächst nach der Standortsform aus dem Wirtschaftsbuch herausgesucht. Danach fuhr ich mit dem Fahrrad zu den Flächen und überzeugte mich von ihrer Schutzwürdigkeit. Weitere Flächen kamen dazu, die bei Erkundungsfahrten außerhalb der Dienstzeiten per Fahrrad als schutzwürdig aufgefallen waren.

Für die geplante Unterschutzstellung bereiteten die Eigentumsverhältnisse überhaupt keine Probleme. Fast alle Flächen waren „staatlich“, es gab nur die Unterscheidung, ob die Forst- oder Landwirtschaft oder Kommunen die Flächen in ihrem Wirtschaftsbereich führten.

Mit den Rechtsträgern, die oft kein Interesse an den „nutzlosen“ Flächen hatten, musste über notwendige Pflegemaßnahmen verhandelt werden, was nicht immer zu unserer vollen Zufriedenheit ausfiel.

Die Größenvorgabe für FND beschränkte sich nach der 1. Durchführungsbestimmung zum Landeskulturgesetz der DDR auf maximal 3 ha (ab 1985 bis 5 ha). Bei der Flächenauswahl für unseren Kreis Güstrow behandelte man das sehr „leger“. So hatte das Range Moor z. B. sogar 39 ha.

Zunächst wurden dem Rat des Kreises 30 Flächen in einer nach heutiger Sicht einfachen Auflistung zur Unterschutzstellung vorgeschlagen.

Als mit Ratsbeschluss Nr. 17 vom 25.7.1984 die einstweilige Sicherung als FND erfolgte, war damals für Angela Martin eine aus ihrer Perspektive „schier endlose Geschichte“ zum Abschluss gebracht worden. Aus heutiger Sicht verlief dieser Prozess aber überraschend schnell und ließe sich in dieser Art jetzt nicht mehr umsetzen.

Unabhängig von dem eingereichten Antrag „sammelte“ Angela Martin weiter kleine interessante und schutzwürdige Flächen für eine spätere Unterschutzstellung. Es bestand die Gefahr, dass Landwirtschaftsbetriebe auch Rest- und Splitterflächen in eine intensive Nutzung überführen könnten. Andererseits unterlagen Flächen einer Sukzession und verloren ihren Wert für den Naturhaushalt. Hier galt es gegenzusteuern. In der zunehmenden Verarmung unserer Landschaft durch immer intensivere Nutzung („Vernutzung“!!) erfüllten gerade solche Flächen die Funktion von Rückzugsgebieten. In Naturschutzkreisen wurde immer stärker darüber debattiert, dass viele bedrohte Pflanzen- und Tierarten mit einem NSG-Netz nicht ausreichend geschützt werden können. Aus diesem Grunde waren kleine Schutzflächen außerhalb von NSG notwendig.

Mit Ratsbeschluss Nr. 65 vom 10.Juni 1987 wurden in ähnlich einfacher Weise schließlich weitere 15 kleine Flächen einstweilig als Flächennaturdenkmal unter Schutz gestellt.

Mit den nunmehr 45 Flächen waren wichtige Standorte geschützter Pflanzen und selten gewordener Pflanzengesellschaften gesichert worden. Sozusagen als "Trittsteine“ 
lagen die FND in unserem Kreis verteilt, konzentrierten sich entsprechend der reicheren Naturraumausstattung im Süden des Kreises (siehe Karte 10 und Tabelle 3).

Die allgemein gefährdetsten Biotope nahmen den größten Teil der Fläche ein. Bei den Mooren und Brüchen (28), überwiegend in Waldlagen, konzentrierte sich das Schutzanliegen auf die Erhaltung des gesamten Lebensraumes Moor mit all seinen Bedeutungen im Naturhaushalt. Dazu gehörte auch deren avifaunistische Relevanz z.B. als Kranich-Brutplatz (damals vor dem Bestandsanstieg noch wichtiger als heute), Lebensraum für den Waldwasserläufer und potenziell auch als Revier für den Schwarzstorch und Schreiadler.

Feuchtwiesen (6), die auf Flachmoorböden vor den durchgreifenden Meliorationsmaßnahmen überall großflächig vorhanden waren, bargen früher eine Fülle geschützter bestandsgefährdeter und vom Aussterben bedrohter Pflanzenarten.

Den Wiesenorchideen galt das besondere Augenmerk. Breit- und Steifblättriges Knabenkraut wurden in ihren größten Vorkommen gesichert. Auch bei geringer Ausdehnung diese Restflächen hatten z.B. die Feuchtwiese am Lohmer See oder die Ochsenwiese am Linstower See auch ornithologisch ihre Bedeutung als Lebensraum für Bekassine und Wachtelkönig.

Die für den kontinentaleren Bereich Mecklenburgs typischen Halbtrocken- und Trockenrasen (6) kommen in unserem Gebiet klimabedingt seltener vor. Die wenigen vorhandenen sind zumeist der Intensivierung zum Opfer gefallen. Der Cesserberg bei Mierendorf und der Abhang am Linstower See waren noch mit relativ artenreichen Pflanzengesellschaften ausgestattet. Magerrasenpflanzen bedeckten ursprünglich die Höhenzüge nördlich von Laage, wobei Wiesen- und Gewöhnliche Kuhschelle die auffälligsten Vertreter waren. Die davon im aufgedüngten Grünland übriggebliebenen Reste könnten sich bei strikter Einhaltung der Behandlungsrichtlinie durch die Landwirtschaft durchaus regenerieren.

Zwei weitere Flächen gehörten den bisher aufgeführten Kategorien nicht an: das Feldgehölz (einer Naturwaldzelle ähnlich) auf dem Hohen Berg bei Kuchelmiß mit einem Saum wärmeliebender Pflanzen und die Eichengruppe bei Zietlitz als Ansammlung von Einzelnaturdenkmalen.

Das Ende der 1970er Jahre gelöschte NSG Jasenberg mit einem wertvollen Bestand von Trauben-Eichen wurde 1987 wie bei der Löschung vorgesehen nunmehr als FND unter Schutz gestellt.

Auch zwei reine Gewässerbiotope wurden in das FNDSystem integriert. Zum einen war das eine frühere Mergelgrube am Rande der Güstrower Südstadt. Sie war Laichgewässer einer großen Population von Wechselkröten, die in der damals angrenzenden Gärtnerei ihren Lebensraum fand.
Zum anderen wurde ein eisenhaltiger Quellbereich eines Nebenbachs zum Teuchelbach bei Bellin unter Schutz gestellt, der in seiner Erscheinung als „Quelltopf “ für unseren Bereich eine sehr seltene Erscheinung ist.

Es war uns klar, dass die Sicherung der Flächen nur ein erster Schritt zur Erhaltung der Artenvielfalt war. Einige Flächen, wie u.a. die Orchideen- und Trollblumenwiesen oder die Kuhschellenstandorte, bedurften regelmäßiger Pflege durch eine Mahd. Ebenso waren andere Gebiete, wie Feuchtwiesen und Magerrasenflächen vor einer Verbuschung zu bewahren. Es musste also gelingen, durch ein Management langfristig die Bedeutung der Flächen zu sichern.

Zu DDR-Zeiten war die einstweilige Sicherung von Schutzgebieten auch über längere Zeiträume gängige Praxis. Nach der Wende fiel es erst der neuen Naturschutzbehörde wieder auf, dass auch diese FND seinerzeit nur dem einstweiligen Schutz unterstellt worden waren. Mit Beschluss Nr. 15 vom 23.10.1990 des Kreistages Güstrow erfolgte umgehend die endgültige Unterschutzstellung der 45 Gebiete als Flächennaturdenkmale. Heute sind die Gebiete im Kartenportal des LUNG als FND dargestellt. Einige davon wurden nach der Wende jedoch in Erweiterungsflächen von $\mathrm{Na}$ turschutzgebieten einbezogen: die Lehmkuppe westlich bei Ahrenshagen in das NSG Nebel, die Glaver Koppel und die Moorwiese am Wadehäng gingen ins NSG Krakower Obersee ein.

In der neuen Naturschutzgesetzgebung wurden bestimmte Lebensräume als gesetzlich geschützte Biotope verankert. Dazu gehören Moore, Sümpfe, Röhrichte und Riede, Nasswiesen, naturnahe Bruchwälder, Feldgehölze und Hecken sowie Quellen. Die ausgewiesenen FND sind damit fast alle auch als sogenannte $§ 20$-Biotope gesetzlich geschützt. Dieser gesetzliche Status hat insofern eine Bedeutung, da die damit geltenden Verbotstatbestände für geschützte Biotope heute konkreter und strenger greifen, als die „laschen“ (zu DDR-Zeiten ausreichenden) Regelungen aus der FNDUnterschutzstellung.

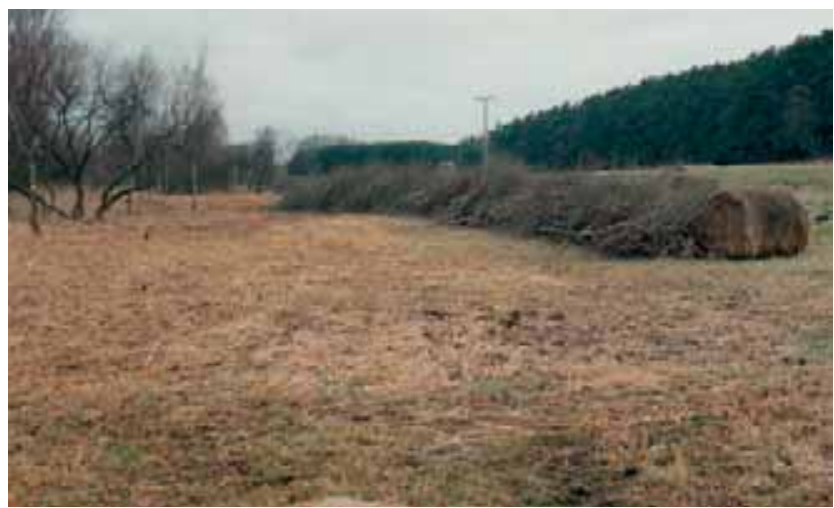

Abb.142: Die Entbuschung auf der Moorwiese am Lohmer See (FND-Nr. 22) wurde 1995 durch das StAUN Rostock aus dem Moorschutz-Programm des Landes bezahlt. Foto: F. Loose. 
Die auf dem Papier stehenden Verbote nützen jedoch wenig, wenn die notwendige Pflege der Biotope nicht abgesichert wird. Während für einige bedeutende Flächen, wie die Moorwiese am Lohmer See, das Bornbruch und den Maeckelberg bei Krakow am See durch die Naturschutzbehörden regelmäßig die Mahd organisiert wurde, blieben andere Flächen unbewirtschaftet liegen.

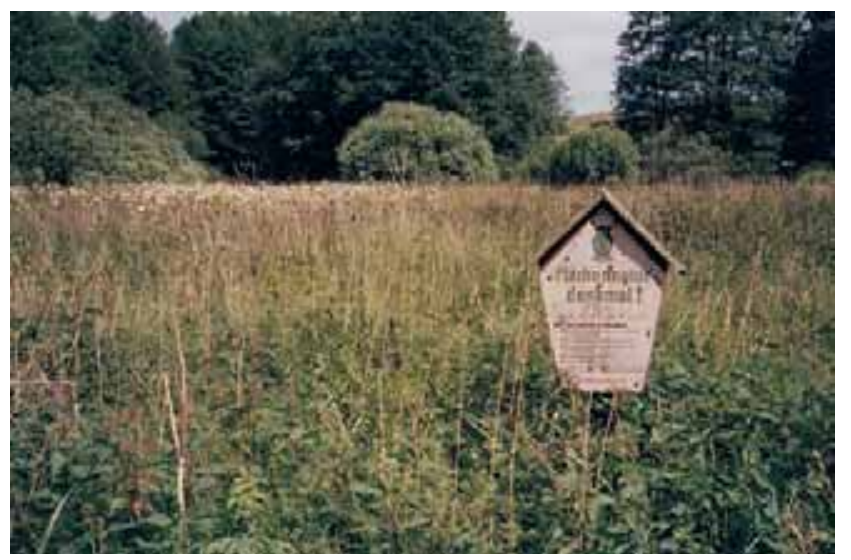

Abb. 143: Blick in das FND Nr. 11 am Korleputbach (Standort von Trollblumen) - Die Trollblumen kommen ohne Mahd nicht mehr gegen die Hochstauden durch. Foto: f. Loose.

Für den Kuhschellenhügel bei Laage hatte sich A. Martin lange um ein Pflegemanagement bemüht. Es gab Hoffnung, dass hier über die Stadt Laage etwas geschieht. Von einer Schülergruppe wurde in einem Projekt sogar ein kleiner Lehrpfad mit Info-Tafeln über Pflanzen und Tiere angelegt und dazu ein Faltblatt erstellt. Der Lehrpfad ist inzwischen nur noch ein Trampelpfad. Eine erhoffte Pflegemahd oder die empfohlene Beweidung der Flächen blieben bisher aus. Bei vielen Moor-FND ist kein Entbuschen als Pflegemaßnahme, sondern „nur“ die Einstellung eines höheren Wasserstandes notwendig. Einige Moore um Reimershagen, aber auch im Norden des Altkreises sind heute trocken gefallen und in der Folge bewaldet. Die zu Zeiten der Unterschutzstellung ursprüngliche vorhandene Moorvegetation ist heute nicht mehr zu finden.

Abb. 144/145: Das FND Nr. 9 „Höhenzüge nördlich Laage“"(Kuhschellen-Standort) hatte am 01.06.1983 offenen Bodenstellen, die am 26.10.2015 mit dicker Grasauflage und Ginsteraufwuchs belegt waren. Fotos: A. Martin und f. Loose.

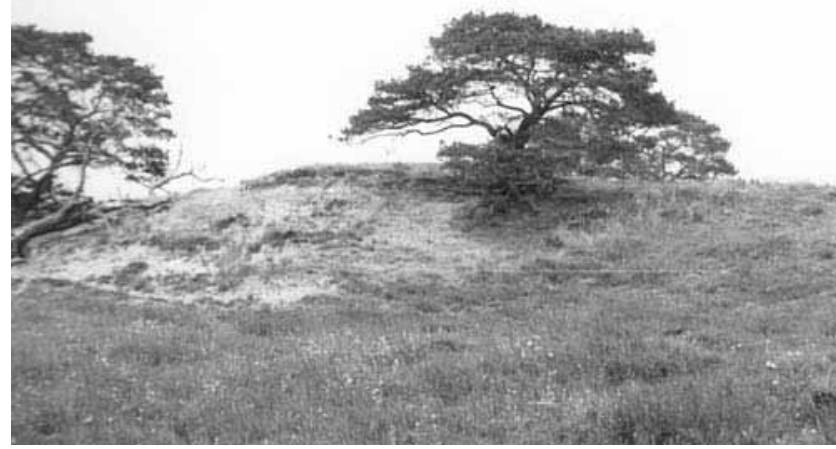

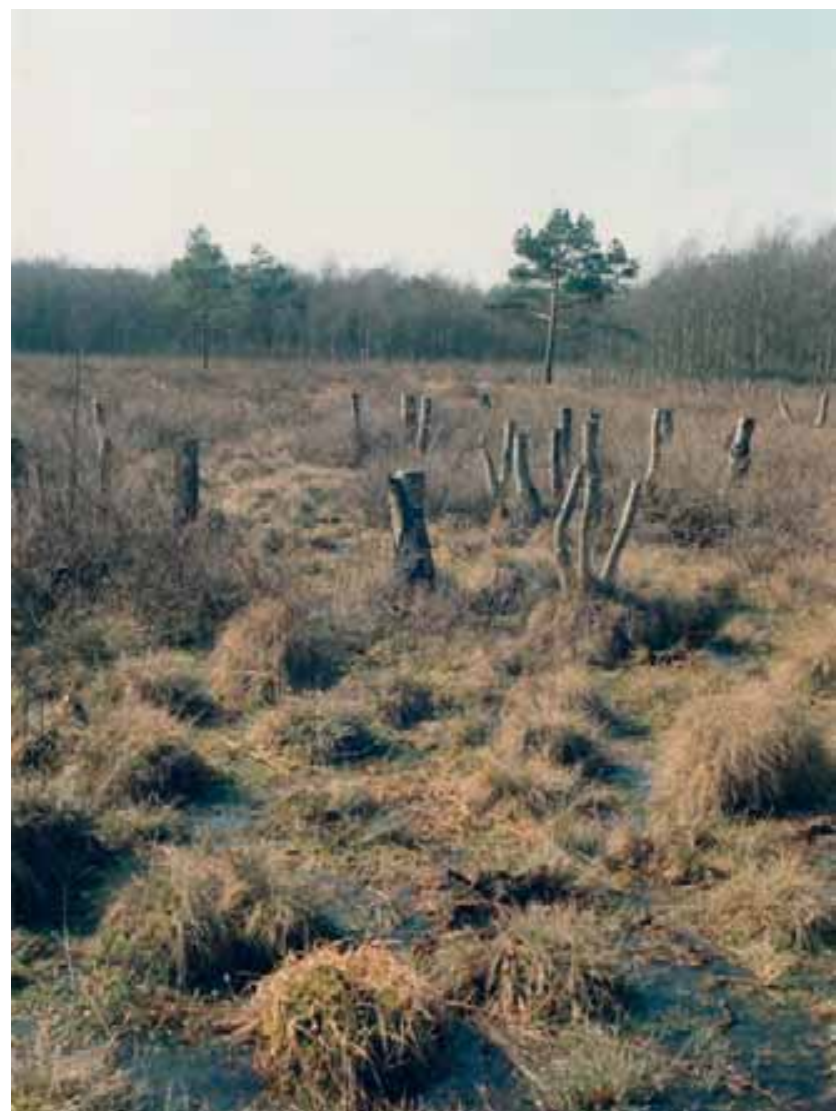

Abb. 146: Im FND Nr. 8 „Rangemoor" wurden Anfang der 1990er Jahre größere Birken gerodet. Jetzt muss nur immer der Wasserstand hoch gehalten werden. Foto: f. Loose.

Eine Betreuung der FND besteht heute darin, dass die Botanik-AG jährlich einige der Gebiete kontrolliert und den aktuellen Zustand feststellt. Darauf folgen Hinweise für notwendige Pflegemaßnahmen an die UNB oder auch die Naturparkverwaltung in Karow.

Seltener wurden Pflegemaßnahme (Entbuschen, Plaggen) in kleinerem Maße auch durch die Gruppe selbst ausgeführt.

So bemühten sich Ende Oktober 2007 zehn Mitglieder der Botanik-AG und der FG Ornithologie und Naturschutz gemeinsam, im Kalkflachmoor „Bornbruch“ am Stadtrand von Krakow am See durch Abplaggen von Wiesenflächen die Lebensbedingungen für den Sumpf-Enzian zu verbessern.

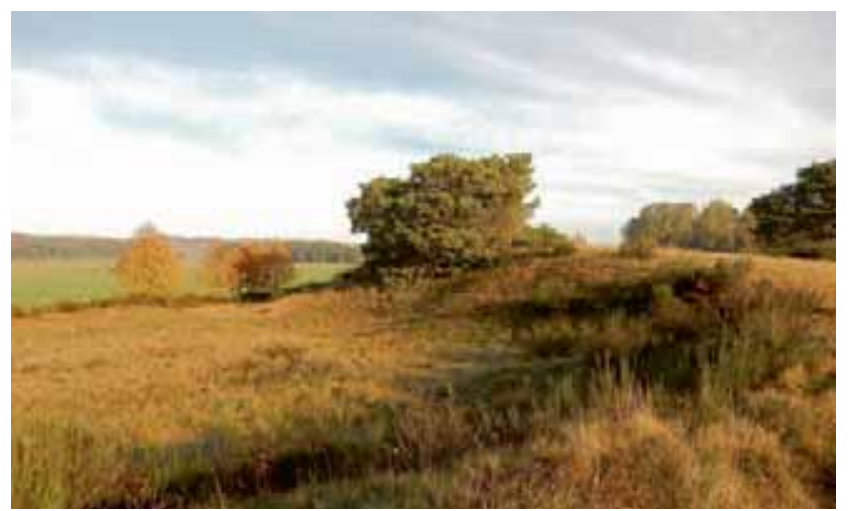


Karte 10: Verteilung der 45 Flächennaturdenkmale (vgl. dazu Tabelle 3)

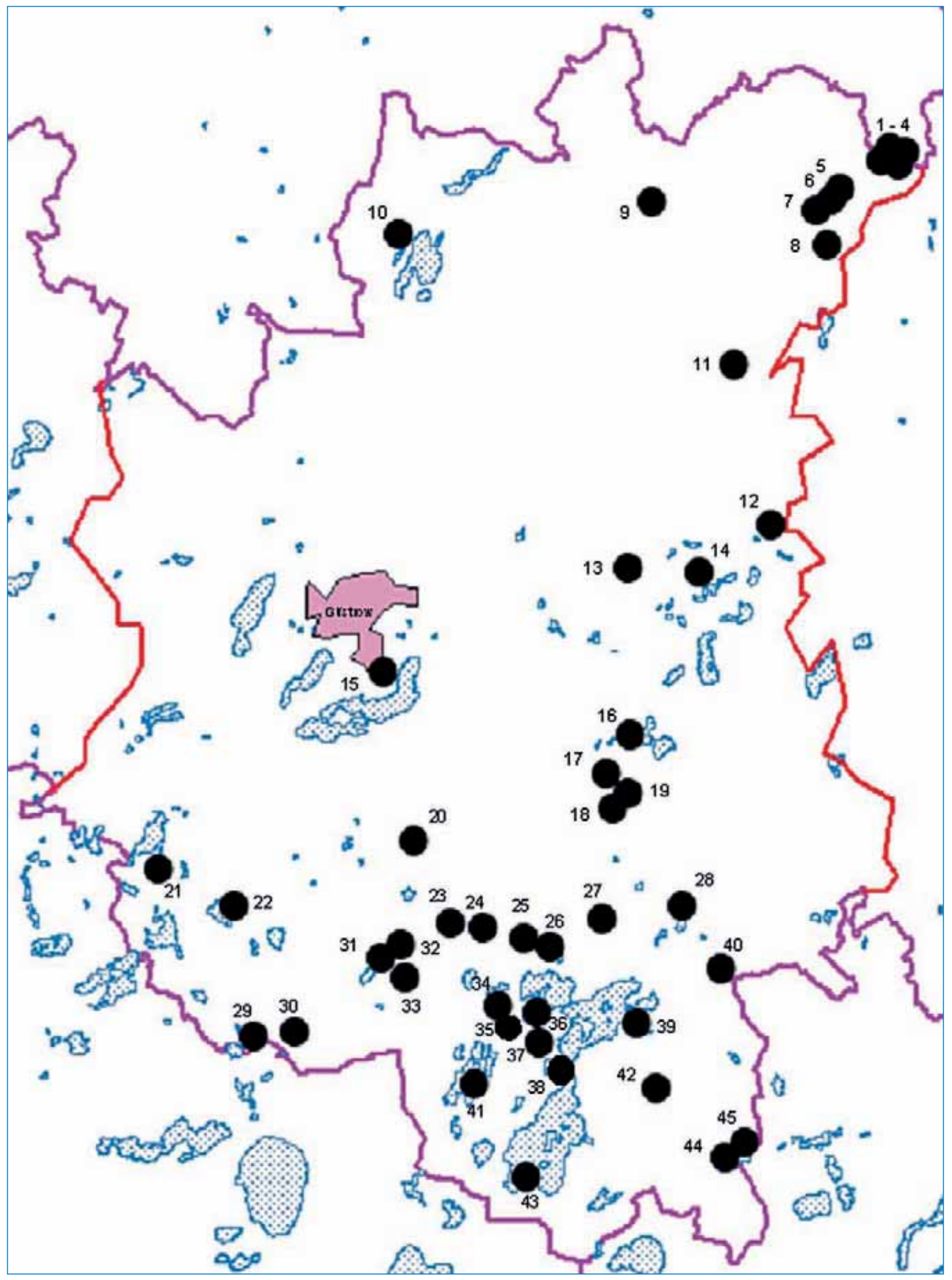


Tabelle 3: Flächennaturdenkmale (FND) im Altkreis Güstrow

\begin{tabular}{|c|c|c|c|c|c|}
\hline $\begin{array}{l}\text { Lfd. } \\
\text { Nr. }\end{array}$ & Gebietsbezeichnung & Größe [ha] & Ökologische Bedeutung & Größe*] [ha] & \begin{tabular}{|l} 
§ 20**] \\
Nr. GUE
\end{tabular} \\
\hline 1 & Lindbeerenbruch & 2,9 & Bruchwald & 1,62 & 08139 \\
\hline 2 & Blänke & 7,0 & Bruchwald & 5,31 & 08143 \\
\hline 3 & Kuhwalzbruch & 2,5 & Bruchwald & 2,51 & 08141 \\
\hline 4 & Bollbruch & 4,7 & Bruchwald & 9,19 & 08141 \\
\hline 5 & Rothe See & 6,9 & Bruchwald & 7,75 & 08021 \\
\hline 6 & Offener Krug & 15,4 & Moorvegetation & 15,58 & 07973 \\
\hline 7 & Sumpfeichenmoor & 0,9 & Moorvegetation & 3,58 & 07953 \\
\hline 8 & Rangemoor & 39,0 & Moorvegetation & 40,23 & 07919 \\
\hline 9 & Höhenzüge N Laage & 3,2 & Halbtrockenrasen [Kuhschelle] & 1,54 & 07511 \\
\hline 10 & Mühlbachniederung [KI. Sprenz] & 2,5 & Feuchtwiese [Orchideen] & 4,91 & 05892 \\
\hline 11 & Feuchtwiese am Korleputbach & 1,3 & Feuchtwiese [Trollblumen] & 2,01 & 08835 \\
\hline 12 & Goldberg & 1,0 & Halbtrockenrasen & 0,60 & 14324 \\
\hline 13 & Cesserberg & 8,0 & Halbtrockenrasen [Oszug] & 6,06 & 13438 \\
\hline 14 & Saures Bruch & 14,2 & Bruchwald & 13,48 & 14167 \\
\hline 15 & Ehem. Mergelgrube [Güstrow] & 1,1 & Laichgewässer für Lurche & 0,62 & 11044 \\
\hline 16 & Crivitzer Moor [Lange Bruch] & 7,1 & Moorvegetation & 13,77 & 13854 \\
\hline 17 & Das Rauhe Bocksmoor & 4,5 & Moorvegetation & 5,05 & 15216 \\
\hline 18 & Lange Moor & 2,3 & Moorvegetation & З,२० & 15198 \\
\hline 19 & Langes Moor & 7,7 & Moorvegetation & 1,85 & - \\
\hline २० & Quellbereich-Zufluss zum Teuchelbach & 0,4 & Quelle & 1,86 & 12523 \\
\hline 21 & Jasenberg & 5,7 & Traubeneichenbestand & 5,76 & - \\
\hline 22 & Moorwiese am Ostufer des Lohmer See & 7,1 & Feuchtwiese [Orchideen] & 9,2 & 12194 \\
\hline 23 & Breite Moor & 3,9 & Moorvegetation & 5,07 & 12916 \\
\hline 24 & Scheide-Moor & 3,2 & Moorvegetation & 3,81 & 15372 \\
\hline 25 & Kohramsmur & 5,9 & Moorvegetation & 8,२2 & 15389 \\
\hline 26 & Feuchtgebiet Revier Windfang & 5,5 & Moorvegetation & 7,91 & 15410 \\
\hline 27 & Lehmkuppe bei Ahrendshagen $\rightarrow$ NSG Nebel & 0,5 & Halbtrockenrasen & 0,73 & - NSG - \\
\hline 28 & Hoher Berg bei Kuchelmiß & 2,3 & Südhangvegetation & 4,75 & 15878 \\
\hline 29 & Torfmoosmoor SO Bolzsee & 1,7 & Moorvegetation & 4,23 & 22561 \\
\hline 30 & Bruch am Brummelvitz See & 3,2 & Bruchwald [Orchideen] & 3,64 & 22617 \\
\hline 31 & Große Moor & 3,6 & Moorvegetation & 2,84 & 12811 \\
\hline 32 & Lange Moor & 5,3 & Moorvegetation & 4,81 & 12815 \\
\hline 33 & Spukmoor [Speumast] & 4,6 & Moorvegetation & 2,99 & 12809 \\
\hline 34 & Rathmannsmoor & 1,5 & Moorvegetation [2 Flächen] & 3,42 & २2896 \\
\hline 35 & Maeckelberg & 3,0 & Halbtrockenrasen & 3,38 & २2892 \\
\hline 36 & Flachmoor am Bornbruch & 0,6 & Kalkflachmoor [Orchideen, Sumpf-Enzian & 0,62 & 22948 \\
\hline 37 & Großes Rahmannsmoor & 3,7 & Moorvegetation & 4,09 & 22912 \\
\hline 38 & Moorwiese am Wadehäng $\rightarrow$ NSG KOS & 0,44 & Feuchtwiese [Orchideen] & 0,50 & 22874 \\
\hline 39 & Feuchtwiese am Grimmsee & 5,7 & Feuchtwiese [Trollblumen] & 5,74 & 23190 \\
\hline 40 & Engelken-Moor & 2,9 & Moorvegetation & 2,81 & 16467 \\
\hline 41 & N-Spitze Schwarzer See bei Bossow & 2,1 & Torfmoosmoor & २,२० & 22675 \\
\hline 42 & Eichengruppe bei Zietlitz & 3,5 & wertvoller Baumbestand [ND] & 9,78 & 23098 \\
\hline 43 & Flachmoor Glaver Koppel $\rightarrow$ NSG KOS & 2,6 & Flachmoorvegetation [Orchideen] & 1,47 & 23307 \\
\hline 44 & Linstower Werder & 6,1 & Halbtrockenrasen, Hutung & 10,71 & 23609 \\
\hline 45 & Ochsenwiese am Linstower See & 3,4 & Feuchtwiese [Orchideen] & 3,32 & 23624 \\
\hline
\end{tabular}

Angaben aus Umweltkartenportal LUNG M-V

*) Größenangabe neu durch die Untere Naturschutzbehörde mit GIS-Programm ermittelt

**) Auch nach $§ 20$ NatSchAG M-V geschützter Biotop - Angabe der Biotop-Nr. (kursiv - Biotop ohne Kartierbogen) 


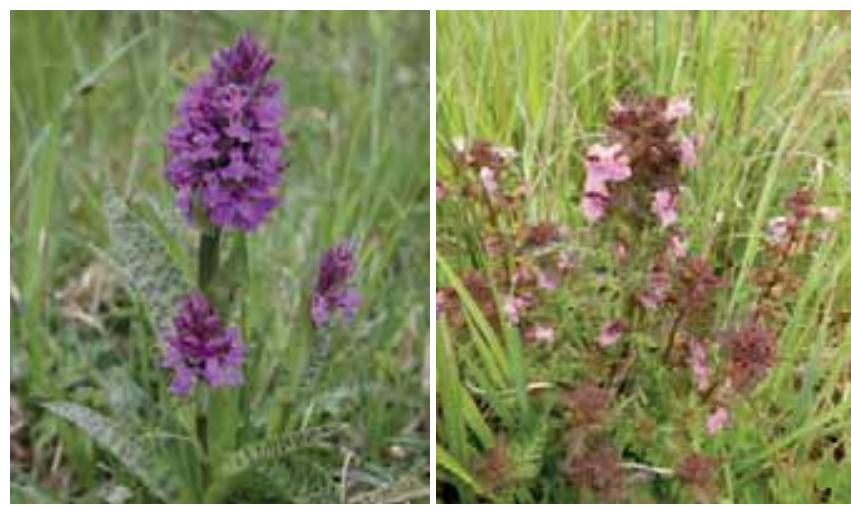

Breitblättriges Knabenkraut
Sumpf-Läusekraut

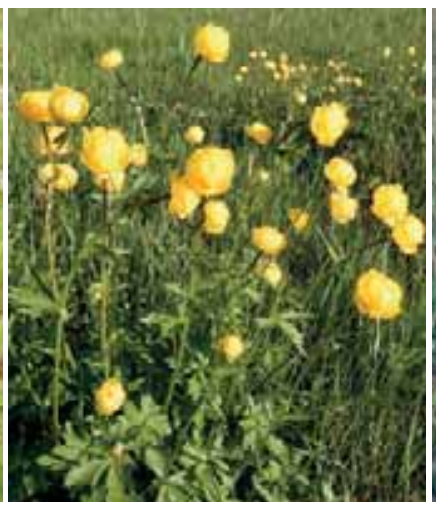

Trollblume

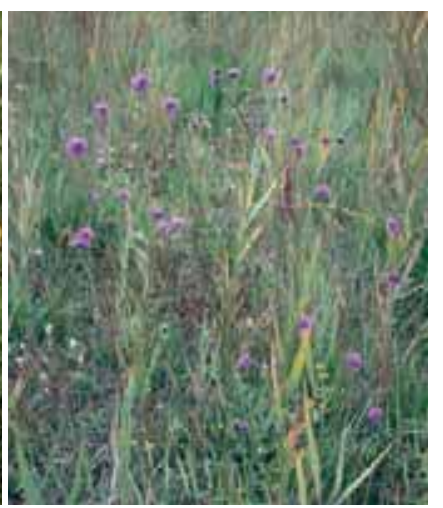

Teufelsabbiss

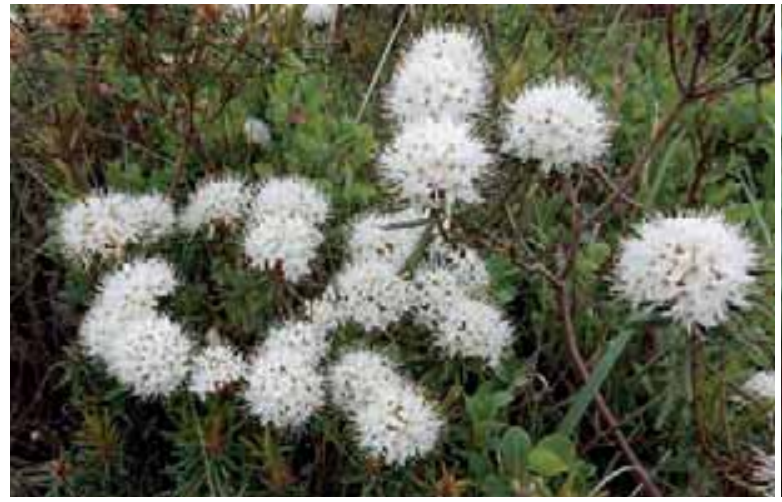

Sumpf-Porst

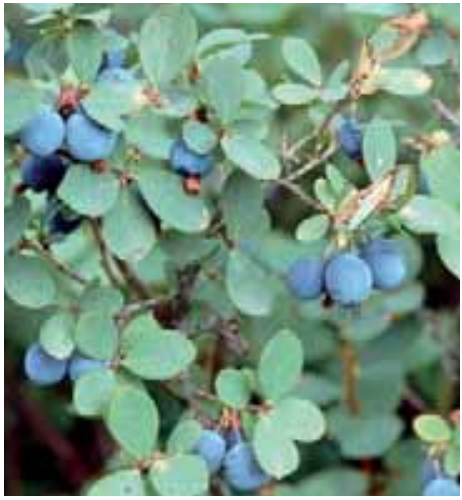

Rauschbeere

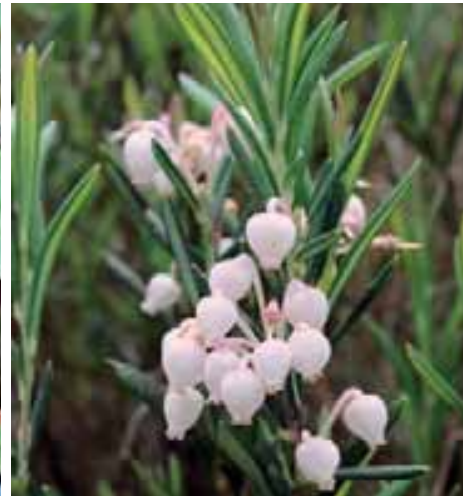

Rosmarinheide oder Poleigränke

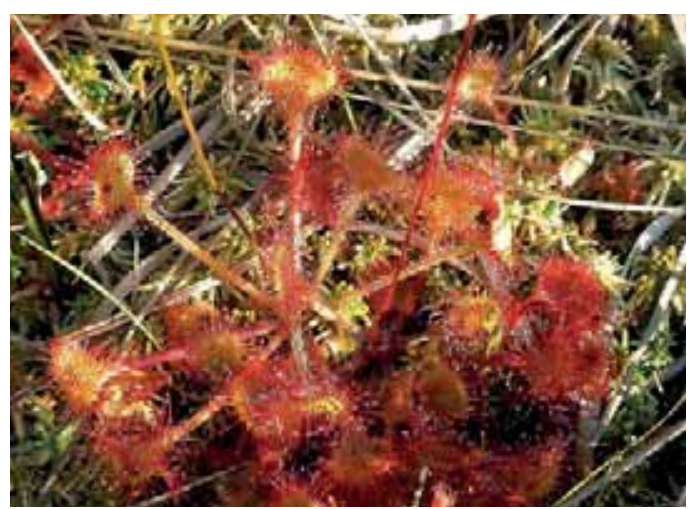

Rundblättriger Sonnentau

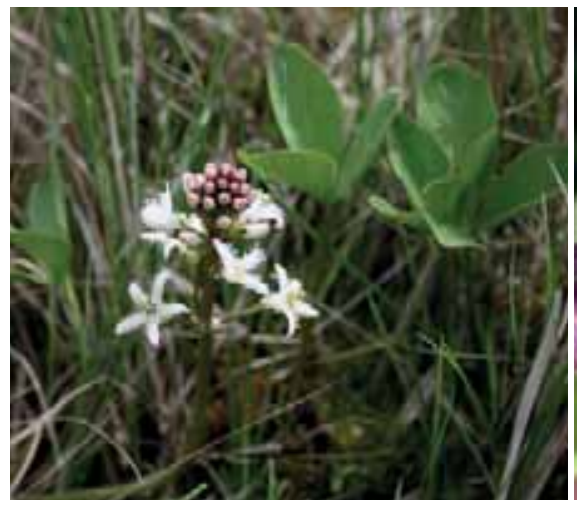

Fieberklee

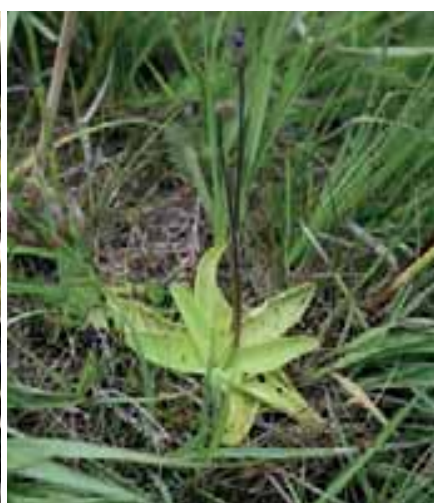

Fettkraut

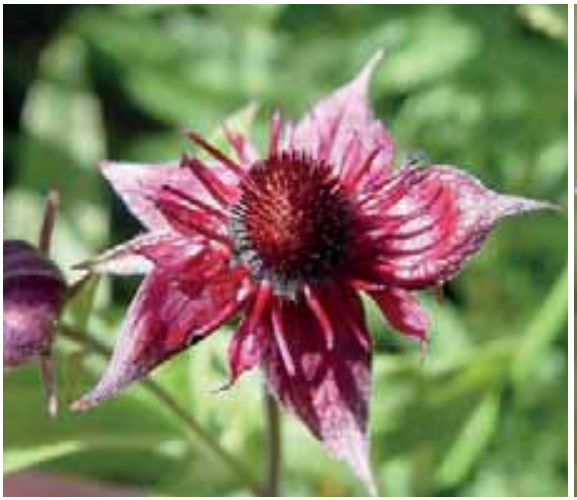

Blutauge

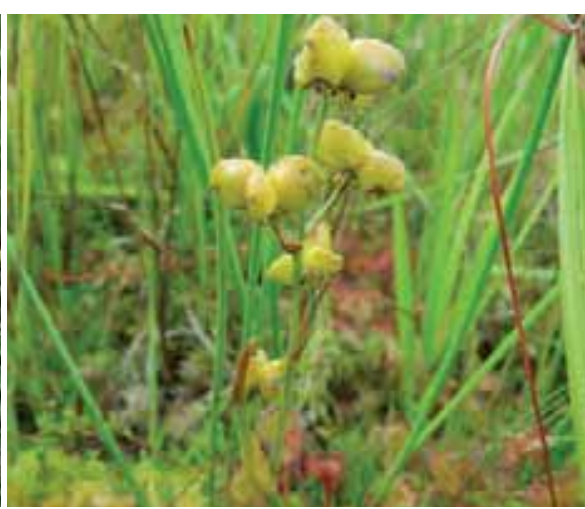

Blasenbinse

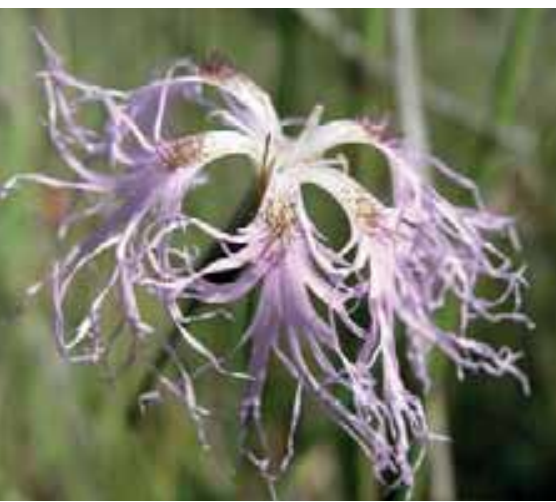

Pracht-Nelke

Abb. 147 bis 159: Zielarten bei der Ausweisung von Flächennaturdenkmalen auf Feuchtwiesen und in Mooren. Fotos: J. Loose 


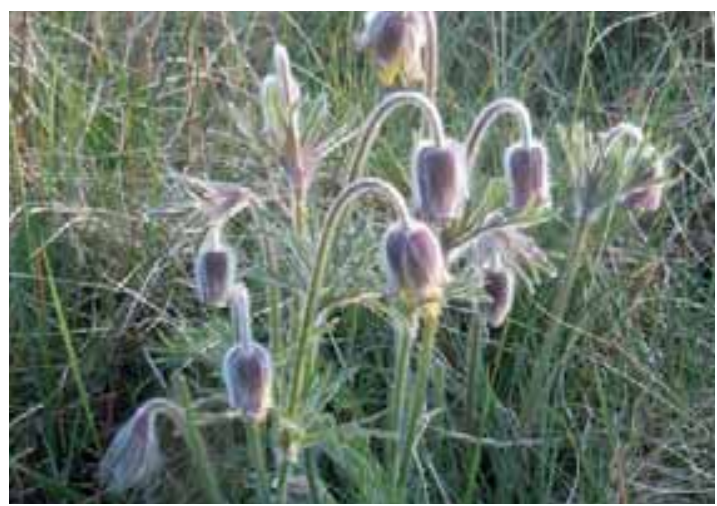

Wiesen-Kuhschelle

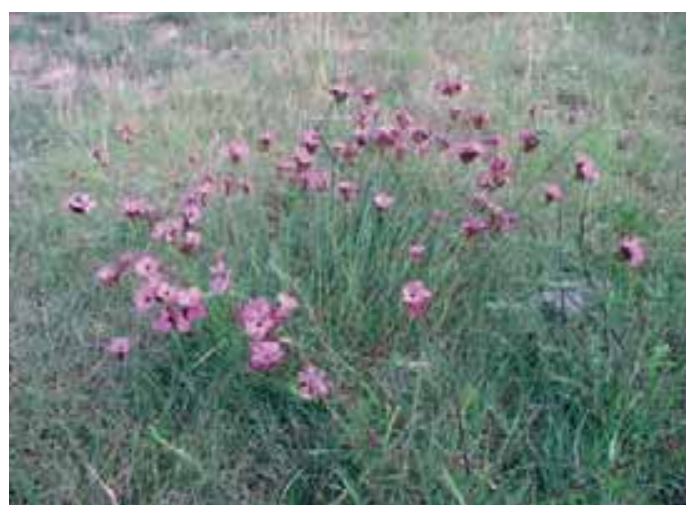

Karthäuser-Nelken

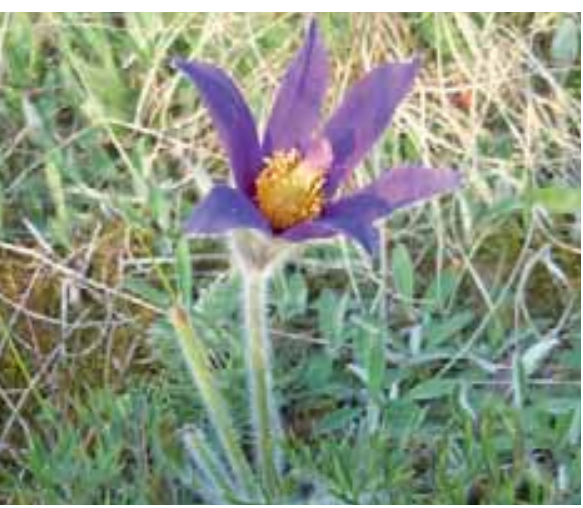

Gemeine Kuhschelle
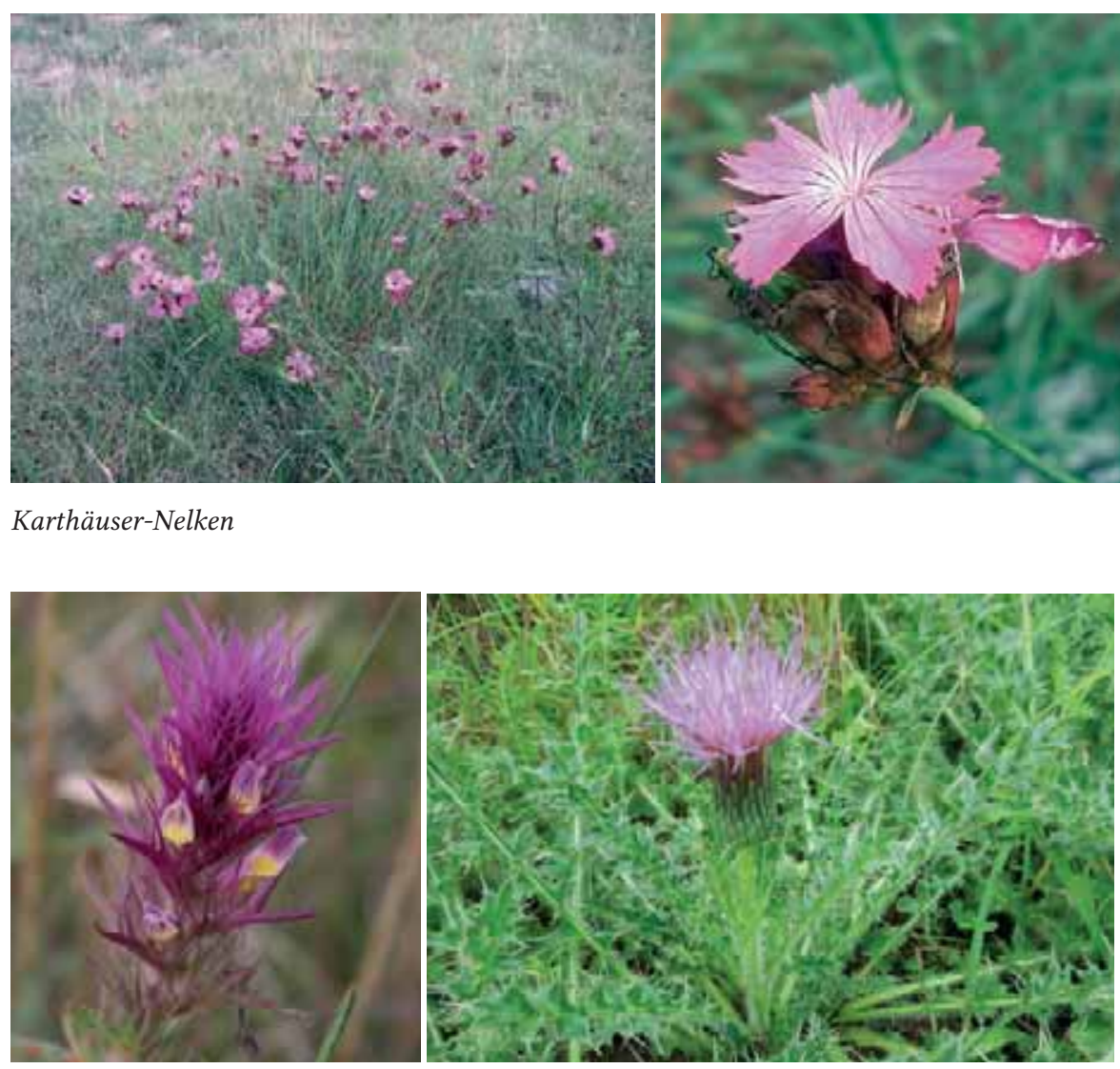

Acker-Wachtelweizen

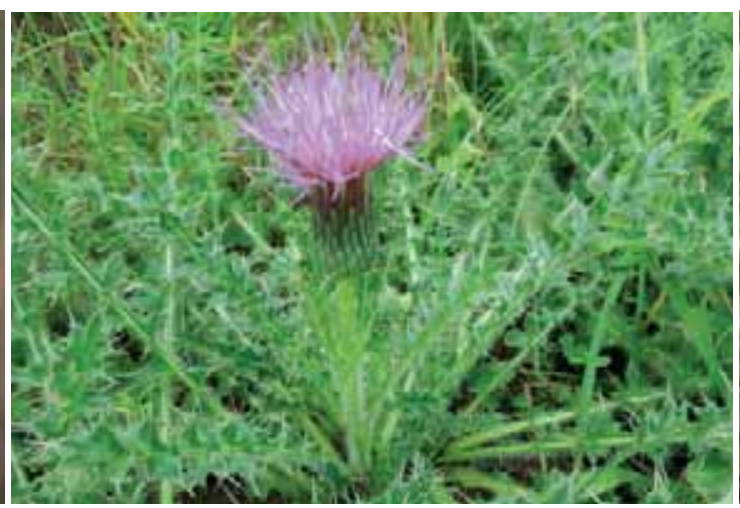

Stengellose Kratzdistel
Heide-Nelke

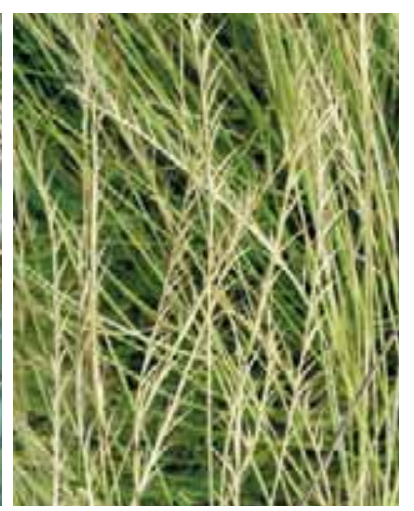

Borstgras
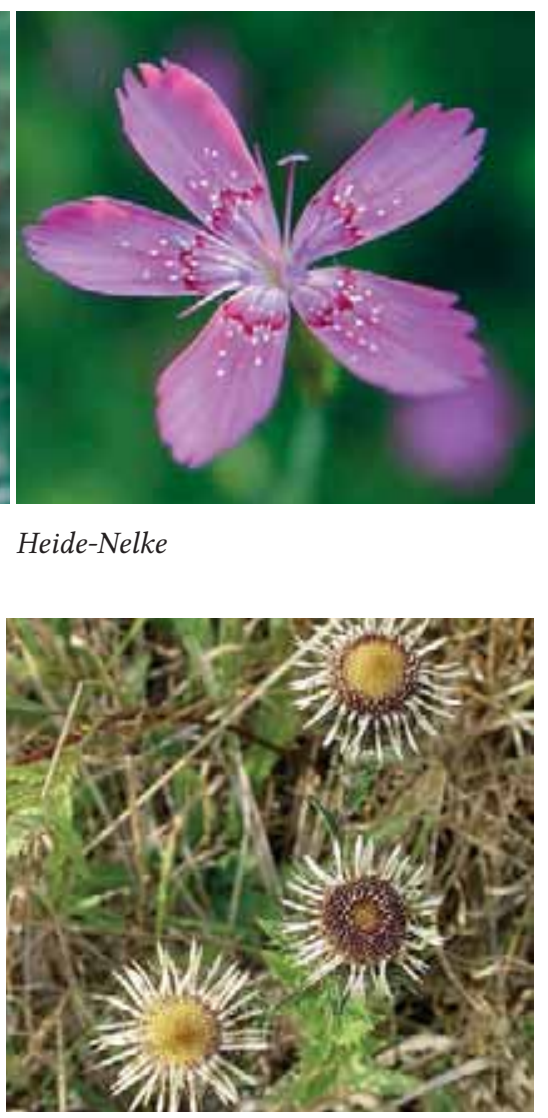

Golddistel

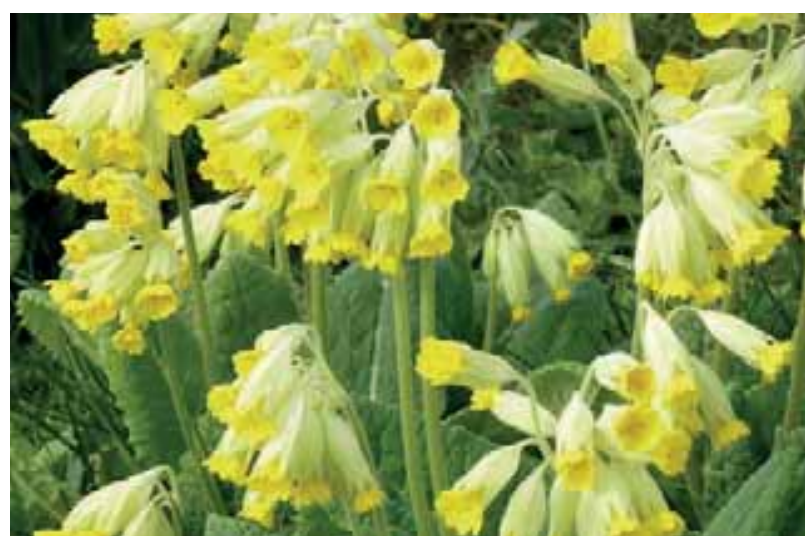

Wiesen-Schlüsselblume

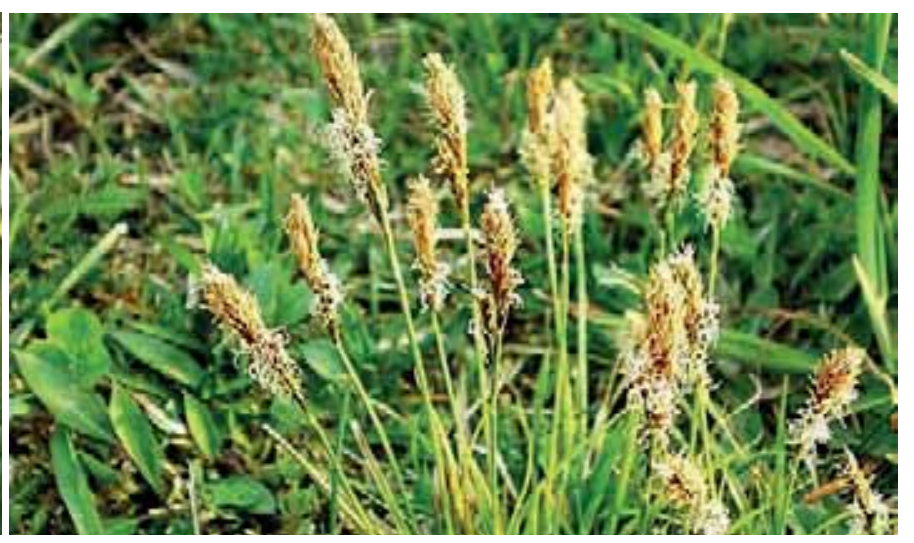

Frühlings-Segge

Abb. 160 bis 170: Zielarten bei der Ausweisung von Flächennaturdenkmalen aufTrockenstandorten. Fotos: 7. Loose. 


\subsection{Entwicklungen und Beobachtungen in anderen Gebieten}

\section{Joachim Loose}

Neben den Naturschutzgebieten, in denen wir regelmäßig beobachtet haben, gelangten auch immer wieder andere Gebiete in den Fokus, wenn es hier zu besonderen Vogelansammlungen kam. Solche Gebiete waren oft kurzzeitig überflutete Acker- oder Wiesenflächen, wie sie nach Hochwässern oder Defekten in Meliorationssystemen entstanden (z. B. Wiesensenke südlich Bellin, Wiesenflächen nördlich Neu Strenz, Polderfläche westlich von Wattmannshagen). Auf diesen Flächen zeigte sich, welches Potenzial auch heute noch in der Landschaft steckt.

\subsubsection{Augrabengebiet}

Mitte der 1990er Jahre wurden im Landkreis Güstrow Flächen gesucht, auf denen eine neue Mülldeponie eröffnet werden könnte. Ein Schweriner Planungsbüro war mit der Standortsuche beauftragt worden. Nach dem geologischen Untergrund kamen Flächen mit vier Standortvarianten im Raum um Recknitz und Kritzkow in Frage. Da man sich schon bewusst war, dass die Nähe zur Augrabenniederung (als bedeutsame Vogelzugleitlinie klassifiziert) naturschutzrechtlich Probleme bereiten könnte, wurde dem Standortgutachten ein Gutachten über Vögel vorgeschaltet. Dieses umfasste eine Brutvogelkartierung sowie Zug- und Rastbeobachtungen in einem ca. 4.720 ha großen Kontrollgebiet, welches etwa durch die Orte Spoitgendorf, Zapkendorf, Knegendorf, Liessow, Weitendorf und Kritzkow sowie die A 19 umgrenzt wurde. Die Gesamtfläche war nach ihrer Biotopausstattung in 59 Einzelflächen unterteilt. Im Untersuchungsgebiet lag auch das NSG Zehlendorfer Moor, in dem lange Zeit keine Vogelerfassungen mehr durchgeführt worden waren. Diese Kartierungen wurden (gesteuert durch die UNB) von Anfang April bis November 1996 von den FG-Mitgliedern Reinhard Becker, Martin Lemke, Joachim Loose und Manfred Montschko übernommen. Einige Ergebnisse sind im FG-Jahresbericht Nr.29/1996 dargestellt worden. Hohe Siedlungsdichten u.a. von Braunkehlchen und Neuntöter in der Augrabenniederung waren nicht erwartet worden und geben heute ein Zeugnis davon, wie häufig früher diese Arten in gemäßen und weitgehend ungestörten Biotopen doch waren.

Es wurden auch Vergleichsdaten für Grauammer, Schlagschwirl und Wachtelkönig angegeben. Zu letzterem gab es ergänzend für das gesamte Augraben-Recknitztal von Güstrow bis Laage 1997 eine Kartierung, die in diesem Jahr bis zu 27 Rufnachweisorte erbrachte. Die Einzelnachweise sind im Jahresbericht Nr. 30/1997 aufgelistet.

Mit heutiger Technik konnten die damals von Hand angefertigten Fundortkarten aufgearbeitet werden.
Wenn es i.d.R. die Landwirte zulassen würden, könnten vielerorts Entwicklungsmaßnahmen umgesetzt werden. Die Beobachtungen der hier festgestellten Wasservogelund Limikolenarten gingen in die Rubrik der bemerkenswerten Beobachtungen der jeweiligen FG-Jahresberichte ein.

In einigen Gebieten außerhalb der NSG-Kulisse beobachteten einzelne Ornithologen unserer FG über einen längeren Zeitraum. Von Zeit zu Zeit fassten sie ihre Ergebnisse in den Jahresberichten zusammen. Über einige solcher Gebiete wird nachfolgend berichtet.

Sie wurden hier nochmals in diese Dokumentation insbesondere als Anregung aufgenommen, die Kartierungen in diesem Bereich nach 20 Jahren zu wiederholen (Karten 11 bis 14).

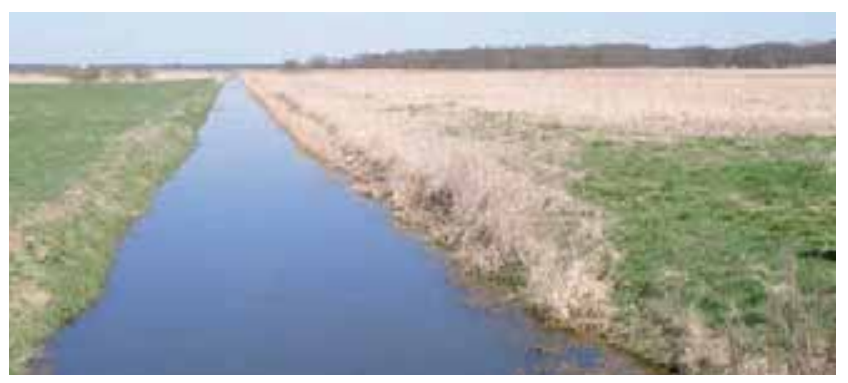

Abb. 171: Der Augraben vom Zehlendorfer Damm mit Blick in Richtung Norden - rechts die NSG Flächen. Foto: f. Loose

Der Untersuchungsraum für die Brutvogelkartierung bestand - neben geringen Waldanteil - zu $88 \%$ aus Offenland, davon waren 56\% Acker-, 29\% Grün- und 2\% Brachland. Die damals separat für die FG ausgewertete Fläche der Augrabenniederung umfasste 1.173 ha $(90 \%$ Wiese und Odland, 4,5\% Brache, 5,4\% Wald und Gebüsch). Zahlreiche Meliorationsgräben durchzogen die Wiesenniederung. Vorrangig in den Hochstaudenfluren am Ufer der Gräben wurden Braunkehlchen registriert. Neuntöter verteilten sich fast flächendeckend an den Strauchstrukturen und an den Waldrändern. Wie zu erwarten war, hielten sich Grauammern am Rande der Niederung entlang der Verkehrswege und Schlagschwirle in den feuchtnassen verschilften Flächen auf.

Für die Augrabenniederung errechneten sich nachfolgende Siedlungsdichten:

\begin{tabular}{c|c|c|c|c}
\hline BP/ $\mathbf{k m}^{\mathbf{2}}$ & $\begin{array}{c}\text { Braun- } \\
\text { kehlchen }\end{array}$ & Neuntöter & $\begin{array}{c}\text { Schlag- } \\
\text { schwirl }\end{array}$ & $\begin{array}{c}\text { Wachtel- } \\
\text { könig }\end{array}$ \\
\hline SD & 4,52 & 2,22 & 0,42 & 0,60 \\
\hline
\end{tabular}




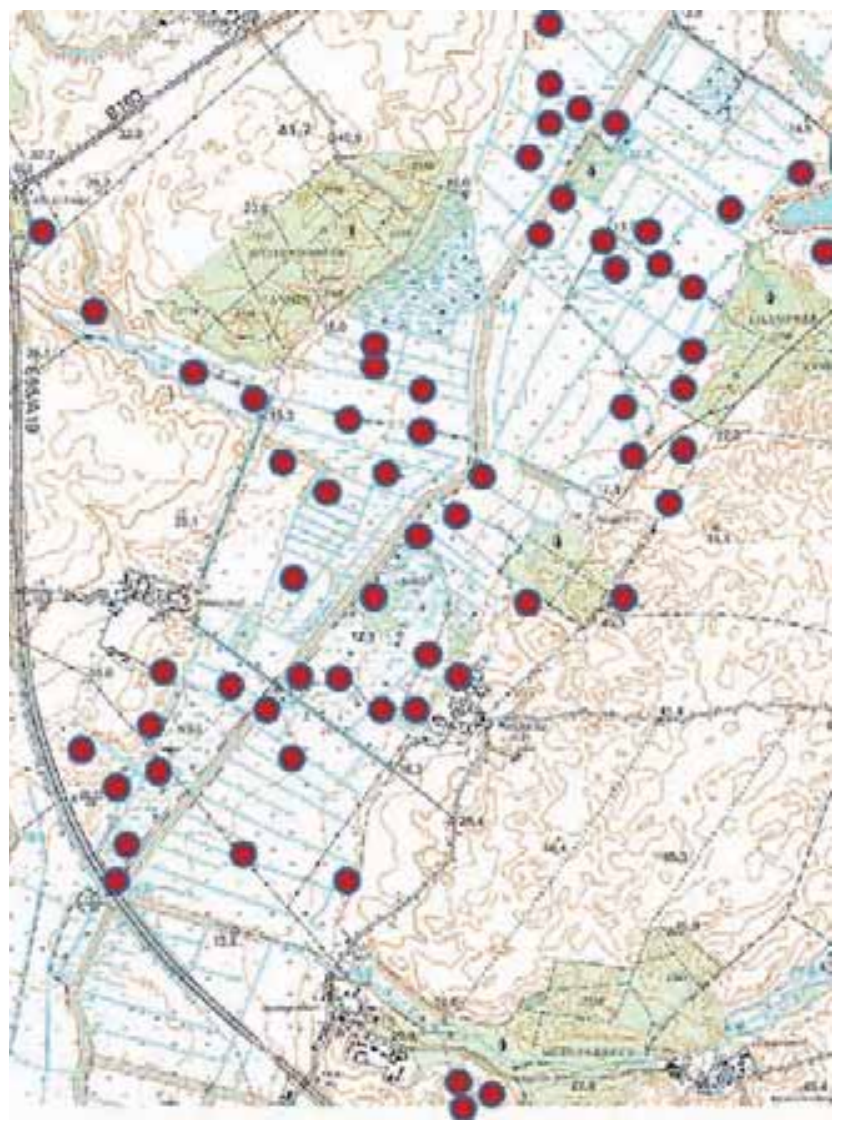

Karte 11: Brutreviere des Braunkehlchen (62) - 1996

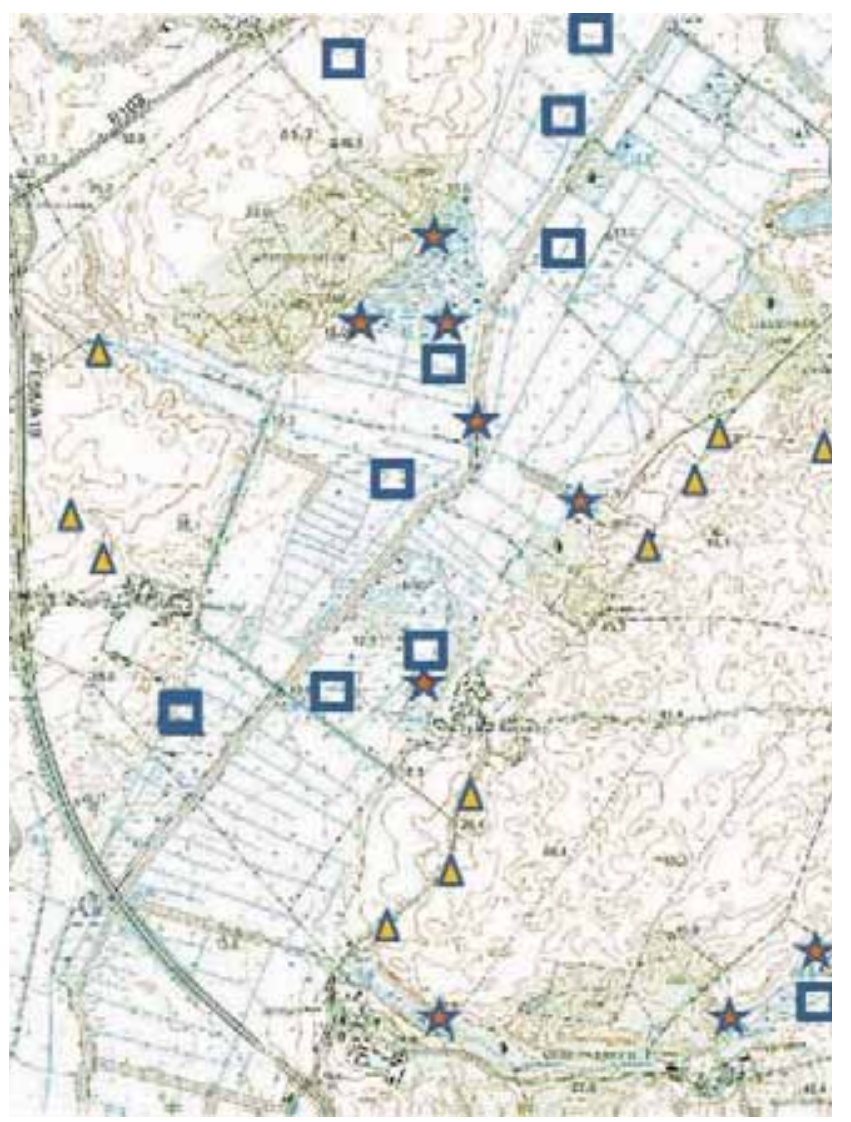

Karte 13: Brutreviere von Grauammer (10), Schlagschwirl (9) und Wachtelkönig (10) -1996

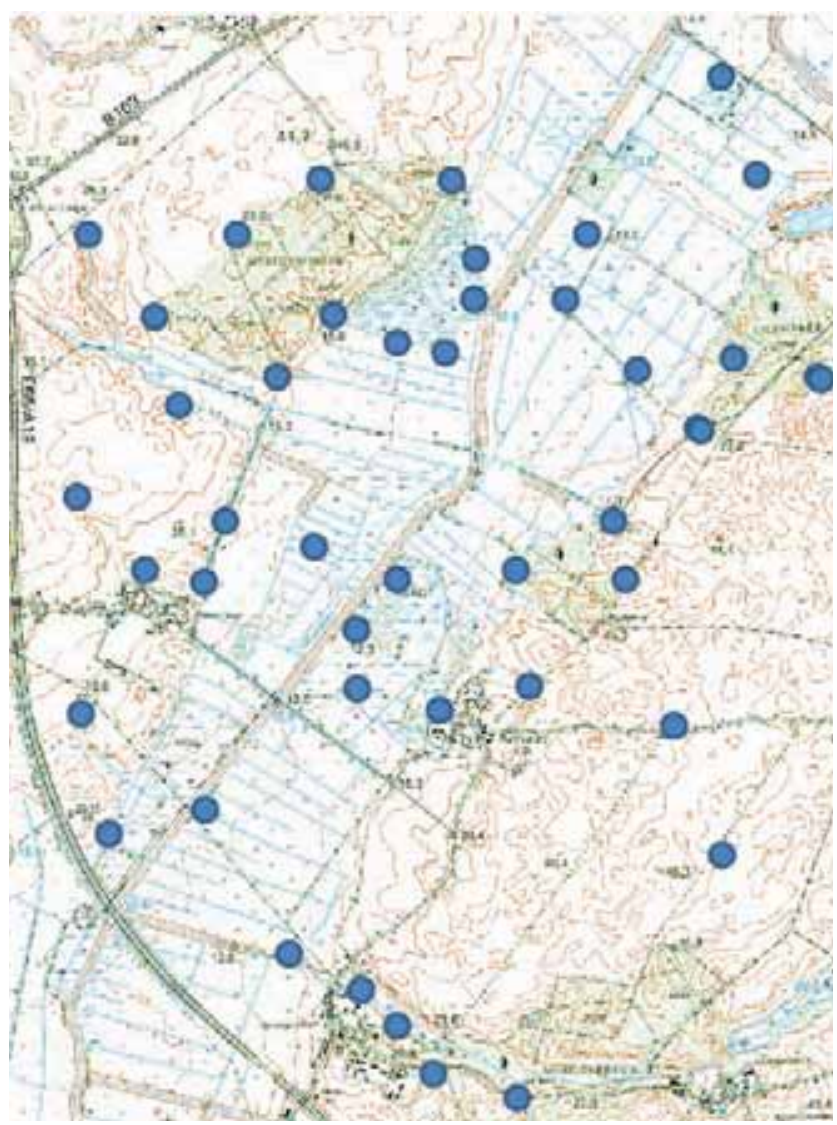

Karte 12: Brutreviere des Neuntöter (43) - 1996

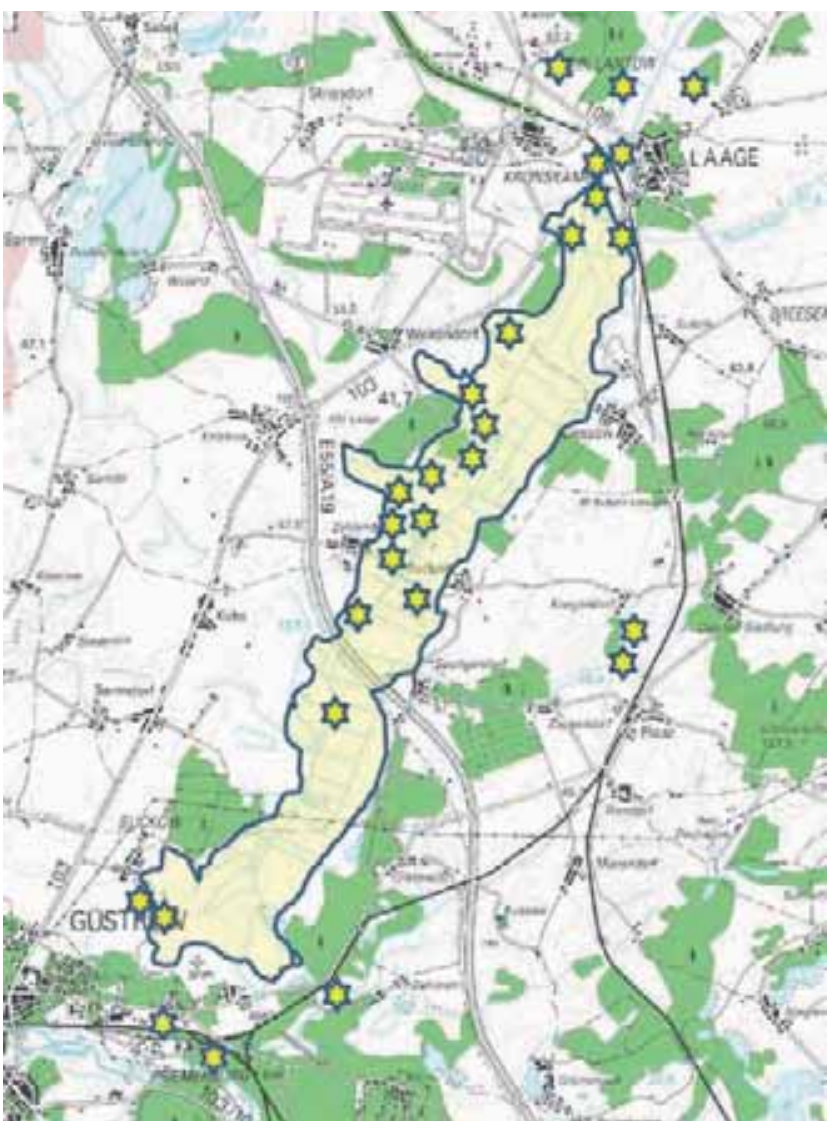

Karte 14: Rufnachweise des Wachtelkönig (27) im Augrabental zwischen Güstow und Laage auf ca. 16 km Länge im Fahre 1997 
In dem vom Schweriner Büro Planung \& Ökologie mit Datum vom 4.6.1997 aus unseren gelieferten Erfassungsdaten zusammengestellten Gutachten zum Standortvergleich - Teil: Vögel - sind darüber hinaus einige Aussagen zu Brutvögeln enthalten, für die unserer FG nicht mehr alle Originaldaten der Kartierungen vorliegen. Diese Angaben sind aber ebenso bemerkenswert, da sie zum heutigen Ver- gleich herangezogen werden können. Sie lassen sich nur nicht mehr in ergänzende Kartendarstellungen umwandeln. Planerisch waren vom geologischen Untergrund her vier verschiedene Standorte für eine Deponie mit sich jeweils überschneidenden Untersuchungsräumen $\mathrm{zu}$ prüfen. Durch die Überlappung der Räume sind nachfolgende Brutpaarangaben in der Tabelle 4 nicht addierbar.

Tabelle 4: Anzahl der Brutreviere je Art in einzelnen Teiluntersuchungsräumen im Vergleich

\begin{tabular}{|c|c|c|c|c|}
\hline \multirow{3}{*}{$\begin{array}{l}\text { UG-Größe } \\
\text { gesamt: } 4.720 \text { ha }\end{array}$} & \multicolumn{4}{|c|}{ Untersuchungsraum } \\
\hline & C & D & $\mathbf{E}$ & $\mathbf{F}$ \\
\hline & 1.592 ha & 1.498 ha & 1.684 ha & 1.776 ha \\
\hline Brutvogelart & \multicolumn{4}{|c|}{ Anzahl der Brutpaare } \\
\hline Bekassine & 2 & 1 & 1 & 1 \\
\hline Braunkehlchen & 49 & 29 & 45 & 35 \\
\hline Grauammer & 7 & 7 & 9 & 9 \\
\hline Flussregenpfeifer & 1 & 1 & 1 & 1 \\
\hline Kiebitz & - & 3 & 4 & - \\
\hline Kranich & 1 & 1 & 1 & 1 \\
\hline Neuntöter & 31 & 25 & 28 & 26 \\
\hline Rotmilan & 1 & 1 & 1 & - \\
\hline Schafstelze & 14 & 13 & 7 & 4 \\
\hline Schlagschwirl & 7 & 4 & 14 & 12 \\
\hline Sperbergrasmücke & - & 1 & 1 & 1 \\
\hline Steinschmätzer & 2 & 1 & - & - \\
\hline Wachtel & 2 & - & 2 & 2 \\
\hline Wachtelkönig & 5 & 5 & 5 & 4 \\
\hline Wiesenpieper & 39 & 17 & 19 & 15 \\
\hline
\end{tabular}

Abgrenzung der Untersuchungsräume:

C süd- und südöstlich von Kritzkow/östlich A 19

D Kritzkow/Weitendorf, Weitendorfer Tannen

E Recknitz/Knegendorf, nördlich der Straße

F Recknitz/Knegendorf/Spoitgendorf/Zapkendorf

Insbesondere die Vorkommen von Schafstelze und Wiesenpieper mit gleichfalls hohen Siedlungsdichten sind weitgehend der Augrabenniederung zuzuschreiben. Hervorzuheben sind die noch damals festgestellten Brutreviere von Bekassine, Kiebitz, Sperbergrasmücke und Steinschmätzer. Zum Glück für die Natur und die Einwohner der umliegenden Ortschaften hatte sich der Landkreis Güstrow bald für

\subsubsection{Zuckerfabrikteiche / PVA-Teich Güstrow}

Am 1.7.1960 wurde an der Verbindungschausee am Stadtrand von Güstrow mit dem Bau einer neuen Zuckerfabrik begonnen, die am 20.10.1962 erstmalig in Betrieb ging. Zur Zuckerfabrik gehörte auch ein Komplex von Absetzteichen (ca. 40 ha) und zwei Verregnungsspeichern (18 ha) am Ostrand der Stadt (Abb. 172).

Bei der Manuskriptabfassung dieses Kapitels gab es von unseren wenigen „Altornithologen“ den bedeutsamen Hinweis, dass es unmittelbar bei Produktionsaufnahme zu- ein anderes Konzept der Müllentsorgung entschieden, so dass die Planungen nicht fortgeführt wurden. Durch diese Erstüberlegungen des Landkreises sind wir jedoch glücklicherweise zu einen Zeitdokument der Vogelverbreitung in einem auch heute noch bedeutsamen Gebiet unseres Altkreises Güstrow gekommen.

nächst an der Verbindungschaussee noch andere Zuckerfabrikteiche in den Wiesen zur Nebel hin gegeben habe. Diese sind heute nicht mehr erkennbar. Die auf Abb. 172 dargestellten Teiche sind erst Ende der 1960er/Anfang der 1970er Jahre entstanden. Auf diesen Flächen stand vorher Wald. 


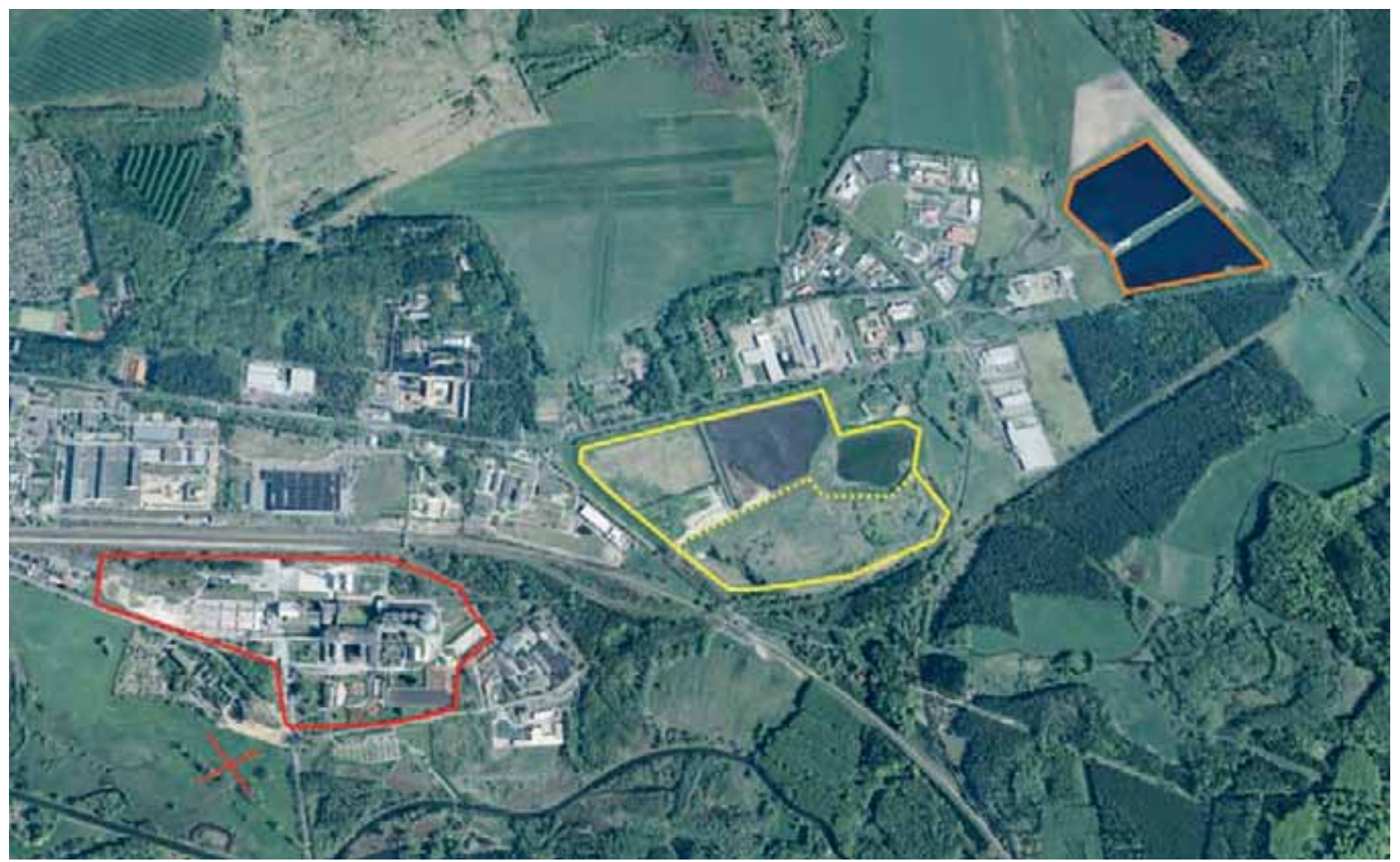

Abb. 172: Standort der ehemaligen Zuckerfabrik Güstrow (rot), Absetzteiche (gelb) und Verregnungsspeicher (orange) - Luftbild nach dem Abriss der Zuckerfabrik (Quelle: Geoportal M-V), X = vermutliche Lage der ersten Zuckerfabrikteiche

Frühzeitig erfolgten durch Mitglieder der FG Vogelbeobachtungen an den Teichen. Als bemerkenswerte Vorkommen (wohl noch an den alten Teichen) wird in den ersten Jahresberichten der FG u. a. nachfolgendes vermerkt:

$\begin{array}{lll}\text { 25.08.1968 } & \text { Sichelstrandläufer } & \text { 1 Ex. } \\ \text { 01.09./8.09.1968 } & \text { Knutt } & \text { 1-2 Ex. } \\ \text { 04.09.1968 } & \text { Brandgans } & \text { 3 Ex. } \\ \text { 08.09.1968 } & \text { Waldwasserläufer } & \text { 3 Ex. } \\ \text { 27.07.1969 } & \text { Zwergstrandläufer } & \text { 2 Ex. } \\ \text { 13.6.1970 } & \text { Flussregenpfeifer } & 1 \mathrm{BP} \\ \text { 03.09/06.09.1970 } & \text { Brandgans } & 1 \text { juv. } \\ \text { 06.09. } 1970 & \text { Wespenbussard } & \text { 1 Ex. } \\ \text { 06.09.1970 } & \text { Knutt } & \text { 1 Ex. }\end{array}$

An den Teichen beobachteten oftmals Gruppen von fünf bis acht Ornithologen der FG. Man hatte die Bedeutung der Teiche erkannt. Die Beobachtungen reizten auch, da hier immer wieder besondere Vogelarten zu entdecken waren, die im Binnenland seltener auftraten. Das damals erwähnte besondere Artenspektrum tritt auch heute nach mehr als 45 Jahren in dem unten beschriebenen kleineren Gebiet noch immer auf.

Ab 1984 gab es für die Zuckerfabrikteiche planmäßige jährliche Beobachtungen in den Spätsommer-Herbstmonaten (IX-XI) von Uwe Gehlhar und Remo Wiechert. Die Beobachtungsintensität wurde durch sie deutlich erhöht. Seit 1992 erstellten die beiden jeweils von Juni bis November nahezu vollständig geschlossene, dekadenweise Zählreihen für das Gebiet.

Im Jahresbericht Nr. 27/1994 legten sie Auswertungen für den „Herbstlichen Wasservogeldurchzug“ vor. Unter den beobachteten 17 Schwimmvogelarten lag der Schwerpunkt bei den Enten. Es wurden bei ihnen bemerkenswerte Maxima erreicht:

Stockenten - bis 700 Ex.,

Krickenten - 400 Ex.,

Löffelenten - 180 Ex. und

Pfeifenten - 120 Ex.

Die Autoren stellten sich die Frage, wo für diese hier längere Zeit anwesenden Vögel die benötigte Nahrung herkommt. Sie kamen zu dem Schluss, dass die von der Zuckerfabrik im Produktionsprozess ausgeschiedenen und in die Teiche eingeleiteten Abwässer zu großen Teilen Humuserde und Scheidekalk enthalten und damit den Teichen große Mengen von Nährstoffen zugeführt werden. Hierdurch dürfte es zu enormer Produktion von neustonischen, planktonischen und benthischen Organismen mit zwar oft geringen Artenspektren, aber dafür um so höherer Individuendichte kommen. Dieser Sachverhalt war im Gebiet noch nicht durch Beprobungen belegt worden. Die Autoren zogen ihre Schlüsse im Vergleich zu ausgewerteten Wasserproben aus den Rieselfeldern Münster, mit deren Naturschutzstation sie Kontakt aufgenommen hatten.

Im Jahresbericht Nr. 29/1996 berichteten Uwe Gehlhar und 
Remo Wiechert dann weiter über „Die Klärteiche als Rastgebiet für Limikolen“. Bis zu dieser Zeit waren hier 23 Limikolenarten notiert worden, darunter auch selten beobachtete wie Austernfischer, Uferschnepfe, Säbelschnäbler und Odinshühnchen.

Häufigste Limikolenarten waren Kiebitz (1.000), Bekassine (310), Bruchwasserläufer (93), Flussuferläufer (58), Zwergstrandläufer (110), Alpenstrandläufer (42) und Kampfläufer (51) sowie Großer Brachvogel (150), der die Teiche abends als Schlafplatz anflog. Bei ausreichend vorliegenden Datenmaterial für häufige Arten (mind. 100 Beobachtungen) stellten die Autoren Zugverläufe beim Wegzug von Bekassinen, Alpenstrandläufer und Kampfläufer für den Zeitraum von Juli bis Oktober dar. Auffällig waren jeweils noch Durchzugsspitzen der Arten im Oktober. Gegenüber dem Rastgeschehen an der Ostseeküste werden Kulminationspunkte an den Zuckerfabrikteichen meist eine Dekade später erreicht. Im Jahresbericht Nr.33/2000 stellt U.Gehlhar einen „Ungewöhnlichen Durchzug des Bruchwasserläufer im Jahr 2000“ an den Klärteichen zur Diskussion. Ende Juli 2000 stieg der Bestand rastender Bruchwasserläufer von einer üblichen Bestandsgröße (bis 30 Ex.) „plötzlich“ auf 250 Vögel an. Als Ursachen für das längere Verweilen sieht der Autor ggf. eine sehr günstige Nahrungstierentwicklung in den Teichen als auch einen hohen Bruterfolg an den skandinavischen Brutplätzen an - siehe dazu auch GEHLHAR (2001)

Mit Schließung und Abriss der Zuckerfabrik Güstrow im Jahre 2008 fiel die Beschickung des Teichsystems aus dem Abwasser weg und die Teichflächen verlandeten zunehmend.

Mit Wegfall der Wasserflächen würde auch bald die Bedeutung als Rast- und Nahrungshabitat verschwinden. Als die Stadt Güstrow eine Überplanung der Teichflächen zur Aufstellung mit Photovoltaikanlagen beschloss, konnte sich die Fachgruppe über die NABU-Ortsgruppe Güstrow mit einem Gutachten über die Bedeutung der Klärteiche und einer Forderung zum Erhalt wenigstens eines Teiches, und zwar des nördlich gelegenen Verregnungsspeichers, einbringen. Dem Appell, der auch von der unteren Naturschutzbehörde gehört wurde, folgte die Stadt mit einer Satzungsfestsetzung zum Erhalt und zur Gestaltung eines Vogelrastgewässers. Dem Investor wurde von der Naturschutzbehörde auferlegt, in einem dreijährigen Monitoring nachzuweisen, dass Belange des Vogelschutzes mit dem zu erhaltenden und herzurichtenden Ersatzteich erfüllt werden können.

\section{Auf seiner Internetplattform}

http://wirsol.de/solar-photovoltaik/unternehmen/ aktuelles-2/deatail/wirsol-baut-31-mw-solarparkauf-alten-nordzucker-flaechen/show/Article/ 079564efd67bf44fb355d3f408fec3b2/

berichtete der Investor bald nach Erteilung der Baugenehmigung: (Auszug)
Durch den Solarpark wird ein einzigartiges Biotop gerettet

>Teile des Areals werden künftig wieder Watvögeln und Amphibien als Rast- und Nahrungshabitat dienen. In die ehemaligen Absetzbecken und Klärteiche wurde seit der Stilllegung der Zuckerproduktion 2008 kein Wasser mehr gepumpt - das Ende des Naturrefugiums stand unmittelbar bevor.

Im Zuge der Solarpark-Projektierung verständigte man sich in intensiven Gesprächen mit den Naturschutzbehörden auf vorgezogene Ausgleichsmaßnahmen. Bei der Installation des Sonnenkraftwerks wird jetzt auf die Nutzung der gesamten Fläche der ehemaligen Teiche als Aufstellflächen verzichtet. „Über die Betriebsdauer der Photovoltaik-Anlagen wird ein 7 ha großer Teil der alten Teichfläche wieder mit Wasser beschickt.,", erklärt der Leiter der NABU-Ortsgruppe, Joachim Loose. „So werden das Biotop erhalten und den Watvögeln langfristig die Schlammflächen zur Zugzeit bereitgestellt. Mitglieder der NABU-Ortsgruppe werden die Entwicklung des Gebiets in den nächsten Jahren fachlich begleiten." <

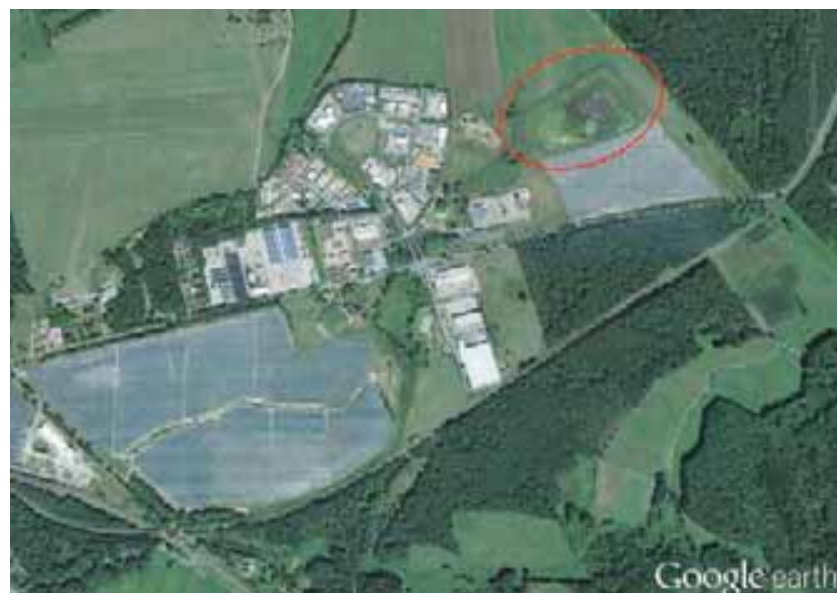

Abb. 173: Solarpark Güstrow 1 und 2 mit dem „PVA-Teich“(rot)

Das Ausgleichsprojekt beinhaltete auch die Installation einer Förderpumpe, mit der bei Bedarf ein Zupumpen von Grundwasser in den Teich ermöglicht wird. Mit der Pumpe wurde eine Förderleistung von $16,5 \mathrm{~m}^{3} / \mathrm{h}$ erreicht. Auf Forderung der Vogelbeobachter und im Entgegenkommen errichtete der Investor auch innerhalb der PVA einen festen Beobachtungsturm und finanzierte die von uns errichtete zweite Beobachtungshütte für einen guten Überblick über den Teich.

Das dem Betreiber der PVA-Güstrow 2 von der Naturschutzbehörde auferlegte und durch W. Köhler und J. Loose durchgeführte dreijährige Vogelmonitoring endete 2014 mit einem Abschlussbericht, aus dem nachfolgend einige bemerkenswerte Ergebnisse als Auszug - insbesondere auch im Vergleich zu den früheren Beobachtungen - dargestellt werden. 
Gegenüber den Beobachtungen, die sich bisher auf den Spätsommer-/Herbstdurchzug konzentrierten, wurden durch das von März bis November laufende Monitoring durchgehende Datenreihen für einzelne Arten gesammelt (vgl. auch Jahresbericht Nr. 47/2014; Manuskript für den ORMV in Arbeit).

Als neue Erkenntnisse gegenüber den bisher vorliegenden Beobachtungen konnte festgestellt werden, dass

- beim Bruchwasserläufer für das Jahr 2014 auch ein intensiver, auf kurze Zeit beschränkter Frühjahrsdurchzug stattfand,

- Kampfläufer sich fast in allen Monaten hier aufhalten und mehrere Durchzugsspitzen auftraten,

- Bekassinen weniger im Frühjahrzug anwesend sind und von Juli bis Oktober mehrere Durchzugsspitzen gezeigt haben.

Es konnte bestätigt werden, dass gegenüber den früheren Zuckerfabrikteichen eine Reihe von Vogelarten nunmehr auf jetzt deutlich kleinerer Fläche dennoch in stattlicher Zahl anzutreffen ist. So wurde z.B. der Teich ab Mitte August von > 1.000 Kiebitzen genutzt und hielten sich über längere Zeit im Herbst bis zu 175 Krickenten hier auf (vgl. Diagramme 7 bis 12).

Die Flächen zwischen den Solarmodulen wurden bald auch von Vogelarten genutzt. Feld- und Heidelerche sowie Gold- und Grauammern hatten hier Brutreviere. In einigen Hohlräumen in den Ständerwerken bauten Bachstelze und Hausrotschwanz Nester. Auf den geschotterten Fahrwegen brüteten mehrere Paare Flussregenpfeifer erfolgreich.
Nach dem Monitoringzeitraum wurden die Planbeobachtungen am PVA-Teich in gleicher Intensität fortgesetzt. Als Problem zeigte sich, dass mit dem Sommerbeginn im Westteil des Teiches große Flächen trocken fallen und damit wie in den Vorjahren als Nahrungshabitat für Limikolen ausfielen. Spätestens ab Juli musste auch 2015 wieder Wasser zugepumt werden.

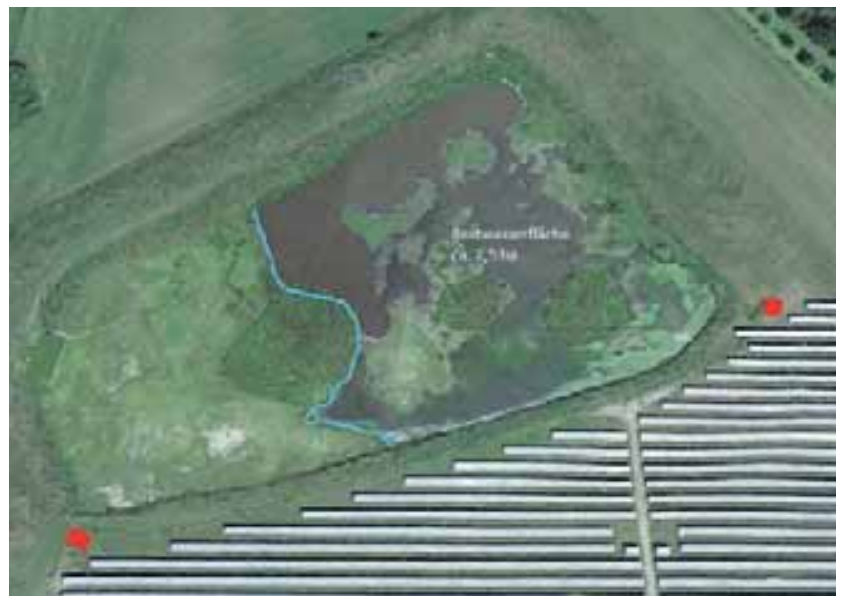

Abb. 174: PVA-Teich im fuli 2014 mit im Westteil trockengefallenen Flächen, Inseln und Beobachtungskanzeln (rot). Quelle Luftbild: Google earth

Bemerkenswert ist, dass die verbleibende Wasserfläche von ca. 2,5 ha immer noch als Schlafplatz von 100-300 Kranichen (kurzzeitig fast 800 Ex.) und im Herbst von weit über 1.000 Grau-, später auch nordischen Gänsen genutzt wird.

Für die Botanik-AG war interessant, wie sich die zunächst sandige Rohbodenfläche mit Pflanzen besiedelte.

Diagramm 7

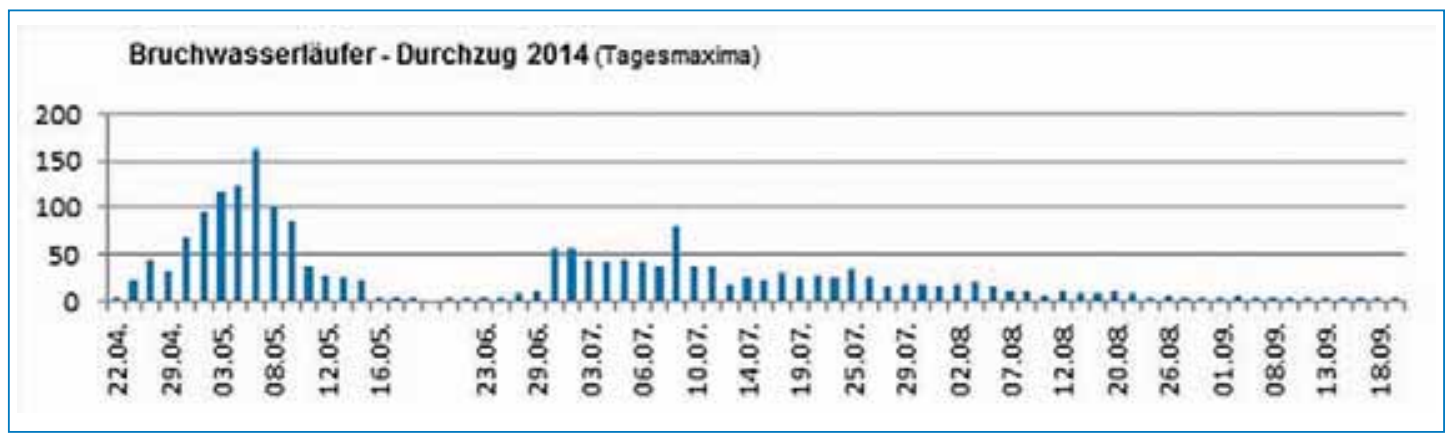

Diagramm 8

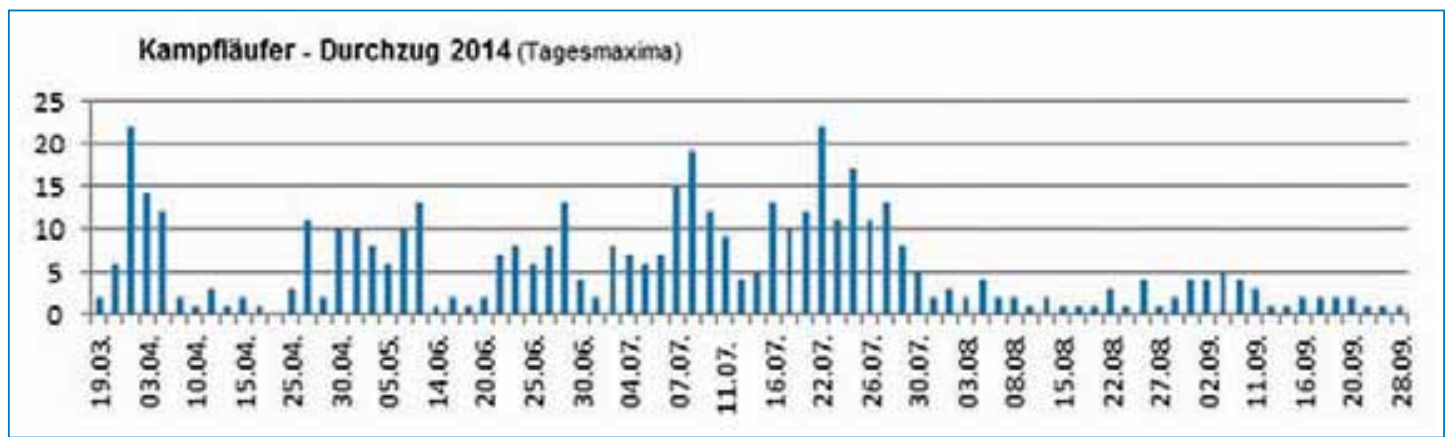


Diagramm 9

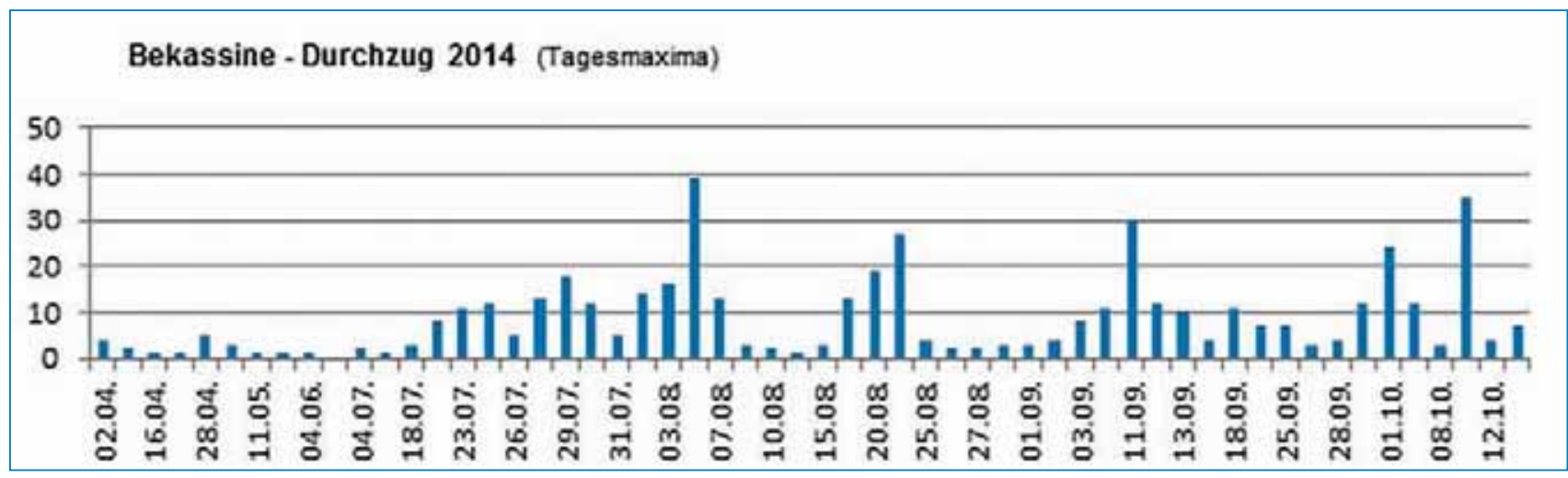

Diagramm 10

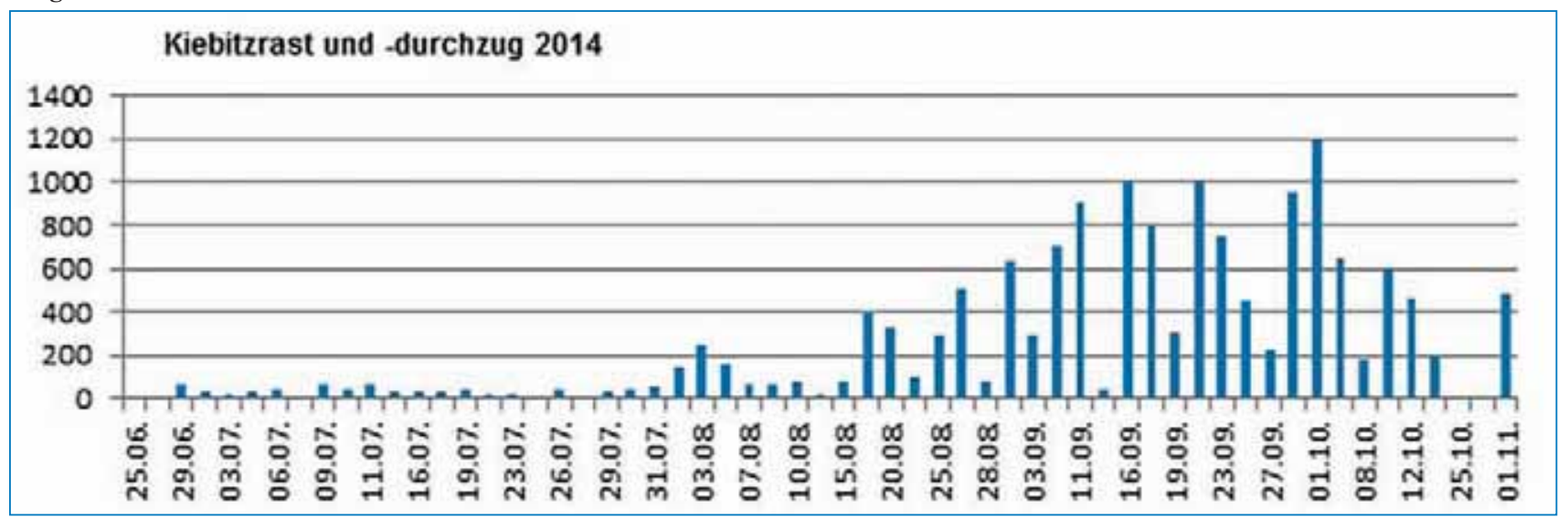

Diagramm 11

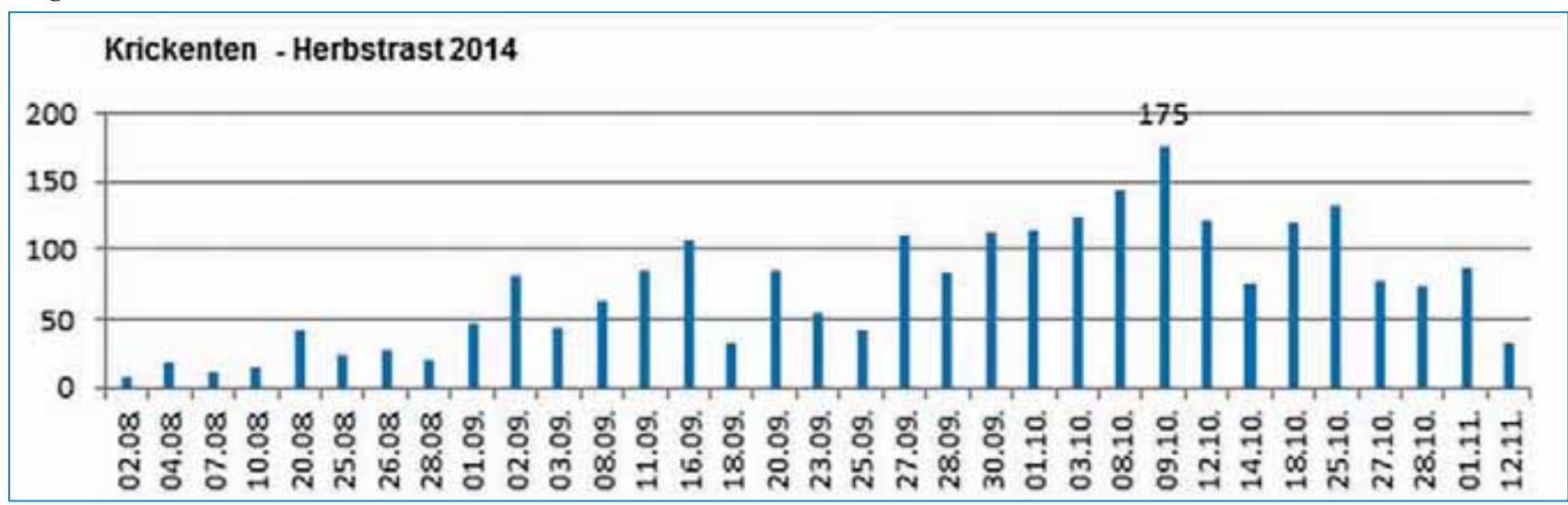

Diagramm 12

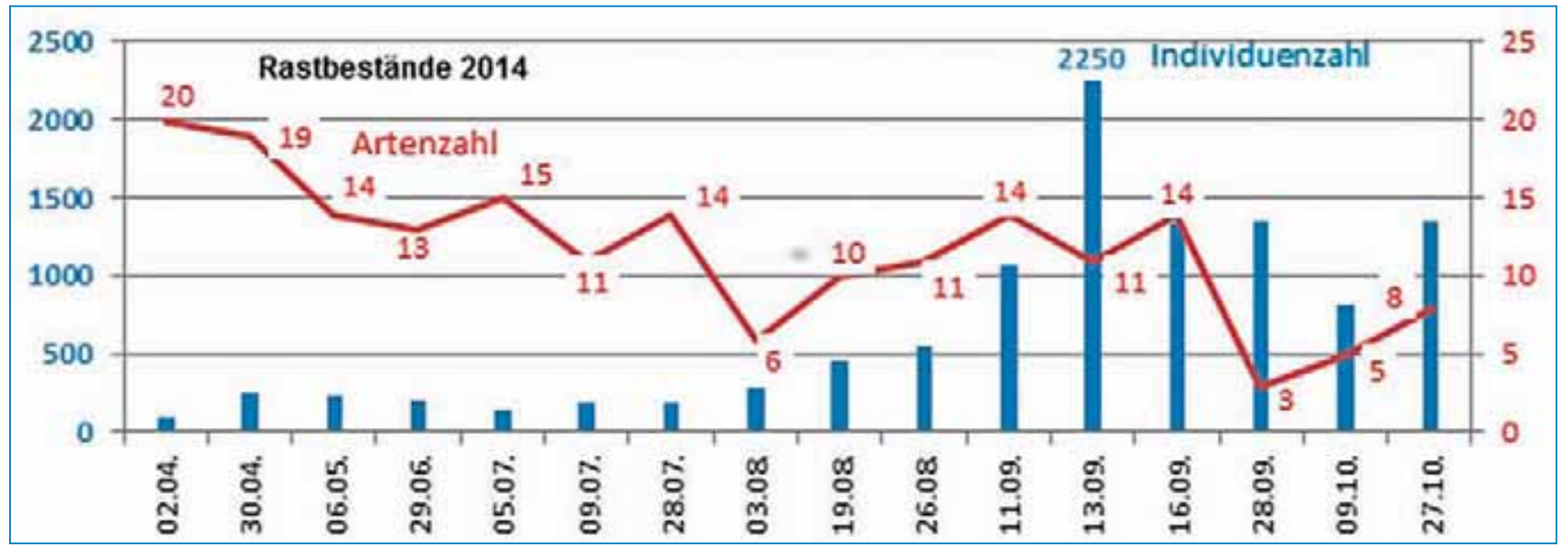



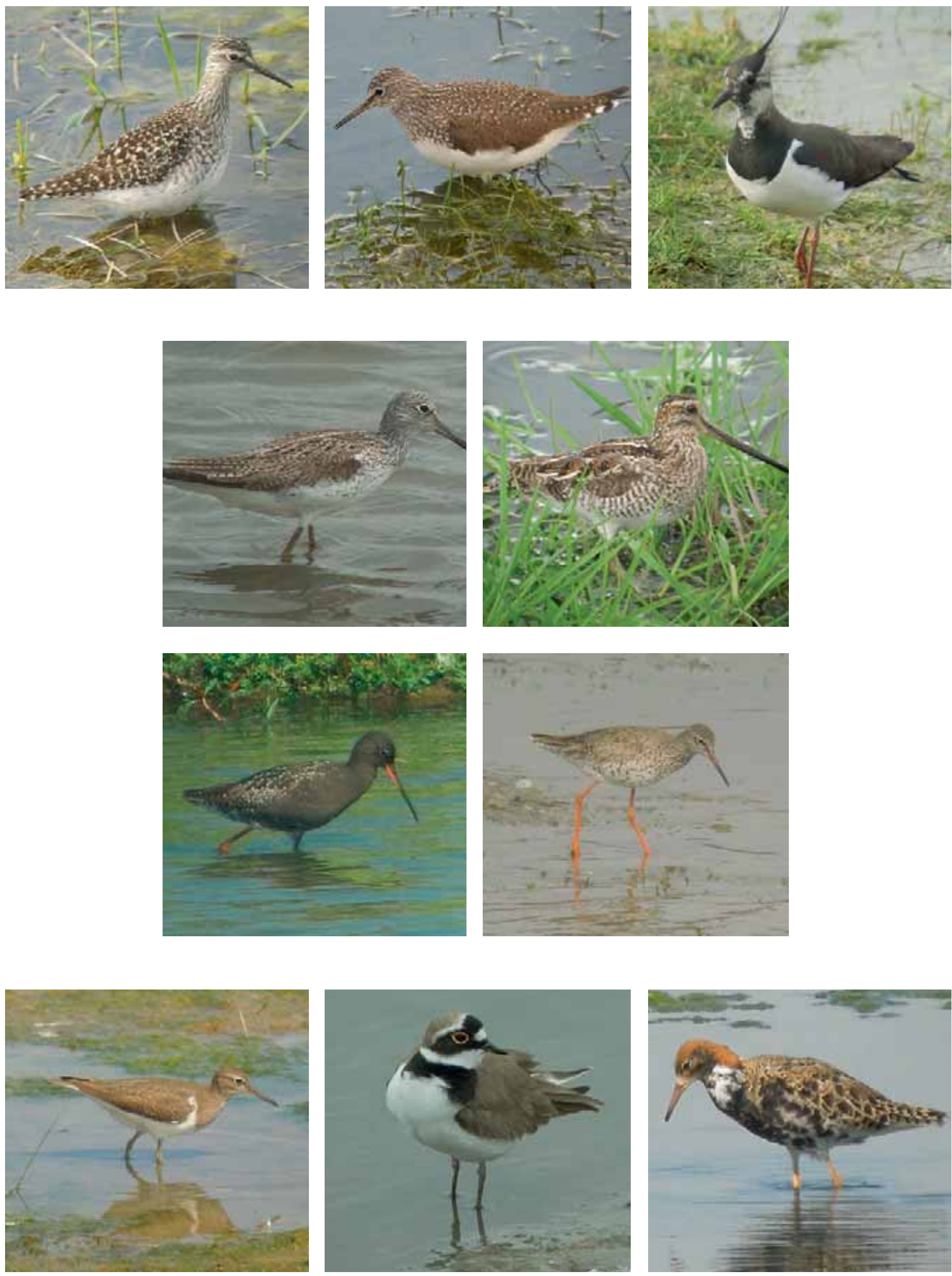

Abb. 175 bis 184: Im PVA-Teich regelmäßig beobachtete Limikolenarten

(v.l.n.r./v.o.n.u.) Bruchwasserläufer, Waldwasserläufer, Kiebitz, Grünschenkel, Bekassine, Dunkler Wasserläufer, Rotschenkel, Flussuferläufer, Flussregenpfeifer, Kampfläufer. Fotos: 7. Loose 


\subsubsection{Polder Gutow}

Trotz Intervention der Fachgruppe gelang es uns nicht, die noch Mitte der 1980er Jahre durchgeführte Melioration der Niederung am südlichen Ende des Sumpfsees zu verhindern. Mit hohem Aufwand waren hier ca. 13,8 km lange Entwässerungsgräben quer durch das ca. 73 ha große Gebiet gezogen und ein Schöpfwerk zur Wasserableitung in den Sumpfsee gebaut worden. Später zeigte sich der geringe Nutzen dieser Maßnahme für die Landwirtschaft. Aber ein Stück naturnahe Niedermoorfläche war damit unwiederbringlich verloren. Mit der politischen Wende gab es einige tiefgreifende Umweltprojekte. Eines davon war die Renaturierung des Gutower Polders.

Bereits von 1990 bis 1999 war das Schöpfwerk im Gutower Polder im Winter abgestellt worden. Man sah regelmäßig das Potenzial, was immer noch in der Fläche steckte. Auf Initiative des Wasser- und Bodenverbandes „Nebel“ wurde zum Sumpfsee hin ein Damm errichtet, um in nicht bewirtschaftbaren Teilen der Polderfläche ganzjährig mehr Wasser zu halten.

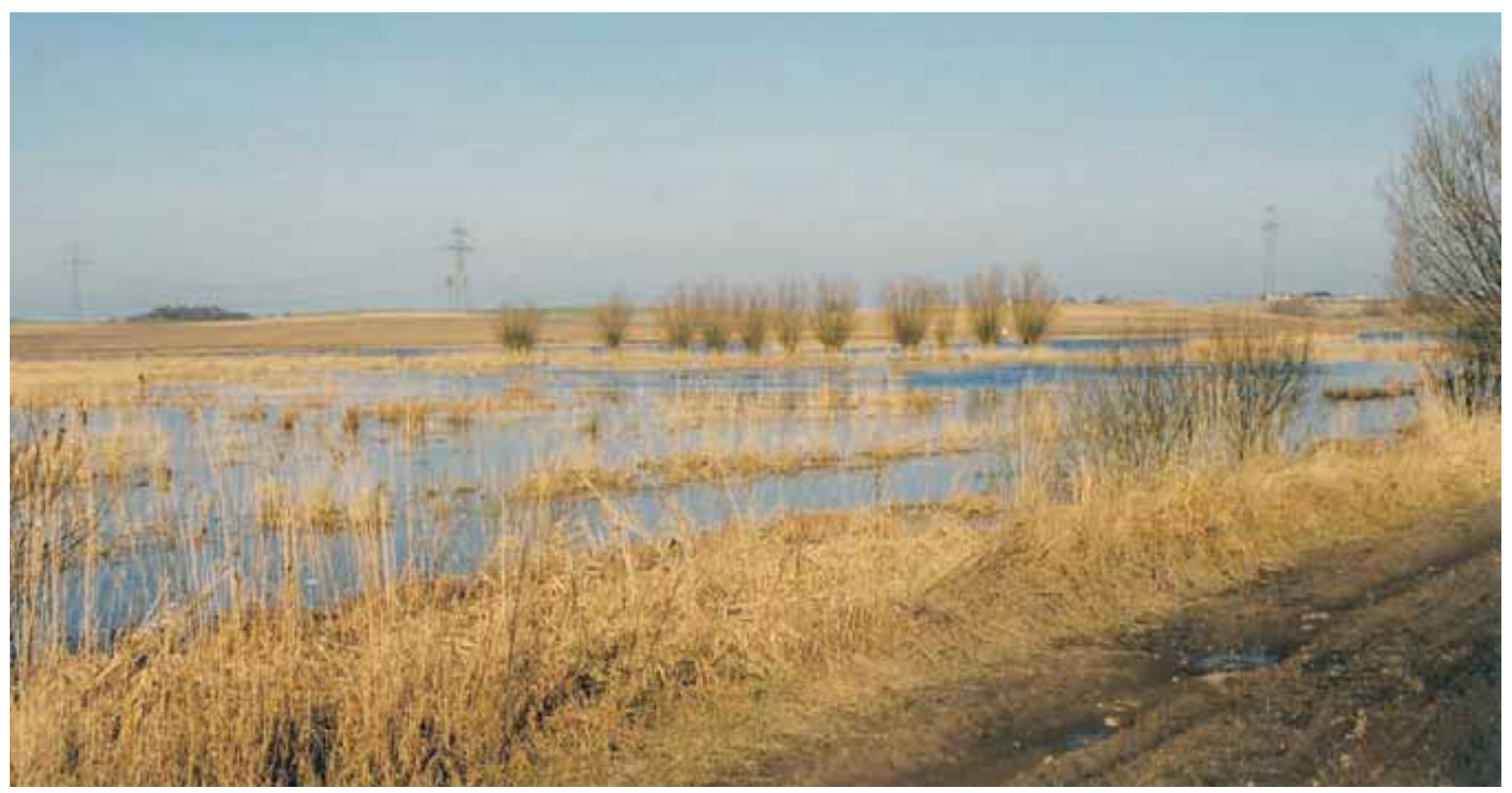

Abb. 185: Die Flächen des Gutower Polders im März 1999 sind voll überflutet. Foto: f. Loose.

Ab 2003 wurde dann ganzjährig kein Wasser mehr abgepumpt, was auf Dauer im südwestlichen Ackerhinterland sicher zu Problemen geführt hätte.

Auch die Wegeverbindung Gutow-Bülow war zeitweilig im Jahr nicht mehr passierbar. Es waren Lösungen zu finden.

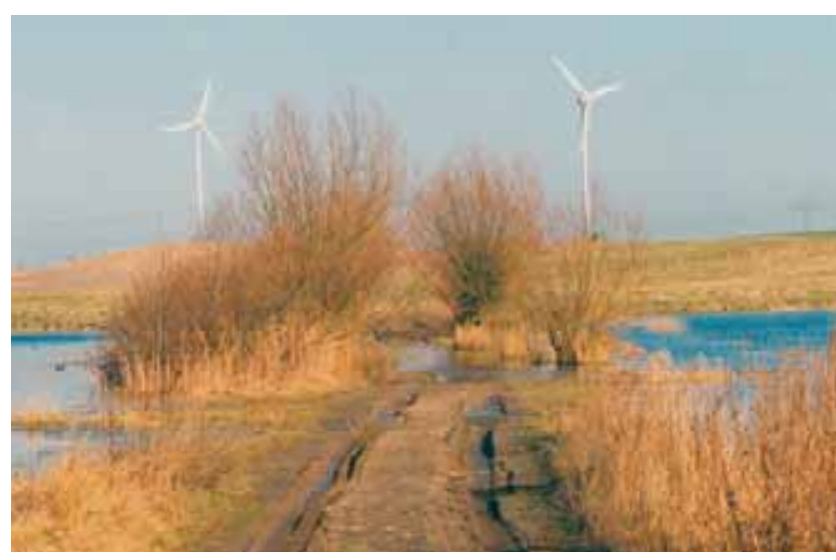

Abb. 186: Der Weg zwischen Gutow und Bülow im März 1999 Foto: 7. Loose.
Unter Mitwirkung der unteren Naturschutzbehörde gelang es, den Gutower Polder in die Liste der zur Renaturierung vorgesehenen Flächen aufzunehmen. 2003/2004 konnte im Rahmen des Moorschutzkonzeptes des Landes M-V nach einer Projektierungsphase durch das Güstrower Ingenieurbüro KULTA die Maßnahme auf einer Projektfläche von 76,93 ha mit Planfeststellungsbeschluss vom 26.08.2005 bautechnisch umgesetzt werden. Projektträger und heutiger Flächenverwalter wurde die Landgesellschaft Mecklenburg-Vorpommern $\mathrm{mbH}$. Eine wie ehedem vorhandene extensiv bewirtschaftete Feuchtwiese ließ sich mangels fehlender Voraussetzungen bei Landwirten nicht wieder etablieren. Mit dauerhaften Wasser- und Schilfflächen wurde hier ein bedeutsamer Lebensraum in erster Linie für die Vogelwelt geschaffen. Die FG empfahl der Gemeinde Gutow, die Errichtung eines öffentlichen Beobachtungsturmes als Projektbestandteil zu fordern. Beim damalige Bürgermeister Herrn Dr. Heinrich Murr ( $\dagger$ ) rannten wir offene Türen ein, und so entstand auf der Kuppe des "Dammbergs“ ein solches Bauwerk, wie es bereits in mehreren NSG er- 
richtet worden war. Leider stimmte der hier wirtschaftende Landwirt unserem etwas weiter nördlich in der Wiese vorgeschlagenen Standort für den Turm nicht zu. Man hätte von dort einen besseren Einblick in die Wasserflächen gehabt als jetzt vom Wanderweg aus. Kontraproduktiv für die Entwicklungsfläche wäre es gewesen, wenn der öffentliche Feldweg zwischen Gutow und Bülow auch weiterhin frei für den Fahrzeugverkehr geblieben wäre. Der musste unbedingt verhindert werden. Einig war man sich in der gemeinsamen Projektdiskussion, dass der Weg nur als Fußund Radweg zu widmen war. Die notwendige Wasserableitung aus dem Westteil der Fläche wurde nicht durch ein Rohr unter dem Weg realisiert, sondern als offener Grabenverlauf, der auf großen Steinen gequert werden kann. Damit war eine wirksame Schikane zur Unterbindung eines motorisierten Verkehrs gefunden.

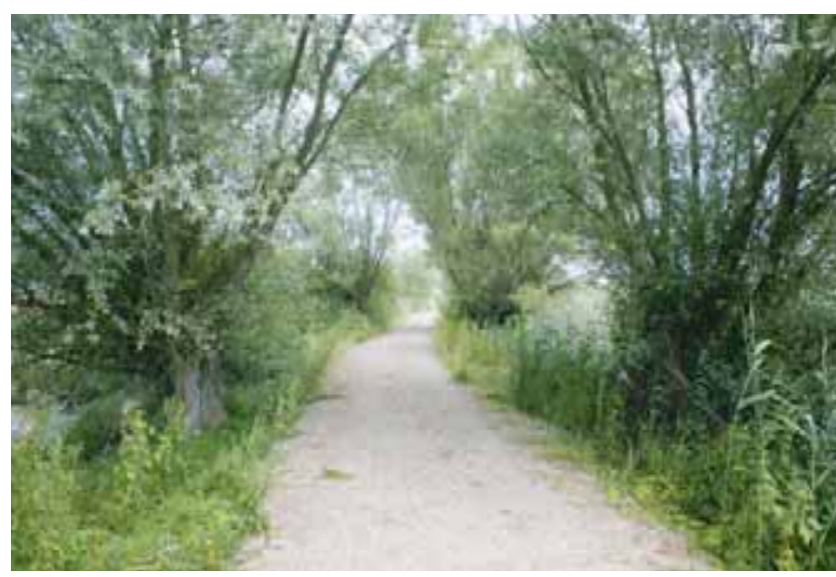

Abb. 187: Mit dem Projekt als Damm neu hergerichteter Fuß- und Radweg zwischen Gutow und Bülow. Foto: f. Loose.

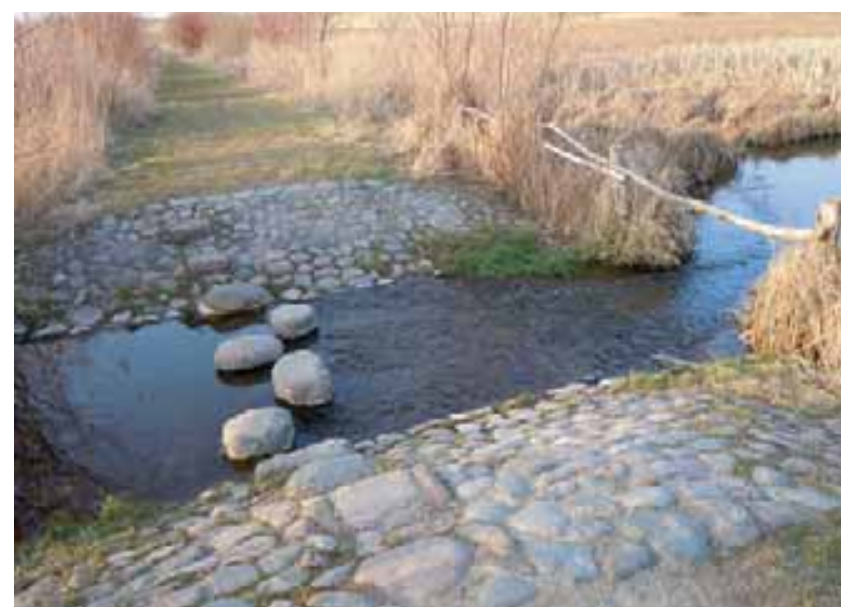

Abb. 188: Eine wirksame Schikane verhindert einen motorisierten Fahrverkehr durch den renaturierten Polder. Foto: 7. Loose

Im Herbst 2001 stand bei einer Gänsezählung am Sumpfsee ein Maler mit einer Staffelei auf einem Hügel, der sich interessiert an den Zähler Joachim Loose wandte. Ihn faszinierten auch die vielen tausend Graugänse. Mit diesem Gespräch war ein neues FG-Mitglied gewonnen. Mit Herald Kusch (KUC) fand sich auch gleich jemand, der als Einstieg in die Materie die zahlreichen Beobachtungsdaten aus un- serer FG-Kartei vom Sumpfsee und Gutower Polder sichtete und im Jahresbericht Nr. 37/2004 zusammenstellte. Mit den Beobachtungen von 2002 bis 2004 konnte die avifaunistische Bedeutung des Gebietes, welches sich künftig wieder naturnah entwickeln sollte, herausgestellt und damit das Renaturierungsprojekt begründet werden.

Die ganzjährig vorhandenen Wasserflächen im Polder ziehen regelmäßig während des Frühjahrszuges größere Entenscharen an. Maximal konnten hier >50 Schnatter-, 120 Spieß-, > 40 Löffel-, 55 Pfeif-, 70-90 Krick-, 10-16 Knäk-, 40 Tafel- und 50 Reiherenten gezählt werden. Als Brutvögel traten Zwerg-, Rot- und Schwarzhalstaucher auf.

In den Röhrichten brüteten Wasser-, Teich- und Blessrallen, Rohrweihe, Kranich, Rohrschwirl, Bartmeisen und alle vier Rohrsängerarten. Auf den kleinen Schlickflächen wurden von FG-Mitgliedern neun rastende Limikolenarten (Bekassine bis 100) notiert. Die von H. Kusch für den Polder insgesamt mit Daten belegten 79 Vogelarten sind sicherlich noch nicht alle hier vorkommenden. Eine weitere Zusammenstellung erfolgte bisher nicht. Im Punkt „Bemerkenswerte Beobachtungen“ der FG-Jahresberichte erscheinen weiterhin zahlreiche Daten aus dem Polder.

Herald Kusch hatte in einem Schaukasten des für die Besucher offenen Beobachtungsturms versucht, über die hier jeweils aktuell vorkommenden Vogelarten zu informieren. Der Turm wird regelmäßig von Spaziergängern aufgesucht, leider auch von solchen, die ihre Spraydosen hier leeren müssen. Die Glasscheibe des Schaukastens im Turm war bald zerschlagen worden. Wir erkannten, dass es zwecklos war, hier weiter ehrenamtliche Arbeit zu investieren und entsprechende Informationen anzubieten. Wir werden warten müssen, bis eine Jugend herangewachsen ist, die sich ohne Frust an der Gesellschaft einfach an dem Reichtum unserer Landschaft erfreuen kann.

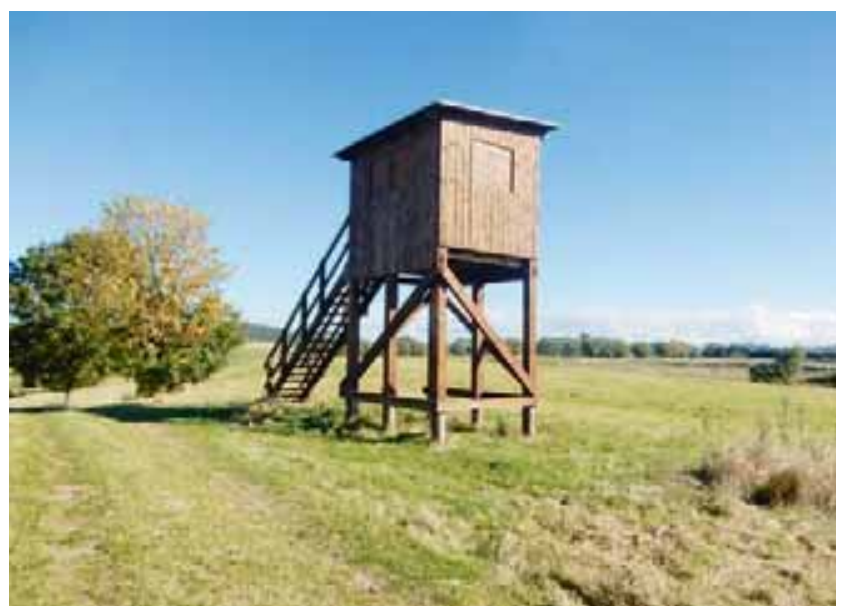

Abb. 189: Vom Beobachtungsturm auf der Kuppe des „Dammbergs" hat man einen Einblick in die Wasserflächen. Foto: f. Loose.

Nach dem Wegzug von H. Kusch aus Güstrow beobachtete Helmut Richter jetzt häufiger hier.

Die ausgedehnten Schilfflächen beherbergen zahlreiche Rallenarten und schilfbewohnende Singvögel. Es ist ver- 
mutlich noch nie ein Ornithologe die 5,4 km lange Strecke um die Renaturierungsfläche gelaufen.

Hier dürfte sich ein Ermitteln von Siedlungsdichten lohnen. In den großen Schilfflächen wird eine hohe Anzahl von brütenden Bartmeisen vermutet. Im Sommer 2015 fing Joachim Loose auf dem Verbindungsweg insgesamt 86 Bartmeisen. Auch Blaukehlchen und Beutelmeisen wurden regelmäßig nachgewiesen. Vor den Toren der Stadt Güstrow gelegen, ist das Gebiet gut erreichbar. Für junge Ornithologen gäbe es ein lohnendes Betätigungsfeld. Spannend dürfte es auch sein, die im Gebiet ablaufende Sukzession weiter zu verfolgen und in Zusammenhang mit Veränderungen in der Vogelwelt zu dokumentieren.

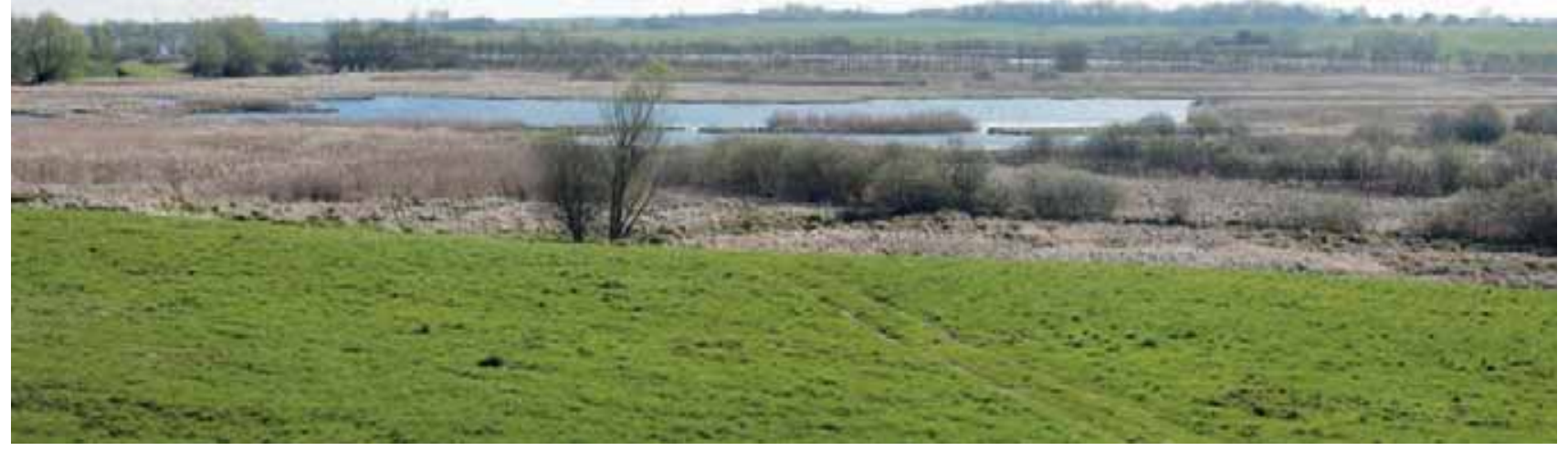

Abb. 190: Blick vom Beobachtungsturm nach Norden in die Wasserflächen, die nicht nur Rastflächen für Entenvögel, sondern auch Schlafplatz zeitweilig für bis zu 700 Kraniche sind. Im Hintergrund das Südende des Sumpfsees. Foto: F. Loose.

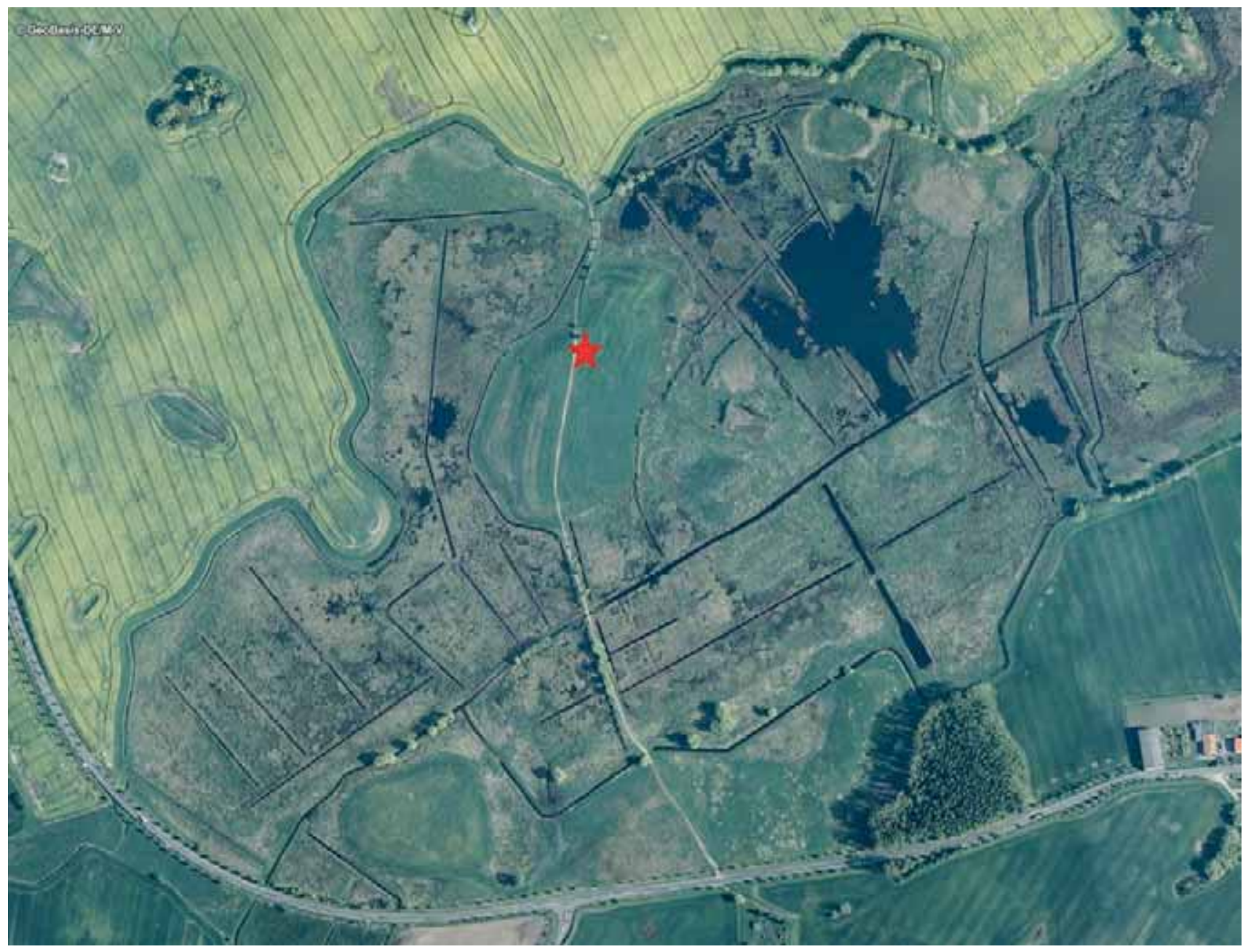

Abb.191: Gutower Polder mit dem ehemalig wirksamen Entwässerungssystem, roter Stern = öffentlicher Beobachtungsturm. (Luftbildquelle: Kartenportal des LUNG) 


\subsubsection{Polder Klaber}

Über eine weitere „ertrunkene Wiese“ - ein neues Feuchtgebiet bei Klaber berichteten Sebastian Lorenz und Wolfgang Neubauer in den Jahresberichten Nr. 32/1999 und 33/2000. Bei einer Exkursion im späten Frühjahr 1998 fiel diese ca. 2 ha große vernässte Senke zu Füßen des Breiten Berges (Höhe 100,9 m) südöstlich von Klaber wohl das erste Mal den Ornithologen der FG auf. Die Autoren berichteten, dass sich das Wasser der umliegenden flachen Hänge in einer abflusslosen Senke sammelt. Bei schwankenden Wasserständen entstanden hier insbesondere in den Sommermonaten durch die Verdunstung kleine Schlickflächen. Bereits 1999 brüteten hier vier Paare des Rothalstauchers und drei des Zwergtauchers erfolgreich. Bei einem Paar der Knäkente wurde die Kopula beobachtet. In einer Tabelle wurden 31 Vogelarten genannt, die unmittelbar mit dem Feuchtgebiet in Verbindung standen. Erstaunlich waren die sich hier im Spätsommer sammelnden > 100 Bleßrallen. Zu dieser Zeit fanden sich auch einige auf den Schlickflächen Nahrung suchende Limikolenarten ein - gezählt wurden mind. 65 Bekassinen, 15 Bruchwasserläufer, ein Flussregenpfeifer, drei Kampfläufer und zwei Waldwasserläufer. Auch im Folgejahr 2000 beobachteten S. Lorenz und W. Neubauer hier planmäßig. Die Fläche fiel nie ganz trocken, und es konnten neue Brutnachweise erbracht werden. Es brüteten erstmalig zehn Paare der Lachmöwe und ein Paar Schwarzhalstaucher, welches am 9. Juli Dunenjunge führte. Der Rothalstaucher brütete mit sieben Paaren und auch der Zwergtaucher wieder mit zwei Paaren. Als neue Limikolenart wurde ein Dunkler Wasserläufer notiert. Wiederum $>100$ Bleßrallen hielten sich im Frühjahr und Spätsommer auf der kleinen Wasserfläche auf. Im August wurde erstmalig ein Trupp von 23 hier einfallender Kraniche gesehen, der das Flachgewässer wahrscheinlich als Schlafplatz nutzte.

Das neu entstandene Kleingewässer hat natürlich auch eine Vorgeschichte. Bereits im Messtischblatt von 1888 ist die Fläche als Wiese mit einem Grabennetz dargestellt. Die hier ertrunkene Wiese gehörte zu jenen Flächen, aus denen zu DDR-Zeiten mit Schöpfwerkspumpen auch noch etwas herausgeholt werden sollte - eine sogenannte Polderfläche, die ohne Wasserstandsenkung weitgehend unter Wasser stehen würde. Ab 1990 hatte man das Schöpfwerk nicht mehr genutzt. Man hatte erkannt, dass die Kosten für eine notwendige Pumpenreparatur nicht im Verhältnis zu dem Nutzen standen, der von dieser Wiese erbracht werden konnte. In der Folge versumpfte die Wiesensenke wieder. Es bildete sich nach und nach jene Wasserfläche, die von Lorenz und Neubauer vorgefunden wurde.

Wie im Gutower Polder wurde 2007 schließlich für eine dauerhafte Renaturierungslösung die Schöpfwerkspumpe abgebaut. Die Behörden und der Wasser- und Bodenverband Nebel einigten sich mit dem hier wirtschaftenden Landwirt aus Klaber auf eine maximale Wasserhöhe für den Überlauf des künftigen Gewässers. Wie in Luftbildern nachfolgender Jahre zu sehen ist, gab es im Sommer später kaum noch Schlammflächen. Dafür nahm die Bedeutung des Flachgewässers als Schlafplatz für Kraniche permanent zu. Bis zu 460 Kraniche wurden hier beim abendlichen Einflug durch die FG-Mitglieder K.-H. Koop und St. Thiel gezählt (Diagramm 13).

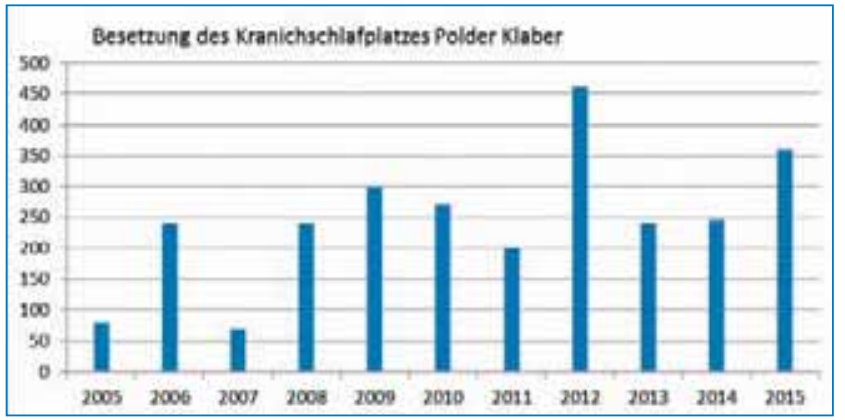

Diagramm 13: Der Kranich-Schlafplatz wurde in einigen fahren stärker genutzt.

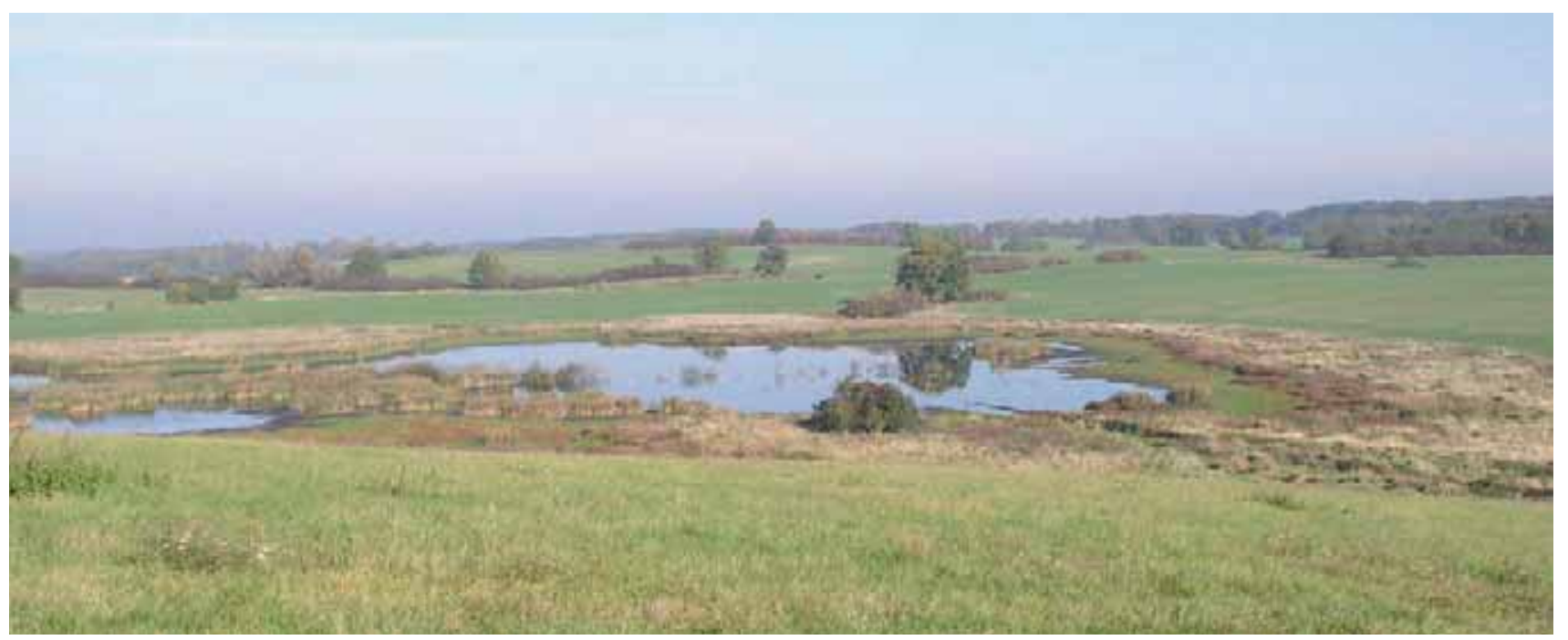

Abb. 192: Blick vom Breiten Berg auf den Polder vor dem Rückbau des Schöpfwerkes. Mai 2006. Foto: A. Martin. 


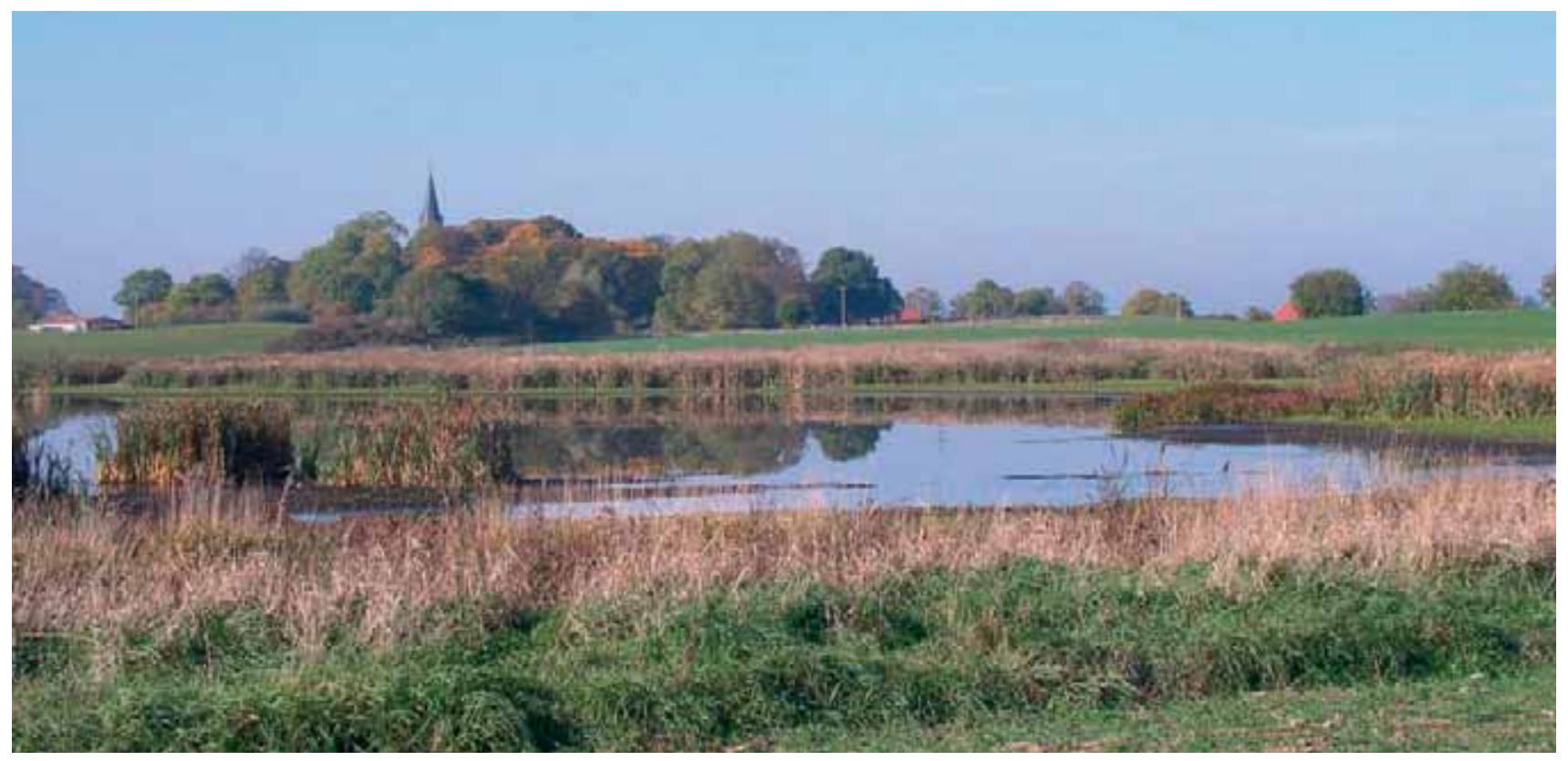

Abb. 193: Blick vom östlich angrenzenden Acker über die Wasserfläche in Richtung Klaber, im Vordergrund Schlickflächen. Mai 2006. Foto: A. Martin

Durch die Fixierung auf abendliche Beobachtungen von einfallenden Kranichen lagen in den Folgejahren kaum noch Daten über andere tagsüber hier vorkommende Vogelarten vor. Im Randbereich des Gewässers kann ein zunehmender Gehölzaufwuchs registriert werden. Das entspricht einem üblichen Sukzessionsablauf auf solchen Flächen. Es wäre interessant, wenn man die vorkommende Vogelwelt in Verbindung mit diesen Biotopverände- rungen darstellen könnte. Bei den Synchronzählungen an Kranichschlafplätzen wurde festgestellt, dass bei hohem Wasserstand im Gewässer die Kraniche zum nahe gelegenen Schlafplatz im Malchiner See auswichen. Andererseits stieg die Zahl im Polder Klaber, wenn die Rastbedingungen am Malchiner See ungünstig waren (vgl. KOOP, K.-H \& S. RETTICH, 2014).

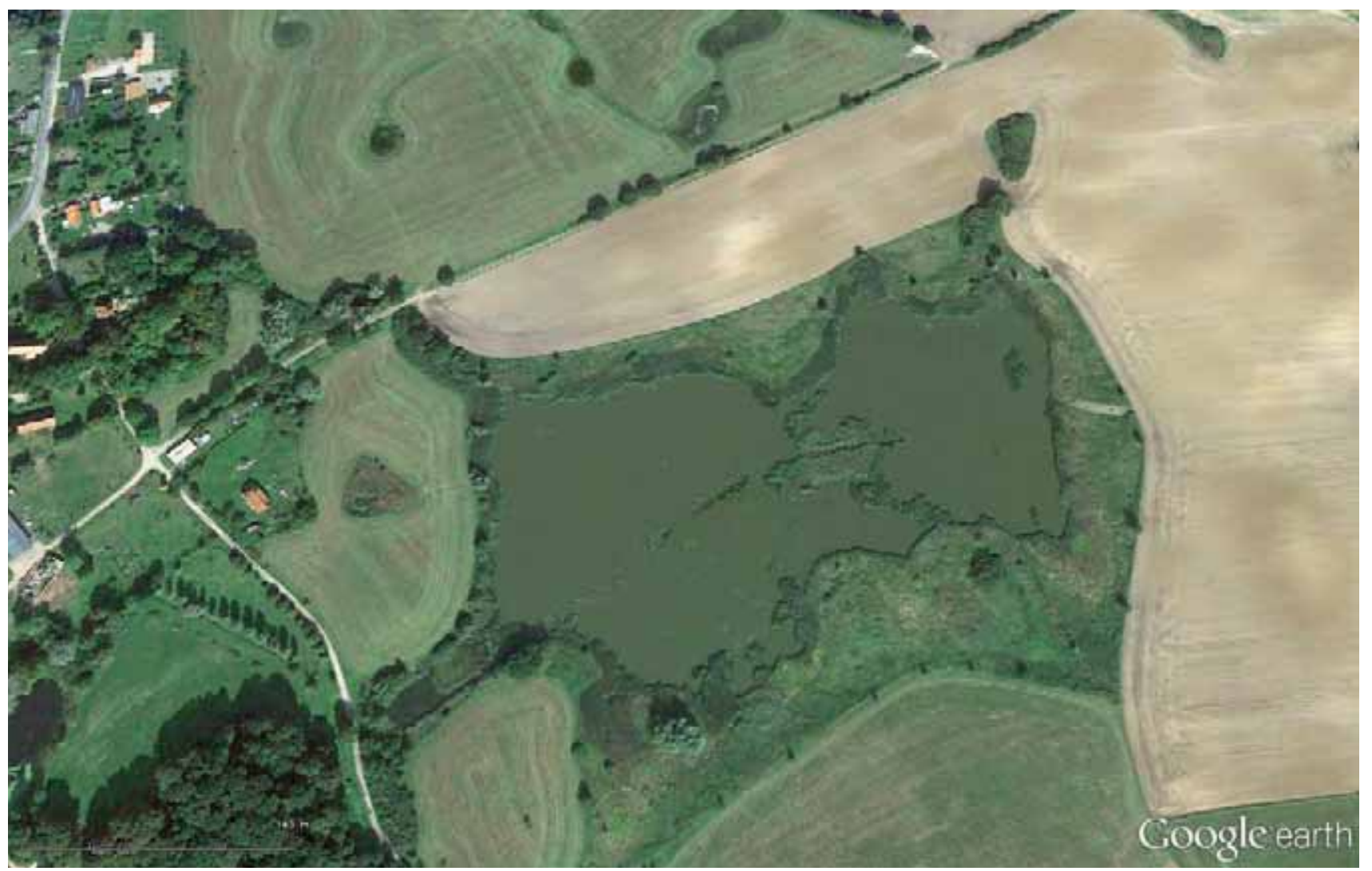

Abb. 194: Der ehemalige Polder Klaber am 05.09.2014. Die am früheren zentralen Graben stehenden Sträucher sind bei höherem Wasserstand weitgehend abgestorben. (Quelle: Google earth). 


\subsubsection{Ochsenauge}

In alten Messtischblättern (Nr. 849/2238) von 1882 bis 1950 wird die heutige Gewässerfläche südlich der Villa Marie in Güstrow als Wiese bzw. Feuchtwiese dargestellt. Der Name „Ochsenauge" taucht erstmalig in aktualisierten Flurkarten auf und deutet darauf hin, dass hier schon früher zumindest zeitweilig eine Wasserfläche vorhanden war.

In unserer Rubrik der „Bemerkenswerten Beobachtungen“ in den FG-Jahresberichten taucht der Gebietsname erstmalig 1990 auf. Hier muss bereits ein größeres Gewässer vorhanden gewesen sein, da ein Brutnachweis des Rothalstauchers mit zwei Jungen notiert wurde. Im Infrarot-Luftbild von 1991 ist die Gewässerfläche etwa 1,3 ha groß. Es kam um 1989 in der Entwässerungsleitung vom Hoppelloschen See, die in das Grabensystem um den Sumpfsee führte, zu einer Verstopfung in Höhe der Feuchtwiese. Zwischen dem Flächeneigentümer, der die Seggenriedwiese ohnehin nicht nutzen konnte, dem Wasser- und Bodenverband Nebel und der unteren Naturschutzbehörde konnte die Erhaltung einer Wasserfläche abgestimmt werden. In den Folgejah- ren gewann diese Fläche an Bedeutung für die Vogelwelt. Auf einer kleinen Insel am Westrand des Gewässers brüteten ab 1990 ca. 100 BP Lachmöwen und ab 1991 die ersten 2 BP Flussseeschwalben. Durch die untere Naturschutzbehörde wurde eine Tiefbaufirma in Verbindung mit einer von ihr begangenen Ordnungswidrigkeit beauflagt, diese Insel durch eine ca. $6 \mathrm{~m}$ breiten tiefen Graben noch stärker vom Festland abzutrennen. Prädatoren sollte es erschwert werden, hier Beute zu machen. Zum Schutz dieses neu entstandenen bedeutsamen Feuchtgebietes für die Vogelwelt stellte die Fachgruppe über die UNB einen Antrag auf einstweilige Sicherung als NSG. Bei der geringen Gebietsgröße war diese Schutzkategorie sehr ungewöhnlich. Das unmittelbar nach der Wende geltenden Naturschutzrecht ließ jedoch keine andere Möglichkeit zu, um einen wirksamen Schutz zu garantieren. Mit Verordnung von 1992 war dann vom Umweltministerium die einstweilige Sicherung als NSG „Ochsenauge“ vorgenommen worden.

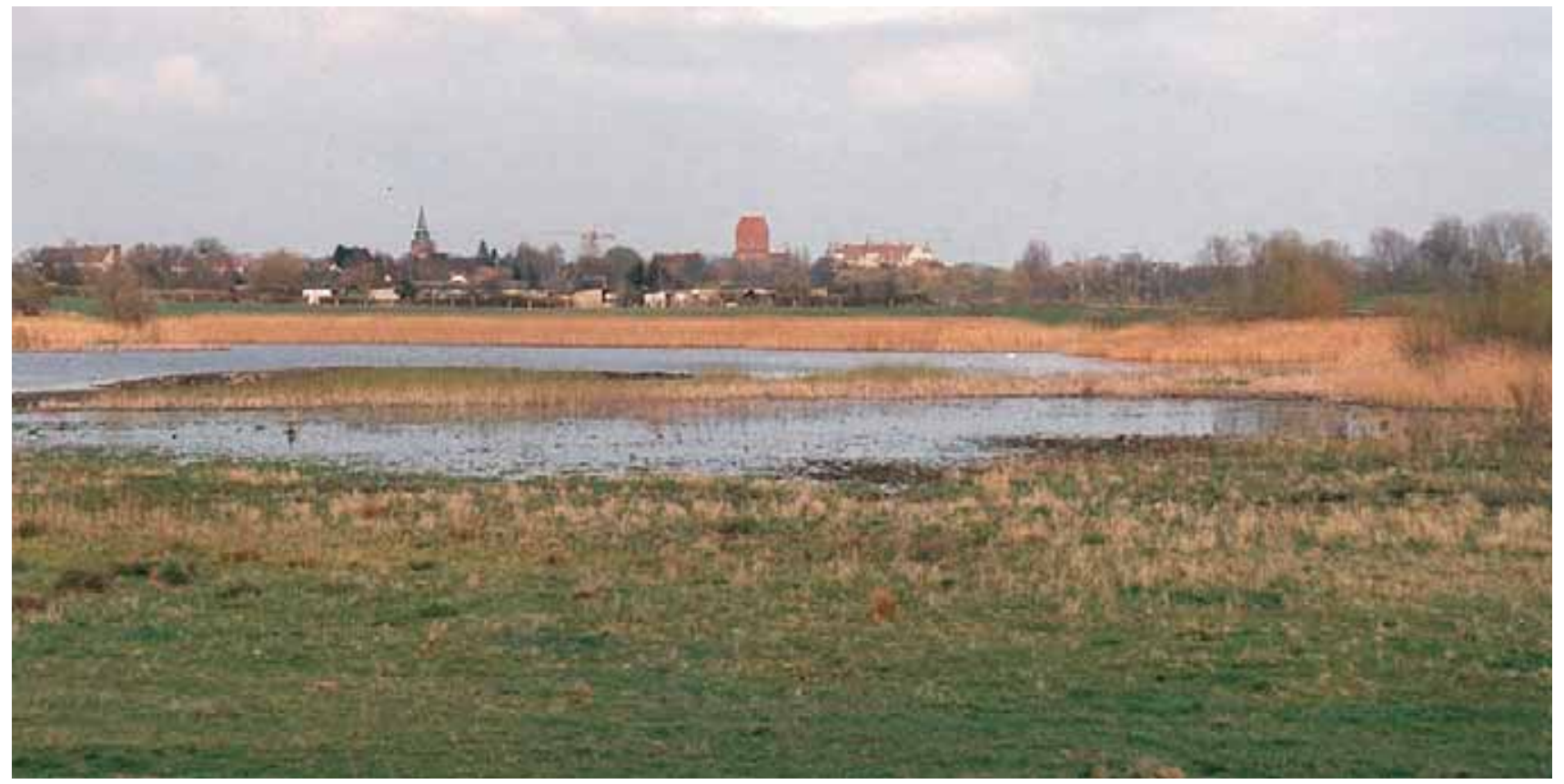

Abb. 195: Blick von Westen auf das Ochsenauge - 1992. Foto: f. Loose.

Schaut man heute in die FG-Jahresberichte, tauchen nach 1991 bemerkenswerten Beobachtungen vom Ochsenauge durchgängig nur bis etwa 1995 auf. Der Brutbestand der Lachmöwe war auf 250 BP gestiegen. Auch Flussseeschwalben brüteten zunehmend mit bis zu 25 BP. Regelmäßig zogen hier 3-5 BP Rothalstaucher erfolgreich ihre Jungen auf. Schwarzhalstaucher (2-4 Ex.) konnten neben Schnatter-, Spieß-, Pfeif-, Knäk- und Löffelenten im Frühjahrsdurchzug beobachtet werden. Das Gebiet wurde im Jahreszyklus relativ häufig durch FG-Mitglieder aufgesucht. So wurden auch einige gelegentlich auf dem Ochsenauge auftauchende seltener zu beobachtende Arten registriert (Streifen- gans, Nilgans, Zwergseeschwalbe). In diesen Jahren beobachteten hier insbesondere M. Fritsche, J. Loose und M. Montschko, gelegentlich auch K. Lingsminat, A. Martin und W. Neubauer.

K. Lingsminat machte uns Mitte der 1990er Jahre darauf aufmerksam, dass am Ufer des Ochsenauges zunehmend Weidensträucher und -bäume aufwuchsen und plädierte für deren Beseitigung. Bald war das Gebiet dann auch zum großen Teil von Gehölzen umstanden. Es machte nur keinen Sinn, in die typischen Sukzessionsabläufe einzugreifen. In regelmäßigen Abständen hätte man das wiederholen müssen. 


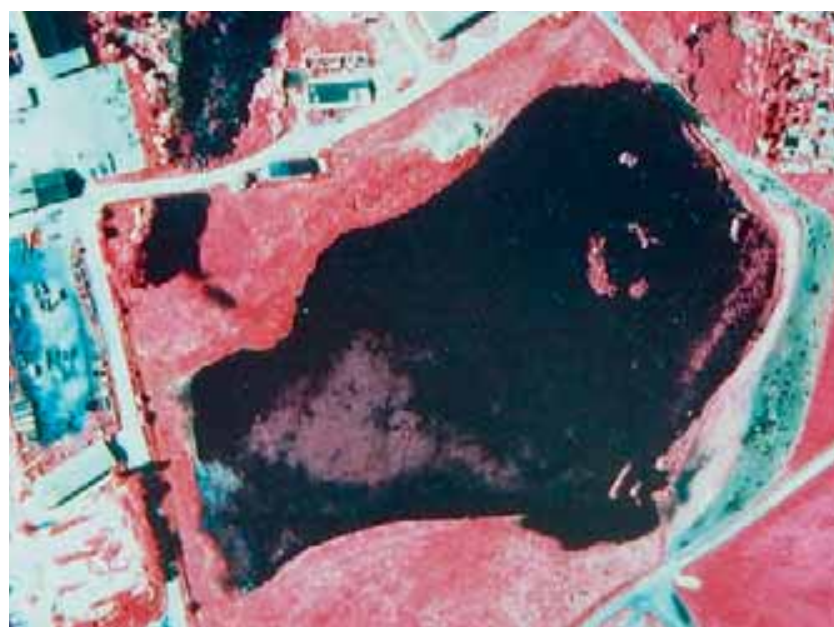

Abb. 196: CIR-Luftbild von 1991 (Quelle: UNB)

$\mathrm{Zu}$ dieser Zeit wurde durch den Wasser- und Bodenverband Nebel der Wasserstand im Sumpfsee erhöht. Im Südwestufer des Sees starben große Flächen des Weidengürtels ab, und es entstanden dort größere Schlickflächen. Die bisher am Ochsenauge brütenden Lachmöwen und Flussseeschwalben zogen nach 1995 in dieses neue Gebiet um. Die Frage, ob der Prädatorendruck am Ochsenauge zu groß geworden war oder am Sumpfseeufer einfach nur die besseren Brutbedingungen herrschten und die Vögel deshalb umgezogen waren, kann nicht beantwortet werden. $\mathrm{Zu}-$ mindest die Flussseeschwalben waren nun etwas dichter an ihrem Nahrungshabitat. Bei Vergrößerung der Lachmöwenkolonie am Sumpfsee brütete ein Teil der Lachmöwen dann 1998 und 2000 nochmals mit 200-250 BP kurzzeitig am Ochsenauge.

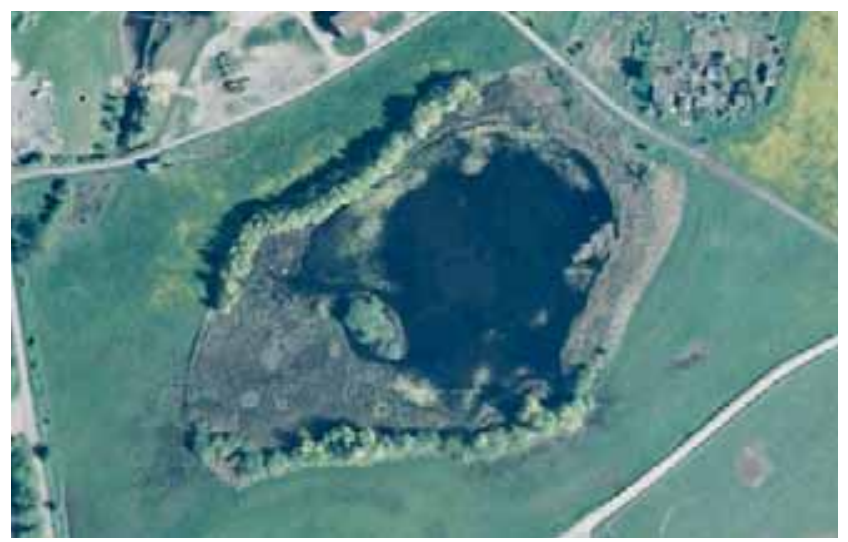

Abb. 197: Luftbild von 2008 - Vor der Insel am Westufer ist der ausgebaggerte Graben noch erkennbar. (Quelle: Google earth).

In den Jahren von 1997 bis 2000 gelangten Kanadagans, Brandgans und Uferschnepfe nochmals als bemerkenswerte Beobachtungen in die Jahresberichte.

Des Weiteren fand sich in den Weiden am Ufer des Ochsenauges im Jahr 2000 erstmalig ein Brutnest der Beutelmeise. Früher am Ochsenauge beobachtete Rot- und Schwarzhalstaucher sowie zahlreiche Entenarten im Frühjahrsdurchzug waren nach der Renaturierung des Polders
Gutow dort anzutreffen. Das Ochsenauge hatte an Bedeutung verloren.

Mit Verordnung des Umweltministerium vom 14.09.1996 wurde die einstweilige Sicherung des Ochsenauges als NSG noch einmal verlängert. Ab 1998 war mit dem 1. Naturschutzgesetz für $\mathrm{M}-\mathrm{V}$ die untere Naturschutzbehörde bevollmächtigt, geschützte Landschaftsbestandteile (GLB) auszuweisen. Mit Verordnung vom 8.10.1998 wurde das Ochsenauge mit seinem Umfeld in einer Größe von 11 ha als GLB einstweilig gesichert. Die mit der Verordnung ausgesprochenen Verbote für dieses Gebiet waren weitreichend und ähnelten denen für Naturschutzgebiete.

Auf Grund der o.g. Veränderungen in der Vogelwelt des Ochsenauges hatte die UNB später auf eine endgültige Unterschutzstellung als GLB verzichtet. Teile des „Ochsenauges" werden heute lediglich als geschützter Biotop (GUE10948 und GUE10949) ausgewiesen. Da das Gewässer größer als 1 ha ist, fällt die Wasserfläche nicht unter den Biotopschutz. Für die im Gewässer vorkommenden Tierarten gelten jedoch allgemeine Artenschutzbestimmungen. Wenngleich sich die Bedeutung des Biotops seit seiner Entstehung insbesondere für die Vogelwelt geändert hat, ist es für uns Ornithologen durchaus lohnenswert, das Gebiet nicht aus den Augen zu verlieren. So nah an der Peripherie der Stadt Güstrow gelegen, sollten wir die weiteren Veränderungen und Entwicklungen beobachten und stärker dokumentieren. Es könnte interessant sein, wie nachfolgende Notizen zeigen: Am 17.4.2003 beobachtete M. Montschko hier auch erneut einen Schwarzhalstaucher. In den Weiden des Ufersaums wurden 2010 und 2011 wiederum brütende Beutelmeisen festgestellt. Auf dem Gewässer hielten sich 2014 zahlreiche Enten auf.

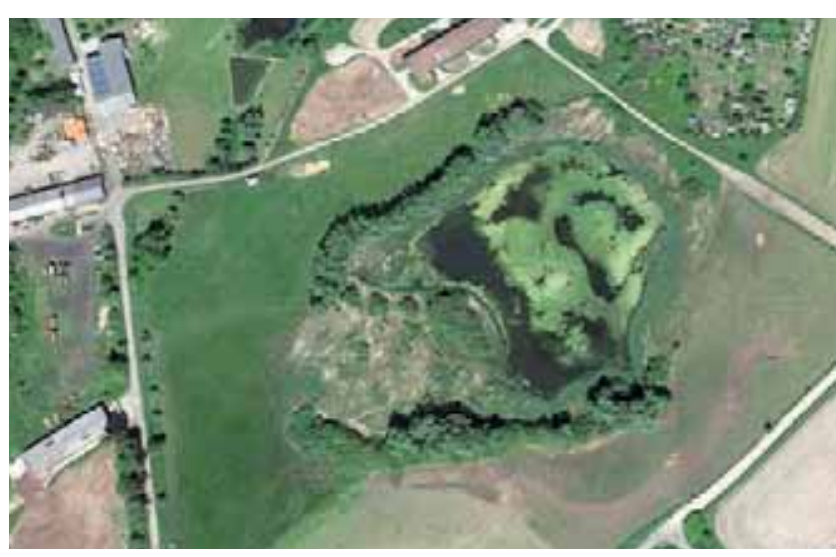

Abb. 198: Luftbild vom 06.06.2014 - Die südlich angrenzende Wiese ist zum Maisacker geworden. (Quelle: Google earth).

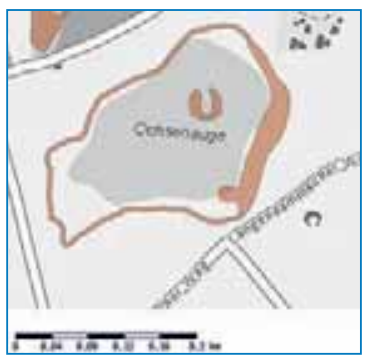

Abb. 199:

Das Ochsenauge mit den als geschützte Biotope farbig ausgewiesenen Flächenteilen.

Quelle: Kartenportal LUNG 


\section{Spezieller Teil}

\section{Ausgewählte Darstellungen von Artbearbeitungen innerhalb von 50 Jahren}

Einer Reihe von Vogelarten galt seit der Gründung der Fachgruppe Ornithologie und Naturschutz Güstrow ein besonderes Augenmerk. Die Bestände dieser Arten wurden jährlich erfasst, und man bemühte sich, so recht schnell einen Überblick zu ihrer Verbreitung in unserem Beobachtungsgebiet zu erhalten. Durch die kontinuierliche Arbeit mit diesen Arten kann heute belegt werden, wie sich über einen langen Zeitraum fast lückenlos die Bestände zum Guten oder Schlechten entwickelt haben. Wenn auch teilweise die Artbetreuer im Laufe der Zeit wechselten, nahmen andere Mitglieder der Fachgruppe deren Plätze ein und widmeten sich mit gleicher Kraft „ihren“ Arten. Es wäre zu wünschen gewesen, dass auch noch einige andere Vogelarten mit gleicher Intensität bearbeitet worden wären.
Illusorisch war sicher das 1973 anvisierte Ziel der Fachgruppe, für jede Vogelart oder Artengruppe einen Artbearbeiter einzusetzen, der sich kontinuierlich um die Datensammlung kümmern sollte.

Auch mit einigen in größeren Zeitabständen in Gemeinschaftsarbeit durch alle FG-Mitglieder wiederholten Erfassungen von ausgewählten Arten konnten die Entwicklungen in den Beständen dargestellt werden. Die Auswirkungen von intensiven Veränderungen in der Umwelt, insbesondere durch die Landwirtschaft, lassen sich mit kontinuierlich erhobenen Daten jedoch deutlich feiner aufzeigen, wie es die nachfolgenden Abschnitte über sechs Vogelarten zeigen.
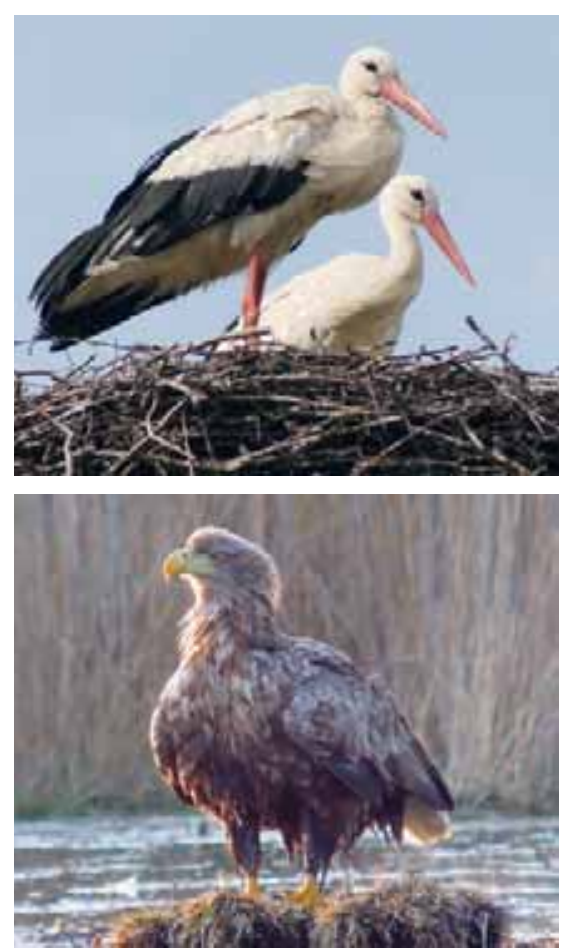
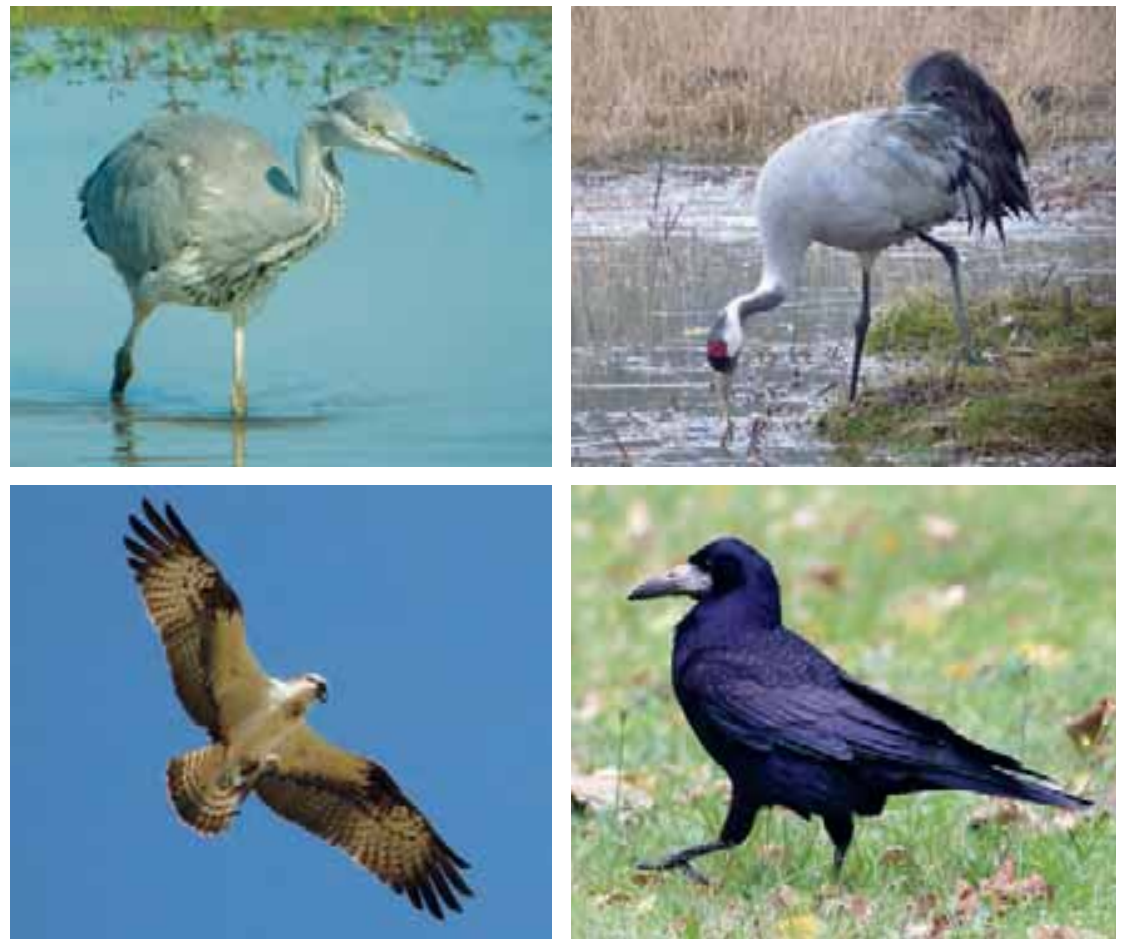


\subsection{Jahre Weißstorch-Erfassung}

\section{Reinhard Schaugstat}

Der ursprüngliche Waldbewohner brütete wie sein schwarzer Verwandter auf Bäumen. Mittelalterliche Rodungen öffneten die Landschaft, und der Storch eroberte als Kulturfolger Dörfer und Städte. Durch die Besiedlungsbewegung des 13. Jhs. bezog er die nach Mecklenburg mitgebrachten Rohr-, selten auch strohgedeckten niederdeutschen Hallenhäuser, später auch Scheunen und Ställe. Auf den sogenannten Weichdächern konnten die Vögel selbständig ihre Nester anlegen.

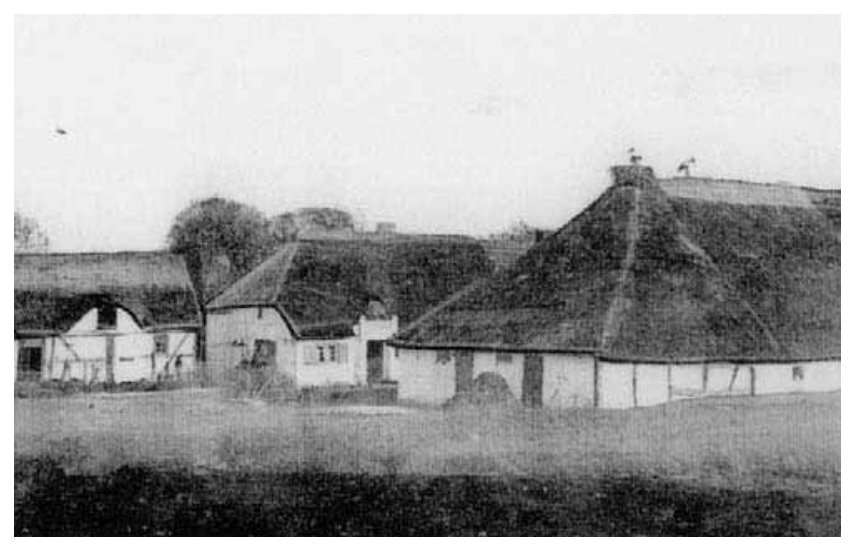

Abb. 200: Storchenhorst in Lalendorf (um 1900).

Foto: Archiv C. Vick.

Manche hochgetürmten Horste waren gut 100 Jahre besetzt (Bansow 1830-1981, Siemitz 1860-1995 und Zehna 18501930).

Infolge Zerfall, Abriss und Neubau vieler Gebäude bezogen die Störche zunehmend nach 1950 Hartdächer aus Ziegel, Dachpappe, Blech, Asbest, die oft eine künstliche Nistunterlage hatten („Reiter“). Spontan wurden auch Bäume, Schornsteine und Türme angenommen, oder die Vögel wichen auf stromführende Elektromasten aus. Mehrfach fackelten die Reisighorste durch Stromkontakte ab.

\section{Zum Brutbestand}

Mitte des 18. Jhs. waren im Oderland so viele Jungstörche geschlüpft, dass sie wie Hühner verspeist wurden. SIEMENS (1793) nannte den mecklenburgischen Storch einen „bekannten und bey unserm Landmann sehr gelittenen Zugvogel“.

Um 1900 ist er deutschlandweit „eine alltägliche Erscheinung“. ZANDER (1862) sagte: „Fast in allen Dörfern ... nistend. In einigen Dörfern sieht man fast auf jedem Gebäude ein Storchennest, ja auf manchen sogar zwei.“

Wüstnei und Clodius (1902) machten erste Bestandserhebungen für Mecklenburg. Die Erfassung im damaligen Amtsgerichtsbezirk Güstrow erfolgte 1901 in 180 Orten und ergab 249 besetzte Nester (Flächenbezug auf das 1952 fest- gesetzte $1.002 \mathrm{~km}^{2}$ große Kreisgebiet Güstrow). Boldebuck allein hatte 7 BP. Von über 20 Orten fehlten Angaben. Die Storchendichte (STD) lag bei mindestens $25 \mathrm{BP} / 100 \mathrm{~km}^{2}$. Der damalige Kreis Güstrow gehörte $\mathrm{zu}$ den storchenreichsten Regionen Deutschlands (Aussage von damals einschl. Altkreis Bützow).

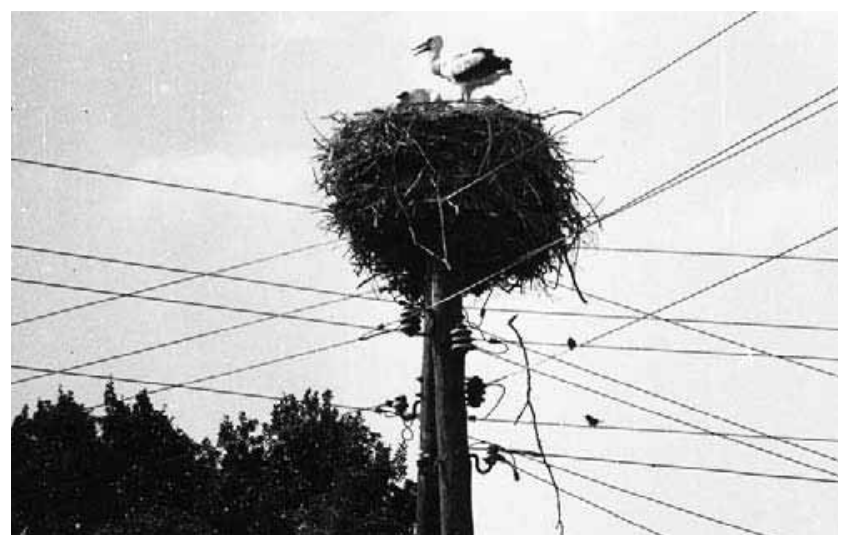

Abb. 201: Storchenhorst auf E-Mast in Reimershagen (1985) Foto: A. Martin.

Bei der nächsten Zählung 1912 wurden nur 87 Horstpaare ermittelt. Der dramatische Rückgang resultierte vornehmlich aus Bejagung und Abschuss. In Mecklenburg war der Vogel für die „Niederjagd schädlich“. 1913 wurde die „Schonung des Storches“ herzoglich angeordet. Bis zum ersten mitteleuropäischen Zensus 1934 stieg die Population deutlich an. Der damalige Kreis Güstrow $\left(1.671 \mathrm{~km}^{2}\right)$ hatte $\mathrm{zu}$ dieser Zeit die höchste mecklenburgische Storchendichte (14,5 BP/100 $\mathrm{km}^{2}$ bezogen auf den Altkreis). - Die STD im Memelgebiet betrug vergleichsweise $69 \mathrm{HP} / 100 \mathrm{~km}^{2}$.

Aus der Kriegszeit fehlen Daten gänzlich. Bei späteren Recherchen sprachen ansässige Bauern einhellig von guten Nestbesetzungen, häufigen „Fünflinge“ und großen Ansammlungen. Um 1950 beobachtete der Landwirt Schippmann aus Weitendorf (mündl.) jährlich bis 120 Vögel in den Recknitzwiesen bei Laage-Weitendorf.

Von 1958-2015 unterlag der Brutbestand intervallartigen Schwankungen. 1971/72 waren Rekordjahre (167 bzw. 142 Junge).

Bis 1974 betrug die STD $6 \mathrm{BP} / 100 \mathrm{~km}^{2}$. Ab $1991 \mathrm{kam}$ es wiederholt zu sog. Störjahren mit einer Jungenanzahl unter 40. Dieser Tiefststand wurde in den Folgejahren kaum ausgeglichen.

2005 brach die Storchenpopulation in M-V zusammen. Als wesentliche Ursachen werden die Nahrungsverarmung infolge Grünlandumbruch und Monokulturanbau sowie extreme Witterung während des Heimzuges und im Brutgebiet angesehen. Auch unser Altkreis erholte sich seitdem nicht und verharrt mit durchschnittlich 20 bis 22 reproduk- 
tiven $\mathrm{BP}$ und einer STD von $3 \mathrm{BP} / 100 \mathrm{~km}^{2}$ auf niedrigstem Niveau. Laut Roter Liste der Brutvögel M-V 2014 ist der Weißstorch in die Kategorie 2 - stark gefährdet - eingestuft worden.

\section{Akteure und Aktionen}

Als 1954 Georg Strache nach Güstrow kam, begann er sich mit dem Storchenbestand des Kreises zu beschäftigen. Seine frühen Aufzeichnungen sind verloren gegangen. Die ersten Bestandserfassungen zum 2. Zensus 1958 und Daten von 1963 waren für spätere Auswertungen noch unvollständig, da sie sich nur auf die Brutergebnisse beschränkten. Genaue Angaben zu den Horststandorten fehlten. Die Auflistung zeigt aber, dass der Weißstorch relativ häufig vorkam. Von 1964 bis 1966 liegen keine Aufzeichnungen vor. Seit 1967 wurden die Erhebungen alljährlich von der FG durchgeführt. Ab 1969 kontrollierten W. Neubauer den Raum um Krakow am See und G. Strache den nördlichen Teil des Kreises. Bis 1980 lieferten auch die FG-Mitglieder M. Böhlke, J. Mewius, K. Pohlmann, I. Schult und R. Wenk Daten aus Teilgebieten, danach auch A. Martin. Auf seinen Sommerfahrten wurde G. Strache oft von F. Anderlik und später von K. Lingsminat begleitet.

Von G. Strache wurde eine Storchenkartei angelegt, in der die 1952 von SCHÜZ vorgeschlagenen Termini für Brutdaten sowie die Beschreibung der Horste und ihre Standorte vermerkt wurden. Allmählich schuf er ein flächendeckendes Betreuungsnetz und fand in jedem Nistort „Adebareltern“, die ihn bei Beobachtungen und Arbeiten an den Horsten unterstützten. Die jährlichen Brutergebnisse des Weißstorches im Altkreis Güstrow wurden erstmalig im Jahresbericht Nr. 5 für das Jahr 1972 genannt. Von der Erfassung 1973 gibt es dann im nachfolgenden Jahresbericht eine Kreisübersichtskarte mit den jeweiligen Horstbesetzungen und Jungenzahlen. Ab nun hatten die jährlichen
Ergebnisse der Storchenerfassungen einen festen Platz in den Jahresberichten der FG. 1974 zählten die FG-Mitglieder auch die Störche im Nachbarkreis Bützow. Dabei wurde deutlich, dass dort die Storchendichte mit 9,2 BP/100 km² deutlich über der vom Altkreis Güstrow lag.

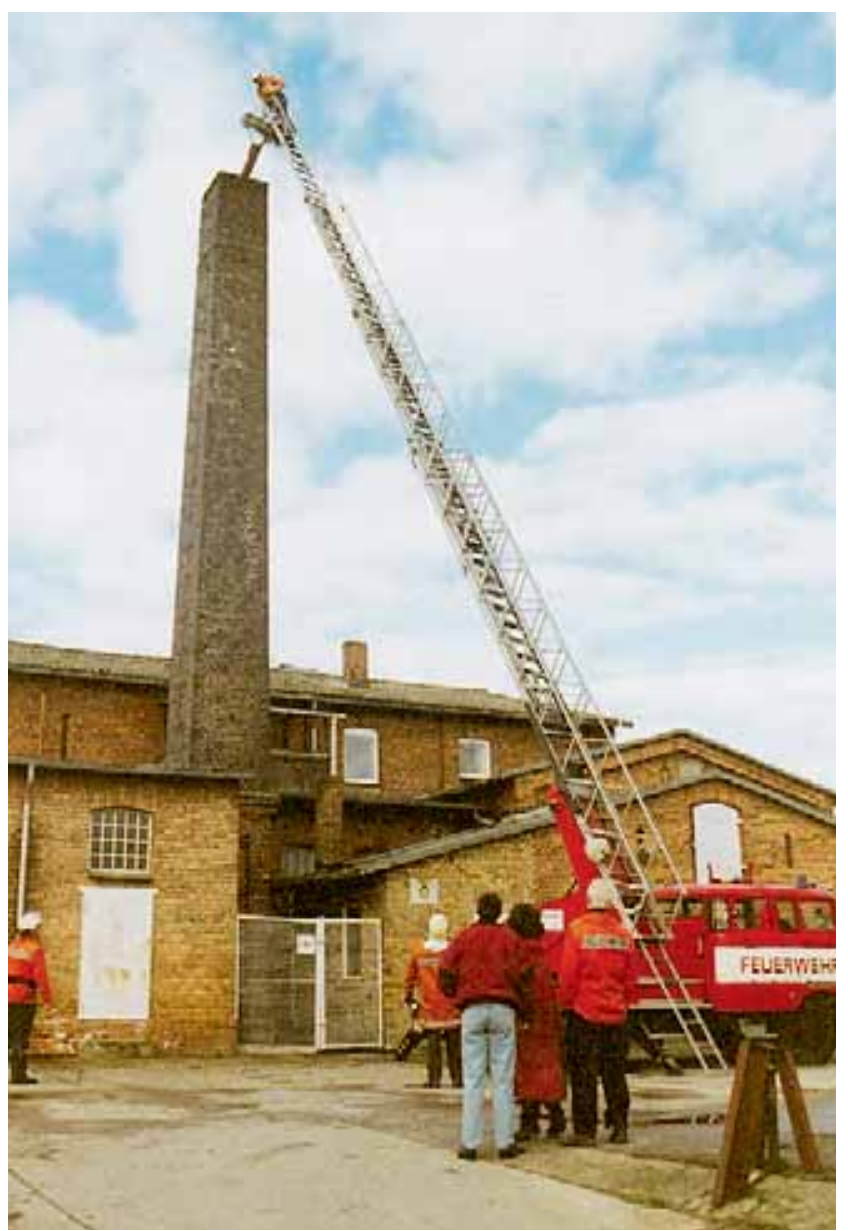

Abb. 203: Mit Hilfe der Feuerwehr wurde der Storchenhorst auf dem Schornstein in Lalendorf errichtet - 25.3. 1995. Foto: Archiv.

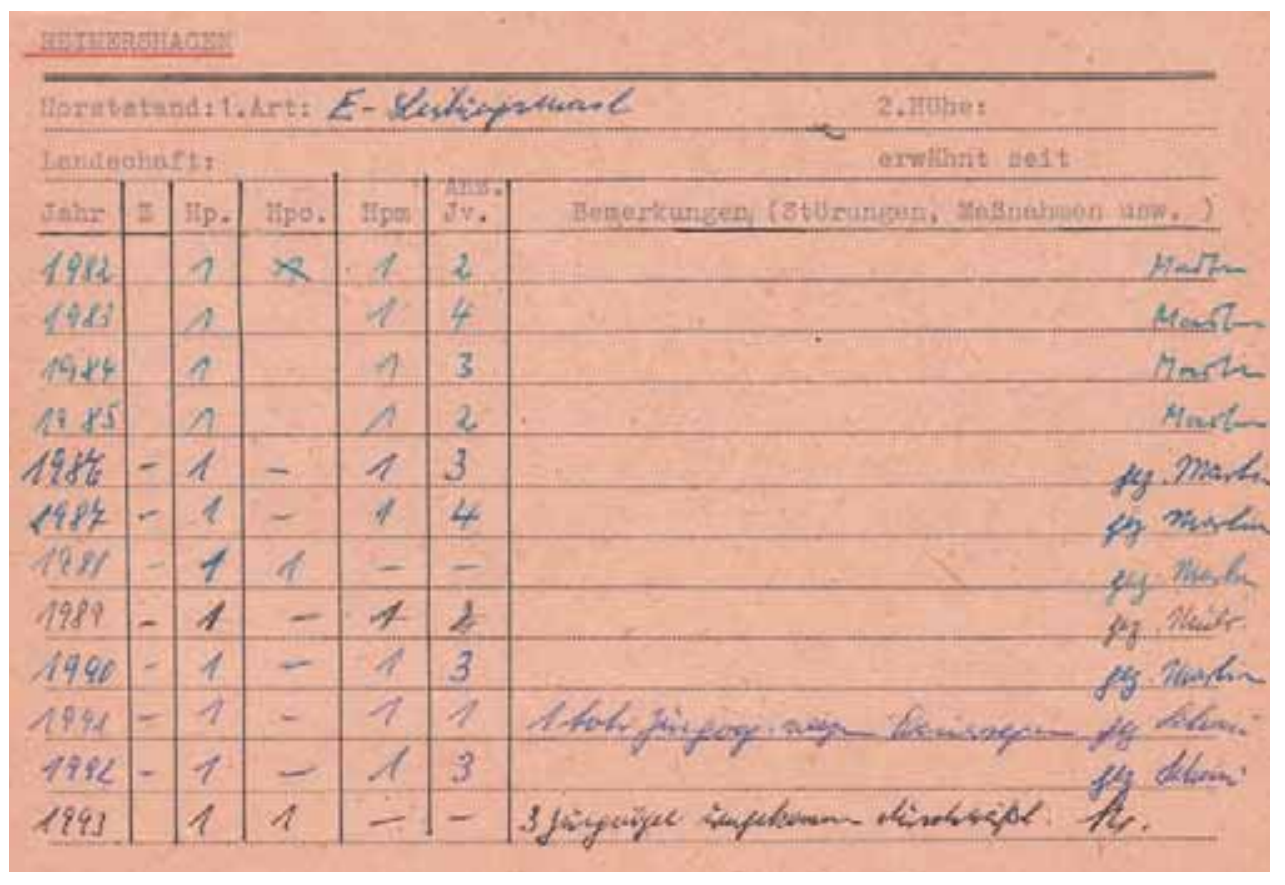

Abb. 202: Karteikarte aus der Storchenkartei für Reimershagen. 
W. Neubauer und G. Strache berichteten über den Weißstorch im Kreis Güstrow in den Ornithologischen Rundbriefen M-V H. 25/1982 und H. 34/1991. Die FG-Mitglieder R. Becker und R. Bischoff engagierten sich anfangs ebenfalls stark für die Weißstörche. Zusammen haben sie insbesondere in den 1960er und 1970er Jahren junge Weißstörche in ihren Horsten beringt. Zusammen mit W. Neubauer, der gleichfalls in dieser Zeit im südlichen Kreisteil junge Weißstörche beringt hatte, waren es bis zum vorgegebenen Abbruch der Beringung von Weißstörchen Ende der 1970er Jahre wohl bis zu 380 Jungstörche.

Bei Neubauer (2004) sind die Rückmeldungen von insgesamt nur elf der bei uns beringten Störche aufgeführt. Interessant sind die Rückmeldungen eines am 3.7.1971 in Goldewin beringten Jungstorches. Der Storch wurde von 1982 bis 1992 jährlich als Brutvogel in Neustadt/Sebnitz (SA) abgelesen. Eine Reproduktion bei Weißstörchen im Alter von mehr als 20 Jahren ist nach Darstellungen der Vogelwarte Hiddensee nicht ungewöhnlich. Als ältester Vogel wurde ein Weißstorch mit 29 Jahren registriert. Rückmeldungen von unseren tot oder verletzt aufgefundenen Störchen liegen auch aus der CSSR, aus Rumänien, Südafrika und zwei Mal aus dem Sudan vor.

Ab 1985 unterstützte R. Schaugstat die Storchenerhebungen und übernahm den südlichen Teil des Kreises. Mit der Kreisgebietsreform 1994 wurde G. Strache der Koordinator für die Datenzusammenstellungen der Ergebnisse aus den Altkreisen Bützow, Güstrow und Teterow, so dass die Naturschutzbehörden (UNB und LUNG) für die neue Gebietsgröße $\left(2.059 \mathrm{~km}^{2}\right)$ zusammengefasste Daten erhielten.

Als im Spätsommer 1999 unser Storchenvater „Schorsch“ (Georg Strache) starb, konnte Reinhard Schaugstat nahtlos die Arbeiten am Weißstorch im Altkreisgebiet fortführen.

Nicht nur die Erfassungen des Brutbestandes standen auf der Agenda der FG. Mit dem Wegfall von Weichdächern als Niststandorte war zunehmend praktische Naturschutzarbeit erforderlich. An geeigneten Nahrungsplätzen flochten Mitglieder der FG Weidennetze über große Holzwagenräder und stellten diese auf Holzmasten montiert mit ansässigen Betrieben, Feuerwehren und LPGen in die Erde. Die älteste, seit 1979 angeflogene „Stange“ besitzt Zehlendorf.

1980 betrug der Anteil aller Masthorste $43 \%$, derzeit sind es 98\%. - Ab 1995 wurden mit freundlicher Hilfe der WEMAG anstelle der Holzmasten ausgediente Betonmasten verwendet. Die verzinkten Nisthilfen ließ bereits seit der Wende die Untere Naturschutzbehörde aus Haushaltsmitteln für den Artenschutz anfertigen und stellte sie uns ehrenamtlich tätigen Helfern zur Verfügung. In der seit Beginn der Erfassungen durch Georg Strache angelegten und von Reinhard Schaugstat fortgeführten Storchenkartei sind von 1967 bis 2015 insgesamt 84 neu aufgestellte Nisthilfen enthalten. Dazu kamen ebenso viele privat errichtete

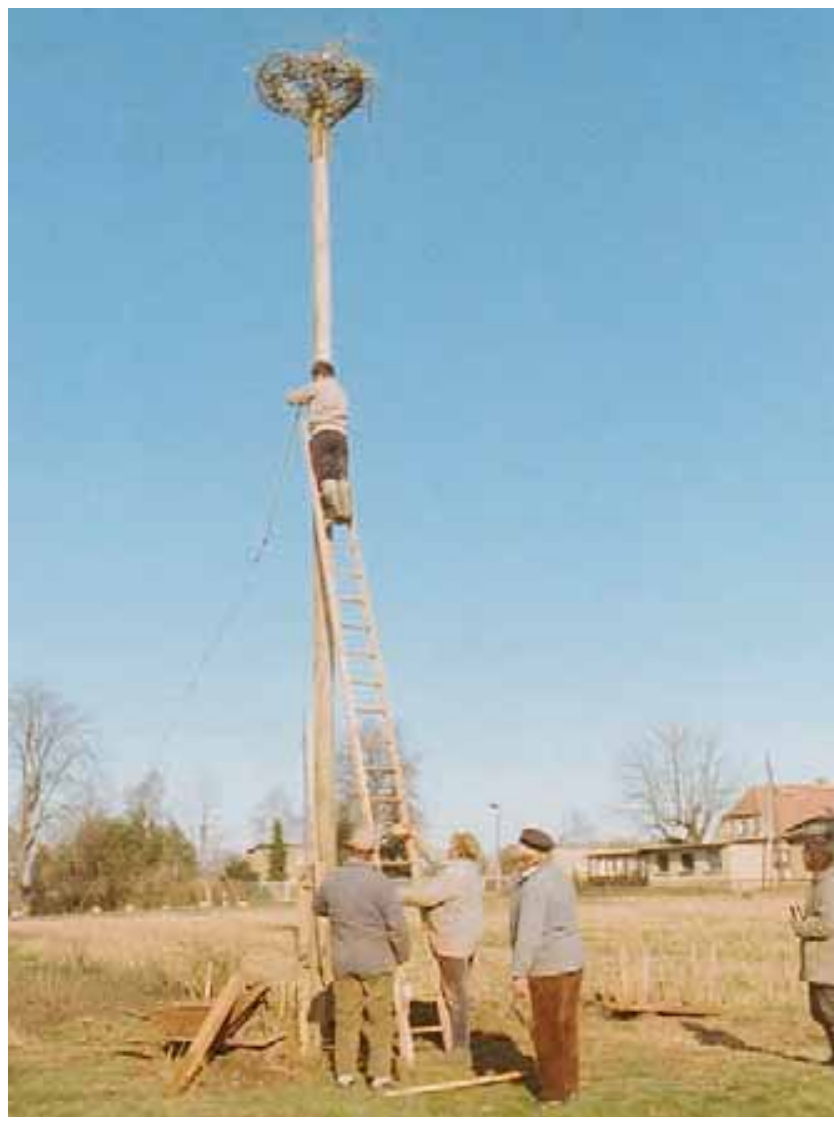

Abb. 204: Aufstellung des Nistmastes in Mamerow am 8.3.1995. Foto: Storchenarchiv der FG.

„Gestelle“. Ein Rückgang der Storchenbrutpaare lässt sich also keineswegs durch ungenügend vorhandene Nistplätze begründen.

Bei den Hilfsmaßnahmen für Störche muss auch der Anteil des Tierparks, des späteren Natur- und Umweltparks (heute Wildpark) Güstrow gewürdigt und Herrn Klaus Tuscher unser Dank ausgesprochen werden. Schon frühzeitig wurden hier kranke und verletzte Vögel aufgenommen. Seit 1982 betreuten mit Unterstützung von Tierarzt H. Mittelsdorf die Tierpflegerinnen Petra Koppe und Liane Kasch mindestens 40 Tiere. Die Mehrzahl konnte nach erfolgreicher Pflege ausgewildert werden. Leider begrenzten die Vogelgrippefälle bei Wildvögeln in den letzten Jahren aus Sicherheitsgründen die Aufnahme von Wildvögeln (vgl. Fälle im Zoo Rostock 2014).

Mit den seit 2003/06 bei Jungstörchen angelegten ELSARingen gelingen neuerdings vermehrt Ablesungen an brütenden Weißstörchen. Mit einem guten Fernglas oder auch auf Fotos von Kameras mit großem Zoom lassen sich die Ringe sehr gut ablesen, so dass heute mehr Daten gesammelt werden können. Von 2010 bis 2015 gelangten Ablesungen bei insgesamt zwölf mit ELSA-Ringen markierten Brutstörchen, vier davon brüteten in mehreren Jahren in unserem Altkreisgebiet. Die Erbrütungsorte dieser Störche lagen im Westen und Südwesten, vier stammten aus 
dem Niederungsbereich der Elbe. Bemerkenswert waren Ansiedlungen je eines Storches 2011 in Ganschow aus Schweden (SVS 763) und 2013 in Striggow aus der Schweiz (SG 672 HES).

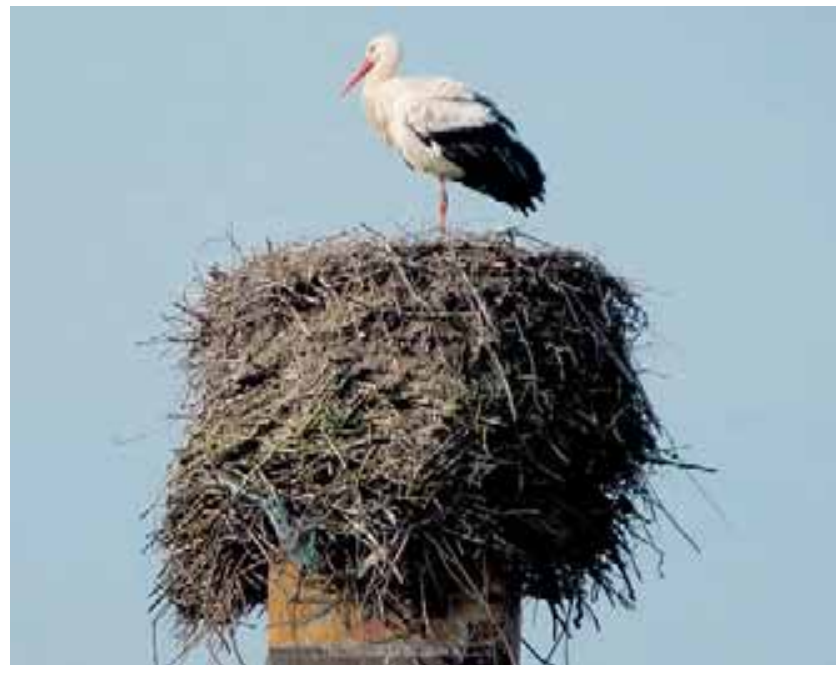

Abb. 205: Der Weißstorch auf dem hochgewordenen Horst in Zehna (Gärtnerei) trägt einen ELSA-Ring. Foto: f. Loose.

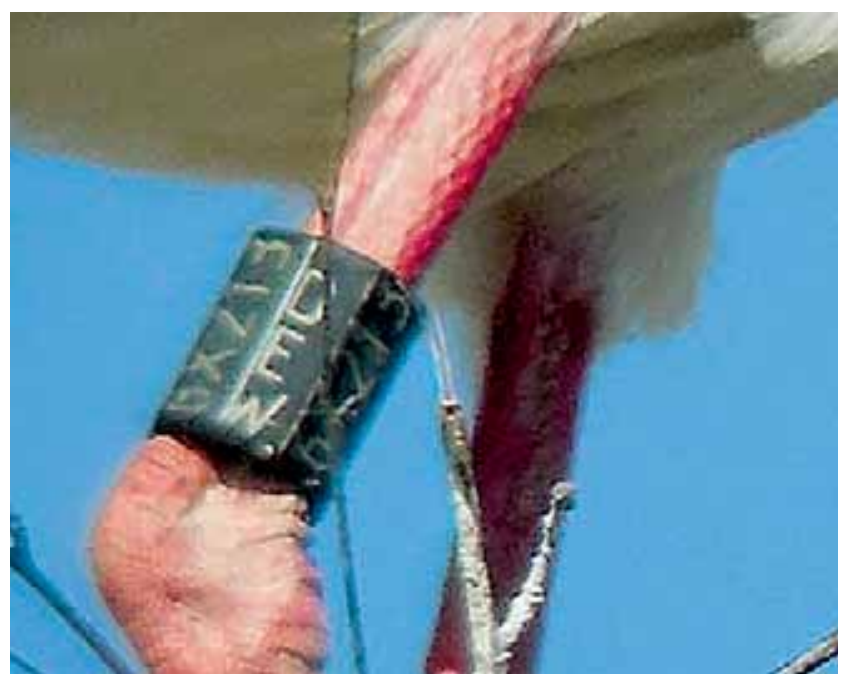

Abb. 206: ELSA-Ring DEW 6X213 der Beringungszentrale Wilhelmshafen - Der 2008 in Biebesheim am Rhein als Jungvogel beringte Storch brütete von 2010-2014 erfolgreich in Zehna und war auch 2015 anwesend. Foto: F. Loose.

Zu würdigen sind die von unseren beiden „Storchenvätern“ bei den Erfassungen aufgewendeten Stunden und Fahrkilometer. Während der Zeitaufwand nicht ausdrückbar ist, können für Georg Strache weit über 20.000 Fahr-Kilometer zunächst mit dem Moped, später mit dem Auto abgerechnet werden. Reinhard Schaugstat radelte ca. $17.500 \mathrm{~km} \mathrm{zu}$ den Störchen.

Von 1958 bis 2015 sind in unserer Storchenkartei 3.805 ausgeflogene Jungvögel registriert. 310 Nestlinge wurden tot unter den Horsten gefunden oder verunglückten bei Flugübungen.
Nach Aufarbeitung der Storchenkartei und Erstellung der Übersicht (Tabelle 5) für den Altkreis Güstrow musste R. Schaugstat Datenkorrekturen in einigen Jahresberichten bzw. auch in veröffentlichten Auswertungen (1982, 1991, 2004 ) von W. Neubauer und G. Strache vornehmen, die z.T. erheblich waren. Abweichungen gibt es bei den Zahlen für $\mathrm{HPa}, \mathrm{HPm}$ und Juv.-Anzahl vom Anfang der Storchenerfassungen bis 1999. Sie resultieren aus Änderungen von HPx in HPo, nicht vollständig erfassten HP-Standorten als auch aus zahlreichen Druckfehlern.

Die damals publizierten Diagramme geben auch bei nunmehr geänderten Zahlen die grundsätzlichen Aussagen richtig wider. Die nachfolgenden Diagramme basieren auf den korrigierten Zahlenangaben.

Die gravierenden Veränderung der Nahrungshabitatflächen für den Weißstorch, in Karte 15 dargestellt für den Raum Zehna/Bellin, werden deutlich, wenn die bis zur Wende vorhandenen Flächennutzungen mit den heutigen verglichen werden.

Ausgangsdaten lieferte die vom Umweltministerium initiierte CIR-Befliegung von 1991. Aus den für M-V flächendeckend vorliegenden Infrarotaufnahmen wurde die Biotopund Nutzungstypenkartierung aller Flächen für 1991 erstellt. Aus aktuellen Luftbildern z. B. von Google Earth 2014 lassen sich deutlich die heutigen Dauergrünlandstandorte erkennen (in Karte 15 die Flächen mit roten Umrisslinien).

Wenn man zu Grunde legt, dass ein Weißstorch sein Futter nur effektiv im Radius von 1 bis $2 \mathrm{~km}$ Entfernung (rote und schwarze Kreise) von seinem Horst suchen kann, erscheint es nicht verwunderlich, dass die in Zehna lange Zeit besetzten zwei Horste 1999 und 2015 aufgegeben bzw. nicht wieder mit einem Brutpaar besetzt wurden. Auch der in Bellin ab 1980 besetzte Horst blieb ab 2011 ohne Brutpaar. Die verbliebenen wenigen Nahrungshabitate bringen offenbar nicht mehr genügend Futter für erfolgreiche Bruten.

Der Wandel in der Flächennutzung sieht in sehr vielen Teilen des Kreises und in Mecklenburg-Vorpommern ähnlich aus. Große Flächen mit Dauergrünland, auf denen auch Kühe weideten, mussten nach der Wende einem verstärkten Raps und Maisanbau weichen.

Grünlandflächen werden in jüngerer Zeit vorwiegend nur noch als intensive Mähwiesen genutzt. 

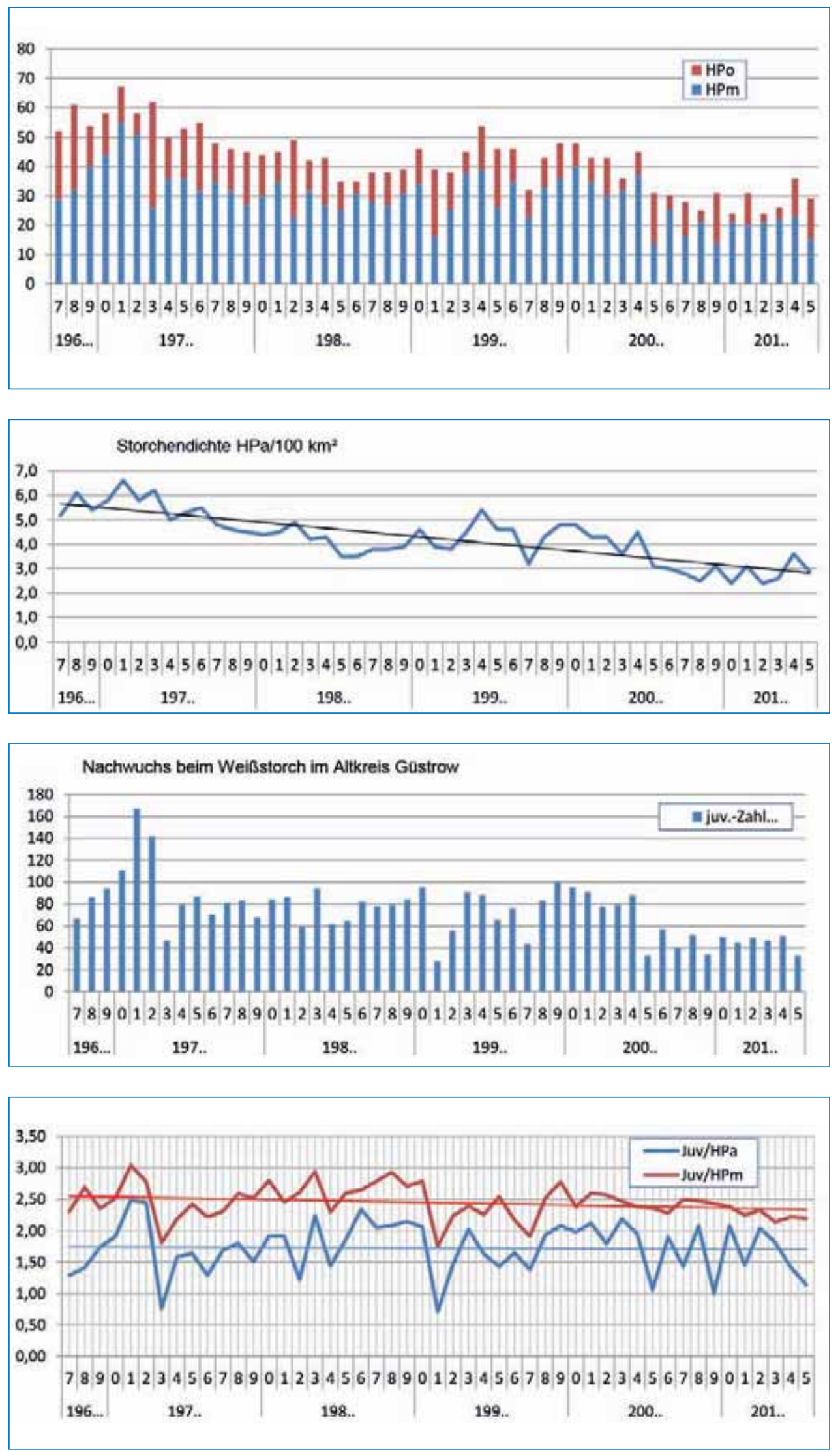

Diagramm 14: Besetzung der Storchennistplätze im Altkreis Güstrow durch Paare mit und ohne Bruterfolg.

Diagramm 15:

Die aus der Zahl der Horstpaare errechnete Storchendichte sank kontinuierlich und pendelt sich in den letzten 10 Jahren um den Wert $3,0 \mathrm{HPa} / 100 \mathrm{~km}^{2}$ ein.

Diagramm 16: Mit dem Sinken der Storchendichte verringert sich auch der Nachwuchs bei den Weißstörchen.

Diagramm 17:

Während die Gesamtjungenzahl mit der HP-Zahl sinkt, bleibt die Jungenzahl je Brutpaar im langjährigen Mittel weitgehend konstant (Trendlinien). 


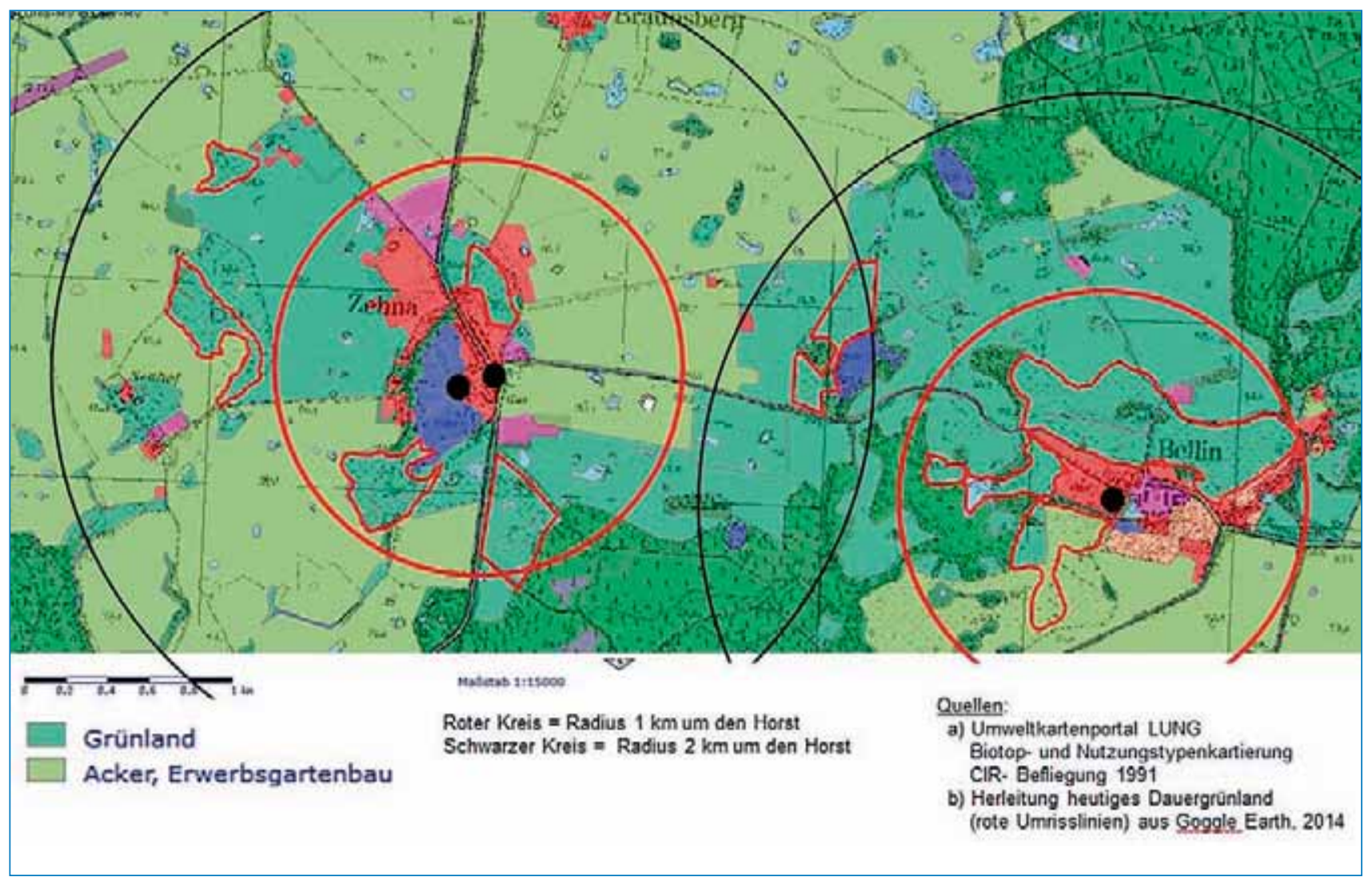

Karte 15: Lebensumfeld für den Weißstorch im Raum Zehna und Bellin im Zeitvergleich 1991 und 2014: Die roten Umrissflächen zeigen die nur noch vorhandenen Grünlandflächen von 2014.

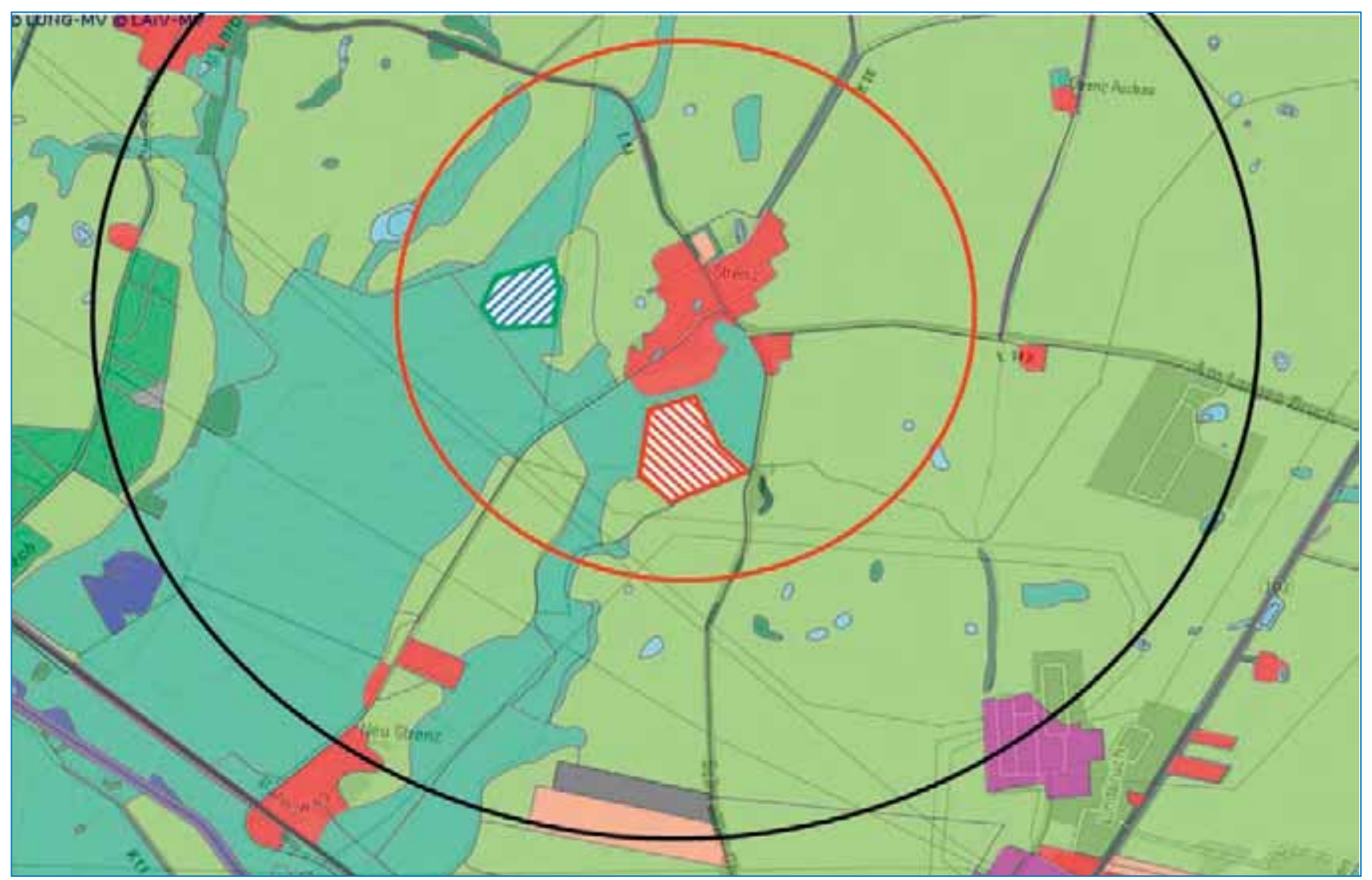

Karte 16: Lebensumfeld für den Weißstorch im Raum Strenz - Bis auf eine kleine Erstaufforstung innerhalb der Grünlandfläche (Fläche grün schraffiert) und einem Teilumbruch von Grünland (Fläche rot schraffiert) sind gemäß aktuellem Luftbild heute die Grünlandflächen noch fast so vorhanden, wie sie 1991 in der Biotop- und Nutzungstypenkartierung ausgewiesen wurden. Seit 1991 ist der Horst in Strenz besetzt worden. (Datenquellen: siehe Karte 15) 
Interessant ist die Feststellung, dass der mit dem ELSA-Ring DEW 6X213 gekennzeichnete und von 2010 bis 2014 erfolgreiche Brutvogel in Zehna (vgl. Abb. 206) im Jahre 2015 bei Ausbleiben seiner Partnerin den Horst verließ und sich neu in Strenz ansiedelte, wo er zunächst mit einem ebenfalls beringten Weibchen (DEH HC 128) eine Brut begann.

Das ursprünglich hier ansässige Brutpaar war noch nicht anwesend und vertrieb das neue Paar später von hier. $\mathrm{Zu}$ diesen Erkenntnissen kam man nur durch die Beringung der Störche.

Im Gegensatz zum Nahrungshabitat um Zehna gab es bis auf eine kleinflächige Aufforstung innerhalb einer Dauergrünlandfläche im Umfeld von Strenz keine gravierenden Eingriffe in die vorhandenen Grünlandbiotope, wie sie in der Biotop- und Nutzungstypenkartierung von 1991 dargestellt wurden. Das Storchenmännchen aus Zehna war offenbar durch das bessere Nahrungshabitate angelockt worden (vgl. Karte 16).

Aber auch in diesem Gebiet wurde bereits aktuell begonnen, einige Wiesenflächen südlich des Ortes in Ackerland umzuwandeln
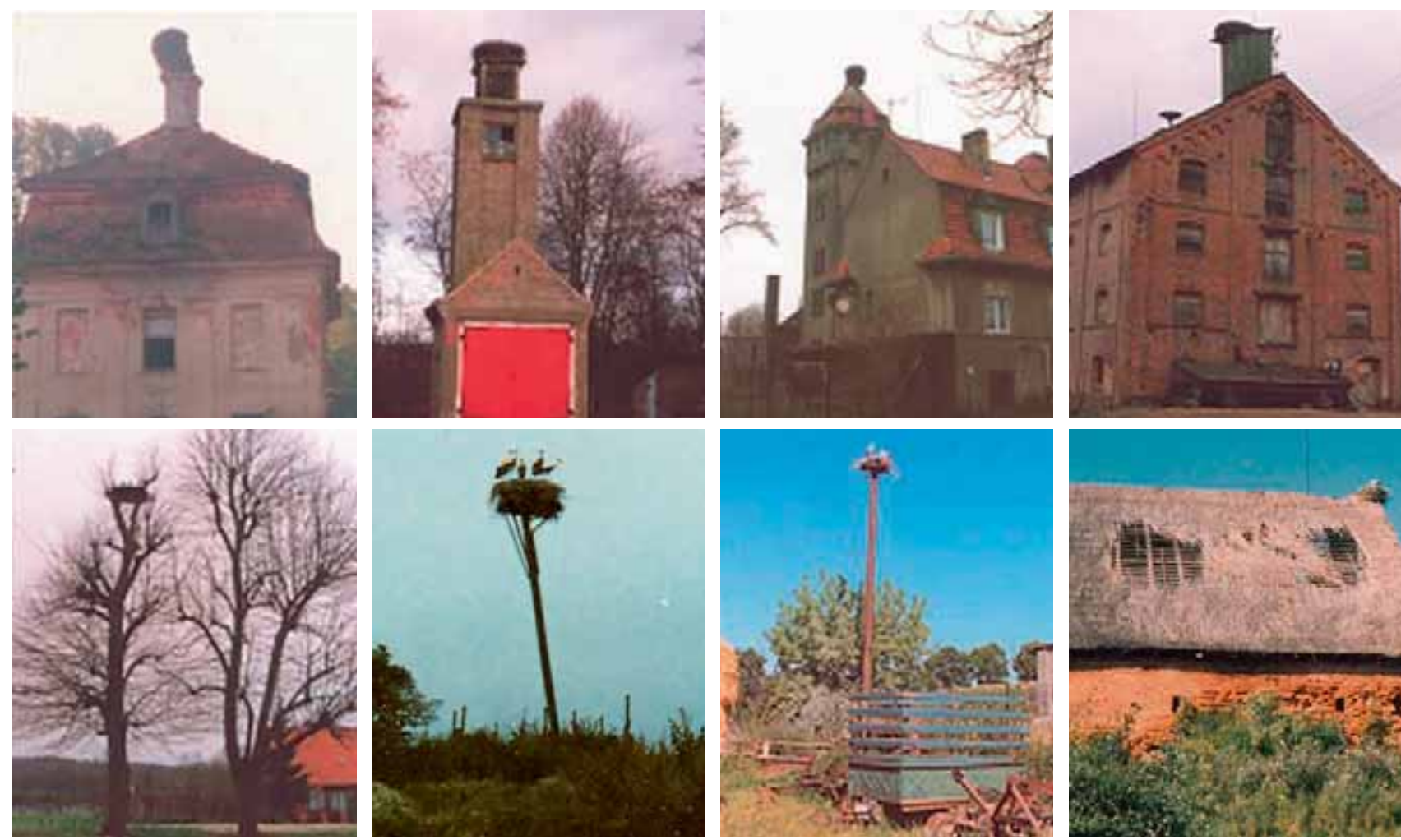

Nach der Jungenreproduktion befinden sich die erfolgreichsten Storchenhorste in Güstrow-Schweriner Straße (119), Tolzin (108), Hohen Sprenz (102), Lüssow (100), Prüzen (99), Plaaz (96) und Karow (89) - in Klammern die Jungenzahl über alle dokumentierten Brutjahre - vgl. Tabelle 5 auf den Folgeseiten.

Schaut man sich zu diesen Orten das Umland an, stellt man mit den Sumpfseewiesen, der Mühlbachniederung, der Niederung südlich von Knegendorf und den Pferdewiesen bei Plaaz sehr schnell fest, dass hier noch größere Grünlandflächen existieren. Hier ist wohl die Nahrungsbasis für Störche noch ausreichend vorhanden.

Abb. 207 bis 214: Historische Fotos von Storchenhorsten in Diekhof - Marstall, Groß Bäbelin, Zehna - Gutshaus, Wardow - Speicher, Niegleve - Baumhorst, Striesdorf (1990), Strenz - Stahlrohr, Scheune Jahmen (1992) (v.l.n.r.) - Fotos: Storchenarchiv der FG. 


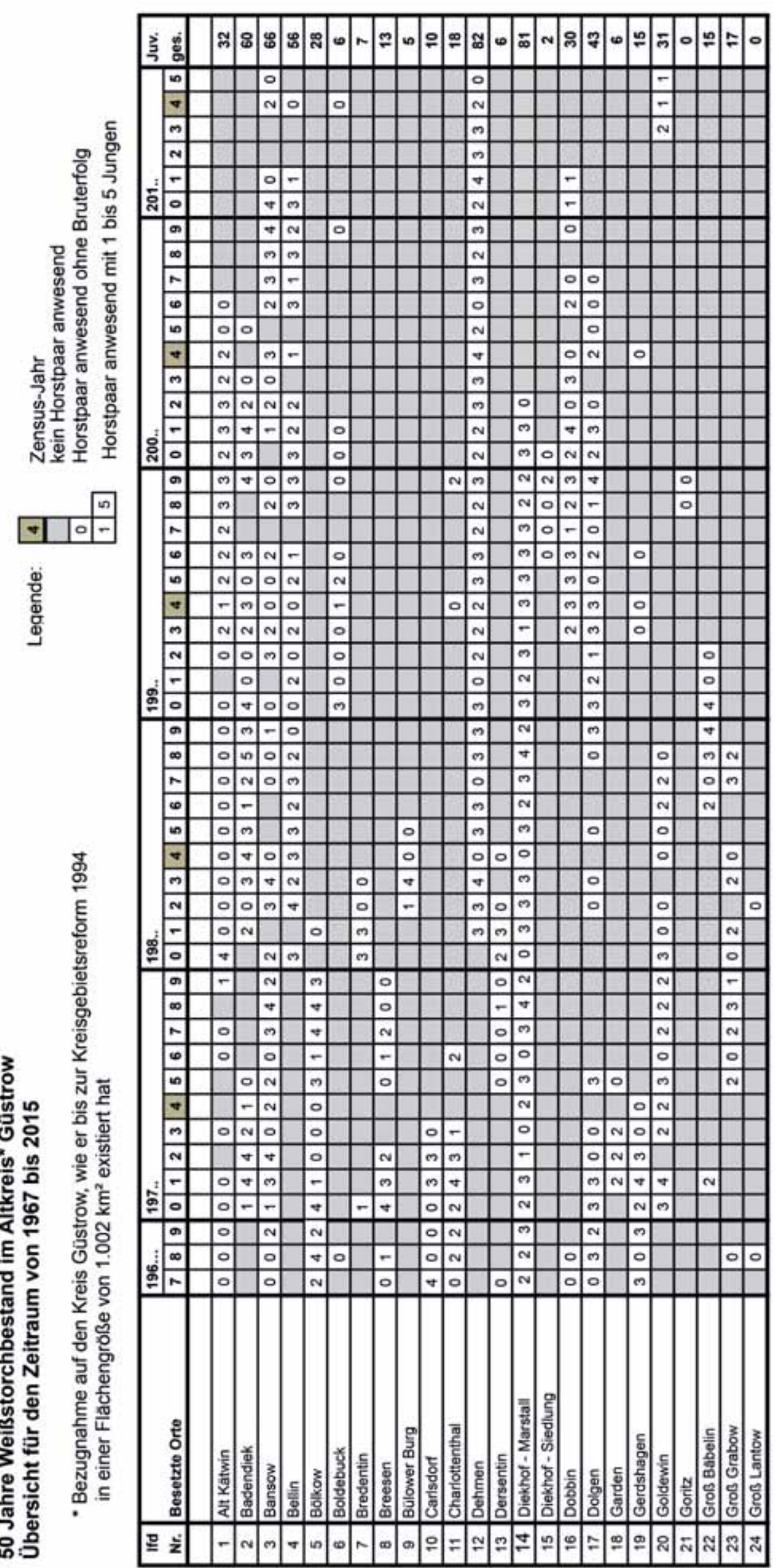




\begin{tabular}{|c|c|c|c|c|c|c|c|c|c|c|c|c|c|c|c|c|c|c|c|c|c|c|c|c|c|}
\hline$引$ & 이 & & & & & $\stackrel{2}{=}$ & & & 흐 & & & & & & & & & $\mathbb{N} \approx$ & & & 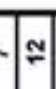 & & & & \\
\hline 6 & m & 응 & & & & ल & & & $N$ & $N$ & & S & 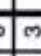 & & & & & & & & & & - & & \\
\hline$\nabla$ & $N$ & $N$ & & & & 寸 & & & 0 & ल & & & $\sqrt{\mathrm{m}}$ & & & & & o & & & & & $N$ & & \\
\hline m & $m$ & & & & & 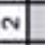 & & & $\circ$ & $N$ & & 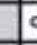 & कल & & & & & & & & & & 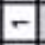 & & \\
\hline N & $m$ & & 의 & & & m & & & $m$ & $m$ & & 。 & कe & & & & & & & & & & ल & & \\
\hline-1 & m & ० & 이 & & & - & & & N & $\nabla$ & & & 1 & & & m & & 00 & & & & & -1 & & o \\
\hline हैं⿰ & $m$ & & & & & ला & & & ल & 의 & & & ल & & & m & & 7 & & & & & ল & & \\
\hline क & $m$ & & 흐 & & & 믜 & & & 0 & $N$ & & & 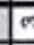 & & & 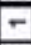 & & 70 & & & & & ल & & \\
\hline$\infty$ & m & & & & & का & & & $N$ & $N$ & & & $a$ & & & m & & N/O & & & & & N & & \\
\hline 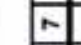 & $m$ & & - & & & का & & & $N$ & ले & & & c & & & $\circ$ & & $\sqrt{20}$ & & & & & 으 & & \\
\hline 0 & $m$ & & 의 & & & ल & & & ल & m & & & 2 & & & $N$ & & \begin{tabular}{c|c} 
\\
\end{tabular} & & & & & N & & \\
\hline$\infty$ & $N$ & & 임 & m & & $N$ & & & ल & N & & & c & c & & 。 & & ला & & & & & - & & \\
\hline$\nabla$ & N & 0 & का & m & & ला & & & $m$ & N & & & $\Omega$ & 7 & & m & & ला & & & - & & N & & \\
\hline का & 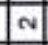 & N & का & m & & $N$ & & & $N$ & - & & & & 7 & & m & & का & & & - & & N & & \\
\hline$N$ & $m$ & N & 寸 & m & & 7 & & & m & ला & & & & 7 & & m & & -1 & & & 0 & & 0 & & \\
\hline & ल & N & 7 & $N$ & & 寸 & & & $m$ & 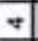 & & (c) & & & & o & & 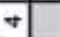 & & 0 & - & & $\square$ & & \\
\hline & $N$ & -1 & -1 & - & & ला & & & 응 & ल & 이 & & $\mathrm{m}$ & 12 & & $\bar{N}$ & & 4 & & \begin{tabular}{l|l}
0 \\
\end{tabular} & o & & N & & \\
\hline ब & $N$ & $\nabla$ & & & & ला & & & $N$ & 7 & & & $\sqrt{2}$ & 5 & & 응 & & जा & & N & 0 & & - & & \\
\hline$\infty$ & 잉 & N| & का & & & ला & & & - & 임 & & & बल & 7 & & & & 4 & & ल & m & & N & & \\
\hline$A$ & & $N$ & & & & m & & & 으 & $N$ & & & & & & - & & $N$ & & & 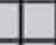 & & - & & \\
\hline 0 & 잉 & & 이 & & & N & & & $N$ & $\mathrm{n}$ & & & & & 10 & - & & $N$ & & & & & m & & \\
\hline$\infty$ & 응 & ल & & & & v & & & m & ल & & r & & o & 10 & 0 & & 이 & & & 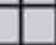 & & m & & \\
\hline$\nabla$ & & $\nabla$ & & & & $N$ & & & $m$ & m & 의 & 8 & $7 c$ & 2 & $m$ & $N$ & 의 & -0 & & & 0 & & $N$ & & \\
\hline m & & ला & $N$ & & & का & & & $N$ & ला & & & a & 4 & 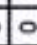 & m & & ला & & & m & & $m$ & & \\
\hline NA & & N| & & & & N & & & m & & & & 7 & F。 & $1-$ & 0 & & -1 & & & 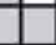 & & N & & \\
\hline-1 & & -1 & & & & ला & & & 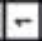 & & 이 & 5 & 7. & 7. & 0 & 0 & & 이 & & & $\square$ & & 0 & & \\
\hline \$ొం & & -1 & & & & 의 & & & m & & - & & $\sqrt{2}$ & & 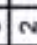 & ल & & 임 & & 임 & 0 & & N & & \\
\hline न & & ल। & & & & 寸 & & & ल & & के & & $\sqrt{2}$ & $T$ & N & $\bar{N}$ & & 아 & & & & & লে & 이 & \\
\hline$\infty$ & & $N$ & & & & 의 & & & 7 & & 7 & & 4 & 5 & $\alpha$ & & & 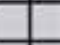 & & & & & & - & \\
\hline$M$ & 0 & o & & & & N & & & $\nabla$ & & ल) & & तल & if & $m$ & & & 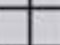 & & & & & - & & \\
\hline 0 & & $m$ & & & & 7 & & & $m$ & & 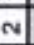 & & $\mathrm{m}$ & 9 & $m$ & & & $N$ & & & & & 4 & & \\
\hline 0 & & m & & & & 의 & & & $m$ & & ल) & & 10 & If & $m$ & & & का & & & & & & & \\
\hline$\nabla$ & $\pi$ & -1 & & & & ल & & & $N$ & & m & & $\sqrt{2}$ & 7 & 0 & & & 이 & & & & & 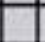 & & \\
\hline$m$ & $N$ & ल & & & & $\nabla c$ & & & $\mathrm{~N}$ & & N & & it & Fo & & & & ला & & & & & 앙 & & \\
\hline N & 0 & 10 & & & & N & & & 0 & & 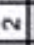 & 9 & 5 & To & & & & \begin{tabular}{c|}
0 \\
\end{tabular} & 10 & & & & 응 & 5 & \\
\hline-1 & $N$ & लि & & & & $N$ & & & $N$ & & & & $\sqrt{\mathrm{Ne}}$ & & & & & \begin{tabular}{l|l}
$m$ \\
\end{tabular} & & 10 & & & N & & \\
\hline Фొन & & 잉 & & & & $\nabla$ & & & $N$ & & 이 & & क & to & & & & 01 & & N & 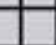 & & 이 & & \\
\hline ब & & ल & & 5 & वा & ला & & & 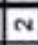 & & & 하 & 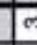 & & & & & তল & & 임 & 0 & & 음 & & \\
\hline$\infty$ & & - & & $\theta$ & -1 & N & & & $m$ & & ला & की & $\pi$ & 40 & & & & $\sqrt{20}$ & & & & & ल & & \\
\hline$N$ & m & ल & & & -1 & N & & & 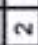 & & N & N & ले & क & 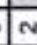 & & & 이- & & 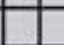 & 0 & & 0 & & \\
\hline$\infty$ & - & m & & & N & N & 응 & $N$ & $\alpha$ & & का & 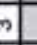 & To & & & & & 00 & & ल & 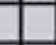 & & & & \\
\hline \begin{tabular}{|l|} 
\\
\end{tabular} & N & ल & & & & N & o & $N$ & & & ल) & $\sqrt{30}$ & $\sqrt{c}$ & ic & & & & নাল & & \begin{tabular}{|l|} 
\\
\end{tabular} & & & & & \\
\hline$\nabla$ & $N$ & ल) & & $r$ & & 이 & o & $N$ & m & & & 5 & 小 & & & & & No & & & 0 & & & & \\
\hline m & - & $m$ & & 5 & & 7 & & $\alpha$ & $\alpha$ & & 의 & 50 & 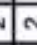 & to & & & & 00 & & $0 \Omega$ & $\pi N$ & & & & \\
\hline N & m & लि & & v & & m & & 7 & m & & ला & 07 & 15 & & 0 & & & +7 & & $\begin{array}{ll} \\
\end{array}$ & $\sqrt{n}-$ & & & so & 讨 \\
\hline & $\Rightarrow$ & 아 & & 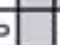 & $\mid$ & ला & o & 寸 & $N$ & & ला & & 4 & & o & & & N| & & লিল & का & & & & คf \\
\hline बै० & m & +1 & & $\theta$ & ला & ला & $N$ & $m$ & $N$ & & N & 7. & $\sqrt{0}$ & & & & & ल $N$ & & ल & 10 & & 잉 & & of \\
\hline न & - & Nা & & $v$ & 이 & ला & $\sqrt{9}$ & m & $\bar{N}$ & & ला & & ल & & 10 & & & $\sqrt{N}$ & & ল & o & 0 & 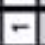 & & 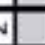 \\
\hline & 잉 & . & & की & & व & n & m & N & & ला & 00 & , & & 0 & & & \begin{tabular}{l|l} 
\\
$N$
\end{tabular} & & 임 & & & 앙 & & \\
\hline$\Phi$ & & N & & 5 & & N & a & m & - & & लि & to & $\sqrt{c}$ & & 0 & & & N & & - & 0 & 0 & & & 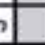 \\
\hline 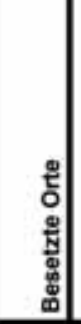 & 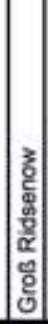 & 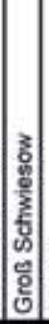 & & : & 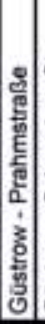 & & & & 훌 & & & & 5 & & & & & 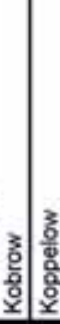 & & 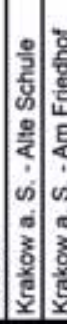 & 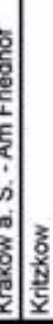 & & 量 & & 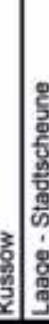 \\
\hline 2 & $\stackrel{\sim}{\mid}$ & \% & & बহ & প & नः: & 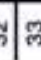 & एँ & $m$ & & के & 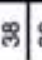 & $\mathrm{D} / \mathrm{S}$ & $f$ & & 7 & 7 & $\frac{7}{7}$ & 5 & क & 98 & & 중 & (ֶ) & in \\
\hline
\end{tabular}




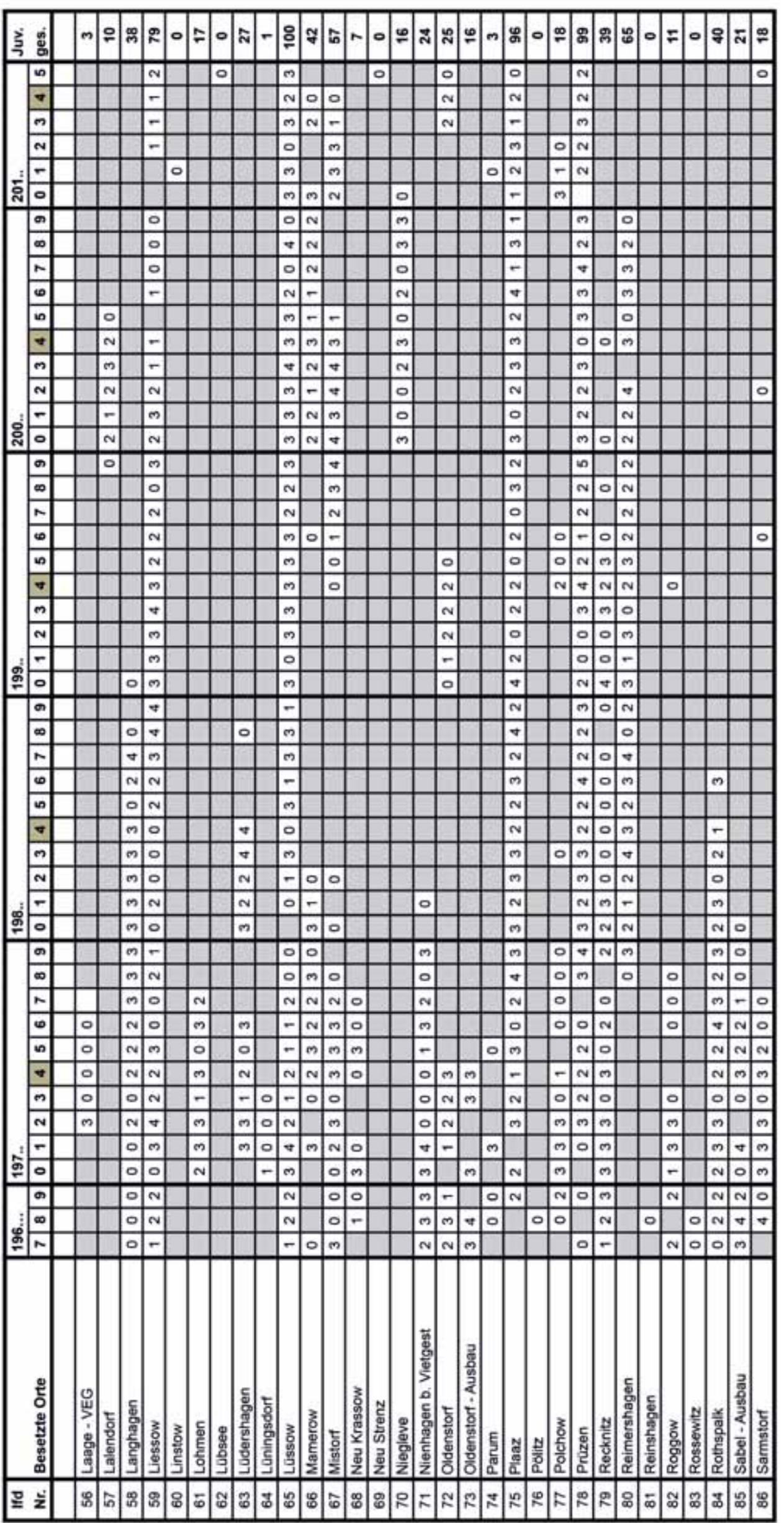




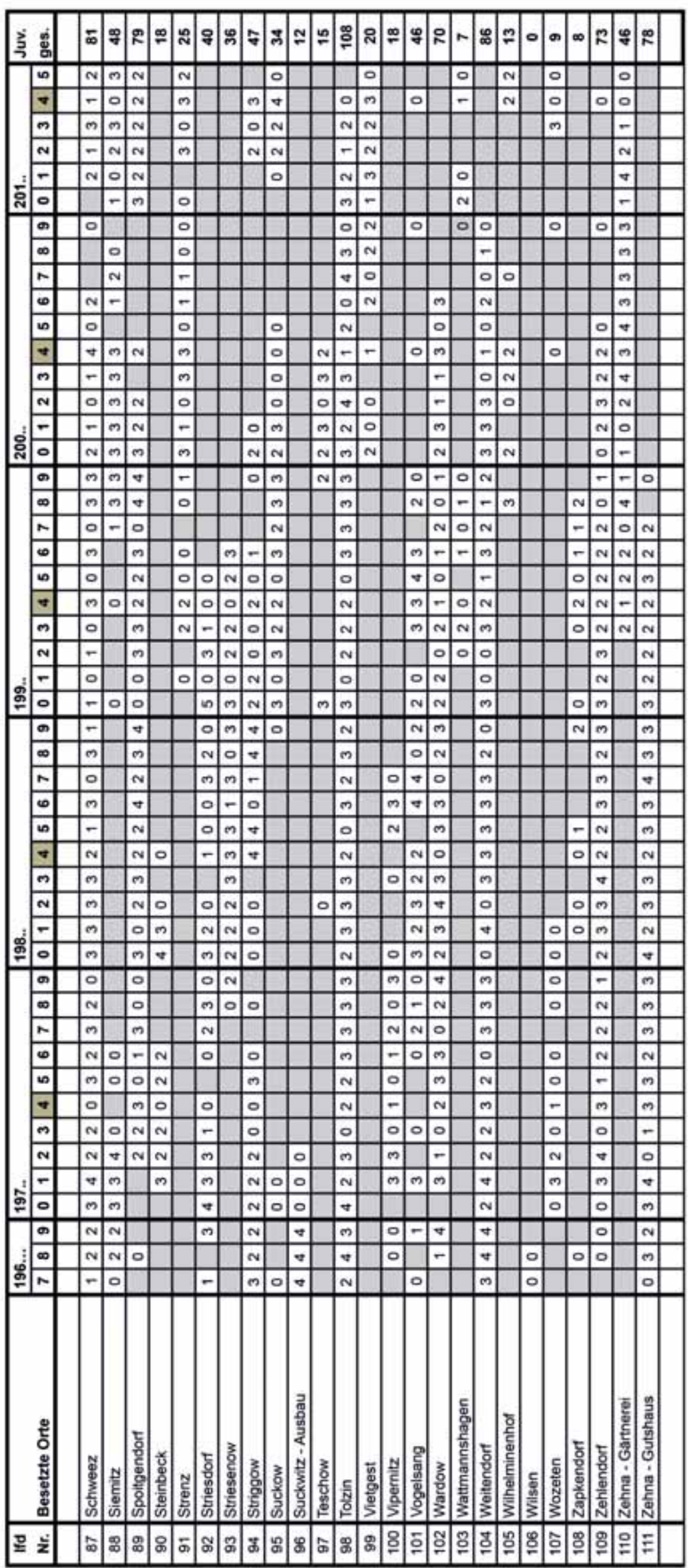




\subsection{Jahre Graureiher-Bestandserfassung im Altkreis Güstrow [1965-2015]}

\section{Reinhard Schaugstat}

Nach dem DDR-Gesetz zur Regelung des Jagdwesens 1962 und 1984 waren Reiher jagdbar, wobei Kolonien Schonzeiten hatten. 1972 bis 1983 sollen nach Aussagen von Anwohnern (E. Boltze u. a. mündl.) aus den Bäumen der Forellenmast am Mühlenhof Kuchelmiß mehrere hundert Vögel geschossen worden sein. An der Forellenzucht Walkmöhl bei Dobbin wurden durch Jäger und Teichwirte zeitweise 50-70 fischende Reiher vertrieben.

Drei erlegte Tiere trugen Ringe der Vogelwarten Hiddensee und Kopenhagen (NEUBAUER, 2004). 1970 ist der Graureiher in der Bundesrepublik zum Jahresvogel gekürt worden.

Derzeit erscheint der für Gewässer charakteristische Vogel seltener. Die Bestände schwanken und verringern sich. Hauptgründe sind Nahrungsmangel, Holzeinschläge in Brutreviernähe (Gülzow) und Witterungseinflüsse. Horstpaare wandern ab oder kehren von ihrer „Winterflucht“ bis Afrika nicht zurück. Andererseits bilden sich spontan Ansiedlungen, die rasch aufblühen und bald erlöschen oder umziehen.

Frühe Anhaltspunkte von Reiherbrutplätzen finden wir in den Mecklenburgischen Flurkarten um 1870. So deuten die Flurnamen „Reiherhorst“ nördlich von Goritz und „Reiherbruch" bei Diekhof auf ehemalige Kolonien.

Detmers vermerkte 1912 im Grenzgebiet der Polchow 5-6 Horste ohne konkrete Angabe.

Kuнк (1939) nannte die „Insel im Hohen Sprenzer See bei Schwaan“ als Niststätte in den Jahren 1933, 1935 und 1936 (mit 40, 30 und 36 Horsten). 1940 bis 1942 existierte bei Hägerfelde nach K. Pohlmann ein starker Bestand mit 70 bis 90 Brutpaaren. In den 1940er Jahren soll nach R. Becker eine Brutkolonie nordwestlich des Hofsees bei Vietgest existiert haben. 1957 gab es im Lantower Holz 16 Reihernester, von denen 6-7 besetzt waren (W. Kintzel).

Eine kleine Brutkolonie lag 1970 bis 1980 im Laager Moor bei Vipernitz (mündl. Schütt). Es wurden auch einige Einzelpaare im Kreisgebiet registriert - 1994 gab es zwei Horste am Dehmer See (R. Becker).

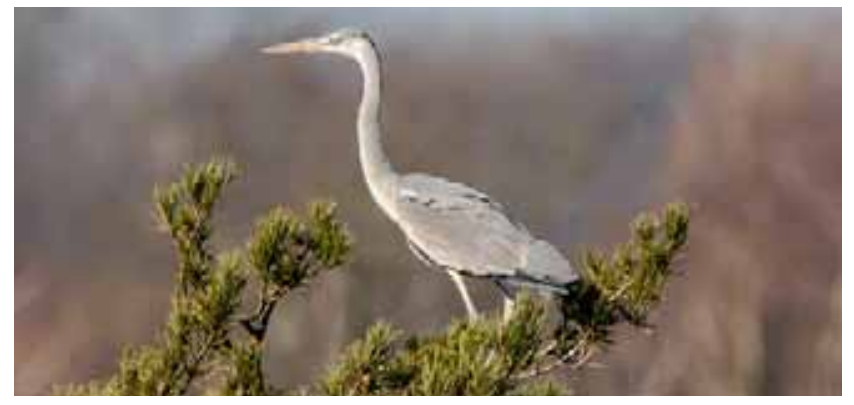

Abb. 215: Graureiher auf Kiefer. Foto: K. Kirschnick.

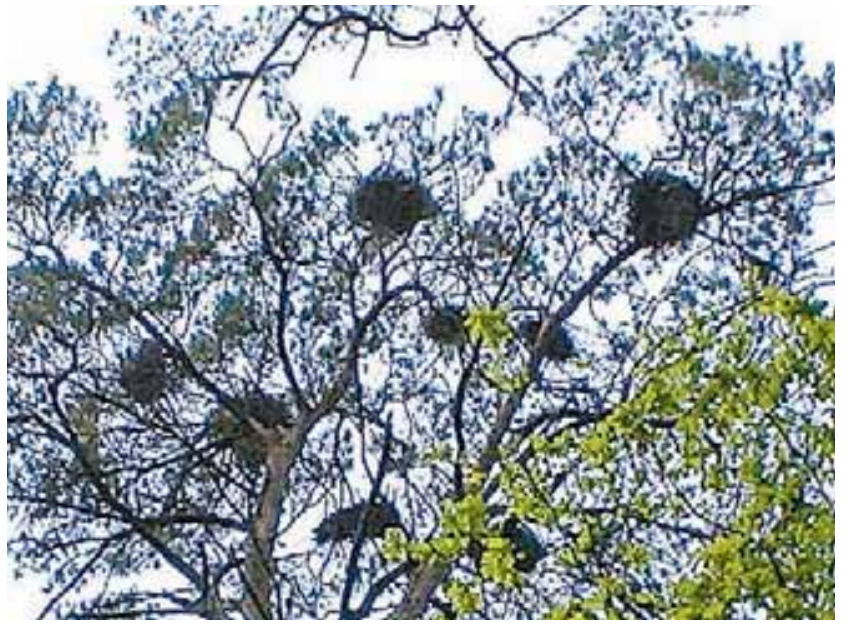

Abb. 216: Ausschnitt der Graureiherkolonie Gülzow auf einer Kiefer - Mai 2007. Foto: J. Loose.

1994 und 1995 brüteten zwei Paare auf der Seeadlervoliere im NUP Güstrow, 2007 zwei Brutpaare mit acht Jungen im Mistorfer Teich (Look, R. Schaugstat). Von 2008 bis 2011 hatten Graureiher die verschilfte Senke südlich von Tolzin als Brutplatz erkoren. Nach Aufgabe dieses Brutplatzes bildete sich eine neue Kolonie bei Wattmannshagen.

Genaue Daten zur Reiherstärke erbrachten fünf zentrale DDR-Zählungen von 1960 bis 1983. Für die Güstrower Fachgruppe erfasste W. Neubauer 1964-1967 die Horstpaare der Kolonie Gülzow. Ab 1971 kontrollierten R. Becker, R. Bischoff und W. Köhler die bekannten Brutkolonien. Nach 1980 beteiligten sich J. Loose und G. Strache an den Erfassungen. Wertvolle Informationen lieferten ferner V. Bösel, M. Fritsche, K.-H. Koop und St. Thiel.

Das beträchtlichste Zahlenmaterial verdanken wir jedoch Reinhard Becker. Während seiner 25-jährigen feldornithologischen Arbeit schuf er, wenn auch lückenhaft, eine solide Datei.

In einzelnen Jahresberichten der FG erschienen unter dem Punkt der bemerkenswerten Beobachtungen gelegentlich auch Ergebnisse aus den Bestanderfassungen in den Brutkolonien. Im Jahresbericht Nr. 16/1983 gibt R. Becker eine erste zusammenfassende Übersicht über die damals drei vorhandenen Brutkolonien in Gülzow, Dolgen und Roggow für den Zeitraum ab 1956. Seit 1994 betreuten K. Lingsminat und R. Schaugstat die Kolonien.

Mit Nr. 27/1994 hatten die Ergebnisse der Graureihererfassung einen festen Platz in den Jahresberichten gefunden. R. Schaugstat berichtete ausführlich über die jährlichen Besetzungen in den Kolonien. Neben den Horstpaarzahlen 
wurden durch ihn besonders die Brutabläufe überwacht und die flüggen Jungvögel gezählt. Die Tabelle 6 gibt eine Übersicht über die Besetzung der Kolonien in unserem Erfassungsbereich.

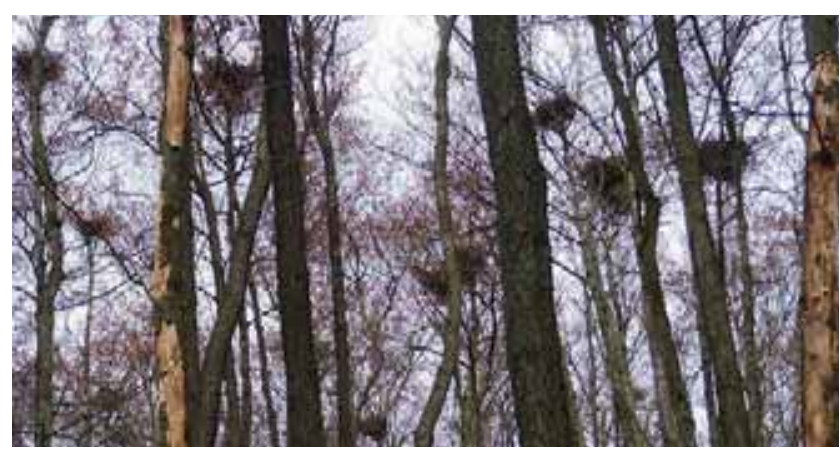

Abb. 217: Graureiherkolonie im Erlenbruchwald bei Serrahn. Foto: R. Schaugstat.

Gegenüber einem Maximalbestand im Jahre 2001 mit 207 Brutpaaren beherbergt der Altkreis Güstrow mit dem aktuellen Graureiherbrutbestand des Jahres 2015 von nur noch ca. 50 Brutpaaren in vier Brutkolonien (Gülzow/Parum, Güstrow-Nebel/NUP, Ridsenow und Wattmannshagen) nicht einmal zwei Prozent des Brutbestandes von Mecklenburg-Vorpommern (vgl. dazu VöLKer, 2014). Die auch im Land ausgewiesene Abnahme des Brutbestandes fällt für den Altkreis Güstrow deutlich krasser aus. Von 2010 bis 2013 reduzierte sich der Landesbestand um ca. $12 \%$. Im Altkreis Güstrow verringerte sich der Bestand von 2008 bis 2015 um ca. $32 \%$. Wie aus den nachfolgenden Diagram- men für die Besetzung der einzelnen Kolonien ersichtlich ist, stiegen in Jahren nach Aufgabe einer Brutkolonie die Brutpaarzahlen in anderen Kolonien an. Die Graureiher siedelten vermutlich aber auch in besser geeignete Gebiete außerhalb unseres Kreises um.

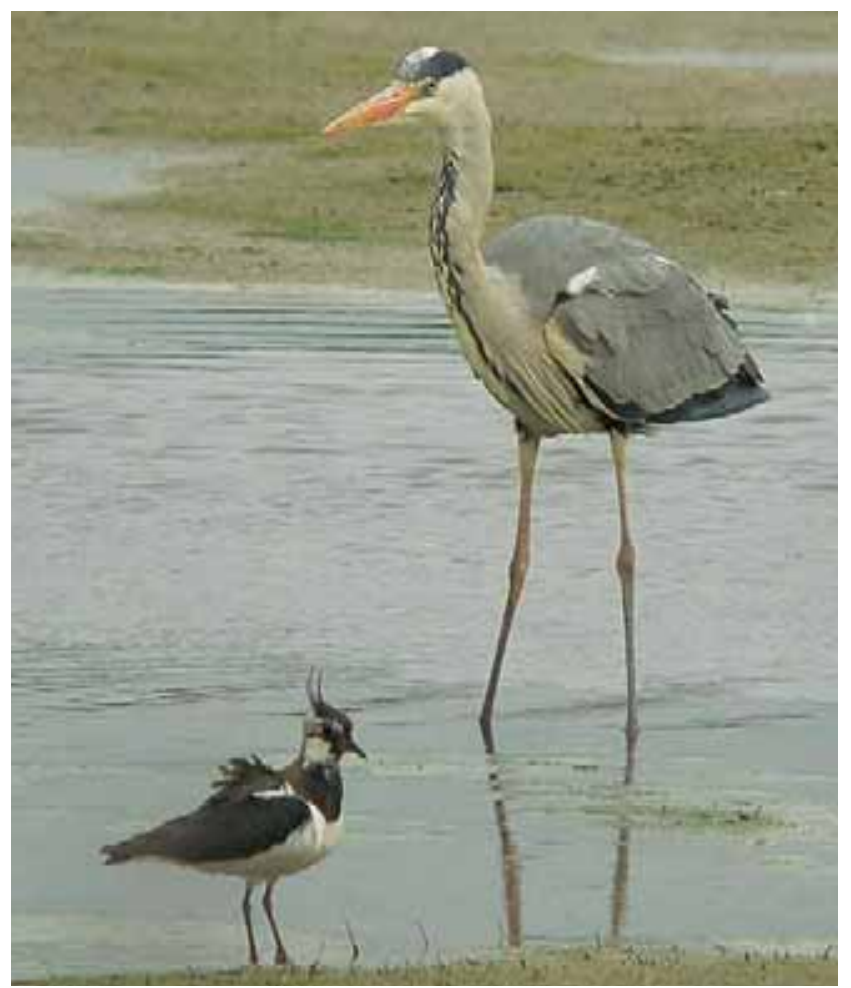

Abb. 218: Graureiher zur Paarungszeit mit orange farbenem Schnabel. Foto: f. Loose.

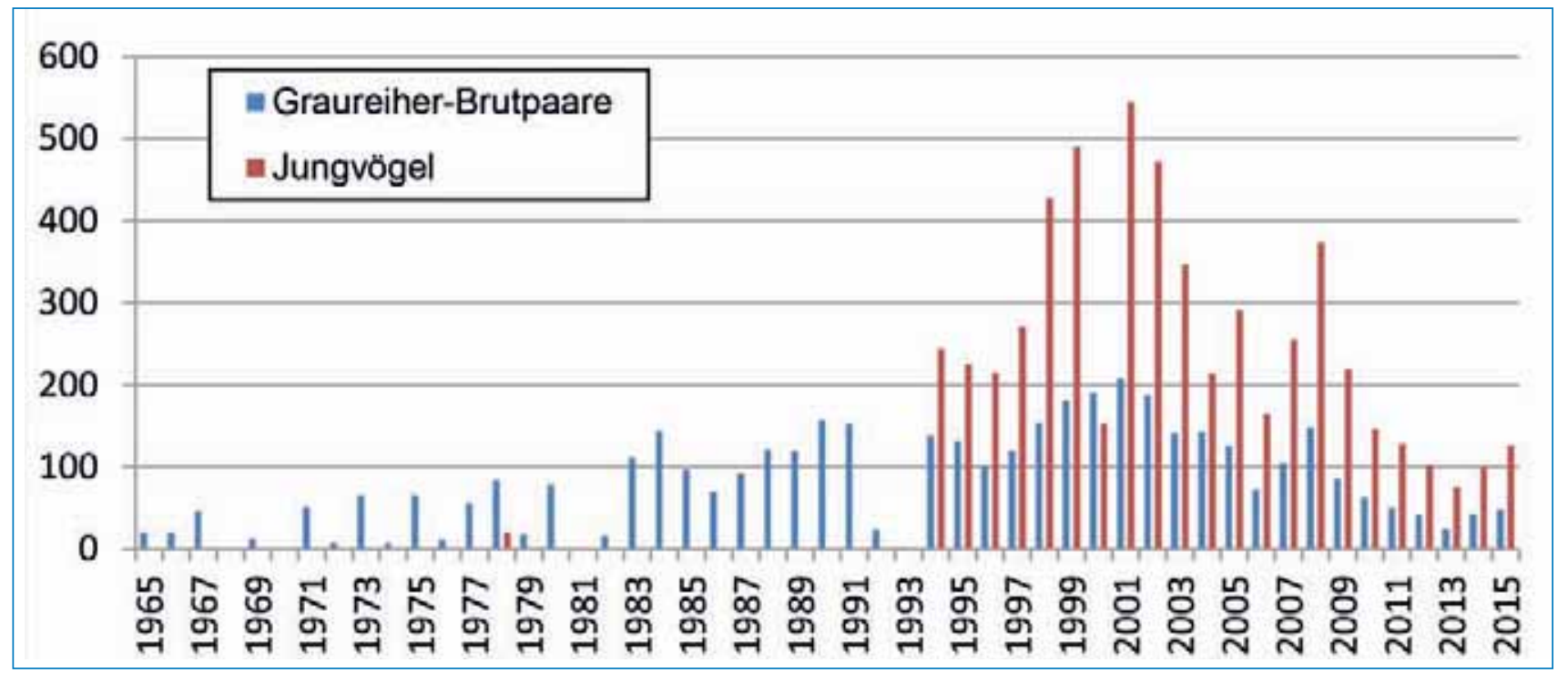

Diagramm 18: Graureiher-Brutpaare und Anzahl der fungvögel im Altkreis Güstrow (Angabe für alle Kolonien) 

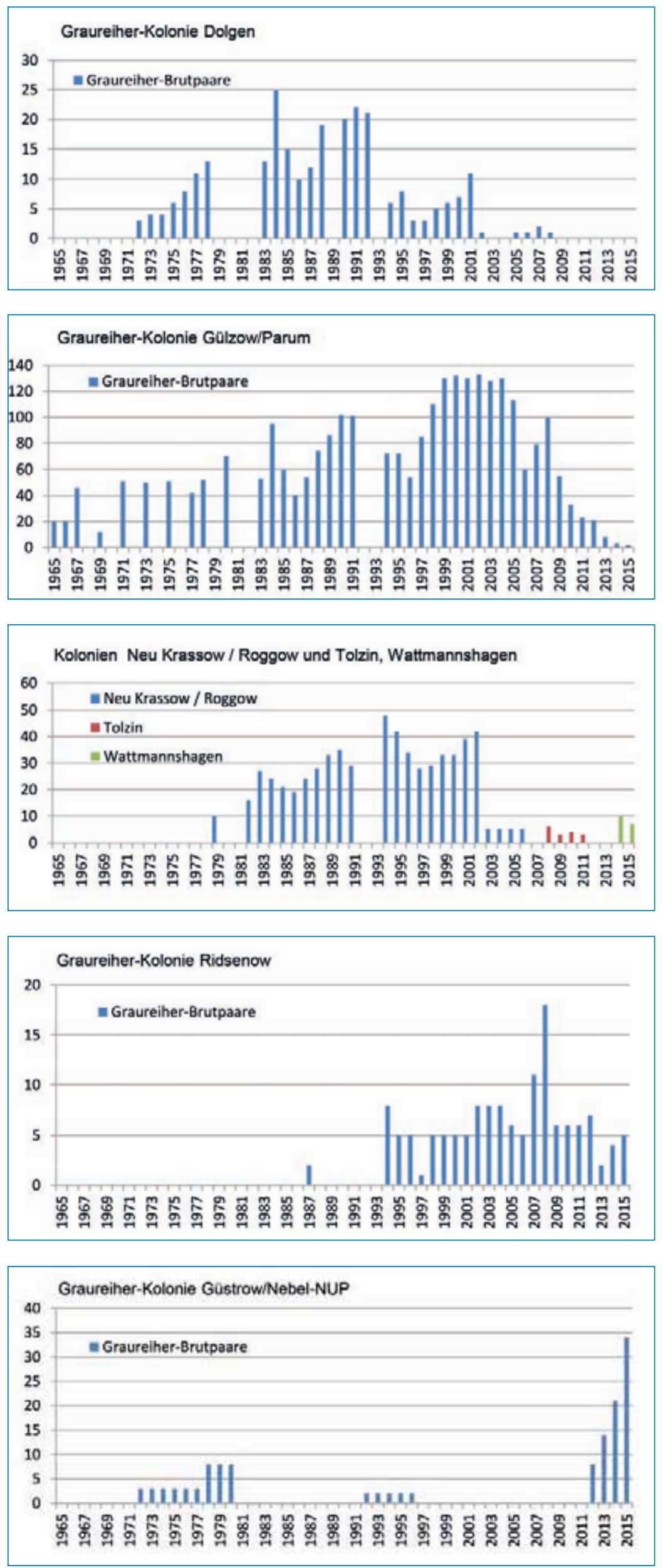
Tabelle 6: Übersicht zur Besetzung der Graureiher-Brutkolonien

\begin{tabular}{|c|c|c|c|c|c|c|c|c|c|c|}
\hline $\begin{array}{l}\text { Kolonie- } \\
\text { standort }\end{array}$ & Dolgen & $\begin{array}{l}\text { Gülzow } \\
\text { Parum }\end{array}$ & $\begin{array}{l}\text { Güstrow } \\
\text { Nebel NUP }\end{array}$ & $\begin{array}{c}\text { Klaber } \\
\text { Wockern }\end{array}$ & $\begin{array}{l}\text { Lüders- } \\
\text { hagen }\end{array}$ & $\begin{array}{c}\text { Neu Kras- } \\
\text { sow Rog- } \\
\text { gow }\end{array}$ & Ridsenow & Serrahn & Tolzin & $\begin{array}{l}\text { Watt- } \\
\text { mannsha- } \\
\text { gen }\end{array}$ \\
\hline \multicolumn{11}{|l|}{ Jahr } \\
\hline 1965 & & $/ 20 /$ & & $30 / /$ & & & & & & \\
\hline 1966 & & $/ 20 /$ & & $25 / /$ & & & & & & \\
\hline 1967 & & $/ 46 /$ & & & & & & & & \\
\hline \multicolumn{11}{|l|}{1968} \\
\hline 1969 & & /12/ & & & & & & & & \\
\hline \multicolumn{11}{|l|}{1970} \\
\hline 1971 & $2 / \mathbf{0} /$ & $51 / \mathbf{5 1} /$ & & & & & & & & \\
\hline 1972 & $4 / \mathbf{3} /$ & & $/ \mathbf{3} /$ & 20/1/1 & & & & & & \\
\hline 1973 & $6 / 4 /$ & $/ 50 /$ & $/ 3 /$ & $20 / 8 /$ & & & & & & \\
\hline 1974 & $5 / 4 /$ & & $/ \mathbf{3} /$ & & & & & & & \\
\hline 1975 & $/ 6 /$ & $/ \mathbf{5 1} /$ & $/ \mathbf{3} /$ & $20 / 8 /$ & & & & & & \\
\hline 1976 & $/ 8 /$ & & $/ \mathbf{3} /$ & & & & & & & \\
\hline 1977 & $15 / \mathbf{1 1} /$ & /42/ & $/ \mathbf{3} /$ & & & & & & & \\
\hline 1978 & $15 / \mathbf{1 3} /$ & $55 / \mathbf{5 1 /}$ & /8/20 & २०/11/ & & & & & & \\
\hline 1979 & & & $/ 8 /$ & & & $/ \mathbf{1 0} /$ & & & & \\
\hline 1980 & $13 / \mathbf{0} /$ & /70/ & /8/ & & & & & & & \\
\hline 1981 & & & $10 /$ & & & & & & & \\
\hline 1982 & & & XXXXXX & & & $/ 16 /$ & & & & \\
\hline 1983 & $16 / \mathbf{1 3} /$ & $58 / \mathbf{5 3} /$ & & $25 / \mathbf{1 8} /$ & & $27 / \mathbf{2 7} /$ & & & & \\
\hline 1984 & /25/ & /95/ & & & & /24/ & & & & \\
\hline 1985 & $/ \mathbf{1 5} /$ & $/ 60 /$ & & & & $23 / \mathbf{2 1 /}$ & $1 / /$ & & & \\
\hline 1986 & $15 / \mathbf{1 0} /$ & $59 / 40 /$ & & & & $24 / \mathbf{1 9} /$ & & & & \\
\hline 1987 & $15 / \mathbf{1 2} /$ & $59 / \mathbf{5 4 /}$ & & & & $26 / \mathbf{2 4 /}$ & /2/ & & & \\
\hline 1988 & 22/19/ & 79/74/ & & & & $31 / \mathbf{2 8} /$ & & & & \\
\hline 1989 & & $92 / \mathbf{8 6} /$ & & & & $35 / \mathbf{3 3} /$ & & & & \\
\hline 1990 & /20/ & /102/ & & & & /35/ & & & & \\
\hline 1991 & /22/ & $110 / \mathbf{1 0 1 /}$ & & & & $34 / \mathbf{2 9} /$ & & & & \\
\hline 1992 & 22/21/ & & $2 / \mathbf{2} /$ & & & & & & & \\
\hline 1993 & & & $3 / \mathbf{2} /$ & & & & & & & \\
\hline 1994 & $10 / 6 / 13$ & 110/72/141 & $3 / \mathbf{2} / 6$ & & /2/ & $58 / 48 / 84$ & $8 / 8 /$ & & & \\
\hline 1995 & $13 / \mathbf{8} / 12$ & 109/72/137 & $2 / \mathbf{2} /$ & & $/ \mathbf{3} /$ & $54 / 42 / 76$ & $/ \mathbf{5} /$ & & & \\
\hline 1996 & $14 / \mathbf{3} / 5$ & $93 / \mathbf{5 4} / 114$ & $2 / \mathbf{2} /$ & & $4 / \mathbf{2} / 6$ & $46 / \mathbf{3 4} / 90$ & $/ \mathbf{5} /$ & & & \\
\hline 1997 & $6 / \mathbf{3} / 7$ & $113 / \mathbf{8 5} / 187$ & $0 / 0 /$ & & $3 / \mathbf{3} / 13$ & $44 / \mathbf{2 8} / 64$ & $/ \mathbf{1} /$ & & & \\
\hline 1998 & $5 / \mathbf{5} / 16$ & $129 / \mathbf{1 1 0} / 319$ & $X X X X X X$ & & $5 / 4 / 13$ & $38 / \mathbf{2 9} / 79$ & $/ 5 /$ & & & \\
\hline 1999 & $8 / 6 / 17$ & $156 / \mathbf{1 3 0} / 357$ & & & 9/7/23 & 40/33/93 & $/ 5 /$ & & & \\
\hline 2000 & 9/7/19 & 153/132/ & & & $17 / \mathbf{1 3} / 49$ & $36 / \mathbf{3 3} / 84$ & $/ 5 /$ & & & \\
\hline 2001 & $11 / \mathbf{1 1} / 25$ & 156/130/356 & & & $24 / \mathbf{2 2 / 6 4}$ & $44 / \mathbf{3 9} / 100$ & $/ \mathbf{5} /$ & & & \\
\hline 2002 & $9 / \mathbf{1} / 0$ & 162/133/342 & & $2 / \mathbf{1} / 2$ & $21 / \mathbf{2} / 0$ & 47/42/107 & $11 / \mathbf{8} / 21$ & & & \\
\hline 2003 & $4 / 0$ & 148/128/326 & & & $X X X X X$ & $43 / \mathbf{5} / 0$ & 8/8/21 & & & \\
\hline 2004 & 0 & 157/130/289 & & & & $22 / \mathbf{5} / 6$ & $9 / \mathbf{8} / 19$ & & & \\
\hline 2005 & $4 / \mathbf{1} / 3$ & 137/113/260 & & & & $16 / 5 / 13$ & $7 / 6 / 15$ & & & \\
\hline 2006 & $4 / \mathbf{1} /$ & $100 / 60 / 139$ & & $2 / \mathbf{2} / 1$ & & $7 / \mathbf{5} / 11$ & $6 / \mathbf{5} / 14$ & $10 / /$ & & \\
\hline 2007 & $3 / \mathbf{2} / 5$ & 103/79/190 & & & & $6 / \mathbf{0} /$ & $12 / \mathbf{1 1} / 27$ & 16/13/33 & & \\
\hline 2008 & $4 / \mathbf{1} / 2$ & $117 / \mathbf{1 0 0} / 240$ & & & & $X X X X X$ & $19 / \mathbf{1 8} / 46$ & 26/23/66 & $6 / 6 / 19$ & \\
\hline 2009 & $2 / 0$ & $81 / \mathbf{5 5} / 134$ & & & & & $11 / \mathbf{6} / 14$ & $24 / \mathbf{2 1 / 6 1}$ & $4 / \mathbf{3} / 10$ & \\
\hline 2010 & $X X X X$ & $45 / \mathbf{3 3} / 79$ & & & & & $/ 6 / 14$ & $24 / \mathbf{1 9} / 53$ & $4 / \mathbf{4} / 12$ & $3 / /$ \\
\hline 2011 & & $39 / \mathbf{2 3} / 55$ & & & & & $/ 6 / 13$ & २२/18/60 & $4 / \mathbf{3} / 0$ & $3 / /$ \\
\hline 2012 & & $41 / \mathbf{2 1} / 61$ & $16 / \mathbf{8} / 20$ & & & & /7/21 & $29 / \mathbf{5} / 0$ & $4 / \mathbf{0} / 0$ & $3 / /$ \\
\hline 2013 & & $40 / 8 / 22$ & $16 / \mathbf{1 4} / 49$ & & & & $4 / 2 / 4$ & $29 / \mathbf{0} / 0$ & $X X X$ & $3 / /$ \\
\hline 2014 & & $15 / \mathbf{3} / 6$ & 23/21/63 & & & & $5 / 4 / 9$ & $20 / \mathbf{5} / 0$ & & 10/10/21 \\
\hline 2015 & & $11 / \mathbf{2} / 0$ & 43/34/90 & & & & $5 / \mathbf{5} / 14$ & $X X X X X$ & & 10/7/22 \\
\hline
\end{tabular}

- Zahlenangaben in der Reihenfolge: Horstanzahl/Anzahl der Brutpaare/Zahl der fungen

- Die Kennzeichnung XXX bedeutet das Ende der Koloniebesetzung. 


\subsection{Arbeit mit den Adlern}

\section{Wolfgang Köhler}

Als die Fachgruppe 1965 gegründet wurde, war über das Vorkommen und die Verbreitung unserer heimischen Adler im Kreisgebiet nicht viel bekannt. Eine systematische Kontrolle erfolgte in der Vergangenheit leider nicht. Vom Seeadler war bekannt, dass er in den großen Kiefernwaldungen südlich von Krakow in einzelnen Brutpaaren vorkommen sollte.

Ähnlich sahen die Kenntnisse über den Fischadler aus. Von ihm waren nur drei Brutpaare bekannt (bei Bossow und bei Koitendorf jeweils auf einer Kiefer und bei Neu Strenz auf einem Elektromast).

Der Schreiadler war zu dieser Zeit bereits kein Brutvogel mehr im Kreisgebiet.

Der Schutz aller Greifvögel, insbesondere der Adler, war zwar gesetzlich geregelt, es gab aber immer noch zum Teil gravierende Störungen. Der Hauptgrund für die offensichtliche Abnahme der Bestände war jedoch der Einsatz von chlorierten Kohlenwasserstoffen. Die Nebenwirkungen dieser Insektizide insbesondere des DDT wurden aber noch nicht erkannt.

Einen Anfang zur systematischen Erfassung der Seeadler machte der Bezirksnaturschutzbeauftragte Dr. Hans Sieber aus Schwerin. Durch eine alljährliche Umfrage bei Gewährsleuten und persönliche Bereisungen wurden die Bestände von ihm im ganzen Bezirk Schwerin erfasst und dokumentiert. Kurze Zeit danach stieß Peter Hauff dazu, der später die Seeadlerkontrolle ganz übernahm. Für den Kreis Güstrow führte ich die jährlichen Kontrollen an den Seeadlerhorsten durch. In den Folgejahren konnten die Störungen in den Adlerrevieren durch Überzeugung und Aufklärungen konsequent zurückgedrängt werden. Trotzdem erholten sich die Bestände nicht, die Nachwuchszahlen waren einfach zu gering. Das änderte sich erst, als die Nebenwirkungen der chlorierten Kohlenwasserstoffe bekannt wurden und man den Einsatz dieser Mittel schließlich gesetzlich verboten hatte.

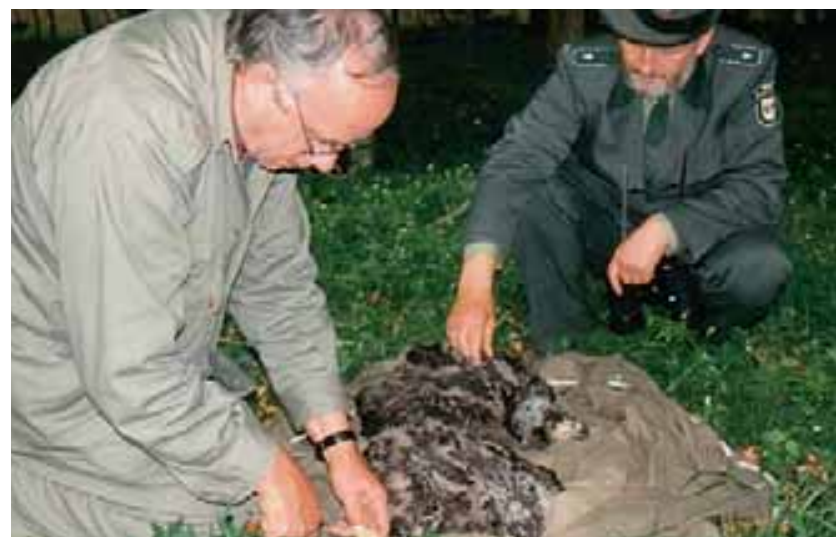

Abb. 219: Peter Hauff und Wolfgang Köhler bei der Beringung von zwei jungen Seeadlern. Foto: R. Langer.
Da anfangs alle Horste des Seeadlers bestiegen wurden, um die Jungadler zu beringen, war es unumgänglich, die Revierförster mit in die Beobachtungen einzubeziehen. Die Überwachung und Betreuung gingen schrittweise an die Revierförster über. Die Überwachungstrecke beim Seeadler läuft inzwischen direkt vom Revierförster zu Peter Hauff, dem Koordinator für ganz Mecklenburg-Vorpommern. Ein eifriger Sucher von neuen Seeadleransiedlungen in unserem Wirkungsbereich ist unser FG-Mitglied Reinhard Schaugstat, der schon mehrere Horste gefunden hat.

Die Fischadlerbrutplätze im Bezirk wurden von Dr. Sieber zunächst nur sporadisch erfasst. Erst Peter Hauff, versuchte eine systematische Erfassung durchzusetzen und band mich in diese Arbeit ein. Mit der Zunahme der Brutpaarzahlen bei See- und Fischadler war die Arbeit und Beringung für beide Arten in einer Hand nicht mehr zu bewältigen, es erfolgte eine Arbeitsaufteilung. Nun übernahm ich die Kontrolle der Fischadler, nicht nur für den Kreis, sondern für den gesamten Bezirk Schwerin. Diese Arbeitsteilung hat sich bewährt. Seit dem Jahre 2000 ist unser FG-Mitglied Steffen Thiel dazu gestoßen, er soll in den kommenden Jahren die Koordinierung bei den Fischadlern übernehmen.

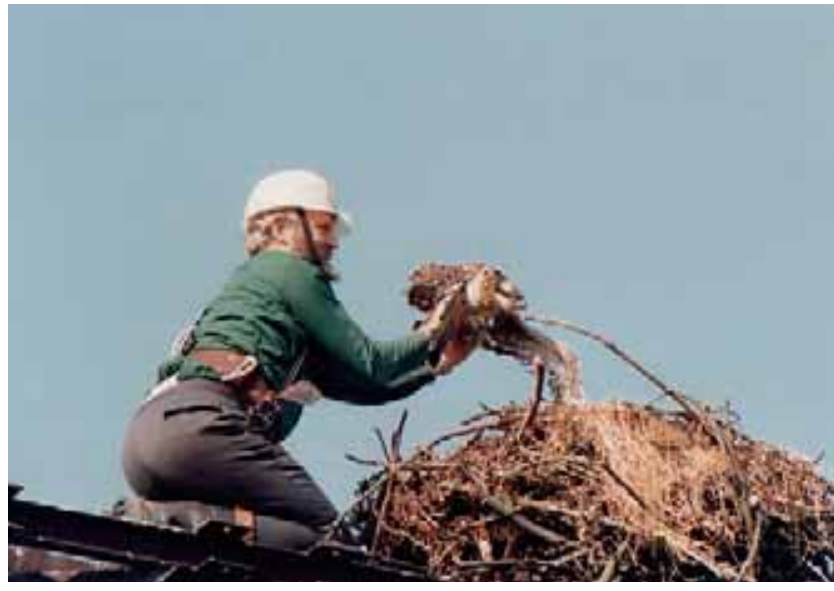

Abb. 220: Wolfgang Köhler an einem Horst des Fischadlers auf dem Mast einer Mittelspannungsleitung beim Beringen. Foto: St. Thiel.

Wurden anfangs alle vom Aussterben bedrohten Tierarten, also auch die Adlerarten, in der DDR von einem speziellen Arbeitskreis (AKSAT) überwacht, ging diese Arbeit nach der Wende an die Länder, in Mecklenburg-Vorpommern an das Landesamt für Umwelt und Natur (LAUN), jetzt Landesamt für Umwelt, Naturschutz und Geologie (LUNG) über. Jährlich werden dort in einer Projektgruppe Großvogelschutz die aktuellen Bestandesentwicklungen sowie aufgetretene Probleme diskutiert und notwendige Schutzmaßnahmen beraten. 
Während sich inzwischen die Bestände beim See- und Fischadler kontinuierlich weiter erholt haben, ist der Bestand beim Schreiadler in $\mathrm{M}-\mathrm{V}$ auf einem kritischen Niveau. Im Wirkungsbereich unserer Fachgruppe ist kein Brutpaar zu finden. Nur gelegentlich kann man Schreiadler an den Grenzen unseres Altkreises beobachten.

Für die im Altkreis Güstrow brütenden Adlerarten verzeichnen wir folgende Brutbestände (Stand 2015):

Seeadler: 16 Brutpaare, 5,5\% von M-V (290 BP)

Fischadler: 19 Brutpaare, 9,9\% von M-V (191 BP)

Von diesen 19 Fischadler-Brutpaaren brüten nur noch vier auf Bäumen, die übrigen auf Strommasten - vier auf $220 \mathrm{kV}$ Leitungen, sieben auf $110 \mathrm{kV}$ Leitungen und jeweils zwei auf $20 \mathrm{kV}$ Trassen und auf Kunsthorsten.

Die überwiegende Nistweise des Fischadlers auf Strommasten bedingte eine enge Zusammenarbeit mit den Energieunternehmen. Am Anfang unserer Arbeit stiegen wir zur Beringung ohne besondere Sicherheitsmaßnahmen auf die Masten der $110 \mathrm{kV}$ bzw. $220 \mathrm{kV}$ Leitungen. Nur die Mittelspannungsleitungen mussten vorher abgeschaltet werden. Im Laufe der Jahre haben sich die Sicherheitsbestimmungen kontinuierlich erhöht. Gegenwärtig dürfen nur noch Mitarbeiter der Energiebetriebe mit Sicherheitsgurten, die an den jeweiligen Streben befestigt werden müssen, auf die Masten steigen. Damit ist das Besteigen eine sehr zeitaufwendige Arbeit geworden. Die Jungvögel werden dann meist über ein Seil in einem Rucksack heruntergelassen und am Boden beringt. Anschließend nehmen sie wieder den gleichen Weg nach oben. In den letzten Jahren haben sich einige Mitarbeiter der Energiebetriebe auch soweit qualifiziert, dass sie die Beringung oben am Horst selbst ausführen können.

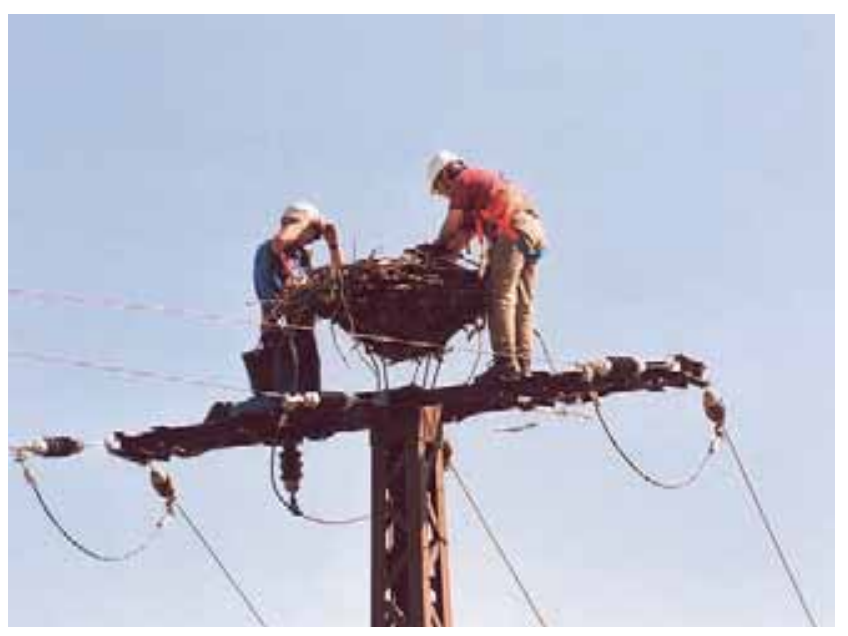

Abb. 221: Steffen Thiel (rechts) und ein Mitarbeiter der WEMAG beringen junge Fischadler gleich oben im Horst. Foto: W. Köhler.

Tabelle 7: Fischadlerbrutplätze des Altkreises Güstrow mit Jungenzahl je Horst von 2003-2015

(als Ergänzung zu den Darstellungen in NEUBAUER, 2004)

\begin{tabular}{|c|c|c|c|c|c|c|c|c|c|c|c|c|c|}
\hline & 2003 & 2004 & 2005 & 2006 & 2007 & 2008 & 2009 & 2010 & 2011 & 2012 & 2013 & 2014 & 2015 \\
\hline Langhagen & 3 & 3 & 2 & 2 & 3 & 1 & 3 & 2 & 3 & 3 & - & 3 & 2 \\
\hline Dersentin & 2 & 3 & 3 & 0 & 3 & 3 & 3 & 2 & 4 & 4 & 2 & 2 & 3 \\
\hline Hinzenhagen & 3 & 3 & 4 & 2 & 0 & 3 & & & & & & & \\
\hline Nienhagen & 1 & 2 & 2 & 3 & 3 & 3 & 1 & 3 & 3 & 2 & 3 & 3 & 2 \\
\hline Charlottenthal & 0 & 3 & 0 & 3 & 3 & 3 & 2 & 3 & 3 & 3 & 2 & 2 & 2 \\
\hline Neu Dobbin & 3 & 1 & 0 & 3 & 2 & 0 & 1 & 2 & 2 & 0 & - & - & 0 \\
\hline Wendorf & 1 & 3 & 1 & 1 & 2 & 3 & 2 & 1 & 3 & 3 & 3 & 2 & 3 \\
\hline Lüssow & 3 & 2 & 2 & 3 & 0 & 3 & 1 & 2 & 3 & 3 & 3 & 3 & 3 \\
\hline Schwiesow & 1 & 3 & 2 & 2 & 3 & 2 & 2 & 2 & 2 & 2 & 0 & - & 2 \\
\hline Windfang & 2 & 4 & 2 & 1 & 2 & 2 & 1 & 1 & 1 & 2 & 2 & 2 & 2 \\
\hline Gerdshagen & 2 & 2 & 2 & 3 & 1 & - & 3 & 0 & 1 & 2 & 2 & 2 & 3 \\
\hline Lohmen & & 0 & 2 & - & 1 & - & - & 2 & 0 & 2 & 2 & 0 & 0 \\
\hline Schwiggerow & & 0 & 3 & 2 & 3 & 3 & 4 & 3 & 3 & 3 & 3 & 2 & 3 \\
\hline Bölkow & & & & 2 & 2 & 0 & 3 & 1 & 3 & 2 & 3 & 2 & 3 \\
\hline Bossower [Kiefer] & & & & & & 2 & 1 & 3 & & & & & \\
\hline Schönwolde & & & & & & 2 & 1 & 1 & 2 & 3 & 2 & - & 2 \\
\hline Bornkrug & & & & & & & & 1 & 1 & 2 & 2 & 2 & 2 \\
\hline Bansow Abz. & & & & & & & & 0 & 2 & - & 3 & & \\
\hline Bansow II & & & & & & & & 0 & 2 & - & 3 & 2 & - \\
\hline Tolzin & & & & & & & & & & 2 & 3 & 2 & 2 \\
\hline Glave & & & & & & & & & & 0 & 3 & 2 & 3 \\
\hline Carlsdorf & & & & & & & & & & 2 & 3 & 3 & 3 \\
\hline Nienhagen II & & & & & & & & & & & & 1 & - \\
\hline Bossow [tote Kiefer] & & & & & & & & & & & & & 3 \\
\hline Horste, besetzt & 11 & 13 & 13 & 13 & 14 & 14 & 14 & 18 & 17 & 18 & 18 & 17 & 19 \\
\hline BP-erfolgreich & 10 & 11 & 11 & 12 & 12 & 12 & 14 & 15 & 16 & 16 & 17 & 16 & 17 \\
\hline Junge & 21 & 29 & 25 & 27 & 27 & 30 & 28 & 29 & 38 & 40 & 44 & 35 & 43 \\
\hline
\end{tabular}


Da die Abschaltungen bei den Mittelspannungsleitungen sehr aufwendig sind und die Horste auf diesen Leitungen oft Kurzschlüsse auslösen, sind die Energiebetriebe bemüht, die Horste von diesen Leitungen zu entfernen. Eine Möglichkeit ergab sich, die Horste bei der Rekonstruktion benachbarter $110 \mathrm{kV}$ Leitungen auf diese umzusiedeln. Als andere Möglichkeit wurde die Aufstellung eines neuen Betonmastes mit Horstkorb in unmittelbarer Nähe praktiziert. Diese Maßnahme setzte aber immer auch das Einverständnis des jeweiligen Flächeneigentümers voraus. Auch war es erforderlich, dass die Horste auf den Betonmasten zur Beringung mit Hubwagen angefahren werden können. Die Umsiedlungen von Fischadlerbrutpaaren verliefen bisher erfolgreich. Sie sind sowohl für die Energieversorger als auch die Betreuer eine Erleichterung.

Die Koordinierung mit den Verantwortungsbereichen der Energieunternehmern (e-dis, WEMAG, 50 Hertz, Meisterbereiche Bützow, Neustadt-Glewe und Lübz) sowie für die einzelnen Leitungen erfordert einen enormen Arbeitsaufwand. Sie wurde dankenswerterweise von Herrn Rudi Langer, einem ehemaligen Mitarbeiter der Energiebetriebe übernommen, der uns seit Jahren bei den Beringungen begleitete.
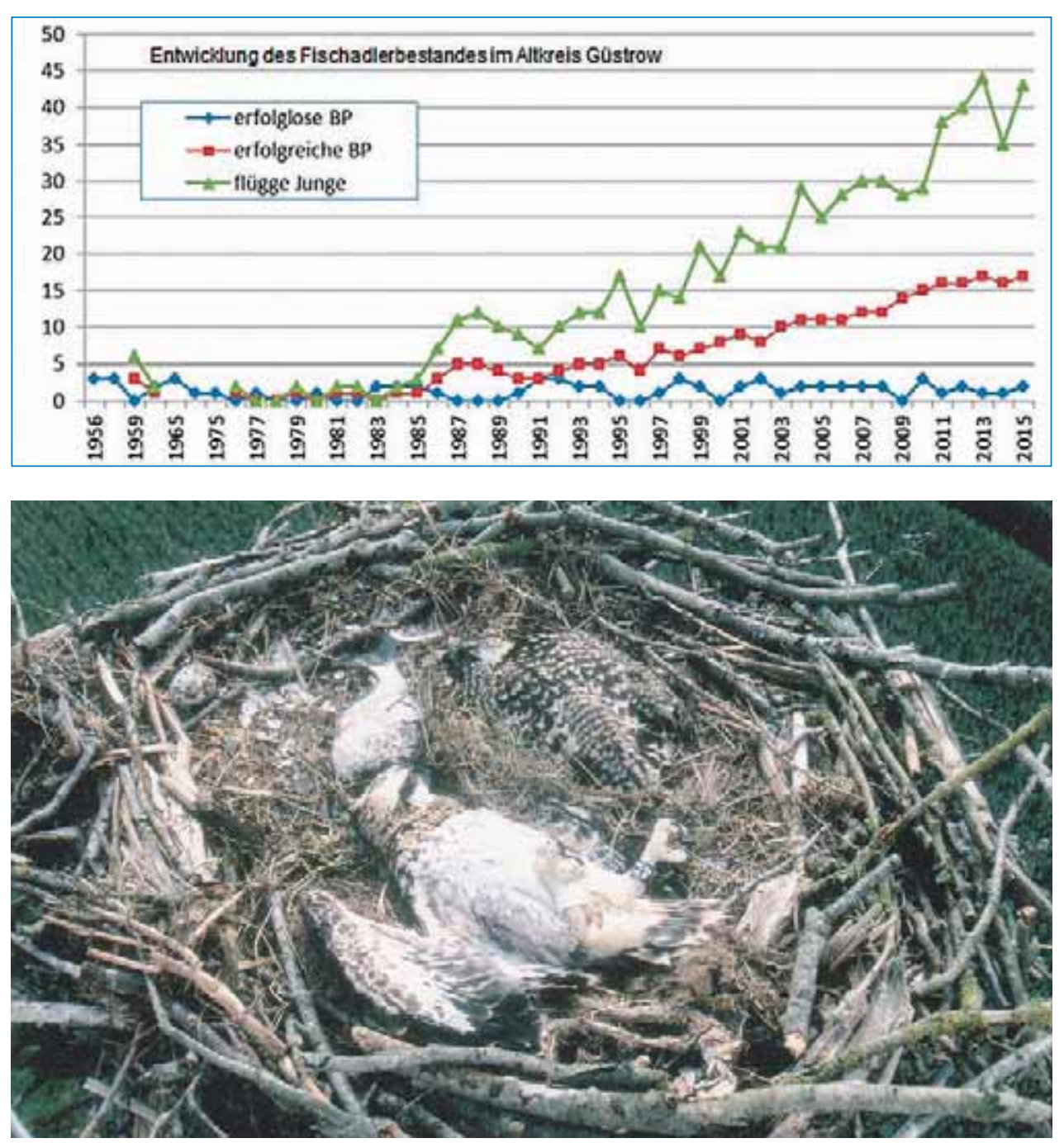

Abb. 223: Bei der Beringung drücken sich die fungadler apathisch ins Nest. Foto: St. Thiel.
Insgesamt wurden in jedem Jahr etwa $3.000 \mathrm{~km}$ mit dem Auto zurückgelegt, um all diese Arbeiten zu erledigen.

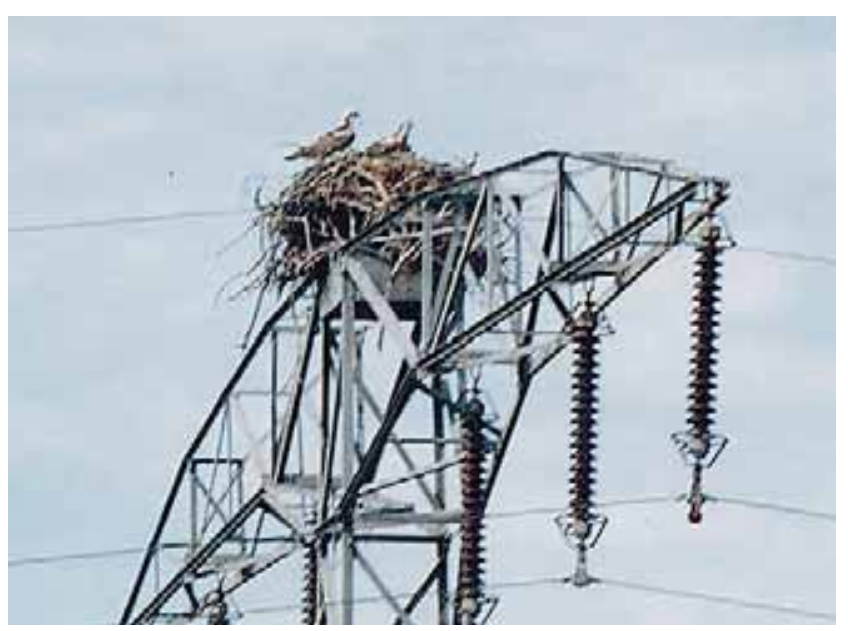

Abb. 222: Fischadler-Brutpaar auf einem 110 kV Mast. Foto: Loose.
Diagramm 24:

Der Bestand der Fischadler zeigt ab Ende der 1980er fahre einen deutlichen positiven Entwicklungstrend.

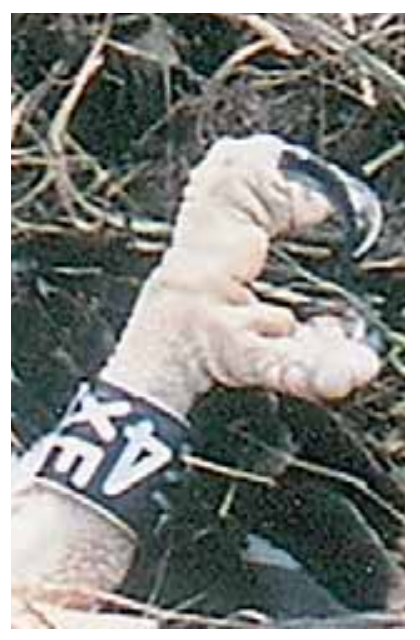

Abb. 224: Fischadler erhalten neben dem Metallring auch einen gut aus der Ferne ablesbaren Kennring - hier mit dem Code 4XE. Foto: St. Thiel. 


\subsection{Kraniche}

\section{Guntram Trost}

Als großer imposanter Vogel stand der Kranich gleich mit Bildung der Fachgruppe für Ornithologie und Naturschutz in Güstrow im Interesse der Mitglieder. Der erste Eintrag in der Fachgruppenkartei stammt vom 20.03.1965 und bezieht sich auf vier ziehende Kraniche über Krakow am See. Aber auch die ersten Brutverdachte stammen aus dem Gründungsjahr der Fachgruppe. Der erste konkrete Brutnachweis findet sich für den 14.05.1968 auf den Karteikarten (Eintrag durch K. Pohlmann): ein Nest mit zwei Eiern am Schlenkengraben. Dieses Brutrevier bestand über viele Jahre, ist heute aber trocken und nicht mehr für die Brut geeignet.

In der ersten Hälfte der 1960er Jahre befand sich die Kranichpopulation in Mecklenburg auf ihrem Tiefststand. Auch deshalb bestand ein großes Interesse der FG-Mitglieder am seltenen Kranich. Eine Bestandserhebung für den Wirkungskreis der Fachgruppe wurde in den Unterlagen erstmalig für 1971 gefunden. An den 17 bekannten Brutplätzen konnten sieben Jungtiere von fünf erfolgreich brütenden Paaren erfasst werden. In den seit 1968 erscheinenden Jahresberichten der Fachgruppe Güstrow findet sich der erste Beitrag zum Kranich in Nr. 7/1974. Dieser Bericht stammt von Wolfgang Köhler und umfasst für den Zeitraum 1965 bis 1974 hauptsächlich den Zug der Kraniche. Ab dem Jahresbericht Nr. 11/1981 gibt es durchgängig den jährlichen Kranichbericht. Autor war von Beginn bis 2012 Karl Heinz Koop, anschließend stellte Guntram Trost diese Darstellungen zusammen.

Nachdem im Jahre 1957 in der DDR ein „Arbeitskreis zum Schutze vom Aussterben bedrohter Tiere“ gebildet wurde, kam es auf dessen Anregung im Jahre 1978 zur Entstehung der „Bezirksarbeitsgruppe Gefährdete Tierarten“ für den Bezirk Schwerin. Die Leitung übernahm neben Wolfgang Mewes und Peter Hauff auch das Güstrower Fachgruppenmitglied Wolfgang Köhler. Durch diese Arbeitsgruppe wurden Kreisbeauftragte für Kranichschutz berufen (Abb. 225). Aus der Güstrower Fachgruppe stellte sich KarlHeinz Koop dieser Aufgabe. Einige Jahre noch in Zusammenarbeit mit Friedrich „Fritz“ Anderlik, stimmte er die Kranicharbeit im Gebiet bis zum Ende des Jahres 2012 ab.

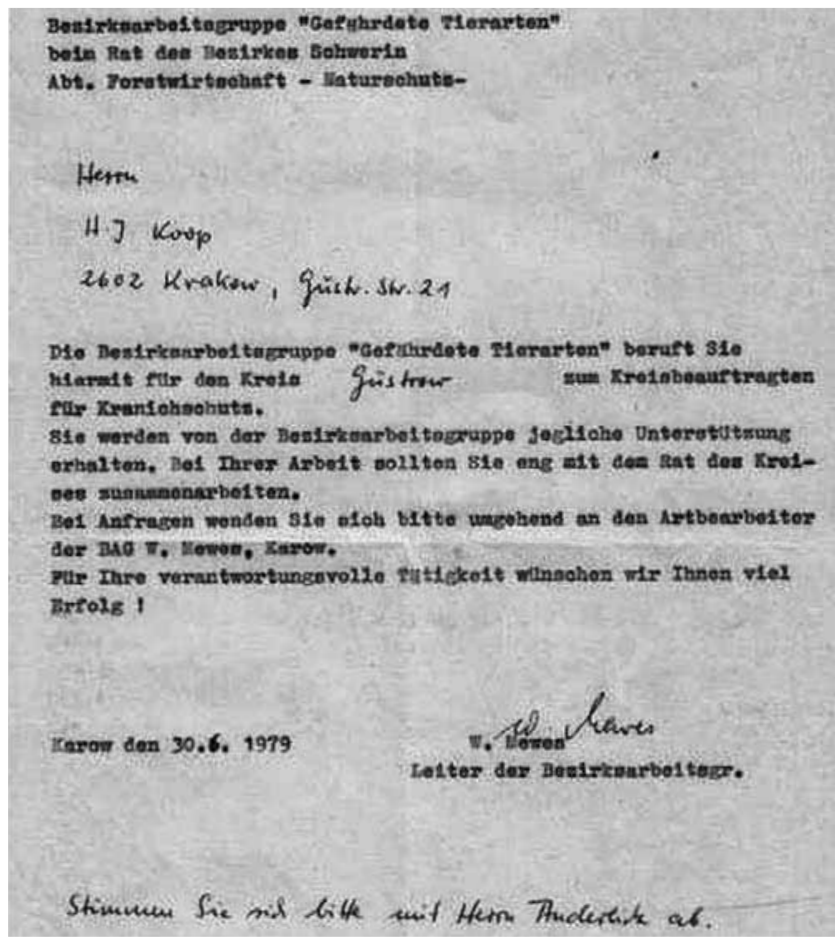

Abb. 225: Berufungsschreiben zum Kranichbetreuer

Anfangs mit Motorrad unterwegs kontrollierte er die Brut oder erfasste neue Brutplätze. Ab 2013 wurde die Koordinierung der Kranicherfassung von Guntram Trost und Beate Meder-Trost übernommen.

In den Anfangsjahren war die Kontrolle der Kranichbrutplätze sehr übersichtlich und mit geringen Fehlern behaftet. Im Laufe der Zeit konnte jedoch eine rasante Zunahme der Zahl der Brutpaare beobachtet werden. 2007 gab es in unserem Altkreisgebiet bereits über 100 bekannte Brutpaare. Die heutige Anzahl der Brutpaare liegt über 300 und eine exakte Kontrolle ist nicht mehr beherrschbar. Die jährlichen Zunahmen der Brutpaare wiesen in den letzten Jahren relativ hohe Zahlen auf: für 2013 bereits 25 Paare, 2014 noch einmal 30 Paare und für 2015 wurden 50 besetzte Brutplätze neu aufgenommen. Einige dieser neuen Brutplätze entstanden jedoch nicht im Jahr der Entdeckung, sondern waren sicherlich schon zuvor belegt. Geschuldet sind diese Ungenauigkeiten der stetig zunehmenden Dichte der Brutplätze, die durch die Kranicherfasser nicht mehr sofort entdeckt werden konnten.

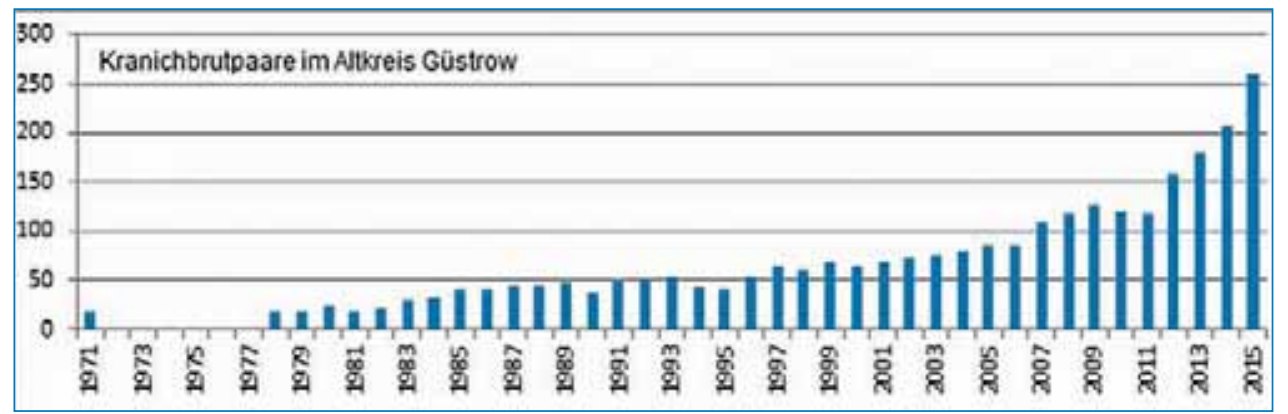

Diagramm 25:

Das Diagramm zeigt die Entwicklung des KranichBrutpaarbestandes im Altkreis Güstrow $\left(1.002 \mathrm{~km}^{2}\right)$ nach Angaben der Fachgruppe Güstrow. 
Die Zugbewegungen der Kraniche und besonders natürlich der Herbstzug, sind sehr auffällig. Zu Beginn der Datenerfassung durch die Fachgruppe waren auch die Zugdaten die häufigsten Eintragungen. Das änderte sich in den Jahren mit der Erkenntnis, dass auch andere Daten sehr wichtig für die Bewertung der Kraniche im Gebiet sind. Heute beziehen sich die meisten Daten auf die Besetzung der Brutreviere und den jährlichen Bruterfolg. Aber auch auf das Sammelgeschehen der heimischen Kraniche und auf den Zuzug der nordischen Vögel wird nun Wert gelegt. In den zehn ersten Jahren des Bestehens der Fachgruppe finden sich jährlich etwa 30 Datensätze zum Kranich auf den Karteikarten. Heute erfasst die Fachgruppe jährlich um die 1.000 Datensätze.

Zählungen schlafender Kraniche wurden in früheren Zeiten nur sehr sporadisch durchgeführt. Die Schlafplätze waren wahrscheinlich nur teilweise bekannt. Manche Plätze wurden nur zwei oder drei Jahre von Kranichen genutzt. An den alten Schlafplätzen (Vorder- und Hintermoor bei Rum Kogel, Großer Werder im Krakower Obersee, Püstenberg bei Seegrube, Koppel westlich Striggow) übernachtete nur eine geringe Zahl von Kranichen, die selten die 200er Marke überstieg. Im Jahre 1995 entstand ein Schlafplatz am Ufer des Breeser Sees, an dem durch den NSG-Betreuer von Anfang an kontinuierliche Zählungen durchgeführt wurden. Mit der Einführung der deutschlandweiten Synchronzählungen an den Schlafplätzen der Kraniche im Jahre 2010 werden alle bekannten Plätze im Fachgruppenbereich systematisch an Stichtagen kontrolliert. Aktuelle Schlafplätze befinden sich neben dem im NSG Breeser See in den renaturierten Poldern Gutow und Klaber, seit 2012 auch im neuen PVA-Teich östlich Güstrow und seit kurzem auch wieder auf dem Großen Werder im Krakower Obersee. Die Kranichschlafplätze können verschiedenen Sammel- und Rastregionen zugerechnet werden (vgl. Sonderheft 1 des ORMV, Band 48, 2014), zwischen denen es einen ständigen Austausch gibt.

Tabelle 8: Maximalzahlen der an Schlafplätzen bei den Synchronzählungen übernachtenden Kraniche

\begin{tabular}{c|c|c}
\hline Jahr & Datum Maximum & Kranichanzahl \\
\hline 2010 & $09.0 k t$. & 1.100 \\
\hline 2011 & $01.0 k t$. & 650 \\
\hline 2012 & $01.0 k t$. & 660 \\
\hline 2013 & $06.0 k t$. & 1.400 \\
\hline 2014 & $18.0 k t$. & 1.600 \\
\hline 2015 & 12. Sept. & 1.600 \\
\hline
\end{tabular}

Der Schlafplatz am Breeser See wird bereits frühzeitig nach der Rückkehr der Kraniche aus dem Winterquartier regelmäßig durch eine hohe Anzahl genutzt. Seit mehreren Jahren wird der Breeser See auch jährlich als Mauserplatz von 20 bis 60 Vögeln genutzt, die Ende Mai bis Mitte Juni, dann meist flugunfähig, die umliegenden Wiesen zur Äsung nutzen. Der Bruchwald des NSG bietet ihnen bei Störungen einen gut geeigneten Rückzugsraum.

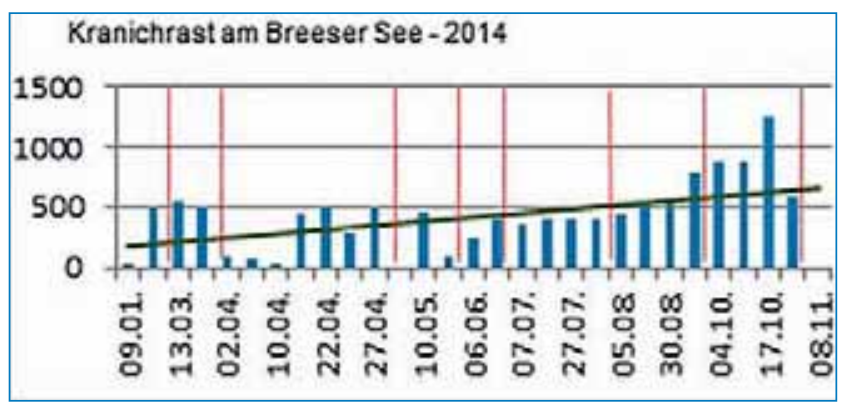

Diagramm 26: Besetzung des Kranichschlafplatzes am Breeser See im Jahresverlauf (Beispiel für 2014)

„Die Farbberingung von Graukranichen Grus grus mit einem Dreifarben-Code und die Besenderung mit Radiosendern erfolgten in Europa erstmals 1988 in Spanien. In Deutschland werden seit 1989 Kraniche im Rahmen eines internationalen Beringungsprojektes mit einer Individualmarkierung versehen. Seit 1990 kommt das im September 1989 auf der internationalen Kranichtagung in Tallinn, Estland, vereinbarte System mit drei verschiedenfarbenen Kunststoffringen zum Einsatz." (Information aus dem Kranichinformationszentrum Groß Mohrdorf - siehe auch http://www.kraniche.de)

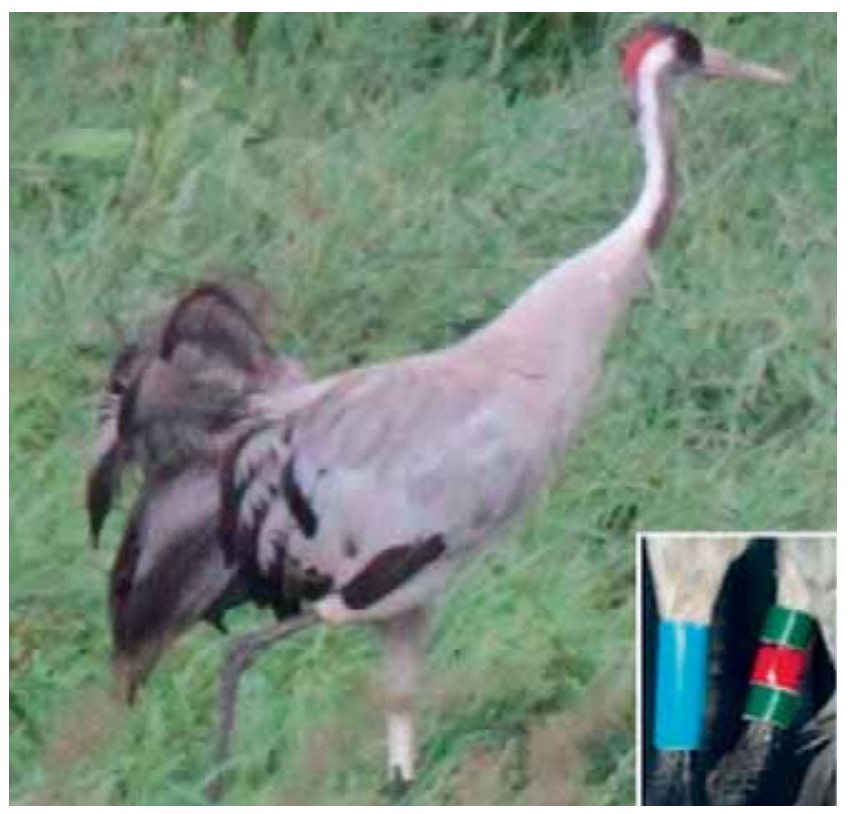

Abb. 226: Der am 29.06. 1996 in Fellen beringte Kranich (kleines Bild: originale Beringung) verlor nach und nach seine Ringe, kann aber mit der Auffälligkeit des Ausbruches am ausgeblassten Ring noch zugeordnet werden. Foto: M. Meder-Trost.

Die anfangs verwendeten individuellen Farbringe blichen leider mit der Zeit aus und konnten dann nicht oder nur schwer zugeordnet werden. Ab 2001 kamen durchgefärbte Ringe zum Einsatz, die nicht ausbleichen. 


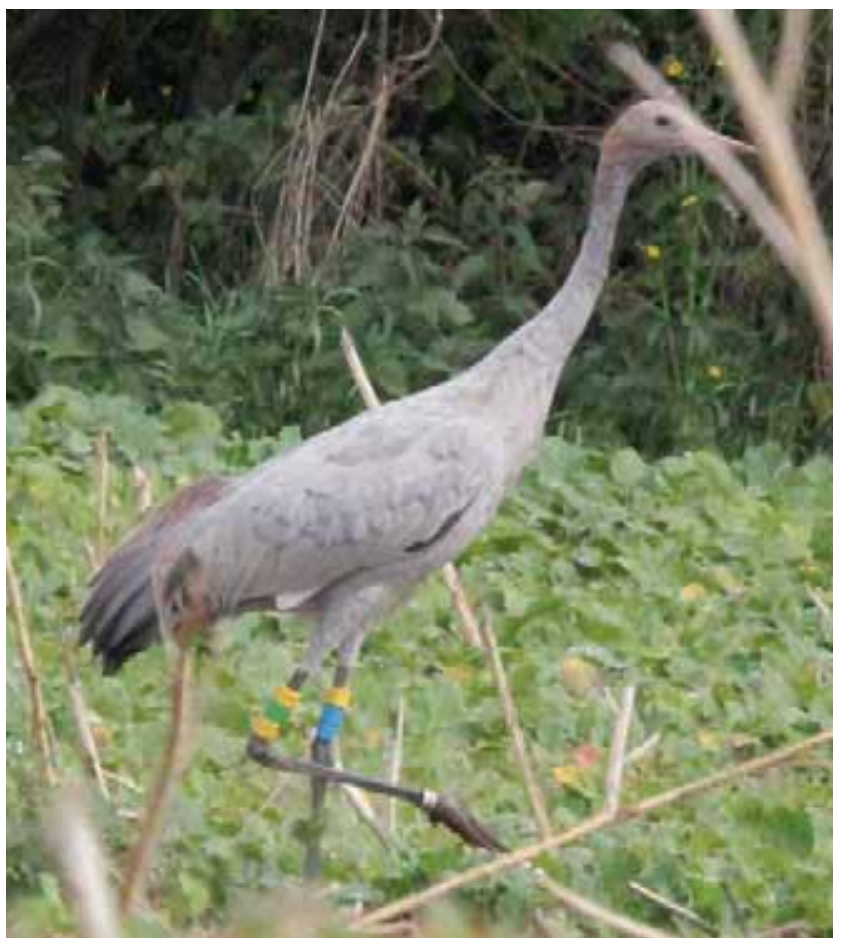

Abb. 227: Dieser fungvogel stammt vom Nest bei Koppelow-Ausbau und wurde am 25.6.2014 beringt. Am linken Bein befindet sich die Länderkennung - hier: gelb-blau-blau. Der Vogelwarten-Ring ist unten am rechten Fuß. Foto: G. Trost.

Seit Beginn der Beringung werden auch Jungkraniche im Bereich Güstrow mit Farbringen ausgestattet. Ablesungen von Farbringen wurden regelmäßig durch zahlreiche Beobachter unter der Internetadresse www.icora.de in eine internationale Datenbank eingegeben, mit der im Jahr 2008 gestartet worden war. Gegenwärtig fehlt leider ein Überblick über diese Farb-Beringungen und eine Auswertung der Ringablesungen im Gebiet. Jeder Melder bekommt jedoch Einblick in die zahlreichen Ablesungen „seiner“ Kraniche und kann deren Weg im Jahreszyklus und inzwischen auch über viele Jahre hin verfolgen. So kommen aber nur zufällig ausgewählte Kraniche zur Auswertung.

Für den Jungkranich in Abb. 227 liegen bis zum 28.12.2015 insgesamt 62 Folgeablesungen vor.

Nach dem Flüggewerden zog er 2014 nicht in ein klassisches Winterquartier nach Frankreich oder Spanien, sondern frühzeitig Ende September lediglich bis Niedersachsen in den Raum von Vechta (Umfeld des Goldenstedter Moores). Bereits ab dem 16.01.2015 wurde er wieder bei Hoppenrade beobachtet. Hier und im Raum Suckwitz und Breeser See hielt er sich dann bis zum 11.10.2015 auf. Auch seinen zweiten Winter begann er mit Aufenthalten wieder im Umfeld des Goldenstedter und Freistetter Moors in Niedersachsen. Da zu vermuten ist, dass der Jungkranich seine erste Reise gemeinsam mit den Eltern begonnen hatte, wird hier verdeutlicht, dass Überwinterungstraditionen wahrscheinlich von den Eltern übernommen werden und ein weiter Wegzug bis nach Spanien immer häufiger ausfällt. Bei uns überwinternde Kraniche werden in den jüngsten Jahren immer häufiger festgestellt. Durch die verringerte Entfernung zu nahen Überwinterungsgebieten finden sich unsere Brutkraniche auch immer früher in ihren Revieren ein.

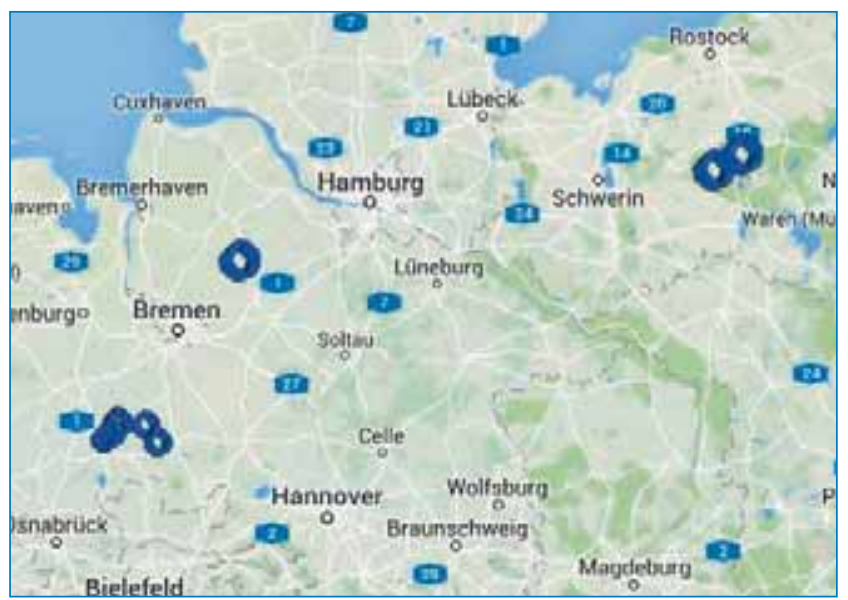

Karte 17: Nachweisorte des Kranichs aus Abb. 227 im ersten und zweiten Fahr. (Karte aus ICORA)

Ablesungen von Ringkombinationen gelingen besonders gut an den Schlafplätzen. Am Breeser See konnte mittels automatischer Wildkamera sehr viele Ringkraniche fotografiert werden.

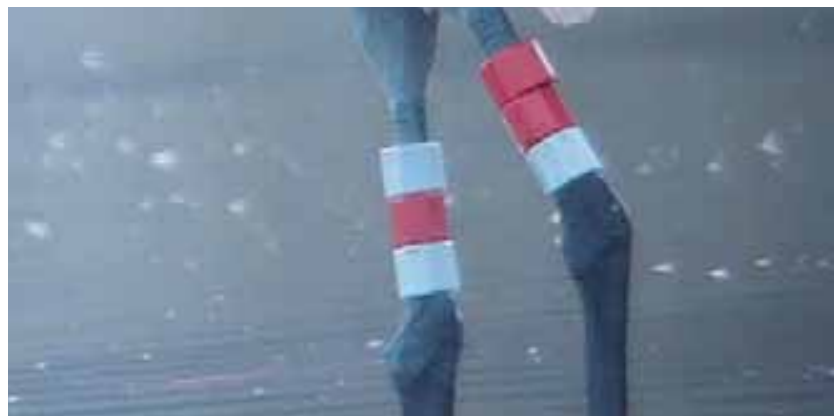

Abb. 228: Seltener waren Kraniche mit roten Ringen, die in Schweden beringt worden waren, zu beobachten. Foto: Loose.

In unserer Region hatte sich Dirk Seemann aus der FG Bützow mit der entsprechenden Empfangstechnik ausgestattet und stellte die Anwesenheit von besenderten Kranichen fest. Er informierte uns regelmäßig über seine Erfassungen.

Bilder aus dem Leben von Kranichfamilien:

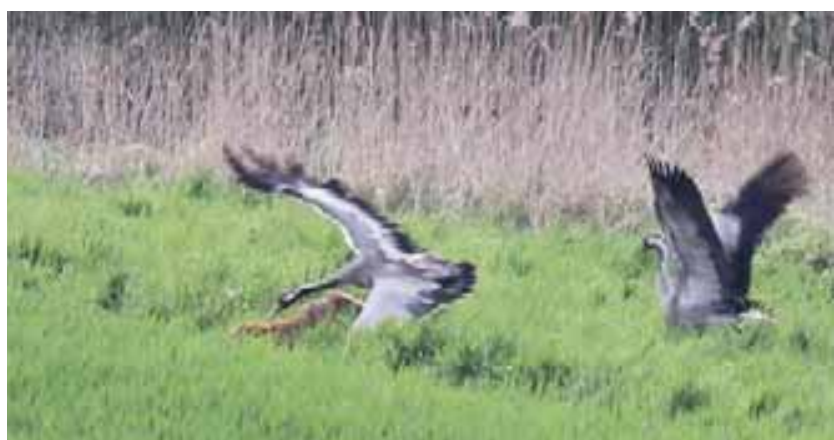

Abb. 229: Kraniche verteidigen ihr Brutrevier gegen Füchse auch schon mal sehr heftig. Foto: B. Meder-Trost. 


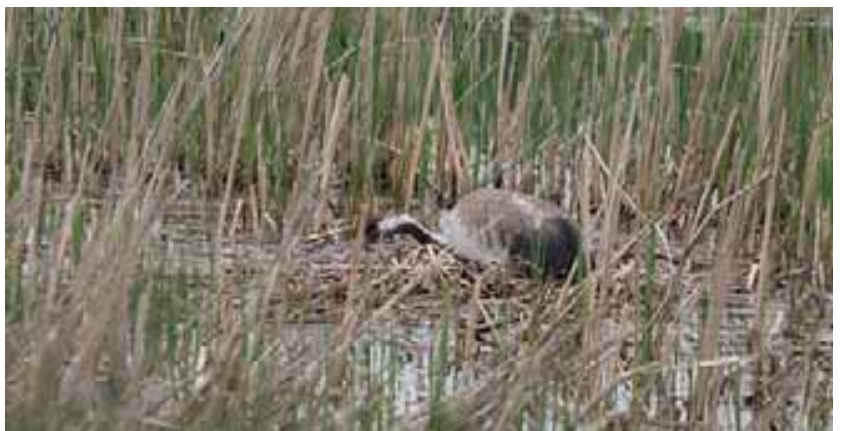

Abb. 230: Dieses Nest liegt knapp $20 \mathrm{~m}$ von einem stark befahrenen Betonweg entfernt. Foto: B. Meder-Trost.

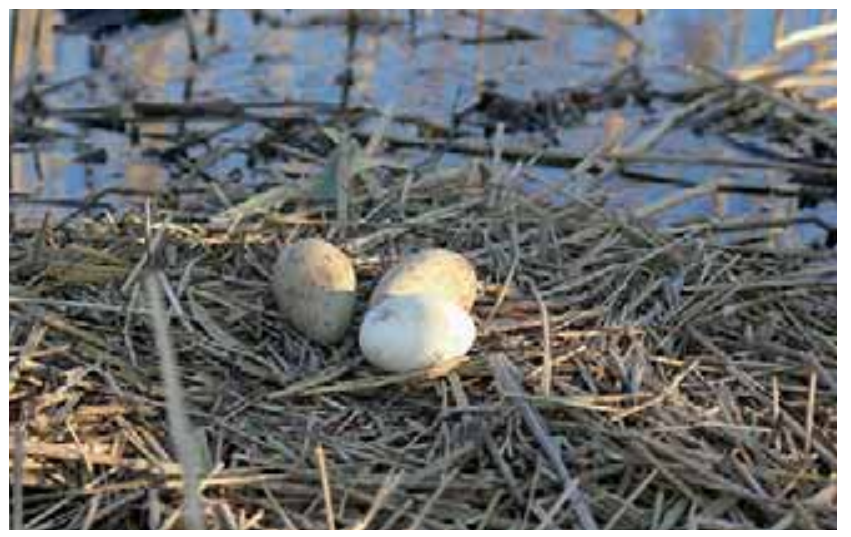

Abb. 231: Das Kranichpaar vom Gänserichsoll bei Lübsee hat ein Gänseei zu ihren Kranicheiern getragen. Foto: G. Trost.

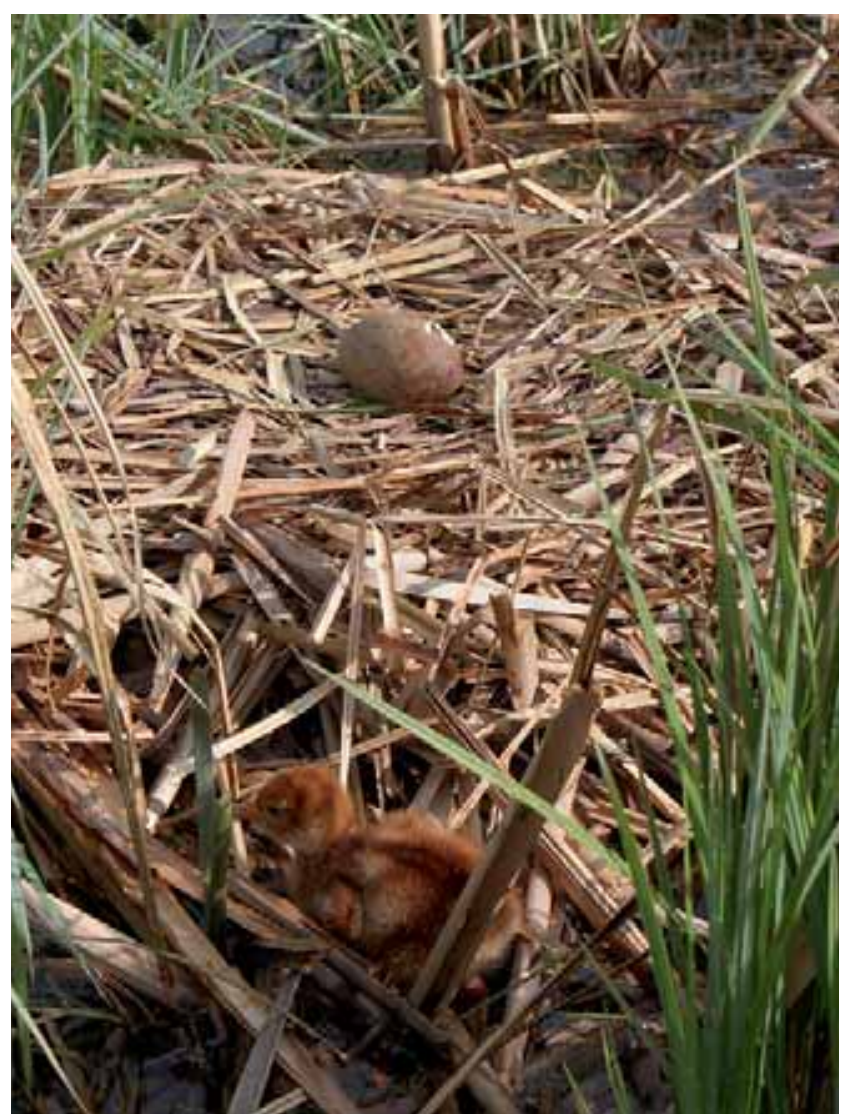

Abb. 232: Im Ackersoll-Nest bei Nienhagen ist ein Küken bereits geschlüpft, das zweite Küken hat seine Eischale angepickt. Foto: B. Meder-Trost.

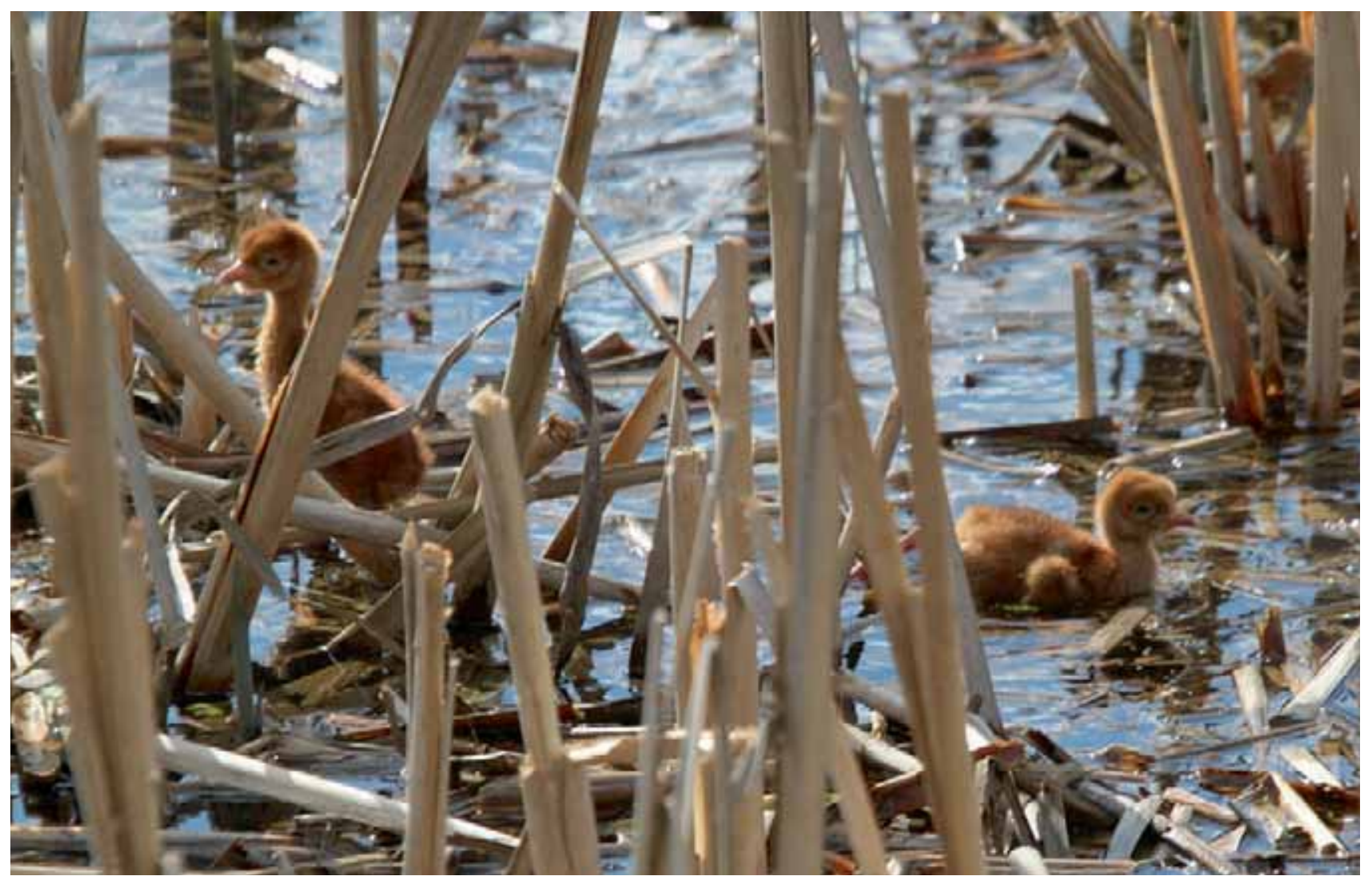

Abb. 233: Die jungen Kranichküken sind noch nicht sehr ängstlich, wie hier am Bahndamm bei Klein Grabow. Foto: B. Meder-Trost. 


\subsection{Saatkrähen}

\section{Joachim Loose}

Der bei uns nur in Ortschaften nistenden Saatkrähe gelang es nie, eine Akzeptanz bei der Bevölkerung wie andere Vögel zu erlangen. Nicht nur, dass sie schwarz sind, machen sie als Koloniebrüter viel Lärm und Dreck und stören. So werden sie bestenfalls zähneknirschend geduldet, wenn man aus gesetzlicher Sicht nichts gegen sie und ihre Niststandorte unternehmen konnte. Oft genug unternahm man aber auch etwas gegen die „lästigen“ Vögel. Zu DDRZeiten war es durchaus üblich, dass die Feuerwehr zu Beginn der Brutzeit ausrückte und die frisch gebauten Nester herunterspritzte. Selbst nach der Wende stellte die Stadt Güstrow mehrfach bei der zuständigen Naturschutzbehörde (LUNG, später UNB) Anträge, um genauso verfahren zu dürfen. Bürger wiesen uns darauf hin, dass die Saatkrähen doch die schönen Platanen, in denen die Krähen ihre Nester errichteten, nachhaltig schädigen würden, weil sie immer wieder die frischen Zweige an den Baumspitzen für den Nestbau abbrächen. Es ist schon interessant, was Leute alles vortragen, um etwas erreichen zu können. Auch Jahrzehnte zuvor hatten die Saatkrähen sich schon jedes Jahr an den Platanen zu schaffen gemacht, und den Bäumen hatte es bisher offenbar nicht geschadet. Natürlich sind die „Nebenwirkungen“ unter den Brutbäumen nicht zu leugnen. Hier gehen Parkplätze verloren, oder man nimmt es in Kauf, dass der Krähenkot auf den Autodächern landet. Leider beginnen die Saatkrähen sehr früh mit der Brut, da haben die Platanen noch kein schützendes Laubdach, das ist dann aber spätestens zum Jungenschlupf vorhanden.

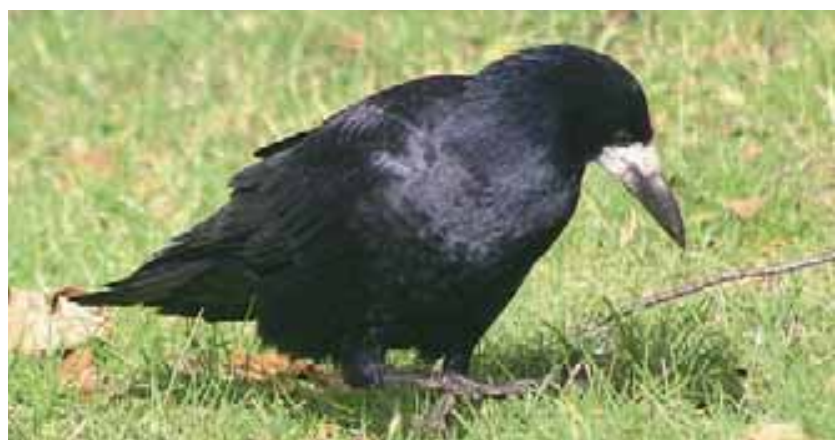

Abb. 234: Adulte Saatkrähen sind an dem markanten weißen Grind an der Schnabelwurzel zu erkennen. Foto: F. Loose.

Wolfgang Neubauer hatte zur Erstellung der Kreisavifauna intensiv recherchiert und alte Literatur ausgewertet. Für die Saatkrähe sind aus den 1930er Jahren Kolonien von nachfolgenden Orten überliefert: bei Kobrow (Blocksberg), Breesen (Parper Tannen), Koppelow (Nebelwaldungen), Krakow am See (Wadehängsche Tannen), Liessow (Sandkruger Tannen), Mamerow (Schützenkopf), Striggow (Fuchsberg) - zusammen max. 1.400 BP.

Anfang der 1950er Jahre erfolgte eine Erfassung durch Mitarbeiter des Pflanzenschutzdienstes. Für die Orte Breesen, Boldebuck, Bülower Burg (Brunnen), Kobrow, Liessow, Neu Mistorf, Oldenstorf und Weitendorf (Friedhof) wird eine Zahl von ca. 2.990 BP genannt. Es wird vermutet, dass die damaligen Erfasser möglicherweise die BP-Zahlen hier etwas höher angesetzt haben, da diese als Grundlage für eine nachfolgende Bekämpfungsaktion dienen sollten.

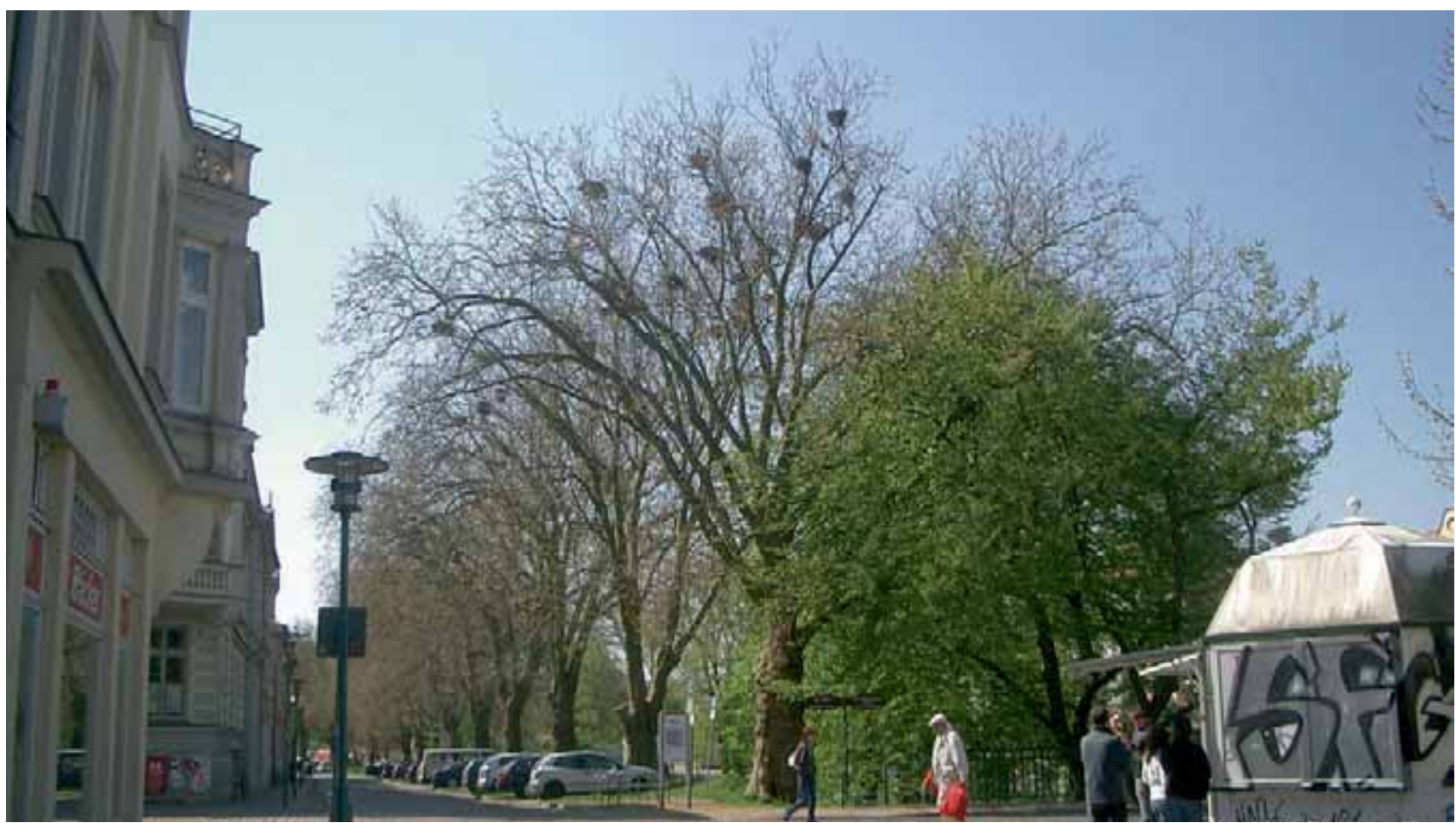

Abb. 235: Brutkolonie am Wall in Güstrow mit Parkplätzen unter den Bäumen. Foto: f. Loose 
Ehemalige Kolonien von Saatkrähen befanden sich in Klaber, Rothspalk, Gülzow, Kobrow und Liessow, die zwischen 1956 und 1971 erloschen. Die kurzzeitig mit bis zu 105 BP in Spotendorf besetzte Brutkolonie wurde 1977 aufgegeben. Eine Brutkolonie im Park von Weitendorf existierte von 1986 bis 2002. Die Saatkrähen zogen in die beiden Städte Güstrow und Laage um. Hier brüten auch aktuell die Saatkrähen, in Güstrow in drei (bis fünf) und in Laage in zwei Teilkolonien im Stadtgebiet verteilt. Im Jahr 2004 gab es ergänzend 30 besetzte Nester am Gutshaus in Kronskamp. 2015 hat sich eine kleine neue Kolonie in Lüssow etabliert.

Durch die Mitglieder der FG wurden bereits sehr früh die Nester der Saatkrähen gezählt. Bestandszahlen für den Altkreis Güstrow waren mit größeren Abständen durch verschiedene FG-Mitglieder in den Jahresberichten aufgelistet worden: für 1975 (335 BP) und 1976 (487 BP) durch M. Böhlke, L. Daubner, A. Hertkorn, R. Otto und I. Schult, für 1982 durch J. Czech und K. Lingsminat. Angaben aus einzelnen Jahren gingen auch in die Rubrik der bemerkenswerten Beobachtungen in die Jahresberichte ein. Über längere Zeitabschnitte wurden die Brutpaarzahlen aller Kolonien in den Jahresberichten Nr. 30/1997 durch J. Loose (1971-1997) und Nr. 39/2006 durch R. Wiechert (1986-2006) aufgelistet. Seit 2001 sind die Zählergebnisse generell in den Jahresberichten bei den Beobachtungen genannt worden.

Bei der Erfassung der Brutpaarzahlen in Güstrow haben sich in den vergangenen Jahren hauptsächlich K. Lingsminat, J. Loose, R. Schaugstat und R. Wiechert beteiligt. Ergänzende Angaben lieferten M. Polzin (ehem. Fritsche) und F. Vökler. Die Zählungen in Laage wurden durch E. Schlüter durchgeführt. Gezählt wurde in der Regel Ende April. Bei auseinanderliegenden Zählterminen verschiedener Zähler waren mitunter erhebliche Differenzen in der Brutpaarzahl festzustellen. Oftmals lag das daran, dass bei vielem Nestmaterialeintrag und dicht nebeneinander gebauten Nestern die wirkliche Nesterzahl schwer zu ermitteln war.

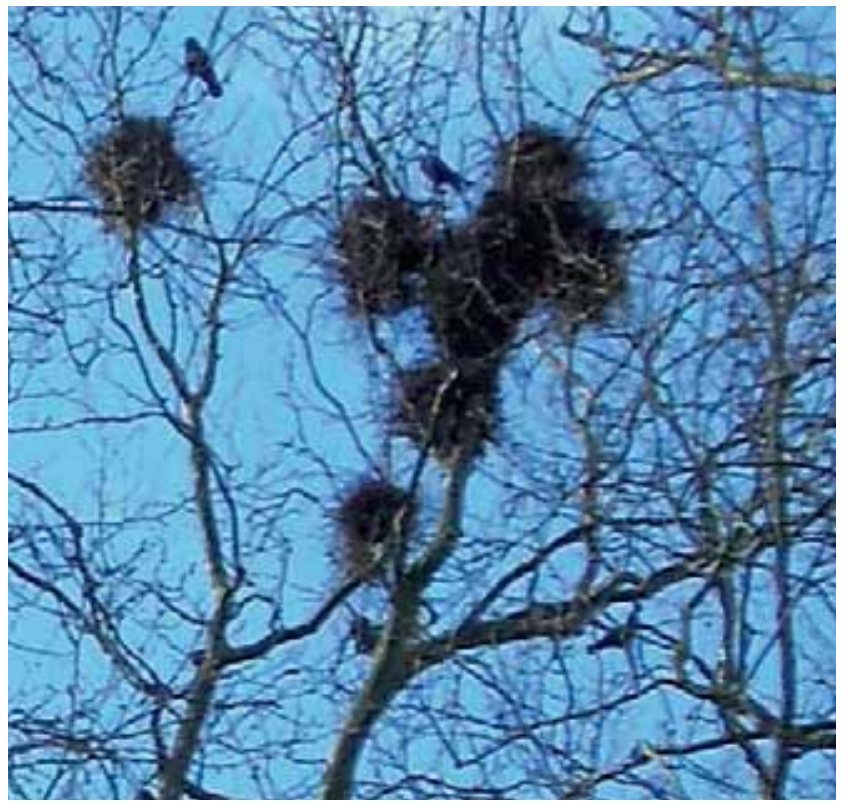

Abb. 236: Bei dicht an dicht gebauten Nestern ist es vom Boden aus schwer, eine tatsächliche Nest-/Brutpaarzahl festzustellen.

Foto: f. Loose.

Bei Erfassungen bereits im ersten Drittel des Monats April lag die Zahl der Nester/Brutpaare oft auch deshalb niedriger, weil die Krähen noch voll in der Bauphase waren. Mitunter fielen auch frische Nester den Frühjahrsstürmen zum Opfer.

Durchgehende Zahlenreihen für die Brutkolonien der Saatkrähen liegen mit einigen Lücken ab 1981 vor.

Es ist erkennbar, dass ab Mitte der 1980er Jahre der Gesamtbrutbestand im Altkreis Güstrow trotz einiger Erfassungslücken (oder Bestandsschwankungen) zugenommen hat.

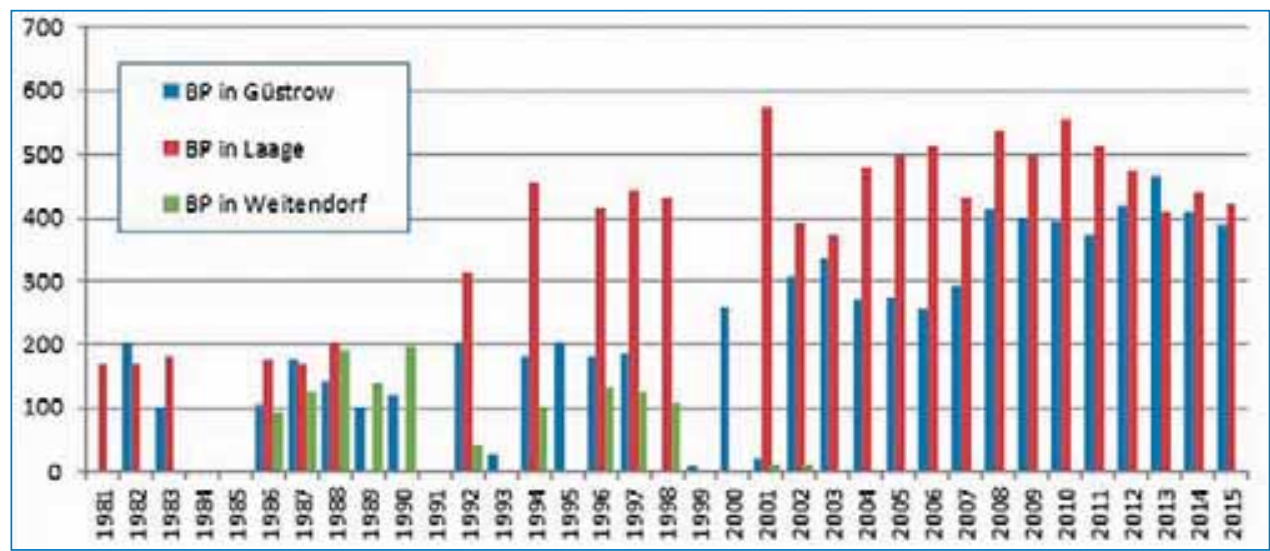

Diagramm 27:

Bestandszahlen in den einzelnen Saatkrähenbrutkolonien 


\section{Saatkrăhen - BP im Altkreis Güstrow gesamt}

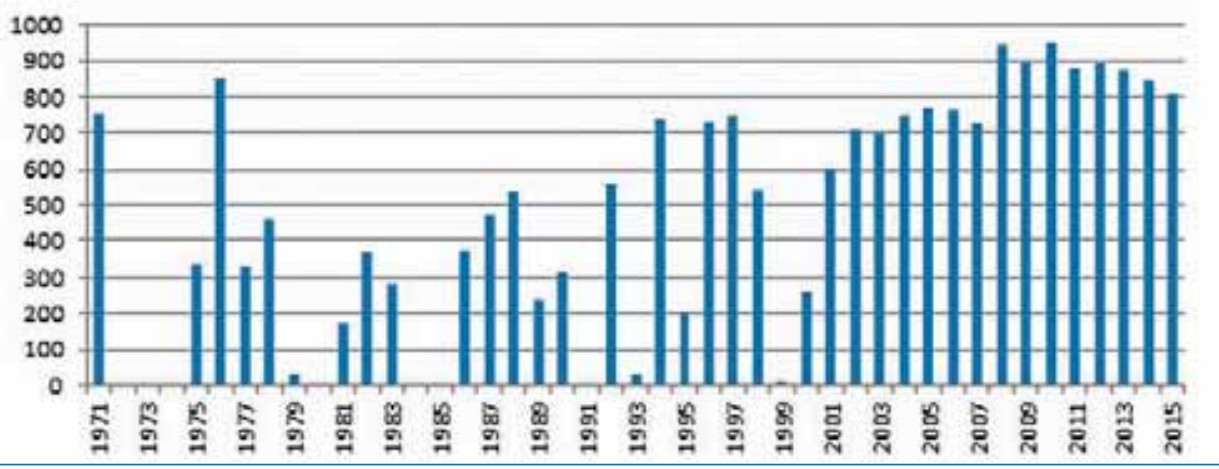

Diagramm 28:

Der Gesamtbrutbestand

an Saatkrähen im Altkreis

Güstrow nahm zunächst ab

Mitte der 1980er Fahre zu und

sank in den letzten fünf Jahren um ca. $3 \%$.

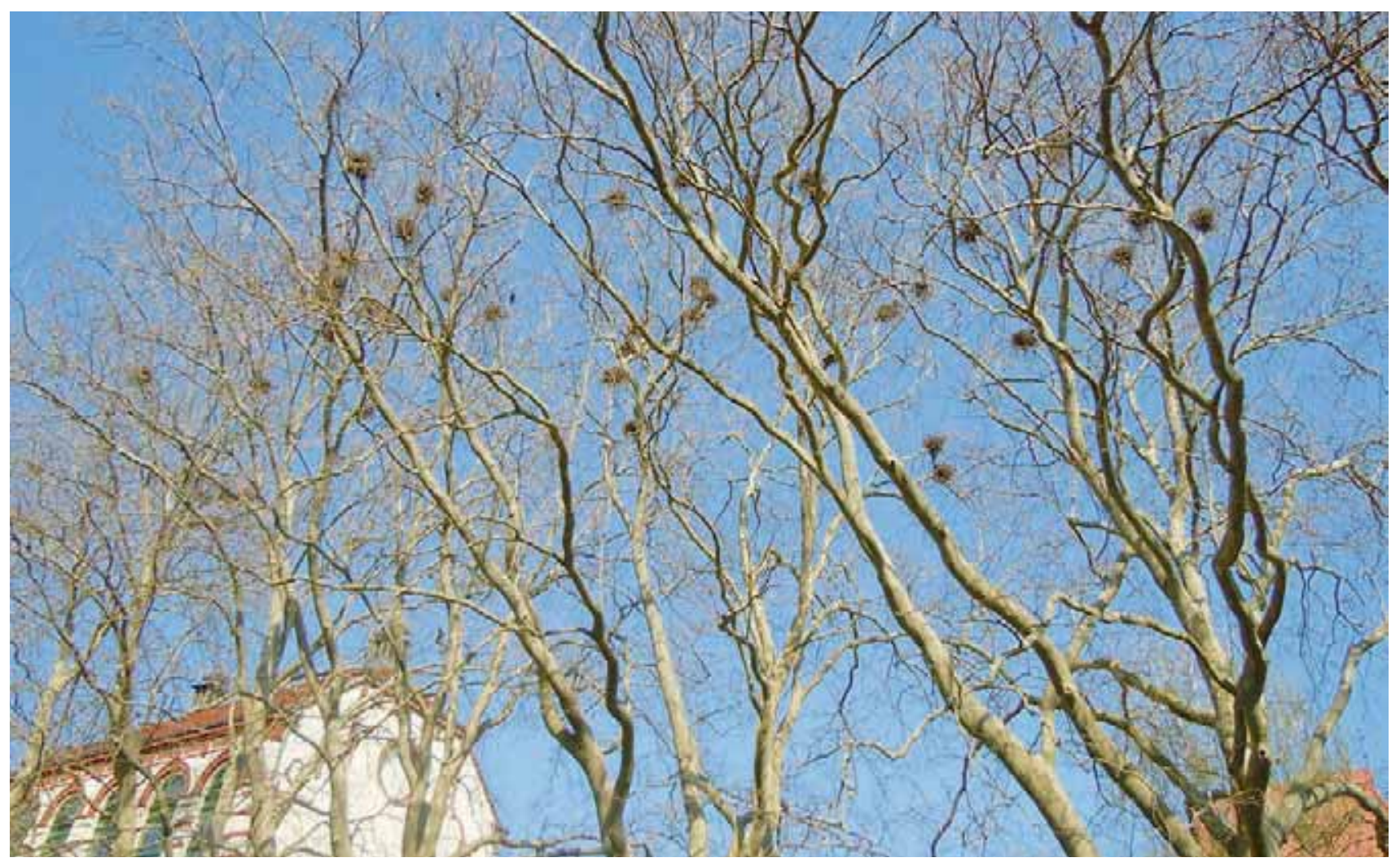

Abb. 237: Lockere Brutkolonie in den Platanen beim Gymnasium am Wall in Güstrow - April 2015. Foto: F. Loose.

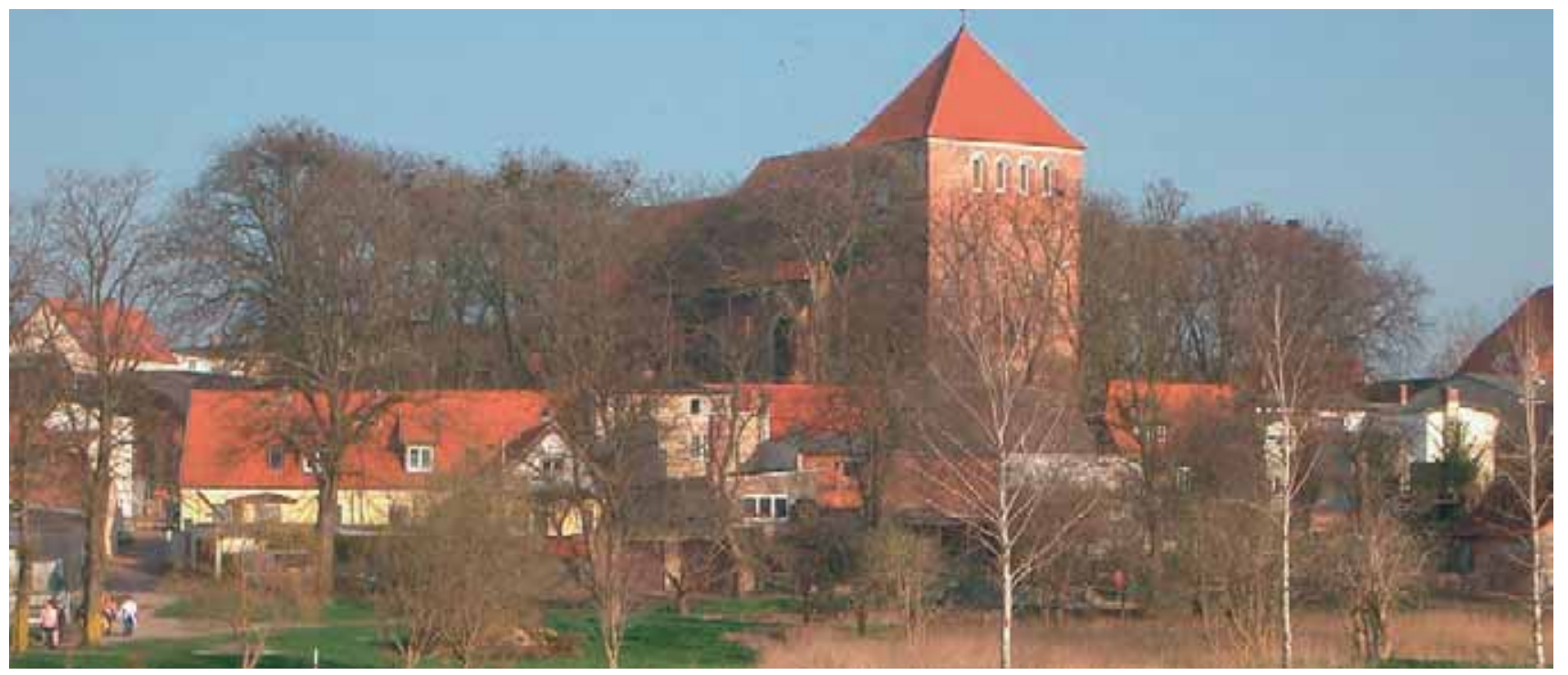

Abb. 238: Brutkolonie in den Linden an der Kirche in Laage - April 2013. Foto: 7. Loose. 


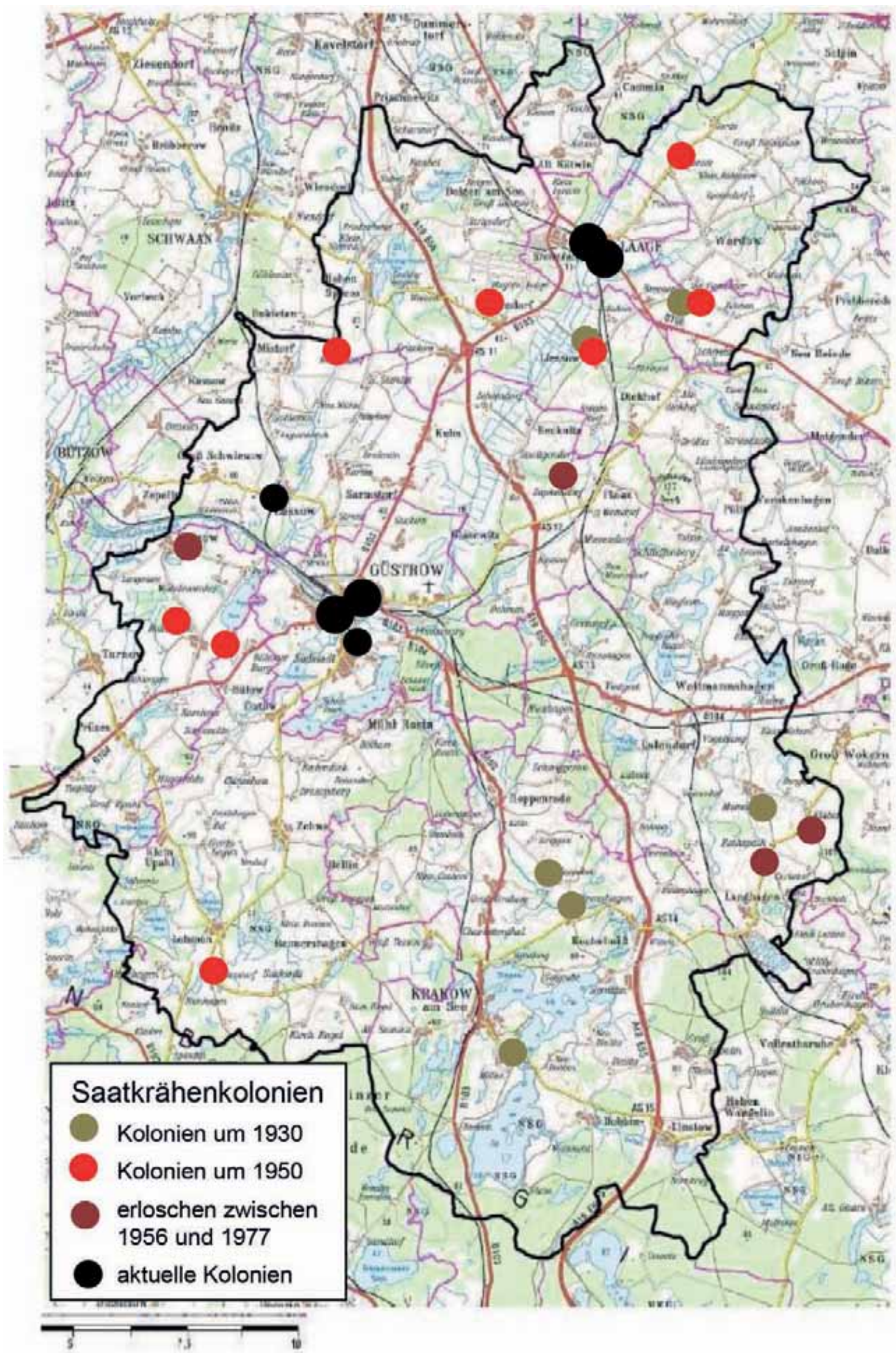

Karte 18: Verteilung der historischen und aktuellen Saatkrähenkolonien im Altkreis Güstrow 


\subsection{Was wir sonst noch zusammengetragen haben}

\subsubsection{Fische, Lurche und Kriechtiere}

\section{Guntram Trost}

Fische - Die Gruppe der hier behandelten Fische bildet keine natürliche Einheit, es ist keine Verwandtschaftsgruppe. Morphologisch ähnliche Wassertiere sind zusammengefasst worden. Auch die Neunaugen werden an dieser Stelle mit aufgeführt.

In der Fachgruppe Ornithologie und Naturschutz Güstrow ist man auch mit der Ichthyologie (Fischkunde) befasst. In den Jahresberichten der FG Nr. 25/1992 und 28/1995 findet man Berichte zur Fischfauna unseres Altkreises.

In der Zeit von 1992 bis 2008 wurden einige Gewässer des Territoriums beprobt. Dabei kamen mehrere Fangmethoden zum Einsatz wie z.B. Elektrofischerei, Fallenund Netzfang, Tätowierungen oder Sichtbeobachtungen (Erfassen der Laichplätze).

Initiiert wurde das Ganze durch eine kleine Fischart. Beim Waten durch Bäche und an Seeufern konnten 1991 mehrmals Schmerlen mit Aquariumskescher gefangen werden, so beispielsweise im Inselsee und Gardener See, in Nebel, Teuchelbach, Korleputer und Lüssower Mühlbach, Lößnitz und im Augraben. Für Mecklenburg-Vorpommern waren bis dahin nur wenige Vorkommen bekannt, so dass eine Verdoppelung der Nachweisorte stattfand. Wie sich später herausstellte, hatte das aber nur mit dem damaligen Erfassungsstand zu tun. Dieser Fisch ist in unserem Bundesland weit verbreitet.

Wie überall in Europa sind strukturreiche, naturnahe Gewässer wesentlich arten- und individuenreicher als begradigte, degradierte Gräben. So konnten 1992 im Pludderbach nur 18 Fische in zwei Arten (Drei- und Neunstachliger Stichling) und in der Polchow 40 Exemplare in 4 Arten (neben den beiden Stichlingsarten noch Hecht und Bachneunauge) nachgewiesen werden. In der Bresenitz waren es dagegen 12 Fischarten mit insgesamt 330 Individuen. Über die Jahre von 1992 bis 1994 wurde die Nebel intensiv befischt. Dazu lag ein Auftrag des Bundesministeriums für Forschung und Technologie vor. Auch in besonders geschützte Bereiche des Naturschutzgebietes gab es dadurch einen erlaubten Zugang. Im Wasser der Nebel konnten 32 Fischarten belegt werden, darunter allerdings auch die allochthonen (gebietsfremden) Arten: Karpfen, Regenbogenforelle und Äsche.

Die Äsche, in mehreren Fließgewässern Mecklenburgs und Vorpommerns ausgesetzt, hatte sich nur in der Nebel zwischen Güstrow und Krakow erwähnenswert etabliert. Gute Bedingungen in der Nebel findet auch die Elritze. Dieses selten über $10 \mathrm{~cm}$ groß werdende Fischchen hat hier das stärkste Vorkommen in M-V. Nach Rückgang der Meerforellenlaichplätze im Bundesland (Tiefstand Mitte 1980er Jahre) konnten ab 1995 durch ein Fachgruppemitglied Laichgruben und Tiere im Nebelzufluss Lüssower Mühlbach nachgewiesen werden. Diese Gruben befanden sich im Mündungsbereich und in der Ortslage Lüssow.

In der Steinbek, einem Nebenbächchen des Teuchelbachs, konnten 1995 auf etwa 100 Meter Fangstrecke 41 Bachneunaugen gefangen werden. Beachtenswert ist auch der Nachweis von über 20 jungen Bachforellen. War doch diese Art etwa 1975 (nach einem „Chemieunfall“?) im Teuchelbachsystem total verschwunden. Einwanderungen aus der $\mathrm{Ne}$ bel in den Teuchelbach konnten wegen der Querverbauung bei Kirch Rosin nicht stattfinden. Also muss die Bachforelle über 20 Jahre übersehen worden sein.

Eine historische Erfassung der Fischfauna durch Befragung von Fischern, die zwischen 1983 bis 1985 im Auftrag von Prof. Dr. sc. nat. H. Bremer von Studenten durchgeführt wurde, ist wissenschaftlich leider nicht brauchbar.

Als Mitglied der Fachgruppe Güstrow bin ich Artbearbeiter für die Fischarten Schlei, Karausche, Giebel, Flussbarsch und Kaulbarsch im „Verbreitungsatlas der Fische, Rundmäuler, Großmuscheln und Großkrebse in MecklenburgVorpommern“ sowie Mitarbeiter für die Einführungstexte.

Für das Gebiet der Fachgruppe Güstrow sind folgende Arten nachgewiesen: (gebietsfremde [all-ochthone] Arten kursiv)

Tabelle 9: Im Altkreisgebiet registrierte Fischarten

\begin{tabular}{|c|c|c|}
\hline Neunaugen & 1 Flussneunauge & 2 Bachneunauge \\
\hline Aale & 3 Aal & \\
\hline Karpfenfische & $\begin{array}{l}4 \text { Döbel } \\
5 \text { Aland } \\
6 \text { Rotfeder } \\
7 \text { Plötz } \\
8 \text { Elritze } \\
9 \text { Moderlieschen } \\
10 \text { Ukelei }\end{array}$ & $\begin{array}{l}11 \text { Blei } \\
12 \text { Güster } \\
13 \text { Schleie } \\
14 \text { Gründling } \\
15 \text { Bitterling } \\
16 \text { Karpfen } \\
17 \text { Karausche } \\
18 \text { Giebel } \\
19 \text { Graskarpfen }\end{array}$ \\
\hline Dorngrundeln & 20 Steinbeißer & 21 Schlammpeitzger \\
\hline Bachschmerlen & २2 Schmerle & \\
\hline Echte Welse & 23 Wels & \\
\hline $\begin{array}{l}\text { Amerikanische } \\
\text { Zwergwelse }\end{array}$ & 24 Zwergwels & \\
\hline Hechte & 25 Hecht & \\
\hline Lachsfische & $\begin{array}{l}26 \text { Forelle } \\
\text { a - Meerforelle } \\
\text { b-Bachforelle }\end{array}$ & $\begin{array}{l}27 \text { Kleine Maräne } \\
28 \text { Äsche } \\
29 \text { Regenbogen- } \\
\quad \text { forelle }\end{array}$ \\
\hline Schellfische & 30 Quappe & \\
\hline Stichlinge & 31 Dreist. Stichling & 32 Neunst. Stichling \\
\hline Echte Barsche & $\begin{array}{l}33 \text { Flußbarsch } \\
34 \text { Zander }\end{array}$ & 35 Kaulbarsch \\
\hline
\end{tabular}


Lurche - Initiiert von Kurt Polmann und fortgeführt durch Angela Martin wurden die Beobachtungen von Lurchen und Kriechtieren über viele Jahre in Karteikarten eingetragen. Die Daten waren jedoch kein Ergebnis systematischer Erfassungen, sondern sporadischer Beobachtungen. Das ist bei der Datenerhebung dieser Tiergruppen bis heute so geblieben. Es ist also nicht mit einem flächendeckenden Kenntnisstand zu rechnen. Alle Daten befinden sich inzwischen in einer landesweiten Datei und bilden so eine wichtige Quelle für die gegenwärtige Erarbeitung eines Verbreitungsatlasses der Lurche und Kriechtiere im Lande Mecklenburg-Vorpommern.

In der folgenden Tabelle 10 wird gezeigt, in wievielen der 37 MTB/Q des Altkreises Güstrow die einzelnen einheimische Lurche bisher nachgewiesen wurden:

Tabelle 10: Lurchart gefunden in Anzahl von MTBQuadranten des Altkreises

\begin{tabular}{lr|lr}
\hline Kammmolch & 21 & Rotbauchunke & 35 \\
\hline Teichmolch & 13 & Laubfrosch & 30 \\
\hline Knoblauchkröte & 21 & Grasfrosch & 30 \\
\hline Erdkröte & 34 & Moorfrosch & 33 \\
\hline Kreuzkröte & 2 & Teichfrosch & 37 \\
\hline Wechselkröte & 10 & Springfrosch & 1 \\
\hline
\end{tabular}

Über die Häufigkeit der Individuen liegen dabei keine Zahlen vor. Im Quadrant mit dem Nachweis des Springfrosches wurde nur ein Tier dieser Art gefunden. Die Art ist in unserem Bereich äußert selten zu beobachten. Ein Nachweis liegt aus dem Jahre 1930 aus dem Umfeld von Schlieffenberg vor. Eine Beobachtung des Springfrosches im Jahre 2008 in der Nähe von Liessow wurde bisher nicht bestätigt. In der Universität Rostock existiert ein historisches Präparat des Springfrosches mit der Ortsangabe „Wald bei Nienhagen“. Da der Ortsname Nienhagen in Mecklenburg mehrmals vorkommt, war eine Zuordnung nicht möglich. Am 13.06. 2011 konnte dann von einem Fachgruppenmitglied ein Springfrosch in einem Wald bei „unserem“ Nienhagen festgestellt werden. Damit kann das UniPräparat mit hoher Wahrscheinlichkeit örtlich zugeordnet werden - der Fundort liegt im Naturwaldreservat Scheefgrund (Neukloster-Teterower-Hügelmoränenbogen) an der Ostgrenze des Altkreises Güstrow.

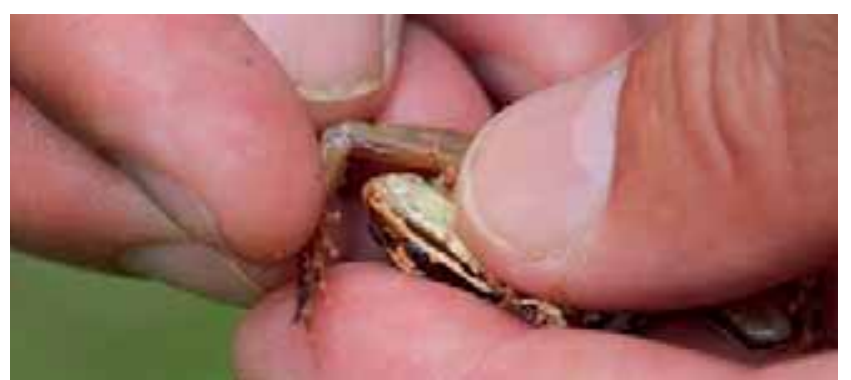

Abb. 239: Der Fersentest zeigt, dass es sich um einen Springfrosch handelt - die Ferse ragt über die Schnauzenspitze.

Foto: B. Meder-Trost.

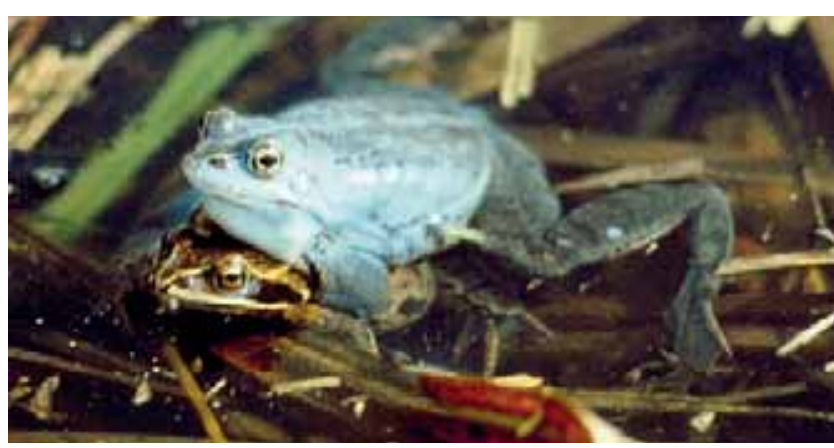

Abb. 240: Moorfrosch-Männchen sind im zeitigen Frühjahr zur Paarungszeit himmelblau. Foto: W. Neubauer.

In der FG-Kartei sind in allen MTB/Q Sichtbeobachtungen des Teichfrosches dokumentiert. Der Teichfrosch ist keine Art im klassischen Sinne, sondern ein Hybride zwischen dem Seefrosch und dem Kleinen Wasserfrosch. Dieser taxonomische Komplex ist schwer überschaubar. Hier ist eine Überprüfung zum Vorkommen vom Kleinen Wasserfrosch und vom Seefrosch notwendig.

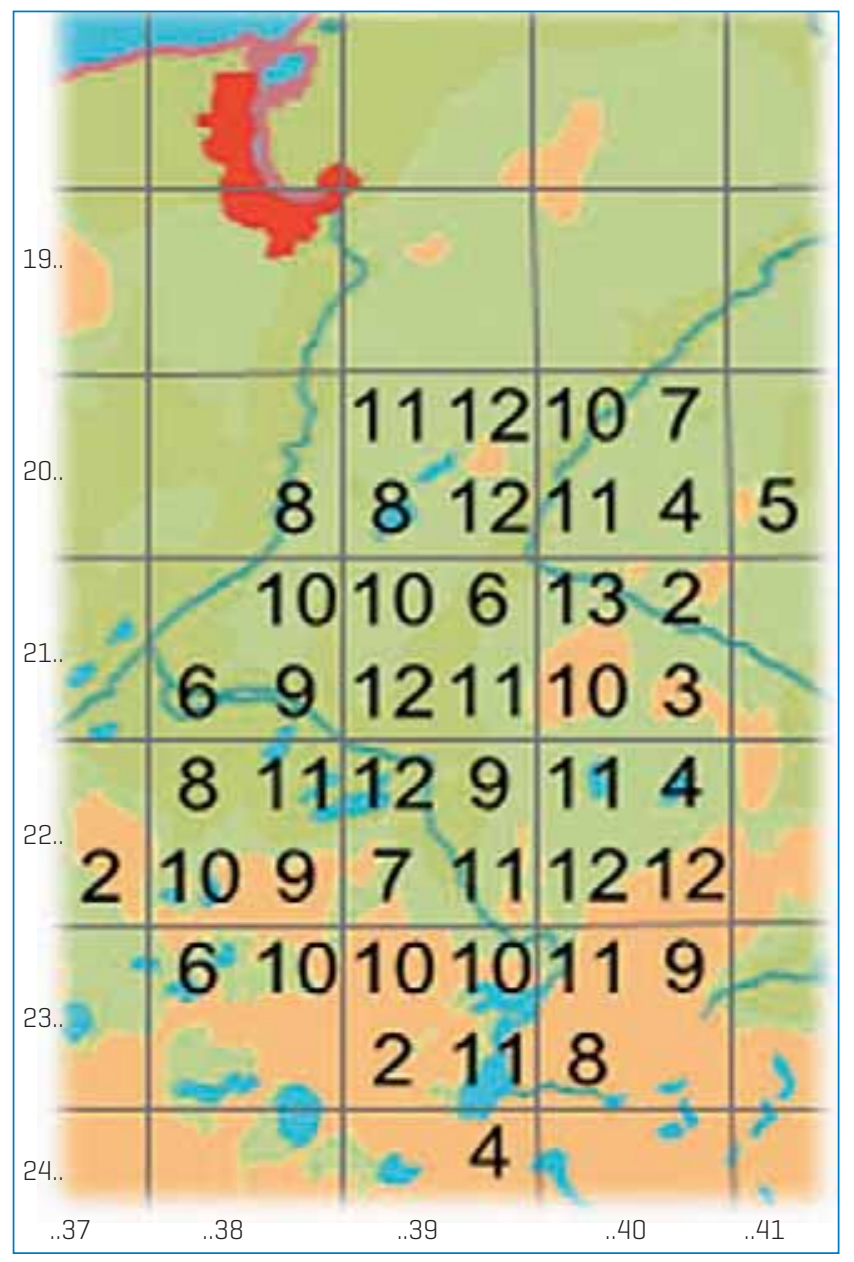

Karte 19: Notierte Artenhäufigkeit der Lurche je MTB/Q 
Kriechtiere - Intensive Untersuchungen zur Reptilienfauna im Altkreis Güstrow gibt es keine. Daten wurden von der Fachgruppe aber immer „nebenbei“ gesammelt. Alle Arten dieser Gruppe haben in ihrem Bestand abgenommen und benötigen Schutz. Nach heutigem Stand weisen Ringelnatter, Blindschleiche und Waldeidechse noch eine größere Verbreitung in geeigneten Habitaten auf. Auch Zauneidechsen werden noch regelmäßig, oft an Bahndämmen, festgestellt. Außerdem zählen noch Kreuzotter, Schlingnatter und Sumpfschildkröte zu den heimischen Arten, auf die nachfolgend eingegangen wird.

In einem Buch über Kirch Rosin beschweren sich die Kinder in den 1920er Jahren über das Anlegen eines Torfstiches an der Nebel. Ihre Angst bestand darin, keine Kreuzottern mehr für den Apotheker in Güstrow fangen zu können. Noch in den 1960er Jahren war die Art nicht selten - im Göldenitzer Moor wurde professionell das „Schlangenmelken“ zur Serumherstellung durchgeführt. Durch Lebensraumverlust und Nachstellung (Totschlagen) ist der Bestand stark zurückgegangen. In M-V gilt die Art als „stark gefährdet“. In der Datenbank der Fachgruppe ist kein aktueller Fundort für den Raum Güstrow zu finden. Aus dem Bereich des Krakower Sees liegen jedoch ernstzunehmende Hinweise vor, denen allerdings noch nachgegangen werden muss.

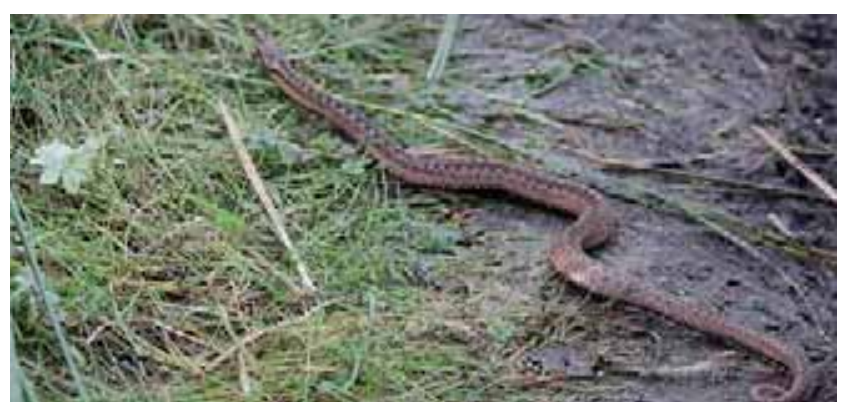

Abb. 241: Am Nothafen Darßerort kroch diese weibliche Kreuzotter vor die Kamera. Foto: B. Meder-Trost.

Die Schlingnatter - auch Glattnatter genannt - ist ein sehr heimliches Tier, das schwer nachzuweisen ist. In Deutschland ist sie die häufigste Schlange, in $\mathrm{M}-\mathrm{V}$ gilt die Art als „vom Aussterben bedroht“. In unserem Umfeld gibt es seit 1929 keine Hinweise mehr auf diese Schlange.

Bei ERhardT, A. (1933) ist dazu zu lesen: „Außerdem teilte mir Graf von Schlieffen mit, er habe die Schlingnatter seit langer Zeit (zuletzt 1929) häufig in einem Walde am kleinen Wendorfer Gardener See ${ }^{*}$ ) wischen Schlieffenberg und Wendorf beobachtet. Hoffentlich werden hier bald Belegexemplare gefangen. “*)

Die Sumpfschildkröte war im Mittelalter in unserem Raum noch häufiges Nahrungsmittel zur Fastenzeit. Hauptsächlich die menschlichen Eingriffe ab den 1950er Jahren

* gemeint war der Garner See haben großen Einfluss auf den Bestand der Schildkröte genommen. Ihr Lebensraum wurde durch Trockenlegung von Sümpfen und Feuchtgebieten, Gewässerbegradigungen, Zersiedelung der Landschaft und Ausbau des Straßennetzes mit erhöhtem Verkehrsaufkommen eingeschränkt und die Eiablageplätze zerstört. Früher hatten ausgewachsene Sumpfschildkröten keine Fressfeinde, heute sind Waschbären eine große Bedrohung der letzten deutschen Bestände in $\mathrm{M}-\mathrm{V}$ und Brandenburg. In $\mathrm{M}-\mathrm{V}$ gilt die Art als „vom Aussterben bedroht“. Im Bereich Güstrow werden einzelne Tiere ab und an, aber sehr selten, nachgewiesen, so beispielsweise an den Torfstichen bei Klueß, einem größeren Soll bei Neu Mierendorf und am Grundlosen See. Historische Vorkommen gab es auch um Güstrow, bei Laage, Krakow am See, Koppelow und Schlieffenberg.

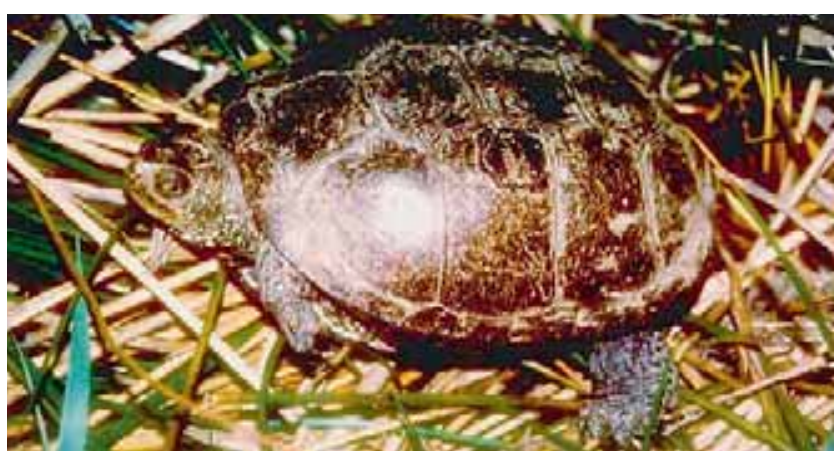

Abb. 242: Diese Sumpfschildkröte wurde im fahre 2009 im Grundlosen See gefangen und wieder ausgesetzt. Foto: R. Wiechert.

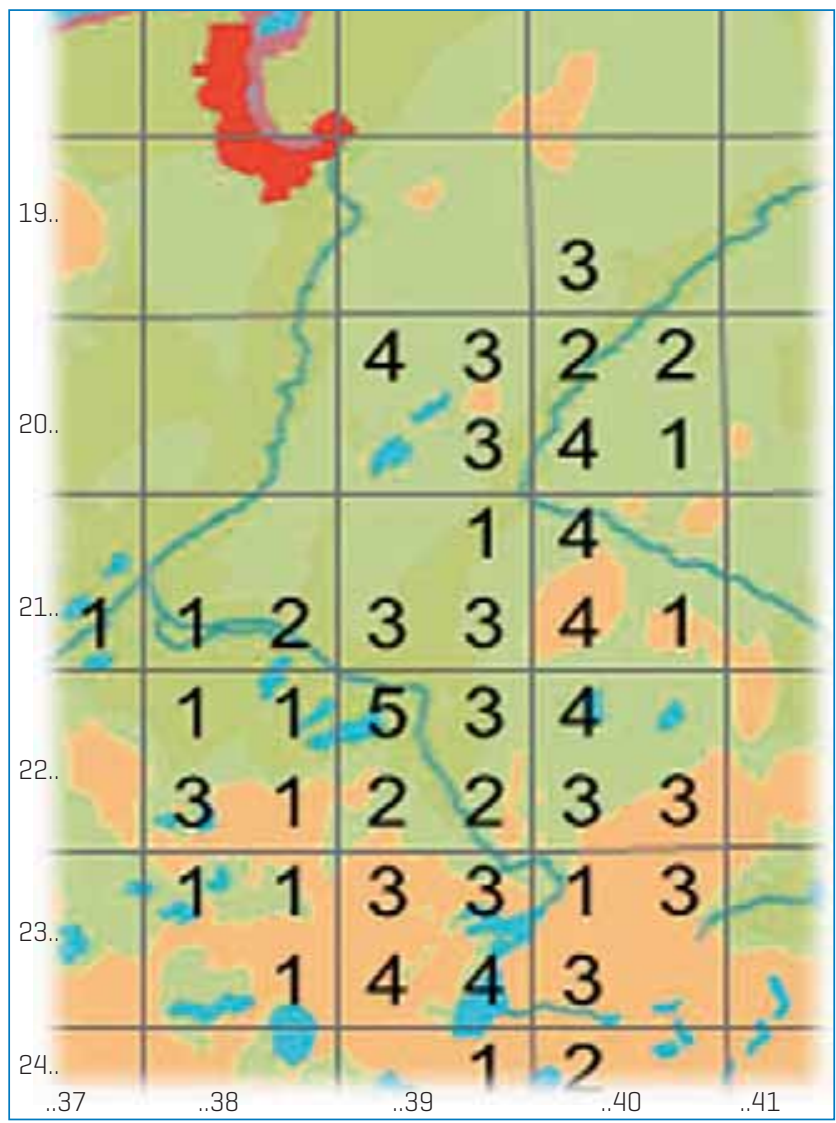

Karte 20: Notierte Artenhäufigkeit der Kriechtiere je MTB/Q 

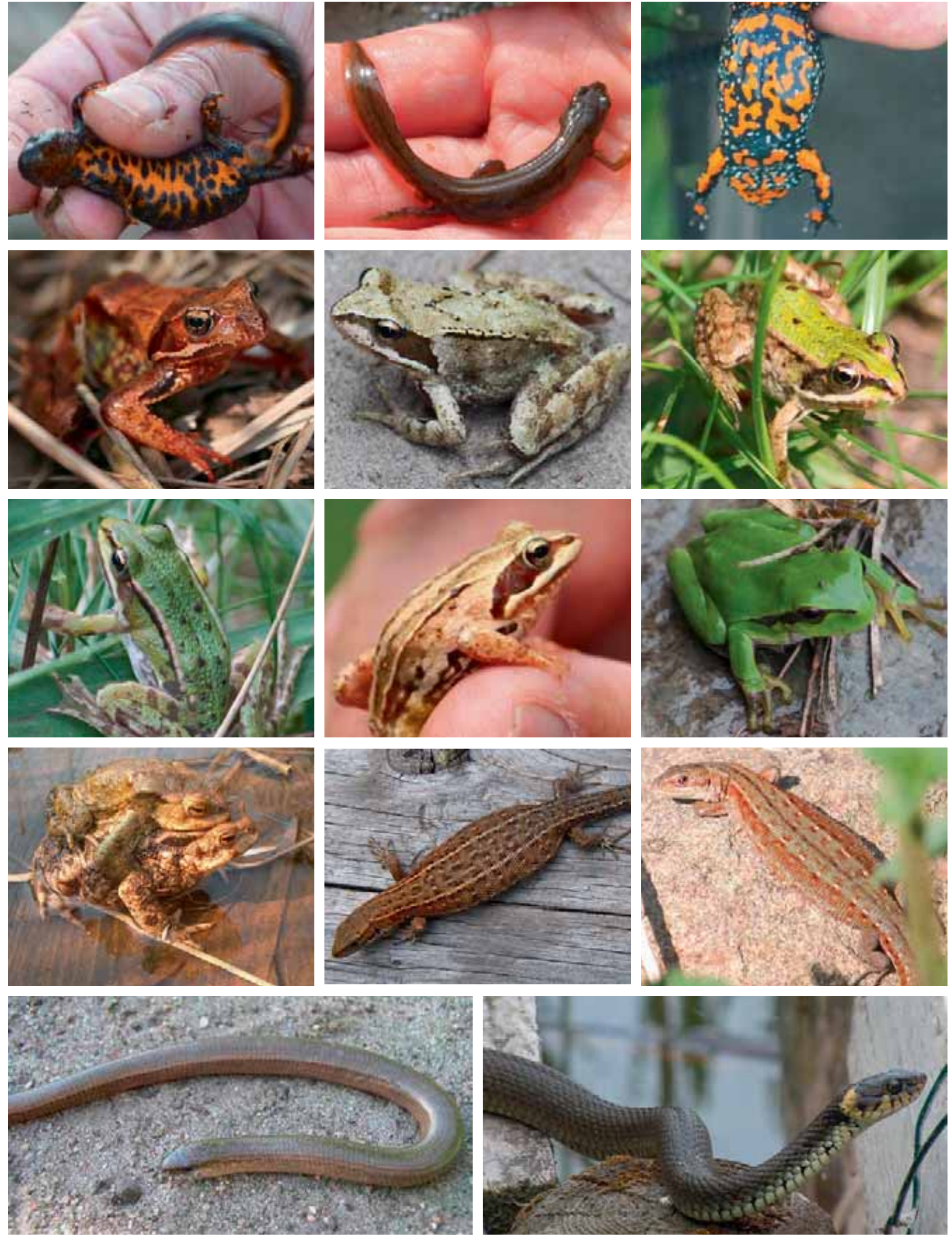

Abb. 243 bis 256: Kammmolch, Teichmolch, Rotbauchunke, Moorfrosch, Grasfrosch, Teichfrosch, Kleiner Wasserfrosch, Springfrosch, Laubfrosch, Erdkröte, Waldeidechse, Zauneidechse, Blindschleiche, Ringelnatter (v.l.n.r. und v. o.n. u.). Fotos: B. Meder-Trost. (Abb. 246, 252, 253 und 256 Foto: Loose) 


\subsubsection{Säugetiere}

\section{Wolfgang Köhler}

Die Säugetiere standen leider nie im Focus unserer Beobachtungstätigkeit. Eine systematische Erfassung und Beobachtung erfolgte daher nicht. Zusammen mit Dr. Ralf Labes $(\dagger)$ habe ich trotzdem 1984 versucht, die Kenntnisse zu diesem Zeitpunkt zusammenzufassen. Unsere Daten stammten insbesondere aus Gewöllanalysen, aus Sichtbeobachtungen und Jagdunterlagen. Im Ergebnis konnten 36 Säugetierarten (ohne Paarhufer) für unser Gebiet nachgewiesen werden (LABES, R. u. W. KöHLER, 1984).

Bemerkenswert war damals die erste Feststellung eines Waschbären. Ein männliches Exemplar wurde am 1.11.1976 tot an einem Elektrozaun bei Güstrow gefunden. Weitere Nachweise wurden bis 1984 nicht getätigt. Heute ist diese Art allgegenwärtig.

Inzwischen ist auch der Marderhund in unseren Kreis eingewandert und wird bei den Jagden häufig erlegt.

Glücklicherweise hat sich die Befürchtung aus dem Jahre 1984 nicht bestätigt, dass mit dem Verschwinden des Fischotters in naher Zukunft zu rechnen sein wird. Die Otterbestände haben sich auf Grund umfangreicher Schutzmaßnahmen und einer verbesserten Wasserqualität deutlich erhöht. Gegenwärtig kann an allen größeren Seen und an allen Fließgewässern mit seinem Auftreten gerechnet werden. Insbesondere die Untersuchungen im Naturpark Nossentiner/Schwinzer Heide haben viele neue Erkenntnisse zur Biologie dieser Art erbracht.

Als weitere Art hat sich inzwischen der Biber bei uns angesiedelt. Seine typischen Nagespuren können nicht nur entlang der Nebel, sondern auch an vielen anderen Stellen entdeckt werden. 1984 galt er noch als vom Aussterben bedroht.

Seitdem Ende der 1990er Jahre erste Wolfsnachweise in Sachsen bestätigt wurden, hat sich der Grauhund kontinuierlich weiter ausgebreitet und wird auch gelegentlich bei uns gespürt. Eine Ansiedlung im Kreis erfolgte allerdings noch nicht.

Bemerkenswert sind die Feststellungen der Siebenschläfervorkommen. Galt die Art in den 1980er Jahren noch als recht selten, können wir heute feststellen, dass Siebenschläfer in allen größeren Buchenwäldern vorkommen. Insbesondere die Arbeit mit Fledermauskästen hat zu Kenntnissen seiner Verbreitung wesentlich beigetragen.

Am Schluss der damaligen Arbeit wurde vermerkt: „Die Fledermausfauna bedarf einer weiteren Erforschung “.

Um dieser Forderung gerecht zu werden, habe ich Kastenreviere in den Revieren Wilsen, Schwaan, Oettelin und Tarnow sowie in einigen anderen Waldgebieten installiert und jahrelang kontrolliert. Des weiteren wurden von mir

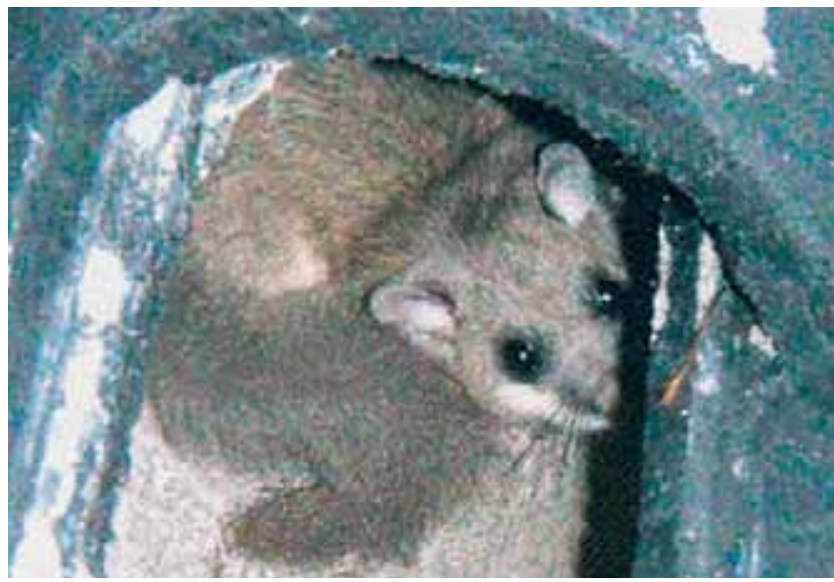

Abb. 257: Siebenschläfer in einem Holzbetonkasten. Foto: W. Köhler

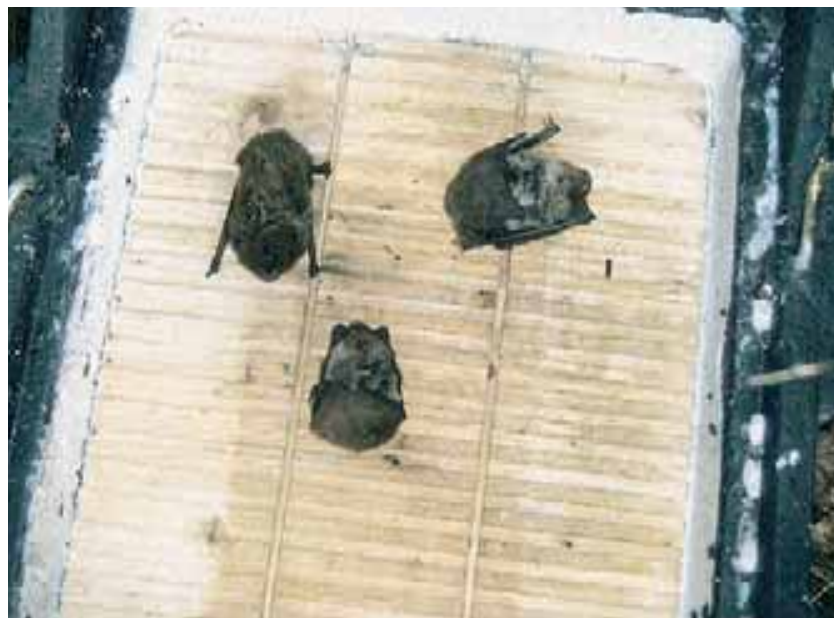

Abb. 258: Fledermäuse in einem geöffneten Spaltenkasten. Foto: W. Köhler

Winterquartiere, soweit sie bekannt waren, in den Monaten Dezember, Januar und Februar kontrolliert. In einigen Fällen mussten sie erst entdeckt oder hergerichtet werden.

Anfang der 1990er Jahre hatte sich Jörg Bußmann von unserer Fachgruppe im Rahmen von ABM-Projekten und auch ehrenamtlich fast 10 Jahre lang mit der Erkundung von Fledermauswinterquartieren und deren Optimierung beschäftigt. Insbesondere die Herrichtung der alten Eiskeller in Carlsdorf, Bülow, Groß Grabow, Lalendorf, Großen und Kleinen Luckow sind seiner Initiative zu verdanken. (vgl. dazu auch Pkt. 10.7) Es gibt allerdings noch einige weitere Eiskeller, die als Winterquartier gestaltet werden müssten.

Diese und auch eine ganze Anzahl weiterer Quartiere wurden von Jörg Bußmann, Ralf Koch und mir in einigen Jahren wiederholt aufgesucht und die Ergebnisse in die zentrale Fledermauskartei des Landes eingegeben.

Nachfolgend werden einige Kontrollergebnisse von ausgewählten Winterquartieren aufgeführt: 
Eiskeller Bülow

\begin{tabular}{l|c|c|c|c|c|c|c}
\hline Jahr & $\begin{array}{c}\text { Wasserfleder- } \\
\text { maus }\end{array}$ & $\begin{array}{c}\text { Fransenfleder- } \\
\text { maus }\end{array}$ & Braunes Langohr & Mausohr & $\begin{array}{c}\text { Zwergfleder- } \\
\text { maus }\end{array}$ & Art unbestimmt & Gesamtzahl \\
\hline $\mathbf{2 0 0 4}$ & 5 & 2 & 1 & & & \\
\hline $\mathbf{2 0 0 5}$ & 2 & 10 & 2 & 5 & & & \\
\hline $\mathbf{2 0 0 6}$ & 3 & 12 & 6 & & & 2 \\
\hline $\mathbf{2 0 0 7}$ & 19 & 27 & & & & 2 \\
\hline $\mathbf{2 0 0 9}$ & 10 & 8 & 4 & 1 & & 2 \\
\hline $\mathbf{2 0 1 3}$ & 7 & 13 & & & 20 \\
\hline
\end{tabular}

Eiskeller Carlsdorf

\begin{tabular}{l|c|c|c|c|c|c|c}
\hline Jahr & $\begin{array}{c}\text { Wasserfleder- } \\
\text { maus }\end{array}$ & $\begin{array}{c}\text { Fransenfleder- } \\
\text { maus }\end{array}$ & Braunes Langohr & Mausohr & $\begin{array}{c}\text { Zwergfleder- } \\
\text { maus }\end{array}$ & Art unbestimmt & Gesamtzahl \\
\hline $\mathbf{2 0 0 4}$ & & & & & & & - \\
\hline $\mathbf{2 0 0 5}$ & 1 & 1 & & & & & 2 \\
\hline $\mathbf{2 0 0 6}$ & & 1 & & & 1 & & 2 \\
\hline $\mathbf{2 0 0 7}$ & 1 & 1 & & & & & 2 \\
\hline $\mathbf{2 0 0 9}$ & & & & & & & - \\
\hline $\mathbf{2 0 1 3}$ & & 2 & 1 & & & & 3 \\
\hline
\end{tabular}

Eiskeller Großen Luckow

\begin{tabular}{l|c|c|c|c|c|c|c}
\hline Jahr & $\begin{array}{c}\text { Wasserfleder- } \\
\text { maus }\end{array}$ & $\begin{array}{c}\text { Fransenfleder- } \\
\text { maus }\end{array}$ & Braunes Langohr & Mausohr & $\begin{array}{c}\text { Zwergfleder- } \\
\text { maus }\end{array}$ & Art unbestimmt & Gesamtzahl \\
\hline $\mathbf{2 0 0 4}$ & 12 & 8 & & & & 2 \\
\hline $\mathbf{2 0 0 5}$ & 16 & 2 & 1 & & & 19 \\
\hline $\mathbf{2 0 0 6}$ & 14 & 1 & 1 & & & 16 \\
\hline $\mathbf{2 0 0 7}$ & 18 & 3 & 1 & & & 24 \\
\hline $\mathbf{2 0 0 9}$ & 9 & & & & & \\
\hline $\mathbf{2 0 1 3}$ & 8 & & & & & \\
\hline
\end{tabular}

Eiskeller Kleinen Luckow

\begin{tabular}{l|c|c|c|c|c|c|c}
\hline Jahr & $\begin{array}{c}\text { Wasserfleder- } \\
\text { maus }\end{array}$ & $\begin{array}{c}\text { Fransenfleder- } \\
\text { maus }\end{array}$ & Braunes Langohr & Mausohr & $\begin{array}{c}\text { Zwergfleder- } \\
\text { maus }\end{array}$ & Art unbestimmt & Gesamtzahl \\
\hline $\mathbf{2 0 0 4}$ & & & & & & \\
\hline $\mathbf{2 0 0 5}$ & 5 & 3 & 1 & 1 & 7 & & 19 \\
\hline $\mathbf{2 0 0 6}$ & 10 & 10 & 1 & 6 & & 2 \\
\hline $\mathbf{2 0 0 7}$ & 10 & 6 & 1 & 1 & & 1 \\
\hline $\mathbf{2 0 0 9}$ & 8 & 5 & & 1 & & 15 \\
\hline $\mathbf{2 0 1 3}$ & & & & & \\
\hline
\end{tabular}

Eiskeller Ziersdorf

\begin{tabular}{l|c|c|c|c|c|c|c|}
\hline Jahr & $\begin{array}{c}\text { Wasserfleder- } \\
\text { maus }\end{array}$ & $\begin{array}{c}\text { Fransenfleder- } \\
\text { maus }\end{array}$ & Braunes Langohr & Mausohr & $\begin{array}{c}\text { Zwergfleder- } \\
\text { maus }\end{array}$ & Art unbestimmt & Gesamtzahl \\
\hline $\mathbf{2 0 0 4}$ & & & & & 3 & 1 \\
\hline $\mathbf{2 0 0 5}$ & 2 & 7 & 2 & 3 & 2 & & 15 \\
\hline $\mathbf{2 0 0 6}$ & 5 & 3 & 2 & 2 & & 4 \\
\hline $\mathbf{2 0 0 7}$ & 6 & 5 & 5 & 1 & & 19 \\
\hline $\mathbf{2 0 0 9}$ & 5 & 5 & 1 & 4 & & \\
\hline $\mathbf{2 0 1 3}$ & 1 & & & & & \\
\hline
\end{tabular}

Durch die Aufgabe des ehemaligen Polizeiobjektes in Bossow konnten die dortigen sechs Bunker zu Fledermausquartieren hergerichtet werden, ehe alle anderen Baulichkeiten abgerissen wurden. Bei der letzten Kontrolle wurden fast 500 (!) Fledermäuse darin festgestellt. In den
Folgejahren wird diese Anzahl sicher noch steigen. Es wurden 7 Arten angetroffen. Am häufigsten waren Zwergund Mückenfledermaus, daneben Fransen- Wasser- und Breitflügelfledermaus sowie Braunes Langohr und Großes Mausohr. 
In den kommenden Jahren soll in Güstrow der Anbau am „Derzschen Haus“ zu einem Fledermausobjekt hergerichtet werden. Wir hoffen, dass es zu einer ähnlich attraktiven Heimstätte für unsere Nachtjäger wird.

Durch die Fledermausgruppe um Herrn Pommeranz aus Rostock wurde in einem Waldgebiet bei Bützow im August 2003 ein nächtlicher Netzfang betrieben, um weitere Erkenntnisse zu gewinnen. Vorrangig ging es um den Nachweis der Mopsfledermaus. Dieser gelang leider nicht, aber wir konnten als neue Art die bisher in unserem Gebiet nicht bekannte Große Bartfledermaus nachweisen.

Neben den Winterquartieren erfolgte durch mich auch die Kontrolle der angelegten Kastenreviere und einiger Naturhöhlen (siehe Tabelle 11).

In den Kästen waren Zwerg-, Wasser-, Fransen-, Rauhautfledermäuse, Große Abendsegler und Braune Langohren. Unter den Zwergfledermäusen können einige Mückenfledermäuse nicht ausgeschlossen werden. Mücken- und Zwergfledermaus wurden erst in neuerer Zeit in zwei eigenständige Arten getrennt. Sie sind sehr schwer zu unterscheiden. Das eigentliche Differenzierungsmerkmal sind die Rufe, die in unterschiedlichen Frequenzen gesendet werden.

Außer den Fledermäusen und den Siebenschläfern wurden auch Hornissen, Wespen, Wildbienen, Mäuse (spec.?) und Nester von Meisen und Baumläufern in den Fledermauskästen vorgefunden.

Die Anlage und regelmäßige Kontrolle von Kastenrevieren ist also eine bewährte Methode um den Flattertieren in unseren höhlenarmen Wäldern Quartiere zu bieten, die Arten zu bestimmen, aber auch um anderen Spezies Unterschlupf zu ermöglichen.

Weitere Aussagen sind mit einmaligen Kontrollen im Jahr nicht möglich.

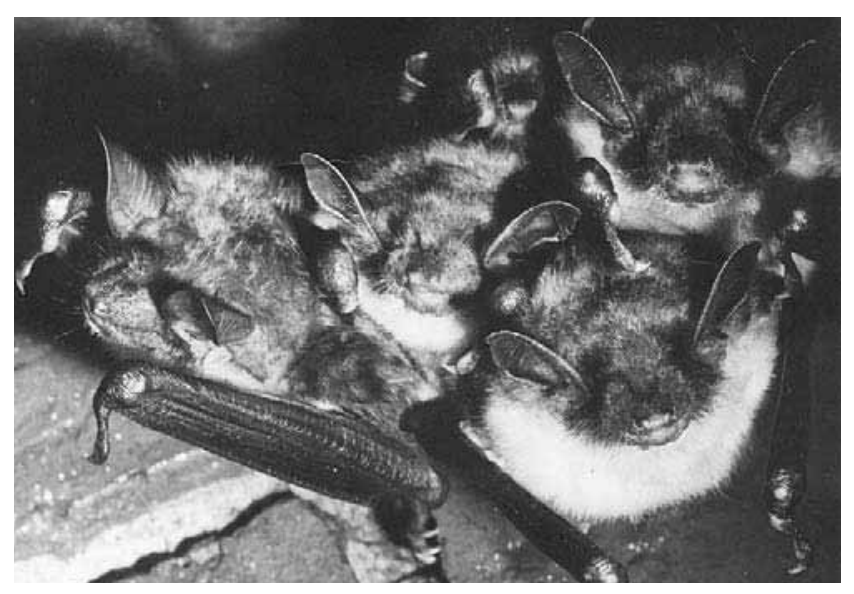

Abb. 259: Braunes Langohr-Fledermausquartier. Foto: W. Köhler.

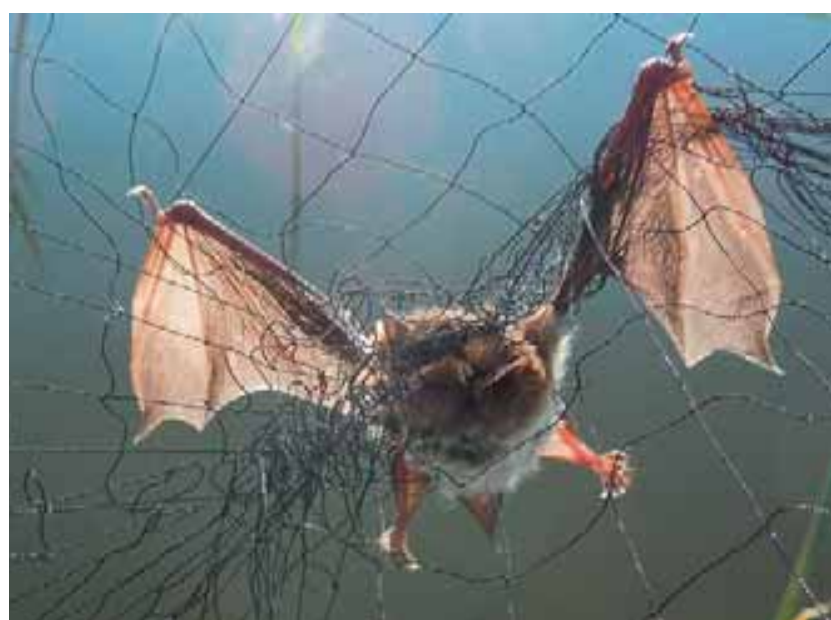

Abb. 260: Bei der Vogelberingung am Breeser See verfangen sich regelmäßig auch Wasserfledermäuse im Japannetz. Foto: f. Loose.

Neuere Darstellungen zu den Kleinsäugern (Mäuseartige) aus dem Güstrow-Bützower-Becken liegen seit der Auswertung von Gewöllen Anfang der 1980er Jahre nicht vor. Joachim Loose hatte bei seinen Kontrollen von 45 Kirchen auf das Vorhandensein von Eulen im Zeitraum von November 1981 bis März 1982 auch eine Vielzahl von Gewöllen aufgesammelt und an Dr. Labes zur Analyse übergeben. Weitere Gewöllaufsammlungen erhielt jener von den FG-Mitgliedern W. Köhler, K.-H. Koop, K. Lingsminat und K. Pohlmann.

Ohne die Aussagen bei Labes R. u. W. Köhler (1984) wiederholen zu wollen, wird zur Anschauung ergänzend das festgestellte Beutespektrum von Waldkauz und Schleiereule wiedergegeben. Markant ist der deutlich höhere Anteil von Feldmäusen und das schmalere Beutespektrum bei der Schleiereule, was mit dem Jagdverhalten in der mehr offeneren Landschaft zusammenhängen dürfte.

Neben den Gewinnern in den letzten Jahren gibt es auch Verlierer. Außer Mauswiesel, Hermelin und Iltis, die Opfer ausgeräumter Landschaften geworden sein dürften, ist vor allem der Niedergang der Bisambestände bemerkenswert. Seit Jahren ist ein deutlicher Rückgang dieser Art festzustellen.

Im Jahre 1984 wurden z.B. entlang des Ufers vom Breeser See auf einer Uferlänge von ca. $2,5 \mathrm{~km}$ noch insgesamt 22 Bisamburgen im Schilf kartiert. Bereits Mitte der 1990er Jahre gab es keine Bisamburgen mehr. Als eine Ursache für das Verschwinden der Bisamratte in den meisten Gewässern wird unsererseits die Zunahme von größeren Raubsäugern vermutet, hier insbesondere wohl auch des Fischotters und des Waschbären, denen die Jungen zum Opfer fallen dürften. 
Tabelle 11: Ausgewählte Ergebnisse einiger Kastenquartiere

\begin{tabular}{|c|c|c|c|c|c|c|c|c|c|c|c|c|c|c|c|c|}
\hline & \multicolumn{4}{|c|}{ Wilsen } & \multicolumn{4}{|c|}{ Tarnow } & \multicolumn{4}{|c|}{ Oettelin } & \multicolumn{4}{|c|}{ Schwaan } \\
\hline & $\mathbf{a}$ & b & c & d & a & b & c & d & $\mathbf{a}$ & b & c & d & a & b & c & d \\
\hline 1986 & 57 & 5 & 1 & 3 & & & & & & & & & & & & \\
\hline 1988 & 57 & 1 & 1 & 1 & & & & & & & & & & & & \\
\hline 1991 & 60 & 49 & 3 & 4 & & & & & & & & & & & & \\
\hline 1992 & 56 & 19 & 2 & 5 & & & & & & & & & & & & \\
\hline 1993 & 51 & 60 & 2 & 4 & & & & & & & & & & & & \\
\hline 1994 & 55 & 15 & 3 & 7 & & & & & & & & & & & & \\
\hline 1997 & & & & & & & & & & & & & 46 & 8 & 2 & - \\
\hline 1998 & & & & & & & & & & & & & & & & \\
\hline 1999 & & & & & & & & & 26 & 1 & 1 & - & 42 & 3 & 2 & - \\
\hline 2000 & & & & & & & & & 26 & 1 & 1 & - & 39 & 24 & 3 & - \\
\hline 2001 & & & & & & & & & 25 & 4 & 1 & - & 39 & 18 & 4 & - \\
\hline 2002 & & & & & & & & & 27 & 10 & 2 & - & 40 & 26 & 3 & - \\
\hline 2003 & & & & & & & & & 26 & 4 & 2 & - & 40 & 4 & 2 & - \\
\hline 2004 & & & & & 60 & 3 & 1 & 4 & 17 & 1 & 1 & - & & & & \\
\hline 2005 & & & & & 60 & 24 & 4 & 7 & & & & & & & & \\
\hline 2006 & & & & & & & & & & & & & 36 & 5 & 2 & - \\
\hline 2007 & & & & & 56 & 11 & 2 & 20 & & & & & 35 & 17 & 3 & - \\
\hline 2008 & & & & & 56 & 16 & 2 & 11 & 17 & 8 & 2 & - & 34 & 4 & 3 & - \\
\hline 2009 & & & & & & & & & 13 & 15 & 1 & - & 31 & 22 & 3 & - \\
\hline 2010 & & & & & 55 & 39 & 3 & 1 & 13 & 13 & 1 & - & 29 & 45 & 4 & - \\
\hline
\end{tabular}

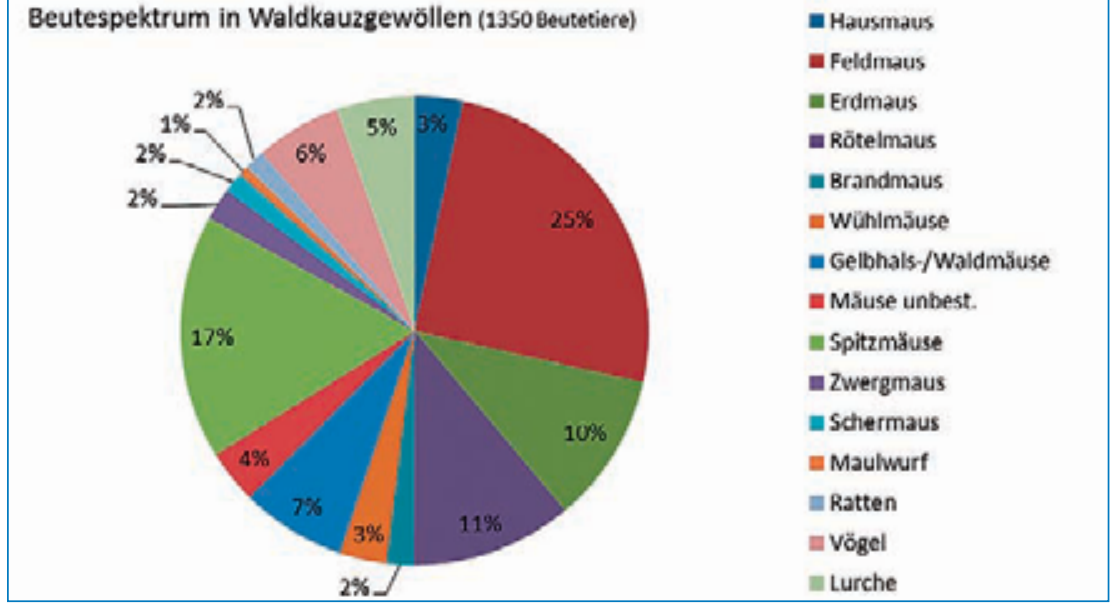

Beutespektrum in Schleiereulengewöllen (349 Beutetiere)

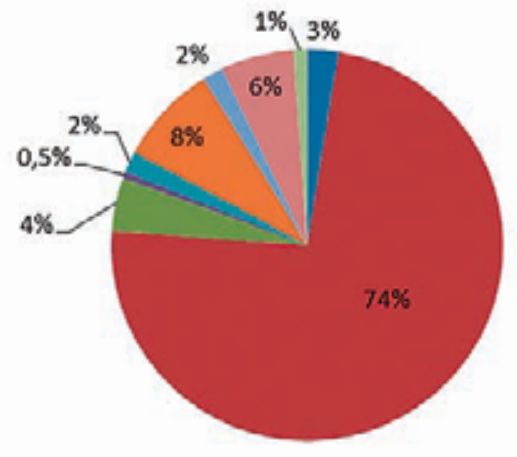

Eausmaus

Eeldmaus

Erdmaus

E Rŏtelmaus

Erandmaus

ㅂ. Wühlmăuse

= Zwergmaus

nin Spitzmãuse

E Vögel
Diagramm 29: Ergebnisse der Beutetieranalyse aus Waldkauzgewöllen
Diagramm 30: Ergebnisse der Beutetieranalyse aus Schleiereulengewöllen 


\subsubsection{Insekten [Libellen, Heuschrecken u. a.]}

\section{Angela Martin}

Die FG „Ornithologie und Naturschutz" beschäftigte sich - wie bereits zu lesen war - nicht nur mit der Vogelwelt. Es lag für uns als „Hobby-Forscher“ auf der Hand, dass wir uns in erster Linie größeren Organismen, also Arten aus anderen Wirbeltierklassen zuwandten. Wir übersahen aber auch die Wirbellosen nicht völlig. Dabei war es aber nur die Klasse der Insekten, die in wenigen Gruppen bei uns Aufmerksamkeit erwecken konnte. Die meisten Ordnungen oder Familien der Insekten verlangen bereits das Wissen von Spezialisten. Es war uns klar, dass wir als NichtEntomologen mit dem Nachweis von Arten natürlich nur kleine Beiträge liefern können. Unser Ziel war und ist es, dass „Nebenbei-Beobachtungen“ der FG-Mitglieder nicht in den Schubladen (sprich: Beobachtungstagebüchern) verschwinden, sondern den entsprechenden Fachkreisen zufließen sollen.

Während die Artbestimmung bei vielen anderen Insektengruppen nur mit Fang und Präparierung möglich ist und ausschließlich Spezialisten vorbehalten bleibt, sind zwei Ordnungen überschaubar und für uns einige Arten bestimmbar. Ohne zusätzlichen Zeitaufwand konnten einige Arten bei unseren feldbiologischen Tätigkeiten sporadisch mit notiert werden: Libellen und Heuschrecken.

Die Libellen sind mit ungefähr 70 Arten in MecklenburgVorpommern vertreten. Es gibt einige Parallelen zur Vogelwelt: Libellen fliegen mehr oder weniger schnell und lassen sich mitunter aus einiger Entfernung, sogar mit Fernglas gut bestimmen.

Einige wenige Mitglieder tragen ihre Libellenbeobachtungen in eine Art-Kartei ein. Ohne eine Häufigkeit einzelner Arten für unseren Altkreis abzuleiten, sind in Tabelle 12 die bisher beobachteten und in der Artkartei enthaltenen 43-45 Arten aufgeführt. (Die Spanne kommt durch selbstkritische Bestimmungszweifel zustande.)

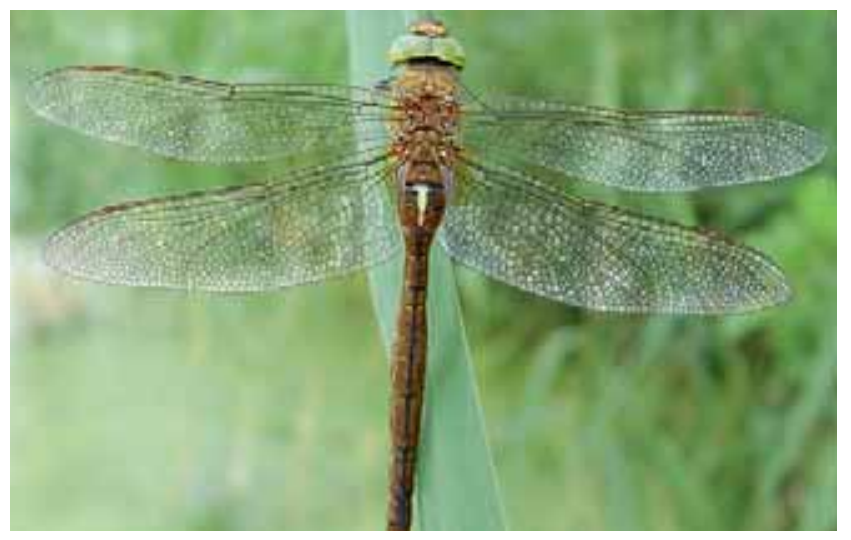

Abb. 261: Der Nachweis der Keilfleck-Mosaikjungfer im NSG Breeser See gelang zuerst über den Fang im Japannetz. Foto: f. Loose
Eine recht gute Zuarbeit wird beim Vogelfang mit Stellnetzen am Breeser See geleistet. Großlibellen gelangen sozusagen als „Beifang“ regelmäßig in unsere Hände. Auf diese Weise erweiterten wir unsere „spärliche“ Artenkenntnis und nahmen einige Arten überhaupt erst oder als „gar nicht so selten" wahr.

Uwe Thamm stellte im Jahresbericht Nr. 25/1992 die bisher im Kreisgebiet nachgewiesenen Libellenarten zusammen. Martin Lemke trug während seiner Güstrower Zeit wesentlich zur Datensammlung bei und brachte uns an einem FGAbend einige Kenntnisse über Libellen näher.

In DDR-Zeiten wurde die Daten an den Entomologen Dr. Wolfgang Zessin weitergeleitet, so dass sie nicht nur in unserer Kartei „verstaubten“.

Die zweite Ordnung, die bei der ornithologischen Arbeit zwangsläufig den „Weg kreuzt“, ist die der Heuschrecken, von der bisher 47 Arten in $\mathrm{M}-\mathrm{V}$ nachgewiesen wurden. Der Gesang der Heuschrecken ist die Parallele zur Vogelwelt. Ein Teil der Arten lässt sich am besten über die Gesänge ansprechen. Ornithologen dürfte dieser Fakt nicht ganz unbekannt vorkommen. Allerdings sind Vogelstimmen bei einem Großteil der Ornithologen eine Achillesferse, dann auch noch Heuschrecken...!?

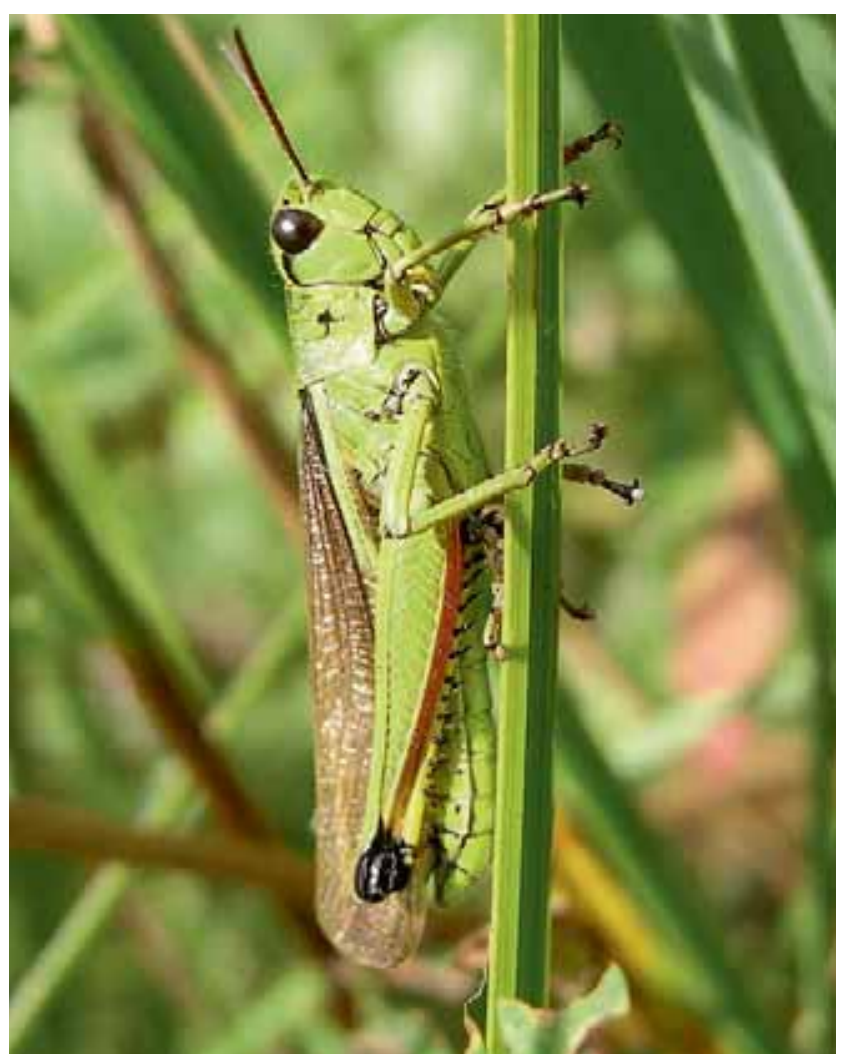

Abb. 262: Die Sumpfschrecke mit markanter rot gefärbter „Beinschiene“ ist leicht bestimmbar. Foto: A. Martin. 
Einen Vorteil haben die Heuschrecken-Gesänge: Ihr Konzert setzt erst ein, wenn die meisten Vogelgesänge im Hochsommer verstummt sind. Es ist also eine sinnvolle Nebenbeschäftigung für Ornithologen bei sommerlichen Beobachtungsgängen, auch die singenden Heuschreckenarten zu notieren.

Die erst seit kurzem für diese Ordnung angelegte Exceltabelle wurde bisher fast allein von mir mit Daten gefüllt. Auslöser meines Interesses für die Heuschrecken war eine unverwechselbare Lautäußerung einer Art, die sich von den schwirrenden Gesängen vieler Arten unterscheidet. Man kann sie getrost als Laienart bezeichnen: die Sumpfschrecke Stethophyma grossum. Ihre Rufe (sog. Knipslaute) erinnern an das Klicken eines Kugelschreibers und unterscheiden sich damit deutlich von den Zirplauten anderer Heuschrecken. Auf jedem einigermaßen feuchten Grünland ist sie zu erwarten. Leider wird sie wie auch einige Vogelarten bei vielen Beobachtungsgängen überhört.

Es gibt auch eine Art, die Gemeine Eichenschrecke Meconema thalassinum, die sich nicht durch die Stimme bemerkbar macht.

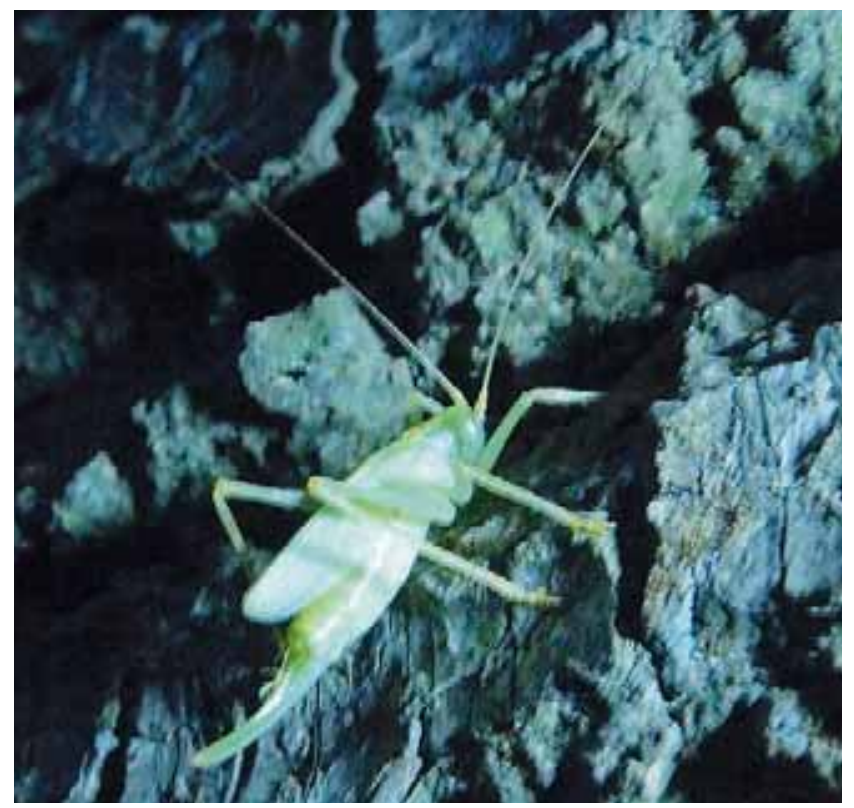

Abb. 263: Die Gemeine Eichenschrecke wird mit Taschenlampenlicht nachgewiesen. Foto: f. Loose.

Man entdeckt sie in der Dämmerung und Dunkelheit an Stämmen von Eichen, aber auch anderen Laubbaumarten. Ab August bis in den Spätherbst kommen die Weibchen aus den Baumkronen nach unten an den Stamm, um hier mit ihrem Legestachel ihre Eier in die Spalten der Borke abzulegen. Mit einer Taschenlampe muss man nur den Baumstamm ableuchten. Die hellgrünen Tiere fallen auf der dunklen Borke leicht auf.

Für gezielte Erkundungsfahrten zur Suche von Eichenschrecken diente uns als Grundlage der Verbreitungsatlas der Heuschrecken Mecklenburg-Vorpommerns (2008, Hrsg:
LUNG M-V und AK Heuschrecken M-V). In drei Jahren haben wir es geschafft, Nachweise auf zehn MTB-Quadranten um Güstrow zu erbringen, auf denen bislang Beobachtungen der Eichenschrecke fehlten.

Unsere Nachweise erhielten die Herren Dr. Wranik und Dr. Meitzner als Autoren des Verbreitungsatlases für die spätere Einarbeitung.

Besonders bei den vom Frühjahr bis Spätherbst 14-tägig stattfindenden Exkursionen der Botanik-AG in die verschiedensten Biotope unseres Altkreises fallen regelmäBig auch Beobachtungen von Insektenarten an. Libellen und Heuschrecken, aber auch Käfer, Haut- und Zweifügler, Schmetterlinge und deren Raupen werden notiert und meist auch zur Dokumentation fotografiert.

Tagfalterarten, die noch häufig oder wenigstens regelmäßig anzutreffen sind, werden von den meisten von uns wahrgenommen. Es gibt jedoch auch darunter einige Arten, über die Fundnotizen dankbar von den entsprechenden Fachleuten angenommen werden.

Im NSG Breeser See hatte J. Loose zur Kartierung der Falter zwar die Entomologen um Volker Thiele ins Gebiet geholt, aber mit Belegfotos aus verschiedenen Flächen des NSG konnte er die Anwesenheit von mindestens 58 Falterarten selbst nachweisen. Ebenso belegte er das Vorkommen von einigen Heuschrecken, Blattwanzen, Zweiflüglern, Wildbienen, Käfern sowie Spinnenarten.

Infolge der raschen Entwicklung der Fototechnik kann bei Zufallsfunden auffälliger Arten durchaus mit der Kamera ein Artnachweis erbracht werden.

Zur Schulung der FG-Mitglieder fanden in zeitlich größeren Abständen für diverse Insektengruppen von FG-eigenen Leuten auch Vorträge bei unseren monatlichen $\mathrm{Zu}$ sammenkünften statt.

Im Oktober 1987 referierte Volker Thiele über geschützte vom Aussterben bedrohte Schmetterlinge und die Ursachen für ihren Rückgang. Erst über ein Jahr später folgte von ihm ein Beitrag zu den mannigfaltigen Schutzmöglichkeiten der Schmetterlingsraupen. Im März 1989 schulte er uns über das Erkennen der wichtigsten Schmetterlingsgruppen. Von Januar bis Juni 1991 stellte er jeweils eine Tagfaltergruppe vor. Im April 1989 gab Angela Martin Hinweise zu leicht erkennbaren Libellenarten.

Neben der Schulungsabsicht wurde auch jedes Mal betont, dass alle Mitglieder der FG doch möglichst viele Beobachtungen außer den Vogelarten für den späteren Eintrag in Artkarteien notieren sollen.

Die Schulungen auch zu diesem Themenkreis traten nach der Wende in den Hintergrund und müssten in Anbetracht der Neuzugänge in der FG wieder in die FG-Pläne aufgenommen werden. 
Tabelle 12: In der Artkartei für den Altkreis Güstrow enthaltene Libellenarten (Stand 12/2015)

\begin{tabular}{|c|c|c|c|}
\hline dt. Name & wiss. Name & dt. Name & wiss. Name \\
\hline Familie Prachtlibellen & Calopterygidae & Familie Edellibellen & Aeshnidae \\
\hline Gebänderte Prachtlibelle & Calopteryx splendens & Blaugrüne Mosaikjungfer & Aeshna cyanae \\
\hline Blauflügel-Prachtlibelle & Calopteryx virgo & Braune Mosaikjungfer & Aeshna grandis \\
\hline Familie Teichjungfern & Lestidae & Keilfleck-Mosaikjungfer & Aeshna isoceles \\
\hline Gemeine Winterlibelle & Sympecma fusca & Torf-Mosaikjungfer & Aeshna juncea \\
\hline Gemeines Binsenjungfer & Lestes sponsa & Herbst-Mosaikjungfer & Aeshna mixta \\
\hline Glänzende Binsenjungfer & Lestes dryas & Grüne Mosaikjungfer & Aeshna viridis \\
\hline Kleine Binsenjungfer & Lestes virens & Große Königslibelle & Anax imperator \\
\hline Weidenjungfer & Chalcolestes viridis & Kleine Königslibelle & Anax parthenope \\
\hline Familie Schlanklibellen & Coenagrionidae & Kleine Mosaikjungfer & Brachythron pratense \\
\hline Becher-Azurjungfer & Enallagma cyathigerum & Familie Flussjungfern & Gomphidae \\
\hline Hufeisen-Azurjungfer & Coenagrion puella & Gemeine Keiljungfer & Gomphus vulgatissimus \\
\hline Fledermaus-Azurjungfer & Coenagrion pulchellum & Kleine Zangenlibelle & Onychogomphus forcipatus \\
\hline Speer-Azurjungfer & Coenagrion hastulatum & Familie Segellibellen & Libellulidae \\
\hline Großes Granatauge & Erythromma najas & Kleine Moosjungfer & Leucorrhinia dubia \\
\hline Kleines Granatauge & Erythromma viridulum & Nordische Moosjungfer & Leucorrhinia rubicunda \\
\hline Frühe Adonislibelle & Pyrrhosoma nymphula & Plattbauch & Libellula depressa \\
\hline Große Pechlibelle & Ischnura elegans & Spitzenfleck & Libellula fulva \\
\hline Kleine Pechlibelle & Ischnura pumilio & Vierfleck & Libellula quadrimaculata \\
\hline Mond-Azurjungfer & Coenagrion vernalis & Großes Blaupfeil & Orthetrum cancellatum \\
\hline Federlibelle & Platycnemis pennipes & Gebänderte Heidelibelle & Sympetrum pedemontanum \\
\hline Familie Falkenlibellen & Corduliidae & Schwarze Heidelibelle & Sympetrum danae \\
\hline Zweifleck & Epitheca bimaculata & Große Heidelibelle & Sympetrum striolatum \\
\hline Glänzende Smaragdlibelle & Somatochlora metallica & Blutrote Heidelibelle & Sympetrum sanguineum \\
\hline Gefleckte Smaragdlibelle & Somatochlora flavomaculata & Gefleckte Heidelibelle & Sympetrum flaveolum \\
\hline Gemeine Smaragdlibelle & Cordulia aenaturfosa & Gemeine Heidelibelle & Sympetrum vulgatum \\
\hline
\end{tabular}
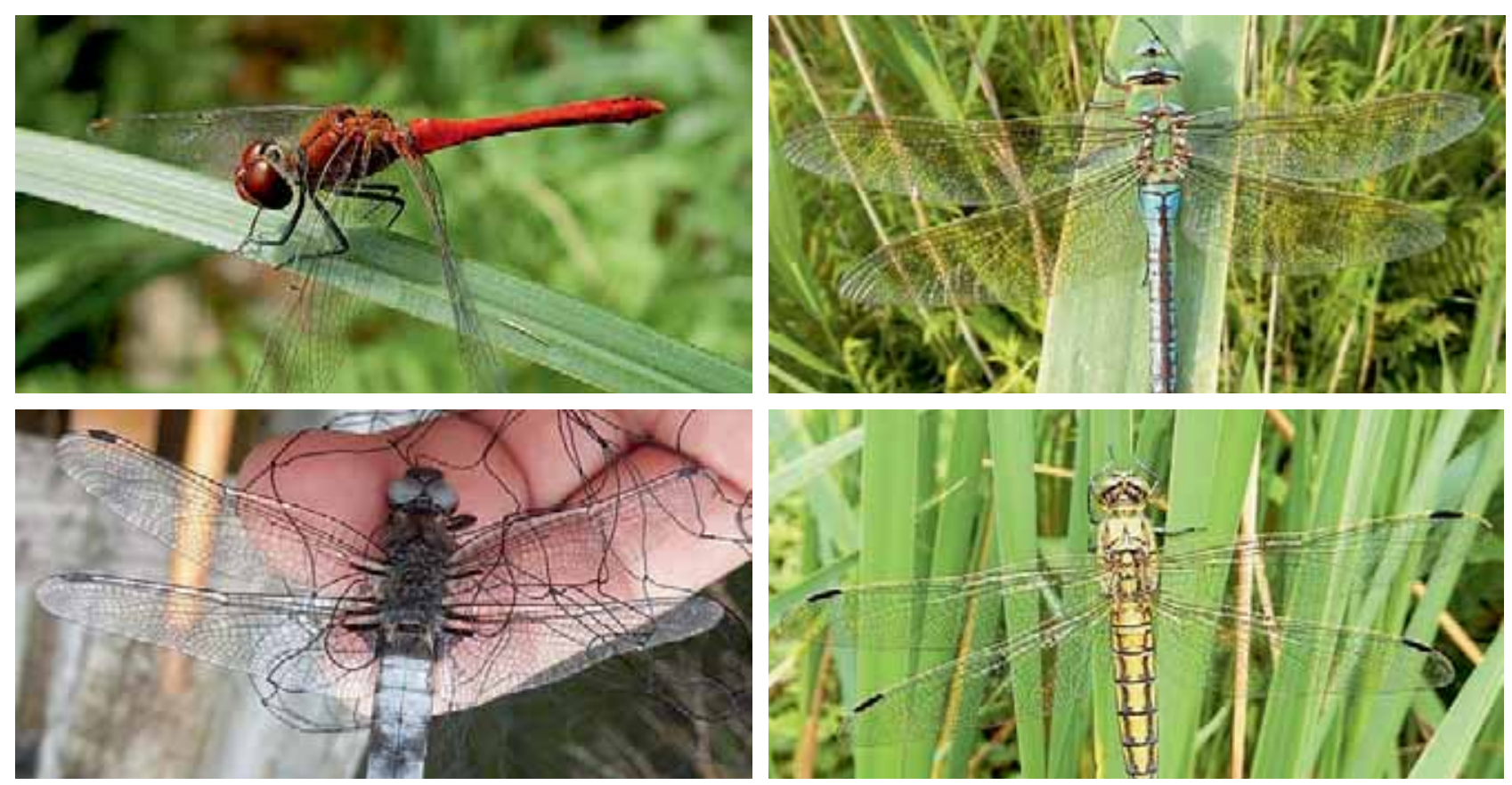

Abb. 264 bis 267: Blutrote Heidelibelle, Große Königslibelle, Plattbauch im Vogelfangnetz, Blaupfeil-Weibchen (v. l.n.r.). Fotos: f. Loose. 


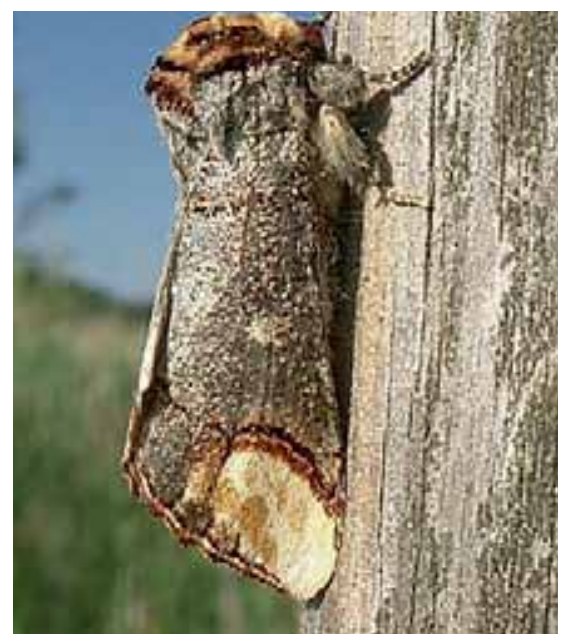

Mondvogel mit Raupe

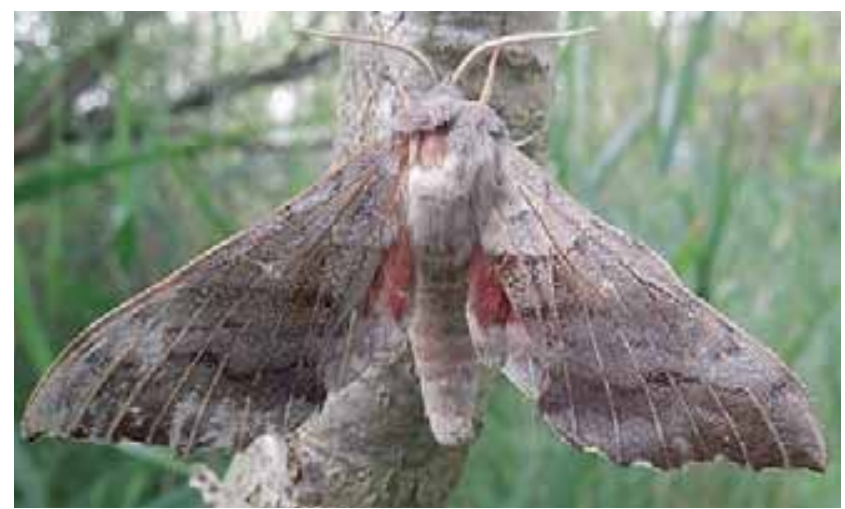

Pappelschwärmer

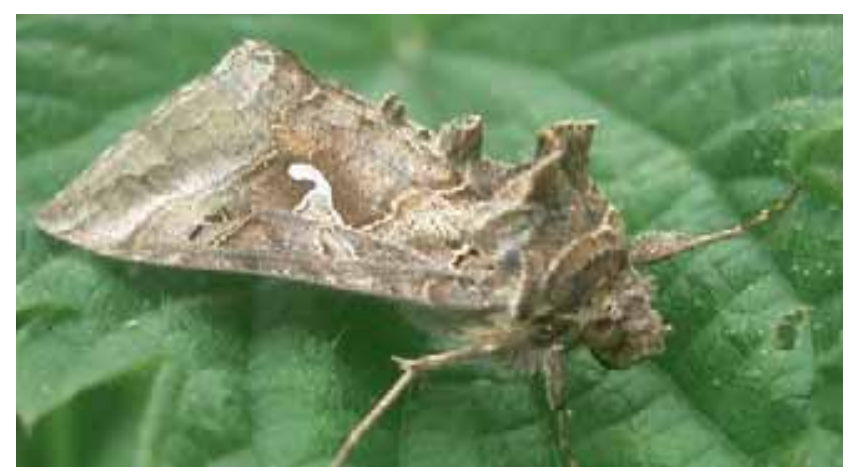

Gammaeule
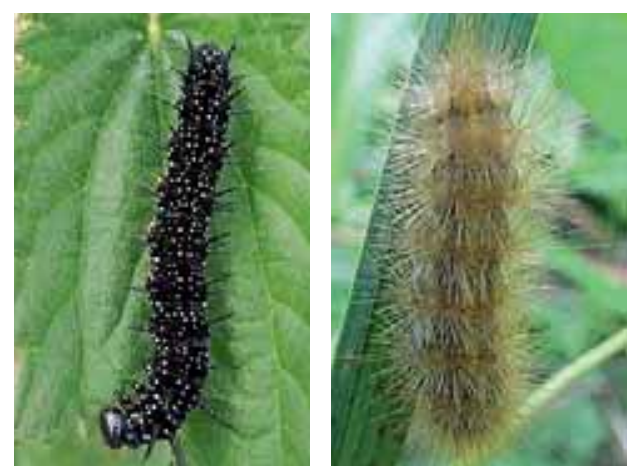
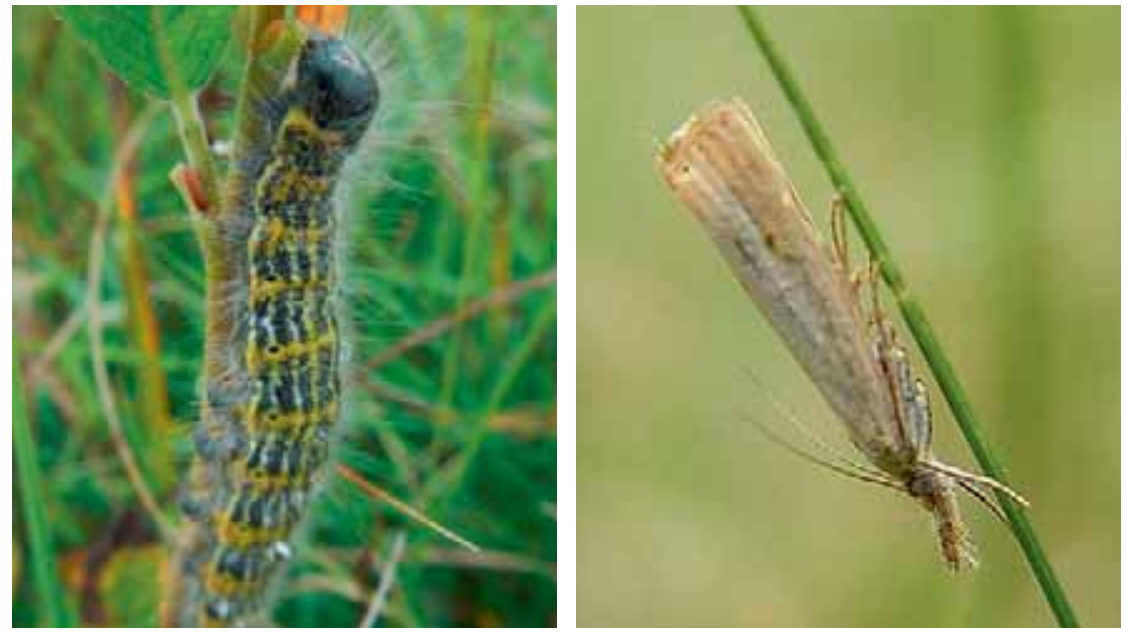

Zünsler (spec.)

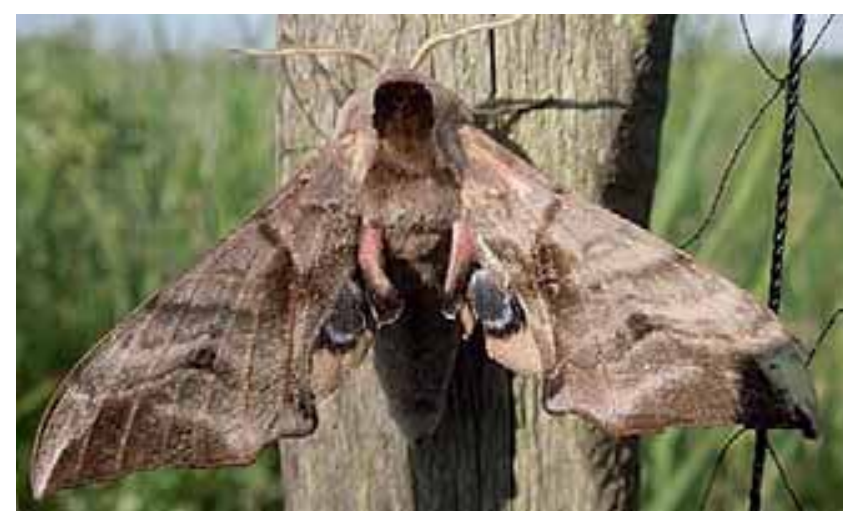

Abendpfauenauge

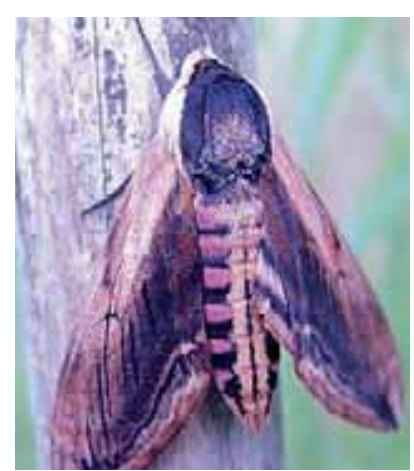

Lingusterschwärmer

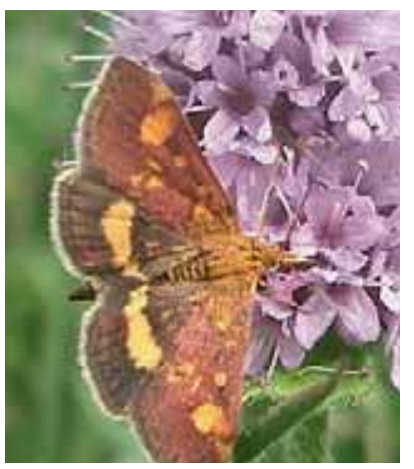

Purpurroter Zünsler
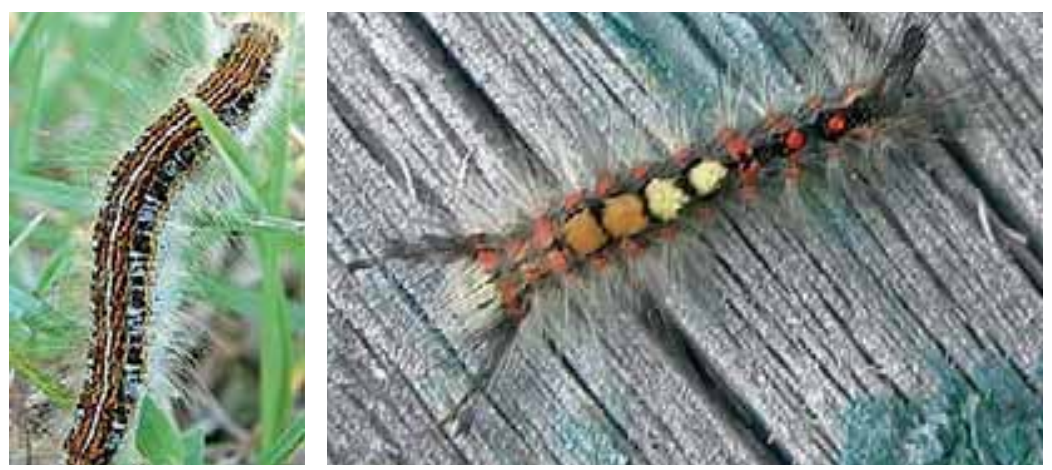

Raupen von Tagpfauenauge, Zimtbär, Gemeinem Ringelspinner und Schlehenbürstenspinner

Abb. 268 bis 279: Vielfältige Formen bei Schmetterlingen und ihren Raupen regen zum Fotografieren an und erweitern durch das erforderliche nachträgliche Bestimmen die Artenkenntnisse. Im Internet findet man leicht Bestimmungshilfen. Fotos: F. Loose. 


\section{Projektarbeiten der Fachgruppe}

Eine ganze Reihe von Aktivitäten einzelner FG-Mitglieder muss bei einer Rückschau auf 50 Jahre näher vorgestellt werden. Über eine oft lange Zeit und mit hohem Engagement haben sich verschiedene Mitglieder speziellen Arten zugewendet, brutbiologische Daten ermittelt und praktische Naturschutzarbeit geleistet. Mit kontinuierlich durchgeführten Vogelzählungen wurden belastbare Daten zur Anwesenheit von Wasservögeln auf ausgewählten Gewässern und in neuerer Zeit von Vögeln in der freien Landschaft im Winter und bisher einmal in der Brutzeit erhoben.

Mit unseren Zählungen stellen wir uns nicht auf eine Stufe mit den vom NABU in bundesweiten Aktionen seit einigen Jahren initiierten Aufrufen zur „Stunde der Gartenvögel“ oder „Stunde der Wintervögel“, bei denen die Bevölkerung zum Zählen von Vögeln aufgefordert wird. Bei diesen Aktionen geht es nicht um exakte Bestandszahlen aller Vögel, sondern vielmehr darum, Häufigkeiten und Trends von Populationen zu ermitteln. Damit dies repräsentativ ist, sollen die Populationsdaten über mehrere Jahre verglichen werden. So hofft man auf neue Erkenntnisse zur Entwicklung einzelner Vogelarten sowie zu regionalen Unterschieden.
Nach Diskussion in unserer FG haben wir uns nicht an diesen Zählaktionen beteiligt, da u. E. nicht genügend Wissenschaftlichkeit dahinter steht.

Im Internet hat der NABU Ergebnisse der Zählungen präsentiert: Für den Landkreis Güstrow (Größe bis 2011: $2059 \mathrm{~km}^{2}$ ) beteiligten sich bei der Gartenvogelzählung 2015 insgesamt 56 Vogelfreunde, die in 44 Gärten oder Parks insgesamt 2.339 Vögel gezählt hatten. In Süddeutschland fand die Aktion deutlich mehr Zuspruch. Die Zahl der im Landkreis Güstrow erfassten Gärten lag im Vergleich zu allen Bundesländern lediglich bei $0,14 \%$, die gezählten Vögel bei $0,2 \%$. Bei der Wintervogelzählung im Januar 2015 lag der Anteil aus den im Landkreis Güstrow erfassten 86 Flächen in gleich niedrigem Niveau $(0,16 \%)$. Gemeldete Vögel haben 0,22\% am Bundesanteil. Die Ergebnisse der Zählungen können für seriöse Aussagen im Bundesmaßstab für unsere Region damit keineswegs repräsentativ sein.

Dennoch sollte ein Blick auf andere Aktionen nie vergessen werden, vielleicht ist ja auch dort etwas für uns Auswertbares dabei. Bei der Gartenvogelaktion 2015 wurde z.B. auch die Beobachtung eines Wiedehopfes aus dem Landkreis gemeldet - seriös?

\subsection{Mehr als 55 Jahre Forschung an Flussseeschwalben}

\section{Joachim Loose}

Wolfgang Neubauer hatte zu Lebzeiten mehrmals von mir die Zusage abverlangt, dass ich seine Arbeiten mit den Flussseeschwalben fortsetzen werde - ein schweres Erbe. Am Breeser See betrieb ich zwar mein Management bei den „Flusen“ auf künstlichen Inseln, und hin und wieder fing ich auch von ihm beringte Vögel. Aber es war doch recht bald klar, dass ich nicht die Kraft finden würde, in gleicher Intensität Flussseeschwalben zu fangen. Neben meinen Aktivitäten am Breeser See würde ich nicht auch noch am Krakower Obersee, im Kieswerk Langhagen, am Drewitzer See und Dreiersee tätig werden können. An diesen Gewässern hatte Wolfgang Neubauer sich über 50 Jahre lang intensiv mit Forschungen an Flussseeschwalben beschäftigt. Nach Durchsicht der auf seinem Computer abgelegten Daten gehe ich davon aus, dass wohl alles von ihm ausgewertet und publiziert worden ist. In verschiedenen Fachzeitschriften hat W. Neubauer mit zwölf Beiträgen zwischen 1969 bis 2010 Themen zur Brutbiologie und zum Verhalten von Flussseeschwalben behandelt. Publikationen von ihm gibt es über Untersuchungen zur akustischen und visuellen Kommunikation von Flussseeschwalben insbesondere bei der Jungenaufzucht, die Nahrung nestjunger Flussseeschwalben, die Beziehungen zwischen Paarbindung, Alter und Bruterfolg sowie zu Zusammenhängen von Brutperiode, Schlupftermin und Überlebenschancen bei Flusssee- schwalben. Als Artbearbeiter für die Flussseeschwalbe in $\mathrm{M}-\mathrm{V}$ pflegte er Kontakte in alle Teile der DDR und erstellte Übersichten über den Brutbestand der Flussseeschwalbe in der DDR (1989) und für Mecklenburg-Vorpommern (1996). So konnte er auch mit vertiefenden Angaben aus den Brutkolonien die Habitatwahl von Flussseeschwalben für Ostdeutschland (Stand bis 1997) auswerten. Durch die Beringung von jungen Flussseeschwalben und zahlreiche Fänge brütender Vögel mit von ihm selbst gebauten speziellen Fangkörben sowie sehr vielen Rückmeldungen von seinen ins Winterquartier ziehenden Seeschwalben konnte er den Zug, aber auch An- und Umsiedlungen der mitteleuropäischen Flussseeschwalben aufzeigen. Nach Ringfunden und Fängen brütender Vögel berichtete W. Neubauer auch über zwei 27-jährige Flussseeschwalben, die noch in diesem hohen Alter an der Reproduktion beteiligt waren.

Alle Auswertungsergebnisse im Detail mögen in seinen Veröffentlichungen (s. Anhang 2) nachgelesen werden. Nachfolgend erfolgt nur eine Übersicht zur Anzahl der von ihm beringten und wiedergefangenen Flussseeschwalben, die in der Form nicht in seinen Publikationen zu finden war. Seit 1958 hat Wolfgang Neubauer nestjunge Flussseeschwalben auf dem Großen Werder im Krakower Obersee beringt, seit 1984 dann auch im Kieswerk Langhagen. Seit 1984 begann er an beiden Orten auch mit dem 
systematischen Fang und den Kontrollen von brütenden Altvögeln auf ihren Nestern. 1998/2000 wurden die Fänge auf vier Teilkolonien ausgedehnt - es kamen der Drewitzund Dreiersee dazu. Aus seinen Literaturangaben und den Kontrolllisten der Beringungszentrale ergab sich die nachfolgende Übersicht der von Wolfgang Neubauer insgesamt von 1958 bis 2013 beringten Flussseeschwalben:

\begin{tabular}{l|r|r|r}
\hline $\begin{array}{l}\text { Beringungen } \\
\text { Ort / Summe }\end{array}$ & \multicolumn{1}{l|}{ Juv. } & \multicolumn{1}{l|}{ FGL } & Summe \\
\cline { 2 - 4 } & 10.896 & 1.482 & 12.378 \\
\hline Krakower Obersee & 6.861 & 775 & 7.636 \\
\hline Krakow [Untersee] & $3 / /^{1}$ & - & 3 \\
\hline Langhagen $^{\text {Drewitz/Dreiersee }}$ & 2.118 & 454 & 2.572 \\
\hline andere $^{2}$ & 1.875 & 253 & 2.128 \\
\hline
\end{tabular}

$/{ }^{1}$ - Solitärgelege auf Fischernetzen an der Promenade in Krakow am See $/^{2}$ - Brutvorkommen am Ochsenauge und Sumpfsee

Nach eigenen Aussagen war es W. Neubauer nie gelungen, in seinen Kolonien sämtliche Küken eines Jahrganges zu fangen. Anfangs brüteten die Flussseeschwalben auf dem Großen Werder außerhalb der Lachmöwenkolonie im niedrigeren Gras. Vermutlich durch den Prädatorendruck siedelten sie sich später innerhalb der Lachmöwenkolonie an.

Bei der zunehmend üppiger werdenden Vegetation wurde es schwieriger, alle weit auseinander liegenden Nester der Seeschwalben zu finden. Kam er zum Beringen nicht unmittelbar nach dem Schlupf der Küken an die Nester, verließen die größeren Küken bei seiner Annäherung das Nest und versteckten sich in der hohen, meist aus Brennnesseln bestehenden Vegetation. Ob die beringten Küken auch flügge geworden sind, ließ sich erst feststellen, wenn sie in den Folgejahren als Brutvögel wieder gefangen wurden.

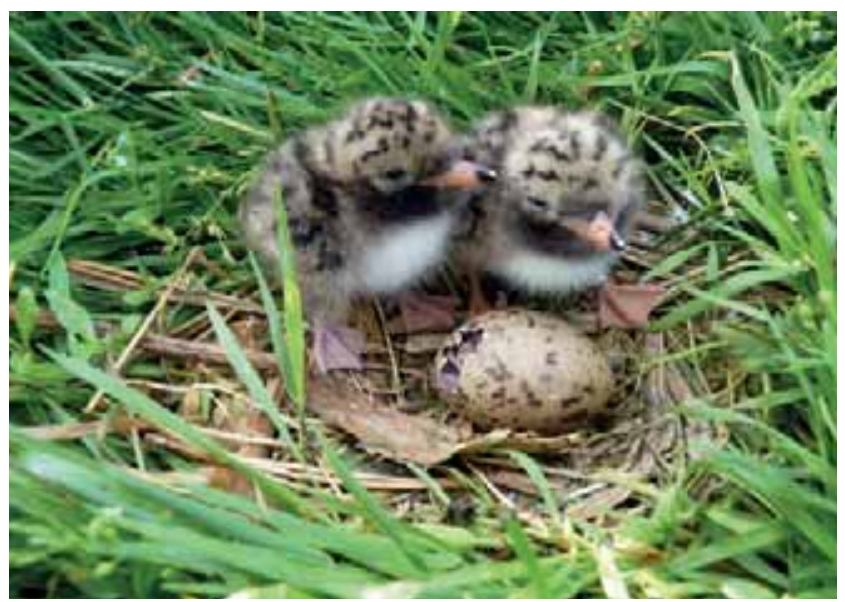

Abb. 280: Flussseeschwalbenküken auf dem Großen Werder im idealen Beringungsalter. Foto: W. Neubauer.

Von 1984 bis 1992 hat sich in den von W. Neubauer kontrollierten Kolonien am Krakower Obersee und im Kieswerk Langhagen die Zahl der beringten Seeschwalben deutlich erhöht. Der Anteil markierter Vögel in der Krakower Kolonie stieg von etwa $50 \%$ auf $90 \%-95 \%$, in der Kolonie Langhagen von etwa $50 \%$ auf $80 \%$. Nur auf dieser Basis waren die o.g. Untersuchungen an den Seeschwalben für W. Neubauer effektiv möglich.

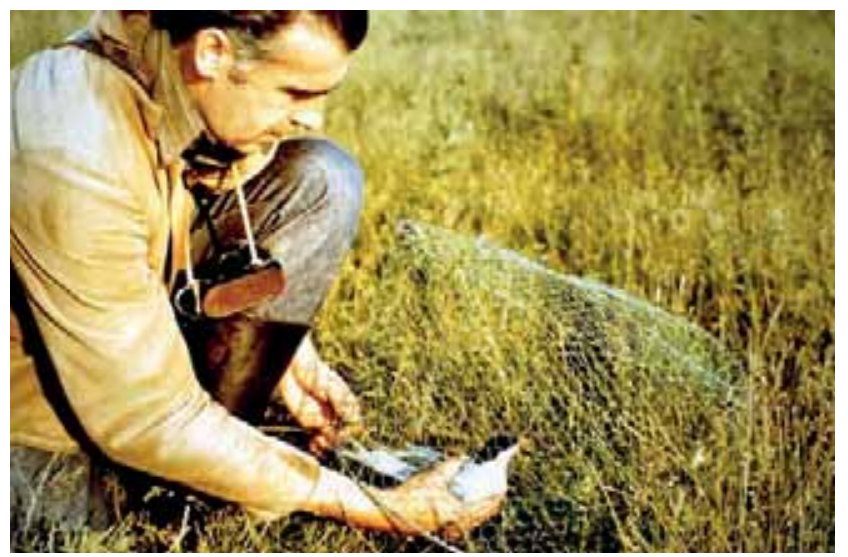

Abb. 281: Wolfgang Neubauer bei der Entnahme einer auf dem Gelege gefangenen adulten Flussseeschwalbe. Foto: H. G. Müller.

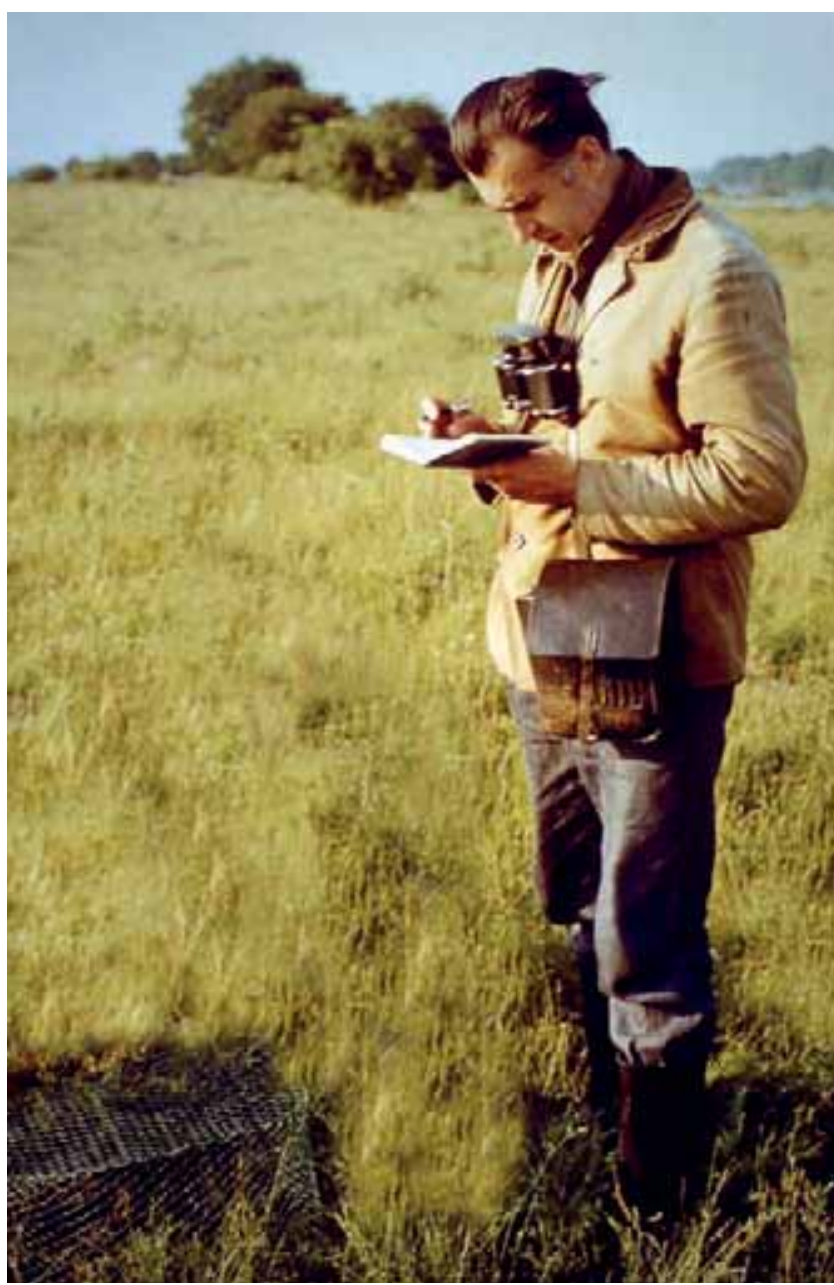

Abb. 282: Ganz wichtig, die Notierung der Daten gleich vor Ort. Foto: H. G. Müller.

Bis einschließlich 2012 tätigte Neubauer die nachfolgende Anzahl von Kontrollfängen an den von ihm gefangenen und beringten Jung- und Altvögeln: 


\begin{tabular}{l|r|r|r}
\hline Kontrollfänge & Gesamt & Individuen & \multicolumn{1}{l}{ Paare } \\
\cline { 2 - 4 } Ort/Summe & 5.896 & 3.106 & 1.395 \\
\hline Krakower Obersee & 3.644 & 1.860 & 892 \\
\hline Langhagen & 1.856 & 986 & 435 \\
\hline Drewitz/Dreiersee & 396 & 260 & 68 \\
\hline
\end{tabular}

Neben „seinen“ Vögeln fing er mit den Körben auch Brutvögel, die fremde Ringe trugen. Bis zum Jahr 2012 stammten die Beringungen aus Spanien (2), Niederlande (2), Belgien (4), Namibia (6), Südafrika (1), Polen (6), Dänemark (2) sowie aus den näheren ostdeutschen Brutkolonien: Breeser See (47), Bergen (1), Heuwiese (1), Kirr (14), Böhmke und Werder (7), Nonnenhof (2), Wismar (8), Walfisch (2), Dambecker Seen (2), Moitin (3), Stolper See (1) und Klosterwalde (1).

Es wurden auch zahlreiche von Neubauer beringte Flussseeschwalben von anderen Orten gemeldet (Stand 12/2015):

Wiederfunde (Zug + Winterquartier)

$\begin{array}{lc}\text { England } & 2 \\ \text { Niederlande } & 11 \\ \text { Belgien } & 3 \\ \text { Frankreich } & 2 \\ \text { Spanien } & 3 \\ \text { Senegal } & 2 \\ \text { Gambia } & 1 \\ \text { Guinea } & 1 \\ \text { Sierra Leone } & 1 \\ \text { Liberia } & 2 \\ \text { Elfenbeinküste } & 1 \\ \text { Ghana } & 8 \\ \text { Togo } & 1 \\ \text { Gabun } & 1 \\ \text { Angola } & 2 \\ \text { Namibia } & 12 \\ \text { Südafrika } & 13\end{array}$

Dänemark 1

Polen 1

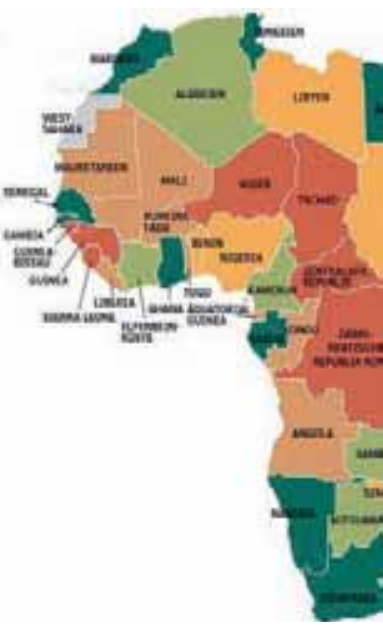

Wiederfunde (als Brutvögel)

Breeser See (4), Waren (1), Langenwerder (4), Walfisch (4), Riether Werder (5), Böhmke und Werder (5) und Molfsee/ SH (1).

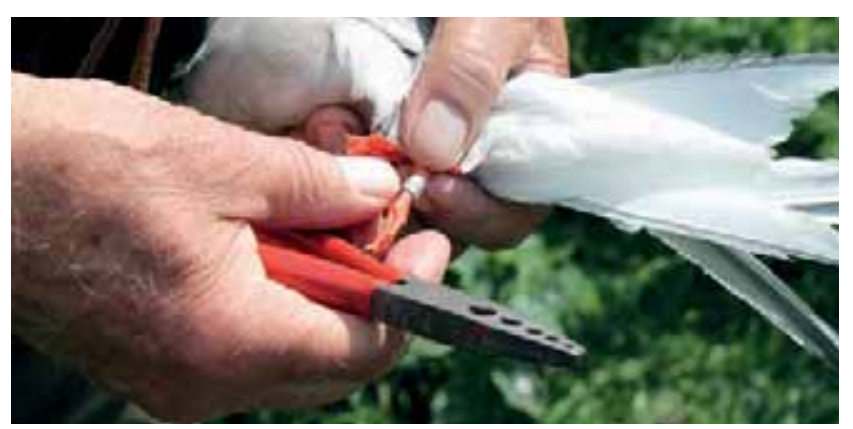

Abb. 283: Wolfgang Neubauer beringte Flussseeschwalben stets am linken Fuß. Zur Unterscheidung beringte foachim Loose am Breeser See stets rechts, so konnten fremde Flusen bereits ohne Fang vermutet werden. Foto: B. Meder-Trost.
$\mathrm{Zu}$ jeder wiedergefangenen Flussseeschwalbe hatte Wolfgang Neubauer eine Karteikarte, geordnet nach Ringnummern, angelegt, auf der neben den Beringungs- und Wiederfangdaten auch die Ring-Nr. der Brutpartner und des Nachwuchses vermerkt wurden. So entstanden sehr viele Familiengeschichten.

Da der Fang von Flussseeschwalben derzeit nicht in der von ihm betriebenen Form fortgeführt wird, wurden die mehr als 1.800 Karteikarten vom KOS im Archiv des Naturparks Nossentiner/Schwinzer Heide deponiert.

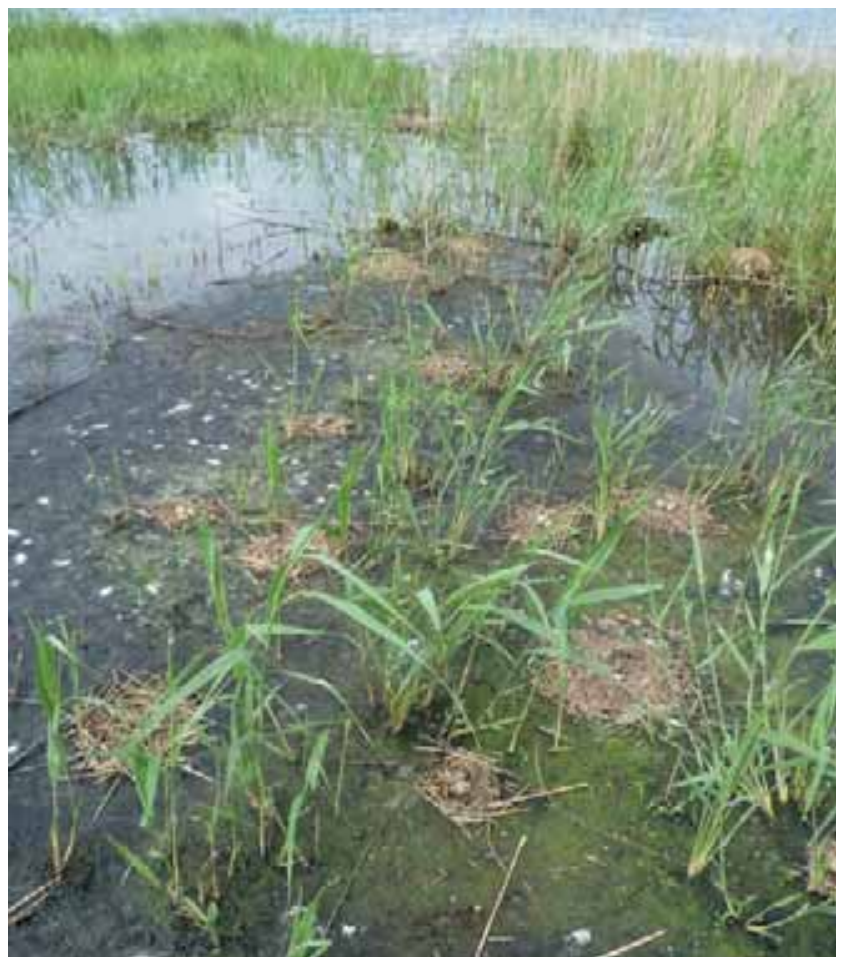

Abb. 284: Ausschnitt aus der Kolonie am Drewitzsee - die Versteckmöglichkeiten für die Küken sind hier eingeschränkt. Foto: W. Neubauer

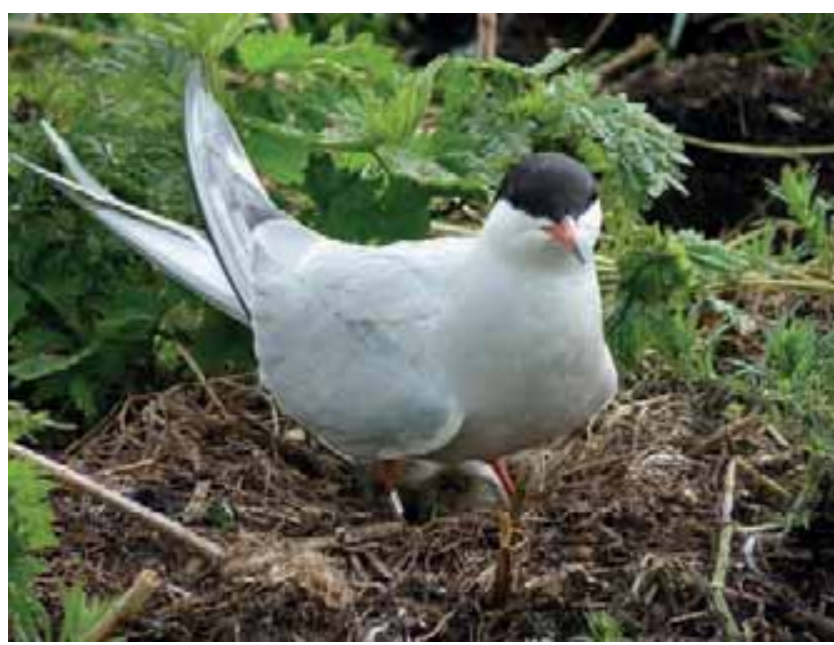

Abb. 285: Diese hier auf dem Großen Werder brütende Flussseeschwalbe stammte nicht vom Krakower Obersee, da sie rechts beringt war (vgl. Abb. 283). Ihr Fang war also besonders wichtig. Foto: W. Neubauer. 
Flussseeschwalben - Brutpaare am KOS

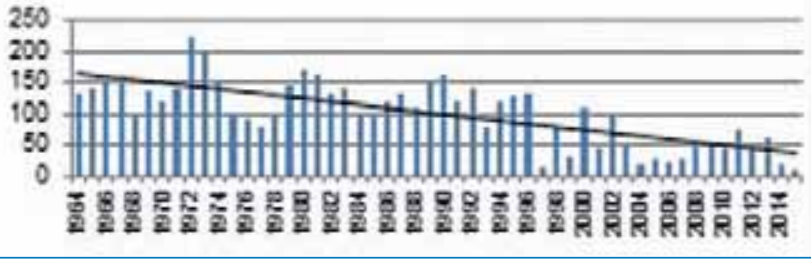

Diagramm 31: Der Brutbestand der Flussseeschwalben am

Krakower Obersee ging in jüngerer Zeit deutlich zurück.
Im Schriftverkehr von Neubauer fanden sich aus dem Jahre 2005 Daten zur vermuteten Polygamie bei 34 brütenden Flussseeschwalben - Vögel waren parallel brütend auf verschiedenen Nestern gefangen worden. Nach seinem Kontakt mit Prof. Dr. Peter H. Becker, Wilhelmshaven, blieben Fragen offen, so dass hier dieses Thema nur erwähnt wird.

\subsection{Jahre Kunstinseln für Flussseeschwalben im NSG Breeser See}

Joachim Loose

Anfang Juni 1989 hatten Flussseeschwalben mehrere Eier etwa 1,80 m über dem Wasserspiegel auf dem nur ca. $1 \mathrm{~m}^{2}$ großen Schilfdach eines Beobachtungsverstecks mitten im Breeser See abgelegt. Ein Brüten war hier chancenlos. Durch den NSG-Betreuer wurde daraufhin am 19.Juni 1989 eine etwa $3 \mathrm{~m}^{2}$ große Holzpattform mit einer spärlichen Kiesschüttung auf vorhandenen Pfählen vor dem Versteck installiert. Diese wurde sofort von einem Flussseeschwalbenpaar angenommen: Am 24. Juni war ein neues Dreiergelege vorhanden, aus dem am 15. Juli ein Küken schlüpfte. Bereits am 4. August war dieses flügge. Die Flussseeschwalbe war damit ab 1989 erfolgreicher neuer Brutvogel im Gebiet. Die fast zehn Jahre zuvor durch die Schüler-AG von Kurt Pohlmann errichtete, aber nicht fertiggestellte Brutinsel erfüllte doch noch ihren Zweck.

\section{Vogelbrutstätte ouf Pfählen im Breesener See \\ Schüler-Arbeitsgemeinschaft der Oberschule Mühl Rosin vermehrt faunistischen und floristischen Reichtum \\ Im Juni des vergangenen Jahres wurde auf der SVZ-Kreisseite übe die Tătigkeit der Schủler-Arbeits- gemeinschaft der Nikolai-Ostrow- ski-Oberschule Mühl Rosin im Na- turschutzgebiet Breesener See (be Lohmen) berichtet, insbesondere über den Bau eines Hochstandes. Dieser wird nun im kommenden Frühjahr intensiv für Beobachtun- gen genutzt werden können. Wei- tere Naturschutzarbeiten wurden und werden in den relativ beob- achtungsarmen Wintermonaten ausgeführt. \\ Naturschutzgebiete sollen von} bleiben - so ist es stets auf Hinweistafeln zu lesen. Das schließt aber nicht aus, daß bestimmte Maßnahmen ergriffen werden, durch die das Gebiet zwar in gewisser Weise verändert, sein faunistischer und floristischer Reichtum aber nicht beeintrăchtigt wird, sondern im Gegenteil vermehrt werden kann.

Der Breesener See zeichnet sich zwar durch einen relativ breiten Schilfgürtel und einen im allgemeinen schwer zugänglichen Uferbereich aus, wodurch für viele Wasser- und Sumpfvögel günstige Nistgelegenheiten vorliegen. Doch etwas fehlt dem See völlig: Insein. Gerade diese aber üben eine besonders hohe Anziehungskraft aui zahlreiche Brutvögel aus, die au hnen, vor Raubtieren geschutzt, ihre Gelege ausbringen können. Aus diesen Erwägungen wurde im Breesener See mit dem Bau einer künstlichen Insel begonnen. Die Lage wurde mit dem Fischereiverantwortlichen abgesprochen, um auch weiterhin eine günstige
Menschenhand nahezu unberührt

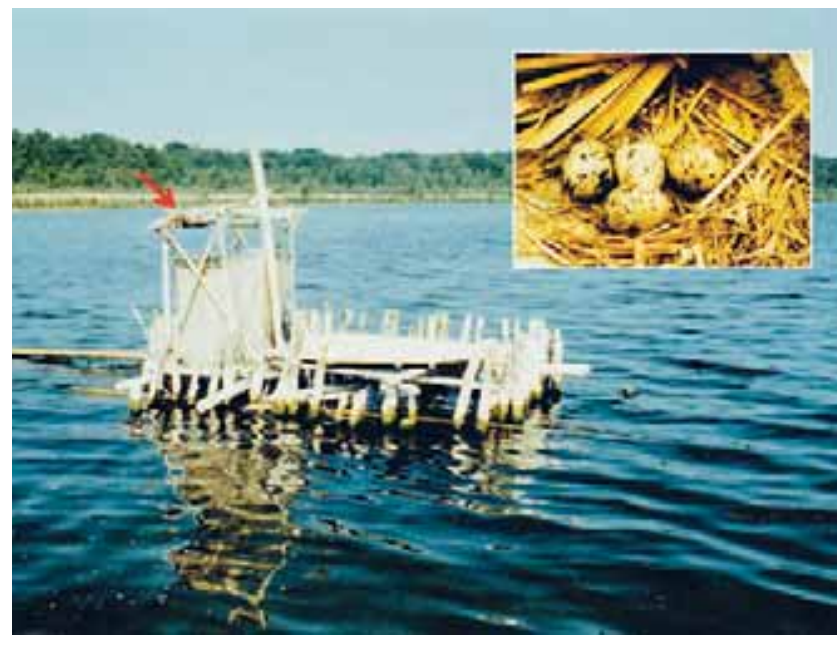

Abb. 286: Auf dem Dach eines Versteckzeltes 1989 abgelegte Eier der Flussseeschwalbe. - Alle Fotos des Kapitels : J. Loose.

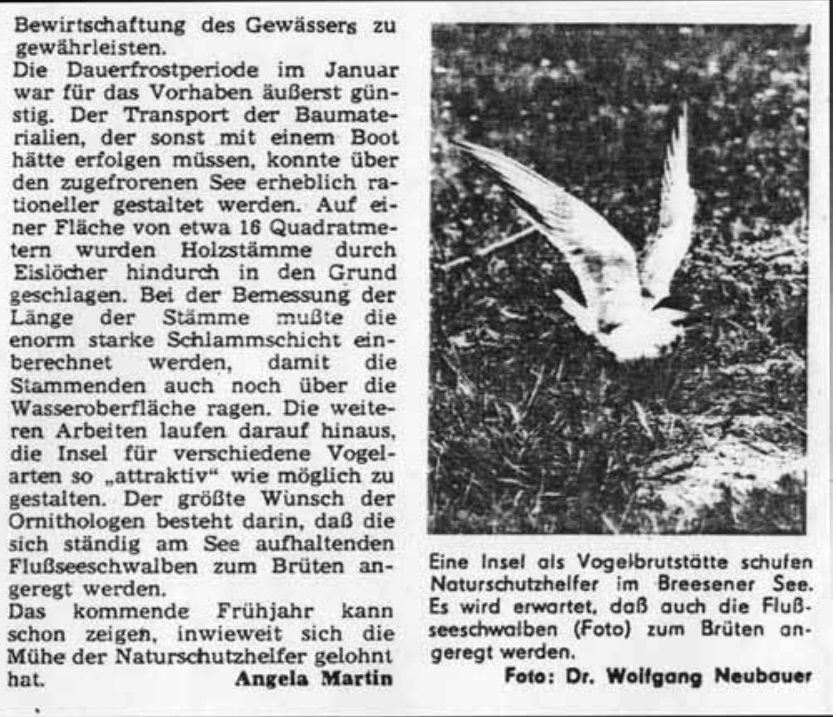

Abb. 287: Der Artikel in der SVZ vom März 1980 fand sogar eine Erwähnung in der Zeitung „Neues Deutschland“. 
Es begann die nachfolgend beschriebene Kolonieentwicklung:

Da Flussseeschwalben auch in den folgenden drei Jahren die eher baufällig wirkende spärlich mit einer zwei Zentimeter hohen Kiesschicht belegte Plattform in zunehmender Brutpaarzahl besiedelten (1992 waren es bereits 9 BP), wurde das Nistplatzangebot durch die Errichtung zweier neuer

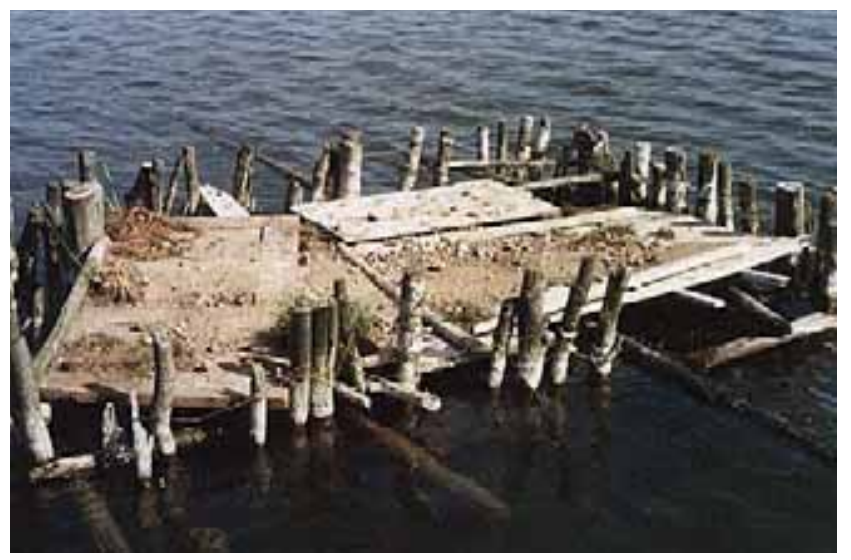

Abb. 288: Insel 1 in den Anfängen der Flussseeschwalbenbruten

Nistmöglichkeiten angepasst. Insel 1 entstand als Neubau über der bisherigen Plattform auf den vorhandenen eingerammten Birkenstämmen (Abb. 289). Die Insel 2 wurde als Floß auf Plastikfässern errichtet. Die jetzt angebotenen Flächengrößen lagen bei 5,2 bis 5,4 $\mathrm{m}^{2}$ (Abb. 290/291). Neben der Kiesschüttung wurden auch einige Rasensoden auf der Flächen locker verteilt, die später bei höher gewachsenem Gras den Küken auch Versteckmöglichkeiten und Witterungsschutz boten. Auch dienten sie zur räumlichen Trennung der oft nur $30 \mathrm{~cm}$ auseinander liegenden Neststandorte (Abb. 292). 1995 war die BP-Zahl bereits auf 40 angestiegen und Insel 3, ebenfalls noch einmal als Brutfloß mit einer Fläche von 5,3 $\mathrm{m}^{2}$, wurde errichtet. Die Inseln waren im See so platziert, das zwischen ihnen Entfernungen von jeweils 350 bis $450 \mathrm{~m}$ bestanden. 2002 kam neben Insel 2 ein neues mit 17,1 $\mathrm{m}^{2}$ Brutfläche größeres Floß zum Einsatz, das als Kompensationsmaßnahme über die UNB durch einen Investor gebaut worden war. (siehe Abb. 303).

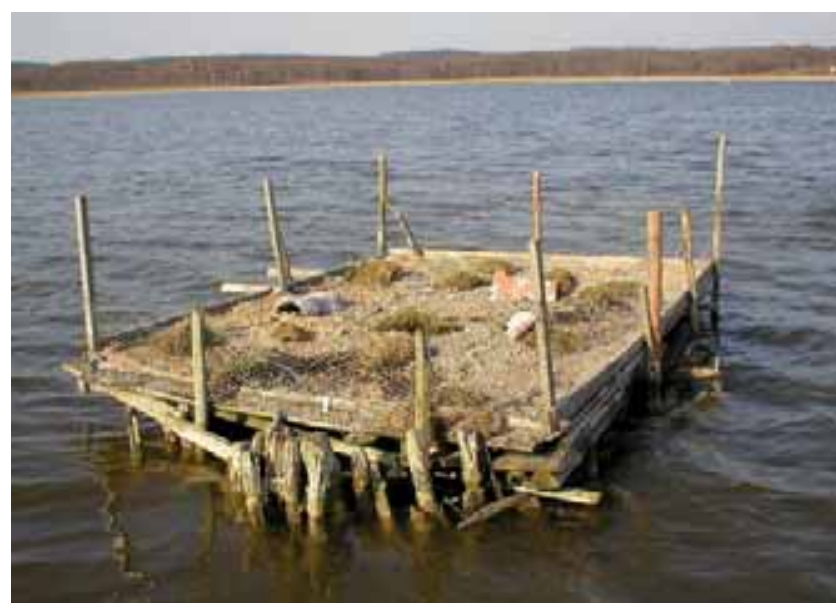

Abb. 289: Insel 1 nach Rekonstruktion.

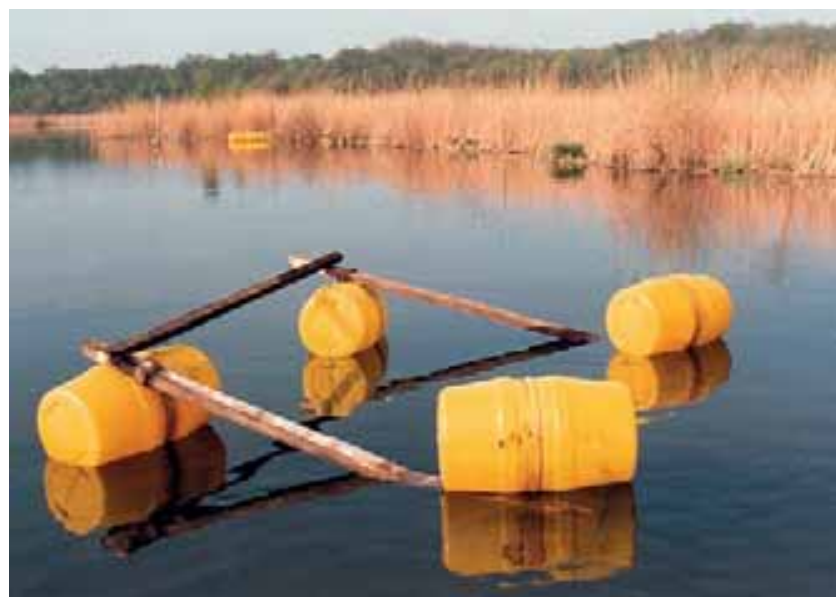

Abb. 290: Insel 2 als Grundgestell aufgebaut auf Plastefässern.

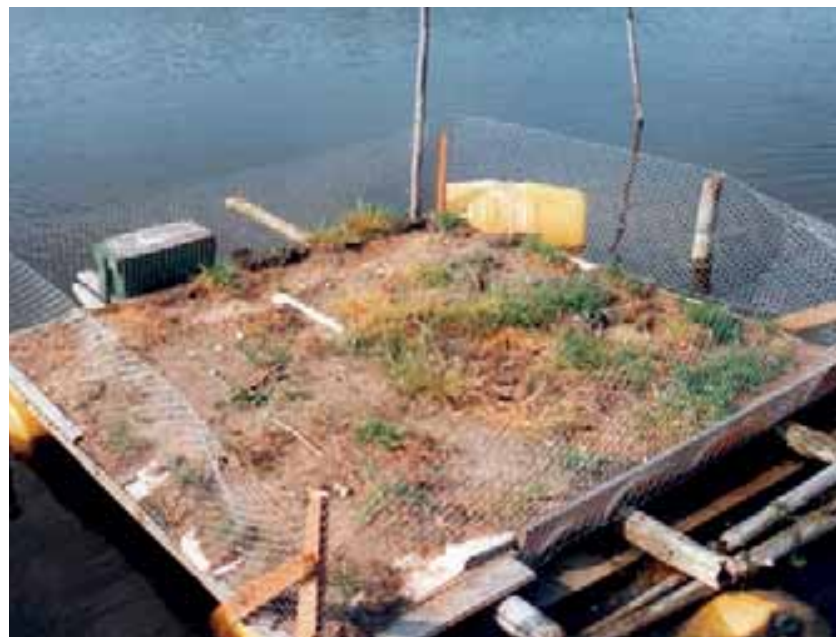

Abb. 291: Insel 2 nach der Fertigstellung.

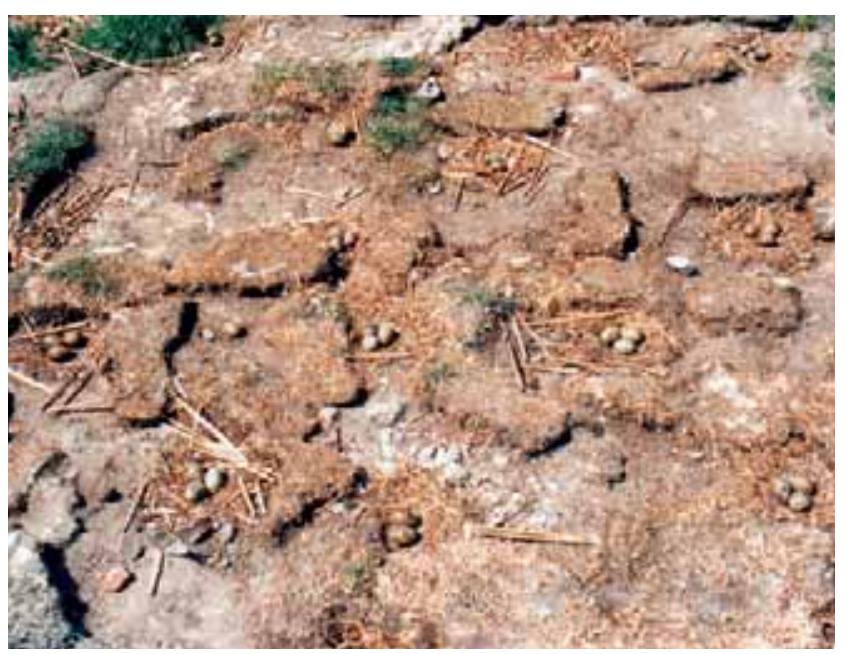

Abb. 292: Die Nester der Flussseeschwalben haben oft nur Abstände von ca. $30 \mathrm{~cm}$ untereinander.

Die Inseln 2 und 3 waren bis dahin erneuert und als Pfahlkonstruktionen neu gegründet worden, da die Plastefässer über die Winter undicht geworden waren. Beim Neubau wurde die Insel 2 bereits 1998 auch gleich noch von 5,2 $\mathrm{m}^{2}$ auf 23,5 $\mathrm{m}^{2}$ vergrößert. Auch in den nachfolgenden Jahren war für die Inselunterhaltung und weitere Neubauten viel „Manpower“ erforderlich. Zäune waren zu erneuern, 


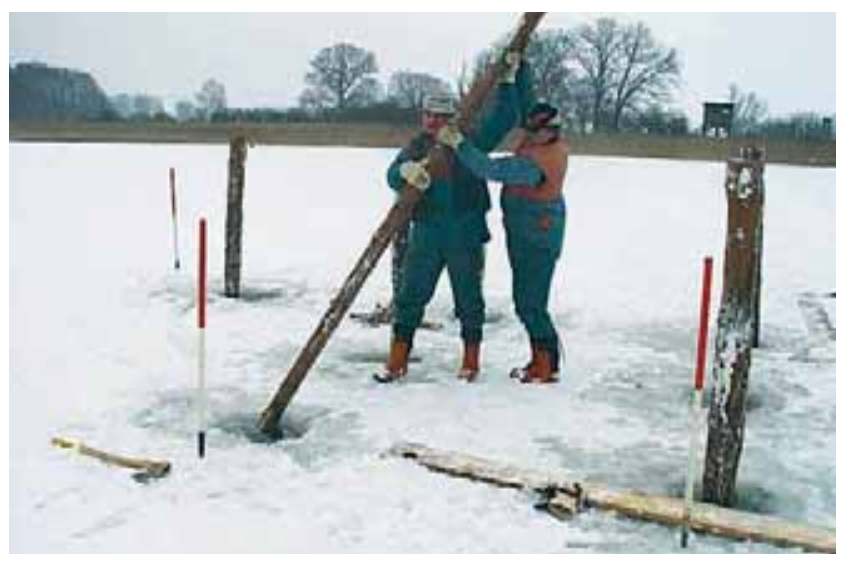

Abb. 293: Beim Aufbau der Insel 4 gab es Unterstützung durch Mitarbeiter des Forstreviers Lohmen.

Substrat auf den Flächen neu auszubringen und verfaulte Bretter zu ersetzen. Beim Inselaufbau auf eingerammten Pfählen kam es immer wieder zum Problem, dass im Laufe der Jahre die Pfähle immer tiefer in den morastigen Untergrund einsanken. Die Plattformen gerieten unter Wasser oder wurden bei Hochwasser im Frühjahr überflutet.

Am einfachsten ließen sich die Standpfähle im Winter bei tragfähigem Eis einrammen.

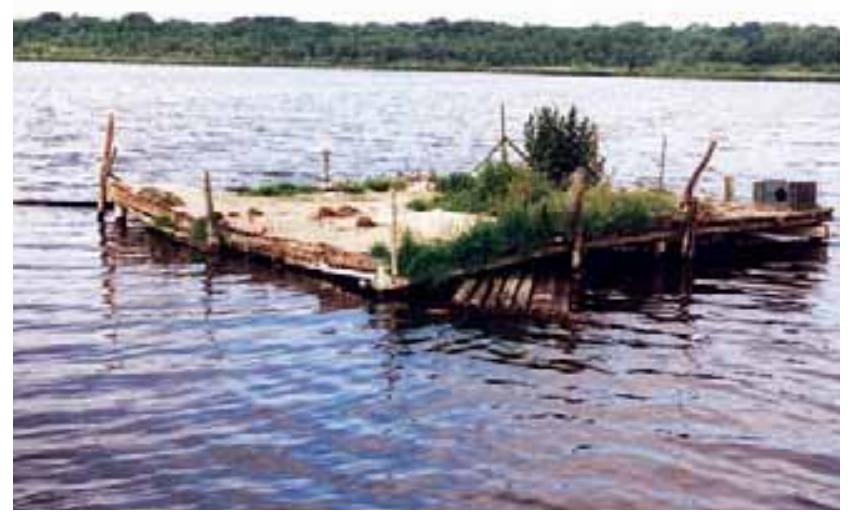

Abb. 294: Neben der Insel wurden schwimmende Plattformen und Hölzer für ausgeflogene Küken angebracht, die hier ausruhen konnten, wenn sie den Flug über den Zaun zurück auf die Insel nicht gleich schafften.

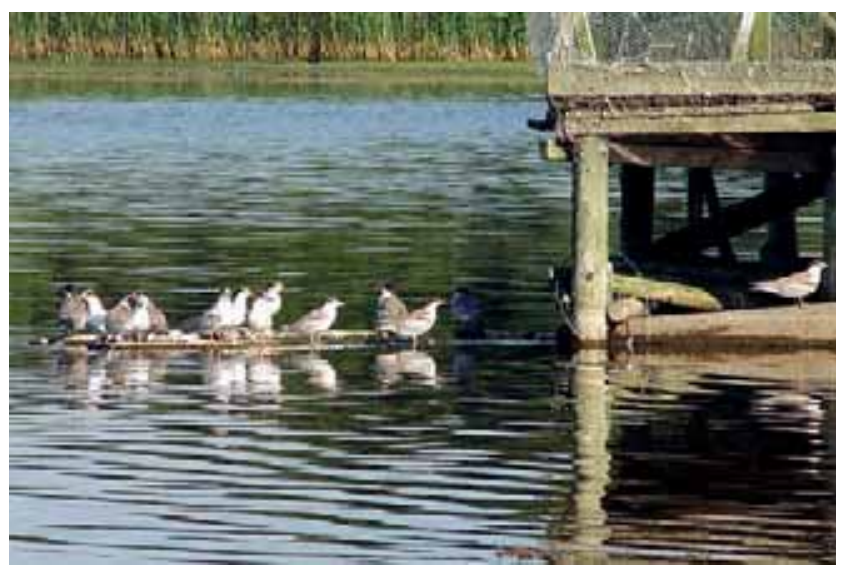

Abb. 295: Erfolgreich ausgeflogene Flussseeschwalben.
Die Entwicklung der Brutplatzangebote kann aus der Gesamtübersicht in Tabelle 13 entnommen werden.

Da während der gesamten Brutzeit wöchentlich ein bis drei Kontrollen zur Erfassung der Gelege, Ei- und Jungenzahlen erfolgten und in der Regel geschlüpfte Küken im Alter von 2-4 Tagen beringt wurden, konnten in den 27 Jahren des Bestehens der Brutkolonie am Breeser See interessante Daten gesammelt und ausgewertet werden. Bei im „Freiland“ ohne Einzäunung geschlüpften Küken in anderen Brutkolonien bleibt es weitgehend unklar, wie viele der Küken tatsächlich flügge geworden sind. Erst durch einen Wiederfang beringter Küken in den Folgejahren erhält man dort Aussagen.

Eine Teilauswertung von Brutergebnissen aus dem Breeser See von 1989 bis 1997 erfolgte bereits für das Themenheft: Flußseeschwalbe (damals noch mit „ $\beta^{\prime \prime}$ geschrieben) der Zeitschrift „Die Vogelwelt“ (LOOSE, J. 1998, Vogelwelt 119: 253-258).

Da die Kunstinseln mit einem ca. $50 \mathrm{~cm}$ hohen Zaun umgeben sind und Küken sich nicht generell verstecken können, war es möglich, Mortalitätsraten (Verluste durch Witterung und Prädatoren) sowie Ausfliegeerfolge alljährlich detailliert zu erfassen. Die Gelege wurden zuvor je Insel kartiert und nummeriert, die Eizahlen, Eiverluste und Schlupfraten, jeweils differenziert nach Erst- und Spätgelegen, aufgenommen. Die mittlere Gelegegröße lag bei Erstgelegen mit 2,80 signifikant über der von Spätgelegen $(2,60)$. In den Anfängen der Koloniegründung bis 1997 konnte festgestellt werden, dass der Bruterfolg selbst unter Einbeziehung der $50 \%$ igen Kükenverluste durch den Habicht mit 1,46 flüggen Jungen je Brutpaar ungewöhnlich hoch (ohne Prädation bis 1995 sogar bei 1,79 Küken/Paar) und damit deutlich höher als in anderen bekannten Brutkolonien war. Nur in den Jahren 1996 und 1997 unterschritt der Bruterfolg 0,9 Küken/ Paar, also den Wert, der derzeit für die mitteleuropäische Population als ausreichend zur Bestandserhaltung angenommen wird (WENDELN \& BECKER 1998). Damit war der Bruterfolg am Breeser See so hoch, dass sich die Kolonie nicht nur selbst erhalten, sondern anwachsen konnte. Dies spiegelt sich im Bestandsanstieg wider, der u.a. auf die Ansiedlung von kolonieeigenen Jungvögeln zurückzuführen war (Nachweise durch Wiederfänge von eigenen beringten Vögeln auf Gelegen).

Mit zunehmendem Alter der Brutkolonie am Breeser See beeinflussten verstärkt verschiedene Prädatoren das Brutund Ausfliegeergebnis der Flussseeschwalben. Während bis 1997 im Wesentlichen nur Habicht und Silbermöwe als Prädatoren beobachtet wurden, erschien 2009 und 2010 auch der Mink auf den Brutinseln und richtete erheblichen Schaden an. Bei hohem Wasserstand nutzten 2011 anfangs der Brutzeit auch Fischotter einige der Inseln und haben durch ihre Anwesenheit auch tagsüber zunächst die Inselbesetzung durch Flussseeschwalben behindert. Möglicherweise sind sie auch für die ersten Gelegeverluste verantwortlich. 
2012 und 2013 waren schließlich totale Ausfalljahre. Zwei bis vier Nebelkrähen hatten sich spezialisiert und räumten kontinuierlich die Gelege der Flussseeschwalben von allen Inseln ab. Es wurde zu keiner Zeit ein vollständiges Dreiergelege aufgefunden, die Seeschwalben gaben die Kolonie frühzeitig auf.

Die Brutsaison 2014 begann trotz der Störungen in den Vorjahren vielversprechend. Nebelkrähen hielten sich von den Brutinseln fern. Anfang Juni wurden wieder 110 Brutpaare auf ihren Vollgelegen registriert. Die ersten Jungen waren geschlüpft, und nun kam es zu massiver Prädation wiederum durch den Mink. Im Ergebnis wurde kein Junges flügge. Die Kolonie wurde erneut vorzeitig von den Altvögeln verlassen. Nach drei Jahren Totalverlust war der Saisonstart 2015 spannend - würden die Seeschwalben wieder kommen? - Sie kamen!

Bis Mitte Mai 2015 hatten wieder 68 Brutpaare die Inseln besetzt. Mitte Juni konnten 67 kleine Küken gezählt werden. Einige wurden zu diesem Zeitpunkt beringt. Als Ende Juni dann auch der Rest beringt werden sollte, gab es kein einziges lebendes Küken mehr auf der Insel.

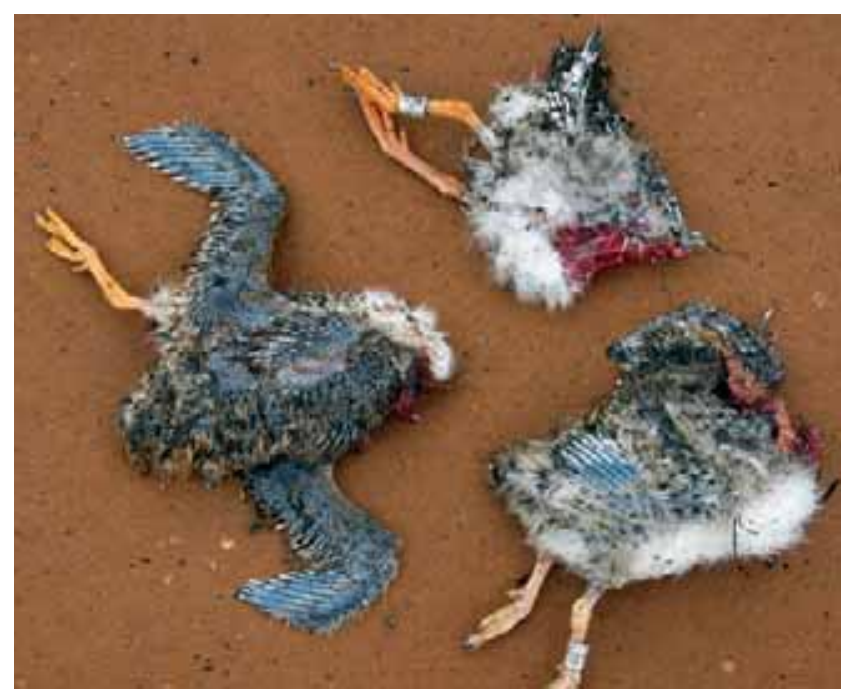

Abb. 296: Fraßreste von Flussseeschwalbenküken, die vermutlich von einem Mink stammten.

Einige wenige Kadaverreste ließen den Schluss zu, dass hier wieder eine Prädation durch den Mink oder auch Fischotter stattgefunden hatte, aber da zu dieser Zeit die Küken alle relativ klein waren, könnten auch andere Beutegreifer tätig gewesen sein. So passen die kleinen Küken in das Beutespektrum des Waldkauzes, der jedoch noch nicht als Prädator bestätigt werden konnte. Auch mehrere Graureiher hielten sich zu dieser Zeit auf dem See auf. Mit einer installierten Wildkamera gelang es bisher noch nicht, Erkenntnisse über die Prädatorenart bei kleinen Küken zu erlangen. Die Inseln sollen künftig lückenloser mit einer Kamera überwacht werden, wenn denn Flussseeschwalben auch nach dem nunmehr vierten Ausfalljahr erneut den Breeser See als Brutplatz nutzen sollten.

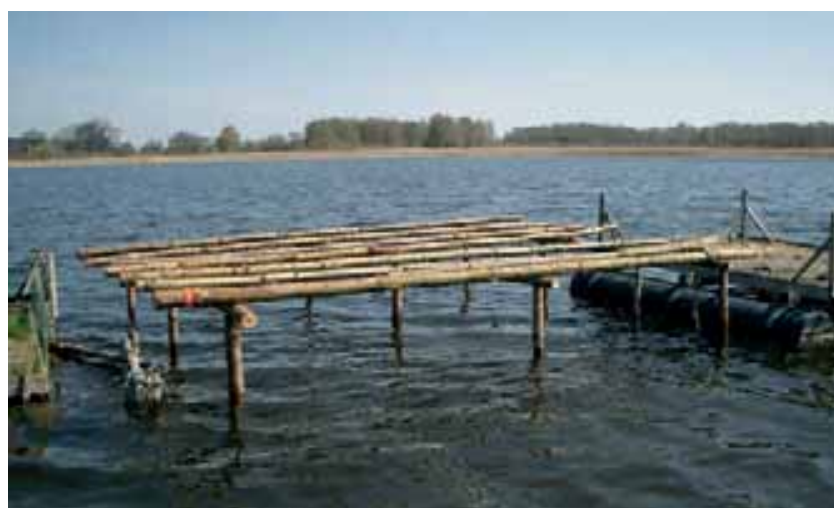

Abb. 297: Das Grundgestell für den Neubau der Insel 1 besteht aus Lärchen-Stangenhölzern aus dem Forstamt Güstrow.

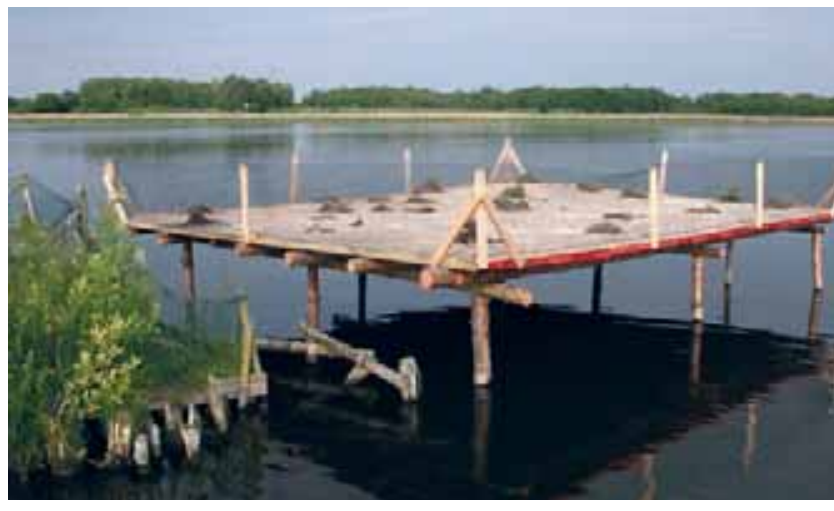

Abb. 298: Ende April 2010 ist die neue Insel 1 ist für die Brutsaison fertiggestellt.

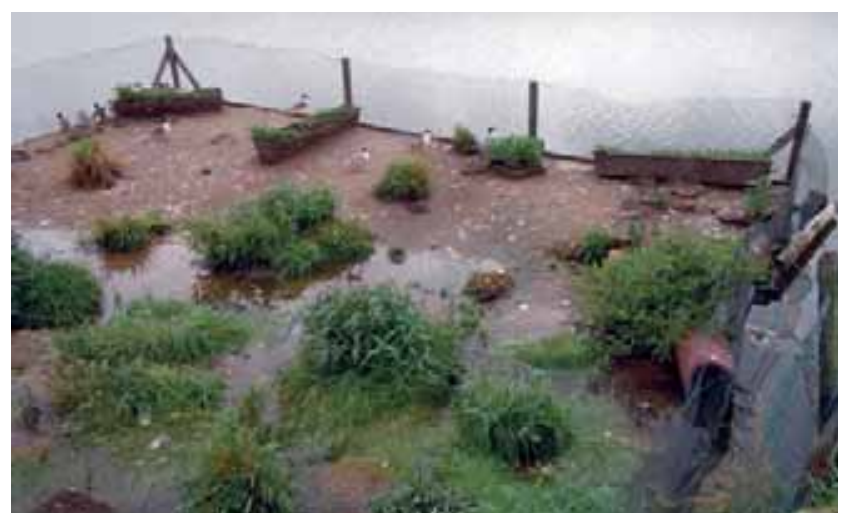

Abb. 299: Beim Neubau der Insel 1 lag die Plattform ca. 80 cm über der Wasseroberfläche. Die Standpfähle sackten in den Folgejahren soweit ab, dass die Plattform bei einem Sommerhochwasser 2012 teilweise überflutet wurde.

Eine tagsüber laufende Kamera zeichnete 2009 zufällig eine Sequenz auf, die zumindest im Einzelfall die Verringerung der Kükenanzahl von einer Kontrolle zur nächsten erklärte, die unter der Rubrik "unbekannt verschwunden" notiert wurde. Es gelang ein Video-Beleg zum Verschleppen eines Kükens durch einen auf Nahrungsraub spezialisierten Altvogel. Als dieser den Fisch aus dem Schnabel des Kükens griff, blieb der Fisch im Schlund des Kükens stecken, und das Küken wurde durch die Seeschwalbe von der Insel weggetragen. Solcherart schmarotzende Seeschwalben wurden mehrfach beobachtet. 


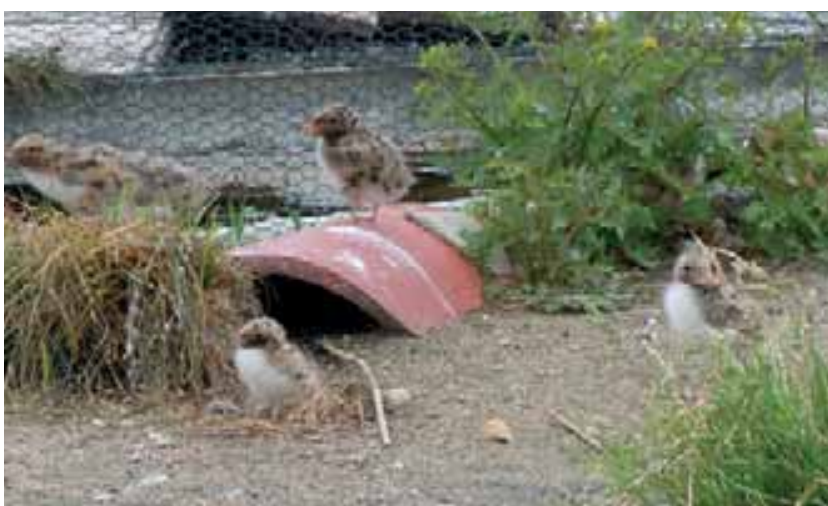

Abb. 300: Für die kleinen Küken befinden sich Dachhauben als Unterschlupf auf den Inseln. Auch die aufwachsenden Pflanzen und Grassoden bieten Versteckmöglichkeiten.

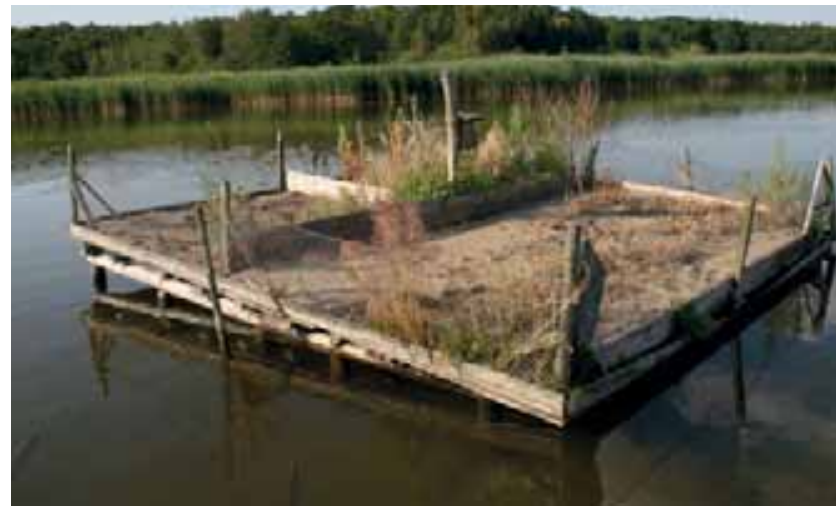

Abb. 301: Insel 3 wurde in mehrere Felder unterteilt, um den Stress für Küken durch adulte Seeschwalben zu reduzieren.

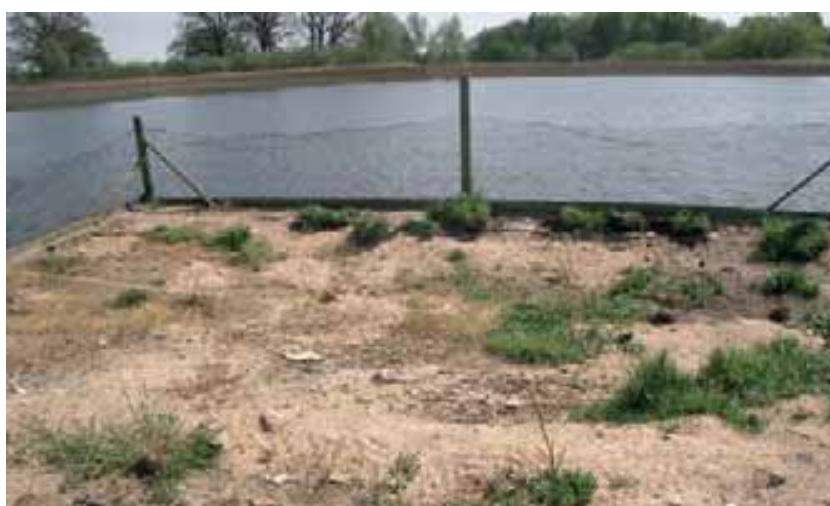

Abb. 302: Insel 2 wurde anfangs weitgehend nur mit Sand und Kies belegt.

Durch die erfolgten Ei- und Kükenprädationen in den Jahren 2012 bis 2015 waren für diesen Zeitraum keine statistischen Auswertungen wie für die Vorjahre möglich. Einerseits konnten durch das Eierabsammeln durch Nebelkrähen keine Zahlen zu den tatsächlich gelegten Eiern ermittelt werden. Andrerseits wurde bei angespannter Situation in der Kolonie auf die bisher durchgeführten 1-3 Kontrollen pro Woche verzichtet, so dass keine absoluten Jungenzahlen erhoben wurden.

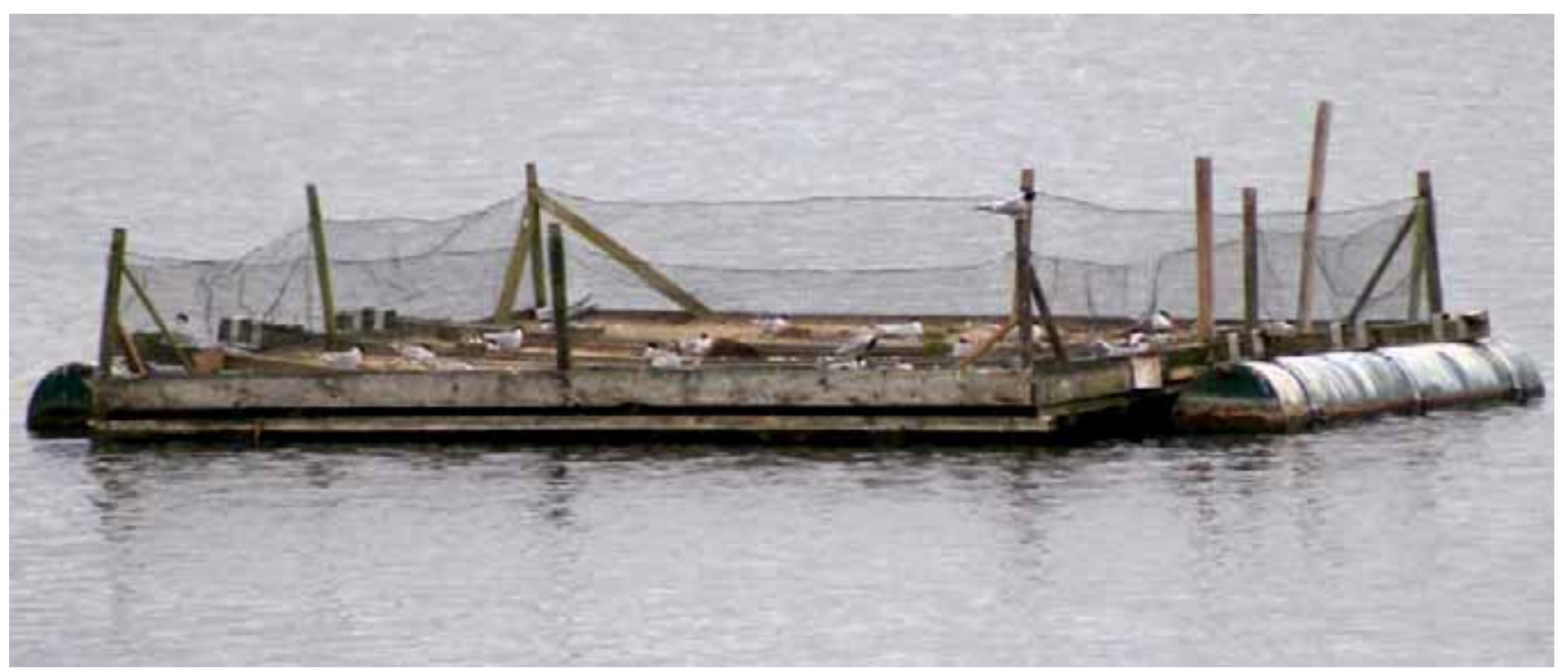

Abb. 303: Das als Kompensationsmaßnahme errichtete Brutfloss wurde zeitweilig von bis zu 50 BP besiedelt. Die geringe Höhe über der Wasseroberfläche machte es anschwimmenden Prädatoren (Mink und Fischotter) trotz des $50 \mathrm{~cm}$ hohen Zauns leicht, auf die Insel zu gelangen. 
Tabelle 13 - Entwicklung in der Flussseeschwalbenkolonie am Breeser See von 1989 bis 2015

\begin{tabular}{|c|c|c|c|c|c|c|c|c|}
\hline Jahr & $\begin{array}{l}\text { Brutpaare } \\
\text { insgesamt }\end{array}$ & $\begin{array}{l}\text { Eizahl } \\
\text { gesamt }\end{array}$ & $\begin{array}{l}\text { Anzahl ge- } \\
\text { schlüpfter } \\
\text { Küken }\end{array}$ & $\begin{array}{l}\text { Flügge } \\
\text { gewordene } \\
\text { Küken*] }\end{array}$ & $\begin{array}{l}\text { Flügge } \\
\text { Küken } \\
\% \text { zum } \\
\text { Schlupf }\end{array}$ & $\begin{array}{l}\text { Flügge } \\
\text { Küken } \\
\text { pro BP }\end{array}$ & $\begin{array}{l}\text { Nistplatzangebot } \\
\text { und Störungen }\end{array}$ & $\begin{array}{l}\text { Gesamte } \\
\text { Nistplatz- } \\
\text { fläche } \\
\text { m² }^{2}\end{array}$ \\
\hline 1989 & 1 & 5 & 1 & 1 & 100 & 1,00 & 1 Insel & $\sim 1,0$ \\
\hline 1990 & 3 & 7 & 4 & 4 & 100 & 1,33 & 1 Insel & 5,20 \\
\hline 1991 & 5 & 15 & 7 & 7 & 100 & 1,40 & 1 Insel/1 Floß & 10,60 \\
\hline 1992 & 10 & 30 & 26 & 19 & 73,1 & 1,90 & 1 Inseln/1 Floß & 10,60 \\
\hline 1993 & 14 & 46 & 37 & 35 & 94,6 & 2,50 & 1 Inseln/1 Floß & 10,60 \\
\hline 1994 & 28 & 120 & 62 & 48 & 77,4 & 1,71 & 2 Inseln/1 Floß & 10,60 \\
\hline 1995 & 40 & 112 & 83 & 67 & 80,7 & 1,68 & 2 Inseln & 10,60 \\
\hline 1996 & 42 & 122 & 69 & 30 & 43,4 & 0,66 & 3 Inseln / Prädation & 16,85 \\
\hline 1997 & 38 & 122 & 12 & 0 & 0 & 0 & $\begin{array}{l}3 \text { Inseln / 100 \% Präd- } \\
\text { ation }\end{array}$ & 15,90 \\
\hline 1998 & 39 & 126 & 59 & 27 & 45,8 & 0,87 & 3 Inseln & 35,२० \\
\hline 1999 & 35 & 108 & 85 & 78 & 91,8 & 2,२2 & 3 Inseln & 35,20 \\
\hline 2000 & 49 & 154 & 114 & 102 & 89,5 & 2,08 & 3 Inseln & 43,70 \\
\hline 2001 & 55 & २०२ & 144 & 82 & 56,9 & 1,49 & 3 Inseln & 43,70 \\
\hline 2002 & 88 & 358 & 155 & 89 & 57,4 & 1,01 & 3 Inseln/1 Floß / Sturm & 38,80 \\
\hline 2003 & 95 & 325 & 192 & 111 & 57,8 & 1,17 & 3 Inseln/1 Floß / Sturm & 66,00 \\
\hline 2004 & 115 & 338 & 235 & 138 & 58,7 & 1,20 & 3 Inseln/1 Floß & 66,00 \\
\hline 2005 & 147 & 423 & 288 & 176 & 61,1 & 1,20 & 3 Inseln/1 Floß & 66,00 \\
\hline 2006 & 162 & 465 & 314 & २०२ & 64,3 & 1,25 & 3 Inseln/1 Floß & 66,00 \\
\hline 2007 & 140 & 400 & 267 & 83 & 31,1 & 0,59 & 3 Inseln/1 Floß & 66,00 \\
\hline 2008 & 143 & - & 204 & 96 & 47,0 & 0,67 & 3 Inseln/1 Floß & 66,00 \\
\hline 2009 & 140 & 410 & 165 & 54 & 32,7 & 0,38 & $\begin{array}{l}4 \text { Inseln/1 Floß, Präd- } \\
\text { ation }\end{array}$ & 78,25 \\
\hline 2010 & 148 & 442 & 278 & 108 & 38,8 & 0,73 & $\begin{array}{l}4 \text { Inseln/1 Floß, Präd- } \\
\text { ation }\end{array}$ & 80,00 \\
\hline 2011 & 150 & 464 & 247 & 158 & 64,0 & 1,18 & 5 Inseln/1 Floß & 84,25 \\
\hline 2012 & 70 & $?$ & 0 & 0 & 0 & 0 & $\begin{array}{l}5 \text { Inseln/1 Floß, } 100 \text { \% Ei- } \\
\text { Prädation - Nebelkrähen }\end{array}$ & 84,25 \\
\hline 2013 & 25 & $?$ & 0 & 0 & 0 & 0 & $\begin{array}{l}5 \text { Inseln/1 Floß, } 100 \text { \% Ei- } \\
\text { Prädation - Nebelkrähen }\end{array}$ & 84,25 \\
\hline 2014 & 114 & {$[305]$} & {$[>69]$} & 0 & 0 & 0 & $\begin{array}{l}4 \text { Inseln/1 Floß } 100 \% \\
\text { Prädation durch Mink }\end{array}$ & 83,75 \\
\hline 2015 & 68 & {$[<168]$} & {$[>67]$} & 0 & 0 & 0 & 4 Inseln, 100\% Prädation & 62,50 \\
\hline \multirow{2}{*}{\multicolumn{2}{|c|}{ Summe: }} & 4.794 & 3.048 & 1.715 & 63,7 & 1,025 & & \\
\hline & & [5.267] & [3.184] & & 1989-2011 & & & \\
\hline
\end{tabular}

*) Differenzen zwischen flügge gewordenen und geschlüpften Küken gehen ohne Prädation zumeist auf Wettereinflüsse (Hitze, Kälte, Starkregen und Sturm) beim Schlupf zurück. Es wurden auch „unbekannt verschwundene Küken“ notiert. 


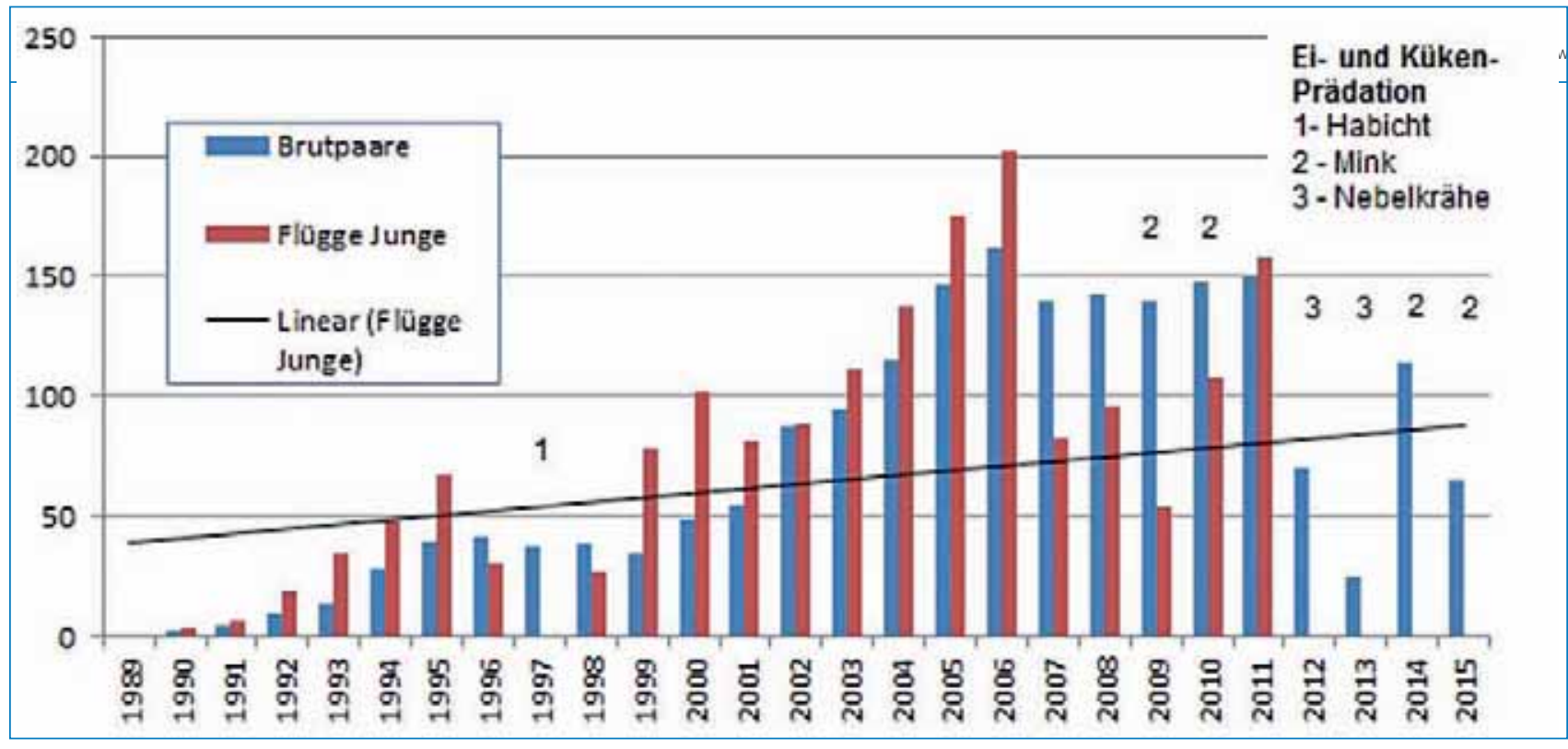

Diagramm 32: Entwicklungen in der Flussseeschwalbenbrutkolonie im NSG Breeser See (Die Trendlinie gibt die Entwicklung der jüngsten fahre bei den fungen nicht wieder.)

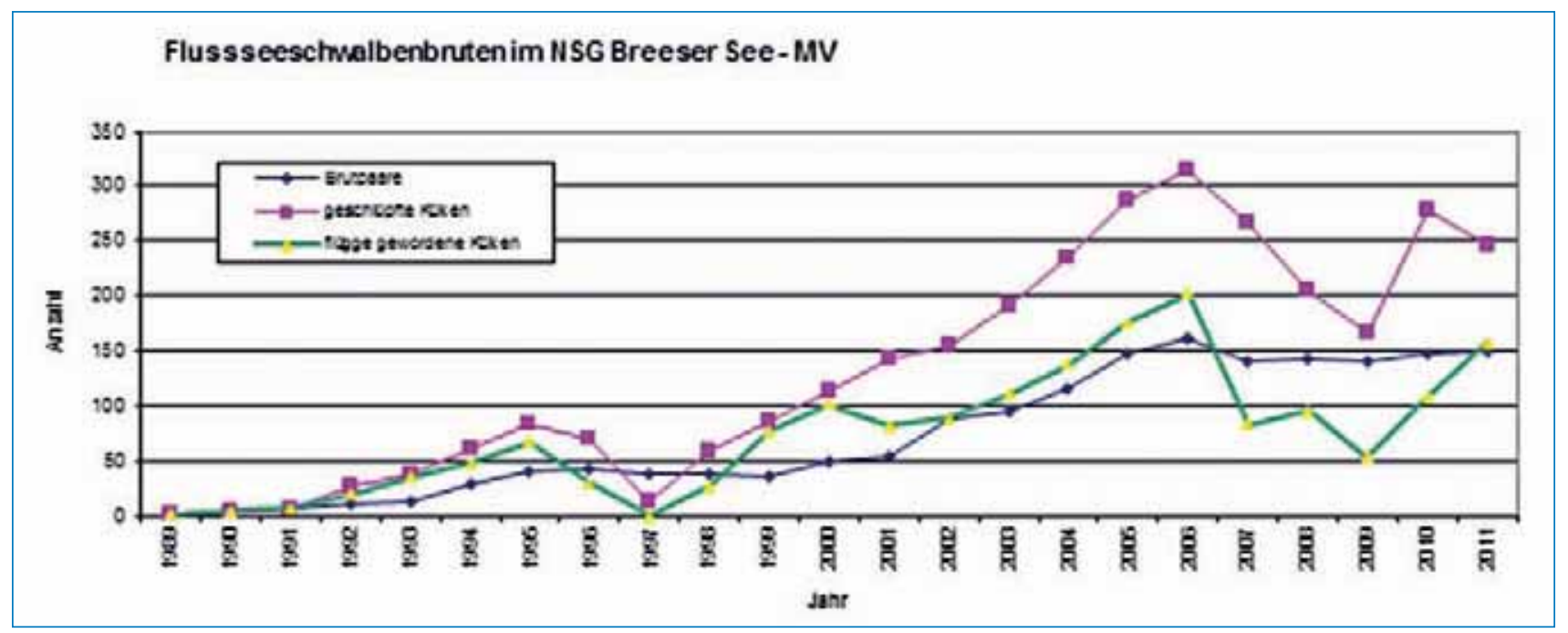

Diagramm 33: Entwicklungen in der Flussseeschwalbenbrutkolonie im NSG Breeser See mit insgesamt geschlüpfter Kükenzahl

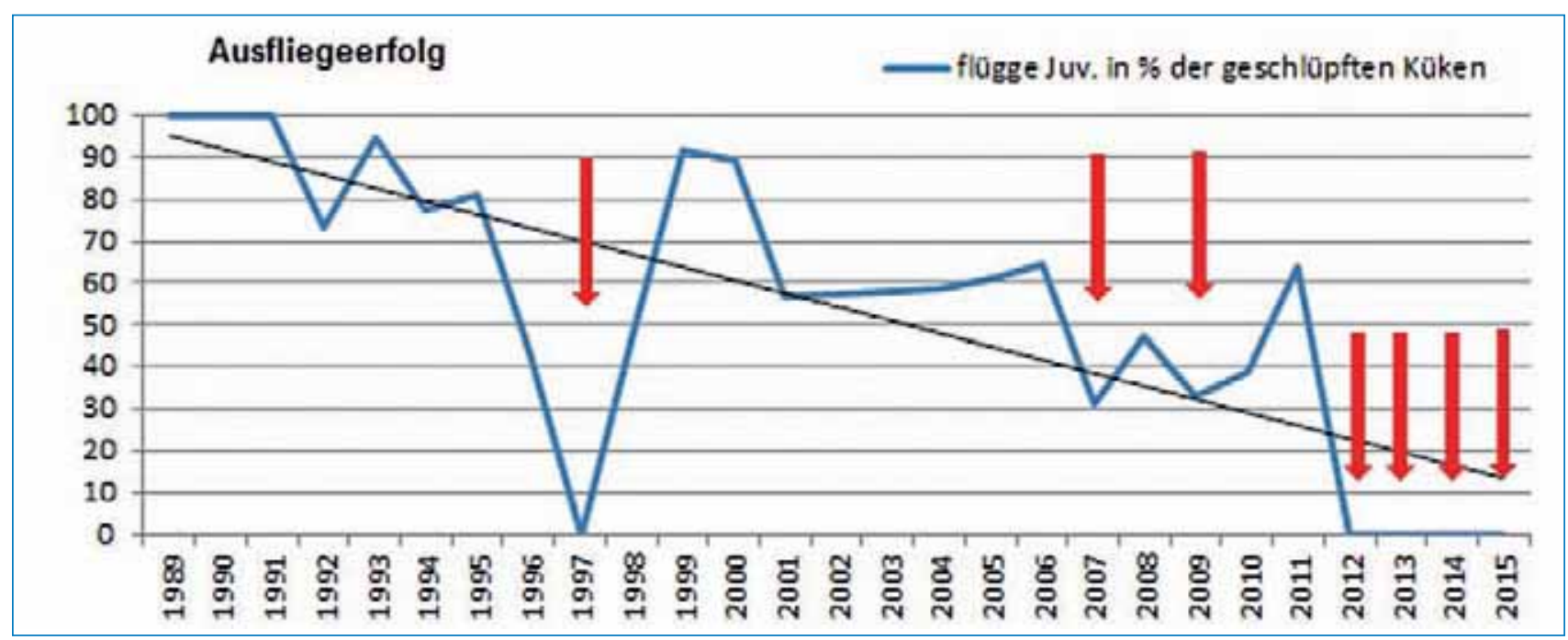

Diagramm 34: Ausfliegeerfolg der Küken von allen Inseln zusammen mit linearer Trendlinie (rote Pfeile - Jahre mit Prädationen) 


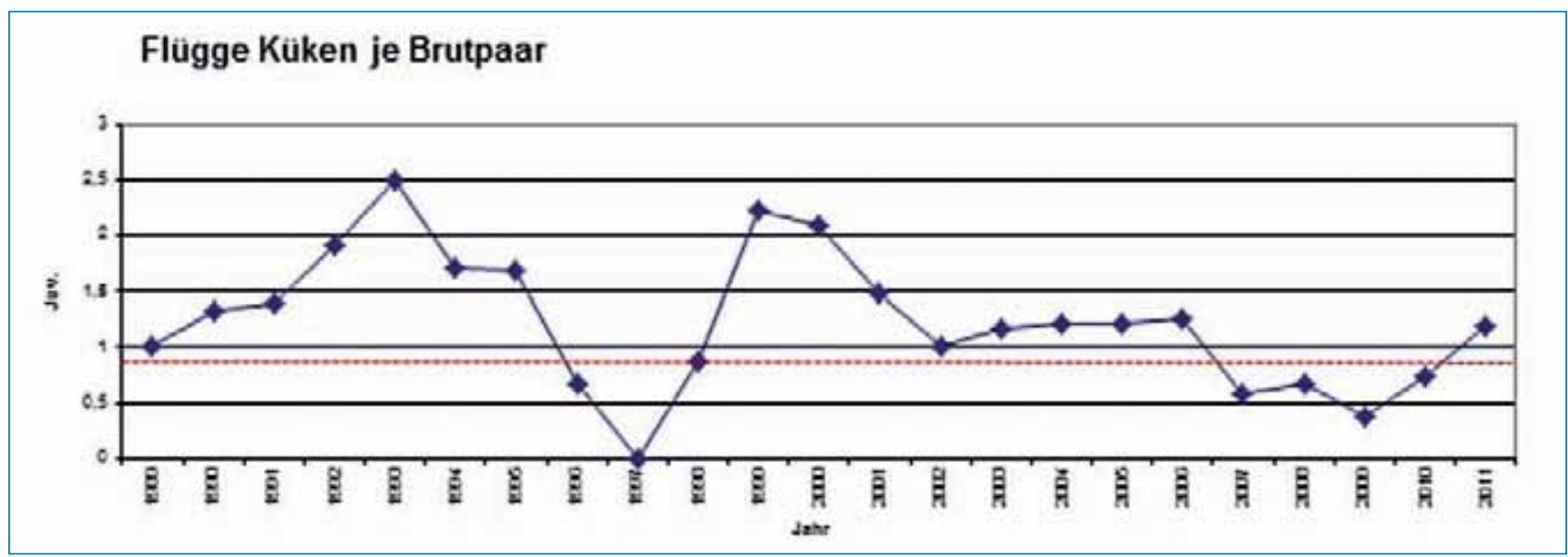

Diagramm 35: Jährlich von allen Inseln flügge gewordenen Küken je Brutpaar. Ab dem Wert von 0,9 Küken/BP gilt, die Kükenzahl ist ausreichend zur Bestandserhaltung. Darüber hinaus kann sich örtliche Population selbst vermehren.

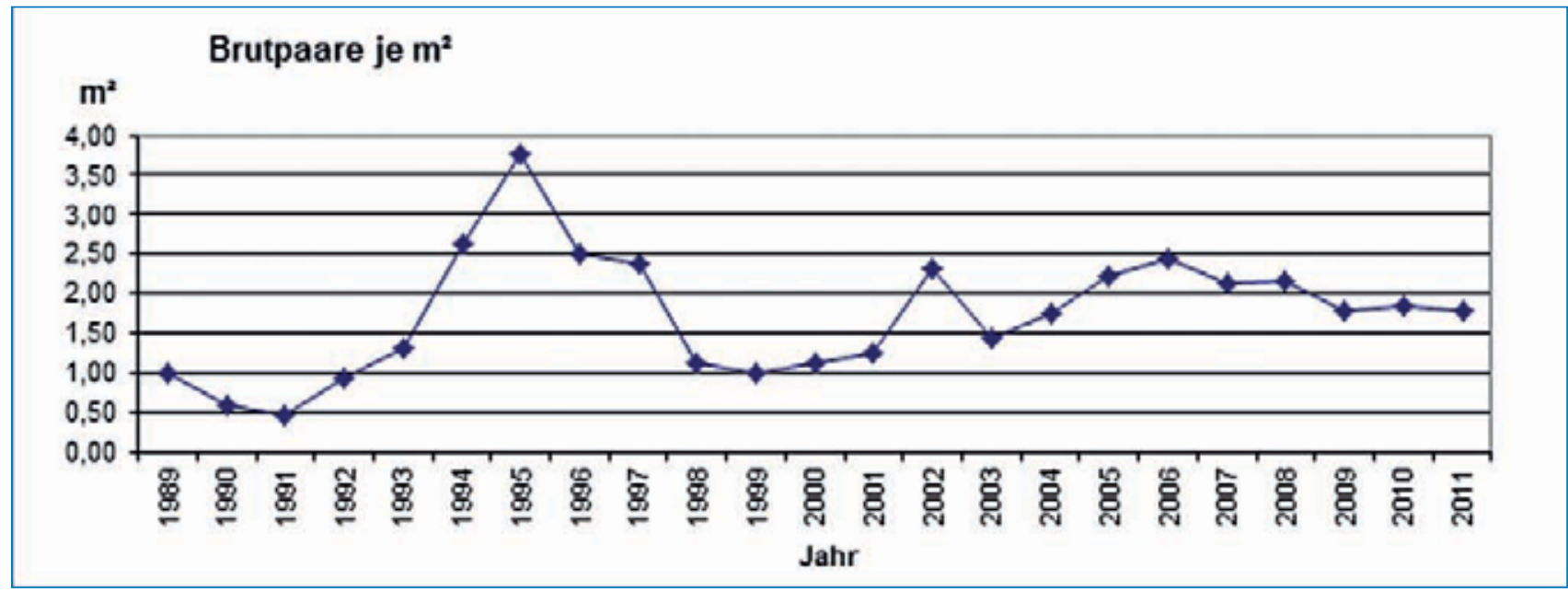

Diagramm 36: Ausnutzung der Brutplatzfläche bezogen auf Brutpaare auf allen Inseln

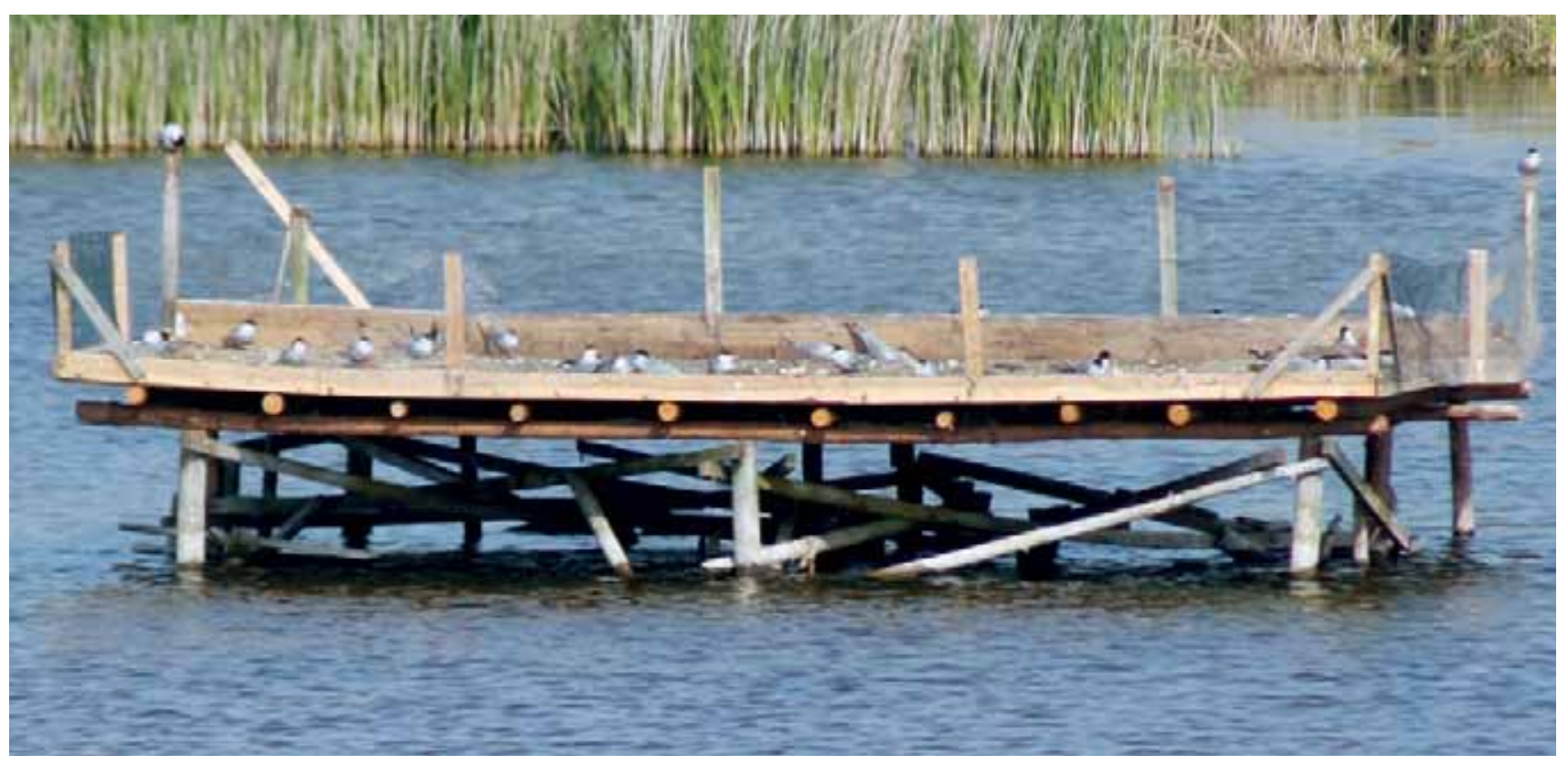

Abb. 304: Neuaufbau der Insel 2 über der abgesackten Plattform. Die unterhalb verbliebenen Latten wurden von ausgeflogenen Küken als Ruheplätze genutzt. Mit dem Überkragen der Plattform sollte es dem Mink erschwert werden, die Insel zu erklimmen. 


\title{
10.3 Haubenlerchen -
}

\section{Farbberingungsprogramm in Güstrow 1987-2003}

\author{
Angela Martin
}

Wenn ich heute in Güstrow durch Neubaugebiete aus den 1980er Jahren gehe, kommen mir diese trotz der umherwimmelnden Menschen „unbelebt“ vor - ich vermisse den lauten melodischen Ruf: „tri-tri-trü“. Vor zwei Jahrzehnten war dieser Vogelruf noch vielerorts allgegenwärtig zu hören und der trippelnde Vogel zwischen den Beinen der Leute zu sehen, die Haubenlerche.

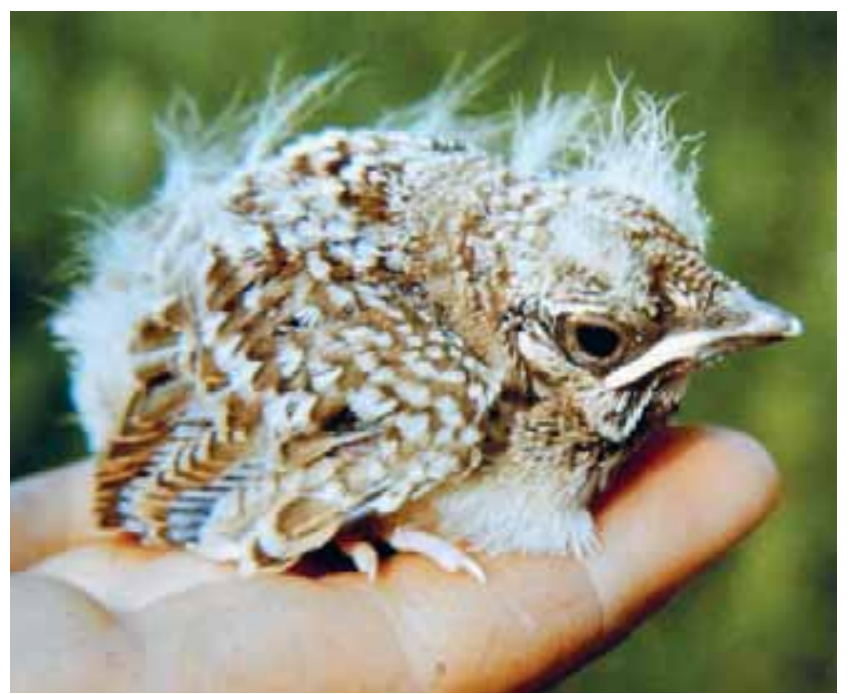

Abb. 305: Funge Haubenlerchen in diesem Alter bleiben nach der Beringung nicht mehr im Nest. Foto: A. Martin.

Im Jahre 1981 hatte ich die Beringerprüfung als einzige Frau in diesem Lehrgang auf Hiddensee abgelegt und suchte nun eine konkrete Aufgabe. Die sollte realisierbar und bisher kaum oder noch gar nicht angepackt worden sein. Eine Bekannte, die in Greifswald studierte, machte mich auf die Art ,Haubenlerche“ als Beringungsobjekt aufmerksam. Die dortige FG praktizierte wohl gerade die nicht ganz einfache Nestersuche.

Da ich bei unterschiedlichen Sperlingsvögeln der Suche der Nester bereits als Kind und Jugendliche gern nachging und sie als spannend empfand, war diese zeitaufwändige Methode kein Novum und nicht abschreckend für mich. Beharrlichkeit und Geduld ließen mich wohl die unendliche Zahl an Beobachtungsstunden in all den Jahren mit Fassung tragen.

Offene Fragestellungen zu der Art waren im „Handbuch der Vögel Mitteleuropas“ - Urs N. Glutz von BLOTZHEIM (Hrsg.) im Kapitel über die Haubenlerche zu finden. Diese waren Basis für die Beantragung eines Farbberingungsprogramms, denn nur so ließ sich klären, ob z.B. die Zweiergemeinschaften im Winter auch die späteren Brutpaare bilden.
Die Annahme, dass wegen der vielen gefundenen Nester nur eine „semi-individuelle“ Beringung, d.h. die Jungen eines Nestes erhalten die gleiche Kombination der Farbringe, in Frage käme, wurde durch die Praxis zerstreut. Bei näherer Prüfung ergab sich dann auch schnell die Einsicht, dass allein mit 6 Farben (weiß, schwarz, blau, grün, rot und gelb) so viele Kombinationen bei Verwendung von ein bis drei Farbringen an zwei Füßen in Verbindung mit dem Metallring der Vogelwarte möglich sind, dass eine größere Anzahl von Haubenlerchen individuell gekennzeichnet werden könnten. Damit waren auch die Auswertungsmöglichkeiten späterer Ablesungen wesentlich erweitert. - In den 17 Jahren Farbmarkierung wurden die Kombinationsmöglichkeiten nicht ausgeschöpft.

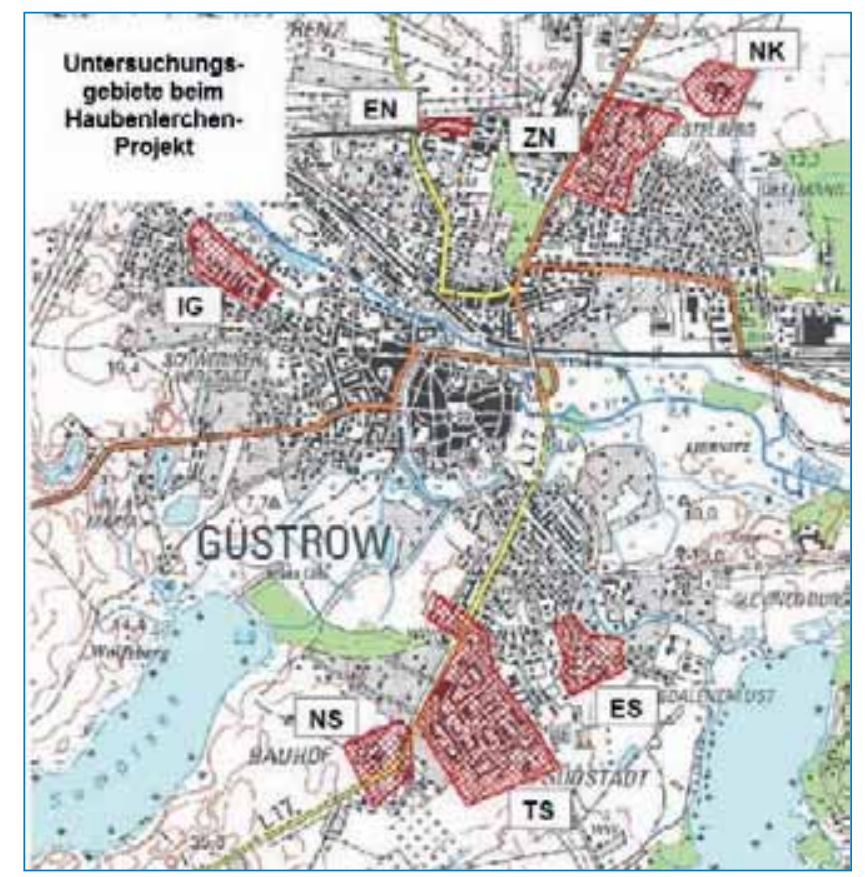

Karte 21: Untersuchte Brutgebiete der Haubenlerche in Güstrow

TS - Teilgebiet der Südstadt - 47 ha (ab 1986)

ES - Neubau, Erweiterung Südstadt - 12 ha (ab 1997)

NS - Neubau, Eigenheimsiedlung Bauhof - 13 ha (ab 1999)

ZN - Zweites Neubaugebiet Nordstadt - 24 ha (ab 1996)

EN - Erweiterung Nordstadt - 2 ha (ab 1999)

NK - Neubau Krankenhaus - 10 ha ( ab 2000)

IG - Industriegebiet (Teilbereich) - 12 ha (ab 2000)

In den Jahren 1987 bis 2003 wurden 149 Nester gefunden und 264 Jungvögel und nur zwei Altvögel farbberingt. Das Fangen von Altvögeln in einem Lebensraum mit sehr dichter Besiedlung durch den Menschen war fast unmöglich. Es gelang zweimal jeweils auf dem Nest mit Jungvögeln 


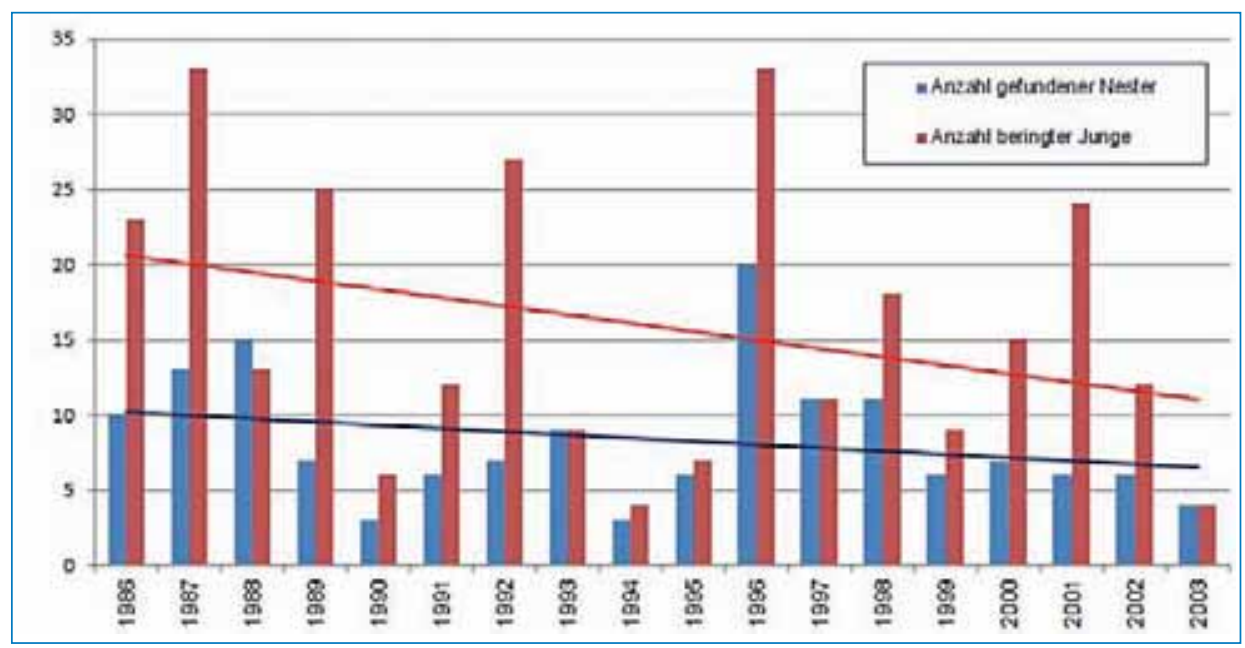

Diagramm 37: Während der Projektlaufzeit jährlich gefundene Nester und Zahl der beringten fungvögel der Haubenlerche in Güstrow jeweils mit den Trendlinien zur Entwicklung.

mit einem Fangkorb, der sonst bei Flussseeschwalben ververwendet wird. Die Auslösung per Hand war nur in zwei kleinen Innenhöfen in Kindergärten möglich.

Die Haubenlerchenberingung wurde bereits 1986, noch bevor der Farbberingungsantrag genehmigt worden war, als „normale“ Beringung begonnen. Insgesamt erhielten also 289 Haubenlerchen Aluringe. Die Zahl beringter Vögel innerhalb eines Jahres schwankte zwischen 4 und 33. Die höchste Zahl wurde nur zweimal erreicht.

Bereits im Jahr 2002 und stärker noch 2003 machte sich ein Bestandsrückgang bemerkbar, den ich aber nicht vordergründig wahrnahm. Ich war so auf das Auffinden der Nester fixiert, dass ich zunächst mehr die „Schuld“ nur als Nichterfolg bei mir sah.

2004 und 2005 war der Bestand bei der Haubenlerche in Güstrow soweit gesunken, dass die Nestersuche einen enormen Zeitaufwand erfordert hätte. Das Beringungsprojekt wurde abgebrochen.

Mit einer kurzen Zusammenfassung im FG-Jahresbericht Nr. 38/2005 wurde die über 18 Jahre laufende und tausende Stunden umfassende Arbeit an den Haubenlerchen abgeschlossen. Nachfolgende Erkenntnisse konnten u.a. aus diesem Projekt gewonnen werden:

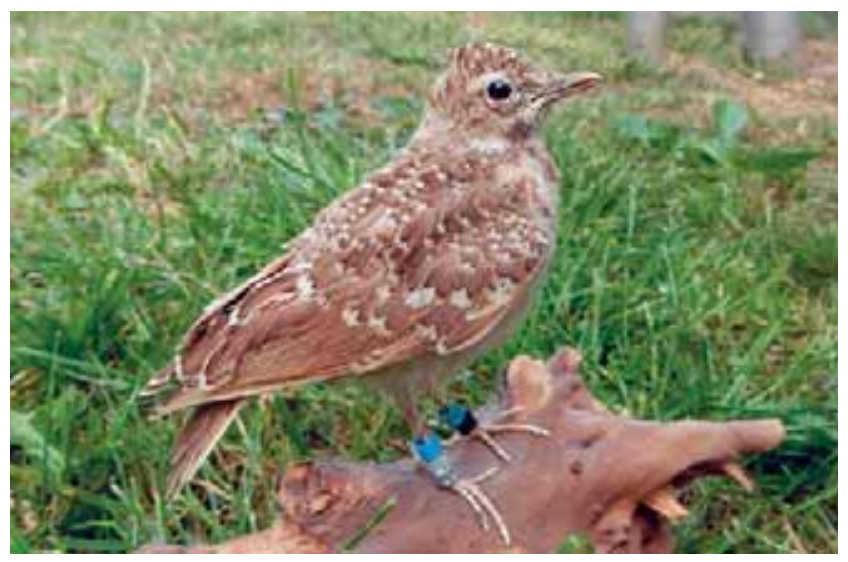

Abb. 306: Präparat einer jungen Haubenlerchen mit angelegter Farbringkombination (rechts: blau über Alu, links: blau-schwarz) nach Straßentod. Foto: A. Martin.
- Haubenlerchen sind bei der Wahl des Nistplatzes sehr anpassungsfähig. Sich in der Nähe bewegende Menschen und laufender Verkehr behindern eine Nestanlage nicht. Eher wird sie begünstigt, da hier der Prädatorendruck geringer ist.

- Haubenlerchen nehmen auch Flächen auf Gründächern in Höhen bis zu 18 m über dem Erdboden als Nistplatz an (KMG-Klinikum in der Nordstadt).

- Die Brutzeit beginnt mit dem Nestbau Ende März/ Anfang April; der früheste Zeitpunkt, an dem fast flügge Jungvögel beringt wurden, war der 22.4., als späteste Beringung wurde der 24.8. registriert.

- Der Erbrütungsort führt nicht zu einer Prägung auf einen bestimmten Biotoptyp. Haubenlerchen, die in einem Innenhof aufwuchsen, siedelten sich in Gegenden ohne Innenhöfe an, am Stadtrand aufgewachsene Vögel behaupteten Reviere im Stadtinneren.

- Die von Jungvögeln im Folgejahr besiedelten Brutreviere wurden in der Nähe des Erbrütungsortes als auch in Entfernungen von bis über $3,7 \mathrm{~km}$ festgestellt. Eine Brutansiedlung außerhalb der Stadt Güstrow konnte nicht belegt werden.

- Haubenlerchen unterliegen offensichtlich einer hohen Mortalitätsrate. Lediglich 15 der insgesamt 266 farbig beringten Vögel konnten noch in nachfolgenden Brutperioden beobachtet werden. Viele Fragestellungen des Projektes ließen sich daher nicht beantworten.

- Gelege- und Jungenverluste treten vor allem durch die Mahd der Flächen, verwilderte Hauskatzen und auf den Flächen frei laufenden Hunden auf. Bei Neststandorten in der Nähe von viel befahrenen Straßen fallen nicht flügge Junge auch dem Straßenverkehr zum Opfer.

- Im Herbst werden offenbar die Reviergrenzen gelockert oder aufgehoben.

- Bei der Art können Vögel auch unverpaart bleiben. Ein vermutlich männlicher Vogel wurde viele Male über eine Zeitdauer von über 1.479 Tagen beobachtet, er war nur kurzzeitig mit einem zweiten Vogel zu sehen. 
Außer den für Haubenlerchen „normalen“ Brutplätzen wie Seitenstreifen an Straßen, Verkehrsinseln und Gründächer, wurde als kurioser Brutplatz auch der Versuch einer Nestanlage auf einem völlig vegetationslosen Schrägdach dokumentiert (Abb. 313). Allerdings kam es dort nicht zur Bebrütungsphase. Da das Nest nicht direkt kontrolliert werden konnte, blieb der Aufgabezeitpunkt unbekannt. Die Brut innerhalb eines Betonbrunnenringes war ebenso ungewöhnlich, da der brütende Vogel keine Möglichkeit zur Beobachtung des Geländes und damit sich annähernder Feinde hatte (Abb. 309).

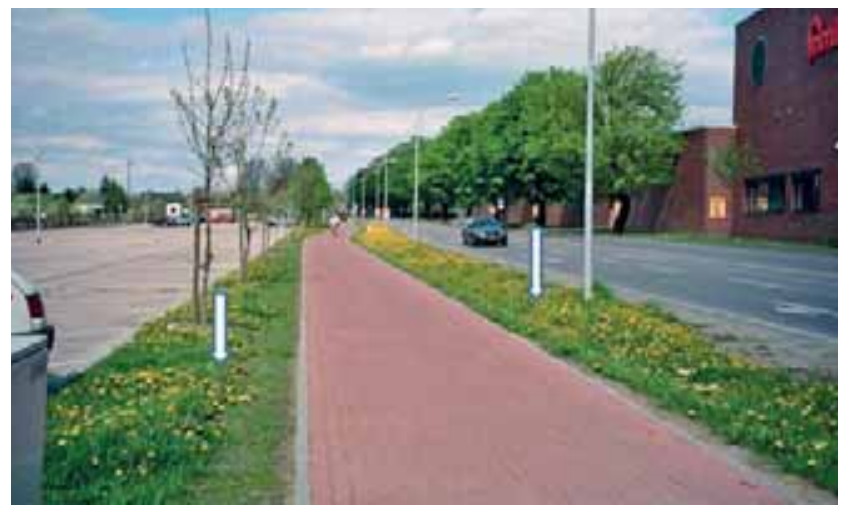

Abb. 307: Bruthabitat der Haubenlerche im Straßenrandbereich. Foto: A. Martin.

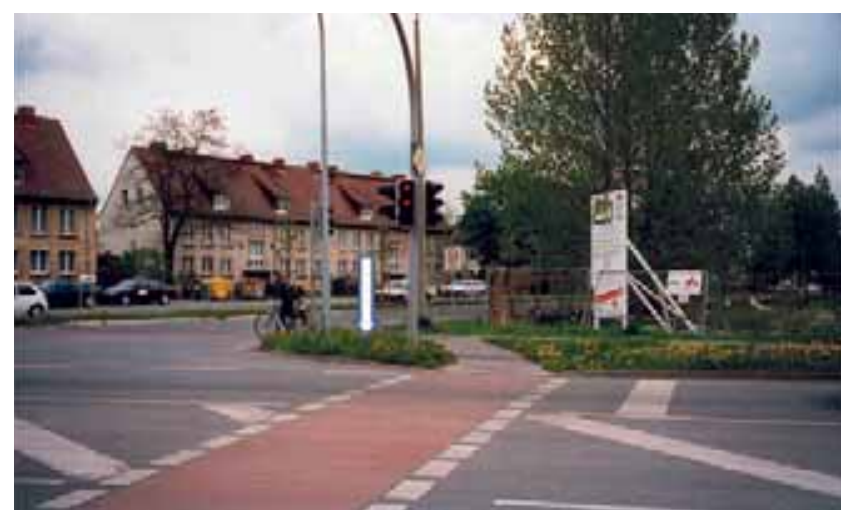

Abb. 308: Bruthabitat der Haubenlerche im Straßenrandbereich auf kleiner Verkehrsinsel. Foto: A. Martin.

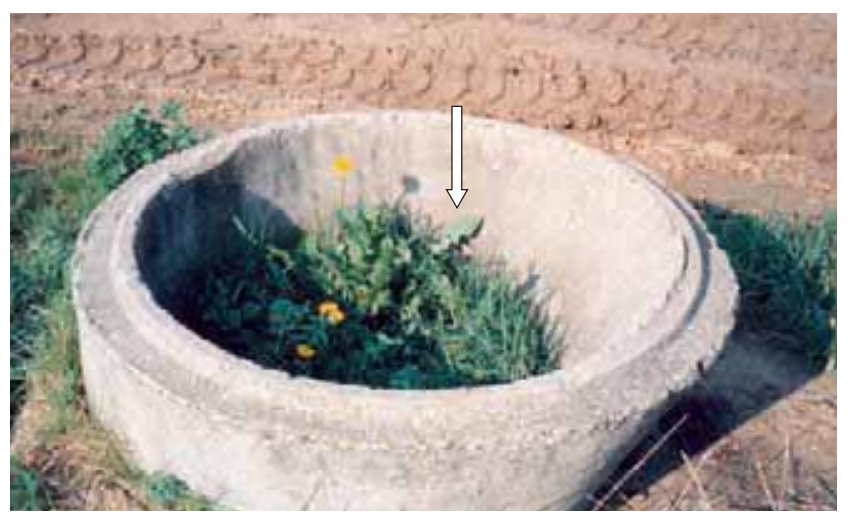

Abb.309: 1995 hatte eine Haubenlerche im Neubaugebiet der Güstrower Nordstadt ein Nest innerhalb eines Brunnenringes am Rande einer Ödlandfläche errichtet. Die Brut verlief nicht erfolgreich. Foto: A. Martin.
Für die eigentlich für 2015 geplante Neuauflage der Avifauna von $\mathrm{M}-\mathrm{V}$ hatte ich mich als Artbearbeiter für die Haubenlerche zur Verfügung gestellt. So konnten Ergebnisse der unzähligen Stunden bei der Beobachtung der Art in die Manuskriptabfassung u. a. wie folgt einfließen:

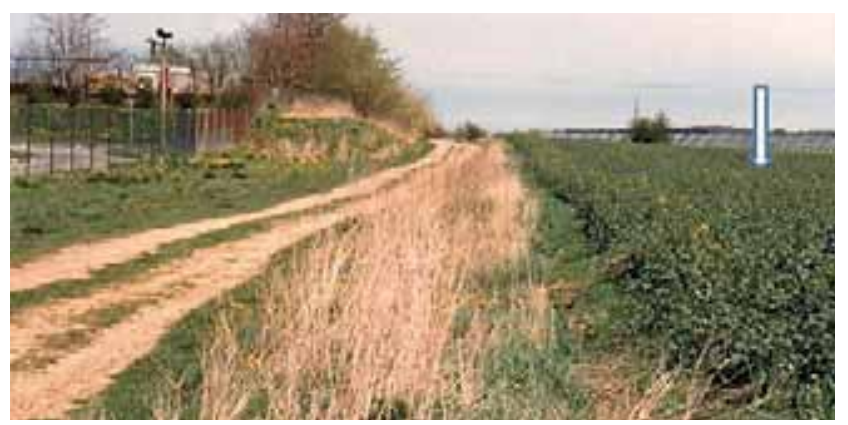

Abb. 310: Ackerrand-Biotop. Im Mai 1997 brütete ein Paar der Haubenlerche sogar fast $10 \mathrm{~m}$ vom Rand entfernt im Rapsfeld. Hier kann es zu Überschneidungen in der Habitatnutzung durch Feldlerchen kommen. Foto: A. Martin.

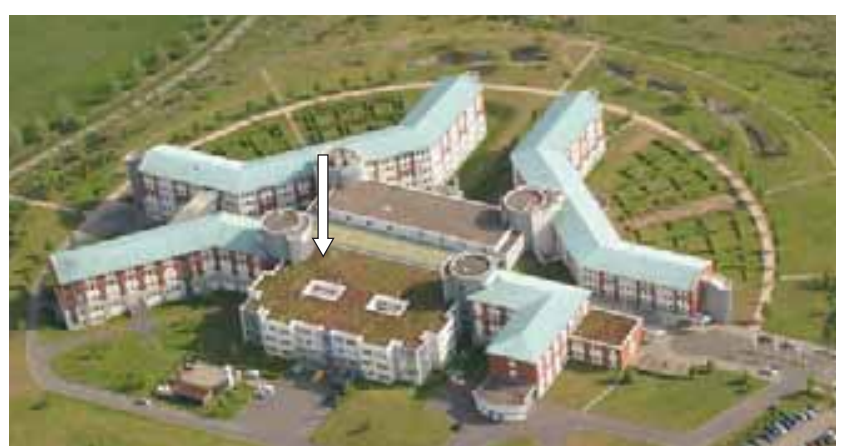

Abb. 311: KMG-Klinikum Güstrow mit großer Gründachfläche. (Luftbildaufnahme Google-Earth)

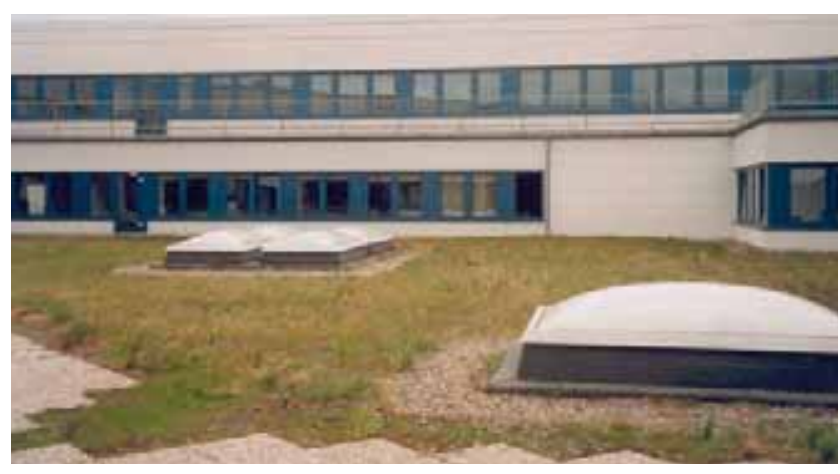

Abb. 312: Innenhof - Gründach in der Südstadt. Foto: A. Martin.

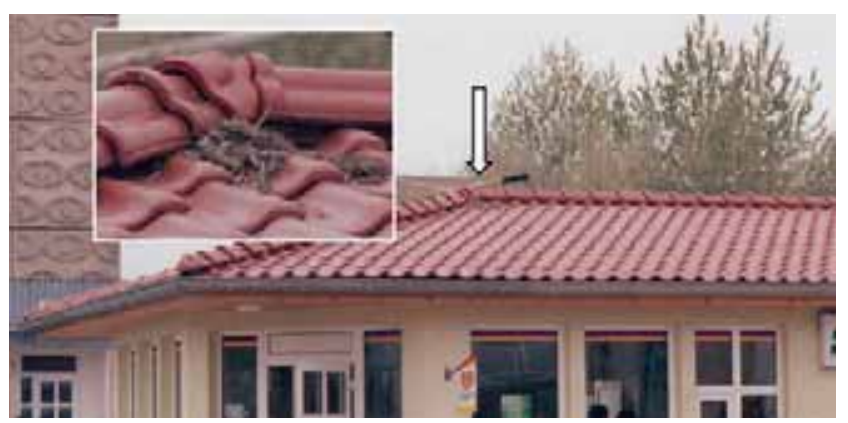

Abb. 313: Außergewöhnlicher Neststandort auf einem Ziegeldach ohne jegliche Deckung. Foto: f. Loose. 


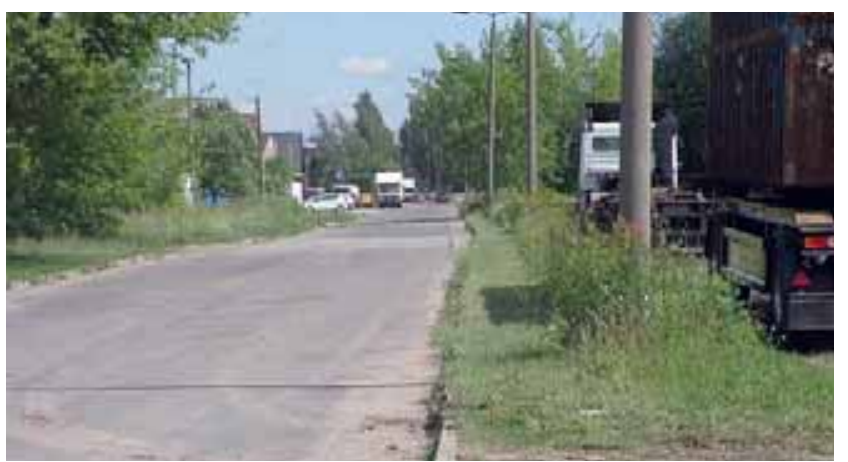

Abb. 314: Nur wenn Straßenränder in der Brutzeit nicht komplett gemäht werden, haben Nester der Haubenlerche eine Chance. Foto: A. Martin.

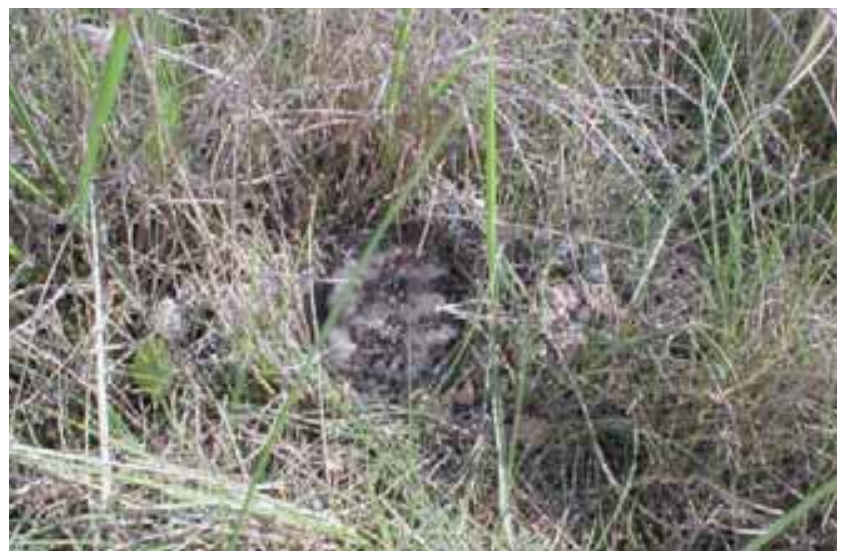

Abb. 315: Küken im Beringungsalter drücken sich in die tiefe Nestmulde; nach dem Beringen verlassen sie sofort das Nest. Foto: A. Martin.

In der Güstrower Südstadt (ca. 47 ha) hielten sich in der Brutzeit bis Anfang des neuen Jahrtausends 5-7 Brutpaare auf, woraus sich eine Siedlungsdichte von 1,06-1,48 BP/ 10 ha ergibt.

Die Gelegestärke betrug durchschnittlich 3,97 Eier. Über alle Untersuchungsjahre ergab sich ein leicht sinkender Durchschnitt. Bei den Güstrower Untersuchungen wurden neben „normalerweise“ drei bis fünf Eiern in den Nestern acht Zweier- und ein Sechsergelege gefunden.

Es traten sehr hohe Gelegeverluste auf. 55 von 143 Gelege gingen vor der Beringung verloren. Sie wurden entweder aus unbekannten Gründen verlassen, oder die Eier oder die Jungen wurden geraubt. Als Prädatoren kamen an erster Stelle verwilderte Hauskatzen in Frage.

Fast jedes Brutpaar musste auf Grund hoher Gelegeverluste einige Nachgelege zeitigen. Aus diesem Grund erstreckte sich die Brutperiode bis über den gesamten August. Die Jungvögel wurden also bis weit in den September hinein gefüttert. Nach dem Verlassen des Nestes waren die Jungen noch total flugunfähig und hielten sich in dieser Zeit sehr versteckt, so dass keine Beobachtungen vor dem 10.Tag nach der Beringung gelangen. Erst im Alter von etwa 30-35 Tagen, wenn sie die volle Flugfähigkeit erreicht hatten, aber noch oft gefüttert wurden, waren die Jungvögel regelmäßig zu beobachten.

\section{Neststandorte - Prozent ( $n=140)$}

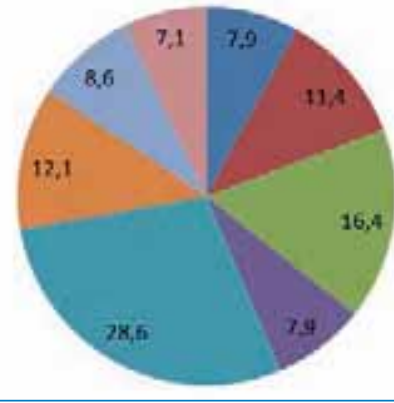

\section{" Verkehrsinsel}

wstr.begleit. Grün

winnenhot

arondach

modland + autgelass. Acker

Easenfläche

m Acker

= sonstige

Diagramm 38: Verteilung der Neststandorte der Haubenlerche auf Habitattypen bei den Güstrower Untersuchungen. (vereinfachte Habitate)

Von 266 farbmarkierten Haubenlerchen konnten in der gesamten Projektlaufzeit nur 37 nach der Beringung (alle zusammen $179 \mathrm{mal}$ ) wieder beobachtet werden. Die Ablesehäufigkeit eines Vogels lag zwischen ein- und 26mal. Nur ein Vogel konnte über eine Zeitdauer von 1.479 Tagen 66 mal kontrolliert werden. Die Ursachen für die geringe Zahl von Rückmeldungen (hohe Mortalität oder Verstreichen der Vögel) sind nicht eindeutig geklärt. Nur drei farbig markierte Haubenlerchen wurden außerhalb der Stadt Güstrow in 5, 16 und $19 \mathrm{~km}$ entfernten Ortschaften (Lüssow, Kronskamp und Möllen) beobachtet.

Das Haubenlerchen-Projekt war auf der Homepage unserer Fachgruppe www.ornithologieguestrow.de mit dem Aufruf zur Meldung von beringten Haubenlerchen vorgestellt worden. Einige Jahre nach dem Projektende fand ich in meinem Posteingang eine Mail mit Betreff ,Haubenlerche'.

Ein Herr Karl-Wilhelm Kirsch (damals Lehrbeauftragter für Ókologie der Uni Lüneburg) hatte durch diese Homepage Kenntnis von meinen Haubenlerchen-Aktivitäten erhalten. Er befasste sich in Niedersachsen in einem NABU-Projekt mit den Haubenlerchen. Wenige Tage später kam es zu einem persönlichen Kontakt, er besuchte mich und ich zeigte ihm in der Güstrower Südstadt einige der früheren Bruthabitate der Haubenlerche. Herr Kirsch meinte, dass die vielen von mir gesammelten Daten eine tiefere Auswertung und Veröffentlichung erfahren müssten. Es sollte eventuell möglich sein, mit den Daten den überall festgestellten Niedergang des Bestandes der Haubenlerchen statistisch zu belegen. Mit Auswertungen meiner alten Aufzeichnungen begann eine lange und intensive Arbeitszeit. Manches hätte früher ausführlicher aufgeschrieben werden müssen. - Aber: Das Manuskript befindet sich nunmehr in der Endphase der Bearbeitung.

Der aktuelle Bestand 2015 beträgt maximal noch zwei Brutpaare der Haubenlerche in Güstrow. 


\subsection{Sperber - der kleine heimliche Greif}

\section{Angela Martin}

Einen dunklen Schatten nur für Sekunden gesehen und danach evtl. Angstgeschrei einer Kleinvogelschar - das sind im Winter mögliche Beobachtungen unseres heimlichsten heimischen Greifs. Mitunter sieht man ihn ganz offen über das Terrain gleiten. Wir haben allerdings in diesem Falle meist keinen einheimischen Sperber bemerkt, sondern einen Wintergast aus skandinavischen Gefilden.

Mein Interesse an dieser heimlich lebenden Art wurde durch einen Zufallsfund eines ornithologisch interessierten Forstlehrmeisters geweckt. Er fand 1983 bei der Arbeit mit den Lehrlingen in einem Kiefernstangenholz einen Sperberhorst. Die Seltenheit dieses Fundes zu jener Zeit wurde dadurch deutlich, dass zwei „altgediente“ Ornithologen unserer FG diesen Horst unbedingt sehen wollten und ihn sich von mir zeigen ließen.

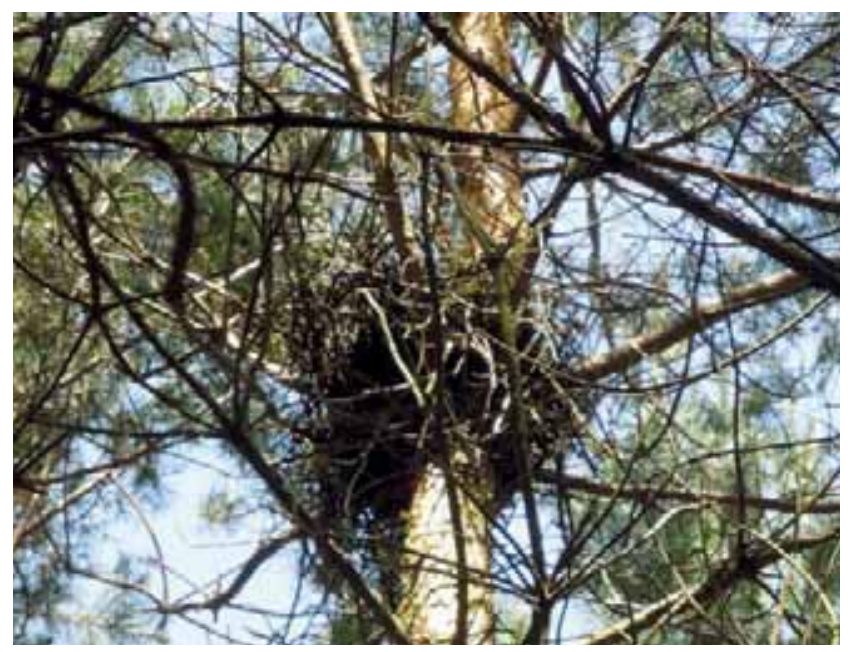

Abb. 316: Ein Sperberhorst befindet sich immer dicht am Stamm. Foto: A. Martin.

Die Standorte von See- und Fischadlerhorsten waren zumindest den Artbearbeitern bekannt, jeder Neufund kam noch Mitte der 1980er Jahre immer wieder einer kleinen Sensation gleich. Ähnliche Aufmerksamkeit hätte der „unattraktive“ Sperber verdient, denn er war als Vogeljäger vom DDT-Einsatz ebenfalls sehr stark betroffen. Man kannte in Mecklenburg Anfang der 1980er Jahre kein besetztes Sperberrevier mehr. Selbst bei unseren langjährigen Ornithologen waren die Kenntnisse über diese Greifvogelart so gering, dass sie damals der Meinung waren, nun den letzten bekannten Horst aufgesucht zu haben. Sie vergaßen dabei (oder wussten es nicht besser), dass nicht wie bei allen anderen heimischen Greifvögeln der bekannte Horst zu kontrollieren ist, denn der Sperber baut jedes Jahr einen neuen Horst. Dieser steht allerdings innerhalb des vom Sperber genutzten Revieres oft nicht weit entfernt vom alten Horst.
1984 und 1985 war das „Vorführrevier“, unser einziges bekanntes, wieder besetzt. Da wir gute Verbindungen zum regionalen Radiosender Schwerin hatten, gelang es mir, die für Naturthemen gut ansprechbare Frau Barbara Klett 1985 hierher zu locken. Der aufgezeichnete Beobachtungsgang ins Sperberrevier wurde kurz darauf auch im Radio gesendet. Damals konnte ich nur auf dieses einzige Revier verweisen. Erst im darauffolgenden Jahr kam ein zweites hinzu, 1987 waren es vier.

Obwohl die meist allein durchgeführten Suchaktionen viele Hektar Waldfläche umfassten, war die Ausbeute äußerst mager. Das lag nur zum einen an der äußerst geringen Dichte, zum anderen aber wohl auch an der bei mir noch mangelnden Erfahrung. Obwohl nach meinem schweren Unfall kaum an ein Weitermachen zu denken war, begann ich bereits 1991 - stets mit fremder Hilfe allerdings - alte Reviere und weitere Flächen mit sperbergeeigneten Baumbeständen abzugehen. Nach einigen Jahren ohne Erfolg, gelang erst 1995 ein Horstfund, der für mich nicht nur ornithologische Bedeutung hatte. Er war sozusagen ein ungewöhnlicher Beitrag für eine schneller fortschreitende Rehabilitation bei mir.

Während die Zahl der Horstfunde zunächst recht bescheiden war, schien 1998 der Knoten mit fünf Horstfunden gerissen, neun Jahre später waren es dann stolze 28 Horste. Die Ergebnisse meiner Untersuchungen in den Jahren 1985 - 2010 an insgesamt 239 Horsten des Sperbers und 525 beringten Jungsperbern habe ich in einem Beitrag in der Fachliteratur publiziert (MARTIN, A., 2012).

In den Folgejahren 2010 bis 2015 wurden meine bisherigen Erkenntnisse an dieser Vogelart bekräftigt.

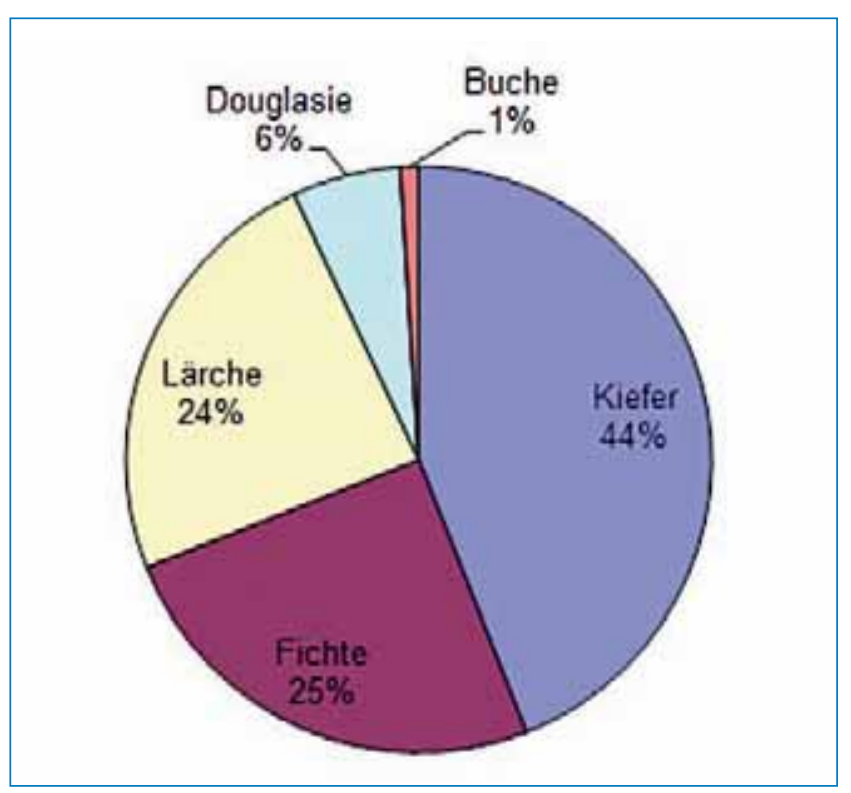

Diagramm 39: Bei der Errichtung der Horste vom Sperber im Raum Güstrow genutzte Baumarten. 


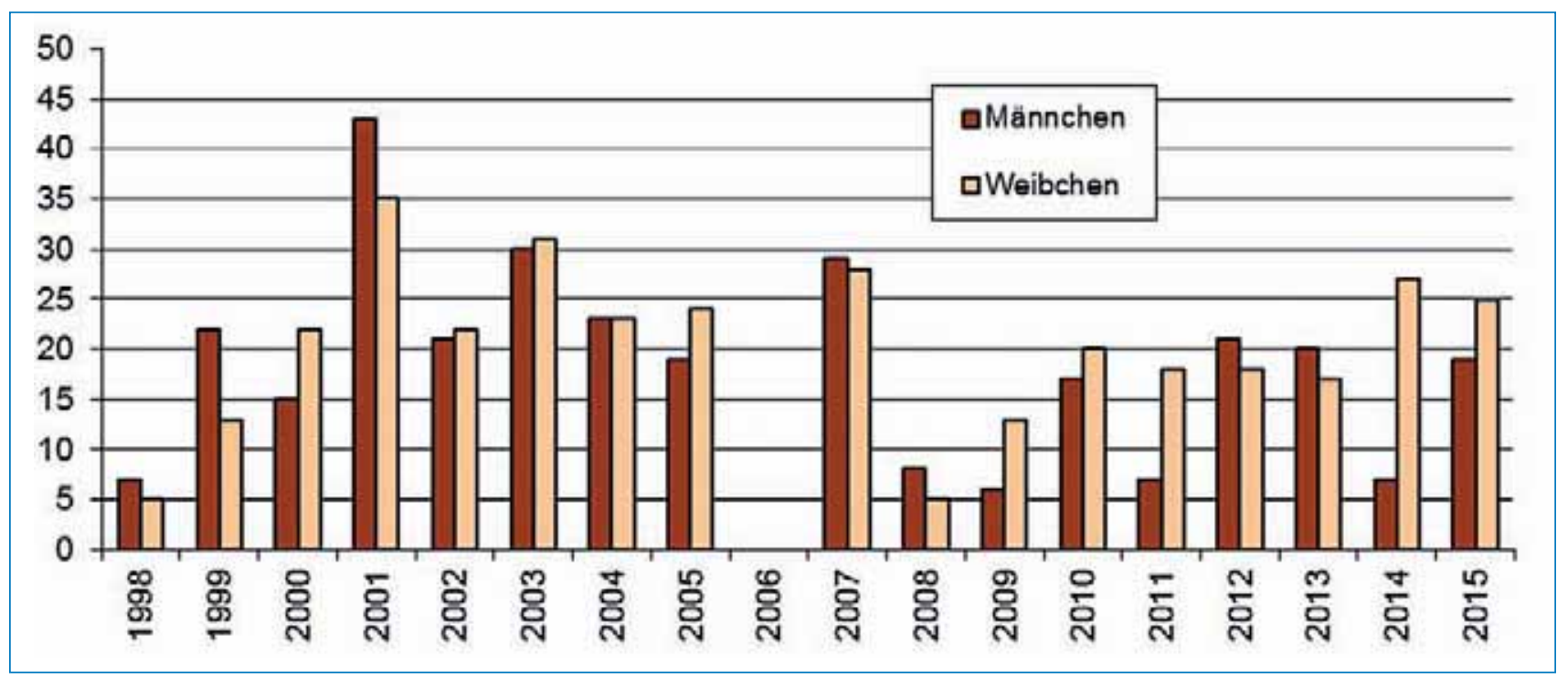

Diagramm 40: Die Geschlechterverteilung bei den fungsperbern ist jährlich ganz unterschiedlich.

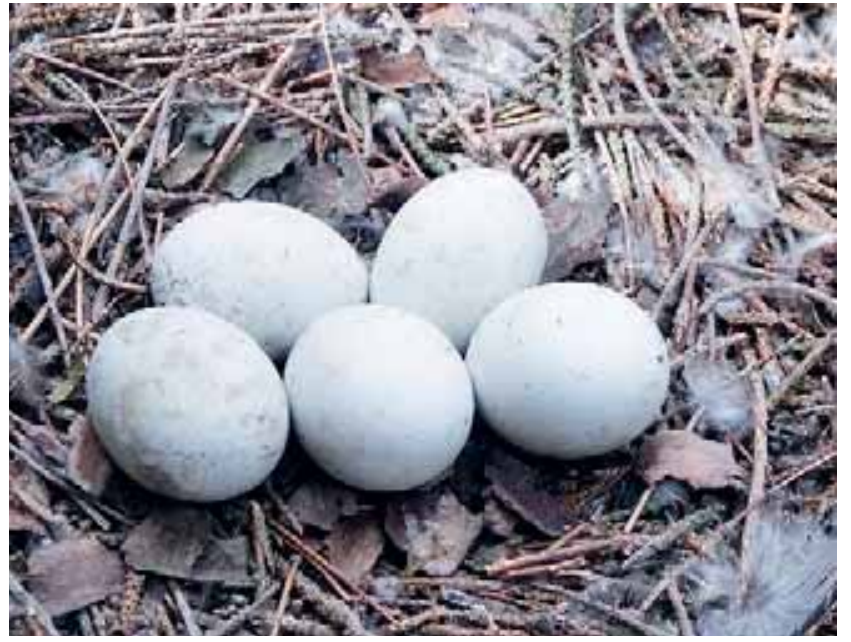

Abb. 317: Am 26.6.2015 gab es noch ein 5er Gelege, während zwei Tage zuvor die fungen in einem anderen Horst bereits zum Beringen zu groß waren (vgl. Abb. 322). Foto: St. Thiel.

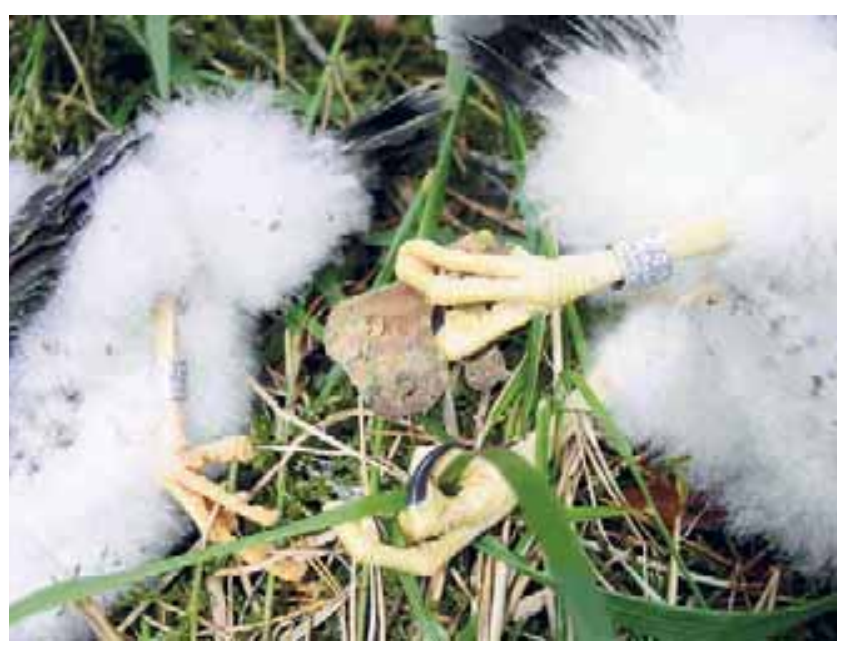

Abb. 318: Die Geschlechter lassen sich bereits bei den Nestlingen an der Größe der Fänge unterscheiden, hier: links ein Männchen, rechts ein Weibchen. Sie erhalten unterschiedliche Ringgrößen. Foto: A. Martin.
Tabelle 12: Brutgrößen in den erstiegenen Horsten von 1985 bis 2015 $(n=187)$

\begin{tabular}{l|r|r|r|r|r|r}
\hline Brutgröße & 1 & 2 & 3 & 4 & 5 & 6 \\
\hline Anzahl & 5 & 14 & 26 & 56 & 66 & 20 \\
\hline
\end{tabular}

Bei meinen Untersuchungen hatte ich den Schwerpunkt auf das Finden vieler besetzter Sperberreviere und -horste gelegt, um dadurch möglichst eine große Anzahl Jungsperber beringen zu können. So ganz selbstverständlich steht hier das Wort ,Beringung;, aber was bedeutet Beringung bei einer Art, die nicht am Boden, im Gebüsch oder in Nistkästen brütet?

Es muss Menschen geben, die diese meist 8-12 $\mathrm{m}$ hoch in Bäumen angelegten Horste erklettern und die Jungen evtl. gleich oben im Horst beringen oder uns am Boden wartenden Ornithologen in einem Eimer herunterlassen. Es fanden sich zunächst stets FG-Mitglieder als Kletterer Wolfgang Köhler und vor allem Fritz Anderlik waren die Aktivposten. Mitte der 1990er Jahren übernahmen es die jüngeren Mitglieder Remo Wiechert, Uwe Gehlhar und Jörg Bußmann.

Als erstmalig 1998 fünf Horste zu Buche standen und die Kletterei immer mehr Aufwand verursachte, konnte diese Arbeit nicht mehr durch FG-Mitglieder geschafft werden. Ich suchte nach anderen Möglichkeiten und fand schließlich Unterstützung bei professionellen Kletterern der Forst. Am 10.6.1999 war es dann soweit. Unser Drei-Mann-Team spielte sich gut ein, es machte von Jahr zu Jahr mehr Spaß. Henning Friz (seitdem alljährlich dabei) und Jannick Weidner waren Zapfenpflücker (heute sagt man ,Baumsteiger'), die in einem Forstrevier angestellt waren. Mit dem Revierleiter sprach ich die Klettertermine zwei Wochen zuvor grob und nach erneuter Kontrolle der Horste ganz konkret ab. 2006 ging alles trotz Vorbereitung kreuz und quer und 
plötzlich das: Die Beringung findet nicht statt. Damit war meine Arbeit einer gesamten Saison zunichte gemacht, obwohl natürlich viele andere Daten trotzdem ermittelt wurden, blieb als Lohn der Arbeit - die „Ernte“ - die Beringung aus. Was war geschehen? Ein Jahr später erklärte sich mir der fatale Irrtum durch Bemerkungen der Kletterer. Mitarbeiter der Forstverwaltung hatten Streit mit meiner Dienststelle, dem LUNG. Diese Mitarbeiter sahen es als selbstverständlich an, dass ich im Auftrag des LUNG arbeitete, so wurde also dem LUNG die Hilfe bei der Beringung nicht gewährt. Wer hätte gedacht, dass eine Privatperson 1.000 Rad-km und hunderte Stunden für nichts und wieder nichts ...! Dass dieser Irrtum selbst in höheren Forstkreisen recht peinlich angekommen sein muss, spüre ich seitdem indirekt in einer jährlichen anstandslosen Bewilligung der Kletterer.

Die Arbeit am Sperber hat mich weiterhin gefesselt, es hat sich mittlerweile auch ein großer Erfahrungsschatz angesammelt. Ab 2011 konzentriere ich mich zumeist auf das Finden aller Reviere und Horste in einem konkret abgegrenzten Untersuchungsgebiet. Das ist die vom Messtischblatt (MTB) 2239 umrissene Fläche einschließlich der unmittelbar angrenzenden Gebiete in einer Flächengröße von $\sim 150 \mathrm{~km}^{2}$.

Es beinhaltet u.a. die große zusammenhängende Waldfläche südöstlich von Güstrow, aber auch viele kleinteilige Bereiche. Es werden auch Reviere in unmittelbar angrenzenden Gebieten gesucht, um handfestere Siedlungsdichteangaben vorweisen zu können. Da die Zahl der beringten Jungsperber weiterhin nicht „ganz unwichtig“ ist, werden alte Reviere, die ohne großen Kraft- und Zeitaufwand zu erreichen sind, „nebenbei“ ergänzend kontrolliert.

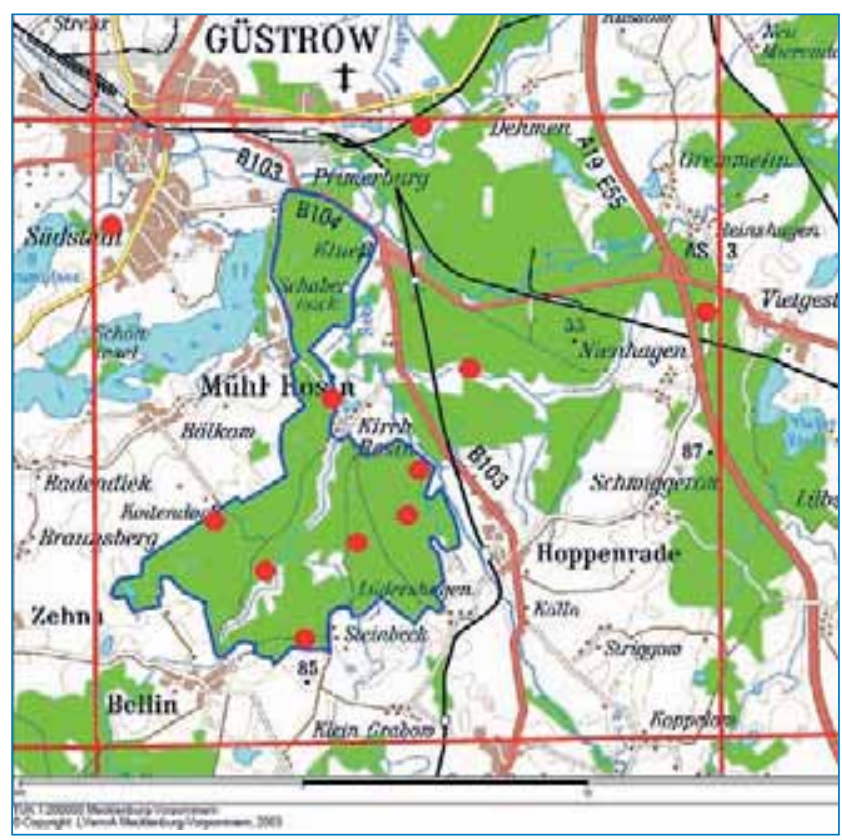

Karte 22: Untersuchungsgebiet MTB 2239 mit Sperberrevieren (rote Punkte) 2007 - die blaue Linie umreist das intensiv bearbeitete Waldgebiet Kirch Rosiner Forst.
Bis einschließlich 2015 wurden 302 Horste gefunden und 704 nestjunge Sperber aus 181 Horsten beringt. Im Vergleich mit den Gesamtberingungsdaten der Beringungszentrale ist festzustellen, dass mehr als die Hälfte der in M-V beringten Nestlinge aus der Güstrower Region stammen. In den Jahren nach 2010 sind es jeweils fast $100 \%$.

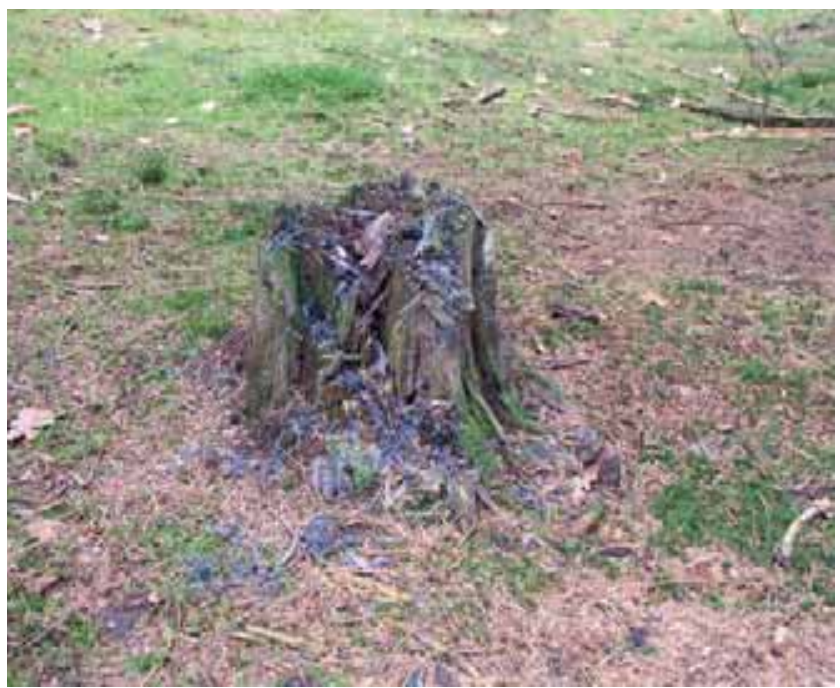

Abb. 319: Rupfplätze des Sperbers befinden sich meist auf einer erhöhten Stelle. Foto: A. Martin.

2015 wurde erstmalig an zwei sehr gut ausgeprägten Rupfplätzen eine Wildkamera installiert. Beim ersten Einsatz konnte als Besonderheit gleich ein beringtes Weibchen fotografiert werden. Ob es sich um ein von uns als Jungvogel beringtes Weibchen gehandelt hat, konnte leider infolge unzureichender Auflösung der Wildkamera nicht durch eine Ringablesung ermittelt werden.

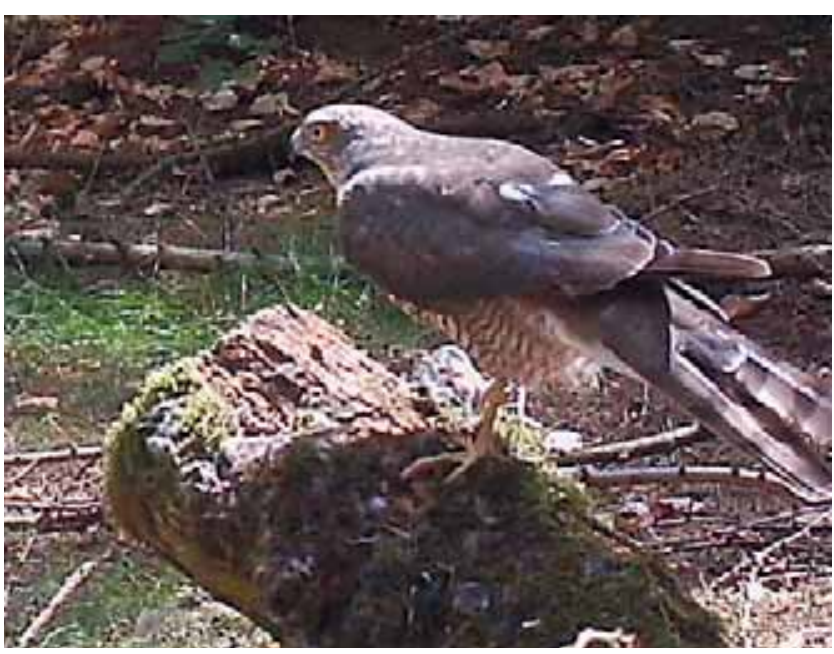

Abb. 320: Aufnahme mit Wildkamera an einem Rupfplatz.

Es entstand die Idee, künftig bei der Beringung junger Sperber eine Zusatzberingung mit Kennring vorzunehmen, wie sie z.B. beim Wanderfalken verwendet wird. Sollte es gelingen, vorzugsweise an Rupfplätzen des Sperbers den Kennring über Fotos einer Wildkamera abzulesen, ließen sich eine Reihe von Fragen beantworten, die derzeit offen 
sind. Bisherige Ringfundrückmeldungen betrafen fast ausschließlich tote oder verunglückte Sperber. Mit dem Kennring wären Daten zu Brutorttreue, eventuelle Prägungen bei der Wahl der Nistbaumart, Partnerbeziehungen u. a. ermittelbar.
Dem Gedanken zeigte sich die Beringungszentrale durchaus gewogen, wir bekamen grünes Licht für eine Antragstellung. Bei entsprechender Ringbereitstellung könnten wir ab 2016 voraussichtlich die Basis für die Gewinnung ergänzender brutbiologischer Daten legen.

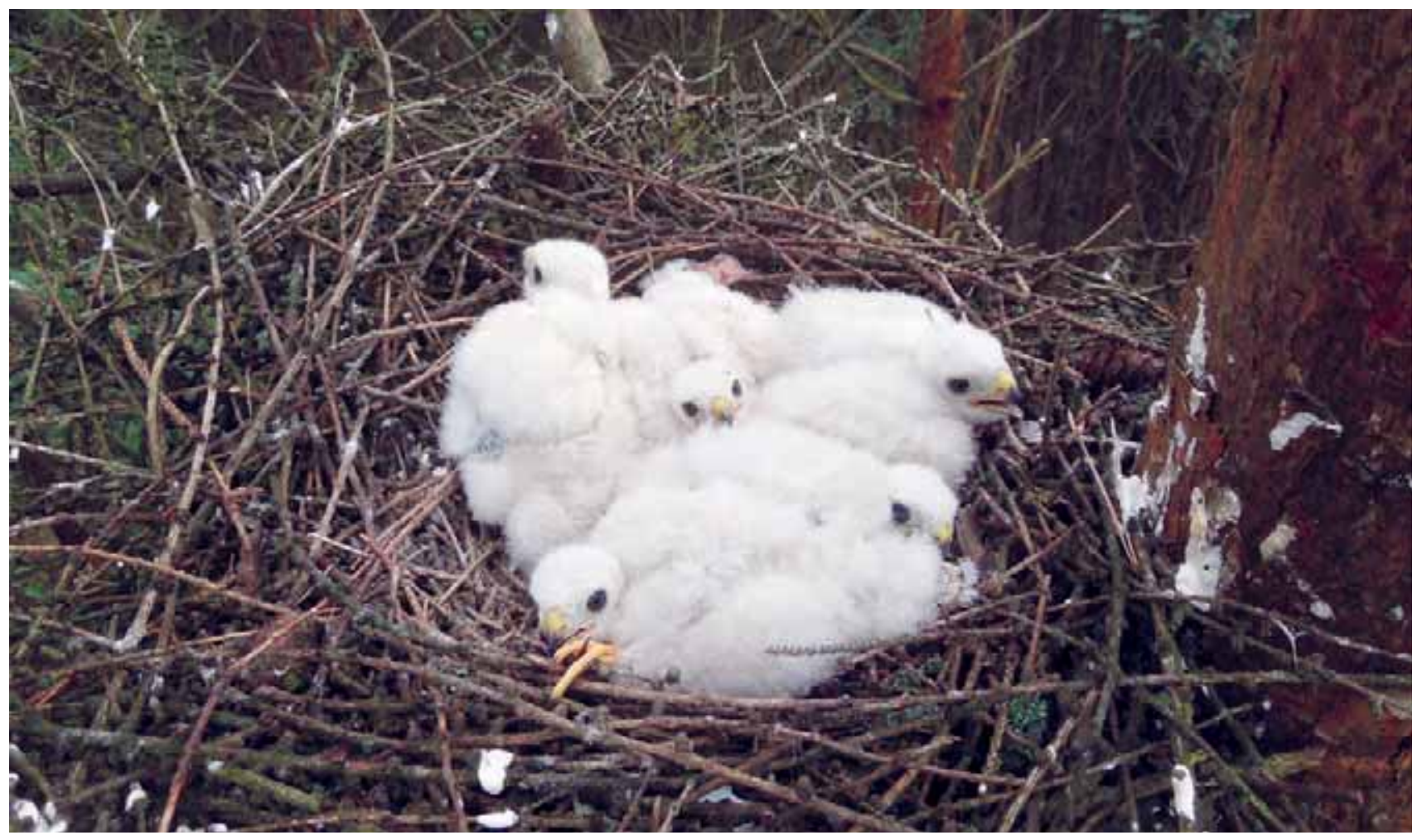

Abb. 321: Die fünf Jungsperber im Horst sind im besten Beringungsalter. Foto: St. Thiel.

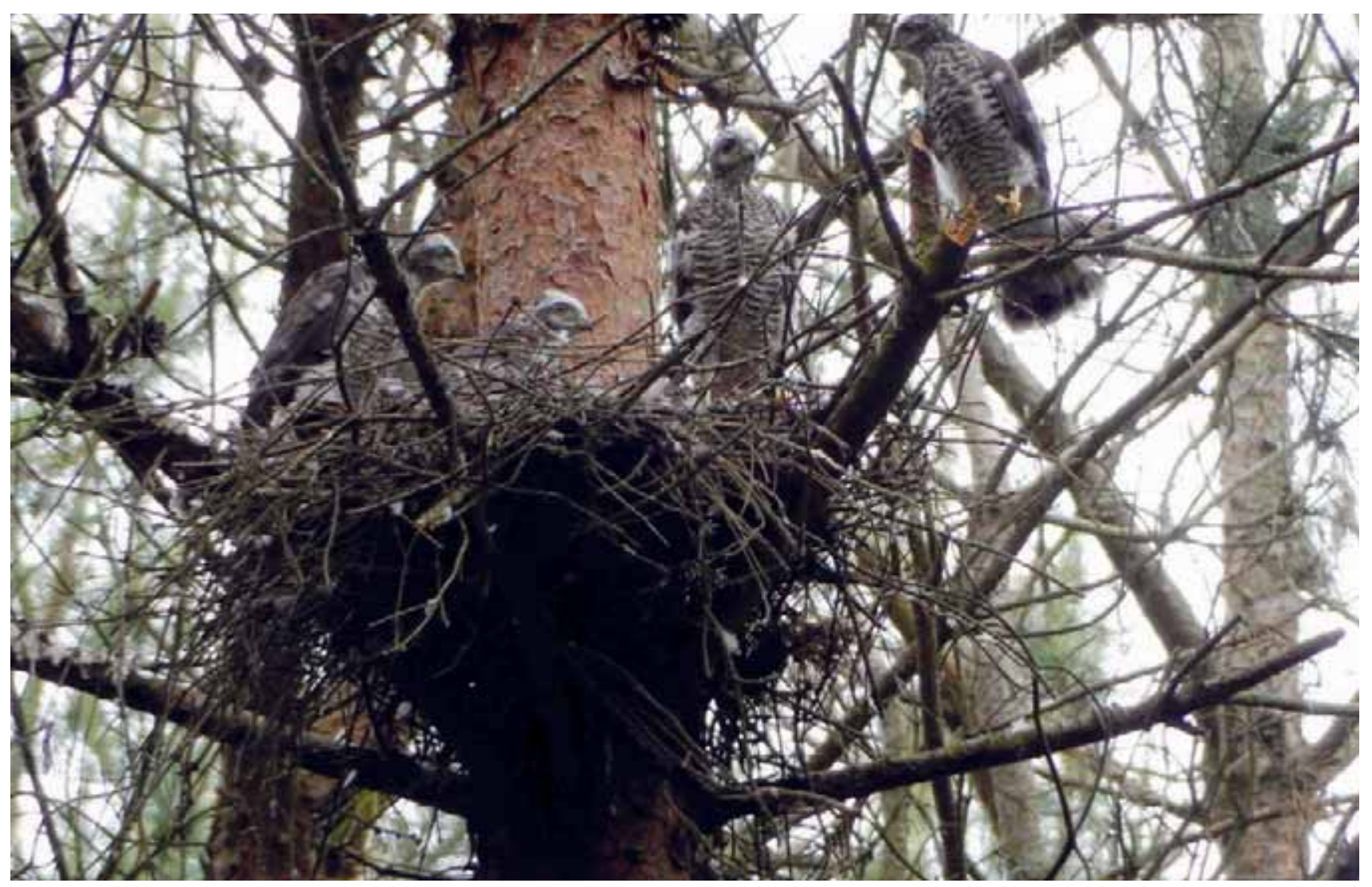

Abb. 322: Diese fungsperber verlassen bereits den Horst. Für die Beringung sind wir hier zu spät gekommen. Foto: 7. Loose. 


\subsection{Das Projekt Wanderfalke - eine erfolgreiche Gemeinschaftsarbeit mit dem Landesjagdverband}

\section{Wolfgang Köhler}

Eine für ganz Mecklenburg-Vorpommern bemerkenswerte Aktion war die Wiederbegründung einer baumbrütenden Wanderfalkenpopulation. Dieses Projekt wurde von einer Projektgruppe unter meiner Leitung initiiert und durchgeführt.

Als Mitte des vorigen Jahrhunderts die organo-chloriden Pestizide auf den Markt kamen, ahnte zunächst niemand, welche negativen Nebenwirkungen und Folgen diese Insektizide haben würden. Ganz besonders die Greifvögel, vor allem Adler und Wanderfalken als Spitzenprädatoren wurden in ihrem Reproduktionsverhalten dermaßen geschädigt, dass die Gefahr bestand, dass sie innerhalb einer überschaubaren Zeitspanne aussterben würden.

Durch den engagierten Einsatz der Falkner gelang es, Nachzuchten bei Wanderfalken zu erzielen und diese schließlich wieder auszuwildern.

Nachdem die Ursachen für die geringe Nachwuchsrate erkannt und anschließend beseitigt wurden, konnte man daran gehen, die enorm geschrumpfte Population wieder aufzubauen.

Die baumbrütenden Wanderfalken, eine durch Prägung in der Ästlingsphase eigene Subpopulation, war aber total ausgestorben. Es bestand die Gefahr, dass das Diluvialgebiet nördlich der Mittelgebirge von Wanderfalken frei bleiben würde.

Wieder waren es einige Falkner, die die Vision hatten, durch Auswilderung und Prägung auf Bäume (in Kunsthorsten) eine neue Baumbrütergeneration zu begründen. Der Anfang wurde in der Naturschutzstation Woblitz in Nordbrandenburg gestartet.

Ich erklärte mich bereit, die Leitung zum Aufbau einer zweiten Auswilderungsstation in Mecklenburg-Vorpommern zu übernehmen. Sofort bekamen wir von Berufskollegen aus Schleswig-Holstein die Zusage, dass wir mit deren Unterstützung rechnen können und von ihnen Jungfalken aus der dortigen Zuchtstation zur Verfügung gestellt würden.

Es stand die Frage, wo der Auswilderungsplatz aufgebaut werden sollte. Die zunächst favorisierte Stelle in der Oberförsterei Krakow zerschlug sich, weil die Strukturen in der Forstwirtschaft nach der Wende völlig umorganisiert wurden. Der Tierpark in Güstrow als Ausweichstandort fiel ebenfalls aus, weil es $\mathrm{zu}$ viele Industriebauten in der Umgebung gab und die Gefahr sehr groß war, dass die Falken aus alter Tradition auf hohe Gebäude als Ersatz für die fehlenden Felsen ausweichen würden.
Inzwischen war es mir gelungen, den neu gegründeten Landesjagdverband (LJV) als Träger der Maßnahme zu gewinnen. Der LJV versteht sich als Naturschutzverband, der nicht nur die Jagd in traditioneller Weise betreibt, sondern auch aktiv für den Naturschutz, speziell den Artenschutz tätig wird. Ein Novum war, dass der Jagdverband eine Tierart mit ansiedeln will, die zwar dem Jagdrecht unterliegt, aber nie bejagt werden wird.

Der LJV war sofort bereit, die nicht unerheblichen Kosten zu tragen und soweit möglich auch personell zu helfen. Durch den Umzug der Geschäftsstelle des LJV von Güstrow nach Damm/Malchow bei Parchim ergab sich auch die Möglichkeit, einen geeigneten Auswilderungsplatz zu finden, der gut zu betreuen war und weit genug von Industriebauten entfernt lag.

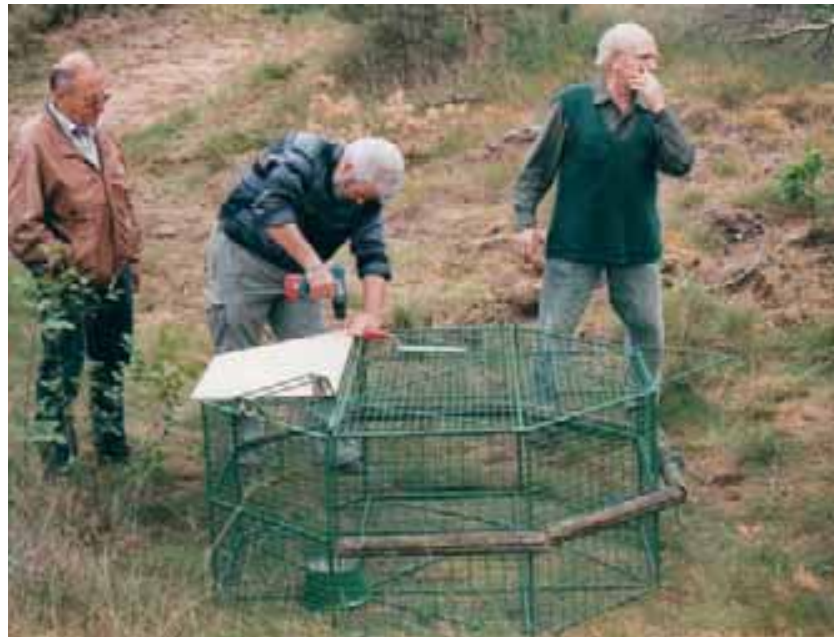

Abb. 323: Aufbau des Wanderfalken-Auswilderungskorbes. Foto: W. Köhler.

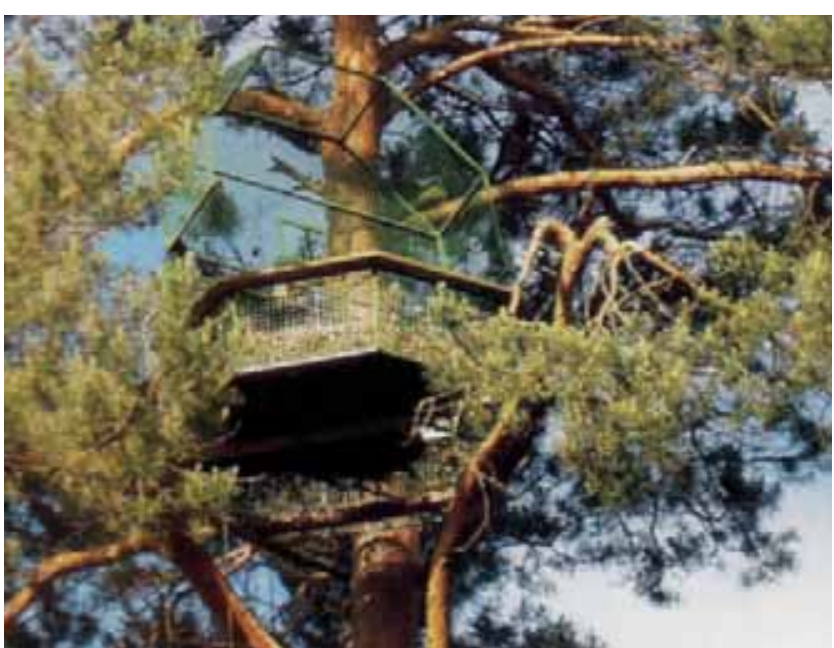

Abb. 324: Der Wanderfalken-Auswilderungskorb wurde bei Damm/Malchow in einer Kiefer installiert. Foto: W. Köhler. 
Der Auswilderungskorb war so gestaltet worden, dass die Jungfalken bis zum Flüggewerden keinen menschlichen Kontakt bekamen - das Futter wurde in einem Napf mit einem Seilzug nach oben transportiert.

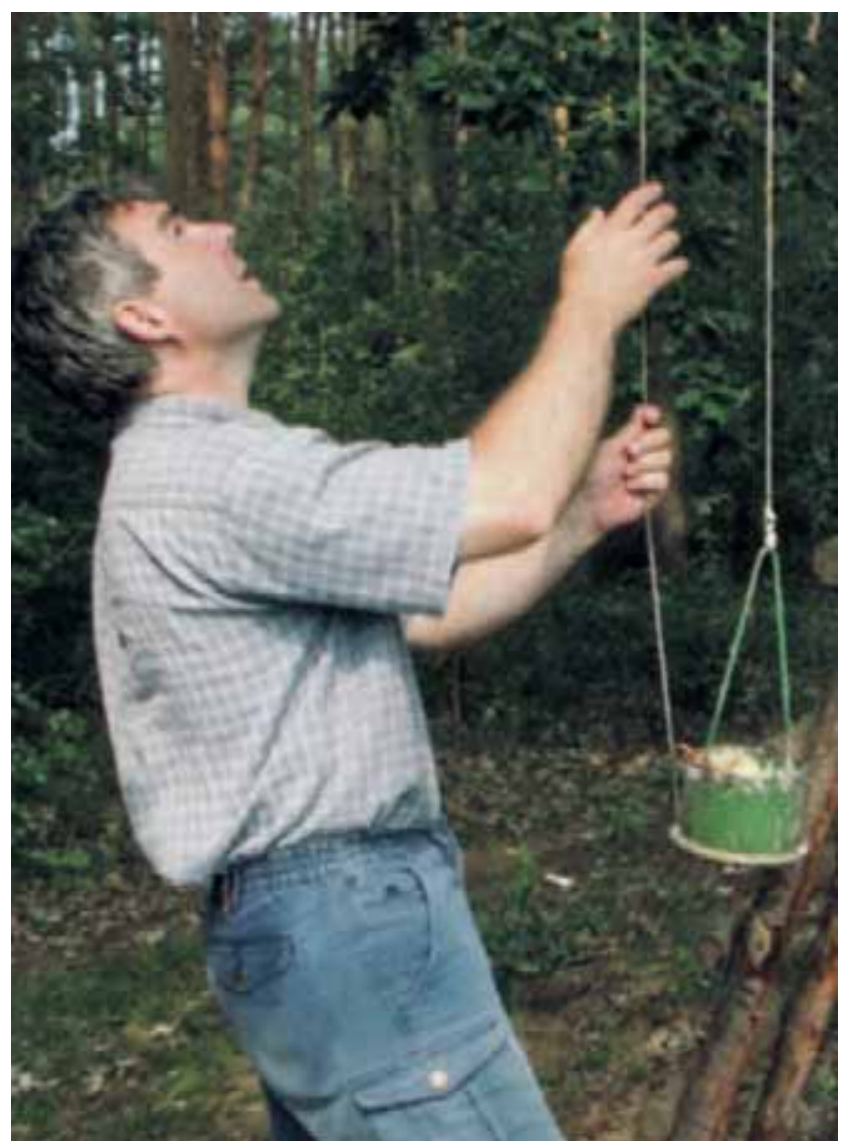

Abb. 325: Steffen Thiel transportiert den gefüllten Futternapf mit dem Seilzug in den Auswilderungskorb. Foto: W. Köhler.

Zunächst gab es zwar Zweifel bei Mitgliedern des Arbeitskreises Wanderfalkenschutz (AWS), ob der Platz wirklich optimal gelegen war. Es wurde vermutet, dass wegen der großen Entfernung zur Naturschutzstation Woblitz (ca. 100 km) kein Austausch mit den dort ausgewilderten Falken stattfinden würde. Wie sich bald zeigte, ging aber alles gut.

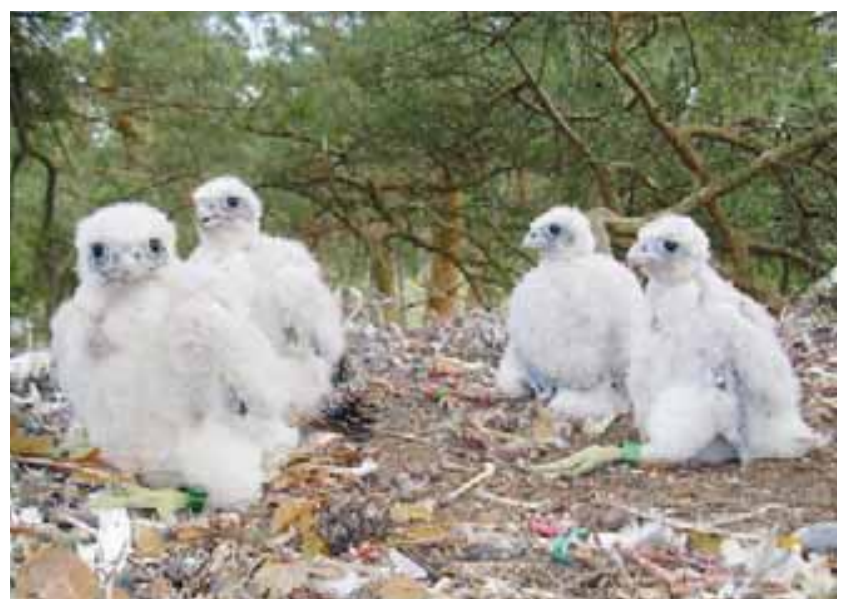

Abb. 326: Jungfalken einer erfolgreichen Wildbrut auf einer Kiefer nach der Beringung. Foto: St. Thiel.
Die ersten Falken wurden in Damm/Malchow 1995 ausgewildert. Im gleichen Jahr erfolgte die erste Wildbrut von Falken in der Nähe von Woblitz, die dort 1990 ausgewildert wurden. Das erste Baum-Brutpaar in $\mathrm{M}-\mathrm{V}$ etablierte sich im Jahre 2000, ebenfalls fünf Jahre nach Beginn der Auswilderung, in der Nähe des Auswilderungskorbes. Der Terzel stammte aus unserem Auswilderungsprogramm, das Weibchen stammte aus Woblitz. Die Bedenken des Nichtfindens waren damit also überflüssig.

Ein schöner erster Erfolg: Es war gelungen, eine Tier(unter)art, die ausgestorben war, durch die gemeinsamen Anstrengungen von Naturschützern, Falknern und Jägern wieder in heimischen Gefilden anzusiedeln. Die Freude bei allen Beteiligten war sehr groß, vor allem beim LJV und beim DJV, der die erfolgreiche erste Brut zum Anlass nahm, der Projektgruppe den DJV-Naturschutzpreis 2001 in Höhe von 10.000,- DM zu zuerkennen.

Durch die Beringung mit Kennringen und ein Monitoring konnte für viele Vögel die Herkunft nachvollzogen und so auch verfolgt werden, wo sich unsere Falken ansiedelten.

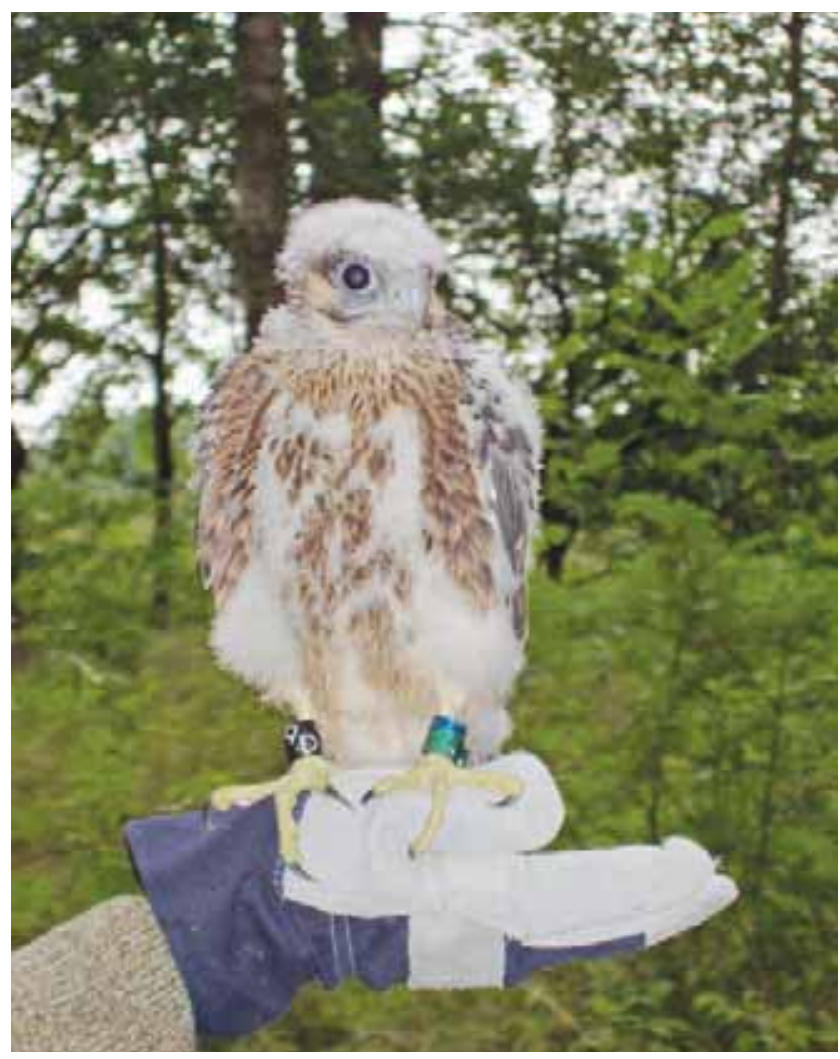

Abb. 327: funger Wanderfalke mit dem Kennring „9D“.

Foto: W. Köhler.

Zwischen 1995 und 2010, dem vorgesehenen Ende der Aussetzungen wurden 201 Falken in Mecklenburg ausgewildert. Große Verluste traten in den ersten Jahren auf, als sich noch kein Paar angesiedelt hatte. Umherstreifende Junghabichte schlugen nachweislich einen erheblichen Anteil der Jungfalken. Im Jahr 2000 trat ein schwerer Verlust ein, als eine Pockenerkrankung den gesamten Jahrgang vernich- 
tete. Das Projekt wurde 2010 offiziell beendet. Es hatten sich bis dahin elf Paare angesiedelt, darunter eine Felsenbrut auf dem traditionellen Brutplatz am Kreidefelsen auf Rügen, neun Baumbruten und auch eine Gebäudebrut.

Auf der feierlichen Abschlussveranstaltung zum Projekt durfte ich als Initiator des Mecklenburger Projektes stellvertretend für alle Beteiligten den Falco-perigrinus-Preis 2010 entgegennehmen.
In Zukunft gilt es, durch eine möglichst lückenlose Dokumentation, die weitere Entwicklung der Population zu begleiten.

Danksagung:

Der Dank der Projektgruppe gilt ganz besonders dem LJV für die allzeit gewährte gute Zusammenarbeit und dem AWS für die stete fachliche Beratung. Ganz besonders sind wir Herrn Prof. Dr. Saar (Hamburg) für die uneigennützige Bereitstellung der Jungfalken zu Dank verpflichtet.

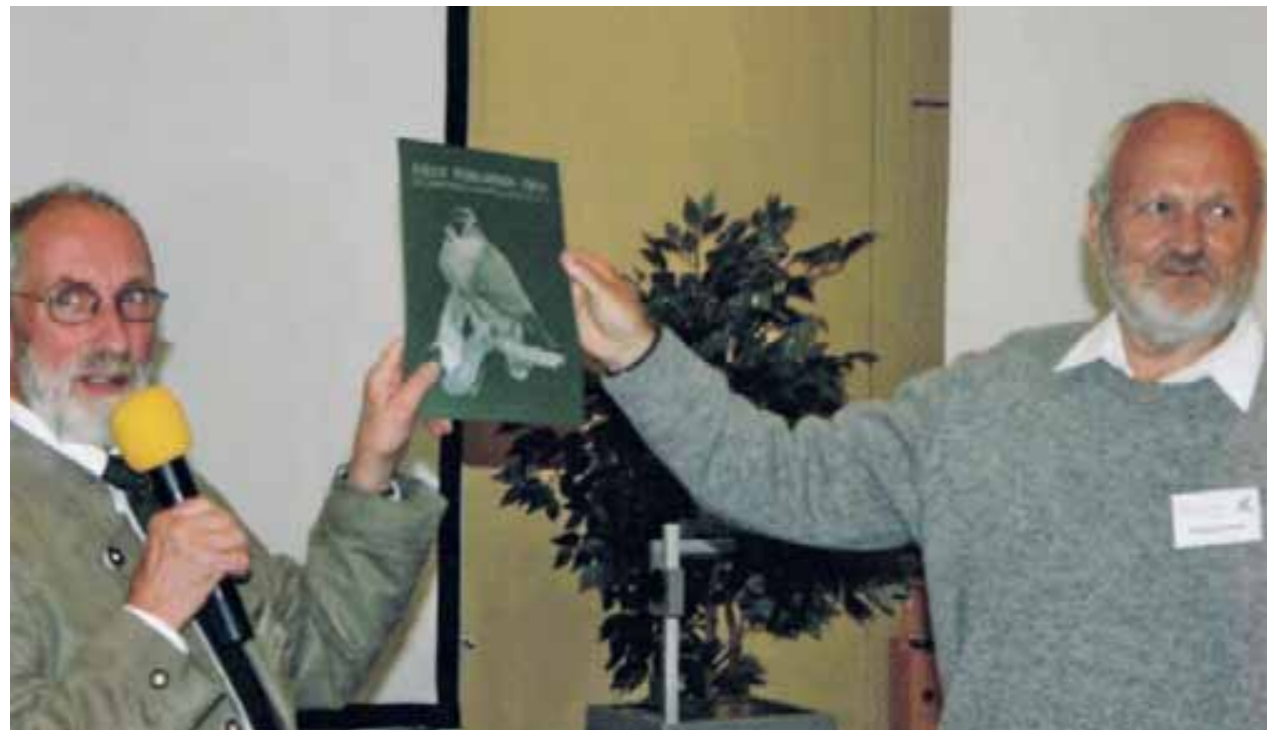

Abb. 328: Übergabe des Preises durch den Vorsitzenden des Arbeitskreises Wanderfalkenschutz Herrn Dr. Gert Kleinstäuber. Foto: Wanderfalken-Archiv.

\section{Interneteintragung bei OAMV.de}

\section{Wanderfalkenbestand in Mecklenburg-Vorpommern wächst weiter.}

2015 wurden weitere Brutplätze dieser Falkenart in Mecklenburg-Vorpommern durch Ornithologen und Urlauber entdeckt. Das durch den Landesjagdverband 1995 gestartete Projekt der Wiederansiedlung baumbrütenden Wanderfalken hat sich zu einem Erfolg entwickelt.

Nach dem Projektende der Jungenauswilderung im Jahre 2010 sind 2015 insgesamt 20 Brutplätze von Wanderfalken in $\mathrm{M}-\mathrm{V}$ bekannt geworden, die ihren Verbreitungsschwerpunkt im Südteil unseres Landes haben. 14 Horste befinden sich auf Bäumen und je zwei in Felsen (Rügen), auf Gebäuden sowie auf Hochspannungsmasten. Weitere Brutplätze werden vermutet und warten auf ihre Entdeckung.

Mitteilungen werden erbeten an:

w-koehler05@web.de

\section{Wolfgang Köhler}

Rövertannen $7 \mathrm{~d}$

18273 Güstrow

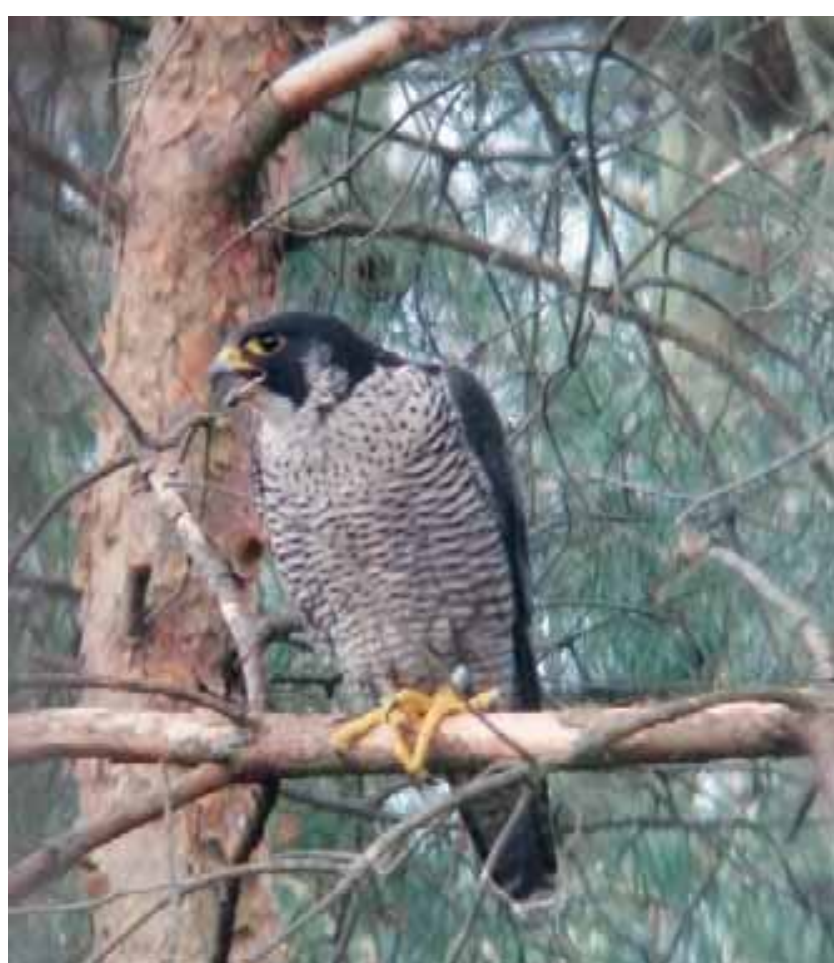

Abb. 329: Adulter Wanderfalke aus erfolgreicher Baumbrut Foto: St. Thiel. 


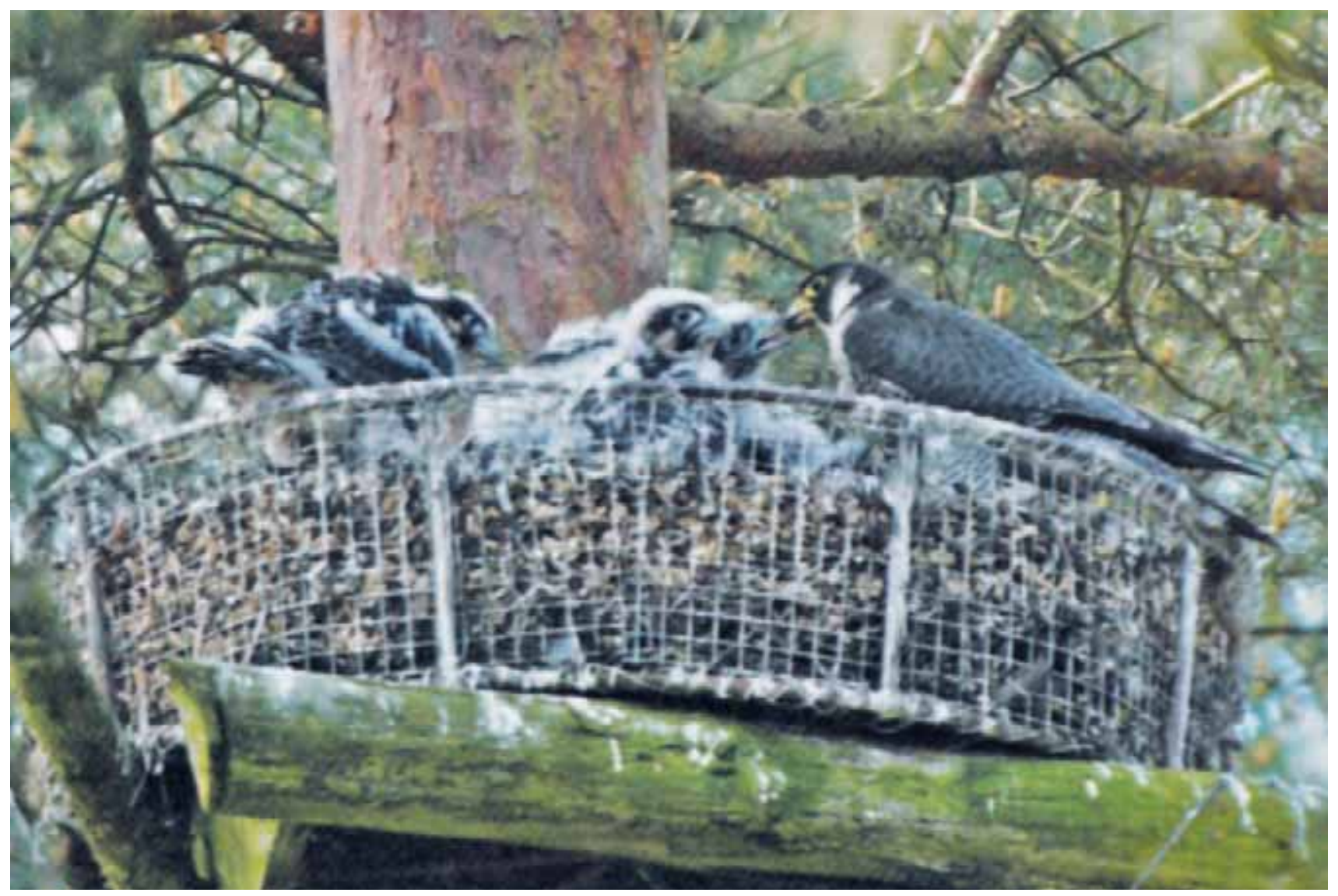

Abb. 330: Da Falken keine eigenen Horste bauen, werden Kunsthorste angeboten und nach der Prägung auf Baumbruten auch von den Wanderfalken angenommen. Foto: St. Thiel.

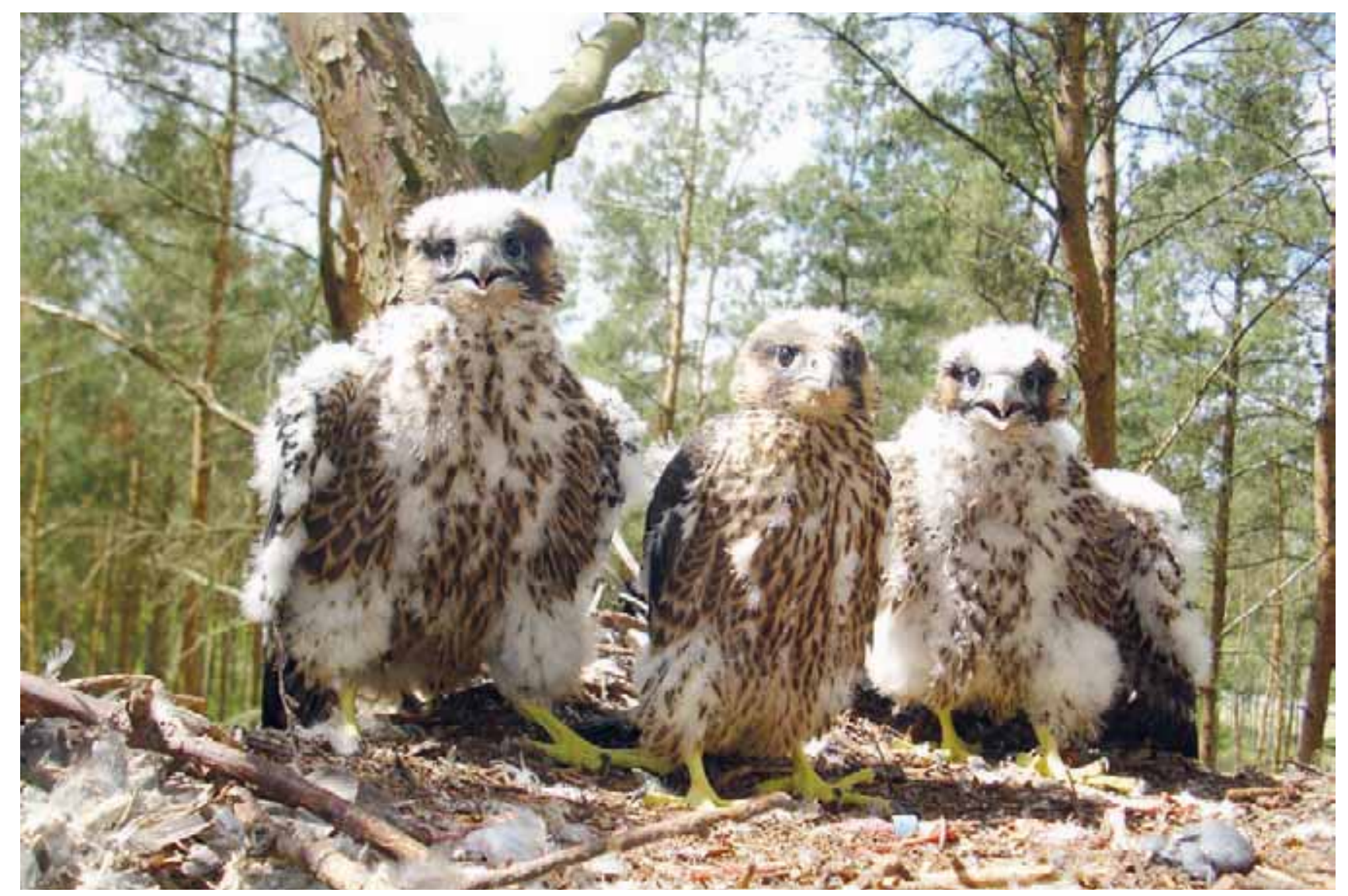

Abb. 331: Junge Wanderfalken einer Wildbrut in einem Baumhorst. Der Beringer kommt gerade noch rechtzeitig. Foto: St. Thiel. 


\subsection{Herrichtung von Trafohäusern als Lebensraum für Tierarten}

\section{Helmut Richter}

Man hört sie selten, man sieht sie kaum, sie fliegen geräuschlos, sie sind nachtaktiv. Sie können sehr gut hören und haben eine weitgehend unbekannte Lebensweise Eulen. Sie gehörten bei unseren Mitgliedern zu einer kaum bearbeiteten Artengruppe. Für sie trifft das Sprichwort zu: „Aus dem Auge aus dem Sinn“.

Bei einer Zwischenauswertung von Erfassungsdaten bei der ersten Brutvogelrasterkartierung für M-V (1978-1982) stellte man im Herbst 1981 in der FG fest, dass die Angaben für alle Eulenarten völlig unzureichend waren. Im Winterhalbjahr 1981/82 untersuchte J. Loose deshalb alle in unserem Wirkungsbereich liegenden Kirchen auf Eulenbesetzungen. Bei der Kontrolle von 33 Kirchen wurde durch Gewöllfunde die Schleiereule in vier und der Waldkauz in 13 Kirchen nachgewiesen. M. Montschko untersuchte 1990 den nördlichen und westlichen Teil des Kreises. Er konnte 18 Bruten der Schleiereule, vornehmlich in Scheunen und Ställen nachweisen. 1998/1999 wurden alle Kirchen des Kreises durch die Kirchenverwaltung im Rahmen eines ABM-Projektes mit Schleiereulenkästen ausgestattet. Seitens der FG-Mitglieder gelang es nicht, diese Kästen in den Kirchen auf Besetzung und Bruterfolge zu kontrollieren, da sich bisher niemand der Artengruppe der Eulen gewidmet hat.

Auf den extremen Rückgang insbesondere der Schleiereule im letzten Jahrzehnt wurden wir durch andere Ornithologen aufmerksam gemacht. Extreme Winter mit langen Schneelagen und insbesondere Veränderungen in der Landwirtschaft dürften die Ursachen für den enormen Bestandseinbruch gewesen sein. In den Siedlungsgebieten gab es nur noch wenig Rückzugsgebiete, die für Bruthabitate in Frage kamen. Stallungen und Scheunen hatten oft keine Einfluglöcher mehr. Die Lagerung von Stroh und Heu erfolgte neuerdings weitgehend auf dem Acker, so dass Kleinnager als Nahrungsquelle im Brutumfeld kaum zur Verfügung standen.

Die von Jörg Bußmann 2004 an unsere Fachgruppe Ornithologie und Naturschutz herangetragene Idee, stillgelegte Trafohäuser des Energieversorgers WEMAG zu Brutstätten für Schleiereulen auszubauen, passte in die zu dieser Zeit geförderten Arbeitsbeschaffungsmaßnahmen (ABM). Die NABU-Ortsgruppe Güstrow stellte für die Fachgruppe einen Antrag auf finanzielle Förderung beim Staatlichen Amt für Umwelt und Naturschutz (StAUN) Rostock, und über die UNB wurde die Ausbaumaßnahme als ABM bei der ARGE mit Dringlichkeit befürwortet. Den Schleiereulen sollte geholfen werden, und unser FG-Mitglied hatte für mehrere Jahre eine sinnvolle Beschäftigung.
Als erstes galt es, die in Frage kommenden Objekte über die WEMAG zu ermitteln und ihre Erhaltungswürdigkeit zu prüfen. Baufällige Trafohäuser sollten nicht in die Wahl kommen. Dann waren die künftigen Eigentumsverhältnisse zu klären. Die NABU-OG oder die FG sollten nicht Eigentümer werden. Es mussten durch J. Bußmann also zahlreiche Verhandlungen und Überzeugungsgespräche mit den Gemeinden oder privaten Eigentümern geführt werden. Im Ergebnis konnte er elf künftige Ersatzquartiere im Altkreis Güstrow für dieses Projekt sichern. Die Gebäude stehen vorwiegend im ländlichen Raum. Diese galt es nun, für die Bedürfnissen u. a. der Schleiereulen herzurichten. Diese benötigen einen relativ großen, dunklen Kasten, der mindestens in zehn Meter Höhe anzubringen war. Um diese Höhe zu erreichen, entschied sich J. Bußmann, Etagen in die entkernten Trafohäuser einzubauen, deren Zugang er mit Treppen ermöglichte. (siehe Modell - Abb. 332)

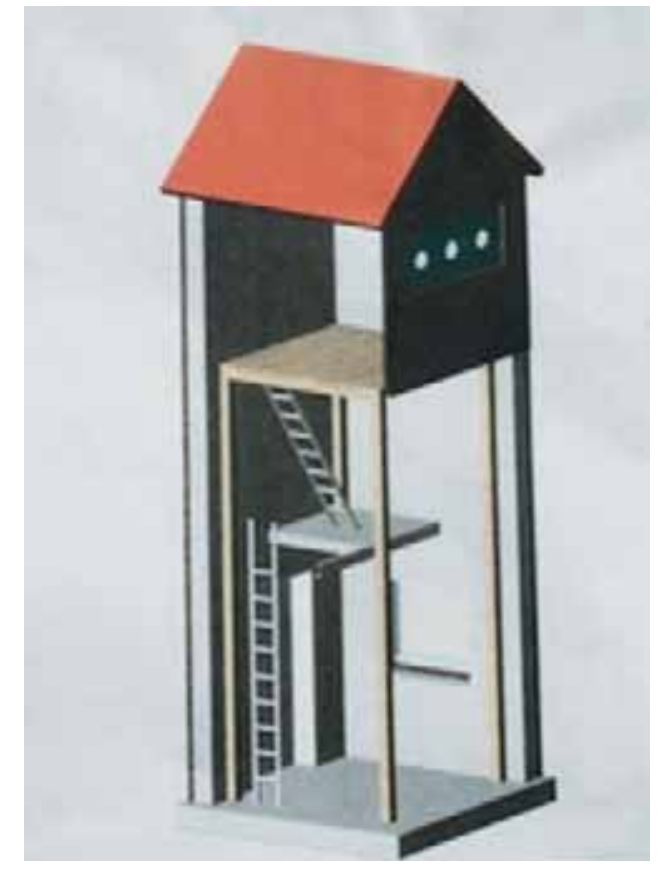

Abb. 332

Auch die Schleiereulenkästen wurden durch ihn angefertigt. Dabei zeigte er sich sehr erfinderisch - um die sperrigen Kästen allein in die Höhe bringen zu können, fertigte er sie in Einzelteilen vor und montierte sie erst an Ort und Stelle. Der Ausbau zog sich mehrere Jahre hin und wurde mit einer Objektbegehung am 8.März 2012 durch die FGMitglieder W. Köhler, J. Loose und J. Bußmann abgeschlossen. Im Abnahmeprotokoll wurde u. a. festgestellt:

„Die im Auftrag der NABU-OG von Jörg Bußmann ausgeführten Arbeiten zur Nachnutzung der Trafostationen als möglicher Nistplatz, insbesondere für Schleiereulen, sind nicht zu beanstanden. Die notwendigen Einbauten von 
Stützen und Zwischendecken sowie Treppen wurden so ausgeführt, dass ein sicheres Betreten der oberen Etagen möglich ist. Ein Einbau von Leitern statt der installierten Treppen wäre keine alternative Lösung (Sicherheits- und Kostenfrage). Die Schleiereulen-Nistkästen entsprechen dem Standard und sind gut für Eulen von außen anfliegbar. Nachteilig für die Nutzung der Stationen durch andere Vogelarten und Tiergruppen sind die in den meisten Stationen vorhandene Zugluft und noch fehlende Nist- und Unterschlupfmöglichkeiten. Diese Defizite sind zu beseitigen.“

Im Abnahmeprotokoll wurden Ziele für die weitere Entwicklung der Trafohäuser festgelegt. Nicht nur Eulen sondern auch Falken, Fledermäuse, Hornissen, Singvögel und Insekten sollten hier Nistmöglichkeiten erhalten. Jörg Bußmann konnte bedingt durch seine Berufstätigkeit nur eingeschränkt diese Arbeit übernehmen, so dass ich für diese Aufgabe angesprochen wurde. Ich sagte zu, ohne dass Abnahmeprotokoll zu kennen. Schnell merkte ich, dass ich eine sehr anspruchsvolle Aufgabe übernommen hatte, die von der naiven Vorstellung Schleiereulen zu beobachten, weit entfernt war. Es ging hauptsächlich erst einmal um Organisation und handwerkliches Geschick. Zur Umsetzung der Aufgaben stellte die NABU-Ortsgruppe einen neuen Förderantrag beim StALUMM Rostock, der mit der beantragten Summe von 2.000,00 € bewilligt wurde.

Um einen Einblick zu geben, werden die wesentlichen ausgeführten Arbeiten nachfolgend aufgeführt:

Die teilweise historische Altbausubstanz der bis zu 100 Jahre alten Transformatorenhäuser führte dazu, dass auch bauliche Maßnahmen mit diesem Geld abgedeckt werden mussten. In Neu Kätwin drohte das Gebäude bedingt durch einen langen Riss im Obergeschoss auseinanderzubrechen. Nur ein Maurermeisterbetrieb war in der Lage, den Totalverlust des Gebäudes aufzuhalten. Die dazu aufgestellte Rüstung nutzte ich, um einen Falkenkasten sowie zwei

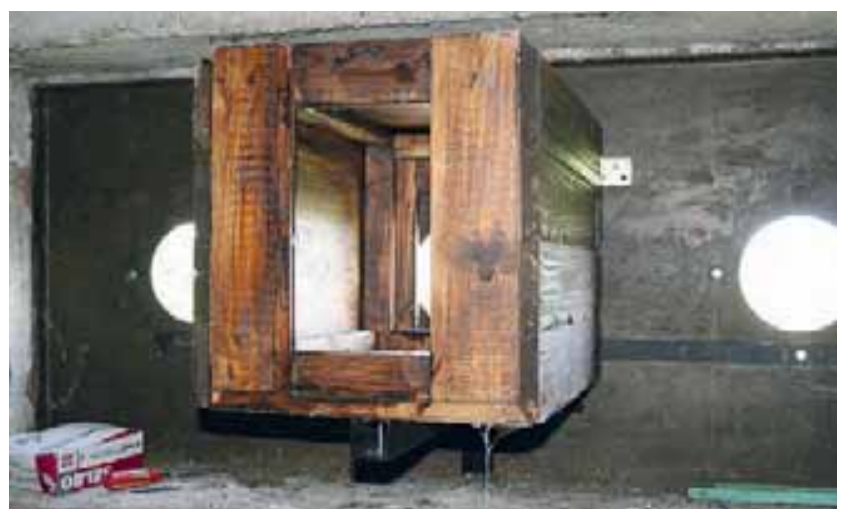

Abb. 333: Nachgerüsteter Turmfalkenkasten im Innenraum von Trafostationen. - Alle Fotos des Kapitels: H. Richter.

Fledermauskästen außen anzubringen. Mit Unterstützung der BB Gesellschaft für Beruf und Bildung GmbH Güstrow wurden alle Halter für die Falkenkästen nach meinen Vorstellungen angefertigt.
Ich entschied mich ansonsten, den größten Teil der Falkenkästen innerhalb der Trafohäuser zu installieren. Inneneinbauten von Brutkästen sind wettergeschützter und lassen sich besser kontrollieren, machen aber einen Mauerdurchbruch erforderlich. Das Entfernen eines Keramikisolators erbrachte die notwendige Öffnung. Ich habe die Falkenkästen mit einer abnehmbaren Rückseite versehen. So kann man den Bruterfolg kontrollieren. In Neu Kätwin und in drei weiteren Objekten waren die Außentüren inklusive der Schließtechnik in einem sehr schlechten Zustand. In Neu Kätwin wurde ein neuer Schließzylinder eingepasst. Die Tür in Bülower Burg wurde vom Bildungsverein ausund eingebaut und in ihrer Werkstatt fachgerecht restauriert. Auch diese Tür erhielt ein neues Kastenschloss. Ebenfalls ein neues Schloss bekam die Tür in Augustenberg, an der zuvor Einbruchspuren im Türblatt zu beseitigen waren. Ein Loch im Dach des Trafohauses machte mir dort große Sorgen. Dieser Schaden war schon im Abnahmeprotokoll vermerkt. Nässeschäden an der Decke waren bereits sichtbar. Die Höhe bis zum Loch im Spitzdach war mit einer normalen Leiter nicht erreichbar. Über den Bürgermeister von Hoppenrade, Herrn Dieter Maßmann, nahm ich Kontakt zur Feuerwehr Koppelow auf und erhielt großartige Unterstützung.

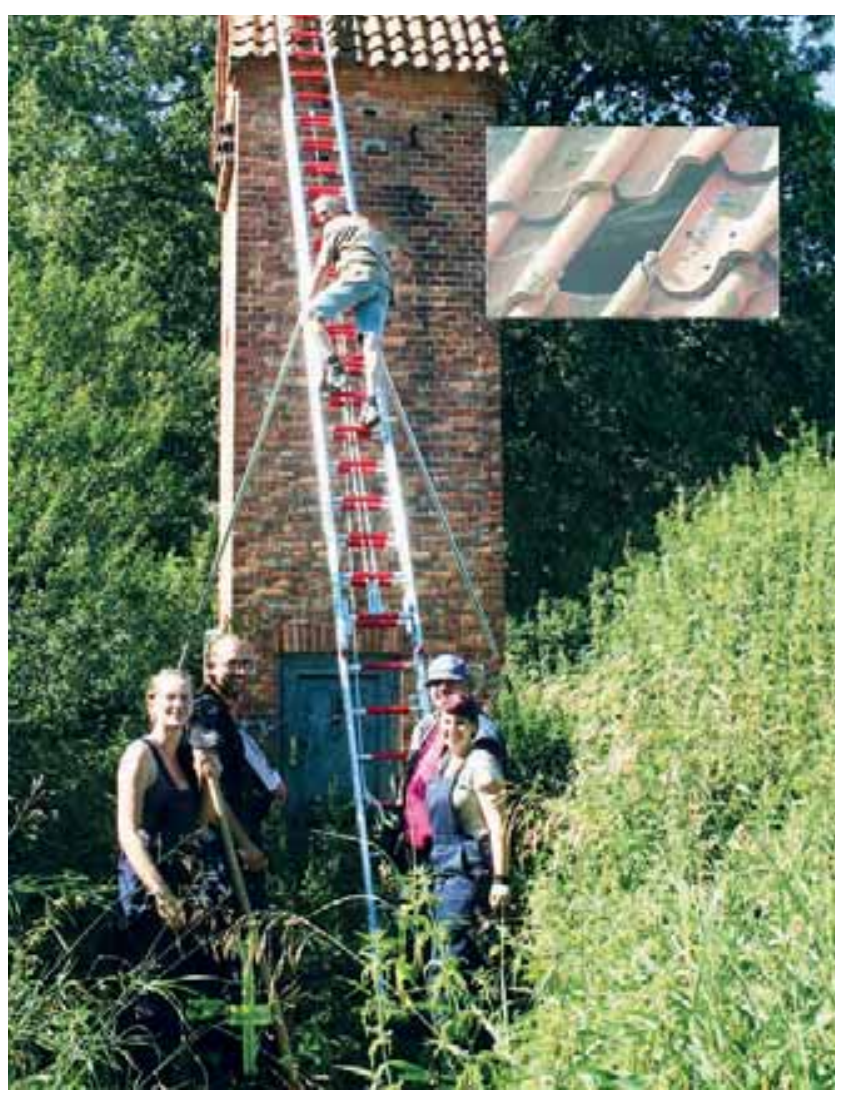

Abb. 334: Bei der Dachreparatur am Trafo Augustenberg halfen sechs KameradenInnen der Feuerwehr Koppelow.

Die neue Feuerwehrleiter der Feuerwehr Koppelow wurde zum ersten Mal von sechs Feuerwehr-Eleven in Augustenberg zum Einsatz gebracht. Dabei stellte sich heraus, 
dass ohne das Dach zu beschädigen es nicht einfach ist, eine Stelzenleiter aufzustellen. Den jungen Leuten, darunter auch zwei Mädchen, machte diese Übung großen Spaß, da das Aufstellen der Leiter Ähnlichkeit mit dem Platzieren eines Liegestuhles hatte. Diesen Standort habe ich dann mit einem Falkenkasten und einem Hornissenkasten aufgerüstet.

Auch für das Trafohaus Hoppenrade waren ein Hornissenkasten, ein Falkenkasten und zwei Fledermauskästen vorgesehen. Die Öffnung des durch Vandalismus zerstörten Glasbausteinfensters bot sich zum Einbau des Falkenkastens an. Die Glasreste habe ich entfernt und die Spalten mit Dichtschaum ausgefüllt. Die Seitentür in Serrahn Ausbau war im unteren Bereich sehr stark durchgerostet, so dass Raubsäuger leichten Zugang hatten. Ich entschloss mich, die Seitentür nicht zu reparieren, sondern sie einfach zuzumauern. Das war nachhaltiger. Die Eingangstür dagegen bekam einen neuen Schließzylinder. Im Obergeschoss wurden alle überzähligen Öffnungen geschlossen. Ein Hornissenkasten, ein Falkenkasten und zwei Fledermauskästen sind dazugekommen. Auch in Oldenstorf, Vogelsang und Neu Strenz erfolgten diese Nachrüstungen.

Um auch Insektenhotels einbauen zu können, informierte ich mich im Internet über deren Zweck, Größe und Material sowie zu Habitatansprüchen von Wildbienen. Mit einer Skizze habe ich mich dann an die Lehrmeister der Gesellschaft für Beruf und Bildung gewandt. Der Betrieb übernahm vollständig die konstruktive und maschinelle Umsetzung der Holzarbeiten und schuf die Grundlage für die Ausgestaltung. Es sollte nun eigentlich ein Leichtes sein, drei leere Kästen mit dem entsprechenden Innenleben auszufüllen.

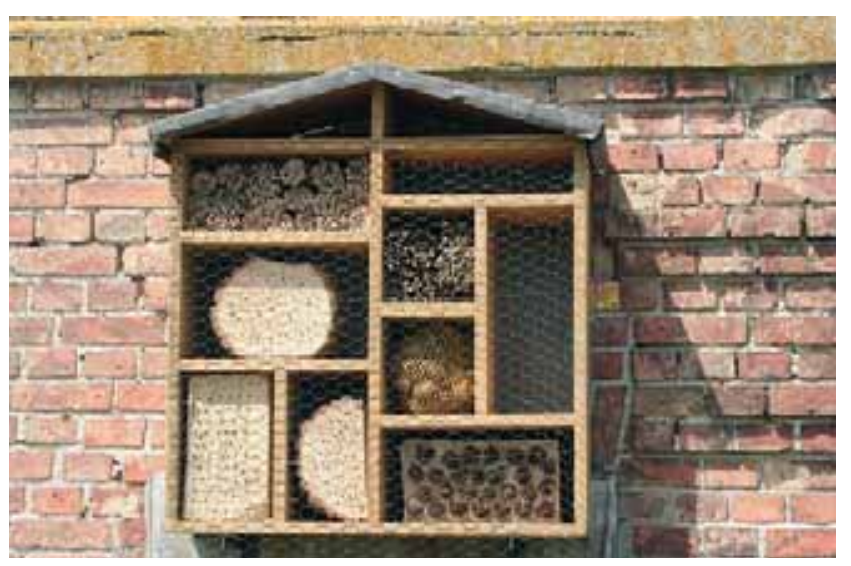

Abb. 335: Insektenhotel an der Südseite des Trafogebäudes in Schabernack.

Beim Entwerfen der Kästen war ich sehr großzügig vorgegangen, was sich dann als Nachteil erwies.

Ich musste eine Menge Materialien verschiedenster Art heranschaffen. Bei der Bereitstellung von Holzscheiben unterstützte mich unser FG-Mitglied und Revierförster a.D.
Volker Bösel. Für die Lochsteine, die ich aus Lehm herstellen wollte, suchte ich nach Angeboten in den Baumärkten und musste feststellen: Lehm ist ein Nischenprodukt.

Durch Recherchen wurde ich in der Region fündig, so dass auch für alle drei Kästen Lehmsteine mit Löchern eingesetzt werden konnten.

Die Nutzung der vervollständigten Trafohäuser durch Tiere war bisher recht unterschiedlich. Das Nahrungsangebot im direkten Umfeld dürfte von Bedeutung gewesen sein.

Mit der zusätzlichen Ausstattung konnten schnell neue Besiedlungen festgestellt werden.

2013/2014 registrierten wir

- eine Schleiereule ohne Brut,

- ein Waldkauzpaar mit fünf Eiern,

- ein Turmfalkenpaar mit drei Eiern,

- 14 Rauchschwalbennester,

- ein Bachstelzennest mit 3 Eiern,

- vier Hornissennester

sowie die Nutzung der Station in Lohmen durch Dohlen und Schleiereulen (Gewöllfunde) in Neu Kätwin.

Bei den 18 angebrachten Fledermauskästen konnten wir noch keine Besiedlung feststellen.

In der Saison 2015 waren erfreulicherweise dann

- eine erfolgreiche Schleiereulenbrut mit fünf Jungen

- eine erfolgreiche Turmfalkenbrut mit sechs Jungen

- eine mit einem Waldkauz besetzte Station

und wiederum Nester von Rauchschwalben und Bachstelzen sowie Hornissennester zu verzeichnen.

Im Fazit ist festzustellen, dass die Trafostationen Heimstätten für Tiere geworden sind und $\mathrm{zu}$ hoffen ist, dass sich das künftig durch eine traditionelle Bindungen noch deutlich erweitern wird. Die Arbeiten sind soweit erledigt. Jetzt können die reinen Beobachtungen und Kontrollen folgen, die mir anfangs vorschwebten.

Bereits 2015 gab es interessante Beobachtungen. Schleiereulen legten ein umfangreiches Nahrungsdepot an. So wurden innerhalb von zwei Wochen 16 Mäuse im Nistkasten, eine sogar im Einflugschacht abgelegt.

Fragen werden zu beantworten sein: Was macht man mit Hornissennestern, die statt im angebrachten Hornissenkasten im Einflugschacht von Schleiereulenkästen angelegt werden?

Bei entsprechender Umgestaltung von Nistkästen mit einem Schieber im Ausflugbereich könnte dazu übergegangen werden, auch die jungen Turmfalken, Schleiereulen und Waldkäuze künftig zu beringen.

Bisher wurde bei bereits zu großen Jungen darauf verzichtet, da ein Abspringen der Jungen befürchtet worden war. 


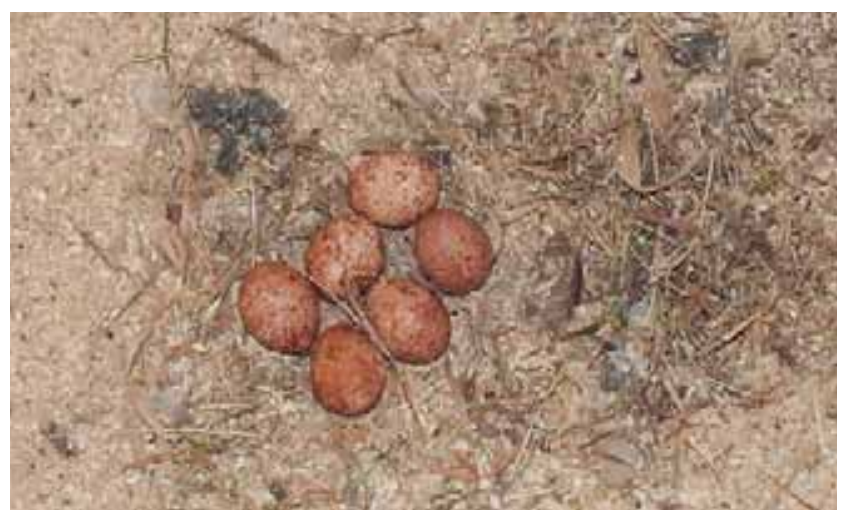

Abb. 336: Turmfalken-Gelege in einem Schleiereulenkasten

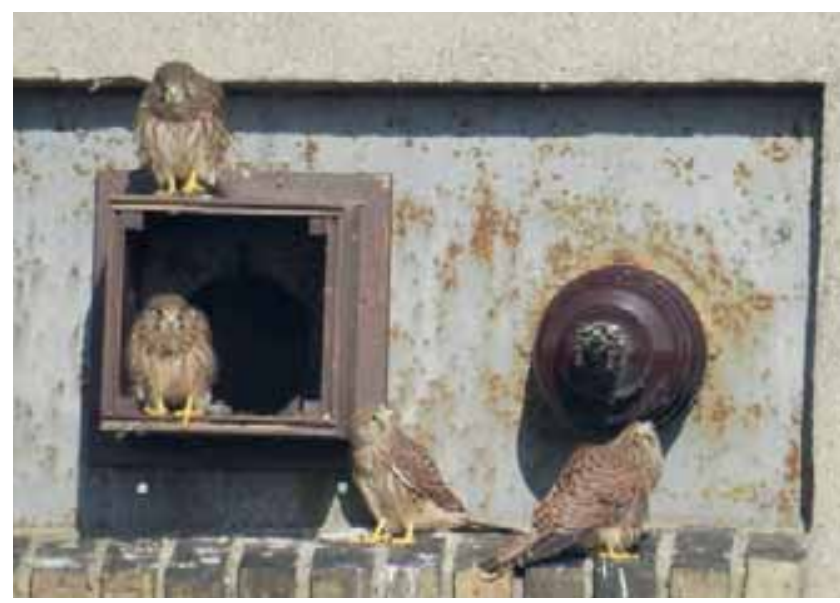

Abb. 337: Die jungen Turmfalken haben das Nest verlassen.

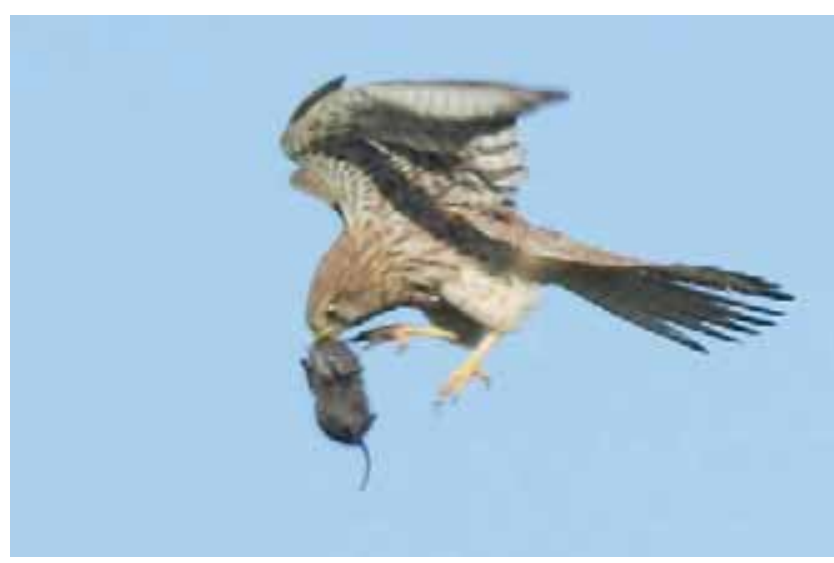

Abb. 338: Ein Altvogel bringt Futter.

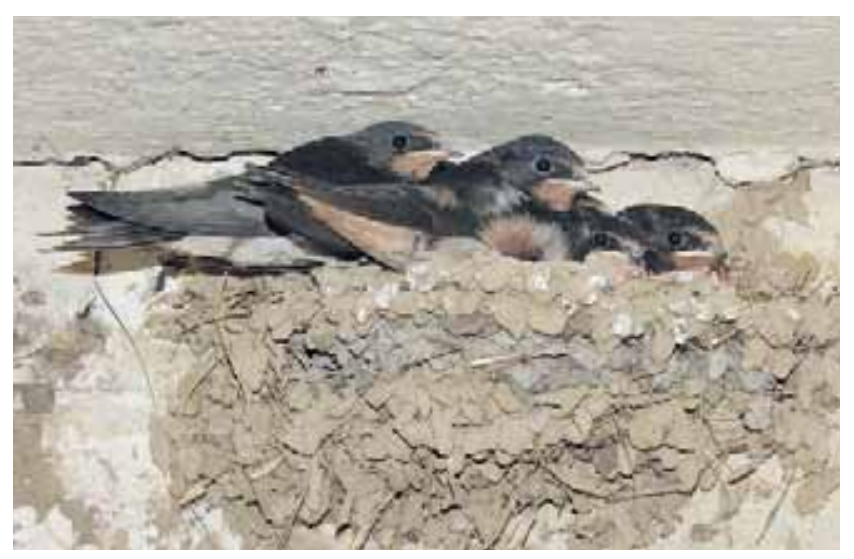

Abb. 339: In vielen Stationen brüten auch Rauchschwalben.

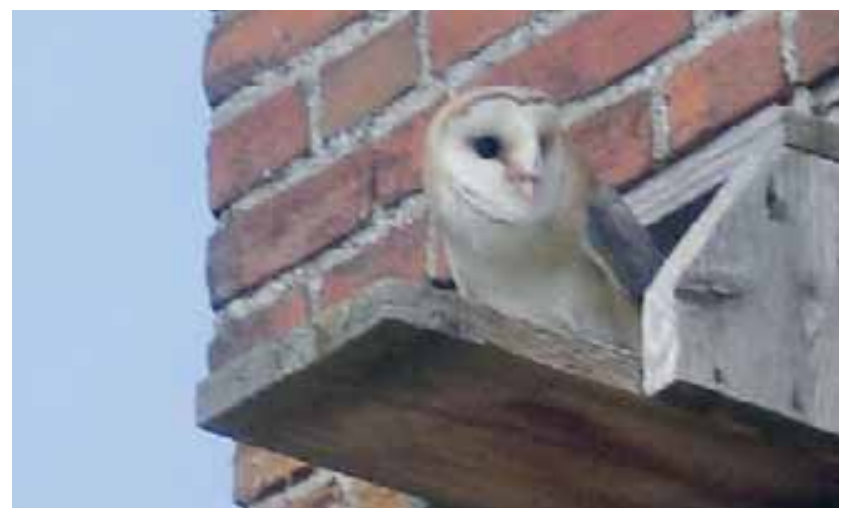

Abb. 340: Adulte Schleiereule vor dem Abfliegen aus der Station.

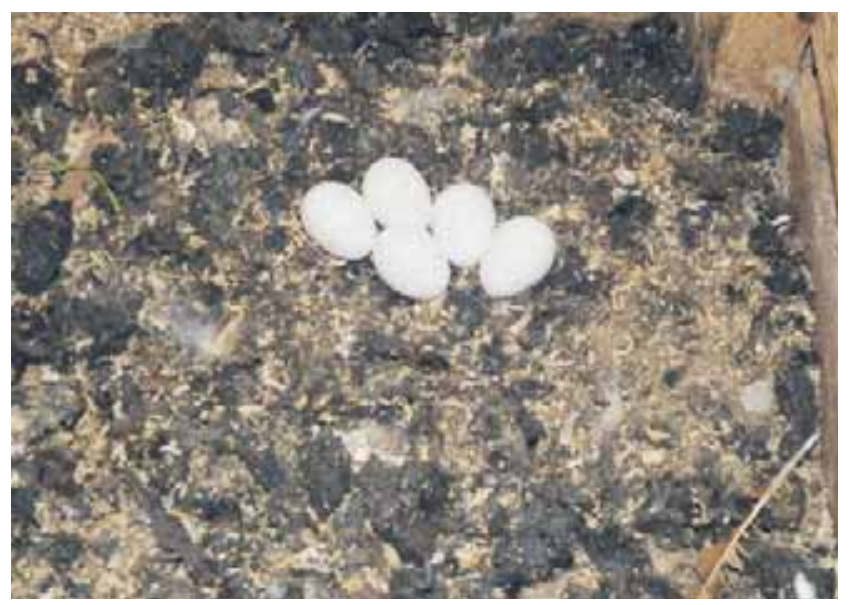

Abb. 341: Vollständiges Schleiereulengelege am 4.4.2015.

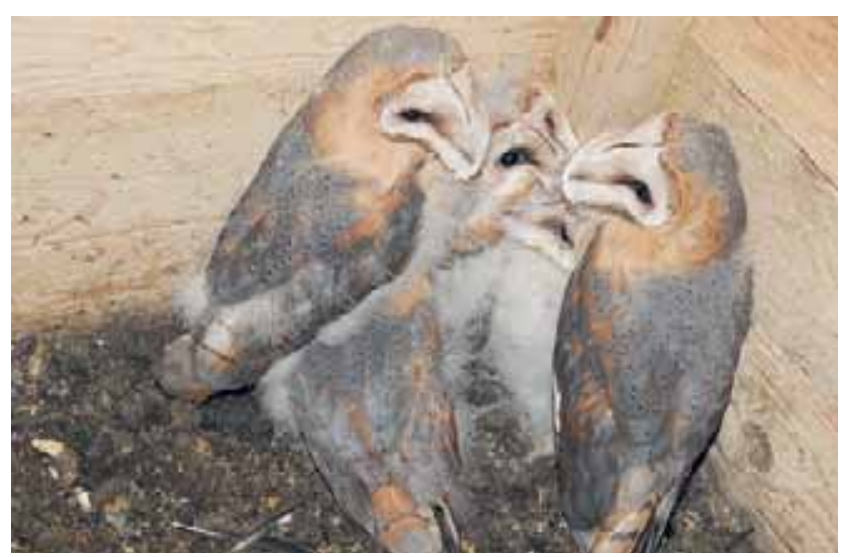

Abb. 342: Die jungen Schleiereulen sind fast flügge - 22.6.2015.

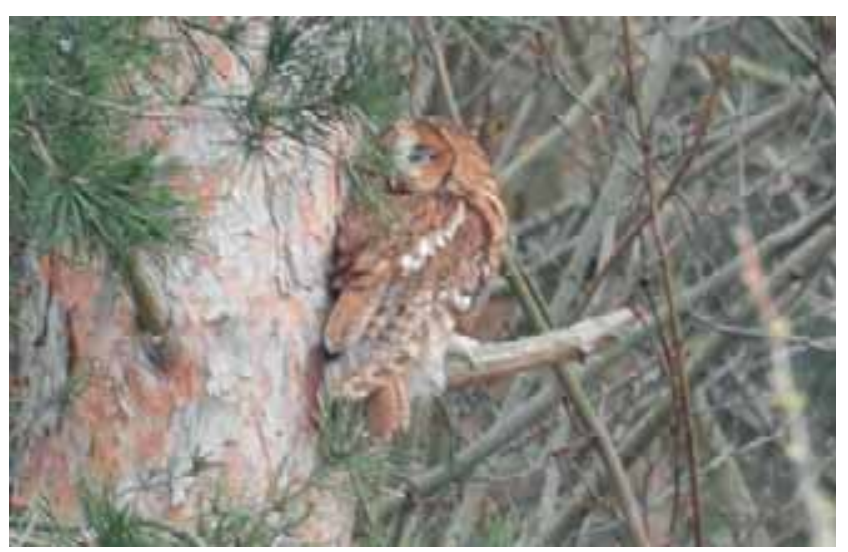

Abb. 343: Ein Waldkauz flog aus der Station Schabernack ab. 
Abb. 344 bis 354: Die hergerichteten Stationen im Überblick. Fotos: alle H. Richter.

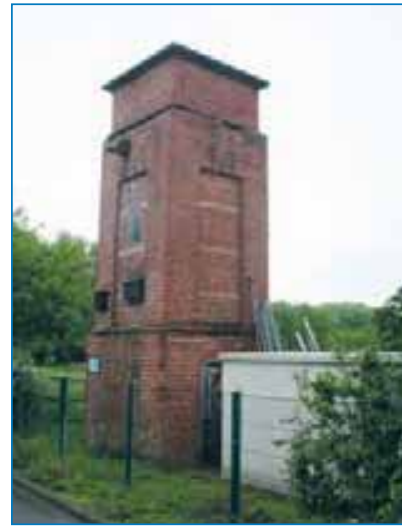

Alt Sammit

(außerhalb Karte 23)

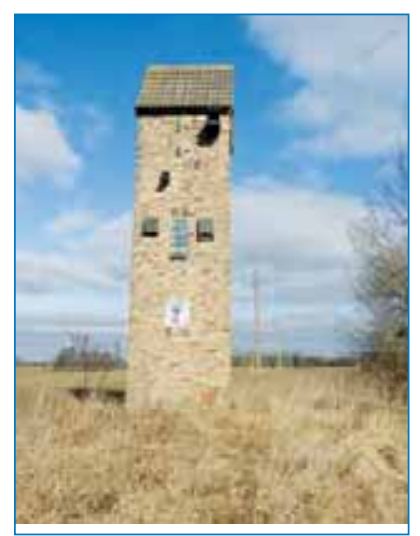

Neu Kätwin (10)

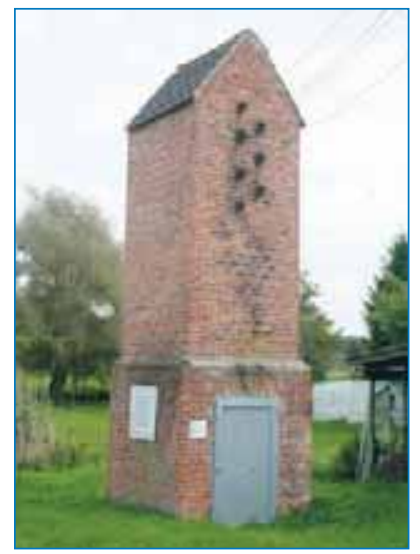

Lohmen (7)

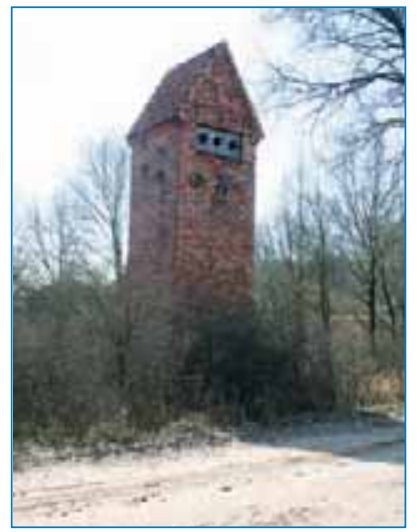

Augustenberg (3)

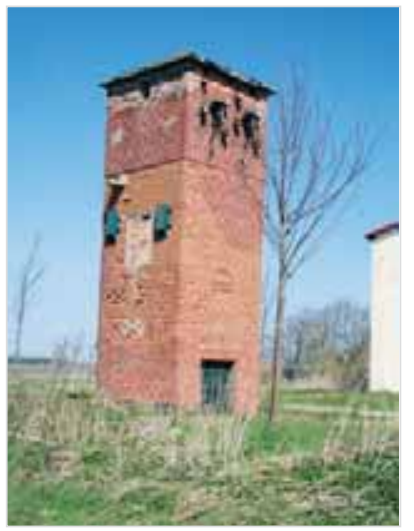

Vogelsang (4)

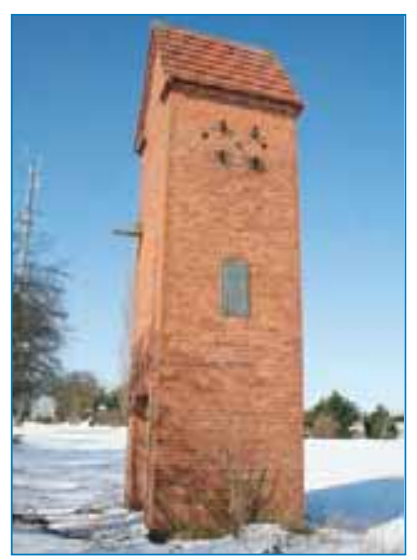

Serahn Ausbau (5)

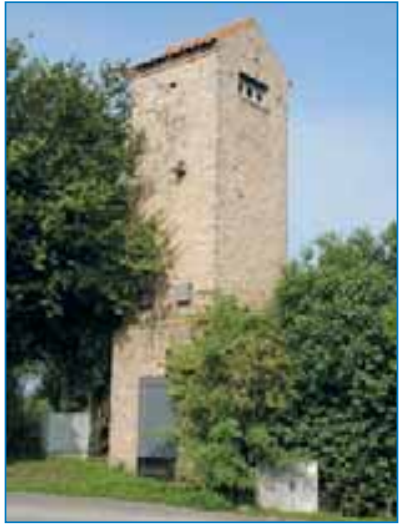

Bülower Burg (8)

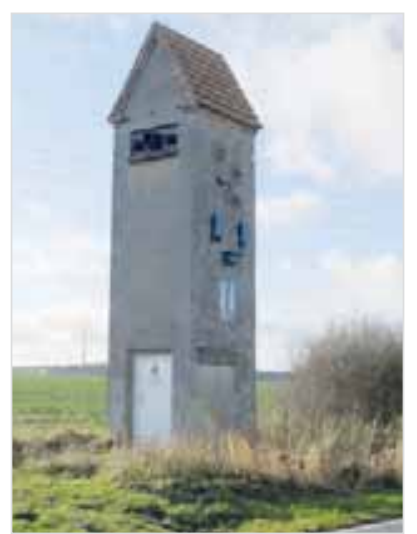

Oldenstorf-Suckwitz (6)

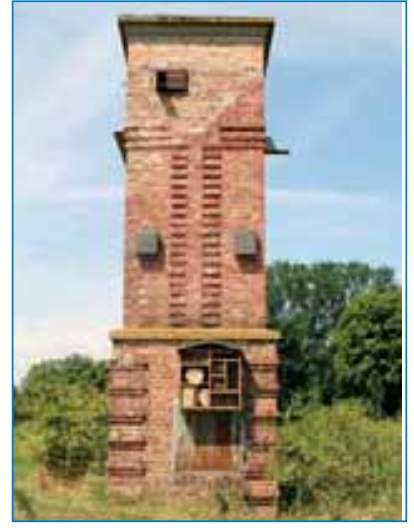

Hoppenrade (2)

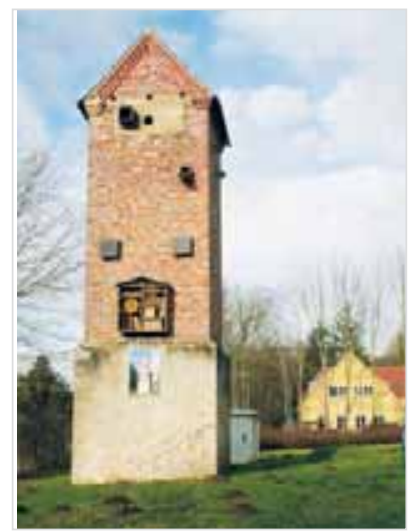

Schabernack (1)

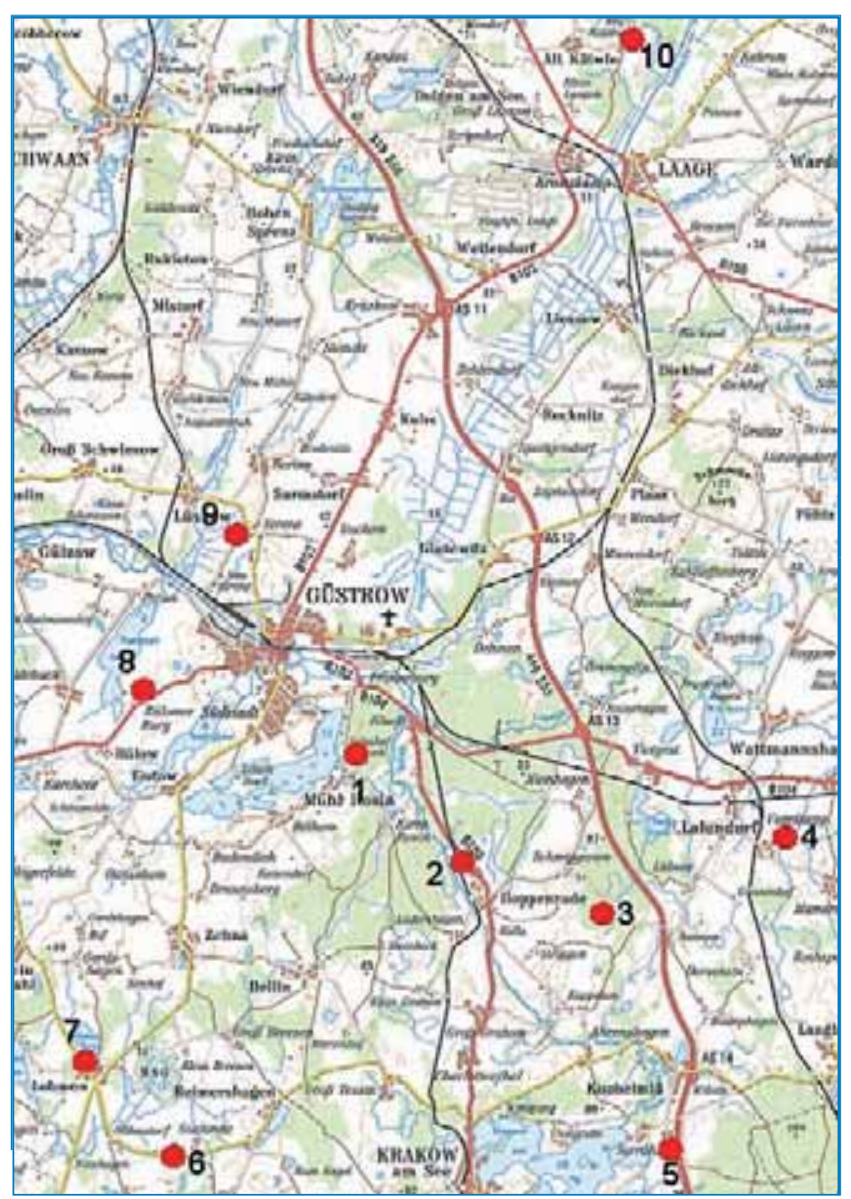

Karte 23: Lage der betreuten Trafostationen

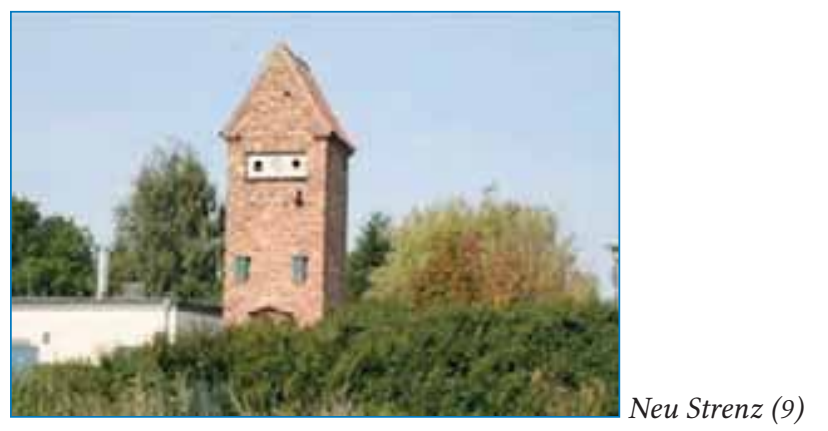




\title{
10.7 Fledermausschutz durch Quartierbereitstellung in Eiskellern
}

\author{
Joachim Loose (nach Informationsmaterial von Jörg Bußmann)
}

Wenn wir mit unserer Broschüre die Aktionen der Fachgruppe darstellen wollen, ist eine Trennung zwischen beruflich durchgeführten Arbeiten und ehrenamtlichen Tätigkeiten nicht immer einfach. Vielfach gibt es einen gleitenden Übergang.

So waren die bereits bei der Herrichtung der Trafostationen von Jörg Bußmann geleisteten Aufwendungen zu einem gewissen Teil als reguläre Arbeit über die ARGE zu bewerten. Ähnlich verhält es sich bei den von Jörg Bußmann vorgenommenen Herrichtungen von ehemaligen Eiskellern zu Quartieren für Fledermäuse. In beiden Fällen gingen die mit großem Engagement erledigten Arbeiten weit über eine von einem Arbeitgeber vorgegebenen Pflichten hinaus. Es war in hohem Maße Eigeninitiative gefragt. Jörg Bußmann war an den Eiskellern auch aus denkmalspflegerischen Aspekten interessiert und hatte sich deren Lage im Kreis erarbeitet. Die meisten ehemaligen Eiskeller waren als Müllkippen genutzt worden, bei vielen war das Gewölbe eingestürzt. Um sie als geeignete Fledermausquartiere herzurichten, waren zunächst erhebliche Entrümpelungsaktionen erforderlich. An erster Stelle war aber das Einverständnis der meist privaten Eigentümer einzuholen, mit denen dann seitens der NABU-OG Vereinbarungen abgeschlossen wurden. Für das Entrümpeln suchte sich Jörg Bußmann Verbündete.

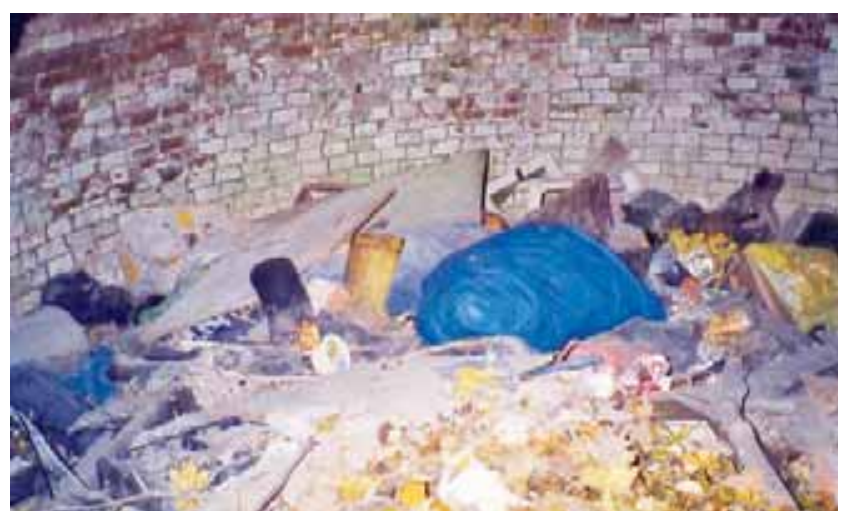

Abb. 355: So vermüllt und schlimmer sahen die meisten Eiskeller zu Beginn der Bauarbeiten aus. Foto: 7. Bußmann.

Vielerorts waren ABM-Kräfte behilflich. Für den Eiskeller in Lalendorf fand er sie z.B. in der dortigen Schule - fünf Schüler der Klasse 10a packten kräftig zu. Weitere Unterstützung gaben auch unsere FG-Mitglieder Herald Kusch und Carsten Vick sowie Siegfried Rüdiger aus der BotanikAG, der gleichfalls im Denkmalsschutz mitarbeitet. Die Abfallbehörde des Landkreises stellte nach Bitte der UNB in allen Fällen kostenlos Müllcontainer für die meist mehreren Kubikmeter Abfall bereit. Nach der Müllberäumung waren Sanierungsarbeiten am Mauerwerk auszuführen und eine Verschließbarkeit des Einganges herzustellen.
Über der Eingangstür blieb ein Einflugspalt für die Fledermäuse offen, die hoffentlich bald Einzug in ein neues Quartier halten sollten. Die Tür war für spätere Kontrollen der Fledermausforscher erforderlich. Jörg Bußmann berichtete, dass am sanierten Eiskeller in Groß Grabow die Schlösser dieser Tür ständig aufgebrochen wurden und er sich schließlich dazu entschließen musste, die Tür bis auf den Spalt einfach zuzumauern (Abb. 358).

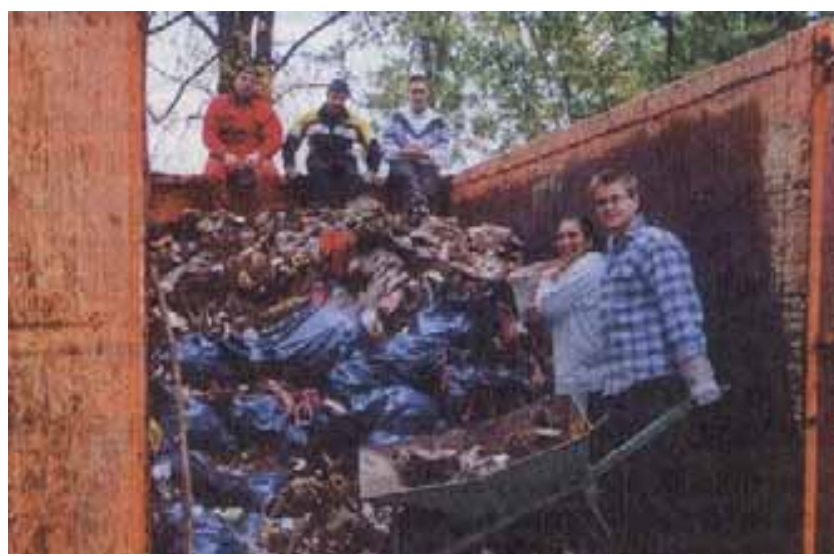

Abb. 356: Entrümpelungsaktion des Eiskellers durch Schüler der Klasse 10 a in Lalendorf. Foto: „Blitz“

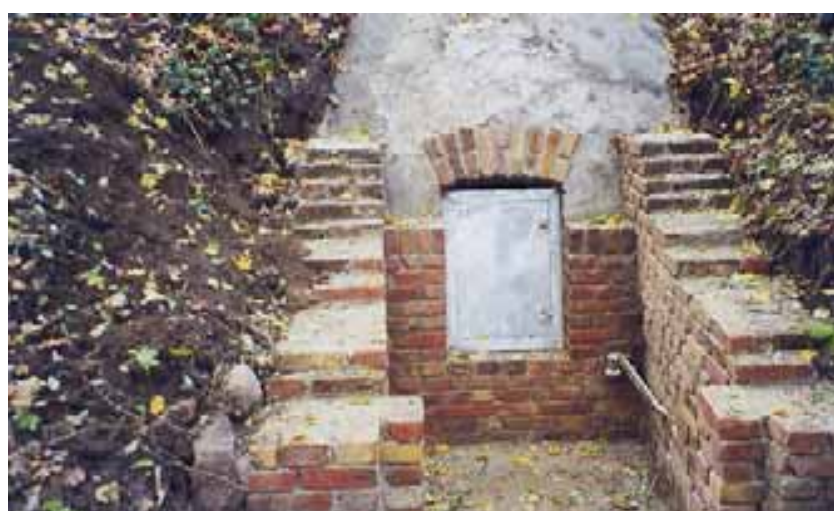

Abb. 357: Fertig sanierter Eiskeller als Fledermausquartier in Lalendorf. Foto: F. Bußmann.

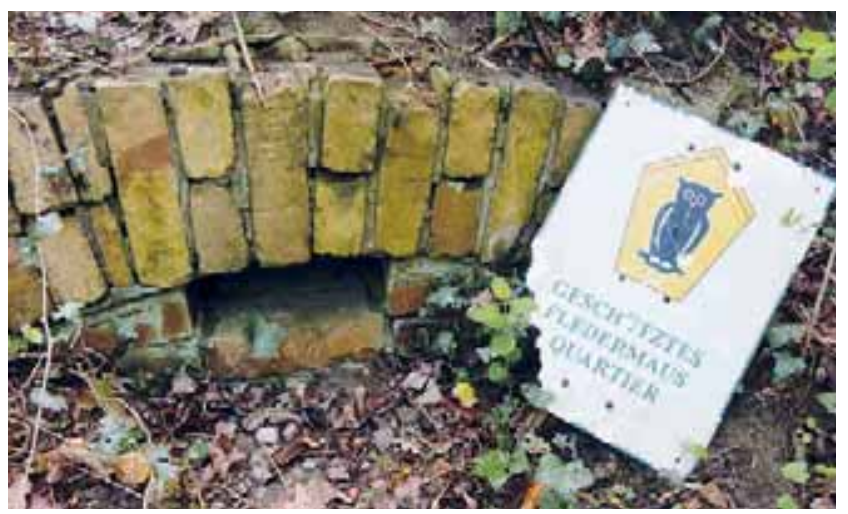

Abb. 358: Von der Unteren Naturschutzbehörde wurden für die sanierten Eiskeller Info-Tafeln bereitgestellt. Foto: f. Loose. 


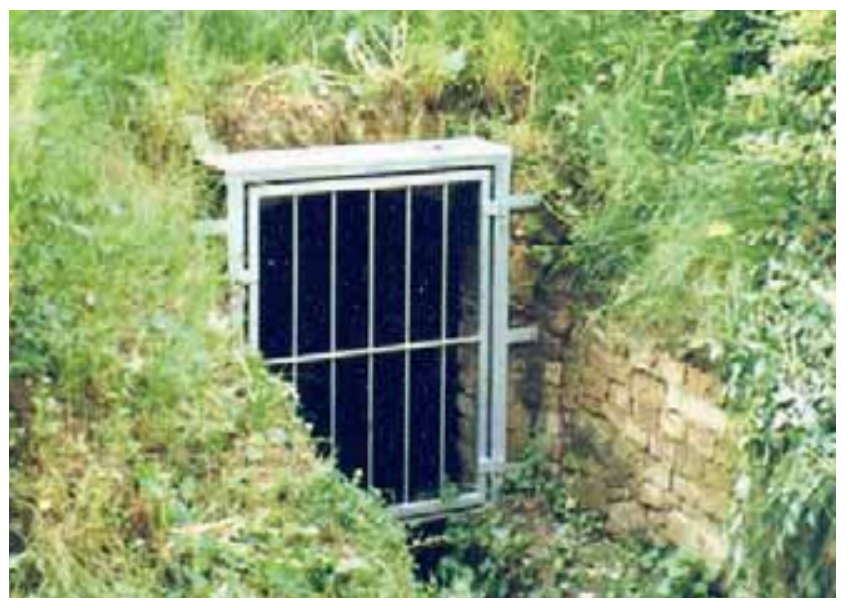

Abb. 359: Die Sicherung des Eiskellers in Groß Grabow anfangs nur mit einer Gittertür war ungenügend. Foto: F. Bußmann.

Als Erfahrung konnte vermittelt werden, dass es nicht reicht, wenn ein Eiskeller lediglich mit einer Gittertür gesichert wird, da damit für Fledermäuse nicht das erforderliche zugluftfreie und feuchte Raumklima geschaffen werden kann. Dass sich die Arbeiten auch gelohnt haben, zeigen die nachträglichen Objektkontrollen zur Besetzung mit Fledermäusen (siehe dazu unter Pkt. 9.7.2). Leider konnten in Groß Grabow durch den zugemauerten Eingang keine Kontrollen durchgeführt werden.

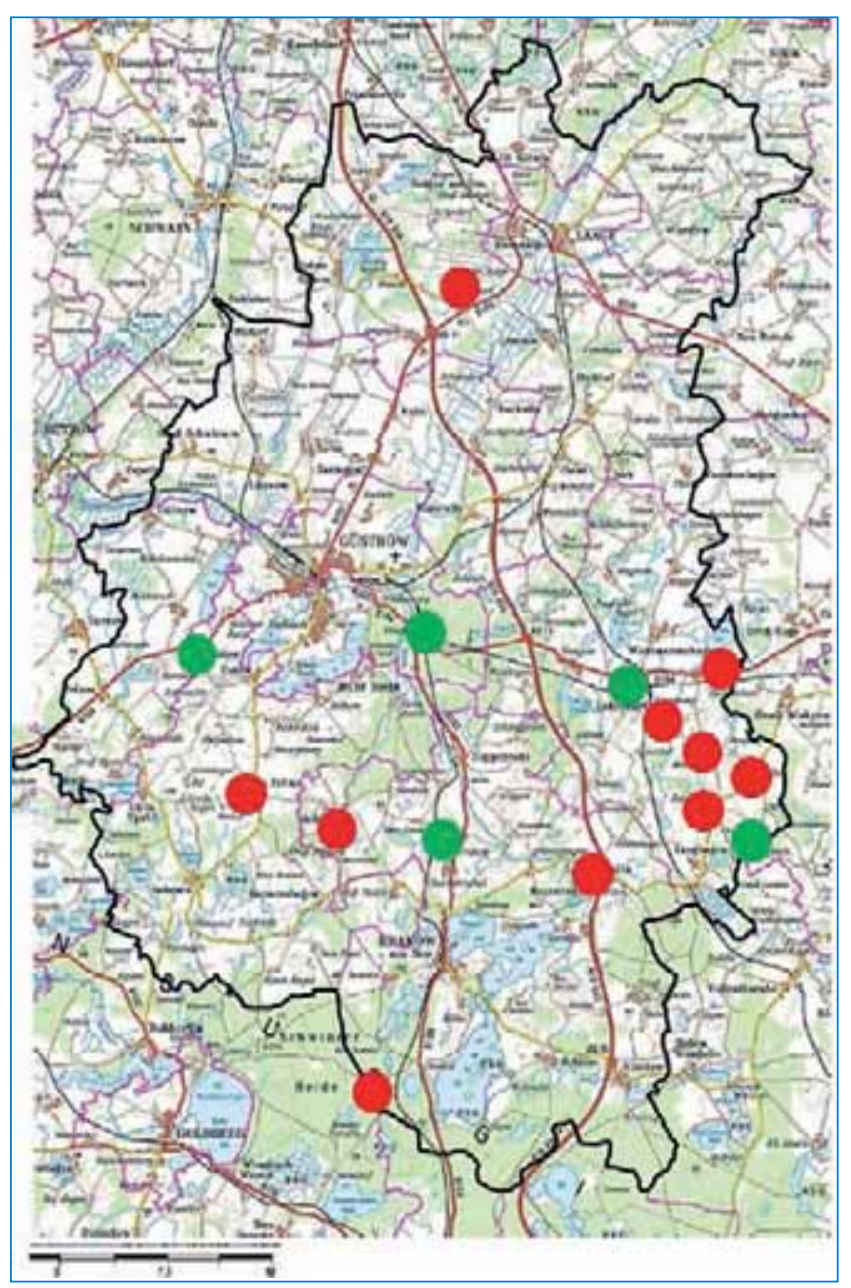

Karte 24: Lage von bekannten Eiskellern im Altkreisgebiet
Inzwischen sind einige Jahre vergangen, so dass man hier jetzt auf mehr Einsicht hoffen kann und den Zugang demnächst noch einmal für qualifizierte Kontrollen herstellen sollte. Wie ein Blick durch die kleine Einflugöffnung ergab, kann davon ausgegangen werden, dass auch dieser Eiskeller von Fledermäusen als Quartier genutzt wird.

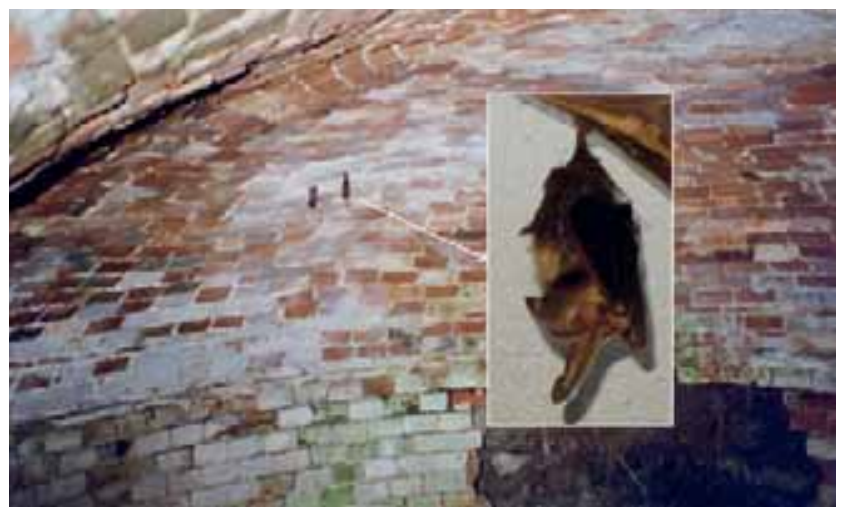

Abb. 360: Im Keller von Groß Grabow hängende Fledermäuse, die nicht näher bestimmt werden konnten. Foto: $\mathrm{F}$. Bußmann.

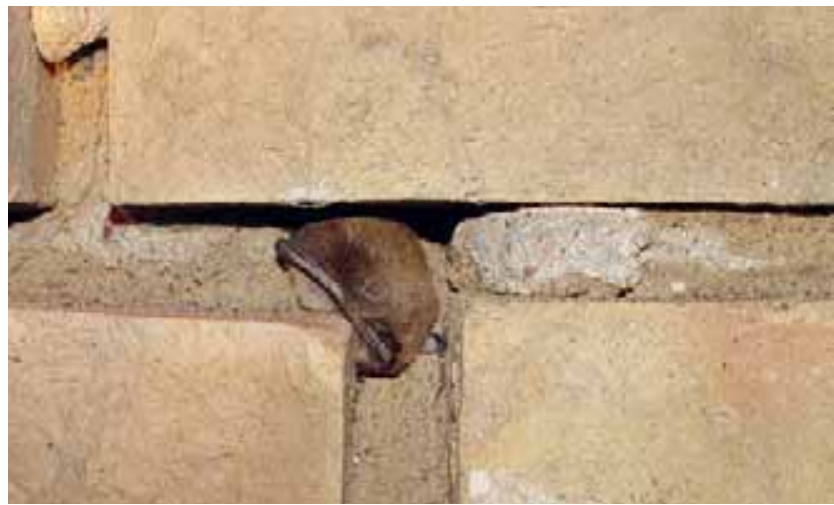

Abb. 361: Kleine Fledermausarten nutzen die Ritzen im Mauerwerk. Foto: f. Loose.

Im Gebiet des Altkreises warten noch weitere Eiskeller auf eine Bewertung und ggf. eine Herrichtung zum Fledermausquartier. Im Rahmen von Kompensationsmaßnahmen für Eingriffe in Natur und Landschaft, die durch die Untere Naturschutzbehörde auferlegt werden, könnte es gelingen, dass weitere Fledermausquartiere entstehen. Für die Prüfung der Entwicklungsfähigkeit der Eiskeller und auch anderer Quartiere bleibt aber weiterhin das ehrenamtliche Engagement gefragt.

\section{Zu Karte 24}

Hergerichtete und von Fledermäusen als Quartiere genutzte Eiskeller (grün) befinden sich in: Bülow, Klueß, Groß Grabow, Lalendorf und Carlsdorf.

Es sind weitere Eiskeller bekannt (rot), die einer Bewertung bedürfen und ggf. zum Fledermausquartier hergerichtet werden müssten:

Weitendorf, Zehna, Bellin, Raden, Vogelsang, Mamerow, Klaber, Rothspalk, Kuchelmiß und Neu Sammit 


\subsection{Nisthilfen für Mauersegler}

\section{Joachim Loose und Angela Martin}

Bald nach der Wende begannen die Allgemeine Wohnungsgenossenschaft (AWG) und die Wohnungsgesellschaft (WGG) in Güstrow mit den ersten Sanierungen von Wohnblöcken in den Plattenbausiedlungen. Die durch Herstellungs- und Montagefehler vorhandenen oder im Laufe der Zeit entstandenen Spalten zwischen den Betonplatten wurden durch Verschlussmasse oder das spätere Anbringen von Dämmplatten abgedeckt.

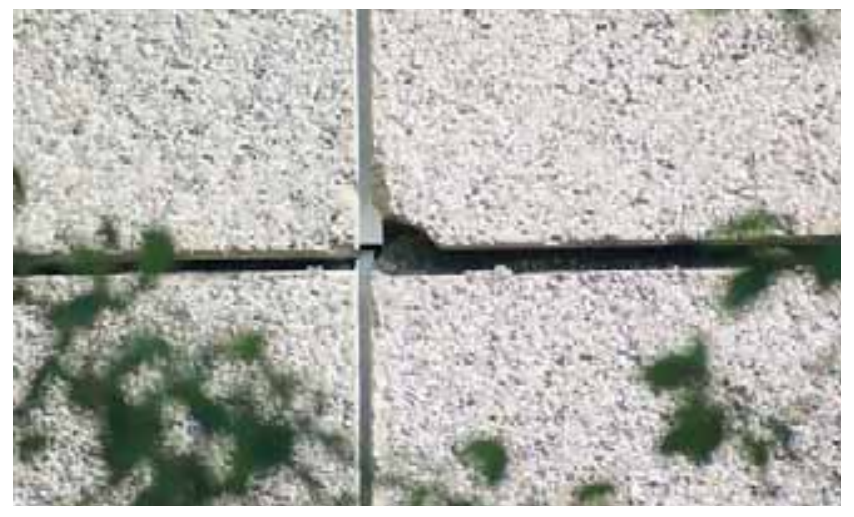

Abb. 362: Die Spalten und Risse in den Giebelwänden der Wohnblöcke boten ideale Quartiermöglichkeiten für Tiere. Foto: J. Loose.

Damit waren im Handumdrehen Nist- und Unterkunftsmöglichkeiten für mehrere Vogel- und Säugetierarten, insbesondere Mauersegler und Fledermäuse, aber auch Haussperlinge, verschwunden. Aus Artenschutzgründen musste sehr schnell etwas dagegen unternommen werden.

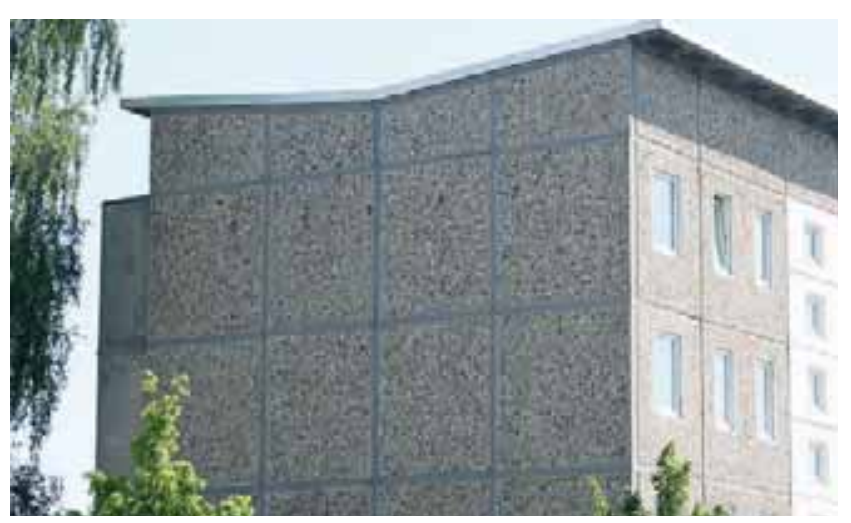

Abb. 363: Nach der Sanierung gibt es an den Giebelwänden keine Nistgelegenheiten mehr. Foto: f. Loose.

Unter den Vogelarten hatte sich der Mauersegler regelrecht auf die Nistmöglichkeiten spezialisiert, die die Spalten zwischen den Platten boten. Energetisch stellten die Spalten Wärmeverlustquellen dar, die es zu beseitigen galt. Dieser Forderung war schwer zu widersprechen.

Um den Bestandsverlust etwas genauer beziffern zu können, hätte der aktuelle Brutbestand der Mauersegler wenigstens grob erfasst werden müssen. Die wenigen FG-
Mitglieder waren bereits mit vielen anderen Aufgaben ausgelastet und andere Bemühungen, u. a. Schüler einzubinden, schlugen fehl. Sporadische Beobachtungen einiger Giebelwände brachten nur wenige sichere Brutnachweise. Irgendwie stand das im krassen Gegensatz zu den individuenreichen Trupps, die vor allem im Juli den Luftraum über der Güstrower Südstadt belebten.

Alle Appelle bei der AWG und der WGG, von sich aus neue Nistmöglichkeiten zu schaffen, verhallten zunächst ungehört. Das hätte Kosten verursacht, und bezüglich der Einhaltungspflicht von Artenschutzbelangen sah man die Nachweispflicht woanders. Durch den Druck der NABUOG gelang es 1994 als Einzelfall im Durchgang des Wohnblocks in der Friedrich-Engels-Straße 15/16 einen Mauerseglerkasten mit 15 Löchern unter dem Dach zu montieren. Unterstützt hatte uns Hans-Hermann Wrobel, der als Umweltamtsleiter vom Landkreis zur AWG gewechselt war. Die AWG wollte die Besiedlung des Kastens abwarten. Sollte das positiv verlaufen, wollte man so weitermachen. Bei der Regionalen Arbeitsförderungs-, Beschäftigungsund Strukturentwicklungsgesellschaft mbH (RABS) konnten Anfang 1997 endlich zwei ABM-Stellen geschaffen werden, die sich mit dieser Gebäudebrüterproblematik beschäftigten und bald straßenzugweise in Güstrow die Gebäude erfassten, in denen Mauersegler ein- und ausflogen. Eine Schulung der gewonnenen Mitarbeiter bei der RABS wurde durch A. Martin in ehrenamtlicher Arbeit abgesichert. Bald lagen lange Adress-Listen vor, auf deren Basis die Untere Naturschutzbehörde bei Sanierungen auch detailliert den Einbau von Nisthilfen auferlegen konnte.

Unser FG-Mitglied Reinhard Becker übernahm einen großen Part dieser anlaufenden Nistkasten-Aktion. Als Vorruheständler (er nutzte die damalige Möglichkeit, mit 55 Jahren aus der Berufstätigkeit auszuscheiden) hatte er sehr viel Zeit dafür aufgewendet. Er baute selbst zahlreiche Nisthilfen ein und leitete Bauarbeiter an. So wurden u.a. am 2.6.1997 nach Abstimmung mit dem Bau- und Schulamt des Landkreises seine Kästen am Distelberggymnasium angebracht. Herr Breitling, Direktor des Gymnasiums, sah die Mauerseglerkästen an seinem Haus gleichzeitig als Maßnahme für die praktische Umweltbildung der Schüler an.

Eine andere Variante probierte R. Becker bei der Sanierung der Wohnblöcke der August-Bebel-Straße 1-5 in der Güstrower Südstadt aus. In den unter dem Dach befindlichen Lüftungsöffnungen brach man einzelne Lamellen aus der Verblendung heraus, so dass hinreichend große Schlitze für den Einflug der Mauersegler entstanden. Nach dem Einbau eines Brettes hinter der Blende als Abgrenzung zum Innendachraum entstanden die Nistplätze für Mauersegler auf dem Mauerwerk des Wanddurchbruches. 


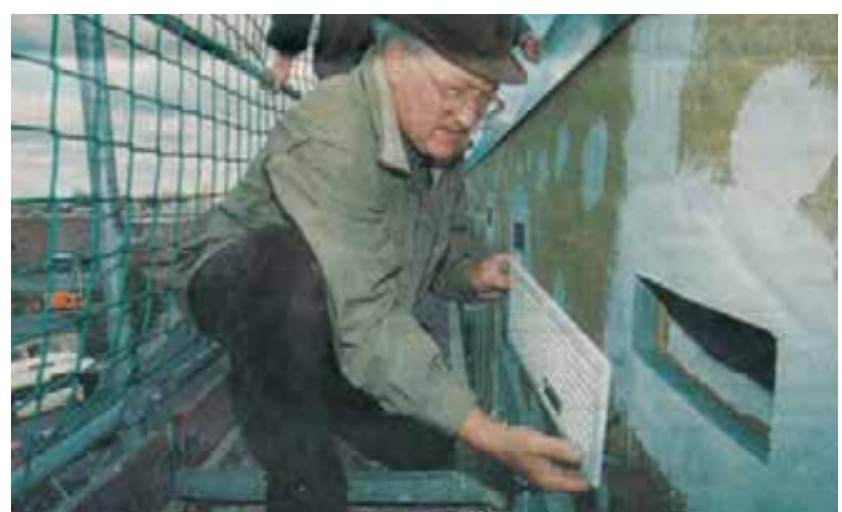

Abb. 364: Reinhard Becker beim Verschließen der Nistnische, die hinter der Lüftungsblende entstand. In der Blende ist die Einschlupföffnung erkennbar. Foto: Menzel, SVZ.

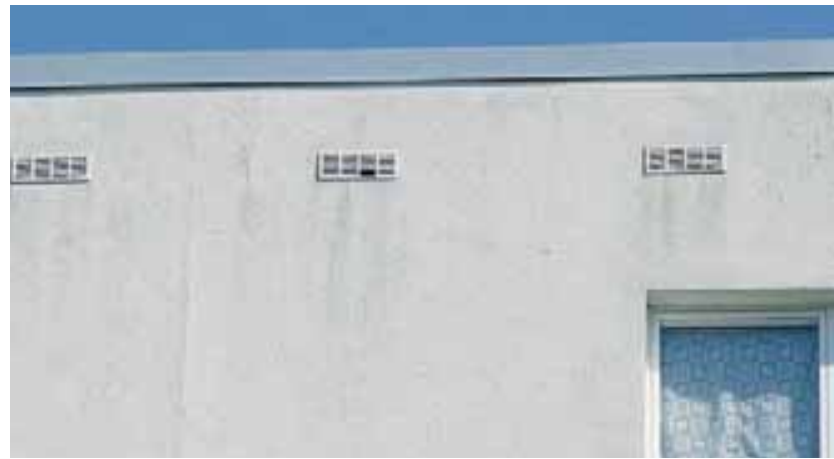

Abb. 365: Auf eine Durchlüftung des Dachinnenraumes konnte man an den Stellen der präparierten Blenden verzichten. Foto: 7. Loose

In dieser Form entstanden so in sanierten Wohnblöcken 25 neue Brutstätten - die Lokalzeitung berichtete im November 1997 mit einem Foto darüber. Der Bauleiter der WGG Herr Stiller war von der einfachen Methode überrascht und unterstützte an anderen Baustellen weitere Maßnahmen. Dort, wo der Dachraum mehr Bewegungsfreiheit bot, wurde eine weitere Variante für den Einbau von Nistkästen praktiziert (Abb. 366/367).

An den fensterlosen Giebeln der Plattenbauten wurden auf der Höhe des obersten Plattenspaltes oder direkt unter dem Dachüberstand Nistkästen für Mauersegler an der Außenwand angebaut oder direkt in die Dämmplatten eingebaut.

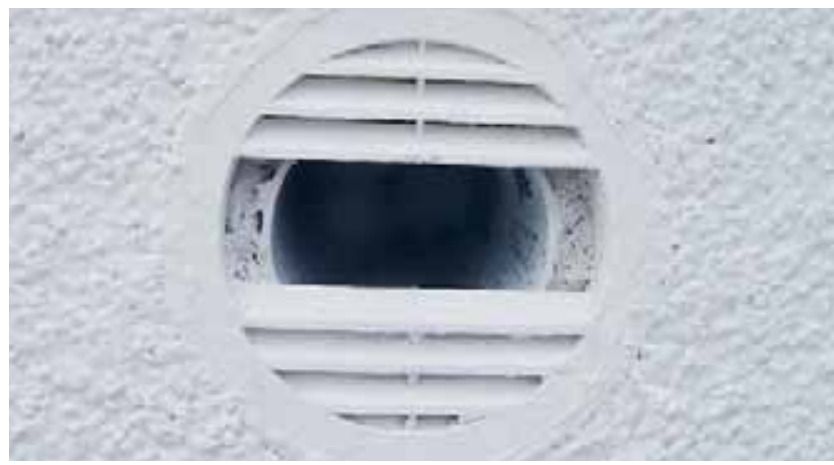

Abb. 366: Ausbruch in der Abdeckung von Lüftungslöchern Foto: 7. Loose.

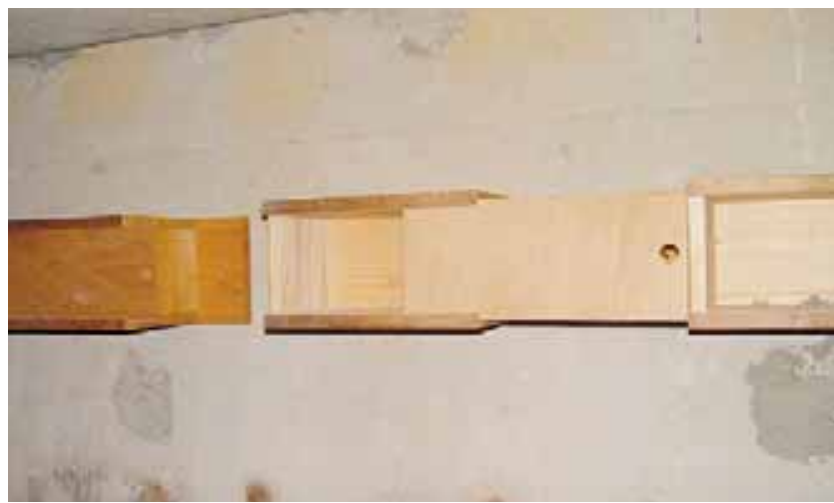

Abb. 367: Hinter den Lüftungslöchern angebrachte Kästen könnten auch kontrolliert werden. (Sanierte Wohnheime der Fachhochschule für öffentliche Verwaltung Güstrow, ehemals PH Güstrow) Foto: 7. Loose

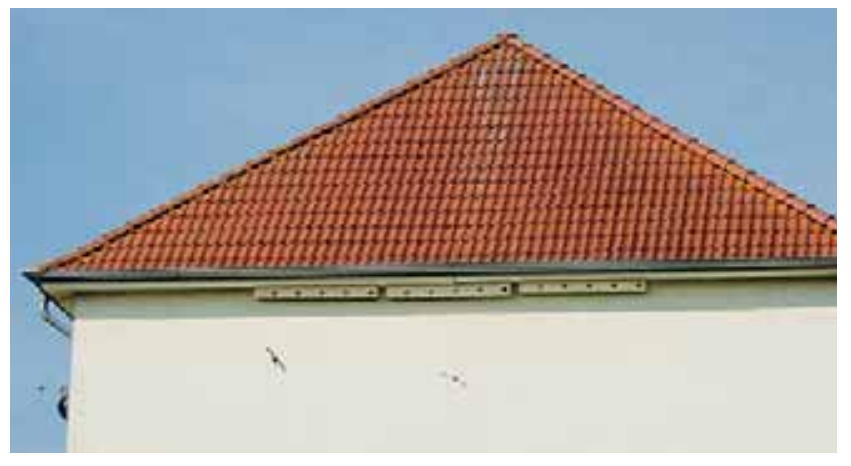

Abb. 368: Unter dem Dach außen angebaute Mauerseglerkästen in der Bürgermeister-Dahse-Straße/Gutower Straße. Foto: Loose.

Nach Erfassung der Mauersegler-Brutplätze wurde bei der RABS eine Folge-ABM angesiedelt, in der man sich auch um den Bau von Mauerseglerkästen und den anschließenden Einbau in Gebäude kümmerte. Fachliche Hinweise zu Nistmöglichkeiten hatte unserer FG zuvor Joachim Stapel aus Neubrandenburg gegeben, die wir an die RABS weitergaben.

Die Aktion der ABM-Kräfte wurde dann kurzzeitig zum „Selbstläufer“, so wie wir es uns als Unterstützung gewünscht hatten. Gemeinsam mit der Kreisvolkshochschule versuchte man, Bürgermeister und Bauämter aus den Städten und Gemeinden in einem Erfahrungsaustausch zu animieren - leider blieb hier die erwartete Resonanz aus.

Mit der Zunahme vorzeigbarer Beispiele für gelungene An- und Einbauten von Niststätten stieg die Bereitschaft bei Gebäudeeigentümern, Bauherren und Baufirmen, in ähnlicher Form Maßnahmen umzusetzen. Nach vielen Bemühungen wurden schließlich auch in Kronskamp und in Laage Nistkästen angebracht.

Durch die Mitarbeiter der RABS wurden die von ihnen oder durch ihr Mitwirken in der Zeit von 1998 bis 2000 angebrachten Nistkästen registriert (siehe Tabelle 15).

Neben dem Eingriff in die Mauerseglerniststätten wurden durch die Wärmedämmung der Plattenbauten auch zahlreiche Quartiere von Fledermäusen verschlossen. Reinhard Becker und Angela Martin kämpften daher auch darum, 


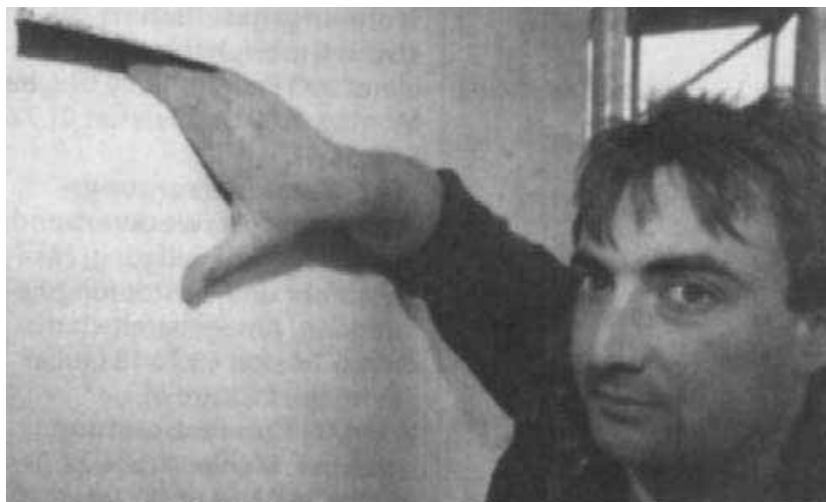

Abb. 369: Hinter dem Fassadenschlitz befindet sich ein Fledermausquartier. Der Kasten wurde in die Dämmplatten eingearbeitet alles ist von außen kaum sichtbar. Foto: SVZ

dass neue Quartiere für Fledermäuse entstehen bzw. alte Spalten in den Platten auch weiterhin zugänglich bleiben. Im Gegensatz zu den zahlreichen Mauersegler-Ersatzquartieren wurden jedoch nur an wenigen Stellen auch Schlitze in die Dämmplatten eingearbeitet.

Der frühe Tod von Reinhard Becker Ende November 1997 verhinderte eine kontinuierliche Weiterarbeit. So erfolgten nach Abschluss der Arbeiten keine Effizienzkontrollen über die Annahme der neuen Brutstätten. Die ABM bei der RABS war im Dezember 2000 ausgelaufen. Wir hatten gehofft, dass die Leute, die sich zuvor sehr engagiert hatten, sich auch danach ehrenamtlich den Mauerseglern widmen würden, was jedoch leider nicht geschah.

Unsere FG-Mitglieder waren mit anderen Aufgaben ausgelastet, so blieb auch bei dieser Vogelart die eigentlich wichtigen Kontrolle bis heute aus. Es gibt einen kleinen Trost: Auch ohne weiteres Zutun von ABM-Kräften oder FG-Mitgliedern wurden in den Folgejahren in Güstrow noch weitere Niststätten für Mauersegler errichtet. Zum Teil resultierte das aus den Auflagen der Naturschutzbehörden, aber es gab auch Eigeninitiativen bei AWG und WWG und privaten Bauherren. Die Erkenntnis, dass man Lebensstätten von geschützten Tieren nicht einfach ohne Ersatzangebote beseitigen darf, hat sich in Kreisen der Bevölkerung vertieft. Einige Bürger haben uns und die Naturschutzbehörde immer öfter darauf hingewiesen, wenn weitere Wohnblocks saniert wurden und man hier mal wieder „vergessen" hatte, Artenschutzmaßnahmen einzuplanen.

Wenn wir sehen, wie Mauersegler heute die angebotenen Nistkästen anfliegen, erinnern wir uns gern an die Aktivitäten von Reinhard Becker, der dazu den Grundstein legte. Es wäre nur wirklich wieder an der Zeit, dass der Bestand des Mauerseglers wenigstens in der Stadt Güstrow erfasst wird, um zu sehen, welchen Nutzen die Maßnahmen gebracht haben. Mit den von der RABS notierten Standorten von Nisthilfen werden gezielte Kontrollen erleichtert. - Wir stellen uns vor, dass das eine gute Projektarbeit für Schüler in der „umweltgerechten“ Stadt Güstrow sein könnte.
Tabelle 15: Zusammenstellung der RABS über eingebaute Nisthilfen für Mauersegler

\begin{tabular}{|c|c|c|c|}
\hline Ort/Eigentum/Adresse & $\begin{array}{l}\text { Datum der } \\
\text { Montage }\end{array}$ & $\begin{array}{l}\text { Kasten- } \\
\text { anzahl }\end{array}$ & $\begin{array}{l}\text { Mögl. } \\
\text { Brut- } \\
\text { plätze }\end{array}$ \\
\hline \multicolumn{4}{|l|}{ Güstow } \\
\hline \multicolumn{4}{|l|}{ - Private Häuser } \\
\hline Schweriner Str. 31 & 03.06.1998 & 1 & 3 \\
\hline Neue Straße 1 b & 13.08.1998 & 1 & 3 \\
\hline Plauer Straße 33 & 04.11 .1999 & $3^{N}$ & \\
\hline Kleine Wallstraße 6 & 23.03.1999 & 2 & 5 \\
\hline Lange Straße 13 & 01.04 .1999 & $2^{N}$ & \\
\hline Prahmstraße 37 & 07.04.1999 & 1 & 3 \\
\hline Ulrichplatz 3 & 14.04 .1999 & $2^{N}$ & \\
\hline Spaldingsplatz 14 & 27.05 .1999 & $3^{N}$ & \\
\hline Ulrichplatz 19 & 31.08 .2000 & 2 & 4 \\
\hline \multicolumn{4}{|l|}{ - Öffentl. Einrichtungen } \\
\hline Parkhaus [Südstadt] & 07.05.1999 & $5^{N}$ & \\
\hline \multicolumn{4}{|l|}{ Seniorenresidenz [VS] } \\
\hline Sankt-Jürgens-Weg & 1999 & $2^{N}$ & \\
\hline Landkreis - Am Wall 4 & 14.06 .1999 & $6^{N}$ & \\
\hline $\begin{array}{l}\text { Ehemal. PH, [VFS, LUNG] } \\
\text { Goldberger Str. }\end{array}$ & 16.08.1999 & 20 & \\
\hline \multicolumn{4}{|l|}{ - Wohnungsgenossenschaft } \\
\hline Elisabethstraße 12-14 & 10.06.1998 & 8 & \\
\hline Elisabethstraße 18-20 & 15.07.1998 & 8 & \\
\hline Elisabethstraße 52-53 & 19.05 .1998 & 6 & \\
\hline W.-Seelenbinder-Str. 12 & 07.04.1998 & 6 & \\
\hline Straße der DSF 52-58 & 14.05 .1998 & 3 & 15 \\
\hline Hans-Beimler-Straße 9-12 & 20.04 .1999 & 8 & \\
\hline \multicolumn{4}{|l|}{ - Wohnungsgenossenschaft Nord } \\
\hline Lindenallee 1-4, 5-8, 9-13 & $\begin{array}{c}\text { Aug.-Sept. } \\
1998 \\
\end{array}$ & 42 & \\
\hline \multicolumn{4}{|l|}{ Lärchenallee 16-19, 20-23 } \\
\hline \multicolumn{4}{|l|}{ Platanenstr. 15-18, 19-22 } \\
\hline \multicolumn{4}{|l|}{ - Wohnungsgesellschaft } \\
\hline Ärztehaus am Distelberg & 13.08.1998 & 10 & \\
\hline Elisabethstraße 15-17 & 05.10.1998 & 10 & \\
\hline Clara-Zetkin-Str. 12-14 & 22.09 .2000 & 10 & \\
\hline Haselstraße 7-10, 11-15 & 14.11 .2000 & 3 & \\
\hline \multicolumn{4}{|l|}{ Laage } \\
\hline \multicolumn{4}{|l|}{ - Private Häuser } \\
\hline Pinnower Straße 35 & 16.04 .1998 & 4 & 8 \\
\hline Breesener Straße 11 & 15.10.1998 & 2 & 4 \\
\hline$?$ & 20.04 .1999 & 1 & 2 \\
\hline \multicolumn{4}{|l|}{ Kronskamp } \\
\hline \multicolumn{4}{|c|}{ - Bützower Wohnungsgesellschaft } \\
\hline \multicolumn{4}{|c|}{ Neubaublocks - Haus } \\
\hline 112-116, 117-121, 122-126 & 10.09 .1999 & 30 & \\
\hline$/^{N}=$ Niststeine & & & \\
\hline
\end{tabular}

In Kronskamp sind zwar inzwischen eine Reihe von Wohnblöcken abgerissen worden, aber auch hier sahen wir 2013 auf Haubenlerchen-Suche im früheren Plattenbauviertel, wie sich ein Mauersegler aus einem der oben beschriebenen Schlitze einer Lüftungsverblendung zwängte. - Sie sind noch da! 


\subsection{Dohlen und andere Kirchenbewohner}

\subsubsection{Die Dohlenkolonie in der Kirche von Laage}

\section{Eckhard Schlüter}

Die Dohle ist der kleinste bei uns lebende Krähenvogel. Sie lebt gesellig, ist im Allgemeinen ein Koloniebrüter, und weist in ihrer Bestandsentwicklung eine stark negative Tendenz aus. Die Ursachen für diesen Bestandsrückgang sind sicherlich vielfältig. Da ist zum einen der nahrungsökologische Aspekt in Zusammenhang mit einer veränderten Landnutzung in den letzten 20 Jahren. Auf der anderen Seite kommt es immer wieder zum „Entzug von Brutstätten durch den Menschen“. (DWENGER, 1995).

Dieses wurde besonders deutlich in den 1990er Jahren, als durch umfangreiche Rekonstruktionsmaßnahmen an Gebäuden die bis dahin von Dohlen genutzten Brutmöglichkeiten verschwanden und für notwendigen Ersatz nicht gesorgt wurde.

Während in Mecklenburg-Vorpommern 1975 noch von fraglichen 5.000 Brutpaaren ausgegangen wurde (PLATH, L. 1989; SCHMIDT, K. 1987), und in den Jahren nach 1945 eine sicherlich noch größere Anzahl von Brutpaaren angenommen werden kann, sank bis zum Jahr 1995 die Anzahl auf ungefähr 800 bis 1.000 Brutpaare - siehe STRACHE, R.-R. (2006) in EICHSTÄDT et al.: Atlas der Brutvögel in Mecklenburg-Vorpommern. Bei den Dohlen war der stärkste Rückgang von allen Krähenvögeln in $\mathrm{M}-\mathrm{V}$ zu verzeichnen. Diese Entwicklung führte dazu, dass in der „Roten Liste"von 1992 eine Einstufung der Dohle in die Rubrik „Gefährdet“ erfolgte. Während die Dohle in der Liste von 2003 in die Kategorie „Vom Erlöschen bedroht“ rutschte, hat sich der Bestand nach der letzten Kartierung 2005-2009 anscheinend stabilisiert. Die Dohle kam in der aktuellen Roten Liste von 2014 in die Vorwarnliste. Der Positivtrend wird auch in Verbindung mit bestandsstützenden Maßnahmen gesehen. Am Beispiel der Kleinstadt Laage soll gezeigt werden, dass umsichtiges und engagiertes Handeln der negativen Bestandsentwicklung entgegenwirken kann.

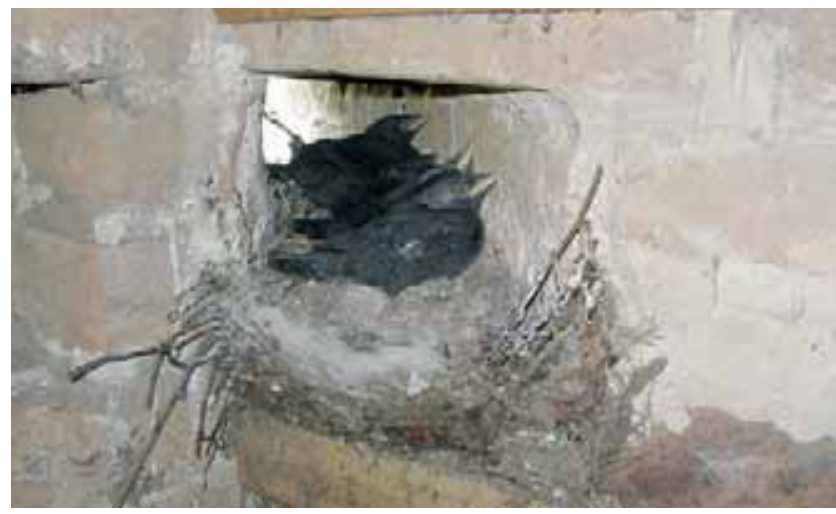

Abb. 370: funge Dohlen in einem Rüstloch der Kirche Laage. Foto: F. Emmerich.
Seit den 1980er Jahren existierte in der Laager Kirche eine Dohlenkolonie, deren Bestand 1985 mit 18 bis 22 Brutpaaren angegeben wurde.

Mitte der 1990er Jahre ging unser FG-Mitglied Reinhard Becker nur noch von einem Bestand von 10 Brutpaaren an der Laager Kirche aus.

$\mathrm{Zu}$ diesem Zeitpunkt startete die Jugendfachgruppe Ornithologie und Vogelschutz des NABU KV Rostock e. V. (seit 2007 NABU Regionalverband Mittleres Mecklenburg e. V.) zusammen mit der Fachgruppe Fledermausschutz Rostock ein Projekt, dass die Sicherung und Schaffung von Nistplätzen und Quartieren geschützter Brutvogel- und Fledermausarten in Mecklenburg Vorpommern zum Ziel hatte und vom StAUN Rostock gefördert wurde.

Am Standort Laage erfolgte im Winterhalbjahr 1995/96 der Einbau von 19 Nisthilfen, die bereits im Folgejahr zu 63\% besetzt wurden und zu einem Anstieg der BP mit einem Maximum von 26 (1998) führte. Es kann als ein Hinweis auf den enormen Bedarf der Dohlen nach sicheren Nistplätzen gewertet werden.

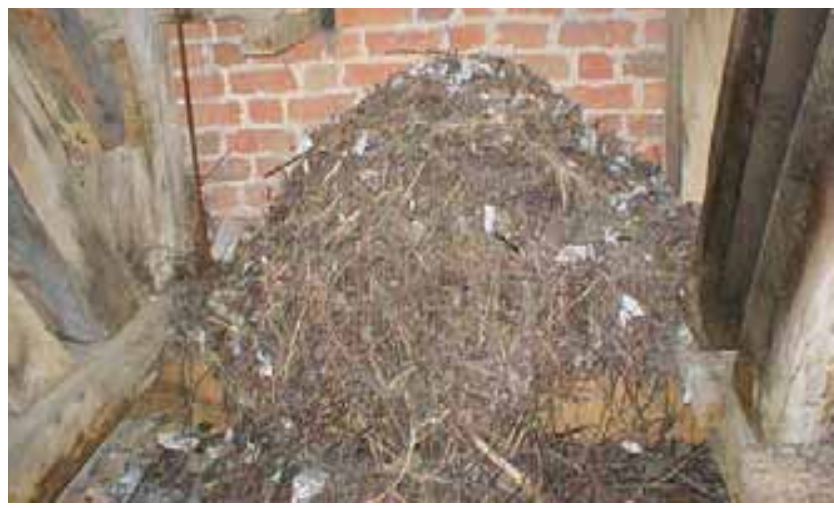

Abb. 371: Ein wesentliches Problem bei offenen Dohlennestern ist über die fahre der enorme Nistmaterialeintrag. Foto: f. Loose.

Ein beabsichtigter Nebeneffekt dieser Maßnahme war, dass eine weitere Verschmutzung des Kircheninnenraumes nicht mehr stattfinden konnte, und so die Akzeptanz für die Dohlen im Kirchengemäuer bei der Kirchgemeinde weiter gestärkt wurde.

Es ist anzunehmen, dass auch die BP der vereinzelten Freinester von der Maßnahme profitierten, da wegen des größeren Angebotes vor allem die sicheren Neststandorte genutzt werden konnten.

Als im Jahre 2004 eine Sanierung des Turmes der Kirche in Laage nötig wurde, legten wir in Zusammenarbeit mit dem zuständigen Planungsbüro umfangreiche Maßnahmen fest, 
die eine Gefährdung des Brutgeschehens ausschlossen. Es konnte durchgesetzt werden, dass die notwendigen Baumaßnahmen außerhalb der Brutzeit durchgeführt wurden, und somit auch im Jahr der Sanierungsmaßnahmen der Bestand an Brutpaaren nicht zurückging.

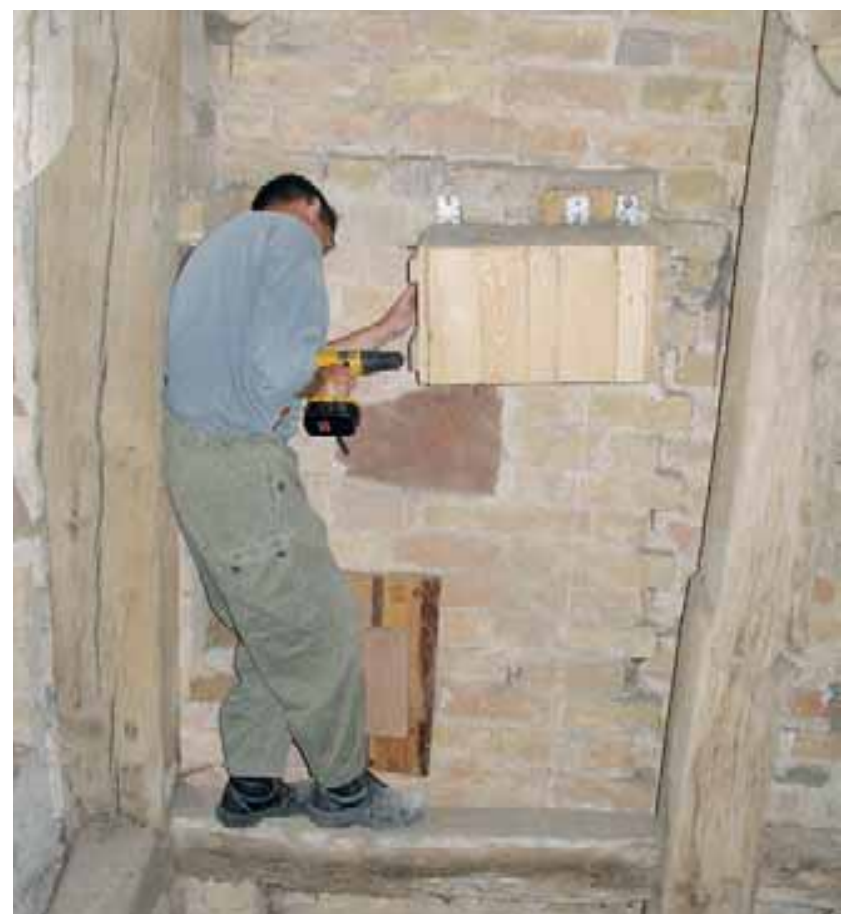

Abb. 372: Ralf Emmerich bei der Anbringung eines Nistkastens hinter einem Mauerloch und eines Nischenbrettes (unten). Foto: F. Emmerich.
Seit dem Anbringen der Nistkästen und Nischenbretter wird regelmäßig der Bestand der Jungdohlen erfasst. Gleichzeitig wurden die Vögel beringt. Seit 1999 erhielten die Nestlinge zusätzlich auch Farbringe. Zwischen 1999 und 2011 dienten die zusätzlichen Farbmarkierungen nur der Zuordnung des beringten Vogels zur Brutkolonie. Durch künftige Beobachtungen der so gekennzeichneten Tiere, ggf. auch an anderen Dohlenbrutkolonien, sollten Fragen zum Verbleib der Jungvögel beantwortet werden. Die im Jahr 2012 zusätzlich zum Metallring erstmalige Beringung mit individualisierenden Farbringen mit Buchstaben-/ Zahlenkombination ermöglichte ein noch besseres Ablesen der Markierungen. Der Kennring ist ca. $2 \mathrm{~cm}$ lang und hat einen 4-teiligen Code aus Buchstaben und Zahlen. Bereits im ersten Jahr mit diesen Zusatzberingungen trafen die ersten Rückmeldungen über beobachtete Tiere ein.

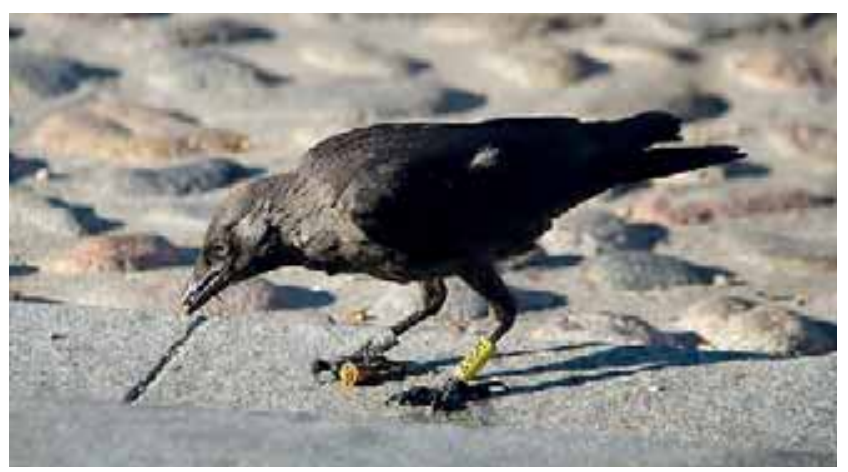

Abb. 373: Mit einem zusätzlichen Farbring mit dem Code X46H markierte Dohle. Foto: NAfU Rostock.

Aus den folgenden Übersichten ist die Entwicklung des Dohlenbestandes an der Kirche in Laage zu entnehmen.

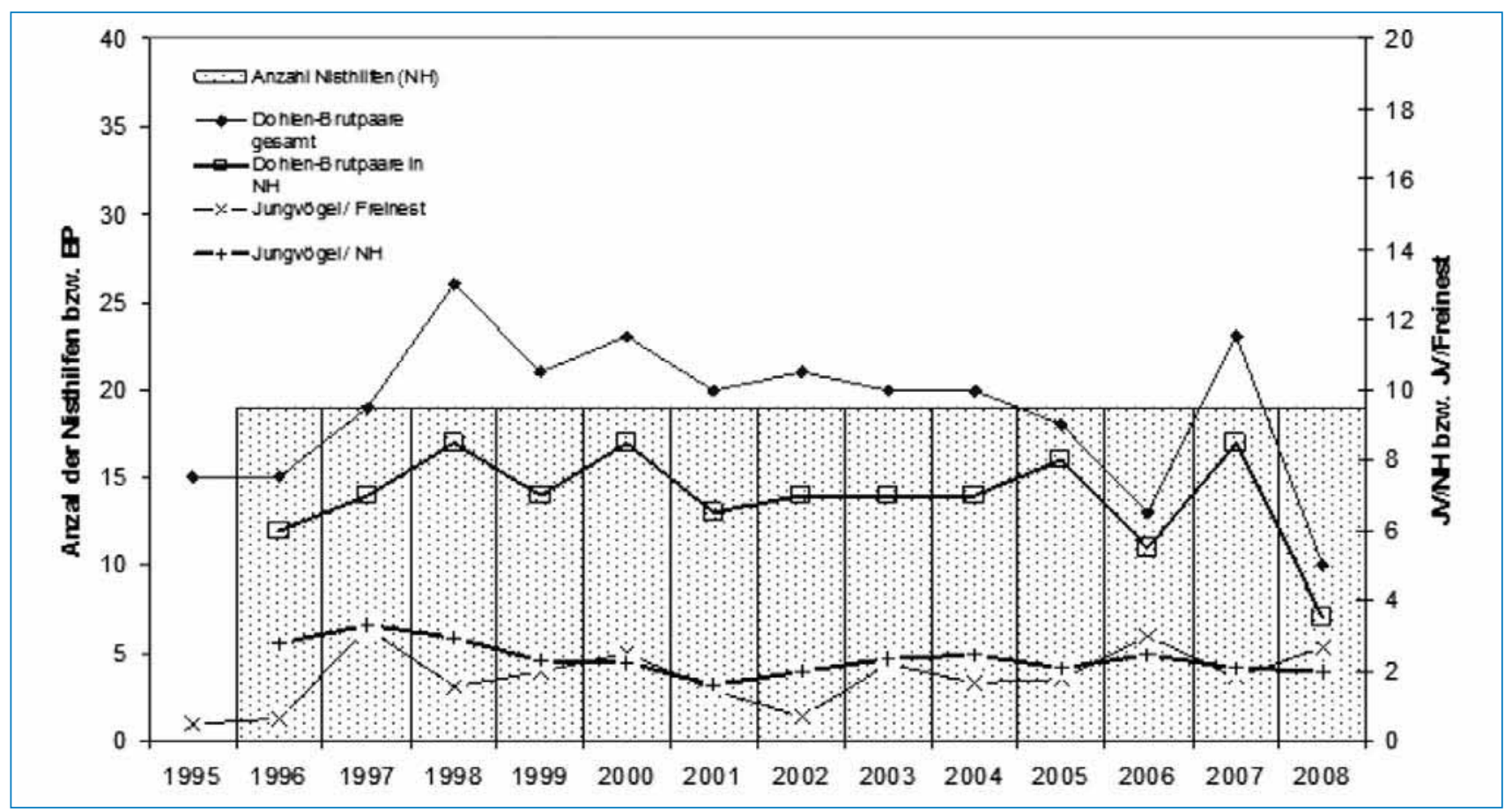

Diagramm 41: Anzahl der Dohlen-BP und durchschnittliche Anzahl der fungvögel in Freinestern bzw. Nisthilfen (NH) in der Kirche Laage 1995-2008 nach R. Emmerich, F. Emmerich, H. Pommeranz, J. Schmidt in Dokumentation der Erfolgskontrollen von Artenschutzmaßnahmen für die Dohle in Nordmecklenburg/Nordvorpommern 1994-2008. (EMMERICH, R. et al. 2008). 
Tabelle 16: Ergebnisse der Bruterfolgskontrollen - Kirche Laage (E. Schlüter u. R. Emmerich, F. Emmerich - JFG Ornithologie \& Vogelschutz Rostock)

\begin{tabular}{c|c|c}
\hline Jahr & Brutpaare & Jungvögel \\
\hline 2009 & 15 & 35 \\
\hline 2010 & 11 & 23 \\
\hline 2011 & 16 & 48 \\
\hline 2012 & 15 & 24 \\
\hline 2013 & 20 & 57 \\
\hline 2014 & 15 & 39 \\
\hline 2015 & 18 & 47 \\
\hline
\end{tabular}

Einige Dohlen nutzten in der Vergangenheit andere vorhandene Nischen zur Aufzucht ihrer Bruten, die aber stets dem Marder zum Opfer fielen. Im Frühjahr 2013 wurden zusätzlich sechs dieser Nistmöglichkeiten auch durch Nischenbretter/Nistkästen gesichert und trugen so zu dem günstigen Ergebnis in diesem Jahr bei.

\subsubsection{Aktionen in Güstrow}

\section{Angela Martin}

In Güstrows Stadtzentrum gibt es ein erhebliches Problem mit dem Kot der verwilderten Haustauben. Im Dachgeschoß des „Schlauchturmes" in der Baustraße musste man u. a. eine mehr als $10 \mathrm{~cm}$ dicke Kotschicht entsorgen. Am Rathaus verursachte Taubenkot ungemein starke Schäden an der Architektur. Deshalb war man bemüht, möglichst alle Nistmöglichkeiten für die Tauben auch in der Pfarrkirche und im Dom zu verschließen. Unter den Bewohnern der Güstrower Kirchen waren aber die Dohlen nicht minder vertreten. Ähnlich wie bei den Mauerseglern entstand für sie eine Wohnungsnot, als man mit Sanierungsarbeiten begann.

Die Rüstlöcher in den Kirchen boten oftmals die einzigen Brutmöglichkeiten für Vogelarten, die auf solche höheren Kunstfelsen angewiesen sind. Mit dem Verschließen der Rüstlöcher wurde nicht nur Tauben der Zutritt verwehrt, sondern auch Dohlen, Turmfalken und Eulen.

Es musste Abhilfe geschaffen werden. Unmittelbar hinter den Rüstlöchern angebrachte Kästen würden verhindern, dass Vögel in den Kircheninnenraum gelangen. Tauben könnten die Kästen genauso annehmen. Wir vertrauten jedoch darauf, dass Dohlen die Tauben aus den Kästen verdrängen.
Hervorzuheben bei den Bemühungen um den Erhalt der Dohlenkolonie ist auch das Verständnis der Kirchgemeinde für die durchgeführten Maßnahmen.

Im Jahre 2011 wurde sie daher vom NABU RV Mittleres Mecklenburg e. V. mit der Plakette „Lebensraum Kirchturm" ausgezeichnet.

Ergänzend zu den Ausführungen über den Dohlenbestand in der Kirche von Laage ist noch zu erwähnen, dass im Stadtgebiet über Jahre hinweg auch „Kamindohlen“ ihre Heimstatt gefunden haben. Mindestens drei BP waren und sind nachzuweisen.

Eine von unserem FG-Mitglied Klaus Lingsminat im Jahr 2000 auf dem Friedhof festgestellte Brut in einer Linde konnte jetzt nicht mehr bestätigt werden.

Es bleibt zu hoffen, dass die Bemühungen um den Erhalt bzw. die Erweiterung des Bestandes dieses sympathischen Krähenvogels von Erfolg begleitet werden, damit „des Pastors schwarze Tauben“ noch lange die Laager Bevölkerung erfreuen.

Mit dieser Argumentation konnten wir Pastoren und Pfarrer überzeugen, dass mit der Anbringung von Nistkästen keiner weiteren oder neuerlichen Beeinträchtigung Tür und Tor geöffnet würde.

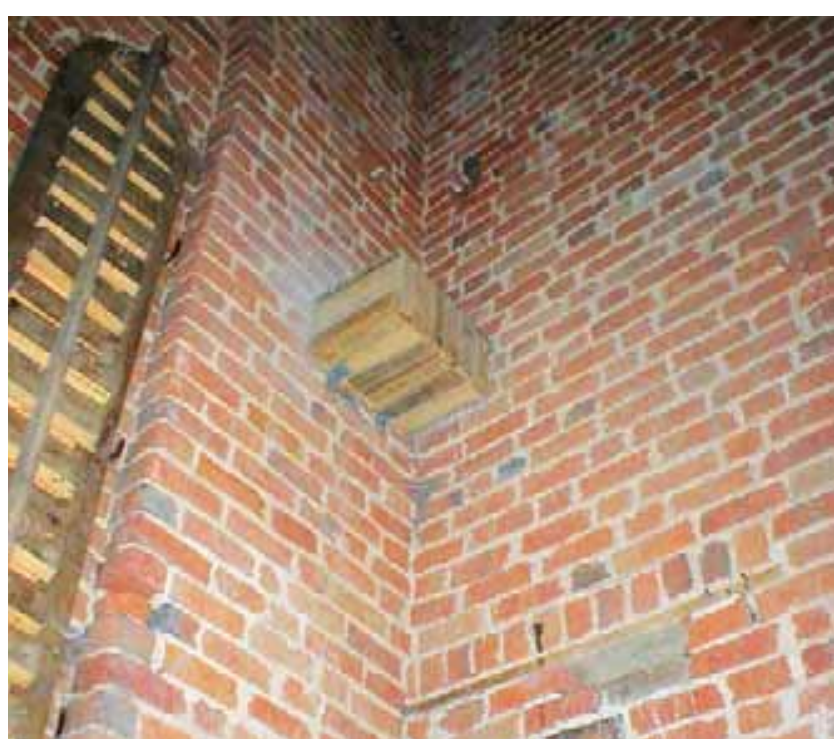

Abb. 374: Die innen eingebauten Nistkästen hinter den Rüstlöchen fallen nicht groß auf. Für den Einbau wurden lange Leitern benötigt. Foto: f. Loose. 
Die Kästen wurden nach Bauanleitung in den Güstrower Werkstätten angefertigt. Am 9.3.1996 war es so weit. Mit Unterstützung der Rostocker NAJU-Gruppe bauten einige aus unserer FG und weitere für diese Aktion gewonnene Personen in Dom und Pfarrkirche insgesamt 28 Kästen fachgerecht ein.

Über diese Aktion lief dann auch eine Sendung im Radio $\mathrm{M}-\mathrm{V}$. Darin wurden fachliche Informationen über die Notwendigkeit dieser Nistkastenaktion gegeben und der hohe organisatorische Aufwand für diese Arbeiten herausgestellt.

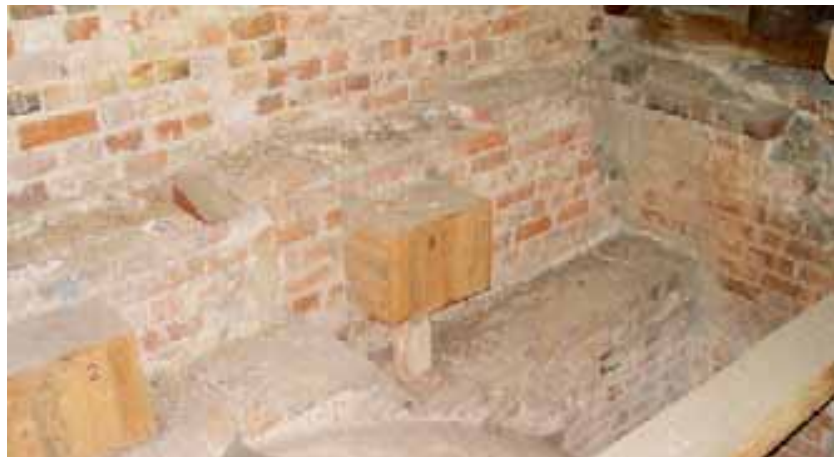

Abb. 375: Im Kirchengewölbe war der Einbau der Nistkästen einfacher, es konnte ohne Leitern gearbeitet werden. Foto: 7 . Loose

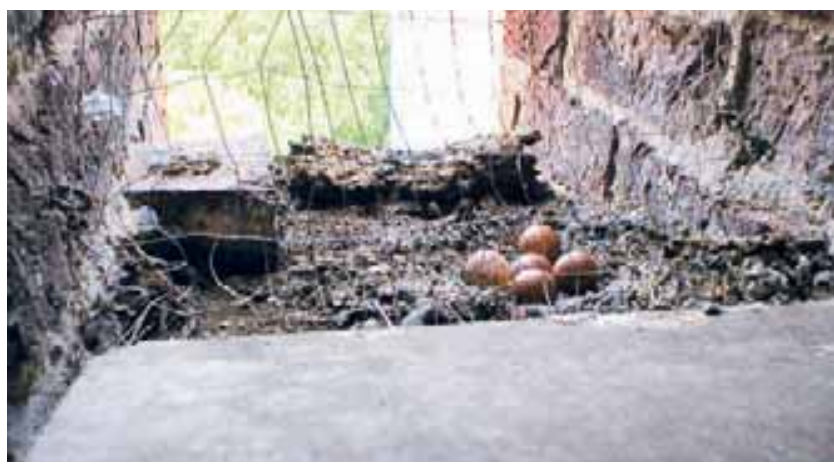

Abb. 376: In größeren Maueröffnungen im Güstrower Dom brüten regelmäßig Turmfalken. Die Löcher sind an der Seite zum Innenraum mit Maschendraht versehen, um zu verhindern, dass Vögel in diesen gelangen können. Foto: f. Loose.
Kritisch anzumerken ist, dass es uns leider nicht gelang, aus unserer FG dauerhaft Leute zu aktivierten, die nach den Kontrollen von 1996/1997 regelmäßig Erfassungen durchgeführt hätten. Daten über die Effizienz unsere Maßnahme und auch konkrete Zahlen über die Brutpaare von Dohlen oder Turmfalken (zwei Nistkästen für diese Art waren im Turm und der Glockenstube der Pfarrkirche installiert worden) wurden über die Jahre daher nicht gesammelt.

Die Rostocker NAJU-Gruppe war gelegentlich nochmals ohne Kontakt zu unserer FG in Güstrow und beringte z. B. die jungen Turmfalken im Nistkasten der Pfarrkirche. Wir stellten das fest, als Reinhard Schaugstat die Turmfalken beringen wollte und plötzlich (zu spät) feststellte, dass die Jungen bereits Ringe trugen - ein Jungvogel flog dann mit zwei Ringen (je einer an jedem Fuß) aus.

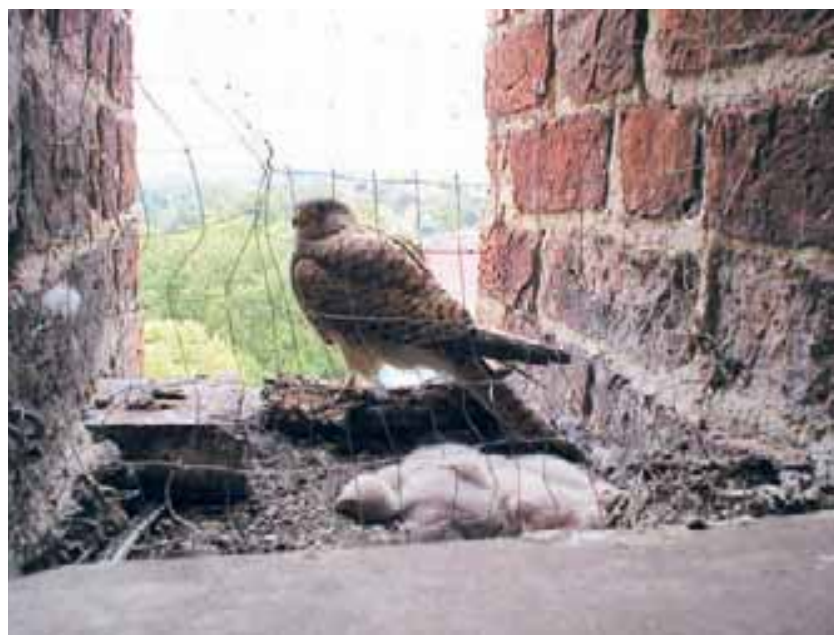

Abb. 378: Die jungen Turmfalken sind geschlüpft. Foto: f. Loose.

Die Kirchenverwaltung in Neubrandenburg startete zu jener Zeit auch ein ABM-Projekt, bei dem wohl fast alle Kirchen des Landes mit Nistkästen für Schleiereulen ausgestattet wurden. Ein nachfolgendes Kontrollmonitoring wurde auch bei diesen Kästen leider von niemandem durchgeführt.

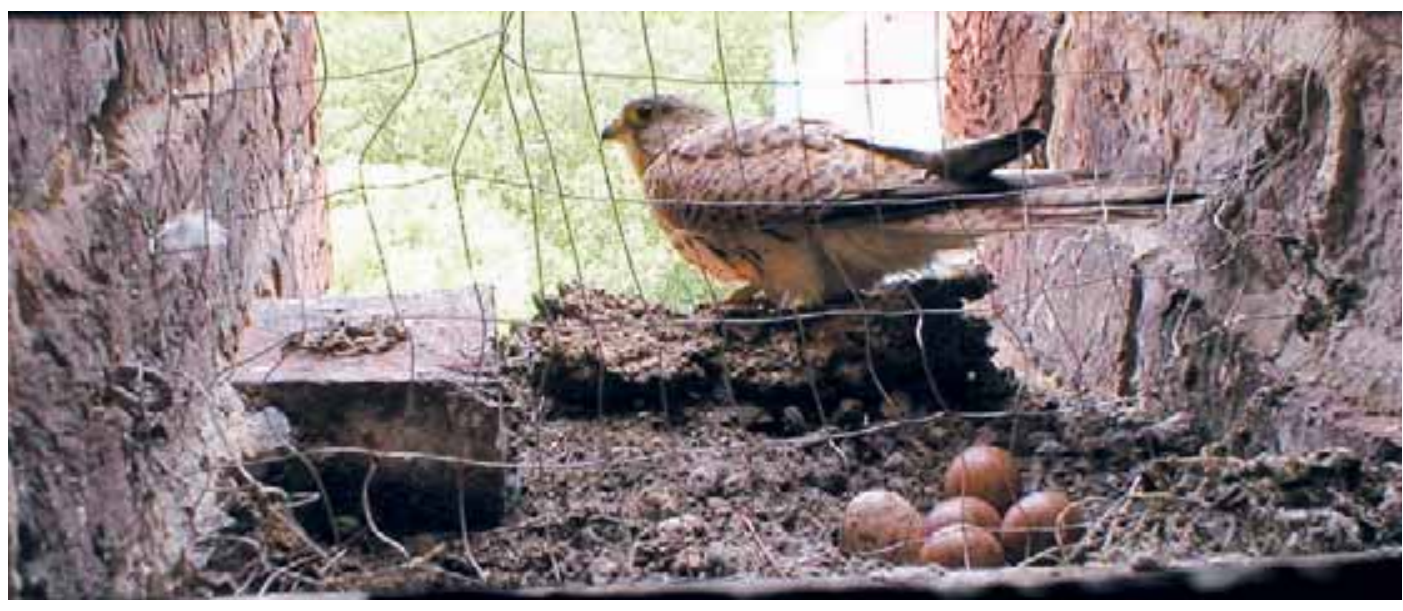

Abb. 377: Das Brutgeschehen konnte vom Innenraum kontrolliert werden. Foto: f. Loose. 
Die Standorte und Nummerierung der Dohlenkästen im Dom und in der Pfarrkirche:

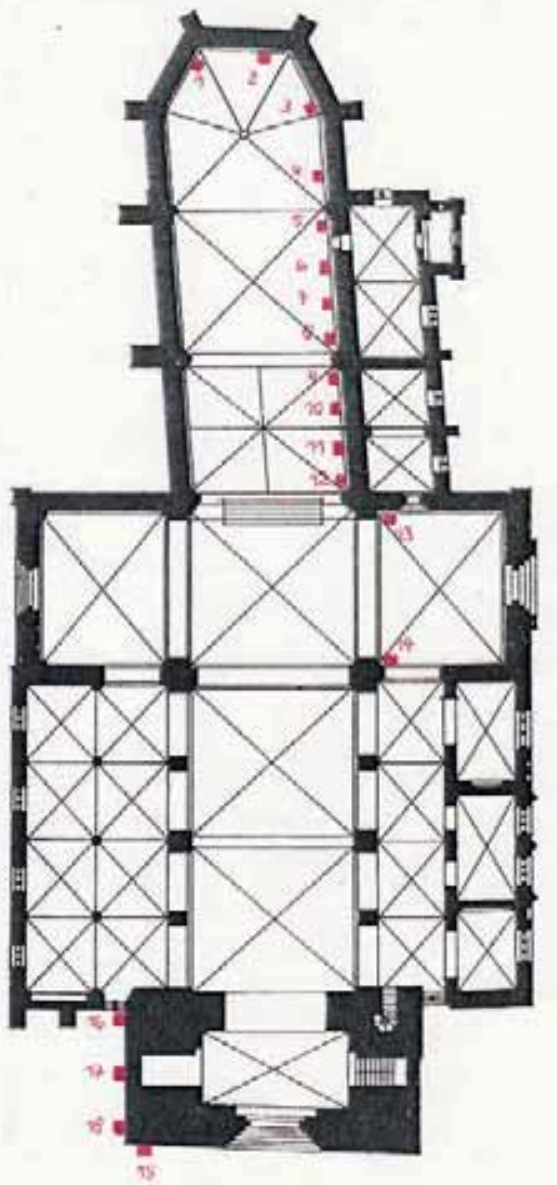

Abb. 379: Anbringungsorte der Dohlenkästen im Dom

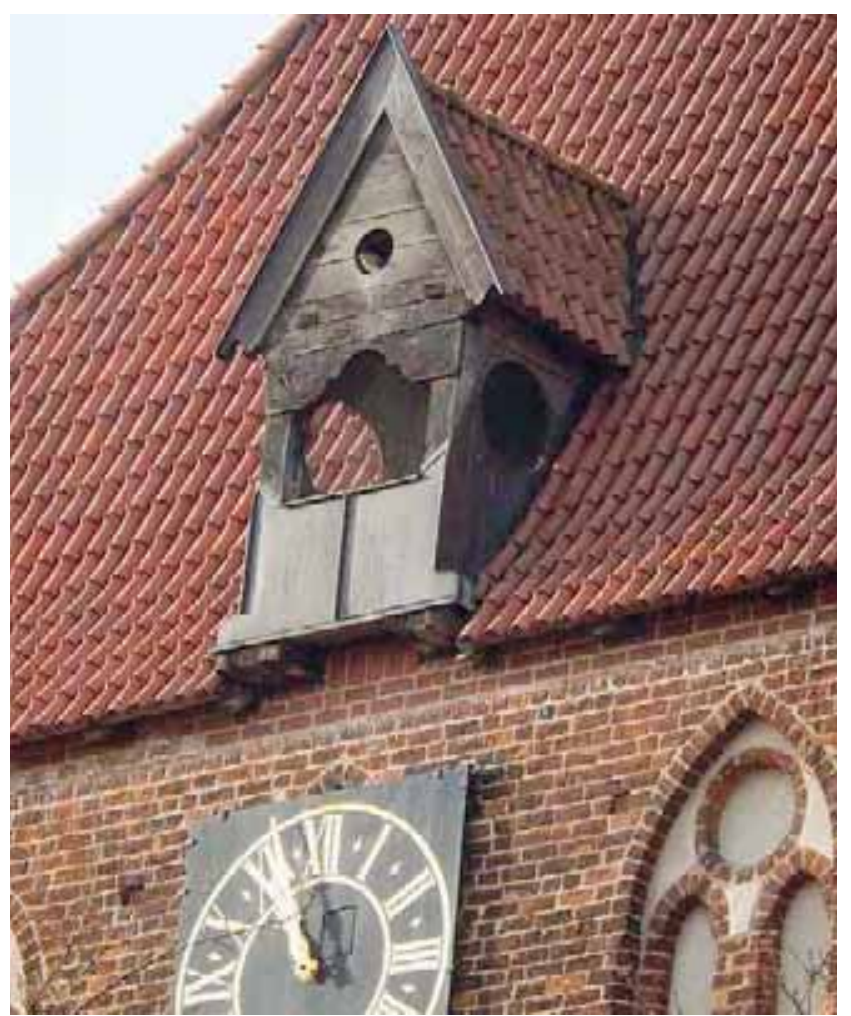

Abb. 381: Turmfalkenkasten über dem „Ausguck“im Dach des Doms (Einbau am 9.3.1996). Foto: A. Martin.

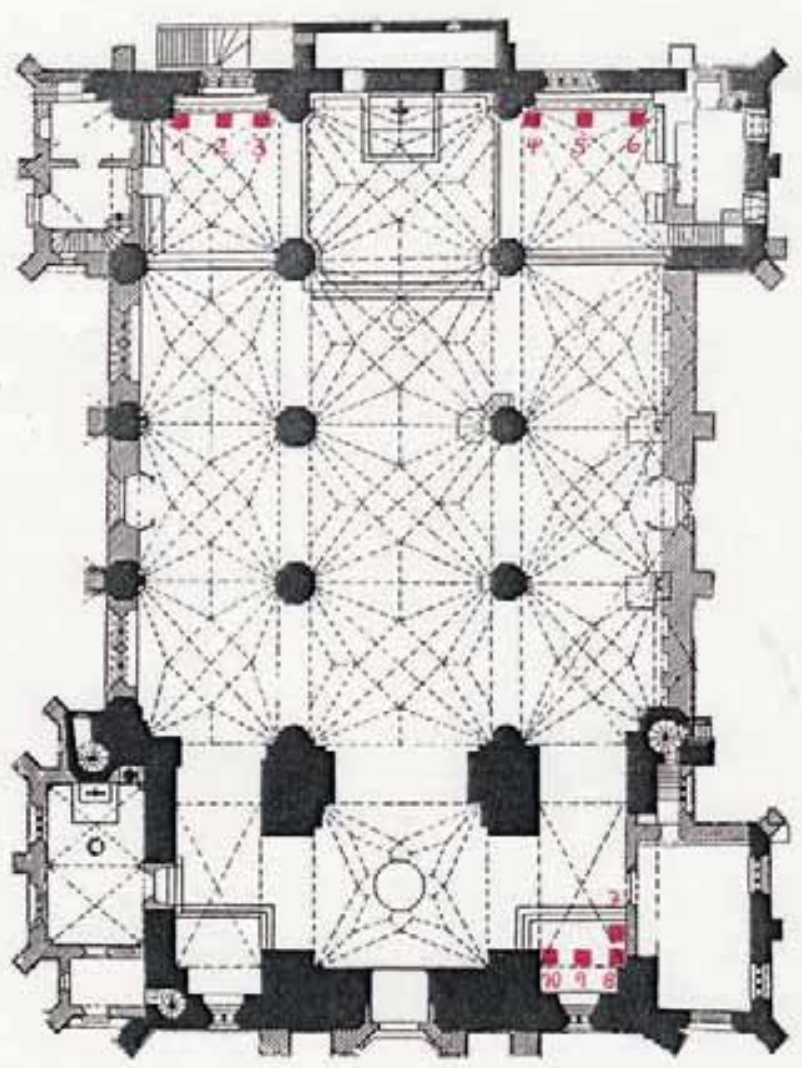

Abb. 380: Anbringungsorte der Dohlenkästen in der Pfarrkirche

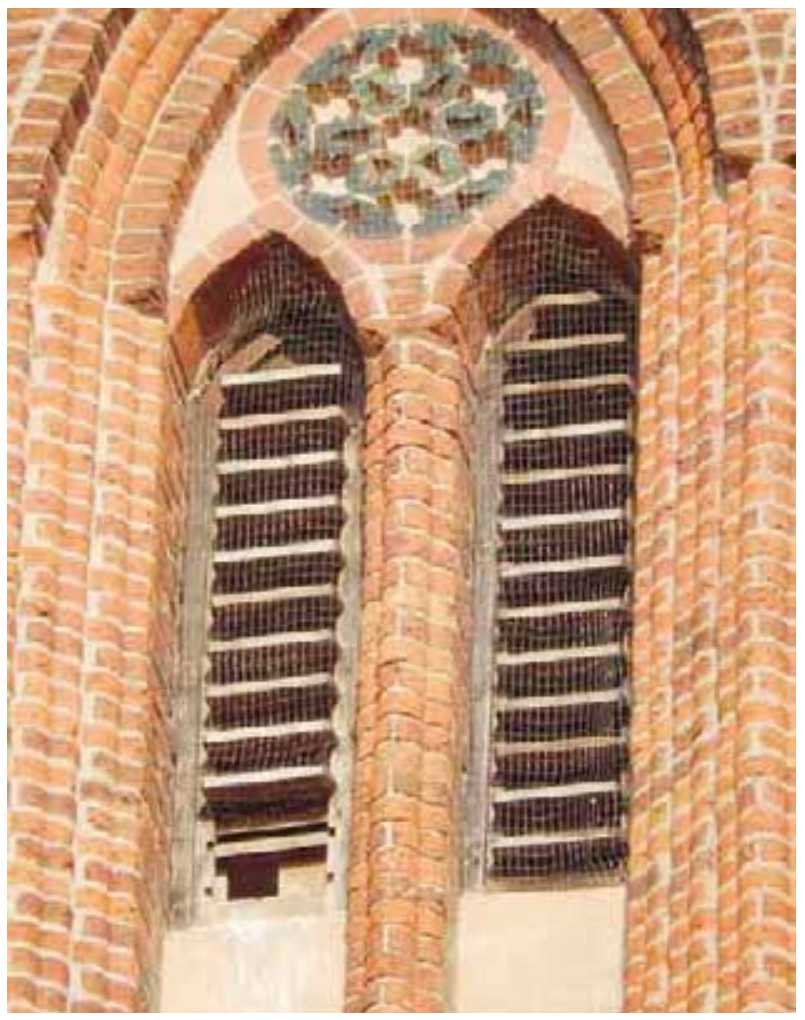

Abb. 382: Turmfalkenkasten hinter den für Tauben verschlossenen Schallluken der Pfarrkirche. Foto: A. Martin. 


\subsection{Wasservogelzählungen}

\section{Joachim Loose}

Die Durchführung der Wasservogelzählungen in den Wintermonaten war eine der frühesten Gemeinschaftsaktionen der Ornithologen in Mecklenburg. Sie wurde für unsere Region durch den Bezirksfachausschuss (BFA) Schwerin koordiniert.

Die Beteiligung an der Wasservogelzählung wird in der ersten Informationsschrift der Fachgruppe von 1967 als eine der Hauptaufgaben der FG genannt. Die vorliegenden Unterlagen geben dabei jedoch keine Auskunft, an welchen Gewässern wer und wann gezählt hatte. Erstmalig wird im Jahresbericht Nr. 5/1972 erwähnt, dass für die Wasservogelzählung (Singular!?) insgesamt ca. 120 Stunden aufgewendet worden sind. Obwohl die Wasservogelzählungen offensichtlich in allen Jahren durchgeführt worden sind, wird über die Zählergebnisse in keinem Jahresbericht der FG berichtet. Aus der Leistungsabrechnung im Jahresbericht Nr. 13/1980 geht hervor, dass für die Wasservogelzählung insgesamt 82 Stunden aufgewendet wurden und sich daran die FGMitglieder R. Becker (mit 6 Std.), R. Kaatz (15), A. Kretschmann (6), K. Lingsminat (8), M. Nehls (15), W. Neubauer (8), K. Pohlmann (10) und G. Strache (14) beteiligt hatten.

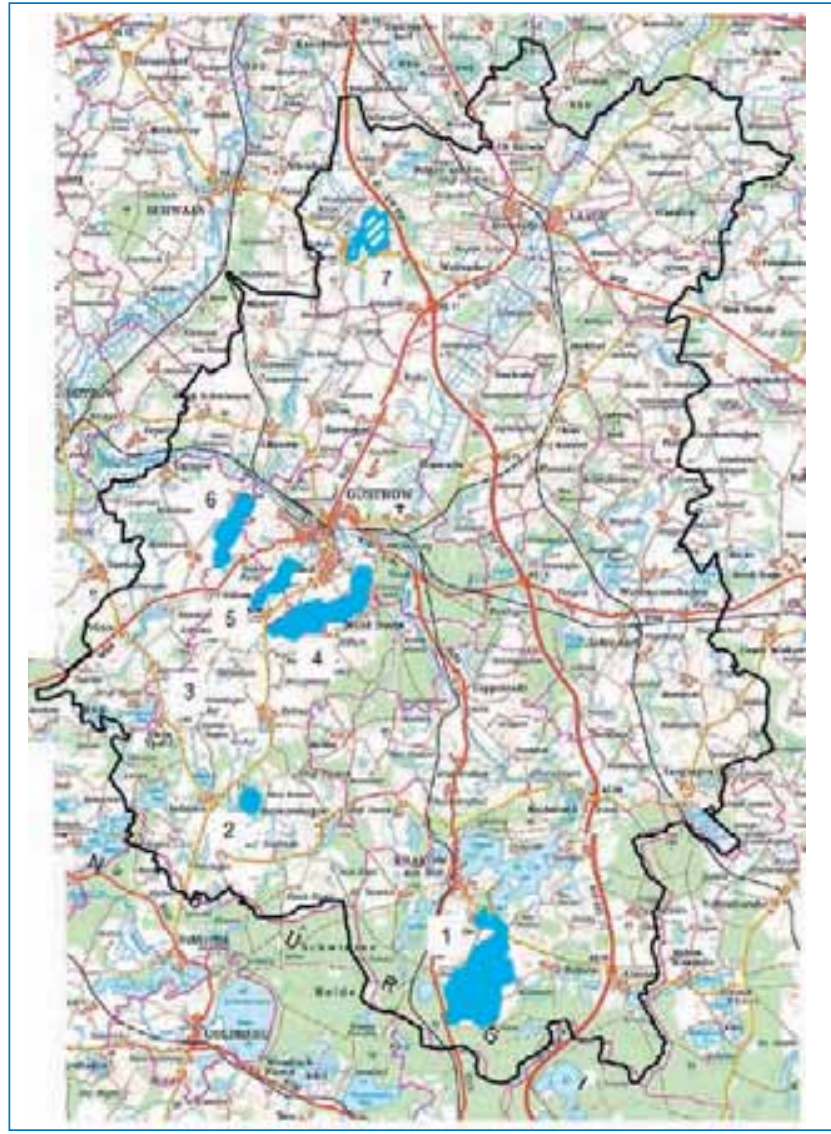

Karte 25: Seen, die bei den Wasservogelzählungen kontrolliert wurden (1 - Krakower Obersee, 2 - Breeser See, 3 -Upahler See, 4 - Inselsee, 5 - Sumpfsee, 6-Parumer See; 7 - Hohen Sprenzer See - nur zeitweilig für Gänsezählungen)
Die Zählergebnisse wurden auf vorgedruckten Lochkarten eingetragen und über den BFA an die für die DDR tätige Zentrale für die Wasservogelforschung bei der Pädagogischen Hochschule Potsdam geleitet. Dort wurden die Daten nach Vorkommen der Arten insgesamt jeweils von Oktober bis März sowie unterteilt nach Bezirken ausgewertet und dann zeitversetzt als Manuskript gedruckt den Zählern zur Verfügung gestellt. Besondere Bedeutung wurde der sog. Mittwinterzählung im Januar beigemessen, da zu dieser Zeit witterungsbedingt mit den größten Migrationen der Wasservögel zu rechnen ist.

Die Zählungen an den in Karte 16 dargestellten Seen wurden in der neueren Zeit durch W. Neubauer/S. Lorenz (1), J. Loose $(2,3,5)$, M. Montschko (4) und K. Lingsminat/ W. Köhler/R. Wiechert/St. Thiel (6) durchgeführt. Sporadische Zählungen am Radener oder Warinsee sowie Gänseerfassungen am Hohen Sprenzer See erfolgten nicht mehr.

Mit der Wende wurde die Zentrale für die Wasservogelforschung aus der Pädagogischen Hochschule Potsdam ausgegliedert und ein Verein für Wasservogelökologie und Feuchtgebietsschutz e.V gegründet. Zur Verbesserung der Datenlage wurden Zählungen auch im September und im April in das Programm aufgenommen. Ab 2008 ging die Koordinierung und Auswertung der Wasservogelzählungen an die Bundesländer über. An unseren Freilanderfassungen hatte sich dadurch nichts geändert. Die vom LUNG für $\mathrm{M}-\mathrm{V}$ vorgelegten Auswertungen (BIOM, 2014) haben durch einen lokalen Bezug nunmehr eine bessere Aussagekraft (vgl. dazu Diagramme 42 bis 45).
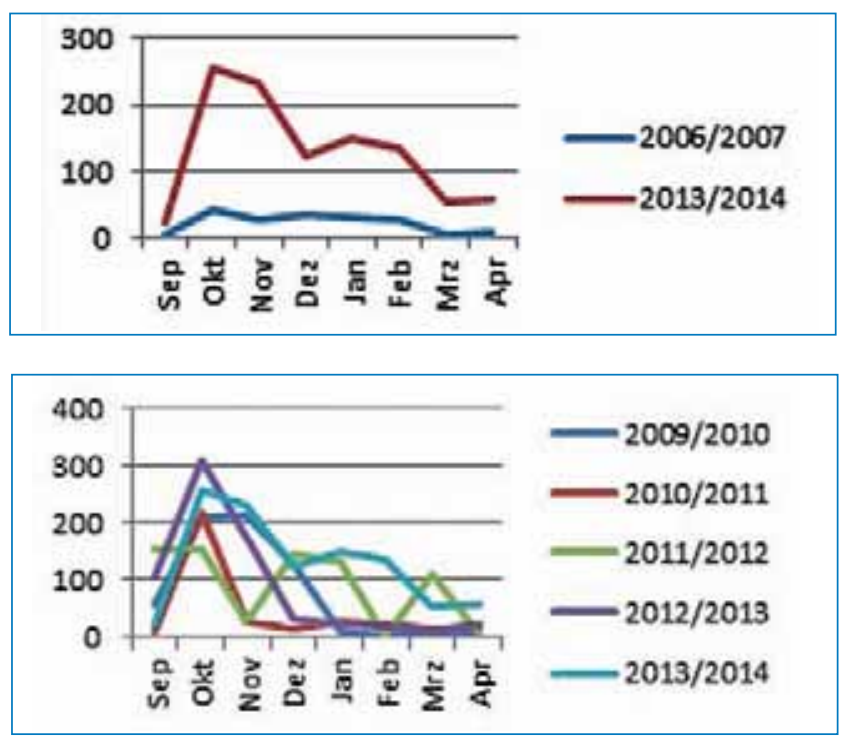

Diagramm 42/43: Beobachtungen des Silberreihers im Winterzeitraum in der Region West von M-V (ehemaliger Bezirk Schwerin) belegen im Jahresvergleich (oben) die allgemeine Zunahme der Art und das Ausweichen in andere Regionen während des Winters. 


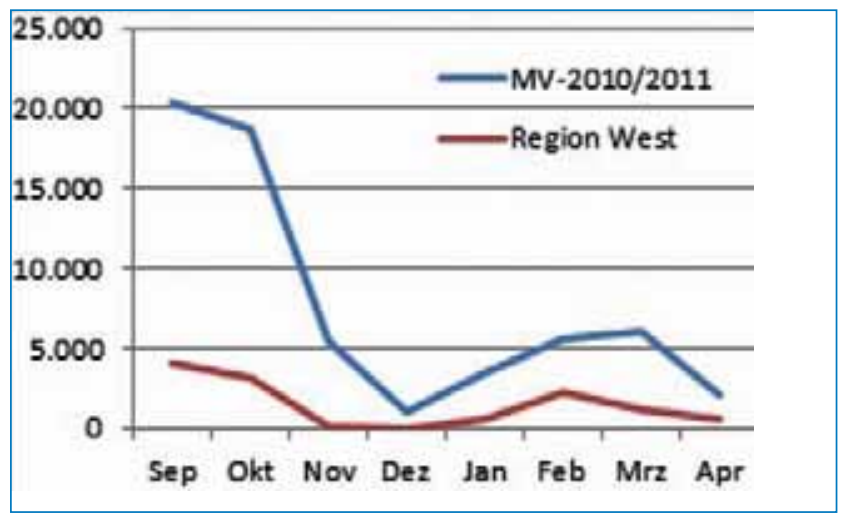

Diagramm. 44: Das Auftreten der Graugans in der Region West kann im Vergleich zum ganzen Land $M-V$ bewertet werden.

Die von uns kontrollierten Seen haben im Vergleich zu den anderen in MV kontrollierten 231 Gewässern und Zählstrecken nur eine geringe Bedeutung für den Aufenthalt von Wasservögeln im Winter. Die bedeutenden Gebiete befinden sich an der Ostseeküste, im Binnenland sind es die großen Seen: die Müritz, der Schweriner See und der Schaalsee.

Wenn die Gesamtzahl der bei den Zählterminen auf unseren Seen notierten Vögel gemäß den Angaben in Tabelle 17 doch vierstellig wird, liegt das an den hier mit erfassten Grau-, Bleß- und Saatgänsen. Sehr gut werden die Durchzugsspitzen bei Ankunft und Heimzug der nordischen Gänse abgebildet.

Auch die besondere Bedeutung des Krakower Obersees (KOS) kommt gut zum Ausdruck. Wenn im Dezember und Januar auf den anderen Seen wegen völliger Vereisung „Nullzählungen“ erfolgten, hatte der KOS zumindest noch einige offene Wasserflächen, auf denen sich die Wasservögel dann konzentrierten.

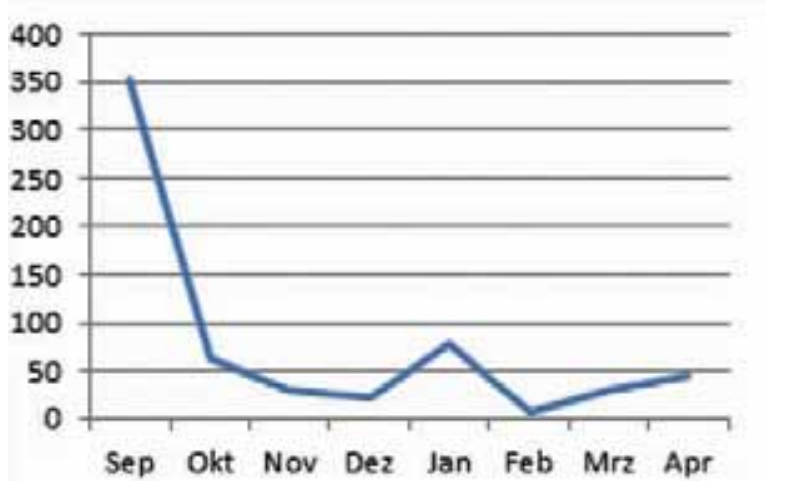

Diagramm 45: Bestand des Haubentaucher auf dem Krakower Obersee in der Zählperiode 2013/2014

Auch der Inselsee nimmt zu Beginn einer Vereisung der Seen zunächst die Wasservögel der Umgebung von Güstrow auf. Die sehr flachen Seen Sumpfsee und Breeser See sind bei Minustemperaturen und Windstille bereits nach wenigen Tagen vollständig geschlossen.

Mit den Stichtagzählungen der Wasservogelerfassungen (immer am Wochenende, das dem 15. des Monats am nächsten liegt) können nicht alle Durchzugs- und Rastbewegungen der Enten, Säger und Taucher erfasst werden. Vielfach wurden maximale Bestände außerhalb der Termine beobachtet.

Wir sollten es daher nicht versäumen, auch in der „unattraktiven" Zeit auf Exkursion zu gehen. Die Beobachtung von Wasservögeln im Winter mit den bunten Farbtupfern von Enten und Gänsesägern und kontrastreichen Schellenten und Zwergsägern sowie den „putzigen“ Zwergtauchern kann Ornithologen und Fotografen gleichermaßen begeistern.

Tabelle 17: Stichtagssummen gezählter Wasservögel (alle Arten ohne „weitere Arten“)

\begin{tabular}{l|l|c|c|c|c|c|c|c|c}
\hline & Zählgebiet & Sep & Okt & Nov & Dez & Jan & Feb & Mrz & Apr \\
\hline $2010 / 2011$ & Inselsee & & 829 & 620 & 134 & 0 & 1.018 & 1.126 & 386 \\
\hline $2012 / 2013$ & & & 105 & 1.166 & 0 & & 0 & 212 & 575 \\
\hline $2010 / 2011$ & Sumpfsee & 698 & 1.547 & 16 & 0 & 0 & 1.023 & 301 & 790 \\
\hline $2012 / 2013$ & & 2.113 & 0 & 0 & 0 & 454 & 0 & 80 \\
\hline $2010 / 2011$ & Parumer See & 123 & 1.295 & 143 & 0 & 0 & 80 & 73 & 310 \\
\hline $2012 / 2013$ & & 14 & 116 & 116 & 0 & 46 & 5.700 & 173 & 25 \\
\hline $2010 / 2011$ & Breeser See & 286 & 82 & 58 & 0 & 0 & 28 & 9 & 93 \\
\hline $2012 / 2013$ & & 4 & 53 & 36 & 0 & 950 & 0 & 1.321 & 63 \\
\hline $2010 / 2011$ & Upahler See & 9 & 64 & 69 & 0 & 0 & 412 & 35 & \\
\hline $2012 / 2013$ & & 16 & 22 & 51 & 0 & 312 & 0 & 304 & 166 \\
\hline $2010 / 2011$ & K0S & 9.552 & 5.930 & 2.090 & 1.394 & 1.180 & 753 & 1.452 & \\
\hline $2012 / 2013$ & & & 3.251 & 1.832 & 527 & 3.088 & & 2.295 & \\
\hline
\end{tabular}

Erläuterungen: 0 = Zählung ohne Anwesenheit von Wasservögeln (Vereisung), grau hinterlegte Felder = keine Zählung durchgeführt 


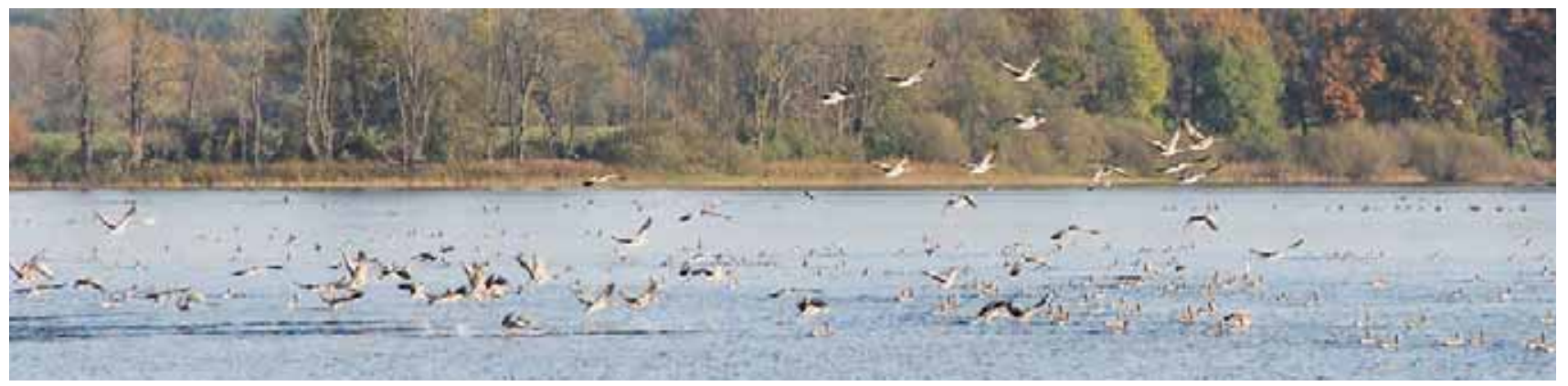

Abb. 383: Wenn die Seen noch eisfrei sind, werden auch Graugänse zunehmend bei den Wasservogelzählungen im November und Dezember angetroffen. Foto: S. Lorenz

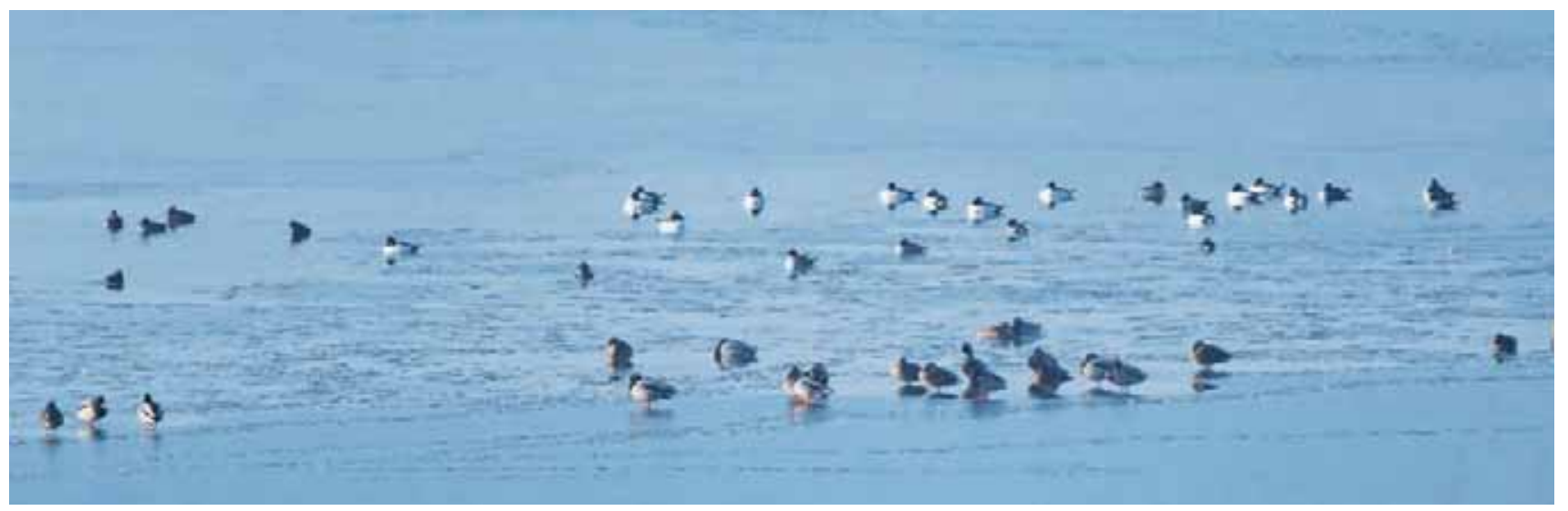

Abb. 384: Stockenten, Schellenten und Gänsesäger an noch eisfreier Stelle im Upahler See. Foto: K. Kirschnick.

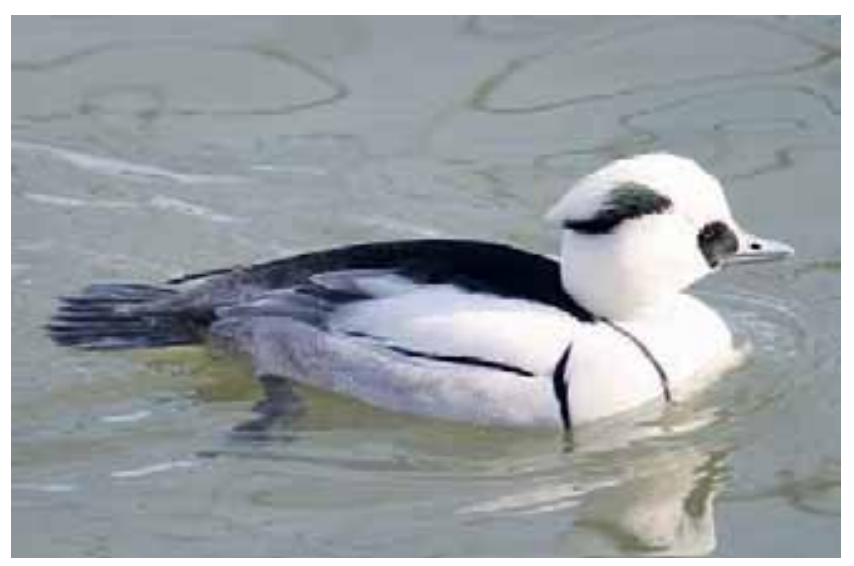

Abb. 385: Zwergsäger-Männchen. Foto: B. Meder-Trost.

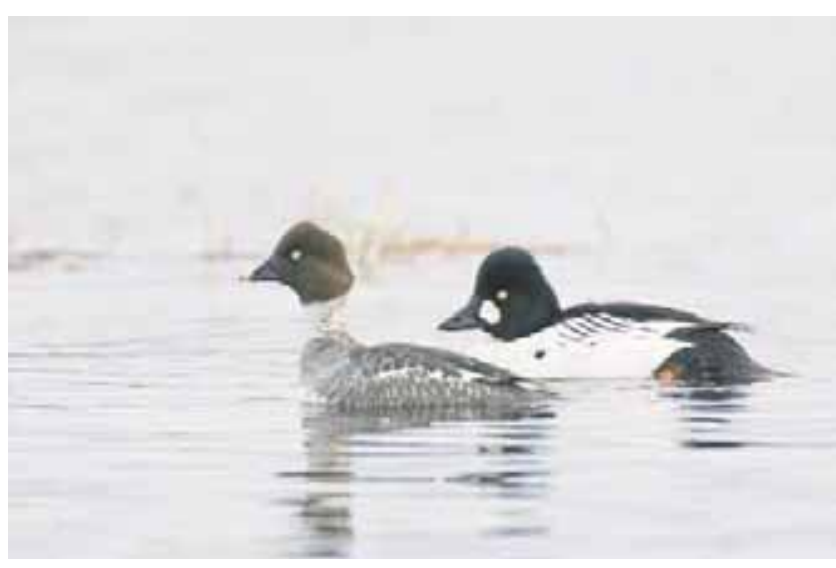

Abb. 386: Schellentenpaar. Foto: B. Meder-Trost.

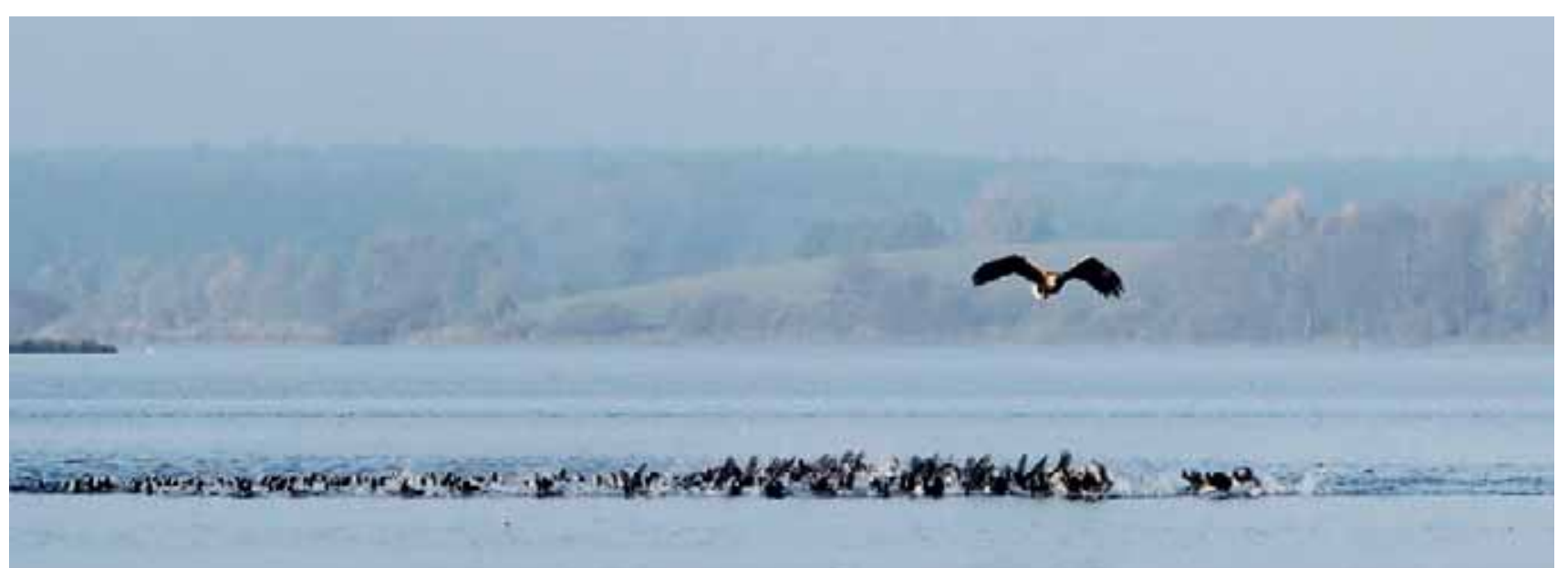

Abb. 387: Seeadler bei winterlicher Fagd auf die Bleßrallen im fast zugefrorenen Krakower Obersee. Foto: S. Lorenz. 


\subsection{Wintervogel- und Agrarvogelzählungen}

\section{Manfred Montschko}

Wintervogelzählungen sind eine „Erfindung der Neuzeit“. Ende des Jahres 2009 rief die Ornithologische Arbeitsgemeinschaft Mecklenburg-Vorpommern (OAMV) mit Dirk Schulze (Neubukow) als Koordinator zur Mitarbeit an der Erfassung der Wintervögel bei frei wählbaren Zählstrecken auf. Ziel war eine Bestandsaufnahme der im Winter in Mecklenburg-Vorpommern vorkommenden Vögel. Die Zählungen sollen als Ergänzung zu den Brutvogelkartierungen die Datenlage zu Vorkommen und Verbreitung vor allem der Wald- und Feldvögel im Winter verbessern, um so qualifizierte Daten auch für eine neue Avifauna von $\mathrm{M}-\mathrm{V}$ zu erhalten.

Die Kartierstrecken sollten eine Mindestlänge von drei bis fünf Kilometern aufweisen, die Fläche möglichst einheitlich strukturiert sein. Es waren zwei Begehungen jeweils Anfang der Monate Januar und Februar durchzuführen. Die erhobenen Daten sowie ergänzend beschreibende Angaben zu den kontrollierten Flächen sollten in bereitgestellte Erfassungsbögen übertragen werden. Es waren nur Vögel aufzunehmen, die im direkten Bezug zur Fläche standen. Überfliegende Individuen waren nicht zu werten. Ab 2011 wurden die festgestellten Vogelarten jeweils in ihrer Anzahl den jeweiligen Lebensräumen zugeordnet gemeldet.
Die Resonanz auf den Aufruf der OAMV war gut, von 2010 bis 2015 wurden in M-V durchschnittlich 69 Zählstrecken ( $n=57$ bis 79) begangen. 2015 waren es 68 Strecken.

Mit Beginn des Erfassungsprogrammes im Januar 2010 übernahmen mit Helmut Richter und Manfred Montschko auch zwei FG-Mitglieder jeweils eine Begehungsstrecke. Nach drei Jahren erfolgreicher Zählungen und Weiterleitung der Unterlagen an die OAMV stellten die beiden Zähler im Gespräch zufällig fest, dass sie (fast) die gleiche Strecke begangen haben! Das war natürlich ärgerlich und wohl auch nicht im Sinne des Programmes. In Vorbereitung der Zählsaison 2013 wurden die Streckenführungen dann abgestimmt.

H. Richter übernahm ab nun eine fünf Kilometer lange Strecke nördlich des Sumpfsees auf dem Langendammschen Weg vom Ortsausgang Güstrow bis Bülow. M. Montschko zählte auf der gleichen Strecke weiter, die bereits in den Vorjahren von ihm begangen wurde. Diese weist eine Länge von 6,3 km auf. Die auch im Jahr 2016 durchgeführten Zählungen auf beiden Strecken wurden hier noch nicht ausgewertet.

Lage und Verlauf der Zählstrecken sind in den Karten 26 und 27 dargestellt.
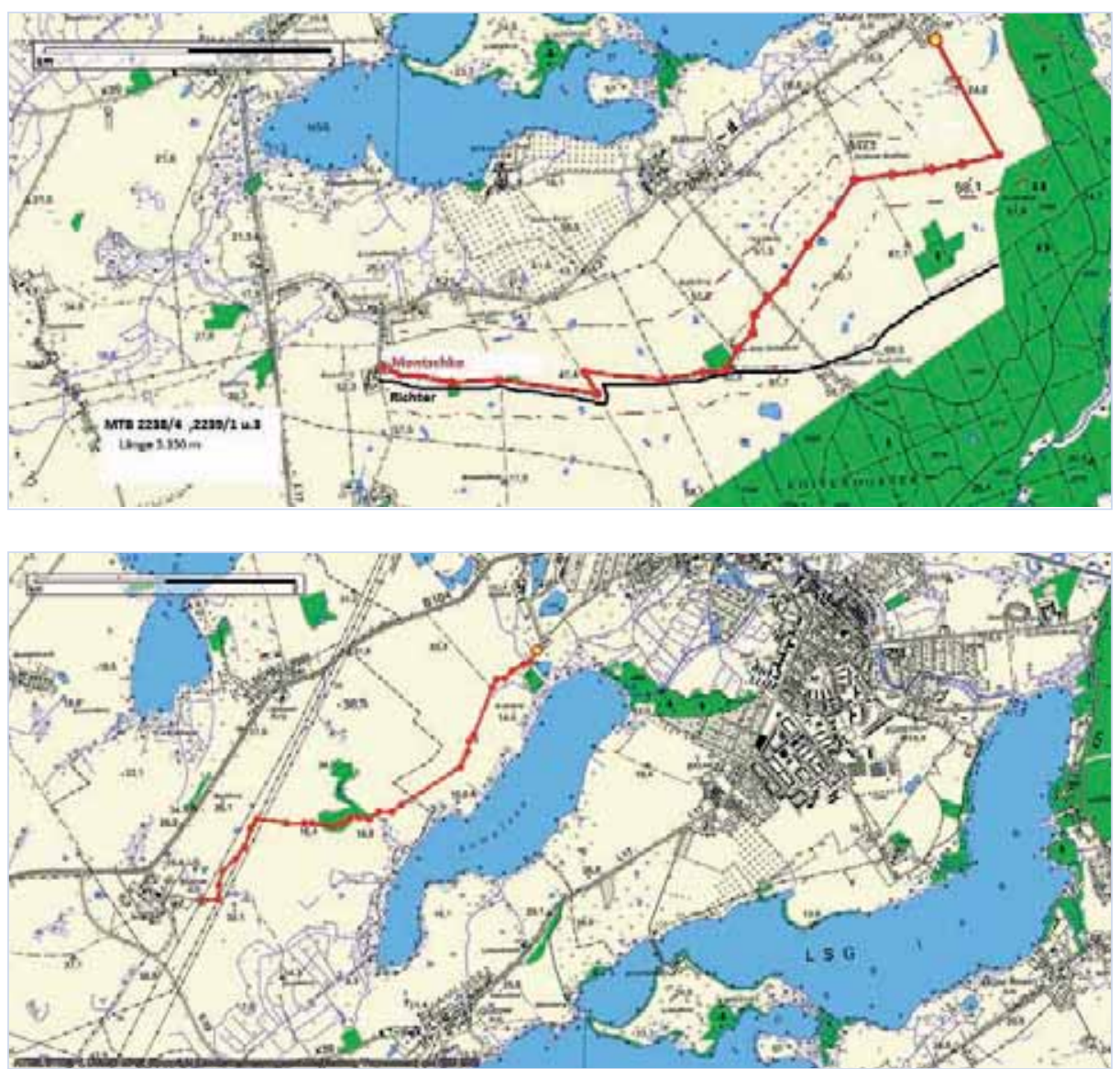

Karte 26: Zählstrecke Badendiek Kirch Rosin / Mühl Rosin 2010 bis 2012 (schwarz - H. Richter) 2010-2015 (rot - M. Montschko)

Karte 27: Zählstrecke Güstrow Bülow 2013 bis 2015 (H. Richter) 
Die nachfolgenden Tabellen 18 und 19 zeigen die Zählergebnisse für die jeweiligen Zählstrecken. (Nicht beobachtete Vogelarten aus der Originalliste wurden zur Verkürzung der Tabellen weggelassen. Die Aufzählung der Arten folgt der Gliederung nach Artengruppen im Original.)

Tabelle 18: Zählergebnisse auf der Strecke Badendiek - Kirch Rosin 2010 bis 2012 und Güstrow - Bülow 2013 bis 2015 ermittelt durch H. Richter

\begin{tabular}{|c|c|c|c|c|c|c|c|c|c|c|c|c|}
\hline \multirow[t]{3}{*}{ Arten } & \multicolumn{12}{|c|}{ Vogelanzahl je Begehung } \\
\hline & \multicolumn{2}{|c|}{2010} & \multicolumn{2}{|c|}{2011} & \multicolumn{2}{|c|}{2012} & \multicolumn{2}{|c|}{2013} & \multicolumn{2}{|c|}{2014} & \multicolumn{2}{|c|}{2015} \\
\hline & 12.01. & 08.02. & 11.01. & 16.02. & 16.01. & 20.02. & 14.01. & 23.02. & 15.01. & 24.02. & 16.01. & 11.02 . \\
\hline Amsel & 2 & 1 & & & 1 & & 7 & & 2 & & & \\
\hline Misteldrossel & & 1 & 1 & & & & & & & & & \\
\hline Rotdrossel & & & & & & & & & & 11 & & \\
\hline Wacholderdrossel & & & & & & & & & & 12 & & \\
\hline Ringeltaube & & & 40 & & & & & & & & & \\
\hline Rotkehlchen & & & & & & & 1 & & & & & \\
\hline Blaumeise & & & 1 & & & & & 2 & & 1 & & \\
\hline Kohlmeise & 1 & & 2 & 4 & 8 & 2 & & 5 & & & & \\
\hline Schwanzmeise & & & & & & 4 & & & & & & \\
\hline Feldsperling & & & & & 12 & & 12 & & & & & \\
\hline Sperlinge allg. & & & & & & 8 & & 25 & & & & \\
\hline Grünfink & & & & & & & & 3 & & & & \\
\hline Bergfink & & & 1 & & & & & & & & & \\
\hline Birkenzeisig & & & 50 & 30 & & & & & & & & \\
\hline Buchfink & & & & & 1 & & & & & & & \\
\hline Erlenzeisig & 30 & & & & & & & & & & & \\
\hline Goldammer & & & & & & 12 & 32 & 5 & 9 & 2 & 9 & 2 \\
\hline Buntspecht & & & & & & 1 & 1 & 1 & & & & \\
\hline Schwarzspecht & & & & & 1 & & & & & & & \\
\hline Eichelhäher & & & & & & & & & & 1 & & \\
\hline Elster & 2 & & 2 & 1 & & & & 3 & & 2 & 1 & 4 \\
\hline Nebelkrähe & & & & & & & & & 2 & 6 & 7 & 2 \\
\hline Rabenkrähe & 3 & & 3 & 4 & 3 & 4 & 1 & 80 & & & & \\
\hline Saatkrähe & & & & & & & & & & & 19 & 8 \\
\hline Mäusebussard & 1 & 1 & & 1 & 1 & & & 1 & & & & 1 \\
\hline Waldbaumläufer & & & & & & & & & & & 2 & \\
\hline Kleiber & & & & & & 2 & & & & & & \\
\hline Wintergoldhähnchen & & & & & & 1 & & & & & & \\
\hline Zaunkönig & 1 & & & & & & & & & & & \\
\hline Gänse allgem. & & & & & & & 1.300 & 120 & & & & \\
\hline Nord. Gänse & & & & 100 & & & & & 235 & & & \\
\hline Blässgänse & & & & & & & & & 89 & & & \\
\hline Saatgans & & & & & & & & & & & & 800 \\
\hline Graugänse & & & & & & & & & 8 & 18 & & \\
\hline Höckerschwan & & & & & & & 2 & 21 & & & & \\
\hline Kranich & & & & 2 & 3 & & & & & 4 & & \\
\hline
\end{tabular}


Tabelle 19: Zählergebnisse auf der Strecke Badendiek - Mühl Rosin 2010 bis 2015 ermittelt durch M. Montschko

\begin{tabular}{|c|c|c|c|c|c|c|c|c|c|c|c|c|}
\hline \multirow[t]{3}{*}{ Arten } & \multicolumn{12}{|c|}{ Vogelanzahl je Begehung } \\
\hline & \multicolumn{2}{|c|}{2010} & \multicolumn{2}{|c|}{2011} & \multicolumn{2}{|c|}{2012} & \multicolumn{2}{|c|}{2013} & \multicolumn{2}{|c|}{2014} & \multicolumn{2}{|c|}{2015} \\
\hline & 06.01. & 06.02. & 05.01. & 11.02. & 06.01. & 06.02. & 02.01. & 02.02. & 03.01. & 02.02. & 03.01. & 07.02. \\
\hline Amsel & 7 & 3 & 2 & & & 6 & 11 & 1 & 16 & 5 & 3 & 6 \\
\hline Rotdrossel & & & & & & & 7 & & 11 & & & \\
\hline Rotkehlchen & & & & & & 2 & & & & & & 1 \\
\hline Wacholderdrossel & & & & & & 8 & 35 & & 67 & 32 & 48 & \\
\hline Ringeltaube & 2 & 1 & 49 & 170 & 150 & & 19 & 31 & & & 3 & 2 \\
\hline Blaumeise & 3 & 2 & 7 & & 2 & 1 & 4 & & & 3 & 1 & 3 \\
\hline Kohlmeise & 3 & 3 & 4 & 2 & 1 & 14 & 5 & & 12 & 8 & 2 & 5 \\
\hline Sumpfmeise & & & & & & & & & & 1 & & 1 \\
\hline Feldsperling & & & & 14 & & & 5 & & 6 & 12 & 19 & 4 \\
\hline Haussperling & 3 & & & & & & 10 & & 8 & 8 & 6 & 4 \\
\hline Bergfink & & 1 & & & & & & & & & & \\
\hline Buchfink & & & & & 4 & & 1 & & 13 & 3 & 16 & 1 \\
\hline Gimpel & 2 & & 7 & & & & 5 & & 2 & 3 & 6 & \\
\hline Grünfink & & & 13 & 74 & & & 90 & 41 & 8 & 7 & 20 & \\
\hline Erlenzeisig & & & & & & & & & & & 50 & \\
\hline Stieglitz & & & & & & & 20 & 14 & & 16 & & 2 \\
\hline Finken allg. & & & 120 & & & & & & & & & \\
\hline Goldammer & 3 & & са. 55 & 7 & 10 & 8 & 19 & 9 & 16 & 29 & 13 & 26 \\
\hline Grauammer & & & & & & & 27 & & & & 5 & \\
\hline Buntspecht & 1 & 1 & & & & & 1 & & 3 & 2 & 1 & 1 \\
\hline Schwarzspecht & & & & & 1 & & & & & 1 & & \\
\hline Eichelhäher & & & 2 & & & 2 & 3 & & 1 & & & 2 \\
\hline Elster & 3 & 1 & 1 & & 1 & & 5 & & 1 & 5 & 1 & \\
\hline Kolkrabe & & & 14 & 9 & 8 & 2 & 9 & 4 & 7 & 3 & 2 & 2 \\
\hline Nebelkrähe & 1 & 1 & 6 & 16 & 1 & & & 1 & & 3 & 5 & \\
\hline Rabenkrähe & & & & & 1 & & 1 & & & & 1 & \\
\hline Saatkrähe & & & 35 & & 5 & & & & & & & \\
\hline Mäusebussard & 4 & 1 & 1 & 3 & 1 & & 3 & & & 1 & 1 & 1 \\
\hline Rauhfußbussard & & & 1 & & & & & 1 & & & & \\
\hline Seeadler & & & & & 1 & & & 3 & & & 1 & \\
\hline Sperber & & & 1 & & & & 1 & & & & & \\
\hline Turmfalke & & & & & & & & & & & 1 & \\
\hline Ohrenlerche & & 7 & & & & & & & & & & \\
\hline Kleiber & & & & & & & & & & 2 & & \\
\hline Zaunkönig & 1 & & & & & & & & & & & \\
\hline Wiesenpieper & & & & & 1 & & & & & & & \\
\hline Höckerschwan & & & & & 2 & & & & & & & \\
\hline Kranich & 5 & & 7 & & 3 & & & 1 & & & & \\
\hline Graugans & & 4 & & & 2 & & 30 & 60 & & & 14 & 2 \\
\hline Saatgans & & & & & 62 & & & & & & & \\
\hline Nord. Gänse & & & 150 & & & & २०० & 670 & 108 & 310 & 120 & \\
\hline Silbermöwe & & & & & & & & & 13 & & & \\
\hline Waldkauz & & & & & & & & 1 & & & & \\
\hline Raubwürger & & & & & & & & & 2 & & & \\
\hline
\end{tabular}


In lokaler Auswertung der bereits für sechs Jahre vorliegenden Beobachtungsdaten ist auffällig und bemerkenswert, dass Raufußbussarde als Wintergäste und Winteransammlungen von Grauammern relativ selten notiert wurden. Auch die ansonsten in Wintermonaten vielfach feststellbaren größeren Schwärme von Wacholder- und Rotdrosseln traten auf den Zählstrecken nur in geringen Stückzahlen auf, was möglicherweise daran liegen könnte, dass entlang der Zählstrecken nicht ausreichend Beeren tragende Sträucher und Hecken vorhanden waren. Als typisch sind die Beobachtungen von größeren Stückzahlen von Ringeltauben bereits Anfang Januar anzusehen. Ebenso wie die Graugänse ziehen viele Ringeltauben im Winter nicht mehr weg oder kommen immer früher zurück.

Wenn bei den jeweils ca. 3 bis 4 Stunden dauernden Zählungen und teilweise widrigen Begleitumständen (Schneelagen und frostige Temperaturen, Fußmarsch auf unbefestigtem Terrain und über Ackerflächen) dann auch mal die Zufallsbeobachtung von sieben Ohrenlerchen (wie von mir am 08.02.2010 gesehen) gelingt, entschädigt das etwas für die Strapazen.

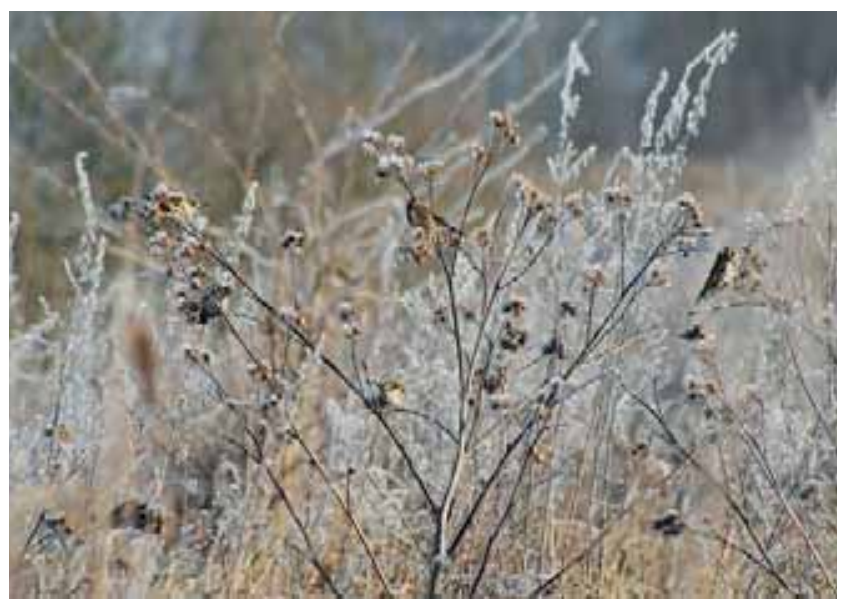

Abb. 388: Stieglitze suchen an Kletten nach Nahrung. Foto: H. Richter.

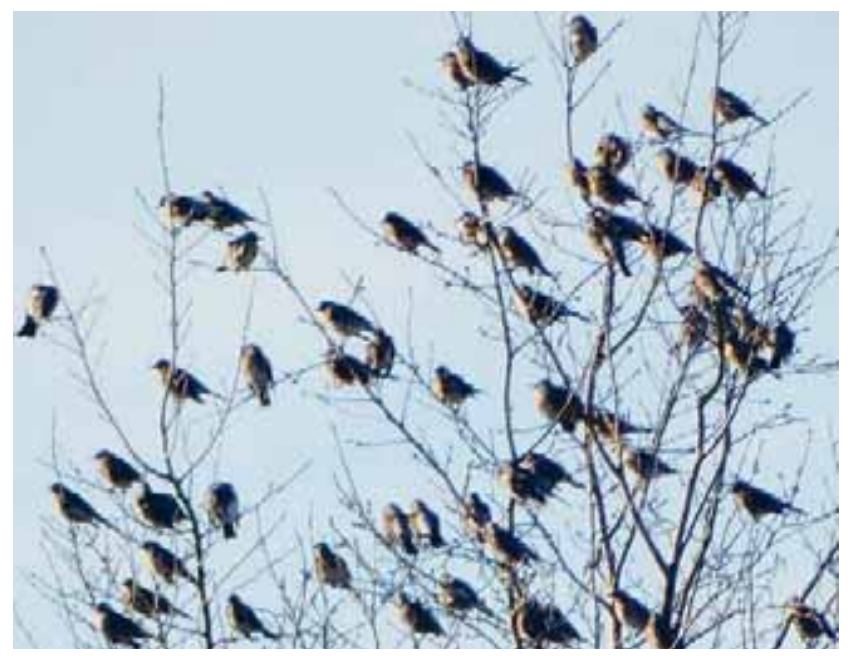

Abb. 389: Rastender Schwarm von Wacholderdrosseln. Foto: 7. Loose.
Zu Agrarvogelzählungen hatte die OAMV im Februar 2015 für das laufende Jahr aufgerufen.

Kiebitz, Feldlerche, Braunkehlchen, Wiesenschafstelze sowie Grau- und Goldammer haben in den letzten Jahren zum Teil drastische Bestandseinbußen hinnehmen müssen. Sie sind zu Problemvögeln geworden und mussten in die Rote Liste der gefährdeten Brutvogelarten MecklenburgVorpommerns aufgenommen werden. Als Vogel der Freiflächen hat lediglich das Schwarzkehlchen in den letzten Jahren kontinuierlich zugenommen. Die Erfassungen sollten zur Verbesserung der Datenbasis bei den erstgenannten Arten führen. Als Koordinator für diese Vorhaben warb Dietrich Sellin um Mitarbeit und hatte für eine einheitliche Dokumentation die Vorgaben erarbeitet. Die Erfassung der Agrarvögel sollte auf selbst zu wählenden Erfassungsstrecken oder -flächen erfolgen. Dabei sollte die Fläche mindestens 100 ha groß bzw. die Wegstrecke mindestens $5 \mathrm{~km}$ lang sein. Im Zeitraum vom 20.04. bis 20.06. waren sechs Begehungen, je Dekade eine, vorgegeben, die in den Morgenstunden zu absolvieren waren. Bei allen Kontrollen war genau die gleiche Fläche/Wegstrecke zu bearbeiten.

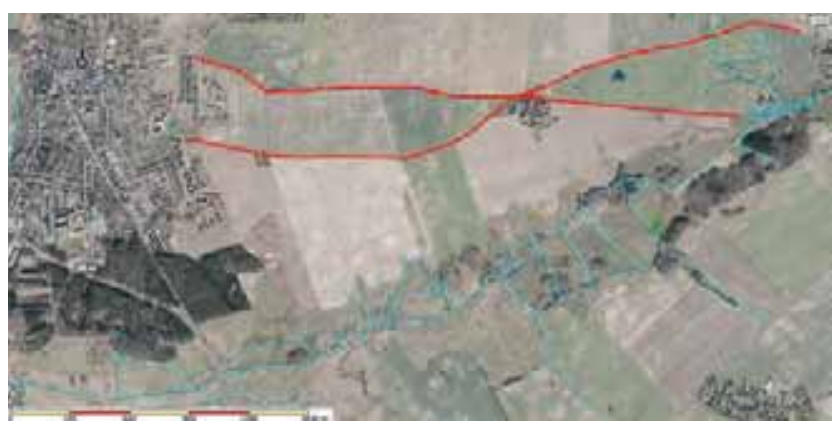

Abb. 390: Zählstrecke Laage - "Die Fünfer", E. Schlüter.

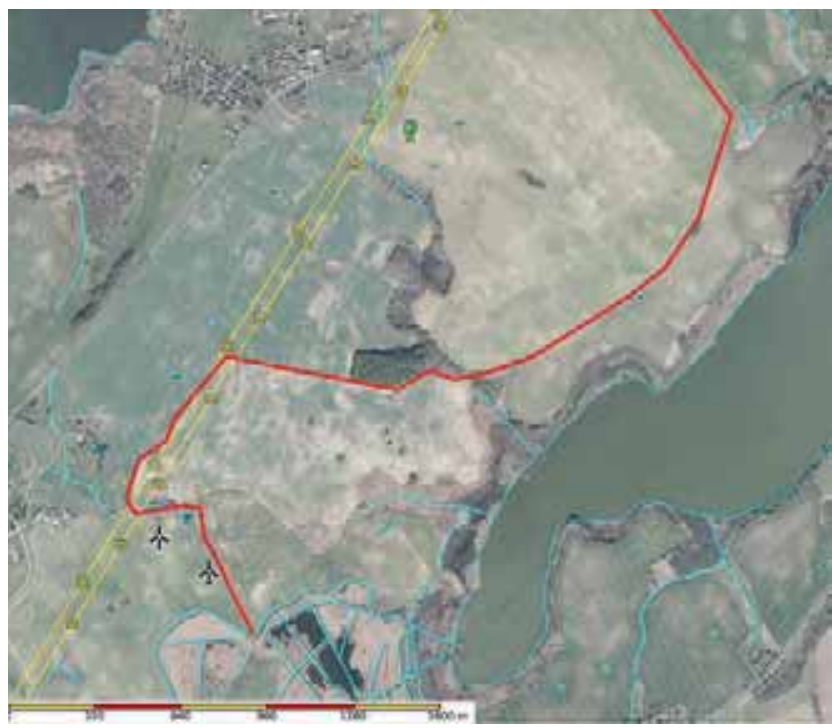

Abb. 391: Zählstrecke Bülow, H. Richter.

Vordergründig sollten Individuen der o.g. Arten mit revieranzeigenden Merkmalen (Gesang, revierverteidigend, Nestbau, fütternd usw.) aufgenommen werden, die Artenliste war offen für Erweiterungen. 


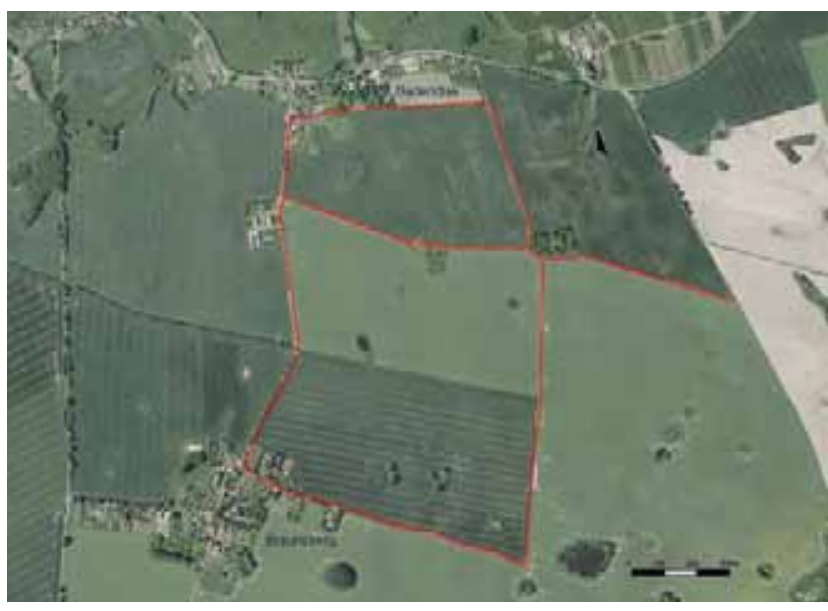

Abb. 392: Zählstrecke Badendiek, M. Montschko.

Aus der Fachgruppe Ornithologie und Naturschutz Güstrow beteiligten sich mit Eckhard Schlüter (Zählstrecke "Die Fünfer"), Helmut Richter (Zählstrecke Bülow) und Manfred Montschko (Zählgebiet Badendiek) drei Mitglieder auf jeweils einer Fläche. Die Lage der Flächen bzw. Wegstrecken sind den Abbildungen 390 bis 392 zu entnehmen. Um landesweit vergleichbare Daten zu erhalten, waren während der Begehungen Angaben zur Beschaffenheit der kartierten Flächen zu machen. Insbesondere sollten die jeweiligen landwirtschaftlichen Kulturen, ihre Bewirtschaftungstermine und Strukturelemente angegeben werden (vgl. dazu Tabelle 20).

Die aufgenommenen Flächengrößen sind dabei wohl mit einem gewissen Ungenauigkeitsfaktor behaftet, da der vermeintlich kontrollierbare Raum beidseitig der begangenen Wege nur geschätzt werden kann und damit stark subjektiv beeinflusst ist.

Tabelle 21: Zählergebnisse Zählstrecke "Die Fünfer" (E. Schlüter)

\begin{tabular}{|c|c|c|c|c|c|c|c|}
\hline \multirow{2}{*}{ Art } & \multicolumn{6}{|c|}{ Datum } & \multirow{2}{*}{$\begin{array}{c}\text { besetzte } \\
\text { Reviere }\end{array}$} \\
\hline & 29.04. & 06.05 . & 20.05 . & 28.05 . & 09.06. & II/Juni & \\
\hline Kiebitz & & & & & 1 & 1 & \\
\hline Feldlerche & $\begin{array}{c}1 \mathrm{sM}+ \\
5\end{array}$ & $\begin{array}{l}3 \mathrm{sM} \\
2 \times 2 \\
4 \times 1\end{array}$ & $\begin{array}{l}4 \mathrm{sM}, \\
3 \times 2 \\
3 \times 1\end{array}$ & $\begin{array}{l}6 \mathrm{sM} \\
1 \times 2 \\
5 \times 1\end{array}$ & $\begin{array}{l}2 \mathrm{sM} \\
+1\end{array}$ & $\begin{array}{l}2 \mathrm{sM} \\
1 \times 2 \\
2 \times 1\end{array}$ & 13 \\
\hline Braunkehlchen & & 1 & & $\begin{array}{l}1 \mathrm{sM} \\
+1\end{array}$ & $2 \times 1$ & $4 \times 1$ & 3 \\
\hline \multicolumn{8}{|l|}{ Schwarzkehlchen } \\
\hline Wiesenschafstelze & & & & & $2 \times 1$ & & \\
\hline Grauammer & $\begin{array}{l}3 \times 2 \\
1 \times 1\end{array}$ & $\begin{array}{l}1 \mathrm{sM} \\
+1\end{array}$ & 1 & $\begin{array}{l}1 \mathrm{sM} \\
+2\end{array}$ & $1 \mathrm{sM}$ & 1 & 3 \\
\hline Goldammer & $\begin{array}{c}1 \mathrm{sM} \\
1 \times 2 \\
+3\end{array}$ & $\begin{array}{l}1 \mathrm{sM}, \\
3 \times 2, \\
5 \times 1\end{array}$ & $\begin{array}{l}1 \mathrm{sM} \\
+2\end{array}$ & $\begin{array}{l}1 \times 2 \\
2 \times 1\end{array}$ & $\begin{array}{l}1 \times 2 \\
1 \times 1\end{array}$ & $2 \times 1$ & 5 \\
\hline
\end{tabular}

Tabelle 20: Beschreibung der Kontrollflächen

\begin{tabular}{|c|c|c|c|c|}
\hline \multirow{2}{*}{$\begin{array}{l}\text { Landwirtschaft- } \\
\text { liche Kulturen }\end{array}$} & \multirow{2}{*}{$\begin{array}{l}\text { Ein- } \\
\text { heit }\end{array}$} & \multicolumn{3}{|c|}{ Zählstrecke } \\
\hline & & $\begin{array}{c}\text { Die } \\
\text { Fünfer }\end{array}$ & Bülow & Badendiek \\
\hline Wintergetreide & ha & 40 & & 70 \\
\hline Raps & ha & 26 & & 170 \\
\hline Mais & ha & 13 & & 30 \\
\hline Sommergetreide & ha & 8 & & \\
\hline Lupinen & ha & 6 & & \\
\hline Grünland & ha & 3 & & 6 \\
\hline andere & ha & & & $20^{1}$ \\
\hline Gesamtgröße & ha & 96 & & 276 \\
\hline \multicolumn{5}{|l|}{ Strukturelemente } \\
\hline Hecken & $\mathrm{m}$ & 250 & 10 & 1.200 \\
\hline Gräben & $\mathrm{m}$ & & & \\
\hline Baumreihen & $\mathrm{m}$ & & & \\
\hline Wege & $\mathrm{m}$ & 6.240 & 5.000 & 5.900 \\
\hline Soll & Stk. & 6 & 2 & 10 \\
\hline andere & Stk. & & & $2^{2}$ \\
\hline
\end{tabular}

Die Ergebnisse der Begehungen sind in den Tabellen 21 bis 23 dargestellt. Nach Abschluss der Begehungen wurden die Ergebnisse in Erfassungsblätter übertragen und an den Koordinator der OAMV Dietrich Sellin zur Auswertung geschickt.

Es erscheint zweckmäßig, dass die Zählungen in den nachfolgenden Jahren weiter geführt werden. Die Auswertung für das gesamte Land wird sicher spannend. Bei lokalbezogener Auswertung bestätigt sich für den Kiebitz nach allgemeinen Beobachtungen, dass er hier kein Brutvogel mehr auf Feldflächen ist. Für die bei uns untersuchten Feldflächen ist festzustellen, dass die Feldlerche keineswegs so selten ist, wie zunächst befürchtet worden war. Die relativ hohe Zahl im Bereich Badendiek täuscht darüber hinweg, dass der Bestand der Feldlerche in den letzten Jahrzehnten gemäß langfristiger Erhebungen tatsächlich aber erheblich geschrumpft ist. Auf dieser Fläche ist anscheinend noch ein guter Bestand vorhanden gewesen. Für Bestandseinschätzungen ist unbedingt $\mathrm{zu}$ bedenken, dass hier nur eine Momentaufnahme erstellt wurde. 
Tabelle 22: Zählergebnisse Zählstrecke Bülow (H. Richter)

Legende: * nur singende Individuen

\begin{tabular}{l|l|l|l|l|l|l|l}
\hline \multirow{2}{*}{ Art } & \multicolumn{5}{c|}{ Datum } & \multirow{2}{*}{$\begin{array}{c}\text { besetzte } \\
\text { Reviere }\end{array}$} \\
\cline { 2 - 8 } & $\mathbf{2 2 . 0 4}$ & $\mathbf{1 1 . 0 5}$ & $\mathbf{1 8 . 0 5}$ & $\mathbf{2 6 . 0 5 .}$ & $\mathbf{0 2 . 0 6}$ & $\mathbf{1 6 . 0 6 .}$ & \\
\hline Kiebitz & 2 & 3 & 4 & 2 & 2 & & 2 \\
\hline Feldlerche & $12^{*}$ & $9 *$ & $11^{*}$ & $12^{*}$ & $9 *$ & $12 *$ & 15 \\
\hline Braunkehlchen & & & & & & & \\
\hline Schwarzkehlchen & & & & & & & \\
\hline Wiesenschafstelze & & 4 & 8 & 4 & 5 & 8 & 7 \\
\hline Grauammer & & & 1 & & & & 1 \\
\hline Goldammer & 4 & 1 & 1 & 2 & 2 & 2 & 6 \\
\hline
\end{tabular}

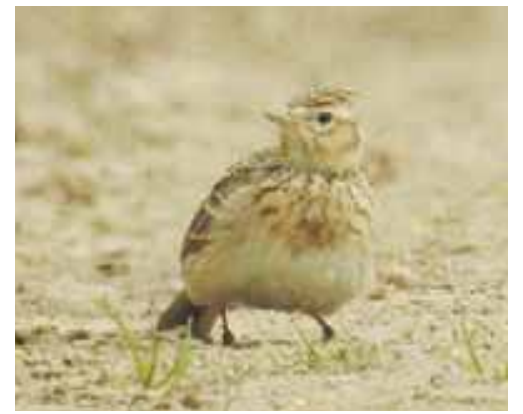

Abb. 393: Feldlerche im Bruthabitat. Foto: H. Richter.

Tabelle 23: Zählergebnisse Zählstrecke Badendiek (M. Montschko)

Legende: $\mathrm{I}$ Mai = 1. Maidekade nicht gezählt $\mathrm{sM}=$ singendes Männchen, ruf. $=$ rufend

\begin{tabular}{|c|c|c|c|c|c|c|c|}
\hline \multirow{2}{*}{ Art } & \multicolumn{6}{|c|}{ Datum/Dekade } & \multirow{2}{*}{$\begin{array}{l}\text { besetzte } \\
\text { Reviere }\end{array}$} \\
\hline & 30.04 . & I/Mai & 17.05 . & 26.05 . & 06.06. & 20.06. & \\
\hline \multicolumn{8}{|l|}{ Kiebitz } \\
\hline Feldlerche & 32 & & 45 & $48 \mathrm{sM}$ & $56 \mathrm{sM}$ & $49 \mathrm{sM}$ & 51 \\
\hline Braunkehlchen & 1 & & 2,1 & $1 \mathrm{sM}$ & $1 \mathrm{sM}$ & $1 \mathrm{sM}$ & 1 \\
\hline \multicolumn{8}{|l|}{ Schwarzkehlchen } \\
\hline Wiesenschafstelze & 2,2 & & $\begin{array}{c}6 \mathrm{sM} \\
+3\end{array}$ & $9 \mathrm{sm}$ & \multicolumn{2}{|l|}{$\begin{array}{c}10 \mathrm{sM} \\
+2\end{array}$} & 9 \\
\hline Grauammer & $1 \mathrm{sM}$ & & $1 \mathrm{sM}$ & $2 \mathrm{sM}$ & $3 \mathrm{sM}$ & $1 \mathrm{sM}$ & 1 \\
\hline Goldammer & $\begin{array}{l}5 \times 1,1 ; \\
5 \times s m\end{array}$ & $\begin{array}{l}6 \times 1,0 \\
1 \times 1,1\end{array}$ & 5,2 & 7,1 & 10,1 & 10 & \\
\hline Rebhuhn & & & & 1,1 & 1,1 & & 1 \\
\hline Wachtel & & & & & & 1 ruf. & \\
\hline
\end{tabular}

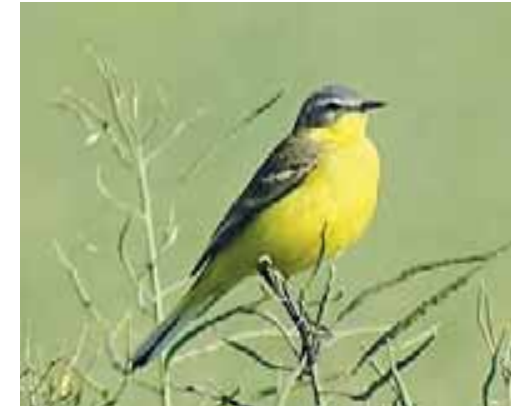

Abb. 394: Eine Wiesenschafstelze nutzt im Brutrevier den Raps als Singwarte. Foto: M. Montschko.

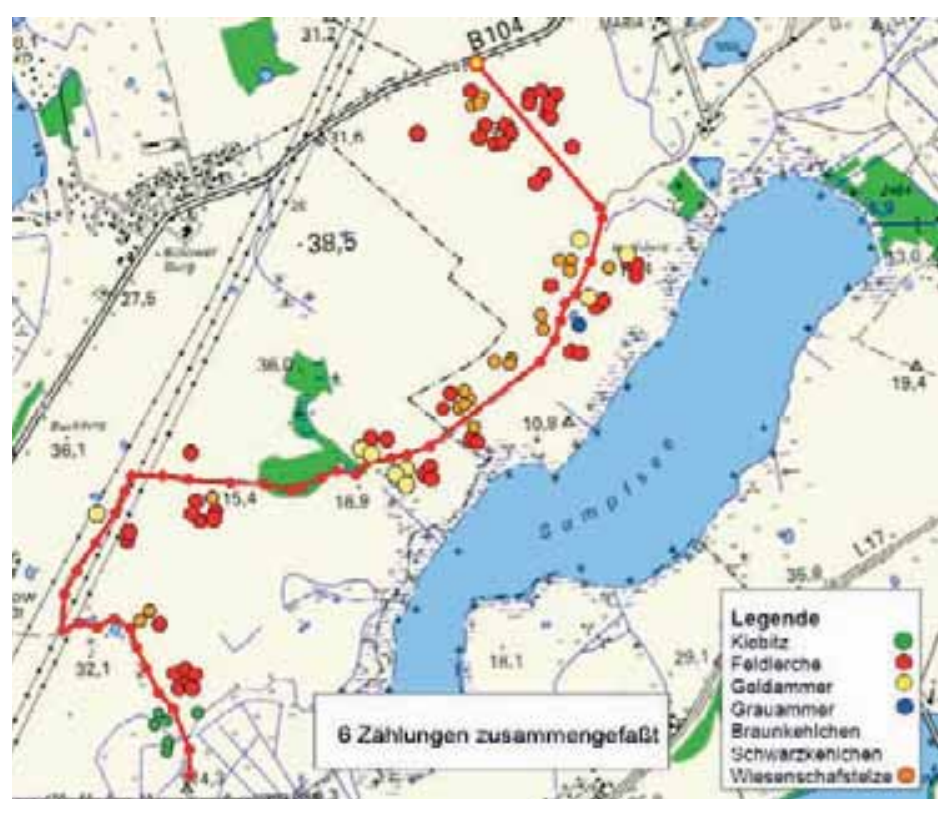

Karte 28: Aus den Punkten der Einzelbeobachtungen je Begehung der Zählstrecke (hier am Beispiel Bülow) können Rückschlüsse auf die besetzten Reviere der einzelnen Arten gezogen werden (vgl. Tabelle 22). 


\subsection{Wissenschaftliche Vogelberingung}

\section{Joachim Loose}

Vogelberingungen hatten bereits frühzeitig einen festen Platz in der Fachgruppenarbeit gefunden.

Die Beringerprüfung bei der Vogelwarte Hiddensee bestanden zuerst Reinhard Becker und Wolfgang Neubauer. Ab 1981 wurde auch Angela Martin offiziell Beringer, 1989 folgte Joachim Loose, nachdem er bereits mehrere Jahre als Beringungshelfer tätig war. Steffen Thiel erhielt 2010 eine eingeschränkte Beringererlaubnis für Greifvogelarten.

Am Breeser See waren frühzeitig auch andere FG-Mitglieder als Beringungshelfer tätig. Eine Vielzahl von Beringungen außerhalb von Krakow am See sind bis zur Wende 1989 als Beringergemeinschaft (BG) Krakow am See bei der Beringungszentrale unter dem Namen von W. Neubauer registriert worden. Dadurch ist eine Aufschlüsselung auf einzelne Beringer heute nur mit großem Aufwand möglich und ließe sich am ehesten über die Beringungsorte erstellen.

Eine erste Übersicht über gefangene und beringte Vögel stellte M. Montschko im FG-Jahresbericht Nr. 6 für 1973 zusammen.

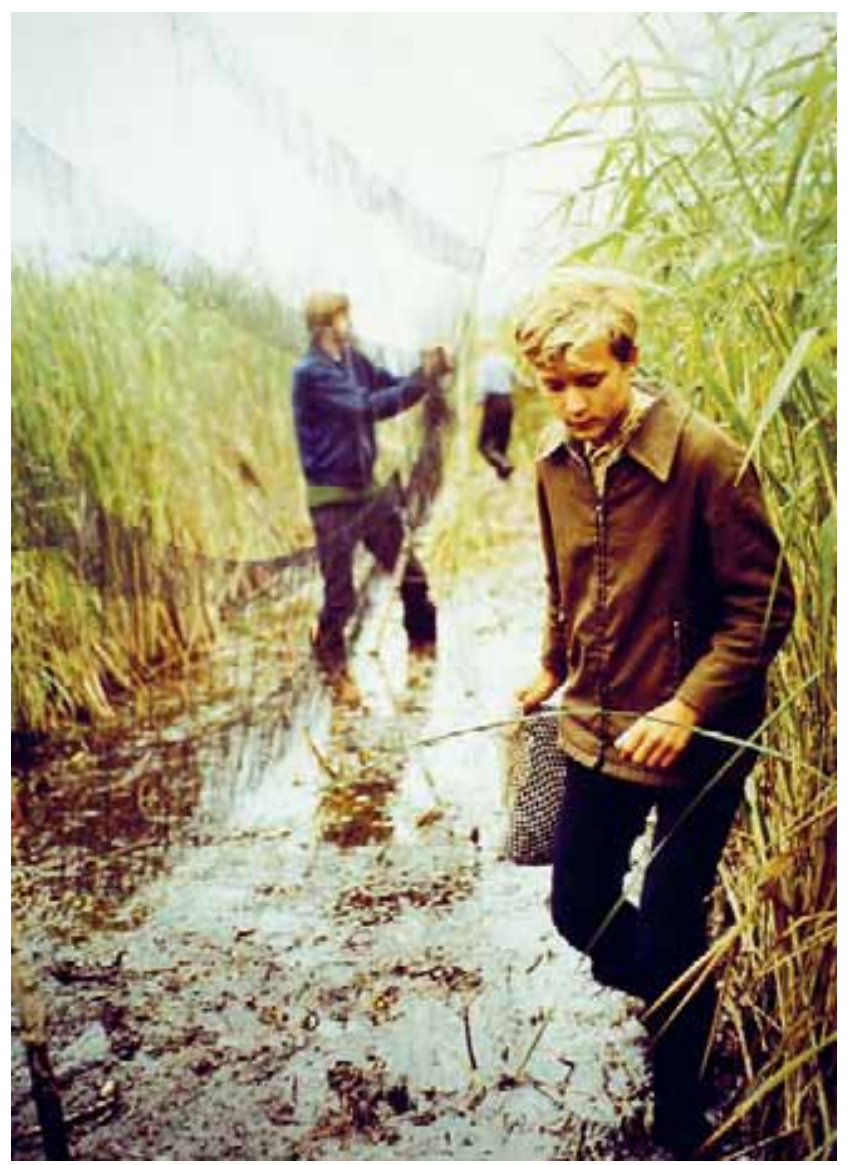

Abb. 395: Fangschneise im Schilf des Breeser See (Beringungshelfer waren Ingolf Schult, Willi Brüshaver und Gerd Möller)

Foto: K. Pohlmann (Archiv M. Montschko).
Am Breeser See waren 324 Vögel in 30 Arten gefangen worden. Das Artenspektrum entsprach dem, wie es im Schilfgürtel des Sees zu erwarten war und auch heute noch vergleichbar auftritt (vgl. dazu Jahresbericht Nr. 22/1989). Bereits damals standen 48 Bartmeisen (7,4 ad. und 37 diesj.) und drei Blaukehlchen (1 ad. $M$ und 2 Juv.) auf der Liste, die das erfolgreiche Brüten der Arten im NSG belegten. Im Jahresbericht Nr. 7/1974 werden die Beringungsergebnisse von Becker (153 Vögel) und Neubauer (408 Vögel) und die häufig beringten Arten einzeln genannt: Weißstorch 169, Flussseeschwalbe 88, Teichrohrsänger 43, Wiesenpieper 40, Bartmeisen 39, Kolkrabe 38, Rohrammer 35, Bachstelze 14, Flussuferläufer 13, Rohrweihe 12, Kiebitz und Eisvogel je 8, Singdrossel 7, Zilpzalp 6, Flussregenpfeifer 5 und weitere 20 Vogelarten unter 5 Exemplaren. Hier wird deutlich, dass es neben einigen gezielten „Programmarten" damals noch weitgehend eine „Wald- und Wiesenberingung" gab und fast alles, was man erreichen konnte, einen Ring bekam.

NEUBAUER (2004) gibt in der „Vogelwelt des Altkreises Güstrow" einen kurzen Einblick in die Schwerpunkte der Beringungstätigkeit der o.g. Beringer bis 2002. Hier können wir entnehmen, dass

- Reinhard Becker vor allem in den 1960er/1970er Jahren Weißstörche (ca. 200), Bekassinen (48), Rohr- und Wiesenweihen (20 bzw.14) beringt hat;

- Joachim Loose am Breeser See das Schwergewicht auf die Beringung von Schilfbewohnern (Bartmeisen 1.064, Blaukehlchen 43, Teichrohrsänger 2.912, Rohrschwirl 159, Rohrammer 716) und seit 1989 auch auf nestjunge Flussseeschwalben (777) aus Bruten auf Kunstinseln am See gelegt hat. Weiterhin hat er die im Natur und Umweltpark Güstrow (NUP) ab 1990 gepflegten und wieder ausgewilderten Vögel beringt.

- Angela Martin (neben Beringungen am Breeser See) ab 1985 bis zu diesem Zeitpunkt 300 Jungsperber und ab 1986 nach aufwendigen Nestsuchen hauptsächlich Haubenlerchen (289, Farbmarkierung) beringte.

- Wolfgang Neubauer Anatiden (Schnatterente 77, Höckerschwan 45), Kiebitze (265), Weißstörche (180), Lachmöwen (278 ad./ 1.000 juv.) Wintergäste (Birkenzeisige 191, Bergfinken 462, Kernbeißer 110, Wasseramseln 33) und intensiv Flussseeschwalben (2.069 ad./ 8.259 juv.) beringte sowie etwa 2.600 brütende Flussseeschwalben kontrollierte.

Unerwähnt blieb, dass Wolfgang Köhler jahrelang in der „BG Hauff“ Seeadler und vor allem zahlreiche Fischadler beringt hatte. Die Fischadlerberingung übernahm ab 2010 Steffen Thiel. 
Erwähnenswert sind die in der Kreisavifauna als Anhang enthaltenen Tabellen über im Kreis beringte Vögel mit Wiederfunden innerhalb und außerhalb des Altkreises (187 Indiv. in 23 Arten) sowie einer Auswahl der zur Verfügung stehenden 3.114 Datensätze von Vögeln, die außerhalb des Kreises beringt und im Altkreis wiedergefangen oder als Totfund registriert worden waren (233 Indiv. in 43 Arten). Nicht aufgelistet wurden hier die 1.535 Wiederfunde und Kontrollen von Flussseeschwalben, da diese gesondert ausgewertet werden sollten.

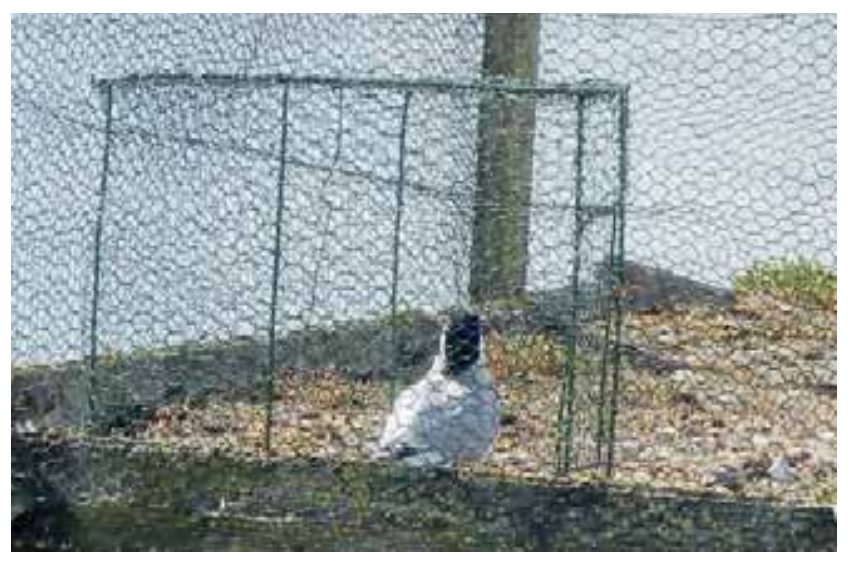

Abb. 396: Brütende Flussseeschwalben wurden mit speziellen Fangkörben auf den Nestern gefangen. Foto: 7 . Loose.

Mit den Daten offenbaren sich vielfach interessante Zugbewegungen und andere durch die Beringung erkennbar gewordene Lebensgeschichten. Nachfolgend einige interessante Beispiele:

- Eine am 12.7.1967 nestjung im Zehlendorfer Moor beringte Wiesenweihe wurde am 23.8.1967 bei Dolni Redice / CSSR erlegt.

- Ein am 3.7.1971 nestjung in Goldewin beringter Weißstorch konnte von 1982 bis 1992 jährlich brütend in Neustadt/Sebnitz (Sachsen) abgelesen werden.

- Für einen nestjung bei Klaber am 4.5.1972 beringten Graureiher liegt eine Rückmeldung vom 15.8.1972 als Totfund in Montemor Velho (Portugal) vor.

- Ein am 10.8.1976 als Fängling in den Zuckerfabrikteichen Güstrow beringter Flussregenpfeifer wurde nach drei Wochen am 3.9.1976 tot in Salina auf Malta (Italien) gefunden.

- Mindestens zwölf der von W. Neubauer am KOS von 1968 bis 1985 beringten Schnatterenten (77) wurden in Frankreich durch Jäger erlegt. (16\%)

- Ein am 27.6.2001 bei Krakow am See nestjung beringtes Sperberweibchen wurde am 15.2.2002 tot bei Belalcazar in Spanien aufgefunden und belegt den Südwestzug junger Sperber über eine Entfernung von mehr als $2.190 \mathrm{~km}$.

- Für 28 am KOS nestjung beringte Lachmöwen sind Ablesungen und Totfunde aus den Niederlanden, Belgien, Frankreich, Großbritannien und Irland aufgeführt.
Ebenso wurden am KOS viele in den genannten Ländern, ergänzend auch in Polen und Finnland beringte Lachmöwen gefangen oder gefunden (In den 1970er Jahren tötete man am KOS Lachmöwen zur Reduzierung der Brutpaarzahlen!).

In einer weiteren Auswahltabelle werden eigene Wiederfänge am Breeser See dokumentiert.

Insbesondere für Teichrohrsänger liegen zahlreiche Rückkehrbelege aus mehreren nachfolgenden Jahren von Individuen über bis zu acht Jahre vor und belegen eine große Ortstreue dieser Art.

W. Neubauer gibt weiterhin eine Übersicht über die gesamte Anzahl von uns beringter Vögel je Vogelart bis zum Jahr 2002: 24.618 Individuen in 96 Arten.

Bis 2015 erhöhte sich die Zahl um weitere 8.868 Vögel auf insgesamt 33.492 beringter Individuen.

In den Jahresberichten Nr. 40/2007 und 43/2010 befinden sich ergänzende Auswertungen und Kommentierungen von Beringungen sowie weitere bemerkenswerte Wiederfunde von beringten Vögeln von 2003 bis 2010. Die in der Kreisavifauna nur pauschal genannte Anzahl beringter Vögel je Art wird für den Zeitraum von 1988 bis 2007 jährlich und auf einzelne Gebiete/Programme bezogen dargestellt. Es wird deutlich, dass bereits Ende der 1980er Jahre die zuvor übliche „Wald- und Wiesenberingung“ eingestellt wurde.

Von den bis 2010 im Jahresbericht aufgelisteten bemerkenswerten Wiederfunden im Altkreis beringter Vögel sind nachfolgend einige aufgeführt:

- Ein am 17.06.2005 bei Krakow am See nestjunges Sperberweibchen wurde am 11.06.2006 erschöpft (später tot) in La Garriga/ Barcelona (Spanien) in einer Entfernung von $1.524 \mathrm{~km}$ aufgegriffen und belegt nochmals einen Zug nach Südwest.

- Eine am Breeser See am 23.07.2006 beringte Bartmeise (ad. M) wurde am 26.9.2007 bei Sörf Järden in Schweden kontrolliert und belegt die Expansion der Art auch nach Norden.

- Für einen am 28.08.1997 nach einer Pflege im NUP ausgewilderten diesjährigen Turmfalken gibt es eine Rückmeldung (Ringfund) vom 18.01.2002 aus N'Gilli/ Kati in Mali.

$\mathrm{Zu}$ den außerhalb des Kreises beringten und im Kreis gefundenen Vögeln sind nachfolgende Angaben interessant:

- Für am Krakower Obersee, Drewitzer See, Dreiersee, Breeser See und Kieswek Langhagen bzw. auch außerhalb unseres Kreises beringte Flussseeschwalben belegen 26 Vögel nochmals die Zugwege bis nach Südafrika. 
- Eine in Polen am 3.7.1985 beringte Flussseeschwalbe wurde nach 25 Jahren am 4.6.2010 am Drewitzer See kontrolliert.

- Eine am 11.09.2004 in Staffanstorf/Malmöhus in Schweden juvenil beringte Heckenbraunelle starb am 28.01.2005 am Stadtrand von Güstrow, vermutlich in dem gewählten Winterquartier.

- Eine am 7.8.2005 im Kreis Schaumburg/Hannover (NS) diesjährige Schleiereule „wollte“ den Bestand in M-V auffüllen, wurde hier aber verhungert am 11.01.2006 bei Matgendorf/Tet. gefunden.

- Ein am 3.7.1988 in einem Horst bei Neuruppin (BB) beringter nestjunger Weißstorch konnte am 19.8.1996 brütend im Horst von Prüzen abgelesen werden und kam am 7.7.2007 ebenda als Brutvogel durch Stromkontakt ums Leben.

Im PC von W. Neubauer befanden sich Beringungs- und Wiederfunddaten von Lachmöwen, die er uns bisher nicht vorgestellt hatte und auch nicht in den Zusammenstellungen im Jahresbericht Nr. 43/2010 berücksichtigt worden waren. Mitte Juni der Jahre 2002 und 2003 hatte W. Neubauer jeweils 200 bzw. 250 nestjunge Lachmöwen in der Kolonie auf dem Großen Werder beringt. Die bis 2008 vorliegenden 24 Rückmeldungen aus dieser Beringungsaktion stammen weitgehend aus Belgien, den Niederlanden sowie Niedersachsen und belegen damit einen Westzug der Lachmöwen ab Spätsommer und das Verweilen während des Winters in diesen Gebieten.

Mit eigenen Wiederfängen am Breeser See konnte die offensichtliche Zunahme des Blaukehlchen in unserer Region (2010 gab es am Breeser See mindestens sieben Gesangsreviere) und ihre Standorttreue belegt werden: Von den von 2000 bis 2015 hier beringten 121 Blaukehlchen (69 ad, 52 flügge Juv.) wurden in den Folgejahren 21 Indiv. (17,4\%) am Breeser See erneut gefangen. Für Bartmeisen hingegen wird deutlich, dass mit ausbleibenden Wiederfängen offensichtlich ein weitgehendes Abwandern in andere Gebiete nach der Brutsaison erfolgt: Von den in der Zeit von 2000 bis 2015 am Breeser See beringten 1.460 Bartmeisen (238 ad., 1.222 flügge Juv.) wurden in den Folgejahren lediglich 20 Individuen $(1,4 \%)$ im Gebiet wiedergefangen.

Außer den Programmberingungen von Flussseeschwalben, später von Haubenlerchen und Sperbern, erfolgten ab Mitte der 1980er Jahre fast ausschließlich nur noch Beringungen in mehreren Fangschneisen am Breeser See. Die Netze standen hier durchschnittlich an 29 Tagen im Jahr zwischen dem 12.4. und 23.10. - die Hauptfangtage lagen in den Monaten Juni bis August. Ab 2001 beteiligten wir uns am bundesweiten Programm zur Beringung von Bartmeisen, welches bis 2015 lief.

\section{Zahl der Fangtage am Breeser See}

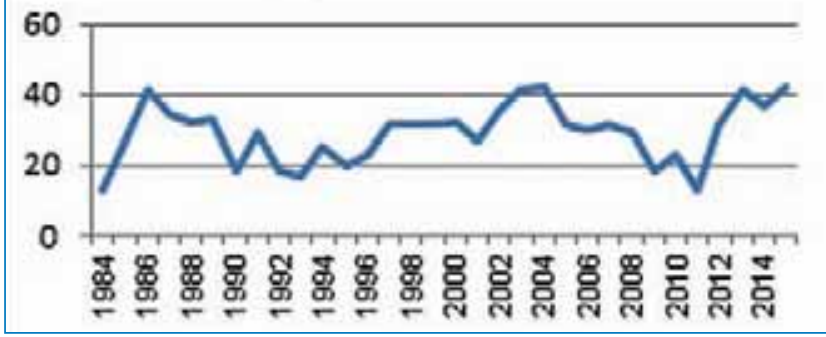

Diagramm 46: Beringungsaktivitäten am Breeser See

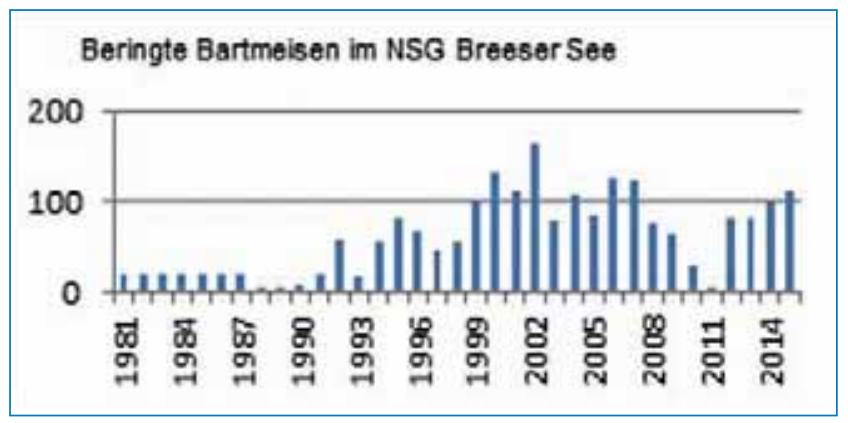

Diagramm 47: Fangübersicht von Bartmeisen

Die als „Nebenprodukt“ der Bartmeisenberingung am Breeser See häufigste gefangene Vogelart war der Teichrohrsänger.

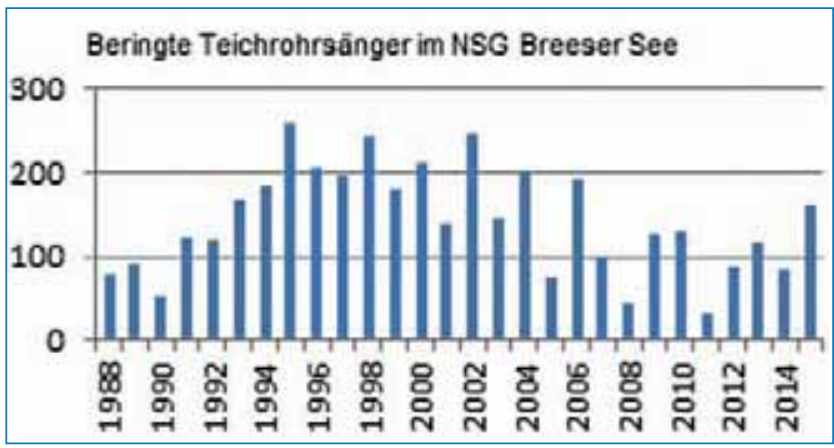

Diagramm 48: Fangübersicht von Teichrohrsängern

Die unterschiedliche Anzahl der jährlich gefangenen Teichrohrsänger lässt sich nicht mit einer eventuell geringeren Zahl der Fangtage/Jahr begründen. Der Anteil von gefangenen Teichrohrsängern zur Gesamtzahl gefangener Vögel lag zwischen 2006 und 2015 bei 19,2 bis 36,0\%, in den beiden Störungsjahren 2008 und 2011 nur bei je 9,0\%. Für die Störungsjahre sind äußere Einflüsse anzunehmen.

Zur klassischen Beringung gehört immer der Wiederfang des beringten Vogels oder sein Totfund, um aus der Beringung weitere Erkenntnisse erzielen zu können. Mit der Methode von zusätzlichen Kennzeichnungen kann man Daten erheben, ohne den Vogel selbst in der Hand gehabt zu haben. Vornehmlich in den 1980er Jahren konnten viele Mitglieder der Fachgruppe bei uns mehrere hundert mit Halsbändern markierte Graugänse ablesen. 
Im Ornithologischen Rundbrief für Mecklenburg-Vorpommern (Heft 34/1991 S. 10-18) hat J. Loose die Zugdynamik an den Spätsommer-/Herbstsammel- und -rastplätze der Graugans im Kreis Güstrow beschrieben. Über die Ablesung des Codes bei 34 mit gelben Halsbändern markierten Graugänsen ließ sich deren Verweildauer in den Monaten August und September 1989 am Sumpfsee dargestellt. Durch Ablesungen am Sumpfsee und später auch an anderen Orten, wurde erkennbar, dass der von RUTSCHKE (1987) beschriebene ansonsten übliche Zug im Herbst vom Binnenland an die Ostseeküste nicht generell stattfindet. Es wurde auch ein Zug von Graugänsen nach Süden ins Binnenland belegt.

Die Halsringmethode wird heute bei nordischen Blessund Saatgänsen angewendet. Im Vergleich zu den früher zahlreich abgelesenen Graugänsen, die mit gelben Halsringen markiert waren, gelingen Sichtbeobachtungen bei nordischen Gänsen heute deutlich seltener. In Lettland und Litauen laufen Programme zur Beringung von Singschwänen. In jüngerer Zeit wurden mit blauen Halsringen markierte Singschwäne auch bei uns vermehrt beobachtet. (Eingabe von Beobachtungen markierter Gänse und Schwäne im Internet unter www.geese.org)

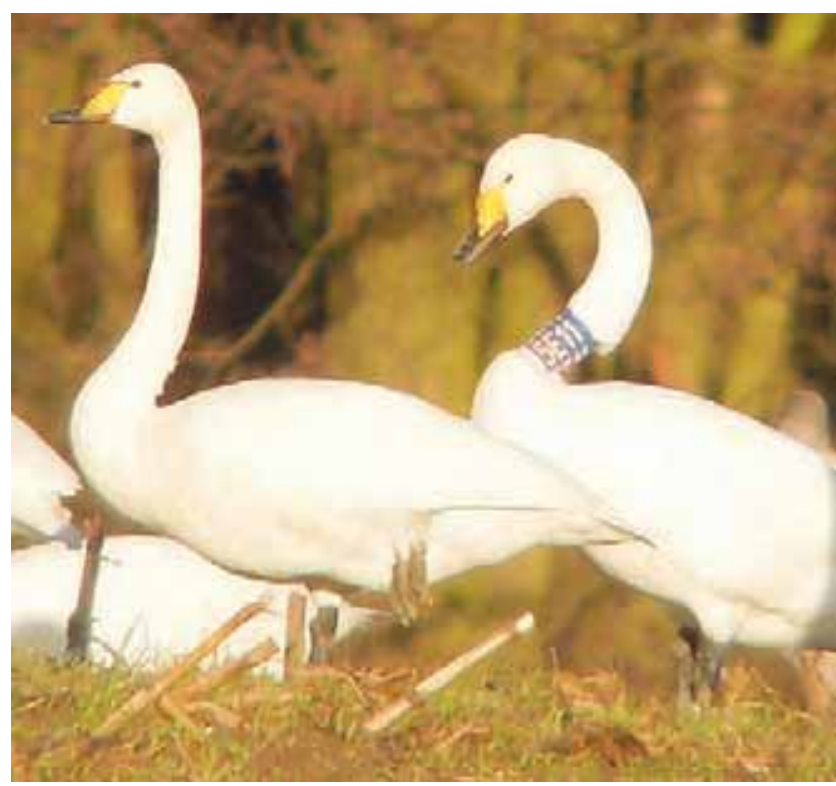

Abb. 397: Der mit Halsring markierter Singschwan (blauer Ring mit orangefarbenen Code 5E11) hielt sich am 13.12.2015 auf einem Acker bei Groß Breesen zusammen mit 70 Artgenossen auf. Foto: 7. Loose

Mit farbigen Fußringen markierte Kraniche haben in neueren Jahren Ablesungen bei Graugänse abgelöst. Vielfach tragen Kraniche heute auch kleine Sender, so dass Spezialisten mit einem Funkempfänger die Vögel im Dunkeln nicht einmal mehr sehen müssen, um deren Anwesenheit festzustellen. Die Möglichkeiten der Meldung von Beobachtungen im Internet (für Kraniche unter www.icora.de) führt heute zu immer schnelleren Auswertungen.

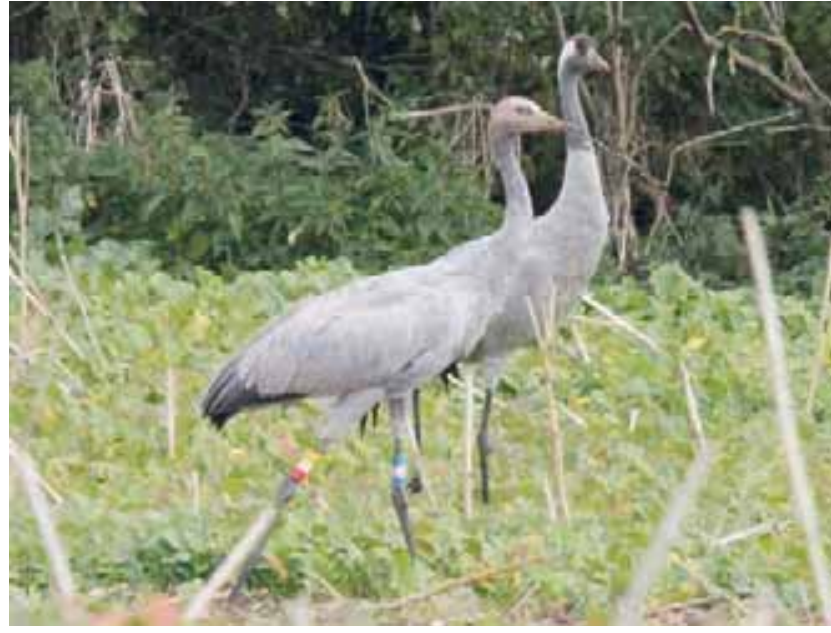

Abb. 398: Diesjähriger mit Fußringen beringter Kranich. Am linken Fuß befindet sich die Länderkennung -blau-weiß-blau, rechts die individuelle Kennzeichnung - gelb-weiß-rot. (Der Vogel wurde am 25.6.2014 bei Striggow beringt.) Foto: B. Meder-Trost.

Die mit Sendern über Satelliten gewonnenen Daten von Vögeln lassen uns heute quasi live ihren Zug ins Winterquartier verfolgen. Die Ornithologie ist publikumswirksamer und spannender geworden. Könnten sich dadurch nicht auch junge Leute aus unserer Region für diese Sache begeistern und so zur „alt gewordenen“ Fachgruppe stoßen?

Das Ablesen von farbmarkierten Wasseramseln im Stadtbereich von Güstrow und an den neu entstandenen Fischtreppen hat zumindest eine Reihe von Bürgern aktiviert, die ansonsten nichts mit Vogelbeobachtungen zu tun hatten.

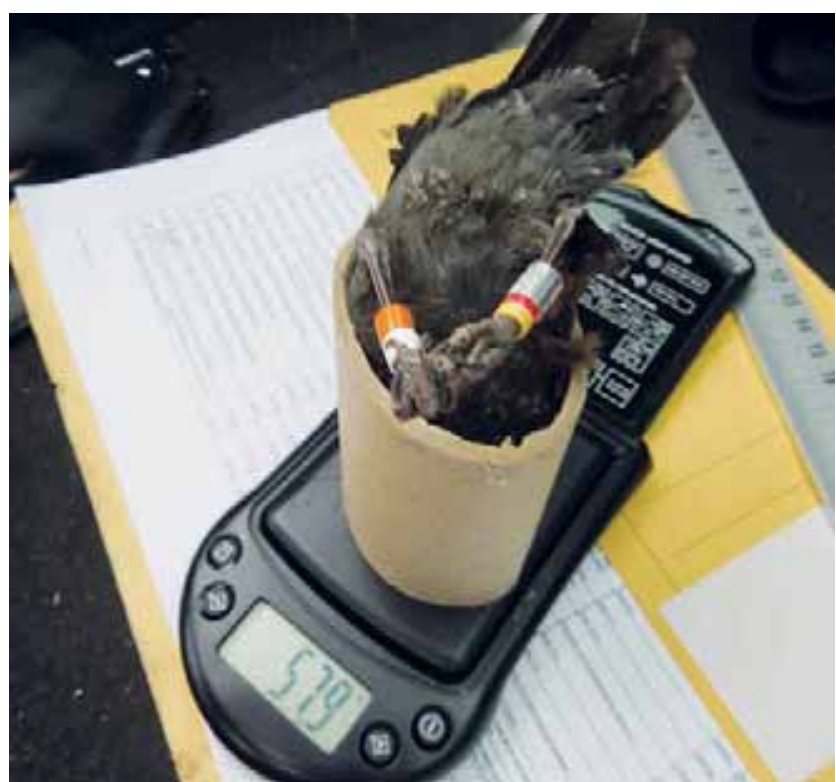

Abb. 399: Mit Farbringkombination am 5.1.2013 an der Fischtreppe im Augraben beringte Wasseramsel. Foto: f. Loose.

Die heute deutlich verbesserten Möglichkeiten der fotografischen Dokumentation mittels Superzoom-Kameras führte zunehmend zu Belegen auch durch Fremde. 


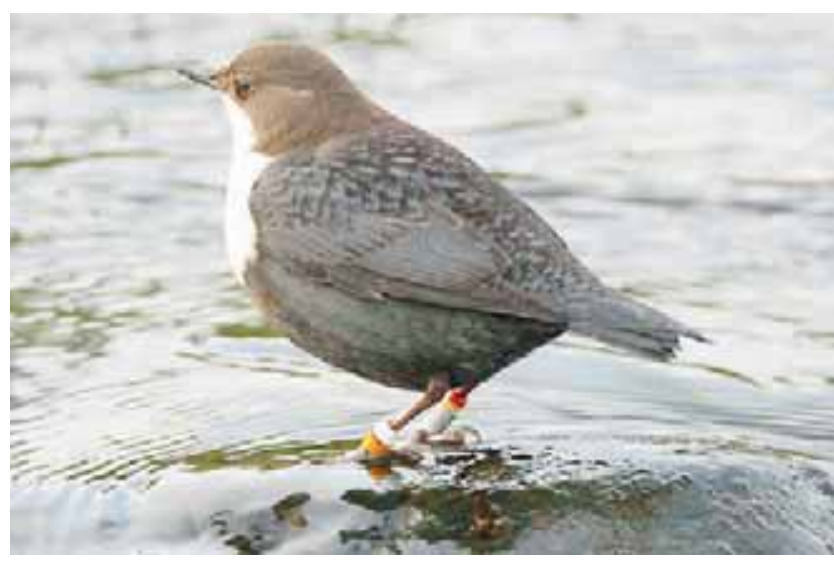

Abb. 400: Die am Nebelwehr Güstrow am 16.2.2015 fotografierte Wasseramsel ist nicht die auf dem Foto zuvor beringte. Die Lage der Farbringe ist genau zu beachten. Foto: K. Kirschnick.
Die mit Spektiven oder auch einfachen Ferngläsern ablesbaren Zusatzberingungen von Großvögeln wie bei Gänsen, Schwänen, Kranichen und vermehrt auch bei Singvögeln (Dohlen, Wasseramseln ...) stellen eine gute Methode zur Datengewinnung dar, ersetzen jedoch nicht die herkömmliche Beringung mit Fußringen und die ornithologische Feldarbeit. Auch die Farbringe müssen erst einmal angelegt werden.

Die zunächst für diese Broschüre geplante Ergänzung der von NEUBAUER (2004, S.173) angelegten Tabelle aller bis 2002 von unseren Beringern beringten Vogelarten würde hier den Rahmen sprengen.

Eine solche ergänzende tabellarische Übersicht wird in einem der nächsten Jahresberichte der FG vorgelegt werden.

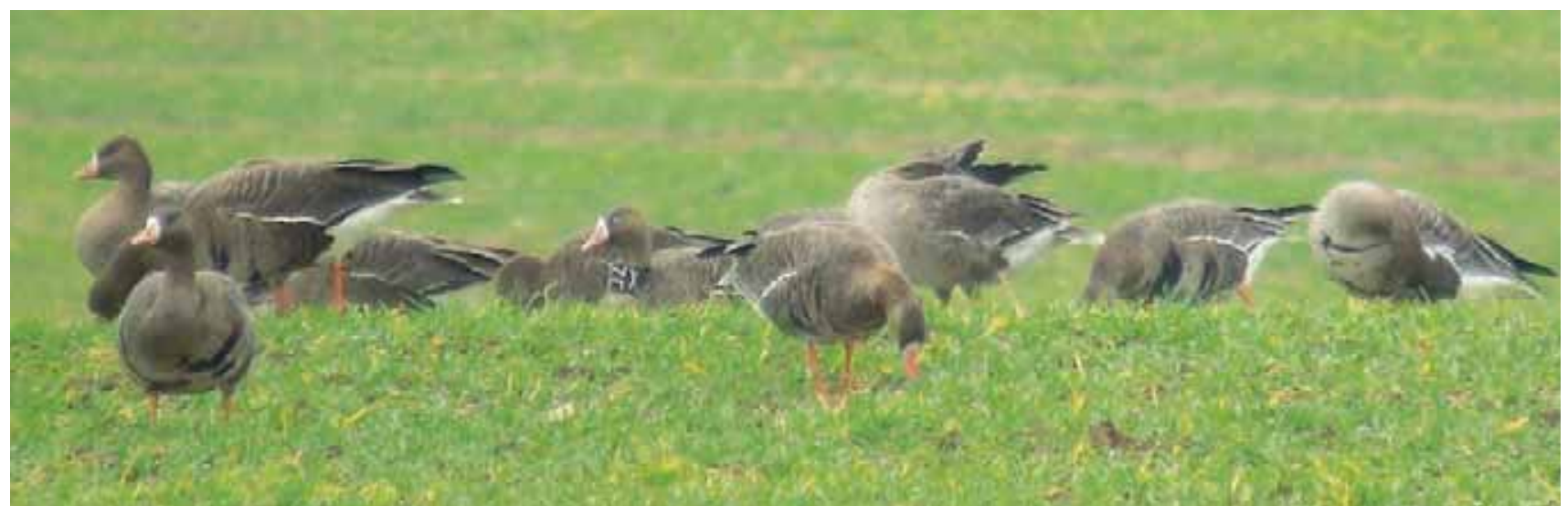

Abb. 401: Mit schwarzem Halsring markierte Bleßgans mit dem Code XZC - auf die Ableserichtung ist zu achten. (Digiskopie mit Nicon Coolpix S8200 durch ein Spektiv Carl Zeiss Diascope $85 T^{*}$ FL). Foto: 7. Loose.

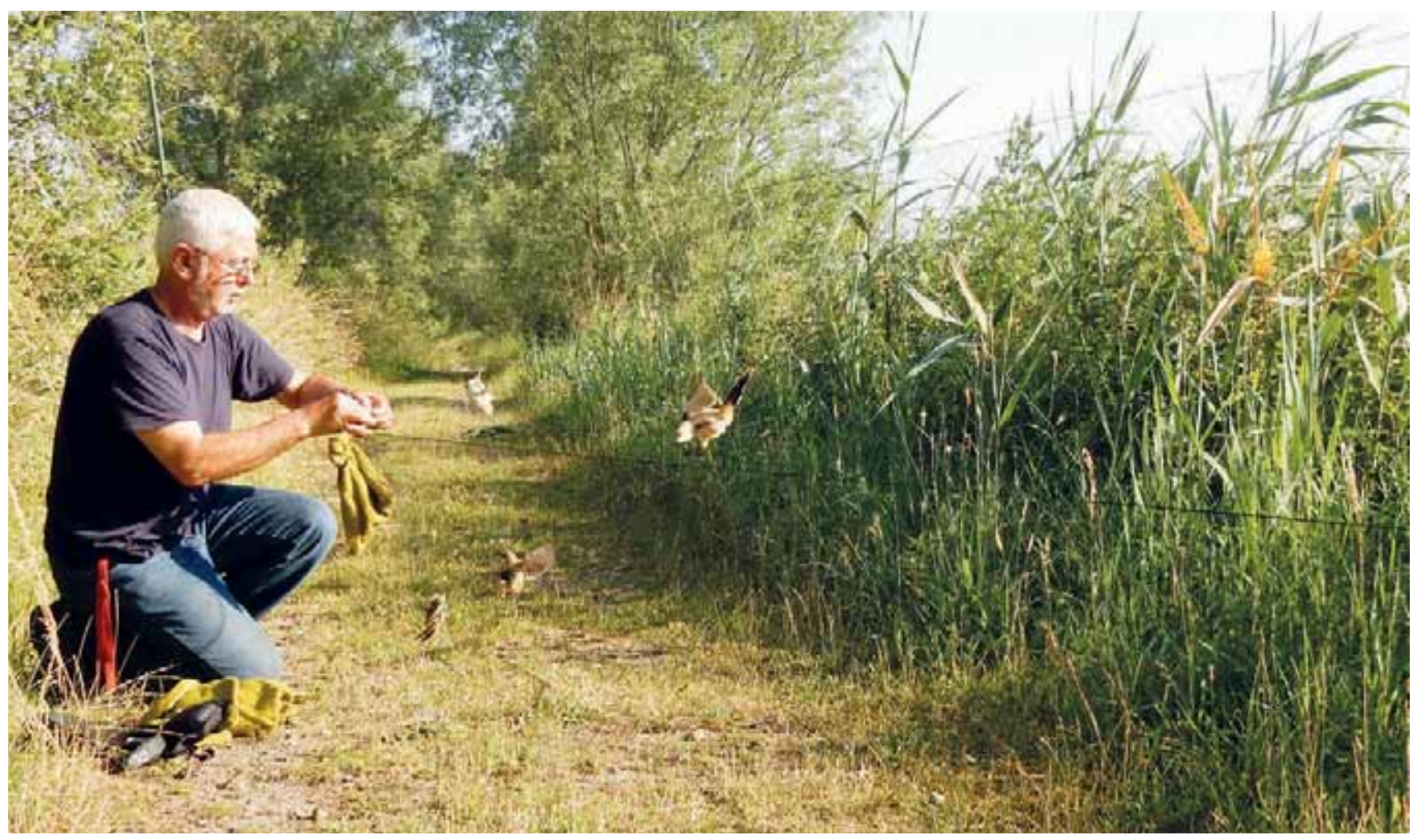

Abb. 402: Joachim Loose beim klassischem Fang von Bartmeisen mit fapannetz auf dem Weg durch den Gutower Polder. Die flüggen fungvögel wechseln hier häufig zwischen den beidseitig liegenden Schilfflächen. (fuli 2015) Foto: K. Kirschnick. 


\section{Resümee und Ausblick für die weitere Arbeit der Fachgruppe}

Die Arbeit eines ehrenamtlich tätigen Ornithologen und Naturschützers war nach der politischen Wende nicht einfacher geworden. Viele Leute haben das Eigentumsrecht an Grund und Boden „wieder entdeckt" und verhalten sich nicht selten abweisend gegenüber Fremden, die mit Ferngläsern durch die Landschaft ziehen.

Früher reichte es in den meisten Fällen, wenn man dem LPG-Vorsitzenden Bescheid gesagt hatte, dass man auf den Flächen nach Vögeln Ausschau halten möchte. In der neuen Zeit müssen wir uns stets auch auf solche „Hindernisse und Beschwerlichkeiten“ einstellen. So ist es mitunter sehr hilfreich, wenn man die im Landesnaturschutzgesetz (§ 25) oder im Waldgesetz des Landes M-V (§ 28) enthaltenen Betretungsrechte kennt und erforderlichenfalls kontern kann. Blamabel ist es, dass wir uns in der ehrenamtlichen Tätigkeit als Feldbiologen heute nicht mehr wie zu DDR-Zeiten als Naturschutzhelfer ausweisen können. Die Mitglieder der Fachgruppe Ornithologie und Naturschutz besaßen fast alle einen bis 1990 gültigen Naturschutzhelferausweis (vgl. Abb. 403).
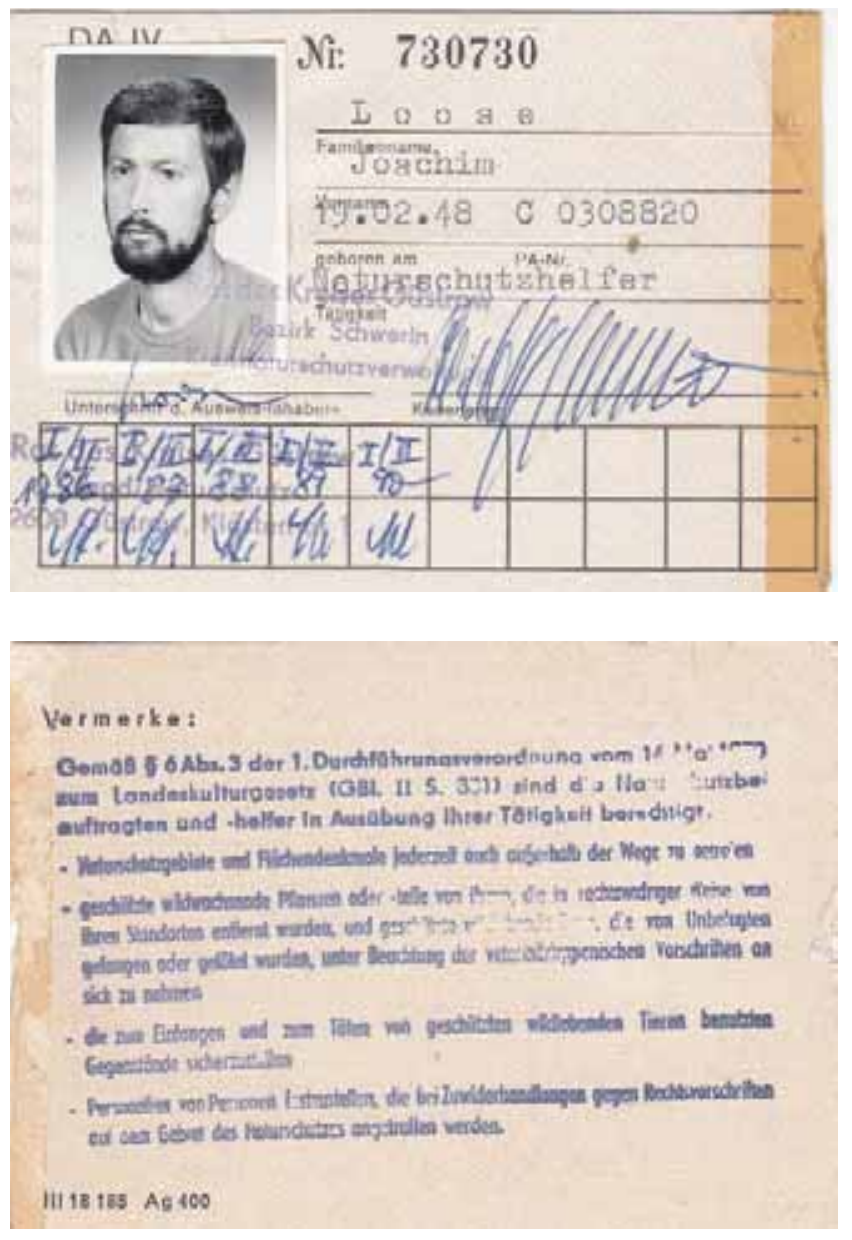

Abb. 403: Bei den Naturschutzhelferausweisen sind insbesondere die auf der Rückseite genannten Berechtigungen zu beachten.
Obwohl mit § 33 im Naturschutzausführungsgesetz für M-V die Berufung von Naturschutzwarten mit entsprechenden Befugnissen (in analoger Form zu den Naturschutzhelfern der DDR) geregelt ist, hat sich die Naturschutzbehörde bis heute geweigert, davon Gebrauch zu machen. Wir gehen zwar unserer Arbeit in den Gebieten und mit den geschützten Arten weiter wie bisher nach, es gibt aber zunehmend erheblichen Frust. Der war bereits in den vorherigen Kapiteln bei den NSG-Betreuungen zum Ausdruck gebracht worden.

Gemäß dem Namen unserer Fachgruppe fühlen wir uns neben der Ornithologie nach wie vor dem Naturschutz verpflichtet. Reine Vogelbeobachtungen können immer nur der Anfang sein - wichtig sind die Interpretationen und Reaktionen auf festgestellte Veränderungen.

Sehr bedauerlich ist, dass seitens der neuen Naturschutzverwaltungen $\mathrm{zu}$ uns ehrenamtlichen Naturschützern die Verbindung nicht in dem Maße gesucht wird, wie sie zu DDR-Zeiten zwischen unserer Gruppe und dem Sekretär für Naturschutz beim Rat des Kreises, Heinz Stegemann, existiert hatte.

In den voranstehenden Kapiteln konnten wir zum Ausdruck bringen, wie unsere FG-Mitglieder in vielfältiger Weise über viele Jahre Schutzgebiete betreut und im Monitoring vieler Arten Daten zusammengetragen haben, die auch den staatlichen Verwaltungen bei Entscheidungen hilfreich sind.

Vielfach werden von staatlichen Stellen Daten von uns abgefragt, damit sie der Berichtspflicht zu FFH- und SPAGebieten überhaupt nachkommen können.

Leider ist in den vergangenen Jahren dieser Informationsfluss immer einseitiger geworden. Weder die Kreisverwaltung, noch das STAUN oder das LUNG haben den Kontakt ehrlich zu uns gesucht, im Gegenteil, wir kamen uns oft wie Bittsteller vor, wenn wir Hilfe brauchten. Wenn heute von ehrenamtlicher Arbeit gesprochen wird, werden im allgemeinen Sprachgebrauch darunter die mannigfaltigen Aktivitäten von Bürgern im sozialen Bereich verstanden. Die vielen hundert Stunden und nicht unwesentlichen Fahrkosten, die unsere FG-Mitglieder für die Gebietsbetreuung und Arterfassungen aufwenden, werden kaum gewürdigt und nur in seltenen Fällen - und dann nur teilweise - finanziell ausgeglichen (vgl. dazu Pkt. 7 - S. 47 Praxis vor 1990). Für die Betreuung von Naturschutzgebieten gab es nur bis 2011 eine vertragliche Regelung zwischen einzelnen FG-Mitgliedern mit dem Ministerium. Nach Übertragung der Zuständigkeiten für NSG an die Untere Naturschutzbehörde läuft alles nur so „auf Zuruf“ weiter. Auf eine Berufung als NSG-Betreuer oder Naturschutzwart verzichtet man behördlicherseits einfach in der Hoffnung, dass 
die Ehrenamtlichen auch so weiterhin ihre Daten liefern werden.

Mit der jüngsten Zuständigkeitsübertragung an die UNB wurde auch der bürokratische Aufwand für die Beringer im Land erhöht. So müssen nunmehr die Beringungsanträge meist jährlich und getrennt für die einzelnen Kreise und gesondert für die Nationalparke bei den jeweiligen UNB eingereicht werden, was besonders für die kreisübergreifenden Beringungen bei Adlern und Wanderfalken stark behindernd ist. Wir sind der Meinung, dass generell die e h r e n a m t l i c h e Arbeit nicht erschwert, sondern erleichtert und gefördert werden sollte.

Wir hoffen darauf, dass sich die Zusammenarbeit mit unseren $\mathrm{P}$ a $\mathrm{r}$ t $\mathrm{n}$ e $\mathrm{r} \mathrm{n}$, den Naturschutzverwaltungen, verbessern wird. Diese Behörden betonen oft, dass sie auf uns Ehrenamtliche bauen, es aber für uns oft bei einer Einbahnstraße belassen.

Von den in unserem Wirkungsbereich liegenden zehn Naturschutzgebieten werden nur noch zwei durchgehend ehrenamtlich betreut. Warum kümmert sich niemand um die anderen Gebiete? Kann hier auf eine Betreuung verzichtet werden? Die Naturschutzbehörde hat sicherlich keine Kapazität, in diesen wertvollen Gebieten auch noch wissenschaftlich zu arbeiten. Wer schaut nach Veränderungen in diesen Gebieten und deckt Schädigungen auf? Warum wurden bei den Entwicklungsmaßnahmen im NSG Zehlendorfer Moor, die mit viel Geld bis heute kaum Wirkungen zeigen, nicht die Erfahrungen der ehrenamtlichen Naturschützer genutzt und die langjährige Betreuerin des Gebietes in die Planungen mit einbezogen?

Neben der notwendigen Kritik soll hier auch ein Blick auf unsere kommenden Arbeiten geworfen werden. Wenn nicht gerade eine spezielle Kartierungsaufgabe ansteht, hat jedes FG-Mitglied sein „bevorzugtes privates“ Beobachtungsgebiet oder seine Erfassungsaufgabe gefunden. In besonders attraktiven Gebieten in unserem Wirkungsbereich werden die Vögel bereits seit längerer Zeit durch einen festen Stamm von Mitgliedern beobachtet. Diese Langzeiterfassungen sollen auf alle Fälle fortgeführt werden, dass gilt auch für die in den Kapiteln dieses Heftes näher genannten Vogelarten. Bei den Beobachtungsgebieten gibt es noch viele unzureichend beachtete Areale, in denen durchaus mit Überraschungen zu rechnen ist.

Auf die zweckmäßige Wiederholung von Siedlungsdichteuntersuchungen im Augrabengebiet im Umfeld des NSG Zehlendorfer Moor wurde bereits im Pkt. 8.3.1 hingewiesen. Die Ergebnisse dürften im Vergleich zu denen vor 20 Jahren sehr interessant sein, auch wenn sie vermutlich nur den Rückgang zahlreicher Arten des Offenlandes belegen werden.

Die renaturierte Fläche des Gutower Polders ist ein noch wenig erforschtes Stiefkind. Wenngleich hin und wieder Durchzugs- und Rastangaben von den Wasserflächen vor- liegen, fehlen doch gerade Siedlungsdichteangaben aus den Schilfflächen während der Brutzeit. Das Vorkommen von Bart- und Beutelmeisen, Blaukehlchen sowie aller drei Schwirl- und Rohrsängerarten sollte bereits Anreiz sein, hier einmal näher in das Gebiet zu schauen. Zudem ist mit der Entwicklung der Fläche nach der Renaturierung auch mit verschiedenen Rallenarten zu rechnen.

Eine hohe Siedlungsdichte bei Wasserrallen wird nach ersten Einschätzungen vermutet und wäre mit Zahlen zu belegen. Der Einsatz von Klangattrappen während der Abendund Nachtstunden dürfte hier gute Dienste leisten.

Für die Beobachtungen an unseren „Ostseen“ (Warinsee, Krummer See, Wülwenowsee, Radener See) fehlt seit dem Tode von Reinhard Becker ein Beobachter. Bei den einzelnen Rasterkartierungen der Brutvögel war deutlich geworden, dass diese Landschaft eine überdurchschnittliche Artenzahl je MTB aufwies.

Ein großes Laubwaldgebiet am Rande der Stadt Güstrow (Primerwald) ist nach der politischen Wende wieder zugänglich geworden. Gemeinsam mit dem Tiefen See und insbesondere der südlich liegenden Feuchtniederung und dem sich zwischen See und Autobahn erstreckenden Ödland (ehemalige Panzerübungsstrecke der sowjetischen Armee) könnten hier interessante Nachweise für einen „Waldläufer" warten.

Die auf der Grundlage der EU-Wasserrahmenrichtlinie (WRRL) bereits erfolgten Renaturierungen von Abschnitten der Nebel zwischen Linstow und Dobbin, bei Hoppenrade und im Verlauf der Alten Nebel von Parum bis Wolken sowie des ersten Abschnitts der Recknitz zwischen Liessow und Laage haben neue Lebensräume entstehen lassen, die mit ihren Randflächen interessante Lebensräume für Vogelarten werden dürften.

Ebenso sind zahlreiche Erstaufforstungsflächen dazugekommen, in denen die Besiedlung mit Vogelarten erfasst und dokumentiert werden sollte.

Der Abbau von Kies und Sand wurde in unserem Altkreis nach der Wende erheblich ausgeweitet.

Die Bedeutung von Kiesabbauflächen war durch Wolfgang Neubauer insbesondere für das große Abbaugebiet Langhagen belegt worden. Neben den dort fortzuführenden Erfassungen (Lachmöwen, Flussseeschwalben) gilt es aber auch die kleineren Gewinnungsflächen bei Charlottental, Zietlitz-Groß Bäbelin, Spoitgendorf und Weitendorf kontinuierlich im Blick zu behalten - die letzte Gesamtzählung des Brutbestandes von Uferschwalben durch unsere Fachgruppe ist bereits lange her.

Nicht ausreichend und regelmäßig beobachtet wird u.a. auch im „Seemoor" bei Jahmen (FFH-Gebiet!) und in verschiedenen kleineren Flächen, die durch Auflagen der Naturschutzbehörde als Kompensationsflächen, meist in Verbindung mit wasserbaulichen Maßnahmen, neu geschaffen wurden (z.B. bei Sarmstorf) oder in Feuchtgebieten S Klaber am Waldrand oder N Kirch Kogel oder in solchen, 
die sich selbst zu Kleingewässern entwickelt haben (z.B. südlich Mühl Rosin, westlich Fuchsberg - Biotop-Nr. GUE10985).

Ein großes „unbekanntes“ Gebiet befindet sich schließlich auch am nordöstlichen Stadtrand von Güstrow zwischen dem Klinikum und dem NSG Bockhorst.

Mit einer derzeitigen Zahl von 15-18 Fachgruppenmitgliedern können diese hier genannten Aufgaben nur schwer vollständig abgearbeitet werden.

An Betätigungsfeldern und Beobachtungsaufgaben für neue Ornithologen mangelt es nicht. Wir müssen realistisch einschätzen, dass wir das Problem, diese neuen Ornithologen $\mathrm{zu}$ finden und $\mathrm{zu}$ aktivieren, nicht über den Aufbau einer Jugendgruppe schaffen können, wie es die Gründungsmitglieder der Fachgruppe Kurt Pohlmann und Wolfgang Neubauer als engagierte Lehrer an ihren Schulen einst taten. Aufkeimendes Interesse bei jungen und sehr jungen Menschen im persönlichen Bekannten- und Verwandtenkreis sollte aber jeder unbedingt bestmöglich fördern.

Wenn man heute in den ornithologischen Online-Portalen (oamv.de, ornitho.de) feststellt, dass hier für unseren Altkreis auch Beobachtungsdaten von Personen eingetragen werden, die bisher keinen Kontakt zu unserer Fachgruppe gesucht haben, ist vielleicht die Hoffnung berechtigt, dass jene mit Herausgabe dieser Informationsschrift über die 50jährige Fachgruppen-Arbeit Interesse zu einer künftigen Mitarbeit entwickeln werden.

Bei unseren Beobachtungen in der Natur sind uns in den vielen Jahren immer wieder Flächen aufgefallen, die kurzzeitig eine größere Bedeutung für Vogelarten erlangt hatten. Oft waren es Vernässungen von Flächen, die durch Havarien oder zerstörte Meliorationsleitungen entstanden und dann wieder repariert worden waren. Wir sehen solche Flächen, bei denen eine Vernässung akzeptiert und auf Dauer erhalten oder bewusst initiiert wird, für die Zukunft als Areale mit einem bedeutenden Entwicklungspotential für Pflanzen- und Tierarten an.

Natürlich kommt auch der Erhaltung von Ödlandflächen mit Hochstaudenvegetation oder von großflächigen Stilllegungsflächen für die Pflanzen- und Tierwelt eine große Bedeutung zu.

Mit der Darstellung einiger ausgewählter potenzieller Vernässungsgebiete in Anhang 6 hegen wir die Hoffnung, dass es künftig einmal gelingen wird, einige Flächen im Sinne des Naturhaushaltes als artenreiche Lebensräume in einer überbeanspruchten Kulturlandschaft zu entwickeln und damit unseren Altkreis für die Vogelwelt und andere Artengruppen noch attraktiver zu machen.

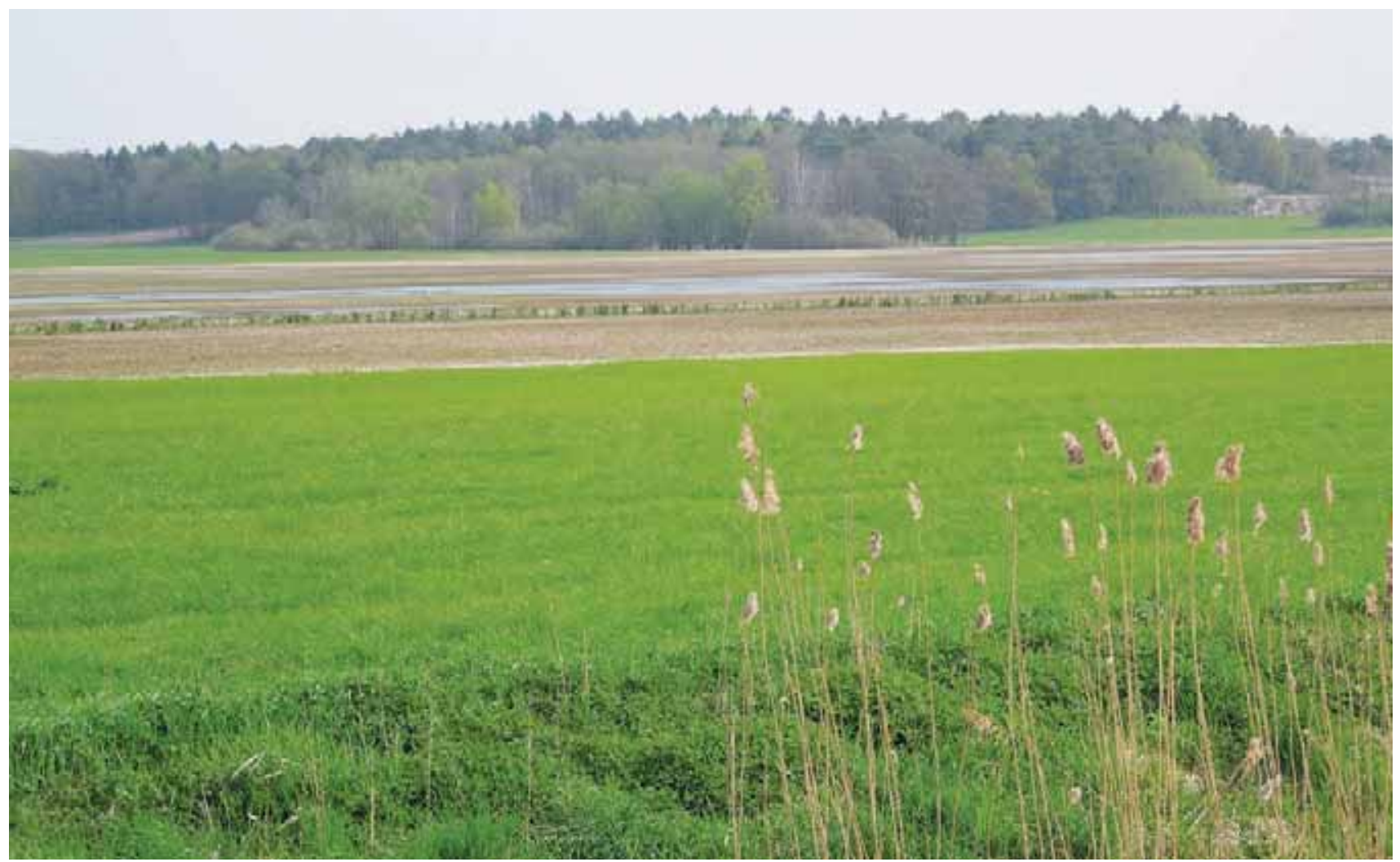

Abb. 404: Die großflächigen Überflutungen von Flächen bei Wattmannshagen im Bereich des Aalbaches östlich vom Warinsee sind regelmäßig genutzte Nahrungshabitatflächen von durchziehenden Limikolenarten - 07.05.2013. Foto: F. Loose. 


\section{Verwendete Abkürzungen}

\begin{tabular}{|c|c|c|c|}
\hline $\mathrm{ABF}$ & Arbeiter und BauernFakultät & LJV & Landesjagdverband \\
\hline $\mathrm{ABM}$ & Arbeitsbeschaffungsmaßnahme & LPG $(\mathrm{P})$ & Landwirtschaftliche Produktions- \\
\hline $\mathrm{ACZ}$ & Agro-Chemisches-Zentrum & & genossenschaft Pflanzenproduktion \\
\hline Ad./ad. & Altvogel, adult & LPG $(\mathrm{T})$ & Landwirtschaftliche Produktions- \\
\hline ADEBAR & Atlas Deutscher Brutvogelarten & & genossenschaft Tierproduktion \\
\hline $\mathrm{AG}$ & Arbeitsgemeinschaft, Arbeitsgruppe & LUNG & Landesamt für Umwelt, Naturschutz und \\
\hline \multirow[t]{2}{*}{ AKSAT } & Arbeitskreis zum Schutz der vom & & Geologie (vorher LAUN) \\
\hline & Aussterben bedrohten Tierarten & MTB, MTB/Q & Messtischblatt, Messtischblattquadrant \\
\hline AWG & Allgemeine Wohnungsgenossenschaft & NABU $(\mathrm{KV} / \mathrm{OG})$ & Naturschutzbund Deutschland \\
\hline BFA & Bezirksfachausschuss & & (Kreisverband/Ortsgruppe) \\
\hline BG & Beringergemeinschaft & NP & Nationalpark \\
\hline $\mathrm{BP}$ & Brutpaar(e) & NSG & Naturschutzgebiet \\
\hline CIR & Luftbilder in Infrarot & NUP & Natur und Umweltpark Güstrow \\
\hline DDA & Dachverband Deutscher Avifaunisten & & (heute: Wildpark Güstrow) \\
\hline \multirow[t]{3}{*}{ DDT } & Dichlordiphenyltrichlorethan & NVA & Nationale Volksarmee der DDR \\
\hline & (in Insektiziden eingesetztes & POS & Polytechnische Oberschule \\
\hline & Kontakt- und Fraßgift) & RABS & Regionale Arbeitsförderungs-, \\
\hline DJV & Deutscher Jagdverband & & Beschäftigungs- und Struktur- \\
\hline DRA & Deutsches Rundfunkarchiv & & entwicklungsgesellschaft \\
\hline EOS & $\begin{array}{l}\text { Erweiterte Oberschule } \\
\text { (heute: Gymnasium) }\end{array}$ & StAUN & $\begin{array}{l}\text { Staatliches Amt für Umwelt und Natur } \\
\text { (später StALU) }\end{array}$ \\
\hline FFH & FloraFaunaHabitat & StALUMM & Staatliches Amt für Landwirtschaft und \\
\hline FG & Fachgruppe & & Umwelt Mittleres Mecklenburg \\
\hline FGL & Fängling & StFB & Staatlicher Forstwirtschaftsbetrieb \\
\hline FND & Flächennaturdenkmal & SPA & Special Protection Area \\
\hline GNU & Gesellschaft für Natur und Umwelt & & (EU-Vogelschutzgebiet) \\
\hline $\mathrm{HPa}$ & Horstpaare allgemein & ORMV & Ornithologischer Rundbrief \\
\hline $\mathrm{HPm}$ & Horstpaare mit Jungen & & Mecklenburg-Vorpommern \\
\hline HPo & Horstpaare ohne Junge & OAMV & Ornithologische Arbeitsgemeinschaft \\
\hline \multirow[t]{2}{*}{ ILN } & Institut für Landschaftsforschung und & & Mecklenburg-Vorpommern \\
\hline & Naturschutz & UNB & Untere Naturschutzbehörde \\
\hline \multirow[t]{2}{*}{$\mathrm{JB}$} & Jahresbericht(e) der Fachgruppe & VD & Vertrauliche Dienstsache \\
\hline & Ornithologie und Naturschutz Güstrow & VEB & Volkseigener Betrieb \\
\hline Juv./ juv. & Jungvogel, juvenil & VEG & Volkseigenes Gut \\
\hline $\mathrm{KB}$ & Kulturbund der DDR & WEMAG & Energieversorgungsunternehmen \\
\hline KNB & Kreisnaturschutzbeauftragter & WGG & Wohnungsgesellschaft Güstrow \\
\hline KOS & NSG Krakower Obersee & WWD & Wasserwirtschaftsdirektion \\
\hline KVHS & Kreisvolkshochschule & & (hier: Küste - mit Sitz in Schwerin) \\
\hline
\end{tabular}




\section{Literatur - Bezugnahme zu den einzelnen Beiträgen}

BECKMANN, H. et al. (2006): Zum aktuellen Zustand der Entomofauna des Naturschutzgebietes „Breeser See“ (Lohmen. LandkreisGüstrow, MecklenburgVorpommern). Arch. Freunde Naturg. Mecklenb. XLV: 55-72.

BLOTZHEIM, Urs N. Glutz von (Hrsg.): Handbuch der Vögel Mitteleuropas“, Band 10/1: Kapitel Haubenlerche, 144186.

BLUM, J., (1888): Die Kreuzotter und ihre Verbreitung in Deutschland. Abhandlungen der Senckenbergischen Naturforschenden Gesellschaft, Band 135).

BRINGMANN, H. D. (2008): Die Bockkäfer (Coleoptera, Cerambycidae) des NSG Breesener See, Virgo, Mitteilungsblatt des Entomologischen Vereins Mecklenburg, 11/1: 80-85.

DETMERS, E. (1912): Ein Beitrag zur Kenntnis der Verbreitung einiger jagdlich wichtiger Brutvögel in Deutschland. Veröff. Inst. Jagdkd. Neudamm 1: 5.

DWENGER, (1995): Die Dohle. Die Neue Brehmbücherei. Reprint.

EICHSTÄDT, W., W. SCHELLER, D. SELLIN, W. STARKE \& K. D. STEGEMANN (2006): Atlas der Brutvögel in Mecklenburg-Vorpommern. Steffen Verlag, Friedland.

EMMERICH, R. und F. EMMERICH, H. POMMERANZ, J. SCHMIDT: Dokumentation der Erfolgskontrollen von Artenschutzmaßnahmen für die Dohle in Nordmecklenburg/Nordvorpommern 1994-2008. NABU.

ERHARDT, A. (1933): Die Glatte Natter oder Schlingnatter (Coronella austriaca austriaca Laur.) in Mecklenburg. - Archiv des Vereins der Freunde der Naturgeschichte in Mecklenburg, N. F. 8: 27-30.

GEHLHAR, U. (2001): Außergewöhnlich starker Durchzug des Bruchwasserläufers Tringa glareola an den Absetzteichen der Zuckerfabrik Güstrow im Jahr 2000. Ornithologischer Rundbrief für MecklenburgVorpommern 43: 71-75.

ILN Halle, (1964): Die Naturschutzgebiete der Deutschen Demokratischen Republik, Hrsg. Akad. d. Landwirtschaftsw. 2. erw. und ergänz. Auflage.
JUEG, U. (1997): Pupilla muscorum (Linneus 1758) im NSG Klädener Plage - Ein Beitrag zur Ökologie, Gehäusemorphologie und Systematik der Art. Mallakologische Abhandlungen 18: 277-285.

KOOP, K. H. \& S. RETTICH (2014): Sammel und Rastregion Mecklenburgische Schweiz in: Kraniche in Mecklenburg-Vorpommern, Ornithologischer Rundbrief für Mecklenburg-Vorpommern 48, Sonderheft 1: 122-125.

KUHK, R. (1939): Die Vögel Mecklenburgs. Güstrow.

LABES, R. \& W. KÖHLER (1984): Beitrag zur Säugetierfauna des Bützow-Güstrower Beckens (Mecklenburg). Säugetierkundliche Informationen 8: 167-174.

LEHMBÄCKER, H. (1998): Zwei Sterne auf dem Wasser funkeln - Mit Uwe Johnson auf dem Großen Werder, 1952. JohnsonJahrbuch Band 5/1998.

LOOSE, J. (1986): Zur Vogelwelt des Naturschutzgebietes „Breeser See“ (Bezirk Schwerin) Ornithologischer Rundbrief Mecklenburgs 29: 60-68.

LOOSE, J. (1990): Nachtrag zur Vogelwelt des Naturschutzgebietes „Breeser See“ (Bezirk Schwerin) Ornithologischer Rundbrief für Mecklenburg-Vorpommern 33: 5459 .

LOOSE, J., MARTIN, A. \& W. NEUBAUER (1992): Landschaftspflege und Naturschutz im Raum Güstrow. $36 \mathrm{~S}$.

LOOSE, J. (1998): Ansiedlung von Flussseeschwalben Sterna hirundo auf Kunstinseln - Ergebnisbericht aus dem Binnenland von Mecklenburg-Vorpommern. Vogelwelt 119: 253-258.

LUNG, Hrsg. (2008): Verbreitungsatlas der Heuschrecken Mecklenburg-Vorpommerns

MARTIN, A., KOOP, K. H. \& W. NEUBAUER (1989): Natur und Naturschutz im Kreis Güstrow (Teil 1). Werbebroschüre. $23 \mathrm{~S}$.

MARTIN, A. (2013): Brutbiologische Daten im Rahmen der Beringung des Sperbers Accipiter nisus im Raum Güstrow 19852010.Ornithologischer Rundbrief für Mecklenburg-Vorpommern 47: 205-218. 
MEWES, W., J. Loose J. \& D. SEEMANN (2014): Sammelund Rastregion Mittelmecklenburgische Seen, Ornithologischer Rundbrief für Mecklenburg-Vorpommern 48, Sonderheft 1: 104114.

MINISTERIUM für Landwirtschaft, Umwelt und Verbraucherschutz Mecklenburg-Vorpommern (Hrsg.): Rote Liste der Brutvögel Mecklenburg-Vorpommerns. 3. Fassung, Juli 2014.

MONTSCHKO, M. (2015): Über das Leben in und mit einer Arbeitsgemeinschaft an der ehemaligen POS Mühl Rosin - Beiträge zur Geschichte der Gemeinde Mühl Rosin. H 13, 2015.

NEUBAUER, W. \& G. STRACHE (1982): Bestandsentwicklung des Weißstorches im Kreis Güstrow. Ornithologischer Rundbrief Mecklenburgs 25: 10-16.

NEUBAUER, W. \& G. STRACHE (1991): Bestandsentwicklung des Weißstorches im Kreis Güstrow. Ornithologischer Rundbrief für Mecklenburg-Vorpommern 34: 7-9.

NEUBAUER, W. (2002): Die Vögel des Naturschutzgebietes Krakower Obersee. Natur und Naturschutz in MV 36: $1-70$.

NEUBAUER, W. (2004): Die Vogelwelt des Altkreises Güstrow (Mitwirkung von J. Loose und S. Lorenz). Natur und Naturschutz in MV; Band XXXIX, 1-176.

NEUBAUER, W. (2012): 80 Jahre Naturschutzgebiet „Krakower Obersee“ Rückblick und Zustand Naturschutzarbeit in MV 55: 53-62.

PLATH, L. (1989): Bestandsdichte und Verbreitung der Dohle in den drei Nordbezirken der DDR. Falke 36: 143-147.
ROWINSKY, V. (2013): Entwicklung und Erhaltung eines extrem tiefgründigen Kesselmoores im Naturschutzgebiet „Schlichtes Moor“ (Mecklenburg-Vorpommern). TELMA 43: 83-106.

SCHMIDT, K. (1987): Mehr Beachtung und Schutz den Brutdohlen Mitteleuropas. Falke 34: 151-159.

SIEMSSEN, A. C. (1794): Handbuch zur systematischen Kenntnis der Mecklenburgischen Land und Wasservögel. Rostock und Leipzig.

UMWELTMINISTERIUM Mecklenburg-Vorpommern Hrsg. (2003): Die Naturschutzgebiete in Mecklenburg-Vorpommern. Demmler Verlag.

VÖKLER, F. (2014): Zweiter Brutvogelatlas des Landes Mecklenburg-Vorpommern, Greifswald.

WEINITSCHKE, H. (Hrsg.) (1980): Handbuch der Naturschutzgebiete der Deutschen Demokratischen Republik, ILN Halle, 2. überarbeitete Auflage.

WENDELN, H. \& P. BECKER (1998): Populationsbiologische Untersuchungen an einer Kolonie der Flussseeschwalbe Sterna hirundo, Vogelwelt 119: 209-213.

WÜSTNEI, C.\& G. CLODIUS (1902): Der weiße Storch in Mecklenburg. Eine Statistik seiner Niststätten im Jahre 1901. Arch. Nat. Meckl 56.

ZANDER, H. D. F. (1862) Systematische Übersicht der Vögel Mecklenburgs. Arch. Nat. Meckl 15. 


\section{Anhang 1}

\section{Mitgliederverzeichnis der FG-Ornithologie und Naturschutz Güstrow}

Die nachfolgend aufgeführten 72 Personen werden unabhängig der Dauer ihres Erscheinens zu den Treffen der Fachgruppe in Güstrow als Mitglieder angesehen. Darunter finden sich auch ehemalige Schüler aus den Arbeitsgemeinschaften von Kurt Pohlmann (Mühl Rosin) und Wolfgang Neubauer (Krakow am See), die sich durch besonderes Interesse hervorhoben und auch später nach der Schüler-AG aktiv blieben.

Einige der aufgeführten Mitglieder verließen die Fachgruppe durch familiär- oder arbeitsbedingten Umzug in andere Gebiete, andere waren nur während des Arbeitsoder Studiumsaufenthalt in Güstrow (z.B. am Pädagogischen Institut, später der Pädagogischen Hochschule) in der FG tätig, wieder andere blieben nach der politischen Wende aus verschiedenen Gründen fern.
$\mathrm{Zu}$ den FG-Versammlungen kamen regelmäßig zwischen 12 und 25 Mitglieder. Die Aktivitäten der einzelnen Mitglieder waren stets weit gestaffelt.

Unabhängig einer Zugehörigkeit zu Organisationen (Kulturbund, NABU, OAMV u.a.) waren der Fachgruppe auch stets solche Personen willkommen, die Interesse zum Vogel- und Naturschutz hatten, sich aber das ornithologische Wissen erst noch aneignen mussten.

Jene Personen, die nur wenige Male zu den FG-Abenden erschienen, dann aber wegblieben, weil sie sich hier vermutlich nicht angesprochen fühlten, werden in der Mitgliederliste nicht aufgeführt.

Zum FG-Stamm gehörten:

\begin{tabular}{|c|c|}
\hline Anderlik, Fritz - (And) & Güstrow \\
\hline Becker, Reinhard $(\dagger)-(\mathrm{Be})$ & Güstrow \\
\hline Bischoff, Reinhard - (Bi) & Raden \\
\hline Böhlke, Manfred & Mühl Rosin \\
\hline Bomke, Angelika & Laage \\
\hline Bomke, Dr. Eckart - (Bo) & Laage \\
\hline Bösel, Volker - (Bö) & Diekhof \\
\hline Brüshaver, Willi - (Br) & Bölkow \\
\hline Busching, Wolf-Dieter $(\dagger)$ & Weitendorf \\
\hline Bußmann, Jörg - (Bu) & Parum \\
\hline Czech, Jürgen & Güstrow \\
\hline Dauber, Klaus $(\dagger)-($ Daub) & Güstrow \\
\hline Daubner, Lothar - (Dau) & Güstrow/Schaber. \\
\hline Dobslaw, Christian - (Db) & Güstrow \\
\hline Eggers, Claus & Laage \\
\hline Eggers, Erika & Laage \\
\hline Fritsche*, Maren - (Fri) & Güstrow \\
\hline Gehlhar, Uwe - (Ge) & Güstrow \\
\hline Hamel, Norbert - (Ha) & Kirch Rosin \\
\hline Hauff, Peter & Güstrow \\
\hline Hertkorn, Andreas - (Her) & Güstrow \\
\hline Holst, Fritz & Güstrow \\
\hline Jahr, Harry & Mühl Rosin \\
\hline Jänicke, Heike - (Jä) & Güstrow \\
\hline Jessen, Otto $(\dagger)$ & Güstrow \\
\hline Kaatz, Reinhard & Bölkow \\
\hline Kainert, Frank & Dobbin \\
\hline Kirschnick, Klaus & Güstrow \\
\hline Köhler, Wolfgang - (Kö) & Güstrow \\
\hline
\end{tabular}

\begin{tabular}{|c|c|}
\hline Koop, Karl-Heinz - (Ko) & Krakow am See \\
\hline Knoche-Ulbricht, Ulrike - (Kn) & Qualitz \\
\hline Kretschmann, Adolf $(\dagger)$ & Groß Upahl \\
\hline Kusch, Herald - (Kuc) & Güstrow \\
\hline Larsson, Käthe & Laage \\
\hline Larsson, Otto & Laage \\
\hline Lemke, Martin - (Le) & Kuhs \\
\hline Lingsminat, Klaus - (Li) & Güstrow \\
\hline Loose, Joachim - (Lo) & Güstrow \\
\hline Lorenz, Sebastian - (Lor) & Krakow am See \\
\hline Marczak, Torsten & Bützow \\
\hline Martin, Angela - (Ma) & Güstrow \\
\hline Meder-Trost, Beate - (Me) & Mühl Rosin \\
\hline Mevius, Jürgen - (Me) & Mühl Rosin \\
\hline Mevius, Heinz & Mühl Rosin \\
\hline Montschko, Manfred - (Mo) & Güstrow \\
\hline Müller, HansGeorg - (Mr) & Güstrow \\
\hline Neubauer, Wolfgang $(\dagger)-(\mathrm{Neu})$ & Krakow am See \\
\hline Petzel, Siegfried - (Pe) & Güstrow \\
\hline Pohlmann, Kurt $(\dagger)-(\mathrm{Pm})$ & Mühl Rosin \\
\hline Rollwitz, Werner - (Rollw) & Gülzow \\
\hline Richter, Helmut - (HR) & Güstrow \\
\hline Ritter, Gerit - (Ri) & Dobbin \\
\hline Schaugstat, Reinhard - (Schau) & Güstrow \\
\hline Schilf, Andreas & Güstrow \\
\hline Schilling, Barbara & Rachow \\
\hline Schlüter, Eckhard - (Schl) & Laage \\
\hline Schneider, Matthias & Lüssow \\
\hline Schult, Ingolf - (Schu) & Mühl Rosin \\
\hline
\end{tabular}

* Fritsche heute verheiratet - Polzin (Pol) 


$\begin{array}{llll}\text { Schulze, Silke }(\dagger)-(\mathrm{Sch}) & \text { Klein Grabow } & \text { Uhlig, Peter } & \text { Güstrow } \\ \text { Suchowski, Herbert } & \text { Kirch Rosin } & \text { Ulbricht, Joachim }-(\mathrm{Ul}) & \text { Qualitz } \\ \text { Strache, Georg }(\dagger)-(\mathrm{Str}) & \text { Güstrow } & \text { Vick, Karsten } & \text { Lalendorf } \\ \text { Thamm, Uwe }(\dagger)-(\mathrm{Th}) & \text { Güstrow } & \text { Völkel, Marga }-(\text { Vö) } & \text { Güstrow/Heidberg } \\ \text { Thiel, Steffen }-(\text { Thi }) & \text { Rothspalk } & \text { Wenk, Andreas }-(\mathrm{AW}) & \text { Krakow am See } \\ \text { Thiele, Volker } & \text { Gülzow } & \text { Wenk, Roland }-(\mathrm{RW}) & \text { Krakow am See } \\ \text { Trost, Guntram - (Tro) } & \text { Mühl Rosin } & \text { Wiechert, Remo }-(\text { Wie }) & \text { Güstrow }\end{array}$

Personen mit einem Namenskürzel haben Daten in die umlaufende FG-Kartei eingetragen.

Der nachfolgende Personenkreis war mehrfach, aber nur über kurze Zeit bei den FG-Abenden oder Exkursionen anwesend:

Ficker, Gabriel, Kurt Gierke, Heinz Goldberg, Henke, Hoffmann, Heino Holst, Dieter Hutte, Malicki, Karl-Heinz Musche, M. Nehls, H. Nauendorf, Palleit, Hubert Polomski, Jörg Röhring, Markus Rudolf sowie Gisela Klingbeil und Elke Zielonka.

(Die beiden Letzteren sind ständige Mitglieder in der Botanik-AG geworden.)
Die in der von Kurt Pohlmann geleiteten Arbeitsgemeinschaft Vogelkunde tätigen Schüler

Hannes Köhler, Bernd Meyer, Gerd-Rüdiger Möller, R. Otto, Walter Schneider, Uwe Steffanowski

lieferten in dieser Gemeinschaft Beobachtungsdaten, fanden aber leider nicht wie einige andere aus der Gruppe den dauerhaften Weg in die Fachgruppenarbeit.

\section{Wie es einmal anfing:}

Kurt Pohlmann stellte im Jahresbericht der Fachgruppe Nr. 3 für 1970 dar, woher die Beobachtungsdaten stammten. 24 Mitglieder der Fachgruppe und 9 Freunde aus anderen Kreisen teilten die Daten im genannten Umfange mit.

$\begin{array}{lr}\text { Kurt Pohlmann } & 61 \\ \text { Dr. Schilf } & 3 \\ \text { Wolfgang Neubauer } & 46 \\ \text { Siegmar Müller } & 2 \\ \text { Georg Strache } & 44 \\ \text { Freund Eske } & 2 \\ \text { Jürgen Mewius } & 31 \\ \text { Freund Palleit } & 2 \\ \text { Wolfgang Köhler } & 21 \\ \text { Herr Grotmann } & 1 \\ \text { Manfred Montschko } & 16 \\ \text { Herr Krägenow } & 1 \\ \text { Norbert Hamel } & 15 \\ \text { Herr Vogler } & 1 \\ \text { Lothar Daubner } & 12 \\ \text { Herr Winkelmann } & 1 \\ \text { Bernd Meyer } & 12\end{array}$

$\begin{array}{ll}\text { Freund Walter } & 1 \\ \text { Reinhard Becker } & 9 \\ \text { Ingolf Schult } & 6 \\ \text { Joachim Malycki } & 5 \\ \text { Gerd Möller } & 5 \\ \text { Willi Brüshaver } & 4 \\ \text { Christian Dobslaw } & 4 \\ \text { Manfred Bölke } & 3 \\ \text { Wolfgang Fritsche } & 3 \\ \text { Herr Held } & 3 \\ \text { Hubert Polomski } & 3 \\ \text { Heino Holst } & 2 \\ \text { Roland Otto } & 2 \\ \text { Peter Hauff } & 1 \\ \text { Herr Jänicke } & 1 \\ \text { Walter Schneider } & 1\end{array}$

Mit 324 Datensätzen waren die eingetragenen Beobachtungen 1970 noch recht überschaubar.

Für den Jahresbericht Nr. 47/2014 musste eine Auswahl aus insgesamt 3.242 Datensätzen der in den FG-Karteikarten von den Mitgliedern eingetragenen Beobachtungen für die Rubrik „Bemerkenswerte Beobachtungen“ getroffen werden. 


\section{Anhang 2}

\section{Literaturverzeichnis der Publikationen von FG-Mitgliedern sowie von anderen Autoren, die besondere von der Fachgruppe betreute Gebiete und Arten behandeln}

(Die aufgeführten Literaturquellen berücksichtigen nur auf unseren Wirkungskreis bezogene Abhandlungen. Insbesondere Publikationen von fremden Autoren wurden nur aufgenommen, wenn der Inhalt unsere Arbeit berührte und wir Kenntnis erlangten.)

BECKMANN, H. et al. (2006): Zum aktuellen Zustand der Entomofauna des Naturschutzgebietes „Breeser See“ (Lohmen, Landkreis Güstrow, MecklenburgVorpommern), Arch. Freunde Naturgeschichte Mecklenb. XLV, 55-72.

BINNER, U., KÖHLER, W. \& R. LABES (1989): Zur Situation des Fischotters (Lutra lutra) in Westmecklenburg (Bezirk Schwerin). Populationsökologie marderartiger Säugetiere. Wiss. Beitr. Univ. Halle 37: 89-110.

BIOM (2014): Abschlussbericht zu Wasservogelzählungen in der Zug- und Überwinterungssaison 2012/2013 (u. a.), erstellt im Auftrag des LUNG

BRINGMANN, H. D. (2008): Die Bockkäfer (Coleoptera, Cerambycidae) des NSG Breesener See, Virgo, Mitteilungsblatt des Entomologischen Vereins Mecklenburg, 11/1: 80-85.

EICHSTÄDT, W., W. SCHELLER, D. SELLIN, W. STARKE \& K. D. STEGEMANN (2006): Atlas der Brutvögel in Mecklenburg-Vorpommern. Steffen Verlag, Friedland

EGGERS, H. \& W. NEUBAUER (1989): Durchzug und Rast des Zwergschwans (Cygnus columbianus) in der DDR. Beitr. Vogelk. 35: 133-140.

EMMERICH, R. und F. EMMERICH, H. POMMERANZ, J. SCHMIDT: Dokumentation der Erfolgskontrollen von Artenschutzmaßnahmen für die Dohle in Nordmecklenburg/Nordvorpommern 1994-2008. NABU

ERHARDT, A. (1933): Die Glatte Natter oder Schlingnatter (Coronella austriaca austriaca Laur.) in Mecklenburg. - Archiv des Vereins der Freunde der Naturgeschichte in Mecklenburg, N. F. 8: 27-30

GEHLHAR, U. (1993): Untersuchungen zur Nahrungsökologie von Reiherenten (Aytya fuligula) am Mauserplatz Krakower Obersee. Unveröffentlichte Diplomarbeit am Institut für Forstbotanik und Forstzoologie Tharandt.
GEHLHAR, U. (2001): Außergewöhnlich starker Durchzug des Bruchwasserläufers Tringa glareola an den Absetzteichen der Zuckerfabrik Güstrow im Jahr 2000. Ornithologischer Rundbrief für MecklenburgVorpommern 43: 71-75.

HAUFF, P., P. ILLMANN \& W. NEUBAUER (1983): Baumbruten der Graugans in Mecklenburg. Der Falke 30: $200-201$.

HAUFF, P., KÖHLER, W. \& MEWES, W. (1986) : Zur Bestandesentwicklung einiger vom Aussterben bedrohter Vogelarten im Bezirk Schwerin. Naturschutzarbeit in Mecklenburg 29: 71-76.

HAUFF, P. \& KÖHLER, W. (1991a): Der Seeadler im Bezirk Schwerin des Landes Mecklenburg-Vorpommern. Falke 38: 157-159.

HAUFF, P. \& KÖHLER, W. (1991b): Der Fischadler im Bezirk Schwerin des Landes MecklenburgVorpommern. Falke 38: 196-198.

ILN Halle, (1964): Die Naturschutzgebiete der Deutschen Demokratischen Republik, Hrsg. Akad. d. Landwirtschaftsw. 2. erw. und ergänz. Auflage.

JUEG, U. (1997): Pupilla muscorum (Linneus 1758) im NSG Klädener Plage - Ein Beitrag zur Ökologie, Gehäusemorphologie und Systematik der Art. Mallakologische Abhandlungen 18: 277-285.

KAISER, K.; GERMER, S.; KÜSTER, M.; LORENZ, S.; STÜVE, P.; BENS, O. (2012a): Seespiegelschwankungen in Nordostdeutschland: Beobachtung und Rekonstruktion. System Erde (2/1): 62-67.

KAISER, K.; LORENZ, S.; GERMER, S.; JUSCHUS, O.; KÜSTER, M.; LIBRA, J.; BENS, O.; HÜTTL, R. F. (2012b): Late Quaternary evolution of rivers, lakes and peatlands in northeast Germany reflecting past climatic and human impact - an overview. - E\&G Quaternary Science Journal 61 (2): 103-132.

KNEIS, P. \& W. NEUBAUER (1984): Nachweis einer Breitflügelfledermaus (Eptesicus serotinus) auf Hiddensee. Säugetierkundliche Informationen 2: 200. 
KÖHLER, W. (1991a): Zur Populationsdynamik des Fischadlers (Pandion haliaetus L.) im Bezirk Schwerin. Populationsökologie Greifvögel und Eulenarten 2: 193-197.

KÖHLER, W. (1991b): Der Fischadler in Mecklenburg/ Vorpommern. Trophäenkatalog des LJV.

KÖHLER, W. (1995): Der Brutbestand des Fischadlers Pandion haliaetos in Mecklenburg-Vorpommern. Vogelwelt 116: 177-179.

KÖHLER, W. (1996): Schutz des Seeadlers Haliaetus albicilla in der Forstwirtschaft in MecklenburgVorpommern. In: Eagle Studies. Herausgegeben von B. U. Meyburg \& R. D. Chancellor. Berlin, London, Paris: 129-134.

KÖHLER, W. (1997): Das Wiederansiedlungsprojekt „Wanderfalke“. Ornithologischer Rundbrief für Mecklenburg-Vorpommern 39: 15-16.

KÖHLER, W. (1998): Nachruf für Reinhard Becker Ornithologischer Rundbrief für Mecklenburg-Vorpommern 40: 94.

KÖHLER, W. (1999a): Bericht zur Wanderfalken-Auswilderung in Mecklenburg-Vorpommern. Greifvögel und Falknerei: 42-43.

KÖHLER, W. (1999b): Wanderfalke. Schriftenreihe des Landesamtes für Umwelt, Naturschutz und Geologie/Heft 1, 49-51.

KÖHLER, W. (2000): Bericht zur Wanderfalken-Auswilderung in Mecklenburg-Vorpommern 2000. Greifvögel und Falknerei: 80-82.

KÖHLER, W.(2002): Bericht zur Wanderfalken-Auswilderung in Mecklenburg-Vorpommern 2001. Greifvögel und Falknerei 2001/2002: 118-123.

KÖHLER, W. (2003): Jahresbericht 2003 zur Auswilderung und zum Brutverlauf des Wanderfalken in Mecklenburg-Vorpommern. Greifvögel und Falknerei: 75-77.

KÖHLER, W. (2004): Jahresbericht 2004 zur Auswilderung und zum Brutverlauf der Wanderfalken in Mecklenburg-Vorpommern. Greifvögel und Falknerei: 63-68.

KÖHLER, W.(2006a): Auswilderung und Brutverlauf des Wanderfalken in Mecklenburg-Vorpommern 2005. Greifvögel und Falknerei 2005/2006: 105-107.

KÖHLER, W.(2006b): Auswilderung und Brutverlauf des Wanderfalken in Mecklenburg-Vorpommern 2006. Greifvögel und Falknerei 2005/2006: 128-130.
KÖHLER, W. (2006c): Fischadler - Pandion haliaetus. 122-123. In EICHSTÄDT et al. (Bearb.):Atlas der Brutvögel in Mecklenburg-Vorpommern. Steffen Verlag, Friedland.

KÖHLER, W. (2007): Auswilderung und Brutverlauf des Wanderfalken in Mecklenburg-Vorpommern 2007. Greifvögel und Falknerei: 51-54.

KÖHLER, W.(2011): Ungewöhnliche Nistplatzwahleines Wanderfalken. Naturschutzarbeit in M-V 54:69.

KUHK, R. (1939): Die Vögel Mecklenburgs. Güstrow.

KUHK, R. (1966): Vogelbeobachtungen aus dem Jahre 1939 am Krakower See in Mecklenburg. Naturschutzarb. in Mecklenburg. 9: 4-5.

LABES, R. \& W. KÖHLER (1984): Beitrag zur Säugetierfauna des BützowGüstrower Beckens (Mecklenburg). Säugetierkundliche Informationen 2: 167-174.

LABES, R. \& W. KÖHLER, W. (1987): Zum Vorkommen der Fledermäuse im Bezirk Schwerin - ein Beitrag zu Fledermausforschung und -schutz. Nyctalus (N. F.) 2: 285-308.

LAMPE, R.; LORENZ, S. (Hrsg.) (2010): Eiszeitlandschaften in Mecklenburg-Vorpommern. - Exkursionsführer zur 35.Hauptversammlung der Deutschen Quartärvereinigung. Greifswald, 164 S. (doi 10.3285/g0005).

LEHMBÄCKER, H. (1998): Zwei Sterne auf dem Wasser funkeln - Mit Uwe Johnson auf dem Großen Werder, 1952. JohnsonJahrbuch Band 5/1998.

LOOSE, J. (1986): Zur Vogelwelt des Naturschutzgebietes „Breeser See“ (Bezirk Schwerin) Ornithologischer Rundbrief Mecklenburgs 29: 60-68.

LOOSE, J. (1990): Nachtrag zur Vogelwelt des Naturschutzgebietes „Breeser See“ (Bezirk Schwerin) Ornithologischer Rundbrief für Mecklenburg-Vorpommern 33: $54-59$.

LOOSE, J. (1991): Spätsommer/Herbstsammel- und -rastplätze der Graugans im Kreis Güstrow Ornithologischer Rundbrief für Mecklenburg-Vorpommern 34: 10-18.

LOOSE, J., MARTIN, A. \& W. NEUBAUER (1992): Landschaftspflege und Naturschutz im Raum Güstrow. $36 \mathrm{~S}$.

LOOSE, J. (1993): Fischtreppe im NSG Nebel. Naturschutzarbeit in M-V 36: 14.

LOOSE, J. (1998): Ansiedlung von Flussseeschwalben Sterna hirundo auf Kunstinseln - Ergebnisbericht aus dem Binnenland von Mecklenburg-Vorpommern. Vogelwelt 119: 253-258. 
LOOSE, J. (2002): NSG Breesener See (Faltblatt), Hrsg. Umweltministerium Mecklenburg-Vorpommern.

LOOSE, J. (2003): NSG Breeser See, S. 530-531 In: Die Naturschutzgebiete in Mecklenburg-Vorpommern, Hrsg. Umweltministerium Mecklenburg-Vorpommern, Demmler Verlag.

LOOSE, J. (2006): Rohrdommel - Botaurus stellaris, 112-113, Zwergdommel Ixobrychus minutus 114-115, Bartmeise - Panurus biamicus, 318-319, In: EICHSTÄDT et al. (Bearb.): Atlas der Brutvögel in Mecklenburg-Vorpommern, Steffen Verlag, Friedland.

LOOSE, J. (2013): Zur Geschichte und Arbeit der Fachgruppe Ornithologie und Naturschutz Güstrow. Ornithologischer Rundbrief für MV 47, Sonderheft 3: 68-80.

LOOSE, J. (1983-2015): Jahresbericht zum NSG Breeser See - unveröff. Manuskript an UNB Güstrow und StAUN/StALUMM Rostock.

LOOSE, J. (2014): Zum Gedenken an Dr. Wolfgang Neubauer. Naturschutzarbeit in MV 56: 66

MARTIN, A. (1979): Die Ackerunkrautvegetation des Kreises Güstrow am Beispiel der LPG Pflanzenproduktion Diekhof. 99 S. Unveröffentlichte Diplomarbeit an der Pädagogischen Hochschule Güstrow.

MARTIN, A. (1982): Das segetale Vorkommen der Veronica-Arten im Kreis Güstrow unter besonderer Beachtung von Veronica praecox. Wiss. Z. Päd. Hochsch. MathNat. Fak. Güstrow 20 1: 31-40.

MARTIN, A. (1983): Ergebnisse des 4. Arbeitstreffens Mecklenburger Floristen vom 17.8. bis 22.8.1982 in Güstrow. Botanischer Rundbrief für den Bezirk Neubrandenburg. Neubrandenburg-Waren.14: $35-44$.

MARTIN, A. (1985a): Die Segetalvegetation in den Winterungen Raps, Wintergerste und Winterweizen auf dem Territorium des Kreises Güstrow. 190 S. Unveröffentlichte Dissertation am Päd. Institut Güstrow

MARTIN, A. (1985b): Ein Netz von Flächennaturdenkmalen im Kreis Güstrow. Naturschutzarbeit in Mecklenburg 28: 7-11.

MARTIN, A. \& W. NEUBAUER (1985): Naturschutzarbeit im Kreis Güstrow. Naturschutzarbeit in Mecklenburg 28: 53-55.

MARTIN, A. \& W. NEUBAUER (1988): Naturschutzarbeit im Kreis Güstrow. Naturschutzarbeit in Mecklenburg 31: 37.
MARTIN, A. (1992): Die Vogelwelt der Stadt Güstrow. Güstrower Jahrbuch 1993:11-12.

MARTIN, A. (1995): Die Naturschutzgebiete das Schlichte und das Zehlendorfer Moor. Das Heimatjahrbuch für den neuen Landkreis Güstrow im Jubiläumsjahr 1995: 106-109.

MARTIN, A. (1996): Seltene Bäume im Park Kuchelmiß. Das Heimatjahrbuch für den Landkreis Güstrow. Jahrgang 1996/97: 89-93.

MARTIN, A. (2001): Beringung von jungen Sperbern. immerGrün 2/2001: 13-14.

MARTIN, A. (2009): Gedanken zu unserer Publikationsreihe „Naturschutzarbeit in $M V^{“}$. Naturschutzarbeit in $\mathrm{M}-\mathrm{V}$ 52: 1-3.

MARTIN, A. (2013): Brutbiologische Daten im Rahmen der Beringung des Sperbers Accipiter nisus im Raum Güstrow 1985-2010. Ornithologischer Rundbrief für Mecklenburg-Vorpommern 47: 205-218.

MARTIN, A. (2014): Langzeituntersuchungen im NSG „Hohe Burg und Schwarzer See“. Naturschutzarbeit in MV 57, 63-74.

MARTIN, A. (2015): Sperberberingung im Güstrower Umfeld 1999-2014. immerGrün 2/2014: 22.

MONTSCHKO, M. (2015): Über das Leben in und mit einer Arbeitsgemeinschaft an der ehemaligen POS Mühl Rosin - Beiträge zur Geschichte der Gemeinde Mühl Rosin. H 13, 2015.

NEUBAUER, W. (1960): Schellenten brüten in künstlichen Nisthöhlen. Naturschutzarbeit in Mecklenburg 7: $25-26$.

NEUBAUER, W. (1962): Brut der Kolbenente am Krakower See. Falke 9: 80 .

NEUBAUER, W. (1964): Zwergammer in Mecklenburg. Falke 11: 174.

NEUBAUER, W. (1966): Das Naturschutzgebiet Krakower Obersee - ein Bericht über seine Vogelwelt. Naturschutzarbeit in Mecklenburg 9, 1966, 6-12.

NEUBAUER, W. (1968): Zum Brutvorkommen des Gänsesägers in Mecklenburg. Ornithologischer Rundbrief Mecklenburgs 8: 28-29.

NEUBAUER, W. (1969a): Zu einigen Fragen der Brutbiologie und des Verhaltens der Flussseeschwalbe (Sterna hirundo). Beitr. Vogelk. 14: 238-241.

NEUBAUER, W. (1969b): Das NSG Krakower Obersee Brutbericht 1967 und 1968. Naturschutzarbeit in Mecklenburg 12: 50. 
NEUBAUER, W. (1971a): NSG Krakower Obersee - Brutbericht 1970. Naturschutzarbeit in Mecklenburg 14: 52 .

NEUBAUER, W. (1971b): Frühjahrsdurchzug des Steinwälzers (Arenaria interpres) im Binnenland. Beitr. Vogelk. 17: 85.

NEUBAUER, W. (1971c): Zum Vorkommen der Kolbenente, Netta rufina (Pallas), in der DDR. Beitr. Vogelk. 17: 331-338.

NEUBAUER, W. (1972): Das NSG Krakower Obersee Bericht 1971. Naturschutzarbeit in Mecklenlenburg 15: 68 .

NEUBAUER, W. (1973a): Das NSG Krakower Obersee Bericht 1972. Naturschutzarbeit in Mecklenburg 16: 64-65.

NEUBAUER, W. (1973b): Ringfunde der Flussseeschwalbe (Sterna hirundo). Auspicium 5, H 4.

NEUBAUER, W. (1974a): Versuche zur Bestandshebung der Schellente (Bucephala clangula). Beitr. Vogelk. 20: 416-420.

NEUBAUER, W. (1974b): Das NSG Krakower Obersee Bericht 1973. Naturschutzarbeit in Mecklenburg 17: 6061.

NEUBAUER, W. (1975): Das NSG Krakower Obersee Bericht 1974. Naturschutzarbeit in Mecklenburg 18: 41-42.

NEUBAUER, W. (1976): Das NSG Krakower Obersee Bericht 1975. Naturschutzarbeit in Mecklenburg 19: 42-43.

NEUBAUER, W. (1977a): Das NSG Krakower Obersee Bericht 1976. Naturschutzarbeit in Mecklenburg 20: $52-54$.

NEUBAUER, W. (1977b): Artkapitel Kolbenente, Schellente, Gänsesäger in Klafs \& Stübs: Die Vogelwelt Mecklenburgs. Jena 1977: 116, 123-124, 126-127.

NEUBAUER, W: (1978a): Das NSG Krakower Obersee Bericht 1977. Naturschutzarbeit in Mecklenburg 21: 48-49.

NEUBAUER, W. (1978b): Experimentelle Untersuchungen zur akustischen und visuellen Kommunikation an der Flussseeschwalbe (Sterna hirundo) unter besonderer Berücksichtigung der Jungenaufzucht. Beitr. Vogelk. 24: 1-71.

NEUBAUER, W. (1979a): Das NSG Krakower Obersee Bericht 1978. Naturschutzarbeit in Mecklenburg 22: 73-75.
NEUBAUER, W. (1979b): Sichtbeobachtungen des Vogelzuges an der Küste der Insel Usedom. Falke 26: 168-170.

NEUBAUER, W. (1979c): Überarbeitung der Artkapitel in der Avifauna - Gänsesäger, Schellente, Kolbenente.

NEUBAUER, W. (1980a): Die Brutvorkommen des Gänsesäger (Mergus m. merganser) in der DDR. Danske fugle 32: $168-170$.

NEUBAUER, W: (1980b): Das NSG Krakower Obersee Bericht 1979. Naturschutzarbeit in Mecklenburg 23: $32-34$.

NEUBAUER, W. (1982a): Der Zug mitteleuropäischer Flussseeschwalben (Sterna hirundo) nach Ringfunden. Berichte der Vogelwarte Hiddensee 2: 59-82.

NEUBAUER, W. (1982b): Kurt Pohlmann zum Gedenken. Naturschutzarbeit in Mecklenburg 25: 45-46.

NEUBAUER, W. (1982c): Wasservogelschutz, Landwirtschaft, Fischerei und Erholungswesen im NSG Krakower Obersee (Feuchtgebiet von internationaler Bedeutung). Beitr. Vogelk 28: 35-40.

NEUBAUER, W. \& G. STRACHE (1982d): Bestandsentwicklung des Weißstorches im Kreis Güstrow. Ornithologischer Rundbrief Mecklenburgs 25: $10-16$.

NEUBAUER, W. (1983a) Der Einflug der Kanadagans im Winter 1978/79 ins Binnenland der DDR. Falke 30, 378-383.

NEUBAUER, W. (1983b): Naturschutzarbeit im Kreis Güstrow. Naturschutzarbeit in Mecklenburg26: 46.

NEUBAUER, W. (1985b): Naturschutzgebiet Krakower Obersee (Faltblatt).

NEUBAUER, W. (1986): An- und Umsiedlung mitteleuropäischer Flussseeschwalben (Sterna hirundo). Berichte der Vogelwarte Hiddensee 7: 42-46.

NEUBAUER, W. (1987): Avifauna Mecklenburgs 3.Auflage, Artkapitel Eisvogel, Flussseeschwalbe, Gänsesäger, Kolbenente, Schellente, Trauerseeschwalbe.

NEUBAUER, W (1988a): Ein Mauserplatz der Tauchenten im NSG Krakower Obersee. Ornithologischer Rundbrief Mecklenburgs 31: 25-29.

NEUBAUER, W. (1988b): Ein Beitrag zum Anatidenvorkommen des Krakower Sees. Beitr. Vogelk. 34: 253-285.

NEUBAUER, W. (1990a): Das Naturschutzgebiet Krakower Obersee - Feuchtgebiet von internationaler Bedeutung. Werbebroschüre $16 \mathrm{~S}$. 
NEUBAUER, W. (1990b): Die Nahrung nestjunger Flussseeschwalben (Sterna hirundo) am Krakower See. Acta ornithoecol. 2: 171-179.

NEUBAUER, W. \& G. STRACHE (1991): Bestandsentwicklung des Weißstorches im Kreis Güstrow. Ornithologischer Rundbrief für MecklenburgVorpommern 34: 7-9.

NEUBAUER, W. (1991): Der Brutbestand der Flussseeschwalbe 1989 in der DDR. Chlidonias 1: 7-8.

NEUBAUER, W. (1994): Das NSG Krakower Obersee Rückblick auf die letzten 14 Jahre. Naturschutzarbeit M-V 37: 41-44.

NEUBAUER, W. (1995a): Das Naturschutzgebiet „Nebeltal“. Das Heimatjahrbuch für den neuen Landkreis Güstrow im Jubiläumsjahr 1995: 32-35.

NEUBAUER, W. (1995b): Das Naturschutzgebiet „Krakower Obersee“. Das Heimatjahrbuch für den neuen Landkreis Güstrow im Jubiläumsjahr 1995: 148-152.

NEUBAUER, W. (1996a): Kleine Moore. Heimatjahrbuch Güstrow 1996/97: 218-221.

NEUBAUER, W. (1996b): Der Brutbestand der Flußseeschwalbe (Sterna hirundo) in MecklenburgVorpommern. Naturschutzarbeit in MV 39: 36-47.

NEUBAUER, W. (1996c): Weitere Baumbruten der Graugans in Mecklenburg-Vorpommern. Ornithologischer Rundbrief für Mecklenburg-Vorpommern 38: 3-5.

NEUBAUER, W. (1997): Beziehungen zwischen Paarbindung, Alter und Bruterfolg bei der Flussseeschwalbe Sterna hirundo. Berichte der Vogelwarte Hiddensee 14: 37-45.

NEUBAUER, W. (1998a): Habitatwahl der Flussseeschwalbe Sterna hirundo in Ostdeutschland. Vogelwelt 119: 169-180.

NEUBAUER, W. (1998b): Vögel im Kieswerk Langhagen. Ornithologischer Rundbrief für M-V 40: 39-45.

NEUBAUER, W. (1999a): Hans-Klose-Preis für Dr. Angela Martin. Naturschutzarbeit in M-V 42: 82.

NEUBAUER, W. (1999b): Georg Strache zum Gedenken. Naturschutzarbeit in M-V 42: 83.

NEUBAUER, W. (2002): Die Vögel des Naturschutzgebietes Krakower Obersee. Natur und Naturschutz in $\mathrm{M}-\mathrm{V}$ 36: 1-70.

NEUBAUER, W. (2004a): Brutperiode, Schlupftermin und Überlebenschancen von Flussseeschwalben Sterna hirundo in Mecklenburg. Apus 12 (Sonderheft): 76-82.
NEUBAUER, W. (2004b): Die Vogelwelt des Altkreises Güstrow (Mitwirkung von J. Loose und S. Lorenz). Natur und Naturschutz in MV; Band XXXIX, 1-176 + (16 Farbtafeln).

NEUBAUER, W. (2006): Atlas der Brutvögel in Mecklenburg-Vorpommern. Herausgeber OAMV. Steffen Verlag. Artkapitel Gänsesäger und Flussseeschwalbe.

NEUBAUER, W. (2007): Naturkundliche Wanderungen am Krakower See. Edition van Derner. 127 S.

NEUBAUER, W. (2008): Beobachtungen in einer Brutkolonie des Haubentauchers Podiceps cristatus am Krakower See. Ornithologischer Rundbrief für Mecklenburg-Vorpommern 46: 113-127.

NEUBAUER, W. (2009): Vögel im Naturschutzgebiet „Großes Holz“ Beobachtungen und Ergebnisse mehrjähriger Siedlungsdichteuntersuchungen. Naturschutzarbeit in MV 52: 5968.

NEUBAUER, W. , W. MEWES (Hsg), V. Günther, F. Hänsel, S. Lorenz (2010): Die Vogelwelt des Naturparks Nossentiner/Schwinzer Heide mit Empfehlungen für ornithologische Exkursionen. Schriftenreihe LUNG und Förderverein Naturpark Nossentiner/ Schwinzer Heide e. V. 2010.

NEUBAUER, W. (2010): Zwei 27jährige Flussseeschwalben Sterna hirundo! Berichte der Vogelwarte Hiddensee 20: 85-86.

NEUBAUER, W. (2012a): Alterszusammensetzung und altersbestimmte Leistungen von Flussseeschwalben Sterna hirundo in einer Brutkolonie in Mecklenburg. Berichte der Vogelwarte Hiddensee 21: 21-31.

NEUBAUER, W. (2012b): 80 Jahre Naturschutzgebiet „Krakower Obersee“ Rückblick und Zustand Naturschutzarbeit in MV 55: 53-62

NEUBAUER, W. (2013): Die Nahrung des Kormorans Phalacrocorax carbo der Kolonie im NSG Krakower Obersee. Unveröff. Manuskript. 7 S., Veröffentlichung p.m. geplant.

PETER, J. und M. MONSCHKO (2005): Vogelnamen; Beiträge zur Geschichte der Gemeinde Mühl Rosin, H 7, 24-28.

POHLMANN, K. (1966): Ein Beitrag zur Kenntnis der Avifauna des Kreises Güstrow unter besonderer Berücksichtigung der Seengebiete und der näheren Umgebung der Stadt Güstrow. 119 S. Unveröffentlichte Staatsexamensarbeit am Päd. Institut Güstrow. 
REUTER, F. (1938): Unveröffentlichter Bericht über die Brutvögel des Krakower Sees um 1910 an den Landesbeauftragten für Naturschutz. Naturschutzakten des Kreises Güstrow.

REUTER, F. (1939): Bericht über die im Auftrage der Landesstelle für Naturschutz in Mecklenburg am 10. und 11. Juni 1939 vorgenommene Untersuchung der Ornithologischen Verhältnisse des Naturschutzgebietes auf dem Krakower See. Unveröffentlicht in den Naturschutzakten des Kreises Güstrow.

ROWINSKY, V. (2013): Entwicklung und Erhaltung eines extrem tiefgründigen Kesselmoores im Naturschutzgebiet „Schlichtes Moor“ (MecklenburgVorpommern). TELMA 43: 83-106.

SCHULZ, W. (1963): Eisrandlagen und Seeterrassen in der Umgebung von Krakow am See in Mecklenburg. Geologie 12: 1152-1168.

SCHULZ, W. (1967): Die geologische Situation im Naturschutzgebeit „Krakower Obersee“. Naturschutzarbeit in Mecklenburg 10: 32-36.

SCHULZ, W. (1968): Spätglaziale und holozäne Spiegelschwankungen an den westlichen Oberen Seen Mecklenburgs. Archiv der Freunde der Naturgeschichte in Mecklenburg, 14: 7-43.

SCHULZ, W. (1994): Die geologische Situation im Naturpark Nossentiner/Schwinzer Heide. Naturschutzarbeit in MecklenburgVorpommem, 37 (1): 33-40.
SPIESS, H. J. und P. BOLBRINKER (2002): Monitoring submerser Makrophyten in nährstoffarmen Klarwasserseen Mecklenburg-Vorpommerns des Jahres 2001, Naturschutzarbeit in MV, 45: 1-8.

THIELE, V., D. GRÄWE \& B. BLUMRICH (2006): Fließgewässertäler in Mecklenburg-Vorpommern typologische und faunistische Aspekte (Lepidoptera), Arch. Freunde Naturgeschichte Mecklenb. XLV, 39-54.

VÖKLER, F. (2014): Zweiter Brutvogelatlas des Landes Mecklenburg-Vorpommern, Greifswald.

WOLLERT, H., P. BOLBRINKER \& J. SCHRAMM (2012): Zur Vegetation von Kessel-Regenmooren in Nordost-Mecklenburg. Arch. Freunde Naturgeschichte Mecklenb. LI: 37-63.

WÜSTNEI, C. (1899): Beiträge zur Vogelfauna Mecklenburgs. Arch. Nat. Meckl. 52: 1-35.

WÜSTNEI, C.. \& G. CLODIUS (1900): Die Vögel der Großherzogthümer Mecklenburg. Güstrow.

ZANDER, H. D. F. (1862) Systematische Übersicht der Vögel Mecklenburgs. Arch. Nat. Meckl 15. 


\section{Anhang 3}

\section{Posterserien der Fachgruppe und der NABU-Ortsgruppe Güstrow [Zu Pkt. 5.2]}

Die ersten Info-Tafeln der Fachgruppe (Abb. 405 bis 415) liefen als Wanderausstellung zum Biotop- und Artenschutz von Mitte 1987 bis Ende Juli 1991, vornehmlich durch die Schulen des Altkreises Güstrow. Die aus farbigem Prospektmaterial gestalteten Tafeln waren in den Abmessungen von 900 x $700 \mathrm{~mm}$ in der Art von Wandzeitungen hergestellt, verglast und wurden mit einem zusammenhängenden Ständersystem aufgestellt, konnten aber auch angehängt werden.
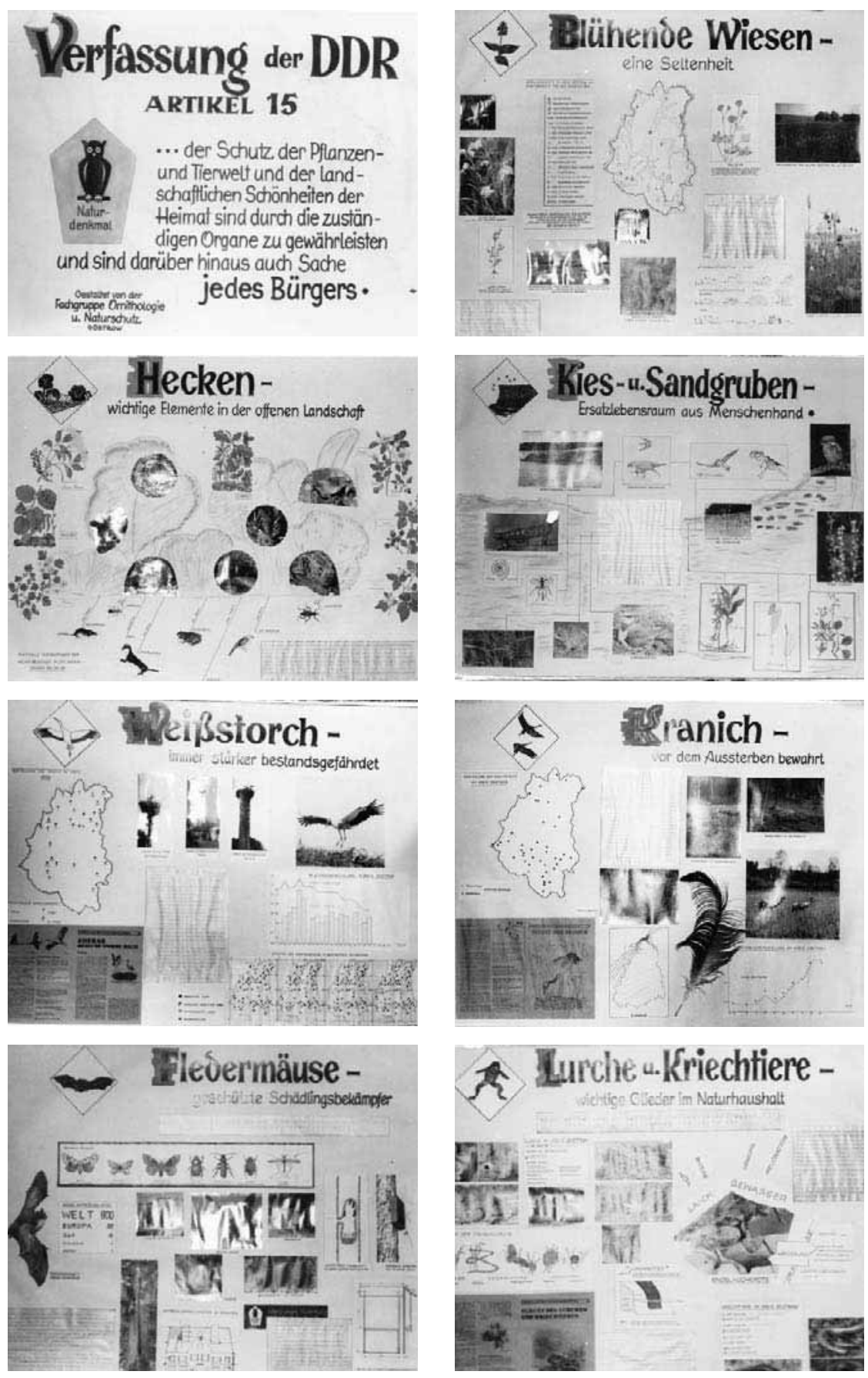

Die Reihe zum Biotop- und Artenschutz wurde bereits 1988 um sechs Tafeln über die von der Fachgruppe Ornithologie und Naturschutz Güstrow betreuten Naturschutzgebiete erweitert (Abb. 416 bis 421). Mit der Ausstellung wurde versucht, bei Schülern ein Interesse für die Natur zu wecken.
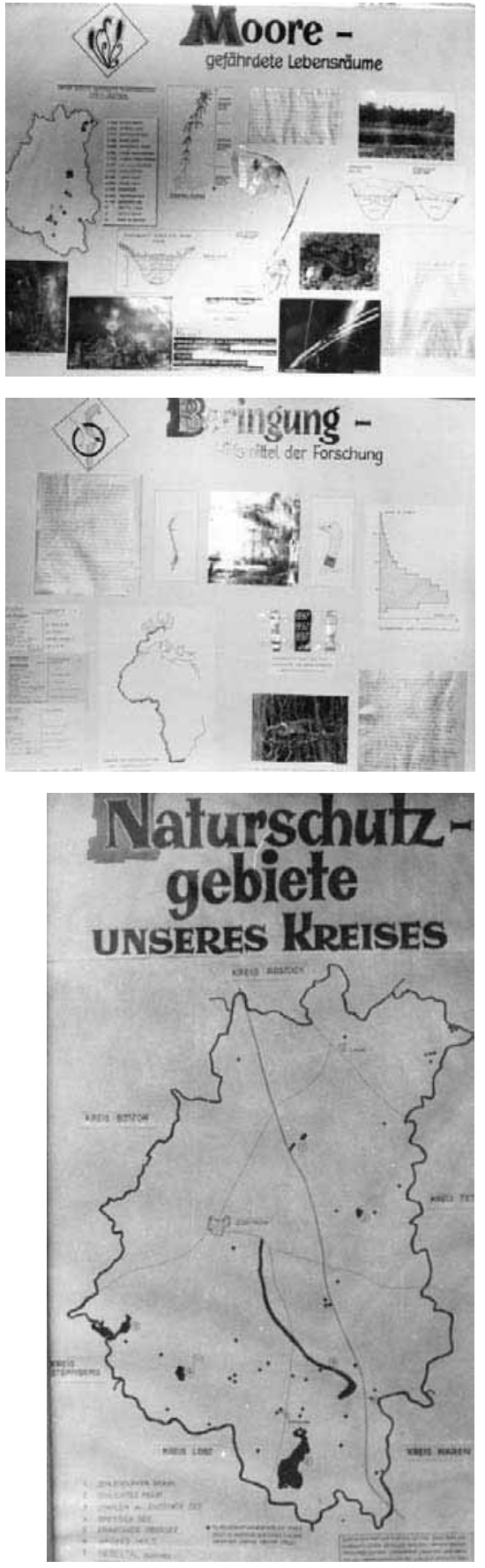

Abb. 405 bis 415 
Sehr viele Eintragungen in einem Begleitheft zur Ausstellung belegen, dass man sich in den Schulen im Unterricht mit den Themen beschäftigt hatte und die Schüler der Klassen 2 bis 9 zumindest kurzzeitig sensibilisiert werden konnten. Ab 1990 machten wir mit den Tafeln auch gleichzeitig Werbung für die neu gegründete NABU-Ortsgruppe
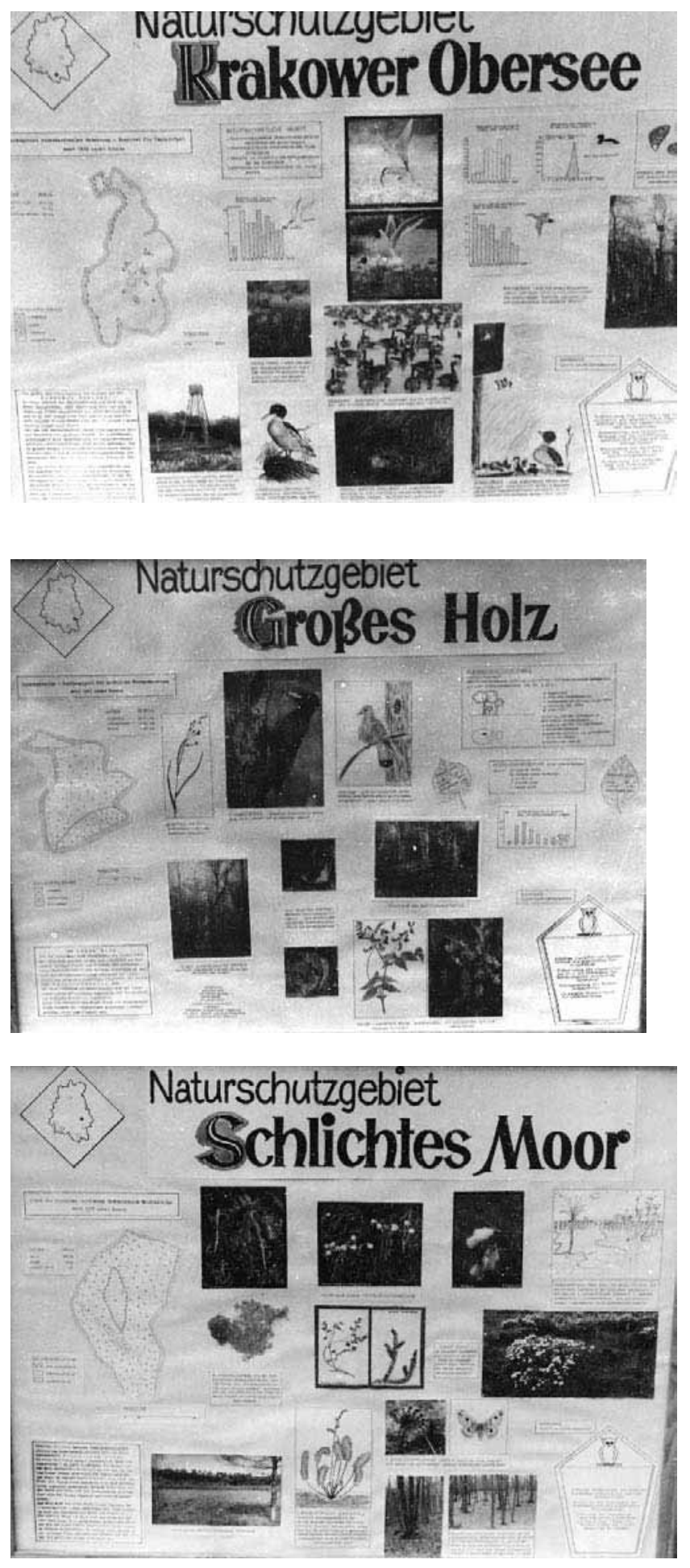

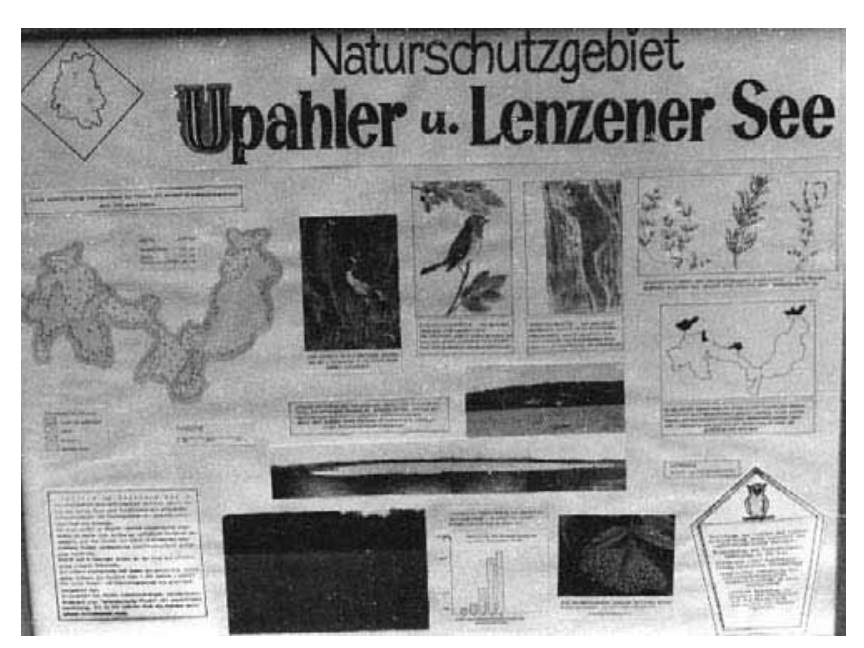

Güstrow. Die Werbung von neuen Mitgliedern brachte jedoch keine Erfolge. Auch die Hoffnung auf die Gründung von Schüler-Arbeitsgemeinschaften bei zunächst interessierten Lehrerinnen und Lehrern zerschlug sich sehr schnell wieder.
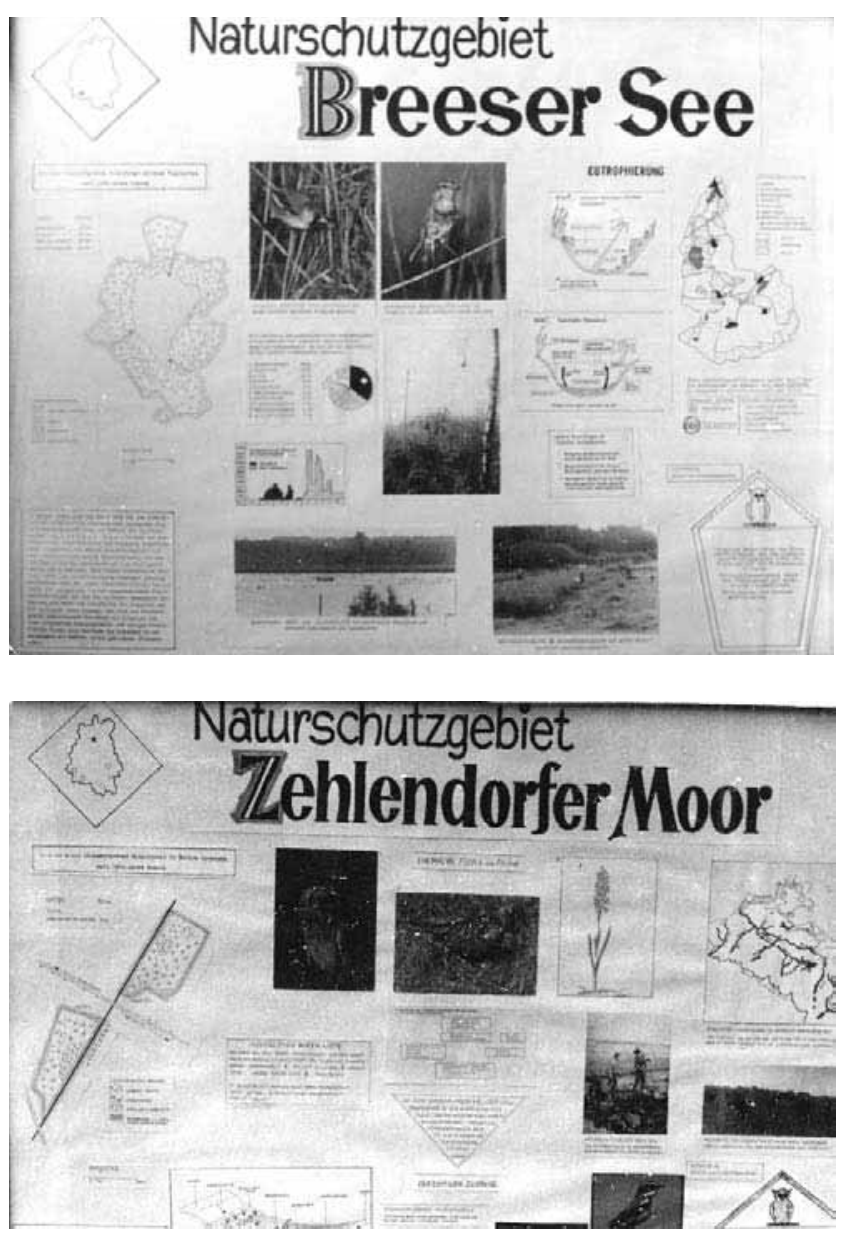

Abb. 416 bis 421 
In den Jahren 2008/2009 entstand eine recht anspruchsvolle Posterserie, mit der sich die NABU-Ortsgruppe Güstrow der Öffentlichkeit vorstellte (Abb. 422). Entsprechend der Dominanz der Fachgruppe Ornithologie und Naturschutz in der Ortsgruppe werden auf den Informationstafeln die Naturschutzgebiete des Landkreises, die von den Mitgliedern der Fachgruppe betreut werden, mit ihren faunisti- schen und floristischen Besonderheiten vorgestellt (Abb. 423 bis 428).

Der zweite Teil der Informationstafeln enthält Darstellungen und Auswertungen langzeitlicher Untersuchungen ausgewählter besonderer Vogelarten im Kreisgebiet (Abb. 429 bis 434).

\section{Die Ortsgruppe Güstrow NABU stellt sich vor}
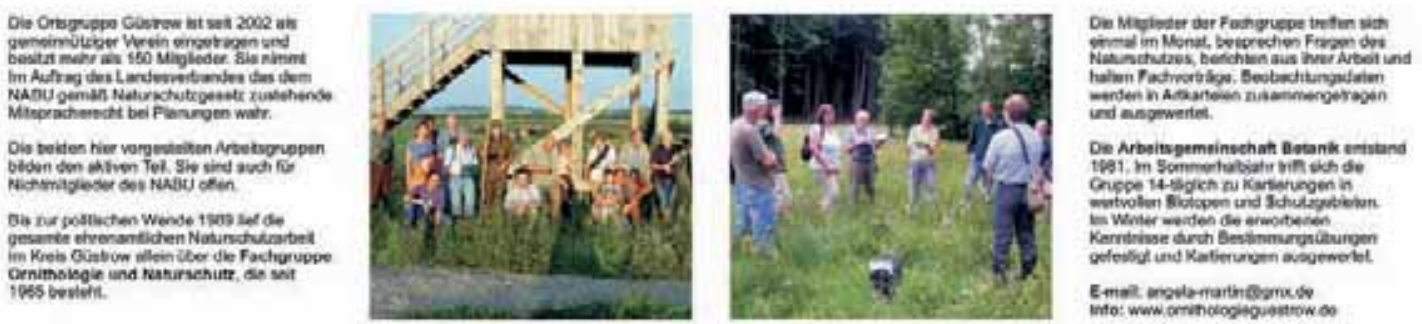

\section{Aus der Arbeit der \\ Fachgruppe "Ornithologie und Naturschutz"}

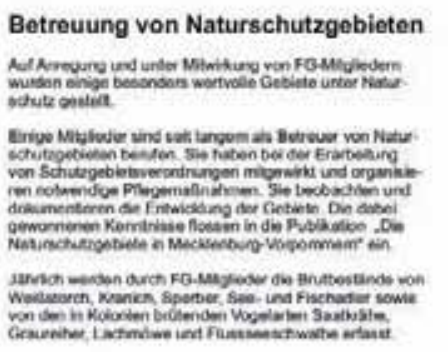

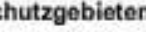

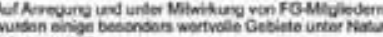

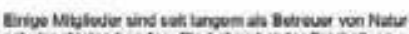

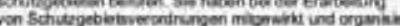

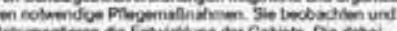

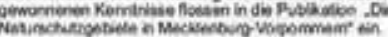

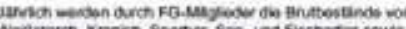

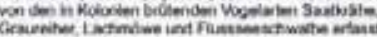

\section{Praktische Naturschutzarbeiten}

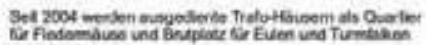
inverat

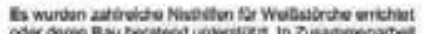

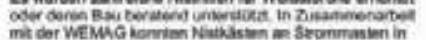

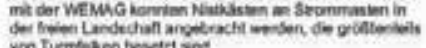

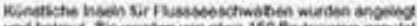

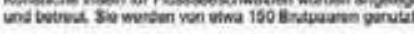

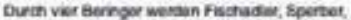

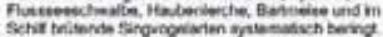

Kartierungen, Veröffentlichungen

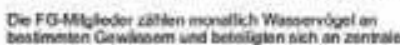

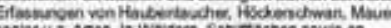

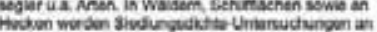
vogen fouctoming

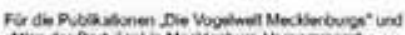

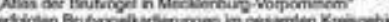

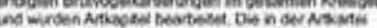

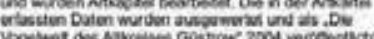

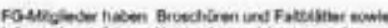

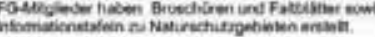

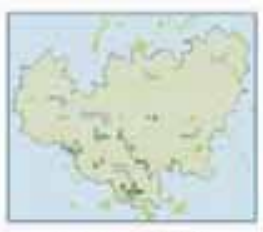

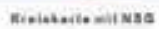

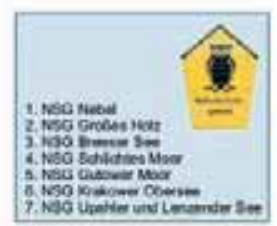

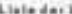

\section{Aus der Arbeit der \\ Arbeitsgemeinschaft "Botanik"}

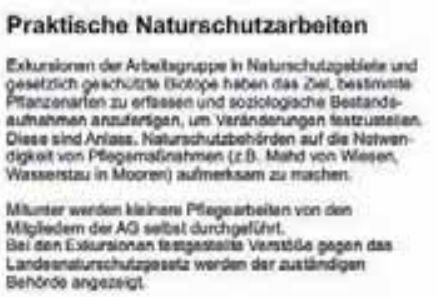

Praktische Naturschutzarbeiten

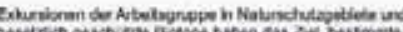

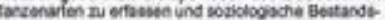
Dieso sind Ansas. giget vos Peopemactas

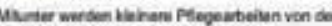

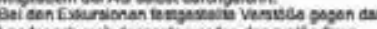
Landnatianduchat:
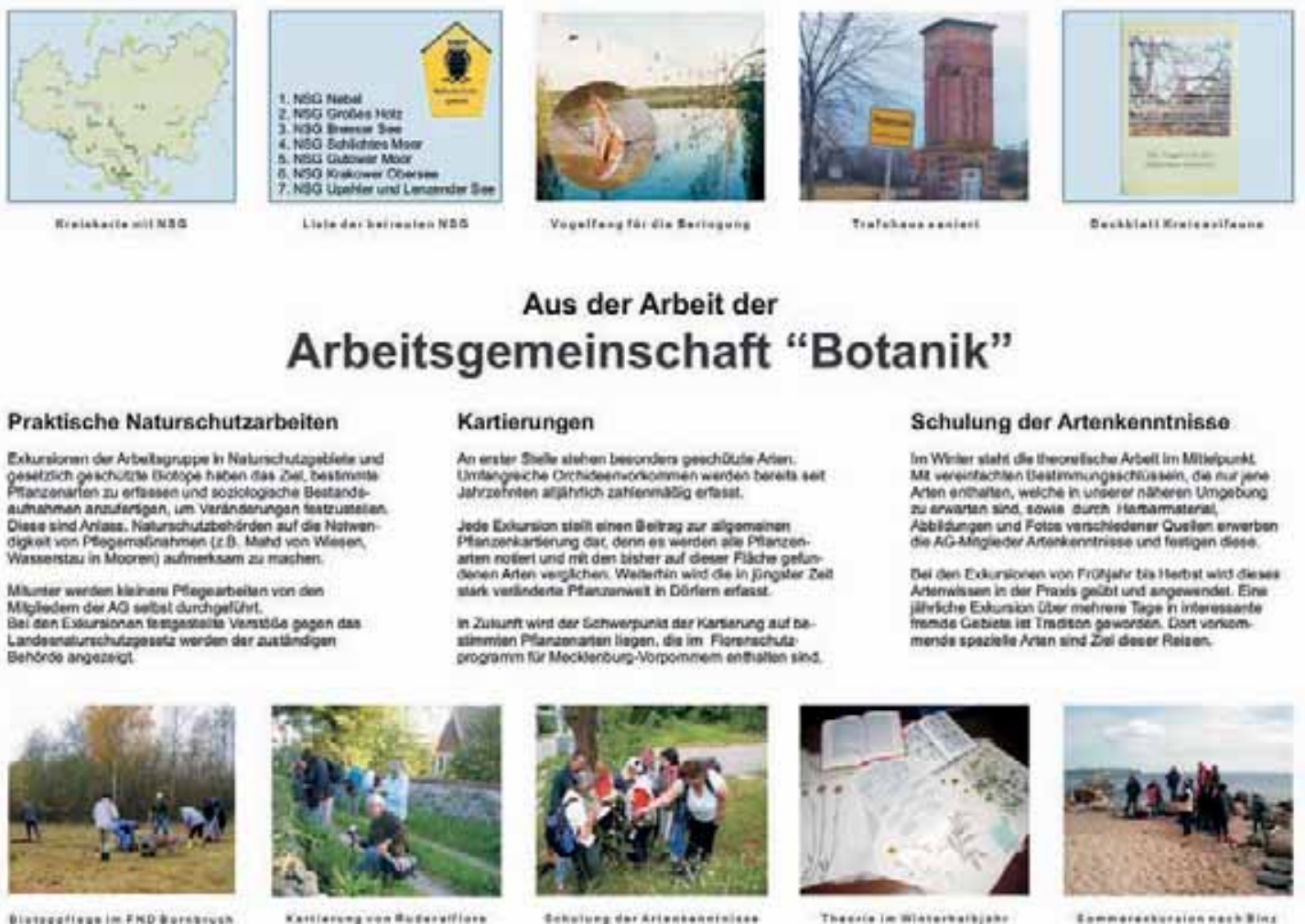

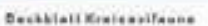

Schulung der Artenkenntnisse

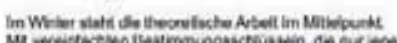

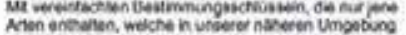

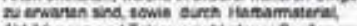

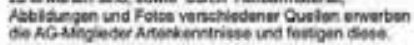

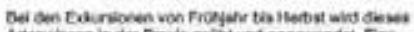

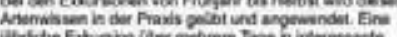

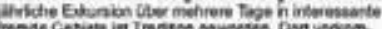

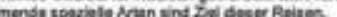

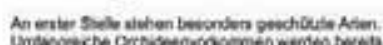

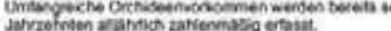

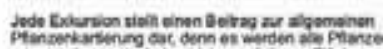

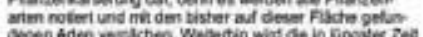

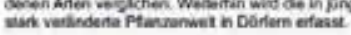
in Zuiven wird cer Lenwepunia der Kasseneg aut be

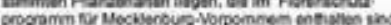

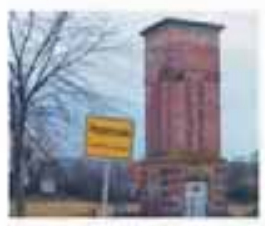

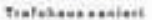

.




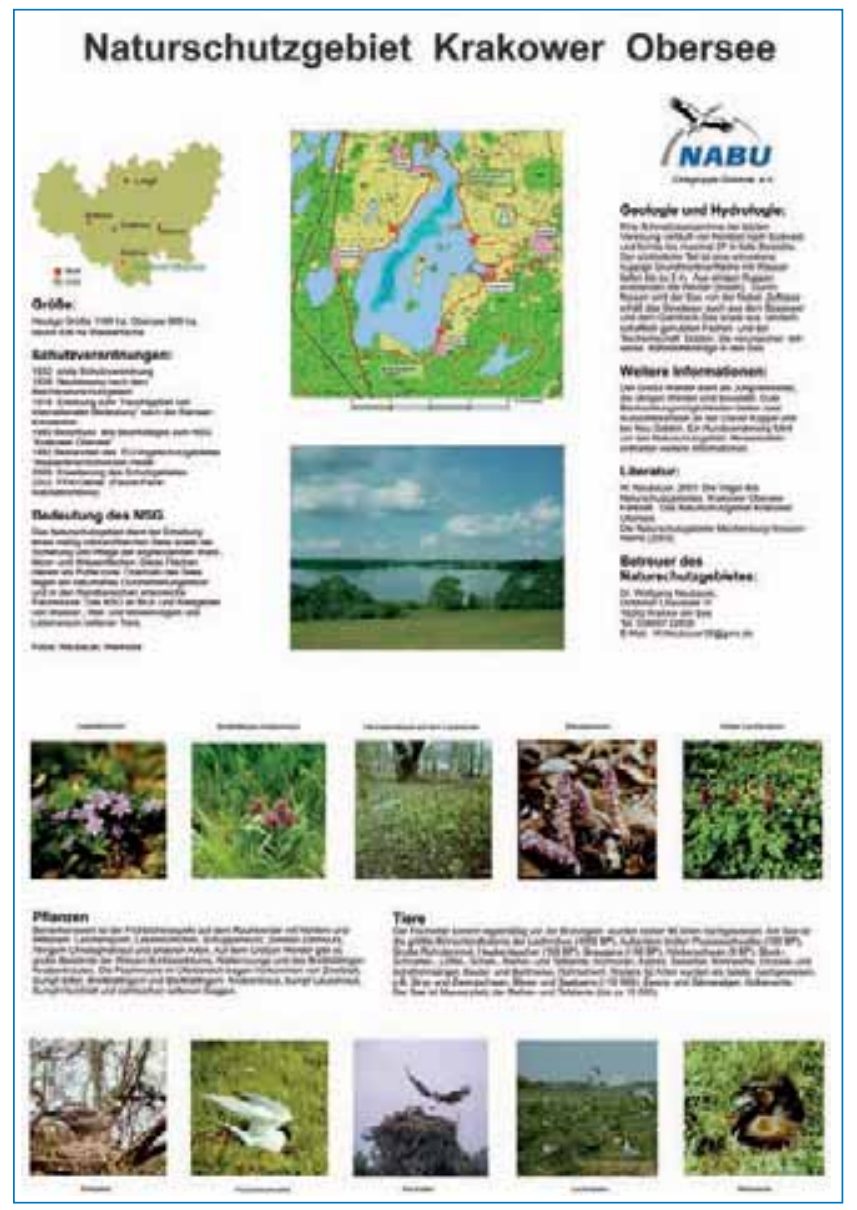

Naturschutzgebiet Upahler und Lenzener See

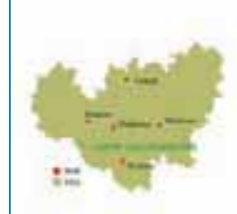

aces

stodiondher

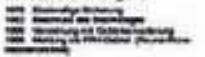
betedive des inos

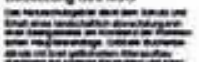

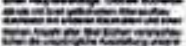
Extrescest

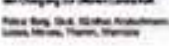
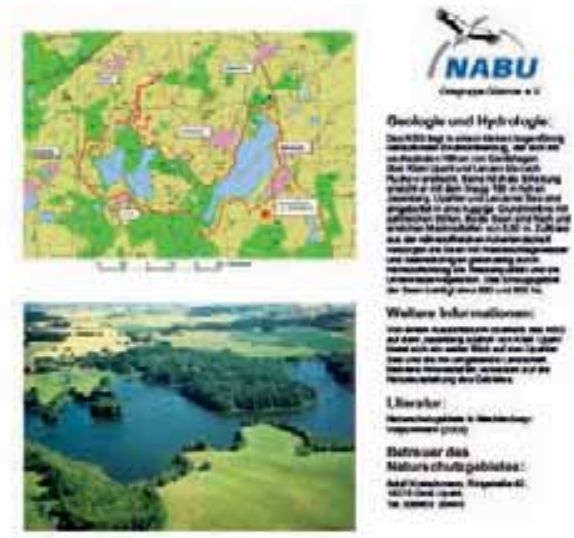

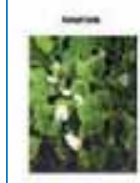

Munmen Minm
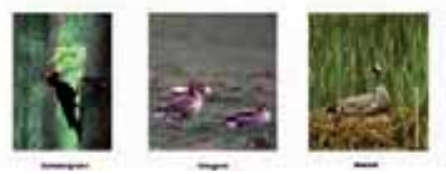
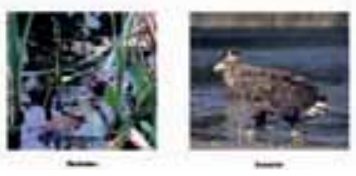

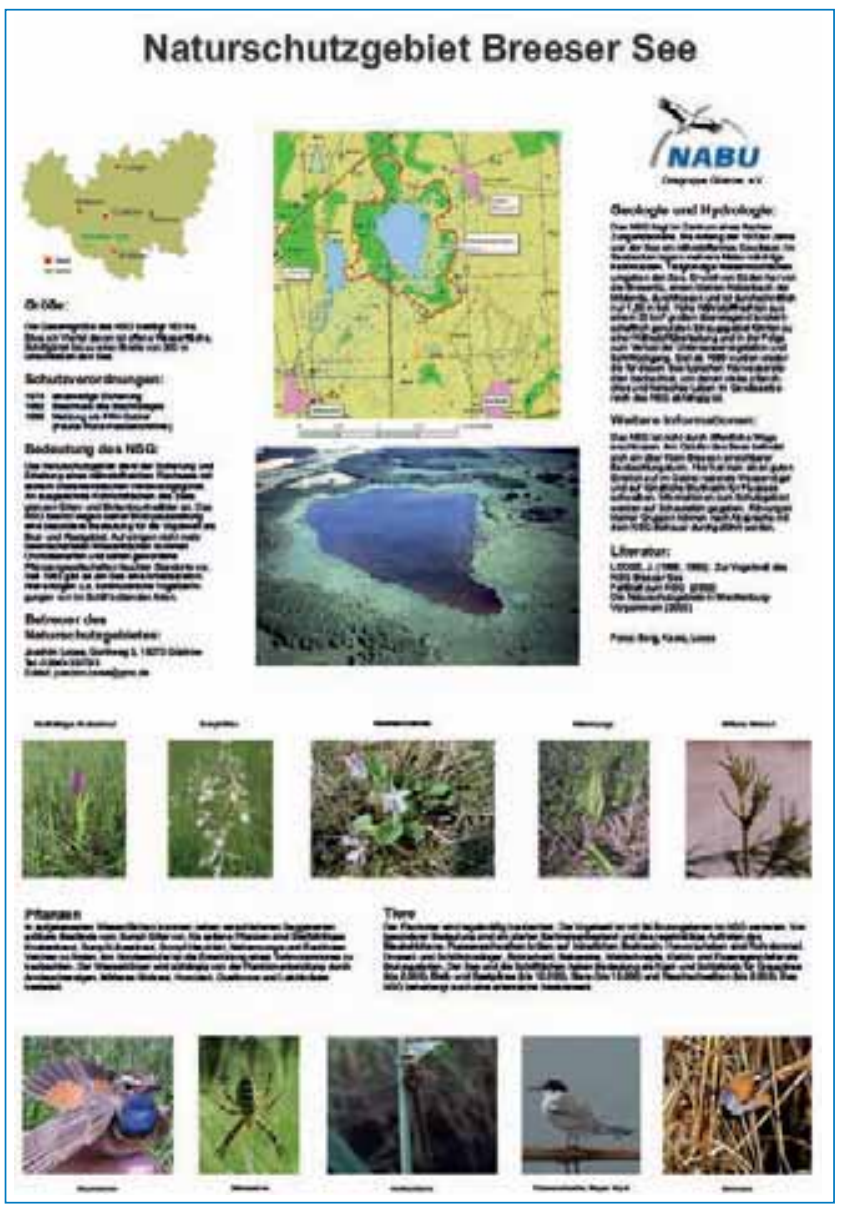

Naturschutzgebiet Schlichtes Moor
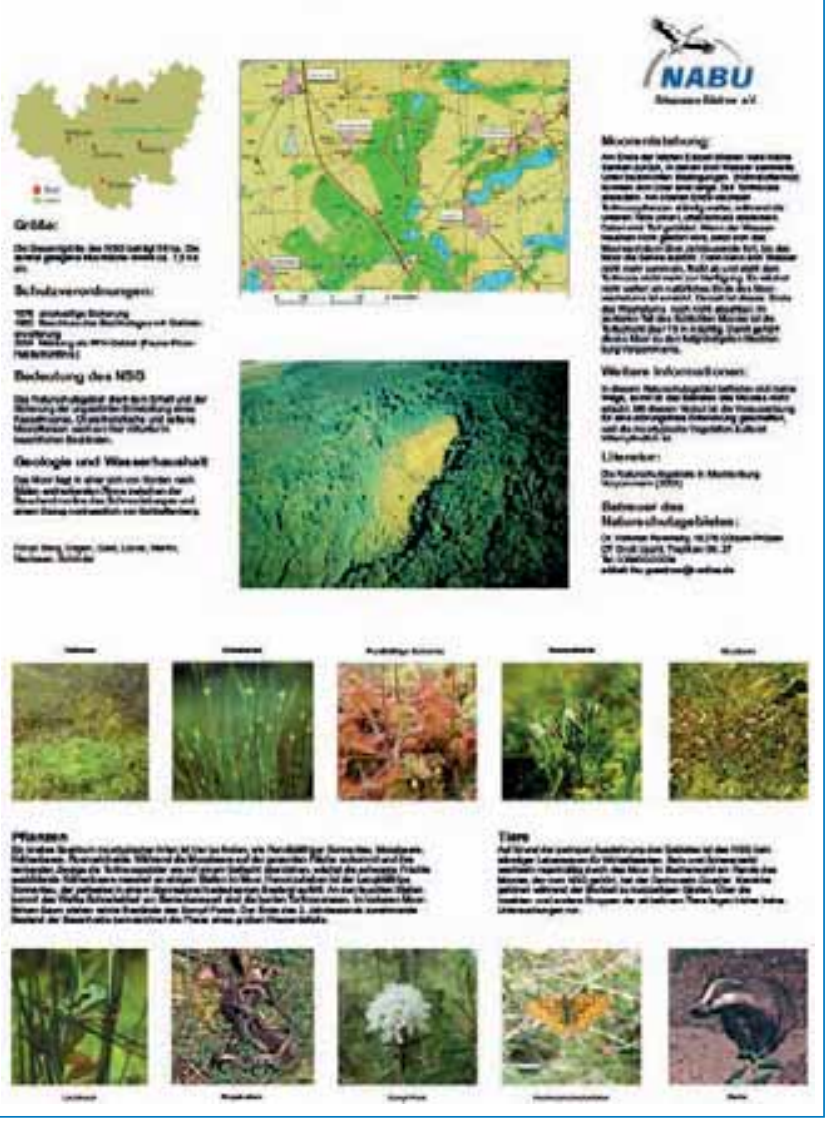

Abb. 423 bis 426 


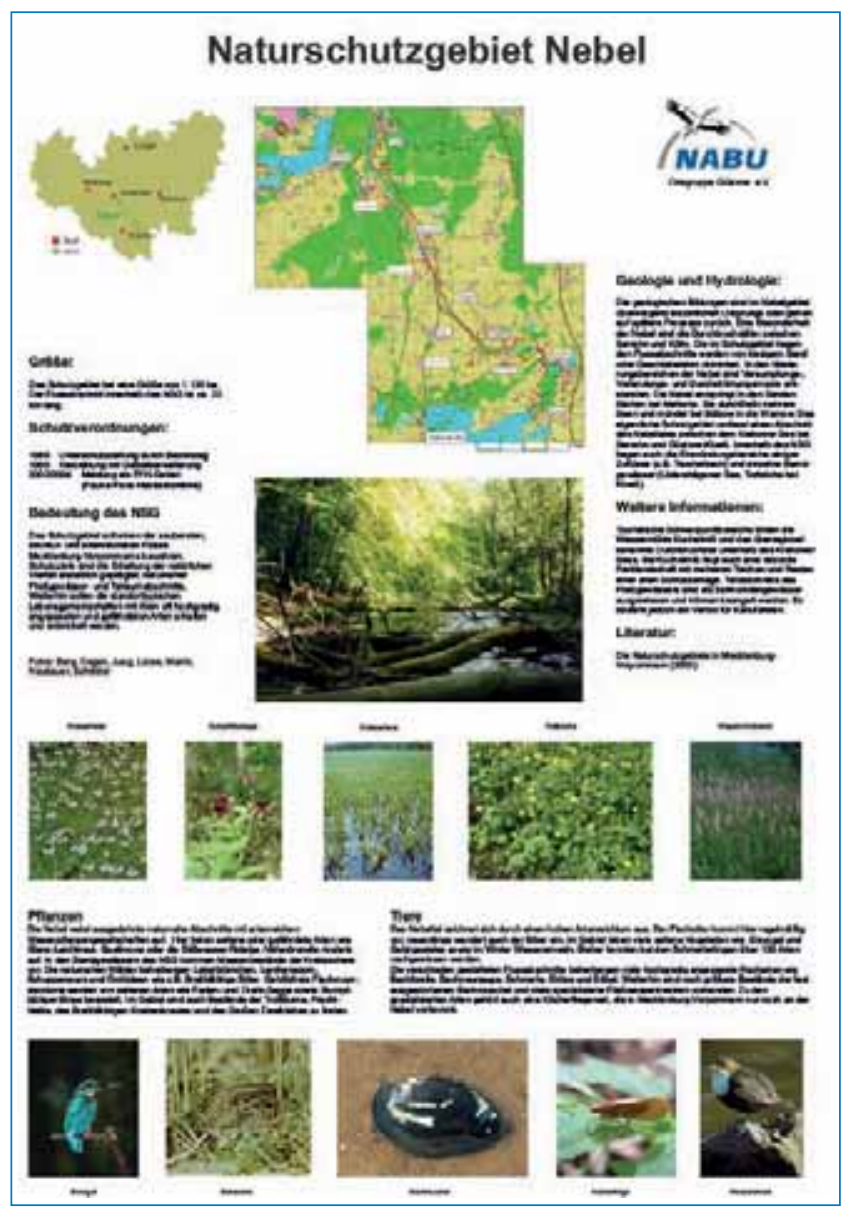

Naturschutzgebiet Gutower Moor u. Schöninsel
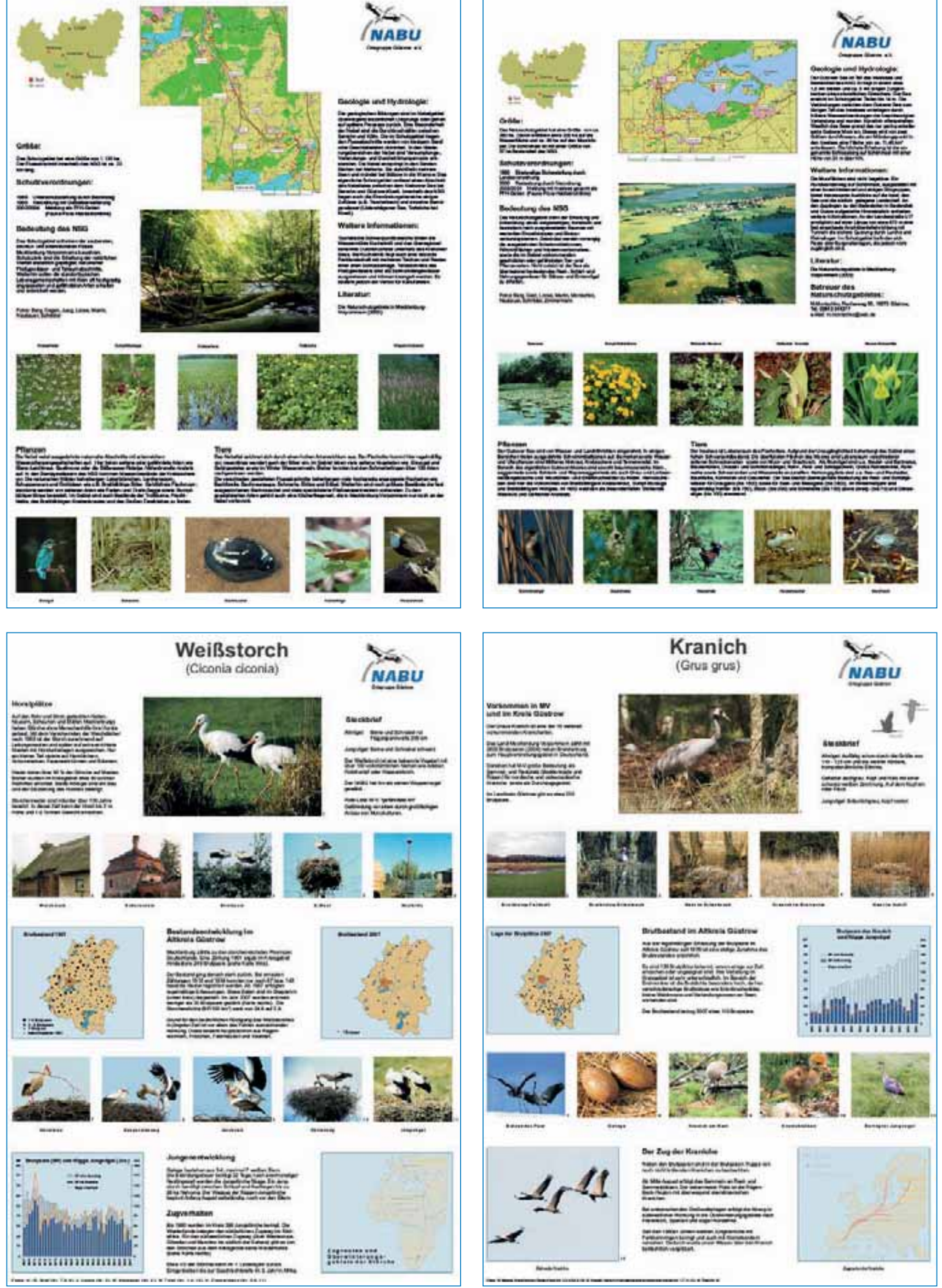

Abb. 427 bis 430 

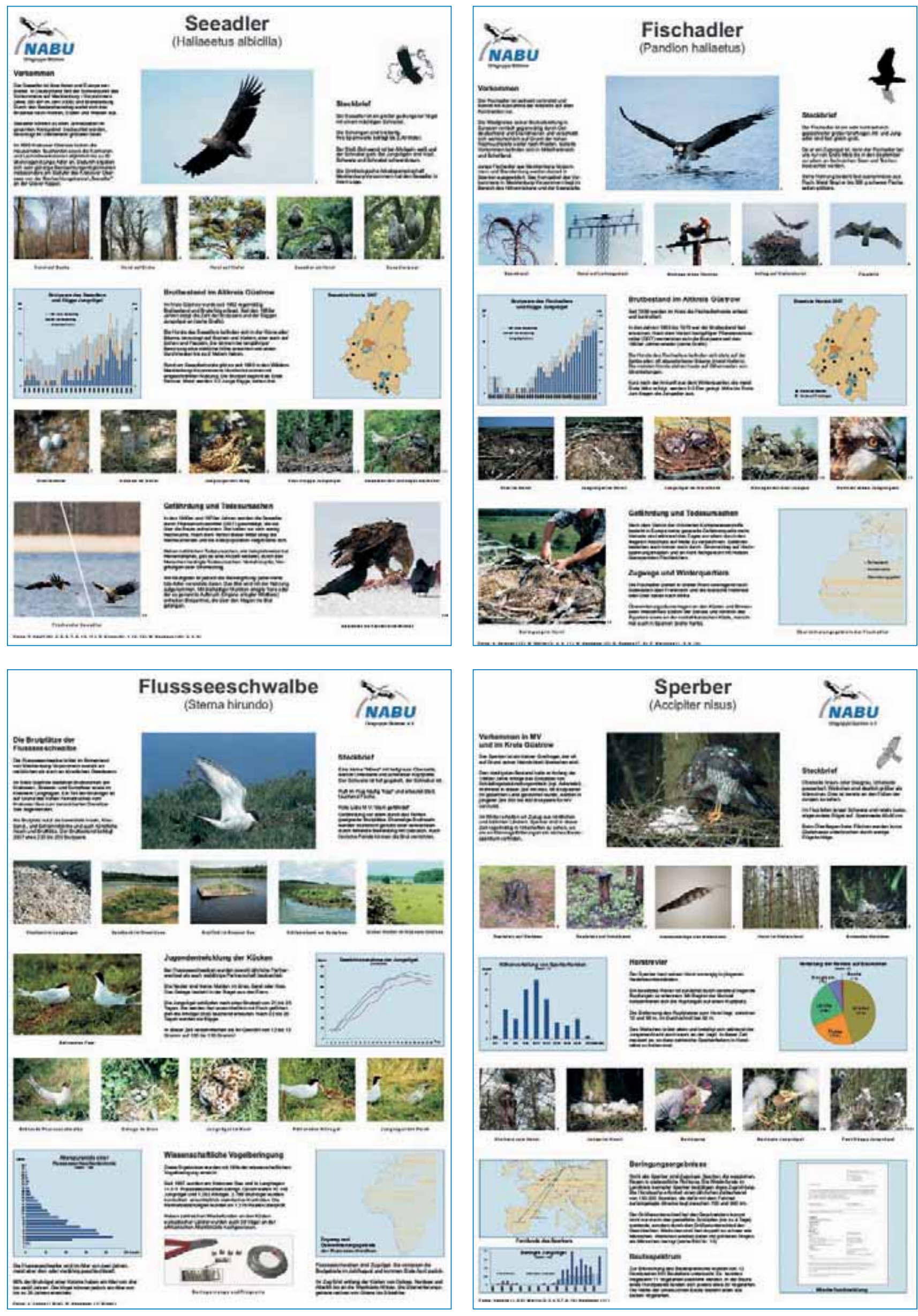

Abb. 431 bis 434 


\section{Anhang 4}

\section{Ausstellung 80 Jahre Naturschutzgebiet Krakower Obersee}

Vom 14.07. bis 04.09.2012 standen die von Wolfgang Neubauer mit Unterstützung durch Joachim Loose, Sebastian Lorenz und Angela Martin erstellten nachfolgend abgebildeten Ausstellungstafeln in der Alten Synagoge Krakow am See. Die hier in geringer Auflösung dargestellten Tafeln dienen nur der Übersicht, sie sind in höherer Auflösung als pdf-Dateien im FG-Archiv vorhanden. Die insgesamt 22 Tafeln waren mit 147 hochwertigen Bildern bestückt.
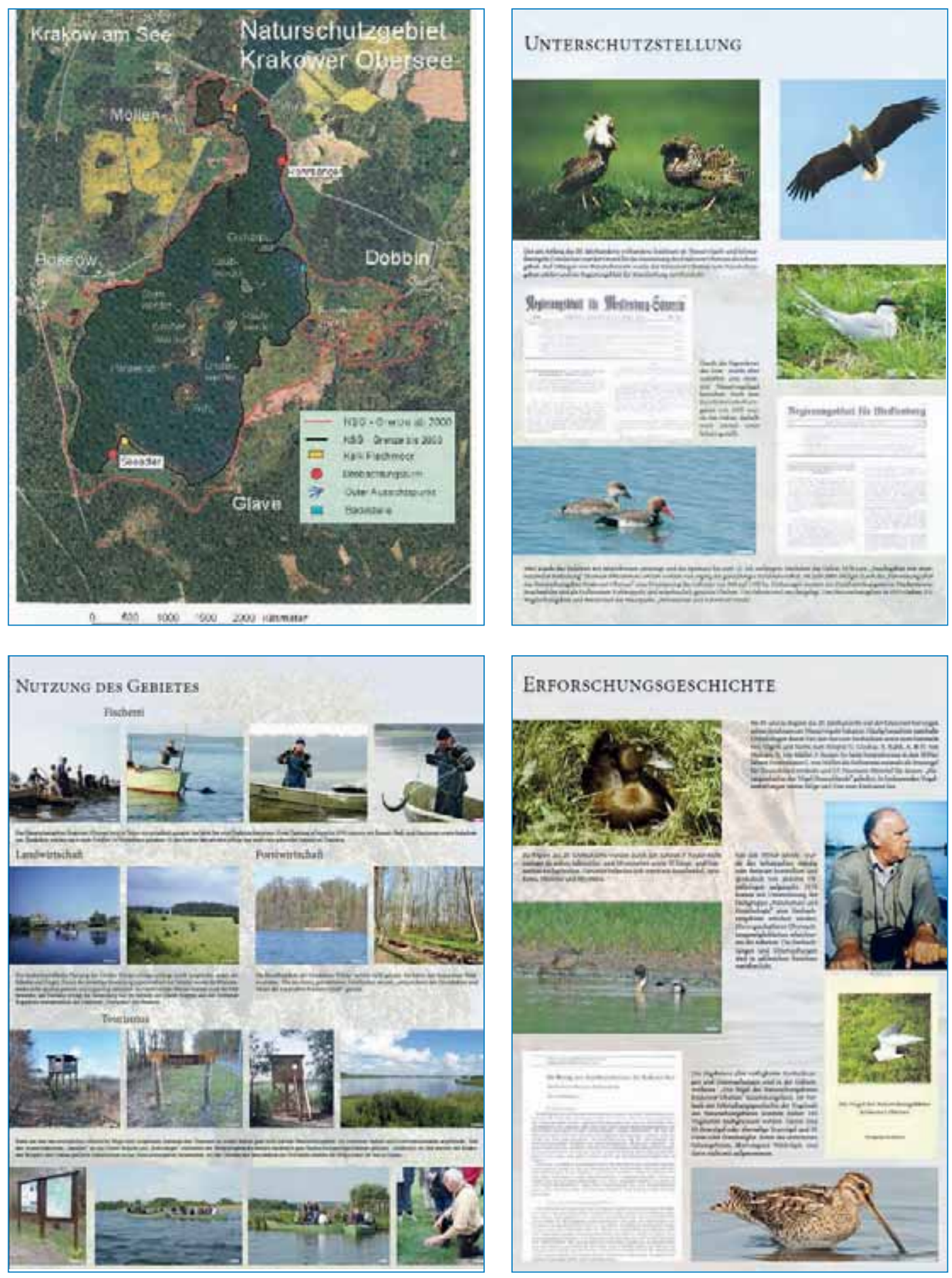

Die 57 von Wolfgang Neubauer stammenden Bilder wurden für die Ausstellung ergänzt durch weitere Fotos von: H. Ebert (1), F. Eilrich (3), D. Hensel (1), F. Folsten (1), O. Krone (6), J. Loose (9), S. Lorenz (2), Th. Martin (3), B. MederTrost (5), H. Müller (1), Neumann (1), G. Nowald (1), F. Prüß (3), J. Reich (3), W. Rolfes (13), W. Spillner (3), U. Steinhäuser (2), N. Stier (2), W. Thiel (2), D. Vorbusch (1), P. Wernicke (4), W. Wiehle (5), H. Zimmermann (19). 

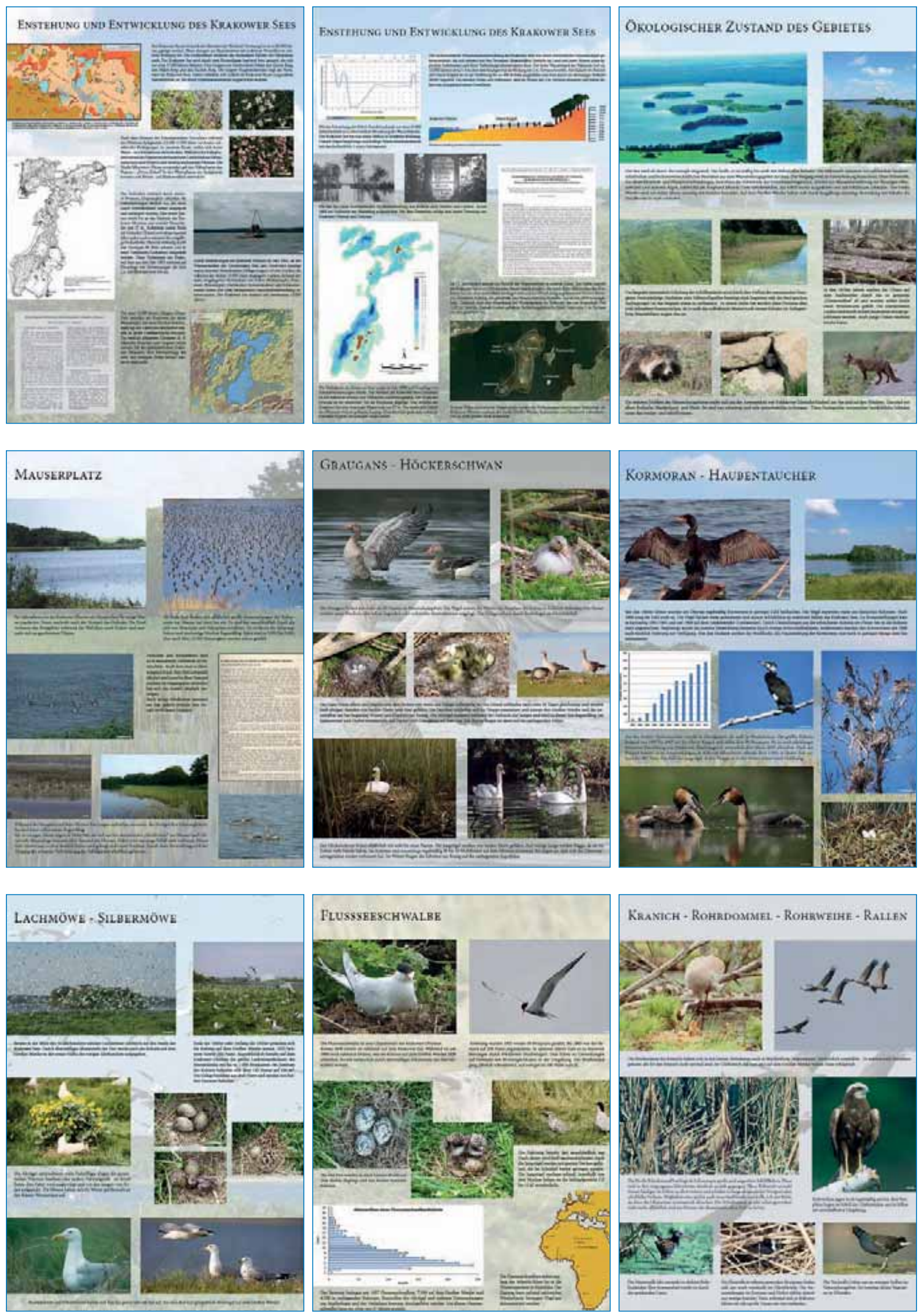

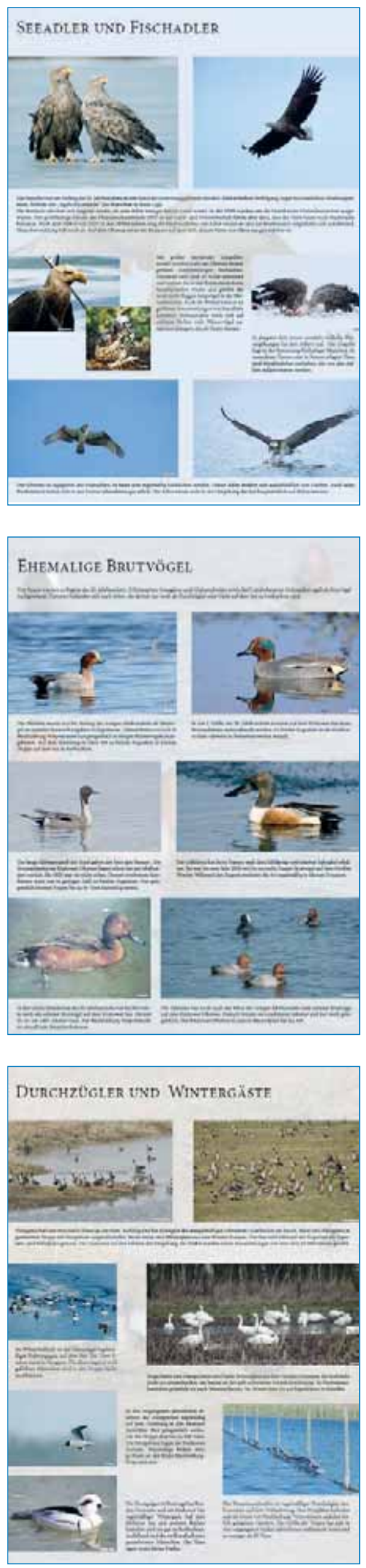
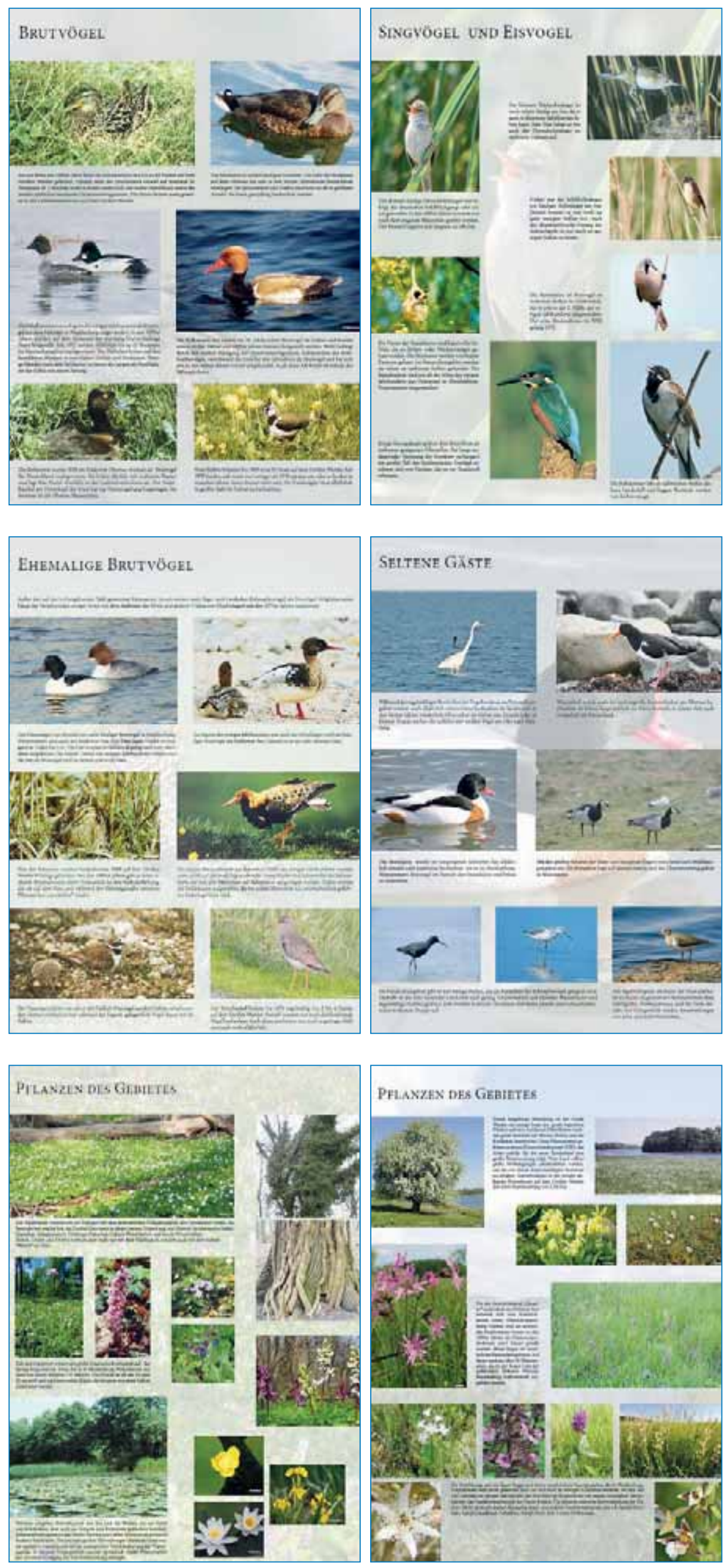


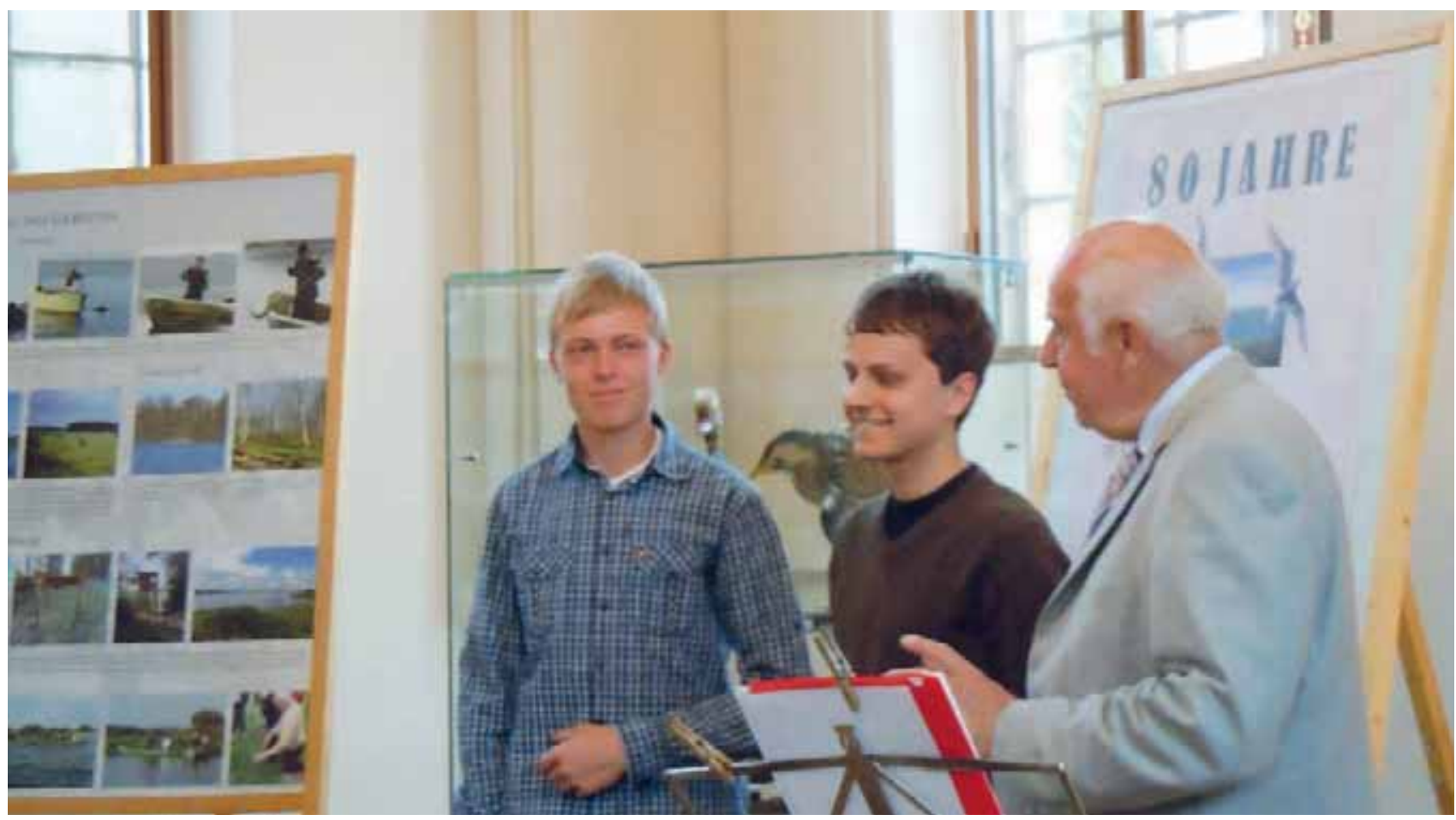

Abb. 435: Dr. Neubauer bedankte sich bei zwei FÖflern aus dem Naturpark Nossentiner/Schwinzer Heide, die die Tafeln endgestaltet hatten. Foto: 7. Loose.
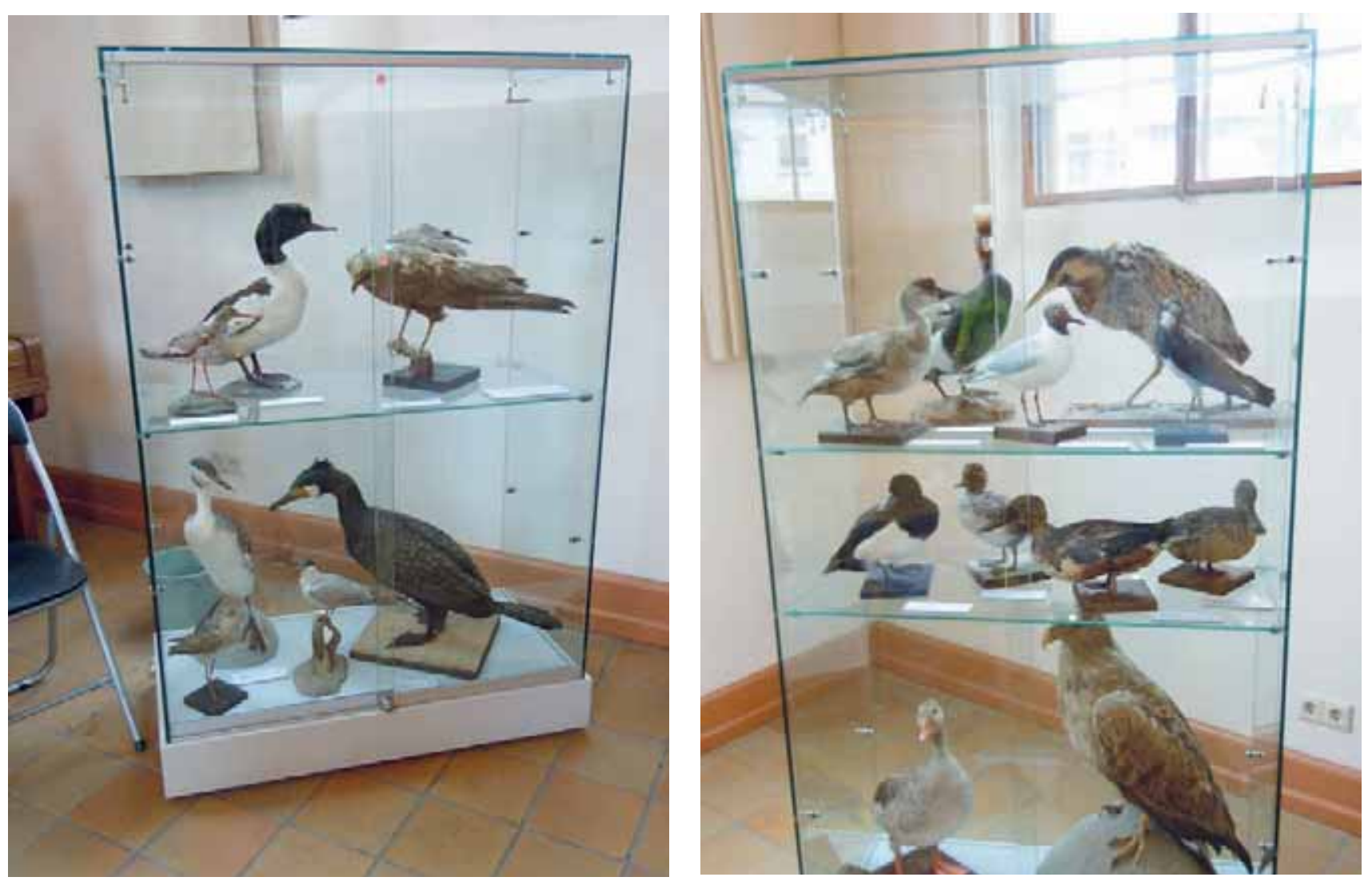

Abb. 436/437: Die Ausstellung wurde passend zum Thema mit Leihpräparaten aus dem Müritzeum Waren gestaltet. Foto: $\mathcal{F}$. Loose 


\section{Anhang 5}

Wahleingabe der FG [siehe Pkt. 8.1.6]

PACHGRUPRE ORITHOLOGT UHD NATURSCHUTZ KREIS GUSTROW

Anschrift des Leiters:

Dr. Wolfgang Ileubauer

Dobbiner Chauseee 11

Irrakow am see

2602

Ilindaterium flir Land-, Porst-

und Nahrungegtiterwirt bohaft

Bere1ch Naturechutz

\section{Kopondale Allee}

\section{7}

Qustrow, 29.4.1989

\section{$B A B a b e$}

ischen Gutow (Inselseeniederung) und Genschow In Kre1s Gustrow 11egen knapp 40 he nleht mehr bewirtachaftetes Grilnland. In den letzten Jahrzehnten entwiokelten sich hier dicht nebeneinander vielfaltige Lebenerllume Plir Pllanzen und Tlere: Rbhrlchte, HochstaudenPluren, extensiv genutzte Wiesen, Weldengeblische, Seggenbertinde. Weben vielen geschlitzten Vogelarten der Kategorle d (Artenechutzbestimang vom 1.10.1984) briten hier zumindest drei geschllzte beatandagerihrdete Arten der Kategorle b: Blaukehlohen, Beutelmeise und Beksasne; die zuerst genannte Art hat hier einen Ihrer beiden eingigen Brutplatze im Bez1rk Sohwerin. We1ter hervorzuhebende Arten olnd: Schilfrohrallinger, Braunkehlchen, alle 3 Schwirlarten, Sproser, Neunt8ter, Fupfelralle und Rohrwe1he. Darther hinaus ist das Geblet lalehplats fur mehrere

\section{Tarcharten.}

Fix vielo Arten lat vor vier Jahren in geringer Intfernung ein wertvoller Lebensraum durch Intensivierung vollstindig vernichtet worden (Sumpfaeenlederung), oo daB der jetzt noch vorhandene eln letstes Rllokzugagebiet flr viele Arten daratellt (Gebletatheraicht olehe Anlage). D1e Brhaltung derartiger Fikchen 1st mit der Artenschutzbest1mmung vom 1.10.1984 gesetzlich festgelegt, und zwar sind zurindest die Lebensrllume flu die geschlititen Arten in der erforderlfchen Qual1tut gu bewahren, da bekanntlicherwe1se ke1ne Art ohne thren spezil1schen Iebensraun existieren jann.

Die LPG (P) Zehna IBBt derze1t eine Aufgabenstellung zur v1edernutzbarmachung dieser Grthlandflichen erarbelten. In einer Anlaupberatung am 7.12. 1988 wurden zwiachen dem Partner der Landwirtachapt, dea Lelloretionsbaues, der Wasserw1rtgchaft, dem kitarbe1ter fur Naturschuts be1m io: st 
Poratwirtsohaftabetrieb und Vertretern des Rates dea Krelses die abslichen Varianten, aupbauend auf elne Studie der 1960er Jahre, int thren Auswirkungen diskut1ert und in der polge dureh die eingelnen Partner Stellungnahnen erarbeltet. D1ese Vexfahreneweise Iet aus der S1cht der Raturechutemitarbelter eret einmal als poultit hervorzuheben, da es vor gar nioht langer zelt lesder in der Praxle thiteh wer, d1e Zuotimuning au Mellorations- und anderen Projekten unter Ternindruek kurs vor der Real1s1erung belm Rat dee

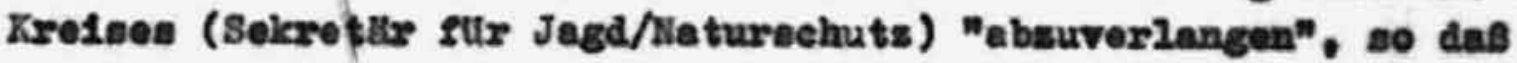

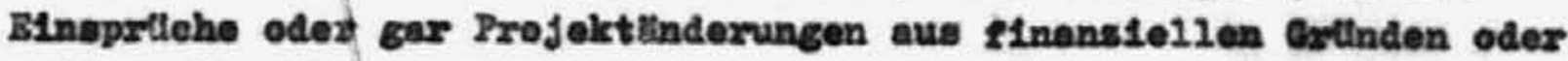
anderen Ursachep ausichtelos waren. Aus der elngange genannten Bedeutung des debleter 1101 de stellungmahme der Naturachutzaelte veretlindlicherweise alo Ablehnung erobfltehlger Blngriffe aus, und zuntichst ging auch die Stellungnahme des Fachberelches des Rates des Ireises in diese Richtung. Letztlich fthrte jedoeh eine Entgeie1dung In Rat des Krelaes Clstrow doch dasu, das gegenwtirtig elne Aupgabenatelfung fir d1eses Vorheben erarbeltet wird.

E. mus leider kondtat1ert werden, das die Vertreter der Iandwirtschaft faet ausnahtisio der Pachkenntnis ther unvere heimische Plora und Faune entbehren. Dartber hinaus aind ale aich in keiner Wolwe 1hrex geaetzilich verankerten Pflicht und Verantwortung gegen-

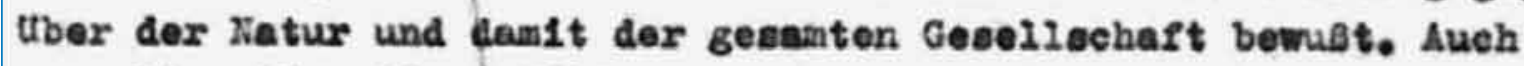
wenn biawelien diese PPI1cht anerkennt wird, so Pehlen doch atets entsprechende Handlungen. In der Vergangenhelt war durch ein mosalkart1ges Kebeneinander kleInex, extensiv in versehiecener HIngleht bewirtechafteter PIEchen elne artenrelcie Iulturlandechaft geachapfen worden. D10 Intonpive Groselichemrirtechaft mit elnex angeetrebten Rivell1erung ihlnolchtl1ch Bodenfruchtbarke1t und waserhauahalt aus der Sehlleen brachte crobe Vexluate an Iobensxllumen in elch. Dan1t einher elngen Abnahnen der Hllus1gke1t oder glinzIloher Verachinden von PSIanzen- und Tlerarten.

Doch auch heute noch 11egen, Inselart1g elngeatreut, beaondere Lobensxllume in der Ackezlandschart: Kle1ngewtlaser, Peuchtw1esen, Trockenrasenkuppen, Ceblicohe. S1e alnd flr viele Arten letzte Refugion. Werden diese auch noeh beae1 $t 1 \mathrm{gt}$, bedeutet dae $20 \mathrm{r}$ zahlrelche Arten den slcheren zod. Deohalb gilt es, von den noch vorhandenen letzton Lobentrliumen so viele wle nur mbel1ch zu exhalten und andererselts vexnlehtote Lobonarlume auch wleder herzusteilen. 
D1e Brhaltung von Axten wus endich ald 'Langze1trkonomie' veretanden werden, de hlerbel eine der wicht1geten Ressour-

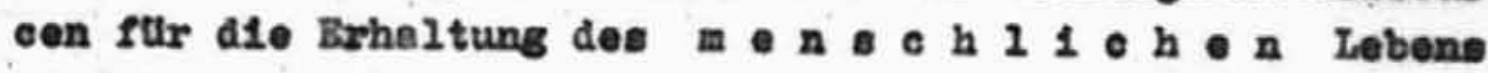
geaschert wird.

Whrend alch in der heut1gen ze1t $95 \%$ der Bingaben aus gans private Belenge beslehen, heben wir hier an elnem Belapiel eIn generelles Problem angeschnitten, dem kelnerled private Ambltionen zu Orunde 11egen. WIr exhobnn hlermlt BInepruch gegen eIn attindiges Zuw1derhandeln gegen d1e Artenschutzbest1mang, und in dem besonderen Pall gegen d1e su befurchtende w1edernutsbermachung des oben genennten Grinlendes dureh d1e LPC $(P)$ Zehna. WIr erwarten eine anteprechende Unteratutzung In fachlicher Beurtellung der exarbelteten Aufgabenatellung be1 erforderl1cher w1chtung der Jaturachutzaapekte.

Auf Grund der vielfultigen ateatlichen und gesellsohaftlichen Init1ativen wichst das bkologische Bewusteein der Blirger in zunehmendem liaBe, und so lat zu hoffen, daB auch in den betreffenden Betrieben der Landwirtschapt die bkologlschen EInsichten wachsen und der Eqnst der S1tuation erkannt wird..

\section{Anlase}

(Der Inhalt dieses Schrelbens wurde be1 der Beratung der FO an 21.4.1939 diekutiert und besteltigt.)

stellvertretend 2 ll die

36 L1SBlieder der FG/

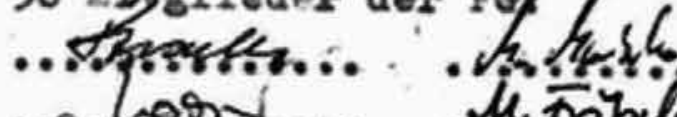

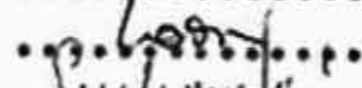

- Juslubuitia.. H, trhelse... .4.
Tachgruppe Ornithologie und Naturachutz Gletrow beIm Kulturbund ger DDR

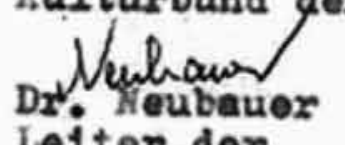

Leiter der

Pachgruppe

-Durchschriften on Rat des Bezirikes und Rat des Zreises 


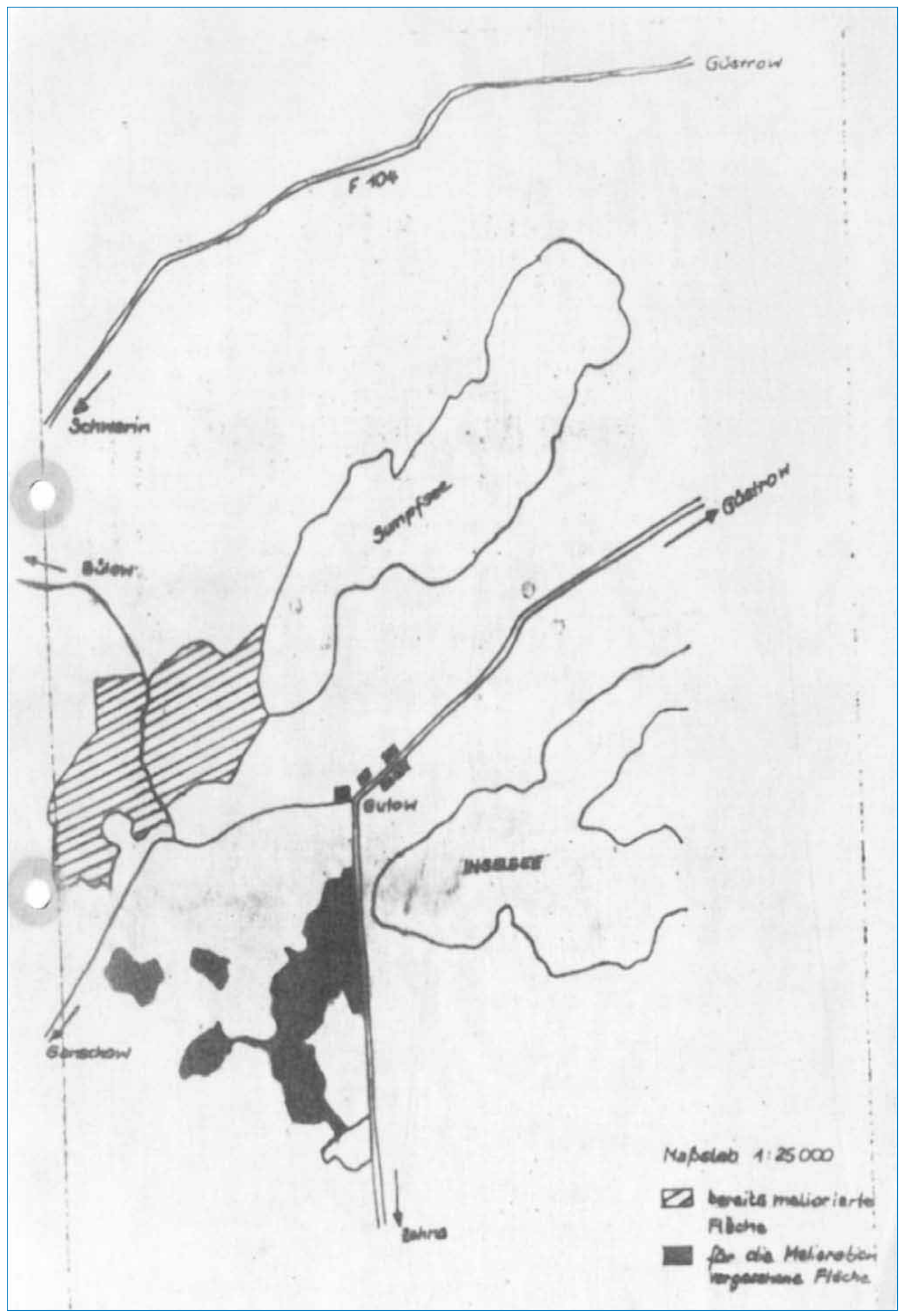




\section{Anhang 6}

\section{Landschaftsentwicklungsvisionen}

Entwicklungsgebiete mit hohem Potenzial, soweit Landwirte einen Wasseranstau zulassen würden (die Flächen standen bereits einmal kurzzeitig unter Wasser)

Die Wiesensenke südwestlich von Bellin stand durch eine defekte Rohrleitung 1993 und 1994 unter Wasser.

Sofort brüteten hier fünf bzw. neun Brutpaare des Rothalstauchers. Die Fläche war in der Durchzugszeit für zahlreiche Entenarten ein schnell angenommenes Rastgewässer.

$A b b .438$

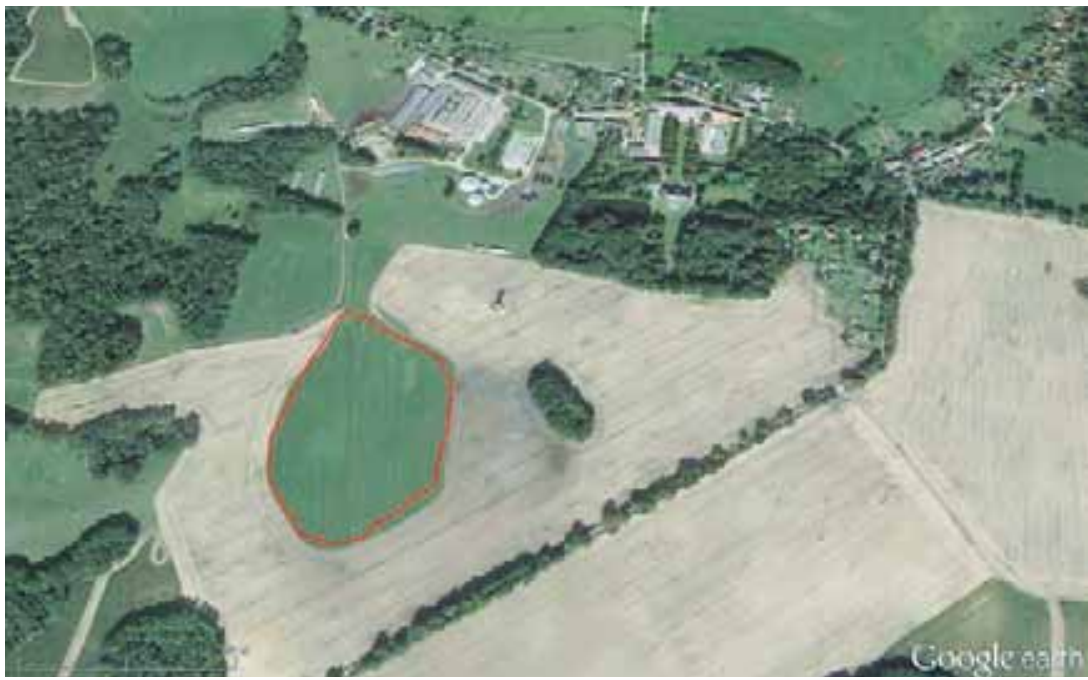

Die Ackersenke südwestlich vom Parumer See mit dem zentralen Soll (Biotop Nr. GUE10350) war Mitte der 1990er Jahre überschwemmt. Die große Wasserfläche mit den schlammigen Ufern wurde sofort zum Rastgewässer von Enten und Limikolenarten.

Abb. 439

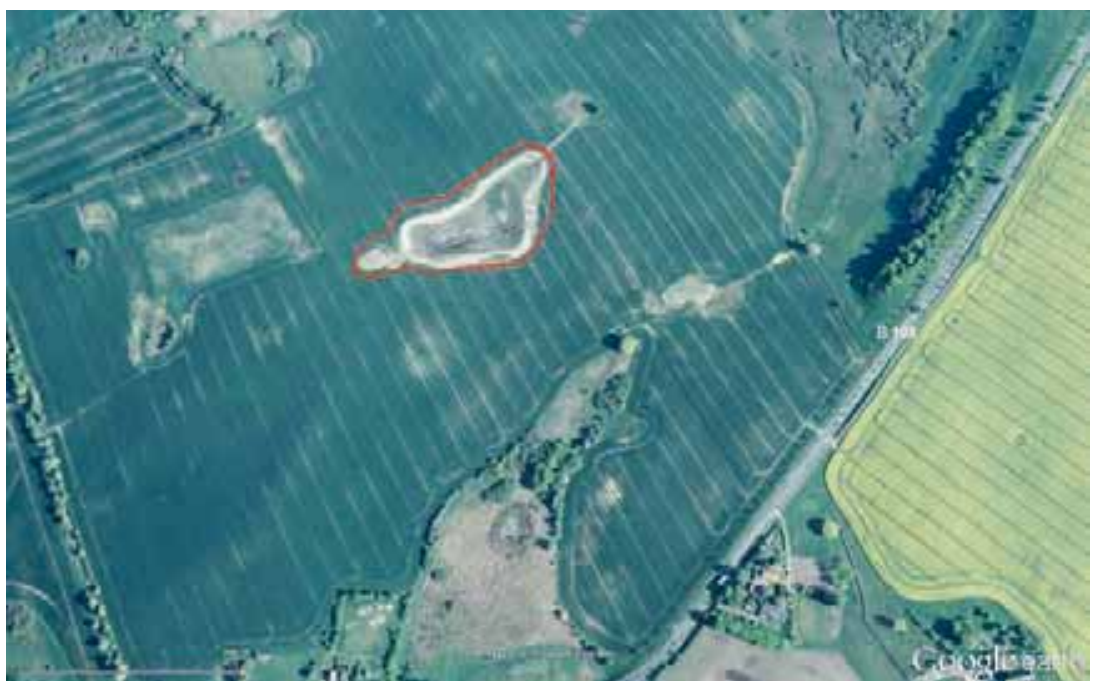

Die Wiesensenke westlich von Gerdshagen Hof an der Gemeindegrenze zu Klein Upahl besitzt am Ostrand Qellhänge und entwässert über eine Rohrleitung nach Nordwesten. Ende der 90er Jahre war die Rohrleitung verstopft und das Wasser floss über den Acker ab. Es war ein Kranichbrutplatz und ein großartiges Laichgewässer für Lurche entstanden.

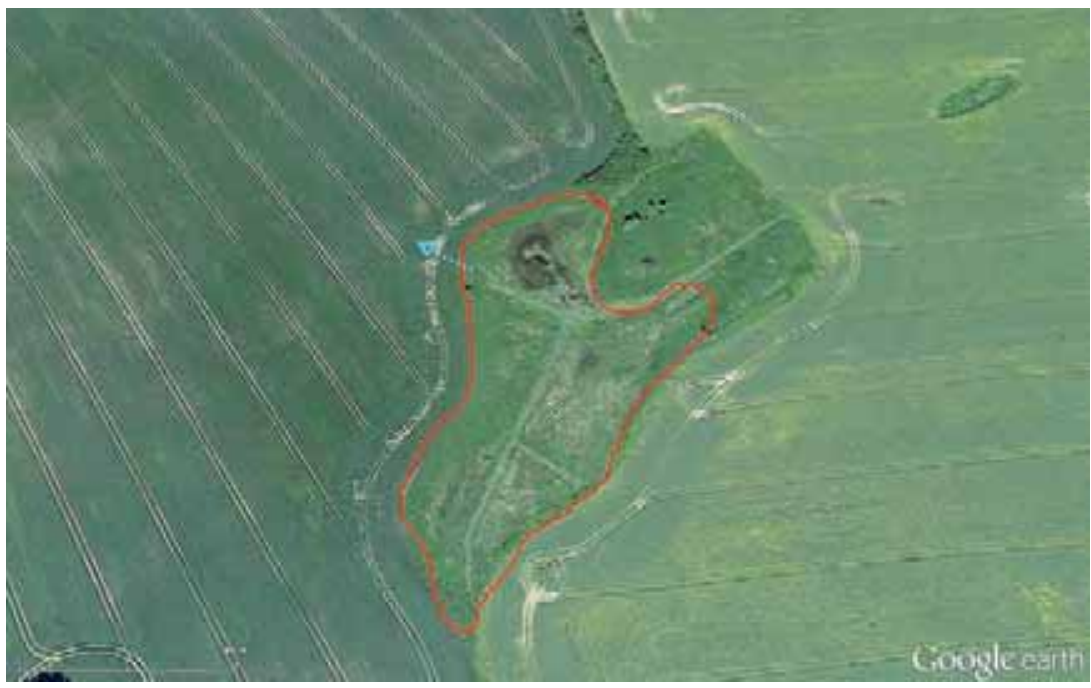



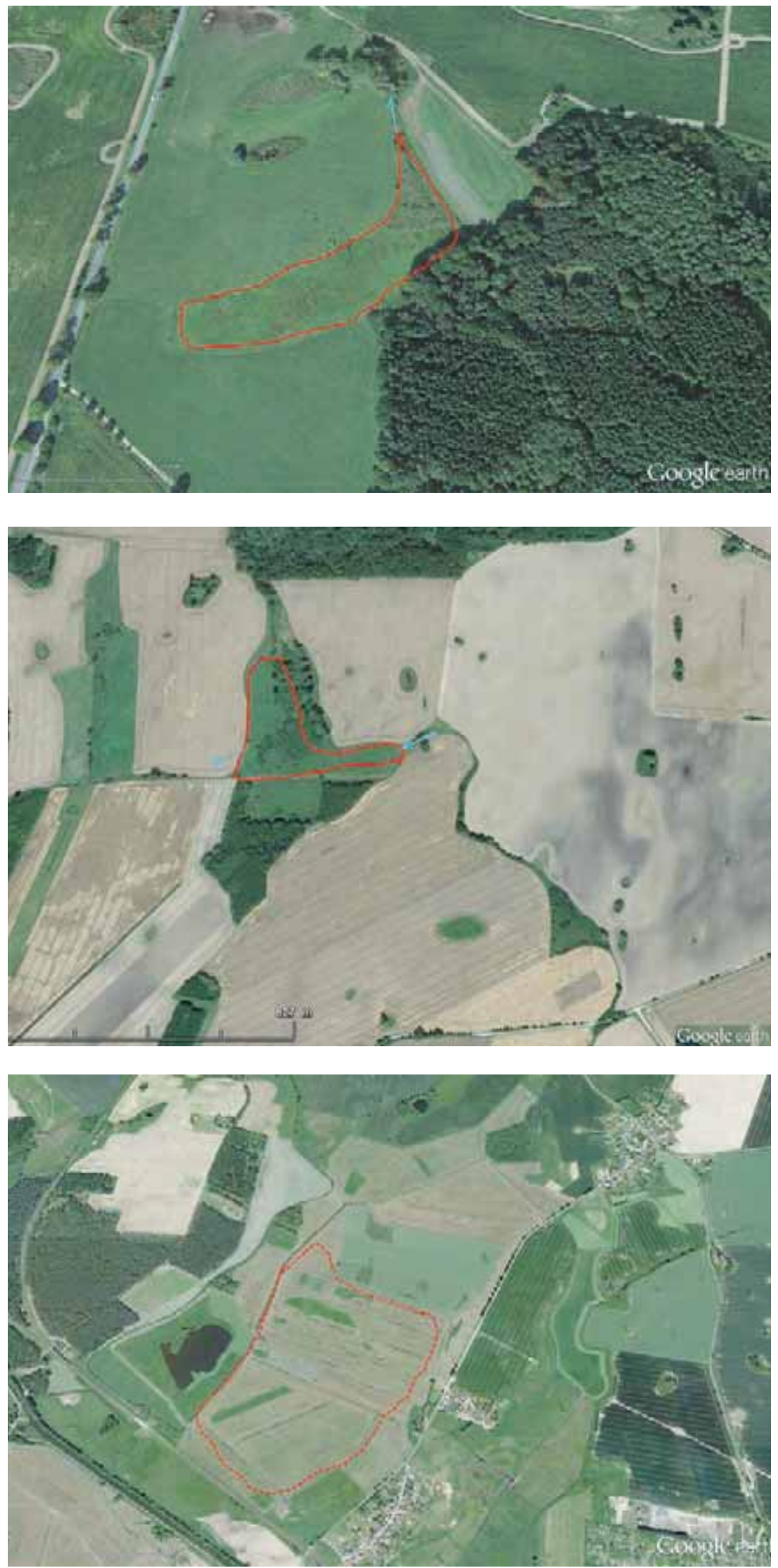

Das Seggenried südlich von Zehna östlich der L17 (nicht als §20 Biotop erfasst) entwässert über einen offenen Graben nach Norden. Durch Einbau einer Sohlschwelle könnte das Seggenried vernässt werden und ein Kranichpaar, welches hier ein Revier besetzt hat, hätte einen geschützteren Brutplatz.

Abb. 441

Das am Südwestrand des Kritzkower Geheges angrenzende Seggenried wird durch einen Vorfluter durchflossen, der nach Westen verrohrt durch die Feldflächen verläuft. Ab Einlauf in die Rohrleitung könnte der Graben sehr einfach angestaut werden und damit das Seggenried wirksam vernässt werden. Bei einem Anstau sind im Oberlauf des Grabenzuges entstehende mögliche Ausuferungen zu beachten, die gleichfalls als aquatische Biotopanreicherung gelten könnten.

Abb. 442

Der Wiesenkomplex nördlich Neu Strenz war im Sommer 2011 überschwemmt worden und sofort von mehr als 1000 Graugänsen und vielen Enten, Kiebitzen u. a. Limikolen genutzt worden.

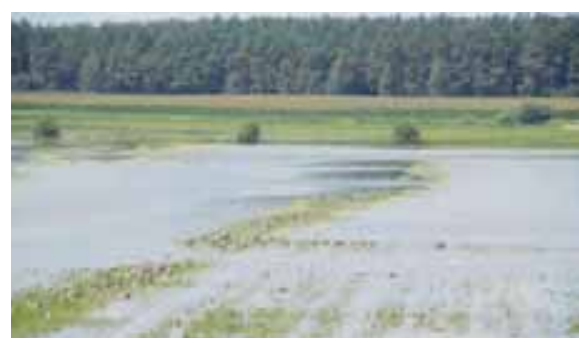

Abb. $443 / 444$ 


\section{Über die Autoren}

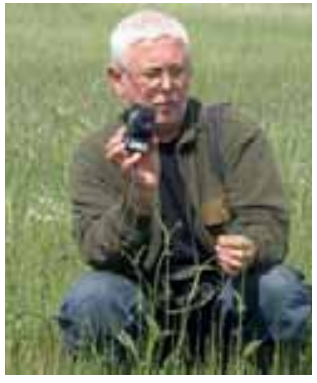

\section{Joachim Loose (geb. am 19. Februar 1948)}

Im Alter von zwölf Jahren hatte er das Glück, dass ihm in der Elbaue südlich von Tangermünde (SA) der zehn Jahre ältere Dipl. Biologe Wolfgang Lippert begegnete. So fand Joachim Loose den Zugang zu der in Gründung befindlichen Gemeinschaft der Ornithologen der Altmark.

Die Beobachtungen in der Elbaue (heute Flächen im Biosphärenreservat Elbaue) und die spätere Betreuung des NSG Schelldorfer See nahe seines Heimatortes sowie gemeinsame Gänsebeobachtungen mit W. Lippert prägten ihn. Als er nach dem Studium der Fertigungstechnik an der TU Dresden 1970 nach Mecklenburg, zunächst nach Parchim, kam, suchte er sofort durch die Vermittlung von Lippert den Kontakt zu Horst Zimmermann in Schwerin und durfte bald als einer von wenigen „Lewitz-Ornithologen“ auch wieder in einem besonderem Gebiet beobachten. Als kurzzeitiger Leiter der FG Ornithologie Parchim vertiefte er den Kontakt zu anderen Ornithologen des Bezirks Schwerin. Mit seinem Umzug im Januar 1978 nach Güstrow war es für ihn selbstverständlich, dass er sich sofort zur Mitarbeit in der Fachgruppe Ornithologie und Naturschutz Güstrow, von der ihm zahlreiche Mitglieder bereits bekannt waren, anmeldete. Ein guter Einstieg für ihn war die gerade anlaufende erste Rasterkartierung der Brutvögel, bei der er ein Messtischblatt zur Bearbeitung übernahm.

Als 1981 Kurt Pohlmann starb, stellte J. Loose sich als Nachfolger für die Betreuung des NSG Breeser See zur Verfügung. Seit dem bringt er sich mit ganzer Kraft hier ein. Gleich frühzeitig hat er den Bau einer Schutzhütte im Gebiet zur Unterstützung der wissenschaftlichen Arbeit und Vogelberingung initiiert. Vorbild dafür waren ihm die guten Erfahrungen in seinem alten NSG Schelldorfer See, wo es eine solche Unterkunft als schwimmende Hütte im Gebiet gab. Als sich mit der politischen Wende 1990 der Aufbau einer Naturschutzverwaltung beim Landkreis Güstrow eröffnete, bewarb sich Joachim Loose auf Anraten von Wolfgang Neubauer als Amtsleiter für Naturschutz und übte diese Tätigkeit als Quereinsteiger (später nach strukturellen Änderungen als Sachgebietsleiter) bis zum Ende seiner beruflichen Arbeit im März 2011 aus. Die ehrenamtliche Arbeit im Naturschutz, die NSG-Betreuung und Vogelberingung sowie in der NABU-Ortsgruppe Güstrow nimmt auch danach weiterhin bei ihm einen breiten Raum ein.

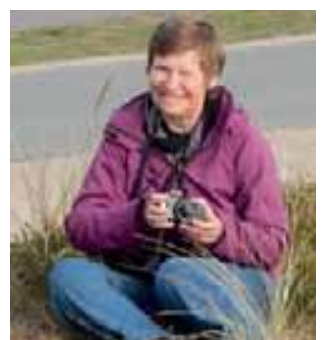

Dr. Angela Martin (geb. am 17. Juli 1956)

Mit knapp zehn Jahren hatte sie den Besuch eines Gewässers in der Dresdner Umgebung bei den Eltern durchgesetzt. Das war wohl die Geburtsstunde des ornithologischen Interesses von Angela Martin. Ein Kleingewässer in der seenarmen Gegend bot ihr erste ornithologischen Beobachtungen - neben den für heutige und mecklenburgische Verhältnisse „alltäglichen“ Arten wie Beutelmeise, Teichralle und Zwergtaucher war hier Ende der 1960er Jahre die Zwergdommel eine Besonderheit. Obwohl die Eltern das erwachte Interesse nach Kräften unterstützten, fehlte es ihr stets an einer fördernden Gemeinschaft. Kurze Kontakte gab es ab 1968 zu Leipziger Ornithologen, bei denen sie in den Sommerferien Vorträgen lauschte, oder zu einer AG Entomologie an der Nachbarschule, die durch den Tod des Leiters ohne Nachfolger abrupt endete.

Am 20.1.1978 kam Angela Martin das erste Mal zur Fachgruppe in Güstrow. Bisher fühlte sie sich mit ihrem Interesse zur Natur und Vogelkunde stets als Außenseiter, sogar an der Pädagogischen Hochschule Güstrow beim Studium unter Biologie-/Chemie-Lehrerstudenten. Wie sie selbst darlegte, war sie mit großen Überwindungsängsten zu diesem Interessenskreis gekommen, aber sie fühlte sich sofort wohl in dieser Gruppe von Menschen, die den gleichen „Spleen“ hatten. Zunächst gab es da aber gewisse Startschwierigkeiten, denn man hatte es vergessen, sie zu der nächsten FG-Sitzung einzuladen. Ab Mai des Jahres 1978 gehörte sie aber endgültig dazu und wurde in der Folge vor allem von Kurt Pohlmann in der Jugendgruppe zu allen Exkursionen mitgenommen. Sie stellte für sich fest, dass wahrscheinlich dieses Erlebnis eines gemeinsamen Interesses und damit das Ablegen der Außenseiterposition mehr zu ihrer Persönlichkeitsentwicklung beigetragen hat, als obenhin gedacht wird.

Nach Abschluss ihres Forschungsstudiums wechselte A. Martin 1983 aus dem Bildungsbereich in die Forstwirtschaft, wo sie die Stelle einer Mitarbeiterin für Landeskultur und Naturschutz im Staatlichen Forstwirtschaftsbetrieb Güstrow bis 1989 besetzen konnte. Hier gelang es ihr durch ihre vorbereitende Tätigkeit, dass in den Kreisen Güstrow und Bützow ein System von 65 Flächennaturdenkmalen 1984 und 1987 durch die Kreistage unter Schutz gestellt wurde.

Nach einem folgenschweren Verkehrsunfall gelang es ihr, mit viel Energie und Ausdauer langsam den Weg zurück in den Alltag zu finden. Nach der Wende wurden ihr in der neuen Struktur der Forstdirektion West die verschiedensten Aufgaben zugemutet, bis sie schließlich ab 2004 zur Landeslehrstätte für Naturschutz beim LUNG wechselte. Mit dem Jahr 2008 stieg sie freiwillig aus dem Berufsleben aus, um sich voll und ganz einer vielfältigen ehrenamtlichen Tätigkeit zu widmen.

Angela Martin leitet seit 1992 die FG Ornithologie und Naturschutz und bereits seit 1981 die von ihr gegründete AG Botanik. 


\section{Die Mitarbeiter an einzelnen Kapiteln im Bild vorgestellt:}

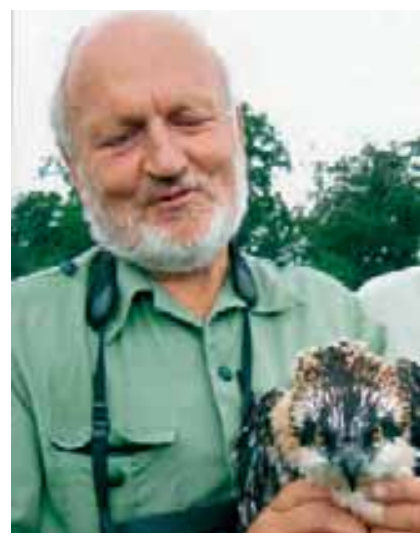

Wolfgang Köhler

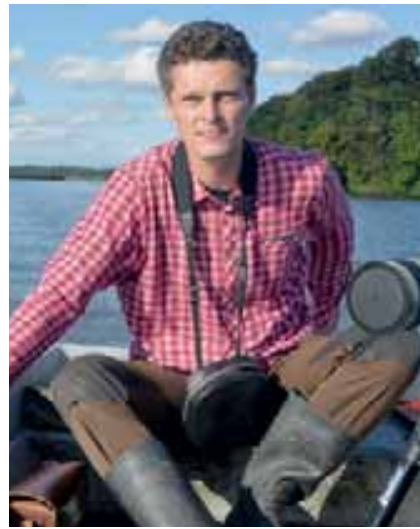

Sebastian Lorenz

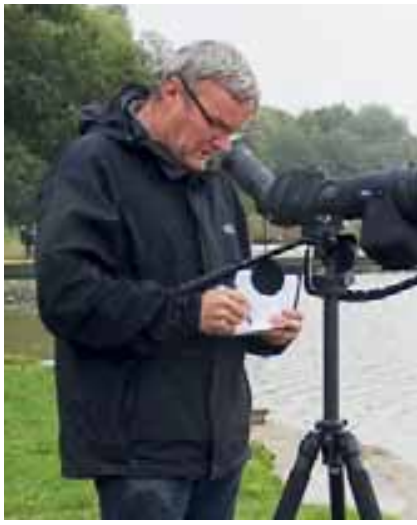

Manfred Montschko

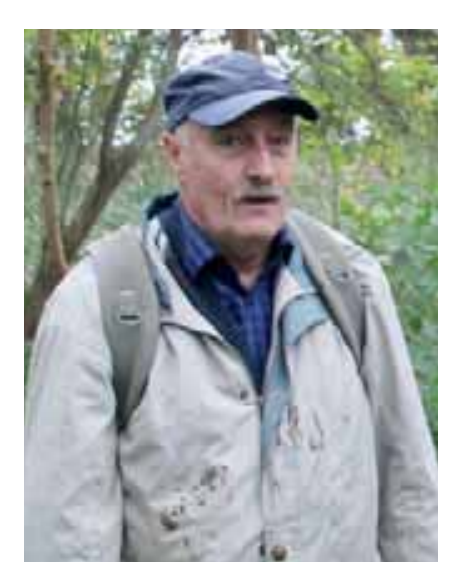

Helmut Richter

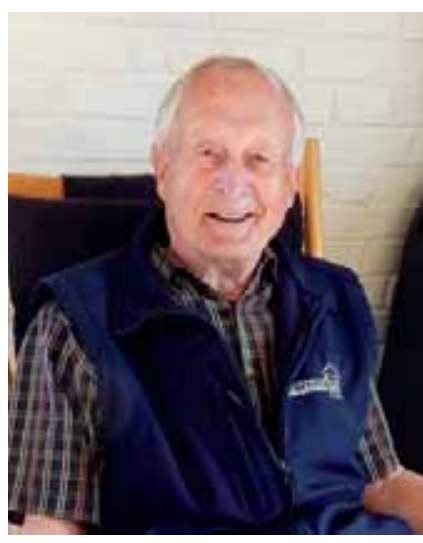

Eckhard Schlüter

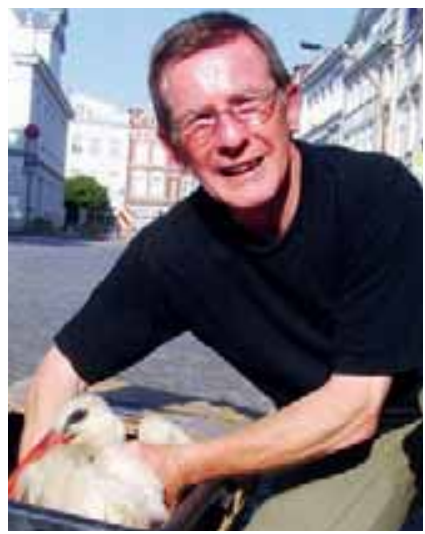

Reinhard Schaugstat

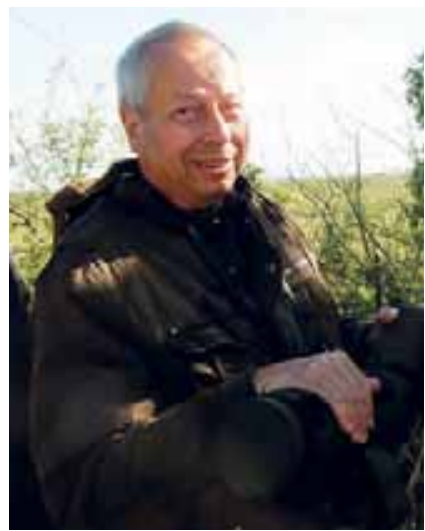

Guntram Trost 


\section{Rückseite}

Vignetten von den Titelseiten der Jahresberichte

Gestaltung der Vignetten: Dr. A. Martin

U. Gehlhar

(Die Vignetten von 23/1990, 24/1991, 34/2001, 38/2005,

39/2006 und 41/2008 stammen von U. Gehlhar.) 


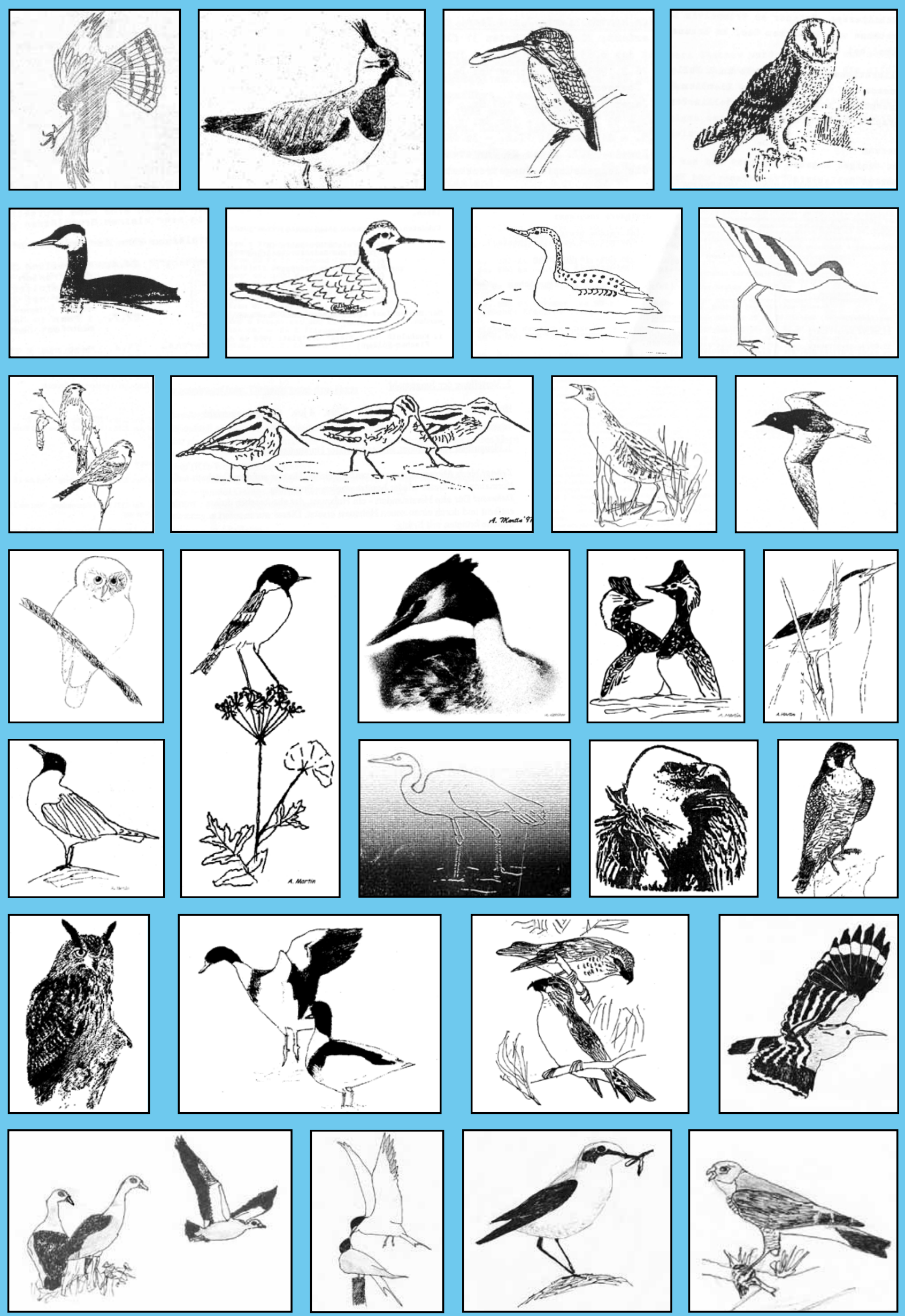